\title{
CHILDREN'S COMPETENCIES DEVELOPMENT IN THE HOME LEARNING ENVIRONMENT
}

EDITED BY: Frank Niklas, Caroline Cohrssen, Simone Lehrl and Amy R. Napoli PUBLISHED IN: Frontiers in Psychology and Frontiers in Education

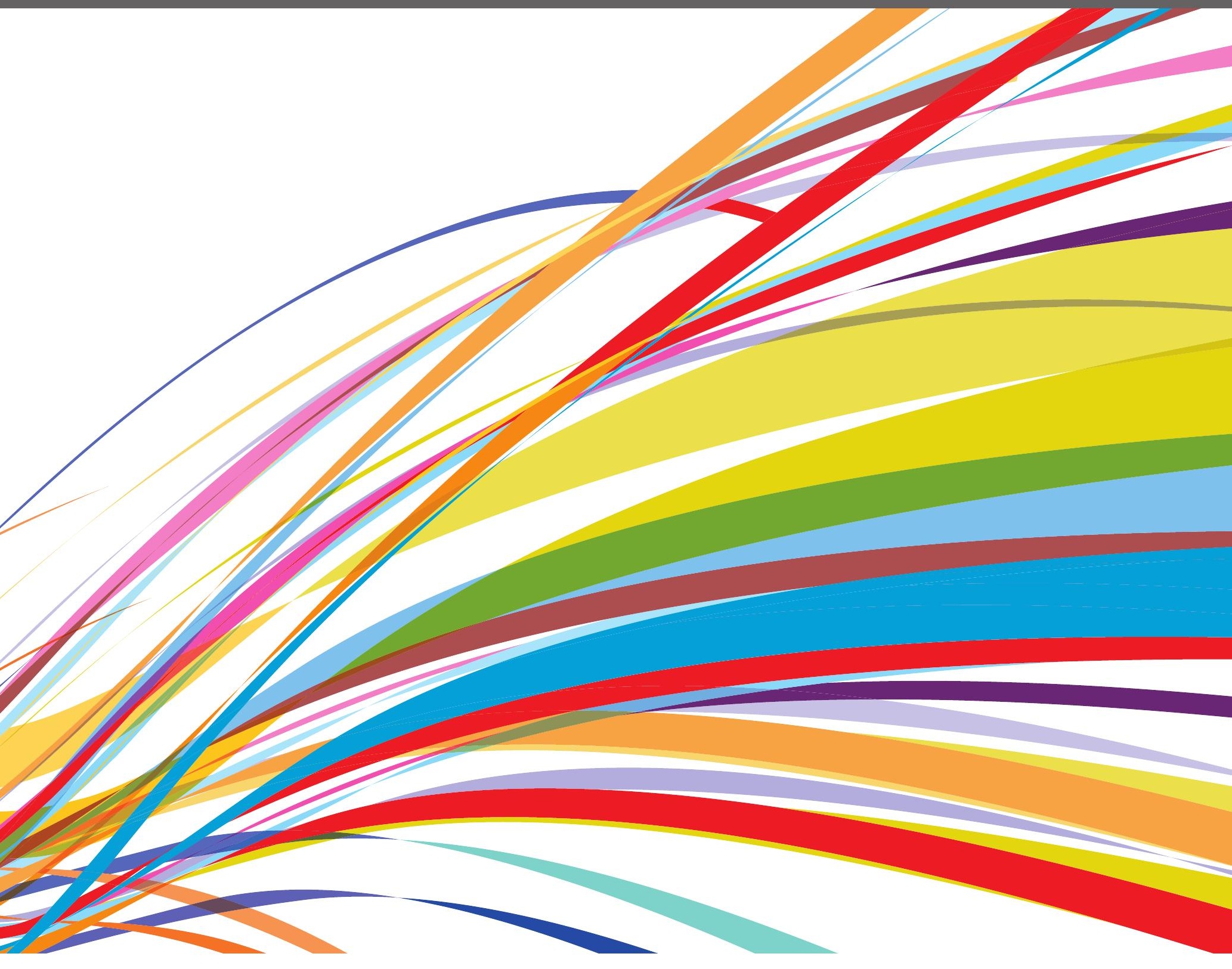

frontiers Research Topics 


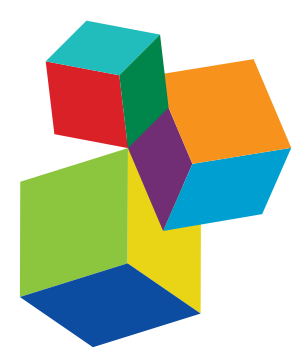

Frontiers eBook Copyright Statement

The copyright in the text of individual articles in this eBook is the property of their respective authors or their respective institutions or funders. The copyright in graphics and images within each article may be subject to copyright of other parties. In both cases this is subject to a license granted to Frontiers.

The compilation of articles constituting this eBook is the property of Frontiers.

Each article within this eBook, and the eBook itself, are published under the most recent version of the Creative Commons CC-BY licence.

The version current at the date of publication of this eBook is CC-BY 4.0. If the CC-BY licence is updated, the licence granted by Frontiers is automatically updated to the new version.

When exercising any right under the CC-BY licence, Frontiers must be attributed as the original publisher of the article or eBook, as applicable.

Authors have the responsibility of ensuring that any graphics or other materials which are the property of others may be included in the

CC-BY licence, but this should be checked before relying on the

CC-BY licence to reproduce those materials. Any copyright notices relating to those materials must be complied with.

Copyright and source acknowledgement notices may not be removed and must be displayed in any copy, derivative work or partial copy which includes the elements in question.

All copyright, and all rights therein, are protected by national and international copyright laws. The above represents a summary only.

For further information please read Frontiers' Conditions for Website

Use and Copyright Statement, and the applicable CC-BY licence.

ISSN 1664-8714

ISBN 978-2-88971-122-2

DOI 10.3389/978-2-88971-122-2

\section{About Frontiers}

Frontiers is more than just an open-access publisher of scholarly articles: it is a pioneering approach to the world of academia, radically improving the way scholarly research is managed. The grand vision of Frontiers is a world where all people have an equal opportunity to seek, share and generate knowledge. Frontiers provides immediate and permanent online open access to all its publications, but this alone is not enough to realize our grand goals.

\section{Frontiers Journal Series}

The Frontiers Journal Series is a multi-tier and interdisciplinary set of open-access, online journals, promising a paradigm shift from the current review, selection and dissemination processes in academic publishing. All Frontiers journals are driven by researchers for researchers; therefore, they constitute a service to the scholarly community. At the same time, the Frontiers Journal Series operates on a revolutionary invention, the tiered publishing system, initially addressing specific communities of scholars, and gradually climbing up to broader public understanding, thus serving the interests of the lay society, too.

\section{Dedication to Quality}

Each Frontiers article is a landmark of the highest quality, thanks to genuinely collaborative interactions between authors and review editors, who include some of the world's best academicians. Research must be certified by peers before entering a stream of knowledge that may eventually reach the public - and shape society; therefore, Frontiers only applies the most rigorous and unbiased reviews.

Frontiers revolutionizes research publishing by freely delivering the most outstanding research, evaluated with no bias from both the academic and social point of view. By applying the most advanced information technologies, Frontiers is catapulting scholarly publishing into a new generation.

\section{What are Frontiers Research Topics?}

Frontiers Research Topics are very popular trademarks of the Frontiers Journals Series: they are collections of at least ten articles, all centered on a particular subject. With their unique mix of varied contributions from Original Research to Review Articles, Frontiers Research Topics unify the most influential researchers, the latest key findings and historical advances in a hot research area! Find out more on how to host your own Frontiers Research Topic or contribute to one as an author by contacting the Frontiers Editorial Office: frontiersin.org/about/contact 


\title{
CHILDREN'S COMPETENCIES DEVELOPMENT IN THE HOME LEARNING ENVIRONMENT
}

\author{
Topic Editors: \\ Frank Niklas, Ludwig Maximilian University of Munich, Germany \\ Caroline Cohrssen, The University of Hong Kong, SAR China \\ Simone Lehrl, University of Bamberg, Germany \\ Amy R. Napoli, University of Nebraska-Lincoln, United States
}

Citation: Niklas, F., Cohrssen, C., Lehrl, S., Napoli, A. R., eds. (2021). Children's Competencies Development in the Home Learning Environment. Lausanne: Frontiers Media SA. doi: 10.3389/978-2-88971-122-2 


\section{Table of Contents}

05 Editorial: Children's Competencies Development in the Home Learning Environment

Frank Niklas, Caroline Cohrssen, Simone Lehrl and Amy R. Napoli

14 Longitudinal Effects of the Family Support Program Chancenreich on Parental Involvement and the Language Skills of Preschool Children Franziska Cohen, Juliane Schünke, Eric Vogel and Yvonne Anders

27 The Early Years Home Learning Environment - Associations With Parent-Child-Course Attendance and Children's Vocabulary at Age 3 Anja Linberg, Simone Lehrl and Sabine Weinert

40 Home Literacy Activities and Children's Reading Skills, Independent Reading, and Interest in Literacy Activities From Kindergarten to Grade 2 Gintautas Silinskas, Monique Sénéchal, Minna Torppa and Marja-Kristiina Lerkkanen

55 Parents' Growth Mindsets and Home-Learning Activities: A Cross-Cultural Comparison of Danish and US Parents

Laura M. Justice, Kelly M. Purtell, Dorthe Bleses and Sugene Cho

66 The Home Literacy Environment as a Mediator Between Parental Attitudes Toward Shared Reading and Children's Linguistic Competencies

Frank Niklas, Astrid Wirth, Sabrina Guffler, Nadja Drescher and Simone C. Ehmig

76 Home Literacy Environment and Early Literacy Development Across Languages Varying in Orthographic Consistency

Tomohiro Inoue, George Manolitsis, Peter F. de Jong, Karin Landerl, Rauno Parrila and George K. Georgiou

87 Construct-Specific and Timing-Specific Aspects of the Home Environment for Children's School Readiness

Yemimah A. King, Robert J. Duncan, German Posada and David J. Purpura

98 Associations Between Children's Media Use and Language and Literacy Skills

Rebecca A. Dore, Jessica Logan, Tzu-Jung Lin, Kelly M. Purtell and Laura M. Justice

108 Examining the Factor Structure of the Home Mathematics Environment to Delineate Its Role in Predicting Preschool Numeracy, Mathematical Language, and Spatial Skills

David J. Purpura, Yemimah A. King, Emily Rolan, Caroline Byrd Hornburg, Sara A. Schmitt, Sara A. Hart and Colleen M. Ganley

122 Shared Storybook Reading and Oral Language Development: A Bioecological Perspective

Lorenz Grolig

142 From Storybooks to Novels: A Retrospective Approach Linking Print Exposure in Childhood to Adolescence

Brittany Tremblay, Monyka L. Rodrigues and Sandra Martin-Chang 
150 The Impact of the Digital Home Environment on Kindergartners' Language and Early Literacy

Eliane Segers and Tijs Kleemans

159 Probing the Relationship Between Home Numeracy and Children's Mathematical Skills: A Systematic Review

Belde Mutaf-Yıldız, Delphine Sasanguie, Bert De Smedt and Bert Reynvoet

180 Differential Effects of the Home Language and Literacy Environment on Child Language and Theory of Mind and Their Relation to Socioeconomic Background

Susanne Ebert, Simone Lehrl and Sabine Weinert

198 Triangulating Multi-Method Assessments of Parental Support for Early Math Skills

Heather J. Bachman, Leanne Elliott, Shirley Duong, Laura Betancur, Monica G. Navarro, Elizabeth Votruba-Drzal and Melissa Libertus

216 What Impacts Early Language Skills? Effects of Social Disparities and Different Process Characteristics of the Home Learning Environment in the First 2 Years

Manja Attig and Sabine Weinert

235 No Association Between the Home Math Environment and Numerical and Patterning Skills in a Large and Diverse Sample of 5- to 6-year-olds

Laure De Keyser, Merel Bakker, Sanne Rathé, Nore Wijns, Joke Torbeyns,

Lieven Verschaffel and Bert De Smedt

248 Home Literacy Environment and Children's English Language and Literacy Skills in Hong Kong

Carrie Lau and Ben Richards

265 Home Numeracy and Preschool Children's Mathematical

Development: Expanding Home Numeracy Models to Include

Parental Attitudes and Emotions

Ann Dowker

274 Home Literacy and Numeracy Environments in Asia

Sum Kwing Cheung, Katrina May Dulay, Xiujie Yang, Fateme Mohseni and Catherine McBride

294 Home Learning Environments of Children in Mexico in Relation to Socioeconomic Status

María Inés Susperreguy, Carolina Jiménez Lira, Chang Xu, Jo-Anne LeFevre, Humberto Blanco Vega, Elia Verónica Benavides Pando and Martha Ornelas Contreras

308 Characteristics Related to Parent-Child Literacy and Numeracy Practices in Preschool

Amy R. Napoli, Irem Korucu, Joyce Lin, Sara A. Schmitt and David J. Purpura

317 The Home Learning Environment in the Digital Age-Associations Between Self-Reported "Analog" and "Digital" Home Learning Environment and Children's Socio-Emotional and Academic Outcomes Simone Lehrl, Anja Linberg, Frank Niklas and Susanne Kuger 


\title{
Editorial: Children's Competencies Development in the Home Learning Environment
}

\author{
Frank Niklas ${ }^{1 *}$, Caroline Cohrssen ${ }^{2}$, Simone Lehrl $^{3}$ and Amy R. Napoli ${ }^{4}$ \\ ${ }^{1}$ Department of Psychology, Ludwig-Maximilians-University Munich, Munich, Germany, ${ }^{2}$ Faculty of Education, The University \\ of Hong Kong, Hong Kong, China, ${ }^{3}$ Institute of Psychology, University of Bamberg, Bamberg, Germany, ${ }^{4}$ Department of \\ Child, Youth, and Family Studies, University of Nebraska-Lincoln, Lincoln, NE, United States
}

Keywords: home learning environment, home numeracy environment, home literacy environment, parent-child interaction, children's competencies development

\section{Editorial on the Research Topic}

\section{Children's Competencies Development in the Home Learning Environment}

The home learning environment (HLE) is one of the contexts within which young children develop important competencies (e.g., Niklas and Schneider, 2013; Lehrl et al., 2020b), and which affects their long-term development (e.g., Niklas and Schneider, 2017; Lehrl et al., 2020a). Primary caregivers may support children's learning during everyday routine interactions and by shared reading or playing games. Here, it is helpful to differentiate between the home literacy and numeracy environment and their respective associations with children's literacy and numeracy learning (e.g., Niklas and Schneider, 2013, 2014; Lehrl et al., 2014). Further, formal aspects of the HLE include explicit teaching by the primary caregiver, whereas informal aspects of the HLE consist of various activities that foster children's learning, although learning is not the main focus of the activity (cf. Sénéchal and LeFevre, 2002; Skwarchuk et al., 2014). Family intervention programs not only enhance the quality of the HLE, but also support children's competencies development (e.g., Niklas et al., 2016). Meta-analyses show that children who grow up in a high-quality HLE develop greater competencies and are better prepared for school (Sénéchal and Young, 2008; e.g., Mol et al., 2008). In addition, the availability of digital media in many families worldwide offers new possibilities for interventions (e.g., Niklas et al., 2020). The HLE is closely associated with family background variables such as the socioeconomic status (SES) of a family (i.e., families with a high SES tend to provide higher quality HLEs) and the migration background (e.g., Aikens and Barbarin, 2008; Anders et al., 2012; Niklas et al., 2015). Consequently, the HLE acts as a mediator between more distal family characteristics and child outcomes. Further, research indicates that the HLE may not only predict concurrent children's early literacy and numeracy competencies (e.g., Burghardt et al., 2020, Napoli and Purpura, 2018), but also later achievement in school (e.g., Niklas and Schneider, 2017; Lehrl et al., 2020a) as well as more general cognitive abilities (e.g., Howard et al., 2017; Niklas et al., 2018) and socio-emotional outcomes (e.g., Rose et al., 2018; Wirth et al., 2020). Despite the research on the HLE and the findings in recent years, we still do not know how best to operationalize the HLE, through which specific mechanisms the HLE impacts children's learning, and which facets of the HLE are the most important. For instance, in a recent paper by Hornburg et al. (2021), international experts in the field of the home mathematics environment (HME) discussed next steps in the measurement of this construct and concluded that much more work is needed to define and operationalize the HME, so that it can be supported more successfully in research and practise across countries and contexts. Despite more research having been conducted on the home literacy environment than the HME, this issue also applies to the home literacy environment. We are also still in need of successful family intervention approaches 
that are non-intensive and appeal to all families, independent of their background (e.g., Purpura et al., 2017). Finally, we do not yet know how digital media may be associated with and influence the HLE, or whether there are specific cultural and regional HLE differences.

The present Research Topic entitled "Children's Competencies Development in the Home Learning Environment" thus aims to provide a platform for showcasing the latest research on the HLE and to provide more insight into a construct of important scientific and societal impact. It focuses on empirical research and reviews on children's learning in the context of the HLE. For instance, some of the 23 contributions investigated the different facets of the home literacy and/or numeracy environment (e.g., parental attitudes, parental teaching, frequency, and quality of interactions) and their association with child competencies, whereas others focused on the HLE and children's longer-term development in kindergarten and school, and on intervention effects. Further, some studies compared the HLE across different countries and languages, and some studies focused on digital media usage within the HLE. We ordered the 23 papers according to different criteria and characteristics. Here, we decided to differentiate between articles that focused on both the home literacy and the home numeracy environment (Part 1) and articles that focused on either the home literacy environment (Part 2) or the home numeracy environment (Part 3). Articles in Part 4 compared the HLE across different countries and orthographies and articles in Part 5 analysed digital media within the family context. Within each of these parts, original research articles are presented first and reviews are listed at the end. Finally, within the original research articles in each part, cross-sectional research is presented before manuscripts reporting longitudinal data and manuscripts reporting data on younger children are listed before those reporting data on older children. Table 1 shows an overview of all articles included in this Research Topic and provides information about the article type, the focus variables, the sample (or the studies included in the reviews), the study type (i.e., cross-sectional, longitudinal, or theoretical), and the focus country/ies of the paper. In the following, we briefly highlight key findings from each paper.

Part 1 consists of three studies that consider a more general HLE and thus aspects of both the home numeracy and the home literacy environment. In the paper by Napoli et al. the authors examine characteristics of the child and family that relate to the frequency of parent-child literacy and numeracy engagement. Although some characteristics (i.e., parent education and children's age) were related to both literacy and numeracy engagement, parents' beliefs about the importance of literacy were not related to literacy engagement but beliefs about the importance of numeracy were related to numeracy engagement. The second paper by Susperreguy et al. analysed the association of the HLE with children's numeracy outcomes in a sample of 173 Mexican children, aged 3 to 6 years, living in families with high- vs. low-SES. Whereas, parents with high-SES reported a higher frequency of home literacy activities compared with families with low-SES, no such differences were found for numeracy activities. However, home numeracy activities were significantly associated with numeracy skills of children from families with high-SES only. Consequently, the authors' findings indicate that the socioeconomic status of the family should be considered a moderator of the relations between the home numeracy environment and children's early numeracy skills. The third paper by King et al. investigated how time-specific and construct-specific aspects of the home learning environment are related to children's academic skills, and externalising behaviours, using data from the NICHD Study of Early Child Care and Youth Development $(N=1,364)$. They show that although the overall, stable HLE indicator as measured through the Early Childhood Home Observation for Measurement of the Environment Inventory (EC-HOME) at 36 and 54 months (Caldwell and Bradley, 1984) was positively associated with language skills and negatively associated with externalising behaviours, there is also a construct- and timespecific association between the HLE and children's language and mathematics skills. The specific construct "stimulation" was uniquely associated with children's language and mathematics skills, above and beyond the quality of the overall home learning environment.

Part 2 focuses explicitly on the home literacy environment. Here, Tremblay et al. analysed 45 parent-adolescent dyads with a retrospective and current book title and author recognition tests in their brief research report. They found that early reading experiences of the adolescents in this study related to their later reading preferences, which in turn were associated with the current literacy skills of these adolescents. Their findings indicate a long-lasting impact of early shared reading experiences on subsequent interest in reading, as well as on later literacy outcomes well into adolescence. The second paper of Part 2 by Lau and Richards examined the relation between the home literacy environment and ethnic Chinese children's development of English as a second language. Specifically, the authors considered children's English vocabulary, phonological awareness, letter knowledge, and word reading skills. The results indicate a wide range of home literacy support for English language development, and differences in the relations between the home literacy environment and children's skills. The study adds to the growing body of literature examining children's home literacy environment in a multilingual context. In the third paper, Attig and Weinert used data from the German National Educational Panel Study (NEPS) to explore longitudinal relations between the process (i.e., parental interaction behaviour and joint picture book reading) and structural (i.e., socioeconomic status) characteristics of the home environment and children's language skills. They found that families' socioeconomic status was related to each process characteristic, and that several of these characteristics were related to children's vocabulary and grammar skills. In the fourth paper by Linberg et al. data from the German NEPS was also used to investigate the specific relations between quantitative (e.g., frequency of shared book reading) and qualitative (e.g., sensitivity and stimulation during parentchild interaction) indicators of the HLE at age 2 years, as well as the specific impact of attending low threshold parent-child courses in shaping children's vocabulary development between 2 and 3 years of age. The results indicate that the attending 
TABLE 1 | Overview of the articles included in the Research Topic on home learning environment and child outcomes.

\begin{tabular}{|c|c|c|c|c|c|c|c|}
\hline Parts & References & Article title & Article type & Focus variables & Sample/Included studies & $\begin{array}{l}\text { Study } \\
\text { type }\end{array}$ & Focus countries \\
\hline \multirow[t]{3}{*}{$\begin{array}{l}\text { Part 1: research } \\
\text { on a general HLE }\end{array}$} & Napoli et al. & $\begin{array}{l}\text { Characteristics related to } \\
\text { parent-child literacy and } \\
\text { numeracy practises in } \\
\text { pre-school }\end{array}$ & $\begin{array}{l}\text { Original research } \\
\text { article }\end{array}$ & $\begin{array}{l}\text { Child and family characteristics underlying HLitE } \\
\text { and HNE-parent education, home literacy and } \\
\text { numeracy practises, parents' beliefs of the } \\
\text { importance of literacy and numeracy }\end{array}$ & $\begin{array}{l}199 \text { pre-school children }(M \\
\text { age }=4.16 \text { years })\end{array}$ & C & US \\
\hline & Susperreguy et al. & $\begin{array}{l}\text { Home learning } \\
\text { environments of children in } \\
\text { Mexico in relation to } \\
\text { socioeconomic status }\end{array}$ & $\begin{array}{l}\text { Original research } \\
\text { article }\end{array}$ & $\begin{array}{l}\text { SES, HLE (frequency of parental formal home } \\
\text { numeracy and literacy activities, parental academic } \\
\text { expectations), and children's numeracy performance }\end{array}$ & $\begin{array}{l}173 \text { pre-school children } \\
\text { (aged 3-6 years) M age (low } \\
\text { SES) = } 56.75 \text { months; M } \\
\text { age (high SES) }=55.56 \\
\text { months }\end{array}$ & C & Mexico \\
\hline & King et al. & $\begin{array}{l}\text { Construct-Specific and } \\
\text { timing-specific aspects of } \\
\text { the home environment for } \\
\text { children's school readiness }\end{array}$ & $\begin{array}{l}\text { Original research } \\
\text { article }\end{array}$ & $\begin{array}{l}\text { construct- and timing-specific aspects of HLE } \\
\text { (stimulation and responsivity construct) for } \\
\text { language, maths, and externalising behaviour; } \\
\text { school readiness }\end{array}$ & $\begin{array}{l}1,364 \text { children }(\mathrm{NICHD} \\
\text { data); } \mathrm{M} \text { age }(\mathrm{t} 1)=36 \\
\text { month; } \mathrm{M} \text { age }(\mathrm{t} 2)=54 \\
\text { months }\end{array}$ & L & US \\
\hline \multirow[t]{5}{*}{$\begin{array}{l}\text { Part 2: research on } \\
\text { the home literacy } \\
\text { environment }\end{array}$} & Tremblay et al. & $\begin{array}{l}\text { From storybooks to novels: } \\
\text { a retrospective approach } \\
\text { linking print exposure in } \\
\text { childhood to adolescence }\end{array}$ & $\begin{array}{l}\text { Brief research } \\
\text { report }\end{array}$ & $\begin{array}{l}\text { shared storybook reading in childhood and current } \\
\text { print exposure in adolescence, vocabulary, word } \\
\text { reading, and spelling skills }\end{array}$ & $\begin{array}{l}45 \text { parent-adolescent } \\
\text { dyads; } \mathrm{M} \text { age (parents) }= \\
47.59, \mathrm{M} \text { age (children) }= \\
\text { Grades } 7-11\end{array}$ & C & Canada \\
\hline & Lau and Richards & $\begin{array}{l}\text { Home literacy environment } \\
\text { and children's english } \\
\text { language and literacy skills } \\
\text { in Hong Kong }\end{array}$ & $\begin{array}{l}\text { Original research } \\
\text { article }\end{array}$ & $\begin{array}{l}\text { HLitE, children's language and literacy development } \\
\text { (English skills) }\end{array}$ & $\begin{array}{l}149 \text { children ( } \mathrm{M} \text { age }=59 \\
\text { months) }\end{array}$ & C & Hong Kong \\
\hline & Attig and Weinert & $\begin{array}{l}\text { What impacts early } \\
\text { language skills? Effects of } \\
\text { social disparities and } \\
\text { different process } \\
\text { characteristics of the home } \\
\text { learning environment in the } \\
\text { first } 2 \text { years }\end{array}$ & $\begin{array}{l}\text { Original research } \\
\text { article }\end{array}$ & HLitE, SES, and children's language skills & $\begin{array}{l}\text { 2,272 families with } \\
2 \text {-year-old children ( } M \text { age }= \\
26 \text { months) }\end{array}$ & L & Germany \\
\hline & Linberg et al. & $\begin{array}{l}\text { The early years home } \\
\text { learning } \\
\text { environment-associations } \\
\text { with parent-child-course } \\
\text { attendance and children's } \\
\text { vocabulary at age } 3\end{array}$ & $\begin{array}{l}\text { Original research } \\
\text { article }\end{array}$ & $\begin{array}{l}\text { HLitE, attendance of low threshold } \\
\text { parent-child-courses, vocabulary development, } \\
\text { family background }\end{array}$ & $\begin{array}{l}1,013 \text { children between } 2 \\
\text { and } 3 \text { years (wave } 1: \mathrm{M} \text { age } \\
=6.97 \text { months; wave } 2: \mathrm{M} \\
\text { age }=13.36 \text { months; wave } \\
\text { 3: } \mathrm{M} \text { age }=26.49 \text { months; } \\
\text { wave } 4: \mathrm{M} \text { age }=38.40 \\
\text { months) }\end{array}$ & L & Germany \\
\hline & Niklas et al. & $\begin{array}{l}\text { The home literacy } \\
\text { environment as a mediator } \\
\text { between parental attitudes } \\
\text { towards shared reading and } \\
\text { children's linguistic } \\
\text { competencies }\end{array}$ & $\begin{array}{l}\text { Original research } \\
\text { article }\end{array}$ & HLitE and parental attitudes & $\begin{array}{l}133 \text { children (average age at } \\
\mathrm{t} 1: 3 \text { years) }\end{array}$ & L & Germany \\
\hline
\end{tabular}


TABLE 1 | Continued

\begin{tabular}{|c|c|c|c|c|c|c|c|}
\hline Parts & References & Article title & Article type & Focus variables & Sample/Included studies & $\begin{array}{l}\text { Study } \\
\text { type }\end{array}$ & Focus countries \\
\hline & Ebert et al. & $\begin{array}{l}\text { Differential effects of the } \\
\text { home language and literacy } \\
\text { environment on child } \\
\text { language and theory of } \\
\text { mind and their relation to } \\
\text { socioeconomic background }\end{array}$ & $\begin{array}{l}\text { Original research } \\
\text { article }\end{array}$ & $\begin{array}{l}\text { home language and literacy environment, language } \\
\text { development, TOM, SES }\end{array}$ & $\begin{array}{l}224 \text { pre-school children }(3 ; 6 \\
\text { years) } \mathrm{M} \text { age }(\mathrm{t} 1)=41.87 \\
\text { months }\end{array}$ & L & Germany \\
\hline & Silinskas et al. & $\begin{array}{l}\text { Home literacy activities and } \\
\text { children's reading skills, } \\
\text { independent reading, and } \\
\text { interest in literacy activities } \\
\text { from kindergarten to grade } 2\end{array}$ & $\begin{array}{l}\text { Original research } \\
\text { article }\end{array}$ & $\begin{array}{l}\text { Home Literacy Model and children's engagement in } \\
\text { literacy activities at home and at school (children's } \\
\text { independent reading, children's interest in literacy, } \\
\text { parent teaching) }\end{array}$ & $\begin{array}{l}378 \text { children from } \\
\text { pre-school through grade } 2 \\
\text { (M age }(t 1)=67.7 \text { months) }\end{array}$ & $\mathrm{L}$ & Finland \\
\hline & Cohen et al. & $\begin{array}{l}\text { Longitudinal effects of the } \\
\text { family support program } \\
\text { Chancenreich on parental } \\
\text { involvement and the } \\
\text { language skills of pre-school } \\
\text { children }\end{array}$ & $\begin{array}{l}\text { Original research } \\
\text { article }\end{array}$ & $\begin{array}{l}\text { (1) Attendance of the Chancenreich program and } \\
\text { attendance of further educational programs; (2) } \\
\text { Family characteristics and attendance rates of } \\
\text { program's course; (3) children's vocabulary and } \\
\text { grammar development }\end{array}$ & $\begin{array}{l}\mathrm{N}(\mathrm{t} 1)=182 ; \mathrm{N}(\mathrm{t} 2)=162 \\
\text { children }(\mathrm{T} 1: \mathrm{M} \text { age }=41 \\
\text { months, } \mathrm{T} 2: \mathrm{M} \text { age }=68 \\
\text { months) }\end{array}$ & L & Germany \\
\hline & Grolig & $\begin{array}{l}\text { Shared storybook reading } \\
\text { and oral language } \\
\text { development: a } \\
\text { bioecological perspective }\end{array}$ & Review & $\begin{array}{l}\text { shared storybook reading and oral language } \\
\text { development; interplay of children's, adults' and } \\
\text { books' characteristics; HLitE, child care learning } \\
\text { environment }\end{array}$ & $\begin{array}{l}\text { Determinants of the shared } \\
\text { reading triad's effects on } \\
\text { language skills: } \\
\text { Bronfenbrenner's } \\
\text { bioecological model (1994); } \\
\text { shared reading in the HLE } \\
\text { (Sénéchal and LeFevre, } \\
\text { 2002) }\end{array}$ & $\mathrm{T}$ & - \\
\hline \multirow[t]{3}{*}{$\begin{array}{l}\text { Part 3: research } \\
\text { on the home } \\
\text { mathematical } \\
\text { environment }\end{array}$} & Purpura et al. & $\begin{array}{l}\text { Examining the factor } \\
\text { structure of the home } \\
\text { mathematics environment to } \\
\text { delineate Its role in } \\
\text { predicting pre-school } \\
\text { numeracy, mathematical } \\
\text { language, and spatial skills }\end{array}$ & $\begin{array}{l}\text { Original research } \\
\text { article }\end{array}$ & $\begin{array}{l}\text { Home mathematical environment (direct numeracy, } \\
\text { indirect numeracy, spatial) and child outcomes } \\
\text { (numeracy, mathematical language, spatial skills) }\end{array}$ & $\begin{array}{l}129 \text { pre-school children } \\
\text { (Mage }=4.71 \text { years })\end{array}$ & C & US \\
\hline & Bachman et al. & $\begin{array}{l}\text { Triangulating multi-method } \\
\text { assessments of parental } \\
\text { support for early math skills }\end{array}$ & $\begin{array}{l}\text { Original research } \\
\text { article }\end{array}$ & $\begin{array}{l}\text { Parental support for early math (math talk, home } \\
\text { math activities; frequency, type, and content of } \\
\text { activities and parental talk) }\end{array}$ & $\begin{array}{l}128 \text { parents }(\mathrm{M} \text { age }= \\
24-56 \text { year old) of } \\
4 \text {-year-old children }\end{array}$ & C & US \\
\hline & De Keyser et al. & $\begin{array}{l}\text { No association between the } \\
\text { home math environment } \\
\text { and numerical and } \\
\text { patterning skills in a large } \\
\text { and diverse sample of } 5 \text { - to } \\
6 \text {-year-olds }\end{array}$ & $\begin{array}{l}\text { Original research } \\
\text { article }\end{array}$ & $\begin{array}{l}\text { HNE (home math activities, parental expectations, } \\
\text { parental attitudes) and children's mathematical skills }\end{array}$ & $\begin{array}{l}353 \text { pre-school children (M } \\
\text { age }=70.03 \text { months) }\end{array}$ & C & Belgium \\
\hline
\end{tabular}


TABLE 1 | Continued

\begin{tabular}{|c|c|c|c|c|c|c|c|}
\hline Parts & References & Article title & Article type & Focus variables & Sample/Included studies & $\begin{array}{l}\text { Study } \\
\text { type }\end{array}$ & Focus countries \\
\hline & Dowker & $\begin{array}{l}\text { Home numeracy and } \\
\text { pre-school children's } \\
\text { mathematical development: } \\
\text { Expanding home numeracy } \\
\text { models to include parental } \\
\text { attitudes and emotions }\end{array}$ & Review & $\begin{array}{l}\text { home numeracy, parental attitudes and beliefs, and } \\
\text { children's mathematical performance, gender } \\
\text { stereotypes, parental mathematics anxiety on } \\
\text { children's anxiety and performance }\end{array}$ & $\begin{array}{l}\text { Home Numeracy Model } \\
\text { (Skwarchuk et al., 2014) }\end{array}$ & $\mathrm{T}$ & $\begin{array}{l}\text { Germany, } \\
\text { Philippines, } \\
\text { Ghana, Chile, Italy }\end{array}$ \\
\hline & Mutaf-Yildiz et al. & $\begin{array}{l}\text { Probing the relationship } \\
\text { between home numeracy } \\
\text { and chldren's mathematical } \\
\text { skills: a systematic review }\end{array}$ & Systematic review & $\begin{array}{l}\text { HNE and children's mathematical skills (formal and } \\
\text { informal skills) }\end{array}$ & $\begin{array}{l}37 \text { articles ( } \mathrm{M} \text { age } 14-70 \\
\text { months approx.) }\end{array}$ & $\mathrm{T}$ & $\begin{array}{l}\text { US, Chile, } \\
\text { Germany, China, } \\
\text { UK, South Africa, } \\
\text { Netherlands, Italy, } \\
\text { Belgium, Russia, } \\
\text { Canada, Greece }\end{array}$ \\
\hline \multirow[t]{3}{*}{$\begin{array}{l}\text { Part 4: research } \\
\text { on the HLE across } \\
\text { countries and } \\
\text { orthograpies }\end{array}$} & Justice et al. & $\begin{array}{l}\text { Parents' growth mindsets } \\
\text { and home-learning } \\
\text { activities: a cross-cultural } \\
\text { comparison of Danish and } \\
\text { US parents }\end{array}$ & $\begin{array}{l}\text { Original research } \\
\text { article }\end{array}$ & $\begin{array}{l}\text { HLE (family learning activities, learning extensions, } \\
\text { parental time investment, parental school } \\
\text { involvement) and parental mindset (ability and effort } \\
\text { mindset) }\end{array}$ & $\begin{array}{l}497 \text { parents with at least } \\
\text { one child aged between } 3 \\
\text { and } 5 \text { years }(N \text { danish }= \\
325 ; N \cup S A=172)\end{array}$ & $\mathrm{C}$ & Denmark, US \\
\hline & Inoue et al. & $\begin{array}{l}\text { Home literacy environment } \\
\text { and early literacy } \\
\text { development across } \\
\text { languages varying in } \\
\text { orthographic consistency }\end{array}$ & $\begin{array}{l}\text { Original research } \\
\text { article }\end{array}$ & $\begin{array}{l}\text { HLitE, early literacy development, and varying } \\
\text { orthographic constistency (parents'teaching of } \\
\text { reading and spelling) }\end{array}$ & $\begin{array}{l}714 \text { first graders into } \\
\text { second grade (aged } 6+ \\
\text { years) M age different in all } \\
\text { countries/samples }\end{array}$ & L & $\begin{array}{l}\text { Canada, } \\
\text { Netherlands, } \\
\text { Austria, Greece }\end{array}$ \\
\hline & Cheung et al. & $\begin{array}{l}\text { Home literacy and } \\
\text { numeracy environments in } \\
\text { Asia }\end{array}$ & Review & $\begin{array}{l}\text { HLE and parents' interest and abilities in } \\
\text { Asia/learning- related beliefs and attitudes of } \\
\text { parents in Asia, HLitE, and HNE, effectiveness of } \\
\text { programs that aim to improve the home learning } \\
\text { environment }\end{array}$ & $\begin{array}{l}\text { Studies that have been } \\
\text { conducted in different parts } \\
\text { of Asia (China, the } \\
\text { Philippines, India, Iran, } \\
\text { Turkey, and the United Arab } \\
\text { Emirates) }\end{array}$ & $\mathrm{T}$ & $\begin{array}{l}\text { China, Philippines, } \\
\text { India, Iran, Turkey, } \\
\text { United Arab } \\
\text { Emirates }\end{array}$ \\
\hline \multirow[t]{3}{*}{$\begin{array}{l}\text { Part 5: research } \\
\text { on the digital } \mathrm{HLE}\end{array}$} & Lehrl et al. & $\begin{array}{l}\text { The home learning } \\
\text { environment in the digital } \\
\text { age-associations between } \\
\text { self-reported "analogue" } \\
\text { and "digital" home learning } \\
\text { environment and children's } \\
\text { socio-emotional and } \\
\text { academic outcomes }\end{array}$ & $\begin{array}{l}\text { Original research } \\
\text { article }\end{array}$ & $\begin{array}{l}\text { Analogue and digital HLE and children's } \\
\text { social-emotional and academic competencies }\end{array}$ & $\begin{array}{l}4,914 \text { children aged } 0-5 \\
\text { years (Growing up in } \\
\text { Germany II data)/M age } \\
\text { (toddler sample) }=27.4 \\
\text { months; } \mathrm{M} \text { age (pre-school) } \\
=58.3 \text { months }\end{array}$ & $\mathrm{C}$ & Germany \\
\hline & $\begin{array}{l}\text { Segers and } \\
\text { Kleemans }\end{array}$ & $\begin{array}{l}\text { The impact of the digital } \\
\text { home environment on } \\
\text { kindergartners' language } \\
\text { and early literacy }\end{array}$ & $\begin{array}{l}\text { Original research } \\
\text { article }\end{array}$ & $\begin{array}{l}\text { Digital HLitE vs. analogue HLitE, children's language } \\
\text { and literacy levels, parental expectations }\end{array}$ & $\begin{array}{l}70 \text { pre-school children }(M \\
\text { age }=5 \text { years, } 11 \text { months })\end{array}$ & $\mathrm{C}$ & Netherlands \\
\hline & Dore et al. & $\begin{array}{l}\text { Associations between } \\
\text { children's media use and } \\
\text { language and literacy skills }\end{array}$ & $\begin{array}{l}\text { Original research } \\
\text { article }\end{array}$ & Media use, children's language, and literacy skills & $\begin{array}{l}1,583 \text { children from } \\
\text { pre-school through } 3 \text { rd } \\
\text { grade }\end{array}$ & L & US \\
\hline
\end{tabular}

HLE, Home Learning Environment; HLitE, Home Literacy Environment; HNE, Home Numeracy Environment; SES, socioeconomic status; ToM, Theory of Mind; c, cross-sectional study; I, longitudinal study; t, theoretical work. 
parent-child courses enriches both aspects of the HLE, which in turn predict children's vocabulary development. The authors conclude that parent-child courses may be an achieveable target for interventions aimed at very young children. In a longitudinal study by Niklas et al., 133 children aged about 3 years at t1 and parents participated. Here, data related to socioeconomic status, home literacy environment, parental attitudes towards shared reading, and children's linguistic competencies were gathered. The results indicate that parental attitudes towards shared reading seemed to be stable across a 1-year period and that the home literacy environment mediated the effect of parental attitudes towards children's linguistic outcomes. As these attitudes vary in the context of different family socioeconomic backgrounds, the authors conclude that they may also be a good target for interventions. The sixth paper of Part 2 by Ebert et al. examined the specific and differential, longitudinal effects of different facets of the HLE and specific parental mental state language input on language and theory of mind (ToM) development between age 4 and 6 years, using data from 224 monolingual German pre-school children. Here, parental mental state language was defined as high-quality verbal interactions with children on decontextualized topics such as mental states of characters in a book. They found that book exposure and quality of verbal interaction during shared reading is related to both later ToM understanding and language skills. However, the effect of book exposure is mediated by earlier language skills at age 4:6 years. Parental mental state language input was not (additionally) associated with ToM or language skills. However, the effects differed for children from varying SES backgrounds: quality of verbal parent-child interaction and parental mental state language seem to be especially important for children from low SES backgrounds with regard to language and ToM development. Thus, supporting the home language and literacy environment from early on might reduce SES differences not only in language but also in social-cognitive development. In the seventh paper by Silinskas et al., the HOME Literacy Model was tested and expanded within a Finnish sample of children $(N=378)$ transitioning from pre- to primary school over a 3-year period. Through cross-lagged panel analyses they found that both aspects of the HLE, the frequency of shared reading and teaching of reading at home predicted the frequency of children's independent reading 1 year later. Furthermore, they identified children's early literacy skills in pre-school to be a significant predictor for independent reading in Grade 1. Another interesting result is that parents adapted their teaching behaviours to their children's early literacy skills, with showing fewer teaching behaviours for children with advanced skills. However, self-reported interest in reading was not associated with HLE or children's early skills. The results add to the Home Literacy Model through investigating the longitudinal patterns of HLE, early literacy skills, and later independent reading and interest. In the intervention study by Cohen et al., the authors examined the effects of the parent support program Chancenreich on parents' participation in additional educational services and children's vocabulary development and grammar. Parents' participation in the program was related to their later participation in educational services, and to children's vocabulary development between the ages of 3 and 5 years. The study offers initial evidence that family support programs may have longitudinal effects on children's language development. Finally, the review by Grolig investigated the relation between shared storybook reading and oral language development in the home literacy environment and the child care literacy environment. A model is proposed to explain the influence of the interplay between child, adult, and book characteristics on shared reading activities. Drawing on socio-constructivist concepts and Bronfenbrenner's (1994) bioecological model, findings are integrated from psychology, education, and linguistics research and indicate that the effect of shared reading is influenced by characteristics of "literacy agents" as well as the relations between these agents. Further, a combination of questionnaires and recognition tests was found to provide a sufficient evaluation of reading practises in the home literacy environment.

Part 3 of the Research Topic includes manuscripts on the home numeracy (or more general mathematics) environment. The first paper by Purpura et al. examined the factor structure of the HME (general HME factor, direct numeracy, indirect numeracy, and spatial) and tested the association of these factors with children's numeracy, mathematical language, and spatial skills of 129 pre-schoolers from the US. Confirmatory factor analyses indicated that a bifactor model fitted the data best (spatial and a general numeracy factor). In structural equation modelling analyses, only the numeracy factor was able to predict child outcomes when controlling for child and family characteristics. The results highlight the importance of parentchild engagement in specific aspects of mathematics-related activities. In the second article by Bachman et al., the authors used a multimethod approach and assessed mathematics talk during semi-structured observations of parent-child interactions, parent reports on a home math activities questionnaire, and time diaries with a sample of 128 4-year-old children from the US. The findings reveal substantial within-measure variability across all three data sources and some convergence across measures. The authors conclude that this multi-method approach holds great promise for furthering our understanding of when and how parents support early mathematics skills with their preschool-aged children. The third paper by De Keyser et al. reports that no association was found between the home mathematics environment, and numerical and patterning skills in a diverse sample of 353 children aged 5 to 6 years in Belgium. Neither gender nor family socio-economic moderated the association between the home mathematics environment and children's mathematics skills. Small mathematics-related differences were observed in parental expectations and attitudes. One explanation proposed for these findings is that the preschool learning environment may play a role due to high participation rates in high quality pre-schools that are fully government subsidised and which include a focus on children's mathematical learning. The fourth paper is a review by Dowker considering the relation between parents' mathematics anxiety and the home numeracy environment of pre-schoolaged children. Dowker argues for the importance of a broader definition of the home mathematics environment that includes parent mathematics attitudes in addition to activities. The 
author also highlights several areas for future research, including broader aspects of mathematics than just numeracy (e.g., measurement) and different aspects of parents' mathematics anxiety. Finally, the review by Mutaf-Yildiz et al. analysed the association of parent-child interactions with numerical content with children's performance in mathematical tasks. Thirty-seven articles were included in their systematic review and the authors found a positive association between home numeracy and children's mathematical skills. Here, more advanced, compared with basic, numeracy interactions were associated with child competencies and most studies used questionnaires, surveyed mothers, analysed a comprehensive total score of mathematical competencies, and focused on formal home numeracy activities. Contradictory results regarding the relation between home numeracy and mathematical skills across studies may be due to differences in these study characteristics.

Part 4 includes articles that compare the HLE across different countries and orthographies. Here, the first paper by Justice et al. analysed parental mindsets (i.e., parental beliefs about the role of ability and effort in learning) and their association with home learning activities across a Danish sample $(N=325)$ and a sample from the US $(N=172)$. The parents of 3- to 5-yearold children in both countries held similar ability and effort mindsets. However, US parents provided more family learning activities, learning extensions, and parental time investment, whereas the Danish parents reported higher levels of school investments. Further, in the US but not in Denmark, higher levels of effort mindset were associated with higher levels of parental time investment. In the second paper by Inoue et al., the authors examined the association between home literacy environment (HLE) and early literacy development in a sample of, on average, 76- to 79-month-old children learning four alphabetic orthographies varying in orthographic consistency (English: $N=172$; Dutch: $N=120$; German: $N=184$; Greek: $N=238$ ). The children were tested four times: at the beginning and the end of Grade 1 and Grade 2. In addition, parents reported on parent teaching (PT), shared book reading (SBR), and access to literacy resources (ALR) at the beginning of Grade 1. The findings indicated that SBR did not predict any cognitive or early literacy skills in any language, whereas PT was associated with letter knowledge or phonological awareness in Dutch and Greek only, and ALR was associated with emergent literacy skills in all languages. No specific trend in the role of orthographic consistency in the aforementioned relations emerged. Finally, the review by Cheung et al. synthesises research studies on the home literacy and numeracy environments that have been conducted in different parts of Asia, such as China, the Philippines, India, Iran, Turkey, and the United Arab Emirates. They explore how parents in this part of the world perceive their roles in supporting children's early literacy and numeracy development, through which activities they engage their young children in literacy and numeracy, and how effective intervention programs are that aim to improve the HLEs in Asia. Consistent with the findings from major western studies, the authors report that the home learning environment tends to play a critical role in children's early development also in Asia. However, the authors highlight some findings that seem to be specific to the Asian context: some parents, especially those in East Asia, tend to place greater emphasis on academic achievement and regard it as their own responsibility to support their children's learning at home. In comparison, play is not always favoured as a form of learning, although this view seems to be slightly changing. Furthermore, the role of non-parental household members in fostering children's development is specific to Asian homes, which sometimes might even involve non-family members such as domestic helpers. Furthermore, another challenge might be that in many contexts, children in Asia have to be proficient in languages they do not necessarily speak at home in order to attain educational success-a circumstance which can be observed in many western countries too. Overall the review provides a deep insight in the HLEs in Asian families.

In Part 5, three papers are listed that analyse media usage in the family context and thus a digital HLE. The first paper by Lehrl et al. explores the differentiation of an analogue and a digital HLE and their associations with children's parentrated academic and socio-emotional outcomes within two age groups in Germany (toddlers and pre-schoolers; total $N=4,914$ ). They found that analogue and digital HLE activities are two separate constructs of the HLE which are associated, but not interchangeable. Both dimensions explain individual differences in young children's socio-emotional, practical life, and academic skills; however, these associations are age-specific. For toddlers, only analogue HLE activities were associated with better socioemotional and practical life skills. For pre-schoolers, digital HLE activities were associated with weaker socio-emotional skills but higher academic skills. However, analogue HLE showed higher effect sizes for the academic outcomes in this age group. The authors conclude that more research is needed on the supporting and detrimental features of the digital HLE. In the second paper by Segers and Kleemans, the authors also tried to differentiate between a digital and an analogue HLE in a sample of 71 families from the Netherlands. Here, the main caregivers of 71 kindergarteners (mean age about 6 years) filled out a questionnaire on the home environment (expectations, activities, and materials), and the children were assessed on language (vocabulary and grammar) and literacy (beginning phoneme awareness, segmentation skill, and grapheme knowledge) skills. Whereas the authors were able to differentiate both forms of the HLE, only the analogue environment was related to children's language abilities (i.e., parental expectations were associated with both language and literacy abilities). Finally, in a longitudinal study by Dore et al., a larger sample from the USA $[N=$ 1,583 children (PreK $N=238$, kindergarten $N=466$, Grade $1 N=307$, Grade $2 N=326$, and Grade $3 N=246$ )] was analysed concerning their media usage and language and literacy skills both at the beginning of the school year and across the school year. The analyses showed that more than $4 \mathrm{~h}$ of media usage a day predicted lower literacy gains, but not language gains. However, these effects did not hold in multilevel models. Similarly, no negative associations were found in the singletime models, when controlling for various variables. Further, the findings indicated that younger children are not more vulnerable to detrimental effects. The authors point out that given the concern and popular press coverage around children's media 
use, it is important to acknowledge non-significant effects in this domain. Their non-significant associations suggest that societal fears around children's media use may be exaggerated. However, characteristics of children's media use, like educational content or adult co-use, may moderate any potential effects.

To sum up, the collection of papers in this Research Topic provides important findings on the complex nature of the HLE and its association with various child outcomes. It assembles 19 empirical articles sampled from 11 nations, namely Austria, Belgium, Canada, Denmark, Finland, Germany, Greece, Hong Kong, Mexico, the Netherlands, and the USA. Further, four reviews are included that either looked at theoretical constructs in the context of the HLE (two reviews) or analysed its association with child outcomes (one review) and across different countries (one review). In these reviews, studies from 18 nations-namely Belgium, Canada, Chile, China, Germany, Ghana, Greece, India, Iran, Italy, the Netherlands, Philippines, Russia, South Africa, Turkey, United Arab Emirates, the UK, and the USwere discussed. Consequently, this Research Topic represents an international and intercultural mix of data sources and perspectives on the HLE.

\section{REFERENCES}

Aikens, N. L., and Barbarin, O. (2008). Socioeconomic differences in reading trajectories: the contribution of family, neighborhood, and school contexts. J. Educ. Psychol. 100, 235-251. doi: 10.1037/0022-0663.100. 2.235

Anders, Y., Roßbach, H.-G., Weinert, S., Ebert, S., Kuger, S., Lehrl, S., et al. (2012). Home and preschool learning environments and their relations to the development of early numeracy skills. Early Childh. Res. Q. 27, 231-244. doi: 10.1016/j.ecresq.2011.08.003

Bronfenbrenner, U. (1994). "Ecological models of human development" in International Encyclopedia of Education, 2nd Edn, Vol. 3. eds T. Husen and T. N. Postlewaite (Oxford: Pergamon and Elsevier), 1643-1647.

Burghardt, L., Linberg, A., Lehrl, S., and Konrad-Ristau, K. (2020). The relevance of the early years home and institutional learning environments for early mathematical competencies. J. Educ. Res. Online 12, 103-125. Available online at: https://www.pedocs.de/frontdoor.php?source_opus $=21188$

Caldwell, B. M., and Bradley, R. H. (1984). Home Observation for Measurement of the Environment. Little Rock, AR: University of Arkansas at Little Rock.

Hornburg, C. B., Borriello, G. A., Kung, M., Lin, J., Litkowski, E., Cosso, J., et al. (2021). Next directions in measurement of the home mathematics environment: an international and interdisciplinary perspective. J. Num. Cogn. Available online at: https://hira.hope.ac.uk/id/eprint/3296/

Howard, S. J., Powell, T., Vasseleu, E., Johnstone, S., and Melhuish, E. (2017). Enhancing preschoolers' executive functions through embedding cognitive activities in shared book reading. Educ. Psychol. Rev. 29, 153-174. doi: 10.1007/s10648-016-9364-4

Lehrl, S., Ebert, S., Blaurock, S., Roßbach, H.-G., and Weinert, S. (2020a). Long-term and domain-specific relations between the early years home learning environment and students' academic outcomes in secondary school. Sch. Effect. Sch. Improve. 31, 102-124. doi: 10.1080/09243453.2019. 1618346

Lehrl, S., Evangelou, M., and Sammons, P. (2020b). The home learning environment and its role in shaping children's educational development. Sch. Effect. Sch. Improve. 31, 1-6. doi: 10.1080/09243453.2020. 1693487

Lehrl, S., Smidt, W., Große, C., and Richter, D. (2014). Patterns of literacy and numeracy activities in preschool and their relation to structural
The articles cover various samples ranging from 45 to almost 5,000 participants (mostly medium-sized samples from $N=100$ to 500) from early infancy to adolescence (although most focus on pre-school age and kindergarten children). Moreover, this collection grounds a wide range of theoretical approaches, conceptual frameworks, and assessment methods. This leads to highly diverse and nuanced findings concerning the HLE and its association with various child competencies. We hope that the contributions from this Research Topic will spark further scientific work on the HLE and inspire and serve policymakers and practitioners, and that it may lead to new developments concerning the definition, operationalisation, and assessment of the HLE as well as act as a basis for the development of meaningful family interventions.

\section{AUTHOR CONTRIBUTIONS}

All authors listed have made a substantial, direct and intellectual contribution to the work, and approved it for publication. characteristics and children's home activities. Res. Pap. Educ. 29, 577-597. doi: 10.1080/02671522.2013.792865

Mol, S. E., Bus, A. G., de Jong, M. T., and Smeets, D. J. H. (2008). Added value of dialogic parent-child book readings: a meta-analysis. Early Educ. Dev. 19, 7-26. doi: 10.1080/10409280701838603

Napoli, A. R., and Purpura, D. J. (2018). The home literacy and numeracy environment in preschool: cross-domain relations of parent-child practices and child outcomes. J. Exp. Child Psychol. 166, 581-603. doi: 10.1016/j.jecp.2017.10.002

Niklas, F., Annac, E., and Wirth, A. (2020). App-based learning for kindergarten children at home (Learning4Kids): study protocol for cohort 1 and the kindergarten assessments. BMC Pediatrics 20:554. doi: $10.1186 / s 12887-020-02432-y$

Niklas, F., Cohrssen, C., and Tayler, C. (2016). Improving preschoolers' numerical abilities by enhancing the home numeracy environment. Early Educ. Dev. 27, 372-383. doi: 10.1080/10409289.2015.1076676

Niklas, F., Cohrssen, C., and Tayler, C. (2018). Making a difference to children's reasoning skills before school-entry: The contribution of the home learning environment. Contemp. Educ. Psychol. 54, 79-88. doi: $10.1016 /$ j.cedpsych.2018.06.001

Niklas, F., and Schneider, W. (2013). Home literacy environment and the beginning of reading and spelling. Contemp. Educ. Psychol. 38, 40-50. doi: $10.1016 /$ j.cedpsych.2012.10.001

Niklas, F., and Schneider, W. (2014). Casting the die before the die is cast: the importance of the home numeracy environment for preschool children. Euro. J. Psychol. Educ. 29, 327-345. doi: 10.1007/s10212-013-0201-6

Niklas, F., and Schneider, W. (2017). Home learning environment and development of child competencies from kindergarten until the end of elementary school. Contemp. Educ. Psychol. 49, 263-274. doi: 10.1016/j.cedpsych.2017.03.006

Niklas, F., Tayler, C., and Schneider, W. (2015). Home-based literacy activities and children's cognitive outcomes: a comparison between Australia and Germany. Int. J. Educ. Res. 71, 75-85. doi: 10.1016/j.ijer.2015.04.001

Purpura, D. J., Napoli, A. R., Wehrspann, E. A., and Gold, Z. S. (2017). Causal connections between mathematical language and mathematical knowledge: a dialogic reading intervention. J. Res. Educ. Effect. 10, 116-137 doi: 10.1080/19345747.2016.1204639

Rose, E., Lehrl, S., Ebert, S., and Weinert, S. (2018). Long-term relations between children's language, the home literacy environment, and socioemotional 
development from ages 3 to 8. Early Education and Development, 29, 342-356. doi: 10.1080/10409289.2017.1409096

Sénéchal, M., and LeFevre, J.-A. (2002). Parental involvement in the development of children's reading skill: a five-year longitudinal study. Child Dev. 73, 445-460. doi: 10.1111/1467-8624.00417

Sénéchal, M., and Young, L. (2008). The effect of family literacy interventions on children's acquisition of reading from kindergarten to grade 3: a meta-analytic review. Rev. Educ. Res. 78, 880-907. doi: 10.3102/0034654308320319

Skwarchuk, S. L., Sowinski, C., and LeFevre, J. A. (2014). Formal and informal home learning activities in relation to children's early numeracy and literacy skills: the development of a home numeracy model. J Exp Child Psychol. 121, 63-84. doi: 10.1016/j.jecp.2013.11.006

Wirth, A., Ehmig, S. C., Drescher, N., Guffler, S., and Niklas, F. (2020). Facets of the early home literacy environment and children's linguistic and socioemotional competencies. Early Educ. Dev. 31, 892-909. doi: $10.1080 / 10409289.2019 .1706826$

Conflict of Interest: The authors declare that the research was conducted in the absence of any commercial or financial relationships that could be construed as a potential conflict of interest.

Copyright (C) 2021 Niklas, Cohrssen, Lehrl and Napoli. This is an open-access article distributed under the terms of the Creative Commons Attribution License (CC BY).

The use, distribution or reproduction in other forums is permitted, provided the original author(s) and the copyright owner(s) are credited and that the original publication in this journal is cited, in accordance with accepted academic practice. No use, distribution or reproduction is permitted which does not comply with these terms. 
OPEN ACCESS

Edited by:

Amy R. Napoli,

University of Nebraska-Lincoln,

United States

Reviewed by:

YaeBin Kim,

University of Nevada, Reno,

United States

Alicia Borre,

Hampton University, United States

*Correspondence:

Franziska Cohen

franziska.cohen@uni-bamberg.de

Specialty section:

This article was submitted to

Educational Psychology,

a section of the journal

Frontiers in Psychology

Received: 20 December 2019

Accepted: 15 May 2020

Published: 12 June 2020

Citation:

Cohen F, Schünke J, Vogel E and Anders Y (2020) Longitudinal Effects

of the Family Support Program

Chancenreich on Parental Involvement and the Language Skills of Preschool Children

Front. Psychol. 11:1282.

doi: 10.3389/fpsyg.2020.01282
Longitudinal Effects of the Family Support Program Chancenreich on Parental Involvement and the Language Skills of Preschool Children

\author{
Franziska Cohen ${ }^{1 *}$, Juliane Schünke ${ }^{2}$, Eric Vogel ${ }^{2}$ and Yvonne Anders ${ }^{1}$ \\ ${ }^{1}$ Lehrstuhl für Elementar- und Familienpädagogik, Otto-Friedrich-Universität Bamberg, Bamberg, Germany, ${ }^{2}$ Arbeitsbereich \\ Frühkindliche Bildung und Erziehung, Freie Universität Berlin, Berlin, Germany
}

When they enter primary school children already vary significantly in their language skills, depending at least in part on their family's social background. In particular, the home learning environment plays a significant role in children's development. For that reason, early intervention programs have been developed to obviate learning difficulties and to promote health, children's development, and educational equality. The family support program Chancenreich aims to encourage the interaction and relationship between parents and children through two different course formats. The present study examines the longitudinal effects of attending the Chancenreich program and different course formats on (a) parents attending further educational services for children after completing the program, (b) children's vocabulary and level of grammar development at the age of 5 and (c) the children's vocabulary development between the ages of 3 and 5. Furthermore, we examine the relationship between family characteristics and the attendance rates of different course formats of the Chancenreich program at the first and second point of measurement. The study follows a longitudinal design with two points of measurements (T1: $\mathrm{M}_{\mathrm{age}}=41$ months, T2: $\mathrm{M}_{\mathrm{age}}=68$ months), and a sample size of 121 parents and their children at T2 in the intervention group and 41 parents and their children in the comparison group. Findings indicate that attendance of the Chancenreich program's courses is related to child and family characteristics and to later patterns of course participation after completing the program. Further, both children's level of vocabulary skills (PPVT) at the age of 5 and their development between the ages of 3 and 5 benefit from the parental participation in parenting skills training at the age of 3. Implications and future research on the effectiveness of family support programs are discussed.

Keywords: family support program, home learning environment, vocabulary skills, grammar understanding, longitudinal 


\section{INTRODUCTION}

Language development is an important milestone for young children, and is relevant for their cognitive and socio-emotional competencies in early childhood and for later school success (Hoff, 2013). In particular, children's vocabulary and their understanding of grammar are relevant for language use in daily conversation and emergent literacy (Ouellette, 2006; Swanson et al., 2008). However, children consistently show early differences in language skills that can be explained by the cultural and social background of their families (Hart and Risley, 1995; Ginsborg, 2006; Senechal, 2011; Hirsh-Pasek et al., 2015). In particular, the quality of the home learning environment (HLE) plays a major role in early development and later academic success (Melhuish et al., 2008; Rodriguez and Tamis-LeMonda, 2011; Skwarchuk et al., 2014; Tamis-LeMonda et al., 2017). Within the theoretical model of the HLE, researchers distinguish between structural characteristics, beliefs, and process quality, with process quality having a direct effect on children's learning outcomes (Kluczniok et al., 2013). These findings have resulted in initiatives to increase the quality of families' HLEs, thus creating early positive learning trajectories in order to prevent socially determined disparities in educational careers.

For that reason, early intervention programs have been developed to obviate learning difficulties and to promote health, children's development, and educational equality (Campbell et al., 2002; Cadima et al., 2017; Heckman et al., 2013). Furthermore, these programs aim to promote parents' knowledge, skills, and confidence and provide guidance on their children's development, the parent-child relationship, and parenting practices. In conclusion, it can be assumed that supporting parents in providing a rich HLE for their young children will have beneficial effects on children's early and later skill development. Furthermore, early positive experiences with family support services motivate parents to cooperate with and use further educational services in their children's later life.

In Germany, empirical evidence on the effectiveness of family and child support programs is rare. Furthermore, existing evaluation studies have been limited to cross-sectional study designs, which do not enable the identification of causal relationships between the program and outcomes (Van der Stede, 2014). For this reason, we will investigate in this study the longitudinal effects of the family support program Chancenreich. This program offers services for families with young children up to the age of three. We examine first the effects of the program on families' attendance rates at different course types and further educational services. Our second aim is to examine the effects of the program on the language development of children at the age of 5 , up to 2 years after completing the program.

The paper begins by introducing the theoretical framework of the HLE that this study applies in order to understand the relationships between the different aspects of children's environments and their effects on children's language skills. Section two provides a brief research review of the characteristics of successful family support programs and their longitudinal effects on children's language development. This chapter is followed by a description of the family support program
Chancenreich and the different course formats. Finally, our research questions are presented. Consequently, we describe the design of our study and the methodological approach used, before presenting our results and discussing them with regard to the status of present research, its limitations, and implications for research, practice, and policy.

\section{Home Learning Environment}

The underlying theory of the family's HLE is defined by the developmental and living conditions in which a child is brought up, including the levels of familial support and encouragement of the child's development (Lehrl, 2018). While many studies have explored and discussed the impact of the family's HLE on children's development (e.g., Gottfried et al., 1998; Melhuish et al., 2008; Niklas et al., 2015), few scientists have provided sound and comprehensive theoretical frameworks. According to Bronfenbrenner and Morris (2006) ProcessPerson-Context-Time (PPCT) model, children's development is affected by contextual, personal, and proximal processes. More specifically, Kluczniok et al. (2013) provide a synthesis of different theoretical assumptions and describe the quality of the home environment as a multidimensional concept comprising three different dimensions: structural quality, parental beliefs, and process quality. The structural aspects of the HLE relate to stable, long-lasting characteristics pertaining to family background and composition (e.g., parental educational level, socio-economic and immigration status, and the availability of learning materials). The second dimension describes educational beliefs, for example the educational aspirations and values regarding a child's upbringing and development. The third dimension - process quality - refers to activities and interactions between parents and their children, interactions among children, and the use of the spatial and material environment in the home. It is assumed that structural aspects and beliefs are directly related to process quality, which in turn directly affects the outcomes of children's development. Furthermore, several studies have shown that structural disadvantages also correlate with fewer positive interactions and fewer enriching activities (Bradley et al., 2001; Sylva et al., 2004). However, numerous researchers argue that structural aspects of the home environment do not entirely predetermine process quality (Sylva et al., 2004; Bornstein and Bradley, 2008).

The concept of the family intervention program Chancenreich can be linked to the structural-process model of the HLE. While considering the background characteristics of the families, Chancenreich focuses on supporting families' process quality as an important predictor for children's developmental outcomes.

\section{Family Support Programs}

Family support programs often comprise various approaches, e.g., house visits and parenting courses, that aim to promote parenting competences or support the parent-child relationship. First, these programs can be distinguished by their universal or target group approaches. Universal preventive programs are offered to all children and families without identifying the individual risk. In comparison, selective and indicated preventive interventions target families and children 
whose risk of developing difficulties or diseases is higher than average or who already face developmental problems (Mrazek and Haggerty, 1994).

Furthermore, Layzer et al. (2001) identify in their metaanalysis stronger positive effects for intervention programs which start earlier in children's lives, before problematic behavior occurs, and which involve parents in training courses provided by professional staff. For example, the results of a metaanalytic review of parent training programs designed to enhance behavior and adjustment in children aged 0-7 showed positive stronger effects from courses that combine a direct targeting of parenting skills and a focus on positive parent-child interaction and communication skills (Kaminski et al., 2008). In addition, programs with longer duration, and a more frequent and regular attendance of intervention programs, seem to be a predictor for better child and parent outcomes (Ramey and Ramey, 1998; Halpern, 2000; Denham and Burton, 2003; Nievar et al., 2010). Intervention programs with a broad approach, offering different services to the parents and children, show greater effects on children's outcomes than interventions that have a very narrow, focused goal. However, a broad approach might only be beneficial in the context of the methods and services offered, and not necessarily with regard to the targeted competences of the parents and children. Compared to these findings, Blok et al. (2005) establish no differentiating effects for program length, intensity, or long-term continuation.

Programs can be further distinguished by their delivery mode. Home-visit programs offer families tailored support in the context of their own homes, while center-based programs work directly with children in an institutionalized context. Research shows that the inclusion of home visits in the program may benefit children's development and improve the HLE (Kendrick et al., 2000), even though the meta-analyses of Sweet and Appelbaum (2004) and Filene et al. (2013) show that no specific home-visit program characteristic was related to the variation of the effects. Blok et al. (2005) reveal in their meta-analysis that, in particular, the combination of center-based and home-based programs is an important success factor.

\section{Longitudinal Effects of Family Support Programs}

One particular finding of longitudinal studies has been to establish the impressive cost-benefit advantages of early intervention programs (Shonkoff and Phillips, 2000; Karoly et al., 2005; Heckman, 2006) and positive detectable effects into adulthood (Reynolds et al., 2001; Nelson et al., 2003). However, we have little in-depth knowledge of these mechanisms and why temporary programs are still beneficial in later childhood.

On the one hand, Slavin et al. (1994) emphasize the beneficial effects of continuously interlinked support programs for children and families across age groups, although they note the difficulties in implementing them, since the early childhood education system is legally and organizationally fragmented due to different procedures in administration and funding (Reynolds et al., 2010). Ramey and Ramey (1998), on the other hand, hypothesize that skills developed earlier form the basis for future skills and, moreover, this skill base enables children to access and implement richer learning environments in a more efficient way. Furthermore, it is assumed that successful learning in early childhood may support the development of positive motivation and self-efficacy in children, promoting learning in later childhood as well. Similar effects can be assumed for the parents. Positive experiences in educational settings with very young children may encourage parents to become more involved in their children's later educational careers by using and demanding more services (Epstein and Sanders, 2000). Parental involvement in their children's development and education can also be transferred across settings (complementary learning). It can be assumed that parents who are familiar with the educational system are able to reduce uncertainty and to make good choices in the prospective educational careers of their children, particularly disadvantaged families who are usually underrepresented in involvement activities (Lösel, 2006; Dearing et al., 2009). Finally, parents who are interested and attentive with regard to their children's education act as role models for their children.

To summarize, we assume that supporting parents in providing a rich HLE for their children throughout childhood, as well as cumulative participation in family support services, have beneficial effects on children's skill development and parents' attendance rates in other educational services.

A variety of professional interventions have been developed worldwide to support parents, promote parenting skills, and raise parental self-efficacy with regard to educational tasks (Cadima et al., 2017). Chancenreich is one example of a family support program in Germany and will be described in the following chapter.

\section{The Chancenreich Program}

Chancenreich is a regional program implemented in Herford, a town in Germany (North Rhine-Westphalia). It aims to enhance parenting skills and child outcomes by offering a variety of services to all parents of children of up to 3 years of age (e.g., home visits, parenting courses), and is therefore considered a part of a universal approach. Chancenreich is unique in Germany for several reasons: (a) it is offered for free to all parents of newborns in the town, regardless of their social or cultural background; (b) it uses a modular approach consisting of many services with different content, from which parents can choose modules according to their needs; (c) Chancenreich offers a monetary incentive of $€ 500$ to all families who participate in at least five of these modules (Wilke et al., 2014). The five mandatory modules in the Chancenreich program relevant for the allocation of the monetary incentive are: use of home visits by pedagogical or pediatric staff, regular pediatric check-ups for the child, participation in a scientific evaluation of the program, enrolment of the child in an ECEC setting by the age of $3^{1}$, and

${ }^{1}$ In the year of the first measurement point of the surveys, 2014, the ECEC rates for the federal state North Rhine-Westphalia were $23.8 \%$ for children under the age of two and $92.4 \%$ for children over the age of three (https://www.destatis.de/DE/ZahlenFakten/GesellschaftStaat/Soziales/ Sozialleistungen/Kindertagesbetreuung/Tabellen/Tabellen_Betreuungsquote. html;jsessionid=32D1E08EC2C8E317BD27EC8B20C1F934.InternetLive1, 07.12.2018). 
the completion of the parenting training module. In this study, we focus on the specific effects of this parenting training module.

The parenting training module offers parents a variety of courses, which differ in their approach, content, length, and intensity of family participation. We categorized the different course formats according to their respective goals, content, and delivery format and labeled them 'parenting-skills focused' and 'parent-child-interaction focused' (Layzer et al., 2001).

\section{Parenting-Skills Focused Courses}

Parenting-skills focused courses are attended exclusively by the parents. Courses of this type primarily focus on the parents and their parenting behaviors and skills. Hence, these courses usually have a stronger educational focus and parents receive feedback about their own behavior from other parents and from the instructor. Additionally, they are given input on their child's development. Parents usually attend these courses for a set period, such as 8 or 10 weeks, and they visit the classes without their child. These courses are developed for parents with toddlers; they are based on cognitive behavioral theories or individual-psychological theories, and aim to help parents prevent child behavior problems (Nowak and Heinrichs, 2008). Examples of parenting-skills focused courses that are common in the Chancenreich program are Triple $\mathrm{P}$ and Strong parents - strong kids. Triple $\mathrm{P}$ is a widely-evaluated parenting course format which has been established to produce positive effects by reducing negative and inconsistent parenting practices (Sanders, 1999; Sanders et al., 2000, 2003). The parents' course Strong Parents - Strong Children aims at strengthening parental skills and thus promotes the development and implementation of a non-violent upbringing. The results of an evaluation study showed that parents were able to increase their self-efficacy and positive parental behavior, reduce negative behavior patterns and parents rated the social behavior of their children as better after attending the course (Rauer, 2009). Previous research on parenting-skills focused courses has demonstrated that parents showed less dysfunctional parenting behavior and an increase in positive parenting behavior and parenting competency (de Graaf et al., 2008; Hahlweg et al., 2010). Early participation in these courses might have an early preventive effect, before a child begins to exhibit problematic behavior.

\section{Parent-Child-Interaction Focused Courses}

Parent-child-interaction courses focus on the overall development of the child and include components that promote parent-child interaction and bonding, while also helping to build social networks among parents (Layzer et al., 2001; Thomas, 2013). Activities involving the participation of both the child and their parents ${ }^{2}$ are central components of these courses. These child-focused programs are usually offered to parents of infants and toddlers. This type of course is very popular in Germany: a third of parents with children below

${ }^{2}$ Usually one caregiver participates in parent-child-interaction courses, typically the mother. the age of 3 attends parent-child groups of this kind (Mühler and Spieß, 2008). The following courses are very well-received by parents and are therefore offered within the Chancenreich program:: Pekip (Höltershinken, 2011), Fun Baby (TschöpeScheffler, 2006), or baby massage courses (Brisch and Hellbrügge, 2010).

Pekip (Prague Parent Child Program) and Fun Baby courses are aimed at parents with babies and toddlers. Together with other parents and babies, the motor skills, the baby's senses and the parent-child interaction are developed in a playful way in a group. Participating parents of the Pekip courses reported, for example, that they are becoming increasingly sensitive to their children (Höltershinken, 2011). The baby massage courses, on the other hand, are designed to promote the baby's healthy physical, social, and emotional development and foster a positive mother-child bond.

At the second point of measurement, the approach of these courses is adapted to the age of the children. Beyond the age of 3 , parent-child-interaction focused courses typically consists of courses designed for joint activities between parents and their children, such as parent-child gymnastics.

Both the parent-child-interaction focused courses and parenting-skills focused courses are implemented in the parenting training module of Chancenreich, but it should be mentioned that they are part of the open educational market. In this case, such courses must be organized and financed by the parents themselves. This can be a challenge for many parents dealing with financial or social challenges, resulting in lower participation rates in such course formats. In comparison, the Chancenreich program offers these courses to all parents free of charge, organizes the courses close to the parents' home and, for example, also reminds them of the next course session. As a result, his offers a lower threshold for disadvantaged parents to participate in such courses.

\section{Early-Education Focused Courses}

Another course format becomes more relevant to a child's life as they get older: early-education focused courses. These courses are not provided by the Chancenreich program, because the target age group of this format is beyond their age of interest (children from ages 3 and older). However, these courses become more relevant in preschool age, and need to be considered when investigating the potential effects of different courses both on the later usage of educational services and on children's development.

Early-education focused courses consist of all types of adultsupervised activities for children that provide opportunities to develop specific skills or knowledge and take place outside the home or preschool. These courses are widely used and available on the educational market. There exists a broad range of activities that are included in this format, e.g., sport classes, early music education classes, creativity classes, and so on. In contrast to the parent-child-interaction focused courses, the child's activity is central, with parents participating, but in a less active, more observational role. These courses are mostly offered to children from ages 3 and older, and research shows benefits of early-education focused courses for children's socio-emotional 
and cognitive outcomes (Metsäpelto and Pulkkinen, 2014; Carolan, 2018).

\section{Research Questions}

To understand the role of family background characteristics in predicting the selection of certain course types, we must first examine the following questions:

- What is the relationship between family characteristics and attendance rates of different course formats of the Chancenreich program at the first and second point of measurement?

Assuming that parental participation in family support services in their children's early years has beneficial effects on parental involvement in their child's development and educational career (Slavin et al., 1994; Ramey and Ramey, 1998; Epstein and Sanders, 2000), we ask:

- What is the relationship between attendance rates for the Chancenreich program and further attendance of courses after completion of the program?

While parent-child-interaction courses focus on the relationship between parents and children, with the children themselves participating in an activity, the participation in parenting-skill focused courses give parents the opportunity to reflect on their parenting behavior and to learn new successful strategies to improve process quality. For that reason, both of the program's course types can be seen as a strategy for improving families' process quality. Drawing on the theoretical model of the HLE, and research evidence on the effects of family support programs on children's development, this paper's other two key research questions are:

- What are the effects of the different course formats of the Chancenreich program on children's levels of language development at the age of 5 ?

- What are the effects of the different course formats of the Chancenreich program on children's language development between the ages of 3 and 5 ?

\section{MATERIALS AND METHODS}

\section{Design}

The data come from the AQuaFam study, which examined the Chancenreich family support program. AQuaFam follows a longitudinal, quasi-experimental design with two points of measurement; it has an intervention group (families who attended the Chancenreich program) and a comparison group. The study consists of data from parents and their children. The data collection for the first time of measurement (T1) took place between November 2013 and May 2014, and for the second measurement (T2) between March and June 2016. For both times of measurement, trained research staff collected data from the families through a standardized family interview, a parents' questionnaire, and by conducting standardized tests of each child's language development at the family's home. Parents have signed an informed consent form to participate in the study.

\section{Participants}

The families of the intervention group were recruited in the town of Herford, Germany, where the Chancenreich program is based. Due to ethical considerations and for reasons of recruitment, families of the comparison group were recruited in a neighboring town through notices in early childcare settings, family education centers, pediatricians' offices, and newsletters ${ }^{3}$.

At the first time of measurement (T1) in 2014, the sample consisted of 184 families in the intervention group who attended the Chancenreich program, and 58 families in the comparison group who did not participate in the program. At $\mathrm{T} 1$ the children had an average age of 41 months old. The same families were asked to participate in the study again 24 months later (T2). Children were now an average of 68 months old. For T2 66\% $(N=121)$ of the families from T1 also participated in the second point of measurement in our study, while $71 \%(N=41)$ of the families from the comparison group participated at T2. In order to check whether the composition of the sample has changed significantly, the families dropped out of the study were examined with regard to certain characteristics such as poverty, migration background and the mother's university degree. Significant differences were found between the families that participated at the second measurement point and those that no longer participated. In the group of families who didn't participate at the study anymore the proportion of poor families was twice as high $(33 \%)$ as in the group of families that remained in the study. The change in the sample composition led to the tendency for the comparison group and the Chancenreich group to converge in their socio-structural composition. The overall response rate of $68.5 \%$ can be considered very good for such studies. Table 1 shows the descriptive statistics for child and family characteristics by both groups at the second point of measurement. The specific composition of the intervention and comparison group must be taken into account when interpreting the results.

\section{Measures}

\section{Language Development}

Two main indicators that reflect the language development of children were measured by using standardized instruments: the Peabody Picture Vocabulary Test - Third Edition (PPVT-III) and the TROG-D. The German research version of the PPVT (Dunn and Dunn, 1997; Roßbach et al., 2005) captures the child's receptive vocabulary and was assessed at both points of measurement, that is the ages of 3 and 5. In this test, children were asked to select the correct picture from a set of four pictures for each given word. The test covered 40 items. The PPVT is one of the most widely used instruments of its kind and reports high internal consistency. A mean score of the PPVT was calculated for the analysis with a theoretical range between 0 and 1. In our sample we found ceiling effects at the second point of measurement (Chancenreich group T1: $M=0.78, S D=0.21$; T2: $M=0.96, S D=0.09$; Comparison group T1: $M=0.81$, $S D=0.18 ; \mathrm{T} 2: M=0.98, S D=0.04)$. The German version of the TROG (TROG-D; Fox, 2013) assesses the child's receptive

\footnotetext{
${ }^{3}$ The comparison group was recruited in another town because almost all families
} in the town where Chancenreich is implemented took part in the program. 
TABLE 1 | Descriptive statistics for familial and individual children's characteristics by intervention and comparison group for the second point of measurement.

\begin{tabular}{|c|c|c|c|c|}
\hline & Intervention group & Comparison group & & \\
\hline & $\% / M(S D)$ & $\% / M(S D)$ & $t$-tests & $\chi^{2}$ - tests \\
\hline Age & $68.98(5.55)$ & $63.51(8.36)$ & $t_{(157)}=-4.69^{\star \star \star}$ & - \\
\hline Female & $45.45 \%$ & $53.85 \%$ & - & $\chi^{2}(1)=0.83$ \\
\hline First-born & $60.50 \%$ & $69.23 \%$ & - & $x^{2}(1)=0.96$ \\
\hline Mother graduated from university ${ }^{a}$ & $36.67 \%$ & $61.54 \%$ & - & $\chi^{2}(1)=7.44^{* *}$ \\
\hline Main spoken language at home ${ }^{b}$ & $22.31 \%$ & $7.69 \%$ & - & $x^{2}(1)=4.14^{*}$ \\
\hline Net equivalent household disposable income ${ }^{c}$ & $1545.87(551.68)$ & $1656.22(439.23)$ & $t_{(149)}=1.12$ & - \\
\hline Poverty $(<€ 1,033)$ & $20.35 \%$ & $7.89 \%$ & - & $\chi^{2}(1)=3.10$ \\
\hline Home learning environment & $4.15(0.69)$ & $4.29(0.50)$ & - & \\
\hline
\end{tabular}

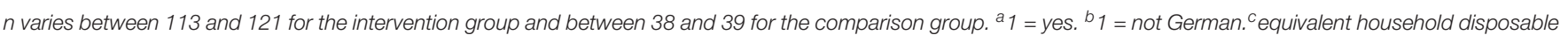
income (Eurostat, 2018). ${ }^{*} p<0.05,{ }^{* *} p<0.01,{ }^{* * *} p<0.001$.

understanding of grammar and was only conducted at the second point of measurement (Chancenreich group: $M=60.84$, $S D=10.43$ Comparison group: $M=58.68, S D=16.48)$. This grammar comprehension test examines the understanding of the grammatical structures of the German language, which are marked by inflection, functional words, and sentence order. This is assessed using target sentences and four pictures, one of which matches the target sentence. The German version of the test consists of 21 item groups of four items each (Lüke et al., 2016).

\section{Course Formats}

As described earlier, the parent-child-interaction focused courses and parenting-skills focused courses are part of the Chancenreich program (and thus relevant for the intervention group) for children up to 3 years old. For that reason, we included the grouping variable in our models of analysis. Further, since these courses do exist on the open market, it cannot be entirely ruled out that comparison group families may attend these courses voluntarily. For that reason, participation in parent-childinteraction focused courses and parenting-skills focused courses was assessed for both the intervention and the comparison group families at the two points of measurement. At the second time of measurement, the Chancenreich families have already completed the program, but they still often attend other courses, as did the families from the comparison group. Additionally, at the second time of measurement, the families were asked about their attendance of early education-focused courses. Parents were asked which courses they had attended exclusively as parents or together with their children, using an open response format. The courses were then summed up and included in the analysis as the number of attended courses. For further analysis, we also calculated the total number of course attendances at the second point of measurement.

Table 2 shows those numbers of courses attended per category by both groups. Both groups attended more parentchild-interaction focused courses when their children were aged 3 (T1) than when they were aged 5 (T2). At the second point of measurement children mostly participated at earlyeducation focused courses. There were no significant differences between the intervention group and the comparison group across all course types.

\section{Control Variables}

In order to take into account the differences between the intervention and comparison group and to avoid any confusion of background characteristics with the model predictors, the following general sociodemographic and specific child characteristics were included in all analyses: children's age and sex, main spoken language at home, net equivalent household disposable income adjusted by the modified equivalent scale of the Organisation for Economic Co-operation and Development (OECD) (Eurostat, 2018), the mother's highest educational degree, the child's birth order status, and the family's HLE. For the latter one, parents were asked how often they engage in home learning activities with their children, ranging between never (0) and every day (7). The measure consists of 31 items (Cronbach's $\alpha=0.86$ ) representing the domains numeracy, science, reading, conversation, and creative and practical activities (e.g., 'Practicing singular numbers or counting together with the child, e.g., counting fingers or throwing dice').

\section{Data Analyses}

The data was checked for missing data and outliers and missing data patterns were analyzed. The percentage of missing data from the variables was $1.2-5.6 \%$. The MCAR test according to Little (1988) indicated that the missing data was missing completely at random (MCAR; $\left.\chi^{2}=43.82, d f=31, p>0.05\right)$. Under

TABLE 2 | Descriptive statistics for families' course participation by intervention and comparison group for the first and second point of measurement.

\begin{tabular}{|c|c|c|c|c|}
\hline & \multirow[t]{2}{*}{ Course types } & $\begin{array}{l}\text { Intervention } \\
\text { group }^{a}\end{array}$ & $\begin{array}{c}\text { Comparison } \\
\text { group }^{b}\end{array}$ & \multirow[b]{2}{*}{$t$-Test } \\
\hline & & $M(S D)$ & $M(S D)$ & \\
\hline \multirow[t]{2}{*}{ T1 } & Parent-child-interaction & $0.78(0.49)$ & $1.03(0.90)$ & $t_{(157)}=0.03$ \\
\hline & Parenting-skills & $0.28(0.49)$ & $0.21(0.41)$ & $t_{(157)}=-0.09$ \\
\hline \multirow[t]{3}{*}{$\mathrm{T} 2$} & Parent-child-interaction & $0.14(0.35)$ & $0.18(0.39)$ & $t_{(158)}=0.059$ \\
\hline & Parenting-skills & $0.12(0.35)$ & $0.21(0.41)$ & $t_{(158)}=1.34$ \\
\hline & Early-education focused & $1.88(1.51)$ & $2.03(1.60)$ & $t_{(158)}=0.50$ \\
\hline
\end{tabular}

The t-test showed no significant differences by group. ${ }^{a} n$ varies between 120 and 121 for the intervention group. ${ }^{b} n=39$. 
the condition that data is completely missing at random, Full Information Maximum-Likelihood (FIML) approach estimates are the most reasonable method to estimate missing data (Enders and Bandalos, 2001). Even though the amount of missing data was generally low, we conducted the FIML approach in all regression models to minimize bias in parameter estimates (Eid et al., 2013).

With multiple regression analyses, Mahalanobis distance scores were generated. Since two cases were above the Mahalanobis distance threshold of $\chi^{2}(14)=36.12$, they were removed for the following analyses (Tabachnick and Fidell, 2007).

OLS multiple regression analysis were conducted to predict: (1) the attendance rates of different course types at two points of measurements, (2) the attendance rates predicted by family background characteristics, (3) the children's level of development at the second time of measurement, and to predict (4) the children's development between the first and second time of measurement. For the latter, the children's outcomes at the first time of measurement were included in the OLS multiple linear regression models.

For the third and the fourth aims, three OLS regression analyses were conducted for each child outcome: model A includes the grouping variable, where the comparison group served as the reference group; model B includes the families' total number of attended courses for each of the categories category "parent-child-interaction focused courses" and "parenting-skills focused courses" at the first and second time of measurement. Finally, model $\mathrm{C}$ combines models $\mathrm{A}$ and $\mathrm{B}$ by including the grouping variable, the families' participation in courses at the first and second time of measurement. For all regression models, the control variables were included in the analysis.

MLR estimator was used because of its robustness according to a violation of the normality assumption (Christ and Schlüter, 2012). All analyses were conducted with Mplus (Version 7.0, Muthén and Muthén, 1998-2012), and SPSS (Version 25.0, IBM Corp, 2017).

\section{RESULTS}

\section{Course Participation}

We first examined the relationship between the number of courses attended and sociodemographic and child characteristics at both times of measurement for the Chancenreich families (Table 3) and the comparison group families (Table 4). The findings presented in Table 3 reveal that children being firstborns $(\beta=0.23 ; S E=0.09 ; p=0.009)$ and the level of joint activities at home $(\beta=-0.22 ; S E=0.10 ; p=0.03)$ were significant predictors for the number of parent-childinteraction focused courses a Chancenreich family attends at the first time of measurement. Parents are more likely to attend these courses with their first-born children. In addition, parents who report engaging in few joint activities with their children at home also attend these courses more often. At the same time, we find that first born status had a significantly negative regression weight on attendance of parenting-skills focused courses $(\beta=-0.32 ; S E=0.09 ; p=0.001)$. After the Chancenreich program has ended, these families still attend courses regardless of their educational background and income. However, we find income to be a significant positive predictor for the attendance of early-educational courses $(\beta=0.24$; $S E=0.07 ; p=0.005)$. Furthermore, children from families whose predominant language at home is not German attend fewer parent-child-interaction focused courses after completing the $\operatorname{program}(\beta=-0.14 ; S E=0.07 ; p=0.04)$.

Among the families in the comparison group (Table 4), we see a slightly different pattern compared to the Chancenreich families. When predicting the number of attended parent-childinteraction courses at the first point of measurement the mother's highest educational level was a significant predictor $(\beta=0.36$; $S E=0.11 ; p=0.001)$. Furthermore, mothers with a higher educational level attend parenting-skills courses more frequently at the second time of measurement when the children are aged $5(\beta=0.26 ; S E=0.13 ; p=0.04)$. Similar to the Chancenreich families, we found that parents of 5-year-old children from the comparison group attend few parent-child-interaction focused courses if the main language spoken at home is not German $(\beta=-0.20 ; S E=0.08 ; p=0.02)$ and if they engage in a higher number of joint activities with their child at home $(\beta=0.32$; $S E=0.11 ; p=0.003)$.

This means that we do indeed find different patterns in attendance rates with regard to child and family characteristics. This illustrates that socio-economic aspects (e.g., the mother's education) for families in the comparison group are predictive of participation in such courses. For the Chancenreich families the quality of HLE is more relevant.

Regarding the second research question, we asked what relationships exist between the attendance of the Chancenreich program and further attendance of courses after completion of the program. We conducted five OLS multiple regression models for the number of attended courses at $\mathrm{T} 2$ on course attendance at T1, presented as rows in Table 5. The first model (M1) includes as a predictor the parent-child-interaction focused courses at the first point of measurement; M2 includes the parenting-skills focused courses at T1; M3 includes only the group variable; M4 includes the parent-child-interaction focused courses and group variables; and M5 includes the parenting-skills focused courses and the group variable. We controlled for family and child characteristics in all conducted regression models.

We found no significant association between the attendance of courses at the first and the second time of measurement. This means that the attendance of courses when the children were 3 years old had no effect on the attendance of courses when the children were 5 years old.

\section{Language-Related Outcomes for Children Aged 5}

Following research question three, we examined what effect the Chancenreich program and the different course formats have on children's levels of language development at the age of 5 . Table 6 presents the results of three regression models for each language outcome, both vocabulary (PPVT) and understanding 
TABLE 3 | OLS regression analysis of number of courses attended by the parents of the Chancenreich program according to sociodemographic and children's characteristics.

\begin{tabular}{|c|c|c|c|c|c|}
\hline \multirow[b]{3}{*}{ Characteristics } & \multicolumn{2}{|c|}{ T1 } & \multicolumn{3}{|c|}{ T2 } \\
\hline & $\begin{array}{l}\text { Parent-child- } \\
\text { interaction courses }\end{array}$ & $\begin{array}{l}\text { Parenting-skills } \\
\text { courses }\end{array}$ & $\begin{array}{l}\text { Parent-child- } \\
\text { interaction courses }\end{array}$ & $\begin{array}{l}\text { Parenting-skills } \\
\text { courses }\end{array}$ & $\begin{array}{c}\text { Early-educational } \\
\text { courses }\end{array}$ \\
\hline & $\beta$ & $\beta$ & $\beta$ & $\beta$ & $\beta$ \\
\hline Child's age & $-0.16(0.10)$ & $0.13(0.08)$ & $-0.13(0.08)$ & $-0.06(0.10)$ & $0.24^{\star \star}(0.07)$ \\
\hline Female & $0.06(0.09)$ & $-0.07(0.09)$ & $0.04(0.09)$ & $-0.13(0.07)$ & $0.18^{\star}(0.08)$ \\
\hline First-born & $0.23^{\star \star}(0.09)$ & $-0.32^{\star \star}(0.09)$ & $0.13(0.08)$ & $-0.03(0.10)$ & $0.07(0.08)$ \\
\hline Mother graduated from university ${ }^{a}$ & $0.11(0.09)$ & $-0.05(0.09)$ & $0.16(0.10)$ & $-0.09(0.78)$ & $0.09(0.09)$ \\
\hline Net equivalent household disposable income ${ }^{b}$ & $0.06(0.11)$ & $0.00(0.10)$ & $0.02(0.10)$ & $-0.12(0.10)$ & $0.24^{\star \star}(0.09)$ \\
\hline Main spoken language at home ${ }^{C}$ & $0.09(0.11)$ & $-0.10(0.09)$ & $-0.14^{\star}(0.07)$ & $-0.07(0.11)$ & $-0.08(0.08)$ \\
\hline HLE & $-0.22^{*}(0.10)$ & $0.14(0.08)$ & $0.04(0.09)$ & $0.24^{\star}(0.10)$ & $0.07(0.07)$ \\
\hline$R^{2}(\mathrm{SE})$ & $0.13^{\star}(0.06)$ & $0.13^{\star}(0.05)$ & $0.10 *(0.04)$ & $0.10(0.06)$ & $0.24^{\star \star \star}(0.07)$ \\
\hline
\end{tabular}

Standard errors are in parentheses. ${ }^{a} 1=$ yes; ${ }^{\circ}$ equivalent household disposable income (Eurostat, 2018$) ;{ }^{c} 1=n o t$ German. $n=121 .{ }^{*} p<0.05 ;{ }^{* *} p<0.01 ;{ }^{* * *} p<0.001$.

TABLE 4 | OLS Regression analysis of number of courses attended by the parents of the comparison group according to child and sociodemographic characteristics.

\begin{tabular}{|c|c|c|c|c|c|}
\hline \multirow[b]{3}{*}{ Characteristics } & \multicolumn{2}{|c|}{ T1 } & \multicolumn{3}{|c|}{ T2 } \\
\hline & $\begin{array}{l}\text { Parent-child- } \\
\text { interaction courses }\end{array}$ & $\begin{array}{l}\text { Parenting-skills } \\
\text { courses }\end{array}$ & $\begin{array}{l}\text { Parent-child- } \\
\text { interaction courses }\end{array}$ & $\begin{array}{l}\text { Parenting-skills } \\
\text { courses }\end{array}$ & $\begin{array}{c}\text { Early-educational } \\
\text { courses }\end{array}$ \\
\hline & $\beta$ & $\beta$ & $\beta$ & $\beta$ & $\beta$ \\
\hline Child's age & $-0.23(0.12)$ & $0.18(0.12)$ & $0.03(0.13)$ & $-0.01(0.14)$ & $0.26(0.15)$ \\
\hline Female & $0.34^{\star \star}(0.11)$ & $-0.19(0.17)$ & $0.09(0.19)$ & $0.08(0.14)$ & $0.12(0.17)$ \\
\hline First-born & $0.47^{\star \star \star}(0.13)$ & $-0.01(0.16)$ & $0.18(0.15)$ & $-0.08(0.17)$ & $0.40^{\star \star}(0.13)$ \\
\hline Mother graduated from university ${ }^{a}$ & $0.36^{\star \star}(0.11)$ & $-0.11(0.15)$ & $0.29(0.17)$ & $0.26^{\star}(0.13)$ & $0.12(0.18)$ \\
\hline Net equivalent household disposable income ${ }^{b}$ & $0.23(0.12)$ & $0.24(0.14)$ & $-0.05(0.14)$ & $0.23(0.15)$ & $0.02(0.16)$ \\
\hline Main spoken language at home ${ }^{c}$ & $-0.02(0.15)$ & $0.30(0.16)$ & $-0.20^{\star}(0.08)$ & $0.03(0.19)$ & $0.07(0.10)$ \\
\hline HLE & $0.13(0.13)$ & $0.12(0.16)$ & $0.32^{\star \star}(0.11)$ & $0.13(0.11)$ & $0.10(0.14)$ \\
\hline$R^{2}$ (SE) & $0.52^{\star \star \star}(0.11)$ & $0.24(0.12)$ & $0.17(0.11)$ & $0.13(0.11)$ & $0.19(0.11)$ \\
\hline
\end{tabular}

Standard errors are in parentheses. ${ }^{a} 1=$ yes. ${ }^{b}$ equivalent household disposable income (Eurostat, 2018$) .{ }^{c} 1=n o t$ German. $n=39 .{ }^{*} p<0.05 ;{ }^{* *} p<0.01 ;{ }^{* * *} p<0.001$.

TABLE 5 | OLS Multiple Regression analysis of number of attended courses by the parents at T2 on participation in Chancenreich program and courses participation at $\mathrm{T} 1$.

Number of courses T2

\begin{tabular}{|c|c|c|c|c|c|c|c|c|c|}
\hline \multirow[b]{2}{*}{ T1 } & & \multicolumn{2}{|c|}{$\begin{array}{l}\text { Parent-child- } \\
\text { interaction-courses }\end{array}$} & \multicolumn{2}{|c|}{$\begin{array}{l}\text { Parenting-skills } \\
\text { courses }\end{array}$} & \multicolumn{2}{|c|}{$\begin{array}{l}\text { Early-education } \\
\text { courses }\end{array}$} & \multicolumn{2}{|c|}{$\begin{array}{l}\text { Total number } \\
\text { of courses }\end{array}$} \\
\hline & & $\beta$ & $R^{2}$ & $\beta$ & $R^{2}$ & $\beta$ & $R^{2}$ & $\beta$ & $R^{2}$ \\
\hline M1 & Parent-child-interaction courses & $-0.09(0.08)$ & $0.10^{\star \star}(0.04)$ & $0.14(0.09)$ & $0.07(0.04)$ & $0.09(0.08)$ & $0.20^{\star \star \star}(0.05)$ & $0.10(0.08)$ & $0.20^{\star \star \star}(0.06)$ \\
\hline $\mathrm{M} 2$ & Parenting-skills courses & $0.14(0.09)$ & $0.11^{\star \star}(0.04)$ & $0.02(0.08)$ & $0.05(0.04)$ & $0.04(0.07)$ & $0.19^{\star \star \star}(0.05)$ & $0.08(0.07)$ & $0.19^{\star \star \star}(0.05)$ \\
\hline M3 & Group (1 = Chancen-reich) & 0.07 (0.09) & $0.10^{*}(0.04)$ & $-0.08(0.09)$ & $0.06(0.03)$ & $-0.05(0.09)$ & $0.19^{\star \star \star}(0.05)$ & $-.05(0.08)$ & $0.19^{\star \star \star}(0.05)$ \\
\hline \multirow[t]{2}{*}{ M4 } & Parent-child-interaction courses & $-0.09(0.07)$ & $0.10^{\star \star}(0.04)$ & $0.14(0.09)$ & $0.07(0.04)$ & $0.09(0.08)$ & $0.20^{\star \star \star}(0.05)$ & $0.10(0.08)$ & $0.20^{\star \star \star}(0.06)$ \\
\hline & Group (1 = Chancen-reich) & $0.07(0.09)$ & & $-0.08(0.09)$ & & $-0.05(0.08)$ & & $-0.05(0.08)$ & \\
\hline \multirow[t]{2}{*}{ M5 } & Parenting-skills courses & $0.07(0.09)$ & $0.12^{\star \star}(0.04)$ & $0.02(0.08)$ & $0.06(0.04)$ & $0.04(0.07)$ & $0.19^{\star \star \star}(0.05)$ & $0.08(0.07)$ & $0.20^{\star \star \star}(0.05)$ \\
\hline & Group (1 = Chancen-reich) & $0.14(0.09)$ & & $-0.08(0.09)$ & & $-0.05(0.09)$ & & $-0.05(0.08)$ & \\
\hline
\end{tabular}

Standard errors are in parentheses. All models control for child's age, sex, and first-born status, mother's university degree, equivalent household disposable income, main spoken language at home, and home learning environment. $n=160 .{ }^{*} p<0.05 ;{ }^{* *} p<0.01 ;{ }^{* *} p<0.001$.

of grammatical structure (TROG-D). No statistically significant differences were found between the children of the Chancenreich group and the comparison group regarding their vocabulary and their understanding of grammatical structure when considering all control variables. However, the attendance of parenting-skills courses is associated with a stronger vocabulary in children at the 
TABLE 6 | OLS Regression models on the level of vocabulary (PPVT) and understanding of grammar structure (TROG-D).

\begin{tabular}{|c|c|c|c|c|c|c|}
\hline & \multicolumn{3}{|c|}{ PPVT } & \multicolumn{3}{|c|}{ TROG-D } \\
\hline & (a) & (b) & (c) & (a) & (b) & (c) \\
\hline & $\beta$ & $\beta$ & $\beta$ & $\beta$ & $\beta$ & $\beta$ \\
\hline Group $^{a}$ & $-0.10(0.06)$ & & $-0.08(0.06)$ & $0.08(0.10)$ & & $0.07(0.10)$ \\
\hline \multicolumn{7}{|l|}{ Number courses $\mathrm{T} 1$} \\
\hline Parent-child-interaction courses & & $-0.02(0.06)$ & $-0.02(0.06)$ & & $-0.15(0.13)$ & $-0.15(0.13)$ \\
\hline Parenting-skills courses & & $0.08(0.05)$ & $0.08(0.05)$ & & $-0.16(0.09)$ & $-0.16(0.09)$ \\
\hline \multicolumn{7}{|l|}{ Number courses T2 } \\
\hline Parent-child-interaction courses & & $-0.08(0.06)$ & $-0.07(0.06)$ & & $0.09(0.07)$ & $0.08(0.07)$ \\
\hline Parenting-skills courses & & $0.09^{\star *}(0.03)$ & $0.09^{\star \star}(0.03)$ & & $0.00(0.06)$ & $0.01(0.06)$ \\
\hline Early-education courses & & $0.11(0.06)$ & $0.10(0.06)$ & & $0.06(0.10)$ & $0.07(0.10)$ \\
\hline$R^{2}$ (SE) & $0.13^{\star}(0.05)$ & $0.14^{\star \star}(0.05)$ & $0.15^{\star \star}(0.05)$ & $0.08(0.04)$ & $0.11^{*}(0.06)$ & $0.11^{*}(0.06)$ \\
\hline
\end{tabular}

Standard errors are in parentheses. ${ }^{a} 1$ = Chancenreich. Models a, b, c: controlling for child's age, sex, and first-born status, mother's university degree, equivalent household disposable income, main spoken language at home, and home learning environment. $n=160 .{ }^{*} p<0.05$; ${ }^{* *} p<0.01 ;{ }^{* * *} p<0.001$.

age of 5 (Model b: $\beta=0.09 ; S E=0.03 ; p=0.005$; Model c: $\beta=0.09$; $S E=0.03 ; p=0.009)$. We found no further relationship regarding the attendance of the other course formats at the first and second point of measurement.

\section{Language Development for Children Between the Ages of 3 and 5}

Finally, we examined the effects of Chancenreich and the three different course formats on the development of children's vocabulary skills between the ages of 3 and 5. For this purpose, we added the PPVT score at the first measuring point as a predictor to the previous regression model (see Table 6) in order to interpret the coefficients as effects on development.

The findings in Table 7 show a significant, positive effect of parenting-skills focused courses on the development of

TABLE 7 | OLS Regression models on vocabulary development (PPVT) between the ages of 3 and 5 .

\begin{tabular}{|c|c|c|c|}
\hline & \multicolumn{3}{|c|}{ PPVT } \\
\hline & (a) & (b) & (c) \\
\hline & $\beta$ & $\beta$ & $\beta$ \\
\hline PPVT T1 & $0.58^{\star \star \star}(0.13)$ & $0.62^{\star \star \star}(0.11)$ & $0.62^{\star \star \star}(0.12)$ \\
\hline Group $^{a}$ & $0.03(0.07)$ & & $0.05(0.07)$ \\
\hline \multicolumn{4}{|l|}{ Number courses T1 } \\
\hline Parent-child-interaction courses & & $-0.07(0.07)$ & $-0.06(0.06)$ \\
\hline Parenting-skills courses & & $0.14^{\star}(0.06)$ & $0.15^{\star}(0.06)$ \\
\hline \multicolumn{4}{|l|}{ Number courses T2 } \\
\hline Parent-child-interaction courses & & $-0.08(0.05)$ & $-0.09(0.05)$ \\
\hline Parenting-skills courses & & $0.09^{\star}(0.04)$ & $-0.06(0.04)$ \\
\hline Early-education courses & & $0.04(0.05)$ & $0.05(0.05)$ \\
\hline$R^{2}$ (SE) & $0.32^{\star \star}(0.11)$ & $0.37^{\star \star}(0.12)$ & $0.36^{\star *}(0.11)$ \\
\hline
\end{tabular}

Standard errors are in parentheses. ${ }^{a} 1=$ Chancenreich. $n=160$. Models $a, b, c$ : controlling for child's age, sex, and first-born status, mother's university degree, equivalent household disposable income, main spoken language at home, and home learning environment. ${ }^{*} p<0.05 ;{ }^{* *} p<0.01$; ${ }^{* * *} p<0.001$. vocabulary skills (Model b: $\beta=0.14 ; S E=0.06 ; p=0.02$; Model c: $\beta=0.15$; $S E=0.06, p=0.01)$. Children of parents who have attended more parenting-skills focused courses by the age of 3 exhibit better vocabulary development than children whose parents attended fewer courses. No effects were found for the participation in the Chancenreich program and for the attendance of the other course formats at the first and second point of measurement. This means that the effect can only be due to participation in parenting-skills focused courses.

\section{DISCUSSION}

Mastering language development is one of the major developmental milestones in early childhood; it plays a key role not only for the ability of children to interact with their social environment, but also impacts their early and later academic success (Hoff, 2006).

According to the theoretical model of the HLE, the structural characteristics of the family and the educational beliefs of the parents are related to process quality, this last element itself being directly related to the child's outcomes (Kluczniok et al., 2013). Families that are prevented from providing a rich HLE are defined as disadvantaged (Melhuish et al., 2008). Intervention programs are developed to encourage these parents in their theoretical knowledge and in their practical parenting skills. However, there exists little evidence on the long-term effects of family support programs in Germany. For this reason it is interesting to understand how early family support of HLE can affect core language competences (e.g., receptive vocabulary, grammar structure). Chancenreich is one example of a family support program that offers families different services in a modular approach. One of the modules is the parent training module. It consists of courses that focus either on parent-childinteraction or on parenting skills. In this paper we examined, on the one hand, the attendance patterns of families in different course types when the children were 3 and 5 years old, and on the other hand, the effects of the family support program 
Chancenreich and different course formats - first on children's vocabulary and understanding of grammatical structure and second on children's vocabulary development between the ages of 3 and 5, which is considered a core competence of language development in early childhood.

\section{Course Participation}

Many family support programs struggle with hard-to-reach families, e.g., socio-economically deprived families or families with a migration background (Cortis et al., 2009; Boag-Munroe and Evangelou, 2010). For this reason, we first examined the role of both a family's sociodemographic characteristics and the child's own characteristics in parental course participation at the first and second point of measurement. The results show a relationship between course participation and several child characteristics. Parents with younger children attend more parent-child-interaction focused courses at the first time of measurement, which can be explained by the content orientation of these courses, which is more appropriate for younger children. In contrast, older children attend early-education focused courses more often. Furthermore, we found a positive 'first-born effect' for parent-child-interaction focused courses and parenting-skills focused courses at the first time of measurement, and a positive effect for the number of early-education focused courses attended at the second point of measurement. These results corroborate existing research on parental time investment and the number of siblings: first-born children are, at least for a period in their early lives, by definition the only child in which parents invest their time and resources (Lawson and Mace, 2009). Therefore, parents might have more time to invest in their child's development and as a result, participate in these courses. Family support programs can address these findings in promoting courses for a second child, or in supporting parents of multiple children by adapting the content of the courses to these particular needs.

Further findings with regard to the Chancenreich families revealed the positive effect of financial resources on the number of early education courses attended at T2, and for the comparison group the positive effect of a higher educational background of the mother on the number of parenting-skills focused courses attended at $\mathrm{T} 1$ and $\mathrm{T} 2$. The findings confirm existing research on the important role of structural familial characteristics in the use of educational services (Dearing et al., 2009; Carolan, 2018). Both course formats are not developed specially for the Chancenreich program, but are rather offered to all parents on the open educational market of early childhood courses. These courses are well-known and widely used in Germany. While course participation for Chancenreich families is free of charge and do not need to be organized by the parents themselves, the comparison group families would be required to pay for the courses and need to find the courses themselves.

After completing the program, Chancenreich families are still free to choose different course formats on the educational free market. Further, we did not find a significant difference between the Chancenreich and the comparison group regarding the number of the attended courses before and after the program. Since these families are usually hard to reach and persuade to attend courses, these results can be interpreted as a success for the Chancenreich program in the context of the effect of the educational background of the mothers. Against the backdrop of the groups' differing compositions with regard to socioeconomic characteristics (a higher number of disadvantaged families in the Chancenreich program), and confirming our theoretical assumptions, there seems to be a transition effect in terms of early positive experiences with the informal educational system during the Chancenreich program. It might motivate and encourage Chancenreich parents to be further involved in their children's development, and transferring this motivation to other educational services even after completion of the program. However, Chancenreich families with lower incomes are less likely to attend early-educational courses at T2. It is reasonable to assume that the continued financial support of families in family support programs might encourage parents to let their children participate in this type of course as well.

\section{Course Participation and Children's Language Skills}

No effects were found for the understanding of grammar at the age of 5, either as an effect of participation (or not) in the Chancenreich program, or for the number of different types of course parents and children attended. However, the number of parenting-skills focused courses parents attend by the time their child is three has a significant, positive effect on the child's level of vocabulary skills at the age of 5 and on the development of vocabulary skills between the ages of 3 and 5. Specifically, in the light of the positive relationship between the number of parent-child-interaction focused courses attended and the children's vocabulary levels at age 3 (Wilke et al., 2017), this effect can be interpreted as a sleeper effect. This means that the effects of early participation in parenting-skills focused courses on children's development remain silent, but were triggered by environmental changes or developmental processes during childhood. We assume that by participating in both course formats, the parent-child interaction is promoted in different ways. Courses that parents attend together with their children directly stimulate interaction and communication. Courses that focus on parenting skills indirectly encourage parents to become more involved with their children and to establish or expand a more positive and beneficial communication. Furthermore, these effects might reflect motivational or attitudinal changes, changes in perception of parental self-efficacy, or the reduction of barriers to effective positive parenting, all of which have long-term, ongoing effects on children's outcomes (Sandler et al., 2011). The overall findings show that motivating parents to participate in a family support program is only one side of the coin; the other is the content orientation of the program and the actual activities of the parents during the program, which have a significant impact on child language development.

\section{Limitations}

The results must be interpreted with regard to the restriction of the study design, the sample size, the selection bias of the groups, and the applied measures. The study is designed as a quasiexperimental study with an intervention group and comparison 
group. A randomization of the groups could not be carried out due to ethical considerations and recruitment strategies. This led to a lower control of possible side conditions and to problems with sample bias. In comparison, a quasi-experimental design has a greater external validity, and it gave us the opportunity to achieve greater accessibility for the participants.

We countered the decreasing sample size, due to random drop out and missings, by conducting FIML approaches in all models.

Furthermore, the standardized PPVT (Dunn and Dunn, 1997; Roßbach et al., 2005) was used to assess the children's vocabulary of the children at both points of measurement - ages 3 and 5 . We apply the same items at both measurement points, which has certain theoretical advantages, but also means the PPTV shows ceiling effects for the older age group; this results in less variance for this measure, as well as a reduction in the ability to differentiate at the upper level of the vocabulary competences.

Another limitation is the group composition. The comparison group contains families with, on average, mothers with higher educational levels. At the second point of measurement, the Chancenreich group lost migrant families and families with lower incomes. Hence, the groups converge in comparison to the first point of measurement. Nevertheless, this limitation must be taken into account when interpreting the results.

\section{Implications}

This study is one the few studies worldwide and the first study in Germany to examine the long-term impact of family support programs and the different types of courses on offer. We found positive effects over time of parents' attendance of parentingskills focused courses on their children's level and development of vocabulary skills. In the context of the theoretical model of the HLE, this indicates that these courses might improve both parental beliefs and process quality, thus positively influencing the development of their children. However, further research should focus on that mechanism and the processes of choosing different course types and the effectiveness of the quality of the courses (quantity of parental attendance and quality of the content of the courses). Additionally, research should examine a broader range of outcomes, including children's social and emotional well-being.

Finally, we found no direct effect of participation in courses of younger children on a later higher rate of course attendance rate in children of preschool age. Further research is needed to investigate if and how early parental contact with the informal educational system affects their educational aspirations, and perhaps reduces barriers to later parental involvement in their children's development in both formal and informal contexts.

With regard to practical implications, monitoring is particularly needed with regard to the content and high-quality implementation of such courses. Programs are particularly successful if they manage to continuously develop content

\section{REFERENCES}

Blok, H., Fukkink, R. G., Gebhardt, E. C., and Leseman, P. P. (2005). The relevance of delivery mode and other program characteristics for the effectiveness of according to the needs and expectations of the target families. In order to ensure a high quality implementation of programme content, the role of professional competencies must be taken into account. In addition, Chancenreich as a local program is a typical example for the system of family support services in Germany. At the same time, however, it is also a role model for other programs when it comes to reviewing and developing programme content through summative and formative evaluations.

\section{DATA AVAILABILITY STATEMENT}

The dataset generated for this study will not be made publicly available. Due to the sensitive nature of the questions asked in this study, study participants were assured data would remain confidential and would not be shared. Requests to access the data should be directed to corresponding author, FC.

\section{ETHICS STATEMENT}

Ethical approval was not required for this study. The study was consistent with the ethical principles of human subjects. The parents were informed about the confidentiality and anonymity of their data. Participating parents signed the informed consent on a voluntary basis.

\section{AUTHOR CONTRIBUTIONS}

All persons who meet authorship criteria are listed as authors, and all authors certify that they have participated sufficiently in the work. FC made substantial contributions to the data analysis and interpretation, and to the conception and design of the article, drafting the article and revising it critically. JS made substantial contributions to data analysis and interpretation, and to drafting and revising the article. EV collected the data and contributed to the data analysis. YA made substantial contributions to the conception and design of the study and critically revised and approved the final version to be published.

\section{FUNDING}

This research was funded by the Carina Stiftung.

\section{ACKNOWLEDGMENTS}

This research was made possible by the Carina Stiftung. Further, we acknowledge support by the Open Access Publication Initiative of Freie Universität Berlin.

early childhood intervention. Intern. J. Behav. Dev. 29, 35-47. doi: 10.1080/ 01650250444000315

Boag-Munroe, G., and Evangelou, M. (2010). From hard to reach to how to reach: a systematic review of the literature on hard-to-reach 
families. Res. Pap. Educ. 27, 209-239. doi: 10.1080/02671522.2010.50 9515

Bornstein, M. H., and Bradley, R. H. (2008). Socioeconomic Status, Parenting, And Child Development. Abingdon: Routledge.

Bradley, R. H., Corwyn, R. F., Burchinal, M., McAdoo, H. P., and García Coll, C. (2001). The home environments of children in the United States part II: relations with behavioral development through age thirteen. Child Dev. 72, 1868-1886. doi: 10.1111/1467-8624.t01-1-00383

Brisch, K. H., and Hellbrügge, T. (eds) (2010). Der Säugling - Bindung, Neurobiologie und Gene: Grundlagen Für(Prävention), Beratung und Therapie, 2nd Edn. Stuttgart: Klett-Cotta.

Bronfenbrenner, U., and Morris, P. A. (2006). "The bioecological model of human development," in Handbook of Child Psychology: Theoretical Models Of Human Development, eds W. Damon, and R. M. Lerner (New York, NY: Wiley), 793-828.

Cadima, J., Nata, G., Evangelou, M., and Anders, Y. (2017). Inventory and Analysis of Promising and Evidence-based Parent- and Family-Focused. Available online at: http://www.isotis.org/wp-content/uploads/2018/06/ISOTIS_D3. 2-Inventory-and-Analysis-of-Promising-and-Evidence-based-Parent-andFamily-Focused-Support-Programs.pdf

Campbell, F., Ramey, C., Pungello, E., Sparling, J., and Miller-Johnson, S. (2002). Early childhood education: young adult outcomes from the abecedarian project. Appl. Dev. Sci. 6, 42-57. doi: 10.1207/s1532480xads0601_05

Carolan, B. V. (2018). Extracurricular activities and achievement growth in kindergarten through first grade: the mediating role of non-cognitive skills. Early Child. Res. Q. 45, 131-142. doi: 10.1016/j.ecresq.2018.06.004

Christ, O., and Schlüter, E. (2012). Strukturgleichungsmodelle mit Mplus. De Gruyter. doi: 10.1524/9783486714807

Cortis, N., Katz, I., and Patulny, R. (2009). Engaging Hard-To-Reach Families And Children (Occasional Paper No. 26). Canberra: Department of Families, Housing, Community Services and Indigenous Affairs.

de Graaf, I., Speetjens, P., Smit, F., de Wolff, M., and Tavecchio, L. (2008). Effectiveness of the triple $\mathrm{P}$ positive parenting program on parenting: a meta-analysis. Fam. Relat. 57, 553-566. doi: 10.1111/j.1741-3729.2008.00 522.x

Dearing, E., Wimer, C., Simpkins, S. D., Lund, T., Bouffard, S. M., Caronongan, P., et al. (2009). Do neighborhood and home contexts help explain why lowincome children miss opportunities to participate in activities outside of school? Dev. Psychol. 45, 1545-1562. doi: 10.1037/a0017359

Denham, S. A., and Burton, R. (2003). Social and Emotional Prevention And Interventionprogramming For Preschoolers. New York, NTY: Kluwer Academic.

Dunn, L. M., and Dunn, D. M. (1997). Peabody Picture Vocabulary Test-III. Circle Pines, MN: American Guidance Service.

Eid, M., Gollwitzer, M., and Schmitt, M. (2013). Statistik und Forschungsmethoden: Lehrbuch, 3rd Edn. Weinheim: Beltz.

Enders, C. K., and Bandalos, D. L. (2001). The relative performance of full information maximum likelihood estimation for missing data in structural equation models. Struct. Equ. Modeling 8, 430-457. doi: 10.1207/ S15328007SEM0803_5

Epstein, J. L., and Sanders, M. G. (2000). "Connecting home, school, and community," in Handbook of the Sociology Of Education, ed. M. T. Hallinan (Boston, MA: Springer).

Eurostat (2018). Equivalised Disposable Income. Available at: https://ec.europa. eu/eurostat/statistics-explained/index.php/Glossary:Equivalised_disposable_ income (accessed May 18, 2019).

Filene, J. H., Kaminski, J. W., Valle, L. A., and Cachat, P. (2013). Components associated with home visiting program outcomes: a meta-analysis. Pediatrics $132,100-109$.

Fox, A. V. (2013). TROG-D: Test zur Überprüfung des Grammatikverständnisses, 6th Edn. Idstein: Schulz-Kirchner.

Ginsborg, J. (2006). “The effects of socio-economic status on children's language acquisition and use," in Language and Social Disadvantage: Theory Into Practice, eds J. Clegg, and J. Ginsborg (New York, NY: Wiley), 9-27.

Gottfried, A. E., Fleming, J. S., and Gottfried, A. W. (1998). Role of cognitively stimulating home environment in children's academic intrinsic motivation: a longitudinal study. Child Dev. 69, 1448-1460. doi: 10.1111/j.1467-8624.1998. tb06223.x
Hahlweg, K., Heinrichs, N., Kuschel, A., Bertram, H., and Neumann, S. (2010). Research long-term outcome of a randomized controlled universal prevention trial through a positive parenting program: is it worth the effort? Child Adoles. Psychiatry Ment. Health 4:14.

Halpern, R. (2000). Early childhood intervention for low-income children and families. Handb. Early Child. Intervention. 2, 361-386. doi: 10.1017/ cbo9780511529320.019

Hart, B., and Risley, T. R. (1995). Meaningful Differences In The Everyday Experience Of Young American Children. Baltimore, MD: Paul H Brookes Publishing.

Heckman, J. (2006). Skill formation and the economics of investing in disadvantaged children. Science 312, 1900-1902. doi: 10.1126/science.1128898

Heckman, J., Pinto, R., and Savelyev, P. (2013). Understanding the mechanisms through which an influential early childhood program boosted adult outcomes. Am. Econ. Rev. 103, 2052-2086. doi: 10.1257/aer.103.6.2052

Hirsh-Pasek, K., Adamson, L. B., Bakeman, R., Owen, M. T., Golinkoff, R. M., Pace, A., et al. (2015). The contribution of early communication quality to lowincome children's language success. Psychol. Sci. 26, 1071-1083. doi: 10.1177/ 0956797615581493

Hoff, E. (2006). How social contexts support and shape language development. Dev. Rev. 26, 55-88. doi: 10.1016/j.dr.2005.11.002

Hoff, E. (2013). Interpreting the early language trajectories of children from lowSES and language minority homes: implications for closing achievement gaps. Dev. Psychol. 49:4. doi: 10.1037/a0027238

Höltershinken, D. (2011). Dortmunder Beiträge zur Pädagogik: Vol. 34. PEKiP dasPrager Eltern-Kind-Programm: Theoretische Grundlagen; Ursprung und Weiterentwicklung (4., überarb. und erg. Aufl.). Bochum: Projektverlag.

IBM Corp (2017). IBM SPSS Statistics for Windows, Version 25.0. Armonk, NY: IBM Corp.

Kaminski, J. W., Valle, L. A., Filene, J. H., and Boyle, C. L. (2008). A meta-analytic review of components associated with parent training program effectiveness. J. Abnorm. Child Psychol. 36, 567-589. doi: 10.1007/s10802-007-9201-9

Karoly, L. A., Kilburn, M. R., and Cannon, J. S. (2005). Proven Benefits Of Early Childhood Interventions. Santa Monica: Rand Corporation.

Kendrick, D., Elkan, R., Hewitt, M., Dewey, M., Blair, M., Robinson, J., et al. (2000). Does home visiting improve parenting and the quality of the home environment? A systematic review and meta analysis. Archiv. Dis. Child. 82, 443-451. doi: 10.1136/adc.82.6.443

Kluczniok, K., Lehrl, S., Kuger, S., and Rossbach, H. G. (2013). Quality of the home learning environment during preschool age-Domains and contextual conditions. Eur. Early Child. Educ. Res. J. 21, 420-438. doi: 10.1080/1350293x. 2013.814356

Lawson, D. W., and Mace, R. (2009). Trade-offs in modern parenting: a longitudinal study of sibling competition for parental care. Evol. Hum. Behav. 30, 170-183. doi: 10.1016/j.evolhumbehav.2008.12.001

Layzer, J. I., Goodson, B. D., Bernstein, L., and Price, C. (2001). National Evaluation of Family Support Programs. Final Report Volume A: The Meta-Analysis. New Delhi: ERIC.

Lehrl, S. (2018). Qualität Häuslicher Lernumwelten im Vorschulalter: Eine Empirische Analyse zu Konzept, Bedingungen und Bedeutung. Berlin: SpringerVerlag.

Little, R. J. A. (1988). A test of missing completely at random for multivariate data with missing values. J. Am. Stat. Assoc. 83, 1198-1202. doi: 10.1080/01621459. 1988.10478722

Lösel, F. (2006). Bestandsaufnahme und Evaluation von Angeboten im Elternbildungsbereich. Erlangen: Friedrich-Alexander-Universität Erlangen-Nürnberg.

Lüke, T., Ritterfeld, U., and Tröster, H. (2016). Erprobung eines gruppentests zur überprüfung des grammatikverständnisses auf der basis des TROG-D. Diagnostica 62, 242-254. doi: 10.1026/0012-1924/a000157

Melhuish, E. C., Phan, M. B., Sylva, K., Sammons, P., Siraj-Blatchford, I., and Taggart, B. (2008). Effects of the home learning environment and preschool center experience upon literacy and numeracy development in early primary school. J. Soc. Issues 64, 95-114. doi: 10.1111/j.1540-4560.2008.00550.x

Metsäpelto, R.-L., and Pulkkinen, L. (2014). The benefits of extracurricular activities for socioemotional behavior and school achievement in middle childhood: an overview of the research. J. Educ. Res. 6, 10-33. 
Mrazek, P. J., and Haggerty, R. J. (1994). Committee on Prevention of Mental Disorders, Institute of Medicine. Reducing Risks for Mental Disorders: Frontiers for Preventive Intervention Research. Washington, DC: National Academies Press.

Mühler, G., and Spieß, C. K. (2008). Informelle Förderangebote in der frühen Kindheit: Eine Empirische Analyse ihrer Nutzung. Frühpädagogische Förderung in Institutionen. Berlin: Springer.

Muthén, L. K., and Muthén, B. O. (1998-2012). Mplus User's Guide. 7th Edn. Los Angeles, CA: Muthén \& Muthén

Nelson, G., Westhues, A., and MacLeod, J. (2003). A meta-analysis of longitudinal research on preschool prevention programs for children. Prevent. Treat. 6, $1-35$.

Nievar, M. A., Van Egeren, L. A., and Pollard, S. (2010). A meta-analysis of home visiting programs: moderators of improvements in maternal behavior. Infant Ment. Health J. 31, 499-520. doi: 10.1002/imhj.20269

Niklas, F., Tayler, C., and Schneider, W. (2015). Home-based literacy activities and children's cognitive outcomes: a comparison between Australia and Germany. Intern. J. Educ. Res. 71, 75-85. doi: 10.1016/j.ijer.2015. 04.001

Nowak, C., and Heinrichs, N. (2008). A comprehensive meta-analysis of triple p-positive parenting program using hierarchical linear modeling: effectiveness and moderating variables. Clin. Child Fam. Psychol. 11, 114-144. doi: 10.1007/ s10567-008-0033-0

Ouellette, G. P. (2006). What's meaning got to do with it: the role of vocabulary in word reading and reading comprehension. J. Educ. Psychol. 98, 554-566. doi: 10.1037/0022-0663.98.3.554

Ramey, C. T., and Ramey, S. L. (1998). Early intervention and early experience. Am. Psychol. 53:109. doi: 10.1037/0003-066x.53.2.109

Rauer, W. (2009). Starke Eltern - Starke Kinder(: Wirkungsanalysen bei Eltern und Ihren Kindern in Verknüpfung mit Prozessanalysen in den Kursen - Eine Bundesweite Studie. Würzburg: Ergon Verlag.

Reynolds, A. J., Rolnick, A. J., Englund, M. M., and Temple, J. A. (eds) (2010) Childhood Programs And Practices In The First Decade Of Life: A Human Capital Integration. Cambridge: Cambridge University Press.

Reynolds, A. J., Temple, J. A., Robertson, D. L., and Mann, E. A. (2001). Age 21 cost-benefit analysis of the Title I Chicago child-parent center program. Executive summary. June 2001. Paper Presented at the Annual Meeting of the Society for Prevention Research, Washington, DC.

Rodriguez, E. T., and Tamis-LeMonda, C. S. (2011). Trajectories of the home learning environment across the first 5 years: Associations with children's vocabulary and literacy skills at prekindergarten. Child Dev. 82, 1058-1075. doi: 10.1111/j.1467-8624.2011.01614.x

Roßbach, H. G., Tietze, W., and Weinert, S. (2005). Peabody Picture Vocabulary Test - Revised. Deutsche Forschungsversion Des Tests von L. M. Dunn \& L. M. Dunn von 1981. Berlin: Universität Bamberg.

Sanders, M. R. (1999). Triple P-positive parenting program: towards an empirically validated multilevel parenting and family support strategy for the prevention of behavior and emotional problems in children. Clin. Child Fam. Psychol. Rev. 2, 71-90.

Sanders, M. R., Cann, W., and Markie-Dadds, C. (2003). The triple P-positive parenting program: a universal population-level approach to the prevention of child abuse. Child Abuse Rev. 12, 155-171. doi: 10.1002/car. 798

Sanders, M. R., Markie-Dadds, C., Tully, L. A., and Bor, W. (2000). The Triple P-positive parenting program: a comparison of enhanced, standard, and selfdirected behavioral family intervention for parents of children with early onset conduct problems. J. Consul. Clin. Psychol. 68, 624-640. doi: 10.1037/0022006x.68.4.624

Sandler, I., Schoenfelder, E., Wolchik, S., and MacKinnon, D. (2011). Longterm impact of prevention programs to promote effective parenting: lasting effects but uncertain processes. Annu. Rev. Psychol. 62, 299-329. doi: 10.1146/ annurev.psych.121208.131619

Senechal, M. (2011). "A model of the concurrent and longitudinal relationship between home literacy and child outcomes," in Handbook of Early Literacy Research, eds S. Neuman, and D. Dickinson (New York, NY: The Guilford Press), 175-188.

Shonkoff, J. P., and Phillips, D. A. (eds) (2000). From Neurons To Neighborhoods: The Science Of Early Childhood Development. Washington, D.C: National Academies Press.

Skwarchuk, S. L., Sowinski, C., and LeFevre, J. A. (2014). Formal and informal home learning activities in relation to children's early numeracy and literacy skills: the development of a home numeracy model. J. Exp. Child Psychol. 121, 63-84. doi: 10.1016/j.jecp.2013.11.006

Slavin, R. E., Madden, N. A., and Karweit, N. L. (1994). "Success for all; a comprehensive approach to prevention and early intervention," in Preventing Early School Failure. Research, Policy And Practice, eds R. E. Slavin, N. L. Karweit, and B. A. Wasik (Boston: Allyn and Bacon).

Swanson, H. L., Rosston, K., Gerber, M., and Solari, E. (2008). Influence of oral language and phonological awareness on children's bilingual reading. J. Sch. Psychol. 46, 413-429. doi: 10.1016/j.jsp.2007.07.002

Sweet, M. A., and Appelbaum, M. I. (2004). Is home visiting an effective strategy? A meta-analytic review of home visiting programs for families with young children. Child Dev. 75, 1435-1456. doi: 10.1111/j.1467-8624.2004.00750.x

Sylva, K., Melhuish, E. C., Sammons, P., SirajBlatchford, I., and Taggart, B. (2004). The Effective Provision Of Pre-School Education (EPPE) Project: Final Report: A Longitudinal Study Funded By The DfES 1997-2004. London: Institute of Education.

Tabachnick, B. G., and Fidell, L. S. (2007). Using Multivariate Statistics, 5th Edn, New York, NY: Allyn and Bacon.

Tamis-LeMonda, C. S., Luo, R., McFadden, K. E., Bandel, E. T., and Vallotton, C. (2017). Early home learning environment predicts children's 5th grade academic skills. Appl. Dev. Sci. 23, 153-169. doi: 10.1080/10888691.2017. 1345634

Thomas, S. (2013). Selbstvergewisserung in Eltern-Kind-Gruppen: doing family in der institutionalisierten Familienbildung. Diskurs Kindheits Jugendforschung 8, 273-285.

Tschöpe-Scheffler, S. (ed.) (2006). Konzepte der Elternbildung: Eine kritische Übersicht (2., Durchgesehene Auflage). Berlin: Verlag Barbara Budrich.

Van der Stede, W. A. (2014). A manipulationist view of causality in cross-sectional survey research. Account. Organ. Soc. 39, 567-574. doi: 10.1016/j.aos.2013.12. 001

Wilke, F., Hachfeld, A., and Anders, Y. (2014). Welche Familien erreichen Angebote zur Familienbildung? Eine Analyse der Teilnehmerstruktur am Beispiel des modularen Projekts Chancenreich. Empirische Sonderpädagogik. 6, 195-210.

Wilke, F., Hachfeld, A., and Anders, Y. (2017). How is participation in parentchild-interaction-focused and parenting-skills-focused courses associated with child development? Early Years 38, 411-428. doi: 10.1080/09575146.2017. 1288089

Conflict of Interest: The authors declare that the research was conducted in the absence of any commercial or financial relationships that could be construed as a potential conflict of interest.

Copyright (c) 2020 Cohen, Schünke, Vogel and Anders. This is an open-access article distributed under the terms of the Creative Commons Attribution License (CC BY). The use, distribution or reproduction in other forums is permitted, provided the original author(s) and the copyright owner(s) are credited and that the original publication in this journal is cited, in accordance with accepted academic practice. No use, distribution or reproduction is permitted which does not comply with these terms. 


\section{OPEN ACCESS}

Edited by:

Raquel Cerdan,

University of Valencia, Spain

Reviewed by:

Christian Tarchi,

University of Florence, Italy

Marian Serrano-Mendizábal,

University of Valencia, Spain

*Correspondence:

Simone Lehr

simone.lehrl@uni-bamberg.de

Specialty section:

This article was submitted to

Educational Psychology,

a section of the journal

Frontiers in Psychology

Received: 28 January 2020

Accepted: 27 May 2020

Published: 30 June 2020

Citation:

Linberg A, Lehrl S and Weinert S

(2020) The Early Years Home Learning Environment - Associations With Parent-Child-Course Attendance and Children's Vocabulary at Age 3.

Front. Psychol. 11:1425.

doi: 10.3389/fpsyg.2020.01425

\section{The Early Years Home Learning Environment - Associations With Parent-Child-Course Attendance and Children's Vocabulary at Age 3}

\author{
Anja Linberg ${ }^{1}$, Simone Lehrl ${ }^{2 *}$ and Sabine Weinert ${ }^{2}$ \\ ${ }^{1}$ Department of Social Monitoring and Methodology, Deutsches Jugendinstitut, Munich, Germany, ${ }^{2}$ Psychology I - \\ Developmental Psychology, University of Bamberg, Bamberg, Germany
}

Although many studies investigated the effects of the home learning environment (HLE) in the preschool years, the constructs that underlie the HLE in the years before the age of three and its effects on language development are still poorly understood. This study therefore investigated the dimensionality of the HLE at age two, its relation to the attendance of low threshold parent-child-courses, and its importance for children's vocabulary development between age 2 and 3 years against the background of differing family background characteristics. Using data from 1,013 children and their families of the Newborn Cohort of the German National Educational Panel Study, structural equation modeling analyses showed that (1) quantitative and qualitative aspects of the early HLE, i.e., the frequency of stimulating activities, and the quality of parent-childinteractions should be differentiated; (2) that family background variables are differentially associated with the HLE dimensions and (3) that attendance at parent-child courses enriches both aspects of the HLE which in turn (4) are related to the children's vocabulary development. Our results highlight the need to differentiate aspects of the early HLE to disentangle which children are at risk in terms of which stimulation at home and the possibility to enrich the HLE through low threshold parent-child courses.

Keywords: home learning environment, socio-economic background, parent-child course, vocabulary development, longitudinal study, parent-child-interaction

\section{INTRODUCTION}

Research consistently documents the great importance of early language skills for children's later language and literacy development and overall school success (Duncan et al., 2007; Marchman and Fernald, 2008; Bornstein et al., 2016). Because of their major importance for reading comprehension (Storch and Whitehurst, 2002) language skills are often described in the framework of "emergent literacy skills," which captures skills preceding formal reading in school, including code-related skills such as phonological awareness and letter knowledge, as well as language related skills, such as vocabulary and grammatical skills (Teale and Sulzby, 1986; Whitehurst and Lonigan, 1998; Sénéchal et al., 2001; Pinto et al., 2017). From early on children differ widely in their vocabulary knowledge with significant disparities associated with their socio-economic background (Hoff, 2003; Brooks-Gunn and Markman, 2005; Dubowy et al., 2008; Hindman et al., 2008; Fernald et al., 2013). These early differences in vocabulary can partly be traced back to experiences in the 
learning environment at home, which might be especially important during the early years, when vocabulary starts to grow quickly (Hart and Risley, 1995). Families stimulate children's language development through various activities and interactions during infancy (NICHD Study of Early Child Care, 1999; Attig and Weinert, 2019). Several factors have been suggested as being of particular relevance: the frequency of stimulating activities, such as joint picture book reading, singing songs, or telling rhymes to a child (Rodriguez and Tamis-LeMonda, 2011), and the overall quality of interaction behavior in parent-child interactions, especially how sensitively the caregiver responds to the child's signals (Ainsworth et al., 1974). The study by Rodriguez and Tamis-LeMonda (2011) for instance, revealed that children with more supportive learning environments in terms of quantity and quality of stimulation within the 1st year of life show comparatively larger vocabulary than children with less stimulation or later-starting stimulation.

Given the impact of the quality of parent-child interactions and the frequency of joint activities in the early home learning environment (HLE) on vocabulary development, enriching the HLE from early on seems to be important. Comprehensive interventions starting early in life have been demonstrated to be effective both with regard to the HLE and child development (Baker et al., 1998; Zigler et al., 2008; Nievar et al., 2011; SamaMiller et al., 2017; Schaub et al., 2019). Although often not integrated within a broader framework of early intervention, parent-child courses are designed to give parents practical information regarding the nutrition or education of their toddlers and thus might enrich the HLE and stimulate child development.

Thus, although the importance of the very early years in children's development is emphasized throughout the research literature, only marginal attempts have been made to investigate the dimensionality of the HLE before the age of three and the importance of such possible different aspects of early HLE and parent-child courses attendance for vocabulary development. In particular, it is unclear whether the HLE at that early age is composed of multiple, separable dimensions of quantitative, and qualitative aspects or whether it is unitary in nature and associated with similar family background characteristics.

The present paper therefore investigates the differential contribution of various HLE measures, including parentchild-course-attendance to vocabulary development against the background of varying family background characteristics.

\section{THE HOME LEARNING ENVIRONMENT OF TODDLERS}

Following the bio-ecological model of human development, child development takes place in various contexts, and the characteristics of these contexts as well as how the child shapes them are important (Bronfenbrenner, 1999). In the first years of a child's life the family is the most important learning environment, and processes in the family context, such as activities or interactions, are important engines of child development.

Of these processes, shared picture book reading is one of the most studied variables in research addressing the HLE in early childhood, and has been shown for decades to be of major importance in explaining differences in preschoolers' language development (Bus et al., 1995; Mol et al., 2008; Flack et al., 2018). However, whether or not the important connection between sharing books with preschoolers and children's language development can be transferred to the very early years has been less studied. The vast majority of parents report that they begin reading to their children when they are around 6 months of age (Debaryshe, 1993; Niklas et al., 2016). Research shows that joint picture book reading with infants and toddlers and the early onset of reading is linked to children's vocabulary (Debaryshe, 1993; Karrass and Braungart-Rieker, 2005; Sénéchal et al., 2008; Niklas et al., 2016; Attig and Weinert, 2019). An intervention study by Karrass and Braungart-Rieker (2005) for instance, demonstrated that presenting 8 month old infants with picture books resulted in advanced vocabulary status at 12 and 16 months, although reading to 4 month olds did not have a similar effect. Furthermore, picture books have been used in a variety of word learning studies to teach new words to children. Research shows that children as young as 15 months learn new words from picture books after a single presentation (Ganea et al., 2009; Horst et al., 2011; Weisleder and Fernald, 2013; Montag et al., 2015). The mechanism behind the effect of sharing books with children on language development may be the provision of focused language input (Bruner, 1985). Besides reading to the child, there are other related activities that have also been shown to stimulate language acquisition such as singing songs or repeating nursery rhymes (Baker, 2013; Skwarchuk et al., 2014). In the following study we refer to the frequency of these language stimulating parent-child activities as a quantitative indicator or aspect of the HLE.

In the first years of children's lives the HLE is not only characterized by these quantitative aspects, but also by the quality of children's interactions with parents both during those activities as well as during daily routines such as feeding or diapering. We will refer to the quality of these interactions as the qualitative aspects or indicators of the HLE. The quality of interaction behavior can be differentiated into two main components: sensitivity and stimulation (Vallotton et al., 2017; Linberg, 2018). Sensitivity refers to the warm, accepting, prompt, and contingent responses parents provide in response to children's affective, vocal, and gestural cues (Ainsworth et al., 1974; Shin et al., 2008). Stimulation refers to interactions and activities between parents and their child that promote the child's cognitive and language development, e.g., by supporting them in exploring their environment, or by presenting them with stimulating materials and toys, or by using rich and varied language (Bradley et al., 2003). The quality of mother-child interactions during the first years of life has been shown to be positively associated with children's vocabulary at the age of 30, 38, and 40 months (Nozadi et al., 2013; Wade et al., 2018). Even the interaction quality that children experience during their prelinguistic phase predicts language development later on. For example, Nicely et al. (1999) demonstrated that the quality of sensitive maternal responses to the signals of their 9-month-old children was associated with children's language development at 21 months. Additionally, Tamis-LeMonda et al. (2001) have shown that 
infants experiencing high quality mother-child interactions during the first 2 years of their lives achieved milestones, such as first words or the vocabulary spurt, 4-6 months earlier compared to infants experiencing lower levels of quality.

However, variations in quality experiences at home have been widely shown to be associated with family's socioeconomic background (Bradley et al., 2003; Kluczniok et al., 2013). Especially maternal education, income poverty, and social resources (e.g., having a partner in the household) have repeatedly shown to be associated with access to books at home, the overall living conditions (e.g., crowding) and the frequency and quality of stimulating activities (Evans, 2006; Mistry et al., 2008, 2010; Lehrl, 2018). Due to the family investment and stress model (Conger and Donnellan, 2007) such associations might emerge because parents that do not suffer from low education, economic hardship or being a single parent, are better able to provide material resources, and experiences that promote children's health and cognitive development, as they experience less parental distress, gather more information on child development, and as a consequence may show less disruptions in parenting behaviors and provide more stimulating HLEs. Previous studies have confirmed the significant association of the HLE and such indicators of the family's socio-economic background, particularly for preschool-aged children (Foster et al., 2005; Forget-Dubois et al., 2009; Bojczyk et al., 2016; Lehrl et al., 2020). Studies with children at younger ages also document this relationship. For example, with regard to the quality of parent-child interaction (qualitative aspect) at toddler age studies demonstrate that more highly educated mothers react in a more sensitive and responsive way to their child's signals such as vocalizations (Gudmundson, 2012; Mills-Koonce et al., 2016; Neuhauser, 2018) and use more complex and varied syntax and vocabulary (Hoff et al., 2002). Linberg et al. (2017) found that, in Germany, disparities in the quality of mother-child interactions are visible by maternal education as early as the age of 7 months. Studies considering both quality of parent-child interactions and the frequency of stimulating activities in a composite score also point to an association between maternal education, income as well as being a single parent and the overall HLE (Bradley et al., 2003; Lugo-Gil and Tamis-LeMonda, 2008; Rowe, 2008; Magnuson et al., 2009). Only a few studies have systematically differentiated qualitative and quantitative aspects. For example, Mistry et al. (2008) showed socioeconomic status (SES), as indicated by income, maternal education, and welfare receipt, to be related to quantitative and qualitative indicators of home stimulation whereas in the group of immigrant-parents the effects sizes were higher for the quantitative aspect (see also Mistry et al., 2010 for similar associations between a cumulative risk-index and HLE). However, in the group of monolingual children the effect sizes of SES on qualitative and quantitative HLE were nearly the same (Mistry et al., 2008). Thus, although there is some research evidence that family socio-economic background variables are associated with children's HLE, there is a lack of research on the specific relations. We therefore focus more explicitly on the specificity of such indicators of socio-economic background and their relationship to children's quantitative and qualitative HLE, and language development at specific points in early childhood.

\section{PARENT-CHILD COURSE ATTENDANCE AS INFORMAL SUPPORT SYSTEMS}

Building on the bio-ecological model, family system intervention models assume that families are embedded within various contexts, and that child development and parenting can be supported within those contexts (Dunst and Trivette, 2009; Anders et al., 2017). Besides highly structured formal support, which is often realized through home-visitation programs or structured programs (Baker et al., 1998; Zigler et al., 2008; Nievar et al., 2011; Sama-Miller et al., 2017; Schaub et al., 2019), opportunities for more informal social support networks could function as resources for meeting family concerns and needs (Campbell et al., 2002; Dunst and Trivette, 2009). Such informal opportunities can be out-of-home activities that parents select for their children through attending specific courses addressed to parents with toddlers, for example, baby swimming, the Prague Parent-Child Program (PEKiP), baby music, and other programmes that provide additional stimulating experiences. Although such generic - as distinguished from language and literacy specific - courses lack a coherent theoretical foundation and empirical evidence on whether they reach their aims, they might be an important source of support in fostering child development and/or parents' parenting competencies through discussion of problems in child rearing with others. This interaction and exchange with other parents might serve as a social support system, which is a key determinant of parenting (Bollen, 1989) and its positive relation to parenting quality has been shown in various studies (Shin et al., 2006; Neuhauser, 2018). Group-based courses might also reduce emotional distress by coming into contact with parents with similar challenges. Results of a meta-analysis point to this, by showing that groupbased training programmes for parents led to short and longterm improvements of emotional distress (Barlow et al., 2012) which in turn could increase positive parenting (McLoyd, 1990; Conger and Donnellan, 2007).

In Germany, nearly $50 \%$ of parents with young children (ages 0-3 years) attend courses of this kind (Mühler and Spieß, 2008). These courses, for which parents normally have to pay in order to attend, usually take place on a weekly basis for a limited time and are partly based on structured programs. They are designed to promote parent-child interaction, to directly foster children's cognitive or motor development, to experience arts and music, or/ and to support the building of social networks among parents (Wilke et al., 2017). Mühler and Spieß (2008) showed that mothers report higher adaptation skills for their 3 year olds when attending such courses compared to mothers who did not attend courses, regardless of the educational level of the mother. Furthermore, Wilke et al. (2017) reported higher receptive vocabulary for 3 to 4 year old children who had attended such courses since birth. The concept of parent-child courses in Germany is, to some extent, comparable to the Sure Start Children's Centers in England, especially to the "stay and play" services, although these are especially designed for families at risk and their services are of no cost (Sammons et al., 2015). Results from an evaluation study show that attending such "stay and play" services programmes is positively 
correlated with the toddler HLE (mean age of the children 14 months) and the preschoolers' HLE (mean age of the children 38 months) (Hall et al., 2019). Furthermore, HLE changes from the toddler to the preschool phase were predicted by attending stay-and play services at 3 years of age, which in turn predicted less externalizing problem behavior. Thus, there is evidence that attending play-based courses might impact children's development via HLE changes. This potential to enrich the HLE to foster children's development has mostly been realized through structured programs (Baker et al., 1998; Zigler et al., 2008; Nievar et al., 2011; Sama-Miller et al., 2017; Schaub et al., 2019). However, how and whether attending parent-child courses affects children's development via HLE changes has not been investigated so far, especially in the German context.

\section{THE PRESENT STUDY}

Parents foster children's language development through various activities and actions. Indicators of the HLE that have been demonstrated to be associated with children's vocabulary may either focus mainly on quantitative aspects or on qualitative aspects of HLE. Quantitative indicators are targeted by the frequency of (language stimulating) joint activities of parents and children. Most prominently, shared book reading has been identified as a meaningful activity promoting children's language development (Mol et al., 2008; Flack et al., 2018). In addition, joint activities such as singing songs or repeating nursery rhymes seem to be important. Qualitative indicators of the HLE focus on the quality of interactions the child experiences in the HLE. Here concepts such as the sensitivity of the parent to the child's signals as well as the quality of stimulation behavior have been addressed (Ainsworth et al., 1974). As with the quantitative aspects of the HLE, these qualitative indicators have also been demonstrated to be associated with children's language development (Nozadi et al., 2013; Wade et al., 2018). Yet, only few studies investigate both dimensions of the HLE, and their differential relation to child's vocabulary: Whereas results of Rodriguez et al. (2009) indicate joint activities as well as maternal engagement in interactions being somewhat equally predictive for vocabulary at 24 months, Schmitt et al. (2011) reports only joint activity but not maternal sensitivity being related to vocabulary. In addition, study results show that both aspects differ according to socio-economic background variables. Depending on their socioeconomic background, children have different experiences both with regard to qualitative as well as to quantitative aspects of their HLE, which might impact children's language development (Hart and Risley, 1995).

However, most studies focused on only one or the other aspect of the HLE. Additionally, although the importance of quality has been demonstrated for children at preschool age, less is known about quality in the framework of HLE in the very early years in life.

Attempts to enrich the HLE in order to foster children's language development have been made through various programmes (for an overview: Sama-Miller et al., 2017). However, these programmes are often cost-intensive and might have a high threshold for participation. More cost- and time-efficient are parent-child courses, which parents often attend with their children in the first years of a child's life. As these courses also include information on stimulating activities and actions, they might contribute to the enrichment of the HLE in the very early years and thus could provide a way to reduce the effects of socio-economic background. However, studies focusing on parent-child courses in the context of enriching the HLE are still sparse.

Thus, the present paper investigates, (1) the dimensionality of the HLE at age two by distinguishing between a quantitative and a qualitative dimension of the HLE at this early age, and (2) by investigating the differential association of the different aspects with family socio-economic background variables, (3) whether parent-child courses substantially enrich the different aspects of the HLE, and (4) how these aspects of the HLE are associated with children's vocabulary development between age two and three. We are assuming that quantitative and qualitative aspects of the HLE are two separate, however, associated dimensions. In line with Mistry et al. (2008) and the family stress model (Conger and Donnellan, 2007) we suspect indicators of socio-economic background, i.e., maternal education and risk of income poverty, as well as social resources, i.e., being a single parent, to be associated with quantitative and qualitative indicators of HLE. As some studies pointed in the direction of specifity effects (Klebanov et al., 1998; Kluczniok et al., 2013) we assume the relations to be specific in terms of family socioeconomic background dimension as well as HLE dimension. However, according to the lack of research regarding the specifitiy of effects in terms of experiencing single aspects of socioeconomic background and their association to differentiated HLE dimensions we cannot make clear assumptions.

Furthermore, we expect the attendance of parent-childcourses to enrich both dimensions of the HLE, as they could foster parenting skills through discussion of problems in child rearing as well as increase positive parenting by reducing emotional distress. However, associations might be more pronounced for the quantitative dimension, as most of these courses also include information on stimulating activities and actions. Additionally, based on previous study results we assume that both, the quantitative and a qualitative dimension of HLE, are associated with child's vocabulary development (see Figure 1). The study carefully considers the direction of effects and potentially confounding variables.

\section{METHODS}

\section{Sample}

To investigate our research questions, we used data of the Starting Cohort 1 - Newborns (SC1) of the German National Educational Panel Study (NEPS) (Weinert et al., 2016; Blossfeld and Roßbach, 2019). Based on a representative sampling frame, a nationwide sample of 3,500 infants born between February and June 2012 and their families were drawn, register-based (response-rate: 41\%), and followed longitudinally (Weinert et al., 2016). We used the first four waves in our analyses and included all cases of mainly German-speaking families (i.e., who stated that their main interaction language at home was only or mostly German) with 


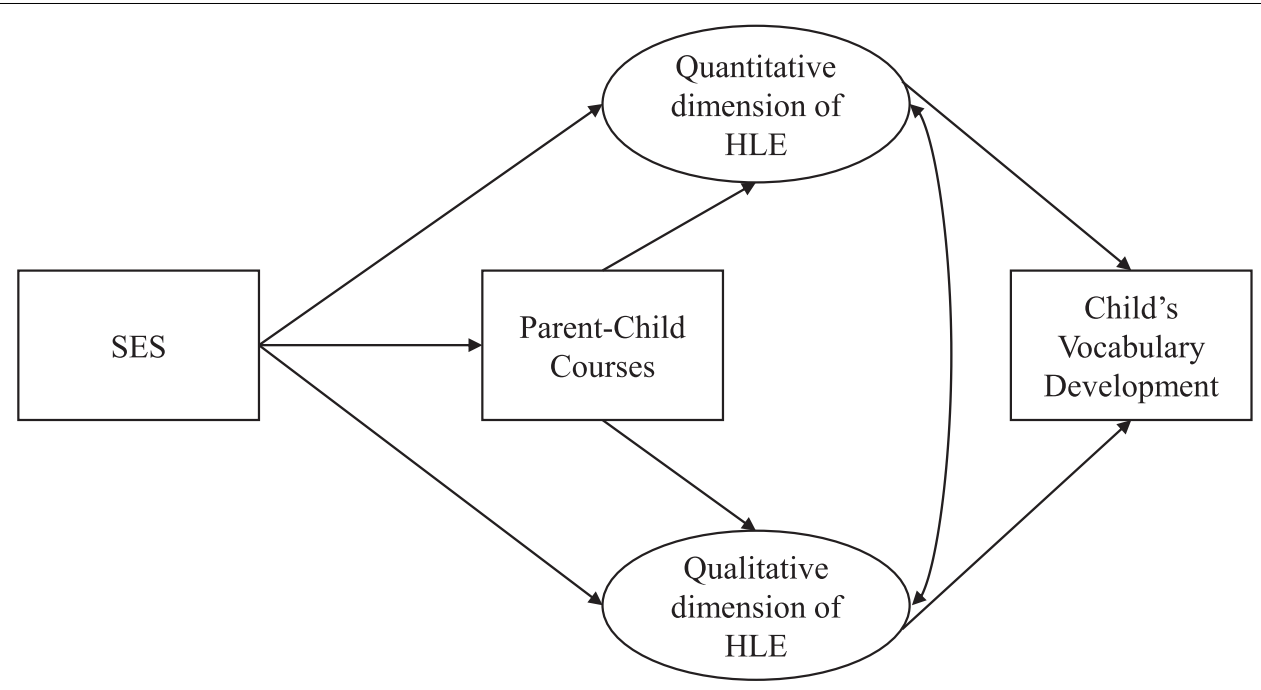

FIGURE 1 | Proposed model on the relation between SES, the qualitative and quantitative dimension of home learning environment, parent-child-courses, and child's vocabulary development.

TABLE 1 | Variables used in main analyses with waves.

\begin{tabular}{lcccc}
\hline & Wave 1 & Wave 2 $^{\text {a }}$ & Wave 3 & Wave 4 \\
\hline Average age of child in months & 7 & 13 & 26 & 38 \\
Quantitative dimension of HLE & $\times$ & & $\times$ & \\
Qualitative dimension of HLE & $x$ & & $x$ & \\
Parent-child courses & $x$ & $x$ & $x$ & \\
Child vocabulary & & & & \\
Socio-economic background & $x$ & & &
\end{tabular}

${ }^{a}$ By design in wave 2 the qualitative measures of HLE were only assessed in half of the sample and therefore not considered in the analyses.

valid information on child's vocabulary and HLE, which resulted in a total sample size of 1013 children. In wave 1 children were 7 months $(M=6.97, S D=0.80)$, in wave 2,13 months $(M=13.36$, $S D=1.30)$, in wave 3,26 months old $(M=26.49, S D=1.19)$, and in wave 4,38 months $(M=38.40 ; S D=0.95$; panel stability $71 \%$ ). Table 1 presents an overview of measures and time-points of measurement used in the present study.

\section{Measures}

Descriptive statistics for all variables included are provided in Table 2. As the first research question refers to the proposed structure of qualitative and quantitative indicators of early HLE, we do not provide internal consistencies for these constructs in this section, but instead placed them in the "Results" section.

\section{Quantitative Dimension of the Home Learning Environment}

The indicators of the quantitative dimension of the HLE was derived from an interview in which the parent (mostly the mother) was asked about the frequency of joint activities of the parent or other persons in the home with their child, adapted from other large scale longitudinal studies (EPPSE-study; Sylva et al., 2014). For the present study we used two time points, when the child was 7 (as control variable; see "Analytic Strategy") and
TABLE 2 | Descriptives of HLE, parent-child courses, child's vocabulary, and control variables.

\begin{tabular}{|c|c|c|c|c|}
\hline & $n$ & $\mathrm{M}(S D) / \%$ & Min & Max \\
\hline \multicolumn{5}{|l|}{ Home Learning Environment } \\
\hline Joint picture book reading at 7 months & 1013 & $3.13(1.45)$ & 1 & 5 \\
\hline Sensitivity at 7 months & 1013 & $4.22(0.72)$ & 1 & 5 \\
\hline Stimulation at 7 months & 1013 & $2.75(0.92)$ & 1 & 5 \\
\hline Positive affect at 7 months & 1013 & $3.31(0.92)$ & 1 & 5 \\
\hline Prevalence of affect at 7 months & 1013 & $2.73(1.05)$ & 1 & 5 \\
\hline Joint picture book reading at 26 months & 1013 & $7.55(0.79)$ & 1 & 8 \\
\hline Visiting Library at 26 months & 1013 & $2.37(1.39)$ & 1 & 8 \\
\hline Nursery Rhymes, Poems at 26 months & 1013 & $6.38(1.86)$ & 1 & 8 \\
\hline Sensitivity at 26 months & 1013 & $3.74(0.78)$ & 1 & 5 \\
\hline Language Stimulation at 26 months & 1013 & $3.40(0.77)$ & 1 & 5 \\
\hline Prevalence of affect at 26 months & 1013 & $3.54(0.86)$ & 1 & 5 \\
\hline \multicolumn{5}{|l|}{ Parent-child-courses } \\
\hline Parent-child courses ( $0=$ no $1=$ yes $)$ & 1013 & $83 \%$ & 0 & 1 \\
\hline \multicolumn{5}{|l|}{ Child vocabulary } \\
\hline Child vocabulary at 38 months & 1013 & $51.6(26.90)$ & 0 & 118 \\
\hline Child vocabulary at 26 months & 1013 & $157.40(57.00)$ & 2 & 260 \\
\hline Child vocabulary at 13 months & 968 & $2.15(0.84)$ & 1 & 5 \\
\hline \multicolumn{5}{|l|}{ Indicators of family background (SES) } \\
\hline Maternal education (years of education) & 1013 & $15.40(2.29)$ & 9 & 18 \\
\hline Income poverty ( 0 = no 1 = yes) & 1013 & $11 \%$ & 0 & 1 \\
\hline Single parent $(0=$ no $1=$ yes $)$ & 1013 & $4 \%$ & 0 & 1 \\
\hline \multicolumn{5}{|l|}{ Controls } \\
\hline Child's age (in months) at 38 months & 1013 & $38.40(0.95)$ & 36 & 41 \\
\hline Child's age (in months) at 26 months & 1013 & $26.30(0.98)$ & 24 & 29 \\
\hline Child's age (in months) at 7 months & 1013 & $6.94(0.80)$ & 4 & 11 \\
\hline Child is a boy ( 0 = no 1 = yes) & 1013 & $50 \%$ & 0 & 1 \\
\hline Number of siblings & 1013 & $0.83(0.91)$ & 1 & 7 \\
\hline
\end{tabular}

26 months old. When the child was 26 months old, parents were asked how often they provide their child with nursery rhymes or songs, visit a library or bookstore together with the child, and 
read to the child / look at picture books. Parents indicated the frequency on an eight-point rating scale ranging from [1] never, [4] several times a month, to [8] several times a day. When the children were 7 months old, age-adjusted items were applied, from which we used the frequency of joint picture book reading (ranging from [0] never to [5] daily).

\section{Qualitative Dimension of the Home Learning Environment}

The quality indicators for the HLE were derived from an observed semi-standardized play situation conducted in the home of the family when the child was 7 (as control variable; see "Analytic Strategy") and 26 months old (Linberg et al., 2019 for a description of the procedure). The measures were adapted from the NICHD Study of Early Child Care (NICHD Early Child Care Research Network, 1998). Parents and children were presented with a standardized toy set and parents were instructed to play with their child and the toys as they normally would. The videotaped interactions were rated afterwards by trained coders according to strict coding rules. The coding system was adapted from the NICHD study; parental as well as the child's interaction behavior was rated on qualitatively defined 5-point scales, which captured to what extent the item was characteristic for the observed behavior of the parent/child, ranging from [1] not at all characteristic to [5] highly characteristic (NICHD Early Child Care Research Network, 1998; Linberg et al., 2019). Coders were extensively trained on the rating system and had to attain at least a 90\% agreement (within 1-point) with "gold standard" ratings of videos before they were allowed to code independently. Inter-rater reliability was assured through randomly selecting $20 \%$ of the videos for double-coding. The average inter-rater agreement was above $90 \%$.

The qualitative dimension of the HLE when children were 26 months old included three items capturing emotional support as well as stimulating interaction behavior. The item "Sensitivity to non-distress" indicates whether and how the parents respond to children's signals of non-distress in a sensitive (prompt, contingent and appropriately warm) manner. The item "Language stimulation" assesses the amount and quality of verbal enrichment of the play situation, such as prompting and expanding child's verbalizations, asking open ended questions, and verbal distancing. The item "Prevalence of affect" measures the dynamics of parental emotions, i.e., whether parents' affect is flat (flat tone of vocal expression, impassive facial expression) or whether the parent shows emotions appropriate to the situation within the usual range. At age 7 months, the same but age-adapted procedure was administered, and the dimension consists of comparable but slightly age-adapted items including sensitivity, stimulation, positive affect, and prevalence of affect.

\section{Parent-Child Courses}

The indicator for "Attendance of parent-child courses" was derived from open questions within the parent interview. Parents were asked whether they attended any parent-child courses during the first 26 months of the child's life. They could state as many courses as they liked $(M=1.82, S D=1.32, \operatorname{Min}=0$,
Max =5). Seventy nine percent of the parents attended parentchild courses with their child and most of them attended more than one course. The reported courses were mainly play or toddler groups (39\%), but motoric- (30\%), music-oriented courses $(23 \%)$, and swimming (37\%) were also reported. $30 \%$ of the parents attended registered trademark courses such as PEKiP or Accompanying Children's Early Development (FenKid). We used the dichotomous indicator whether parents did (1) or did not $(0)$ attend at least one parent-child course within the first 26 months of the child's life. In doing so, we captured sheer courseattendance as we did not suppose a straight linear effect, meaning more courses resulting in an equally higher quality of HLE or larger vocabulary.

\section{Vocabulary at 26 Months}

Child's (expressive) vocabulary at 26 months was assessed using a standardized German vocabulary check-list ("Elternfragebogen für zweijährige Kinder: Sprache und Kommunikation"(ELFRA2); Grimm and Doil, 2006). This parent checklist is a German version of the internationally well-known "MacArthur Communicative Development Inventories (Toddler Form) CDI" (Fenson et al., 1993) and the "Language Development Survey - LDS” (Rescorla and Achenbach, 2002). The ELFRA-2 contains 260 words, including nouns and verbs, for which the parents indicate whether the child already uses them actively (productive vocabulary). We used the sum of words actively used by the child as the indicator for children's vocabulary. The validity of parent checklists and the ELFRA-2 has been assured through high correlations with standardized language tests (e.g., $r=0.78$; of ELFRA-2 and the Reynell Developmental Language Scales III RDLS-III (Edwards et al., 1997; Sachse et al., 2007); and expressive vocabulary has been shown to be more reliably accessible by parents than receptive vocabulary.

\section{Vocabulary at 38 Months}

At the age of 38 months child's (receptive) vocabulary was tested via the German version of the Peabody Picture Vocabulary TestRevision IV (Dunn and Dunn, 2007; Lenhard et al., 2015). The test was administered in the home of the children on a tablet computer on which the child had to tap on the one out of four pictures fitting to the orally presented word. A maximum of 19 sets with 12 items each were administered in this way and the task continued until the child got eight of 12 words incorrect in one section (LIfBi, 2019).

\section{Indicators of Family Socio-Economic Background}

We included three measures: risk of income poverty $(0=$ no; $1=$ yes) was calculated for each family by identifying whether the equivalized household income lies below $60 \%$ of the median of nationwide equalized income (OECD, 2013). Living in a single parent household $(0=$ no; $1=$ yes $)$ indicates whether a partner lives in the household. Furthermore, maternal education as the sum of years of primary, secondary and tertiary education was considered.

\section{Controls}

Except for the confirmatory factor analyses we controlled for a standard set of family and child characteristics. These include 
child gender ( $1=$ male), age of the child (in months) in the concurrent wave, number of siblings living in the household, and a rough proxy for children's early vocabulary at the age of 13 months. Here, parents were asked how many things or persons the child already names correctly, so that the parent is able to understand the child, ranging from [1] none to [5] more than 20 persons or objects.

\section{Analytic Strategy}

For analysing the structural relationship between the quantitative and qualitative dimension of the HLE, their association with family socio-economic background variables, parent-child courses and children's vocabulary, we modeled the respective paths within structural equation modeling. To test for the structure of the dimensions of the early HLE, we modeled the frequency of language stimulating joint activities (quantitative dimension) as well as the quality of parent-child interaction (qualitative dimension) as two separate but associated aspects and tested this model against a competing unidimensional HLE model. Model fit was evaluated by chi-square, root mean square error approximation (RMSEA), and comparative fit index (CFI) (Hu and Bentler, 1999). We relied on the following benchmarks for assessing fit: RMSEA $<0.05$ signifies a good fit; CFI > 0.90 represents a good fit (Bollen, 1989; Hu and Bentler, 1999). In a second step we included indicators of family background, child's vocabulary at the age of 26 and 38 months and parentchild courses to test for the relation between the early HLE and family background variables as well as children's vocabulary development and the effect of parent-child-courses on the early HLE. To rule out the possibility that the expected indirect effect of attending parent-child courses via HLE is due to a confounded effect of very early HLE on vocabulary, or, in other words, that parents with high compared to lower early HLEs tend to more often attend parent-child courses, we simultaneously controlled in this model for quantitative and qualitative indicators of HLE at 7 months. Thus, HLE at 24 months represents an indicator of change in HLE. As mentioned before, we also controlled for child characteristics and family background.

All analyses were carried out using Stata 15. To deal with missing data, we chose the full information maximum likelihood (FIML) approach using valid information of all observations for model estimation (Enders, 2001; Acock, 2013).

\section{RESULTS}

Results demonstrate that the frequency of joint activities and the quality of interactions are two separate aspects of the HLE in the early years that are moderately related $(r=0.25, p<$ 0.001; Figure 2). A comparative model, which considers only one latent variable demonstrates insufficient model fit $\left[\chi^{2}(9)=143.90\right.$ $p<0.001$; RMSEA $=0.12$; CFI $=0.79$; Figure 3].

As shown in Table 3 and depicted in Figure 4, these dimensions of the HLE are differentially related to family socio-economic background variables. Whereas maternal education is significantly associated with the quantitative and qualitative dimension of HLE at age 7 months (Table 3), at

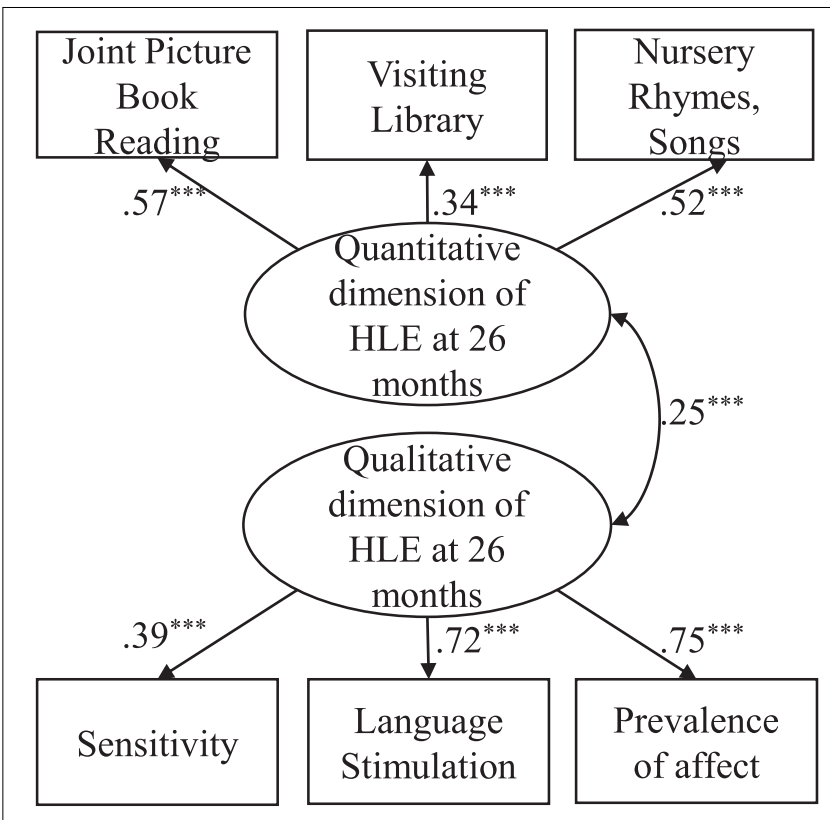

FIGURE 2 | Two factor model of the structural relation between the qualitative and quantitative dimension of home learning environment. $N=1013$; Standardized coefficients, ${ }^{+} p<0.10,{ }^{*} p<0.05,{ }^{* *} p<0.01,{ }^{* * *} p<0.001$; Model Fit: $\chi^{2}(8)=12.92, p<0.01$; RMSEA $=0.03 ; \mathrm{CFI}=0.99$.

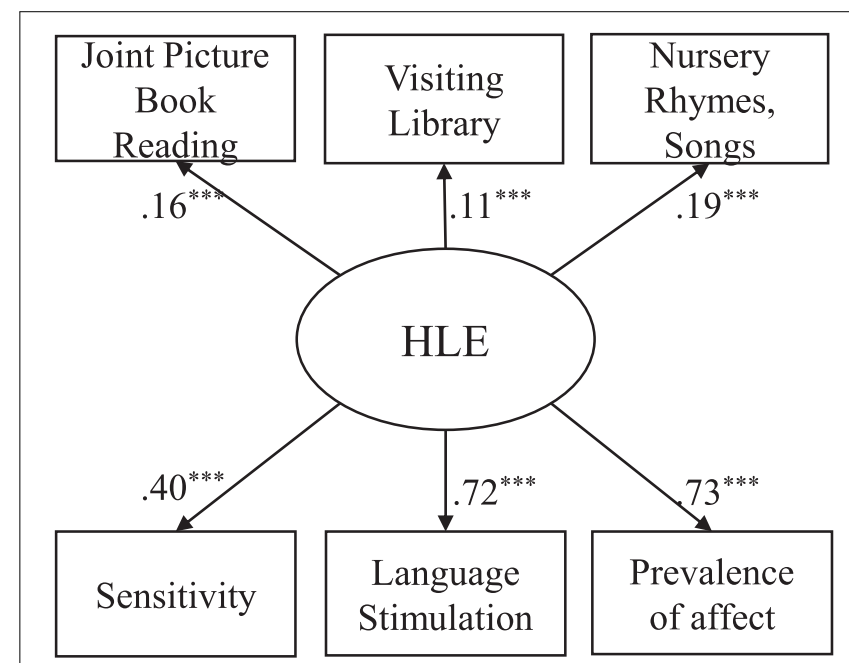

FIGURE 3 | One factor model of the qualitative and quantitative indicators of home learning environment as unitary HLE construct. $N=1013$; Standardized coefficients, ${ }^{+} p<0.10,{ }^{*} p<0.05,{ }^{* *} p<0.01,{ }^{* * *} p<0.001$; Model Fit: $\chi^{2}(9)=143.90, p<0.001 ;$ RMSEA $=0.12 ; \mathrm{CFI}=0.79$.

26 months (Table 3 and Figure 4), maternal education is still significantly connected to the change of the quantitative dimension of HLE; $r=0.22, p<0.001$.), but not to the change of quality of parent-child interaction (qualitative dimension of HLE). Moreover, being a single parent $(r=-0.09, p<0.10)$, as well as risk of income poverty $(r=-0.12, p<0.01)$, are significantly related to the change of quantity of stimulating activities of the HLE at 24 months though not to the change of the 
TABLE 3 | Standardized effects of the model on the relation between SES, the two dimensions of HLE and vocabulary development.

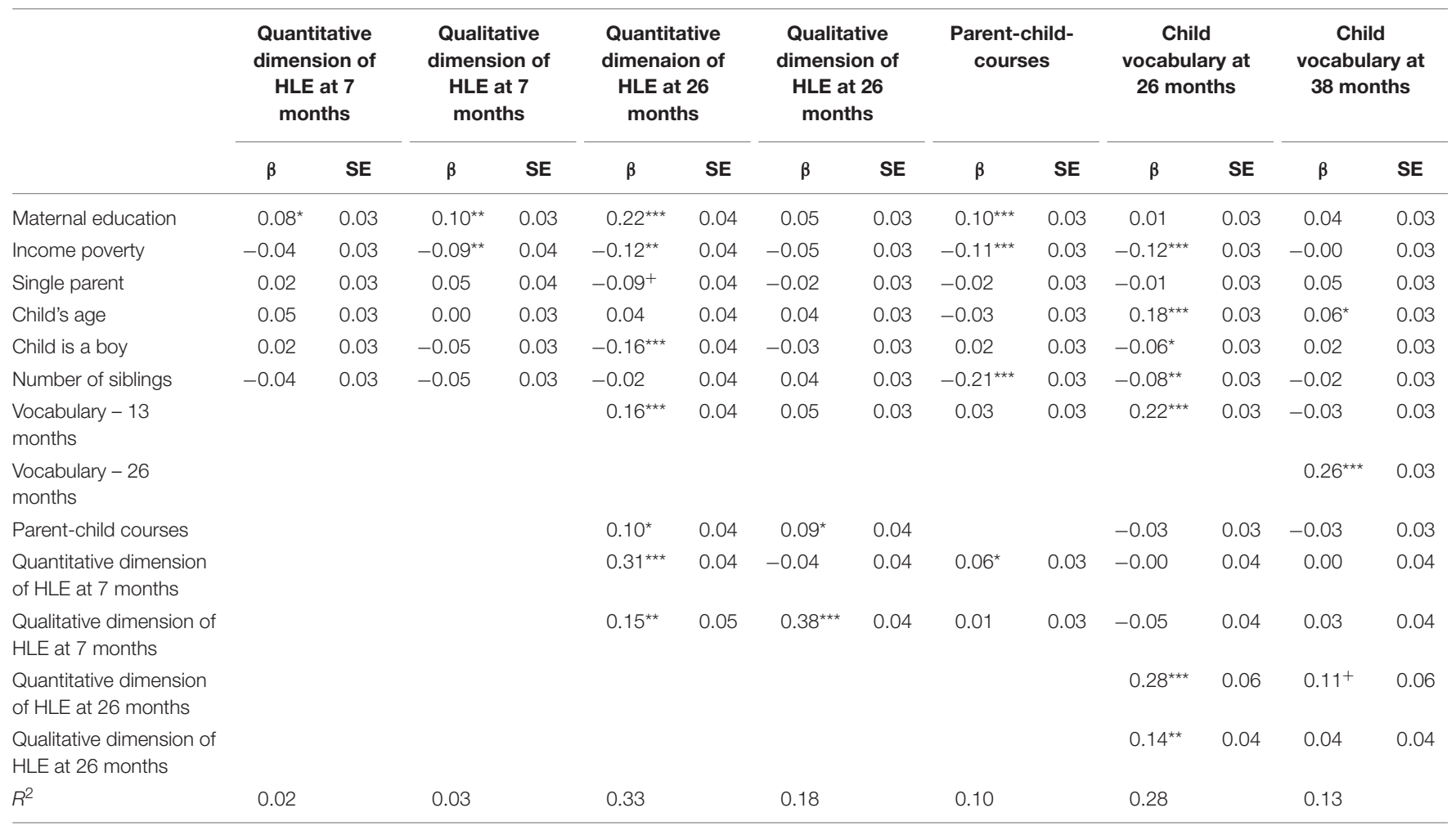

$N=1013 ;$ Standardized coefficients, ${ }^{+} p<0.10,{ }^{*} p<0.05,{ }^{* *} p<0.01,{ }^{* * *} p<0.001$.

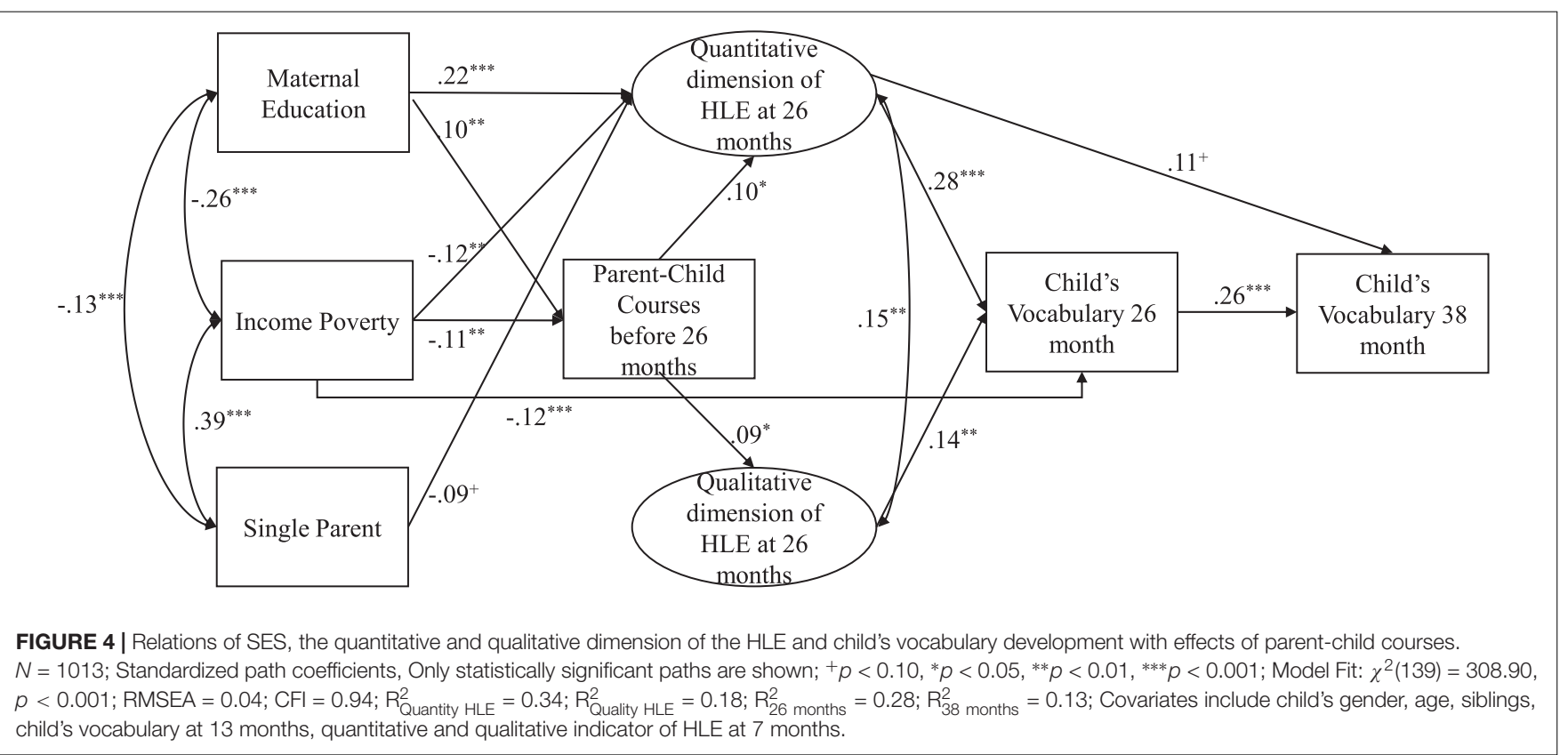

quality dimension (Figure 4). Income poverty, however, was also associated with the qualitative dimension of HLE at 7 months (Table 3). With regard to the relation of the HLE and children's vocabulary development results indicate (Figure 4 and Table 3), even while controlling for the child's vocabulary at 13 months, that the quantitative and the qualitative dimension of the HLE explain both unique variance of vocabulary development at the age of 26 months $(r=0.28, p<0.001 ; r=0.14, p<0.001)$, respectively. At the age of 38 months, only the quantitative dimension adds to the effect of earlier vocabulary development on later receptive vocabulary $(r=0.11, p<0.10$; Figure 4 and Table 3). 
When examining the effects of the attendance of parentchild courses (Figure 4 and Table 3 ), it can be seen that the two dimensions of HLE are both predicted by the attendance of parent-child courses, with similar effect sizes $(r=0.10, p<$ $0.001 ; r=0.09, p<0.05$, respectively). Note that this effect is apparent even under the statistical control of the quantitative and qualitative dimension of the HLE at 7 months, which should reduce (and control for) the feasible effect that parents with comparatively higher early HLE or/and SES tend to attend more parent-child courses (see Table 3 for detailed results).

\section{DISCUSSION}

The first years of a child's life are an important phase for stimulating children's development, as this is a time of rapid change in different developmental areas. For children from the age of 3 years onwards it is well documented that they experience different and differentiated HLEs and that the kind, frequency, and quality of stimulating activities and interactions are at least partly associated with the socio-economic resources (such as income, education) of their families (Kluczniok et al., 2013). In addition, it has been shown that different dimensions of the HLE impact developmental progress in various areas of development differentially (Lehrl et al., 2020). With regard to vocabulary, many children fall behind their peers already at young ages (BrooksGunn and Markman, 2005; Dubowy et al., 2008; Hindman et al., 2008; Fernald et al., 2013). This is particularly challenging as vocabulary is linked to the development of receptive and productive oral language proficiency and reading skills and thus to opportunities for academic success and social participation. While these issues are extensively studied in children from the age of 4 years onwards, studies focusing on children in the very first years of their lives are comparatively sparse, especially those treating the HLE as a multi-dimensional environment. In addition, it is largely unclear to what extent low-threshold offers, such as parent-child courses, contribute to the strengthening of HLE at an early age and thus contribute to the child's vocabulary development. Therefore, this paper examined: (1) the relation between different aspects of the early HLE, i.e., whether qualitative and quantitative aspects of stimulation are separable dimensions or whether they represent a unitary construct of the HLE, (2) whether they are differentially related to SES, and (3) whether attending parent-child courses contributes to enriched HLEs which in turn (4) predict the child's vocabulary development between age two and three.

Our results indicate that quantitative and qualitative aspects of the early HLE should be differentiated. Although these aspects are slightly linked to each other, they do not share much common variance. Thus, an overall factor characterizing a more or less stimulating HLE did not account for the observed differences between HLEs. While only a few studies distinguished these process characteristics of the HLE in the very early years, the few studies that did so also indicate that a distinction is not only possible and meaningful from a theoretical perspective but also necessary to adequately describe different learning environments in the first years of life. Mistry et al. (2008) found that the quality of interactions between mother and child at age one and two was only slightly related to the frequency of literacy stimulation at the same age. Further, results from Linberg (2018) indicate that even more differentiated distinctions within the qualitative aspects of mother-child interactions are possible and necessary to explain environmental effects on child development. In particular, study results show that the differentiation of dimensions of learning environments, such as global and domain-specific stimulating and emotionally supportive aspects of the learning environment, might be important from early on (Leseman and de Jong, 1998; LeFevre et al., 2010; Lehrl et al., 2020). The differentiation of quantitative and qualitative aspects of the HLE also proves to be particularly useful as our analyses indicate that these dimensions tend to be specifically associated with the different indicators of socio-economic background of the family. As early as the age of 7 months, children experience a different quality in stimulation dependent on their mother's educational level and household income, whereas the quantitative dimension (the frequency of activities) depends on maternal education only. All of the considered SES indicators, however, were associated with the (change) in the quantitative dimension of the HLE when children were about 2 years of age (however, different in extent) but not with the (change in the) qualitative dimension. Potentially the social and economic resources might be particularly relevant to changes in the frequency of stimulating activities, parents engage with their child, but less with the change of quality of interaction with their child (Lehrl, 2018). According to the family investment and stress model (Conger and Donnellan, 2007) single parents might lack of time for a high frequency of the considered activities, families suffering from economic hardship might lack the financial resources to provide children with stimulating materials that in turn offer chances for frequent stimulating activities and they might suffer from stress leading to emotional distress and as a consequence in non-functional parenting. However, it must be mentioned that relationships are rather weak. Somewhat more pronounced is the association of maternal education with the quantitative aspects of the HLE. This may be due to the fact that mothers with higher education tend to obtain more information on children's development (Huang et al., 2005; Bornstein et al., 2010; Fagan, 2017) which in turn might lead to more frequent use of stimulating activities (such as reading more often to the child) rather than to a change of concrete interaction behavior (such as interacting more sensitively with a young child). However, it should not be prematurely concluded that SES does not affect the qualitative dimension at all. There is some evidence that the qualitative dimension may only be reduced when multiple SES-risk factors are cumulated (Mistry et al., 2010; Linberg, 2018). With regard to the question to what extent the two dimensions of the HLE are related to the development of children's vocabulary results showed that, similar to existing research with older children (Bus et al., 1995; Mol et al., 2008; Flack et al., 2018) the HLE at a very early age is already related to the child's vocabulary at the age of 2 years. In addition, our study results show that the dimensions are both associated with the development of children's vocabulary at age two (although not as pronounced) when controlling for a proxy of early vocabulary, through 
adding both unique variance in early vocabulary development. Further, the relationship between the quantitative aspect and children's vocabulary development between age two and three is additionally present, revealing stronger effects of the quantitative aspects, although both quantitative and qualitative aspects include language-promoting parenting behaviors. There is a very active discussion on the importance of quality vs. quantity of language-stimulating activities particularly with respect to shared book reading. Study results show that reading practices such as those realized in dialogic reading programmes are far more effective than verbatim reading to young children, asking closed yes-no questions or interactions characterized by a less frequent use of various language-teaching or distancing strategies (Whitehurst et al., 1988; Landry et al., 2012) that actively engage the child in the conversation. This points to the importance of the quality of these activities. Other studies, which partly use natural experiments, demonstrate that a sheer increase in joint reading is associated with advanced language skills (Barnes and Puccioni, 2017; Price and Kalil, 2019) which hints to the importance of frequency. However, note that we did not measure the quality of the activities we used for measuring the quantitative aspects of stimulation.

With regard to parent-child courses, our results indicate that sheer attendance of parent-child courses during the first 2 years of a child's life seems to enrich the early HLE in both dimensions. This, albeit small, effect might be explained by the content of most parent-child courses, which often focus on stimulating activities as well as interactions during the course itself. This might stimulate parents to adopt these activities into their own everyday life at home.

However, we cannot completely rule out that the effect, which we interpret as an enrichment of the HLE by parent-child courses, results from the fact that parents with a higher HLE tend to attend parent-child courses more often. By controlling for the early HLE at the age of 7 months and socio-economic background characteristics, we account, to some degree, for this possibility, however, well designed intervention studies are needed to substantiate causal effects of attending parent-childcourses. Additionally we did not include potential moderators (such as emotional distress or social support) which might also drive the effect of parent-child-courses on HLE.

Concerning the reliability of the indicators of the HLE, it must be noted that although observational methods are considered as rather objective measures, the short observation time, which only observes one play situation, might not give a full picture of the quality of interactions at home. Although, Vogel et al. (2015) have demonstrated that the mother's interaction behavior assessed with the same instrument in a play situation is significantly correlated with the interaction behavior in other situations, this rather short impression of the quality of the HLE, might explain why the association found between HLE and child's vocabulary is rather low in effect size.

Another limitation of the present study is the missing information on the specific content of the parent-child courses or their quality, and the resulting missing classification according to content areas. Research results for studies on intervention programs, however, point to the importance of the quality of these courses (Cadima et al., 2017). Thus, when investigating the effects of such interventions research should consider content and aspects of quality of such courses.

\section{CONCLUSION}

Research on improving language skills and reducing SES-related disparities in acquiring language skills is an area of strong interest for researchers, educators, and policy makers, as it lays the basis for effectively promoting long-term educational success for all children. Variations in the HLE have therefore been of major research interest in the last several decades. The results of the present study show that the HLE, even at this very young age of 1 and 2 years old children, can be differentiated according to quantitative and qualitative aspects, that those aspects vary as a function of socio-economic family background, and that they predict vocabulary development in children. Furthermore, the present study reveals that attending low-threshold courses that aim at providing parents with information on nutrition, play, and motor development, and that at the same time enable exchanges with other parents, is positively associated with the HLE dimensions which in turn are predictive for child vocabulary development.

Practitioners who work with parents or parent-child-dyads should be aware of the various aspects of the HLE that affect children's development, including the frequency of joint activities, e.g., shared book reading, the quality of parents' interactions with children during such activities, and, although not studied in the present study, the materials that parents provide to their children to stimulate learning. Additionally, parent-child-courses, which are cost- and time-efficient and have a low threshold for participation, might be a possibility to approach the enrichment of the HLE in the very early years. Making these courses more accessible to particularly low SES families could be a way of addressing social disparities from the early on. Although, the effects are hardly comparable to elaborate programmes, parent-child courses might be cost- and time-efficient to initiate changes for a wider low-SES public. However, if and to what extent unequal starting conditions can be compensated by low-threshold courses and which elements of those courses are particularly meaningful for enriching the HLE are questions for future research.

\section{DATA AVAILABILITY STATEMENT}

Data from the National Educational Panel Study (NEPS): Starting Cohort Newborns, doi: 10.5157/NEPS:SC1:6.0.0 which were used in this study are available as scientific use file. See http://www.neps-data.de.

\section{ETHICS STATEMENT}

Ethical review and approval was not required for the study on human participants in accordance with the local legislation and institutional requirements. Written informed consent from the participants' legal guardian/next of kin was not required 
to participate in this study in accordance with the national legislation and the institutional requirements.

\section{AUTHOR CONTRIBUTIONS}

AL organized the database and performed the statistical analysis. SL wrote the first draft of the manuscript. All authors wrote the sections of the manuscript, contributed to the design, the idea of the study, the manuscript revision, and read and approved the submitted version.

\section{REFERENCES}

Acock, A. C. (2013). Discovering Structural Equation Modeling Using Stata. College Station, TX: Stata Press.

Ainsworth, M., Bell, S., and Stayton, D. (1974). "Infant-mother attachment and social development: socialization as a product of reciprocal responsiveness to signals," in The Integration of a Child Into a Social World, ed. M. Richards (Cambridge: Cambridge University Press), 99-135.

Anders, Y., Cadima, J., Evangelou, M., and Nata, G. (2017). Parent and Family-Focused Support to Increase Educational Equality Central Assumptions and Core Concepts. ISOTIS Final Report. Available online at: http://isotis.org/wp-content/uploads/2017/04/ISOTIS_D3.1-Parentand-family-focused-support-to-increase-educational-equality_CENTRALASSUMPTIONS-AND-CORE-CONCEPTS.pdf

Attig, M., and Weinert, S. (2019). Häusliche Lernumwelt und Spracherwerb in den ersten Lebensjahren. Sprache Stimme Gehör 43, 86-92. doi: 10.1055/a-08519049

Baker, A. J. L., Piotrkowski, C. S., and Brooks-Gunn, J. (1998). The effects of the Home Instruction Program for Preschool Youngsters (HIPPY) on children's school performance at the end of the program and one year later. Early Childh. Res. Q. 13, 571-588. doi: 10.1016/S0885-2006(99)80061-1

Baker, C. E. (2013). Fathers' and mothers' home literacy involvement and children's cognitive and social emotional development: implications for family literacy programs. Appl. Dev. Sci. 17, 184-197. doi: 10.1080/10888691.2013.836034

Barlow, J., Smailagic, N., Huband, N., Rollof, V., and Bennet, C. (2012). Groupbased parenting programmes for improving parental psychosocial health. Cochrane Database. Syst. Rev. 1-156.

Barnes, E., and Puccioni, J. (2017). Shared book reading and preschool children's academic achievement: evidence from the Early Childhood Longitudinal Study - Birth cohort. Infant. Child Dev. 26:e2035. doi: 10.1002/icd.2035

Blossfeld, H.-P., and Roßbach, H.-G. (2019). Education As a Lifelong Process. The German National Educational Panel Study (NEPS). Wiesbaden: Springer.

Bojczyk, K. E., Davis, A. E., and Rana, V. (2016). Mother-child interaction quality in shared book reading. Relation to child vocabulary and readiness to read. Early Childh. Res. Q. 36, 404-414. doi: 10.1016/j.ecresq.2016.01.006

Bollen, K. A. (1989). A new incremental fit index for general structural equation models. Sociol. Methods Res. 17, 303-316. doi: 10.1177/0049124189017003004

Bornstein, M. H., Cote, L. R., Haynes, O. M., Hahn, C.-S., and Park, Y. (2010). Parenting knowledge: Experiential and sociodemographic factors in European American mothers of young children. Dev. Psychol. 46, 1677-1693. doi: 10. 1037/a0020677

Bornstein, M. H., Hahn, C.-S., and Putnick, D. L. (2016). Long-term stability of core language skill in children with contrasting language skills. Dev. Psychol. 52, 704-716. doi: 10.1037/dev0000111

Bradley, R. H., Corwyn, R., McAdoo, H., and Coll, C. (2003). The home environments of children in the United States. Part I: variations by age, ethnicity, and poverty status. Child Dev. 72, 1844-1867. doi: 10.1111/14678624.t01-1-00382

Bronfenbrenner, U. (1999). "Environments in developmental perspective: theoretical and operational models," in Measuring Environment Across the Life Span. Emerging Methods and Concepts, eds S. L. Friedman and T. D. Wachs (Washington, DC: American Psychological Association), 3-28. doi: 10.1037/ 10317-001

\section{ACKNOWLEDGMENTS}

This manuscript used data from the National Educational Panel Study (NEPS): Starting Cohort Newborns, doi: 10.5157/NEPS:SC1:6.0.0. From 2008 to 2013, NEPS data was collected as part of the Framework Programme for the Promotion of Empirical Educational Research funded by the German Federal Ministry of Education and Research (BMBF). As of 2014, NEPS was carried out by the Leibniz Institute for Educational Trajectories (LIfBi) at the University of Bamberg in cooperation with a nationwide network.

Brooks-Gunn, J., and Markman, L. B. (2005). The contribution of parenting to ethnic and racial gaps in school readiness. Future Child 15, 139-168. doi: 10. 1353/foc. 2005.0001

Bruner, J. (1985). "The role of interaction formats in language acquisition," in Language and Social Situations, ed. J. P. Forgas (New York, NY: Springer), 31-46. doi: 10.1007/978-1-4612-5074-6_2

Bus, A. G., van Ijzendoorn, M. H., and Pellegrini, A. D. (1995). Joint book reading makes for success in learning to read: a meta-analysis on intergenerational transmission of literacy. Rev. Educ. Res. 65, 1-21. doi: 10.3102/ 00346543065001001

Cadima, J., Nata, G., Evangelou, M., and Anders, Y. (2017). Inventory and Analysis of Promising and Evidence-Based Parent- and FamilyFocused Support Programs. ISOTIS Final Report. Available online at: http://www.isotis.org/wp-content/uploads/2018/06/ISOTIS_D3.2-Inventoryand-Analysis-of-Promising-and-Evidence-based-Parent-and-FamilyFocused-Support-Programs.pdf

Campbell, F. A., Ramey, C. T., Pungello, E., Sparling, J., and Miller-Johnson, S. (2002). Early childhood education: young adult outcomes: from the abecedarian project. Appl. Dev. Sci. 6, 42-57. doi: 10.1207/s1532480xads0601_05

Conger, R. D., and Donnellan, M. B. (2007). An interactionist perspective on the socioeconomic context of human development. Annu. Rev. Psychol. 58, 175-199. doi: 10.1146/annurev.psych.58.110405.085551

Debaryshe, B. D. (1993). Joint picture-book reading correlates of early oral language skill. J. Child Lang. 20, 455-461. doi: 10.1017/s0305000900008370

Dubowy, M., Ebert, S., von Maurice, J., and Weinert, S. (2008). Sprachlich-kognitive Kompetenzen beim Eintritt in den Kindergarten. Ein Vergleich von Kindern mit und ohne Migrationshintergrund. Zeitschrift Entwicklungspsychologie Pädagogische Psychologie 40, 124-134. doi: 10.1026/0049-8637.40.3.124

Duncan, G. J., Dowsett, C. J., Claessens, A., Magnuson, K., Huston, A. C., Klebanov, P., et al. (2007). School readiness and later achievement. Dev. Psychol. 43, 1428-1446. doi: 10.1037/0012-1649.43.6.1428

Dunn, L. M., and Dunn, L. M. (2007). PPVT-4 :Peabody Picture Vocabulary Test. Minneapolis, MN: Pearson Assessments.

Dunst, C. J., and Trivette, C. M. (2009). Using research evidence to inform and evaluate early childhood intervention practices. Topics Early Childh. Spec. Educ. 29, 40-52. doi: 10.1177/0271121408329227

Edwards, S., Fletcher, P., Garman, M., Hughes, A., Letts, C., and Sinka, I. (1997). The Reynell Developmental Language Scales III - RDLS III. Göttingen: HogrefeTestzentrale.

Enders, C. K. (2001). The performance of the full information maximum likelihood estimator in multiple regression models with missing data. Educ. Psychol. Measur. 6, 713-740. doi: 10.1177/00131640121971482

Evans, G. W. (2006). Child development and the physical environment. Annu. Rev. Psychol. 57, 423-451. doi: 10.1146/annurev.psych.57.102904.19 0057

Fagan, J. (2017). Income and cognitive stimulation as moderators of the association between family structure and preschoolers' emerging literacy and math. J. Fam. Issues 38, 2400-2424. doi: 10.1177/0192513X16640018

Fenson, L., Dale, P., Reznick, J. S., Thal, D., Bates, E., Hartung, J., et al. (1993). The MacArthur Communicative Development Inventories: User's Guide and Technical Manual. San Diego, CA: Singular Publishing Group. 
Fernald, A., Marchman, V. A., and Weisleder, A. (2013). SES differences in language processing skill and vocabulary are evident at 18 months. Dev. Sci. 16, 234-248. doi: 10.1111/desc. 12019

Flack, Z. M., Field, A. P., and Horst, J. S. (2018). The effects of shared storybook reading on word learning: a meta-analysis. Dev. Psychol. 54, 1334-1346. doi: 10.1037/dev0000512

Forget-Dubois, N., Dionne, G., Lemelin, J.-P., Pérusse, D., Tremblay, R. E., and Boivin, M. (2009). Early child language mediates the relation between home environment and school readiness. Child Dev. 80, 736-749. doi: 10.1111/j.14678624.2009.01294.x

Foster, M. A., Lambert, R., Abbott-Shim, M., McCarty, F., and Franze, S. (2005). A model of home learning environment and social risk factors in relation to children's emergent literacy and social outcomes. Early Childh. Res. Q. 20, 13-36. doi: 10.1016/j.ecresq.2005.01.006

Ganea, P. A., Allen, M. L., Butler, L., Carey, S., and DeLoache, J. S. (2009). Toddlers' referential understanding of pictures. J. Exp. Child Psychol. 104, 283-295. doi: 10.1016/j.jecp.2009.05.008

Grimm, H., and Doil, H. (2006). ELFRA. Elternfragebögen für die Früherkennung von Risikokindern. Göttingen: Hogrefe.

Gudmundson, J. A. (2012). Links Between Maternal Education and Parenting Quality During Children's First Three Years: The Moderating Role of Income and Partner Status. Dissertation, University of North Carolina, Chapel Hill.

Hall, J., Sammons, P., Smees, R., Sylva, K., Evangelou, M., Goff, J., et al. (2019). Relationships between families' use of Sure Start Children's Centres, changes in home learning environments, and preschool behavioural disorders. Oxford Rev. Educ. 45, 367-389. doi: 10.1080/03054985.2018.1551195

Hart, B., and Risley, T. R. (1995). Meaningful Differences in the Everyday Experience of Young American Children. Baltimore: Paul H. Brookes Publishing Co.

Hindman, A. H., Connor, C. M., Jewkes, A. M., and Morrison, F. J. (2008). Untangling the effects of shared book reading: multiple factors and their associations with preschool literacy outcomes. Early Childh. Res. Q. 23, 330350. doi: 10.1016/j.ecresq.2008.01.005

Hoff, E. (2003). "Causes and consequences of SES-related differences in parent-tochild speech," in Socioeconomic Status, Parenting, and Child Development, eds M. H. Bornstein and R. H. Bradley (Mahwah: Lawrence Erlbaum Associates), 145-160.

Hoff, E., Laursen, B., and Tardif, T. (2002). “Socioeconomic status and parenting," in Handbook of Parenting. Volume 2: Biology and Ecology of Parenting, ed. M. H. Bornstein (Mahwah: Lawrence Erlbaum Associates), 231-252.

Horst, J. S., Parsons, K. L., and Bryan, N. M. (2011). Get the story straight. Contextual repetition promotes word learning from storybooks. Front. Psychol. 2:17. doi: 10.3389/fpsyg.2011.00017

Hu, L. T., and Bentler, P. M. (1999). Cutoff criteria for fit indices in covariance structure analysis: coventional criteria versus new alternatives. Struct. Equ. Model. 6, 1-55. doi: 10.1080/10705519909540118

Huang, K.-Y., O’Brien Caughy, M., Genevro, J. L., and Miller, T. L. (2005). Maternal knowledge of child development and quality of parenting among White, African-American and Hispanic mothers. J. Appl. Dev. Psychol. 26, 149-170. doi: 10.1016/j.appdev.2004.12.001

Karrass, J., and Braungart-Rieker, J. M. (2005). Effects of shared parent-infant book reading on early language acquisition. J. Appl. Dev. Psychol. 26, 133-148. doi: 10.1016/j.appdev.2004.12.003

Klebanov, P. K., Brooks-Gunn, J., McCarton, C., and McCormick, M. C. (1998). The contribution of neighborhood and family income to developmental test scores over the first three years of life. Child Dev. 69, 1420-1436. doi: 10.1111/ j.1467-8624.1998.tb06221.x

Kluczniok, K., Lehrl, S., Kuger, S., and Roßbach, H.-G. (2013). Quality of the home learning environment during preschool age - Domains and contextual conditions. Eur. Early Childh. Educ. Res. J. 21, 420-438. doi: 10.1080/1350293X. 2013.814356

Landry, S. H., Smith, K. E., Swank, P. R., Zucker, T., Crawford, A. D., and Solari, E. F. (2012). The effects of a responsive parenting intervention on parentchild interactions during shared book reading. Dev. Psychol. 48, 969-986. doi: 10.1037/a0026400

LeFevre, J., Polyzoi, E., Skwarchuk, S.-L., Fast, L., and Sowinski, C. (2010). Do home numeracy and literacy practices of Greek and Canadian parents predict the numeracy skills of kindergarten children? Int. J. Early Years Educ. 18, 55-70. doi: $10.1080 / 09669761003693926$
Lehrl, S. (2018). Qualität häuslicher Lernumwelten im Vorschulalter. Wiesbaden: Springer Verlag.

Lehrl, S., Ebert, S., Blaurock, S., Rossbach, H.-G., and Weinert, S. (2020). Longterm and domain-specific relations between the early years home learning environment and students' academic outcomes in secondary school. Sch. Effect. Sch. Improv. 31, 102-124. doi: 10.1080/09243453.2019.1618346

Lenhard, A., Lenhard, W., Segerer, R., and Suggate, S. (2015). Peabody Picture Vocabulary Test-Revision IV German Adaption, PPVT-IV. Frankfurt: Pearson.

Leseman, P. P. M., and de Jong, P. F. (1998). Home literacy: opportunity, instruction, cooperation and social emotional quality predicting early reading achievement. Read. Res. Q. 33, 294-318. doi: 10.1598/rrq.33.3.3

LIfBi. (2019). Information on Direct Measures and on Competence Testing. NEPS Starting Cohort 1 - Newborns Education From the Very Beginning. Wave 4: 37-39 months. Bamberg: Leibniz Institute for Educational Trajectories.

Linberg, A. (2018). Interaktion zwischen Mutter und Kind. Dimensionen, Bedingungen und Effekte. Waxmann: Münster.

Linberg, A., Freund, J.-D., and Mann, D. (2017). "Bedingungen sensitiver Mutter-Kind-Interaktionen," in Interaktionsgestaltung in Familie und Kindertagesbetreuung, eds H. Wadepohl, K. Mackowiak, K. Fröhlich-Gildhoff, and D. Weltzien (Wiesbaden: Springer VS), 27-52. doi: 10.1007/978-3-658-10276-0_2

Linberg, A., Mann, D., Attig, M., Vogel, F., Weinert, S., and Roßbach, H.-G. (2019). Assessment of Interactions with the Macro-Analytic Rating System of ParentChild-Interactions in the NEPS at the Child's Age of 7, 17, and 26 months (NEPS Survey Paper No. 51). Leibniz Institute for Educational Trajectories, National Educational Panel Study. Available online at: https://www.neps-data.de/Portals/ 0/Survey\%20Papers/SP_LI.pdf

Lugo-Gil, J., and Tamis-LeMonda, C. S. (2008). Family resources and parenting quality: links to children's cognitive development across the first 3 years. Child Dev. 79, 1065-1085. doi: 10.1111/j.1467-8624.2008.01176.x

Magnuson, K. A., Sexton, H. R., Davis-Kean, P. E., and Huston, A. C. (2009). Increases in maternal education and young children's language skills. MerrillPalmer Q. 55, 319-350. doi: 10.1353/mpq.0.0024

Marchman, V. A., and Fernald, A. (2008). Speed of word recognition and vocabulary knowledge in infancy predict cognitive and language outcomes in later childhood. Dev. Sci. 11, F9-F16. doi: 10.1111/j.1467-7687.2008.00671.x

McLoyd, V. (1990). The impact of economic hardship on black families and children: psychological distress, parenting, and socioemotional development. Child Dev. 61, 311-346. doi: 10.2307/1131096

Mills-Koonce, W. R., Willoughby, M. T., Garrett-Peters, P., Wagner, N., and Vernon-Feagans, L. (2016). The interplay among socioeconomic status, household chaos, and parenting in the prediction of child conduct problems and callous-unemotional behaviors. Dev. Psychopathol. 28, 757-771. doi: 10.1017/ S0954579416000298

Mistry, R. M., Benner, A. D., Biesanz, J. C., Clark, S. L., and Howes, C. (2010). Family and social risk and parental investments during early childhood years as predictors of low-income children's school readiness outcomes. Early Childh. Res. Q. 25, 432-449. doi: 10.1016/j.ecresq.2010.01.002

Mistry, R. S., Biesanz, J. C., Chien, N., Howes, C., and Benner, A. D. (2008). Socioeconomic status, parental investments, and the cognitive and behavioral outcomes of low-income children from immigrant and native households. Early Childh. Res. Q. 23, 193-212. doi: 10.1016/j.ecresq.2008.01.002

Mol, S. E., Bus, A. G., and Jong, M. T. (2008). Added value of dialogic parentchild book readings: a meta-analysis. Early Educ. Dev. 19, 7-26. doi: 10.1080/ 10409280701838603

Montag, J. L., Jones, M. N., and Smith, L. B. (2015). The words children hear: picture books and the statistics for language learning. Psychol. Sci. 26, 14891496. doi: 10.1177/0956797615594361

Mühler, G., and Spieß, C. K. (2008). "Informelle Förderangebote - Eine empirische Analyse ihrer Nutzung in der frühen Kindheit," in Frühpädagogische Förderung in Institutionen (Zeitschrift für Erziehungswissenschaft. Sonderheft, eds H.-G. Roßbach and H.-P. Blossfeld (Wiesbaden: Springer VS), 29-46. doi: 10.1007/ 978-3-531-91452-7_3

Neuhauser, A. (2018). Predictors of maternal sensitivity in at-risk families. Early Child Dev. Care 188, 126-142. doi: 10.1080/03004430.2016.120 7065

Nicely, P., Tamis-LeMonda, C. S., and Bornstein, M. H. (1999). Mothers' attuned responses to infant affect expressivity promote earlier achievement of language 
milestones. Infant Behav. Dev. 22, 557-568. doi: 10.1016/s0163-6383(00) 00023-0

NICHD Early Child Care Research Network. (1998). Relations between family predictors and child outcomes: are they weaker for children in child care? Dev. Psychol. 34, 1119-1128. doi: 10.1037/0012-1649.34.5.1119

NICHD Study of Early Child Care (1999). Mother-child-interaction - SemiStructured Procedure (six-month home visit): Phase 1 Instrument Document. Bethesda, MD: NICHD Study of Early Child Care*.

Nievar, M. A., Jacobson, A., Chen, Q., Johnson, U., and Dier, S. (2011). Impact of HIPPY on home learning environments of Latino families. Early Childh. Res. Q. 26, 268-277. doi: 10.1016/j.ecresq.2011.01.002

Niklas, F., Cohrssen, C., and Tayler, C. (2016). The sooner, the better: early reading to children. Sage Open 6, 1-11. doi: 10.1177/2158244016672715

Nozadi, S. S., Spinrad, T. L., Eisenberg, N., Bolnick, R., Eggum-Wilkens, N. D., Smith, C. L., et al. (2013). Prediction of toddlers' expressive language from maternal sensitivity and toddlers' anger expressions: a developmental perspective. Infant Behav. Dev. 36, 650-661. doi: 10.1016/j.infbeh.2013. 06.002

OECD. (2013). Framework of Statistics on the Distribution of Household Income, Consumption And Wealth. Paris: OECD Publishing.

Pinto, G., Bigozzi, L., Tarchi, C., and Vezzani, C. (2017). Emergent literacy and reading acquisition: a longitudinal study from kindergarten to primary school. Eur. J. Psychol. Educ. 32, 571-587. doi: 10.1007/s10212-016-0314-9

Price, J., and Kalil, A. (2019). The Effect of Mother-Child Reading Time on Children'sReading Skills. Evidence From Natural Within-Family Variation. Child Dev. 90, e688-e702. doi: 10.1111/cdev.13137

Rescorla, L., and Achenbach, T. M. (2002). Use of the language development survey (LDS) in a national probability sample of children 18 to 35 months old. J. Speech Lang. Hear Res. 4, 733-743. doi: 10.1044/1092-4388(2002/059)

Rodriguez, E., and Tamis-LeMonda, C. S. (2011). Trajectories of the home learning environment across the first 5 years: associations with children's vocabulary and literacy skills at prekindergarten. Child Dev. 82, 1058-1075. doi: 10.1111/j.14678624.2011.01614.x

Rodriguez, E. T., Tamis-LeMonda, C. S., Spellmann, M. E., Raikes, H., Lugo-Gil, J., et al. (2009). The formative role of home literacy experiences across the first three years of life in children from low-income families. J. Appl. Dev. Psychol. 30, 677-694. doi: 10.1016/j.appdev.2009.01.003

Rowe, M. (2008). Child-directed speech. Relation to socioeconomic status, knowledge of child development and child vocabulary skill. J. Child Lang. 35, 185-205. doi: 10.1017/s0305000907008343

Sachse, S., Anke, B., and von Suchodoletz, W. (2007). Früherkennung von Sprachentwicklungsstörungen - ein Methodenvergleich. Zeitschrift Kinder Jugendpsychiatrie Psychotherapie 35, 323-331. doi: 10.1024/1422-4917.35.5.323

Sama-Miller, E., Akers, L., Mraz-Esposito, A., Avellar, S., Paulsell, D., and Del Grosso, P. (2017). Home Visiting Programs: Reviewing Evidence of Effectiveness. Washington, DC: U.S: Department of Health and Human Services.

Sammons, P., Hall, J., Smees, R., Goff, J., Sylva, K., Smith, T., et al. (2015). The Impact of Children's Centres: Studying the Effects of Children's Centres in Promoting Better Outcomes For Young Children and Their Families: Evaluation of Children's Centres in England (ECCE, Strand 4). London: Department for Education.

Schaub, S., Ramseier, E., Neuhauser, A., Burkhardt, S. C. A., and Lanfranchi, A. (2019). Effects of home-based early intervention on child outcomes: a randomized controlled trial of Parents as Teachers in Switzerland. Early Childh. Res. Q. 48, 173-185. doi: 10.1016/j.ecresq.2019.03.007

Schmitt, S. A., Simpson, A. M., and Friend, M. (2011). A longitudinal assessment of the home literacy environment and early language. Infant Child Dev. 20, 409-431. doi: 10.1002/icd.733

Sénéchal, M., Lefevre, J., Smith-Chant, B. L., and Colton, K. V. (2001). On refining theoretical models of emergent literacy the role of empirical evidence. J. Sch. Psychol. 39, 439-460. doi: 10.1016/S0022-4405(01)00081-4

Sénéchal, M., Pagan, S., Lever, R., and Ouellette, G. P. (2008). Relations among the frequency of shared reading and 4-year-old children's vocabulary, morphological and syntax comprehension, and narrative skills. Early Educ. Dev. 19, 27-44. doi: 10.1080/10409280701838710
Shin, H., Park, Y.-J., and Kim, M. J. (2006). Predictors of maternal sensitivity during the early postpartum period. J. Adv. Nurs. 55, 425-434. doi: $10.1111 / \mathrm{j} .1365-$ 2648.2006.03943.X

Shin, H., Park, Y.-J., Ryu, H., and Seomun, G.-A. (2008). Maternal sensitivity: a concept analysis. J. Adv. Nurs. 64, 304-314. doi: 10.1111/j.1365-2648.2008. 04814.x

Skwarchuk, S.-L., Sowinski, C., and LeFevre, J.-A. (2014). Formal and informal home learning activities in relation to children's early numeracy and literacy skills: the development of a home numeracy model. J. Exp. Child Psychol. 121, 63-84. doi: 10.1016/j.jecp.2013.11.006

Storch, S. A., and Whitehurst, G. J. (2002). Oral language and code-related precursors to reading: evidence from a longitudinal structural model. Dev. Psychol. 38:934. doi: 10.1037/0012-1649.38.6.934

Sylva, K., Melhuish, E., Sammons, P., Siraj, I., and Taggart, B. (2014). Students' educational and developmental outcomes at age 16. Effective Preschool, Primary and Secondary Education 3-16 Project (EPPSE 3-16). London: Department for Education.

Tamis-LeMonda, C. S., Bornstein, M. H., and Baumwell, L. (2001). Maternal responsiveness and children's achievement of language milestones. Child Dev. 72, 748-767. doi: 10.1111/1467-8624.00313

Teale, W. H., and Sulzby, E. (1986). Emergent Literacy: Writing and Reading. Norwood: Ablex.

Vallotton, C. D., Mastergeorge, A., Foster, T., Decker, K. B., and Ayoub, C. (2017). Parenting supports for early vocabulary development. Specific effects of sensitivity and stimulation through infancy. Infancy 22, 78-107. doi: 10.1111/ infa. 12147

Vogel, F., Freund, J. D., and Weinert, S. (2015). "Vergleichbarkeit von Interaktionsmaßen über verschiedene Situationen bei Säuglingen: ergebnisse des Projekts ViVA. Poster. 22," in Proceedings of the Tagung der Fachgruppe Entwicklungspsychologie der Deutschen Gesellschaft für Psychologie. Frankfurt.

Wade, M., Jenkins, J. M., Venkadasalam, V. P., Binnoon-Erez, N., and Ganea, P. A. (2018). The role of maternal responsiveness and linguistic input in preacademic skill development. A longitudinal analysis of pathways. Cogn. Dev. 45, 125-140. doi: 10.1016/j.cogdev.2018.01.005

Weinert, S., Linberg, A., Attig, M., Freund, J.-D., and Linberg, T. (2016). Analyzing early child development, influential conditions, and future impacts: prospects of a German newborn cohort study. Int. J. Child Care Educ. Policy 10, 1-20. doi: 10.1186/s40723-016-0022-6

Weisleder, A., and Fernald, A. (2013). Talking to children matters: early language experience strengthens processing and builds vocabulary. Psychol. Sci. 24, 2143-2152. doi: 10.1177/0956797613488145

Whitehurst, G. J., Falco, F. L., Lonigan, C. J., Fischel, J. E., DeBaryshe, B. D., ValdezMenchaca, M. C., et al. (1988). Accelerating language development through picture book reading. Dev. Psychol. 24, 552-559. doi: 10.1037//0012-1649.24. 4.552

Whitehurst, G. J., and Lonigan, C. J. (1998). Child development and emergent literacy. Child Dev. 69, 848-872. doi: 10.1111/j.1467-8624.1998.tb06247.x

Wilke, F., Hachfeld, A., and Anders, Y. (2017). How is the participation in parent -child-interaction-focused and parenting-skills-focused courses associated with development? Early Years 38, 411-428. doi: 10.1080/09575146.2017.128 8089

Zigler, E., Pfannenstiel, J. C., and Seitz, V. (2008). The Parents as Teachers program and school success. A replication and extension. J. Prim. Prevent. 29, 103-120. doi: $10.1007 /$ s10935-008-0132-1

Conflict of Interest: The authors declare that the research was conducted in the absence of any commercial or financial relationships that could be construed as a potential conflict of interest.

Copyright (c) 2020 Linberg, Lehrl and Weinert. This is an open-access article distributed under the terms of the Creative Commons Attribution License (CC BY). The use, distribution or reproduction in other forums is permitted, provided the original author(s) and the copyright owner(s) are credited and that the original publication in this journal is cited, in accordance with accepted academic practice. No use, distribution or reproduction is permitted which does not comply with these terms. 


\section{OPEN ACCESS}

Edited by:

Simone Lehrl,

University of Bamberg, Germany

Reviewed by:

Sina Fackler,

Leibniz Institute for Educational

Trajectories (LG), Germany

Sherri Horner,

Bowling Green State University,

United States

*Correspondence:

Gintautas Silinskas

gintautas.silinskas@jyu.fi

Specialty section:

This article was submitted to

Educational Psychology,

a section of the journal

Frontiers in Psychology

Received: 03 April 2020

Accepted: 05 June 2020

Published: 02 July 2020

Citation:

Silinskas G, Sénéchal M, Torppa M and Lerkkanen M-K (2020)

Home Literacy Activities

and Children's Reading Skills,

Independent Reading, and Interest

in Literacy Activities From

Kindergarten to Grade 2.

Front. Psychol. 11:1508.

doi: 10.3389/fpsyg.2020.01508

\section{Home Literacy Activities and Children's Reading Skills, Independent Reading, and Interest in Literacy Activities From Kindergarten to Grade 2}

\author{
Gintautas Silinskas ${ }^{1 *}$, Monique Sénéchal' ${ }^{2}$, Minna Torppa ${ }^{3}$ and \\ Marja-Kristiina Lerkkanen ${ }^{3}$
}

\begin{abstract}
${ }^{1}$ Department of Psychology, University of Jyväskylä, Jyväskylä, Finland, ${ }^{2}$ Department of Psychology, Carleton University, Ottawa, ON, Canada, ${ }^{3}$ Department of Teacher Education, University of Jyväskylä, Jyväskylä, Finland
\end{abstract}

According to the Home Literacy Model (Sénéchal and LeFevre, 2002, 2014), young children can be exposed to two distinct types of literacy activities at home. First, meaning-related literacy activities are those where print is present but is not the focus of the parent-child interaction, for example, when parents read storybooks to their children. In contrast, code-related literacy activities focus on the print, for example, activities such as when parents teach their children the names and sounds of letters or to read words. The present study was conducted to expand the Home Literacy Model by examining its relation with children's engagement in literacy activities at home and at school as Finnish children transitioned from kindergarten to Grades 1 and 2. Two facets of children's engagement were examined, namely, children's independent reading at home and their interest in literacy activities. Children $(N=378)$ were tested and interviewed at the ends of kindergarten, Grade 1, and Grade 2. Mothers completed questionnaires on their home literacy activities at each test time, and they reported the frequency with which their children read independently twice when children were in grade school. Tested was a longitudinal model of the hypothesized relations among maternal home literacy activities (shared reading and teaching of reading), children's reading skills, independent reading, and their interest in literacy activities/tasks as children progressed from kindergarten to Grade 2. Stringent path analyses that included all auto-regressors were conducted. Findings extended previous research in four ways. First, the frequency of shared reading and teaching of reading at home predicted the frequency of children's independent reading 1 year later. Second, children with stronger early literacy skills in kindergarten read independently more frequently once they were in Grade 1 . Third, parents adapted, from kindergarten to Grade 1, their teaching behaviors to their children's progress in reading, whereas shared reading decreased over time. Fourth, children's own reports of interest in literacy activities were mostly not linked to other variables. Taken together, these results add another layer to the Home Literacy Model.

Keywords: home literacy activities, independent reading, early literacy, reading skills, kindergarten to Grade 2 


\section{INTRODUCTION}

Parents contribute to their children's reading acquisition by exposing them to a rich home literacy environment (Torppa et al., 2006; Manolitsis et al., 2011; Niklas and Schneider, 2013). The types and the frequency of literacy activities at home prior to formal schooling have been linked longitudinally to the development of children's reading acquisition by enhancing children's language and early literacy skills (Sénéchal et al., 1998; Hood et al., 2008). Whereas most studies focused on home literacy activities before the start of formal schooling or Grade 1, fewer studies examined changes in home literacy activities once children enter formal schooling (e.g., Silinskas et al., 2012; Sénéchal and LeFevre, 2014). Moreover, recent concurrent and longitudinal evidence suggests that children's engagement in literacy activities also plays a role in the relation between the home literacy environment and children's reading skills (Sénéchal, 2006; Silinskas et al., 2012, 2013). The present study was conducted to expand the Home Literacy Model (Sénéchal and LeFevre, 2002) by examining its relation with children's engagement in literacy activities at home and at school as Finnish children transitioned from kindergarten to Grades 1 and 2. Two facets of children's engagement were examined, namely, children's independent reading at home and their interest in literacy activities.

\section{The Home Literacy Model}

According to the Home Literacy Model (Sénéchal et al., 1998; Sénéchal and LeFevre, 2002), young children can be exposed to two distinct types of literacy activities at home. First, meaning-related literacy activities (also often labeled as informal literacy activities) are those where print is present but is not the focus of the parent-child interaction, for example, when parents read storybooks to their children. In contrast, coderelated literacy activities at home (often labeled as formal literacy activities) focus on the print, for example, activities such as when parents teach their children the names and sounds of letters or to read words. Meaning-related activities predict children's reading acquisition indirectly by enhancing language development, whereas code-related activities predict reading indirectly by enhancing children's early literacy skills. Support for this model has been found in opaque orthographies, such as English (Hood et al., 2008; Sénéchal and LeFevre, 2014) and French (Sénéchal, 2006) as well as some support in transparent orthographies, such as Greek (Manolitsis et al., 2011; Manolitsis et al., 2013), Lithuanian (Silinskas et al., submitted), German (Lehrl et al., 2013; Niklas and Schneider, 2013, 2017; Rose et al., 2018) and Finnish (Torppa et al., 2006, 2007; Silinskas et al., 2012; Silinskas et al., 2020). Although the Home Literacy Model postulates that parental literacy activities at home enhance children's literacy outcomes, other evidence has shown that children's own reading as well as children's interest in literacy activities predict their literacy outcomes (Levin et al., 1997; Pomerantz and Eaton, 2001; Martini and Sénéchal, 2012; Silinskas et al., 2012, 2013; Torppa et al., 2019).

\section{Children's Independent Reading}

Children's independent reading can be defined as the frequency with which children voluntarily read on their own in anticipation of the satisfaction that is obtained from reading (Frijters et al., 2000; Leppänen et al., 2005; Clark and Rumbold, 2006). Although the term independent reading is used herein, other interchangeable terms include reading for pleasure (Sénéchal, 2006), voluntary reading (Krashen, 2004), leisure reading (Torppa et al., 2019), and a child's own reading outside school/out-of-school reading habits (Silinskas et al., 2013).

Concurrent evidence suggests that children's independent reading is positively related to their reading skills (for a review, see Schiefele et al., 2012). In a meta-analysis, Mol and Bus (2011) found seven studies, representing 517 Grades 1 and 2 children that included correlations between exposure to print through reading and word recognition. For these studies, print exposure was moderately, but significantly, associated with children skills (Mean $r=0.33$ ). Yet, a limited number of short-term longitudinal studies showed a somewhat stronger association from skills to independent reading than the other way around (e.g., Aarnoutse and van Leeuwe, 1998). For instance, Leppänen et al. (2005) showed stronger cross-lagged paths from Grade 1 reading skills to Grade 2 frequency of independent reading than from independent reading to reading skills. In another study, wordreading skills in Grade 1 predicted independent reading of books in Grade 2, not the other way around (Torppa et al., 2019). In older children, Harlaar et al. (2011) also found a significant crosslagged effect from Grade 5 reading skills (a composite of accuracy and comprehension) to the Grade 6 frequency of independent reading, but the reverse path was not significant.

Examination of the longitudinal relation between children's independent reading and home literacy practices has been limited to a single study that showed that parental shared reading in kindergarten predicted children's reports of independent reading for pleasure in Grade 4 after controlling for parent education, kindergarten early skills, Grade 1 reading, as well as Grade 4 reading comprehension (Sénéchal, 2006). In contrast, parent teaching in kindergarten did not predict the frequency of reading for pleasure. One goal of the present research was to investigate the reciprocal associations among parental home literacy activities and children's independent reading. In contrast to Sénéchal who assessed independent reading only in Grade 4, in the present study independent reading was measured at the end of Grades 1 and 2. The rationale was that given the transparency of Finnish, children might become autonomous readers earlier (Lerkkanen et al., 2004) than in opaque languages such as in English or French. Moreover, this early autonomy might be predicted not only by shared reading, but also by parent teaching.

\section{Children's Interest in Literacy}

Child interest can be defined as the perceived intrinsic value of a task, namely, the degree to which a task is enjoyable (Eccles et al., 1993). Certainly, children's emotional engagement in reading activities is a key component of their interest to read (De Naeghel et al., 2012). In the present study, we examined how much children liked doing literacy activities at home and at school (Lerkkanen et al., 2012). Nurmi and Aunola (2005) reported that 
most young Finnish children in their study $(N=211)$ generally enjoyed doing literacy activities, with less than $16 \%$ of them reporting low interest in literacy tasks across the beginning and ends of Grades 1 and 2.

Studies provide mixed evidence on the links between children's interest in literacy and their literacy outcomes. For example, in their meta-analysis of 26 correlational studies examining young children's interest and literacy outcomes, Dunst et al. (2011) showed that children's interest was positively associated with their alphabet knowledge (8 studies: Mean effect size $=0.14,95 \%$ CIs: $0.08-0.20)$ as well as word recognition (7 studies: Mean effect size $=0.32$, 95\% CIs: 0.28-0.35). Also, 5-yearold children's reports of interest in literacy activities contributed unique variance to alphabet knowledge after controlling for parent education, child gender and vocabulary (Baroody and Diamond, 2012). In contrast, other studies reported that finding links between child interest and child literacy skills was challenging. For instance, Kikas et al. (2015) did not find that child interest predicted child reading longitudinally in their cross-over analyses of data from 334 Estonian children. Also, Walgermo et al. (2018) did not find a direct link between children's interest and their emergent literacy skills in a large sample of 1171 Norwegian children.

Empirical evidence on the relations between child interest in literacy and their home literacy environment is scarce. Based on a few reports that are available, child's interest has been found to be positively related to their home literacy environment (Martini and Sénéchal, 2012; Hume et al., 2016; Carroll et al., 2019). For instance, concurrent and longitudinal associations were found between exposure to book reading (e.g., the amount of children's books, shared reading, and children observing parent read) and children's interest in books, whereas parent teaching literacy (e.g., teaching letters, pointing out words, and playing rhyming games) was concurrently and longitudinally associated with children's interest in the alphabet and words (Hume et al., 2015).

Finally, some researchers reported positive associations between children's interest and their reading independently from Grade 1 to Grade 2 (Frijters et al., 2000; Dunst et al., 2011; Baroody and Diamond, 2012). Consequently, we investigated this interrelation. In addition, we explored associations between children's interest in literacy, their literacy outcomes, and their parents' home literacy activities. However, due to mixed and scarce previous findings and due to the tendency of the young children to report liking literacy activities, we did not set any specific hypotheses.

\section{Longitudinal Changes in Home Literacy Activities}

Studies examining changes in home literacy practices as children transition into school revealed novel patterns of associations. In a sample of English-speaking children schooled in French, Sénéchal and LeFevre (2014) found that the frequency of parent teaching and expectations about literacy in kindergarten positively predicted growth in English literacy skills from kindergarten to the beginning of Grade 1. Moreover, parent teaching and listening to their children read at the beginning of Grade 1 positively predicted child reading skills in English at the end of Grade 1 after controlling for beginning of Grade 1 reading, phoneme awareness, and vocabulary. In sharp contrast, parent teaching and listening to the child read in Grade 1 was negatively related to reading skills at the end of Grade 2. Importantly, child reading skills at the beginning of Grade 1 was a negative predictor of parent teaching/listening at the end of Grade 2. Sénéchal and LeFevre interpreted these findings as an indication that parents were responsive to their children's reading skills in that they provided more support when their children had more difficulty reading. In fact, parents who increased their teaching from Grade 1 to 2 had children with lower reading scores at the end of Grade 1 as compared to parents who maintained or who decreased their teaching.

The longitudinal associations between children's reading skills and parental involvement may differ as a function of orthographic transparency. For instance, English is an opaque orthography because it has multiple exceptions to phonemegrapheme connections (e.g., the phonology of ea in bear vs. beard) whereas Finnish is a transparent orthography in which letters consistently map on to the sound of the spoken language. It is well established that differences in transparency across languages affect the speed of children's reading acquisition (Ziegler et al., 2010). Due to the transparency of the Finnish orthography paired with phonics instruction, children learn to read very fast in comparison to children in many other countries (Seymour et al., 2003; Silinskas et al., 2010b; Silinskas, 2012). In fact, the vast majority of Finnish children master decoding during the first half of Grade 1 (Lerkkanen et al., 2004). Because learning to read in Finnish is easier than learning in English, one could anticipate that parents might become responsive to their children's reading behaviors earlier. There is some evidence that this is the case (Silinskas, 2012; Silinskas et al., 2015). In Finnish samples, the parent-child home literacy activities were positively correlated with children's skills in kindergarten, whereas the relation became negative in Grade 1 (Silinskas et al., 2010a, 2012). This evidence supports the notion that one needs to consider orthographic transparency when studying the reciprocity between skills and home literacy activities.

\section{The Present Study}

In Finland, compulsory education (Grade 1) begins in the year of the child's seventh birthday. Immediately before Grade 1, children attend kindergarten for 1 year. The main objectives of the kindergarten curriculum emphasize children's personal and social growth. Although emerging literacy skills are not systematically taught, they are promoted by playful activities involving letters, phonological awareness, and shared reading activities. Once children enter Grade 1, they receive $7 \mathrm{~h}$ of literacy teaching per week focusing on learning to decode and practice fluency and comprehension. Because decoding reaches a high level of accuracy for most Grade 1 students after only a few months of school (Lerkkanen et al., 2004), students' commitment and motivation for silent reading is supported daily from Grade 1 onward. Gains in reading fluency and comprehension are encouraged by the availability of high-interest texts at multiple levels of difficulty and by giving students the freedom to choose reading materials. Children are also given time to read what they choose, without being evaluated (Torppa et al., 2016). 
The goal of the present study was to investigate, in a large sample of Finnish families, the longitudinal interplay among mothers' reports of home literacy activities (shared reading and teaching of reading), children's independent reading, their interest in reading, and their reading skills during the transition to primary school. Mothers completed questionnaires about home literacy activities, and children's skills and interest were assessed at the ends of kindergarten, Grade 1, and Grade 2. Prior to testing the predicted longitudinal links, it was necessary to verify whether the relations among the kindergarten variables were consistent with the two key components of the Home Literacy Model. First, mothers' reported frequency of teaching to read in kindergarten should be positively linked to children's early literacy, but not to vocabulary. In contrast, mothers' reported frequency of shared reading in kindergarten should be positively linked to children's vocabulary, but not to early literacy (Sénéchal et al., 1998).

Listed below are six longitudinal predictions, based on past research, that led to the hypothesized theoretical model presented in Figure 1. This model included all auto-regressors of parent and child measures. Of special note, when longitudinal predictions were based on findings obtained in English, the timeline was shortened to reflect the documented rapid reading gains made by Grade 1 Finnish children.

(1) Shared reading and parent teaching in kindergarten should be positively linked to Grade 1 children's independent reading at home (Leppänen et al., 2005; Sénéchal, 2006; Hume et al., 2015). This link should only be present from kindergarten to Grade 1 given the rapidity with which Finnish children acquire reading skills as well as the inclusion of all available auto-regressors in the model.

(2) Parent teaching in kindergarten should be linked to growth in reading skills in Grade 1 and in turn Grade 1 reading skills should be linked negatively to the frequency of parent teaching in Grade 2 (Silinskas et al., 2010a, 2013).

(3) The strength of children's early literacy skills should influence the frequency of parent teaching at the end of Grade 1 (Silinskas et al., 2012; Sénéchal and LeFevre, 2014). Specifically, children's early literacy skills feed back onto parent teaching such that the relation becomes negative: Parents of children with greater early literacy skills in kindergarten age should report teaching less at the end of Grade 1, and vice versa.

(4) Children's early literacy skills in kindergarten should be positively linked to the frequency with which they read independently at home after 1 year of formal schooling (i.e., end of Grade 1; Frijters et al., 2000; Baroody and Diamond, 2012).

(5) There should be positive cross-over links between reading skills and reading independently from Grade 1 to Grade 2 (Leppänen et al., 2005; Torppa et al., 2019).

(6) In addition, there should be positive cross-over links between children's interest and their reading independently from Grade 1 to Grade 2 (Frijters et al., 2000; Dunst et al., 2011; Baroody and Diamond, 2012; Martini and Sénéchal, 2012).
When testing the hypothesized model, child vocabulary and maternal education were included because these two variables were associated with reading skills and home literacy activities in previous studies (e.g., Frijters et al., 2000; Torppa et al., 2006, 2007; Baroody and Diamond, 2012; Carroll et al., 2019).

An ancillary goal of the present research was to understand better the predicted negative association between mother teaching and child reading. To do so, we tested the hypothesis that Finnish mothers who were responsive to their children's reading skills increased their teaching when their children had lower reading skills, whereas mothers of children with higher literacy skills either decreased or maintained the same teaching frequency (Sénéchal and LeFevre, 2014).

\section{METHODS}

\section{Participants and Procedure}

The data came from a large-scale longitudinal study of approximately 2,000 children followed from kindergarten to Grade 9, their parents and teachers (Lerkkanen et al., 20062016). The subsample selected for the present study included all the 378 children (179 girls, 199 boys) for whom children's interest in reading was assessed and for whom mothers were asked to complete questionnaires about their children's independent reading. The participants were recruited from four Finnish municipalities. Only children with written parental consent were tested. As is typical of the school population in Finland, the sample was highly homogeneous in ethnic and cultural background. All children lived in families where Finnish language was spoken at home, and only $3 \%$ of children also spoke an additional language at home (e.g., English, Russian, and Swedish).

\section{Children}

The children (Mage $=67.7$ months, $S D=3.4$, at the first measurement point) were followed across three time-points: at the ends of kindergarten (April; $N=377 ; \mathrm{K}$ ), Grade 1 (April; $N=377 ; \mathrm{G} 1$ ), and Grade 2 (April; $N=365 ; \mathrm{G} 2$ ). In kindergarten $(\mathrm{K})$, children were individually tested on their emergent literacy and vocabulary skills and children were individually interviewed on their interest in reading activities. In Grades 1 and 2, one reading test (ALLU) was administered in group/classroom situations, whereas the other reading test (Lukilasse) and the interview concerning reading interest were conducted individually. Although the sample size was slightly different at each measurement point (e.g., due to children missing a testing session), no systematic differences were observed between participants who had participated in the study and those whose data was not available at certain time-point.

\section{Mothers}

Mothers (ages ranged from 24 to $55 ; M=37.4, S D=5.2$ ) answered questionnaires at three time points: the ends of kindergarten (K, April; $N=338$ ), Grade 1 (G1; April; $N=283$ ), and Grade 2 (G2, April; $N=289$ ). $88 \%$ of mothers reported on their 


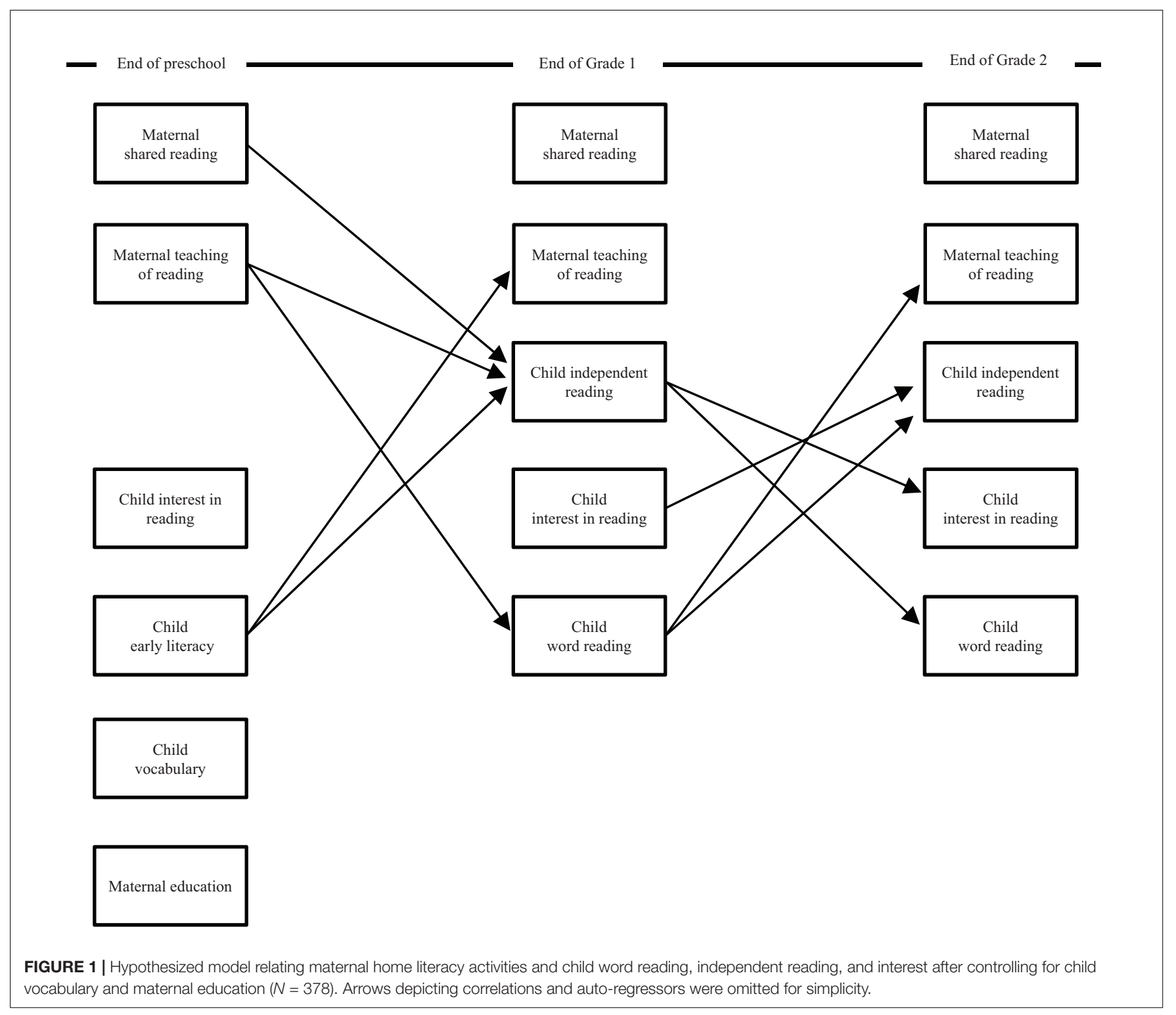

educational attainment and the distribution was as follows: $2.8 \%$ of mothers had no vocational education after the 9year compulsory schooling; $1.4 \%$ completed a short vocational course; $25.4 \%$ had a vocational school qualification; $23.9 \%$ had a vocational college qualification; $14.1 \%$ a polytechnic degree or a Bachelor's degree; $27.3 \%$ a Master's degree; and in $5.1 \%$ of mothers had a licentiate or doctoral degree. This distribution is representative of the attainment in Finland (Statistics Finland, 2007). Mothers also reported on family composition: $77.1 \%$ of the children lived in families with two parents; $9.8 \%$ of the children lived in families where the mother or father had a new spouse and children; $11.6 \%$ of the children lived with a single mother; and $1.5 \%$ of the children lived in families with shared parenthood after divorce or separation. The number of children in a family ranged from one to nine $(M=2.42, S D=1.20) ; 22.3 \%$ of the mothers reported being unemployed.

\section{MATERIALS}

The measures' psychometric properties, including scale reliabilities, were calculated for the sample $(N=378)$ and presented in Table 1.

\section{Maternal Questionnaire} Home Literacy Activities (K, G1, and G2)

The questionnaire on home literacy activities, from this largescale study (Lerkkanen et al., 2006-2016), was based on the work of; Sénéchal et al. (1998), Sénéchal and LeFevre (2002), and Sénéchal (2006). The questions captured both current and retrospective frequency of home literacy activities.

Shared reading was assessed by asking mothers to report on the frequency with which they read to or with their child. In kindergarten, shared reading was assessed by How often do you read books to your child or together with your child? A five-point 
TABLE 1 | Descriptive statistics and psychometric properties at the ends of kindergarten (K), Grade 1 (G1), and Grade 2 (G2).

\begin{tabular}{|c|c|c|c|c|c|c|c|c|}
\hline \multirow[t]{2}{*}{ Variable } & \multirow[t]{2}{*}{$\mathbf{n}$} & \multirow[t]{2}{*}{$\mathbf{M}$} & \multirow[t]{2}{*}{ SD } & \multirow[t]{2}{*}{ ICC } & \multirow[t]{2}{*}{ Reliability Cronbach $\alpha$} & \multicolumn{2}{|c|}{ Range } & \multirow[t]{2}{*}{ Skewness } \\
\hline & & & & & & Potential & Actual & \\
\hline \multicolumn{9}{|l|}{ Home learning environment } \\
\hline Shared reading $(\mathrm{K})$ & 336 & 2.88 & 1.18 & 0.012 & & $1-5$ & $1-5$ & -0.12 \\
\hline Shared reading (G1) & 282 & 2.63 & 1.10 & 0.064 & & $1-5$ & $1-5$ & 0.05 \\
\hline Shared reading (G2) & 289 & 2.21 & 1.02 & 0.055 & & $1-5$ & $1-4$ & 0.56 \\
\hline Teach reading $(\mathrm{K})$ & 338 & 2.20 & 0.99 & 0.099 & & $1-5$ & $1-5$ & 0.49 \\
\hline Teach reading (G1) & 279 & 2.32 & 1.21 & 0.154 & & $1-5$ & $1-5$ & 0.64 \\
\hline Teach reading (G2) & 289 & 1.59 & 1.03 & 0.067 & & $1-5$ & $1-5$ & 1.88 \\
\hline \multicolumn{9}{|l|}{ Child measures } \\
\hline Vocabulary (K) & 377 & 20.07 & 3.28 & 0.081 & 0.61 & $1-30$ & $8-29$ & -0.35 \\
\hline \multicolumn{9}{|l|}{ Early literacy } \\
\hline Alphabet (K) & 377 & 23.29 & 6.38 & 0.020 & 0.95 & $1-29$ & $1-29$ & -1.38 \\
\hline Word reading $(\mathrm{K})$ & 376 & 3.81 & 4.27 & 0.112 & 0.92 & $1-30$ & $0-10$ & 0.55 \\
\hline \multicolumn{9}{|l|}{ Word reading ${ }^{a}$} \\
\hline Test 1 (G1) & 377 & 18.50 & 9.02 & 0.082 & 0.97 & $1-80$ & $0-50$ & 0.63 \\
\hline Test 1 (G2) & 369 & 28.20 & 12.04 & 0.032 & 0.97 & $1-80$ & $0-66$ & 0.00 \\
\hline Test 2 (G1) & 365 & 24.78 & 7.49 & 0.036 & 0.98 & $1-90$ & $3-58$ & 0.39 \\
\hline Test 2 (G2) & 358 & 40.63 & 9.67 & 0.041 & 0.98 & $1-90$ & $2-75$ & -0.21 \\
\hline Interest in reading ${ }^{\mathrm{b}}(\mathrm{K})$ & 377 & 3.93 & 0.99 & 0.122 & 0.63 & $1-5$ & $1-5$ & -0.97 \\
\hline Interest in reading ${ }^{b}(\mathrm{G} 1)$ & 369 & 3.81 & 1.01 & 0.059 & 0.80 & $1-5$ & $1-5$ & -0.77 \\
\hline Interest in reading ${ }^{b}(G 2)$ & 358 & 3.75 & 0.91 & 0.045 & 0.78 & $1-5$ & $1-5$ & -0.69 \\
\hline Independent reading ${ }^{\mathrm{C}}(\mathrm{G} 1)$ & 282 & 2.47 & 0.85 & 0.058 & 0.73 & $1-5$ & $1-5$ & 0.63 \\
\hline Independent reading ${ }^{\mathrm{C}}$ (G2) & 288 & 2.67 & 0.86 & 0.046 & 0.72 & $1-5$ & $1-5$ & 0.33 \\
\hline
\end{tabular}

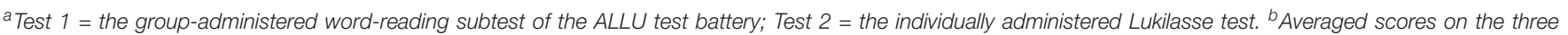

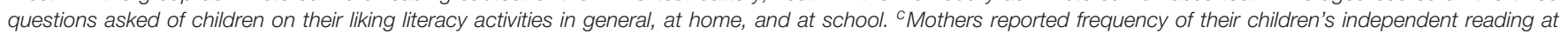
home averaged across four book types.

scale was used $(1=$ less than once a week; $2=1-3$ times a week; $3=4-6$ times a week; $4=$ once $a$ day; and $5=$ more than once a day). In Grades 1 and 2, the question was How often does the mother read a book or a newspaper/magazine with the child? Mothers responded on a five-point scale [ $1=$ not at all or rarely; 2 = once or twice a week (on 1 to 2 days); 3 = several days $a$ week (on 3 to 6 days); 4 = once a day/daily; 5 = several times $a$ day]. Although measuring the frequency of shared reading by a single item does not capture the richness of informal literacy activities at home, a meta-analysis showed that shared reading had similar relations to child language and literacy outcomes regardless of whether a single item or a composite of items was used (Bus et al., 1995).

Teaching of reading was assessed by asking mothers to report on the frequency they taught their child to read. In kindergarten, the question, How often do you teach/have you previously taught your child to read, was answered on a five-point scale with two defined anchors: $1=$ not at all/very rarely to $5=$ very often/daily. In Grades 1 and 2, the question was How often do you teach your child to read? that was answered on a five-point scale in Grade 1 ( 1 = not at all; 2 = rarely; 3 = once or twice a week; 4 = several days a week; 5 = once a day/daily) and a six-point scale in Grade $2(0=$ not anymore; because the child has acquired the skill; 1 = never; 2 = rarely; 3 = once or twice a week; $4=$ several days a week; 5 = every day). To make the scale in Grade 2 similar to the scales in the previous time-points, the first two categories, 0 and
1 , were combined. This decision was based on the similarity of the meaning between these two categories, namely, that parents are not teaching. Also $4.2 \%$ of mothers answered " $1=$ not at all" in Grade 1, and the combination of the two points in Grade 2 resulted in a similar percentage. Although measuring constructs with a single item is not optimal, teaching of reading is the key aspect of code-related home literacy activities for the children of this developmental stage. For instance, Martini and Sénéchal (2012) showed that it was the teaching of this higher level skill that was associated with child literacy outcomes. Moreover, Aunola and Nurmi (2007) reported that daily parental reports of reading-related teaching and the overall parental perception of the frequency of their teaching of reading in Grade 1 correlated by $0.28(p<0.01)$.

\section{Children's Independent Reading (G1 and G2)}

The frequency of independent reading can be reported by children (Sénéchal, 2006), parents (Silinskas et al., 2013), and teachers and observers (Baroody and Diamond, 2013). We relied on parental reports due to the young age of the children and because we were interested in the frequency of the reading instances outside school. When their children were in Grades 1 and 2, mothers answered four questions on children's independent reading: How often does your child do the following things: My child independently reads (1) comics or children's magazines, (2) picture books, (3) unillustrated books, and (4) 
non-fiction books (for instance, about animals). Answers were provided on a five-point scale: $1=$ not at all or rarely; $2=$ once or twice a week (1-2 days); 3 = several days a week (3-6 days); 4 = once a day/daily; and $5=$ several times a day. The average of the four items was used in the analyses.

\section{Child Measures}

\section{Interest in Reading (K, G1, and G2)}

At each time point, children's interest in reading was assessed with the Task Value Scale for Children (TVS-C; Nurmi and Aunola, 1999; Nurmi and Aunola, 2005). The scale is based on the ideas of Eccles et al., 1993, and has been also used in studies among Finnish 6- to 7-year-old children (Lerkkanen et al., 2012; Viljaranta et al., 2014). This scale consists of three items measuring children's interest in activities and tasks involving letters in kindergarten and reading in Grades 1 and 2: (1) How much do you like letter/reading activities?; (2) How much do you like doing letter/reading tasks in kindergarten/in school?; (3) How much do you like doing letter/reading tasks at home? During testing, the questions were read aloud to the children, and children were presented with a set of five faces drawn to depict an assessment scale ranging from a big frown (i.e., very negative) to a big smile (i.e., very positive). After each question, the children were asked to point to the picture that best described the liking of a particular reading task ( 1 = "I do not like it at all/I dislike doing those tasks"; 5 = "I like it very much/I really enjoy doing those tasks"). An average score of the three items was used in the subsequent analyses. Prior to testing, the task was explained and children practiced indicating their interest in three practice items (e.g., sports and music) to ensure that children understood the procedure/task.

\section{Early Literacy (K)}

Early literacy was assessed individually with two subtests from the ARMI test battery (Lerkkanen et al., 2006-2016). First, a letternaming test required children to name all 29 uppercase letters of the Finnish alphabet, presented in a random order. Second, a test of reading accuracy was administered where children were asked to read 10 uppercase words. The words were of increasing difficulty; children were given as much time as needed to read the words accurately. The word reading test was discontinued after three unsuccessful attempts.

\section{Reading Skills (G1 and G2)}

Reading was assessed with two tests. First, children were assessed with the group-administered reading-fluency subtest of a nationally normed reading test battery (ALLU; Lindeman, 1998). The subtest included 80 items, each of which consisted of a picture with four phonologically similar words attached to it. The child read the four words silently, after which he or she had to draw a line between the picture with and the word semantically matching it. The final score was the number of answers completed correctly in a 2-min time limit. Second, an individually administered word-list reading test was used (Lukilasse test for 6- to 12-year-old children; Häyrinen et al., 1999). A child was presented with a list of 90 real words divided into four columns. The words ranged from 1- to 7-syllabic word forms, written in lowercase letters. The child was instructed to read the words aloud; the final score was the number of words read correctly within a 45-s time limit.

\section{Vocabulary}

In kindergarten, children's receptive vocabulary was assessed with a 30-item shortened version of the Peabody Picture Vocabulary Test-Revised (PPVT-R, Form L; Dunn and Dunn, 1981). The tester said a word, and children had to select which one of four pictures correctly represented the spoken word. The items of the shortened version were selected to represent a range of difficulty levels based on the data from the full-scale administration of the PPVT-R in the Jyväskylä Longitudinal Study of Dyslexia (see Lyytinen et al., 2004). Each correct response received one point (max. 30).

\section{Data Analysis Strategy}

A path model was used to test the hypothesized model, with all the analyses run with the Mplus statistical package, version 8 (Muthén and Muthén, 1998-2010). Missing data for the study variables ranged from 0.3 to $26.2 \%(M=11.1 \%, S D=10.5 \%)$, and these data were not missing completely at random based on Little's (1988) MCAR test $\left(\chi^{2}[424]=481.08, p=0.03\right)$. Attrition analyses between kindergarten (K) and Grade 1 (G1) revealed that mothers of children with better vocabulary skills tended to stay in the study $(\Delta M=-1.28, p<0.01$, Cohen's $d=0.39$ ), whereas there were no systematic differences on any of the study's variables between Grade 1 (G1) and Grade 2 (G2). Given that vocabulary was a control variable rather than an outcome and given the lack of systematic differences on parent reports and child literacy and interest, we applied the standard full-information maximum likelihood (FIML) method to account for missingness. This method takes all available data to estimate the model without imputing data. Some variable distributions were skewed. Therefore, the model parameters were estimated using the MLR estimator (maximum likelihood with robust standard errors). This estimator is implemented in Mplus and produces chi-square test statistics and standard errors for missing data with non-independent observations and non-normally distributed variables.

The data were nested because children came from 151 classes. Therefore, intra-class correlations (ICCs) were calculated to estimate the effect of classroom membership. The ICC represents the proportion of the total score variance that is attributable to an individual's membership in a particular class. As presented in Table 1, the ICCs across all measures varied from 0.012 to 0.154 (from $p>0.05$ to $p<0.001$ ). Because some ICCs were statistically significant, the Mplus TYPE = COMPLEX option was used to include kindergarten classrooms as a clustering variable. This resulted in the computation of corrected standard errors and the calculation of model fit tests that took the nested structure of the data into account.

Following $\mathrm{Hu}$ and Bentler (1999), model fit was examined with a combination of indices in order to minimize Type I and Type II errors. Three fit indices, appropriate for large samples, were used and evaluated based on the criteria suggested by $\mathrm{Hu}$ and Bentler to be indicative of a good model: Comparative Fit 
Index $(\mathrm{CFI})>0.95$, root mean square error of approximation (RMSEA) $<0.06$, and standardized root mean square residual $($ SRMR $)<0.08$.

\section{RESULTS}

The descriptive data, including scale reliabilities, are presented in Table 1. On average, Finnish mothers indicated reading books to their children up to six times a week in kindergarten and Grade 1, and then reduced their reading to once or twice a week in Grade 2. As for teaching their children to read, mothers reported, on average, that they taught their children but did so infrequently. Children indicated, at each test point, that they liked doing letter tasks or reading in school, selecting, on average, the smiley face on each of the three questions at each test point. Finally, mothers reported, on average, that their children read on their own several days a week in Grades 1 and 2.

Examination of the zero-order correlations in Table 2 are in accord with the Home Literacy Model (Sénéchal and LeFevre, 2002). First, the mother-reported frequency of shared reading in kindergarten was positively related to children's vocabulary, but not to early literacy. Of note, the correlation between shared reading and vocabulary remained significant after controlling for parent education, partial $r=0.20, p<0.01$. Second, the motherreported frequency of teaching in kindergarten was positively and longitudinally related to literacy outcomes across time, whereas shared reading was not related to literacy outcomes or was related negatively. Third, the expected change from positive to negative associations between teaching and literacy outcomes was found once children were in grade school. Examining the stability of home literacy activities across time is also informative. Interestingly, shared reading behaviors seemed more stable over time with correlations between 0.58 and 0.69 across kindergarten to Grade 2. In contrast, reports of teaching in kindergarten were not correlated with subsequent teaching $(r s<0.06)$, whereas the correlation increased to 0.46 between Grades 1 and 2. This latter pattern suggests changes in teaching behaviors across families during the transition to grade school.

Novel findings concerned children's autonomous reading at home. Here, both shared reading and teaching in kindergarten were positively and longitudinally associated with children's independent reading. Moreover, children's independent reading was positively, longitudinally, and reciprocally associated with literacy skills.

Additional novel findings concerned children's own reports of how much they liked doing literacy activities in kindergarten and school. Unexpectedly, child interest in literacy activities at school was nearly not associated with any of the other variables tested. In fact, only two small coefficients were significant of the 36 correlations between interest and other measures. Given that the probability of obtaining spurious results was 1.8 tests out of 36 conducted, then these two significant coefficients could be due to chance. Therefore, it was decided not to analyze interest further, and consequently, interest measures were removed from the path model.

\section{Testing the Home Literacy Model}

Figure 2 depicts the standardized parameter estimates for the longitudinal links from kindergarten to Grade 2

TABLE 2 | Concurrent and longitudinal correlations ${ }^{\mathrm{a}}$ among home literacy variables and child measures at the ends of kindergarten (K), Grade 1 (G1), and Grade 2 (G2).

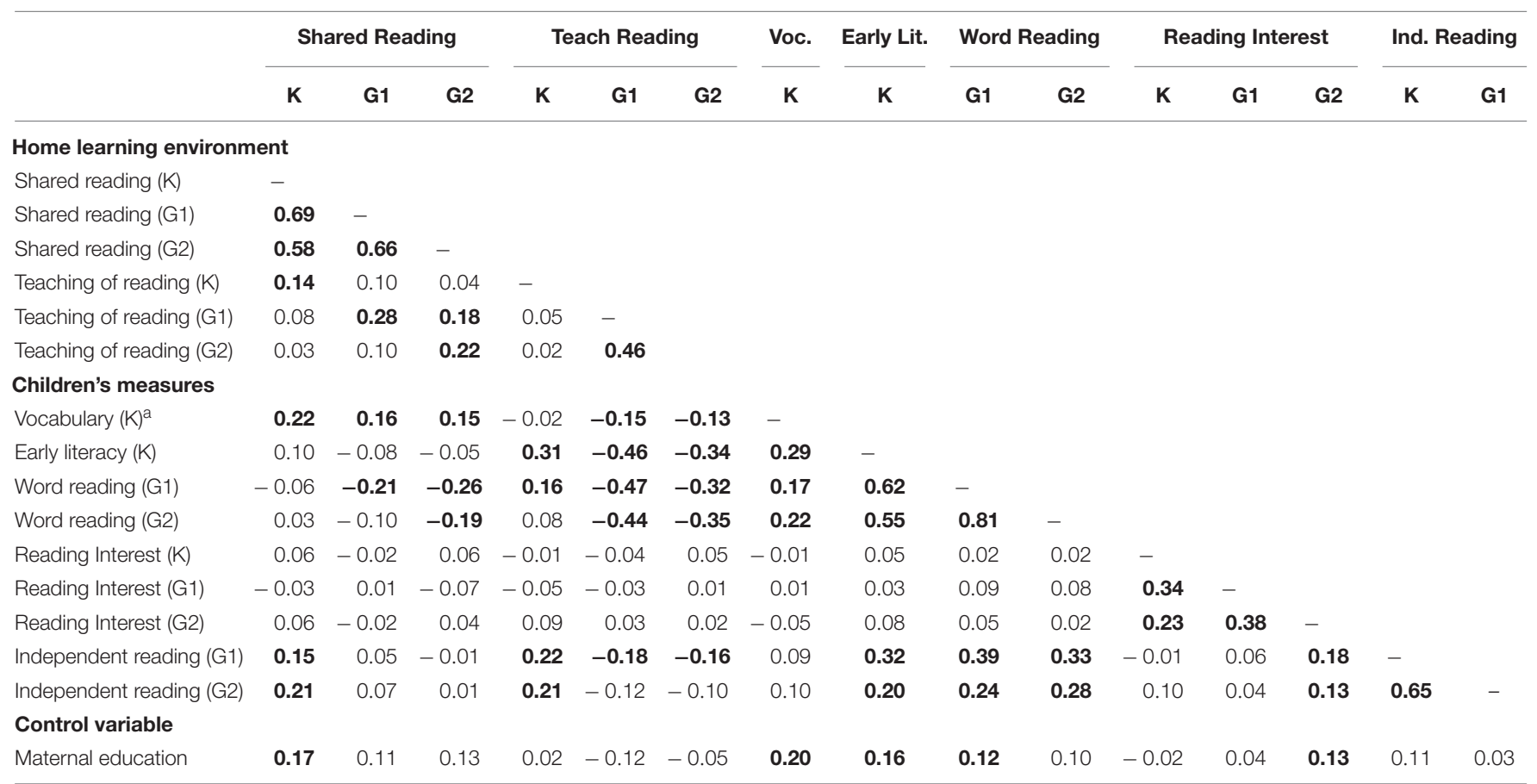

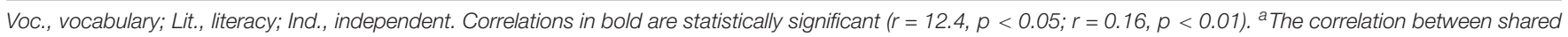
reading and vocabulary remained significant after controlling for parent education, partial $r=0.20, p<0.01$. 


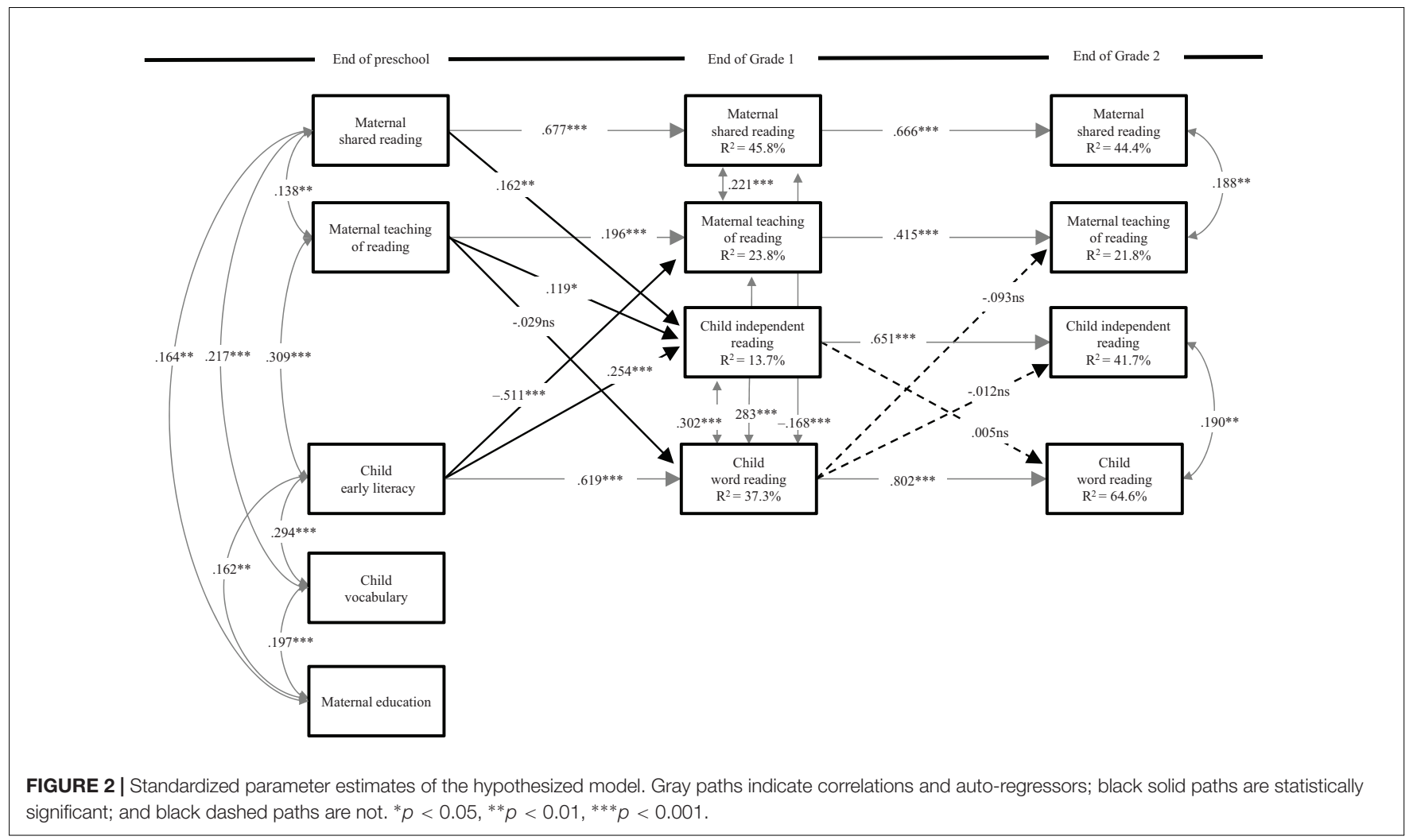

for the hypothesized model once child interest measures were excluded. Importantly, the indices of the model met the $\mathrm{Hu}$ and Bentler (1999) criteria indicating good model fit, CFI $=0.96$, SRMR $=0.05$, RMSEA $=0.06$, 95\% CIs [0.05-0.08].

The predicted cross-over links between teaching and literacy skills from kindergarten to Grade 1 were partially supported. Although parental teaching of reading during kindergarten was not predictive of word reading 1 year later, mothers were responsive to their children's early literacy skills as evidenced by the negative and moderately strong path from early skills in kindergarten to the frequency of mother teaching at the end of Grade 1 over and above the auto-regressor. That is, mothers of children who had weaker early literacy skills seem to have increased their teaching. This level of responsiveness was not found between Grades 1 and 2 because reading skills at the end of Grade 1 did not predict change in the frequency of mother teaching 1 year later.

As expected, mothers' reported frequency of shared reading and teaching reading in kindergarten positively predicted child independent reading at the end of Grade 1 . The more mothers reported engaging in shared reading and teaching reading in kindergarten, the more frequently they reported, 1 year later, that their children were involved in independent reading activities at home. Moreover, stronger early literacy in kindergarten also predicted children's independent reading at the end of Grade 1. However, the predicted cross-over links between the frequency independent reading and word reading across Grades 1 and 2 were not statistically significant.
Multicollinearity is a common problem in correlational research, thus we investigated its manifestation in our data. Overall, the non-autoregressive correlations (correlations between different constructs) were moderate at best (highest correlation between word reading in Grade 1 and teaching of reading in Grade $1 ; r=-0.47, \mathrm{p}<0.01)$. We also calculated tolerance levels and the variance inflation factor (VIF) for the variables in Figure 2. The obtained tolerance levels ranged from 0.354 to 0.542 and the VIF ranged from 1.845 to 2.824. These ranges are below those suggested to be indicative of multicollinearity (see O’Brien, 2007). Therefore, multicollinearity was not an issue.

Finally, to make sure that including/excluding interest would not have an influence on our reported results (Figure 2), we ran analyses where interest was included to the model. In particular, stabilities of interest across time were specified, as were the significant correlations from Table 2 and all concurrent associations between all variables within each measurement point. Including interest to the model did not change the results reported in Figure 2 (i.e., results were the same), thus providing one more justification to exclude interest from our final model.

\section{Mothers' Responsiveness to Their Children's Reading Skills}

As did Sénéchal and LeFevre (2014), we assessed whether the patterns of negative associations between maternal home literacy activities and children's reading skills were such that mothers of children with lower literacy skills increased their 
home literacy activities over time whereas mothers of children with higher literacy skills either decreased or maintained home literacy activities. The analyses included participants with no missing values on maternal reports for teaching of reading and shared reading $(N=253)$. Then, we divided the sample in four equal groups (i.e., $25 \%$ of participants in each group) based on children's word-reading skills at the end of Grade 2 (G2). The groups were therefore labeled as poor, below average, above average, and good readers. Doing so allowed us to investigate change in maternal teaching of reading with a mixed-design ANOVA. Time, as a within-subject variable, included three levels: the ends of kindergarten (K), Grades 1 (G1), and Grade 2 (G2). Reading skills was the between-subject variable with four levels. The same design was used to explore change in shared reading.

The analysis for teaching revealed significant main effects of Time $\left(F[2,492]=44.97, p<0.001 ; \eta_{\mathrm{p}}^{2}=0.16\right)$ and Reading Skills $\left(F[3,246]=12.22, p<0.001 ; \eta_{\mathrm{p}}^{2}=0.13\right)$. However, these two main effects have to be interpreted in light of a significant interaction between Time and Reading Skills $(F[6,492]=10.41$, $\left.p<0.001 ; \eta_{\mathrm{p}}^{2}=0.11\right)$. Post hoc Bonferroni contrasts revealed differences across groups that help explain the change from positive to negative associations between children's reading skills and maternal teaching. As shown in Figure 3A, mothers initially reported similar frequencies of teaching, but the patterns changed in grade school. Specifically, for poor readers the frequency of maternal teaching increased from kindergarten to Grade 1 $(\Delta M=-1.00, S . E .=0.21, p<0.001)$, whereas mothers of the good readers decreased the frequency of teaching at the end of Grade $1(\Delta M=0.78, S . E .=0.14, p<0.001)$. In contrast, the frequency of teaching did not change significantly for below average readers $(\Delta M=-0.27, S . E .=0.19, p=0.47)$ and above average readers $(\Delta M=-0.05, S . E .=0.17, p=1.00)$. Although mothers of all four groups reported teaching less in Grade 2 than in Grade 1 $(p<0.001)$, mothers of poor readers and below average readers still reported teaching more than did mothers of good readers $(\Delta M=0.97$, S.E. $=0.17, p<0.001$ and $\Delta M=0.46$, S.E. $=0.17$, $p<0.05$, respectively).

As for shared reading, there was a significant effect of Time only $\left(F[2,498]=77.77, p<0.001 ; \eta_{\mathrm{p}}^{2}=0.24\right)$. Post hoc Bonferroni contrasts confirmed the pattern shown in Figure 3B: Mothers reported reading less in Grade 1 than in kindergarten $(\Delta M=0.30$, S.E. $=0.06, p<0.001)$, and less at the end of Grade 2 than in Grade $1(\Delta M=0.43, S . E .=0.06, p<0.001)$. The Reading Skills main effect was not significant $(F[3,249]=1.71, p=0.17$; $\left.\eta_{\mathrm{p}}^{2}=0.02\right)$ nor did it interact with shared reading $(F[6,498]=1.97$, $p=0.07 ; \eta_{\mathrm{p}}^{2}=0.02$ ). Here, we found that mothers of poorer readers reported reading more than mothers of better readers at the end of Grade $1(\Delta M=0.35, S . E .=0.14, p<0.05)$, presumably because the stronger readers were reading independently.

\section{DISCUSSION}

The present study aimed at expanding the Home Literacy Model (Sénéchal and LeFevre, 2002, 2014) by examining the role of two child variables, namely, children's interest in literacy activities at kindergarten/school/home and their independent reading at home. Finnish families and children were followed from kindergarten to Grade 2. The obtained findings demonstrated that parental practices and children's literacy skills predict children's independent reading rather than the reverse. There are four key findings. A first novel finding is that both maternal shared reading and teaching of reading in kindergarten positively predicted child independent reading at the end of Grade 1. Second, children with stronger early literacy skills in kindergarten read independently more frequently once they were in Grade 1. Third, the results extended to Finnish families previous findings showing that parents, in the early school years, adapt the frequency of their teaching of reading and shared reading to their children growing literacy skills. Fourth, children's interest was not linked to other variables.

\section{Home Literacy Activities and Children's Independent Reading}

We found that literacy activities at home prior to school positively predicted the frequency with which Finnish children read independently at the end of Grade 1 . The novelty of the finding stems from the fact that both shared reading as well as parent teaching were significant predictors. Previous findings with children acquiring reading in French (Sénéchal, 2006) had shown that shared reading, but not parent teaching, in kindergarten predicted the frequency of children reading on their own in Grade 4. The findings in the present study and in Sénéchal were robust because the models controlled for children's literacy skills, child vocabulary, and parent education.

As children's first educators, parents can stimulate their children's interest in reading in different ways. Sénéchal (2006) suggested that shared reading is an enjoyable activity from which children may learn that reading is fun. Of course, parents who value shared reading may also value reading as a desirable activity, read for pleasure themselves, and may have a home library (for a review, see Sénéchal, 2012). Parents who teach early literacy skills can also facilitate children's entry into the autonomous reading. In the present study, the small but significant concurrent correlation between these two types of literacy activities at home suggests that there is variability across Finnish families in what they choose to promote. In addition, the magnitude of the coefficients in the path model suggests that the impact of these two types of home activities over and above early literacy skills is modest but it has a lasting effect over and above the instruction that children received in Grade 1. This novel addition to the Home Literacy Model now requires replication in other orthographies.

\section{Children's Independent Reading and Reading Skills}

The frequency with which children read independently at the end of Grades 1 and 2 was positively correlated with children's literacy skills at all time points. Yet, in our complex model, the only significant longitudinal path was from early literacy skills at the end of kindergarten to independent reading at the end of Grade 1. These results suggest that children who enter Grade 1 with stronger skills might become autonomous readers more quickly, 

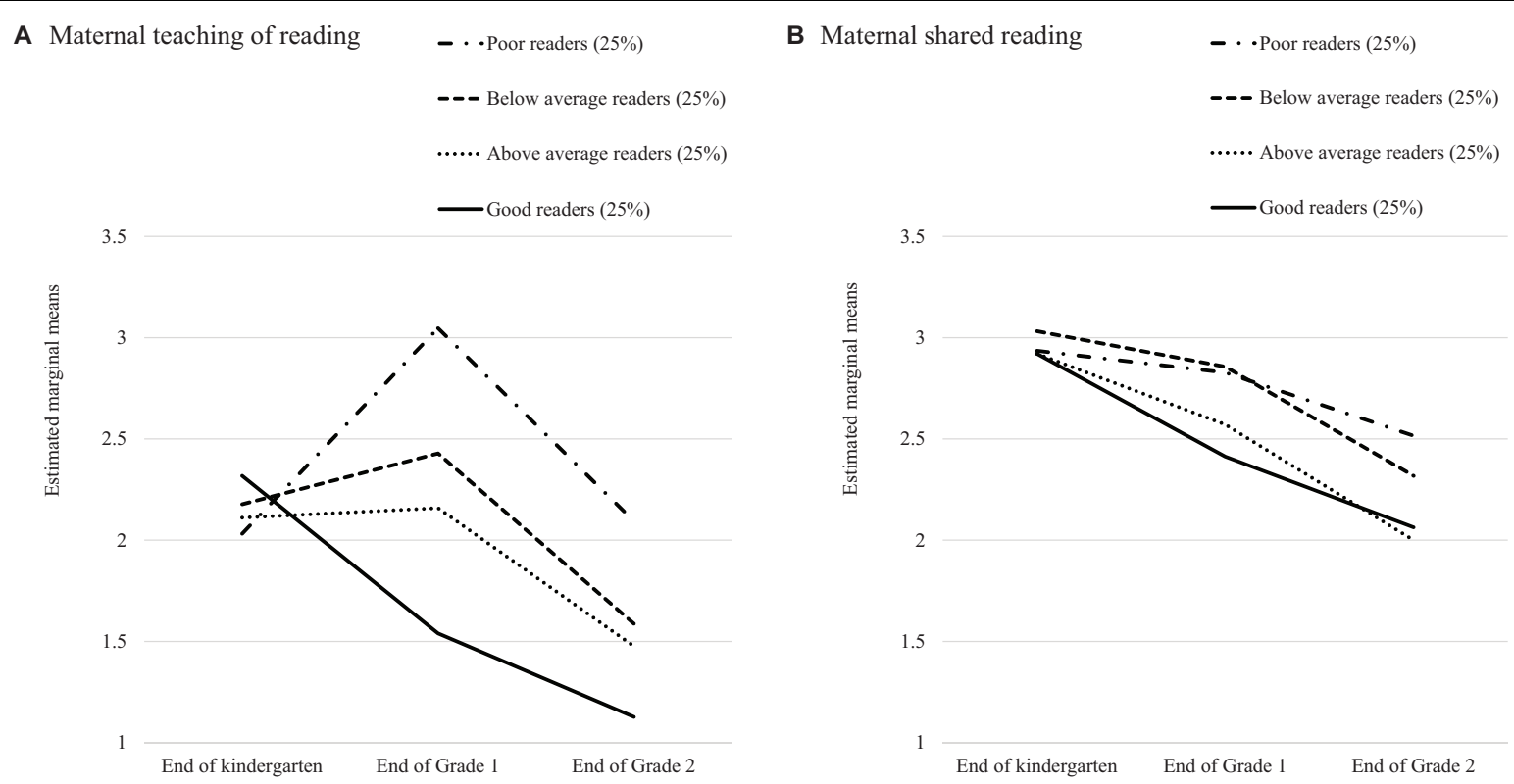

FIGURE 3 | Estimated marginal means of the frequency of maternal teaching reading (A) and shared reading (B) at three time points as a function of children's word-reading skills at the end of Grade 2.

or at the very least read more frequently, than children with weaker skills. Cunningham and Stanovich (1998) have provided sound evidence of this in their review. That the longitudinal effect was present only during the transition from kindergarten to Grade 1 might be due to the ease of learning to read in Finnish. For instance, previous reports showed that one third of Finnish children can read already at the end of kindergarten (Silinskas et al., 2010b), and most will read accurately by the end of the school year (Lerkkanen et al., 2004). Given this rapid progress, it might not be surprising that we did not find evidence of a relation between independent reading and reading skills across Grades 1 and 2 despite positive longitudinal correlations. In fact, Torppa et al. (2019) showed that the reciprocal relation between independent reading and word reading between Grades 1 and 2 was limited to reading comprehension, not word reading, when using the entire sample of about 2,000 children in the large study. It might be the case that the transparency of Finnish is such that it is higher level skills that show a robust association with reading frequency as children progress in grade school. Future research in transparent orthographies could examine whether this pattern also holds for higher-level measures, such as vocabulary and background knowledge, found to be associated with the frequency of autonomous reading in English (e.g., Hirsch, 2003; Mol and Bus, 2011).

\section{Mothers' Responsiveness to Their Children's Reading Skills}

In contrast to Sénéchal and LeFevre (2014), we did not find that the frequency of mother reports of teaching at the end of kindergarten was linked longitudinally to growth in children's reading skills from the end of kindergarten to the end of Grade 1. In Sénéchal and LeFevre, however, a significant path between teaching and growth in early literacy was found when measuring teaching and literacy at the beginning of the school years. As such, the English-speaking children in their study had not received much formal instruction whereas the children in the present study had received a full year of literacy instruction. This difference in the timing of measurement might also explain similar findings obtained by Silinskas et al. (2012). Further, Silinskas et al. (2020) found, with the full sample of about 2,000 Finnish families, that teaching reading at the end of kindergarten predicted early literacy skills (i.e., letter knowledge and reading skills) at the beginning of Grade 1 . Therefore, it seems that a key factor to explain the discrepancy across studies seems to be the timing of measurement.

In terms of mothers' responsiveness, we did find the expected shift from positive to negative correlations between the frequency of teaching and children's literacy skills as children progressed from kindergarten to Grade 2 in the correlations (see Table 2) as well as the path model. Specifically, we found that children's early literacy in kindergarten predicted negatively parental teaching at the end of Grade 1. The interpretation of this finding required subgroup analyses that clarified the pattern of teaching behaviors. As was the case in Sénéchal and LeFevre (2014), these analyses confirmed that mothers were responsive to their children's developing literacy skills (see Figure 3A). Mothers of children who had the lowest level of word-reading skill at the end of Grade 2 increased the frequency of their teaching starting in Grade 1 whereas mothers of the children with the strongest skills decreased their teaching of reading. In contrast, mothers of children with reading closer to the sample average maintained the frequency of teaching across time. As such the present findings allow for a clear interpretation of similar findings obtained with the same dataset (Silinskas et al., 2012) 
and a different dataset (Silinskas et al., 2010a). It is not that parents are inefficient teachers, but rather, that parents are responsive to the pace of their children's learning to read. The fact that a similar pattern was found in two different cultures and orthographies is remarkable.

\section{Child Interest}

Across time points, children indicated that they were interested in letters and reading activities, with $74 \%$ of them choosing one of the two smiling faces. This is not to say, however, that children's reports were highly stable. In fact, the intercorrelations among interest reports across time points ranged from 0.23 to 0.36 . This latter finding suggest that, despite the skewness of the responses, there was more variability across time than the stability of the means indicated (Sperling and Head, 2002; Hume et al., 2015). Contrary to our predictions, child-reported interest was not correlated with other measures except for two modest coefficients with the mother-reported independent reading amount. However, the latter two coefficients were excluded from the path model because of the probability of chance findings. It is possible that during the early grades in Finland, when reading teaching is highly individualized, the children receive instruction that is well fitted to their individual levels and thus interest is retained even when reading skills are developing slower than average.

The absence of association between child interest and reading has been found in other recent reports (Kikas et al., 2015; Walgermo et al., 2018; Pezoa et al., 2019). In another report, the association was very modest and negative (e.g., $r=-0.08$, $p=0.05, N=1,171$, McTigue et al., 2019). In addition, lack of associations between child interest and reading skills might be a consequence of children's overestimation of their own competences. For instance, in German studies, children in Grades 1 and 2 held overoptimistic self-concepts and, thus, high correlations with achievement were unlikely (Helmke, 1999). Finally, although small scale studies among preschoolers had found positive links between children's degree of interest and skills on specific dimensions such as the alphabet (Frijters et al., 2000; Martini and Sénéchal, 2012), large scale studies among kindergarteners suggest that other aspects of motivation, such as task persistence might show stronger links to children's reading skills (Kikas and Silinskas, 2016; Viljaranta et al., 2018).

\section{Limitations}

There are limitations in the present study that require mention. First, maternal self-reports were used to assess home literacy practices and children's independent reading. It is therefore possible that social desirability might be a factor in their answers. The distribution of responses as well as the lack of skewness suggest that, in this sample, there was variability in mothers' responses. Although previous research has often used similar selfreports, future studies should consider observational measures (Tracey and Young, 2002), diary method (Pomerantz and Eaton, 2001) and in-depth interviews (Xu and Corno, 1998) with parents to confirm and expand the present findings. Second, maternal home literacy activities were measured by single items, which is not optimal. We asked mothers to report on teaching of reading as the key aspect of code-related activities, whereas other studies also included a wider range of items, such as teaching letters or writing (Aram and Levin, 2002; Reese et al., 2010). We asked mothers about the frequency of their shared reading as the key aspect of meaning-related home literacy activities, although more questions, for instance, about duration of shared reading, exposure to shared reading from other people could have been included (Scarborough and Dobrich, 1994). This being acknowledged, the present findings are consistent with previous studies that relied on multiple measures of each construct (e.g., Sénéchal and LeFevre, 2002, 2014).

\section{Practical Implications}

The present study has some practical implications. First, parents should be encouraged to engage in literacy activities with their children at home. This engagement seems especially important in kindergarten, because not only was it related to growth in children's skills from kindergarten to Grade 1, it was also related longitudinally to children's reading on their own. Second, parents were responsive to children's pace of reading acquisition, especially in Grade 1. Given this, teachers and other practitioners could use this opportunity to advise parents on the optimal ways of engaging in home literacy activities with their struggling children. Third, the results of the current study were based on the representative sample of Finnish families in terms of home language, SES, culture, and ethnicity. They also were based on children learning to read a transparent written language, and for whom Grade 1 begins at age 7. As such, they could be generalizable to families in other countries with relatively homogenous language environments and cultures (e.g., Silinskas et al., submitted). At the same time, it is important to note that similar findings to the ones presented here were obtained in opaque language environments, albeit appearing later than in Grade 1 (e.g., Sénéchal and LeFevre, 2014).

\section{Conclusion}

This study documented the longitudinal interrelations among parental home literacy activities, children's reading skills, interest, and their independent reading from kindergarten to Grade 2. This design allowed us to expand the Home Literacy Model (Sénéchal and LeFevre, 2002, 2014) in three ways. First, we demonstrated that both shared reading and parent teaching in addition to early literacy skills, all measured in kindergarten, predicted longitudinally Finnish children's independent reading at the end of Grade 1 . Second, children with stronger early literacy skills in kindergarten read independently more frequently once they were in Grade 1. Third, we showed that mothers quickly adapted their teaching behaviors to their children's progress in reading. As such, the present findings add support for the often cited notion that parents are key partners in their young children's education.

\section{DATA AVAILABILITY STATEMENT}

The data analyzed in this study are subject to the following licenses/restrictions: The dataset used in this manuscript was 
from the First Steps Study (www.jyu.fi/alkuportaat Director: professor M-KL, University of Jyväskylä, Finland, marjakristiina.lerkkanen@jyu.fi). The information in this dataset is anonymized following the guidelines of the Finnish Social Science Data Archive. An experienced data manager of the project is responsible for data storage, management, and documentation. Therefore, we are confident that any risks related to data management are minimal. Requests to access the dataset can be made by emailing professor M-KL and the data manager Dr. Kenneth Eklund. Requests to access these datasets should be directed to Dr. Kenneth Eklund, kenneth.m.eklund@jyu.fi.

\section{ETHICS STATEMENT}

The studies involving human participants were reviewed and approved by The Ethical Committee of University of Jyväskylä. Written informed consent to participate in this study was provided by the participants' legal guardian/next of kin.

\section{REFERENCES}

Aarnoutse, C., and van Leeuwe, J. (1998). Relation between reading comprehension, vocabulary, reading pleasure, and reading frequency. Educ. Res. Eval. 4, 143-166. doi: 10.1076/edre.4.2.143. 6960

Aram, D., and Levin, I. (2002). Mother-child joint writing and storybook reading: Relations with literacy among low SES kindergartners. Merrill Palmer Q. 48, 202-224. doi: 10.1353/mpq.2002.0005

Aunola, K., and Nurmi, J.-E. (2007). VALO [The Light Study: Parents, Teachers, and Children's Learning Study]. Finland: University of Jyväskylä.

Baroody, A. E., and Diamond, K. E. (2012). Links among home literacy environment, literacy interest, and emergent literacy skills in preschoolers at risk for reading difficulties. Top. Early Child. Spec. Educ. 32, 78-87. doi: 10.1177/ 0271121410392803

Baroody, A. E., and Diamond, K. E. (2013). Measures of preschool children's interest and engagement in literacy activities: Examining gender differences and construct dimensions. Early Child. Res. Q. 28, 291-301. doi: 10.1016/j.ecresq. 2012.07.002

Bus, A. G., van IJzendoorn, M. H., and Pellegrini, A. D. (1995). Joint book reading makes for success in learning to read: a meta-analysis on intergenerational transmission of literacy. Rev. Educ. Res. 65, 1-21. doi: 10.3102/ 00346543065001001

Carroll, J. M., Holliman, A. J., Weir, F., and Baroody, A. E. (2019). Literacy interest, home literacy environment and emergent literacy skills in preschoolers. J. Res. Read. 42, 150-161. doi: 10.1111/1467-9817.12255

Clark, C., and Rumbold, K. (2006). Reading for Pleasure: A Research Overview. London: National Literacy Trust.

Cunningham, A. E., and Stanovich, K. E. (1998). "The impact of print exposure on word recognition," in Word Recognition in Beginning Reading, eds J. L. Metsala and L. C. Ehri (Mahwah, N. J: Laurence Earlbaum), 235-262.

De Naeghel, J., Van Keer, H., Vansteenkiste, M., and Rosseel, Y. (2012). The relation between elementary students' recreational and academic reading motivation, reading frequency, engagement, and comprehension: A self-determination theory perspective. J. Educ. Psychol. 104, 1006-1021. doi: 10.1037/a0027800

Dunn, L. M., and Dunn, L. M. (1981). Peabody Picture Vocabulary Test-Revised. Circle Pines, MN: American Guidance Service.

Dunst, C. J., Jones, T., Johnson, M., Raab, M. R., and Hamby, D. W. (2011). Role of children's interests in early literacy and language development. CELLreviews 4, $1-18$.

Eccles, J., Wigfield, A., Harold, R. D., and Blumenfeld, P. (1993). Age and gender differences in children's self-and task perceptions during elementary school. Child Dev. 64, 830-847.

\section{AUTHOR CONTRIBUTIONS}

The data are archival and taken from a large-scale study conducted in Finland. GS, MS, MT, and M-KL contributed to the hypothesized model tested. GS conducted the analyses and wrote an initial draft of the manuscript. MS completed the draft, while the remaining authors provided feedback. All authors have read and approved the content of the submitted manuscript.

\section{FUNDING}

First Steps project: grants from the Academy of Finland approval numbers 213486 for 2006-2010, 263891 for 2011-2013, and 268586 for 2013-2017. For Silinskas' work on the present manuscript: Academy of Finland (grants 296082, 331525, and 336148). For Sénéchal's work on the present manuscript as well as open access publication fees: Social Sciences and Humanities Research Council, Grant \#311335 to MS.

Frijters, J. C., Barron, R. W., and Brunello, M. (2000). Direct and mediated influences of home literacy and literacy interest on prereaders' oral vocabulary and early written language skill. J. Educ. Psychol. 92, 466-477. doi: 10.1037/ 0022-0663.92.3.466

Harlaar, N., Deater-Deckard, K., Thompson, L. A., DeThorne, L. S., and Petrill, S. A. (2011). Associations between reading achievement and independent reading in early elementary school: A genetically informative cross lagged study. Child Dev. 82, 2123-2137. doi: 10.1111/j.1467-8624.2011. 01658.x

Häyrinen, T., Serenius-Sirve, S., and Korkman, M. (1999). Lukilasse. Lukemisen, Kirjoittamisen ja Laskemisen Seulontatestistö Peruskoulun Ala-Asteen Luokille, 1-6. Helsinki: Psykologien Kustannus Oy.

Helmke, A. (1999). "From optimism to realism? Development of children's academic self-concept from kindergarten to Grade 6," in Individual Development from 3 to 12: Findings from the Munich Longitudinal Study, eds F. E. Weinert and W. Schneider (Cambridge: Cambridge University Press).

Hirsch, E. D. (2003). Reading comprehension requires knowledge-of words and the world. Am. Educ. 27, 10-13.

Hood, M., Conlon, E., and Andrews, G. (2008). Preschool home literacy practices and children's literacy development: a longitudinal analysis. J. Educ. Psychol. 100, 252-271. doi: 10.1037/0022-0663.100.2.252

$\mathrm{Hu}$, L.-T., and Bentler, P. (1999). Cutoff criteria for fit indices in covariance structure analysis: Conventional criteria versus new alternatives. Struct. Equ. Model. 6, 1-55. doi: 10.1080/10705519909540118

Hume, L. E., Allan, D. M., and Lonigan, C. J. (2016). Links between preschoolers' literacy interest, inattention, and emergent literacy skills. Learn. Individ. Differ. 47, 88-95. doi: 10.1016/j.lindif.2015.12.006

Hume, L. E., Lonigan, C. J., and McQueen, J. D. (2015). Children's literacy interest and its relation to parents' literacy promoting practices. J. Res. Read. 38, 172-193. doi: 10.1111/j.1467-9817.2012.01548.x

Kikas, E., and Silinskas, G. (2016). Task persistence mediates the effect of children's literacy skills on mothers' academic help. Educ. Psychol. 36, 975-991. doi: 10. 1080/01443410.2015.1045836

Kikas, E., Silinskas, G., and Soodla, P. (2015). The effects of children's reading skills and interest on teacher perceptions of children's skills and individualized support. Int. J. Behav. Dev. 39, 402-412. doi: 10.1177/0165025415573641

Krashen, S. D. (2004). The Power of Reading: Insights from the Research. Santa Barbara, CA: ABC-CLIO.

Lehrl, S., Ebert, S., and Roßbach, H.-G. (2013). "Facets of preschoolers' home literacy environments: what contributes to reading literacy in primary school?," in The Development of Reading Literacy from Early Childhood to Adolescence, eds M. Pfost, C. Artelt, and S. Weinert (Bamberg: University of Bamberg Press), $35-62$. 
Leppänen, U., Aunola, K., and Nurmi, J. (2005). Beginning readers' reading performance and reading habits. J. Res. Read. 28, 383-399. doi: 10.1111/j.14679817.2005.00281.x

Lerkkanen, M.-K., Kiuru, N., Pakarinen, E., Viljaranta, J., Poikkeus, A.-M., RaskuPuttonen, H., et al. (2012). The role of teaching practices in the development of children's interest in reading and mathematics in kindergarten. Contemp. Educ. Psychol. 37, 266-279. doi: 10.1016/j.cedpsych.2011.03.004

Lerkkanen, M.-K., Niemi, P., Poikkeus, A.-M., Poskiparta, M., Siekkinen, M., and Nurmi, J.-E. (2006-2016). The First Steps study [Alkuportaat]. Finland: University of Jyväskylä.

Lerkkanen, M.-K., Poikkeus, A.-M., and Ketonen, R. (2006). ARMI - Luku- ja Kirjoitustaidon Arviointimateriaali 1. luokalle. [ARMI - A tool for Assessing Reading and Writing Skills in First Grade]. Helsinki: WSOY.

Lerkkanen, M.-K., Rasku-Puttonen, H., Aunola, K., and Nurmi, J.-E. (2004). Predicting reading performance during the first and the second year of primary school. Br. Educ. Res. J. 30, 67-92. doi: 10.1080/01411920310001629974

Levin, I., Levy-Shiff, R., Applebaum-Peled, T., Katz, I., Komar, M., and Meiran, N. (1997). Antecedents and consequences of maternal involvement in children's homework: a longitudinal analysis. J. Appl. Dev. Psychol. 18, 207-227. doi: 10.1016/s0193-3973(97)90036-8

Lindeman, J. (1998). Allu - Ala-asteen lukutesti. [Reading Test for Primary School]. Turku: University of Turku.

Little, R. J. A. (1988). A test of missing completely at random for multivariate data with missing values. J. Am. Stat. Assoc. 83, 1198-1202. doi: 10.2307/2290157

Lyytinen, H., Aro, M., Eklund, K., Erskine, J., Guttorm, T. K., Laakso, M.-L., et al. (2004). The development of children at familial risk for dyslexia: Birth to school age. Ann. Dyslexia 54, 184-220. doi: 10.1007/s11881-004-0010-3

Manolitsis, G., Georgiou, G. K., and Tziraki, N. (2013). Examining the effects of home literacy and numeracy environment on early reading and math acquisition. Early Child. Res Q. 28, 692-703. doi: 10.1016/j.ecresq.2013. 05.004

Manolitsis, G., Georgiou, G., and Parrila, R. (2011). Revisiting the home literacy model of reading development in an orthographically consistent language. Learn. Instr. 21, 496-505. doi: 10.1016/j.learninstruc.2010. 06.005

Martini, F., and Sénéchal, M. (2012). Learning literacy skills at home: parent teaching, expectations, and child interest. Can. J. Behav. Sci. 44, 210-221. doi: 10.1037/a0026758

McTigue, M., Solheim, O. J., Walgermo, B., Frijters, J., and Foldnes, N. (2019). How can we determine students' motivation for reading before formal instruction? Results from a self-beliefs and interest scale validation. Early Child. Res. Q. 48, 122-133. doi: 10.1016/j.ecresq.2018.12.013

Mol, S. E., and Bus, A. G. (2011). To read or not to read: A meta-analysis of print exposure from infancy to early adulthood. Psychol. Bull. 137, 267-296. doi: $10.1037 / \mathrm{a} 0021890$

Muthén and Muthén (1998-2010). Mplus User's Guide, 6th Edn. Los Angeles, CA: Muthén and Muthén.

Niklas, F., and Schneider, W. (2013). Home literacy environment and the beginning of reading and spelling. Contemp. Educ. Psychol. 38, 40-50. doi: 10.1016/j. cedpsych.2012.10.001

Niklas, F., and Schneider, W. (2017). Home learning environment and development of child competencies from kindergarten until the end of elementary school. Contemp. Educ. Psychol. 49, 263-274. doi: 10.1016/j. cedpsych.2017.03.006

Nurmi, J. E., and Aunola, K. (2005). Task-motivation during the first school years: A person-oriented approach to longitudinal data. Learn. Instruct. 15, 103-122. doi: 10.1016/j.learninstruc.2005.04.009

Nurmi, J.-E., and Aunola, K. (1999). Task-Value Scale for Children (TVS-C). Finland: University of Jyväskylä.

O’Brien, R. M. (2007). A caution regarding rules of thumb for variance inflation factors. Qual. Quant. 41, 673-690. doi: 10.1007/s11135-006-9018-6

Pezoa, J. P., Mendive, S., and Strasser, K. (2019). Reading interest and family literacy practices from prekindergarten to kindergarten: contributions from a cross-lagged analysis. Early Child. Res. Q. 47, 284-295. doi: 10.1016/j.ecresq. 2018.12.014

Pomerantz, E. M., and Eaton, M. M. (2001). Maternal intrusive support in the academic context: Transactional socialization processes. Dev. Psychol. 37, 174-186. doi: 10.1037/0012-1649.37.2.174
Reese, E., Sparks, A., and Leyva, D. (2010). A review of parent interventions for preschool children's language and emergent literacy. J. Early Child. Lit. 10, 97-117. doi: 10.1177/1468798409356987

Rose, E., Lehrl, S., Ebert, S., and Weinert, S. (2018). Long-term relations between children's language, the home literacy environment, and socioemotional development from ages 3 to 8. Early Educ. Dev. 29, 342-356. doi: 10.1080/ 10409289.2017.1409096

Scarborough, H. S., and Dobrich, W. (1994). On the efficacy of reading to preschoolers. Dev. Rev. 14, 245-302. doi: 10.1006/drev.1994. 1010

Schiefele, U., Schaffner, E., Möller, J., and Wigfield, A. (2012). Dimensions of reading motivation and their relation to reading behavior and competence. Read. Res. Q. 47, 427-463. doi: 10.1002/RRQ.030

Sénéchal, M. (2006). Testing the home literacy model: Parent involvement in kindergarten is differentially related to grade 4 reading comprehension, fluency, spelling, and reading for pleasure. Sci. Stud. Read. 10, 59-87. doi: 10.1207/ s1532799xssr1001_4

Sénéchal, M. (2012). "Language and literacy development at home," in Handbook of Family Literacy, ed. B. H. Wasik (New York: Routledge), 38-50.

Sénéchal, M., and LeFevre, J. A. (2014). Continuity and change in the home literacy environment as predictors of growth in vocabulary and reading. Child Dev. 85, 1552-1568. doi: 10.1111/cdev.12222

Sénéchal, M., and LeFevre, J.-A. (2002). Parental involvement in the development of children's reading skills: A five-year longitudinal study. Child Dev. 73, 445-460. doi: 10.1111/1467-8624.00417

Sénéchal, M., LeFevre, J.-A., Thomas, E. M., and Daley, K. E. (1998). Differential effects of home literacy experiences on the development of oral and written language. Read. Res. Q. 33, 96-116. doi: 10.1598/rrq.33.1.5

Seymour, P. H. K., Aro, M., and Erskine, J. M. (2003). Foundation literacy acquisition in European orthographies. Br. J. Psychol. 94, 143-174. doi: 10.1348/ 000712603321661859

Silinskas, G. (2012). Parental Involvement and children's Academic Skills. Doctoral dissertation, University of Jyväskylä, Finland: University of Jyväskylä.

Silinskas, G., Aunola, K., Lerkkanen, M.-K., and Raiziene, S. (2020/submitted). Parental teaching of reading and spelling across the transition from kindergarten to grade 1 . Submitted for publication.

Silinskas, G., Dietrich, J., Pakarinen, E., Kiuru, N., Aunola, K., Lerkkanen, M.K., et al. (2015). Children evoke similar affective and instructional responses from their teachers and mothers. Int. J. Behav. Dev. 39, 432-444. doi: 10.1177/ 0165025415593648

Silinskas, G., Kiuru, N., Tolvanen, A., Niemi, P., Lerkkanen, M.-K., and Nurmi, J.E. (2013). Maternal teaching of reading and children's reading skills in grade 1. Learn. Individ. Differ. 27, 54-66. doi: 10.1016/j.lindif.2013.06.011

Silinskas, G., Leppänen, U., Aunola, K., Parrila, R., and Nurmi, J. (2010a). Predictors of mothers' and fathers' teaching of reading and mathematics during kindergarten and grade 1. Learn. Instruct. 20, 61-71. doi: 10.1016/j.learninstruc. 2009.01.002

Silinskas, G., Lerkkanen, M. K., Tolvanen, A., Niemi, P., Poikkeus, A. M., and Nurmi, J. E. (2012). The frequency of parents' reading-related activities at home and children's reading skills during kindergarten and Grade 1. J. Appl. Dev. Psychol. 33, 302-310. doi: 10.1016/j.appdev.2012.07.004

Silinskas, G., Parrila, R., Lerkkanen, M. K., Poikkeus, A. M., Niemi, P., and Nurmi, J. E. (2010b). Mothers' reading-related activities at home and learning to read during kindergarten. Eur. J. Psychol. Educ. 25, 243-264. doi: 10.1007/s10212010-0014-9

Silinskas, G., Torppa, M., Lerkkanen, M. K., and Nurmi, J. E. (2020). The home literacy model in a highly transparent orthography. Sch. Eff. Sch. Improv. 31, 80-101. doi: 10.1080/09243453.2019.1642213

Sperling, R. A., and Head, D. M. (2002). Reading attitudes and literacy skills in prekindergarten and kindergarten children. Early Child. Educ. J. 29, 233-236. doi: 10.1023/A:1015129623552

Statistics Finland (2007). Statistical database. Available online at: http://www.stat. ?/tup/tilastotietokannat/indexen.html (accessed May 5, 2011).

Torppa, M., Georgiou, G. K., Lerkkanen, M.-K., Niemi, P., Poikkeus, A.M., and Nurmi, J.-E. (2016). Examining the simple view of reading in a transparent orthography: A longitudinal study from kindergarten to grade 3. Merril Palmer Q. 62, 179-206. doi: 10.13110/merrpalmquar1982.62.2. 0179 
Torppa, M., Niemi, P., Vasalampi, K., Lerkkanen, M.-K., Tolvanen, A., and Poikkeus, A.-M. (2019). Leisure reading (but not any kind) and reading comprehension support each other-a longitudinal study across grades 1 and 9. Child Dev. 91, 876-900. doi: 10.1111/cdev.13241

Torppa, M., Poikkeus, A. M., Laakso, M. L., Tolvanen, A., Leskinen, E., Leppanen, P. H., et al. (2007). Modeling the early paths of phonological awareness and factors supporting its development in children with and without familial risk of dyslexia. Sci. Stud. Read. 11, 73-103. doi: 10.1080/108884307093 36554

Torppa, M., Poikkeus, A.-M., Laakso, M.-L., Eklund, K., and Lyytinen, H. (2006). Predicting delayed letter name knowledge and its relation to grade 1 reading achievement in children with and without familial risk for dyslexia. Dev. Psychol. 42, 1128-1142. doi: 10.1037/0012-1649.42.6.1128

Tracey, D. H., and Young, J. W. (2002). Mothers' helping behaviors during children's at-home oral-reading practice: Effects of children's reading ability, children's gender, and mothers' educational level. J. Educ. Psychol. 94, 729-737. doi: 10.1037/0022-0663.94.4.729

Viljaranta, J., Silinskas, G., Lerkkanen, M.-K., Hirvonen, R., Pakarinen, E., Poikkeus, A.-M., et al. (2018). Maternal homework assistance and children's task-persistent behavior in elementary school. Learn. Instruct. 56, 54-63. doi: 10.1016/j.learninstruc.2018.04.005

Viljaranta, J., Tolvanen, A., Aunola, K., and Nurmi, J. E. (2014). The developmental dynamics between interest, self-concept of ability, and academic performance. Scand. J. Educ. Res. 58, 734-756. doi: 10.1080/00313831.2014.90 4419

Walgermo, B. R., Frijters, J. C., and Solheim, O. J. (2018). Literacy interest and reader self-concept when formal reading instruction begins. Early Child. Res. Q. 44, 90-100. doi: 10.1016/j.ecresq.2018.03.002

Xu, J., and Corno, L. (1998). Case studies of families doing third-grade homework. Teach. Coll. Rec. 100, 402-436.

Ziegler, J. C., Bertrand, D., Tóth, D., Csépe, V., Reis, A., Faísca, L., et al. (2010). Orthographic depth and its impact on universal predictors of reading: a cross-language investigation. Psychol. Sci. 21, 551-559. doi: $10.1177 /$ 0956797610363406

Conflict of Interest: The authors declare that the research was conducted in the absence of any commercial or financial relationships that could be construed as a potential conflict of interest.

Copyright (C) 2020 Silinskas, Sénéchal, Torppa and Lerkkanen. This is an openaccess article distributed under the terms of the Creative Commons Attribution License (CC BY). The use, distribution or reproduction in other forums is permitted, provided the original author(s) and the copyright owner(s) are credited and that the original publication in this journal is cited, in accordance with accepted academic practice. No use, distribution or reproduction is permitted which does not comply with these terms. 


\title{
Parents' Growth Mindsets and Home-Learning Activities: A Cross-Cultural Comparison of Danish and US Parents
}

\author{
Laura M. Justice ${ }^{1 *}$, Kelly M. Purtell' ${ }^{1}$, Dorthe Bleses ${ }^{2}$ and Sugene Cho ${ }^{1}$ \\ ${ }^{1}$ Crane Center for Early Childhood Research and Policy, The Ohio State University, Columbus, OH, United States, \\ ${ }^{2}$ Trygfonden Centre for Child Research, Aarhus University, Aarhus, Denmark
}

OPEN ACCESS

Edited by:

Frank Niklas,

Ludwig Maximilian University

of Munich, Germany

Reviewed by:

George Manolitsis,

University of Crete, Greece

Kirsi Tirri,

University of Helsinki, Finland

${ }^{*}$ Correspondence:

Laura M. Justice

justice.57@osu.edu

Specialty section:

This article was submitted to

Educational Psychology,

a section of the journal

Frontiers in Psychology

Received: 23 March 2020

Accepted: 22 May 2020

Published: 08 July 2020

Citation:

Justice LM, Purtell KM, Bleses D and Cho S (2020) Parents' Growth

Mindsets and Home-Learning

Activities: A Cross-Cultural

Comparison of Danish and US

Parents. Front. Psychol. 11:1365.

doi: 10.3389/fpsyg.2020.01365
Mindset is a term commonly used to represent an individual's beliefs about the role of ability and effort in learning. In this study, we assessed parental mindset-ability mindset and effort mindset-for 497 parents in two countries (United States and Denmark), all of whom had at least one child between 3 and 5 years of age. Of primary interest was assessing the relations between parental mindset and home-learning activities of four types: family learning activities, learning extensions, parental time investment, and parental school involvement. Findings showed that parents in the United States and Denmark held similar ability and effort mindsets, but differed significantly in homelearning activities, with US parents providing significantly more family learning activities, learning extensions, and parental time investment than Danish parents, although the latter had significantly higher levels of school investment. Furthermore, findings showed that parents' effort mindset was a significant predictor of family learning activities and parental time investment and that country moderated the relations between effort mindset and parental time investment. For US parents, higher levels of effort mindset were associated with higher levels of parental time investment, but this was not the case for Danish parents. We call for experimental work to determine the causal relations between parental mindset and home-learning activities, and rigorous cross-cultural research to explore the universality of parental mindset in distinctive cultural settings.

Keywords: growth mindset, home-learning environment, mindset, cross-culture, preschool

\section{INTRODUCTION}

The experiences we have in early childhood profoundly shape the rest of our lives (Duncan et al., 2010; Evans and Kim, 2013). In light of this, researchers have sought to develop and test interventions targeting this critical developmental period, to include interventions that enhance parents' behaviors toward their children (Fishel and Ramirez, 2005; Roberts and Kaiser, 2011). However, changing the behaviors of parents can be notoriously challenging (Wagner et al., 2002). One potential reason for this is that parents' beliefs about their children, and their own roles in shaping their children's development, may be incompatible with the goals of these interventions. For instance, parents may be reluctant to talk frequently with their very young children, a frequently targeted goal in parent-focused early intervention activities (e.g., Lederer, 2001) if they do not understand that this is a mechanism through which language development occurs (Rowe, 2008). 
Recent research has focused on parents' mindsets as a key factor that may shape parenting behaviors and potentially moderate the success of parent-focused interventions (e.g., Rowe, 2008). Parents' mindsets refers to the beliefs that caregivers hold regarding whether their children's development is fixed or malleable as well as the importance of effort for learning (Sisk et al., 2018). There is currently great interest in exploring whether modifications to parents' mindsets might influence their children's development. For example, a recent large-scale intervention in Denmark found that providing parents with information about the malleability of children's reading skills, in combination with reading materials, led to sizeable effects on children's reading and writing skills, and these effects were largest when parents held fixed beliefs about the malleability of language skills prior to intervention (Andersen and Nielsen, 2016). More recently, Rowe and Leech examined use of a parent mindset intervention to improve parents' non-verbal interactions with their 10-month-old infants (Rowe and Leech, 2018). Parents assigned to a treatment condition participated in training emphasizing the malleability of early language skills and that parents can play a key role in facilitating these skills through non-verbal interactions. Compared to parents in a control group, the trained parents non-verbally interacted more frequently with their children at 12 months of age, and this effect was particularly strong for parents with fixed mindsets at baseline, similar to the result reported by Andersen and Nielsen (2016). Such work suggests that parental ability mindsets may be a key target for interventions aiming to improve children's early experiences and development, and should be incorporated into parent-focused interventions.

Yet, empirical understanding of the mindsets of parents with young children is still only emerging, and there is a need to increase knowledge about the variability among caregivers in their mindset toward their children, in particular the role that mindset may play in fostering children's development. The present study was designed to increase our knowledge of parental mindset toward their preschool-aged children, to include assessing the extent to which parents' ability and effort mindsets were associated with home-learning activities with their children, and to do so in two cultures-the United States and Denmark. As we will discuss, these two cultural contexts differ significantly in terms of societal inequality, availability of social benefits, and the frequency of "dual earner" couples; we speculated that parental mindset and time investments with their children may vary across these distinct cultural contexts. To our knowledge, this is the first cross-cultural investigation of how parents view their role in their children's lives using a mindset lens, and results may help to inform future interventions designed to improve the developmental experiences of young children.

\section{Learning in the Home Environment and Parental Mindset}

Considerable evidence shows that the home-learning environment provides young children with key opportunities to develop skills in a variety of domains, including early literacy, language, and numeracy (Breit-Smith et al., 2010; Manolitsis et al., 2013; Niklas et al., 2016). However, there is also significant variability in the extent to which young children experience those opportunities that facilitate early learning in the home environment. For instance, a study of the homelearning environment for children in Israel showed distinct differences in the volume of key experiences for children from lower-socioeconomic status (SES) homes compared to children from higher-SES homes: the former had significantly fewer educational games and books in the home and were read to less often than the latter group of children (Korat et al., 2007). Some evidence suggests that SES may represent a proxy for caregivers' attitudes and knowledge about the importance of home-literacy opportunities, as more highly educated parents report higher regard for the importance of reading to their children and their own roles in facilitating early skill development than less-educated parents. In turn, such attitudes are positively correlated with the volume of learning opportunities provided to children in the home (Curenton and Justice, 2008). There are other reasons, however, that may explain variability in the home-learning experiences of young children, such as children's gender (Baker and Milligan, 2016) and parent employment outside of the home (Heiland et al., 2017). For the latter, some evidence suggests that time investments in children decline as a function of maternal employment: as maternal work hours increase, there is an inverse effect on the time parents directly invest in their children (Heiland et al., 2017).

In the present study, we build upon such work by examining the extent to which caregiver mindsets-in particular, their mindset regarding the malleability of their children's skills and perceptions regarding the importance of effort-were associated with home-learning activities, to include time investments. We examined four dimensions of home-learning activities, namely, family learning activities, learning extensions, parental time investments, and parental school involvement. Family learning activities, the most common aspect of the homelearning environment studied (e.g., Curenton and Justice, 2008), represent concrete activities caregivers do in the home with their children, such as telling stories and sharing books. Studies typically find a moderate association between the frequency of family learning activities and children's early skills (Korat et al., 2007), with structural models (e.g., Christian et al., 1998) and experimental studies (e.g., Justice et al., 2011) supporting causal relations between these activities and children's skill development. Learning extensions represent activities that might enhance children's skills beyond the immediate home environment, such as visits to libraries and bookstores. Evidence suggests that such learning extensions is a distinct factor of the home-learning environment (Gonzalez et al., 2011) and serves to differentiate clusters of families in the nature of home-learning opportunities (Davis et al., 2016). Parenting time investments represent the actual amount of time parents report directly engaging with their children. Parents vary significantly in the amount of time they report to spend with their children (Kalil et al., 2014), and these differences are associated with household SES, family structures, and child birth order (Neidell, 2000; Mammen, 2011), as well as children's early and later 
skill development (Bono et al., 2016). Finally, parental school involvement reflects the extent to which parents are engaged in their children's early schooling. Research consistently finds positive effects of parents' involvement in their children's schools, including actual engagement in school-based activities as well as ongoing communication with children's teachers, and is positively associated with children's short- and longer-term academic development (Dearing et al., 2008; Bono et al., 2016).

For these four dimensions of the home-learning environment, we examined interrelations with parent mindset as measured across two dimensions, which we refer to as ability mindset and effort mindset. Both dimensions serve to capture variability in an individual's implicit theories of intelligence and ability (Blackwell et al., 2007). Ability mindset captures parents' beliefs regarding the fixedness of children's skills, which may range along a continuum reflecting, on one end, the perspective that children's skills are fixed/stable to and, on the other end, the perspective that children's skills are malleable (Sisk et al., 2018). A parent with a fixed mindset would tend to believe that her child cannot improve, for instance, her reading skills, even with considerable work, as reading skills are fixed, whereas a parent with a growth-oriented ability mindset would believe that her child can significant improve her reading skills with work. Effort mindset captures parents' beliefs regarding the specific importance of effort as an impetus to their children's learning; parents with high effort beliefs perceive that hard work leads to greater learning (and thus place value on hard work), relative to parents with low effort beliefs, who would perceive that working hard is irrelevant or unimportant as it cannot override stable skills. Often, investigations of one's perspectives about the role of effort in skill development has focused on adolescents (e.g., Blackwell et al., 2007), although in this study, we considered parental perspectives as to whether their children's effort can contribute to early learning as an augment to focusing specifically on mindset.

\section{Parental Mindset and Early Learning: Cross-Cultural Considerations}

The present study was designed to examine variability in parental mindset across two dimensions (ability mindset and effort mindset) and also the interrelations among mindset and homelearning activities, including parental time investment in their children. We also sought to explore whether this phenomenon may vary cross-culturally, potentially due to cultural conditions that contribute to variability in parental time with their children as a function of universal childcare. Here, we consider two countries-the United States and Denmark-which vary substantially in the degree of societal inequality, as a function in part of welfare provision as a means to reduce inequality, including universal childcare. In countries with considerable equality in income distribution, the Gini index is low, whereas in countries with considerable inequality in income distribution, the Gini index is high. Based on data from the Central Intelligence Agency collected across the 2000s and 2010s, countries in the lowest quintile for inequality, based on the Gini index $(<31)$, are almost uniform in Europe (e.g., Denmark, France, Germany,
Iceland, and Norway), whereas those in the highest quintile (>46) are largely in Africa (e.g., Botswana, Namibia, Rwanda, and Zambia) and Latin America (e.g., Chile, Colombia, Guatemala, Nicaragua, and Panama) (Central Intelligence Agency, 2020). The United States is in the second highest quintile (Gini index $=45$ ), with inequality similar to that reported for Guanaya and Thailand (44.6), Peru (45.3), and Mozambique (45.6). One avenue for reducing income disparities is the provision of social welfare, including universal childcare to caregivers with young children.

For the present study, we conducted cross-cultural comparisons of parental mindset and home-learning activities for parents in the United States and Denmark; these countries' Gini indices were 41.4 (2016) and 28.7 (2017), respectively (World Bank, 2020). This allows a comparison of a setting with limited investment in childcare versus a near-universal system of care. Both countries are in the 36-member Organisation for Economic Co-operation and Development (OECD) and represent the lowest level of inequality among members (Denmark) and among the highest (United States) based on a recent report from the OECD (Organisation for Economic Co-operation and Development, 2015). An additional important distinction between these settings concerns parent involvement in the labor market and the provision of numerous supports in welfare states to enable labor-force participation, including universal childcare (Sayer and Gornick, 2012). In turn, this can affect caregivers' time investments with their children; for instance, Danish partnered mothers spend about $3 \mathrm{~h}$ less time with their children compared to their counterparts in the United States (Sayer and Gornick, 2012).

We might speculate that variabilities in the provision of universal child-care and labor-force participation patterns that distinguish these two cultures may contribute to differences in parental mindset and home-learning activities. Drawing from Bronfenbrenner's ecological theory concerning the impacts of environment on child development (Bronfenbrenner, 1994), societal inequality and welfare access represent an important characteristics of the exosystem in which parents are rearing their children and children are developing and which may influence parenting behaviors and children's development. In terms of the more proximal microsystem, access to a strong system of social supports, as is available in welfare-based societies, caregivers may have more positive perceptions of their own role in shaping their children's development and may provide enhanced earlylearning experiences for their children (Armstrong et al., 2005). Nonetheless, it is also the case that, in socialized economies like Denmark, where early childhood care and education is heavily subsidized with capped monthly fees and income-related sliding scales, there is far higher labor-force participation by mothers (more than $80 \%$ of mothers with children aged $0-14$ are in work, which is the second highest in OECD; Organisation for Economic Co-operation and Development, 2020a), and higher volumes of time spent working by adults (more than $70 \%$ of couples are "full-time dual earner" couples which is the highest in OECD), which may detract from parents' opportunities to provide homelearning activities for their children, irrespective of mindset. 


\section{Study Aims}

The overarching goal of this study was to examine how parental mindset may be associated with caregivers' engagement in homelearning activities, specifically across distinct cultural contexts: the United States and Denmark. First, we conducted crosscultural comparisons of the level of parental mindset and homelearning activities by comparing whether parental mindsets and home-learning activities differ across the United States and Denmark. Given the lack of prior cross-cultural investigation of parental mindset, we did not set forth a priori hypotheses for potential differences across US and Danish parents. However, we speculated that Danish parents may engage in fewer homelearning activities given that Danish parents report having far less time with their children than US parents. Next, we investigated the associations between parental mindset and home-learning activities. We hypothesized that parents with growth-oriented mindsets toward their children's abilities and efforts may engage in more home-learning activities, irrespective of cultural context. Last, we investigated country as a moderator of the link between parental mindset and home-learning activities to test if these relations differ by culture.

\section{MATERIALS AND METHODS}

\section{Participants}

Participants were recruited separately from United States and Denmark upon meeting the eligibility criterion of having at least one child between 3 and 5 years of age. Participant recruitment and participation occurred in parallel. First, the Denmark participants were recruited from a national online panel with $\sim 200,000$ panelists, which is hosted by Epinion, and were contacted via mail. The US participants were recruited via e-mail, postcards, and in-person invitations from a pool of parents of children who participated in recent research projects and parents whose child attend a local preschool in a midwestern state. The final sample consisted of a total of 497 parents (325 Danish and 172 United States) who completed the self-administered online or paper questionnaire, with the same general content but written in each country's official language. Although we altered wordings of few response items to fit each cultural context (e.g., parental educational attainment), the majority of the questions contained identical information. The descriptive statistics of focal variables by country including comparison statistics are provided in Table 1.

Whereas the Denmark sample showed a similar gender distribution of the parents (female $=48.77 \%$ ), the US parent sample was highly female dominant (female $=91.23 \%$ ). Due to the lack of variance in the US sample, gender was not controlled for the final analyses. Parents' average age was $\sim 35$ years in both countries. Relatively more parents in the Denmark sample were employed full-time (Denmark $=76.85 \%$; United States $=61.05 \%)$, married (Denmark $=69.14 \%$; United States $=55.56 \%)$, and cohabiting (Denmark $=24.38 \%$; United States $=10.53 \%$ ) compared to the US sample. Whereas the majority of the Danish parents were using formal child-care services (i.e., childcare
TABLE 1 | Descriptive statistics and comparison of focal variables by country.

\begin{tabular}{|c|c|c|c|}
\hline & Denmark $^{a}$ & United States $^{b}$ & $t$ or $\chi^{2 c}$ \\
\hline & $M(S D)$ or $\%$ & $M(S D)$ or $\%$ & \\
\hline \multicolumn{4}{|l|}{ Parental mindset } \\
\hline Ability mindset & $5.05(0.71)$ & $5.15(0.73)$ & 1.54 \\
\hline Effort mindset & $5.28(0.75)$ & $5.34(0.55)$ & 0.99 \\
\hline \multicolumn{4}{|l|}{ Home-learning activities } \\
\hline Family learning activities & $2.66(0.46)$ & $3.03(0.51)$ & $8.07^{\star \star \star}$ \\
\hline Learning extensions & $2.13(1.41)$ & $3.04(1.59)$ & $6.55^{\star \star \star}$ \\
\hline Parental time investment & $3.26(0.93)$ & $4.77(1.04)$ & $16.55^{\star \star \star}$ \\
\hline Parental school involvement & $3.10(1.29)$ & $2.59(1.49)$ & $-3.92^{\star \star \star}$ \\
\hline \multicolumn{4}{|l|}{ Covariates } \\
\hline Parent age & $35.87(5.79)$ & $34.10(6.58)$ & $-3.09^{\star \star}$ \\
\hline Parent education ${ }^{d}$ & $5.40(1.45)$ & $4.42(2.13)$ & \\
\hline \multicolumn{4}{|l|}{ Parent occupational status } \\
\hline Employed full-time & 76.85 & 61.05 & $14.05^{\star \star}$ \\
\hline Employed part-time & 8.95 & 13.37 & \\
\hline Not employed & 14.20 & 25.58 & \\
\hline \multicolumn{4}{|l|}{ Parent marital status } \\
\hline Married & 69.14 & 55.56 & $66.96^{\star \star \star}$ \\
\hline Cohabiting & 24.38 & 10.53 & \\
\hline Other & 6.48 & 33.92 & \\
\hline Formal childcare & 98.15 & 58.68 & $132.63^{\star \star \star}$ \\
\hline
\end{tabular}

$S D$, standard deviation. ${ }^{a} n=324,{ }^{b} n=172,{ }^{c}$ t-test statistics are for continuous variables, and $\chi^{2}$ are for categorical variables. ${ }^{d}$ The scale range was identical but specific response values differed by country. ${ }^{*} p<0.01$ and ${ }^{* *} p<0.001$.

by non-relatives that takes place in either residential or nonresidential school-like settings, 98.15\%), a higher percentage of US parents were providing parental care (30.54\%) as their primary childcare.

\section{Measures}

\section{Parental Mindset}

We captured two parental mindsets: "ability mindset" and "effort beliefs." The ability mindset scale was based on Dweck's (1999) Theories of Intelligence (TOI) scale, which distinguishes individuals' view of intelligence as a trait that is fixed and stable vs. malleable and improvable. For this study, we used selected items from Andersen and Nielsen's (2016) scale, which was originally based on the study of Muenks et al. (2015) that developed and validated measures of parents' specific beliefs about the fixedness of their child's math and verbal abilities. Andersen and Nielsen (2016) further adapted their measure to fit parents of primary school children. Our final measure consisted of the following four items: "After a certain point in childhood, my child's ability to learn how to read cannot improve; My child can always improve their ability to learn how to read, no matter how old they are; My child's ability to learn how to read can only be substantially improved during a specific period in their development; My child is past the age at which he/she can substantially improve their ability to learn how to read." We reverse coded some items to represent the extent to the parents think their child's ability can improve. 
The effort mindset scale was based on Blackwell et al. (2007), who developed measures to capture youth's belief that efforts lead to positive outcomes. We used selected items from the measure and adapted them to fit the perspective of the parents' regarding their preschool child. The final scale consisted of the following three items: "The harder my child works at something, the better they will be at it; To tell the truth, when my child seems to work too hard at learning activities, it makes me feel like they are not very smart; If my child is not good at learning activities, working hard won't make them good at it." We reverse coded some items to represent the extent to parents think their child's efforts lead to positive outcomes.

Answers for all the items in both the ability mindset and effort mindset scales ranged from 1 (strongly disagree) to 6 (strongly agree), and we used the mean values of the items in each scale for our final analyses (ability mindset $\alpha=0.62$; and effort mindset $\alpha=0.61$ ).

\section{Home-Learning Activities}

Home-learning activities consisted of four measures: (a) family learning activities, (b) learning extensions, (c) parental time investment, and (d) parental school involvement. All four measures were adopted from the Early Childhood Longitudinal Study: Kindergarten Class of 2010-2011 (ECLS$\mathrm{K}: 2011$ ), a longitudinal study that followed a sample of children from kindergarten through the fifth grade to examine topics such as child development and early school experiences. While ECLS-K collected data from several sources including parents and classroom teachers, we only used the parent questionnaire developed for the Kindergarten Year (20102011) as they fit the child's developmental period of our interest. For some scales, we did not include items that were deemed irrelevant to our focal interests (e.g., for the parental school involvement scale, "have you or other adults in the family gone to a meeting of a parent advisory group or policy council?").

Family learning activities consisted of 10 items on how often family members engage in activities with their child such as telling stories, singing songs, doing science projects, playing sports, or exercising together, among others, with answers ranging from 1 (not at all) to 4 (every day). We used the mean value for final analyses $(\alpha=0.82)$. Learning extensions were made up of six items asking whether or not anyone in the family has engaged in the suggested six learning extensions including visiting the library and bookstores $(\alpha=0.53)$. For our final analyses, we used the sum of six items. Parental time investment was based on a question asking how much time family members at home spend playing with their child, ranging from 1 (no time) to 6 (more than $3 \mathrm{~h}$ ). Since the same question was asked for both a typical school and weekend day, we used the mean value of the two items given their high correlation $(r=0.72$, $p<0.001 ; \alpha=0.83$ ). For parental school involvement, we used five items regarding whether or not adults in the household has done each of the five activities including attending an open house and serving as a volunteer in school $(\alpha=0.65)$. The sum of the five items was used for our final analyses.

\section{Covariates}

Covariates in this study include parental age, education level, occupational status (i.e., full-time, part-time, and not employed), and marital status (i.e., married, cohabiting, and other). The parent education measure was an ordinal measure, and the specific values differed by country based on their cultural context [e.g., United States = 3 (some college experience), 6 (some postgraduate experience), 9 (MD, Law, Ph.D., or other advanced degree); Denmark = 2 (less than high school), 4 (vocational or technical school), 6 (BA, professional BA), and 8 (MD, Law, Ph.D., or other advanced degree)]. We also controlled for a dichotomous indicator of whether the child was involved in formal childcare (i.e., childcare by non-relatives that takes place in either residential or non-residential school-like settings) as opposed to parental care and other informal childcare (i.e., childcare by relatives or less frequently by a non-relative taking place in residential home).

\section{Analysis Plan}

All analyses were conducted in STATA 13. The first research aim comparing the levels of parental mindset and home-learning activities was examined using $t$-tests to indicate whether there are significant differences in the means of each measure by country. We also conducted ordinary least squared (OLS) linear regression regressing parental mindset on the country indicator and all covariates. For the second research aim investigating the relationships between parental mindset and home-learning activities, we conducted OLS linear regression predicting each home-learning activity from parental mindsets and covariates using both the US and Danish samples and controlling for the country indicator (i.e., Denmark $=1$ ). The last research aim investigated the moderating role of country on the associations between parental mindset and home-learning activities, which was tested by including the interaction terms of the county indicator and two parental mindset scales into the direct effect models. For significant interaction effects, we further examined the simple slopes of the association between parental mindset and home learning activities by country.

\section{RESULTS}

\section{Cross-Cultural Comparison of Parental Mindset and Home-Learning Activities}

The results for the first research question comparing the levels of parental mindset and home-learning activities across countries are shown in the right column of Table 1 . Our results show that there were no cross-cultural differences in the levels of ability mindset $[t(494)=1.54, p=0.125]$ or effort mindset $[t(494)=0.99$, $p=0.323$ ] between Denmark and the United States. However, as we speculated, US parents were engaging in higher levels of home-learning activities, including family learning activities $[t(494)=8.07, p<0.001]$, learning extension $[t(494)=6.55$, $p<0.001]$, and parental time investment $[t(494)=16.55$, $p<0.001]$ compared to the Danish parents. One exception was parental school involvement, which was higher among the Danish parents than the US parents $[t(494)=3.92, p<0.001]$. 
TABLE 2 | Predicting parental mindset from country and covariates.

\begin{tabular}{|c|c|c|}
\hline & Ability mindset & Effort mindset \\
\hline & $b(S E)$ & $b(S E)$ \\
\hline Denmark sample & $-0.14(0.08)$ & $-0.04(0.08)$ \\
\hline \multicolumn{3}{|l|}{ Covariates } \\
\hline Parent age & $0.01(0.01)$ & $0.00(0.01)$ \\
\hline Parent education ${ }^{a}$ & $0.00(0.02)$ & $0.03(0.02)$ \\
\hline \multicolumn{3}{|c|}{ Parent work status (ref = not employed) } \\
\hline Employed full-time & $0.08(0.09)$ & $-0.09(0.09)$ \\
\hline Employed part-time & $0.21(0.12)$ & $0.08(0.12)$ \\
\hline \multicolumn{3}{|c|}{ Parent marital status ( ref = single) } \\
\hline Married & $-0.04(0.10)$ & $-0.01(0.10)$ \\
\hline Cohabiting & $-0.00(0.12)$ & $-0.01(0.11)$ \\
\hline Formal childcare & $0.04(0.11)$ & $-0.11(0.11)$ \\
\hline$R^{2}$ & 0.018 & 0.016 \\
\hline
\end{tabular}

SE, standard error; Ref, reference group. ${ }^{a}$ The scale range was identical, but specific response values differed by country.

We also regressed the parental mindset measures on the country indicator as shown in Table 2, and the results indicate that neither the country indicator nor any of the covariates significantly predicted the parental mindset measures.

\section{Association Between Parental Mindset and Home-Learning Activities}

Tables 3-5 display the results of the second research aim investigating the universal association between parental mindset and home-learning activities across both cultures. First, Table 3 displays the correlation of focal variables of each country, respectively. According to the results, parental ability mindset was not associated with majority of the home-learning activities in both Denmark and the United States. One exception was the positive and significant correlation between parental ability mindset and time investment among the US parents $(r=0.16$, $p=0.038$ ). Parental effort mindset was not significantly correlated with any of the home-learning activities, but only among the US parents. In contrast, although these correlations are small in nature, parental effort mindset was positively correlated with their family learning activities $(r=0.16, p=0.004)$ and parental time investment $(r=0.12, p=0.026)$ among the Danish parents.

The regression results predicting parental mindset from home-learning activities across both cultures with covariates included are shown in Tables 4, 5. According to the results, parental ability mindset was not associated home learning activities, whereas parental effort mindset was positively and significantly associated with their engagement in family learning activities $(b=0.09, S E=0.03, p=0.005)$ and parental time investment $(b=0.16, S E=0.07, p=0.016)$. Furthermore, when examining our covariates, being in the Denmark sample was the most common predictor and was negatively associated with family learning activities $(b=-0.37, S E=0.06, p<0.001)$, learning extensions $(b=-1.19, S E=0.17, p<0.001)$, and parental time investment $(b=-1.41, S E=0.11, p<0.001)$, and positively predicted parental school involvement $(b=0.52$, $S E=0.17, p<0.001)$.

\section{Cultural Context as a Moderator of the Association Between Parental Mindset and Home-Learning Activities}

To address the third research question investigating the moderating role of cultural context on the link between parental mindset and home-learning activities, we regressed homelearning outcomes on the interaction terms of each parental mindset variable and the Denmark indicator. First, we found that county did not moderate the relationship between parental effort mindset and home-learning activities (results not shown in table). However, the country indicator was found to moderate the association between parental ability mindset and parental time investment (see Table 6). Specifically, the association between parental ability mindset and time investments was significantly weaker for Danish parents compared to the US parents $(b=-0.29, S E=0.13, p=0.029)$. The simple slopes in Figure 1 show that for Danish parents, ability mindset was not associated with their parental time investment $(b=-0.10$, $S E=0.08, p=0.212$ ), whereas US parents showed a marginal and positive association between ability mindset and time investment $(b=0.24, S E=0.12, p=0.052)$.

\section{DISCUSSION}

The present study adds to an emerging research base concerning the role of parental mindset in shaping behaviors and is a unique contribution to this base given our focus on the relations between parental mindset and home-learning activities for US and Danish parents. Given the importance of parental beliefs to their children's development (Curenton and Justice, 2008; Andersen and Nielsen, 2016; Davis et al., 2016), it is necessary to learn more about mindset as a particular dimension of parental beliefs, as it may influence their behaviors toward their children. We speculated that caregivers whose mindset is more growthoriented may provide their children with more frequent homelearning opportunities, as caregivers with a growth-oriented mindset would view these opportunities as catalysts for child development, as suggested by recent intervention research (Rowe and Leech, 2018). We further speculated that caregivers whose belief system values the role of effort in development and learning would provide their children with more frequent home-learning opportunities as well. In addition, we also explored whether there is variability in caregiver mindset cross-culturally by comparing parental mindset in a culture with relatively modest investments in social welfare, including childcare provision, and one with considerable welfare investments including universal childcare.

We highlight several major contributions of this study. First, we found that for our full sample of parents, parents' effort mindset, but not ability mindset, was positively associated with the frequency of family learning activities and parental time investment. Specifically, parents whose belief system values the role of effort in learning tended to engage in more learning activities with their children, such as telling stories and sharing 
TABLE 3 | Correlation between main variables.

\begin{tabular}{|c|c|c|c|c|c|c|}
\hline Denmark/United States & 1 & 2 & 3 & 4 & 5 & 6 \\
\hline (1) Ability mindset & & $0.34^{\star \star \star}$ & 0.04 & 0.11 & $0.16^{\star}$ & 0.01 \\
\hline (2) Effort mindset & $0.43^{\star \star \star}$ & & 0.07 & -0.00 & 0.09 & 0.05 \\
\hline (3) Family learning activities & 0.02 & $0.16^{\star \star}$ & & $0.44^{\star \star \star}$ & $0.51^{\star \star \star}$ & $0.16^{\star}$ \\
\hline (4) Learning extensions & -0.10 & -0.01 & $0.35^{\star \star \star}$ & & $0.18^{\star}$ & $0.21^{\star *}$ \\
\hline (5) Parental time investment & -0.02 & $0.12^{\star}$ & $0.41^{\star \star \star}$ & 0.09 & & -0.05 \\
\hline (6) Parental school involvement & -0.07 & -0.04 & $0.15^{\star \star}$ & $0.19^{\star \star \star}$ & 0.01 & \\
\hline
\end{tabular}

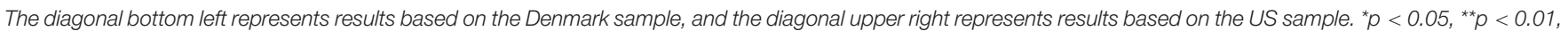
${ }^{* * *} p<0.001$.

TABLE 4 | Predicting family learning activities and learning extensions from parental mindset.

\begin{tabular}{|c|c|c|c|c|}
\hline & \multicolumn{2}{|c|}{ Family learning activities } & \multicolumn{2}{|c|}{ Learning extensions } \\
\hline & $\begin{array}{c}\text { Model } 1 \\
b(S E)\end{array}$ & $\begin{array}{c}\text { Model } 2 \\
b(S E)\end{array}$ & $\begin{array}{c}\text { Model } 1 \\
b(S E)\end{array}$ & $\begin{array}{c}\text { Model } 2 \\
b(S E)\end{array}$ \\
\hline \multicolumn{5}{|l|}{ Parental mindset } \\
\hline Ability mindset & & $-0.01(0.03)$ & & $-0.09(0.10)$ \\
\hline Effort mindset & & $0.09(0.03)^{\star \star}$ & & $0.01(0.10)$ \\
\hline \multicolumn{5}{|l|}{ Covariates } \\
\hline Parent age & $-0.00(0.00)$ & $-0.00(0.00)$ & $0.01(0.01)$ & $0.01(0.01)$ \\
\hline Parent education ${ }^{\mathrm{a}}$ & $0.01(0.01)$ & $0.01(0.01)$ & $0.03(0.04)$ & $0.03(0.04)$ \\
\hline \multicolumn{5}{|c|}{ Parent work status (ref = not employed) } \\
\hline Employed full-time & $-0.12(0.06)^{\star}$ & $-0.11(0.06)$ & $0.08(0.19)$ & $0.09(0.19)$ \\
\hline Employed part-time & $-0.18(0.08)^{\star}$ & $-0.18(0.08)^{\star}$ & $-0.39(0.26)$ & $-0.37(0.26)$ \\
\hline \multicolumn{5}{|c|}{ Parent marital status (ref $=$ other) } \\
\hline Married & $0.12(0.07)$ & $0.12(0.07)$ & $0.26(0.21)$ & $0.26(0.21)$ \\
\hline Cohabiting & $0.02(0.08)$ & $0.02(0.08)$ & $0.01(0.24)$ & $0.01(0.24)$ \\
\hline Formal childcare & $-0.00(0.07)$ & $0.01(0.07)$ & $0.34(0.22)$ & $0.34(0.22)$ \\
\hline Denmark sample & $-0.37(0.06)^{\star \star \star}$ & $-0.37(0.06)^{\star \star \star}$ & $-1.18(0.17)^{\star \star \star}$ & $-1.19(0.17)^{\star \star \star}$ \\
\hline$R^{2}$ & $0.141^{\star \star \star}$ & $0.156^{\star \star \star}$ & $0.112^{\star \star \star}$ & $0.114^{\star \star \star}$ \\
\hline
\end{tabular}

SE, standard error; Ref, reference group. ${ }^{a}$ The scale range was identical but specific response values differed by country. ${ }^{*} p<0.05,{ }^{* *} p<0.01,{ }^{* *} p<0.001$.

books; in addition, they reported to spend more time with their children overall. This finding represents a unique contribution to the literature on mindset, much of which has focused on the relations between students' mindsets and their academic achievement (Sisk et al., 2018). Although the average correlation between mindset and achievement is very modest, based on recent meta-analytic methods (Sisk et al., 2018), mindset can be easily modified and thus offers a potential valuable mechanism to improve students' efforts and, in turn, their achievement over time. The present study is one of the first to explore the relations between parents' mindsets toward their children and engagement in home-learning activities and provide a potentially viable approach toward enhancing home-learning opportunities for children via mindset-focused interventions.

Results of the present work suggest, potentially, that increasing parents' effort beliefs may result in increased learning activities in the home environment, although this needs to be tested causally. Some support for this conjecture is derived from a recent experimental study by Rowe and Leech (2018), who embedded training on parental mindset into a language-focused intervention delivered to parents of toddlers. These researchers found that parents' language-facilitation behaviors improved most prominently for parents with fixed mindsets at study start. Perhaps, this is because parents with a growth-oriented mindset already engage in significant home-learning activities with their children, buffering the effects of the intervention, whereas those with a fixed mindset can be induced to improve home-learning opportunities by modifying their beliefs about their children's abilities and efforts.

One might question why parents' effort mindset, rather than ability mindset, was associated with parents' homelearning opportunities, including time investments with their children. Recall that effort mindset captures parents' beliefs in the role of effort as influential to learning, whereas ability mindset captures parents' beliefs about the malleability of their children's skills. We speculate that parents' effort mindset toward their children may reflect their beliefs about effort more generally; specifically, parents who believe that effort is important may therefore be included to direct effort toward their children's learning in the home environment. If this is the case, it would explain why parents who value effort would direct more effort toward their children in 
TABLE 5 | Predicting parental time investment and parental school involvement from parental mindset.

\begin{tabular}{|c|c|c|c|c|}
\hline & \multicolumn{2}{|c|}{ Parental time investment } & \multicolumn{2}{|c|}{ Parental school involvement } \\
\hline & $\begin{array}{c}\text { Model } 1 \\
b(S E)\end{array}$ & $\begin{array}{c}\text { Model } 2 \\
b(S E)\end{array}$ & $\begin{array}{c}\text { Model } 1 \\
b(S E)\end{array}$ & $\begin{array}{c}\text { Model } 2 \\
b(S E)\end{array}$ \\
\hline \multicolumn{5}{|l|}{ Parental mindset } \\
\hline Ability mindset & & $0.00(0.07)$ & & $-0.11(0.10)$ \\
\hline Effort mindset & & $0.16(0.07)^{\star}$ & & $-0.03(0.10)$ \\
\hline \multicolumn{5}{|l|}{ Covariates } \\
\hline Parent age & $-0.03(0.01)^{\star \star \star}$ & $-0.03(0.01)^{\star \star \star}$ & $0.01(0.01)$ & $0.01(0.01)$ \\
\hline Parent education ${ }^{a}$ & $-0.02(0.03)$ & $-0.03(0.03)$ & $0.05(0.04)$ & $0.05(0.04)$ \\
\hline \multicolumn{5}{|c|}{ Parent work status (ref = not employed) } \\
\hline Employed full-time & $-0.06(0.12)$ & $-0.04(0.12)$ & $-0.21(0.17)$ & $-0.20(0.17)$ \\
\hline Employed part-time & $-0.16(0.17)$ & $-0.17(0.17)$ & $-0.20(0.24)$ & $-0.17(0.24)$ \\
\hline \multicolumn{5}{|c|}{ Parent marital status (ref = other) } \\
\hline Married & $0.14(0.13)$ & $0.14(0.13)$ & $0.26(0.19)$ & $0.25(0.19)$ \\
\hline Cohabiting & $0.14(0.16)$ & $0.14(0.16)$ & $-0.08(0.23)$ & $-0.08(0.23)$ \\
\hline Formal childcare & $-0.20(0.14)$ & $-0.18(0.14)$ & $-0.19(0.22)$ & $-0.19(0.22)$ \\
\hline Denmark sample & $-1.42(0.11)^{\star \star \star}$ & $-1.41(0.11)^{\star \star \star}$ & $0.54(0.17)^{\star \star}$ & $0.52(0.17)^{\star \star}$ \\
\hline$R^{2}$ & $0.390^{\star \star \star}$ & $0.399^{\star \star \star}$ & $0.053^{\star \star}$ & $0.057^{\star \star}$ \\
\hline
\end{tabular}

SE, standard error; Ref, reference group. ${ }^{a}$ The scale range was identical but specific response values differed by country. ${ }^{\star} p<0.05,{ }^{* *} p<0.01,{ }^{\star * *} p<0.001$.

TABLE 6 | Predicting home-learning activities from interaction of country and ability mindset.

\begin{tabular}{|c|c|c|c|c|}
\hline & Family learning activities & Learning extensions & Parental time investment & Parental school involvement \\
\hline & $b(S E)$ & $b(S E)$ & $b(S E)$ & $b(S E)$ \\
\hline \multicolumn{5}{|l|}{ Parental mindset } \\
\hline Ability mindset & $0.01(0.05)$ & $0.18(0.17)$ & $0.19(0.11)$ & $-0.09(0.16)$ \\
\hline Effort mindset & $0.10(0.03)^{\star \star}$ & $0.04(0.11)$ & $0.18(0.07)^{\star \star}$ & $-0.03(0.10)$ \\
\hline \multicolumn{5}{|l|}{ 2-way interaction terms } \\
\hline Ability mindsetDenmark & $-0.04(0.07)$ & $-0.40(0.20)$ & $-0.29(0.13)^{\star}$ & $-0.03(0.19)$ \\
\hline \multicolumn{5}{|l|}{ Covariates } \\
\hline Parent age & $0.00(0.00)$ & $0.01(0.01)$ & $-0.03(0.01)^{\star \star \star}$ & $0.01(0.01)$ \\
\hline Parent education ${ }^{a}$ & $0.01(0.01)$ & $0.03(0.04)$ & $-0.03(0.03)$ & $0.05(0.04)$ \\
\hline \multicolumn{5}{|c|}{ Parent work status (ref = not employed) } \\
\hline Employed full-time & $-0.11(0.06)$ & $0.09(0.19)$ & $-0.04(0.12)$ & $-0.20(0.18)$ \\
\hline Employed part-time & $-0.19(0.08)^{*}$ & $-0.39(0.26)$ & $-0.19(0.17)$ & $-0.17(0.24)$ \\
\hline \multicolumn{5}{|c|}{ Parent marital status (ref = other) } \\
\hline Married & $0.12(0.07)$ & $0.26(0.21)$ & $0.15(0.13)$ & $0.25(0.19)$ \\
\hline Cohabiting & $0.02(0.08)$ & $0.01(0.24)$ & $0.14(0.15)$ & $-0.08(0.23)$ \\
\hline Formal childcare & $0.01(0.07)$ & $0.34(0.22)$ & $-0.18(0.14)$ & $-0.19(0.22)$ \\
\hline Denmark sample & $-0.19(0.34)$ & $0.85(1.06)$ & $0.05(0.68)$ & $0.68(0.99)$ \\
\hline$R^{2}$ & $0.156^{\star \star \star}$ & $0.121^{\star \star \star}$ & $0.405^{\star \star \star}$ & $0.057^{\star \star}$ \\
\hline
\end{tabular}

SE, standard error; Ref, reference group. ${ }^{a}$ The scale range was identical but specific response values differed by country. ${ }^{*} p<0.05$, ${ }^{* *} p<0.01,{ }^{* *} p<0.001$.

terms of provision of family-learning activities and actual time investments.

The second contribution that we seek to emphasize concerns our focus on potential cross-cultural differences in parental mindset across our US and Danish samples. As we discuss in the introduction, these two cultural contexts vary in key ways that might lead to differences in parental mindset and provision of home-learning activities; these include distinctions between the countries in terms of societal inequality, adults' labor-force participation, parents' time investments with their children, and access to childcare. Our cross-cultural study had several interesting findings. First, the samples were quite distinct in several compelling but unexpected ways. Although all parents recruited into the study had children of preschool age, the US parents were slightly younger, less likely to be cohabiting, more likely to be employed part-time, and less likely to be using formal childcare compared to the Danish parents. In addition, the US parents reported higher rates of family learning activities, 


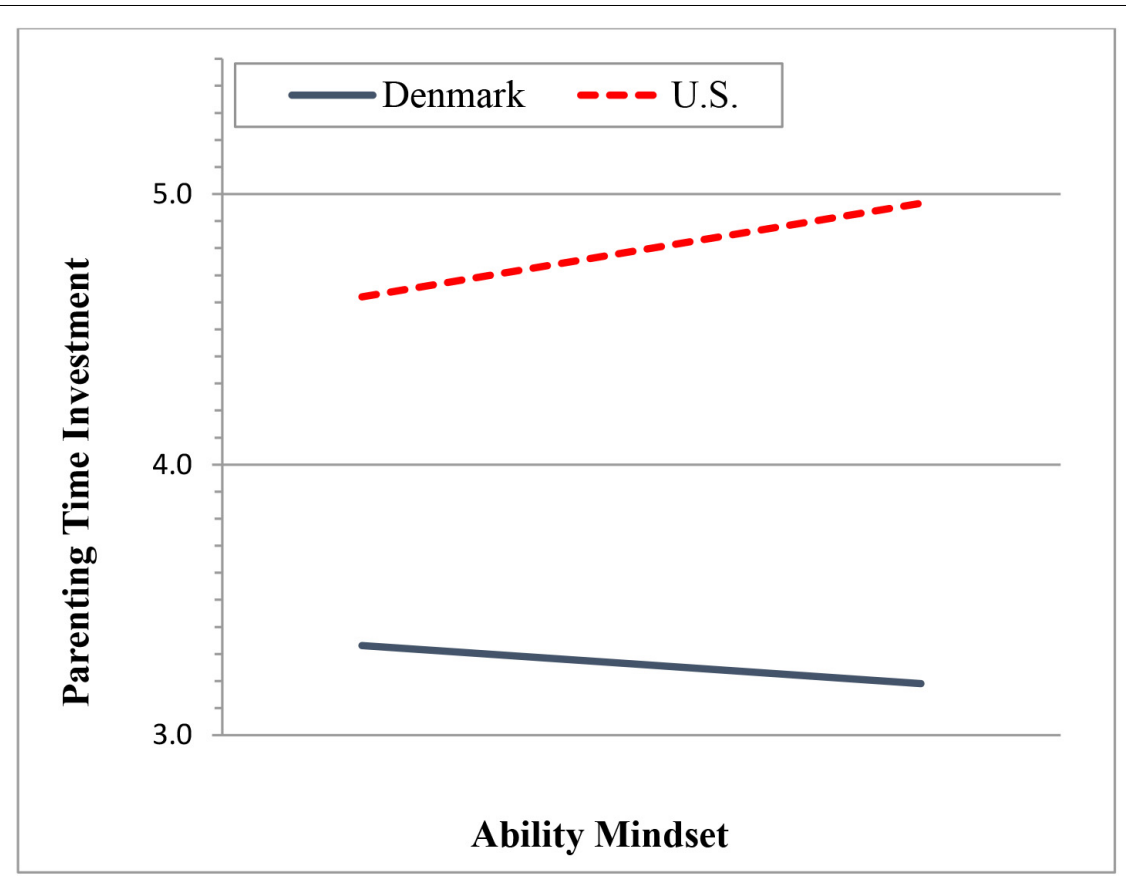

FIGURE 1 | Association between parental ability mindset and parental time investment by country.

learning extensions, and time investment compared to Danish parents. This was to be expected based on evidence showing that Danish parents' time investments with their children tends to be lower than parents in other countries, including the United States (Craig and Mullan, 2012), possibly because of their high level of access to childcare and high rates of labor-force participation by parents. Danish parents did report more school involvement than US parents, perhaps in part because preschool attendance is more common in Denmark and because parents are more likely to enroll their children in preschool at earlier ages in Denmark, which in turn, may facilitate parent involvement and parent-teacher relationships. For example, according to the most recent OECD data for each country, 56\% of Danish children ages 0-2 are enrolled in childcare (in 2017), compared to only $28 \%$ of US children (in 2011: Organisation for Economic Co-operation and Development, 2020b). Interestingly, however, we found no meaningful difference between US and Danish parents with respect to their mindset: both sets of parents held similar perspectives regarding ability mindset and effort mindset, indicating that these types of parental beliefs are not conditioned on cross-cultural differences. It is interesting to find that despite distinct differences across these cultures in parent time investments with their children and labor-force participation (Craig and Mullan, 2012), parents hold similar beliefs regarding ability and effort.

A finding of additional note concerns the interplay among country (United States and Denmark), parents' effort mindset, and parental time investment. Although it is established that Danish parents tend to spend less time with their children than parents in other countries (Craig and Mullan, 2012), the present findings show an interesting phenomenon: namely, a positive relationship between US parents' effort mindset and time investments with their children, yet the absence of such a relationship for the Danish parents. This phenomenon may reflect the limited time Danish parents have with their children, as shown specific to our sample but also in larger samples of Danish parents compared to parents in other settings. For instance, Craig and Mullan (2012) showed that for partnered mothers, Danish mothers reported spending $\sim 3 \mathrm{~h}$ fewer caring for their young children compared to US and Australian mothers. This being the case, the limited time availability of Danish moms to care for their children may serve to dampen the relations between effort mindset and time investments. This suggests that in some circumstances, efforts to modify parents' mindset toward their children may offer limited benefits in terms of the home-learning environment; further research should examine whether parental mindset shapes decisions about children's out-of-home care in contexts where dual parental employment is high. However, in other circumstances, such as the United States, helping parents to develop a stronger orientation toward the role of effort in learning may lead to heightened time investments with their children as a mechanism for improved child outcomes.

We highlight several limitations of this work as well as future research directions. First, we relied on parent report for measures of parental mindset and home-learning opportunities, and unfortunately, our measures of parental mindset showed relatively low reliabilities. This work would have been strengthened with direct observations of home-learning opportunities and alternative approaches to assessing parental mindset. Likewise, there is a need for more methodological work to be conducted in developing mindset questionnaires 
with increased reliability. Relatedly, with the reliance on parent report for all measurements in this study, we did not address measurement invariance among the sample. Second, our samples of US and Danish parents differed in key ways, possibly due to differences in ascertainment activities. Future work should use identical ascertainment activities if possible. Despite these limitations, the present work provides evidence that parental mindset corresponds to the volume of home-learning activities that they provide to their young children, paving the way for additional work on this topic. We propose several important lines of work. First, there is a need for causally interpretable studies that assess whether mindset-focused interventions delivered to parents of young children improves the home-learning environment. Second, there is a need for further cross-cultural work to determine whether parental mindset is a universal phenomenon of importance and how cultural contexts may contribute to mindset. Collectively, such efforts can lead to fundamental improvements in the mindset construct and its relevance to parenting and child development in global contexts.

\section{DATA AVAILABILITY STATEMENT}

The raw data supporting the conclusions of this article will be made available by the authors, without undue reservation, to any qualified researcher.

\section{REFERENCES}

Andersen, S. C., and Nielsen, H. S. (2016). Reading intervention with a growth mindset approach improves children's skills. Proc. Natl. Acad. Sci. U.S.A. 113, 12111-12113. doi: 10.1073/pnas.1607946113

Armstrong, M. I., Birnie-Lefcovitch, S., and Ungar, M. T. (2005). Pathways between social support, family well being, quality of parenting, and child resilience: what we know. J. Child Family Stud. 14, 269-281. doi: 10.1007/s10826-005-5054-4

Baker, M., and Milligan, K. (2016). Boy-girl differences in parental time investments: evidence from three countries. J. Hum. Capital 10, 399-441. doi: $10.1086 / 688899$

Blackwell, L. S., Trzesniewski, K. H., and Dweck, C. S. (2007). Implicit theories of intelligence predict achievement across an adolescent transition: a longitudinal study and an intervention. Child Dev. 78, 246-263. doi: 10.1111/j.1467-8624. 2007.00995.x

Bono, E. D., Francesconi, M., Kelly, Y., and Sacker, A. (2016). Early maternal time investment and early child outcomes. Econ. J. 126, F96-F135.

Breit-Smith, A., Cabell, S. Q., and Justice, L. M. (2010). Home literacy experiences and early childhood disability: a descriptive study using the national household education surveys (NHES) program database. Lang. Speech Hear. Serv. Sch. 41, 96-107. doi: 10.1044/0161-1461(2009/08-0048)

Bronfenbrenner, U. (1994). Ecological models of human development. Read. Dev. Child. 2, 37-43.

Central Intelligence Agency, (2020). Country Comparison: Distribution Of Family Income - Gini Index. The World Factbook. Available at: https://www.cia.gov/ library/publications/the-world-factbook/rankorder/2172rank.html (accessed March 2, 2020).

Christian, K., Morrison, F. J., and Bryant, F. B. (1998). Predicting kindergarten academic skills: interactions among child care, maternal education, and family literacy environments. Early Child. Res. Q. 13, 501-521. doi: 10.1016/s08852006(99)80054-4

Craig, L., and Mullan, K. (2012). Lone and partnered mothers' childcare time within context in four countries. Eur. Soc. Rev. 28, 512-526.

\section{ETHICS STATEMENT}

The studies involving human participants were reviewed and approved by The Ohio State University and Aarhus University. The patients/participants provided their written informed consent to participate in this study.

\section{AUTHOR CONTRIBUTIONS}

LJ, DB, and KP conceptualized the overarching goals of the study. $\mathrm{DB}$ and KP wrote funding proposals and managed data collection and data entry at two sites. SC, DB, and KP researched and developed the questionnaires for the study. SC was engaged in direct data collection at one site, conducted data analyses, and wrote much of the methods and results. LJ wrote much of the literature review and discussion. LJ, DB, KP, and SC reviewed and edited the entire draft. All authors contributed to the article and approved the submitted version.

\section{FUNDING}

This work was supported by grants received from the Office of Research, College of Education and Human Ecology, The Ohio State University (PI: KP), and the TrygFonden's Centre for Child Research, Aarhus University (PI: DB).

Curenton, S. M., and Justice, L. M. (2008). Children's preliteracy skills: influence of mothers' education and beliefs about shared-reading interactions. Early Educ. Dev. 19, 261-283. doi: 10.1080/1040928080196 3939

Davis, H. S., Gonzalez, J. E., Pollard-Durodola, S., Saenz, L. M., Soares, D. A., Resendez, N., et al. (2016). Home literacy beliefs and practices among lowincome Latino families. Early Child Dev. Care 186, 1152-1172. doi: 10.1080/ 03004430.2015.1081184

Dearing, E., Kreider, H., and Weiss, H. B. (2008). Increased family involvement in school predicts improved child-teacher relationships and feelings about school for low-income children. Marriage Fam. Rev. 43, 226-254. doi: 10.1080/ 01494920802072462

Duncan, G. J., Ziol-Guest, K. M., and Kalil, A. (2010). Early-childhood poverty and adult attainment, behavior, and health. Child Dev. 81, 306-325. doi: 10.1111/j. 1467-8624.2009.01396.x

Dweck, C. S. (1999). Caution-praise can be dangerous. Am. Educ. 23, 4-9.

Evans, G. W., and Kim, P. (2013). Childhood poverty, chronic stress, selfregulation, and coping. Child Dev. Perspect. 7, 43-48. doi: 10.1111/cdep.12013

Fishel, M., and Ramirez, L. (2005). Evidence-based parent involvement interventions with school-aged children. Sch. Psychol. Q. 20, 371-402. doi: 10.1521/scpq.2005.20.4.371

Gonzalez, J. E., Taylor, A. B., McCormick, A. S., Villareal, V., Kim, M., Perez, E., et al. (2011). Exploring the underlying factor structure of the home literacy environment (HLE) in the English and Spanish versions of the familia inventory: a cautionary tale. Early Child. Res. Q. 26, 475-483. doi: 10.1016/j. ecresq.2010.12.001

Heiland, F., Price, J., and Wilson, R. (2017). Maternal employment and time investments in children. Rev. Econ. Househ. 15, 53-67. doi: 10.1007/s11150014-9278-1

Justice, L., Skibbe, L. E., McGinty, A. S., Piasta, S. B., and Petrill, S. (2011). Feasibility, efficacy, and social validity of home-based storybook reading intervention for children with language impairment. J. Speech Lang. Hear. Res. 54, 523-538. doi: 10.1044/1092-4388(2010/09-0151) 
Kalil, A., Ryan, R., and Chor, E. (2014). Time investments in children across family structures. Ann. Am. Acad. Polit. Soc. Sci. 654, 150-168. doi: 10.1177/ 0002716214528276

Korat, O., Klein, P., and Segal-Drori, O. (2007). Maternal mediation in book reading, home literacy environment, and children's emergent literacy: a comparison between two social groups. Read. Writ. 20, 361-398. doi: 10.1007/ s11145-006-9034-x

Lederer, S. H. (2001). Efficacy of parent-child language group intervention for late-talking toddlers. Infant Toddler Intervention 11, 223-236.

Mammen, K. (2011). Fathers' time investments in children: do sons get more? J. Popul. Econ. 24, 839-871. doi: 10.1007/s00148-009-0272-5

Manolitsis, G., Georgiou, G. K., and Tziraki, N. (2013). Examining the effects of home literacy and numeracy environment on early reading and math acquisition. Early Child. Res. Q. 28, 692-703. doi: 10.1016/j.ecresq.2013. 05.004

Muenks, K., Miele, D. B., Ramani, G. B., Stapleton, L. M., and Rowe, M. L. (2015). Parental beliefs about the fixedness of ability. J. Appl. Dev. Psychol. 41, 78-89.

Neidell, M. J. (2000). Early Parental time Investments in Children's Human Capital Development: Effects of time in the First year on Cognitive and Non-Cognitive Outcomes. UCLA Department of Economics Working Paper, 806 Los Angeles, CA: University of California.

Niklas, F., Cohrssen, C., and Tayler, C. (2016). Improving preschoolers' numerical abilities by enhancing the home numeracy environment. Early Educ. Dev. 27, 372-383. doi: 10.1080/10409289.2015.1076676

Organisation for Economic Co-operation and Development (2015). In It Together: Why Less Inequality Benefits All. Paris: OECD.

Organisation for Economic Co-operation and Development (2020a). Family Database. Available online at: https://stats.oecd.org/Index.aspx? DataSetCode= FAMILY (accessed March 2, 2020).

Organisation for Economic Co-operation and Development (2020b). Income Inequality. Available online at: https://data.oecd.org/inequality/incomeinequality.htm (accessed March 2, 2020).
Roberts, M. Y., and Kaiser, A. P. (2011). The effectiveness of parent-implemented language interventions: a meta-analysis. Am. J. Speech Lang. Pathol. 20, 180199. doi: 10.1044/1058-0360(2011/10-0055)

Rowe, M. L. (2008). Child-directed speech: relation to socioeconomic status, knowledge of child development and child vocabulary skill. J. Child Lang. 35, 185-205. doi: 10.1017/s0305000907008343

Rowe, M. L., and Leech, K. A. (2018). A parent intervention with a growth mindset approach improves children's early gesture and vocabulary development. Dev. Sci. 22:e12792. doi: 10.1111/desc.12792

Sayer, L. C., and Gornick, J. C. (2012). Cross-national variation in the influence of employment hours on child care time. Eur. Sociol. Rev. 28, 421-442. doi: 10.1093/esr/jcr008

Sisk, V. F., Burgoyne, A. P., Sun, J., Butler, J. L., and Macnamara, B. N. (2018). To what extent and under which circumstances are growth mind-sets important to academic achievement? Two meta-analyses. Psychol. Sci. 29, 549-571. doi: 10.1177/0956797617739704

Wagner, M., Spiker, D., and Linn, M. I. (2002). The effectiveness of the Parents as Teachers program with low-income parents and children. Topics Early Child. Spec. Educ. 22, 67-81. doi: 10.1177/02711214020220020101

World Bank (2020). GINI Index (World Bank estimate) - United States. Available at: https://data.worldbank.org/indicator/SI.POV.GINI?locations=US (accessed March 2, 2020).

Conflict of Interest: The authors declare that the research was conducted in the absence of any commercial or financial relationships that could be construed as a potential conflict of interest.

Copyright (c) 2020 Justice, Purtell, Bleses and Cho. This is an open-access article distributed under the terms of the Creative Commons Attribution License (CC BY). The use, distribution or reproduction in other forums is permitted, provided the original author(s) and the copyright owner(s) are credited and that the original publication in this journal is cited, in accordance with accepted academic practice. No use, distribution or reproduction is permitted which does not comply with these terms. 
OPEN ACCESS

Edited by:

Ying Guo,

University of Cincinnati, United States

Reviewed by:

Christian Tarchi,

University of Florence, Italy

Kelly Farquharson,

Florida State University, United States

*Correspondence: Frank Niklas

niklas@psy.Imu.de

Specialty section:

This article was submitted to Educational Psychology,

a section of the journal

Frontiers in Psychology

Received: 03 March 2020

Accepted: 16 June 2020

Published: 21 July 2020

Citation:

Niklas F, Wirth A, Guffler $S$

Drescher N and Ehmig SC (2020) The Home Literacy Environment as

a Mediator Between Parental

Attitudes Toward Shared Reading

and Children's Linguistic Competencies

Front. Psychol. 11:1628 doi: 10.3389/fpsyg.2020.01628

\section{The Home Literacy Environment as a Mediator Between Parental Attitudes Toward Shared Reading and Children's Linguistic Competencies}

\author{
Frank Niklas ${ }^{1 *}$, Astrid Wirth ${ }^{1}$, Sabrina Guffler ${ }^{2}$, Nadja Drescher ${ }^{2}$ and Simone C. Ehmig ${ }^{3}$ \\ ${ }^{1}$ Department of Psychology, Ludwig-Maximilians-University, Munich, Germany, ${ }^{2}$ Department of Educational Psychology, \\ Julius-Maximilians-University, Würzburg, Germany, ${ }^{3}$ German Reading Foundation, Mainz, Germany
}

The home learning environment plays an important role for children's early competencies development. In particular, the early home literacy environment (HLE) that consists of all literacy resources and interactions in a family that support children's linguistic and literacy learning is closely associated with children's language comprehension and production. A key aspect of the HLE is shared reading that should start early in children's life and should be part of a regular routine in the family. However, parental attitudes toward (shared) reading have hardly been analyzed.

In this longitudinal study, we analyzed the associations between parental attitudes toward shared reading and children's linguistic competencies and whether these associations may be mediated by the HLE. Further, we were interested in changes of parental attitudes over time and their association with child and family background characteristics. The sample consisted of $N=133$ children with an average age of about 3 years at $\mathrm{t} 1$. Children were tested two more times with a 6-month period inbetween each assessment. Parental attitudes toward shared reading, socioeconomic status (SES), and the HLE were assessed via parental survey. Children's sentence comprehension, productive language, and grammar were measured with a standardized test battery. Children whose parents had a more positive attitude toward shared reading not only lived in a greater quality HLE but also performed better in the linguistic tests. In a structural equation model, an indirect effect was found showing that the HLE mediated the effect of parental attitudes on children's linguistic competencies. Further, parental attitudes toward shared reading did not change significantly across t1 to t3, and a lower score in the SES scale was associated with a less positive attitude toward shared reading. Consequently, parental attitudes toward shared reading seem to be an important basis for individual differences in the quality of the HLE and also for children's linguistic competencies. As these attitudes vary in the context of different family SES backgrounds, they may be a good target for interventions to support the quality of the HLE and young children's linguistic learning.

Keywords: home literacy environment, parental attitude toward reading, linguistic competencies, kindergarten children, development of early child competencies 


\section{INTRODUCTION}

Attitudes are of great interest for psychologists and educators as attitudes influence our perception and may have an impact on our behavior (cf. Eysenck, 2004; Schwarz, 2007). In the family context, parental attitudes play a major role for young children as parents are very attractive role models for their children (cf. Niklas, 2015). Further, parents create the environment their children experience, and thus parental attitudes are most likely to influence the home learning environment and children's learning within this context (e.g., Bingham, 2007; Park, 2008; Skibbe et al., 2008).

Shared reading with children is a key aspect of the home literacy environment (HLE) that supports children's development of linguistic and literacy competencies (Niklas et al., 2016b). However, although shared reading is deemed important by most parents in Germany, some children, and in particular, children from families with a low socioeconomic status (SES), are rarely read to (German Reading Foundation, 2010). As maternal literacy beliefs are closely associated with the HLE and child outcomes (Weigel et al., 2006), such attitudes may be a good target for interventions.

In this study, we analyze the associations of parental attitudes toward shared reading, the quality of the HLE, and young children's linguistic outcomes in a longitudinal design. Further, we were interested in whether parental attitudes change across 1 year and whether these attitudes were associated with child and family characteristics.

\section{The Development of Children's Early Linguistic Competencies}

An important early linguistic ability is the ability to understand spoken language, often referred to as language comprehension skills. Language comprehension skills consist of basic abilities such as the activation of word meanings and understanding sentences, of receptive vocabulary, the knowledge of text and sentence structures, and language production skills such as children's expressive vocabulary (Lepola et al., 2016; Niklas et al., 2016a). Both receptive and expressive language skills are closely related (e.g., Cutting and Dunn, 1999). Further, these abilities are highly stable competencies from kindergarten age onward (Whitehurst and Lonigan, 2001).

In their concept of emergent literacy, Whitehurst and Lonigan (1998) differentiate between such language competencies as outside-in skills and inside-out skills such as phonological awareness and letter knowledge. Indeed, inside-out skills are also important predictors of later reading and writing abilities; however, these skills develop at a later age and are not formally taught in German kindergartens and preschools (Niklas and Schneider, 2015). As our analytic sample consists of 3- to 4-yearold children, we only focus on outside-in skills.

Early linguistic and literacy competencies are essential for a successful school career, and precursors of these abilities develop long before children enter school. An early assessment of these skills is preferable, as specific precursors of later literacy competencies such as language comprehension and production are important predictors of academic performance in school (e.g., Joshi, 2005; Juel, 2006; Claessens et al., 2009). Consequently, precursors of literacy abilities and children's later literacy competencies lie on a continuum (e.g., Torppa et al., 2007; Lepola et al., 2016). Further, individual differences in vocabulary and language comprehension skills in early years predict not only later reading abilities but also motivational and behavioral outcomes in children (Laitinen et al., 2017).

\section{The Home Literacy Environment and Early Linguistic Competencies}

Children develop early linguistic competencies during the interaction with their parents (Vygotsky, 1978). Consequently, the HLE provides numerous opportunities for teaching and learning activities that support the development of children's linguistic and literacy abilities (Niklas and Schneider, 2017a). The HLE is a multifaceted construct comprising current parental reading habits, shared reading habits in the family, and more general aspects of family literacy such as the frequency of library visits and the number of books in a household. These aspects can be further differentiated into a cultural capital and a cultural praxis (e.g., Niklas et al., 2013). Whereas in the context of the HLE cultural capital refers to the number of books and children's books in a household, cultural praxis consists of all literacy activities in the family such as shared reading. Both aspects are closely associated; however, they may still differ in the role they play for the development of children's linguistic competencies (e.g., McElvany et al., 2009).

The association between the HLE and children's linguistic and literacy competencies is also evident in intervention studies that try to enhance the quality of the HLE to support children's competency development. Indeed, various family literacy programs have demonstrated small to large effects (e.g., Harper et al., 2011; Lever and Sénéchal, 2011). For instance, Niklas and Schneider $(2015,2017 b)$ showed that even nonintensive interventions that just comprised one parent evening and one individual session may change the HLE and subsequently impact on children's development of their vocabulary and phonological awareness.

The observation that the HLE and subsequent child competencies can be improved by interventions has been also confirmed in comprehensive meta-analyses. Sénéchal and Young (2008) and Mol et al. (2008) each analyzed 16 intervention studies that focused either on parental involvement in kindergarten and primary school children's development of reading and spelling abilities or on dialogic reading (for more information on dialogic reading, see Cohrssen et al., 2016) and its effect on children's vocabulary. Mean effect sizes of Cohen's $d=0.65$ and 0.42 , and thus small to medium effects were found. Consequently, the HLE is a very important factor in children's development of linguistic and literacy competencies.

\section{Parental Attitudes Toward Shared Reading}

Some studies explicitly regard parental attitudes toward literacy as an aspect of a broader construct of the HLE (e.g., 
Niklas and Schneider, 2017b) or differentiate between the HLE and these attitudes as separate variables (e.g., Park, 2008), whereas in other studies on the HLE, attitudes are not taken into account (e.g., Niklas and Schneider, 2013). As children learn by interacting with and observing more knowledgeable others, in the early years often their parents (Vygotsky, 1978), they also take notice of parental attitudes displayed during these interactions and observations. Parents act as important role models for their young children (Bandura, 1977), and their attitudes are very likely to impact on children's own attitudes and interests. Consequently, it is to be expected that parental attitudes toward shared reading shape children's interest in literacy and books and in turn may also impact on children's linguistic and literacy competencies (Bingham, 2007; Skibbe et al., 2008). Therefore, parental attitudes toward reading and literacy in general, and in families with young children, the attitudes toward shared reading, specifically, may be important for children's development (Weigel et al., 2006; cf. Niklas, 2015).

According to the model of Zanna and Rempel (1988), objects are evaluated according to three different components: (1) cognitive, (2) affective, and (3) behavioral. In regard to shared reading, this model implies that parents will put a certain value on shared reading, will feel more or less positive about it, and finally, initiate shared reading session more or less often with their children and in a way that triggers more or less reading motivation. The attitude toward shared reading develops over time, may change from situation to situation, and will be closer associated with actual behavior when specific and concrete attitudes are assessed (cf. Schwarz and Bohner, 2001). However, given that attitudes also comprise a behavioral component, it is likely that parental attitudes toward shared reading will be closely associated with the HLE, in particular with the cultural practice (cf. Niklas et al., 2013). Actually, in a study by Tambyraja et al. (2017), caregivers' own reading habits were a predictor of the general HLE in the family.

The development of parental attitudes toward shared reading depends on various experiences the parents had encountered such as their own shared reading experiences as children and in general their socialization (cf. Eysenck, 2004). Consequently, it is to be expected that the attitude toward shared reading should be associated with the socioeconomic status (SES) of the family (e.g., Park, 2008; Skibbe et al., 2008; Becker and McElvany, 2018), similar to the association of the SES with the HLE (Aikens and Barbarin, 2008; Niklas et al., 2013). When trying to tackle different linguistic and literacy outcomes of children from different family backgrounds, parental attitudes might be a worthwhile target.

\section{Research Focus}

The association between the HLE and children's early and later linguistic and literacy outcomes is well established (e.g., Sénéchal and LeFevre, 2002; Niklas and Schneider, 2013; Hemmerechts et al., 2017). However, less is known about the role parental attitudes toward shared reading play in this association, in particular for younger children (for an example, see Bingham, 2007). Further, it is still not clear whether we see changes in these attitudes across time and whether they are associated with child and family characteristics as many studies in this context only used cross-sectional data (e.g., Park, 2008; Hemmerechts et al., 2017).

We analyzed the development of child competencies across a 1-year period and assessed parental attitudes toward shared reading, the HLE, and linguistic outcomes. Here, we expected the parental attitudes toward reading and the quality of the HLE to be stable across the 1-year period (cf. Niklas, 2015). Further, we expected that a more positive attitude toward shared reading and a greater quality in the HLE should be associated with greater linguistic competencies in children. Finally, we assumed that the HLE should act as a mediator between parental attitudes and child outcomes.

\section{MATERIALS AND METHODS}

\section{Sample}

In total, $N=133$ children were assessed using a longitudinal research design with three measurement points (t1-t3) across 12 months (6 months in-between each measurement). Power analysis with $G^{*}$ Power (Faul et al., 2007) indicated a sample size above $N=129$ participants to be sufficient for the planned analyses. At $\mathrm{t} 1$, children were between 26 and 45 months old $(M=36.6, \mathrm{SD}=4.1)$. In the sample, gender was almost equally distributed, with $46 \%$ girls $(N=61)$. More than a third of the children $(37.6 \%, N=50)$ had a migration background with at least one parent being born outside of Germany.

All participating parents were asked about their occupation and their partner's occupation to assign prestige values to these occupations (Wegener, 1988; cf. Christoph, 2005). Here, values ranged from 20 (an unskilled laborer) to 186.8 (a physician), and for the analyses, the highest prestige score in the household was used. Information about the SES could be obtained from $N=122$ families with a mean of $M=86.86(\mathrm{SD}=40.53)$, a value assigned to the occupation of a salesman.

\section{Procedure}

Formal consent to conduct the study was obtained from the center coordinators and parents, and ethics approval was obtained from the University of Würzburg, Germany. Randomly selected kindergartens in two German states were contacted and invited to participate in our study. In Germany, most children are enrolled in kindergarten from 2 to 3 years of age until the beginning of formal schooling at the age of 6. Kindergarten refers to a nursery school or preschool setting, with a focus on playing and practical activities (see further Niklas et al., 2018). $N=21$ kindergartens agreed to participate and handed out information and consent forms for all parents with children in the age group between 26 and 45 months. In each participating kindergarten, between $N=4$ and $N=13$ children (and their parents) participated in our study. At each measurement point, trained psychologists assessed children's competencies in their kindergartens, whereas parents were asked to fill in surveys. Parental response rates lay between $84.1 \%$ and $75.8 \%$ for each measurement point (between $N=21$ and $N=32$ parents did not return the 
survey). Between $N=12$ and $N=21$ of the study children could not be tested at least once due to absence or refusal to participate. We address the handling of missing data in our analytic approach.

\section{Surveys and Test Instruments}

At each measurement point, parents were asked about their family's HLE and their attitude toward shared reading. Further, they were asked to provide information about their family background.

\section{Home Literacy Environment}

The HLE survey was an adapted version of a survey used by Niklas et al. (2016a). This survey contained seven items covering different facets of the HLE: the number of books at home, the number of children's books at home, the frequency of reading to the child and the frequency of both parents' own reading, the frequency of the child looking at picture books, and the frequency of library visits with the child. Each item had a range from 0 to 4 . Both items concerning the number of (children's) books at home were used to estimate the cultural literacy capital in a family (example: "How many children's books does your child own?"), whereas the remaining five items assessed a family's cultural literacy praxis (example: "How often do you read to your child?"; cf. Niklas et al., 2013). The cultural capital scale had a maximum attainable sum score of 8 , with Cronbach's $\alpha=0.78$ at $\mathrm{t} 1,0.86$ at $\mathrm{t} 2$, and 0.84 at $\mathrm{t} 3$. The cultural praxis scale had a maximum attainable sum score of 20, with Cronbach's $\alpha=0.67$ at $\mathrm{t} 1,0.60$ at $\mathrm{t} 2$, and 0.65 at $\mathrm{t} 3$. The sum score of the global HLE scale was a reliable measure (Cronbach's $\alpha=0.78$ at $\mathrm{t} 1,0.74$ at $\mathrm{t} 2$, and 0.71 at $\mathrm{t} 3$ ) with a maximum attainable score of 28 . Retest reliability for the global HLE scale was high, with $r_{12}=0.80, r_{13}=0.71$, and $r_{23}=0.79$.

\section{Parental Attitudes}

In the parent survey, 11 items assessed attitudes, behaviors, and family situations in the context of shared reading. We conducted an exploratory factor analysis in SPSS to identify common factors. Only the first factor explained a major part of the variance, and four items on cognitive attitudes loaded on this factor. All other items either did not load on a specific factor or were the only items to load on an additional factor. Consequently, we assessed parental attitudes toward shared reading with four items on 5point Likert scales. The items ranged from 0 (I do not agree) to 4 (I agree completely). Here, all items focused on cognitive attitudes toward shared reading and assessed the value attached to reading at home, perceived interest in reading by the child, and parental motivation toward reading and shared reading (item example: "Reading is regarded as an important activity at our home"). The parental attitudes toward shared reading subscale had a maximum attainable sum score of 16, with Cronbach's $\alpha=0.90$ at $\mathrm{t} 1,0.90$ at $\mathrm{t} 2$, and 0.86 at $\mathrm{t} 3$. Parental attitudes toward shared reading were fairly stable across $\mathrm{t} 1$ to $\mathrm{t} 3$, with $r_{12}=0.60$, $r_{13}=0.73$, and $r_{23}=0.71$. The four items assessing cognitive attitudes toward shared reading had been used in previous studies (e.g., Park, 2008; Niklas et al., 2016a; Wirth et al., 2019).

\section{Linguistic Abilities}

Children's level of linguistic abilities was assessed with the standardized German language development test instrument SETK 3-5 (Grimm et al., 2010) that comprises subscales for language comprehension and language production. Reliability (Cronbach's $\alpha$ ) was at least $\alpha=0.70$ for each subscale (Neugebauer and Becker-Mrotzek, 2013). Each subtest started with a sample item to demonstrate how to approach the question and to provide feedback for the child. During the test phase, no further feedback was given.

At $\mathrm{t} 1$ and $\mathrm{t} 2$, the language comprehension scale consisted of three subtests. In the first one, children were asked to select a picture out of four similar pictures, matching the sentence that had been read out to them (nine items, maximum attainable score of 9). In the following two subtests, children were asked to act according to short instructions (for example, "Put the red buttons on the box"). Both subtests consisted of five items each, with a maximum attainable score of 5 , respectively. At $\mathrm{t} 3$, subtest 1 was omitted due to children's age and according to the test manual and instead another five items were added in which children were asked to act according to more complex instructions (for example, "The yellow ball, that is pushed by the white ball, falls from the table"). Consequently, the attainable maximum score was lower at $\mathrm{t} 3$ compared to $\mathrm{t} 1$ and $\mathrm{t} 2$.

Language production consisted of two subtests for $t 1$ and $t 2$, assessing the encoding of semantic relations and morphological rule-making. Both subtests were $z$-transformed and summed up into the language production scale at $t 1$ and $t 2$. At $t 3$, when all participating children were older than 3 years old, language production was assessed with a more comprehensive morphological rule-making test. To be consistent, this test was also z-transformed.

In the subtest "encoding of semantic relations," children were asked to describe 11 pictures to assess their use of prepositions (for example, "The children walk across the street."). There is no maximum attainable score as children were free to describe pictures with an unlimited number of words, which were counted for each child individually. In the subtest "morphological rule-making," children were asked to say plural forms of different nouns (for example, "car-cars"). Here, the maximum attainable score was 20 at $\mathrm{t} 1$ and $\mathrm{t} 2$ and 36 at $\mathrm{t} 3$ due to eight additional test items.

We created an index score combining both $\mathrm{z}$-transformed language comprehension and language production scales into a general linguistic abilities scale. Retest reliability for the general linguistic abilities was very high, with $r_{12}=0.85, r_{13}=0.75$, and $r_{23}=0.88$.

\section{Non-verbal Intelligence}

In addition to children's age, sex, and their family's SES, all analyses were controlled for children's non-verbal intelligence. Children's non-verbal intelligence was assessed at t1 and t3 with the Columbia Mental Maturity Scale (CMM; Burgemeister et al., 1972), assessing 3- to 5-year-old children's capability for abstraction and logical reasoning. Here, children had to identify the odd picture in an array of three to five pictures (e.g., four identical dogs and one cat), and a maximum 
of 57 points was attainable. Split-half reliability in German contexts ranges from 0.92 to 0.96 , and the CMM proved to be a good indicator of children's general cognitive abilities in recent German studies (Esser, 2002; Hasselhorn et al., 2012; Niklas and Schneider, 2017a).

All descriptive data and the sample sizes for all variables are shown in Table 1.

\section{Analytic Approach}

Data analyses were conducted using SPSS 24 (Ibm Corp, 2016) for descriptive and correlative analyses and Mplus 7 (Muthén and Muthén, 2012) for structural equation modeling (SEM). As some parental surveys were not or only partially completed, and some children's test scores were missing, several cases were incomplete. After analyzing the missing data for patterns, we estimated missing data using the full information maximum likelihood option (MLR estimator) in Mplus.

First, results of bivariate correlational analyses (Pearson's $r$ ) of all study variables for the three measurement points are presented. Here, we analyzed whether parental attitudes and HLE were associated with the control variables and the linguistic outcomes. In a second step, we carried out univariate variance analyses with repeated measurement (rm ANOVA) to test whether parental attitudes toward shared reading and the quality of the HLE varied across $t 1$ to $t 3$.

Finally, we used SEM to analyze the association between parental attitudes toward shared reading and children's linguistic competencies and whether this association may be mediated by the HLE. We examined this association controlling for various child and family characteristics.

\section{RESULTS}

\section{Correlational Analyses}

Table 2 shows the cross-sectional results for the correlational analyses at $\mathrm{t} 1, \mathrm{t} 2$, and $\mathrm{t} 3$.

As expected, significant medium effect size correlations were observed between the HLE with its subscales cultural praxis and cultural capital and children's linguistic abilities at all three measurement points $(r=0.37-0.55)$ as well as large effect size correlations of the HLE with parental attitudes toward shared reading $(r=0.49-0.65)$. Further, linguistic abilities were also significantly correlated with parental attitudes toward shared reading at all three measurement points $(r=0.37-$ 0.39). Children's level of linguistic skills seemed to be partly dependent on other influencing variables, such as age, gender, intelligence, and the family's socioeconomic background (mainly small to medium effect size correlations). Whereas the HLE and parental attitudes toward reading to their children were strongly associated with families' SES ( $r=0.40-0.58)$, the correlations with the other control variables were much smaller and mostly not significant.

\section{Change in Parental Attitudes Toward Shared Reading and the Quality of the Home Literacy Across t 1 to t3}

In order to investigate whether the necessary conditions for rm ANOVA had been met, Mauchly's test of sphericity was conducted. The results indicated that the assumption of sphericity had been violated for parental attitudes, with $\chi^{2}(2)=11.67, p<0.05$. Therefore, a Huynh-Feldt correction was applied. For the HLE, Mauchly's test of sphericity was not violated, with $\chi^{2}(2)=2.02, p<0.05$. We did not find significant effects of time on parental attitudes and the HLE, with $F(2,130)=2.11, p=0.13, \eta^{2}=0.03$ and $F(2,138)=0.01, p=0.99$, $\eta^{2}=0.00$. Consequently, no significant and meaningful change in the quality of the HLE and parental attitudes toward shared reading was observed between $\mathrm{t} 1$ and $\mathrm{t} 3$.

\section{The Association of Parental Attitudes Toward Shared Reading, the Home Literacy Environment, and Children's Linguistic Competencies}

We used SEM to address the main research question concerning the associations between parental attitudes toward shared reading and children's linguistic competencies and whether this association may be mediated by the HLE. In a first model, we tested the direct prediction of linguistic competencies by parental attitudes toward shared reading (Figure 1). Latent variables were

TABLE 1 | Descriptive statistics for the study variables at $\mathrm{t} 1$, $\mathrm{t} 2$, and $\mathrm{t3}$ (sample sizes, means, standard deviations, observed ranges).

\begin{tabular}{|c|c|c|c|c|}
\hline Variables & $N$ & $M$ & SD & Observed range \\
\hline Intelligence & $121 /-/ 112$ & 27.8/-/38.2 & $13.4 /-/ 10.7$ & $0.0-50.0 /-/ 0.0-54.0$ \\
\hline SES $^{1}$ & 122 & 86.89 & 40.84 & $20.00-186.80$ \\
\hline HLE & $108 / 100 / 94$ & $19.2 / 19.5 / 19.4$ & $4.5 / 4.2 / 4.2$ & 5.0-26.0/6.0-26.0/7.0-26.0 \\
\hline HLE-Cultural capital & $111 / 102 / 96$ & $7.02 / 7.15 / 7.29$ & $1.56 / 1.45 / 1.37$ & 2.0-8.0/2.0-8.0/2.0-8.0 \\
\hline HLE-Cultural praxis & $110 / 103 / 103$ & $12.07 / 12.41 / 12.41$ & $3.47 / 3.18 / 3.18$ & 3.0-18.0/3.0-18.0/3.0-18.0 \\
\hline Parental attitudes & $109 / 101 / 94$ & $12.43 / 12.89 / 12.84$ & $3.55 / 3.19 / 2.73$ & 0.0-16.0/3.0-16.0/5.0-16.0 \\
\hline Linguistic abilities ${ }^{2}$ & $114 / 112 / 101$ & 0.53/0.01/0.78 & $3.19 / 3.19 / 3.78$ & -5.5 to $7.8 /-7.6$ to $5.5 /-8.9$ to 7.3 \\
\hline Language comprehension ${ }^{3}$ & $118 / 116 / 112$ & $7.94 / 10.99 / 8.00$ & $4.67 / 5.06 / 4.28$ & 0.0-19.0/0.0-18.0/0.0-15.0 \\
\hline Language production 4 & $115 / 113 / 112$ & $-0.01 / 0.01 / 0.00$ & $1.77 / 1.85 / 1.00$ & -2.9 to $4.1 /-3.7$ to $2.9 /-2.0-1.9$ \\
\hline
\end{tabular}

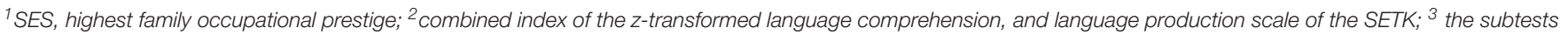

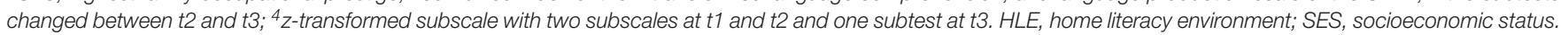




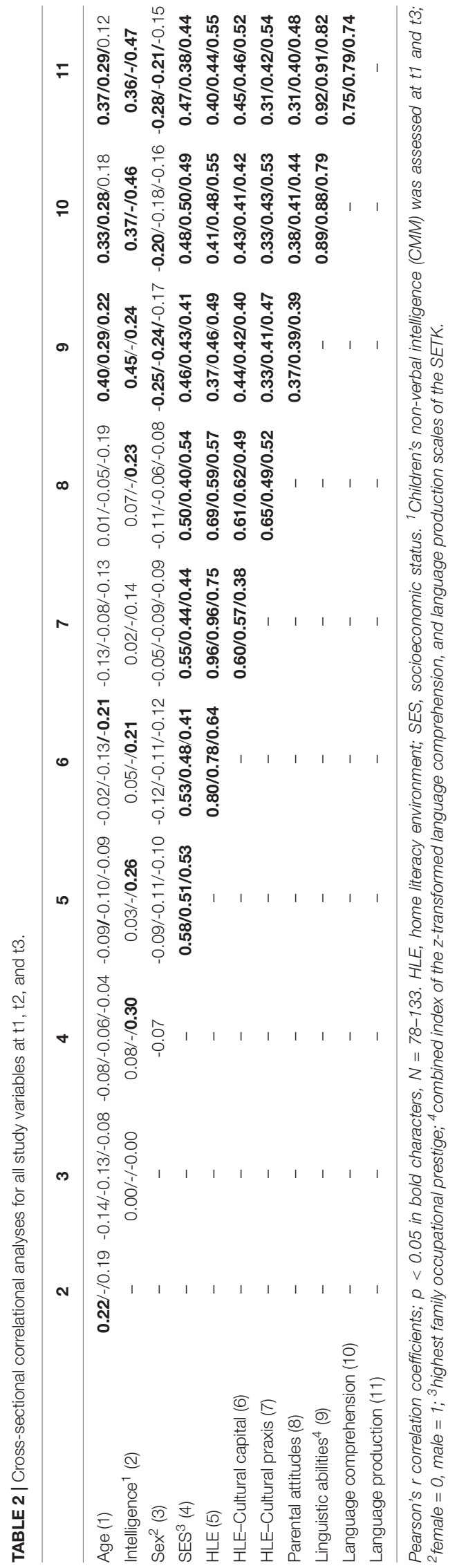

modeled for parental attitudes and children's level of linguistic abilities. Here, parental attitudes were modeled using the four items for cognitive attitudes toward reading, whereas the latent linguistic abilities variable included the language comprehension and language production scales of the SETK. In addition, we controlled for children's age, sex, intelligence, and family's SES. Parental attitudes toward shared reading at $\mathrm{t} 1$ were a significant predictor of children's linguistic abilities at $\mathrm{t} 3$. The proposed model fit the data well, with $\chi^{2}(23)=37.92, p>0.05$, root mean square error of approximation (RMSEA) $=0.07$, comparative fit index (CFI) $=0.97$, Tucker-Lewis index $(\mathrm{TLI})=0.94$, standardized root mean residual $(\mathrm{SRMR})=0.05$.

In the final model (Figure 2), the HLE at $\mathrm{t} 2$ was added as a latent variable. The HLE comprised the cultural capital and cultural praxis subscales, and again we controlled for children's age, sex, intelligence, and family's SES. When the HLE was added as a mediator to the model, parental attitudes toward shared reading were no longer direct significant predictors of children's linguistic abilities. Instead, parental attitudes toward shared reading predicted the HLE, which, in turn, predicted children's linguistic abilities. Consequently, in this full mediation, parents' attitudes toward shared reading at $\mathrm{t} 1$ were significant predictors of children's linguistic abilities at $\mathrm{t} 3$ only indirectly via the HLE at $\mathrm{t} 2$ with a total standardized indirect effect of 0.28 $(p<0.05)$.

In addition, children's age was predictive of their linguistic abilities with a standardized beta coefficient of $0.26(p<0.01)$, but neither children's sex, intelligence, nor the family's SES. However, the family's SES significantly predicted children's HLE with a standardized beta coefficient of $0.37, p<0.01$, and parent's attitudes toward reading with a standardized beta coefficient of $0.57, p<0.001$. No other control variables were significantly associated with the HLE and parent's attitudes. The proposed model fit the data very well, with $\chi^{2}(27)=43.09, p>0.05$, $\mathrm{CFI}=0.98 / \mathrm{TLI}=0.97, \mathrm{SRMR}=0.04, \mathrm{RMSEA}=0.04$.

\section{DISCUSSION}

The home learning environment that young children experience is a good predictor of early and later literacy and numeracy competencies (Melhuish et al., 2008; Niklas and Schneider, 2017a). Here, aspects such as the onset, frequency, and quality of shared reading which can be summarized as cultural praxis and the number of books at home as an indicator for cultural capital are specific predictors of children's linguistic and literacy outcomes (McElvany et al., 2009; Niklas et al., 2013; Niklas, 2015). All these aspects are part of a global HLE construct (e.g., Cohrssen et al., 2016; Wirth et al., 2020). However, not much is known about the association of parental attitudes toward shared reading with the HLE, whether these attitudes should be integrated into a broader construct of the HLE or whether they should be treated as an independent variable, and about the association among attitudes, HLE, and children's linguistic outcomes.

Our findings indicate that whereas the correlations between parental attitudes toward shared reading and the HLE are substantial, there is still reason to differentiate between both 


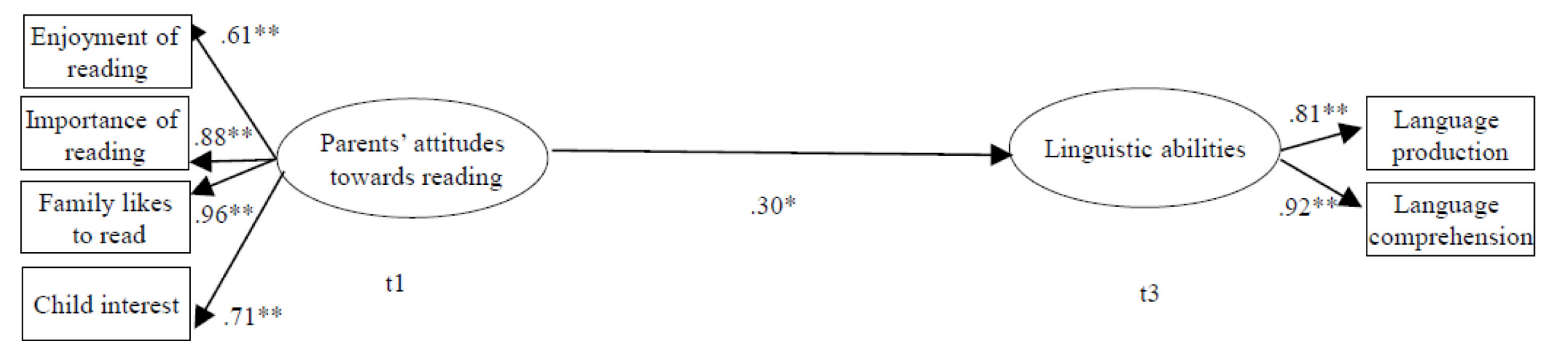

FIGURE 1 | Parental attitudes as a predictor of children's linguistic abilities. $N=133$. Standardized beta coefficients with ${ }^{\star *} p<0.01 ;{ }^{*} p<0.05$. HLE, home literacy environment. All analyses are controlled for age, sex, intelligence, and parental socioeconomic status (SES) (occupational prestige); $\chi^{2}(23)=37.92, p>0.05$, root mean square error of approximation $(\mathrm{RMSEA})=0.07$, comparative fit index $(\mathrm{CFI})=0.97$, Tucker-Lewis Index $(\mathrm{TLI})=0.94$, standardized root mean residual $(\mathrm{SRMR})=0.05$

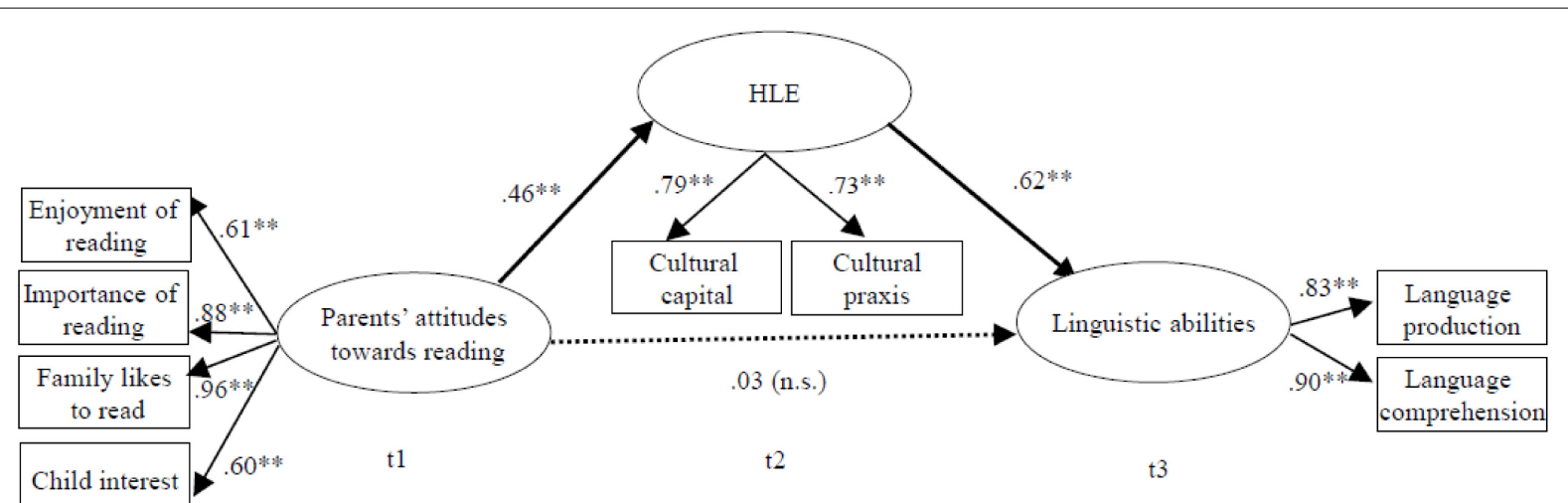

FIGURE 2 | Parental attitudes and their association with children's linguistic abilities mediated by the home literacy environment. $N$ = 133. Standardized beta coefficients with ${ }^{* *} p<0.01$. HLE, home literacy environment. All analyses are controlled for age, sex, intelligence, and parental socioeconomic status (SES) (occupational prestige); root mean square error of approximation (RMSEA) $=0.04$, comparative fit index $($ CFI) $=0.98$, Tucker-Lewis Index (TLI) $=0.97$, standardized root mean residual $(S R M R)=0.04$.

constructs (see also Bingham, 2007; Park, 2008). Further support for this differentiation comes from our SEM, as the fit was very good for our final model (Figure 2) that treated parental attitudes and the HLE as separate latent variables. On the other hand, we found large effect size correlations between both constructs, and therefore, it is comprehensible why some studies combined them (e.g., Niklas and Schneider, 2017b). In our view, both operationalizations may be applied in research, depending on the research focus of a study. Here, it is decisive whether parental attitudes toward shared reading are the main research focus and thus should be considered as independent variables or whether they need to be taken into account, but are not in the center of interest, in which case they could be treated as a part of the global HLE.

Our results indicate that parental attitudes toward shared reading might impact on the quality of the HLE parents provide for their children and that, in turn, the HLE positively influences children's linguistic abilities. Consequently, there was a significant indirect effect of parental attitudes on children's linguistic outcomes mediated by the HLE. Here, our two SEM models indicate that a full mediation takes place. A significant direct path from parental attitudes toward shared reading was found in Model 1, and this significant association disappeared once the HLE was included as a mediator in the model (Figure 2).

Obviously, the specific parental attitudes toward shared reading that were assessed in our parent survey predicted the literacy behavior of parents in the family context and thus shaped the quality of the HLE (cf. Schwarz and Bohner, 2001, see also Tambyraja et al., 2017). Parents with a more positive attitude toward shared reading also seem to read more often themselves, possess more books, and read more frequently to their child (cf. Niklas, 2015). We further replicated the finding that the early HLE is a very important predictor for young children's language comprehension and production and that a greater quality in the HLE leads to greater linguistic competencies of children living in such an a HLE (Sénéchal and LeFevre, 2002; Niklas et al., 2013; Niklas and Schneider, 2015; however, see also Puglisi et al., 2017, for a debate of this causal link). Consequently, our results point out that parental attitudes toward shared reading seem to have an indirect impact on child outcomes via the literacy interactions that occur in the family context.

Given that our sample consisted of young children who are only about to learn inside-out skills such as phonological awareness and letter knowledge, we focused on language 
competencies as an indicator for outside-in skills (cf. Whitehurst and Lonigan, 1998). Here, it would be of great interest to test the associations we found for an older sample and inside-out skills. It could be expected that parental attitudes might play an even more important role for such skills as these are closely associated with the formal HLE and thus with aspects such as parental teaching (Sénéchal and LeFevre, 2002). These formal HLE activities were not assessed in our study and would be an interesting target for future studies on parental literacy attitudes.

Another interesting finding is that the parental attitudes toward shared reading are closely associated with the family SES, similarly to the HLE (Niklas and Schneider, 2013, see also Skibbe et al., 2008). SES-related differences in family literacy attitudes and behaviors were also found in elementary school children (Park, 2008; Becker and McElvany, 2018). Our findings indicate that parents with a higher SES (i.e., more prestigious occupations) tend to put more value to shared reading and seem to provide a greater quality HLE for their children. Consequently, it can be assumed that parental attitudes toward shared reading and HLE might act as a mediator between SES and children's linguistic outcomes (cf. Aikens and Barbarin, 2008; Niklas et al., 2013). In an exploratory SEM analysis, we indeed found significant paths from SES to parental attitudes and the HLE, but the model fit was poorer. The associations between SES, HLE, parental attitudes, and children's linguistic abilities need to be analyzed in future research.

Given that attitudes and behavior can be successfully changed by interventions (for a recent example in the health context, see Abel Mangueira et al., 2019), parental attitudes may be a very good target for educational interventions. Meta-analyses show that interventions in the HLE may have a positive impact on children's linguistic and literacy development (e.g., Mol et al., 2008; Sénéchal and Young, 2008), and successful family literacy interventions often include parental education or general information for parents on how to enhance the quality in the HLE (e.g., Niklas and Schneider, 2017b; cf. Saracho, 2017). Such approaches may change attitudes and actual behavior in parents. As attitudes can be changed more easily than, for instance, the socioeconomic background, interventions in the HLE should always consider parental literacy attitudes.

\section{Limitations}

Some limitations mark this study. First, the information about parental attitudes and the HLE was only assessed via parental survey and thus may be biased due to social desirability. However, our results are similar to the results of other studies that used parental surveys, and such surveys are often reliable measurement instruments (Bingham, 2007; Skibbe et al., 2008). Other assessments such as children's book checklists or direct observations in the families (e.g., Sénéchal and LeFevre, 2002) still may have offered a better insight into the association of attitudes, HLE, and child outcomes.

Second, not all children could be assessed at all measurement points, and some parental information was missing.
Consequently, the correlational analyses and $\mathrm{rm}$ ANOVAs were conducted with a reduced sample. However, the percentage of missing data was similar to those of previous studies on the HLE (e.g., Niklas and Schneider, 2017b). In addition, in our final analyses with SEM, the full information maximum likelihood option in Mplus was applied that takes into account all available information without deleting cases, and thus our results should be reliable.

Third, a small sample of young children participated in our study. Although a power analysis indicated that the sample size was large enough, it would have been preferable to include more children. With a larger sample, it would have been possible to apply a full-forward SEM in which all variables predict all other variables that were assessed at a later time. Further, it would be interesting to assess children with a larger age span to test whether the associations of parental literacy attitudes and the HLE with child linguistic outcomes differ across different age groups. For instance, parents of children who are about to enter school may be more apt to provide a better quality HLE for their children independent of their attitudes toward shared reading. Further, a replication with samples from other countries would be preferable, as the association between our study variables seems to vary across different cultural and economic contexts (Park, 2008).

In addition, our sample was not statistically representative for German children of this age group. However, parental reading habits and the average highest household SES (occupational prestige) in this sample were comparable to other German studies (e.g., Niklas and Schneider, 2017b). Finally, although we included assessments across three measurement points with attitudes assessed at t1, HLE at t2, and linguistic abilities at $\mathrm{t} 3$, we still conducted correlational analyses and thus our findings cannot be interpreted as causal associations, although previous studies also point to a causal relation (cf. Hemmerechts et al., 2017).

\section{Conclusions}

The home learning environment is an important predictor for children's early and later competencies development (Melhuish et al., 2008; Niklas and Schneider, 2017a). Here, shared reading is an important aspect of the HLE and should start early in children's life and should be part of a regular routine in the family (Niklas et al., 2016a; Wirth et al., 2020). However, little work has focused on the role that parental literacy attitudes play in this context (Bingham, 2007; Skibbe et al., 2008).

In this longitudinal study, we analyzed the associations between parental attitudes toward shared reading and children's language comprehension and production and found that this association was mediated by the HLE. Further, families with a high SES report more positive attitudes toward shared reading (see also Park, 2008; Becker and McElvany, 2018), and without interventions, such attitudes seem to remain stable across time. Consequently, parental attitudes toward shared reading seem to be an important basis for individual differences in the quality of the HLE and for children's linguistic competencies and may thus be good targets for family literacy interventions (cf. Saracho, 2017). 


\section{DATA AVAILABILITY STATEMENT}

The datasets generated for this study are available on request to the corresponding author.

\section{ETHICS STATEMENT}

The studies involving human participants were reviewed and approved by the Ethics Committee, Department of Psychology at the University of Würzburg. Written informed consent to

\section{REFERENCES}

Abel Mangueira, F. F., Smania-Marques, R., Dutra Fernandes, I., Alves Albino, V., Olinda, R., Acácia Santos-Silva, T., et al. (2019). The prevention of arboviral diseases using mobile devices: a preliminary study of the attitudes and behaviour change produced by educational interventions. Trop. Med. Int. Health 24, 1411-1426. doi: 10.1111/tmi.13316

Aikens, N. L., and Barbarin, O. (2008). Socioeconomic differences in reading trajectories: the contribution of family, neighborhood, and school contexts. J. Educ. Psychol. 100, 235-251. doi: 10.1037/0022-0663.100.2.235

Bandura, A. (1977). Social Learning Theory. Englewood Cliffs, NJ: Prentice Hall.

Becker, M., and McElvany, N. (2018). The interplay of gender and social background: a longitudinal study of interaction effects in reading attitudes and behavior. Br. J. Educ. Psychol. 88, 529-549. doi: 10.1111/bjep.12199

Bingham, G. E. (2007). Maternal literacy beliefs and the quality of motherchild book-reading interactions: associations with children's early literacy development. Early Educ. Dev. 18, 23-49. doi: 10.1080/10409280701274428

Burgemeister, B., Blum, L., and Lorge, J. (1972). Columbia Mental Maturity Scale. New York, NY: Harcourt Brace Jovanovich.

Christoph, B. (2005). Zur messung des berufsprestiges. aktualisierung der magnitude-prestigeskala auf die berufsklassifikation isco88 [on the assessment of occupational prestige. revision of the magnitude prestige scale in regard to the occupational classification isco88]. ZUMA Nachrichten 29, 79-127.

Claessens, A., Duncan, G., and Engel, M. (2009). Kindergarten skills and fifthgrade achievement: evidence from the ECLS-K. Econ. Educ. Rev. 28, 415-427. doi: 10.1016/j.econedurev.2008.09.003

Cohrssen, C., Niklas, F., and Tayler, C. (2016). 'Is that what we do?'. J. Early Child. Lit. 16, 361-382. doi: 10.1177/1468798415592008

Cutting, A. L., and Dunn, J. (1999). Theory of mind, emotion understanding, language, and family background: individual differences and interrelations. Child Dev. 70, 853-865. doi: 10.1111/1467-8624.00061

Esser, G. (2002). BUEVA - Basisdiagnostik für Umschriebene Entwicklungsstörungen im Vorschulalter [BUEVA - Basis Diagnostics for Developmental Disorders at Pre-School Age]. Göttingen: Beltz.

Eysenck, M. W. (2004). Psychology: an International Perspective. New York, NY: Psychology Press.

Faul, F., Erdfelder, E., Lang, A. G., and Buchner, A. (2007). G* Power 3: a flexible statistical power analysis program for the social, behavioral, and biomedical sciences. Behav. Res. Methods 39, 175-191. doi: 10.3758/bf03193146

German Reading Foundation (2010). Lesefreude trotz Risikofaktoren. Eine Studie zur Lesesozialisation von Kindern in der Familie [Joy of Reading Despite Risk Factors. a Study on the Reading Socialisation of Children in the Family Context]. Mainz: Papers of the German Reading Foundation.

Grimm, H., Aktaş, M., and Frevert, S. (2010). SETK 3-5: Sprachentwicklungstest für drei-bis fünfjährige Kinder (3; 0-5; 11 Jahre); Diagnose von Sprachverarbeitungsfähigkeiten und Auditiven Gedächtnisleistungen; Manual. Göttingen: Hogrefe.

Harper, S., Platt, A., and Pelletier, J. (2011). Unique effects of a family literacy program on the early reading development of english language learners. Early Educ. Dev. 22, 989-1008. doi: 10.1080/10409289.2011.590778

Hasselhorn, M., Schöler, H., Schneider, W., Ehm, J.-H., Johnson, M., Keppler, I., et al. (2012). Gezielte zusatzförderung im modellprojekt "schulreifes kind" auswirkungen auf schulbereitschaft und schulischen lernerfolg [Additional participate in this study was provided by the participants' legal guardian/next of kin.

\section{AUTHOR CONTRIBUTIONS}

SE and FN were the PIs of this study. FN wrote the first draft of the manuscript. AW, ND, and SG were responsible for the acquisition of the data. AW and SG conducted the analyses. All authors contributed to the manuscript revision and read and approved the submitted version.

support in the model project" school readiness in children" - effects on school readiness and academic success]. Frühe Bildung 1, 3-10. doi: 10.1026/21919186/a000019

Hemmerechts, K., Agirdag, O., and Kavadias, D. (2017). The relationship between parental literacy involvement, socio-economic status and reading literacy. Educ. Rev. 69, 85-101. doi: 10.1080/00131911.2016.1164667

Ibm Corp (2016). IBM SPSS Statistics for Windows, Version 24.0. Armonk, NY. Author.

Joshi, R. M. (2005). Vocabulary: a critical component of comprehension. Read. Writ. Q. 21, 209-219. doi: 10.1080/10573560590949278

Juel, C. (2006). The impact of early school experiences on initial reading. Handb. Early Lit. Res. 2, 410-426.

Laitinen, S., Lepola, J., and Vauras, M. (2017). Early motivational orientation profiles and language comprehension skills: from preschool to Grade 3. Learn. Individ. Differ. 53, 69-78. doi: 10.1016/j.lindif.2016.11.002

Lepola, J., Lynch, J., Kiuru, N., Laakkonnen, E., and Niemi, P. (2016). Early oral language comprehension, task orientation, and foundational reading skills as predictors of Grade 3 reading comprehension. Read. Res. Q. 51, 373-390. doi: 10.1002/rrq. 145

Lever, R., and Sénéchal, M. (2011). Discussing stories: on how a dialogic reading intervention improves kindergartners' oral narrative construction. J. Exp. Child Psychol. 108, 1-24. doi: 10.1016/j.jecp.2010.07.002

McElvany, N., Becker, M., and Lüdtke, O. (2009). Die bedeutung familiärer merkmale für lesekompetenz, wortschatz, lesemotivation und leseverhalten [The role of family variables in reading literacy, vocabulary, reading motivation, and reading behaviour]. Zeitschrift für Entwicklungspsychologie und Pädagogische Psychologie 41, 121-131. doi: 10.1026/0049-8637.41. 3.121

Melhuish, E. C., Phan, M. B., Sylva, K., Sammons, P., Siraj-Blatchford, I., and Taggart, B. (2008). Effects of the home learning environment and preschool center experience upon literacy and numeracy development in early primary school. J. Soc. Issues 64, 95-114. doi: 10.1111/j.1540-4560.2008.00550.x

Mol, S. E., Bus, A. G., de Jong, M. T., and Smeets, D. J. H. (2008). Added value of dialogic parentchild book readings: a meta-analysis. Early Educ. Dev. 19, 7-26. doi: 10.1080/10409280701838603

Muthén, L. K., and Muthén, B. O. (2012). Mplus: Statistical Analysis with Latent Variables; User's Guide; [version 7].

Neugebauer, U., and Becker-Mrotzek, M. (2013). Die Qualität von Sprachstandsverfahren im Elementarbereich. Eine Analyse und Bewertung [The quality of linguistic assessment tools in early Childhood. an Analysis and Evaluation], Cologne. Germany: Mercator-Institut für Sprachförderung und Deutsch als Zweitsprache.

Niklas, F. (2015). Die familiäre lernumwelt und ihre bedeutung für die kindliche kompetenzentwicklung [The learning environment provided by the family and its impact on the development of child competencies]. Psychologie in Erziehung und Unterricht 62, 106-120. doi: 10.2378/peu2015.art11d

Niklas, F., Cohrssen, C., and Tayler, C. (2016a). Parents supporting learning: literacy and numeracy in the home learning environment. Int. J. Early Years Educ. 24, 121-142. doi: 10.1080/09669760.2016.1155147

Niklas, F., Nguyen, C., Cloney, D., Tayler, C., and Adams, R. (2016b). Selfreport measures of the home learning environment in large scale research: measurement properties and associations with key developmental outcomes. Learn. Environ. Res. 19, 181-202. doi: 10.1007/s10984-016-9206-9 
Niklas, F., Cohrssen, C., Vidmar, M., Segerer, R., Schmiedeler, S., Galpin, R., et al. (2018). Early childhood professionals' perceptions of children's school readiness characteristics in six countries. Int. J. Educ. Res. 90, 144-159. doi: 10.1016/j.ijer. 2018.06.001

Niklas, F., Möllers, K., and Schneider, W. (2013). Die frühe familiäre lernumwelt als mediator zwischen strukturellen herkunftsmerkmalen und der basalen lesefähigkeit am ende der ersten klasse [The early home learning environment as mediator between structural family characteristics and basic reading abilities at the end of Grade 1]. Psychologie in Erziehung und Unterricht 60, 94-111. doi: 10.2378/peu2013.art08d

Niklas, F., and Schneider, W. (2013). Home literacy environment and the beginning of reading and spelling. Contemp. Educ. Psychol. 38, 40-50. doi: 10.1016/j. cedpsych.2012.10.001

Niklas, F., and Schneider, W. (2015). With a little help: improving kindergarten children's vocabulary by enhancing the home literacy environment. Reading and Writing: An Interdisciplinary Journal 28, 491-508. doi: 10.1007/s11145014-9534-Z

Niklas, F., and Schneider, W. (2017a). Home learning environment and development of child competencies from kindergarten until the end of elementary school. Contemp. Educ. Psychol. 49, 263-274. doi: 10.1016/j. cedpsych.2017.03.006

Niklas, F., and Schneider, W. (2017b). Intervention in the home literacy environment and kindergarten children's vocabulary and phonological awareness. First Lang. 37, 433-452. doi: 10.1177/0142723717698838

Park, H. (2008). Home literacy environments and children's reading performance: a comparative study of 25 countries. Educ. Res. Eval. 14, 489-505. doi: 10.1080/ 13803610802576734

Puglisi, M. L., Hulme, C., Hamilton, L. G., and Snowling, M. J. (2017). The home literacy environment is a correlate, but perhaps not a cause, of variations in children's language and literacy development. Sci. Stud. Read. 21, 498-514. doi: 10.1080/10888438.2017.1346660

Saracho, O. N. (2017). Literacy in the twenty-first century: children, families and policy. Early Child Dev. Care 187, 630-643. doi: 10.1080/03004430.2016. 1261513

Schwarz, N. (2007). Attitude construction: evaluation in context. Soc. Cogn. 25, 638-656. doi: 10.1521/soco.2007.25.5.638

Schwarz, N., and Bohner G., (2001). "The construction of attitudes," in Blackwell Handbook of Social Psychology: Intraindividual Processes, eds A. Tesser and N. Schwarz (Oxford: Blackwell), 436-457.

Sénéchal, M., and LeFevre, J. A. (2002). Parental involvement in the development of children's reading skill: a five-year longitudinal study. Child Dev. 73, 445-460. doi: 10.1111/1467-8624.00417

Sénéchal, M., and Young, L. (2008). The effect of family literacy interventions on children's acquisition of reading from kindergarten to grade 3: a meta-analytic review. Rev. Educ. Res. 78, 880-907. doi: 10.3102/0034654308320319
Skibbe, L. E., Justice, L. M., Zucker, T. A., and McGinty, A. S. (2008). Relations among maternal literacy beliefs, home literacy practices and the emergent literacy skills of preschoolers with specific language impairment. Early Educ. Dev. 19, 68-88. doi: 10.1080/10409280701839015

Tambyraja, S. R., Schmitt, M. B., Farquharson, K., and Justice, L. M. (2017). Home literacy environment profiles of children with language impairment: associations with caregiver-and child-specific factors. Int. J. Lang. Commun. Disord. 52, 238-249. doi: 10.1111/1460-6984.12269

Torppa, M., Tolvanen, A., Poikkeus, A. M., Eklund, K., Lerkkanen, M. K., Leskinen, E., et al. (2007). Reading development subtypes and their early characteristics. Ann. Dyslexia 57, 3-32. doi: 10.1007/s11881-007-0003-0

Vygotsky, L. S. (1978). Mind in Society: the Development of Higher Psychological Processes. Cambridge, MA: Harvard University.

Wegener, B. (1988). Kritik des Prestiges [Critique of the Occupational Prestige], Opladen. Germany: Westdeutscher Verlag. doi: 10.1007/978-3-322-85834-4

Weigel, D. J., Martin, S. S., and Bennett, K. K. (2006). Mothers' literacy beliefs: connections with the home literacy environment and pre-school children's literacy development. J. Early Childh. Lit. 6, 191-211. doi: 10.1177/ 1468798406066444

Whitehurst, G. J., and Lonigan, C. J. (1998). Child development and emergent literacy. Child Dev. 69, 848-872. doi: 10.1111/j.1467-8624.1998.tb06247.x

Whitehurst, G. J., and Lonigan, C. J. (2001). Emergent literacy: development from prereaders to readers. Handb. Early Lit. Res. 1, 11-29.

Wirth, A., Ehmig, S. C., Heymann, L., and Niklas, F. (2020). Das vorleseverhalten von eltern mit kindern in den ersten drei lebensjahren in zusammenhang mit familiärer lernumwelt und sprachentwicklung [Reading to children aged 0-3 years and the association with home literacy environment and early language development]. Frühe Bildung 9, 1-7. doi: 10.1026/2191-9186/a000464

Wirth, A., Ehmig, S. C., Drescher, N., Guffler, S., and Niklas, F. (2019). Facets of the early home literacy environment and children's linguistic and socioemotional competencies. Early Educ. Dev. doi: 10.1080/10409289.2019.1706826 (in press).

Zanna, M. P., and Rempel J. K. (1988). “Attitudes: a new look at an old concept," in The Social Psychology of Knowledge, D. Bar-Tal and A. W. Kruglanski (Hrsg.) (New York, NY: Cambridge University Press). (315-334)

Conflict of Interest: The authors declare that the research was conducted in the absence of any commercial or financial relationships that could be construed as a potential conflict of interest.

Copyright (c) 2020 Niklas, Wirth, Guffler, Drescher and Ehmig. This is an open-access article distributed under the terms of the Creative Commons Attribution License (CC BY). The use, distribution or reproduction in other forums is permitted, provided the original author(s) and the copyright owner(s) are credited and that the original publication in this journal is cited, in accordance with accepted academic practice. No use, distribution or reproduction is permitted which does not comply with these terms. 
OPEN ACCESS

Edited by:

Frank Niklas,

Ludwig Maximilian University

of Munich, Germany

Reviewed by:

Heikki Juhani Lyytinen,

University of Jyväskylä, Finland

Simone Lehrl,

University of Bamberg, Germany

*Correspondence:

Tomohiro Inoue

tinoue@cuhk.edu.hk

Specialty section:

This article was submitted to

Educational Psychology,

a section of the journal

Frontiers in Psychology

Received: 30 March 2020

Accepted: 13 July 2020

Published: 31 July 2020

Citation:

Inoue $T$, Manolitsis $G$, de Jong PF, Landerl K, Parrila R and Georgiou GK

(2020) Home Literacy Environment and Early Literacy Development

Across Languages Varying

in Orthographic Consistency.

Front. Psychol. 11:1923.

doi: 10.3389/fpsyg.2020.01923

\section{Home Literacy Environment and Early Literacy Development Across Languages Varying in Orthographic Consistency}

\author{
Tomohiro Inoue ${ }^{1 *}$, George Manolitsis ${ }^{2}$, Peter F. de Jong ${ }^{3}$, Karin Landerl ${ }^{4,5}$, \\ Rauno Parrila ${ }^{6}$ and George K. Georgiou ${ }^{7}$
}

${ }^{1}$ Department of Psychology, Chinese University of Hong Kong, Shatin, Hong Kong, ${ }^{2}$ Department of Preschool Education, University of Crete, Rethymnon, Greece, ${ }^{3}$ Faculty of Social and Behavioural Sciences, University of Amsterdam, Amsterdam, Netherlands, ${ }^{4}$ Institute of Psychology, University of Graz, Graz, Austria, ${ }^{5}$ Department of Cognitive Science, Macquarie University, Sydney, NSW, Australia, ${ }^{6}$ Department of Educational Studies, Macquarie University, Sydney, NSW, Australia, ${ }^{7}$ Department of Educational Psychology, University of Alberta, Edmonton, AB, Canada

We examined the relation between home literacy environment (HLE) and early literacy development in a sample of children learning four alphabetic orthographies varying in orthographic consistency (English, Dutch, German, and Greek). Seven hundred and fourteen children were followed from Grade 1 to Grade 2 and tested on emergent literacy skills (vocabulary, letter knowledge, and phonological awareness) at the beginning of Grade 1 and on word reading fluency and spelling at the end of Grade 1, the beginning of Grade 2, and the end of Grade 2. Their parents responded to a questionnaire assessing HLE [parent teaching (PT), shared book reading (SBR), access to literacy resources (ALR)] at the beginning of Grade 1. Results showed first that PT was associated with letter knowledge or phonological awareness in Dutch and Greek, while ALR was associated with emergent literacy skills in all languages. SBR did not predict any cognitive or early literacy skills in any language. Second, PT and ALR had indirect effects on literacy outcomes via different emergent literacy skills in all languages. These findings suggest that not all HLE components are equally important for emergent literacy skills, reading fluency, and spelling. No specific trend in the role of orthographic consistency in the aforementioned relations emerged, which suggests that other factors may account for the observed differences across languages when children start receiving formal reading instruction in Grade 1.

Keywords: emergent literacy skills, home literacy environment, longitudinal, orthographic transparency, reading fluency, spelling

\section{INTRODUCTION}

Bronfenbrenner's $(1979,1995)$ ecological systems theory of human development emphasizes that in order to understand children's development we need to consider multiple levels of analyses that encompass the child and both proximal, microsystem (e.g., family and school) and distal, macrosystem (e.g., language and culture) environmental factors. In light of this, it is not surprising that previous studies have shown a significant effect of home literacy environment (HLE) on children's language and literacy development across a variety of languages and cultural contexts 
(e.g., de Jong and Leseman, 2001; Silinskas et al., 2012, 2020; Niklas and Schneider, 2013; Inoue et al., 2018; Liu et al., 2018; Zuilkowski et al., 2019). However, despite a growing body of literature on the relations between HLE and children's literacy skills, most existing studies on HLE have been conducted in a single language and cultural context, thereby focusing primarily on microsystem factors only. Indeed, only a few crosslinguistic studies have been conducted and they have been pairwise comparisons between English and another language (e.g., Bruck et al., 1997; Manolitsis et al., 2009; LeFevre et al., 2010; Niklas et al., 2015). No studies have compared longitudinally the relations between HLE and children's literacy skills across multiple cultures and orthographies varying in consistency (Silinskas et al., 2020). Given the reported differences in the frequency of distinct home literacy activities across languages, it remains unclear whether the relations between these HLE components and literacy skills also vary across languages. Thus, in the current study, we examined the role of HLE in early literacy development in a sample of children learning four European alphabetic orthographies varying in orthographic consistency (English, Dutch, German, and Greek).

\section{The Home Literacy Model}

To date, most studies on HLE have been guided by the Home Literacy Model (Sénéchal and LeFevre, 2002; Sénéchal, 2006; Sénéchal et al., 2017), according to which parent-child interactions during home literacy activities are grouped into two categories: code-related (formal) and meaning-related (informal) activities. Code-related activities engage children directly with print through activities such as teaching of reading and spelling. In contrast, meaning-related activities are those for which the meaning carried by the print is the main focus of the activities, such as parents' shared book reading with their children (Sénéchal, 2006). Code-related activities have usually been assessed in terms of frequency of parents' teaching of letters/words, while meaning-related activities have usually been assessed in terms of frequency of shared book reading and access to literacy resources (including the number of children's books at home; see e.g., Sénéchal, 2006; Sénéchal and LeFevre, 2014). Several studies have shown that (a) code-related activities are associated with later reading through letter knowledge and (b) meaning-related activities are associated with later reading through oral language skills including vocabulary (for a review, see Sénéchal et al., 2017).

Previous longitudinal studies have consistently supported these predictions across a wide range of linguistic and cultural contexts (e.g., Lehrl et al., 2013; Manolitsis et al., 2013; Sénéchal and LeFevre, 2014; Hamilton et al., 2016; Niklas and Schneider, 2017a). For example, in a longitudinal study with a sample of English-speaking Canadian children, Sénéchal and LeFevre (2014) found that shared book reading during the kindergarten year predicted growth in receptive vocabulary from kindergarten to Grade 1, whereas the frequency of parent teaching of reading predicted growth in early literacy from kindergarten to Grade 1 and growth in word reading during Grade 1. Similarly, Silinskas et al. (2010a) found that mothers' teaching of reading predicted the development of reading skills among Finnish kindergarten children.

\section{Cross-Linguistic Studies on HLE}

Existing cross-linguistic studies have also provided evidence in support of the important role of HLE in literacy acquisition across languages (Bruck et al., 1997; Manolitsis et al., 2009; Niklas et al., 2015). For example, in a cross-linguistic study with a sample of English- and Greek-speaking children, Manolitsis et al. (2009) found that parents' teaching of letter names and sounds at home (called direct teaching) was associated with letter knowledge in both languages. Niklas et al. (2015) in turn found the associations between home-based literacy activities and children's verbal and cognitive abilities in English-speaking Australian and German children. Moreover, cross-cultural studies based on international survey data [e.g., Progress in International Reading Literacy Study (PIRLS); Program for International Student Assessment (PISA)] have consistently shown robust relationships between the amount of reading materials at home and children's early literacy skills across sociocultural contexts (Chiu et al., 2012; Arya et al., 2014; Araújo and Costa, 2015; Lenkeit et al., 2018; Zuilkowski et al., 2019).

Despite the consistent evidence of positive associations between HLE and children's literacy development (e.g., Hood et al., 2008; Kirby and Hogan, 2008; Silinskas et al., 2010b; Manolitsis et al., 2011; Dulay et al., 2018), the existing studies have some important limitations. First, most previous crosslinguistic studies were pairwise comparisons between English and one other language (Bruck et al., 1997; Manolitsis et al., 2009; Niklas et al., 2015). Indeed, we are not aware of any study directly comparing these relationships between more than two languages varying in orthographic consistency. Additionally, the few crosslinguistic studies that included more than two languages have assessed relatively limited aspects of HLE (e.g., number of books at home) and have covered only one grade level (e.g., Grade 4; see Chiu and McBride-Chang, 2006, 2010). Second, because many previous studies have assessed meaning-related HLE in terms of both frequency of shared book reading and access to literacy resources, it remains unclear whether it is the former or the latter that is driving the relation between meaning-related HLE and children's vocabulary knowledge. In fact, recent studies have shown that access to literacy resources can be a separable construct from shared book reading (e.g., Dulay et al., 2018; Esmaeeli et al., 2019; Zhang et al., 2019) and plays a unique and important role in children's literacy development over and above parent teaching and shared reading (e.g., van Bergen et al., 2017; Vasilyeva et al., 2018; Zuilkowski et al., 2019). Finally, the main focus of previous research on HLE has been on its relationship with reading (e.g., Chiu and McBride-Chang, 2006; Arya et al., 2014; Araújo and Costa, 2015), and there is a dearth of research examining the relationship between HLE and spelling development across languages. This is important as many parents engage not only in reading activities with their children but also in writing activities. For example, Aram and Levin $(2001,2004)$ have shown that maternal writing mediation in kindergarten predicts children's literacy outcomes in school beyond the early literacy measures assessed in kindergarten. 


\section{The Present Study}

In this study, we examined the developmental relations between HLE and literacy skills in a 2-year longitudinal study with children learning four European alphabetic orthographies varying in orthographic consistency: English, Dutch, German, and Greek. These languages were selected to vary widely in their orthographic consistency, namely, English being the most inconsistent, Greek being the most consistent, and Dutch, and German lying in between English and Greek in the orthographic consistency continuum (Seymour et al., 2003; Borgwaldt et al., 2004). Guided by the Home Literacy Model and the previous findings from within- and cross-language studies reviewed above, we expected that (a) parents' teaching of reading and spelling (the code-related activities) would predict letter knowledge and phonological awareness in all languages (Lehrl et al., 2013; Manolitsis et al., 2013; Hamilton et al., 2016; Silinskas et al., 2020), and their association would be stronger in English than in the other languages because children learning to read in English might need more elaborate teaching as its inconsistent graphemephoneme associations cannot be acquired through simple paired associate learning as in consistent orthographies (Manolitsis et al., 2009); (b) shared book reading (the meaning-related activities) would predict vocabulary in all languages (Manolitsis et al., 2013; Sénéchal and LeFevre, 2014; Inoue et al., 2018; Krijnen et al., 2020; Lehrl et al., 2020), but their association would be limited when access to literacy resources is taken into account separately (van Bergen et al., 2017; Zhang et al., 2019); (c) access to literacy resources would be uniquely associated with literacy skills over and above the effects of parent teaching and shared book reading and its effect would be similar across languages (Chiu and McBride-Chang, 2006; Araújo and Costa, 2015), and (d) all of the HLE aspects would have mediated effects on later reading and spelling via emergent literacy skills in all languages (Hamilton et al., 2016; Inoue et al., 2018; Lehrl et al., 2020).

\section{MATERIALS AND METHODS}

\section{Participants}

Our sample consisted of 714 children followed from the beginning of Grade 1 until the end of Grade 2. One hundred and seventy-two children ( 82 girls [47.7\%]; $M_{\text {age }}=75.87$ months at the first measurement point) were native speakers of English and were recruited from six public elementary schools in Edmonton, Canada; 120 children (63 girls [52.5\%]; $M_{\text {age }}=78.52$ months at the first measurement point) were native speakers of Dutch and were recruited from five public elementary schools in Amsterdam, the Netherlands; 184 children (85 girls [46.2\%]; $M_{\text {age }}=79.12$ months at the first measurement point) were native speakers of German and were recruited from five public elementary schools in Graz, Austria; and 238 children (120 girls [50.4\%]; $M_{\text {age }}=76.10$ months at the first measurement point) were native speakers of Greek and were recruited from six public elementary schools in Heraklion, Greece. Our participants were recruited on a voluntary basis (letters of information were sent to the parents of all children attending Grade 1 in the participating schools) and were tested four times: at the beginning and end of Grade 1, and at the beginning and end of Grade 2. By the end of Grade 2, our sample consisted of 157 English-speaking (9\% attrition), 107 Dutch-speaking (11\% attrition), 167 Germanspeaking ( $9 \%$ attrition), and 219 Greek-speaking (8\% attrition) children. In all countries, children start school at 6 years of age. The children in each site came mostly from families of middle socioeconomic background (based on the location of the schools and parents' education), and none were experiencing any intellectual, emotional, or sensory difficulties. Parental and school consent was obtained prior to testing.

\section{Measures}

\section{Parent Teaching}

Two 5-point Likert scale questions were used to assess parent teaching. The first asked "When your child was in Kindergarten, how often did you (or someone else at home) teach him or her to read words?" and parents responded on a scale ranging from Never (0 points) to Daily (4 points). The other question was worded similarly but replaced "to read words" with "to spell words."

\section{Shared Book Reading}

Two 5-point Likert scale questions were used to assess shared book reading. The first asked "When your child was attending Kindergarten, how many hours did you (or someone else) read to your child on a typical weeknight (Monday to Friday)?" and parents responded on a scale ranging from Less than $5 \mathrm{~min}$ a day (0 points) to $2 \mathrm{~h}$ or more (4 points). The other question was worded similarly but replaced "on a typical weeknight (Monday to Friday)" with "on the weekend (Saturday and Sunday)."

\section{Access to Literacy Resources (ALR)}

To assess ALR, we first asked parents to report how many children's books they had at home by using a 5 -point scale $(0=$ none, $1=1-20,2=21-60,3=61-150$, and $4=$ more than 150 books). Second, we asked parents to report how many adult's books they had at home by using a 5 -point scale $(0=$ less than $100,1=100-299,2=300-499,3=500-1000$, and $4=$ more than 1000 books).

\section{Letter Knowledge}

Letter-Sound Knowledge task was administered in each language. Although we also assessed Letter-Name Knowledge, it was at the ceiling in English and for this reason, we only used LetterSound Knowledge in this study. Children were shown each of the uppercase letters on an A4 paper and asked to say what sound each made; short vowel sounds were accepted for vowel letters, and consonant sounds with the following vowel for consonants. The score was the number of correct letter-sounds produced. The maximum score was 26 in English, 24 in Dutch, 22 in German, and 24 in Greek. Reliability of this measure has been reported to be higher than 0.90 in each language.

\section{Phonological Awareness (PA)}

To assess PA, we used Phoneme Elision in each language. The task included four practice items and 24 experimental items designed so as to match items phonologically across languages 
(see Landerl et al., 2019, for more information). Children were presented with one item at a time and then asked to repeat it with a specified phonological unit deleted. The score was the total number correct. Raykov's (2001) omega coefficients for each orthography ranged from 0.84 to 0.91 .

\section{Vocabulary}

Expressive vocabulary from Wechsler Intelligence Scales for Children (WISC; Wechsler, 2003) was used to assess vocabulary. Children were asked to define words of increasing difficulty and their answer in each item was scored with 0 (incorrect), 1 (partly correct), or 2 (fully correct). A participant's score was the sum of scores aggregated across all responded items.

\section{Reading Fluency}

To assess reading ability, we administered a word reading fluency task. We adapted existing reading fluency tasks in each language (English: Torgeson et al., 1999; Dutch: van den Bos et al., 1994; Brus and Voeten, 1995; German: Moll and Landerl, 2010; Greek: Georgiou et al., 2012) by arranging their items in four columns on a page. Children were asked to read as many words as possible within a 60 -s time limit. A practice trial with eight words preceded timed testing to allow children to familiarize themselves with the task demands. A participant's score was the total number of syllables in the correctly read words within the specified time limit. This scoring procedure was necessary because of differences in the length of the words included in each task across languages. Test-retest reliability has been reported to be higher than 0.85 for elementary school children (Brus and Voeten, 1995; Torgeson et al., 1999; Moll and Landerl, 2010; Georgiou et al., 2012).

\section{Spelling}

To assess spelling ability, we adopted an existing spelling to dictation task in each language (English: Wechsler, 2001; Dutch: Geelhoed and Reitsma, 1999; German: Moll and Landerl, 2010; Greek: Mouzaki et al., 2007). The tester first said a target word followed by a sentence in which the target word was embedded, and then repeated the target word. Children were then asked to write the target word in the space provided. The items in each language were ordered in terms of increasing difficulty and a discontinuation rule of six consecutive errors was applied. A participant's score was the total number of correct responses. Internal consistency has been reported to be higher than 0.90 for elementary school children (Geelhoed and Reitsma, 1999; Wechsler, 2001; Mouzaki et al., 2007; Moll and Landerl, 2010).

\section{Procedure}

Letter knowledge, PA, and vocabulary were assessed at the beginning of Grade 1 (Time 1), and word reading fluency and spelling were assessed at the end of Grade 1 (Time 2 ), the beginning of Grade 2 (Time 2), and the end of Grade 2 (Time 3). All testing took place in quiet rooms in the children's school during school hours by trained research assistants. The tests were administered in one session lasting about 25 min. Administration and scoring were standardized across all children and languages.

\section{Statistical Analysis}

First, to test the measurement equivalence of the latent HLE constructs across languages, we evaluated a model of metric invariance (Meredith, 1993), in which factor loadings were set to be equal across languages (Steenkamp and Baumgartner, 1998; Chen, 2007), using Mplus 8 (Muthén and Muthén, 19882017). To identify the model, the variance of each latent factor was fixed to 1 and the mean of each factor was fixed to 0 . Second, to examine the relationships between HLE, children's emergent literacy skills at the beginning of Grade 1 (Time 1), and literacy outcomes at the end of Grade 1 to the end of Grade 2 (Times 2-4), we constructed a longitudinal model (see Figure 1). Additionally, to test whether the associations between HLE and emergent literacy skills differ between languages, we performed multigroup analyses. Finally, to examine the indirect effect of HLE on later literacy outcomes, we conducted mediation analyses (MacKinnon et al., 2007; Hayes, 2013) using a bias-corrected bootstrapping technique with 2,000 resamples (Preacher and Hayes, 2008; Hayes and Scharkow, 2013).

All analyses handled missing data by the full information maximum likelihood estimator implemented in Mplus (Muthén and Muthén, 1988-2017), which has been found to result in trustworthy, unbiased estimates for missing values (Graham, 2009) and represents an adequate means of managing missing data in longitudinal study design (Jeličić et al., 2009). Model fits were examined using chi-square values and four fit indices: the comparative fit index (CFI), the Tucker-Lewis index (TLI), the root-mean-square error of approximation (RMSEA), and the standardized root-mean-square residual (SRMR). A nonsignificant chi-square value, CFI and TLI values above 0.95, RMSEA values below or at 0.06 , and SRMR values below 0.08 indicate good model fit (Kline, 2015).

\section{RESULTS}

\section{Descriptive Statistics and Measurement Invariance}

The descriptive statistics for parent measures are shown in Table 1. We first evaluated a model of metric invariance, in which factor loadings were set to be equal across languages. The results of CFA are shown in Table 2. The model showed an excellent fit, $\chi^{2}=38.85, d f=33, p=0.22$, CFI $=0.99$, TLI $=0.99$, RMSEA $=0.04,90 \% \mathrm{CI}=0.00$ to 0.07 , SRMR $=0.04$, and the factor loadings were all substantial (all $p$ s $<0.001$; see Table 2). Additionally, there was no significant difference in the model fit between the measurement model and the model with free factor loadings for all paths $\left(\Delta \chi^{2}=10.55, d f=9, p=0.31\right)$. These results indicate that our HLE questionnaire showed measurement equivalence across the four languages. The results of one-way ANOVAs with language as a factor showed that parent teaching was more frequent in English than in all other orthographies (Hedges' $g$ s ranged from 0.84 to 1.04 ). Shared book reading was less frequent in Dutch (Hedges' gs ranged from 0.62 to 0.89 ), while ALR was greater in German (Hedges' gs ranged from 0.44 to 0.79 ) than in all other orthographies. The descriptive statistics 


\section{A English}

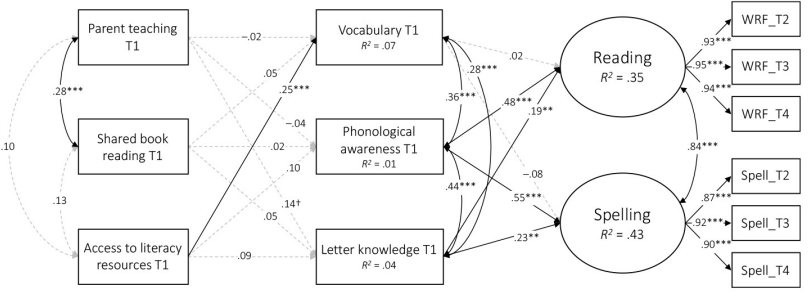

B Dutch

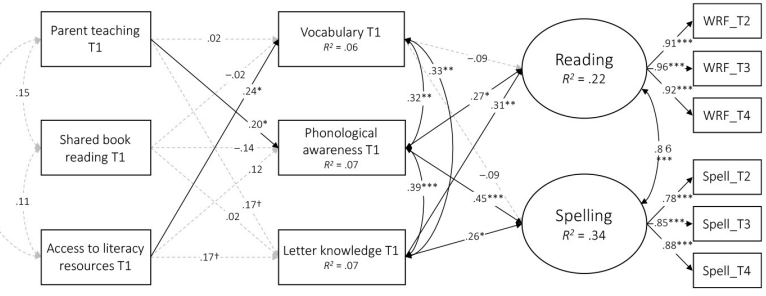

C German

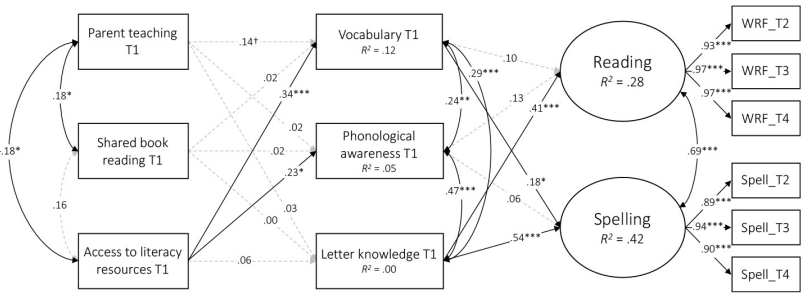

D Greek

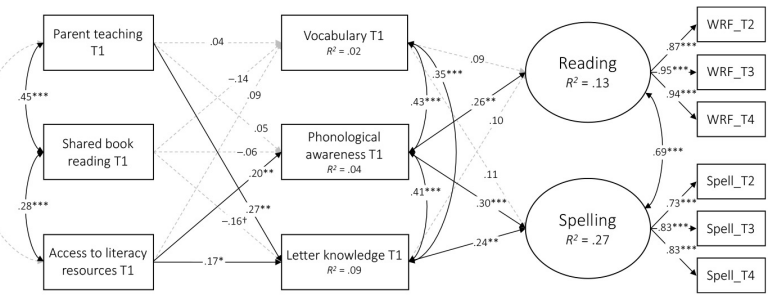

FIGURE 1 | The models for the associations between HLE, emergent literacy skills, and later literacy outcomes in each orthography (standard solution): (A) English; (B) Dutch; (C) German; and (D) Greek. WRF, word reading fluency; T1, Time 1; T2, Time 3; T1, Time 3; T4, Time 4. ${ }^{\dagger} p<0.10,{ }^{*} p<0.05,{ }^{* *} p<0.01$, ${ }^{* * *} p<0.001$.

TABLE 1 | Descriptive statistics for parent measures within each orthography.

\begin{tabular}{|c|c|c|c|c|c|c|c|c|c|c|c|c|}
\hline & \multicolumn{3}{|c|}{ English } & \multicolumn{3}{|c|}{ Dutch } & \multicolumn{3}{|c|}{ German } & \multicolumn{3}{|c|}{ Greek } \\
\hline & $N$ & $M$ & $S D$ & $N$ & $M$ & $S D$ & $N$ & $M$ & $S D$ & $N$ & $M$ & $S D$ \\
\hline Teach to read words ${ }^{1}$ & 172 & 3.06 & 0.94 & 89 & 1.94 & 1.06 & 128 & 1.84 & 1.38 & 174 & 1.91 & 1.23 \\
\hline Teach to print letters/words ${ }^{1}$ & 172 & 2.75 & 0.85 & 90 & 2.18 & 1.01 & 130 & 1.96 & 1.11 & 176 & 2.35 & 1.04 \\
\hline Read to child (weeknight) ${ }^{2}$ & 172 & 1.45 & 0.76 & 90 & 1.17 & 0.48 & 132 & 1.53 & 0.81 & 176 & 1.66 & 0.97 \\
\hline Read to child (weekend) ${ }^{2}$ & 172 & 1.56 & 0.81 & 90 & 1.08 & 0.52 & 132 & 1.92 & 0.92 & 176 & 1.67 & 0.94 \\
\hline Number of children's books ${ }^{3}$ & 172 & 3.09 & 0.88 & 89 & 2.43 & 0.86 & 132 & 2.83 & 0.82 & 173 & 2.31 & 0.84 \\
\hline Number of adults' books ${ }^{4}$ & 172 & 0.95 & 1.02 & 89 & 0.91 & 1.13 & 132 & 1.97 & 1.32 & 174 & 1.18 & 1.12 \\
\hline
\end{tabular}

${ }^{1} \mathrm{O}=$ Never, $4=$ Daily; ${ }^{2} \mathrm{O}=$ Less than $5 \mathrm{~min}$ a day, $4=2 \mathrm{~h}$ or more; ${ }^{3} \mathrm{O}=$ none, $1=1-20,2=21-60,3=61-150$, and $4=$ more than 150 books; ${ }^{4} 0=$ less than 100 , $1=100-299,2=300-499,3=500-1000$, and $4=$ more than 1,000 books.

for child measures are shown in Table 3 and the correlation matrices between all the variables for each orthography are shown in Table 4.

\section{Relations Between Home Literacy Environment, Children's Emergent Literacy Skills, and Later Literacy Outcomes}

Next, a longitudinal structural model was constructed (Figure 1). The model fit the data very well, $\chi^{2}=269.38, d f=178, p<0.001$, $\mathrm{CFI}=0.98$, TLI $=0.96$, $\mathrm{RMSEA}=0.06,90 \% \mathrm{CI}=0.05$ to $0.08, \mathrm{SRMR}=0.05$. Neither parent teaching nor shared book reading was significantly associated with emergent literacy skills in English or German, but parent teaching was in Dutch and Greek. ALR, on the other hand, was significantly associated with emergent literacy skills in all languages. More specifically, parent teaching was uniquely associated with children's phonological awareness in Dutch $(\beta=0.20, p<0.05)$ and letter knowledge in
Greek $(\beta=0.27, p<0.01)$. ALR was uniquely associated with vocabulary in English $(\beta=0.25, p<0.001)$, Dutch $(\beta=0.24$, $p<0.05)$, and German $(\beta=0.34, p<0.001)$. ALR was also associated with PA in German $(\beta=0.23, p<0.05)$ and both PA and letter knowledge in Greek ( $\beta$ s were $0.20, p<0.01$, and 0.17 , $p<0.05$, for PA and letter knowledge, respectively). In contrast, shared book reading did not have a unique association with any outcome measure.

The results of multigroup analyses showed that the fit of the multigroup model deteriorated significantly when the association between parent teaching and letter knowledge was constrained to be equal between German and Greek $\left(\Delta \chi^{2}=4.30, d f=1\right.$, $p<0.05)$. Similarly, when the association between ALR and vocabulary was constrained to be equal between German and Greek, the model fit deteriorated significantly $\left(\Delta \chi^{2}=4.54, d f=1\right.$, $p<0.05)$. Taken together, these results indicate that parent teaching was more strongly associated with letter knowledge in Greek than in German, while ALR was more strongly associated with vocabulary in German than in Greek. 
TABLE 2 | The standardized factor loadings for the measurement model of the HLE questionnaire in each orthography.

\begin{tabular}{|c|c|c|c|c|c|c|c|c|c|c|c|c|}
\hline & \multicolumn{3}{|c|}{ English } & \multicolumn{3}{|c|}{ Dutch } & \multicolumn{3}{|c|}{ German } & \multicolumn{3}{|c|}{ Greek } \\
\hline & PT & SBR & ALR & PT & SBR & ALR & PT & SBR & ALR & PT & SBR & ALR \\
\hline Teach to print letters/words & 0.707 & & & 0.831 & & & 0.844 & & & 0.793 & & \\
\hline Read to child (weeknight) & & 0.642 & & & 0.658 & & & 0.678 & & & 0.634 & \\
\hline Read to child (weekend) & & 0.916 & & & 0.957 & & & 0.997 & & & 0.868 & \\
\hline Internal consistency ${ }^{\mathrm{a}}$ & 0.673 & 0.742 & 0.473 & 0.824 & 0.764 & 0.605 & 0.840 & 0.790 & 0.727 & 0.786 & 0.728 & 0.700 \\
\hline
\end{tabular}

PT, parent teaching; SBR, shared book reading; ALR, access to literacy resources. ${ }^{a}$ Spearman-Brown coefficient.

TABLE 3 | Descriptive statistics for child measures at beginning of grade 1, beginning of grade 2, and end of grade 2 within each orthography.

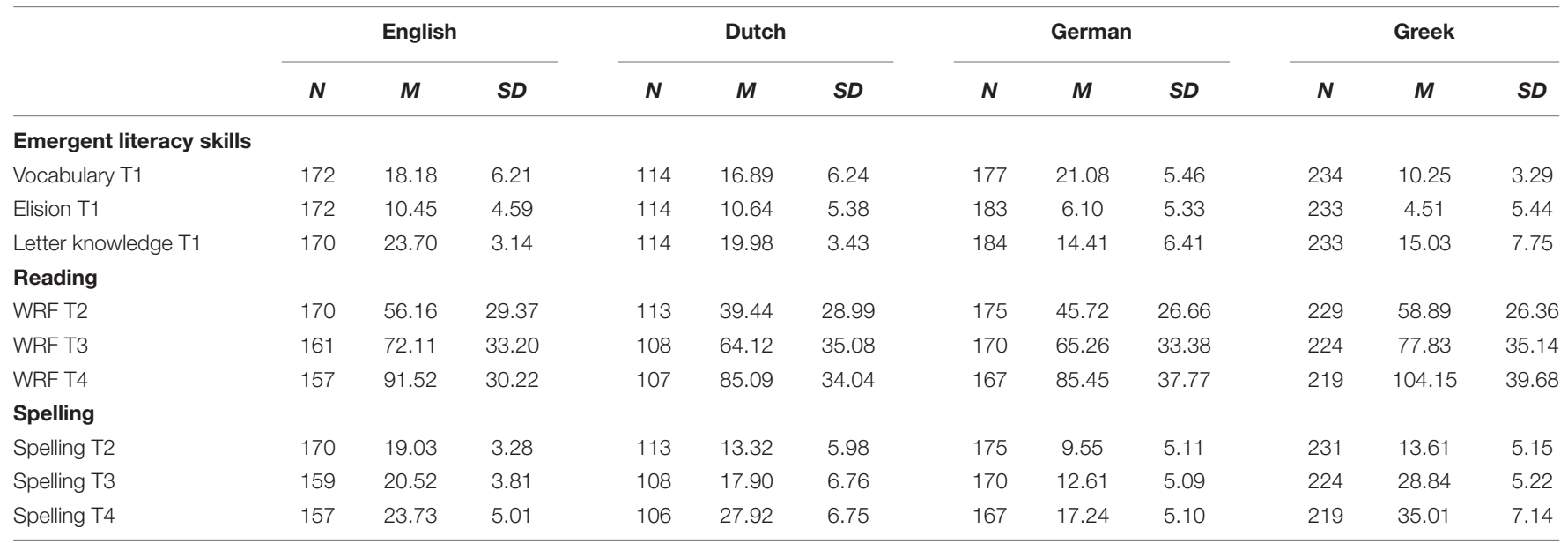

WRF, word reading fluency; T1, Time 1; T2, Time 3; T3, Time 3; T4, Time 4.

Finally, we estimated the indirect effects of HLE on later literacy skills mediated by the emergent literacy skills. The results of mediation analyses for each orthography are shown in Table 5. Parent teaching had an indirect effect on reading via letter knowledge or PA in English and Dutch, while it had an indirect effect on spelling via emergent literacy skills in all languages. Similarly, ALR had an indirect effect on reading via letter knowledge or PA in Dutch and Greek, while it had an indirect effect on spelling via emergent literacy skills in all languages except English. In contrast, shared book reading did not have a significant indirect effect on either literacy outcome.

\section{DISCUSSION}

The purpose of this study was to examine the longitudinal relations between home literacy environment, emergent literacy skills, and later literacy outcomes across alphabetic orthographies varying in orthographic consistency. By doing so, we aimed to reveal whether and to what extent language and culture (elements of the macrosystem in Bronfenbrenner's ecological systems theory) can modulate the relation between HLE (microsystem) and literacy development (behavioral outcomes). The results showed first that neither parent teaching nor shared book reading were uniquely associated with emergent literacy skills in English and German, while parent teaching was in Dutch and Greek. It should be noted, however, that the correlation between parent teaching and letter knowledge was significant in English (see Table 4), albeit weak. We should also keep in mind that children's letter knowledge was assessed with a lettersound knowledge task instead of letter-name knowledge task in this study. As parents usually teach the names of letters to their child more frequently than teaching the sounds of letters (e.g., Martini and Sénéchal, 2012; Inoue et al., 2018), the observed associations between parent teaching and letter knowledge in this study might be somewhat underestimated. Taken together, our findings suggest that, in line with the predictions of the Home Literacy Model and the findings of previous studies in alphabetic orthographies (e.g., Manolitsis et al., 2009, 2013; Hamilton et al., 2016; Inoue et al., 2018), parent teaching was associated with children's code-related skills (letter knowledge and PA) in all included orthographies except German. This result differs from previous findings with German-speaking population (Niklas and Schneider, 2013; Niklas et al., 2015). Given our results showing that parents' teaching was less frequent in German than in all other languages (see Table 1), one possible interpretation would be that German-speaking Austrian parents may follow a low involvement strategy, possibly because they value their 
TABLE 4 | Correlations among the observed variables for each orthography.

\begin{tabular}{|c|c|c|c|c|c|c|c|c|c|c|c|}
\hline & 1 & 2 & 3 & 4 & 5 & 6 & 7 & 8 & 9 & 10 & 11 \\
\hline \multicolumn{12}{|c|}{ English $(N=172)$} \\
\hline \multicolumn{12}{|l|}{ (1) $\mathrm{PT}_{-} \mathrm{T} 1$} \\
\hline (2) SBR_T1 & $0.28^{\star \star}$ & & & & & & & & & & \\
\hline (3) ALR_T1 & 0.10 & 0.12 & & & & & & & & & \\
\hline (4) Voc_T1 & 0.02 & 0.07 & $0.25^{\star \star}$ & & & & & & & & \\
\hline (5) Elision_T1 & -0.02 & 0.02 & 0.09 & $0.37^{\star \star}$ & & & & & & & \\
\hline (6) $L K \_T 1$ & $0.18^{*}$ & 0.10 & 0.11 & $0.29^{\star \star}$ & $0.44^{\star \star}$ & & & & & & \\
\hline (7) WRF_T2 & 0.04 & 0.07 & 0.05 & $0.25^{\star \star}$ & $0.60^{* \star}$ & $0.43^{\star \star}$ & & & & & \\
\hline (8) WRF_T3 & 0.09 & 0.03 & 0.09 & $0.21^{*}$ & $0.56^{\star \star}$ & $0.41^{* \star}$ & $0.86^{\star \star}$ & & & & \\
\hline (9) WRF_T4 & 0.11 & 0.05 & 0.12 & $0.31^{\star *}$ & $0.58^{\star \star}$ & $0.37^{\star \star}$ & $0.87^{\star \star}$ & $0.90^{\star \star}$ & & & \\
\hline (10) Spelling_T2 & -0.01 & 0.07 & 0.05 & $0.18^{\star}$ & $0.54^{\star \star}$ & $0.46^{\star \star}$ & $0.79^{\star \star}$ & $0.72^{\star \star}$ & $0.66^{\star \star}$ & & \\
\hline (11) Spelling_T3 & 0.00 & 0.08 & 0.08 & $0.17^{\star}$ & $0.58^{\star \star}$ & $0.42^{* \star}$ & $0.80^{\star \star}$ & $0.78^{\star \star}$ & $0.74^{\star \star}$ & $0.83^{\star \star}$ & \\
\hline (12) Spelling_T4 & -0.02 & 0.06 & 0.03 & $0.17^{\star}$ & $0.59^{\star \star}$ & $0.34^{* \star}$ & $0.78^{\star \star}$ & $0.79^{\star \star}$ & $0.75^{\star \star}$ & $0.76^{\star \star}$ & $0.82^{\star \star}$ \\
\hline \multicolumn{12}{|l|}{ Dutch $(N=120)$} \\
\hline \multicolumn{12}{|l|}{ (1) $\mathrm{PT} \_\mathrm{T} 1$} \\
\hline (2) SBR_T1 & 0.15 & & & & & & & & & & \\
\hline (3) ALR_T1 & 0.09 & 0.11 & & & & & & & & & \\
\hline (4) Voc_T1 & 0.04 & 0.01 & $0.24^{\star}$ & & & & & & & & \\
\hline (5) Elision_T1 & $0.20^{\dagger}$ & -0.10 & 0.12 & $0.32^{\star \star}$ & & & & & & & \\
\hline (6) $\mathrm{LK}_{-} \mathrm{T} 1$ & $0.19^{\dagger}$ & 0.06 & 0.18 & $0.34^{\star \star}$ & $0.39^{\star \star}$ & & & & & & \\
\hline (7) WRF_T2 & 0.14 & -0.07 & $0.30^{\star \star}$ & 0.13 & $0.38^{\star \star}$ & $0.38^{\star \star}$ & & & & & \\
\hline (8) WRF_T3 & 0.17 & 0.01 & $0.23^{\star}$ & 0.14 & $0.31^{\star \star}$ & $0.31^{\star \star}$ & $0.85^{\star \star}$ & & & & \\
\hline (9) WRF_T4 & $0.20^{\dagger}$ & -0.06 & $0.23^{*}$ & 0.06 & $0.25^{\star}$ & $0.30^{\star \star}$ & $0.80^{\star *}$ & $0.86^{\star \star}$ & & & \\
\hline (10) Spelling_T2 & 0.11 & 0.00 & 0.09 & $0.29^{\star \star}$ & $0.52^{\star \star}$ & $0.36^{\star \star}$ & $0.65^{\star \star}$ & $0.61^{\star \star}$ & $0.53^{\star \star}$ & & \\
\hline (11) Spelling_T3 & 0.18 & -0.06 & 0.13 & 0.08 & $0.46^{\star \star}$ & $0.24^{*}$ & $0.61^{\star \star}$ & $0.60^{\star \star}$ & $0.53^{\star \star}$ & $0.71^{\star \star}$ & \\
\hline (12) Spelling_T4 & 0.19 & -0.04 & 0.11 & 0.09 & $0.39^{\star \star}$ & $0.34^{\star \star}$ & $0.71^{\star \star}$ & $0.72^{\star \star}$ & $0.76^{\star \star}$ & $0.64^{\star \star}$ & $0.69^{\star \star}$ \\
\hline \multicolumn{12}{|c|}{ German $(N=184)$} \\
\hline \multicolumn{12}{|c|}{ (1) $\mathrm{PT} \_\mathrm{T} 1$} \\
\hline (2) SBR_T1 & 0.17 & & & & & & & & & & \\
\hline (3) ALR_T1 & $-0.20^{\star}$ & 0.16 & & & & & & & & & \\
\hline (4) Voc_T1 & 0.10 & 0.12 & $0.32^{\star *}$ & & & & & & & & \\
\hline (5) Elision_T1 & -0.01 & 0.03 & $0.21^{\star}$ & $0.31^{\star \star}$ & & & & & & & \\
\hline (6) $\mathrm{LK} \_\mathrm{T} 1$ & 0.01 & -0.03 & 0.03 & $0.26^{\star \star}$ & $0.45^{\star \star}$ & & & & & & \\
\hline (7) WRF_T2 & -0.12 & 0.16 & $0.29^{\star \star}$ & $0.21^{\star}$ & $0.42^{\star \star}$ & $0.40^{\star \star}$ & & & & & \\
\hline (8) WRF_T3 & -0.09 & 0.14 & $0.27^{\star \star}$ & $0.22^{\star}$ & $0.37^{\star \star}$ & $0.38^{* \star}$ & $0.84^{\star \star}$ & & & & \\
\hline (9) WRF_T4 & -0.07 & $0.21^{\star}$ & $0.22^{*}$ & $0.22^{\star}$ & $0.34^{\star \star}$ & $0.37^{\star \star}$ & $0.84^{\star \star}$ & $0.95^{\star \star}$ & & & \\
\hline (10) Spelling_T2 & -0.11 & 0.08 & $0.31^{\star \star}$ & $0.26^{\star \star}$ & $0.43^{\star \star}$ & $0.49^{\star \star}$ & $0.67^{\star \star}$ & $0.67^{\star \star}$ & $0.66^{\star \star}$ & & \\
\hline (11) Spelling_T3 & -0.03 & 0.04 & $0.28^{\star \star}$ & $0.32^{\star \star}$ & $0.42^{\star \star}$ & $0.52^{\star \star}$ & $0.65^{\star \star}$ & $0.69^{\star \star}$ & $0.70^{\star \star}$ & $0.84^{\star \star}$ & \\
\hline (12) Spelling_T4 & -0.05 & 0.17 & $0.25^{\star}$ & $0.26^{\star \star}$ & $0.34^{\star \star}$ & $0.44^{\star \star}$ & $0.62^{\star \star}$ & $0.67^{\star \star}$ & $0.69^{\star \star}$ & $0.77^{\star \star}$ & $0.83^{\star \star}$ \\
\hline \multicolumn{12}{|l|}{ Greek $(N=238)$} \\
\hline \multicolumn{12}{|l|}{ (1) PT_T1 } \\
\hline (2) SBP_T1 & $0.45^{\star \star}$ & & & & & & & & & & \\
\hline (3) ALR_T1 & 0.11 & $0.27^{\star \star}$ & & & & & & & & & \\
\hline (4) Voc_T1 & 0.00 & -0.08 & 0.07 & & & & & & & & \\
\hline (5) Elision_T1 & 0.06 & 0.03 & $0.20^{*}$ & $0.40^{\star \star}$ & & & & & & & \\
\hline (6) $L K \_T 1$ & $0.23^{\star \star}$ & 0.01 & $0.15^{\dagger}$ & $0.30^{\star \star}$ & $0.44^{\star \star}$ & & & & & & \\
\hline (7) WRF_T2 & 0.07 & -0.05 & $0.19^{*}$ & $0.26^{\star \star}$ & $0.43^{\star \star}$ & $0.33^{\star \star}$ & & & & & \\
\hline (8) WRF_T3 & 0.07 & -0.01 & $0.21^{\star}$ & $0.29^{\star \star}$ & $0.37^{\star \star}$ & $0.26^{\star \star}$ & $0.84^{\star \star}$ & & & & \\
\hline (9) WRF_T4 & 0.06 & -0.03 & 0.12 & $0.24^{\star \star}$ & $0.29^{\star \star}$ & $0.22^{\star \star}$ & $0.83^{\star \star}$ & $0.91^{\star \star}$ & & & \\
\hline (10) Spelling_T2 & 0.12 & 0.04 & $0.14^{\dagger}$ & $0.22^{\star \star}$ & $0.29^{\star \star}$ & $0.25^{\star \star}$ & $0.49^{\star \star}$ & $0.51^{\star \star}$ & $0.47^{\star \star}$ & & \\
\hline (11) Spelling_T3 & 0.11 & -0.06 & $0.16^{\dagger}$ & $0.31^{\star \star}$ & $0.40^{\star \star}$ & $0.31^{\star \star}$ & $0.59^{\star \star}$ & $0.62^{\star \star}$ & $0.58^{\star \star}$ & $0.55^{\star \star}$ & \\
\hline (12) Spelling_T4 & 0.07 & -0.02 & $0.18^{*}$ & $0.33^{\star \star}$ & $0.44^{\star \star}$ & $0.37^{\star \star}$ & $0.62^{\star *}$ & $0.68^{\star \star}$ & $0.67^{\star \star}$ & $0.52^{* \star}$ & $0.69^{* \star}$ \\
\hline
\end{tabular}

PT, parent teaching: SBR, shared book reading; ALR, access to literacy resources; Voc, vocabulary; LK, letter knowledge; WRF, word reading fluency. T1, Time 1; T2, Time 2; T3, Time 3; T4, Time 4. ${ }^{\dagger} p<0.10,{ }^{*} p<0.05,{ }^{* *} p<0.01$. 
TABLE 5 | Indirect effects of HLE on literacy outcomes in each orthography.

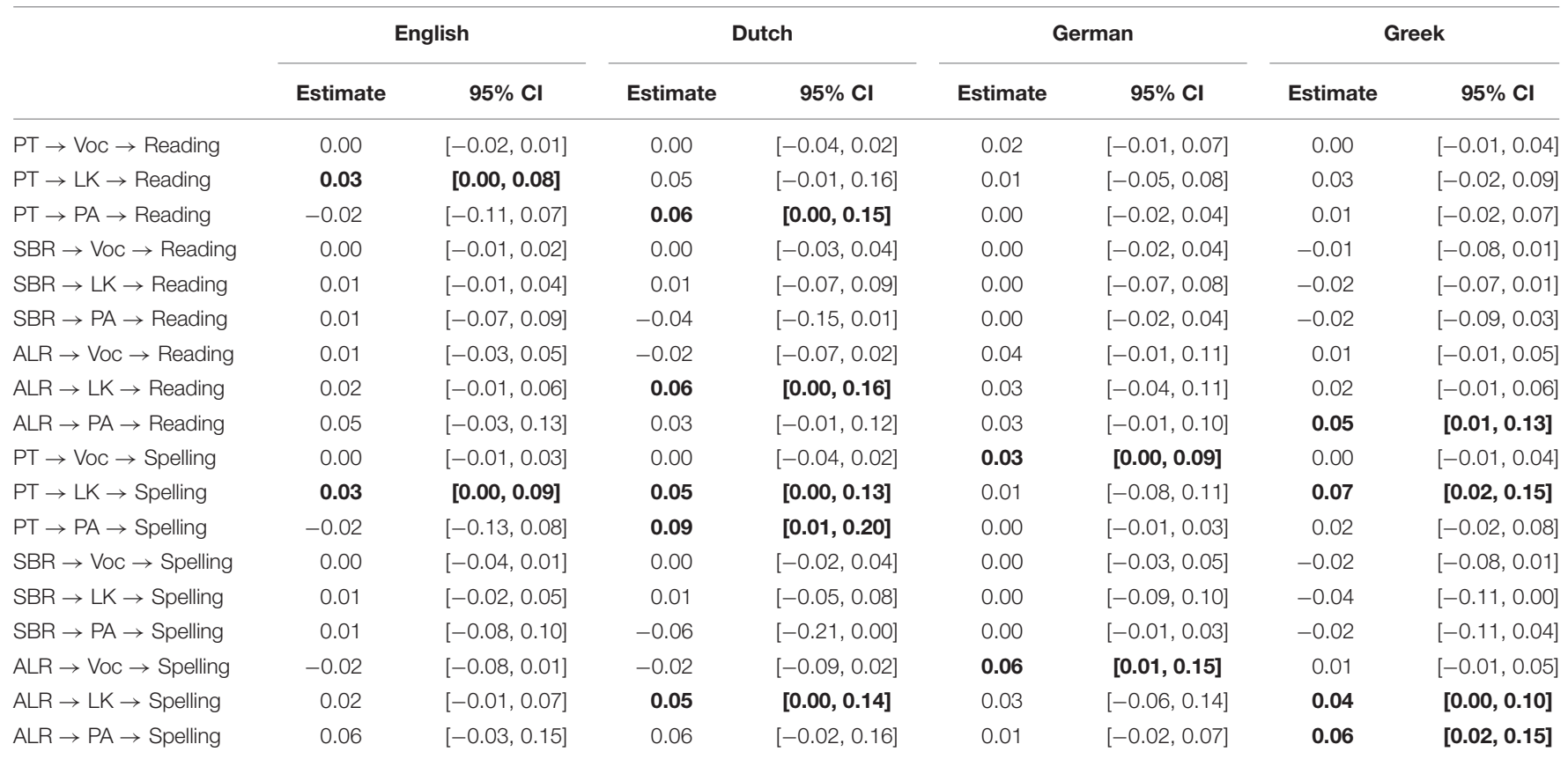

Values shown in bold font are significant at the alpha level of 0.05. Cl, confidence interval; PT, parent teaching; SBR, shared book reading; ALR, access to literacy resources; LK, letter knowledge; PA, phonological awareness; Voc, vocabulary.

child's autonomy (Ziehm et al., 2013) and rarely think their child needs much help in learning to read and spell before the beginning of Grade 1. Contrary to our expectation, the strongest association between parent teaching and letter knowledge was found in Greek, not in English. This may be at least partly due to the fact that parents teaching was the most frequent in English and there was only limited variability on this measure. In fact, the correlations between parent teaching and letter knowledge were of similar magnitude in English, Greek, and Dutch (see Table 4).

Access to literacy resources, on the other hand, was significantly associated with emergent literacy skills in all languages and, as hypothesized, it was uniquely associated with children's vocabulary knowledge in English, Dutch, and German. The strongest association between access to literacy resources and vocabulary was found in German (see Lehrl et al., 2013, for a similar finding in German). Additionally, access to literacy resources was the greatest and the average score on Vocabulary was the highest in German among the four languages. These results suggest that it may be access to literacy resources rather than parents' reading to their children that is driving the relation between HLE and vocabulary. In other words, child-initiated activities, in which they can take control of the activity and play, may have a larger impact on their learning than parent-initiated activities (see Grolnick and Ryan, 1987, 1989). This implies that by providing more printed materials at home, parents may increase their children's opportunities to learn new words and this, in turn, can enhance their child's autonomy in accessing written materials as well as some active interest in learning new words (for a relevant discussion, see van Bergen et al., 2017). These findings, together with the findings of existing cross-cultural studies (Chiu et al., 2012; Arya et al., 2014; Araújo and Costa, 2015; Lenkeit et al., 2018; Zuilkowski et al., 2019), suggest that there might be value in revising the Home Literacy Model so that 'presence of reading materials at home, which can facilitate childdirected activities, is separated from the 'shared book reading' component and becomes part of a broader 'access to literacy resources' component.

The results further showed that parent teaching and access to literacy resources had indirect effects on literacy outcomes via emergent literacy skills in all languages, a finding that is consistent with those of previous studies with English-speaking participants (e.g., Hamilton et al., 2016; Inoue et al., 2018). However, it should be noted that the pathways for the indirect effects did not follow the same pattern across languages. More specifically, whereas parent teaching had an indirect effect on reading and/or spelling through code-related skills in English, Dutch, and Greek, its effect on spelling was mediated by vocabulary in German. Similarly, while access to literacy resources had an indirect effect on spelling via vocabulary in German, its effects on the literacy outcomes were mediated by letter knowledge and/or PA in Dutch and Greek. Taken together, our results suggest that the effects of HLE on later literacy development are distributed via more pathways than previously thought, and the possible pathways for the mediated effects are likely to be modulated by language and culture. No particular trend in the role of orthographic consistency in the aforementioned relations emerged, which further suggests that other factors, either distal (e.g., educational context; Arya et al., 2014; Solheim et al., 2020) or proximal 
(e.g., parenting style; Steinberg et al., 1992; Kiuru et al., 2012) to HLE may account for the observed differences across languages.

An important educational implication of our findings would be to inform parents that increasing access to literacy resources at home may enhance children's literacy development. However, our results that shared book reading was not uniquely associated with children's literacy skills suggest that parents may not necessarily know how to effectively engage their children in shared reading activities. Given this, an implication of our findings would be to encourage researchers and educators to suggest the means by which the home literacy activities, shared book reading in particular, could be beneficial for their children's literacy development (see e.g., Mol et al., 2008; Niklas and Schneider, 2017b; Burgoyne et al., 2018; Noble et al., 2019).

Some limitations of our study are worth mentioning. First, our findings can be generalized only for the age range of the participants in our sample. In order to more fully reveal the relations between HLE and literacy development, future studies should capture longer developmental processes ranging from pre-reading to fluent reading (including measures of reading comprehension) for each language. Second, home literacy activities were assessed retrospectively with a self-report questionnaire to the parents, and this may have resulted in inflated estimates of their literacy-related activities at home due to social-desirability bias (assuming that parents attach a high value to these aspects of home environment). Third, we used observed variables instead of latent variables for HLE and the cognitive constructs in the models, and this might have resulted in the underestimation of the relations between HLE and literacy skills due to measurement error. Fourth, the possible influence of schooling on children's performance across the testing points was not captured in this study partly because school-level variables were not our primary focus in the present study. Future studies should consider taking school-level variables into account to better understand how schooling, another microsystem affecting children's literacy development, interact with the effect of HLE. Finally, because developing strictly comparable cognitive and literacy measures across such a diverse group of languages is extremely difficult given the unique features of each language, we decided to use existing measures of cognitive and literacy skills that follow the same administration and scoring procedures across languages. Although the observed differences in the relationships between HLE and literacy outcomes in our study might be partly due to the characteristics of the cognitive and literacy measures used in each language, we also acknowledge that fully controlling for the effect of item characteristics across four diverse languages is almost impossible.

To conclude, the present study examined the developmental relations between HLE, emergent literacy skills, and literacy outcomes in a 2-year longitudinal study with children learning four alphabetic orthographies (English, Dutch, German, and Greek). The results indicated that parent teaching was associated more strongly with letter knowledge and PA in English, Dutch, and Greek, while access to literacy resources is associated more strongly with vocabulary knowledge in English, Dutch, and German. In contrast, the results did not provide evidence for a unique association of shared book reading with cognitive or early literacy skills in any language. Moreover, parent teaching and access to literacy resources had indirect effects on later literacy skills via different emergent literacy skills. These findings suggest that not all HLE components are equally important for specific facets of emergent literacy skills, reading fluency, and spelling across orthographies. The current findings add to the cross-linguistic literature on HLE as this is the first analysis directly comparing associations between HLE and literacy outcomes across different orthographies varying in orthographic consistency.

\section{DATA AVAILABILITY STATEMENT}

The raw data supporting the conclusions of this article will be made available by the authors, without undue reservation, to any qualified researcher.

\section{ETHICS STATEMENT}

This study was carried out in accordance with the recommendations of the University of Alberta Human Research Ethics Board with written informed consent from all subjects (parental consent) in accordance with the Declaration of Helsinki. The protocol was approved by the University of Alberta Human Research Ethics Board.

\section{AUTHOR CONTRIBUTIONS}

TI contributed to the conception and design of the work, ran the analyses, interpreted the findings, and took the lead on writing the manuscript. GM, PJ, and $\mathrm{KL}$ organized the data collection at each site, contributed to the interpretation of the findings, and revised the work critically. RP contributed to the conception and design of the work, the interpretation of the findings, and revised the work critically. GG conceptualized the research project, organized the data collection, contributed to the conception and design of the work, and supported the writing of the manuscript. All authors contributed to the article and approved the submitted version.

\section{FUNDING}

This research was funded by a grant from the Social Sciences and Humanities Research Council of Canada (RES0002344) to GG. 


\section{REFERENCES}

Aram, D., and Levin, I. (2001). Mother-child joint writing in low SES Sociocultural factors, maternal mediation, and emergent literacy. Cogn. Dev. 16, 831-852. doi: 10.1016/S0885-2014(01)00067-3

Aram, D., and Levin, I. (2004). The role of maternal mediation of writing to kindergarteners in promoting literacy in school: a longitudinal perspective. Read. Writ. Interdiscip. J. 17, 387-409. doi: 10.1023/B:READ.0000032665. 14437.e0

Araújo, L., and Costa, P. (2015). Home book reading and reading achievement in EU countries: the progress in international reading literacy study 2011 (PIRLS). Educ. Res. Eval. 21, 422-438. doi: 10.1080/13803611.2015.1111803

Arya, D. J., McClung, N. A., Maul, A., and Cunningham, A. E. (2014). The effects of early home literacy environments on fourth-grade literacy achievement: an international comparison. Int. J. Quant. Res. Educ. 2, 1-17. doi: 10.1504/IJQRE. 2014.060971

Borgwaldt, S. R., Hellwig, F. M., and De Groot, A. M. B. (2004). Word-initial entropy in five languages: letter to sound and sound to letter. Written Lang. Literacy 7, 165-184. doi: 10.1075/wll.7.2.03bor

Bronfenbrenner, U. (1979). The Ecology of Human Development. Cambridge, MA: Harvard University Press.

Bronfenbrenner, U. (1995). "Developmental ecology through space and time: a future perspective," in Examining Lives in Context: Perspectives on the Ecology of Human Development, eds P. Moen, G. H. Elder, and K. Luscher (Washington, DC: American Psychological Association), 619-647. doi: 10.1037/10176-018

Bruck, M., Genesee, F., and Caravolas, M. (1997). "A cross-linguistic study of early reading acquisition," in Foundations of Reading Acquisition and Dyslexia: Implications for Early Intervention, ed. B. A. Blachman (Lawrence: Erlbaum Associates), 145-162.

Brus, B., and Voeten, B. (1995). Eén-minuut-test: vorm A en B: Verantwoording en handleiding (One Minute Test Form a and B: Accountability and Manual). Lisse: Swets \& Zietlinger.

Burgoyne, K., Gardner, R., Whiteley, H., Snowling, M. J., and Hulme, C. (2018). Evaluation of a parent-delivered early language enrichment programme: evidence from a randomised controlled trial. J. Child Psychol. Psychiatry 59, 545-555. doi: 10.1111/jcpp.12819

Chen, F. F. (2007). Sensitivity of goodness of fit indexes to lack of measurement invariance. Struct. Equ. Model. Multidiscip. J. 14, 464-504. doi: 10.1080/ 10705510701301834

Chiu, M. M., and McBride-Chang, C. (2006). Gender, context, and reading: a comparison of students in 43 countries. Sci. Stud. Read. 10, 331-362. doi $10.1207 /$ s1532799xssr1004_1

Chiu, M. M., and McBride-Chang, C. (2010). Family and reading in 41 countries: differences across cultures and students. Sci. Stud. Read. 14, 514-543. doi $10.1080 / 10888431003623520$

Chiu, M. M., McBride-Chang, C., and Lin, D. (2012). Ecological, psychological, and cognitive components of reading difficulties: testing the component model of reading in fourth graders across 38 Countries. J. Learn. Disabil. 45, 391-405. doi: $10.1177 / 0022219411431241$

de Jong, P. F., and Leseman, P. P. M. (2001). Lasting effects of home literacy on reading achievement in school. J. Sch. Psychol. 39, 389-414. doi: 10.1016/S00224405(01)00080-2

Dulay, K. M., Cheung, S. K., and McBride, C. (2018). Environmental correlates of early language and literacy in low- to middle-income Filipino families. Contemp. Educ. Psychol. 53, 45-56. doi: 10.1016/j.cedpsych.2018.02.002

Esmaeeli, Z., Kyle, F. E., and Lundetrae, K. (2019). Contribution of family risk, emergent literacy and environmental protective factors in children's reading difficulties at the end of second-grade. Read. Writ. Interdiscip. J. 38, 1-25. doi: 10.1007/s11145-019-09948-5

Geelhoed, J., and Reitsma, P. (1999). PI-dictee (PI: Dictation). Lisse: Swets \& Zeitlinger.

Georgiou, G. K., Papadopoulos, T. C., Fella, A., and Parrila, R. (2012) Rapid naming speed components and reading development in a consistent orthography. J. Exp. Child Psychol. 112, 1-17. doi: 10.1016/j.jecp.2011. 11.006

Graham, J. W. (2009). Missing data analysis: making it work in the real world. Annu. Rev. Psychol. 60, 549-576. doi: 10.1146/annurev.psych.58.110405. 085530
Grolnick, W. S., and Ryan, R. M. (1987). Autonomy in children's learning: an experimental and individual difference investigation. J. Pers. Soc. Psychol. 52, 890-898. doi: 10.1037//0022-3514.52.5.890

Grolnick, W. S., and Ryan, R. M. (1989). Parent styles associated with children's self-regulation and competence in school. J. Educ. Psychol. 81, 143-154. doi: 10.1037/0022-0663.81.2.143

Hamilton, L. G., Hayiou-Thomas, M. E., Hulme, C., and Snowling, M. J. (2016) The home literacy environment as a predictor of the early literacy development of children at family-risk of dyslexia. Sci. Stud. Read. 20, 401-419. doi: 10.1080/ 10888438.2016.1213266

Hayes, A. F. (2013). Introduction to Mediation, Moderation, and Conditional Process Analysis: A Regression-based Approach. New York, NY: Guilford Press.

Hayes, A. F., and Scharkow, M. (2013). The relative trustworthiness of inferential tests of the indirect effect in statistical mediation analysis. Psychol. Sci. 24, 1918-1927. doi: 10.1177/0956797613480187

Hood, M., Conlon, E., and Andrews, G. (2008). Preschool home literacy practices and children's literacy development: a longitudinal analysis. J. Educ. Psychol. 100, 252-271. doi: 10.1037/0022-0663.100.2.252

Inoue, T., Georgiou, G. K., Parrila, R., and Kirby, J. R. (2018). Examining an extended home literacy model: the mediating roles of emergent literacy skills and reading fluency. Sci. Stud. Read. 22, 273-288. doi: 10.1080/10888438.2018. 1435663

Jeličić, H., Phelps, E., and Lerner, R. M. (2009). Use of missing data methods in longitudinal studies: the persistence of bad practices in developmental psychology. Dev. Psychol. 45, 1195-1199. doi: 10.1037/a0015665

Kirby, J. R., and Hogan, B. (2008). Family literacy environment and early literacy development. Except. Educ. Can. 18, 112-130.

Kiuru, N., Aunola, K., Torppa, M., Lerkkanen, M.-K., Poikkeus, A.-M., Niemi, P., et al. (2012). The role of parenting styles and teacher interactional styles in children's reading and spelling development. J. Sch. Psychol. 50, 799-823. doi: 10.1016/j.jsp.2012.07.001

Kline, R. B. (2015). Principles and Practice of Structural Equation Modeling, 4th Edn. New York, NY: Guilford Press.

Krijnen, E., van Steensel, R., Meeuwisse, M., Jongerling, J., and Severiens, S. (2020). Exploring a refined model of home literacy activities and associations with children's emergent literacy skills. Read. Writ. Interdiscip. J. 33, 207-238. doi: 10.1007/s11145-019-09957-4

Landerl, K., Freudenthaler, H. H., Heene, M., de Jong, P. F., Desrochers, A. Manolitsis, G., et al. (2019). Phonological awareness and rapid automatized naming as longitudinal predictors of reading in five alphabetic orthographies with varying degrees of consistency. Sci. Stud. Read. 23, 220-234. doi: 10.1080/ 10888438.2018 .1510936

LeFevre, J.-A., Polyzoi, E., Skwarchuk, S.-L., Fast, L., and Sowinski, C. (2010). Do home numeracy and literacy practices of Greek and Canadian parents predict the numeracy skills of kindergarten children? Int. J. Early Years Educ. 18, 55-70. doi: 10.1080/09669761003693926

Lehrl, S., Ebert, S., Blaurock, S., Rossbach, H.-G., and Weinert, S. (2020). Longterm and domain-specific relations between the early years home learning environment and students' academic outcomes in secondary school. Sch. Effect. Sch. Improv. 31, 102-124. doi: 10.1080/09243453.2019.1618346

Lehrl, S., Ebert, S., and Rossbach, H.-G. (2013). "Facets of preschoolers' home literacy environments: what contributes to reading literacy in primary school?," in The Development of Reading Literacy from Early Childhood to Adolescence. Empirical Findings from the Bamberg BiKS Longitudinal Studies, eds M. Pfost, C. Artelt, and S. Weinert (Bamberg: University of Bamberg Press), 35-62.

Lenkeit, J., Schwippert, K., and Knigge, M. (2018). Configurations of multiple disparities in reading performance: longitudinal observations across France, Germany, Sweden and the United Kingdom. Assess. Educ. Principles Policy Pract. 25, 52-86. doi: 10.1080/0969594X.2017.1309352

Liu, C., Georgiou, G. K., and Manolitsis, G. (2018). Modeling the relationships of parents' expectations, family's SES, and home literacy environment with emergent literacy skills and word reading in Chinese. Early Child. Res. Q. 43, 1-10. doi: 10.1016/j.ecresq.2017.11.001

MacKinnon, D. P., Fairchild, A. J., and Fritz, M. S. (2007). Mediation analysis Annu. Rev. Psychol. 58, 593-614. doi: 10.1146/annurev.psych.58.110405.085542

Manolitsis, G., Georgiou, G. K., and Parrila, R. (2011). Revisiting the home literacy model of reading development in an orthographically consistent language. Learn. Instr. 21, 496-505. doi: 10.1016/j.learninstruc.2010.06.005 
Manolitsis, G., Georgiou, G. K., Stephenson, K., and Parrila, R. (2009). Beginning to read across languages varying in orthographic consistency: comparing the effects of non-cognitive and cognitive predictors. Learn. Instr. 19, 466-480. doi: 10.1016/j.learninstruc.2008.07.003

Manolitsis, G., Georgiou, G. K., and Tziraki, N. (2013). Examining the effects of home literacy and numeracy environment on early reading and math acquisition. Early Child. Res. Q. 28, 692-703. doi: 10.1016/j.ecresq.2013.05.004

Martini, F., and Sénéchal, M. (2012). Learning literacy skills at home: parent teaching, expectations, and child interest. Can. J. Behav. Sci. Rev. Can. Sci. Comport. 44, 210-221. doi: 10.1037/a0026758

Meredith, W. (1993). Measurement invariance, factor analysis and factorial invariance. Psychometrika 58, 525-543. doi: 10.1007/BF02294825

Mol, S. E., Bus, A. G., de Jong, M. T., and Smeets, D. J. H. (2008). Added value of dialogic parent-child book readings: a meta-analysis. Early Educ. Dev. 19, 7-26. doi: 10.1080/10409280701838603

Moll, K., and Landerl, K. (2010). SLRT-II: Lese- und Rechtschreibtest (Reading and Spelling Test). Berne: Hans Huber.

Mouzaki, A., Protopapas, A., Sideridis, P., and Simos, G. (2007). Psychometric properties of a new test of spelling achievement in Greek. Educ. Sci. 1, $129-146$.

Muthén, L. K., and Muthén, B. O. (1998-2017). Mplus User's Guide, 8th Edn. Los Angeles, CA: Mutheìn \& Mutheìn.

Niklas, F., and Schneider, W. (2013). Home literacy environment and the beginning of reading and spelling. Contemp. Educ. Psychol. 38, 40-50. doi: 10.1016/j. cedpsych.2012.10.001

Niklas, F., and Schneider, W. (2017a). Home learning environment and development of child competencies from kindergarten until the end of elementary school. Contemp. Educ. Psychol. 49, 263-274. doi: 10.1016/j. cedpsych.2017.03.006

Niklas, F., and Schneider, W. (2017b). Intervention in the home literacy environment and kindergarten children's vocabulary and phonological awareness. First Lang. 37, 433-452. doi: 10.1177/0142723717698838

Niklas, F., Tayler, C., and Schneider, W. (2015). Home-based literacy activities and children's cognitive outcomes: a comparison between Australia and Germany. Int. J. Educ. Res. 71, 75-85. doi: 10.1016/j.ijer.2015.04.001

Noble, C., Sala, G., Peter, M., Lingwood, J., Rowland, C., Gobet, F., et al. (2019). The impact of shared book reading on children's language skills: a meta-analysis. Educ. Res. Rev. 28:100290. doi: 10.1016/j.edurev.2019.100290

Preacher, K. J., and Hayes, A. F. (2008). Asymptotic and resampling strategies for assessing and comparing indirect effects in multiple mediator models. Behav. Res. Methods 40, 879-891. doi: 10.3758/BRM.40.3.879

Raykov, T. (2001). Estimation of congeneric scale reliability using covariance structure analysis with nonlinear constraints. Br. J. Math. Stat. Psychol. 54, 315-323. doi: 10.1348/000711001159582

Seymour, P. H. K., Aro, M., and Erskine, J. M. (2003). Foundation literacy acquisition in European orthographies. Br. J. Psychol. 94, 143-174. doi: 10.1348/ 000712603321661859

Sénéchal, M. (2006). Testing the home literacy model: parent involvement in kindergarten is differentially related to grade 4 reading comprehension, fluency, spelling, and reading for pleasure. Sci. Stud. Read. 10, 59-87. doi: 10.1207/ s1532799xssr1001_4

Sénéchal, M., and LeFevre, J.-A. (2002). Parental involvement in the development of children's reading skill: a five-year longitudinal study. Child Dev. 73, 445-460. doi: $10.1111 / 1467-8624.00417$

Sénéchal, M., and LeFevre, J.-A. (2014). Continuity and change in the home literacy environment as predictors of growth in vocabulary and reading. Child Dev. 8, 1552-1568. doi: $10.1111 /$ cdev.12222

Sénéchal, M., Whissell, J., and Bildfell, A. (2017). "Starting from home: home literacy practices that make a difference," in Theories of Reading Development, eds K. Cain, D. Compton, and R. Parrila (Amsterdam: John Benjamins), 383-408. doi: 10.1075/swll.15.22sen

Silinskas, G., Leppänen, U., Aunola, K., Parrila, R., and Nurmi, J.-E. (2010a). Predictors of mothers' and fathers' teaching of reading and mathematics during kindergarten and Grade 1. Learn. Instr. 20, 61-71. doi: 10.1016/j.learninstruc. 2009.01.002

Silinskas, G., Lerkkanen, M.-K., Tolvanen, A., Niemi, P., Poikkeus, A.-M., and Nurmi, J.-E. (2012). The frequency of parents' reading-related activities at home and children's reading skills during kindergarten and Grade 1. J. Appl. Dev. Psychol. 33, 302-310. doi: 10.1016/j.appdev.2012.07.004

Silinskas, G., Parrila, R., Lerkkanen, M.-K., Poikkeus, A.-M., Niemi, P., and Nurmi, J.-E. (2010b). Mothers' reading-related activities at home and learning to read during kindergarten. Eur. J. Psychol. Educ. 25, 243-264. doi: 10.1007/s10212010-0014-9

Silinskas, G., Torppa, M., Lerkkanen, M.-K., and Nurmi, J.-E. (2020). The home literacy model in a highly transparent orthography. Sch. Effect. Sch. Improve. 31, 80-101. doi: 10.1080/09243453.2019.1642213

Solheim, O. J., Torppa, M., Uppstad, P. H., and Lerkkanen, M.-K. (2020). Screening for slow reading acquisition in Norway and Finland: a quest for context specific predictors. Scand. J. Educ. Res. doi: 10.1080/00313831.2020.1739130

Steenkamp, J. B. E. M., and Baumgartner, H. (1998). Assessing measurement invariance in cross-national consumer research. J. Consum. Res. 25, 78-107. doi: $10.1086 / 209528$

Steinberg, L., Lamborn, S., Dornbusch, S., and Darling, N. (1992). Impact of parenting practices on adolescent achievement: authoritative parenting, school involvement, and encouragement to succeed. Child Dev. 63, 1266-1281. doi: 10.1111/j.1467-8624.1992.tb01694.x

Torgeson, J. K., Wagner, R. K., and Rashotte, C. A. (1999). Test of Word Reading Efficiency (TOWRE). Austin, TX: Pro-Ed.

van Bergen, E., van Zuijen, T., Bishop, D., and de Jong, P. F. (2017). Why are home literacy environment and children's reading skills associated? What parental skills reveal. Read. Res. Q. 52, 147-160. doi: 10.1002/rrq.160

van den Bos, K. P., lutje Spelberg, H. C., Scheepstra, A. J. M., and deVries, J. R. (1994). De Klepel: Een test Voor de Leesvaardigheid van Pseudowoorden (Klepel Manual: A Test for the Reading Skills of Pseudo Words). Lisse: Swets \& Zeitlinger.

Vasilyeva, M., Dearing, E., Ivanova, A., Shen, C., and Kardanova, E. (2018). Testing the family investment model in Russia: estimating indirect effects of SES and parental beliefs on the literacy skills of first-graders. Early Child. Res. Q. 42, 11-20. doi: 10.1016/j.ecresq.2017.08.003

Wechsler, D. (2001). Wechsler Individual Achievement Test-second edition (WIATII). London: Pearson.

Wechsler, D. (2003). WISC-IV: Wechsler Intelligence Scale for Children, 4th Edn. New York, NY: Psychological Corporation.

Zhang, S. Z., Inoue, T., Shu, H., and Georgiou, G. K. (2019). How does home literacy environment influence reading comprehension in Chinese? Evidence from a 3-year longitudinal study. Read. Writ. Interdiscip. J. 106, 1-23. doi: 10.1007/s11145-019-09991-2

Ziehm, J., Trommsdorff, G., Heikamp, T., and Park, S.-Y. (2013). German and Korean mothers' sensitivity and related parenting beliefs. Front. Psychol. 4:561. doi: 10.3389/fpsyg.2013.00561/abstract

Zuilkowski, S. S., McCoy, D. C., Jonason, C., and Dowd, A. J. (2019). Relationships among home literacy behaviors, materials, socioeconomic status, and early literacy outcomes across 14 Low- and middle-income countries. J. Cross Cult. Psychol. 50, 539-555. doi: 10.1177/0022022119837363

Conflict of Interest: The authors declare that the research was conducted in the absence of any commercial or financial relationships that could be construed as a potential conflict of interest.

Copyright (c) 2020 Inoue, Manolitsis, de Jong, Landerl, Parrila and Georgiou. This is an open-access article distributed under the terms of the Creative Commons Attribution License (CC BY). The use, distribution or reproduction in other forums is permitted, provided the original author(s) and the copyright owner(s) are credited and that the original publication in this journal is cited, in accordance with accepted academic practice. No use, distribution or reproduction is permitted which does not comply with these terms. 


\title{
Construct-Specific and Timing-Specific Aspects of the Home Environment for Children's School Readiness
}

\author{
Yemimah A. King*, Robert J. Duncan, German Posada and David J. Purpura \\ Department of Human Development \& Family Studies, Purdue University, West Lafayette, IN, United States
}

Prior evidence supports that the home environment is related to children's development of school readiness skills. However, it remains unclear how construct- and timingspecific aspects of the home environment are related to children's school readiness skills, unique from overall, stable aspects of home quality. Unpacking associations due to specific constructs and timing of the home environment may provide insights on the theoretical processes that connect the home environment to school readiness. Using data from the NICHD Study of Early Child Care and Youth Development $(N=1,364)$, the current study examines how timing (36 and 54 months) and constructs (educational

OPEN ACCESS

Edited by: Simone Lehrl, University of Bamberg, Germany

Reviewed by: Minna Torppa, University of Jyväskylä, Finland Katharina Kluczniok, Freie Universität Berlin, Germany

*Correspondence: Yemimah A. King kingy@purdue.edu

Specialty section: This article was submitted to Educational Psychology, a section of the journa

Frontiers in Psychology

Received: 15 April 2020

Accepted: 15 July 2020

Published: 05 August 2020

Citation:

King YA, Duncan RJ, Posada G and Purpura DJ (2020)

Construct-Specific

and Timing-Specific Aspects of the Home Environment for Children's

School Readiness.

Front. Psychol. 11:1959 doi: 10.3389/fpsyg.2020.01959 stimulation and socio-emotional responsivity) of the home environment, relative to overall levels across time, relate to children's language skills, math skills, and externalizing behaviors. The overall, stable aspects of the home environment were significantly associated with children's language skills and externalizing problems. Additionally, there were significant paths from the stimulation construct at 54 months to math skills, language skills, and externalizing problems. These findings provide evidence that although the overall home environment is predictive of school readiness, the stimulation construct of the home environment at 54 months has additional concurrent relations to children's school readiness. Implications for the role of the home environment and children's school readiness are discussed.

\footnotetext{
Keywords: home learning environment, school readiness, early childhood education, language ability, math skills, externalizing behaviors, parent-child interaction
}

\section{INTRODUCTION}

Preschoolers' language ability, math skills, and externalizing behaviors are key indicators of school readiness and are predictive of children's success in the formal school environment (Ramey and Ramey, 2004; High, 2008). Language is one of the most important skills for learning and is foundational for reading development and later academic achievement (Chomsky, 1972; Whitehurst et al., 1988; Durham et al., 2007; Dickinson et al., 2010). Early math skills before kindergarten entry are an important predictor of later achievement in both math and reading (Duncan et al., 2007; Watts et al., 2014). Additionally, children exhibiting fewer externalizing behaviors tend to be more successful at following rules and developing positive social relationships with peers and teachers when they start school (Ladd and Sechler, 2012; Roskam, 2018), and having positive relationships with teachers is related to long-term student success (Hamre and Pianta, 2001; Burchinal et al., 2002). Although the home environment has been related to these skills and 
behaviors in prior research (Leventhal et al., 2004) there still remains a gap in understanding how the specific constructs and timing of the home environment relate to children's school readiness.

Using a longitudinal dataset, the current study examined the associations between children's early home environments and school readiness skills (i.e., math, language, externalizing behaviors). Specifically, we examine to what extent these associations vary as a function of specific constructs (i.e., educational stimulation and socio-emotional responsivity) and specific timing (i.e., 36 and 54 months) of the home environment relative to overall, stable aspects of home quality. Educational stimulation is a specific aspect of the home environment that refers to experiences that promote cognitive development (e.g., parent encouraging child to read and learn numbers). Socio-emotional responsivity is a specific aspect of the home environment that refers to experiences that support socioemotional development (e.g., parent praising child). Addressing these issues will provide insight into how the home environment contributes to children's school readiness. For instance, it addresses whether specific constructs of the home environment are uniquely associated with each school readiness skill beyond what is common across the constructs. Similarly, this study examines the relative associations due to the specific timing of experiences (i.e., 36 and 54 months) that go beyond what is common across time.

Theoretically, it is important to understand whether the specific constructs and timing of experiences are uniquely related to children development of school readiness beyond overall levels of home environment quality. Specifically, the estimates that are time- and construct-specific may be less biased when controlling for overall, stable levels of home quality. This is because the overall, stable levels of the home environment are subjected to potential omitted variable biases (i.e., stable characteristics of the child or family that influence both the home and child outcomes). In models that do not control for overall, stable levels, the construct- and/or time-specific estimates would be subject to these same biases. Disentangling these connections provides insight for developmental theories on how the timing of different kinds of experiences contribute to children's school readiness skills, and potentially provide insights on the types of interventions or experiences that would be most impactful for promoting school readiness. To the authors' knowledge, no studies to date have simultaneously examined how specific constructs of the home environment at different developmental time points are related to construct specific school readiness skills, while accounting for the overall, stable levels of the home environment.

\section{Overall Levels Versus Specific Constructs of the Home Environment for Language, Math, and Externalizing Behaviors}

A number of studies have provided evidence that the home environment contributes to the development of various school readiness outcomes (Bradley et al., 1989; Bradley, 1993; Jackson et al., 2000; National Institute of Child Health,, 2000; Forget-Dubois et al., 2009; Hartas, 2016). Studies measuring overall levels of the home environment have found strong associations between the home environment and children's language development (Elardo et al., 1977; Gottfried and Gottfried, 1984; Storch and Whitehurst, 2001; Connor et al., 2005; Foster et al., 2005) such that children exposed to cognitively stimulating and supportive home environments have higher language competence. High quality home environments are also predictive of young children's math achievement (Melhuish et al., 2008; Anders et al., 2012; Young-Loveridge, 1989) and fewer externalizing behavior problems (Jackson et al., 2000; Fanti and Henrich, 2007, 2010; Price et al., 2013). These studies provide support for theoretical claims that young children's home environment, which is composed of the quality and quantity of cognitive stimulation and emotional support in a safe physical environment (Bradley, 1993; Linver et al., 2004) contributes to school readiness skills. However, it is unknown to what extent specific constructs of the home environment are differentially related to children's language, math, and externalizing behaviors while accounting for associations due to the overall home environment.

Correlational studies have developed and used subscales of the early home environment to find that most or all constructs of the home environment are associated with children's intelligence and achievement scores at the start of school (Bradley, 1993). In one study, Leventhal et al. (2004) used five large-scale data sets and found that subscales measuring learning stimulation and access to reading in the home environments of 3-yearold were most robustly associated with children's cognitive and behavioral outcomes at 5-year-old. Additionally, researchers have focused on measuring domain-specific aspects of the home environment, such as the home literacy environment or the home numeracy environment, and have found that domain-specific home environments are predictive of preschoolers' language ability and numeracy skills (Melhuish et al., 2008; Anders et al., 2012; Niklas and Schneider, 2015; Lehrl et al., 2020). Further, specific aspects of the home environment, such as maternal negative behavior and lack of home organization, are related to externalizing problems in young children transitioning into elementary school (Eamon, 2000; Price et al., 2013; Yildirim and Roopnarine, 2015). Although these studies provide evidence that construct-specific home environments are strongly associated with specific child outcomes, these studies do not tease apart the extent to which the relations between specific constructs of the home environment and child outcomes are unique or due to shared variance of the overall quality in the home environment. Specifically, certain constructs (e.g., educational stimulation) may be more correlated with outcomes because they are also more closely related to the overall home environment, and not uniquely due to the specific construct. If that is the case, the estimates for specific constructs of the home would be confounded by the overall levels in home quality (and any omitted variables that impact overall levels in home quality and the outcome). 


\section{Overall Levels Versus Specific Timing of the Home Environment for Language, Math, and Externalizing Behaviors}

Many studies on the home environment support the longitudinal explanation that early experiences in the home are related to school readiness skills and future academic outcomes (Elardo et al., 1977; Connor et al., 2005; Mccarty et al., 2005; Melhuish et al., 2008; Fanti and Henrich, 2010). For example, research shows that the home environment at 54 months of age was predictive of language skills at 54 months of age, as well as literacy skills at the end of first grade (Connor et al., 2005). Another study suggests that the home environment at 5 years of age predicted numeracy skills concurrently and at age 7 (Melhuish et al., 2008). Further, research suggests that the early home environment measured at 6 and 15 months of age predicted externalizing problems measured between 2 and 12 years of age (Fanti and Henrich, 2010).

Previous studies have focused on longitudinal relations between the early home environment and school readiness skills that develop before formal school entry (Elardo et al., 1977; Senechal and LeFevre, 2002; Roberts et al., 2005; Torppa et al., 2007; Gonzalez et al., 2010; Napoli and Purpura, 2018; Susperreguy et al., 2020). Additionally, strong concurrent associations have been found between the home learning environment and school readiness skills (Connor et al., 2005; Rodriguez et al., 2009; Son and Morrison, 2010; Anders et al., 2012; Cristofaro and Tamis-LeMonda, 2012). It is unknown, however, whether the specific timing of experiences in the early home environment (i.e., experiences at 36 or 54 months) are uniquely related to school readiness skills beyond stability in the quality of the home environment. This is important because if associations reported are primarily due to stability in the home environment, then the associations implied are subjected to omitted variable bias that exert influences on both the stability of the home environment and children's school readiness. Conversely, if associations emerge with school readiness skills that are unique to a specific time period in development and not overall stability in home quality, it is likely a less biased estimate of that association because omitted variables that exert stable influences on home quality and child outcomes are controlled for. Thus, we are unpacking whether associations are due to variations at specific points in children's development unique from stability in the home environment quality; here the omitted variables that have stable influences on the home environment and school readiness skills are controlled for in the model by the overall, stable home factor (though time-specific confounds remain a concern).

\section{CURRENT STUDY}

The aim of the current study is to simultaneously examine the relations between construct- and timing-specific aspects of the home environment and children's school readiness skills. The current study extends previous literature by examining the extent to which associations between the home environment and preschooler's math, language, and externalizing behaviors vary as a function of specific constructs (i.e., stimulation and responsivity) and the specific timing (i.e., 36 and 54 months) of the home environment relative to overall, stable levels across time. This study addresses to what extent the stimulation and responsivity constructs at 36 and 54 months of the home environment differentially relate to children's school readiness outcomes when holding constant overall, stable aspects of the home environment.

\section{MATERIALS AND METHODS}

\section{Participants}

A sample of 1,364 children (52\% were male) from the NICHD Study of Early Child Care and Youth Development was used for this study. Participants were recruited during hospital visits with mothers at birth of their infant in 1991 across 10 sites in the United States (Little Rock, AR; Irvine, CA; Lawrence, KS; Boston, MA; Hickory, NC; Philadelphia, PA; Pittsburgh, PA; Charlottesville, VA; Seattle, WA; Madison, WI). Majority of the mothers were European American (80\%) and they averaged 14.23 years of education (i.e., the average mother completed a little more than 2 years of college). The maximum for years of education was 21 years and means that a mother completed 5 years beyond a bachelor's degree. See Table 1 for summary statistics of demographic characteristics.

\section{Measures}

\section{Early Childhood Home Observation for Measurement of the Environment Inventory}

Children's home environments were measured using the Early Childhood Home Observation for Measurement of the Environment Inventory (EC-HOME) at 36 and 54-month-old (Caldwell and Bradley, 1984). The EC-HOME is a reliable and valid measure for the preschool age range (Bradley, 1994). The EC-HOME is composed of 55 items clustered into eight subscales: (1) Learning Materials, (2) Language Stimulation, (3) Physical Environment, (4) Responsivity, (5) Academic Stimulation, (6) Modeling, (7) Variety, and (8) Acceptance. However, this study focuses on the six subscales (Learning Materials, Language Stimulation, Responsivity, Academic Stimulation, Modeling, and Acceptance) that are theoretically important for cognitive and behavior outcomes. These six subscales are separated into the stimulation and responsivity constructs. The stimulation construct consists of Learning Materials (e.g., child has educational toys, games, books), Language Stimulation (e.g., parent encourages verbal communication and vocabulary development), and Academic Stimulation (e.g., child is encouraged to read, learn colors, learn numbers, etc.) which are subscales that represent the quality of cognitive stimulation available to the child at home. The responsivity construct consists of Responsivity (e.g., parent hugs child, answers child's questions, praises child), Modeling (e.g., parent allows child to express negative emotions without retaliation), and Acceptance (e.g., parent does not spank child), which are subscales that represent the quality of social/emotional 
TABLE 1 | Descriptive statistics for variables included in the study.

\begin{tabular}{|c|c|c|c|c|c|}
\hline Home Scales & $\mathbf{N}$ & $\mathbf{M}$ & SD & Min & Max \\
\hline Learn 36 & 1179 & 7.16 & 2.52 & 0 & 11 \\
\hline Language 36 & 1179 & 6.02 & 1.14 & 0 & 7 \\
\hline Academic 36 & 1179 & 3.37 & 1.22 & 0 & 5 \\
\hline Responsive 36 & 1179 & 5.61 & 1.36 & 0 & 7 \\
\hline Modeling 36 & 1179 & 3.17 & 1.13 & 0 & 5 \\
\hline Acceptance 36 & 1179 & 3.39 & 0.92 & 0 & 4 \\
\hline Learn 54 & 1039 & 9.43 & 1.53 & 1 & 11 \\
\hline Language 54 & 1044 & 6.62 & 0.71 & 1 & 7 \\
\hline Academic 54 & 1045 & 3.86 & 1.06 & 0 & 5 \\
\hline Responsive 54 & 1044 & 5.23 & 1.29 & 0 & 7 \\
\hline Modeling 54 & 1043 & 3.51 & 1.03 & 0 & 5 \\
\hline Acceptance 54 & 1044 & 3.61 & 0.75 & 0 & 4 \\
\hline \multicolumn{6}{|l|}{ Outcomes } \\
\hline Language 54 & 1053 & 99.63 & 20.39 & 50 & 137 \\
\hline Math 54 & 1053 & 102.94 & 15.63 & 41 & 153 \\
\hline Externalizing 54 & 1061 & 51.69 & 9.39 & 30 & 82 \\
\hline \multicolumn{6}{|l|}{ Covariates } \\
\hline Male & 1364 & 0.52 & 0.50 & 0 & 1 \\
\hline White & 1364 & 0.80 & 0.40 & 0 & 1 \\
\hline Black & 1364 & 0.13 & 0.34 & 0 & 1 \\
\hline Hispanic & 1364 & 0.05 & 0.21 & 0 & 1 \\
\hline Other & 1364 & 0.02 & 0.14 & 0 & 1 \\
\hline Father in Home & 1305 & 0.82 & 0.35 & 0 & 1 \\
\hline Family income & 1302 & 3.62 & 2.87 & 0.14 & 22.47 \\
\hline Mom Vocabulary & 1167 & 99.01 & 18.35 & 40 & 159 \\
\hline Mom Education & 1363 & 14.23 & 2.51 & 7 & 21 \\
\hline Externalizing 24 & 1189 & 52.32 & 8.48 & 30 & 89 \\
\hline MDI 24 & 1162 & 92.15 & 14.64 & 50 & 150 \\
\hline Vocabulary 24 & 1073 & 44.27 & 29.43 & 0 & 99 \\
\hline
\end{tabular}

support and responsivity available at home. The EC-HOME was collected during home visits using direct observation and semistructured interviews with mothers. All observers maintained $>90 \%$ agreement with the master coder at both time points. The alpha coefficient for the total EC-HOME score is 0.93 with alphas for subscales ranging from 0.53 to 0.88 .

\section{Preschool Language Scale-3}

Children's language outcomes were directly assessed using the Preschool Language Scale-3 (PLS-3; Zimmerman et al., 1979). The PLS-3 assessed vocabulary, grammar, morphology, and language reasoning at 54 months of age. The test is comprised of two parts: (a) the auditory comprehension scale that measures what children "know" or understand, but may not "say," and; (b) the expressive communication scale that assesses what children actually say or produce. Items are scored as 1 for each question if the pass criterion is met or if the child self-corrects a response. A score of 0 is given for each item if the pass criterion is not met or for partially correct or incomplete responses. Raw scores are computed for each subscale by subtracting the number of " 0 " scores after the "true" basal from the number of the last subscale task administered (i.e., the "true" ceiling). The PLS-3 standard scores have a normed mean of 100 and a standard deviation of 15 and were used in this study.

\section{Woodcock-Johnson Applied Problems}

Children's math outcomes were directly assessed at 54 months using the Woodcock-Johnson Applied Problems (Woodcock and Johnson, 1989). This instrument is valid and reliable for this age range (McGrew et al., 1991). Applied Problems assesses children's ability to solve mathematical problems that include basic counting, addition, subtraction, and multiplication primarily through word problems read to the child. In order to solve the problems, the subject must recognize the procedure to be followed and then perform relatively simple calculations. Each assessment item is scored as 1 (correct response) or 0 (incorrect or no response) and the raw score is the total number of correct responses. Standard scores, which are based on a normed mean of 100 and a standard deviation of 15, were used in analyses.

\section{Child Behavior Checklist/4-18}

Children's externalizing behavior was measured using the parent/caregiver reported Child Behavior Checklist/4-18 (CBCL/4-18) at 54 months of age (Achenbach and Edelbrock, 1991). The CBCL/4-18 is the most widely used screening instrument available for tracking the emergence of behavior problems in children. The CBCL includes items that illustrate childhood behavioral and emotional problems which were selected from previous literature, as well as interviews with parents and mental health professionals. Mothers were asked to rate 33 externalizing items about how characteristic each behavior was of their child over the last 2 months $(0=$ not true, 1 = sometimes true, 2 = very true).

\section{Covariates}

Control variables include measures of children's mental development, language skills, and externalizing behavior when they were 24 months old. Measures of mothers' vocabulary knowledge when their child was 36 months old was also used as a control variable. Additionally, race, gender, family composition (e.g., father lives with mother), and family income were included as controls.

\section{Bayley Scales of Infant Development-Revised}

Children's level of cognitive development was directly assessed using the Revised Bayley Scales (Bayley, 1991). The Mental Development Index (MDI) of the Bayley was used to assess cognitive skills (e.g., memory, early verbal communication, problem solving, etc.) at 24 months of age. The MDI is one of the most widely used and valid measure of cognitive ability.

\section{MacArthur Communicative Development Inventories (CDI) for Infants and Toddlers}

Mothers' reported on their child's vocabulary production at 24 months of age using the CDI/Toddler (Fenson et al., 1991). The CDI checklist measured words that children used, as well as, syntactic/morphological development and nominal/pronominal style. Internal consistency for this measure was 0.96. This measure includes two parts. The first consists of a 680 word vocabulary production checklist, organized into 
22 semantic categories such as "animals" and action word followed by five questions aimed at assessing the child's ability to differentiate past, future, and absent objects and events. The second part consists of 125 items that are designed to assess syntactic and morphological development, as well as nominal/pronominal style.

\section{Child Behavior Checklist/2-3}

Children's externalizing behavior was measured using the parent/caregiver reported Child Behavior Checklist/2-3 (CBCL/2-3) at 24 months of age (Achenbach and Edelbrock, 1991). Mothers were asked to rate 99 items describing child's behavioral problems over the last 2 months $(0=$ not true, $1=$ sometimes true, 2 = very true).

\section{Peabody Picture Vocabulary Test-Revised}

Mothers' language outcomes were directly assessed using the Peabody Picture Vocabulary Test - Revised (PPVT-R; Dunn and Dunn, 1981). The PPVT-R assessed mothers' receptive vocabulary knowledge when their child was 36 months of age. Participants selected one of four pictures that represented each vocabulary word they were presented. Internal consistency for this measure ranged from 0.80 to 0.83 . The PPVT-R consists of 175 plates with four pictures on each plate. Plates are arranged in increasing order of difficulty. PPVT-R standard scores were used for analyses.

\section{Analytic Strategy}

All data management and descriptive analyses were run in Stata 15 (StataCorp,, 2017) and all structural equation models were run in Mplus 8 (Muthén and Muthén, 2017). Our analyses begin by descriptively examining the aspects of the HOME scale at 36 and 54 months. Before running our structural equation model with path estimates to address our primary research question, we ran a series of factor models to determine which conceptual model best fit the HOME data. Specifically, we test whether the data support (1) a random intercept HOME factor, (2) a random intercept HOME factor with time-specific factors (36 versus 54 months), (3) a random intercept HOME factor with construct-specific factors (stimulation versus responsivity), or (4) a random intercept HOME factor with time- and constructspecific factors. The random intercept HOME factor with timeand construct-specific factors would allow us to investigate the associations between time- and construct-specific factors and school readiness, while controlling for the overall, stable HOME factor (the random intercept).

Once the final factor model was selected for the HOME, a comprehensive set of covariates are included as predictors of each of three school readiness outcomes (i.e., math, language, and externalizing) along with the HOME factor/s. Time- and construct-specific factors are included one at a time to determine if they relate to the outcomes above and beyond the overall, stable HOME random intercept factor and covariates. As a robustness check to the final model, covariates for children's cognitive, language, and externalizing at 24 months were removed. This was done to test whether our pattern of results is changed when examining overall levels in externalizing, language, and math versus when controlling for prior knowledge and behavior at 24 months.

All analyses used full information maximum likelihood (FIML) to address issues related to missing data (see Table $\mathbf{1}$ for the number of observations for all variables included in analyses). Although relatively little missing data occurred on any of the variables, FIML is a recommended strategy that uses all available information to provide less biased estimates than restricting to only cases that provide complete data (Acock, 2012).

\section{RESULTS}

\section{Descriptive Statistics and Correlations}

The number of observations, means, standard deviations, and ranges for all variables are included in Table 1. In general, HOME scales tended to be positively endorsed with higher scores at 54 months compared to 36 months. Language, math, and externalizing scores were close to nationally normed averages (100 for language and math; 50 for externalizing), suggesting the sample is representative of typical development during this age period. Correlations between the HOME scales and children's outcomes are included in Table 2. All HOME scales were significantly correlated with one another and significantly correlated with each of the three school readiness skills. Additionally, families with higher incomes and mothers with more education and better vocabulary tended to have higher HOME scores and children with better school readiness skills.

\section{Factor Structure of the HOME at 36 and 54 Months}

The factor structure of the HOME was tested in multiple ways before selecting the final measurement model used in the structural equation models that included outcomes and control variables that addressed the primary research question of interest. First, all indicator variables (scales) were standardized so the overall factor (random intercept) could represent what is equally shared across all scales independent of scaling characteristics (scales with more or fewer items included) and across both time points. Second, residual correlations were included between all common scales assessed at each time point (e.g., 36-month academic stimulation with 54-month academic stimulation). Next, a series of models were run that examined comparison of model fit between models that specified (1) a HOME random intercept only, (2) a HOME random intercept with time-specific factors (all 36 months scales loading onto a common factor), (3) a HOME random intercept with construct-specific factors (e.g., academic stimulation, language stimulation, and learning materials all loading onto a common factor, called stimulation), and (4) a HOME random intercept model with time- and construct-specific factors.

Fit indices for the measurement models are presented in Table 3. Fit indices improved with each specification, ultimately supporting the model with time- and construct-specific factors. However, this model (Model 4 in Table 3) included all nonsignificant loadings onto the responsivity factor at 54 months. Removing this factor (model 5) resulted in improved fit in terms 
TABLE 2 | Correlations for variables included in the study.

\begin{tabular}{|c|c|c|c|c|c|c|c|c|c|c|c|c|c|c|c|}
\hline & 1 & 2 & 3 & 4 & 5 & 6 & 7 & 8 & 9 & 10 & 11 & 12 & 13 & 14 & 15 \\
\hline \multicolumn{16}{|l|}{ (1) Learn 36} \\
\hline (2) Language 36 & $0.51^{*}$ & & & & & & & & & & & & & & \\
\hline (3) Academic 36 & $0.53^{\star}$ & $0.53^{\star}$ & & & & & & & & & & & & & \\
\hline (4) Responsivity 36 & $0.36^{\star}$ & $0.37^{*}$ & $0.33^{\star}$ & & & & & & & & & & & & \\
\hline (5) Modeling 36 & $0.38^{\star}$ & $0.32^{*}$ & $0.26^{\star}$ & $0.29^{\star}$ & & & & & & & & & & & \\
\hline (6) Acceptance 36 & $0.29^{\star}$ & $0.21^{*}$ & $0.15^{\star}$ & $0.23^{\star}$ & $0.33^{\star}$ & & & & & & & & & & \\
\hline (7) Learn 54 & $0.61^{*}$ & $0.33^{*}$ & $0.34^{*}$ & $0.29^{\star}$ & $0.29^{\star}$ & $0.25^{\star}$ & & & & & & & & & \\
\hline (8) Language 54 & $0.32^{\star}$ & $0.39^{\star}$ & $0.30^{*}$ & $0.21^{\star}$ & $0.19^{\star}$ & $0.16^{\star}$ & $0.34^{*}$ & & & & & & & & \\
\hline (9) Academic 54 & $0.36^{\star}$ & $0.37^{\star}$ & $0.39^{\star}$ & $0.18^{\star}$ & $0.19^{\star}$ & $0.12^{\star}$ & $0.37^{\star}$ & $0.44^{*}$ & & & & & & & \\
\hline (10) Responsivity 54 & $0.26^{\star}$ & $0.19^{\star}$ & $0.17^{\star}$ & $0.31^{*}$ & $0.17^{\star}$ & $0.16^{\star}$ & $0.29^{\star}$ & $0.29^{*}$ & $0.18^{*}$ & & & & & & \\
\hline (11) Modeling 54 & $0.31^{*}$ & $0.26^{\star}$ & $0.22^{*}$ & $0.22^{*}$ & $0.30^{\star}$ & $0.25^{\star}$ & $0.32^{*}$ & $0.29^{\star}$ & $0.23^{\star}$ & $0.30^{*}$ & & & & & \\
\hline (12) Acceptance 54 & $0.19^{\star}$ & $0.14^{*}$ & $0.08^{*}$ & $0.12^{\star}$ & $0.20^{*}$ & $0.31^{*}$ & $0.23^{\star}$ & $0.18^{\star}$ & $0.15^{\star}$ & $0.18^{*}$ & $0.29^{*}$ & & & & \\
\hline (13) Language 54 & $0.47^{\star}$ & $0.31^{\star}$ & $0.30^{*}$ & $0.32^{*}$ & $0.27^{\star}$ & $0.23^{*}$ & $0.45^{\star}$ & $0.28^{*}$ & $0.32^{*}$ & $0.29^{*}$ & $0.27^{\star}$ & $0.24^{*}$ & & & \\
\hline (14) Math 54 & $0.42^{*}$ & $0.24^{*}$ & $0.24^{\star}$ & $0.27^{\star}$ & $0.20^{\star}$ & $0.23^{\star}$ & $0.36^{\star}$ & $0.21^{*}$ & $0.24^{*}$ & $0.23^{*}$ & $0.19^{*}$ & $0.21^{*}$ & $0.70^{\star}$ & & \\
\hline (15) Externalizing 54 & $-0.14^{\star}$ & $-0.10^{\star}$ & $-0.09^{\star}$ & $-0.10^{\star}$ & $-0.14^{\star}$ & $-0.17^{\star}$ & $-0.21^{\star}$ & $-0.08^{*}$ & $-0.10^{\star}$ & $-0.11^{*}$ & $-0.17^{*}$ & $-0.20^{\star}$ & $-0.14^{*}$ & $-0.06^{*}$ & \\
\hline Male & $-0.09^{\star}$ & -0.05 & $-0.06^{\star}$ & -0.04 & $-0.06^{\star}$ & $-0.07^{\star}$ & -0.05 & -0.05 & $-0.06^{\star}$ & $-0.09^{*}$ & -0.01 & $-0.08^{*}$ & $-0.15^{\star}$ & $-0.12^{\star}$ & $-0.08^{\star}$ \\
\hline White & $0.37^{\star}$ & $0.17^{\star}$ & $0.17^{\star}$ & $0.21^{*}$ & $0.19^{\star}$ & $0.08^{*}$ & $0.28^{\star}$ & $0.10^{*}$ & $0.08^{*}$ & $0.24^{*}$ & $0.20^{*}$ & $0.10^{*}$ & $0.33^{\star}$ & $0.28^{*}$ & -0.05 \\
\hline Black & $-0.36^{\star}$ & $-0.11^{\star}$ & $-0.17^{\star}$ & $-0.18^{\star}$ & $-0.16^{\star}$ & $-0.09^{\star}$ & $-0.31^{\star}$ & $-0.10^{\star}$ & $-0.09^{\star}$ & $-0.24^{*}$ & $-0.20^{\star}$ & $-0.12^{\star}$ & $-0.34^{\star}$ & $-0.32^{\star}$ & 0.05 \\
\hline Hispanic & $-0.11^{*}$ & $-0.10^{\star}$ & -0.03 & $-0.09^{\star}$ & $-0.08^{\star}$ & -0.02 & -0.04 & -0.01 & 0.01 & -0.03 & -0.03 & 0.00 & -0.05 & -0.02 & 0.02 \\
\hline Other & -0.03 & $-0.08^{\star}$ & -0.03 & -0.03 & -0.03 & 0.02 & -0.02 & -0.02 & -0.03 & -0.05 & -0.05 & 0.02 & -0.04 & 0.00 & -0.00 \\
\hline Father in Home & $0.38^{*}$ & $0.18^{\star}$ & $0.18^{\star}$ & $0.26^{\star}$ & $0.21^{\star}$ & $0.16^{\star}$ & $0.34^{*}$ & $0.13^{\star}$ & $0.10^{*}$ & $0.19^{*}$ & $0.19^{\star}$ & $0.13^{*}$ & $0.25^{\star}$ & $0.25^{*}$ & $-0.10^{\star}$ \\
\hline Family income & $0.39^{\star}$ & $0.20^{\star}$ & $0.17^{\star}$ & $0.24^{*}$ & $0.26^{\star}$ & $0.17^{\star}$ & $0.39^{\star}$ & $0.16^{\star}$ & $0.16^{\star}$ & $0.20^{\star}$ & $0.21^{*}$ & $0.16^{\star}$ & $0.39^{*}$ & $0.33^{\star}$ & $-0.10^{\star}$ \\
\hline Mom Vocabulary & $0.47^{\star}$ & $0.26^{\star}$ & $0.23^{\star}$ & $0.26^{\star}$ & $0.30^{*}$ & $0.21^{*}$ & $0.42^{*}$ & $0.18^{*}$ & $0.16^{*}$ & $0.28^{*}$ & $0.26^{*}$ & $0.23^{*}$ & $0.49^{\star}$ & $0.44^{*}$ & $-0.12^{\star}$ \\
\hline Mom Education & $0.48^{\star}$ & $0.26^{\star}$ & $0.25^{\star}$ & $0.30^{\star}$ & $0.34^{\star}$ & $0.24^{*}$ & $0.48^{\star}$ & $0.19^{*}$ & $0.22^{*}$ & $0.27^{*}$ & $0.27^{*}$ & $0.26^{\star}$ & $0.46^{\star}$ & $0.39^{*}$ & $-0.14^{\star}$ \\
\hline Externalizing 24 & $-0.22^{\star}$ & $-0.11^{*}$ & -0.12 & $-0.14^{\star}$ & $-0.16^{\star}$ & $-0.17^{\star}$ & $-0.24^{*}$ & $-0.09^{\star}$ & $-0.14^{*}$ & $-0.17^{*}$ & $-0.15^{\star}$ & $-0.18^{*}$ & $-0.26^{\star}$ & $-0.22^{*}$ & $0.55^{\star}$ \\
\hline MDI 24 & $0.42^{*}$ & $0.24^{*}$ & $0.26^{\star}$ & $0.28^{\star}$ & $0.28^{*}$ & $0.20^{\star}$ & $0.34^{*}$ & $0.25^{\star}$ & $0.26^{*}$ & $0.26^{\star}$ & $0.24^{*}$ & $0.19^{*}$ & $0.64^{*}$ & $0.57^{\star}$ & $-0.07^{\star}$ \\
\hline Vocabulary 24 & $0.25^{\star}$ & $0.17^{\star}$ & $0.20^{\star}$ & $0.14^{\star}$ & $0.11^{*}$ & 0.02 & $0.18^{*}$ & $0.20^{\star}$ & $0.21^{*}$ & 0.05 & $0.09^{\star}$ & 0.03 & $0.35^{\star}$ & $0.28^{*}$ & -0.03 \\
\hline
\end{tabular}

of the Bayesian Information Criteria (BIC) and was selected as the measurement model for the primary analyses (Kline, 2005). Correlations between the factors for stimulation and responsivity at 36 months and between the factors for 36- and 54-month stimulation were included. A correlation between responsivity at 36 months and stimulation at 54 months was tested but found to be non-significant and was therefore excluded in the primary structural equation models.

\section{Time- and Construct-Specific Associations Between HOME and Children's School Readiness}

Once the final measurement model for the HOME scales was selected, covariates were entered along with the HOME factor/s as predictors of children's math, language, and externalizing behaviors at 54 months. Controls for cognitive, language, and externalizing at 24 months were included to control for earlier skills and behaviors that likely contribute to these school readiness skills at 54 months. The overall HOME factor was included in all models to control for the influence of shared variance across HOME scales, across time. The time- and construct-specific factors were entered one at a time on each outcome with all significant associations included in the final model (see Figure 1). The final model explained 43, 31, and
$35 \%$ of the variance for language, math, and externalizing behaviors, respectively.

The overall HOME factor was significantly associated with 54 months language $(\beta=0.21, p<0.001)$, and externalizing $(\beta=-0.23, p<0.001)$, such that overall better home environments (regardless of construct or time point) were associated with increases in language abilities and decreases in externalizing behaviors. The stimulation factor at 54 months had additional significant associations with math $(\beta=0.09$, $p=0.047)$, language $(\beta=0.13, p=0.023)$, and externalizing $(\beta=0.06, p=0.049)$. This suggests that beyond the degree to which the overall home factor influences learning materials, academic stimulation, and language stimulation at 54 months, this construct- and time-specific factor also relates to children's school readiness development uniquely. It should be noted that the association for stimulation at 54 months to externalizing is in the opposite direction than the overall HOME factor, suggesting that the association between HOME scales other than stimulation at 54 months (e.g., scales from the responsivity construct) are more directly related to reductions in externalizing than the HOME scales contributing to stimulation at 54 months. Conceptually this makes sense, as the overall HOME factor consists of scales that represent the responsivity construct (i.e., responsivity, modeling, and acceptance) at both 36 and 54 months which are hypothesized to be more related to 
TABLE 3 | Fit indices for measurement models of the home scales.

\begin{tabular}{|c|c|c|c|c|c|c|}
\hline \multicolumn{2}{|c|}{ Measurement Models } & \multirow{2}{*}{$\begin{array}{c}\text { (df) } \mathbf{x}^{2} \\
\text { (59) } 632.77\end{array}$} & \multirow{2}{*}{$\begin{array}{c}\mathbf{p} \\
0.000\end{array}$} & \multirow{2}{*}{$\begin{array}{c}\text { CFI } \\
0.824\end{array}$} & \multirow{2}{*}{$\begin{array}{c}\text { RMSEA } \\
0.090\end{array}$} & \multirow{2}{*}{$\frac{\text { BIC }}{35354}$} \\
\hline (1) & Random Intercept Only & & & & & \\
\hline (2) & RI + Time-Specific Factors & (46) 172.93 & 0.000 & 0.961 & 0.048 & 34987 \\
\hline (3) & $\mathrm{Rl}+$ Construct-Specific Factors & (46) 232.66 & 0.000 & 0.943 & 0.058 & 35046 \\
\hline (4) & RI + Time- and Construct-Specific Factors & (43) 129.23 & 0.000 & 0.974 & 0.041 & 34964 \\
\hline (5) & Model 4 without the 54 months Responsivity Factor & (48) 146.25 & 0.000 & 0.970 & 0.041 & 34946 \\
\hline
\end{tabular}

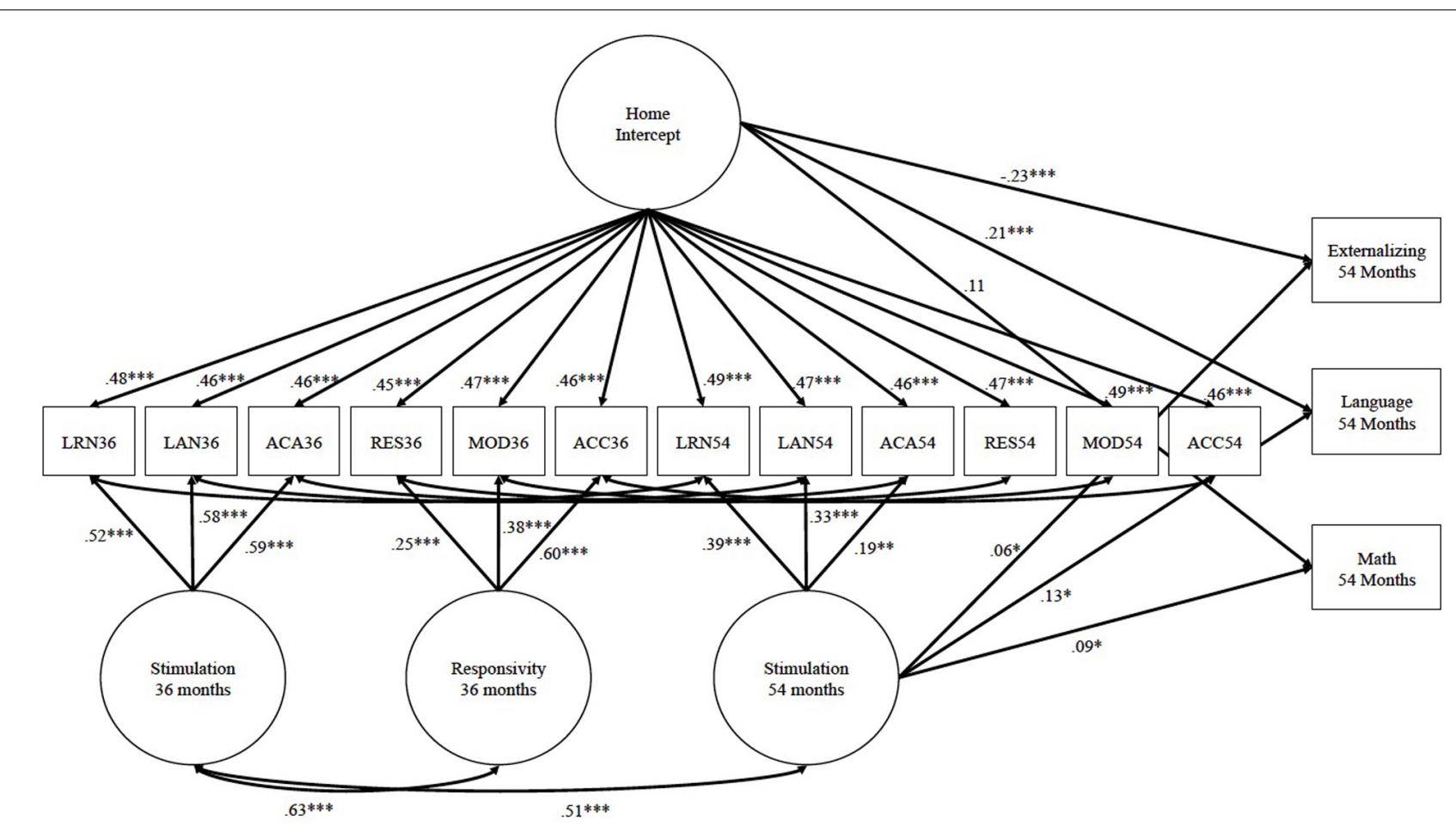

FIGURE 1 | Associations between home factors and children's math, language, and externalizing. All estimates are standardized. Control variables include: gender, race, whether the father was in the home, family income, mother vocabulary, mother education, externalizing behaviors at 24 months, mental development index at 24 months, and vocabulary skills at 24 months. ${ }^{*} p<0.05,{ }^{* *} p<0.01$, and ${ }^{* * *} p<0.001$.

reductions in externalizing, though it also includes early stimulation scales at 36 months (which may be related to reductions in externalizing behaviors as well). See Table 4 for all unstandardized estimates from the model.

\section{Removing 24 Months Cognitive, Language, and Externalizing Controls}

We conducted a sensitivity check by removing the control variables for cognitive, language, and externalizing behaviors at 24 months to see if model conclusions changed. The only substantive change that occurred is that the stimulation factor at 36 months was significantly associated with language $(\beta=0.11, p=0.028)$ and math outcomes $(\beta=0.12, p=0.041)$ above and beyond the HOME random intercept. However, stimulation at 54 months was also significantly associated with language $(\beta=0.20, p=0.003)$ and math outcomes ( $\beta=0.14, p=0.011$ ) above and beyond the HOME random intercept, and once the 36 and 54 stimulation factors were included simultaneously, only the 54-month stimulation factor paths remained significant for math and language. Thus, model conclusions (with regard to significant associations) were very similar regardless of whether 24-month-old skills and externalizing behavior variables were included.

\section{DISCUSSION}

This study examined the relation between construct- and timespecific aspects of the home environment and preschooler's development of school readiness skills. The results suggest that overall, stable home environment quality was positively associated with language skills and negatively associated with externalizing behaviors. Independent of the overall, stable HOME factor, results also indicate that the stimulation construct of the home environment at 54 months of age was significantly related to language skills, math skills, and externalizing behaviors. These findings are potentially less biased because they are 
TABLE 4 | Unstandardized estimates from model.

\begin{tabular}{|c|c|c|c|c|c|c|c|c|c|}
\hline & \multicolumn{3}{|c|}{ Math } & \multicolumn{3}{|c|}{ Language } & \multicolumn{3}{|c|}{ Externalizing } \\
\hline & $B$ & $S E$ & $p$ & $B$ & $S E$ & $p$ & $B$ & $S E$ & $p$ \\
\hline HOME RI & 3.24 & 1.76 & 0.065 & 7.94 & 1.17 & 0.000 & -4.47 & 1.09 & 0.000 \\
\hline Stimulation 54 & 5.39 & 2.25 & 0.017 & 9.92 & 4.56 & 0.030 & 2.19 & 1.25 & 0.079 \\
\hline Male & -1.11 & 0.61 & 0.067 & -2.88 & 0.88 & 0.001 & -2.04 & 0.40 & 0.000 \\
\hline Black & -3.60 & 1.17 & 0.002 & -4.28 & 1.87 & 0.022 & -1.36 & 0.91 & 0.134 \\
\hline Hispanic & 0.76 & 2.18 & 0.737 & -1.36 & 2.04 & 0.507 & -0.79 & 1.32 & 0.547 \\
\hline Other & 1.68 & 2.34 & 0.473 & -4.36 & 3.98 & 0.273 & 0.02 & 2.12 & 0.991 \\
\hline Father in Home & 0.57 & 1.25 & 0.650 & -1.09 & 0.84 & 0.194 & 0.08 & 1.03 & 0.941 \\
\hline Family income & 0.17 & 0.13 & 0.184 & 0.42 & 0.17 & 0.011 & 0.06 & 0.09 & 0.522 \\
\hline Mom Vocabulary & 0.15 & 0.03 & 0.000 & 0.21 & 0.05 & 0.000 & -0.00 & 0.02 & 0.881 \\
\hline Mom Education & 0.33 & 0.16 & 0.039 & 0.42 & 0.23 & 0.073 & -0.04 & 0.15 & 0.811 \\
\hline Externalizing 24 & -0.08 & 0.04 & 0.018 & -0.12 & 0.05 & 0.017 & 0.61 & 0.05 & 0.000 \\
\hline MDI 24 & 0.42 & 0.07 & 0.000 & 0.54 & 0.06 & 0.000 & 0.06 & 0.03 & 0.026 \\
\hline Vocabulary 24 & 0.01 & 0.02 & 0.611 & 0.05 & 0.02 & 0.015 & 0.00 & 0.01 & 0.901 \\
\hline
\end{tabular}

HOME RI = random intercept HOME factor.

independent of factors (i.e., omitted variable biases) that exert stable influences on both home environments and school readiness skills. They provide evidence that the stimulation construct of the home environment at 54 months has unique relations to children's math and language development, as well as externalizing behaviors (though these were in the opposite direction than the overall home factor). Prior work on the theoretical connections between specific aspects of the home environment and children's school readiness has yielded challenging to interpret associations due to the shared variance across constructs in home quality (Melhuish et al., 2008; Anders et al., 2012; Lehrl et al., 2020). This has been similarly, problematic when measuring the home environment across time points but not fully accounting for what is relatively stable across time. The current study addresses these issues, yielding support for strong associations between the overall home environment and externalizing behaviors and language at 54 months, with construct- and time-specific associations between 54-month stimulation and children's language and math abilities.

\section{Construct-Specific and Timing-Specific Associations Between the Home Environment and School Readiness}

Results of the current study suggest that there is a construct and time-specific association between the stimulation construct and children's language and math skills. The current study found that the stimulation construct at 54 months was uniquely associated with children's language and math skills, above and beyond the quality of the overall home environment (i.e., 36 to 54 months). It is not surprising that the quantity and quality of learning materials, language stimulation, and academic stimulation at 54 months are likely important for children's skills at 54 months. This finding is consistent with previous studies providing support for the relation between construct-specific home learning activities and children's language and math skills (Manolitsis et al., 2013; Skwarchuk et al., 2014) although these studies did not account for shared variance in home experiences across constructs. For example, home literacy activities are predictive of language development and home numeracy activities are predictive of math development (Senechal and LeFevre, 2002; Skwarchuk et al., 2014). Additionally, our results support a concurrent association which is likely stronger because home stimulation and school readiness skills were measured during the same period of time. It is important to note that the size of effects of the relation between home activities and child skills in the present study appear to be smaller than the size of effects in previous studies, though the current study may provide less biased estimates because it controls for overall levels of the home environment across time.

Previous research also suggests that parents may engage their preschool aged children in more advanced learning activities as they get closer to school entry (Thompson et al., 2017). It is possible that specific parent-child interactions that take place when children are 54 months are more proximal to academic school readiness skills. The idea that specific parent-child interactions at 54 months are more proximal to academic school readiness skills seems to particularly be the case for the relation between the home environment and children's math skills. Although the stimulation construct at 54 months was related to math skills, the overall home environment across time was not significantly related to math skills. It may be that parents begin engaging children in more math related activities when they are closer to approaching school entry (e.g., more advanced math activities when child is 4 years old rather than 3 years old; Thompson et al., 2017). Additionally, cross-domain associations supporting positive relations between numeracy activities and children's language outcomes, as well as positive relations between literacy activities and children's math outcomes have been found likely due to the shared variance across domains and the role of language and how it underlies the development of 
early math skills (LeFevre et al., 2010; Anders et al., 2012; Napoli and Purpura, 2018).

In contrast, both the overall home environment across time points and the stimulation construct at 54 months (above and beyond the overall factor) are related to children's language skills. Although language stimulation is important well before preschool age (Hirsh-Pasek et al., 2015) parents may engage children in more advanced language and literacy activities as their child's language acquisition grows and the child approaches school entry, which is consistent with scaffolding theories (Vygotsky, 1978). This study along with previous studies further supports the theoretical importance of the quantity and quality of learning materials, language stimulation, and academic stimulation being present in the home environment specifically to support the development of children's skills during the preschool period.

Somewhat unexpectedly, the stimulation construct at 54 months was positively associated with externalizing behaviors, however, the overall home environment was negatively associated with externalizing behaviors (and substantially larger in magnitude). These two results need to be interpreted simultaneously, such that aspects of the home environment other than 54-month stimulation (i.e., 36-month stimulation and responsivity, and 54-month responsivity) were more closely associated with reductions in externalizing behaviors than was 54-month stimulation. Notably, bivariate correlations indicate that 54-month stimulation variables were negatively correlated with externalizing behaviors (Table 2), thus the direction of associations changes only when simultaneously considering the overall, stable HOME factor as well. In this regard, these findings are not surprising and are consistent with hypotheses. This is also consistent with prior research that a better overall home environment is related to decreased behavior problems (Jackson et al., 2000; Fanti and Henrich, 2010).

\section{LIMITATIONS AND FUTURE DIRECTIONS}

Although the results of the current study yield important insights regarding the construct- and timing-specific relations between the home environment and preschoolers school readiness outcomes, limitations of the study and areas for future research should be noted. One limitation is that this study uses a nonexperimental design, and therefore, causal implications cannot be inferred. Additionally, there may be child effects and omitted variable bias that accounts for the obtained findings. For example, children with more advanced language, math, and social skills may elicit more responsive and stimulating engagement from parents in their home environment. However, a key advantage of this the current study is that it advances on previous studies that have not controlled for the overall levels and stability in home environments when making time- and constructspecific assertions. Although we controlled for prior cognitive and language abilities and externalizing behaviors at 24 months, auto-regressors were not available for all school readiness skills. Additional research is needed to evaluate whether or not there are bidirectional relations between construct- and timing-specific aspects of the home environment and school readiness skills.

Additionally, our findings for 54-month stimulation just reached traditional thresholds for statistical significance in most instances (i.e., 0.05). The magnitudes of effect sizes were also relatively small, around 0.10 . However, we think these are potentially less biased estimates and should be considered within the overall rigor of the analytic models that teased apart shared variance across constructs and time of the home measures. Regardless, we encourage future evaluation and replication to understand if these associations remain in other samples and when using other instruments that capture the quality of the home environment.

It is possible that social desirability could have influenced the way mothers interacted with their children and answered certain questions while researchers administered the home environment measure (EC-HOME) during home visits. Further, the EC-HOME did not capture the quantity and quality of other experiences that children have in their daily lives, such as interactions with fathers or siblings and experiences within early childhood education institutions, which are also related to children's cognitive skills and behaviors (Dunn and Plomin, 1990; Shonkoff and Phillips, 2000; Bradley et al., 2001). Although many young children are enrolled in some form preschool before they begin kindergarten, this study focused on experiences within the home environment because preschoolers tend to spend more time at home and may be receiving more individualized engagement than what is possible in a typical classroom. However, the preschool environment is an important factor for school readiness and should be considered in future studies that focus on how a child's environment is related to school readiness. Better indicators of domain-specific aspects of the home environment (e.g., home math environment) may improve this area of research. Future research should continue to investigate different aspects of the environment (e.g., home and childcare experiences) that are related to child development by using models that simultaneously control for each proximal environmental factor because children do not experience different aspects of their environment in isolation.

\section{CONCLUSION}

This study contributes to the home environment literature by providing evidence for unique concurrent associations between the stimulation construct and children's development of language and math skills. Specifically, engagement in high quality stimulating activities was related to higher language and math skills when children were 54 months old. These findings were particularly robust considering that the models controlled for overall, stable aspects of the home quality, children's cognitive, language, and externalizing behaviors at 24 months, as well as key sociodemographic factors (i.e., mother's education, mother's vocabulary ability). These findings indicate that there may be specific stimulation-related activities occurring at 54 months of age that are particularly important for the development of language and math abilities, while the 
overall home environment (particularly the aspects other than 54-month stimulation) is important for the reduction of externalizing behaviors. Findings suggest that researchers should be sensitive to the target construct and timing of intervention efforts for the development of some school readiness outcomes, while other outcomes may be influenced by more comprehensive interventions.

\section{DATA AVAILABILITY STATEMENT}

Publicly available datasets were analyzed in this study. This data can be found here: https://www.icpsr.umich.edu/icpsrweb/ ICPSR/series/00233.

\section{REFERENCES}

Achenbach, T. M., and Edelbrock, C. (1991). The Child Behavior Checklist Manual. Burlington, VT: The University of Vermont.

Acock, A. C. (2012). "What to do about missing values", in Data Analysis and Research Publication. APA Handbook of Research Methods in Psychology, Vol. 3, eds H. Cooper, P. M. Camic, D. L. Long, A. T. Panter, D. Rindskopf, and K. J. Sher, (Washington, DC: American Psychological Association), 27-50. doi: 10.1037/13621-002

Anders, Y., Rossbach, H.-G., Weinert, S., Ebert, S., Kuger, S., Lehrl, S., et al. (2012). Home and preschool learning environments and their relations to the development of early numeracy skills. Early Child. Res. Q. 27, 231-244. doi: 10.1016/j.ecresq.2011.08.003

Bayley, N. (1991). Bayley Scales of Infant Development: (Standardization Version), 2nd Edn. New York, NY: The Psychological Corporation.

Bornstein, M. H. (2005). Handbook of Parenting: Volume I: Children and Parenting. Hove: Psychology Press.

Bradley, R. H. (1993). Children's home environments, health, behavior, and intervention efforts: a review using the HOME inventory as a marker measure. Genet. Soc. Gen. Psychol. Monogr. 119, 437-490.

Bradley, R. H. (1994). "The home inventory: review and reflections," in Advances in Child Behavior and Development, Vol. 25, ed. H. W. Reese, (San Diego, CA: Academic Press), 241-288. doi: 10.1016/s0065-2407(08)60054-3

Bradley, R. H., Caldwell, B. M., Rock, S. L., Ramey, C. T., Barnard, K. E., Gray, C., et al. (1989). Home environment and cognitive development in the first 3 years of life: a collaborative study involving six sites and three ethnic groups in North America. Dev. Psychol. 25, 217-235. doi: 10.1037/0012-1649.25.2.217

Bradley, R. H., Corwyn, R. F., Burchinal, M., McAdoo, H. P., and García Coll, C. (2001). The home environments of children in the United States part II: relations with behavioral development through age thirteen. Child Dev. 72, 1868-1886. doi: 10.1111/1467-8624.t01-1-00383

Burchinal, M. R., Peisner-Feinberg, E., Pianta, R., and Howes, C. (2002). Development of academic skills from preschool through second grade: family and classroom predictors of developmental trajectories. J. Sch. Psychol. 40, 415-436. doi: 10.1016/S0022-4405(02)00107-3

Caldwell, B. M., and Bradley, R. H. (1984). Home Observation for Measurement of the Environment. Little Rock, AR: University of Arkansas at Little Rock.

Caldwell, B. M., and Bradley, R. H. (2003). Home Observation for Measurement of the Environment: Administration Manual. Tempe, AZ: Arizona State University.

Chomsky, C. (1972). Stages in language development and reading exposure. Harv. Educ. Rev. 42, 1-33. doi: 10.17763/haer.42.1.h781676h28331480

Connor, C. M., Son, S.-H., Hindman, A. H., and Morrison, F. J. (2005). Teacher qualifications, classroom practices, family characteristics, and preschool experience: complex effects on first graders' vocabulary and early reading outcomes. J. Sch. Psychol. 43, 343-375. doi: 10.1016/j.jsp.2005.06.001

Cristofaro, T. N., and Tamis-LeMonda, C. S. (2012). Mother-child conversations at 36 months and at pre-kindergarten: relations to children's school readiness. J. Early Child. Lit. 12, 68-97. doi: 10.1177/1468798411416879

\section{ETHICS STATEMENT}

The studies involving human participants were reviewed and approved by Internal Review Board (IRB) at Purdue University. Written informed consent to participate in this study was provided by the participants' legal guardian/next of kin.

\section{AUTHOR CONTRIBUTIONS}

YK and RD contributed conception and design of the study. RD organized the database and performed the statistical analysis. All authors contributed to the writing of the manuscript, revision, read, and approved the submitted version.

Dickinson, D. K., Golinkoff, R. M., and Hirsh-Pasek, K. (2010). Speaking out for language: why language is central to reading development. Educ. Res. 39, 305-310. doi: 10.3102/0013189X10370204

Duncan, G. J., Dowsett, C. J., Claessens, A., Magnuson, K., Huston, A. C., Klebanov, P., et al. (2007). School readiness and later achievement. Dev. Psychol. 43, 1428-1446. doi: 10.1037/0012-1649.43.6.1428

Dunn, J., and Plomin, R. (1990). Separate Lives: Why Siblings are so Different. New York, NY: Basic.

Dunn, L. M., and Dunn, L. M. (1981). Peabody Picture Vocabulary Test-Revised. Circle Pines, MN: American guidance service.

Durham, R. E., Farkas, G., Hammer, C. S., Bruce Tomblin, J., and Catts, H. W. (2007). Kindergarten oral language skill: a key variable in the intergenerational transmission of socioeconomic status. Res. Soc. Stratif. Mobil. 25, 294-305. doi: 10.1016/j.rssm.2007.03.001

Eamon, M. K. (2000). Structural model of the effects of poverty on externalizing and internalizing behaviors of four-to five-year-old children. Soc. Work Res. 24, 143-154. doi: 10.1093/swr/24.3.143

Elardo, R., Bradley, R. H., and Caldwell, B. M. (1977). A longitudinal study of the relation of infants' home environments to language development at age three. Child Dev. 48, 595-603.

Fanti, K. A., and Henrich, C. C. (2007). The relation of home and childcare/school environment to differential trajectories of externalizing problems. Int. J. About Parents Educ. 1, 117-123.

Fanti, K. A., and Henrich, C. C. (2010). Trajectories of pure and co-occurring internalizing and externalizing problems from age 2 to age 12: findings from the National Institute of Child Health and Human Development Study of Early Child Care. Dev. Psychol. 46, 1159-1175. doi: 10.1037/a0020659

Fenson, L., Dale, P. S., Reznick, J. S., Thal, D., Bates, E., Hartung, J. P., et al. (1991). Technical Manual for the MacArthur Communicative Development Inventories. San Diego, CA: San Diego State University.

Forget-Dubois, N., Dionne, G., Lemelin, J.-P., Pérusse, D., Tremblay, R. E., and Boivin, M. (2009). Early child language mediates the relation between home environment and school readiness. Child Dev. 80, 736-749. doi: 10.1111/j.14678624.2009.01294.x

Foster, M. A., Lambert, R., Abbott-Shim, M., McCarty, F., and Franze, S. (2005). A model of home learning environment and social risk factors in relation to children's emergent literacy and social outcomes. Early Child. Res. Q. 20, 13-36. doi: 10.1016/j.ecresq.2005.01.006

Gonzalez, J. E., Rivera, V., Davis, M. J., and Taylor, A. B. (2010). Foundations of children's vocabulary development: the role of the home literacy environment (HLE). Early Child. Serv. 10, 55-72.

Gottfried, A. W., and Gottfried, A. E. (1984). "Home environment and cognitive development in young children of middle-socioeconomic-status families," in Home Environment and Early Cognitive Development, ed. A. Gottfried, (Amsterdam: Elsevier), 57-115. doi: 10.1016/B978-0-12-293460-5.50 008-0

Hamre, B. K., and Pianta, R. C. (2001). Early teacher-child relationships and the trajectory of children's school outcomes through eighth grade. Child Dev. 72, 625-638. doi: 10.1111/1467-8624.00301 
Hartas, D. (2016). Young people's educational aspirations: psychosocial factors and the home environment. J. Youth Stud. 19, 1145-1163. doi: 10.1080/13676261. 2016.1145634

High, P. C. (2008). School readiness. Pediatrics 121, e1008-e1015. doi: 10.1542/ peds.2008-0079

Hirsh-Pasek, K., Adamson, L. B., Bakeman, R., Owen, M. T., Golinkoff, R. M., Pace, A., et al. (2015). The contribution of early communication quality to lowincome children's language success. Psychol. Sci. 26, 1071-1083. doi: 10.1177/ 0956797615581493

Jackson, A. P., Brooks-Gunn, J., Huang, C., and Glassman, M. (2000). Single mothers in low-wage jobs: financial strain, parenting, and preschoolers' outcomes. Child Dev. 71, 1409-1423. doi: 10.1111/1467-8624.00236

Kline, R. B. (2005). Principles and Practice of Structural Equation Modeling, 2nd Edn. New York, NY: Guilford Press.

Ladd, G. W., and Sechler, C. M. (2012). Young Children's Peer Relations and Social Competence. Abingdon: Routledge. doi: 10.4324/9780203841198.ch3

LeFevre, J.-A., Polyzoi, E., Skwarchuk, S.-L., Fast, L., and Sowinski, C. (2010). Do home numeracy and literacy practices of Greek and Canadian parents predict the numeracy skills of kindergarten children? Int. J. Early Years Educ. 18, 55-70. doi: 10.1080/09669761003693926

Lehrl, S., Ebert, S., Blaurock, S., Rossbach, H. G., and Weinert, S. (2020). Longterm and domain-specific relations between the early years home learning environment and students' academic outcomes in secondary school. Sch. Eff. Sch. Improv. 31, 102-124. doi: 10.1080/09243453.2019.1618346

Leventhal, T., Martin, A., and Brooks-Gunn, J. (2004). The EC-home across five national data sets in the 3rd to 5th year of life. Parenting 4, 161-188. doi: $10.1080 / 15295192.2004 .9681269$

Linver, M. R., Brooks-Gunn, J., and Cabrera, N. (2004). The home observation for measurement of the environment (HOME) inventory: the derivation of conceptually designed subscales. Parenting 4, 99-114. doi: 10.1080/15295192. 2004.9681266

Manolitsis, G., Georgiou, G. K., and Tziraki, N. (2013). Examining the effects of home literacy and numeracy environment on early reading and math acquisition. Early Child. Res. Q. 28, 692-703. doi: 10.1016/j.ecresq.2013.05.004

Mccarty, C. A., Zimmerman, F. J., Digiuseppe, D. L., and Christakis, D. A. (2005). Parental emotional support and subsequent internalizing and externalizing problems among children. J. Dev. Behav. Pediatr. 26, 267-275. doi: 10.1097/ 00004703-200508000-00002

McGrew, K. S., Werder, J. K., and Woodcock, R. W. (1991). WJ-R Technical Manual. Allen, TX: DLM.

Melhuish, E. C., Phan, M. B., Sylva, K., Sammons, P., Siraj-Blatchford, I., and Taggart, B. (2008). Effects of the home learning environment and preschool center experience upon literacy and numeracy development in early primary school. J. Soc. Issues 64, 95-114. doi: 10.1111/j.1540-4560.2008.00 550.x

Muthén, L. K., and Muthén, B. O. (2017). Mplus User's Guide (1998-2017). Los Angeles, CA: Muthén \& Muthén.

Napoli, A. R., and Purpura, D. J. (2018). The home literacy and numeracy environment in preschool: cross-domain relations of parent-child practices and child outcomes. J. Exp. Child Psychol. 166, 581-603. doi: 10.1016/j.jecp.2017.10. 002

National Institute of Child Health, (2000). The relation of child care to cognitive and language development. Child Dev. 71, 960-980. doi: 10.1111/1467-8624. 00202

Niklas, F., and Schneider, W. (2015). With a little help: improving kindergarten children's vocabulary by enhancing the home literacy environment. Read. Writ. 28, 491-508. doi: 10.1007/s11145-014-9534-z

Price, J. M., Chiapa, A., and Walsh, N. E. (2013). Predictors of externalizing behavior problems in early elementary-aged children: the role of family and home environments. J. Genet. Psychol. 174, 464-471. doi: 10.1080/00221325. 2012.690785

Ramey, C. T., and Ramey, S. L. (2004). Early learning and school readiness: can early intervention make a difference? Merrill Palmer Q. 50, 471-491. doi: 10. 1353/mpq.2004.0034

Roberts, J., Jergens, J., and Burchinal, M. (2005). The role of home literacy practices in preschool children's language and emergent literacy skills. J. Speech Lang. Hear. Res. 48, 345-359. doi: 10.1044/1092-4388(200 $5 / 024$
Rodriguez, E. T., Tamis-LeMonda, C. S., Spellmann, M. E., Pan, B. A., Raikes, H., Lugo-Gil, J., et al. (2009). The formative role of home literacy experiences across the first three years of life in children from low-income families. J. Appl. Dev. Psychol. 30, 677-694. doi: 10.1016/j.appdev.2009.01.003

Roskam, I. (2018). Externalizing behavior from early childhood to adolescence: prediction from inhibition, language, parenting, and attachment. Dev. Psychopathol. 31, 587-599. doi: 10.1017/S0954579418000135

Senechal, M., and LeFevre, J.-A. (2002). Parental involvement in the development of children's reading skill: a five-year longitudinal study. Child Dev. 73, 445-460. doi: 10.1111/1467-8624.00417

Shonkoff, J. P., and Phillips, D. A. (2000). From Neurons to Neighborhoods: The Science of Early Childhood Development. Washington, DC: National Academies Press. doi: 10.17226/9824

Skwarchuk, S.-L., Sowinski, C., and LeFevre, J.-A. (2014). Formal and informal home learning activities in relation to children's early numeracy and literacy skills: the development of a home numeracy model. J. Exp. Child Psychol. 121, 63-86.

Son, S.-H., and Morrison, F. J. (2010). The nature and impact of changes in home learning environment on development of language and academic skills in preschool children. Dev. Psychol. 46, 1103-1118. doi: 10.1037/a0020065

StataCorp, (2017). Stata Structural Equation Modeling Reference Manual Release 15. College Station, TX: StataCorp.

Storch, S. A., and Whitehurst, G. J. (2001). The role of family and home in the literacy development of children from low-income backgrounds. New Dir. Child Adolesc. Dev. 2001, 53-72. doi: 10.1002/cd.15

Susperreguy, M. I., Douglas, H., Xu, C., Molina-Rojas, N., and LeFevre, J. A. (2020). Expanding the home numeracy model to Chilean children: relations among parental expectations, attitudes, activities, and children's mathematical outcomes. Early Child. Res. Q. 50, 16-28. doi: 10.1016/j.ecresq.2018.06.010

Thompson, R. J., Napoli, A. R., and Purpura, D. J. (2017). Age-related differences in the relation between the home numeracy environment and numeracy skills. Infant Child Dev. 26:e2019. doi: 10.1002/icd.2019

Torppa, M., Poikkeus, A.-M., Laakso, M.-L., Leskinen, E., Tolvanen, A., Leppänen, P. H. T., et al. (2007). Modeling the early paths of phonological awareness and factors supporting its development in children with and without familial risk for dyslexia. Sci. Stud. Read. 11, 73-103. doi: 10.1080/10888430709336554

Vygotsky, L. S. (1978). Mind in Society: The Development of Higher Psychological Processes. Cambridge, MA: Harvard University Press.

Watts, T. W., Duncan, G. J., Siegler, R. S., and Davis-Kean, P. E. (2014). What's past is prologue: relations between early mathematics knowledge and high school achievement. Educ. Res. 43, 352-360. doi: 10.3102/0013189X14553660

Whitehurst, G. J., Falco, F. L., Lonigan, C. J., Fischel, J. E., DeBaryshe, B. D., ValdezMenchaca, M. C., et al. (1988). Accelerating language development through picture book reading. Dev. Psychol. 24, 552-559. doi: 10.1037/0012-1649.24. 4.552

Woodcock, R. W., and Johnson, M. B. (1989). Woodcock-Johnson PsychoEducational Battery - Revised. Allen, TX: DLM.

Yildirim, E. D., and Roopnarine, J. L. (2015). The mediating role of maternal warmth in the associations between harsh parental practices and externalizing and internalizing behaviors in Hispanic American, African American, and European American families. Cultur. Divers. Ethnic Minor. Psychol. 21, 430439. doi: $10.1037 / \mathrm{a} 0038210$

Young-Loveridge, J. M. (1989). The relationship between children's home experiences and their mathematical skills on entry to school. Early Child Dev. Care 43, 43-59. doi: 10.1080/0300443890430105

Zimmerman, I. L., Pond, R. E., and Steiner, V. G. (1979). Preschool Language Scale, Revised Edn. New York, NY: Chares E. Merrill.

Conflict of Interest: The authors declare that the research was conducted in the absence of any commercial or financial relationships that could be construed as a potential conflict of interest.

Copyright $(2020$ King, Duncan, Posada and Purpura. This is an open-access article distributed under the terms of the Creative Commons Attribution License (CC BY). The use, distribution or reproduction in other forums is permitted, provided the original author(s) and the copyright owner(s) are credited and that the original publication in this journal is cited, in accordance with accepted academic practice. No use, distribution or reproduction is permitted which does not comply with these terms. 
OPEN ACCESS

Edited by:

Frank Niklas,

Ludwig Maximilian University

of Munich, Germany

Reviewed by:

Simone Lehrl,

University of Bamberg, Germany

Dan Zhang,

Tsinghua University, China

${ }^{*}$ Correspondence:

Rebecca A. Dore

dore.13@osu.edu

Specialty section:

This article was submitted to

Educational Psychology,

a section of the journal

Frontiers in Psychology

Received: 31 March 2020

Accepted: 23 June 2020

Published: 05 August 2020

Citation:

Dore RA, Logan J, Lin T-J,

Purtell KM and Justice LM (2020)

Associations Between Children's

Media Use and Language

and Literacy Skills.

Front. Psychol. 11:1734.

doi: 10.3389/fpsyg.2020.01734

\section{Associations Between Children's Media Use and Language and Literacy Skills}

\author{
Rebecca A. Dore ${ }^{1 *}$, Jessica Logan ${ }^{2}$, Tzu-Jung Lin ${ }^{1,2}$, Kelly M. Purtell ${ }^{1,3}$ and \\ Laura M. Justice ${ }^{1,2}$ \\ ${ }^{1}$ Crane Center for Early Childhood Research and Policy, The Ohio State University, Columbus, OH, United States, \\ ${ }^{2}$ Department of Educational Studies, The Ohio State University, Columbus, OH, United States, ${ }^{3}$ Department of Human \\ Sciences, The Ohio State University, Columbus, $\mathrm{OH}$, United States
}

Media use is a pervasive aspect of children's home experiences but is often not considered in studies of the home learning environment. Media use could be detrimental to children's language and literacy skills because it may displace other literacyenhancing activities like shared reading and decrease the quantity and quality of caregiver-child interaction. Thus, the current study asked whether media use is associated with gains in children's language and literacy skills both at a single time point and across a school year and whether age moderates any association. Children $(N=1583)$ were from preschool through third grade classrooms and language and literacy skills were measured in the fall and spring of the school year. Parents reported how much time their child spends using media on a typical school day. Regression analyses showed that using $4 \mathrm{~h}$ or more of media was related to lower literacy gains, but not to language gains. Multilevel models conducted as a robustness check showed that this effect did not hold when accounting for classroom. In neither set of models was there an interaction between age and media use. Single-time-point models did show some associations that did not manifest in more stringent models, highlighting the limitations of correlational designs that do not have measures of children's skills over time. Given the concern and popular press coverage around children's media use, it is important to acknowledge non-significant effects in this domain. These nonsignificant associations suggest that societal fears around children's media use may be exaggerated. Notably, however, characteristics of children's media use, like educational content or adult co-use, may moderate any effects. The relation between media use and language and literacy growth did not differ across the age range investigated suggesting that, within this range, younger children are not more vulnerable to detrimental effects.

Keywords: media, language, literacy, screen time, children

\section{INTRODUCTION}

Social-constructivist theories assert that children's knowledge and skills develop in the context of interactions with others who have more experience, such as parents, caregivers, and other adults (Bruner, 1978). In line with this theoretical tradition, research has shown that the home learning environment, which captures both materials and opportunities for interactions, is linked 
to child development and learning across domains, including language and literacy (NICHD Early Child Care Research Network, 1999; Barnett et al., 2012; Hirsh-Pasek et al., 2015). Previous research has sought to understand how specific aspects of children's experiences at home relate to language and literacy skills. For example, the number of picture books in the home and the frequency of parent-child shared reading are related to preschoolers' language ability (Payne et al., 1994), as is time spent engaging in other educational or enriching activities like talking to adults (Fiorini and Keane, 2014).

However, media use is an increasingly pervasive activity in children's lives in the 21 st century, but it is often not considered in the context of research on the home environment. Children under 8 spend over $2 \mathrm{~h}$ a day with media and time spent using mobile devices tripled from 2013 to 2017 (Rideout, 2017). Indeed, children spend more time using media than in any other single leisure activity (Bianchi et al., 2006) and recent evidence suggests that early childhood technology use has increased by $32 \%$ in the last two decades (Goode et al., 2019).

Although the frequency of children's media use is well established, its association with language outcomes is not as well understood. However, some research suggests that media use may be detrimental to children's language and literacy skills because it may displace other literacy-enhancing activities like shared reading and decrease the quantity and quality of caregiver-child interaction. For example, Khan et al. (2017) found that higher levels of television viewing were associated with lower levels of parent-child book reading among a nationally representative sample of 4-year-olds. Furthermore, both the quantity and quality of caregiver speech and caregiver-child engagement is lower during television viewing compared with free play or other activities (Nathanson and Rasmussen, 2011; Pempek et al., 2011; Lavigne et al., 2015). This is critical because early caregiverchild interactions in the home are highly influential to language development (e.g., Hirsh-Pasek et al., 2015).

In line with these data, several studies have found that media exposure during toddlerhood or preschool is associated with lower language development in subsequent years (Clarke and Kurtz-Costes, 1997; Duch et al., 2013; Pagani et al., 2013). Furthermore, one recent study shows an association between children's screen media use and lower microstructural integrity of brain white matter in areas related to language and emergent literacy (Hutton et al., 2019). However, findings are inconsistent, with other studies finding no association between media exposure and children's language development (Patterson, 2002; Taylor et al., 2017; Pence and Alamos, 2019).

Notably, societal and parental concern about potential effects of media use on child development run counter to research showing that media can have some benefits for children. A large body of research shows that by preschool, children can learn from high-quality educational media, including in the domain of language and early literacy skills (e.g., Penuel et al., 2012; Mares and Pan, 2013; Hurwitz, 2018; Dore et al., 2019). There is also evidence that active video games or exergames, like Wii Fit or Just Dance, can increase children's physical activity and fitness (e.g., Flynn et al., 2018; Gao et al., 2018). Although research is in its early stages, open-ended, multi-player games like Minecraft may also have the potential to promote creativity and collaboration (Lane and Yi, 2017). In line with these ideas, most parents believe that their child benefits from media use, especially in the areas of learning and creativity (Rideout, 2017). Thus, to the extent that families limit media because of concerns about effects on child development, including language and literacy, children may be missing out on positive aspects of media use.

Importantly, much of the literature focusing on the role of media use in language development has focused on infants, toddlers, and preschoolers, with less focus on older children. The preschool years are a time of immense language growth, as there are large increases in neural connections in the prefrontal cortex during this period that are influenced by early experiences (Huttenlocher, 2002). Thus, one might predict that media use would be more detrimental in preschool than during the elementary years. However, parents of 5- to 8-yearolds are even more likely than parents of younger children to believe that their child spends too much time with screen media and are less likely to believe that media use helps their child's learning (Rideout, 2017), indicating that concerns about screen media use are still prevalent for this age group. Examining the relation between media use and language and literacy development with older children and across a wider age range is important to understand whether any relation is consistent across childhood or whether early childhood is an especially vulnerable time period for possible disruptions to the development of language and literacy skills. Investigating this question in the understudied age range used here (PreK to Grade 3) is particularly important to provide developmentally specific recommendations for parents and caregivers about children's screen media use. We expect that there will be a stronger association between screen media use and language and literacy skills during early childhood, given rapid growth in these domains during the preschool years.

Another limitation of the existing research is that it focuses largely on vocabulary as an outcome to the exclusion of more comprehensive measures of language and literacy development. Although vocabulary is a vital aspect of language development and is predictive of later reading ability (Cunningham and Stanovich, 1997; Kim, 2016, 2017), letter knowledge and decoding are also necessary components of reading (e.g., Hoover and Gough, 1990; Chen and Vellutino, 1997; Kendeou et al., 2009) and media use may affect these skills via different mechanisms. Theoretically, whereas vocabulary may be affected if media leads to reduced opportunities for adult-child interaction and conversation, literacy skills are more likely to be affected if media displaces shared book reading and other print-focused activities. Thus, it is vital for research to examine multiple aspects of language and literacy development in relation to children's media use to determine whether there are differential relations between media use and these skills.

Finally, many previous studies have examined the correlation between media use and language skills at one time point (e.g., Clarke and Kurtz-Costes, 1997) or have only an earlier measure of media use and a later measure of language skills (Pagani et al., 2013). Although experimental designs are necessary to draw strong conclusions about causality, using a design with measures 
of children's language skills at two time points can begin to further our understanding of potential directionality of influence by controlling for initial levels of language and literacy skills and examining the unique relation between media use and change in these skills over time. Notably, we conduct analyses using both a single time point (i.e., analysis of correlation) and using two time points (i.e., analysis of pre-post changes) to test the extent to which media use was more associated with children's language and literacy skills at the end of the academic year or the growth of these skills across the academic year.

Thus, the current study addresses four research questions: (1) To what extent is media use associated with gains in the language skills of children in PreK to 3rd grade across the school year? (2) To what extent is media use associated with gains in the literacy skills of children in PreK to 3rd grade across a school year? (3) Does age moderate any association between media use and language and literacy skills? (4) To what extent do the results of models assessing skill gains differ from single-time-point models?

\section{MATERIALS AND METHODS}

\section{Participants}

Children from preschool through 3rd grade were recruited via their classroom teachers in two school districts in a Midwestern City in the United States. Every student within each classroom was asked to participate and $66.0 \%$ consented. Of the children whose parents consented for them to participate, approximately $74 \%$ of families returned the survey that included the media questions to be included in the current analysis. Of those, approximately $77 \%$ had data for the variables of interest for the current research questions. Thus, data from 1583 children (PreK $n=238$, kindergarten $n=466$, grade $1 n=307$, grade $2=326$, and grade $3=246 ; 49.7 \%$ males) are included. Note that the sample size varies slightly for each analysis as a result of variable missingness across assessments, and so on. See Table 1 for sample demographics.

\section{Procedures}

Children's language and literacy skills were directly assessed in the fall and the spring of the academic year. In the spring, caregivers reported on children's media use, as well as other child and family demographic characteristics.

\section{Measures}

\section{Caregiver Report of Child Media Use}

As part of a larger family background questionnaire, parents responded to two binary items asking whether their child watched "any kind of video, including TV, movies or short clips on any type of device" and played "games on any type of electronic device" on a typical school day. If parents reported that their child used any media on a typical school day, they were then asked how much time their children spends using media from five response options: $0-1,2-3,4-5,6-7$, and $8+h$. For analyses, the last three categories were combined into one category for $4 \mathrm{~h}$ or more, given small cell sizes.
TABLE 1 | Descriptive statistics for all study variables.

\begin{tabular}{lcc}
\hline Continuous variables & Mean & SD \\
\hline WJ picture vocabulary (Fall) & 478.0 & 14.4 \\
WJ picture vocabulary (Spring) & 482.0 & 14.4 \\
WJ letter word identification (Fall) & 416.8 & 62.4 \\
WJ letter word identification (Spring) & 440.0 & 62.4 \\
\hline
\end{tabular}

Factors Percentage

Media use on a typical school day

$0-1 \mathrm{~h}$

$39.9 \%$

2-3h

$53.4 \%$

$4 \mathrm{~h}$ or more

$6.8 \%$

Mother's education

Less than high school diploma

High school diploma or GED

Associate's degree

Bachelor's degree

Master's degree

Doctoral degree

Number of adults in the home

One

Two

More than two

$6.6 \%$

$27.2 \%$

$12.4 \%$

$29.6 \%$

$20.5 \%$

$3.8 \%$

$8.7 \%$

$79.5 \%$

Child's race

White

Hispanic or Latino

$11.3 \%$

Black or African-American

Asian

American Indian or Alaska Native

Multiple races/ethnicities

$75.0 \%$

$7.8 \%$

$4.5 \%$

$5.9 \%$

$0.02 \%$

$10.8 \%$

\section{Language Skills}

To assess language skills, children completed the Picture Vocabulary subtest of the Woodcock Johnson Test of AchievementIII (WJ-III; Woodcock et al., 2007) in the fall and the spring of the school year. The initial items of the subtest require children to choose the picture that fits the named word for the initial items and then later items require children to provide names for each picture (44 items total). Six consecutive correct items are needed to establish test basal and six consecutive incorrect responses terminate the test. Reliability was adequate $(0.80)$ and $W$-scores were used to examine student growth.

\section{Literacy Skills}

To assess literacy skills, children completed the LetterWord Identification subtest of the Woodcock Johnson Test of Achievement-III (WJ-III; Woodcock et al., 2007) in the fall and the spring of the school year. This subtest (76 items total) requires children to identify individual letters and then read individual words of increasing difficulty. Six consecutive correct items are needed to establish test basal and six consecutive incorrect responses terminate the test. Reliability was adequate (0.94) and $W$-scores were used to examine student growth.

\section{Demographic Characteristics}

Several background demographic characteristics were assessed and included as control variables in our analyses. Specifically, 
age, gender, race, mother's education, and number of adults in the household were reported by the caregiver as part of the larger family background questionnaire.

\section{Analysis Plan}

We first report descriptive statistics and assess demographic characteristics as predictors of media use to understand the characteristics of children's media use in the sample. Next, to assess the first two research questions, whether media use was related to gains in children's language and literacy skills in early and middle childhood, we conduct regression analyses separately for language skills and literacy skills. Children's spring $W$-scores are dependent variables and models control for fall scores to assess change. The models also control for age, gender, race, mother's education, and number of adults in the household. Pursuant to the third research question, whether the relation between media use and children's language development was moderated by age, we add an interaction between age and media

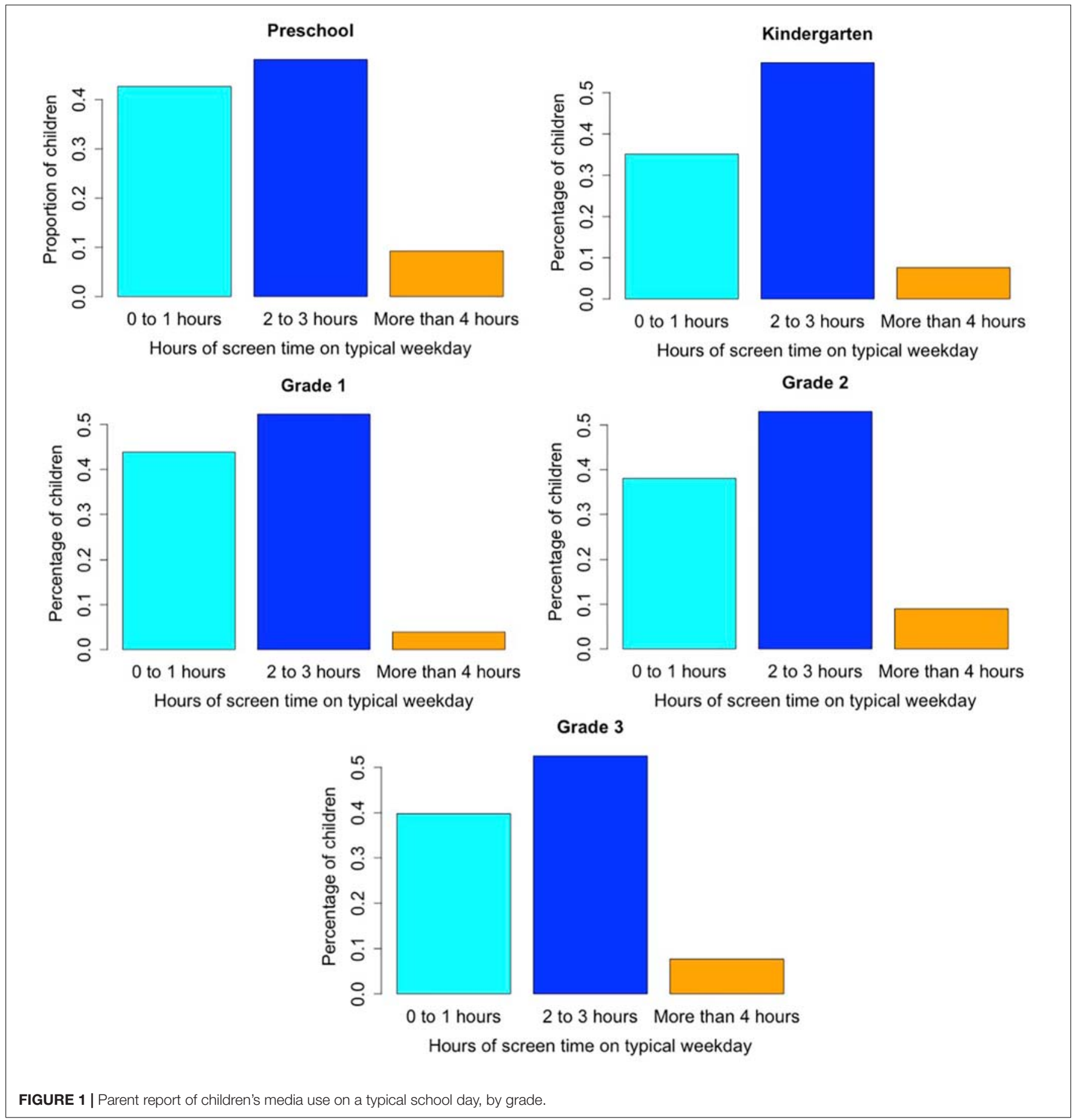


use into the previously described models by multiplying the age and media use variables and examining whether the interaction variable is statistically significant predictor of children's spring $W$-scores. Then, although our research questions are at the child level given that recruitment was conducted in classrooms and ICCs indicate that the grade and classroom accounted for a significant portion of the variability in the outcomes of interest (language ICC $=0.56$; literacy ICC $=0.84$ ), as a robustness check for our initial models we also conduct multilevel models accounting for classroom, testing for both main effects of media use and interactions with age. Finally, to be able to provide comparable results with previous studies using a single time point, we conduct separate regression analyses predicting children's spring language and literacy scores from media use, also reported in the spring.

\section{RESULTS}

\section{Descriptive Statistics and Predictors of Children's Media Use}

We first report descriptive statistics related to children's media use. See Table 1 for descriptive statistics for all study variables. Parents reported that $71.5 \%$ of children both watch videos and play games on a typical school day, with an additional $22.2 \%$ watching video but not playing games and $1.4 \%$ playing games but not watching video. Only $4.8 \%$ of children were reported to not use any media on a typical school day. Of those children who were reported to use media on a typical school day, $39.4 \%$ use media for $0-1 \mathrm{~h}, 53.0 \%$ use media for $2-3 \mathrm{~h}$, and $7.6 \%$ use media for $4 \mathrm{~h}$ or more (see Figure 1).

Children's media use was related to mother's education ( $p s<0.0003$ ), with children of mothers with lower education more likely to use $2-3 \mathrm{~h}$ or $4 \mathrm{~h}$ or more of media on a typical school day. Media use was also related to race $(p=0.04)$, such that White children were more likely to use $2-3 \mathrm{~h}$ of media on a typical school day (54\%) than 0-1 h (38\%), whereas non-White children were more evenly split between these categories (47 and $43 \%$, respectively). Similarly, boys were more likely to use $2-3 \mathrm{~h}$ of media on a typical school day (56\%) than $0-1 \mathrm{~h}(35 \%)$, whereas girls were more evenly split between these categories (49 and 44\%, respectively). Children with a larger number of adults in the home were more likely to use $2-3 \mathrm{~h}$ of media on a typical school day than to use $0-1 \mathrm{~h}, p=0.04$. Media use was not related to child age, $p s>0.40$.

\section{Relation Between Media Use and Language and Literacy Gains}

Results of a model predicting children's language gains showed that there was no association between media use and language gains, $p s>0.11$, see Table 2 . The interaction was not significant, ps $>0.21$.

In the model for literacy, results showed that children who used 4 or more hours of media on a typical school day had significantly smaller literacy gains than children who used $0-1 \mathrm{~h}$ of media per day $(B=5.2, p=0.002)$ or those who used $2-3 \mathrm{~h}$ of
TABLE 2 | Predicting language gains: results of a regression model $(N=1574)$.

\begin{tabular}{|c|c|c|c|c|}
\hline Predictor & $B$ & $\beta$ & $S E$ & $p$ \\
\hline Intercept & 156.33 & & 6.87 & $<0.0001^{\star \star \star}$ \\
\hline Baseline language & 0.65 & 0.70 & 0.02 & $<0.0001^{\star \star \star}$ \\
\hline Media use (2-3 h) & -0.54 & -0.02 & 0.34 & 0.12 \\
\hline Media use (more than $4 \mathrm{~h}$ ) & 0.06 & 0.001 & 0.66 & 0.93 \\
\hline Gender & -0.62 & -0.02 & 0.32 & $0.06^{+}$ \\
\hline Age & 0.15 & 0.20 & 0.01 & $<0.0001^{\star \star \star}$ \\
\hline Race (white) & 1.80 & 0.05 & 0.47 & $0.0001^{\star \star}$ \\
\hline Mother's education & 0.83 & 0.08 & 0.13 & $<0.0001^{\star \star \star}$ \\
\hline \multirow[t]{2}{*}{ Number of adults in household } & 0.30 & 0.01 & 0.27 & 0.27 \\
\hline & & & \multicolumn{2}{|c|}{ Adjusted $R^{2}=0.769$} \\
\hline
\end{tabular}

Outcome is Picture Vocabulary W-scores. Media use reference group is " $0-1 \mathrm{~h} . "$ The interaction between media use and age was not significant and was removed from the model. ${ }^{+} p<0.10,{ }^{* *} p<0.001$ and ${ }^{* * *} p<0.0001$.

media per day ( $B=4.7, p=0.005$; see Table 3 and Figure 2). Using media $2-3 \mathrm{~h}$ per day was not associated with smaller gains than $0-$ $1 \mathrm{~h}$ per day, $p=0.58$. As aforementioned, we added an interaction between age and media use into the previously described model to test our third research question. There was no interaction between age and screen media, $p s>0.21$.

In the multilevel robustness check model for language, as in the initial model, there was no association between media use and language gains, $p s>0.16$, see Table 4 . The interaction between age and media use was also not significant, $p s>0.27$.

Unlike the initial model, the association between media use and literacy gains was not significant in the multilevel robustness check model, $p s>0.10$, see Table 5. We expect that this difference is a result of reduced power in the more stringent model and of the effects of classroom on children's literacy skills that wash out smaller associations with home media use. The interaction between age and media use was also not significant, $p s>0.54$.

\section{Relation Between Media Use and Language and Literacy Skills at a Single} Time Point

To address our fourth research question, about the extent to which the results of models assessing skill gains differ from singletime-point models, we examined the association between media use and language skills at a single time point. Results showed a significant interaction $(B=-0.16, p=0.004$; see Table 6). Followup regression analyses for each age quartile showed that there was only a negative association between media use and language skills for children in the oldest quartile, 99 months (or a little over 8 years) and older, among whom having more than $4 \mathrm{~h}$ a day of media use per day was associated with lower language skills than having $0-1 \mathrm{~h}$ of media use $(B=-4.36, p=0.03)$, whereas there was no significant association between media use and language skills for younger children, $p$ s $>0.13$.

When examining the association between media use and literacy skills at a single time point, results showed a significant main effect of media use, such that using 2-3 h of media per day was associated with lower literacy scores than using $0-1 \mathrm{~h}$ of media use $(B=-6.00, p=0.0002)$ and using more than $4 \mathrm{~h}$ of 
TABLE 3 | Predicting literacy gains: results of a regression model $(N=1582)$.

\begin{tabular}{|c|c|c|c|c|}
\hline Predictor & $B$ & $\beta$ & $S E$ & $p$ \\
\hline Intercept & 75.99 & & 3.41 & $<0.0001^{\star \star \star}$ \\
\hline Baseline literacy & 0.83 & 0.91 & 0.01 & $<0.0001^{\star \star \star}$ \\
\hline Media use (2-3 h) & -0.48 & -0.004 & 0.86 & 0.58 \\
\hline Media use (more than $4 \mathrm{~h}$ ) & -5.17 & -0.02 & 1.70 & $0.002^{\star \star}$ \\
\hline Gender & 0.45 & 0.004 & 0.82 & 0.59 \\
\hline Age & 0.19 & 0.06 & 0.05 & $<0.0001^{\star \star \star}$ \\
\hline Race (white) & -0.46 & -0.003 & 1.15 & 0.69 \\
\hline Mother's education & -0.88 & -0.02 & 0.33 & $0.008^{\star \star}$ \\
\hline \multirow[t]{2}{*}{ Number of adults in household } & 1.45 & 0.02 & 0.69 & $0.04^{\star}$ \\
\hline & & & \multicolumn{2}{|c|}{ Adjusted $R^{2}=0.920$} \\
\hline
\end{tabular}

Outcome is Letter Word $W$-scores. Media use reference group is " $0-1$ h." * $p<$ $0.05,{ }^{* *} p<0.01$ and ${ }^{* * *} p<0.001$.

media per day was associated with lower literacy scores than using either 0 to hours $(B=-12.01, p=0.0001)$ or $2-3 \mathrm{~h}(B=6.01$, $p=0.049$; see Table 7$)$. The interaction between media use and age was not significant. ${ }^{1}$

\section{DISCUSSION}

This investigation was motivated by mixed findings in previous research, with some studies showing that media use was related

${ }^{1}$ These models were also conducted as multilevel models accounting for classrooms and results were similar. to lower language development and others showing no relation. The current study had several strengths, including a large sample and data on children's language and literacy skills collected at two time points. In our initial gain models, we found that only high levels of media use were related to smaller gains in skills and only for literacy, not for language. Furthermore, a robustness check indicated that even this effect was not strong enough to emerge in a model that accounted for the nested structure of the data. However, in single-time-point models, we found main effects of media use on children's literacy skills and an interaction between media use and age predicting language skills, such that there was an association only for the older children in our sample.

The discrepancy between the single-time-point and gain models highlights the limitations of correlational designs that do not have measures of children's skills over time. If we were relying on a single time point, we would draw markedly different conclusions from these data. If children's media use has a detrimental effect on language and literacy skills, we would expect it to continue to operate and manifest in gains over time. Instead, we find that the effects in the single-time-point models are not significant in the most robust gain models. This suggests that perhaps there is a third variable problem where media use is acting as a proxy for other family or home characteristics that are also associated with children's language and literacy skills. Accounting for fall scores largely eliminates these associations, leaving only the unique association between media use and language and literacy gains.

Given the concern and popular press coverage around children's media use, it is important to acknowledge

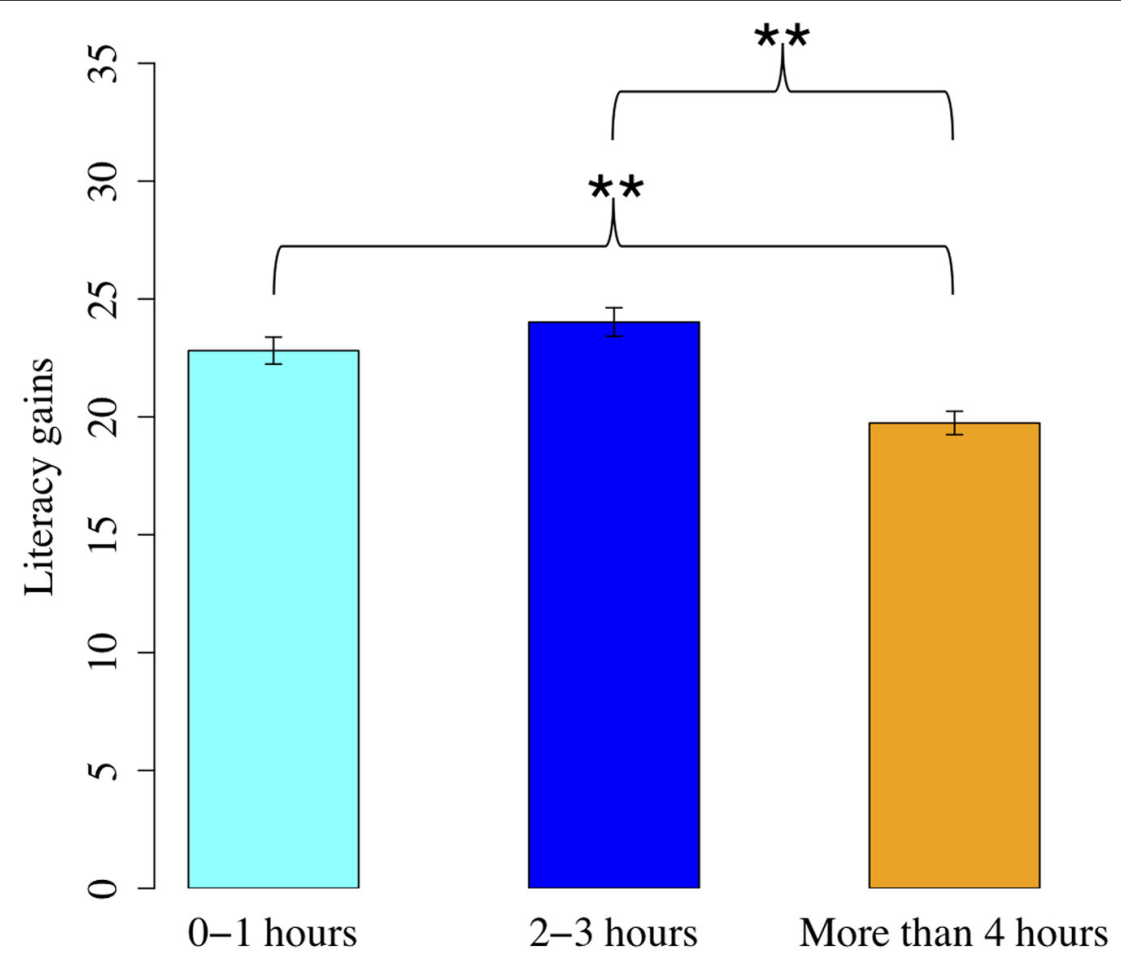

FIGURE 2 | Association between media use and literacy gains. ${ }^{* \star} p<0.001$. 
TABLE 4 | Predicting language gains: results of multilevel regression model $(N=1570)$.

\begin{tabular}{|c|c|c|c|c|}
\hline Predictor & $B$ & $\beta$ & SE & $p$ \\
\hline Intercept & 155.60 & & 6.95 & $<0.0001^{\star \star \star}$ \\
\hline Baseline language & 0.65 & 0.70 & 0.02 & $<0.0001^{\star \star \star}$ \\
\hline Media use (2-3 h) & -0.48 & -0.02 & 0.34 & 0.16 \\
\hline Media use (more than $4 \mathrm{~h}$ ) & 0.23 & 0.005 & 0.66 & 0.72 \\
\hline Gender & -0.61 & -0.02 & 0.32 & $0.06^{+}$ \\
\hline Age & 0.15 & 0.19 & 0.01 & $<0.0001^{\star \star \star}$ \\
\hline Race (white) & 1.81 & 0.05 & 0.48 & $0.0002^{\star *}$ \\
\hline Mother's education & 0.83 & 0.08 & 0.13 & $<0.0001^{\star \star \star}$ \\
\hline Number of adults in household & 0.31 & 0.01 & 0.27 & 0.26 \\
\hline & & & \multicolumn{2}{|c|}{ Adjusted $R^{2}=0.776$} \\
\hline
\end{tabular}

Outcome is Picture Vocabulary $\mathrm{W}$-scores. Media use reference group is " $0-1 \mathrm{~h} . "$ The interaction between media use and age was not significant and was removed from the model. ${ }^{+} p<0.05,{ }^{* *} p<0.001$ and ${ }^{* * *} p<0.0001$.

TABLE 5 | Predicting literacy gains: results of multilevel regression model $(N=1578)$.

\begin{tabular}{|c|c|c|c|c|}
\hline Predictor & $B$ & $\beta$ & SE & $p$ \\
\hline Intercept & 76.71 & & 4.66 & $<0.0001^{\star \star \star}$ \\
\hline Baseline literacy & 0.83 & 0.91 & 0.01 & $<0.0001^{\star \star \star}$ \\
\hline Media use (2-3 h) & -0.35 & -0.003 & 0.75 & 0.64 \\
\hline Media use (more than $4 \mathrm{~h}$ ) & -2.42 & -0.01 & 1.49 & 0.10 \\
\hline Gender & 0.59 & 0.01 & 0.70 & 0.40 \\
\hline Age & 0.18 & 0.05 & 0.05 & $0.0008^{\star \star}$ \\
\hline Race (white) & -1.46 & -0.01 & 1.05 & 0.16 \\
\hline Mother's education & 0.04 & 0.001 & 0.33 & 0.91 \\
\hline \multirow[t]{2}{*}{ Number of adults in household } & 0.88 & 0.01 & 0.60 & 0.15 \\
\hline & & & \multicolumn{2}{|c|}{ Adjusted $R^{2}=0.946$} \\
\hline
\end{tabular}

Outcome is Letter Word $W$-scores. Media use reference group is " $0-1 h$." The interaction between media use and age was not significant and was removed from the model. ${ }^{* *} p<0.001$ and ${ }^{* * *} p<0.0001$.

TABLE 6 | Predicting spring language scores: results of a regression model $(N=1583)$.

\begin{tabular}{lrrrc}
\hline Predictor & $\boldsymbol{B}$ & $\boldsymbol{\beta}$ & $\boldsymbol{S E}$ & $\boldsymbol{p}$ \\
\hline Intercept & 423.91 & & 2.12 & $<0.0001^{\text {***}}$ \\
Media use (2-3 h) & 3.50 & 0.13 & 2.47 & 0.16 \\
Media use (more than 4 h) & 13.53 & 0.25 & 4.75 & $0.004^{\text {}}$ \\
Gender & -0.50 & -0.02 & -1.09 & 0.28 \\
Age & 0.54 & 0.69 & 0.02 & $<0.0001^{\text {*** }}$ \\
Race (white) & 7.10 & 0.19 & 0.65 & $0.0001^{\text {}}$ \\
Mother's education & 2.33 & 0.24 & 0.17 & $<0.0001^{\text {}}$ \\
Number of adults in household & 0.32 & 0.01 & 0.39 & 0.41 \\
Media use (2-3 h) $\times$ age & -0.05 & -0.16 & 0.03 & $0.099^{+}$ \\
Media use (more than 4 h) $\times$age & -0.16 & -0.26 & 0.05 & $0.004^{\text {}}$ \\
& & & Adjusted $R^{2}=0.534^{\text {*** }}$
\end{tabular}

Outcome is Picture Vocabulary $W$-scores. Media use reference group is " $0-1$ h." ${ }^{+} p<0.05,{ }^{* *} p<0.01$ and ${ }^{* * *} p<0.0001$.

non-significant effects in this domain. There has been fear around the effects of novel technologies and mediums in the past, including concerns about the effects of exposure to early
TABLE 7 | Predicting spring literacy scores: results of a regression model $(N=1583)$.

\begin{tabular}{lrrrc}
\hline Predictor & $\boldsymbol{B}$ & $\boldsymbol{\beta}$ & $\boldsymbol{S E}$ & $\boldsymbol{p}$ \\
\hline Intercept & 191.53 & & 5.23 & $<0.0001^{\text {**}}$ \\
Media use (2-3 h) & -6.00 & -0.05 & 1.59 & $0.0002^{\star \star}$ \\
Media use (more than 4 h) & -12.01 & -0.05 & 3.12 & $0.0001^{\star \star}$ \\
Gender & 2.29 & 0.02 & 1.5 & 0.13 \\
Age & 2.78 & 0.82 & 0.04 & $<0.0001^{\text {}}$ \\
Race (white) & -2.18 & -0.01 & 2.11 & 0.30 \\
Mother's education & 6.53 & 0.15 & 0.57 & $<0.0001^{\star \star \star}$ \\
Number of adults in household & 0.49 & 0.01 & 1.27 & 0.70 \\
& & & Adjusted $R^{2}=0.728$
\end{tabular}

Outcome is Letter Word W-scores. Media use reference group is " $0-1$ h." The interaction between media use and age was not significant and was removed from the model. ${ }^{* *} p<0.001$ and ${ }^{* * *} p<0.0001$.

radio shows in the 1920s and moral panic about children reading comic books in the 1950s (Wartella and Jennings, 2000; Tilley, 2012). Although children's media use in the 21st century may appear extreme and strikingly different from the childhood their parents experienced 30 or 40 years ago, non-significant associations such as those reported here suggest that societal fears around children's media use may be exaggerated.

Importantly, even in our initial gain models, we only found associations between media use and literacy gains for high levels of use, whereas literacy gains did not differ between more moderate levels of use and low use. These data suggest that any effect of media use on literacy skills may represent a threshold effect, rather than a linear relationship. In addition to the use of single-time-point approaches, this type of relation may explain mixed findings in the literature because analyses testing only for a linear relationship may not be sensitive enough to detect this kind of threshold. Why might this threshold effect exist? One possible explanation is that media use has a negative effect on literacy skills when it is used in large amounts on a daily basis and thus displaces important educational activities like shared book reading and other activities with a print focus. On the other hand, more moderate amounts of media use may be less likely to displace such activities or may not displace them to the extent that it disrupts literacy development. The somewhat small proportion of children falling into the highest category of media use $(7.6 \%$ using media for 4 or more hours on a typical school day) may contribute to lower power to detect effects of this extreme amount of use in our robustness check models.

Given previous findings suggesting that media use can displace important language- and literacy-enhancing activities, the non-significant effects reported here are somewhat surprising. However, there are several possible explanations for these findings. Importantly, media use is not monolithic, and some media experiences could be more supportive of language development than others (Linebarger and Vaala, 2010; Dore et al., 2017). We measured only quantity of media use but features of that media use may moderate any effects on language development. First, the relation between media and language development may depend on how much adults engage with children during media use. In other words, the role that media 
use plays in a child's language and literacy development may differ depending on whether she primarily uses media by herself or whether most of her media use involves a caregiver using and discussing media with her. When this type of joint media engagement is frequent, language and literacy development may be more positive because the media experience does not replace caregiver-child interaction and instead extends it to a new context. Second, given the importance of joint attention and serve-and-return responding to language development (e.g., Tomasello and Farrar, 1986), it may be significant that some types of media are themselves interactive. That is, digital games and apps can be responsive to the child's actions in a way that a television show is not (Sheehan and Uttal, 2016). Although the interactivity afforded by digital devices is less flexible and responsive than a caregiver might be, the proportion of children's media use that includes interactive rather than non-interactive media may differentially predict language and literacy skills because children are more likely to be actively engaged when media uses interactive features. Third, educational media may be more supportive of language and literacy development than content that is intended primarily for entertainment, as research suggests that children can learn from high-quality television (Mares and Pan, 2013). Because most previous research and the current study focus solely on quantity of media use and do not allow for an examination of these factors, null effects and conflicting findings may mask important effects that would emerge when these moderators are considered.

Another possible contributor to these findings relates to the age range of our sample. Most previous research that has found negative relations between media use and language development has been conducted with younger children. Media use may not displace the same activities for older children as it does for toddlers and younger preschoolers. For younger children, media use may most commonly displace activities like storybook reading and parent-child interaction, whereas for older children who are becoming more independent, it may be more likely to displace peer and independent play which are likely to be less important for language and literacy development. In line with this idea, a recent study showed that media use was associated with lower physical activity among 6- to 11-year-olds but not with time for unstructured play (Goode et al., 2019).

An important contribution of the current study is that we used a wide age range, including older children than have typically been studied in past research in this domain. Many of the previous studies have focused on infants and toddlers, and little research has investigated the relation between media use and language and literacy for children in the early elementary grades. Our findings show that the inverse relation between these variables may not extend to this older age range, perhaps because early childhood is a more sensitive time for language development. Notably, we also found that the relation between media use and language and literacy growth did not differ across the age range investigated (PreK to 3rd grade), suggesting that any effects in early childhood may be restricted to toddlers and the early preschool years.

Although we find non-significant relations between media use and language and literacy skills in our most robust models, there may be detrimental effects of media use in other domains. For example, children's media use, and evening media in particular, has been associated with increased sleep problems and changes in sleep patterns (Garrison et al., 2011; Beyens and Nathanson, 2019). Some studies also find that preschoolers' media use is correlated with lower social skills (Hinkley et al., 2018) and executive function skills (Nathanson et al., 2014). It will be important for future research to investigate the relation between media use and other domains of child development. Furthermore, although we had a large and somewhat diverse sample, we did not have data for all of the children in our sample because of missing surveys and items, and our findings may not generalize to other populations. Future research should investigate these relations in a representative sample of children and families.

Although additional research is needed to further elucidate the role that media plays in child development, the current findings suggests that, at least by PreK and for language and literacy skills, any role of media use in children's development is likely to be small at most. There may be important moderators that were not examined here, such that certain types of media use or media use in certain contexts may be more strongly associated with children's skills. Importantly, children may also benefit from some media use, such as video games and exergames (Blumberg et al., 2019), and overgeneralizations that demonize media use could lead to children missing out on valuable opportunities for media to contribute to positive aspects of their lives. Given its prevalence in children's lives, media use is a fundamental aspect of the home environment and it will be important for future research to investigate how it relates to both other aspects of the home environment and to children's developing skills.

\section{DATA AVAILABILITY STATEMENT}

The raw data supporting the conclusions of this article will be made available by the authors, without undue reservation, to any qualified researcher.

\section{ETHICS STATEMENT}

The studies involving human participants were reviewed and approved by The Ohio State University Institutional Review Board. Written informed consent to participate in this study was provided by the participants' legal guardian/next of kin.

\section{AUTHOR CONTRIBUTIONS}

LJ, KP, T-JL, and JL contributed to conceptualization of the larger project and obtained funding. $\mathrm{RD}$ and JL contributed to the conceptualization of the current study and conducted data analyses. RD drafted the work. JL, LJ, KP, and T-JL contributed to editing and revising and gave final approval of the version to be submitted. All authors contributed to the article and approved the submitted version. 


\section{FUNDING}

The research reported here was supported by Institute of Education Sciences, through Grant R305N160024 awarded to The Ohio State University (LJ).

\section{REFERENCES}

Barnett, M. A., Gustaffson, H., Deng, M., Mills-Koonce, W. R., and Cox, M. (2012). Bidirectional associations among sensitive parenting, language development, and social competence. Infant Child Dev. 21, 374-393.

Beyens, I., and Nathanson, A. I. (2019). Electronic media use and sleep among preschoolers: evidence for time-shifted and less consolidated sleep. Health Commun. 34, 537-544. doi: 10.1080/10410236.2017.1422102

Bianchi, S. M., Robinson, J. P., and Milke, M. A. (2006). The Changing Rhythms of American Family Life. New York, NY: Russel Sage Foundation.

Blumberg, F. C., Deater-Deckard, K., Calvert, S. L., Flynn, R. M., Green, C. S., Arnold, D., et al. (2019). Digital games as a context for children's cognitive development: research recommendations and policy considerations. Soc. Policy Rep. 32, 1-33. doi: 10.1002/sop2.3

Bruner, J. (1978). The role of dialogue in language acquisition. The Child's Conception of Language, 241-256.

Chen, R. S., and Vellutino, F. R. (1997). Prediction of reading ability: a crossvalidation study of the simple view of reading. J. Lit. Res. 29, 1-24.

Clarke, A. T., and Kurtz-Costes, B. (1997). Television viewing, educational quality of the home environment, and school readiness. J. Educ. Res. 90, 279-285. doi: 10.1080/00220671.1997.10544584

Cunningham, A. E., and Stanovich, K. E. (1997). Early reading acquisition and its relation to reading experience and ability 10 years later. Dev. Psychol. 33:934. doi: 10.1037//0012-1649.33.6.934

Dore, R. A., Shirilla, M., Hopkins, E., Collins, M., Scott, M., Schatz, J., et al. (2019). Education in the app store: using a mobile game to support U.S. preschoolers' vocabulary learning. J. Child. Media 13, 452-471. doi: 10.1080/17482798.2019. 1650788

Dore, R. A., Zosh, J. M., Hirsh-Pasek, K., and Golinkoff, R. M. (2017). "Plugging into word learning: the role of electronic toys and digital media in language development," in Cognitive Development In Digital Contexts, eds F. Blumberg, and P. Brooks (Waltham, MA: Elsevier), 75-91.

Duch, H., Fisher, E. M., Ensari, I., Font, M., Harrington, A., Taromino, C., et al. (2013). Association of screen time use and language development in hispanic toddlers: a cross-sectional and longitudinal study. Clin. Pediatr. 52, 857-865. doi: 10.1177/0009922813492881

Fiorini, M., and Keane, M. P. (2014). How the allocation of children's time affects cognitive and noncognitive development. J. Lab. Econ. 32, 787-836.

Flynn, R. M., Staiano, A. E., Beyl, R., Richert, R. A., Wartella, E., and Calvert, S. L. (2018). The influence of active gaming on cardiorespiratory fitness in black and Hispanic youth. J. Sch. Health 88, 768-775. doi: 10.1111/josh.12679

Gao, Z., Zeng, N., Pope, Z. C., Wang, R., and Yu, F. (2018). Effects of exergaming on motor skills competence, perceived competence, and physical activity in preschool children. J. Sport Health Sci. 8, 106-113.

Garrison, M. M., Liekweg, K., and Christakis, D. A. (2011). Media use and child sleep: the impact of content, timing, and environment. Pediatrics 128, 29-35. doi: 10.1542/peds.2010-3304

Goode, J. A., Fomby, P., Mollborn, S., and Limburg, A. (2019). Children's Technology Time in Two US Cohorts. Child Indic. Res. 13, 1107-1132.

Hinkley, T., Brown, H., Carson, V., and Teychenne, M. (2018). Cross sectional associations of screen time and outdoor play with social skills in preschool children. PLoS One. 13:e0193700. doi: 10.1371/journal.pone.0193700

Hirsh-Pasek, K., Adamson, L. B., Bakeman, R., Owen, M. T., Golinkoff, R. M., Pace, A., et al. (2015). The contribution of early communication quality to low-income children's language success. Psychol. Sci. 26, 1071-1083.

Hoover, W. A., and Gough, P. B. (1990). The simple view of reading. Read. Writ. 2, $127-160$.

Hurwitz, L. B. (2018). Getting a read on ready to learn media: a meta-analysis review of effects on literacy. Child Dev. 90, 1754-1771.

\section{ACKNOWLEDGMENTS}

We would like to thank the research team, staff, and families without whom this research would not have been possible.

Huttenlocher, P. R. (2002). Neural Plasticity: The Effect of Environment on the Development of Cerebral Cortex. Cambridge, MA: Harvard University Press.

Hutton, J. S., Dudley, J., Horowitz-Kraus, T., DeWitt, T., and Holland, S. K. (2019). Associations between screen-based media use and brain white matter integrity in preschool-aged children. JAMA Pediatr. 2019:e193869.

Kendeou, P., Van den Broek, P., White, M. J., and Lynch, J. S. (2009). Predicting reading comprehension in early elementary school: the independent contributions of oral language and decoding skills. J. Educ. Psychol. 101:765. doi: $10.1037 / \mathrm{a} 0015956$

Khan, K. S., Purtell, K. M., Logan, J., Ansari, A., and Justice, L. M. (2017). Association between television and parent-child reading in the early home environment. J. Dev. Behav. Pediatr. 38, 521-527. doi: 10.1097/DBP. 0000000000000465

Kim, Y. S. G. (2016). Direct and mediated effects of language and cognitive skills on comprehension of oral narrative texts (listening comprehension) for children. J. Exp. Child Psychol. 141, 101-120. doi: 10.1016/j.jecp.2015.08.003

Kim, Y. S. G. (2017). Why the simple view of reading is not simplistic: Unpacking component skills of reading using a direct and indirect effect model of reading (DIER). Sci. Stud. Read. 21, 310-333. doi: 10.1080/10888438.2017.1291643

Lane, H. C., and Yi, S. (2017). Playing with virtual blocks: minecraft as a learning environment for practice and research. Cogn. Dev. Digi. Context. 2017, $145-166$.

Lavigne, H. J., Hanson, K. G., and Anderson, D. R. (2015). The influence of television coviewing on parent language directed at toddlers. J. Appl. Dev. Psychol. 36, 1-10. doi: 10.1016/j.appdev.2014.11.004

Linebarger, D. L., and Vaala, S. E. (2010). Screen media and language development in infants and toddlers: an ecological perspective. Dev. Rev. 30, 176-202. doi: 10.1016/j.dr.2010.03.006

Mares, M.-L., and Pan, Z. (2013). Effects of sesame street: a meta-analysis of children's learning in 15 countries. J. Appl. Dev. Psychol. 34, 140-151. doi: 10.1016/j.appdev.2013.01.001

Nathanson, A. I., Aladé, F., Sharp, M. L., Rasmussen, E. E., and Christy, K. (2014). The relation between television exposure and executive function among preschoolers. Dev. Psychol. 50:1497. doi: 10.1037/a0035714

Nathanson, A. I., and Rasmussen, E. E. (2011). TV viewing compared to book reading and toy playing reduces responsive maternal communication with toddlers and preschoolers. Hum. Commun. Res. 37, 465-487. doi: 10.1111/j. 1468-2958.2011.01413.x

NICHD Early Child Care Research Network (1999). Child care and mother-child interaction in the first 3 years of life. Dev. Psychol. 35, 1399-1413. doi: 10.1037/ 0012-1649.35.6.1399

Pagani, L. S., Fitzpatrick, C., and Barnett, T. A. (2013). Early childhood television viewing and kindergarten entry readiness. Pediatr. Res. 74, 350-355. doi: 10. 1038/pr.2013.105

Patterson, J. L. (2002). Relationships of expressive vocabulary to frequency of reading and television experience among bilingual toddlers. Appl. Psycholinguist. 23, 493-508.

Payne, A. C., Whitehurst, G. J., and Angell, A. L. (1994). The role of home literacy environment in the development of language ability in preschool children from low-income families. Early Childh. Res. Q. 9, 427-440.

Pempek, T. A., Demers, L. B., Hanson, K. G., Kirkorian, H. L., and Anderson, D. R. (2011). The impact of infant-directed videos on parentchild interaction. J. Appl. Dev. Psychol. 32, 10-19. doi: 10.1016/j.appdev.2010. 10.001

Pence, K., and Alamos, P. (2019). "Electronic media use profiles and school readiness competencies for preschoolers from low-income backgrounds," in Poster Presented At The Biennial Meeting Of The Society For Research In Child Development, Baltimore, MD.

Penuel, W. R., Bates, L., Gallagher, L. P., Pasnik, S., Llorente, C., Townsend, E., et al. (2012). Supplementing literacy instruction with a media-rich intervention: 
results of a randomized controlled trial. Early Childh. Res. Q. 27, 115-127. doi: 10.1016/j.ecresq.2011.07.002

Rideout, V. (2017). The Common Sense Census: Media Use By Kids Age Zero To Eight. San Francisco, CA: Common Sense Media.

Sheehan, K. J., and Uttal, D. H. (2016). Children's learning from touch screens: a dual representation perspective. Front. Psychol. 7:1220. doi: 10.3389/fpsyg.2016. 01220

Taylor, G., Monaghan, P., and Westermann, G. (2017). Investigating the association between children's screen media exposure and vocabulary size in the UK. J. Child. Media 12, 51-65. doi: 10.1080/17482798.2017.1365737

Tilley, C. L. (2012). Seducing the innocent: fredric wertham and the falsifications that helped condemn comics. Inf. Cult. 47, 383-413. doi: 10.1353/lac.2012.0024

Tomasello, M., and Farrar, J. (1986). Joint attention and early language. Child Dev. $57,1454-1463$.

Wartella, E. A., and Jennings, N. (2000). Children and computers: new technology. old concerns. Future Child. 10, 31-43.
Woodcock, R. W., Shrank, F. A., McGrew, K. S., and Mather, N. (2007). WoodcockJohnson III Normative Update (W J III NU). Itasch, IL: Riverside Publishing.

Disclaimer: The opinions expressed are those of the authors and do not represent views of the Institute or National Center for Education Research.

Conflict of Interest: The authors declare that the research was conducted in the absence of any commercial or financial relationships that could be construed as a potential conflict of interest.

Copyright $(2020$ Dore, Logan, Lin, Purtell and Justice. This is an open-access article distributed under the terms of the Creative Commons Attribution License (CC BY). The use, distribution or reproduction in other forums is permitted, provided the original author(s) and the copyright owner(s) are credited and that the original publication in this journal is cited, in accordance with accepted academic practice. No use, distribution or reproduction is permitted which does not comply with these terms. 
OPEN ACCESS

Edited by:

Frank Niklas,

Ludwig Maximilian University

of Munich, Germany

Reviewed by:

Tijs Kleemans,

Radboud University Nijmegen,

Netherlands

Susanne Ebert,

Norwegian University of Science

and Technology, Norway

*Correspondence:

David J. Purpura

purpura@purdue.edu

Specialty section:

This article was submitted to

Educational Psychology,

a section of the journal

Frontiers in Psychology

Received: 20 November 2019

Accepted: 13 July 2020

Published: 06 August 2020

Citation:

Purpura DJ, King YA, Rolan E, Hornburg CB, Schmitt SA, Hart SA and Ganley CM (2020) Examining the Factor Structure of the Home

Mathematics Environment to Delineate Its Role in Predicting Preschool Numeracy, Mathematical

Language, and Spatial Skills.

Front. Psychol. 11:1925.

doi: 10.3389/fpsyg.2020.01925

\section{Examining the Factor Structure of the Home Mathematics Environment to Delineate Its Role in Predicting Preschool Numeracy, Mathematical Language, and Spatial Skills}

David J. Purpura ${ }^{1 *}$, Yemimah A. King ${ }^{1}$, Emily Rolan'1, Caroline Byrd Hornburg ${ }^{2}$, Sara A. Schmitt ${ }^{1}$, Sara A. Hart ${ }^{3}$ and Colleen M. Ganley ${ }^{3}$

\footnotetext{
${ }^{1}$ Department of Human Development and Family Studies, Purdue University, West Lafayette, IN, United States, ${ }^{2}$ Department of Human Development and Family Science, Virginia Tech, Blacksburg, VA, United States, ${ }^{3}$ Department of Psychology, Florida State University, Tallahassee, FL, United States
}

A growing body of evidence suggests that the ways in which parents and preschool children interact in terms of home-based mathematics activities (i.e., the home mathematics environment; $\mathrm{HME}$ ) is related to children's mathematics development (e.g., primarily numeracy skills and spatial skills); however, this body of evidence is mixed with some research supporting the relation and others finding null effects. Importantly, few studies have explicitly examined the factor structure of the HME and contrasted multiple hypothesized models. To develop more precise models of how the HME supports children's mathematics development, the structure of the HME needs to be examined and linked to mathematics performance. The purpose of this study was to extend prior work by replicating the factor structure of the HME (as one general HME factor and three specific factors of direct numeracy, indirect numeracy, and spatial) and using those factors to predict direct assessments of children's numeracy, mathematical language, and spatial skills. It was hypothesized that the general HME factor would be related to each direct assessment, the direct numeracy factor would be related to both numeracy and mathematical language, and the spatial factor would be related to spatial skills. Using a sample of 129 preschool children $(M$ age $=4.71$ years, $S D=0.55 ; 46.5 \%$ female), a series of confirmatory factor analyses were conducted. Results diverged somewhat from prior work as the best fitting model was a bifactor model with a general HME factor and two specific factors (one that combined direct and indirect numeracy activities and another of spatial activities) rather than three specific factors as had previously been found. Further, structural equation modeling analyses suggested that, in contrast to expectations, only the direct + indirect numeracy factor was a significant predictor of direct child assessments when accounting for age, sex, and parental education. These findings provide evidence that a bifactor model is important 
in understanding the structure of the HME, but only one specific factor is related to children's outcomes. Delineating the structure of the HME, and how specific facets of the HME relate to children's mathematics skills, provides a strong foundation for understanding and enhancing the mechanisms that support mathematics development.

Keywords: home mathematics environment, mathematics, parent-child interactions, numeracy skills, mathematical language, spatial skills, preschool

\section{INTRODUCTION}

The home learning environment that parents provide for their children is an important context for the development of academic skills, including mathematics (Manolitsis et al., 2013). Children typically acquire early mathematics skills in everyday informal settings and experiences, such as interacting with parents in the home (Ginsburg, 1977; Baroody and Wilkins, 1999; Dickinson and Tabors, 2001; Melhuish et al., 2008). Emerging evidence suggests that the "home mathematics environment" (HME), a term used to describe mathematics-related activities children engage in with their parents, is a significant predictor of children's broad mathematics skills (e.g., encompassing specific skills such as numeracy, geometric reasoning and spatial skills, patterning skills, and measurement; Blevins-Knabe and Musun-Miller, 1996; LeFevre et al., 2009; Kleemans et al., 2012; Levine et al., 2012; Niklas and Schneider, 2014; Hart et al., 2016; Zippert and RittleJohnson, 2018). Despite this growing body of work, few studies have explicitly examined and contrasted if there are distinct aspects of the HME for a preschool-age population or the extent to which these different aspects may uniquely predict direct assessments of children's mathematics outcomes. Further, studies on the HME typically only include child skills such as numeracy and spatial skills because they are two of the strongest predictors of broader mathematics skills development (Nguyen et al., 2016; Mix, 2019). Other domains such as mathematical language, an important foundation for numeracy development in young children (Purpura and Logan, 2015), has not previously been linked to the HME. The present study addressed these limitations by (1) comparing multiple factor structures of the HME in a sample of preschoolers, and (2) examining the extent to which different HME factors predict children's numeracy skills, mathematical language skills, and spatial skills, which are key abilities that predict more advanced mathematics development (Aunola et al., 2004; Toll and Van Luit, 2014; Verdine et al., 2014; Nguyen et al., 2016).

\section{Structure of the Home Mathematics Environment}

The HME has been identified as a critical context where young children develop their early mathematics skills (Blevins-Knabe and Musun-Miller, 1996; Gunderson and Levine, 2011; Anders et al., 2012; Blevins-Knabe, 2012; Manolitsis et al., 2013; Niklas et al., 2016). For example, children whose parents used more number talk (e.g., counting and labeling large sets of objects at home) with them when they were between 14 and 30 months old had higher mathematics skills than their peers at age three (Gunderson and Levine, 2011). In another study, when families attended meetings that provided them with information on the importance of the HME and the principles of counting, the frequency of parent-child engagement in mathematics-related activities increased and children had higher mathematics skills than children from families who did not attend those sessions (Niklas et al., 2016). Yet, understanding of the HME is still in development (Elliott and Bachman, 2017), particularly in terms of what are its unique aspects and how these aspects individually relate to young children's mathematics skills.

The HME has been conceptualized in a variety of ways, but most work has typically focused on the numeracy aspects of the HME (LeFevre et al., 2009; Thompson et al., 2017). Specifically, these studies focus on two components of the construct: direct and indirect numeracy activities (LeFevre et al., 2009, 2010; Manolitsis et al., 2013; Skwarchuk et al., 2014; Thompson et al., 2017). Direct activities are specific experiences that parents provide for their children that explicitly teach quantitative skills (e.g., counting, reading number storybooks). Indirect activities consist of a broader range of everyday experiences that implicitly teach quantitative skills (e.g., measuring ingredients, talking about money). Direct numeracy and indirect numeracy activities have also been called formal numeracy and informal numeracy activities, respectively (Manolitsis et al., 2013).

More recent work has pointed to the direct and indirect numeracy environments as being just two components of a broader HME, which also includes non-numeracy components such as the spatial environment (Dearing et al., 2012; Hart et al., 2016) and patterning environment (Zippert and Rittle-Johnson, 2018). For example, Dearing et al. (2012) proposed an alternative model to the direct numeracy and indirect numeracy structure of the HME that consisted of two factors: numeracy activities and spatial activities. Spatial activities included experiences that involve the perception of objects in space (e.g., drawing maps, measuring objects, building, playing with puzzles). In a more recent study that also considered spatial activities, Hart et al. (2016) tested a range of plausible models of the HME, that included both the 'direct vs. indirect' and 'numeracy vs. spatial' models, and also included testing bifactor models. Bifactor models allow the item variance to be partitioned into that which goes with a full general factor, and that which should be separated into specific factors. In this context, they found that that the best fit was a bifactor model that consisted of a general factor (general HME; this factor accounted for the common variance from across all the aspects of the HME) and three specific factors (direct numeracy environment, indirect numeracy environment, and spatial environment; these factors included the variance specific to each component after removing the common variance shared across all items). 
Beyond a few studies, empirical evidence explicitly evaluating the factor structure of the HME is relatively limited. Some studies have assumed the HME to be a unidimensional construct (Blevins-Knabe and Musun-Miller, 1996) or identified a unidimensional construct through exploratory factor analysis (Blevins-Knabe and Musun-Miller, 1996; Kleemans et al., 2012). Other studies have shown the HME is multi-dimensional through exploratory factor analyses (LeFevre et al., 2009, 2010; Dearing et al., 2012; Manolitsis et al., 2013) or by using confirmatory factor analysis to test the model fit of one potential model (Van Hoof et al., 2020). However, only Hart et al. (2016) have explicitly contrasted multiple potential factor structures to examine the best-fitting factor structure. Examining the structure of the HME is important for understanding the extent to which a broad indicator of the HME best represents the construct or whether the construct is comprised of distinct, but related components. Further, understanding the structure of the HME is critical for identifying if specific components of the HME are differentially related to mathematics outcomes-and thereby, if more complex models of how the home environment potentially impacts development of specific mathematics skills are needed. There is a critical need to further evaluate the structure and test these potential models in a new sample to provide further empirical evidence for the structure of the HME. In doing so, we can better clarify if there are different aspects of the HME and what characterizes these aspects.

\section{Relations Between the Home Mathematics Environment and Preschool Mathematics Skills}

One of the core purposes of understanding the structure of the HME is to then link it to children's performance on measures of mathematics skills-in order to develop more precise models of which aspects of the home environment may support children's mathematics development. Importantly, children's early mathematics skills are not a unitary construct; they encompass a broad range of concepts including numeracy, geometric reasoning and spatial skills, patterning, and measurement (Milburn et al., 2019) - though, most empirical work on early mathematics has focused on aspects of numeracy (Methe et al., 2011) and spatial skills (Mix and Cheng, 2012) because they are most predictive of long-term mathematics development (Nguyen et al., 2016; Mix, 2019). Paralleling this work, studies of the HME also primarily focus on children's numeracy skills (e.g., counting, numerical relations, and operations; Purpura and Lonigan, 2013). However, some work has also explicitly examined the unique effects that spatial activities within the HME may have on children's mathematics outcomes (Dearing et al., 2012; Zippert and Rittle-Johnson, 2018). Furthermore, no work has evaluated the relation between the HME and mathematical language-a construct that appears to underlie both numeracy (Purpura et al., 2011) and spatial skills (Casasola et al., 2020). It is important to note that, regardless of which aspect of children's performance is considered, the literature linking the HME to mathematics skills is somewhat mixed.

\section{Numeracy}

Most of the work linking the HME to numeracy skills has focused on the direct numeracy vs. indirect numeracy structure of HME and found that direct numeracy activities are a more consistent predictor of numeracy skills than are indirect numeracy activities (LeFevre et al., 2010; Manolitsis et al., 2013; Skwarchuk et al., 2014; Thompson et al., 2017), though there are a few exceptions (LeFevre et al., 2009; Skwarchuk et al., 2014). For example, Skwarchuk et al. (2014) found that direct numeracy and indirect numeracy activities were related to different aspects of kindergarteners' numeracy skills, such that direct numeracy activities predicted children's symbolic number system knowledge (e.g., knowledge of exact quantities) and indirect numeracy activities predicted children's non-symbolic number knowledge (e.g., approximate estimation of quantities). In contrast, results of the Hart et al. (2016) bifactor model suggested the general HME factor predicted parent reports of 3-to 8-year-olds' general mathematics skills, whereas the direct numeracy and indirect numeracy factors were not significant predictors. However, this study was limited by its use of a broad measure of parent-reported mathematics skills instead of direct assessments of children's skills which may have introduced assessor bias into the models (parents rated both the HME and children's performance which may have inflated the general relation among the variables). Moreover, the parent report of children's skills included ratings of children's "mathematics," "numeracy," and "spatial" skills which also may explain why a relation was found with the general HME factor rather than specific factors. If a direct assessment of children's numeracy skills was used, it would be expected that the direct numeracy factor would be uniquely related.

\section{Spatial Skills}

Spatial skills have been identified as a core component and predictor of broad mathematical skills such as geometric reasoning (Verdine et al., 2014; Rittle-Johnson et al., 2019) and are malleable through intervention (Casey et al., 2008; Schmitt et al., 2018). Some evidence also suggests that parent-child engagement-specific to spatial engagement-may be associated with young children's spatial language and spatial skills (Ferrara et al., 2011). For example, parents' use of spatial language at home is longitudinally related to children's use of spatial language (Pruden et al., 2011; Pruden and Levine, 2017). Further, preschool children perform better on spatial transformation tasks when they have parents who engaged with them in more puzzle play activities between the ages of two and four (Levine et al., 2012). However, there is limited work linking parent report of parentchild engagement in spatial activities with children's spatial skills (e.g., Dearing et al., 2012; Zippert and Rittle-Johnson, 2018), particularly at the preschool level. For example, Zippert and Rittle-Johnson (2018) did not find a significant relation between parent ratings of the home spatial environment and children's spatial skills, though neither the factor structure of the HME nor the item composition of the factor were explicitly evaluated in that study. Further, in older children (6- to 7-year olds), although Dearing et al. (2012) did examine the factor structure of the HME and separated out spatial and numerical activities, spatial 
activities did not predict spatial skills. Finally, in a sample that spanned the preschool and early elementary school period, Hart et al. (2016) found evidence that the home spatial environment was distinct from other aspects of the HME, but they did not find a direct relation between the factor and parent report of children's performance. However, as similar to the limitations noted in the numeracy section, the parent report was a broad indicator of children's mathematics skills (encompassing broad mathematics, numeracy, and spatial skills). Using a more refined measure of the home spatial environment and a direct assessment of preschool children's spatial skills, it could be expected that a relation between the spatial environment and children's spatial skills might be found.

\section{Mathematical Language}

One additional aspect of children's early mathematics skills that has been linked to both numeracy (Purpura and Reid, 2016) and spatial skills (Casasola et al., 2020) is mathematical language (e.g., understanding words and concepts such as many, most, few, fewest, before, after, near, far). Mathematical language has been shown to be an important predictor of children's mathematics development during both preschool (Purpura and Logan, 2015) and early elementary school (Toll and Van Luit, 2014). Though existing work has not directly linked parent reported HME to mathematical language, there is a growing body of evidence that would support that link. For example, recent evidence in an experimental setting suggests that parent-child interactions that are explicitly focused on teaching mathematics (direct numeracy activities) show greater amounts of math-related talk during these activities than in less direct mathematicsrelated activities or non-mathematics related activities (Eason and Ramani, 2020)_-suggesting that when parents are engaged in direct mathematics activities, they are more likely to use (and potentially support) mathematical language compared to when they are engaged in less directed activities. Moreover, the direct activities that parents and children engage in most frequently (e.g., counting and comparing; Thompson et al., 2017) involve the numeracy skills that are most closely related to children's mathematical language knowledge (Hornburg et al., 2018). These findings suggest that when parents engage in direct mathematics activities, there may be opportunities that not only support children's knowledge of numeracy, but also their mathematical language skills. In terms of parent-reported HME, a recent study also revealed that parent report of direct home numeracy activities not only predicts preschoolers' numeracy performance, but also their general vocabulary knowledge, but it does not predict specific early literacy skills (Napoli and Purpura, 2018). Given that mathematical language is an aspect of both language and mathematics, this finding would also suggest that high quality direct numeracy activities may support mathematical language; however, this relation needs to be empirically evaluated. Furthermore, as there is some evidence that parent spatial talk is linked with children's spatial skills, there is not sufficient evidence to directly hypothesize whether or not the spatial environment, when accounting for the direct numeracy environment, will also be a predictor of mathematical language.

\section{Current Study}

Given the questions regarding the structure of the HME and the relation of specific factors to direct assessments of children's skills, the current study was designed to replicate and extend the Hart et al. (2016) study of the relation between the measurement structure of the HME and a parent-reported broad measure of children's mathematics skills, by using direct assessments of specific preschool mathematics and spatial skills. We focused on a preschool-aged sample because this is an important time when young children are developing mathematics-related skills (Baroody and Wilkins, 1999), such as early numeracy skills, spatial skills, and mathematical language knowledge. Based on the results of Hart et al. (2016), it was hypothesized that the factor structure of the HME would consist of one general HME factor and three specific factors representing the direct numeracy environment, the indirect numeracy environment, and the spatial environment. We also examined the role of the HME in predicting direct assessments of preschoolers' specific mathematics skills, including numeracy, mathematical language, and spatial skills. Expanding on the work of Hart et al. (2016) who used a combined measure of parent-reported mathematics and spatial skills, we used direct assessments of children's numeracy, mathematical language, and spatial skills. It was expected that the bifactor model with three specific factors (direct numeracy environment, indirect numeracy environment, and spatial environment) with the broad HME factor would be replicated. It was also expected that the general HME factor would significantly predict all three direct assessments (numeracy, mathematical language, and spatial skills) because it is reflective of a broad positive HME, but given that there is greater precision of measurement with direct assessments of children's skills than with parent report, it was also expected that the direct numeracy environment factor would be positively related to children's numeracy skills and mathematical language and that the spatial environment factor would be positively related to children's spatial skills.

\section{MATERIALS AND METHODS}

\section{Participants}

Participants were recruited from 18 early childhood centers in the Midwestern region of the United States. Letters explaining the study, consent forms, and questionnaires were sent home to all parents of preschool children attending these centers. Parents of 132 preschoolers completed consent forms. Three families did not complete the home survey and, thus, were not included in this study. The 129 preschoolers (60 females and 69 males) included in the analyses were on average 4.71 years old $(S D=0.55), 79.1 \%$ were White/Caucasian, $2.3 \%$ were Black/African-American, $4.7 \%$ were Latino/Hispanic, $4.7 \%$ were Asian, $7.0 \%$ were other/multiracial, and $2.3 \%$ did not report race/ethnicity information. Of these families, $89.9 \%$ reported that English was the primary language spoken at home, $4.5 \%$ reported that a language other than English (e.g., Chinese) was the primary language at home, and 5.5\% reported that both English and another language (e.g., Chinese, Spanish) were spoken at home. 
Parent education was relatively diverse with $44.2 \%$ of parents reporting less than a college degree, $28.7 \%$ reporting a 2- or 4-year degree, and $27.2 \%$ reporting a graduate degree.

\section{Measures}

\section{Home Mathematics Environment Survey}

As part of a larger survey on the home environment, parents were asked to complete a researcher-created questionnaire on the frequency of parent-child engagement in 24 specific mathematics-related activities in the home (that fit into the categories of direct numeracy [10 items], indirect numeracy [seven items], and spatial activities [seven items]) by responding to the prompt "In the past month, how often did you and your child engage in the following activities?" with six options ranging from "never" (0), "one to three times per month" (1), "once a week" (2), "a few times per week" (3), "every day" (4), to "multiple times per day" (5; see Table 1 for descriptive statistics of all HME items). The questionnaire was based on previous research by LeFevre et al. (2009) and Hart et al. (2016). Specific items chosen from these prior scales were selected based on past performance and appropriateness for the preschool age level. Specifically, the research team did not include items (e.g., "wears a watch") that were used in prior work, but had low engagement rates (i.e., mostly "never" was endorsed).

\section{Numeracy Skills}

The Preschool Early Numeracy Skills Screener - Brief Version (PENS-B; Purpura et al., 2015) was used to evaluate preschoolers' numeracy skills. The PENS-B is a 24-item measure which assesses broad numeracy skills that children are exposed to in preschool and kindergarten. For all items, children are asked verbal questions. For some questions, children are shown a picture and asked about the picture (e.g., "Which box has the most dots?" while displaying a picture of four boxes of dots). Specific assessment areas include set comparison, numeral comparison, one-to-one correspondence, counting a subset, number order, numeral identification, ordinality, and number combinations. Children received one point for each correct answer. Although all 24 items were administered, a ceiling rule consistent with the measure development process (Purpura et al., 2015) was applied during analyses and children did not receive points for any correct responses after three consecutive incorrect responses. The PENS-B had high internal consistency $(\alpha=0.88)$ for this sample.

\section{Mathematical Language}

The mathematical language assessment used was the Preschool Assessment of the Language of Mathematics (PALM; Purpura and Logan, 2015). The PALM is a 16-item measure of mathematics-specific language. Children were awarded one point for each correct response. In prior work (Purpura and Logan, 2015), these items were selected from a larger battery including a broader range of items using an item-response theory framework. The selected items had a range of difficulty parameters and strong discrimination parameters. The specific words included in this measure were intended to be broadly representative of the quantitative and spatial language associated with mathematics. Quantitative words included: take away, a little bit, most, more, fewest, and less. Spatial words included: nearest, under, first, far, below, front, middle, end, last, and before. All items were designed to be completed without exact quantitative skills and in a non-numeracy context. For example, the quantitative questions were asked in different ways: (a) comparing dots with such a gross difference that children would be able to respond correctly regardless of numeracy ability as long as they knew the meaning of the language terms (e.g., 10 vs. 2) and (b) using a picture of mostly full and mostly empty glasses when asking "Which glass has the most water?" or "Which glass has less water?" This mathematical language task had an internal consistency of 0.80 for this sample.

\section{Spatial Skills}

The spatial transformation task was from previous research by Levine et al. (1999). This task consisted of 32 problems, each involving a different target shape. On each problem, the child was shown two halves of a shape that had been divided along the vertical axis and was asked to "point to the picture the pieces make." The child's task was to select the whole shape from among four choices in a $2 \times 2$ array that could be formed from the halves. Four different forms of the task were used in this study. The forms varied in the positioning of the target pieces for a particular target shape. The 32 target shapes were randomly matched with one of the four different task forms. For example, target shape 1 used form (a) where the pieces were displayed in a horizontal translation configuration; target shape 2 used form (d) where the pieces were displayed in a diagonal rotation configuration; target shape 3 used form (b) where the pieces were displayed in a diagonal translation configuration; target shape 4 used form (c) where the pieces were displayed in a horizontal rotation configuration. This spatial task had an internal consistency of 0.76 for this sample.

\section{Covariates}

Child age, sex $($ male $=0$, female $=1)$, and highest parent education (on a 9-point scale ranging from eighth grade or less to doctoral degree) were included as covariates.

\section{Procedure}

\section{Assessment Procedure}

Assessments took place in the preschools in a room designated by the school directors or teachers. Assessments were administered in a counterbalanced order and were conducted across multiple sessions as needed. All assessments were conducted by graduate or undergraduate research assistants studying in social science fields. All assessors completed two 2- to 3-h training sessions and were required to demonstrate their competence and knowledge of assessments by "testing out" in order to participate in data collection. The testing out process involved administering each of the assessments to a lead project member who ensured that administration and scoring were done correctly.

\section{Analytical Procedure}

To identify the best-fitting factor structure of the HME, a series of seven confirmatory factor analyses (CFAs) were conducted in Mplus (Muthén and Muthén, 2012) largely in the same process 
TABLE 1 | Response rates, factor membership, and descriptive statistics for all home mathematics environment items.

\begin{tabular}{|c|c|c|c|c|}
\hline Item number & Item description & $\%$ of parents responding "never" & $M$ & $S D$ \\
\hline \multicolumn{5}{|c|}{ Direct numeracy factor } \\
\hline 1 & Count objects & 0.8 & 3.60 & 0.95 \\
\hline 2 & Print numbers & 14.7 & 2.16 & 1.38 \\
\hline 3 & Read number storybooks & 3.9 & 2.35 & 1.24 \\
\hline 4 & Use number activity books & 14.7 & 1.86 & 1.28 \\
\hline 5 & Count down $(10,9,8,7 \ldots)$ & 16.3 & 2.07 & 1.43 \\
\hline 6 & Learn simple sums (i.e., $2+2=\_$) & 32.6 & 1.40 & 1.29 \\
\hline 7 & Identify names of written numbers & 23.3 & 2.05 & 1.46 \\
\hline 8 & Recite numbers in order & 0.8 & 3.27 & 1.12 \\
\hline 9 & Use number flashcards & 45.0 & 1.09 & 1.33 \\
\hline 10 & Note numbers on signs when driving or walking & 20.9 & 1.95 & 1.50 \\
\hline \multicolumn{5}{|c|}{ Indirect numeracy factor } \\
\hline 11 & Measure ingredients when cooking & 20.9 & 1.78 & 1.30 \\
\hline 12 & Play board games with die or spinner (e.g., Chutes and Ladders, Trouble, etc.) & 14.0 & 1.85 & 1.25 \\
\hline 13 & Talk about money when shopping (e.g., Which costs more?) & 20.2 & 1.73 & 1.31 \\
\hline 14 & Play games that involve counting, adding or subtracting & 17.1 & 1.81 & 1.24 \\
\hline 15 & Play card games that use numbers or counting (e.g., Go Fish, War) & 29.5 & 1.47 & 1.35 \\
\hline \multicolumn{5}{|l|}{ Spatial factor } \\
\hline 16 & Play computer/video games involving spatial tasks (e.g., Tetris) & 27.9 & 1.67 & 1.43 \\
\hline 17 & Play with puzzles (such as picture puzzles, tangrams, slide puzzles, 3D puzzles) & 8.5 & 2.40 & 1.30 \\
\hline 18 & Build with Legos, blocks, Lincoln Logs, or construction set (e.g., Duplo, Mega blocks, etc.) & 5.4 & 2.74 & 1.38 \\
\hline 19 & Talk about location using terms such as in, on, under, around & 3.1 & 3.01 & 1.20 \\
\hline 20 & Sort things by size, color or shape & 6.2 & 2.56 & 1.27 \\
\hline 21 & Recognize shapes in the everyday world (signs, toys, blocks, games, etc.) & 3.1 & 3.05 & 1.27 \\
\hline \multicolumn{5}{|c|}{ Items not included in the model fitting analyses } \\
\hline 22 & Talk about math while watching sports (e.g., talk about the score, compare the scores, etc.) & 55.6 & 0.78 & 1.08 \\
\hline 23 & Play with Dominoes & 66.7 & 0.51 & 0.85 \\
\hline 24 & Draw maps/plans of buildings or locations & 56.6 & 0.74 & 1.04 \\
\hline
\end{tabular}

as Hart et al. (2016). Before fitting the models, items with low usage were dropped from the data. These three items all had more than $50 \%$ of parents report they never engaged their children in these activities (see bottom of Table 1). Initially, a single factor CFA was fitted, encompassing all possible mathematics-related activities parents could engage in with their children in the home. Next, three 2-factor CFAs were fitted. The first 2-factor model had two factors representing direct numeracy (i.e., activities explicitly meant to teach children quantitative skills) and other activities (i.e., indirect numeracy and spatial items). The second 2-factor model had two factors representing spatial and other activities (direct numeracy and indirect numeracy items). The third 2factor model had two factors representing indirect numeracy (i.e., activities associated with quantitative skills but not overt) and other activities (direct numeracy and spatial items). Then, a 3-factor CFA was fitted, with three factors representing direct numeracy, indirect numeracy, and spatial activities. Finally, following the process of Hart et al. (2016), we fit a bifactor model that included the specific factors of direct numeracy, indirect numeracy, and spatial environment, as well as a general HME factor that incorporated all items from the three specific factors. However, given model comparison results discussed later, we also fit an additional bifactor model similar to the 2-factor model that included a direct + indirect numeracy factor and a spatial factor, but that also included a general HME factor.
The bifactor model allows us to assess the overlapping variance among all the items (i.e., the general HME factor), as well as examine the remaining variance (i.e., residualized variance) that is specific to the types of home mathematics activities being conducted (e.g., direct numeracy, indirect numeracy, and spatial factors). This is done through regressing all items onto the general factor and the domain-specific items onto their specific domains and restricting the correlations between the factors to zero. Essentially, a bifactor model may provide a more precise measure of each specific factor by removing that which is common across the specific items. Critically, it allows us to better understand the domain-specific factors (i.e., direct numeracy, indirect numeracy, and spatial) after partialing out the general HME, as well as test whether the specific factors predict child outcomes over and above the general HME (Chen et al., 2006). For more detailed descriptions of bifactor models, see Reise (2012).

To compare model fit across the various models, the $\chi^{2}$ difference test was used to compare nested models where significant $\chi^{2}$ difference test indicates a worse fit for the more constrained model (i.e., in this instance, the model with fewer factors). Akaike Information Criterion (AIC) and sample-size adjusted Bayesian Information Criterion (BIC) were used to evaluated relative model fit of all models. Lower AIC and BIC values-typically differences of 10 or more-indicated a better fitting model (Kass and Raftery, 1995; Hu and Bentler, 1999; 
Burnham et al., 2011). Once the best-fitting factor model was determined, an item dropping process was conducted to remove poor fitting items (specifically, items that either did not load or loaded negatively on one of the sub-factors). Finally, a structural equation model was conducted to investigate the relations of the individual factors with measures of numeracy, mathematical language, and spatial skills, controlling for children's age, sex, and parent education. As there was some missing data on some of the direct assessments (4.7 to $7.0 \%$ ), full information maximum likelihood was used in the analyses.

\section{RESULTS}

Descriptive statistics for key study variables can be found in Table 2. Correlations between the final latent factors and all outcome variables (i.e., numeracy, mathematical language, and spatial skills) are presented in Table 3.

\section{Evaluating the Factor Structure of the Home Mathematics Environment Items}

The first goal of this study was to examine the factor structure of the HME. The fit statistics for the five initial models (1factor, three 2-factor, 3-factor) are displayed in Table 4. Overall, none of the models tested provided an excellent fit to the data according to fit indices (SRMR $\leq 0.10$, CFI and TLI $\geq 0.90$, RMSEA $\leq$ 0.08; Hu and Bentler, 1999). Among these models, the 2-factor model that combined direct numeracy and indirect numeracy (Model 3) was a better fit to the data than either of the other 2-factor models (compared to Model 2, $\triangle \mathrm{AIC}>10$, $\Delta \mathrm{BIC}>10$; compared to Model $4, \Delta \mathrm{AIC}>10, \Delta \mathrm{BIC}>10)$ and

TABLE 2 | Descriptive statistics for key demographic variables and direct assessments.

\begin{tabular}{lcccccc}
\hline & N & $\boldsymbol{M}$ & SD & $\begin{array}{c}\text { Observed } \\
\text { range }\end{array}$ & Skewness & Kurtosis \\
\hline Age (years) & 129 & 4.71 & 0.55 & $3.07-6.03$ & -0.29 & 0.12 \\
$\begin{array}{l}\text { Parent } \\
\text { education }\end{array}$ & 129 & 6.07 & 1.93 & $2-9$ & -0.07 & -1.01 \\
$\begin{array}{l}\text { Numeracy skills } \\
\text { Mathematical }\end{array}$ & 121 & 12.57 & 5.93 & $0-24$ & -0.27 & -0.82 \\
language & 120 & 12.34 & 3.08 & $1-16$ & -1.21 & 1.06 \\
Spatial skills & 123 & 13.08 & 5.12 & $4-27$ & 0.41 & -0.53 \\
\hline
\end{tabular}

TABLE 3 | Correlations between home mathematics environment factors and direct assessments.

\begin{tabular}{lcccccc}
\hline & $\mathbf{1}$ & $\mathbf{2}$ & $\mathbf{3}$ & $\mathbf{4}$ & $\mathbf{5}$ & $\mathbf{6}$ \\
\hline 1. Direct + indirect numeracy & - & & & & & \\
2. Spatial & 0.00 & - & & & & \\
3. HME & 0.00 & 0.00 & - & & & \\
4. Numeracy skills & $0.36^{\star \star \star}$ & 0.00 & $-0.20^{\star}$ & - & & \\
5. Mathematical language & $0.36^{\star \star \star}$ & 0.04 & $-0.21^{\star}$ & $0.61^{\star \star \star}$ & - & \\
6. Spatial skills & $0.25^{\star \star}$ & 0.13 & 0.01 & $0.45^{\star \star \star}$ & $0.27^{\star \star \star}$ & - \\
\hline
\end{tabular}

HME, home mathematics environment. ${ }^{*} p<0.05$, ${ }^{* *} p<0.01,{ }^{* * *} p<0.001$. the 1-factor model $\left(\Delta \chi^{2}=37.48, d f=1, p<0.001 ; \Delta\right.$ AIC $>10$, $\triangle \mathrm{BIC}>10)$. Moreover, it did not significantly differ in fit from the 3-factor model $\left(\Delta \chi^{2}=3.60, d f=2, p=0.165 ; \Delta\right.$ AIC $<10$, $\triangle \mathrm{BIC}<10)$. This is likely because of the very high correlation between the direct numeracy and indirect numeracy factors $(r=0.93)$, whereas the correlations between the direct numeracy factor and the spatial factor $(r=0.72)$ and the indirect numeracy factor and spatial factor $(r=0.77)$ were, though still high, more differentiable. Given these findings, two bifactor models were analyzed-one 3-factor bifactor model and a 2-factor bifactor model. The 2-factor model included a factor that combined direct and indirect numeracy items, a spatial factor, and a general HME factor (this model was aligned with Model 3, but also included the general HME factor). As can be seen in Table 4, the two bifactor models did not fit significantly differently $(\triangle \mathrm{AIC}<10$, $\triangle \mathrm{BIC}<10$ ), but both demonstrated better fit indices than the non-bifactor models ( $\triangle \mathrm{AIC}$ and $\triangle \mathrm{BIC}>10$ for all model comparisons). Thus, for parsimony, the 2-factor bifactor model was selected as the preferred model. After selection of the 2factor bifactor model, and because the model fit indices did not consistently indicate an excellent fit to the data, an exploratory model fitting approach was conducted to improve overall model fit that aligned with the process in Hart et al. (2016). This was done because we intended to use this model in further structural equation modeling in the second research goal. Items that either did not significantly load onto one of the specific factors in the bifactor model, or that negatively loaded onto a factor were removed from the final model because this would indicate that the item does not provide any information for the specific factor on which it was theoretically placed.

The initial step of item dropping resulted in 10 items being dropped, eight for non-significant loadings onto the direct + indirect numeracy factor (Items 1, 4, 8, 9, 10, 11, 13, and 15), and two for non-significant loadings onto the spatial factor (Items 16 and 17). Although modification indices suggested that the model could be improved by loading Item 8 (recite numbers in order) onto the spatial factor, the item was removed as it did not logically fit on the spatial factor and did not significantly load onto the direct + indirect numeracy factor. Although the removal of these 10 items resulted in two more items being non-significant on their factors (Item 6 on the general HME factor and Item 18 on the spatial factor) when the model was rerun, additional reduction of items resulted in models where the residual covariance matrix was not positive definite. Thus, the model that included Items 6 and 18 was determined to be the final model. This resulted in an excellent fitting model (7a) as can be seen in Table 4 in bold font. The final model included 11 items (seven on the direct + indirect numeracy factor and four on the spatial factor). All factor loadings for the direct + indirect numeracy, spatial, and general HME factors can be seen in Table 5, with the model displayed in Figure 1. To ensure that the item dropping process did not alter the model structure, we conducted two subsequent model checks. Using the final selected items, we reran Models 1 and 3 (1-factor and 2factor direct + indirect numeracy models) without the 10 items that were dropped. These resulted in Models 8 and 9 (see Table 4). Neither of these models fit better than the 2-factor bifactor 
TABLE 4 | Model fit indices for each tested model representing the home mathematics environment.

\begin{tabular}{|c|c|c|c|c|c|c|c|c|c|c|c|c|}
\hline$\#$ & & $x^{2}$ & $d f$ & $p$ & AIC & Adj. BIC & RMSEA & $\begin{array}{l}\text { RMSEA lower } \\
\text { bound }\end{array}$ & $\begin{array}{l}\text { RMSEA upper } \\
\text { bound }\end{array}$ & CFI & TLI & SRMR \\
\hline \multicolumn{13}{|c|}{ Initial models } \\
\hline 1 & $\begin{array}{l}\text { 1-Factor home } \\
\text { mathematics } \\
\text { environment }\end{array}$ & 479.31 & 189 & $<0.001$ & 8544.72 & 8724.89 & 0.11 & 0.10 & 0.12 & 0.68 & 0.64 & 0.09 \\
\hline 2 & $\begin{array}{l}\text { 2-Factor IHNE + spatial } \\
\text { vs. DHNE }\end{array}$ & 466.83 & 188 & $<0.001$ & 8534.24 & 8514.86 & 0.11 & 0.10 & 0.12 & 0.69 & 0.66 & 0.09 \\
\hline 3 & $\begin{array}{l}\text { 2-Factor DHNE + IHNE } \\
\text { vs. spatial }\end{array}$ & 441.83 & 188 & $<0.001$ & 8509.24 & 8489.86 & 0.10 & 0.09 & 0.12 & 0.72 & 0.66 & 0.09 \\
\hline 4 & $\begin{array}{l}\text { 2-Factor } \\
\text { DHNE + spatial vs. } \\
\text { IHNE }\end{array}$ & 476.19 & 188 & $<0.001$ & 8543.60 & 8726.63 & 0.11 & 0.10 & 0.12 & 0.68 & 0.65 & 0.09 \\
\hline 5 & $\begin{array}{l}\text { 3-Factor DHNE, IHNE, } \\
\text { and spatial }\end{array}$ & 438.23 & 186 & $<0.001$ & 8509.64 & 8489.65 & 0.10 & 0.09 & 0.12 & 0.72 & 0.69 & 0.09 \\
\hline \multicolumn{13}{|c|}{ Bifactor models } \\
\hline 6 & $\begin{array}{l}\text { 3-Factor bifactor } \\
\text { solution }\end{array}$ & 337.95 & 168 & $<0.001$ & 8445.35 & 8419.91 & 0.09 & 0.08 & 0.10 & 0.81 & 0.77 & 0.08 \\
\hline 7 & $\begin{array}{l}\text { 2-Factor bifactor } \\
\text { DHNE + IHNE vs. } \\
\text { spatial }\end{array}$ & 334.50 & 168 & $<0.001$ & 8441.90 & 8416.46 & 0.09 & 0.07 & 0.10 & 0.82 & 0.77 & 0.07 \\
\hline \multicolumn{13}{|c|}{ Final model } \\
\hline $7 a$ & $\begin{array}{l}\text { 2-Factor bifactor } \\
\text { DHNE + IHNE vs. } \\
\text { spatial with } 10 \text { items } \\
\text { removed }\end{array}$ & 51.53 & 33 & 0.021 & 4465.49 & 4452.17 & 0.07 & 0.03 & 0.10 & 0.95 & 0.92 & 0.05 \\
\hline \multicolumn{13}{|c|}{ Model checks } \\
\hline 8 & $\begin{array}{l}\text { 2-Factor DHNE + IHNE } \\
\text { vs. spatial with } 10 \text { items } \\
\text { removed }\end{array}$ & 87.92 & 43 & $<0.001$ & 4481.88 & 4471.59 & 0.09 & 0.06 & 0.12 & 0.87 & 0.85 & 0.08 \\
\hline 9 & $\begin{array}{l}\text { 1-Factor with } 10 \text { items } \\
\text { removed }\end{array}$ & 176.25 & 44 & $<0.001$ & 4568.21 & 4558.22 & 0.15 & 0.13 & 0.18 & 0.66 & 0.58 & 0.11 \\
\hline
\end{tabular}

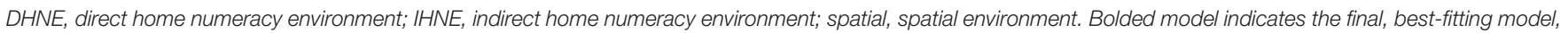
a 2-factor bifactor model that consists of direct + indirect numeracy, spatial, and general home mathematics environment factors, after adjusting item selection.

model with the 10 items dropped (i.e., Model 7a; $\Delta$ AICs $>10$, $\triangle$ BICs $>10$ ). The 3 -factor model (Model 5) was not rerun because only two indirect numeracy items were retained which would have been insufficient to run the model.

\section{Do the Home Mathematics Environment Factors Predict Preschoolers' Numeracy, Mathematical Language, and Spatial Skills?}

Correlations for key HME factors and direct assessments can be found in Table 3. A structural equation model was used to examine how parent-child home mathematics activities were associated with children's mathematics skills (see Figure 2). The direct assessments of children's numeracy, mathematical language, and spatial skills were regressed on the three HME factors (general HME, direct + indirect numeracy, and spatial) as well as covariates (age, sex, parent education). The model fit statistics were good $(\mathrm{CFI}=0.91$, TLI $=0.87$, RMSEA $=0.07$, SRMR $=0.07)$. Among the covariates, both age and parent education significantly predicted all three direct assessments; sex was not a significant predictor of any of the three direct assessments. Overall findings suggest that only the direct + indirect numeracy factor significantly predicted child performance on numeracy $(\beta=0.36, p=0.004)$, mathematical language $(\beta=0.36, p=0.001)$, and spatial skills $(\beta=0.25$, $p=0.022)$. Neither the general HME factor nor the spatial factor were significant predictors of any of the three direct assessments.

\section{Post hoc Analyses}

These findings may suggest that, even though the bifactor model is the one that best represents the structure of the HME, only the direct + indirect numeracy factor is important in uniquely predicting child outcomes, which raises the issue of whether the bifactor structure is necessary. To address this issue, we conducted post hoc analyses using just the direct + indirect numeracy factor (and covariates) in predicting the three direct assessments. These results indicated that, without the bifactor model, the direct + indirect numeracy factor was only significantly related to children's spatial skills $(\beta=0.22$, $p=0.015)$ and not numeracy $(\beta=0.15, p=0.088)$ or mathematical language $(\beta=0.16, p=0.084)$. Similar results are found when just using the general HME factor as a predictor (with covariates in the model), in which the general HME factor was only significantly related to children's spatial skills $(\beta=0.19, p=0.028)$ 
and not numeracy $(\beta=0.06, p=0.522)$ or mathematical language $(\beta=0.07, p=0.438)$. These supplemental analyses suggest that the bifactor structure may be necessary in understanding how the HME is related to children's skills because it provides a "more pure" measure of the specific factors (i.e., with the

TABLE 5 | Standardized factor loadings from the final, best-fitting model, a 2 -factor bifactor model.

\begin{tabular}{lccc}
\hline & $\begin{array}{c}\text { Direct + indirect } \\
\text { numeracy }\end{array}$ & Spatial & $\begin{array}{c}\text { General home } \\
\text { mathematics } \\
\text { environment }\end{array}$ \\
\hline Print numerals & 0.44 & - & 0.34 \\
Number story books & 0.29 & - & 0.52 \\
Count down & 0.55 & - & 0.34 \\
Identify numerals & 0.64 & - & 0.23 \\
Simple sums & 0.70 & - & 0.18 \\
Math board games & 0.39 & - & 0.37 \\
Math games & 0.34 & - & 0.67 \\
Talk about location & - & 0.72 & 0.27 \\
Recognize shapes & - & 0.45 & 0.65 \\
Sort things & - & 0.42 & 0.69 \\
Build & - & 0.23 & 0.44 \\
\hline
\end{tabular}

All items significantly loaded onto each factor with the exceptions of the "simple sums" item which did not significantly load on the general home mathematics environment factor and the "build" item which did not significantly load on the spatial factor. However, both were retained in the model as removing them resulted in models in which the residual covariance matrices were not positive definite. Italicized items were originally on the indirect factor. bifactor model it is measuring what is unique to the specific direct + indirect numeracy factor after removing what is more general to the HME).

\section{DISCUSSION}

A growing body of research has begun to examine the relation between the HME and children's mathematics performance. However, much of this literature utilizes models of the HME that are based on prior work, but does not explicitly test the measurement models within their specific study. Moreover, few studies empirically contrast multiple models found in prior literature. The first objective of the present study was to address this limitation by attempting to replicate the factor structure of the HME (Hart et al., 2016) in a different sample by comparing it to several alternative, but plausible models. The second objective in this study was to extend the findings of Hart et al. (2016) to examine the relations between the identified HME factors and direct assessments of children's numeracy, mathematical language, and spatial skills (as opposed to only using parent reports of children's mathematics and spatial skills as was done in Hart et al., 2016). In contrast to Hart et al. (2016), who found a 3-factor bifactor model (general HME, direct numeracy, indirect numeracy, and spatial), we found that a 2-factor bifactor model (general HME, direct + indirect numeracy, and spatial) was the more parsimonious model. Moreover, whereas Hart et al. (2016) found that the general HME factor was the aspect of the HME that was related to parent

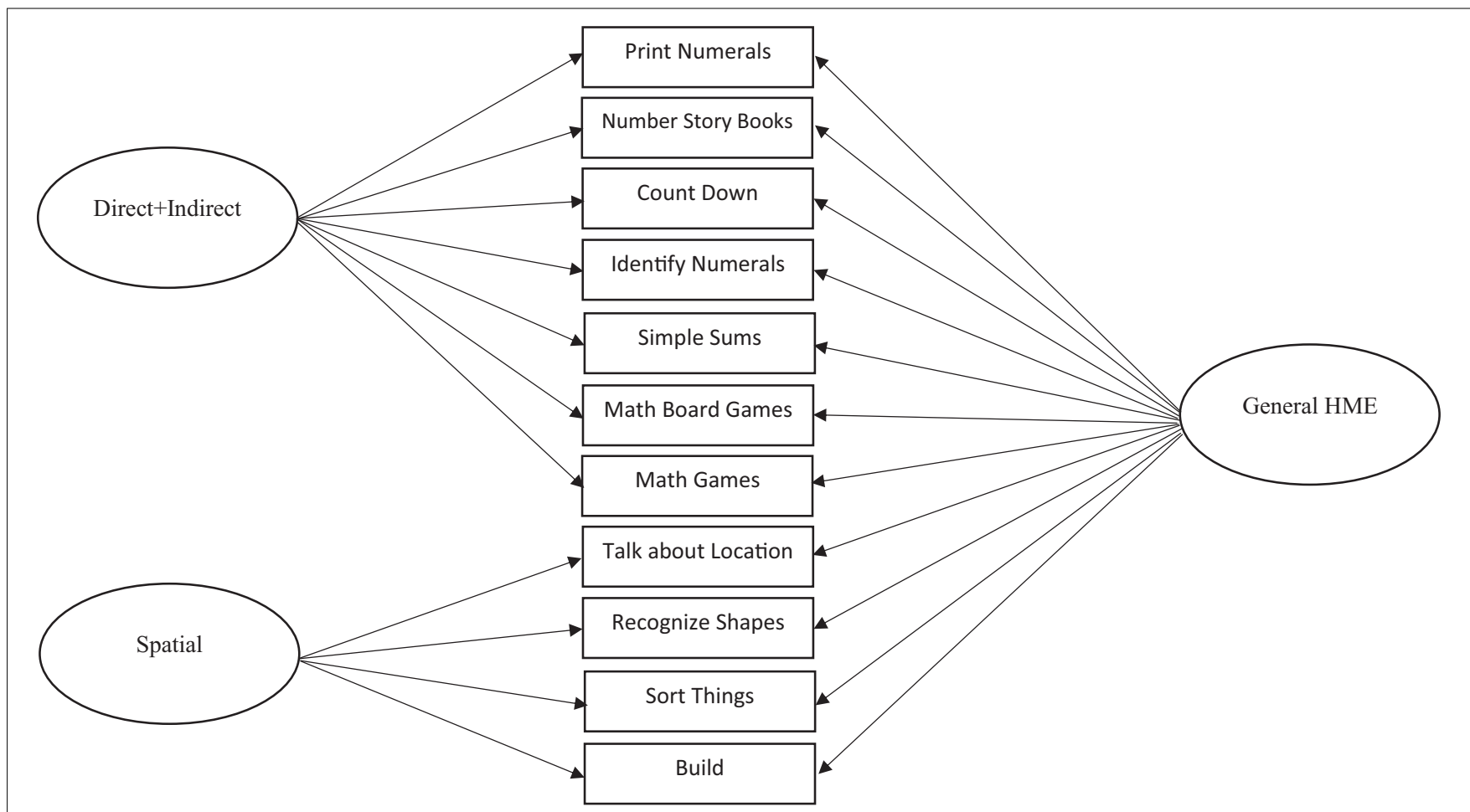

FIGURE 1 | Best-fitting model, the final 2-factor bifactor model (direct + indirect numeracy, spatial, and a general home mathematics environment [HME] factor). 


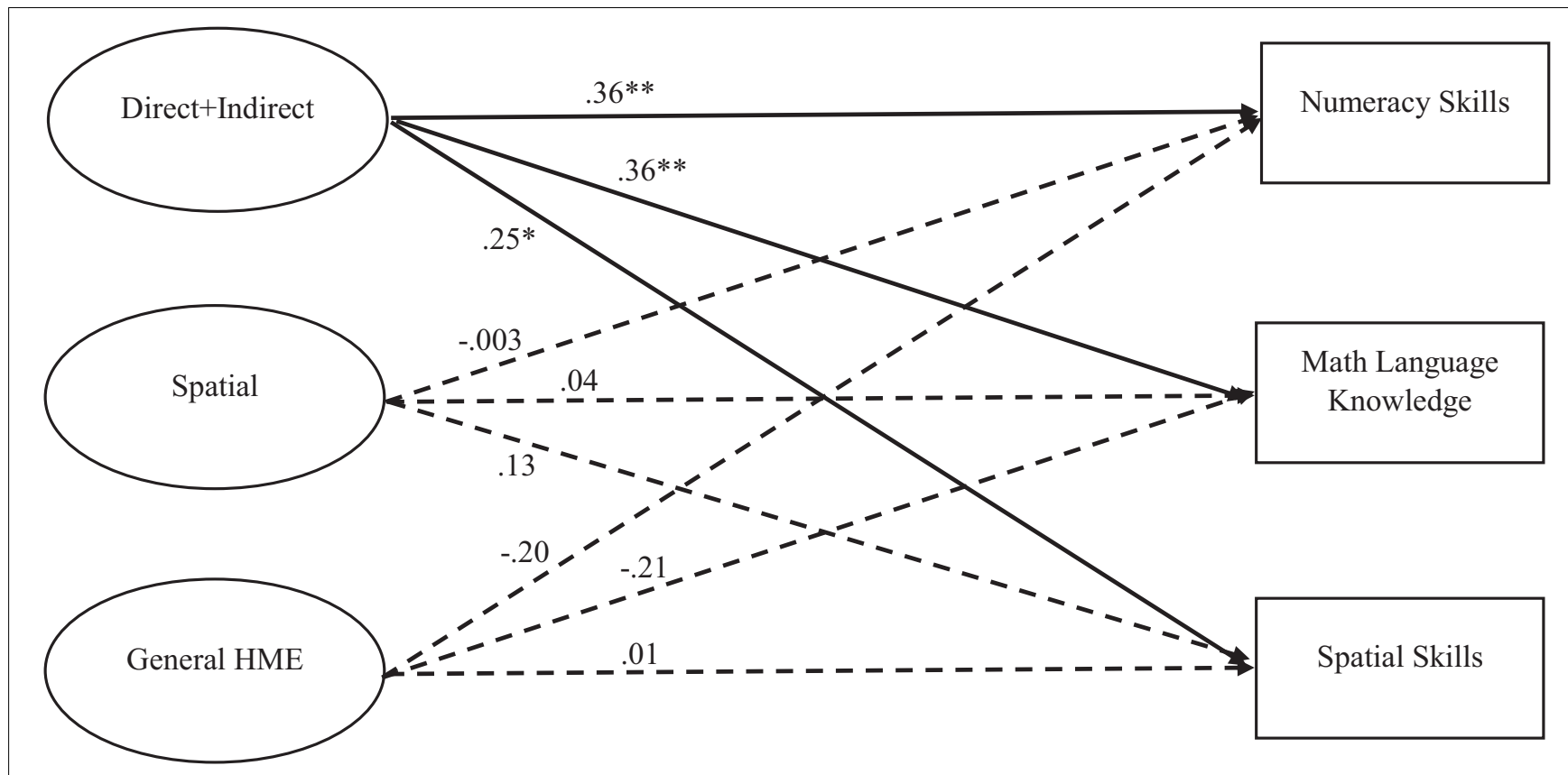

FIGURE 2 | Relations between home numeracy environment factors and direct assessments of children's numeracy skills, mathematical language knowledge, and spatial skills. Standardized coefficients are presented in the figure. ${ }^{*} p<0.05,{ }^{* *} p<0.01$.

reports of children's mathematics performance, we found that the direct + indirect numeracy factor was the only aspect of the HME that was related to direct assessments of children's numeracy, mathematical language, and spatial skills. Although the current findings diverge from the findings of Hart et al. (2016), they both suggest the importance of including the bifactor structure. The differences between specific predictors in the current study and the Hart et al. (2016) study may be a result of a number of reasons discussed below. Importantly, the post hoc analyses indicated the bifactor structure was necessary to understand the link between the HME and children's mathematics skills because it allows for a more precise estimate of the specific factors than models that do not include the bifactor structure.

\section{The Home Mathematics Environment Factor Structure}

The bifactor model with an overarching HME factor and specific factors of direct + indirect numeracy and spatial skills is largely similar to the model proposed by Dearing et al. (2012) suggesting that numeracy and spatial factors separate into distinct categories rather than more refined categories within those areas (e.g., direct vs. indirect). This may be due to the nature of direct versus indirect items included in these models. For example, the types of indirect activities that loaded on the direct + indirect numeracy factor (those items italicized in Table 5) were primarily game-based mathematics activities where there is likely an intentionality of focusing on mathematics during the games (e.g., mathematics games) or even if there is no intentionality in explicitly teaching mathematics during the games, there are ample opportunities for mathematics-related discussions to arise (e.g., mathematics-related board games). As these were the types of indirect items retained in the final models, it may indicate that measurement of the HME, when specifically referring to the numerical component, must center on activities where there is direct intentionality of teaching mathematics, or where the opportunities of engaging with mathematics content are explicit. Notably, other indirect numeracy items where the numerical content was not as explicit (e.g., measuring ingredients) were dropped from the model as they did not contribute to the direct + indirect numeracy factor. An additional important result of the item reduction process was that the HME was effectively measured through only a relatively small number of items (seven total items for the direct + indirect factor and four spatial items). The small number of items may support enhanced feasibility of collecting similar data in future studies as parents would not have to complete extensive surveys.

Building upon the work of both Dearing et al. (2012) who suggested a numeracy versus spatial activities factor structure and Hart et al. (2016) who incorporated a bifactor structure, the bifactor framework in the current study was also found to be the best fit for the data. The bifactor model allows for the items from all the specific factors to load onto a more general factor that captures the general variance in the HME. Importantly, the specific factors (direct + indirect numeracy, spatial) represent the unique variance from the factor-specific items that were not accounted for (i.e., the residualized variance) on the general HME factor. The specific factors from the current bifactor model differ slightly from the specific factors in the bifactor model from Hart et al. (2016) as they found the direct and indirect numeracy factors to be separable. The consolidation 
of the direct and indirect factors in the current study was not surprising given the high correlation between these two factors in the original three factor model (Model 5). This relation could be due to the specific types of indirect activities that were included (e.g., talk about money when shopping, play games that involve counting) because, even though they are indirect numeracy activities, parents may engage in them with their child intentionally to support mathematics skills which would effectively make them a more direct activity. Future work should examine parent intentionality in engaging in indirect activities and how that may affect the association with direct activities.

The inclusion of the bifactor structure in the current model enables us to parse out the aspects of the HME that are more general to parent-child mathematics interactions and those that are construct specific. This may reflect an intentionality of focus (engaging in explicit and directed activities focused on mathematics) for the specific factors versus broad engagement for the general HME factor. Alternatively, the general HME factor could capture the variance that is more general to the overall home learning environment (even beyond mathematics) and the specific factors may account for the mathematics-specific variance. However, more work is needed to explicitly test these assumptions. In particular, work that extends domain-specific home environment evaluations to examine the structure of multiple facets of the home environmentincluding mathematics, literacy, and self-regulation-will enable researchers to better understand the domain-general and domain-specific aspects of the home environment that support children's learning.

\section{Relations Between the Home Mathematics Environment and Preschool Numeracy, Mathematical Language, and Spatial Skills}

After identifying the HME factor structure, we examined the extent to which the HME predicted direct assessments of preschoolers' numeracy, mathematical language, and spatial skills. The findings suggest that the direct + indirect numeracy aspect of the HME is an important predictor of children's performance, in line with previous research (Blevins-Knabe and Musun-Miller, 1996; Kleemans et al., 2012). Specifically, results from the structural equation model indicated that the direct + indirect numeracy factor positively predicted direct observations of preschoolers' numeracy, mathematical language, and spatial skills, but the spatial environment factor did not predict any of the outcomes. This may be because of the type and frequency with which activities occur in the spatial environment. Notably, most of the spatial items in the final spatial factor are ones that occur with high frequency (means of around "a few times per week" which was relatively high compared to other types of items), but also are activities in which children may do more on their own than in an interactive setting with adults (e.g., sorting, building). Thus, even though children may engage in these activities, they may not be receiving the feedback and scaffolding necessary to develop these targeted skills as would be found with more guided or interactive play opportunities (Toub et al., 2018). Thus, these findings do not suggest that the home spatial environment activities are not a valid target for future assessment or intervention, but rather that simply measuring the quantity of this type of play may not be sufficient for linking it to children's mathematics or spatial performance. Given that other studies (Dearing et al., 2012; Zippert and Rittle-Johnson, 2018) also did not find specific relations between the home spatial environment and children's spatial skills, but studies that measure the direct engagement of parent-child spatial language do demonstrate relations (Ferrara et al., 2011), future research should extend this work to examine the quality of these activities and parents' explicit focus on spatial properties during such activities, as well as additional factors such as parent spatial skills that has previously been found to be related to children's performance (Zippert and Rittle-Johnson, 2018).

Importantly, though previous work (Napoli and Purpura, 2018) found a link between the HME and children's general vocabulary, this is the first study to establish a link between the HME and children's mathematical language skills. The parentchild interactions that occur during HME activities may involve specific uses of mathematical language terms. For example, if parents and children are counting, a parent may ask "What number comes next?" or "What is the number after four?" When playing mathematics games with their children, parents may ask, "Who has more [or the most] points?" Knowledge of these terms and concepts may be supported through HME interactions. Conversely, as these data are concurrent, it is also possible that the directionality of the relation is such that children's knowledge of mathematical language supports engagement in HME activities. Specifically, knowledge of mathematical language terms and concepts may provide children with access to understanding the concepts presented through the HME which, then, may enable the HME to support children's numeracy development. Moreover, it may be that children who know mathematical language terms and concepts may prompt more parent initiations of mathematics activities. Future longitudinal research that addresses the potential mediational role of mathematical language should be conducted to better examine these mechanisms. Moreover, it is important to highlight that all the direct assessments, but particularly mathematical language and numeracy, were significantly related. These strong relations may potentially explain why the direct + indirect factor was related to all direct assessments. It may be that when parents engage their children in mathematics-focused activities, they may go beyond just explicit teaching and also use significant amounts of math talk (Eason and Ramani, 2020). It is possible that this math talk may expand beyond simple numeracy-related talk to include mathematical language and spatial skills; however, the specific types of talk parents use during these types of activities at home needs to be further investigated.

The current findings contrast with Hart et al. (2016) in that the general HME factor was not the factor that was related to children's performance. This may be because the age range measured in Hart et al. (2016) was twice as large as the age range in the current study ( 3 to 8 versus 3 to 5 years old). With the broader age range, the specific skills associated with the direct + indirect numeracy factor may not have been as indicative 
of performance because different HME indicators have been found to be differentially related to performance at different ages (Thompson et al., 2017). Thus, the general HME factor may have been measuring more of the overarching mathematics-related practices. The relation between the general HME factor and mathematics performance in Hart et al. (2016) may be because the general factor was accounting for important variance across the items that were more general across ages. In contrast, with the narrower age range in the current study, the direct + indirect numeracy factor may have been capturing more of the specific skills associated with children's mathematics development at this age while the general HME factor may have simply been capturing the broader environment that may not necessarily be specific to mathematics performance. Alternatively, this could be indicative of developmental change in the functioning of the HME in that a more explicit and intentional focus may be necessary during the younger years, whereas a broader supportive environment may be important as children are in early elementary school. However, it should be cautioned that these age-related hypotheses cannot be evaluated through the current study as the age range is more narrow than the Hart et al. (2016) study and that further work explicitly testing these hypotheses and disentangling potential age-related differences in these models is needed.

\section{Limitations and Future Directions}

The present study should be considered within the context of specific limitations. Similar to Hart et al. (2016) the reliance on parent-reported HME may have biased the results if parents indicated higher frequencies for HME activities due to social desirability. However, there were a few activities that were rated by many parents as infrequent, suggesting that response bias may not be a large concern. Our view of the HME was also limited by having one parent reporting on the home environment (mostly mothers). Parents may individually and uniquely contribute to children's home environments, which we could not capture with a single parent reporting in instances where there are two parents or caregivers in the home. Additionally, it may be plausible that the HME may act as a proxy for genetics and parent mathematics skills, given that children's genes for mathematics skills are correlated with their home environment and there is evidence of some genetic influence on different aspects of mathematics performance (Plomin et al., 1977; Scarr and McCartney, 1983; Hart et al., 2016). However, the data needed to test for a gene-environment correlation or account for parent mathematics skills were not available in the current study. Future research on the HME should account for gene-environment correlations. Similarly, children with greater mathematics skills (i.e., numeracy, mathematical language, or spatial skills) may elicit or initiate a greater number of mathematics-related interactions in the home; however, given the cross-sectional nature of this data we cannot test the directionality of the association (Hart et al., 2019). Thus, future research should consider using longitudinal data to test the directionality of the association between the HME and children's mathematics skills. Furthermore, the CFA was limited by a small sample size. Specifically, a weakness of utilizing a bifactor model is the prevalence of over-extraction which is compounded by small sample sizes (Rindskopf, 1984). Future research should replicate the current study's CFA with a larger sample size. Furthermore, inclusion of only a core set of mathematicsrelated skills (numeracy, mathematical language, and spatial skills) that have most strongly been linked with mathematics development more broadly were included in the study. Future work should consider a broader range of HME facets (e.g., patterning, geometry) such as was done by Zippert and RittleJohnson (2018) and their connected skills. Subsequent work should also use multiple measures of each of the child assessments to reduce measurement bias. Finally, both quantitative and spatial language were included in the mathematical language measure, and it is unclear if the home spatial factor would have been related to a measure of spatial language that was independent of quantitative language. As it is not possible to disentangle these types of mathematical language in the current study, future work should examine the factor structure of mathematical language and if distinct aspects of the HME are uniquely related to the various aspects of mathematical language.

\section{CONCLUSION}

In conclusion, we worked to replicate and extend previous work by separating the HME into direct + indirect numeracy and spatial components with an overarching general HME factor, and testing these factors' associations with preschoolers' numeracy, mathematical language, and spatial skills. The results indicate that only the direct + indirect numeracy factor predicted preschoolers' specific mathematics skills, highlighting the importance of parent-child engagement in specific aspects of mathematics-related activities.

\section{DATA AVAILABILITY STATEMENT}

The datasets for this study will not be made publicly available because we are not allowed to share data outside the key personnel for the project by our IRB. Requests to access the datasets should be directed to the corresponding author.

\section{ETHICS STATEMENT}

The studies involving human participants were reviewed and approved by Purdue University Institutional Review Board. Written informed consent to participate in this study was provided by the participants' legal guardian/next of kin.

\section{AUTHOR CONTRIBUTIONS}

DP, YK, ER, SS, SH, and CG contributed to the conceptualization and design of the study. DP, ER, and SH contributed to data analysis and results. All authors contributed to the writing of the manuscript. 


\section{FUNDING}

This project was supported in part by a grant from the Clifford B. Kinley Trust (Award \# 208424). Findings

\section{REFERENCES}

Anders, Y., Rossbach, H. G., Weinert, S., Ebert, S., Kuger, S., Lehrl, S., et al. (2012). Home and preschool learning environments and their relations to the development of early numeracy skills. Early Childhood Res. Q. 27, 231-244. doi: 10.1016/j.ecresq.2011.08.003

Aunola, K., Leskinen, E., Lerkkanen, M. K., and Nurmi, J. E. (2004). Developmental dynamics of math performance from preschool to Grade 2. J. Educ. Psychol. 96, 699-713. doi: 10.1037/0022-0663.96.4.699

Baroody, A. J., and Wilkins, J. L. M. (1999). "The development of informal counting, number, and arithmetic skills and concepts," in Mathematics in the Early Years, ed. J. V. Copley (Washington, DC: National Association for the Education of Young Children), 48-65.

Blevins-Knabe, B. (2012). "Fostering early numeracy at home (Rev. ed.)," in Encyclopedia of Language and Literacy Development, (London, ON: Western University), 1-9. Available online at: http://www.literacyencyclopedia.ca/pdfs/ topic.php?topId=245

Blevins-Knabe, B., and Musun-Miller, L. (1996). Number use at home by children and their parents and its relationship to early mathematical performance. Early Dev. Parent. 5, 35-45. doi: 10.1002/(sici)1099-0917(199603)5:1<35::aidedp113>3.0.co;2-0

Burnham, K. P., Anderson, D. R., and Huyvaert, K. (2011). AIC model selection and multimodel inference in behavioral ecology: some background, observation, and comparisons. Behav. Ecol. Sociobiol. 65, 23-25. doi: 10.1007/ s00265-010-1029-6

Casasola, M., Wei, W. S., Suh, D. D., Donskoy, P., and Ransom, A. (2020). Children's exposure to spatial language promotes their spatial thinking. J. Exp. Psychol. Gen. 149, 1116-1136. doi: 10.1037/xge0000699

Casey, B. M., Andrews, N., Schindler, H., Kersh, J. E., Samper, A., and Copley, J. (2008). The development of spatial skills through interventions involving block building activities. Cogn. Instr. 3, 269-309. doi: 10.1080/07370000802177177

Chen, F. F., West, S. G., and Sousa, K. H. (2006). A comparison of bifactor and second-order models of quality of life. Multiv. Behav. Res. 41, 189-225. doi: 10.1207/s15327906mbr4102_5

Dearing, E., Casey, B. M., Ganley, C. M., Tillinger, M., Laski, E., and Montecillo, C. (2012). Young girls' arithmetic and spatial skills: the distal and proximal roles of family socioeconomics and home learning experiences. Early Childhood Res. Q. 27, 458-470. doi: 10.1016/j.ecresq.2012.01.002

Dickinson, D. K., and Tabors, P. O. (2001). Beginning Literacy With Language: Young Children Learning at Home and School. Baltimore, MD: Paul H Brookes Publishing.

Eason, S. H., and Ramani, G. B. (2020). Parent-child math talk about fractions during formal learning and guided play activities. Child Dev. 91, 546-562. doi: $10.1111 /$ cdev.13199

Elliott, L., and Bachman, H. J. (2017). How do parents foster young children's math skills. Child Dev. Perspect. 12, 16-21. doi: 10.1111/cdep.12249

Ferrara, K., Hirsh-Pasek, K., Newcombe, N. S., Golinkoff, R. M., and Lam, W. S. (2011). Block talk: spatial language during block play. Mind Brain Educ. 5, 143-151. doi: 10.1111/j.1751-228X.2011.01122.x

Ginsburg, H. P. (1977). Children's Arithmetic: The Learning Process. New York, NY: D. Van Nostrand.

Gunderson, E. A., and Levine, S. C. (2011). Some types of parent number talk count more than others: relations between parents' input and children's cardinalnumber knowledge. Dev. Sci. 14, 1021-1032. doi: 10.1111/j.1467-7687.2011. 01050.x

Hart, S. A., Ganley, C. M., and Purpura, D. J. (2016). Understanding the home math environment and its role in predicting parent report of children's math skills. PLoS One 11:e0168227. doi: 10.1371/journal.pone.0168227

Hart, S. A., Little, C., and van Bergen, E. (2019). Nurture might be nature: cautionary tales and proposed solutions. PsyArXiv [Preprint]. doi: 10.31234/osf. io/j5x7g from this study do not necessarily reflect the views of the funder. Publication of this article was funded in part by Purdue University Libraries Open Access Publishing Fund.
Hornburg, C. B., Schmitt, S. A., and Purpura, D. J. (2018). Relations between preschoolers' mathematical language understanding and specific numeracy skills. J. Exp. Child Psychol. 176, 84-100. doi: 10.1016/j.jecp.2018.07.005

Hu, L. T., and Bentler, P. M. (1999). Cutoff criteria for fit indexes in covariance structure analysis: conventional criteria versus new alternatives. Struct. Equ. Model. A Multidiscip. J. 6, 1-55. doi: 10.1080/10705519909540118

Kass, R. E., and Raftery, A. E. (1995). Bayes factors. J. Am. Stat. Assoc. 90, 773-795. doi: 10.1080/01621459.1995.10476572

Kleemans, T., Peeters, M., Segers, E., and Verhoeven, L. (2012). Child and home predictors of early numeracy skills in kindergarten. Early Childhood Res. Q. 27, 471-477. doi: 10.1016/j.ecresq.2011.12.004

LeFevre, J., Polyzoi, E., Skwarchuk, S., Fast, L., and Sowinski, C. (2010). Do home numeracy and literacy practices of Greek and Canadian parents predict the numeracy skills of kindergarten children? Int. J. Early Years Educ. 18, 55-70. doi: 10.1080/09669761003693926

LeFevre, J., Skwarchuk, S., Smith-Chant, B. L., Fast, L., Kamawar, D., and Bisanz, J. (2009). Home numeracy experiences and children's math performance in the early school years. Can. J. Behav. Sci. 41, 55-66. doi: 10.1037/a001 4532

Levine, S. C., Huttenlocher, J., Taylor, A., and Langrock, A. (1999). Early sex differences in spatial skill. Dev. Psychol. 35, 940-949. doi: 10.1037/0012-1649. 35.4.940

Levine, S. C., Ratliff, K. R., Huttenlocher, J., and Cannon, J. (2012). Early puzzle play: a predictor of preschoolers' spatial transformation skill. Dev. Psychol. 48, 530-542. doi: 10.1037/a0025913

Manolitsis, G., Georgiou, G. K., and Tziraki, N. (2013). Examining the effects of home literacy and numeracy environment on early reading and math acquisition. Early Childhood Res. Q. 28, 692-703. doi: 10.1016/j.ecresq.2013.05. 004

Melhuish, E. C., Phan, M. B., Sylva, K., Sammons, P., Siraj-Blatchford, I., and Taggart, B. (2008). Effects of the home learning environment and preschool center experience upon literacy and numeracy development in early primary school. J. Soc. Issues 64, 95-114. doi: 10.1111/j.1540-4560.2008. 00550.x

Methe, S. A., Hojnoski, R., Clarke, B., Owens, B. B., Lilley, P. K., Politylo, B. C., et al. (2011). Innovations and future directions for early numeracy curriculumbased measurement: commentary on the special series. Assess. Effect. Intervent. 36, 200-209. doi: 10.1177/1534508411414154

Milburn, T. F., Lonigan, C. J., DeFlorio, L., and Klein, A. (2019). Dimensionality of preschoolers' informal mathematical abilities. Early Childhood Res. Q. 47, 487-495. doi: 10.1016/j.ecresq.2018.07.006

Mix, K. S. (2019). Why are spatial skill and mathematics related. Child Dev. Perspect. 13, 121-126. doi: 10.1111/cdep.12323

Mix, K. S., and Cheng, Y.-L. (2012). The relation between space and math: developmental and educational implications. Adv. Child Dev. Behav. 42, 197-243. doi: 10.1016/B978-0-12-394388-0.00006-X

Muthén, L. K., and Muthén, B. O. (2012). Mplus 7 [Computer Program]. Los Angeles, CA: Muthén \& Muthén.

Napoli, A. R., and Purpura, D. J. (2018). The home literacy and numeracy environment in preschool: cross-domain relations of parent-child practices and child outcomes. J. Exp. Child Psychol. 166, 581-603. doi: 10.1016/j.jecp.2017.10. 002

Nguyen, T., Watts, T. W., Duncan, G. J., Clements, D. H., Sarama, J. S., Wolfe, C., et al. (2016). Which preschool mathematics competencies are most predictive of fifth grade achievement? Early Childhood Res. Q. 36, 550-560. doi: 10.1016/j. ecresq.2016.02.003

Niklas, F., Cohrssen, C., and Tayler, C. (2016). Improving preschoolers' numerical abilities by enhancing the home numeracy environment. Early Educ. Dev. 27, 372-383. doi: 10.1080/10409289.2015.1076676

Niklas, F., and Schneider, W. (2014). Casting the die before the die is cast: the importance of the home numeracy environment for preschool 
children. Eur. J. Psychol. Educ. 29, 327-345. doi: 10.1007/s10212-0130201-6

Plomin, R., DeFries, J. C., and Loehlin, J. C. (1977). Genotype-environment interaction and correlation in the analysis of human behavior. Psychol. Bull. 84, 309-322. doi: 10.1037/0033-2909.84.2.309

Pruden, S. M., and Levine, S. C. (2017). Parents' spatial language mediates a sex difference in preschoolers' spatial-language use. Psychol. Sci. 28, 1583-1596. doi: 10.1177/0956797617711968

Pruden, S. M., Levine, S. C., and Huttenlocher, J. (2011). Children's spatial thinking: does talk about the spatial world matter? Dev. Sci. 14, 1417-1430. doi: 10.1111/ j.1467-7687.2011.01088.x

Purpura, D. J., and Logan, J. A. R. (2015). The nonlinear relations of the approximate number system and mathematical language to early mathematics development. Dev. Psychol. 51, 1717-1724. doi: 10.1037/dev000 0055

Purpura, D. J., and Lonigan, C. J. (2013). Informal numeracy skills: the structure and relations among numbering, relations, and arithmetic operations in preschool. Am. Educ. Res. J. 50, 178-209. doi: 10.3102/0002831212465332

Purpura, D. J., and Reid, E. E. (2016). Mathematics and language: individual and group differences in mathematical language skills in young children. Early Child. Res. Q. 36, 259-268. doi: 10.1016/j.ecresq.2015.12.020

Purpura, D. J., Hume, L. E., Sims, D. M., and Lonigan, C. J. (2011). Early literacy and early numeracy: the value of including early literacy skills in the prediction of numeracy development. J. Exp. Child Psychol. 110, 647-658. doi: 10.1016/j. jecp.2011.07.004

Purpura, D. J., Reid, E. E., Eiland, M. D., and Baroody, A. J. (2015). Using a brief preschool early numeracy skills screener to identify young children with mathematics difficulties. Sch. Psychol. Rev. 44, 41-59. doi: 10.17105/spr44-1. 41-59

Reise, S. P. (2012). The rediscovery of bifactor measurement models. Multiv. Behav. Res. 47, 667-696. doi: 10.1080/00273171.2012.715555

Rindskopf, D. (1984). Structural equation models: empirical identification, Heywood cases, and related problems. Sociol. Methods Res. 13, 109-119. doi: $10.1177 / 0049124184013001004$

Rittle-Johnson, B., Zippert, E. L., and Boice, K. L. (2019). The roles of patterning and spatial skills in early mathematics development. Early Childhood Res. Q. 46, 166-178. doi: 10.1016/j.ecresq.2018.03.006

Scarr, S., and McCartney, K. (1983). How people make their own environments: a theory of genotype? environment effects. Child Dev. 54, 424-435. doi: 10.2307/ 1129703
Schmitt, S. A., Korucu, I., Napoli, A. R., Bryant, L. M., and Purpura, D. J. (2018). Using block play to enhance preschool children's mathematics and executive functioning: a randomized controlled trial. Early Childhood Res. Q. 44, 181-191. doi: 10.1016/j.ecresq.2018.04.006

Skwarchuk, S.-L., Sowinski, C., and LeFevre, J.-A. (2014). Formal and informal home learning activities in relation to children's early numeracy and literacy skills: the development of a home numeracy model. J. Exp. Child Psychol. 121, 63-84. doi: 10.1016/j.jecp.2013.11.006

Thompson, R. J., Napoli, A. R., and Purpura, D. J. (2017). Age-related differences in the relation between the home numeracy environment and numeracy skills. Infant Child Dev. 26:e2019. doi: 10.1002/icd.2019

Toll, S. W. M., and Van Luit, J. E. H. (2014). Explaining numeracy development in weak performing kindergartners. J. Exp. Child Psychol. 124, 97-111. doi: 10.1016/j.jecp.2014.02.001

Toub, T. S., Hassinger-Das, B., Nesbitt, K. T., Ilgaz, H., Weisberg, D. S., and HirschPasek, D. K. (2018). The language of play: developing preschool vocabulary through play following shared book-reading. Early Childhood Res. Q. 45, 1-17. doi: 10.1016/j.ecresq.2018.01.010

Van Hoof, J., Bojorque, G., Torbeyns, J., Van Nijlen, D., and Verschaffel, L. (2020). Validating a home numeracy questionnaire in Ecuador using factor analysis. Int. J. Educ. Res. Rev. 5, 37-42. doi: 10.24331/ijere.650861

Verdine, B. N., Irwin, C. M., Golinkoff, R. M., and Hirsh-Pasek, K. (2014). Contributions of executive function and spatial skills to preschool mathematics achievement. J. Exp. Child Psychol. 126, 37-51. doi: 10.1016/j.jecp.2014. 02.012

Zippert, E. L., and Rittle-Johnson, B. (2018). The home math environment: more than numeracy. Early Childhood Res. Q. 50, 4-15. doi: 10.1016/j.ecresq.2018.07. 009

Conflict of Interest: The authors declare that the research was conducted in the absence of any commercial or financial relationships that could be construed as a potential conflict of interest.

Copyright (๑ 2020 Purpura, King, Rolan, Hornburg, Schmitt, Hart and Ganley. This is an open-access article distributed under the terms of the Creative Commons Attribution License (CC BY). The use, distribution or reproduction in other forums is permitted, provided the original author(s) and the copyright owner(s) are credited and that the original publication in this journal is cited, in accordance with accepted academic practice. No use, distribution or reproduction is permitted which does not comply with these terms. 
OPEN ACCESS

Edited by:

Caroline Cohrssen,

The University of Hong Kong,

Hong Kong

Reviewed by:

Sherri Horner,

Bowling Green State University,

United States

Janet Scull,

Monash University, Australia

${ }^{*}$ Correspondence:

Lorenz Grolig

grolig@posteo.de

Specialty section:

This article was submitted to

Educational Psychology,

a section of the journal

Frontiers in Psychology

Received: 25 April 2020

Accepted: 01 July 2020

Published: 26 August 2020

Citation:

Grolig L (2020) Shared Storybook

Reading and Oral Language

Development: A Bioecological

Perspective.

Front. Psychol. 11:1818.

doi: 10.3389/fpsyg.2020.01818

\section{Shared Storybook Reading and Oral Language Development: A Bioecological Perspective}

\author{
Lorenz Grolig* \\ Max Planck Research Group Reading Education and Development (REaD), Max Planck Institute for Human Development, \\ Berlin, Germany
}

Shared reading research has become increasingly multidisciplinary and has incorporated a multitude of assessment methods. This calls for an interdisciplinary perspective on children's shared reading experiences at home and at the child care center and their relationships to oral language development. Here, we first discuss Bronfenbrenner's bioecological model of human development (Bronfenbrenner and Morris, 2006) regarding the relationship between shared storybook reading and oral language development. Second, we develop a framework for investigating effects of shared reading on language development in two important microsystems: the home literacy environment (HLE) and the child care literacy environment (CCLE). Zooming in on shared storybook reading as a proximal process that drives oral language development, we then develop a triad model of language learning through shared storybook reading that integrates approaches and evidence from educational psychology, developmental psychology, psycholinguistics, and corpus linguistics. Our model describes characteristics of children, adults, and books, and how their interplay influences shared reading activities. Third, we discuss implications for the Home Literacy Model (Sénéchal and LeFevre, 2002, 2014) regarding the conceptualization of shared reading as an important source of oral language development. Finally, to facilitate integrated research designs that include the two most important microsystems, we provide a critical discussion of assessment methods used in research that investigates the HLE and the CCLE and relate them to the shared reading triad in our bioecological model of shared storybook reading. We conclude with directions for future research.

Keywords: shared storybook reading, home literacy environment, language development, vocabulary, narrative, comprehension, ecological model, assessment

\section{INTRODUCTION}

Being proficient in the majority language is a key competence for learning in educational contexts, such as child care and school (Hoff, 2013; Kempert et al., 2019). Evidence from empirical developmental studies favors a usage-based theory of language acquisition (e.g., Tomasello, 2009) over theories postulating that language development is by and large an innate process (e.g., Chomsky, 1980). To become proficient speakers of a language, children need both communicative opportunities and proficient language models (Hoff, 2006). Longitudinal studies show marked differences in children's vocabulary and grammar skills and in their rate of language acquisition as early as the first year of life, and these individual differences are strongly related to children's language environments (Kidd et al., 2018). 
Oral language comprehension is a major limiting factor in reading comprehension after children have acquired basic reading skills (i.e., fluent and accurate decoding of single words). Reading research differentiates between lower level language skills, which are related to word and sentence processing (e.g., vocabulary and grammar skills), and higher level language skills, which are related to the processing of texts (e.g., comprehension monitoring and narrative skills). The simple view of reading (Hoover and Gough, 1990) describes reading comprehension as the product of decoding and linguistic comprehension. Accordingly, both are necessary for understanding written texts. A child with poor decoding or oral language skills will most likely show poor reading comprehension. Oral language skills become increasingly important for reading comprehension in relation to word reading skills between Grades 1 and 4 (Storch and Whitehurst, 2002; Language and Reading Research Consortium, 2015a; Lervåg et al., 2018; Hjetland et al., 2019). This developmental trajectory has been found in relatively transparent orthographies, such as Spanish, Slovak, Czech (Caravolas et al., 2019), Finnish (Torppa et al., 2016), and German (Ennemoser et al., 2012).

Even though our understanding of reading acquisition has seen considerable progress in recent decades (e.g., Castles et al., 2018), there is still a substantial proportion of children who experience severe difficulties while learning to read. For example, results from the Progress in International Reading Literacy Study (PIRLS) 2016 study show that by the end of Grade 4, there are already large differences between high achievers and low achievers in Germany (Bos et al., 2017). At the end of Grade 4, about 19\% of the school children in Germany have severe reading comprehension problems and need additional support to acquire adequate reading skills (Bos et al., 2017). Therefore, more research investigating the impact of early literacy environments on children's language development is needed.

Previous reviews have synthesized evidence from shared reading research and developed models of environmental influences on language development (Fletcher and Reese, 2005; Hoff, 2006; Jaeger, 2016). In the present review, we take an interdisciplinary perspective on children's shared storybook reading experiences at home and at the child care center and how they are related to the development of oral language and reading skills. To establish a theoretical framework, we discuss models of environmental influences on child development, focusing on Bronfenbrenner's bioecological model with regard to language development during early childhood in section Environments and Language Development. We summarize evidence for the role of socio-cultural, educational, and familial factors for language development. In addition, we develop a framework for the effects of shared reading on language development in the home literacy environment (HLE) and the child care literacy environment (CCLE). In section Shared Reading in the HLE, we summarize evidence regarding concrete characteristics of the HLE that are related to the development of language and reading abilities. We develop a triad model of oral language learning through shared book reading that integrates approaches and evidence from educational psychology, developmental psychology, psycholinguistics, and corpus linguistics research. The model describes characteristics of children, adults, and books, and how their interplay influences shared reading activities. We propose modifications to the Home Literacy Model (Sénéchal and LeFevre, 2002, 2014) regarding the conceptualization of shared reading as an important source of language development, and the language outcomes are proposed. In section Assessment of Literacy Environments and Shared Reading, in order to facilitate integrated research designs that include the two most important microsystems, we provide a critical overview of assessment methods used in HLE and CCLE research, such as measures of socioeconomic status (SES), literacy environment questionnaires, behavior observations, diary methods, and recognition and recall tests. Finally, in section Summary and Directions for Future Research, we summarize the evidence for the triad model of shared reading and discuss avenues for future research.

\section{ENVIRONMENTS AND LANGUAGE DEVELOPMENT}

In this section, we first summarize Bronfenbrenner's bioecological framework for understanding human development. Afterwards, we take a look at shared reading and early literacy research through the lens of Bronfenbrenner's framework and develop a bioecological model of oral language learning through shared reading.

\section{Bronfenbrenner's Bioecological Model}

Bronfenbrenner characterizes human development as a function of the interplay between psychological, biological, and environmental factors. The bioecological model of human development (Bronfenbrenner, 1977; Bronfenbrenner and Morris, 2006) describes different social spheres as the environmental contexts in which child development occurs. The interplay between a child and another person (e.g., family members, child care workers, and peers) is conceptualized as a microsystem, which is a "pattern of activities, social roles, and interpersonal relations experienced by the developing person in a given faceto-face setting with particular physical, social, and symbolic features that invite, permit, or inhibit, engagement in sustained, progressively more complex interaction with, and activity in, the immediate environment" (Bronfenbrenner, 1994, p. 1654). Microsystems influence the child's development directly and are also reciprocally influenced by the child. Due to the direct engagement of children in microsystems, these environments are regarded as proximal influences on child development. The combination of and relationships between two or more interacting microsystems is called mesosystem (e.g., communicative practices at home and at the child care center).

An exosystem, by contrast, is conceptualized as distally influencing child development. It consists of connections and transmissions between two or more settings, of which at least one is not an immediate environment to the child (e.g., a parent's workplace), and therefore, an exosystem can have indirect effects on a child's development (e.g., a parent who works late spends less time interacting with the child in the evening). The exosystem includes, for example, characteristics 
of the parents' workplace that affect the time parents spend with their children or regulations by educational institutions that affect preschool curricula. Finally, the most distal influence on child development is exerted by the macrosystem, which consists of cultural values, norms, and laws that can be specific for people of different social classes, religious confessions, or nationalities (Bronfenbrenner and Morris, 2006).

Earlier versions of the bioecological model have stressed the importance of investigating the influence of each system component on human development (e.g., Bronfenbrenner, 1977). Most of the ensuing research, however, has revealed that proximal processes in microsystems are the "primary engines of development" (Bronfenbrenner and Morris, 2006, p. 798), which has led to an intensified interest in these processes. Proximal processes are the interactions between a child and other persons in the child's immediate external environment. Proximal processes need to operate regularly and over a sufficient time span to have an effect on the person's development. The latest version of the bioecological model describes human development primarily as a function of a "progressively more complex reciprocal interaction between an active, evolving biopsychological human organism and the persons, objects, and symbols in its immediate external environment [...]" (Bronfenbrenner and Morris, 2006, p. 797). Proximal processes that are developmentally effective include active involvement of the developing person and reciprocal interactions between people, objects, and symbols. Proximal processes develop in accordance with the developmental course of the involved persons. Over time, they become more complex to meet the developmental needs and to support further development of the persons.

To investigate environmental influences on development, research should take into account that the power of proximal processes (e.g., shared reading) depends both on the environmental context (e.g., shared reading at home and at the child care center) and characteristics of the person (e.g., memory; Bronfenbrenner and Morris, 2006). Interactions between environmental factors and person variables are of key interest in bioecological research: "The form, power, content, and direction of the proximal processes effecting development vary systematically as a joint function of the characteristics of the developing person and the environment - both immediate and more remote - in which the processes are taking place [...]" (Bronfenbrenner and Morris, 2006, p. 798). Effects of proximal processes vary as a function of the developing person's characteristics, most notably a child's dispositions for engaging in proximal processes that can help to initiate and sustain proximal processes. For example, children who show an active interest in picture books are more likely to ask caregivers to be read to, and they might prefer this activity over other activities such as watching a series or physical activities. By contrast, children who find it in general hard to focus on the story of picture books are less likely to demand being read to, and they might prefer other activities over shared reading.

Additionally, personal resources are important developmental variables, such as ability, experience, and knowledge (Bronfenbrenner and Morris, 2006). For example, effects of shared reading on oral language skills might depend on children's prior oral language skills, shared reading experiences, and knowledge about the contents of a picture book. In turn, developmental outcomes of these proximal processes (e.g., vocabulary and narrative skills that were facilitated through shared reading) are themselves resources that help to extend the effects of the proximal processes (e.g., more advanced extratextual talk between a child and the caregiver during shared reading that supports the development of higher level language skills). According to Bronfenbrenner and Morris (2006), bioecological research should focus on the specific aspects of the behaviors that are assumed to be most closely related to the developmental outcome, for example, investigating which aspects of literacy environments are most closely related to oral language development. Finally, effects of proximal processes also vary as a function of the more remote environmental contexts into which the proximal processes are embedded, the historical periods in which the proximal processes occur, and the developing person's biological systems. The biological systems within a developing organism both limit individual development and represent at the same time the potential for development that can be realized through adequate experiences (Bronfenbrenner and Morris, 2006).

\section{A Bioecological Model of Language Development Through Shared Reading}

In this section, we develop a bioecological model of oral language development through shared reading (see Figure 1 for an overview of the components). Most children acquire sufficient oral language skills for everyday communication purposes, regardless of the amount or quality of shared reading they experience. Meta-analytic evidence shows that the correlation between oral language skills, such as vocabulary and grammar skills, and print exposure increases considerably between preschool $(r=0.34)$ and college $(r=0.66$; Mol and Bus, 2011). Shared reading (and later independent reading) is not the only proximal process that fosters oral language development, but it is one main driving force behind oral language individual differences, and the most important source of variability in oral language skills that are precursors of reading comprehension (e.g., vocabulary; Montag et al., 2015).

The proximal process of shared reading can be described through relationships between child, adult, and book, which we describe in our triad model of oral language development through shared reading (see section Determinants of the Shared Reading Triad's Effects on Language Skills). According to Vygotsky (1978), children can extend their language skills when they act in the zone of proximal development in collaboration with adults: Children's learning is facilitated through a guided participation in culturally determined, meaningful situations. Children's language skills are supported by adults' input, questions, and feedback, which creates a "scaffold" that facilitates children's development in the zone of proximal development, allowing them to reach a higher level of functioning. Repeated scaffolding enables children to internalize these more advanced modes of action and apply them independently in similar situations. Crucially, the influence of adults on the language development of children is mediated through the shared use of psychological and technical "tools" that are culturally shaped, such as children's books. During the 


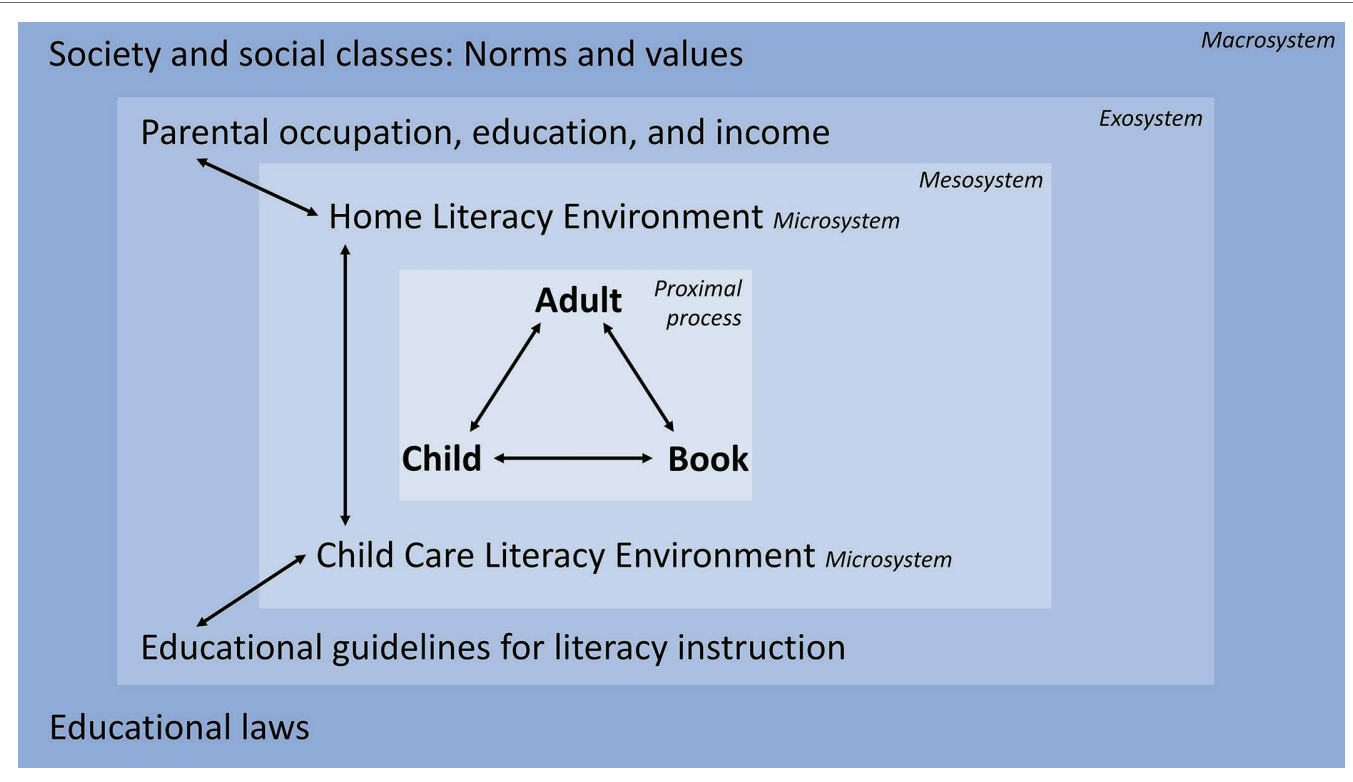

FIGURE 1 | A bioecological model of oral language development through shared reading.

interaction, a conversation or activity is co-constructed between a child and another person (Vygotsky, 1978). Children can become more active in the co-construction of narratives and also understand the more difficult concepts if they are embedded in concepts that they have already mastered, and adults can discuss in a more sophisticated way about the story after a basic understanding of the story has been established (van Kleeck, 2003).

Regarding the model presented in Figure 1, several person variables can influence how children and caregivers interact during shared reading. Bronfenbrenner and Morris (2006) distinguish between resource characteristics (e.g., oral language skills, general cognitive skills), demand characteristics (e.g., literacy interest), and force characteristics (e.g., reading motivation). Moreover, shared genes and gene-by-environment interactions constrain the extent to which children's oral language skills are malleable through environmental factors such as shared reading. Several studies found that the shared environment explains more variance in oral language skills than genetic differences in early childhood (Spinath et al., 2004; Chow et al., 2011; Olson et al., 2011; Hayiou-Thomas et al., 2012). One longitudinal study reported that oral language skills have a low heritability before school entry, but heritability increases between age 7 and 16 (Tosto et al., 2017). In conclusion, both genetic and shared environment influences constrain the maximum effect of early literacy interventions on young children's oral language skills. A preliminary conclusion drawn from the limited empirical evidence is that aiming to support the development of oral language skills seems to be reasonable because their heritability at preschool age and subsequent years is lower than the heritability of decoding precursors, potentially benefitting reading comprehension in early primary school (Tosto et al., 2017). Finally, the proximal effects of shared reading on oral language skills also depend on book characteristics, such as the lexical and grammatical diversity of the text (Montag et al., 2015).

On the microsystem level, educational research has identified two environments that are related to children's oral language development through shared reading: the HLE and the CCLE (Sénéchal et al., 1996; Weigel et al., 2005; Ebert et al., 2013; Niklas and Schneider, 2013; Weinert and Ebert, 2013). Some studies found that the HLE is more closely related to oral language than the CCLE (Ebert et al., 2013; Weinert and Ebert, 2013; Grolig et al., 2019), whereas other studies found that the influence of both literacy environments had a similar magnitude (Weigel et al., 2005; Schmerse et al., 2018).

On the mesosystem level, there are potential connections between HLE and CCLE, but few studies have investigated connections between the two (Weigel et al., 2005; Schmerse et al., 2018). In a large-scale German study, children's vocabulary skills benefitted more from high child care language process quality if they experienced a medium or high quality HLE rather than a low quality HLE (Schmerse et al., 2018). By contrast, a U.S. study did not find that interactions between caregivers' activities or beliefs in the HLE and CCLE predicted vocabulary skills or development (Weigel et al., 2005). Due to the limited number of studies, the magnitude and the source of concurrent and longitudinal environmental effects are unclear (see Hoff, 2006, for a review).

On the exosystem level, parents' occupation, education, and income are important predictors of oral language skills at preschool age (Hoff, 2006). As they are highly interdependent, the three predictors are often combined to form a SES variable (Buckingham et al., 2014). Children from lower SES families are exposed to only about one-third of the oral language input quantity that children from higher SES families get (Hart and Risley, 1995). On average, kindergarten children from poor neighborhoods 
receive much less language input and less diverse language input with regard to vocabulary and grammar from their parents and teachers than children from lower middle class neighborhoods during shared reading, play situations, and classes, leading to slower growth rates in expressive vocabulary skills (Neuman et al., 2018). The language of parents with a lower SES often has a lower lexical diversity in comparison to the language of parents with a higher SES (Burchinal et al., 2008; Huttenlocher et al., 2010). As a consequence of these input differences, children with a higher SES background often have a larger vocabulary (Hart and Risley, 1995; Hoff, 2006; Gilkerson et al., 2017) and more often use diverse and advanced grammatical constructions than children from lower SES families (Huttenlocher et al., 2002). Importantly, communicative and shared reading practices not only vary between families as a function of their SES, but they can also differ considerably between families with a similar SES. Within groups of SES (lower vs. middle vs. upper SES), there is a large variability of communicative practices, such as the amount and linguistic characteristics of talk between parents and children and the frequency of shared book reading in the family (Hoff, 2006; van Steensel, 2006). Therefore, SES does not determine the amount and quality of literacy activities at home, even though children from lower SES households are on average more likely to receive less literacy activities than children from higher SES households. Another important influence on the exosystem level is educational guidelines for language education and language fostering in the child care center (e.g., Ruberg and Rothweiler, 2012) because they provide an orientation for effective oral language activities. For example, recent approaches to child care language education highlight the importance of the professional's understanding of the general linguistic background of language development, the instrumental use of language as a key motivator for children, and the use of general communicative principles in everyday situations for implicit language teaching (Ruberg and Rothweiler, 2012).

On the macrosystem level, reading research and educational policies have influenced the norms and values connected to shared reading practices. In the last 50 years, research has accumulated a large body of evidence showing that shared reading in the first years of childhood is important for literacy development in general, and for oral language development in particular (Bus et al., 1995; Mol and Bus, 2011). At the same time, the main benefits that caregivers associate with children's books in early child care have changed since the 1980s from social, emotional, play, and general cognitive skills to specific early literacy skills, such as vocabulary, grammar, and narrative skills (van Kleeck and Schuele, 2010). Concerning parents' literacy activities, there are some SES differences regarding the attitudes, beliefs, and values connected to education in general and early literacy in specific, which become apparent in "characteristic modes of language use and interaction" (Hoff, 2006, p. 75). For example, compared to parents with a higher SES, parents with a lower SES tend to value the promotion of their children's literacy development less (Kluczniok et al., 2013), tend to value reading to their preschool children less (DeBaryshe, 1995), and exhibit a lower interaction quality with their child during shared reading (e.g., asking less questions, larger proportion of parent talk in relation to child talk, and less verbal distancing; Lehrl et al., 2012).

Another important factor on the macrosystem level is that in many countries, educational laws make it an obligation for child care workers to document and foster language development, especially if the children's native language is not the majority language (e.g., Senatsverwaltung für Bildung, Jugend und Wissenschaft, 2017). Professional associations and educational administrations encourage parents and child care workers to use children's books as a means for promoting children's emergent literacy skills (e.g., National Association for the Education of Young Children, 2009; Senatsverwaltung für Bildung, Jugend und Wissenschaft, 2014). As a consequence, shared reading is almost universally seen as a highly desirable activity for child development promotion in Western societies, and depriving children of shared reading experiences is therefore often described as a major disadvantage with respect to later success in school in the public discourse (e.g., Stiftung Lesen, 2018).

In sum, Bronfenbrenner's bioecological model of development highlights that psychological and technical tools (e.g., language and books) are used for the co-construction of meaning between a caregiver and a child. Ideally, caregivers scaffold children's processes of meaning-making by providing a developmentally appropriate context in which children can relate new language knowledge to prior language knowledge (zone of proximal development; Vygotsky, 1978), thereby refining their oral language skills. Bronfenbrenner and Morris (2006) posit a strong reciprocity of caregiver-child interactions, emphasizing the active involvement of young children in educational processes such as shared reading. Moreover, development is conceptualized as an outcome of interactions between environmental and person variables, whereby proximal processes that take place in microsystems are considered to be the main drivers of change. Applied to oral language development, shared reading as a proximal process depends on child, adult, and book characteristics, and relationships between these three literacy agents. Studies have identified the HLE and the CCLE as the two main environments that are directly related to oral language development through shared reading. In comparison, parental SES is a more distal variable with regard to language development, which is nevertheless related to differences in shared reading practices and the diversity of parent language, and ultimately, children's oral language development.

\section{SHARED READING IN THE HLE}

Several studies have investigated the components of the HLE that are related to oral language development. Section HLE Components and Relationships to Early Literacy Skills summarizes which components of the HLE can be distinguished, and which of them are related to different early literacy skills. In section Determinants of the Shared Reading Triad's Effects on Language Skills, we summarize evidence for a triad model of shared reading that is proposed as a framework for more detailed investigations of shared reading as a proximal process. In section A Modified Home Literacy Model: Introducing the Shared Reading Triad, we propose a modified version of the 
Home Literacy Model (Sénéchal and LeFevre, 2002) that incorporates this shared reading triad, allowing a more detailed understanding of how interactions between child, adult, and book and their characteristics affect language development.

\section{HLE Components and Relationships to Early Literacy Skills}

Components of the HLE can be divided into environment resources and exposure to literacy activities (see Figure 2). The latter includes passive HLE (model learning) and active HLE (shared reading, TV time). In addition, Sénéchal and LeFevre's (2002) conceptualization of the HLE distinguishes formal teaching of writing and reading from shared storybook reading. Many studies have found that differences in the active HLE explain variance in early literacy and language skills over and above parent SES, literacy resources, and the passive HLE (e.g., Sénéchal et al., 1996; Burgess et al., 2002). This finding is consistent with the bioecological model of human development (Bronfenbrenner and Morris, 2006), positing that reciprocal interactions between active children and the persons and objects in their immediate environment are the main driving force of development. Therefore, more recent reading acquisition research has focused more on the active HLE than on the other components.

The Home Literacy Model (Sénéchal and LeFevre, 2002, 2014; see Figure 3) has been particularly influential. The model proposes that there are two independent parental influences that shape the HLE: Shared reading activities between parents and children, called informal HLE, support the development of oral language skills, such as vocabulary. By contrast, parental teaching of reading and writing skills, called the formal HLE, supports the development of decoding precursors, such as letter knowledge and phonological awareness.

The aim of the Home Literacy Model is to describe which specific parental activities and early literacy experiences support the acquisition of oral language skills and precursors of decoding skills in young children (Sénéchal and LeFevre, 2002). Evidence from longitudinal studies that were conducted in different cultures (e.g., Hood et al., 2008; Chen et al., 2010; Lehrl et al., 2013;
Sénéchal and LeFevre, 2014) supports this proposed dichotomy. For example, a 5-year longitudinal study with English-speaking children found that informal and formal home literacy activities were not correlated, and that storybook exposure of kindergarten children predicted vocabulary development and comprehension skills at the beginning of Grade 1, which in turn predicted reading comprehension at the end of Grade 3 (Sénéchal and LeFevre, 2002). In the same study, parental teaching of reading and writing skills during kindergarten predicted precursors of decoding at the end of Grade 1, which in turn predicted reading comprehension in Grade 3.

Overall, the Home Literacy Model (Sénéchal and LeFevre, 2002, 2014) is a parsimonious evidence-based model. However, from a bioecological perspective, the model has several shortcomings. In particular, shared reading as a proximal process that drives oral language development seems to be underspecified. First, characteristics of child, adult, and book as literacy agents, their bivariate relationships, and their interplay should be taken into consideration. For example, motivation for leisure time reading in primary school declines during the first grades, exacerbating individual differences in reading skills (Wigfield et al., 2016). A more differentiated understanding of how children's engagement during shared storybook reading can be enhanced could help to identify approaches for supporting reading motivation in primary school or even before. Second, even though different oral language skills on the word, sentence, and text level are highly correlated before school entry (Language and Reading Research Consortium, 2015b), there is some evidence that lower versus higher level language skills are each unique predictors of reading comprehension (Lepola et al., 2012; Kim, 2014; Catts et al., 2015; Silva and Cain, 2015). Therefore, a model of HLE's effects on oral language should distinguish these two sets of language skills, and studies should investigate how they are related to shared reading.

\section{Determinants of the Shared Reading Triad's Effects on Language Skills}

On the level of shared reading as a proximal process of development (Bronfenbrenner and Morris, 2006), the communication during Limiting Environment/Resources
Parent Education + Occupation
Educational Aspirations
FIGURE 2 | Components of the home literacy environment (HLE).
Model Learning:
Reading + TV 


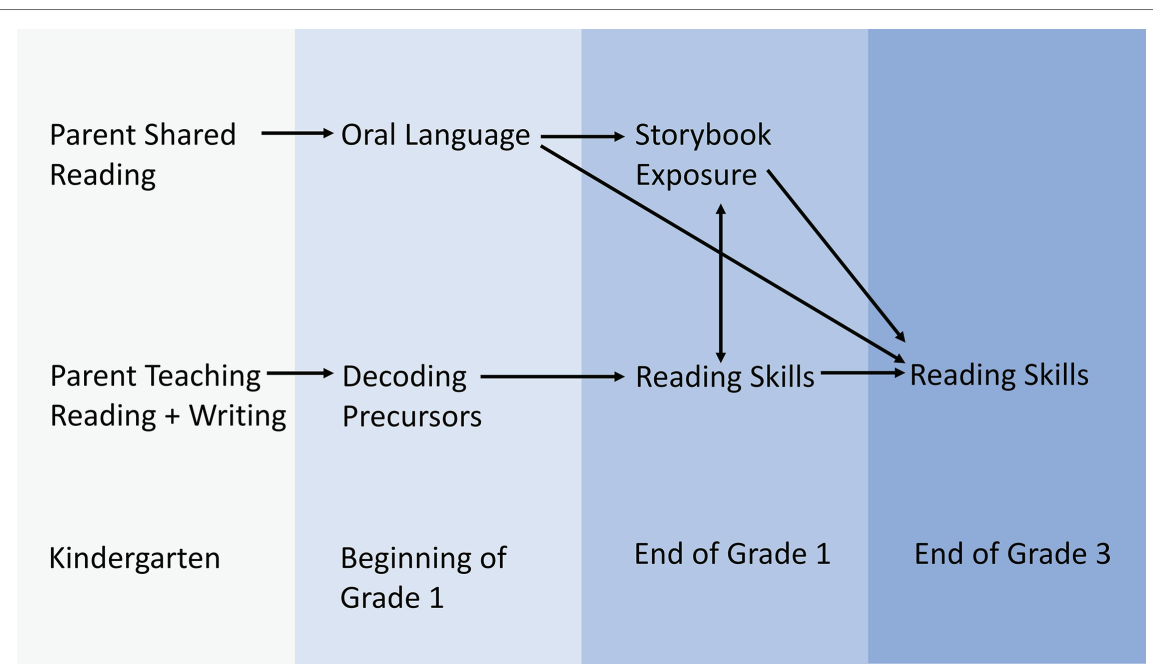

FIGURE 3 | Home Literacy Model (adapted from Sénéchal and LeFevre, 2002).

() 2002 by the Society for Research in Child Development, Inc. Adapted with permission.

shared reading and its effects on oral language skills depend on the fit between the three literacy agents child, adult, and book (van Kleeck, 2003; Fletcher and Reese, 2005). Experimental and intervention studies investigating shared reading effects often observe that children only learn a fraction of the target words (Wasik et al., 2016). Many study designs are based on the manipulation of only a few shared reading variables and fail to mention other characteristics of the shared situation that are potentially important for secondary analyses (e.g., meta-analyses). To develop a better understanding of the interplay between these agents, it is helpful to consider the cognitive, motivational, emotional, and material characteristics that influence the shared reading process, including the specifics of the written language contained in children's books. In addition to the characteristics of these three components, the relationships between them affect both the process and effectiveness of shared reading.

The inner rectangle in Figure $\mathbf{1}$ displays the triad model of shared reading in literacy environments in which adults, children, and books are involved in a proximal process that facilitates oral language development. This model is based on theoretical accounts of shared reading and literacy environments (van Kleeck, 2003; Fletcher and Reese, 2005; Jaeger, 2016) and evidence from empirical studies (see Hoff, 2006; Mol et al., 2008; Mol and Bus, 2011; Wasik et al., 2016; Flack et al., 2018, for reviews and meta-analyses). The main difference in comparison with previous models is a differentiation between characteristics of adults, children, and books involved in the shared reading process, their bivariate relationships, and the interplay of all three agents during shared reading. In the following, we discuss how characteristics of literacy agents and their relationships can affect shared reading.

\section{Characteristics of Child, Adult, and Book}

Theoretically, children's language learning from shared reading should be related to differences in perceptive and cognitive functions that predict differential language learning from any environmental language input, such as phonetic distinction, wording segmentation from the speech stream, attentional functions (working memory and executive functions), and statistical learning (see Kidd et al., 2018, for a review). In a correlational study, the relationship between children's storybook exposure and vocabulary skills was not moderated by verbal short-term memory, inhibitory control, or sustained attention (Davidse et al., 2011). In another correlational study, by contrast, working memory capacity moderated the relationship between HLE and language skills: The average language skills of children were lowest if they had a lower working memory capacity and came from a home that provided less shared reading activities (Leseman et al., 2007). Overall, evidence is scarce and inconclusive regarding the moderating role of children's general cognitive functions with respect to language development. Moreover, there is a lack of research investigating whether effects of early literacy and language interventions are moderated by working memory or executive functions (Hasselhorn, 2010), which would allow causal inferences. The few studies that investigated differential effects of shared reading activities on language skills did not focus on such general cognitive functions but on verbal abilities (i.e., vocabulary) as moderator. Experimental studies found that children with higher pre-intervention vocabulary had larger language gains from shared reading (e.g., Sénéchal et al., 1995b; Coyne et al., 2009; Lenhart et al., 2019). Similarly, a meta-analysis of intervention studies found that dialogic reading with parents had very small effects on the oral language skills of children at risk for literacy and language impairments, whereas the effects on children not at risk were moderate (Mol et al., 2008).

Parents who believe that education and reading are important for child development provide shared reading activities to their children more often (DeBaryshe, 1995; Kluczniok et al., 2013). Additionally, parents who enjoy reading themselves are more likely to engage actively in shared reading with their children (Sonnenschein et al., 1997; Bus et al., 2000). Even more fundamentally, the language and reading skills of an adult, which depend to a large part on leisure time reading ( $\mathrm{Mol}$ and Bus, 2011), are likely to determine the amount and quality of shared 
reading. For example, adults with low reading comprehension skills engage less frequently in shared reading activities with their children than adults with higher reading comprehension skills, presumably because reading is not an overly joyful leisure time activity to them (Neuman et al., 2018), and therefore, they are less likely to choose shared reading over other leisure time activities.

The characteristics of written language in children's books are also important for explaining effects of shared reading on oral language skills. A children's book can be analyzed as a "language model" (Hoff, 2006) that enables children to develop their language skills with the help of a reading person. On the word level, analyses of linguistic corpora have demonstrated that children's books contain more diverse vocabulary than the language adults use in everyday situations with their children (called child-directed speech, CDS; Massaro, 2015; Montag et al., 2015). More specifically, the texts in books for children aged birth to 6 years contain more unique words, so-called types, than CDS of adults talking to children in the same age range (Montag et al., 2015). Moreover, children's books contain a larger proportion of low frequency words (defined as words occurring less than 10 times per 1 million word tokens in a book corpus) than CDS in oral conversations (Crain-Thoreson et al., 2001; De Temple and Snow, 2003; Montag and MacDonald, 2015; Mesmer, 2016). Books present such words in semantic contexts that differ more than the semantic contexts of the CDS outside shared reading. Unlike most talk about the immediate environment, storybooks introduce words and concepts to the adult-child conversation that is independent from the situation in which the shared reading takes place (decontextualized language; Snow and Ninio, 1986; Nyhout and O'Neill, 2013). Being exposed to the same word in different contexts facilitates word learning and word recognition (Hills et al., 2010; Hsiao and Nation, 2018). As a consequence, shared reading not only facilitates the basic learning of new words (vocabulary breadth), but also the acquisition of the words' semantic features (vocabulary depth; Ouellette, 2006). On the sentence level, corpus analyses have shown that children's books contain more complex grammatical constructions than CDS (Cameron-Faulkner and Noble, 2013; Montag, 2019). Finally, on the text level, children's books contain different narrative structures, providing a context in which children can learn to understand and (re-)produce narratives (Pantaleo and Sipe, 2012; Wagner, 2013, 2017).

\section{Relationships Between Child, Adult, and Book During Shared Reading}

The effects of shared reading on oral language development depend on the relationship and interaction between child and adult (Fletcher and Reese, 2005). Adults need to calibrate their communication to the child's development in order to facilitate their learning in the zone of proximal development. More specifically, adults need to have a knowledge of a child's language skills and prior world knowledge in order to select adequate books and ask questions of adequate difficulty. For example, the oral language skills of children with higher language scores benefit more from discussing stories than from the labeling and description of pictures, whereas children with lower language scores benefit more from the latter than from discussing stories (Reese and Cox, 1999; Zucker et al., 2010).
In order to be effective, adults need to explicitly direct their talk during shared reading at the child (and maintain contact with the child) because talk that is not directed to children does not improve their oral language skills (Shneidman et al., 2013; Weisleder and Fernald, 2013).

Even before they become independent readers, children exhibit large differences in their interest in books, their motivation for shared reading, and their engagement during shared reading activities (Frijters et al., 2000; Hume et al., 2015). Studies have found that, while maternal reading behavior was not related to children's engagement during shared reading, children's engagement predicted language development and reading achievement (CrainThoreson and Dale, 1992; Dale et al., 1995). Similarly, the more questions children responded to during shared reading, the more words they learned (Sénéchal et al., 1995a; Sénéchal, 1997).

The relationship between adults and books is also an important factor in shared reading effectiveness. Adults differ in their preferences for reading over other leisure activities (Stanovich et al., 1995) and show large differences in print exposure (the amount of contact with written text; Stanovich and West, 1989). Moreover, adults with more print exposure exhibit better oral language skills (Mol and Bus, 2011), which are likely to influence their language use during shared reading. For example, while describing pictures, adults with more print exposure tend to use more complex grammatical constructions than adults with less print exposure (Montag and MacDonald, 2015). Parents often choose more complex books for shared reading with their preschool-aged children than for their younger children, reflecting that they are at least to some degree aware of their developmental differences (van Kleeck and Beckley-McCall, 2002).

\section{Children's and Caregivers' Extratextual Talk During Shared Reading}

The effects of some shared reading behaviors on language learning depend on the fit and the active coordination between all three literacy agents; for example, joint attention, extratextual talk, storybook selection, and repeated readings. One key question is how caregivers can facilitate children's active engagement and language production during shared reading, and, in turn, their language learning.

The language production of adults and children in everyday situations is highly context-sensitive (Griffin and Ferreira, 2006; Dickinson et al., 2014). Children's books allow the activation of a more diverse vocabulary than other communication settings because they provide very diverse language production contexts (Montag et al., 2015). For example, mothers' talk during storybook shared reading with 5-year-old children contained more infrequent words (that were not included in the text of the book) than their talk during other activities (mealtime, toy play, magnet play, and information book reading; Weizman and Snow, 2001). The proportion of infrequent words was an important longitudinal predictor of children's vocabulary in second grade (Weizman and Snow, 2001). In addition, several studies found that parents produce more grammatically complex sentences when reading a book with their children in comparison to their CDS while playing with their child. The mean length of parents' utterances is longer, 
they respond more to the utterances of their children, and they use more abstract language (see Fletcher and Reese, 2005, for a review).

Language learning through shared reading is facilitated when adults and children engage in a sustained situation of joint attention (Ninio and Bruner, 1978; Fletcher et al., 2008; Farrant and Zubrick, 2013), which means that adults and children share a common (visual) focus with respect to a children's book and that the two interact in this framework (e.g., pointing at and conversing about certain details of illustrations). For example, an experimental study found that instructing children to point at the illustrations of a children's book during shared reading facilitates their word learning in comparison to passively listening to the adult's reading (Sénéchal et al., 1995a). In addition, an intervention study found that caregiver contingent talk with infants facilitated their language production (McGillion et al., 2017). Other studies have found that infants can acquire a new object's verbal label just by overhearing its name, which indicates that joint attention is not always necessary for some aspects of word learning (e.g., Gampe et al., 2012). Overhearing alone, however, is unlikely to be sufficient for acquiring a deep and nuanced comprehension of word meaning (i.e., vocabulary depth).

To establish joint attention, an adult activates and scaffolds a child's thinking by (a) asking questions about a book's contents (van Kleeck et al., 1997), such as asking the child to label depicted objects or asking to explain what happens on a certain page, (b) expanding the child's answers, and which in turn (c) elicits new utterances from the child, and so on (dialogic cycle of communication during shared reading, Ninio and Bruner, 1978; Zevenbergen and Whitehurst, 2003). Many studies have found that asking basic comprehension questions during shared reading increases the effects on oral language skills in comparison to reading storybooks aloud without asking questions (see Wasik et al., 2016; Flack et al., 2018, for reviews). Asking such literal comprehension questions both serves to attain joint attention and to establish a fundamental understanding of concepts and events. Discussing the meanings of new words in the context of the story and in other contexts facilitates a deeper word understanding (Coyne et al., 2009).

Asking inferential comprehension questions in addition to literal comprehension questions can further enhance the positive effects of shared reading on vocabulary learning (Hindman et al., 2008; van Kleeck, 2008). Inferential questions also facilitated the production of narrative structures in two experimental studies (Silva et al., 2014; Silva and Cain, 2017), however, such a transfer effect was not found in an intervention study (Grolig et al., 2020a). Children's books contain story grammar elements of which parents make use during shared reading: They produce story grammar elements that are contained both in the text and in the pictures of the books (Breit-Smith et al., 2017). Presumably, this exposure to story grammar elements and discussing them during shared reading helps children build an inner representation of story schemata, which in turn helps their understanding of oral and written stories (Fiorentino and Howe, 2004; Westerveld et al., 2008). Parents, however, rely heavily on contextualized utterances, that is, they stick closely to the literal textual and visual contents of books, focus often on the actions and only rarely combine this with more abstract contents such as inferences regarding figures inner states or plans (Breit-Smith et al., 2017). Even though inferential questions support the acquisition of higher level language skills such as narrative comprehension, parents generally ask more literal comprehension questions than inferential questions about the contents of a story (van Kleeck et al., 1997; Huebner and Meltzoff, 2005). How an adult and a child interact about a book depends on the interplay of all three literacy agents, such as (a) the adult's propensity to ask open-ended questions during shared reading, (b) the child's responsiveness to the adult's questions and the contents in a storybook, and (c) features of the book that invite discussion, such as odd events.

The amount of pictorial information in relation to text-based information is also related to children's engagement and the amount of extratextual talk. Using children's books with illustrations during shared reading increases children's engagement and parent-child extratextual talk compared to using matched books without illustrations (Greenhoot et al., 2014). In comparison to using children's books with text during shared reading, using wordless picture books facilitates interactions between caregivers and children (Sénéchal et al., 1995a) and boosts the verbal production of both (Sénéchal et al., 1995a; Chaparro-Moreno et al., 2017). More specifically, in the study by Chaparro-Moreno et al. (2017), children produced more words (number of tokens), more diverse words (lexical diversity), and more sentences (number of utterances). At the same time, teachers produced more diverse words when using wordless picture books in comparison to storybooks with text. By contrast, the mean length of teachers' utterances (sentences) was longer when using storybooks with texts compared to wordless picture books (Chaparro-Moreno et al., 2017), which is probably due to written sentences being longer and also more complex than spoken sentences in CDS (Cameron-Faulkner and Noble, 2013; Montag, 2019). Therefore, using wordless picture books instead of storybooks with text during dialogic reading is likely to be more effective in fostering vocabulary skills, but also likely to be less effective in fostering grammatical skills. Another study found that the amount and quality of mothers' extratextual talk [i.e., lexical diversity and mean length of utterances (MLU)] does not differ when they read picture books with their children that contain more versus less text (Muhinyi and Hesketh, 2017), resulting in a doubled amount of extratextual talk during shared reading when using text-reduced children's books, with no reduction in lexical diversity or mean length of utterances. Overall, evidence from these studies suggests that using wordless picture books during shared reading facilitates children's oral language comprehension and production, with the exception of grammatical constructions that are typically found in written text.

Repeated readings of the same books can also increase children's engagement (Morrow, 1988; Fletcher and Jean-Francois, 1998) and enhance their language learning through shared reading (Snow and Goldfield, 1983). Children who read a familiar book talk more than when reading a novel book (Fletcher and Reese, 2005). Moreover, parents and children talk more about related content or their own experiences when re-reading the same book, which also increases children's world knowledge (Hayden and Fagan, 1987; Haden et al., 1996). 
For children with lower language abilities, repeated readings of the same book increase engagement in comparison to readings of different books (Morrow, 1988). Repeated readings provide multiple opportunities for repeated imitation (Ninio, 1983) and processing of novel words in a meaningful context (Sénéchal, 1997). Experimental studies have found that children's expressive vocabulary is enhanced after two or more readings of the same book, whereas one reading often does not result in significant vocabulary gains (e.g., Sénéchal and Cornell, 1993; Sénéchal, 1997; Horst et al., 2011; McLeod and McDade, 2011).

\section{A Modified Home Literacy Model: Introducing the Shared Reading Triad}

In sum, effects of shared reading on oral language are related to characteristics of children, adults, and books, such as (a) children's prior oral language skills and presumably also their general cognitive functions, such as memory, (b) adults' own reading habits and their beliefs about and attitudes toward shared reading, and (c) children's books' characteristics, such as lexical and grammatical diversity and narrative structures. Moreover, it is also important to consider bivariate relationships between children, adults, and books, because effects of shared reading on oral language skills depend on (d) adults' ability to attract and sustain children's attention and adjust their extratextual talk to children's oral language skills level, (e) children's interest in books and their engagement during shared reading, and (f) adults' provision of children's books at home, their ability to select developmentally appropriate books for shared reading with their children at different ages, and also their own print exposure, which is related to their oral language and reading skills. Finally, concerning the interplay of children, adults, and books, children's engagement and language learning through shared reading can be enhanced by (g) establishing a common conversational focus with basic comprehension questions and (h) inferential comprehension questions during extended extratextual talk about vocabulary and story elements.
Moreover, (i) repeated readings of (j) wordless picture books (or children's books with relatively little text in comparison to pictures) facilitate children's engagement and language production, and thus are effective means for increasing children's oral language skills.

Based on the evidence summarized above, Figure 4 shows a modified model of the HLE. In comparison to the original HLE model (Sénéchal and LeFevre, 2002), the modified model (a) adds child and book as literacy agents to shared reading as a key activity before school entry that influences later oral language and reading development, (b) highlights the active role of children (cognitive, motivational, and socio-emotional variables), (c) highlights the role of book characteristics and book selection, incorporating evidence from corpus linguistics into a shared reading research framework, (d) differentiates between direct effects of literacy agents and the reciprocal influences between three literacy agents that also affect oral language development, and (e) differentiates between lower and higher level language skills as outcome measures of shared reading.

This modified model of the HLE conceptualizes shared reading as a complex process. In addition, shared reading as a proximal process is itself dynamic, changing over time in relation to children's language, attention, and socio-emotional development, which is presumably related to changes in adults' shared reading behaviors and characteristics of children's books for different ages. This implies that key variables for the effects of shared reading on oral language skills need to be identified to allow a complexity reduction in empirical studies. Effects of shared reading appear to be small when measured over a few months (Mol et al., 2009, Noble et al., 2019), but substantial when measured over several years (DeBaryshe, 1993; Farrant and Zubrick, 2013). Ideally, then, assessment of shared reading practices should capture the effects of shared reading activities over a relatively long time period. Otherwise, shared reading effects are likely to be underestimated (Noble et al., 2019).

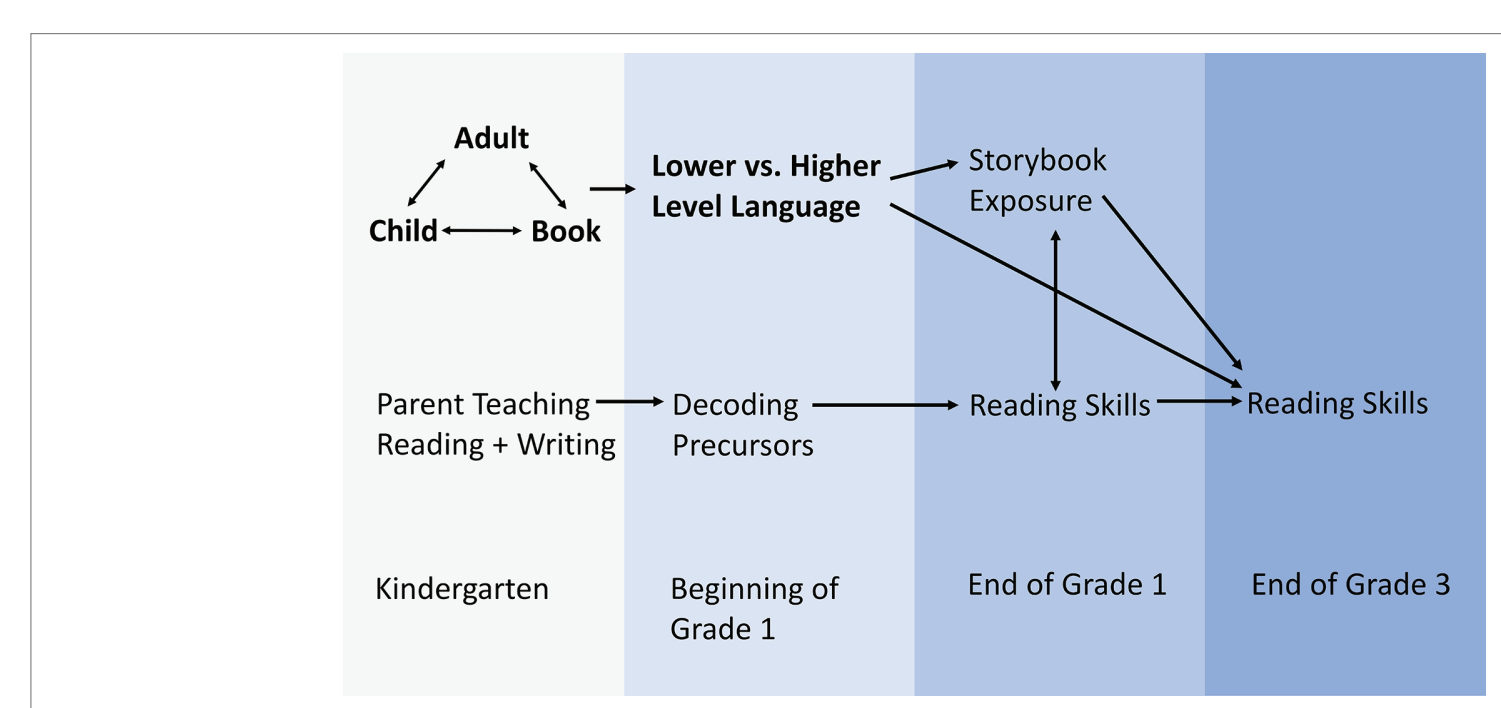

FIGURE 4 | Modified Home Literacy Model with shared reading triad (adapted from Sénéchal and LeFevre, 2002; van Kleeck, 2003; Fletcher and Reese, 2005). () 2002 by the Society for Research in Child Development, Inc. Adapted with permission. 
The following section discusses how literacy environments and shared reading activities in the HLE and the CCLE can be measured.

\section{ASSESSMENT OF LITERACY ENVIRONMENTS AND SHARED READING}

Investigating how shared reading in microsystems (HLE and CCLE) is related to oral language development in early childhood depends on the availability of adequate assessment methods. Pioneering correlational and longitudinal studies often had severe methodological shortcomings, among them measures with low reliability and social desirability bias (Lonigan, 1994). Since then, the field has developed and validated methods that capture different aspects of literacy environments and shared reading, which can be categorized as measures of (a) early literacy activities and shared reading input (e.g., literacy questionnaires and author recognition test (ART); section Measures of Literacy Environments), (b) the interactional quality during literacy activities and shared reading (e.g., environment rating scales and linguistic quality measures; section Interaction Measures of Shared Reading), and (c) memory outcomes of engaging in meaningful shared reading activities (e.g., recall of story details, recognition of storybook titles; section Outcome Measures of Shared Reading). Finally, we discuss which assessment methods are best suited for specific research questions and how they are related to environmental models of language learning (section Which Method for Which Research Question(s)?).

\section{Measures of Literacy Environments}

As measures of the input provided for children through literacy environments and shared reading, studies have used SES, caregiver questionnaires, activity diaries, and the ART. In addition, linguistic approaches to oral language learning through shared reading have recently started to investigate the relationship between the lexical and grammatical input qualities of storybooks and children's language development (e.g., Montag et al., 2015; von Lehmden et al., 2017; Wagner, 2017). In the future, this research will hopefully provide methods that are useful for the assessment of literacy environments and shared reading activities.

\section{Socioeconomic Status}

SES is a comparatively broad construct that is often operationalized as parent education, occupation, and income, or some combination of these variables (Buckingham et al., 2014). In the bioecological model (see Figure 1), it is situated on the exosystem level. Correlational and longitudinal studies corroborate that parent SES is positively associated with literacy activities (Fletcher and Reese, 2005; Hoff, 2006; van Steensel, 2006) as well as language and reading development during early childhood (Hart and Risley, 1995; Huttenlocher et al., 2002; Gilkerson et al., 2017). For example, parents with a middle SES report more shared reading than parents with a lower SES (Heath, 1983; Teale, 1986; Adams, 1990; Hammer, 2001; Britto et al., 2002). Whereas lower SES of parents is often associated with less frequent shared book reading, the effect of shared reading is not moderated by SES (Bus et al., 1995; Noble et al., 2019), indicating that children's oral language skills benefit from shared reading regardless of their social background.

Measures of SES provide important information on the broader context in which children grow up. They are, however, less helpful in determining which specific activities are particularly effective in fostering language development (Lonigan, 1994). SES is a "catch-all" variable that is theoretically difficult to grasp because it includes many aspects that are shared with HLE activities and resources (e.g., number of books in a household), but also many additional aspects that are more generally related to child development (e.g., nutrition, healthcare, amount of stress experienced by parents and children, and time available for educational activities; Lonigan, 1994). In sum, SES is an important context variable for estimating the extent to which social inequalities are related to differences in language development. In educational research, it should be used in combination with indicators of proximal processes that provide specific insights into how oral language skills can be fostered.

\section{Literacy Environment Questionnaires}

Between the 1950s and 1990s, the informal HLE has most often been measured by single or multiple items in parent questionnaires, such as frequency of shared reading, the number of children's books at home, parental leisure reading habits, family TV consumption, and frequency of family library visits (Bus et al., 1995). Meta-analyses have found that literacy activities (frequency of shared reading) and literacy resources (number of children's books at home) are particularly robust predictors of language skills, and that questionnaire measures of the HLE explain about $8-12 \%$ of variance in children's language skills (Bus et al., 1995; Mol and Bus, 2011).

Regarding the CCLE, few studies have used staff questionnaires to assess literacy activities and resources in the child-care setting (e.g., Weigel et al., 2005; Slot et al., 2015) and found that literacy activities in the CCLE were a unique predictor of vocabulary growth (Weigel et al., 2005). A meta-analysis found that domain-specific questionnaires did not explain a significant amount of variance in children's outcomes (e.g., language and literacy skills), possibly due to a lack of reliable questionnaire measures available for the assessment of the quality of literacy activities in the CCLE (Ulferts et al., 2019).

In sum, questionnaires are valid and cost-effective proximal measures of literacy activities and resources in the HLE. There are, however, several disadvantages to them that limit their predictive power. First, at least in Western societies, norms and values prescribe that reading to children is important for their development, often resulting in social desirability bias when questionnaire measures are used. Parents tend to overreport literacy activities, thereby diminishing the usefulness of questionnaire measures for differentiating between children who experience more versus less shared reading activities (DeBaryshe, 1995). This can also constrain the variability of responses to questionnaire items and result in ceiling effects (e.g., Sénéchal et al., 1996; Davidse et al., 2011), reducing the magnitude of correlations between such questionnaire measures and language skills. Second, even if there is sufficient variability, 
questionnaire items can be still problematic when they ask for the average number of shared reading sessions or the average time spend with shared reading during a week. Due to memory constraints, most participants are not capable of providing reliable retrospective accounts of the average time they spend with different activities over periods of time (e.g., Bradburn et al., 1987; Burt and Kemp, 1991).

\section{Activity Diaries}

Activity diaries can be less prone to social desirability bias when participants are not informed that the research is specifically about leisure reading (Greaney, 1980). Participants fill in a form with a time grid for each day in which they describe everything they have done on this day (e.g., Smith, 2000; Ennemoser and Schneider, 2007). Activity diaries allow a more precise estimation of absolute reading times and rely less on participants' memory abilities than questionnaire items that ask for retrospective estimation of average reading time. Even the duration estimation of recent events, however, is not immune to retrospection problems (Bradburn et al., 1987; Burt and Kemp, 1991). The main disadvantage of activity diaries is that they have to be filled in for several weeks to allow a generalization in terms of participants' average leisure reading time. Therefore, diary measures require a high implementation effort, and participants need to be very motivated to comply over an extended period of time (Carp and Carp, 1981; Bolger et al., 2003).

\section{Author Recognition Test}

To circumvent social desirability and recall issues that come with literacy questionnaires and activity diaries, Keith Stanovich and colleagues developed a recognition test format that has been used with primary school children, adolescents, and adults (Stanovich and West, 1989; Cunningham and Stanovich, 1990; Allen et al., 1992). In the ART, participants indicate on checklists which names of bestselling authors they recognize. To discourage guessing, participants are informed that the list also contains fake authors (foils). To calculate a print exposure score that is corrected for guessing, the proportion of checked foils is subtracted from the proportion of checked real authors. ART scores are positively correlated with other measures of print exposure, such as reading habit questionnaires and activity diaries (Allen et al., 1992; see Mol and Bus, 2011, for a meta-analysis), real-world reading behaviors (West et al., 1993), and participant age (Grolig et al., 2020b). Moreover, adults' ART scores also correlate positively with children's and adults' language and reading skills (West et al., 1993; Stanovich et al., 1995). Whereas activity diaries measure absolute reading times, recognition tests estimate relative differences in leisure reading time and related literacy activities.

In sum, the ART is a reliable, valid, and objective measure of print exposure that does not suffer from ceiling effects, social desirability bias, or imprecisions of event duration recall. With an administration time of about $5 \mathrm{~min}$, the ART is also a very cost-effective measure. In early childhood research, parents' scores in the ART are often used as a proxy of parental literacy (Sénéchal et al., 1996, 2008) or children's print exposure (Puglisi et al., 2017). The main disadvantage of the ART is that the familiarity with author names differs between cultures. Therefore, the ART has been adapted for different cultures, including Chinese (Chen and Fang, 2015), Dutch (Brysbaert et al., 2020), German (Grolig et al., 2020b), and Korean (Lee et al., 2019). Also, the popularity of authors changes over comparatively short time spans. Therefore, the ART should be updated every 5 to 10 years for an optimal assessment of print exposure.

\section{Interaction Measures of Shared Reading}

Whereas literacy environment questionnaires, activity diaries, and recognition tests focus on the quantity of shared reading, interaction measures also aim to assess quality features of literacy activities. In pedagogical research, observation measures are often used to characterize the quality of literacy-related interaction processes in the HLE and CCLE (section Observation Measures of Literacy Activities). Another approach to characterizing the quality of shared reading interactions is to analyze features of caregivers' language during shared reading as predictors of children's language development (section Linguistic Measures of Caregivers' Speech and Extratextual Talk).

\section{Observation Measures of Literacy Activities}

Even though observation measures are considered to be less biased by social desirability than HLE questionnaires (Bus et al., 1995), few observation rating scales have to date been developed for the HLE that focus on early literacy activities or shared book reading in particular. For example, in a longitudinal large-scale study that tracked children's development between age 3 and 10 in Germany (Pfost et al., 2013), a semi-standardized shared book reading task was used for rating the quality of the caregiver-child interaction (Family Rating Scale; Kuger et al., 2005; see Lehrl, 2018, for details). Raters assessed verbal distancing, nonverbal behavior, amount of (complex) questions, parent extratextual language, amount of children talk in relation to parent talk, and phonological cues (Lehrl, 2018). Interactional quality explained unique variance in grammar skills at age 3, but not in vocabulary skills. A brief HLE questionnaire (three items: quantity of books and children's books in the household, shared reading frequency) explained unique variance in vocabulary and grammar skills at age 3 above the variance explained by the Family Rating Scale (Lehrl, 2018).

In educational research, standardized observation protocols and rating scales administered by external assessors are often used to characterize the quality of literacy-related interaction processes in the CCLE. Two of the most often used scales are the Early Childhood Environment Rating Scales (ECERS-R; Harms et al., 1998; ECERS-E; Sylva et al., 2003) and the Classroom Assessment Scoring System (CLASS; Pianta et al., 2008). Some of these scales, however, also assess structural aspects of early childhood education and care (ECEC) in addition to teacherchild interactions. Nevertheless, meta-analyses have reported positive correlations with children's vocabulary skills. Both the ECERS-R total score and the language-reasoning subscale (using books and pictures, encouraging children to communicate, using language to develop reasoning skills, and informal use of language) are weakly related to the vocabulary skills of 30- to 72-month-old children (Brunsek et al., 2017). Moreover, the CLASS scale Instructional Support (concept development, quality of feedback, 
language modeling, literacy focus) is weakly correlated with vocabulary skills (Perlman et al., 2016). In addition, a metaanalysis of longitudinal studies found that environment rating scales that focus on the interaction quality and the observation of the process quality of domain-specific activities (e.g., language and literacy) result in relatively stronger correlations with vocabulary skills than scales that focus on the physical surroundings or questionnaire measures. The effect sizes, however, are in general small (Ulferts et al., 2019).

In sum, environment rating scales are reliable and valid direct measures of proximal processes that provide a detailed evaluation of the caregiver-child interaction. Scores are based on external raters which prevents bias due to social desirability. Considering that the literacy-related interactional quality in child care centers is often lower than desirable (Slot et al., 2015; Ulferts et al., 2019), environment rating scales are particularly useful for professional development interventions aiming to increase interactional quality (McNerney et al., 2006). On the other hand, the administration of environment rating scales is comparatively expensive because raters need to be trained for several hours, and on-site ratings often take two or more hours per classroom (e.g., Abreu-Lima et al., 2012). In addition, rating scales are not always significant predictors of preschoolers' language skills (e.g., Powell et al., 2010; Hindman et al., 2012; Lehrl, 2018), possibly because the assessment is based on observations during one or 2 days, which might not be representative of the average quality of literacy activities in the CCLE (Slot et al., 2015). Interestingly, environment rating scales and questionnaires that aim to assess the same quality aspects of ECEC are only weakly correlated (Slot et al., 2015). Therefore, environment rating scales could be complemented by other measures that assess the average amount and quality of literacy activities over longer periods of time.

\section{Linguistic Measures of Caregivers' Speech and Extratextual Talk}

Oral language development also depends on the quality of caregivers' child-directed speech (CDS) and the extratextual talk associated with shared book reading. Linguistic measures of caregivers' CDS, such as lexical diversity and mean length of utterances, are longitudinal predictors of preschoolers' oral language development (Hoff-Ginsberg, 1998; Hoff and Naigles, 2002; Huttenlocher et al., 2010; Rowe, 2012; Weisleder and Fernald, 2013). These linguistic measures have also been used to investigate the effects of linguistic quality of extratextual talk.

In the HLE, parents use more low frequency words and complex sentences when they read a book with their children in comparison to other activities (e.g., Crain-Thoreson et al., 2001; Noble et al., 2019). In turn, the proportion of low frequency words and the syntactic complexity in parents' extratextual talk during shared reading both predict preschoolers' growth of vocabulary skills (Weizman and Snow, 2001; Baker et al., 2015). In the CCLE, the lexical diversity and syntactic complexity of caregivers' CDS is also higher during shared book reading than during other activities (Dickinson et al., 2014). Similar to the findings in the HLE, the proportion of low frequency words (Dickinson and Porche, 2011) and complex syntax (Huttenlocher et al., 2002; Vasilyeva et al., 2006) in caregivers' CDS predicts children's growth in vocabulary and grammar skills.

In sum, deriving linguistic measures from observations of CDS is a valid and objective method for assessing literacy environments and shared reading activities. Similar to environment rating scales that provide detailed information about caregiverchild interactions on a behavioral level, linguistic measures provide a characterization of interactional quality features in educational settings that aim to foster oral language development (see Rowe and Snow, 2019, for a review that discusses linguistic, interactional, and conceptual dimensions of language input). Therefore, evidence from linguistic measures can be used for the development of preschool curricula, and also for professional development feedback. Linguistic measures, however, often cannot be derived automatically from recorded speech (see Gilkerson et al., 2017, as an example of automated analysis). More often, the audio material is manually coded, requiring many hours of work by trained staff. Therefore, linguistic measures are comparatively expensive.

\section{Outcome Measures of Shared Reading}

By adopting the rationale behind the ART (Stanovich and West, 1989), early childhood researchers have developed specific recognition and recall tests for the assessment of young children's storybook exposure. Whereas the ART is an input measure of literacy environments, storybook recognition and recall tests are outcome measures of shared reading activities. They assess relative differences in the recall of details from popular storybooks (section Storybook Knowledge Recall Tests) and the recognition of popular storybooks' titles (section Storybook Title Recognition Tests). Storybook information is memorized and retained as a result of shared reading activities that are meaningful to children.

\section{Storybook Knowledge Recall Tests}

Children are asked to name a book's title after they have seen its title page. If a title is correctly recalled, children are asked to tell some of the story details in order to control for guessing (Sénéchal et al., 1996; Davidse et al., 2011; Zhang et al., 2018). The recall scores explain a substantial amount of unique variance in children's vocabulary skills after controlling for the broader HLE and background variables (Sénéchal et al., 1996; Davidse et al., 2011; Zhang et al., 2018).

Storybook knowledge recall tests are objective and valid measures of print exposure. The administration time depends on the number of book covers presented to children. This test format, however, is rarely used, presumably because it has disadvantages that reduce its explanatory power. Most notably, a successful recall of book title and story details poses high demands on children's cognitive skills, which could explain the floor effects often found in these measures (Sénéchal et al., 1996; Davidse et al., 2011). Also, confounds with memory, attention, and language skills are problematic in studies investigating the relationship between shared reading and oral language skills.

\section{Storybook Title Recognition Tests}

Storybook title recognition tests (TRTs) are often used for examining the relationship between shared reading activities in the HLE and children's language development (see Mol and Bus, 2011, 
for a meta-analysis). TRTs are most often administered as paper and pencil tests in which parents mark the storybook titles that they recognize (e.g., Hood et al., 2008; Hamilton et al., 2016) but can also be administered as audio decision tests to preschoolers (Grolig et al., 2017). As in the ART, the proportion of checked foils is subtracted from the proportion of checked real titles, resulting in a hit rate that is corrected for guessing. Parents' TRT score is moderately correlated with HLE questionnaire measures and is considered to be a proxy of children's print exposure (Mol and Bus, 2011).

In sum, storybook TRTs are objective, reliable, and valid measures of shared reading activities in the HLE that are less confounded with children's cognitive skills than storybook knowledge recall tests. The test administration of the TRT takes about $5 \mathrm{~min}$. The TRT has been adapted for many cultures in the last decades (e.g., Australian: Hood et al., 2008; Chinese: Ho, 2014; English: Hamilton, 2013; German: Grolig et al., 2017). The main disadvantage of the TRT is that the popularity of storybooks changes over time. Therefore, the storybook titles in the TRT need to be updated every 5-10 years for an optimal assessment of storybook exposure.

\section{Which Method for Which Research Question(s)?}

Overall, there is no single method that fits all research questions. Each method has strengths and shortcomings. Therefore, combining measures with complementing strengths is the most reasonable approach to a comprehensive assessment of environmental influences on oral language learning. To understand how effects of shared storybook reading on oral language development are situated in communication settings, a comprehensive assessment of environmental factors should take into account distal environmental variables that are situated on the exosystem level (e.g., SES), proximal environmental variables that are situated on the microsystem level (e.g., descriptions of literacy environments), and descriptions or results of the proximal process itself, such as interaction or outcome measures of shared storybook reading.

In general, the measures that were discussed in this section show an adequate dispersion of scores, with the exception of storybook knowledge recall tests, where floor effects can be problematic. In addition, the reliability of the measures is in general adequate or good, with the exception of staff questionnaires for the CCLE, where the reliability for some measures is relatively low (Ulferts et al., 2019). Figure 5 summarizes measures for the assessment of literacy environments and shared storybook reading and locates them in the shared reading triad of the modified home literacy model that was developed in section Determinants of the Shared Reading Triad's Effects on Language Skills.

Considering that the influence of both HLE and CCLE on oral language should be assessed in sufficiently large samples to provide robust evidence for a bioecological model of language learning through shared reading, the amount of administration time and implementation effort are also critical factors that have to be considered. Most of the measures are relatively brief and cheap to implement; however, interactional measures (environment rating scales and linguistic measures) and activity diaries are much more time-intensive for researchers and participants, respectively. Therefore, environment rating scales and linguistic measures are probably used best when the evaluation of the interactional quality during shared reading or providing feedback during interventions is the focus of a study. Activity diaries provide the most reliable estimate of absolute leisure reading time, and therefore should be used in studies that investigate this specific variable.

Questionnaires about the HLE and CCLE are cost-effective measures for assessing the quantity of shared reading activities and resources. They also provide some basic description of shared reading activities and the physical environment but they often do not cover qualitative aspects. In addition, caregivers

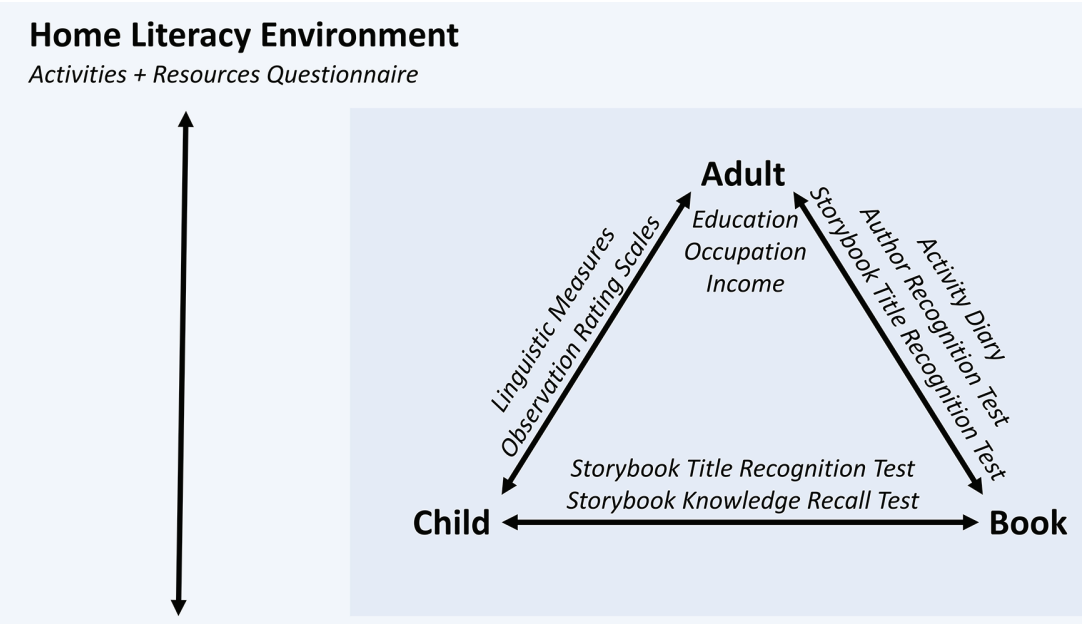

Child Care Literacy Environment

Activities + Resources Questionnaire

FIGURE 5 | Measures for the assessment of literacy environments and shared book reading. 
are aware that reading with children is beneficial for their development, which makes it more likely that they overstate the amount of shared reading. Besides this social desirability bias, items often ask for average occurrences of activities over an extended period of time, which leads to biases due to common event recall problems. Recognition test scores use foils as an effective control measure for social desirability. Also, they are based on the recognition of authors or titles, which is a simple memory process in comparison to averaging occurrences of shared reading over an extended time period, and therefore should be less confounded with memory abilities than questionnaire measures. Finally, recognition test scores reflect both long-term habits of leisure reading and recent reading activities because they contain classic and new authors (or storybook titles), capturing relative differences in shared reading activities over several years. Therefore, a cost-effective estimation of the relationships between the amount of shared reading in the HLE and the CCLE microsystems and language skills can be achieved by combining questionnaires and recognition tests.

\section{SUMMARY AND DIRECTIONS FOR FUTURE RESEARCH}

Based on Bronfenbrenner's bioecological model of human development (Bronfenbrenner and Morris, 2006), we developed a bioecological perspective on oral language learning through shared storybook reading and described how available research methods can be utilized to investigate key relationships between child, caregiver, and book, called the shared reading triad. In this review, we have integrated findings from psychological, educational, and linguistics research into an interdisciplinary bioecological framework that allows a comprehensive investigation of shared reading effects. We focused specifically on shared reading as a complex and changing proximal process that is a main driver of individual differences in oral language development.

Evidence from a large number of studies supports our triad model of shared storybook reading. This model can serve both as a research framework and provide some guidance for practitioners. First, effects of shared reading on oral language are related to characteristics of literacy agents, most notably children's prior language skills, adults' reading habits, and motivation toward shared reading, and children's books' lexical and grammatical diversity and narrative structures. Second, effects of shared reading are also related to relationships between these literacy agents. According to correlational and experimental studies, shared reading effects depend on children's literacy interest and engagement as well as joint attention and adjusting extratextual talk to children's oral language skills level. Moreover, regarding the relationship between adults and books, shared reading effects also depend on the provision of children's books at home, adults' ability to select developmentally appropriate storybooks, and also their leisure reading. Third, shared reading effects depend on the interplay of literacy agents. To get children engaged in shared storybook reading and activate their thinking, adults can use basic and inferential comprehension questions. Language learning is also facilitated by repeated readings and the use of wordless picture books because both increase children's engagement and language production during shared reading. Another important outcome of this review is an evidence-based, modified Home Literacy Model that adds child and book as literacy agents, thereby highlighting the active involvement of children and book characteristics. The modified model differentiates both between direct effects of literacy agents and the reciprocal connections between them and between lower and higher level language skills as outcome measures. Finally, our discussion of assessment methods revealed that the combination of literacy environment questionnaires and recognition tests allows a cost-effective and sufficiently descriptive evaluation of long-term shared reading practices in literacy environments when qualitative aspects of shared reading interactions are not in the focus of the research.

Throughout this review, we have pointed out gaps in shared storybook reading research. The HLE and the CCLE are important microsystems in which children are likely to experience shared reading in a regular basis. Studies about their relative effects on oral language development and interactions between the two microsystems could inform practice and policy in order to support the development of children who come from disadvantaged families. More specifically, future studies of shared reading should aim to disentangle contributions of child, adult, and book plus their bivariate relationships and their interplay regarding effects on oral language skills. In particular, the moderating role of individual differences in language processing and gene by environment interactions need to be studied in detail. On these grounds, the magnitude of language education effects can be estimated, and individually tailored interventions could be developed. Presumably, text characteristics of storybooks contribute to oral language learning. Storybooks designed for experimental purposes will help to shed more light on this topic. Finally, children's active engagement and language production during shared reading appear to be of key importance to language learning. In correlational and experimental research, a comprehensive description of the shared reading situation is needed to understand the contributions of these factors and their relationships, especially regarding secondary analyses. The triad model of shared storybook reading could help to establish a unified framework for shared storybook reading research.

\section{AUTHOR CONTRIBUTIONS}

LG contributed conception and design of the study. LG wrote the manuscript and revised the manuscript.

\section{FUNDING}

This review is based on a doctoral dissertation by LG which was supported by Stiftung Mercator and Rat für kulturelle Bildung e.V. (grant 14-001-4). Open access funding by Max Planck Society.

\section{ACKNOWLEDGMENTS}

I thank Sascha Schroeder and Sarah Eilers for feedback on an earlier version of this manuscript. 


\section{REFERENCES}

Abreu-Lima, I. M. P., Leal, T. B., Cadima, J., and Gamelas, A. M. (2012). Predicting child outcomes from preschool quality in Portugal. Eur. J. Psychol. Educ. 28, 399-420. doi: 10.1007/s10212-012-0120-y

Adams, M. J. (1990). Learning to read: Thinking and learning about print. Cambridge, MA: MIT Press.

Allen, L., Cipielewski, J., and Stanovich, K. E. (1992). Multiple indicators of children's reading habits and attitudes: construct validity and cognitive correlates. J. Educ. Psychol. 84, 489-503. doi: 10.1037/0022-0663.84.4.489

Baker, C. E., and Vernon-Feagans, L., and the Family Life Project Investigators. (2015). Fathers' language input during shared book activities: links to children's kindergarten achievement. J. Appl. Dev. Psychol. 36, 53-59. doi: 10.1016/j. appdev.2014.11.009

Bolger, N., Davis, A., and Rafaeli, E. (2003). Diary methods: capturing life as it is lived. Annu. Rev. Psychol. 54, 579-616. doi: 10.1146/annurev. psych.54.101601.145030

Bos, W., Valtin, R., Hußmann, A., Wendt, H., and Goy, M. (2017). "IGLU 2016: wichtige Ergebnisse im Überblick" in IGLU 2016. Lesekompetenzen von Grundschulkindern in Deutschland im internationalen Vergleich. eds. A. Hußmann, H. Wendt, W. Bos, A. Bremerich-Vos, D. Kasper, E. -M. Lankes et al. (Münster and New York: Waxmann), 13-28.

Bradburn, N., Rips, L., and Shevell, S. (1987). Answering autobiographical questions: the impact of memory and inference on surveys. Science 236, 157-161. doi: 10.1126/science.3563494

Breit-Smith, A., Kleeck, A., Prendeville, J. -A., and Pan, W. (2017). Preschool children's exposure to story grammar elements during parent-child book reading. J. Res. Read. 40, 345-364. doi: 10.1111/1467-9817.12071

Britto, P. R., Fuligni, A. S., and Brooks-Gunn, J. (2002). "Reading, rhymes, and routines: american parents and their young children" in Child rearing in America: Challenges facing parents with young children. eds. N. Halfon, K. T. McLearn and M. A. Schuster (Cambridge, UK: Cambridge University Press), 117-145.

Bronfenbrenner, U. (1977). Toward an experimental ecology of human development. Am. Psychol. 32, 513-531. doi: 10.1037/0003-066X.32.7.513

Bronfenbrenner, U. (1994). "Ecological models of human development" in International encyclopedia of education. 2nd Edn. Vol. 3. eds. T. Husen and T. N. Postlewaite (Oxford, England: Pergamon and Elsevier), 1643-1647.

Bronfenbrenner, U., and Morris, P. A. (2006). "The bioecological model of human development" in Handbook of child psychology: Theoretical models of human development. 6th Edn. Vol. 12. eds. W. Damon and R. M. Lerner (Hoboken, NJ: Wiley), 793-828.

Brunsek, A., Perlman, M., Falenchuk, O., McMullen, E., Fletcher, B., and Shah, P. S. (2017). The relationship between the early childhood environment rating scale and its revised form and child outcomes: a systematic review and meta-analysis. PLoS One 12:e0178512. doi: 10.1371/journal.pone.0178512

Brysbaert, M., Sui, L., Dirix, N., and Hintz, F. (2020). Dutch author recognition test. J. Cogn. 3, 1-14. doi: 10.5334/joc.95

Buckingham, J., Beaman, R., and Wheldall, K. (2014). Why poor children are more likely to become poor readers: the early years. Educ. Rev. $66,428-446$. doi: 10.1080/00131911.2013.795129

Burchinal, M., Vernon-Feagans, L., Cox, M., and Key Family Life Project Investigation (2008). Cumulative social risk, parenting, and infant development in rural low-income communities. Parenting 8, 41-69. doi: 10.1080/ 15295190701830672

Burgess, S. R., Hecht, S. A., and Lonigan, C. J. (2002). Relations of the home literacy environment (HLE) to the development of reading-related abilities: a one-year longitudinal study. Read. Res. Q. 37, 408-426. doi: 10.1598/rrq.37.4.4

Burt, C. D. B., and Kemp, S. (1991). Retrospective duration estimation of public events. Mem. Cogn. 19, 252-262. doi: 10.3758/bf03211149

Bus, A. G., Leseman, P. P. M., and Keultjes, P. (2000). Joint book reading across cultures: a comparison of surinamese-dutch, turkish-dutch and dutch parent-child dyads. J. Lit. Res. 32, 53-76. doi: 10.1080/10862960009548064

Bus, A. G., van IJzendoorn, M. H., and Pellegrini, A. D. (1995). Joint book reading makes for success in learning to read: a meta-analysis on intergenerational transmission of literacy. Rev. Educ. Res. 65, 1-21. doi: $10.3102 / 00346543065001001$

Cameron-Faulkner, T., and Noble, C. (2013). A comparison of book text and child directed speech. First Lang. 33, 268-279. doi: 10.1177/0142723713487613
Caravolas, M., Lervåg, A., Mikulajová, M., Defior, S., Seidlová-Málková, G., and Hulme, C. (2019). A cross-linguistic, longitudinal study of the foundations of decoding and reading comprehension ability. Sci. Stud. Read. 23, 386-402. doi: $10.1080 / 10888438.2019 .1580284$

Carp, F. M., and Carp, A. (1981). The validity, reliability and generalizability of diary data. Exp. Aging Res. 7, 281-296. doi: 10.1080/03610738108259811

Castles, A., Rastle, K., and Nation, K. (2018). Ending the reading wars: reading acquisition from novice to expert. Psychol. Sci. Public Interest 19, 5-51. doi: $10.1177 / 1529100618772271$

Catts, H. W., Herrera, S., Nielsen, D. C., and Bridges, M. S. (2015). Early prediction of reading comprehension within the simple view framework Read. Writ. Interdiscip. J. 28, 1407-1425. doi: 10.1007/s11145-015-9576-x

Chaparro-Moreno, L. J., Reali, F., and Maldonado-Carreño, C. (2017). Wordless picture books boost preschoolers' language production during shared reading. Early Child. Res. Q. 40, 52-62. doi: 10.1016/j.ecresq.2017.03.001

Chen, S. Y., and Fang, S. P. (2015). Developing a Chinese version of an author recognition test for collegestudents in Taiwan. J. Res. Read. 38, 344-360. doi: 10.1111/1467-9817.12018

Chen, X., Zhou, H., Zhao, J., and Davey, G. (2010). Home literacy experiences and literacy acquisition among children in Guangzhou, South China. Psychol. Rep. 107, 354-366. doi: 10.2466/04.11.17.21.28.PR0.107.5.354-366

Chomsky, N. (1980). "On cognitive structures and their development: a reply to Piaget" in Language and learning: The debate between jean piaget and noam chomsky. ed. M. Piattelli-Palmarini (Cambridge, MA: Harvard University Press), 35-54.

Chow, B. W. -Y., Ho, C. S. -H., Wong, S. W. -L., Waye, M. M. Y., and Bishop, D. V. M. (2011). Genetic and environmental influences on Chinese language and reading abilities. PLoS One 6:e16640. doi: 10.1371/journal. pone. 0016640

Coyne, M. D., McCoach, D. B., Loftus, S., Zipoli, R. Jr., and Kapp, S. (2009). Direct vocabulary instruction in kindergarten: teaching for breadth versus depth. Elem. Sch. J. 110, 1-18. doi: 10.1086/598840

Crain-Thoreson, C., Dahlin, M. P., and Powell, T. A. (2001). Parent-child interaction in three conversational contexts: variations in style and strategy. New Dir. Child Adolesc. Dev. 92, 23-38. doi: 10.1002/cd.13

Crain-Thoreson, C., and Dale, P. S. (1992). Do early talkers become early readers? Linguistic precocity, preschool language, and emergent literacy. Dev Psychol. 28, 421-429. doi: 10.1037/0012-1649.28.3.421

Cunningham, A. E., and Stanovich, K. E. (1990). Assessing print exposure and orthographic processing skill in children: a quick measure of reading experience. J. Educ. Psychol. 82, 733-740. doi: 10.1037/0022-0663.82.4.733

Dale, P. S., Crain-Thoreson, C., and Robinson, N. M. (1995). Linguistic precocity and the development of reading: the role of extralinguistic factors. Appl. Psycholinguist. 16, 173-187. doi: 10.1017/s0142716400007074

Davidse, N. J., de Jong, M. T., Bus, A. G., Huijbregts, S. C., and Swaab, H. (2011). Cognitive and environmental predictors of early literacy skills. Read. Writ. 24, 395-412. doi: 10.1007/s11145-010-9233-3

De Temple, J., and Snow, C. (2003). "Learning words from books" in On reading books to children. eds. K. van Kleeck, S. Stahl and E. Bauer (Mahwah, NJ: Erlbaum), 16-36.

DeBaryshe, B. D. (1993). Joint picture-book reading correlates of early oral language skill. J. Child Lang. 20, 455-461. doi: 10.1017/s0305000900008370

DeBaryshe, B. D. (1995). Maternal belief systems: linchpin in the home reading process. J. Appl. Dev. Psychol. 16, 1-20. doi: 10.1016/0193-3973(95)90013-6

Dickinson, D. K., Hofer, K. G., Barnes, E. M., and Grifenhagen, J. F. (2014). Examining teachers' language in head start classrooms from a systemic linguistics approach. Early Child. Res. Q. 29, 231-244. doi: 10.1016/j. ecresq.2014.02.006

Dickinson, D. K., and Porche, M. V. (2011). Relation between language experiences in preschool classrooms and children's kindergarten and fourth-grade language and reading abilities. Child Dev. 82, 870-886. doi: 10.1111/j.1467-8624. 2011.01576.x

Ebert, S., Lockl, K., Weinert, S., Anders, Y., Kluczniok, K., and Rossbach, H. -G. (2013). Internal and external influences on vocabulary development in preschool children. Sch. Eff. Sch. Improv. 24, 138-154. doi: 10.1080/09243453. 2012.749791

Ennemoser, M., Marx, P., Weber, J., and Schneider, W. (2012). Spezifische Vorläuferfertigkeiten der Lesegeschwindigkeit, des Leseverständnisses und 
des Rechtschreibens [Specific precursors of reading speed, reading comprehension, and spelling]. Z Entwicklungspsychol Padagog Psychol 44, 53-67. doi: 10.1026/0049-8637/a000057

Ennemoser, M., and Schneider, W. (2007). Relations of television viewing and reading: findings from a 4-year longitudinal study. J. Educ. Psychol. 99, 349-368. doi: 10.1037/0022-0663.99.2.349

Farrant, B. M., and Zubrick, S. R. (2013). Parent-child book reading across early childhood and child vocabulary in the early school years: findings from the longitudinal study of Australian children. First Lang. 33, 280-293. doi: $10.1177 / 0142723713487617$

Fiorentino, L., and Howe, N. (2004). Language competence, narrative ability, and school readiness in low-income preschool children. Can. J. Behav. Sci. 36, 280-294. doi: $10.1037 / \mathrm{h} 0087237$

Flack, Z. M., Field, A. P., and Horst, J. S. (2018). The effects of shared storybook reading on word learning: a meta-analysis. Dev. Psychol. 54, 1334-1346. doi: $10.1037 / \operatorname{dev} 0000512$

Fletcher, K. L., Cross, J. R., Tanney, A. L., Schneider, M., and Finch, W. H. (2008). Predicting language development in children at risk: the effects of quality and frequency of caregiver reading. Early Educ. Dev. 19, 89-111. doi: $10.1080 / 10409280701839106$

Fletcher, K. L., and Jean-Francois, B. (1998). Spontaneous responses during repeated reading in young children from "at risk" backgrounds. Early Child Dev. Care 146, 53-68. doi: 10.1080/0300443981460106

Fletcher, K. L., and Reese, E. (2005). Picture book reading with young children: a conceptual framework. Dev. Rev. 25, 64-103. doi: 10.1016/j.dr.2004.08.009

Frijters, J. C., Barron, R. W., and Brunello, M. (2000). Direct and mediated influences of home literacy and literacy interest on prereaders' oral vocabulary and early written language skill. J. Educ. Psychol. 92, 466-477. doi: 10.1037/ 0022-0663.92.3.466

Gampe, A., Liebal, K., and Tomasello, M. (2012). Eighteen-month-olds learn novel words through overhearing. First Lang. 32, 385-397. doi: 10.1177/ 0142723711433584

Gilkerson, J., Richards, J. A., Warren, S. F., Montgomery, J. K., Greenwood, C. R., Kimbrough Oller, D., et al. (2017). Mapping the early language environment using all-day recordings and automated analysis. Am. J. Speech Lang. Pathol. 26, 248-265. doi: 10.1044/2016ajslp-15-0169

Greaney, V. (1980). Factors related to amount and type of leisure time reading. Read. Res. Q. 15:337. doi: 10.2307/747419

Greenhoot, A., Beyer, A., and Curtis, J. (2014). More than pretty pictures? how illustrations affect parent-child story reading and children's story recall. Front. Psychol. 5:738. doi: 10.3389/fpsyg.2014.00738

Griffin, Z. M., and Ferreira, V. S. (2006). "Properties of spoken language production" in Handbook of psycholinguistics. eds. M. J. Traxler and M. A. Gernsbacher (London: Academic Press), 21-59.

Grolig, L., Cohrdes, C., and Schroeder, S. (2017). Der Titelrekognitionstest für das Vorschulalter (TRT-VS): erfassung des Lesevolumens von präkonventionellen Lesern und Zusammenhänge mit Vorläuferfertigkeiten des Lesens [the title recognition test for kindergarteners (TRT-VS): assessment of preconventional readers' print exposure and its relations to precursors of reading]. Diagnostica 63, 309-319. doi: 10.1026/0012-1924/a000186

Grolig, L., Cohrdes, C., Tiffin-Richards, S., and Schroeder, S. (2019). Effects of preschoolers' storybook exposure and literacy environments on lower level and higher level language skills. Read. Writ. Interdiscip. J. 32, 1061-1084. doi: 10.1007/s11145-018-9901-2

Grolig, L., Cohrdes, C., Tiffin-Richards, S. P., and Schroeder, S. (2020a). Narrative dialogic reading with wordless picture books: a cluster-randomized intervention study. Early Child. Res. Q. 51, 191-203. doi: 10.1016/j. ecresq.2019.11.002

Grolig, L., Tiffin-Richards, S. P., and Schroeder, S. (2020b). Print exposure across the reading life span. Read. Writ. Interdiscip. J. 33, 1423-1441. doi: 10.1007/s11145-019-10014-3

Hamilton, L. (2013). The role of the home literacy environment in the early literacy development of children at family-risk of dyslexia. doctoral dissertation, University of York. Available at: http://etheses.whiterose.ac.uk/4823/1/Lorna\%20 Hamilton\%20PhD\%20Thesis.pdf (Accessed April 24, 2020).

Hamilton, L. G., Hayiou-Thomas, M. E., Hulme, C., and Snowling, M. J. (2016). The home literacy environment as a predictor of the early literacy development of children at family-risk of dyslexia. Sci. Stud. Read. 20, 401-419. doi: $10.1080 / 10888438.2016 .1213266$
Hammer, C. S. (2001). '“'Come and sit down and let Mama read": book reading interactions between African American mothers and their infants" in Literacy in African American communities. eds. J. L. Harris and A. G. Kamhi (Mahwah, NJ: Erlbaum), 21-43.

Harms, T., Clifford, M., and Cryer, D. (1998). Early childhood rating scale-revised edition (ECERS-R). Williston, VT: Teachers College Press.

Hart, B., and Risley, T. R. (1995). Meaningful differences in the everyday experiences of young american children. Baltimore, MD: Paul H. Brookes.

Hasselhorn, M. (2010). Möglichkeiten und Grenzen der Frühförderung aus entwicklungspsychologischer Sicht [opportunities and limitations of early education from a developmental perspective]. Zeitschrift für Pädagogik 56, 168-177.

Haden, C. A., Reese, E., and Fivush, R. (1996). Mothersextratextual comments during storybook reading: stylistic differences over time and across texts. Discourse Process. 21, 135-169. doi: 10.1080/01638539609544953T

Hayden, H. M. R., and Fagan, W. T. (1987). Keeping it in context: strategies for enhancing literacy awareness. First Lang. 7, 159-171. doi: 10.1177/ 014272378700702007

Hayiou-Thomas, M. E., Dale, P. S., and Plomin, R. (2012). The etiology of variation in language skills changes with development: a longitudinal twin study of language from 2 to 12 years. Dev. Sci. 15, 233-249. doi: 10.1111/j. 1467-7687.2011.01119.x

Heath, S. B. (1983). Ways with words: Language, life, and work in communities and classrooms. Cambridge: Cambridge University Press.

Hills, T. T., Maouene, J., Riordan, B., and Smith, L. B. (2010). The associative structure of language: contextual diversity in early word learning. J. Mem. Lang. 63, 259-273. doi: 10.1016/j.jml.2010.06.002

Hindman, A. H., Connor, C. M., Jewkes, A. M., and Morrison, F. J. (2008). Untangling the effects of shared book reading: multiple factors and their associations with preschool literacy outcomes. Early Child. Res. Q. 23, 330-350. doi: 10.1016/j.ecresq.2008.01.005

Hindman, A. H., Erhart, A. C., and Wasik, B. A. (2012). Reducing the matthew effect: lessons from the ExCELLHead start intervention. Early Educ. Dev. 23, 781-806. doi: 10.1080/10409289.2010.549443

Hjetland, H. N., Lervåg, A., Lyster, S.-A. H., Hagtvet, B. E., Hulme, C., and Melby-Lervåg, M. (2019). Pathways to reading comprehension: a longitudinal study from 4 to 9 years of age. J. Educ. Psychol. 111, 751-763. doi: 10.1037/edu0000321

Ho, C. S. (2014). Preschool predictors of dyslexia status in Chinese first graders with high or low familial risk. Read. Writ. 27, 1673-1701. doi: 10.1007/ s11145-014-9515-2

Hoff, E. (2006). How social contexts support and shape language development. Dev. Rev. 26, 55-88. doi: 10.1016/j.dr.2005.11.002

Hoff, E. (2013). Interpreting the early language trajectories of children from low-SES and language minority homes: implications for closing achievement gaps. Dev. Psychol. 49, 4-14. doi: 10.1037/a0027238

Hoff-Ginsberg, E. (1998). The relation of birth order and socioeconomic status to children's language experience and language development. Appl. Psycholinguist. 19, 603-629. doi: 10.1017/S0142716400010389

Hoff, E., and Naigles, L. (2002). How children use input to acquire a lexicon. Child Dev. 73, 418-433. doi: 10.1111/1467-8624.00415

Hood, M., Conlon, E., and Andrews, G. (2008). Preschool home literacy practices and children's literacy development: a longitudinal analysis. J. Educ. Psychol. 100, 252-271. doi: 10.1037/0022-0663.100.2.252

Hoover, W. A., and Gough, P. B. (1990). The simple view of reading. Read. Writ. 2, 127-160. doi: 10.1007/BF00401799

Horst, J. S., Parsons, K. L., and Bryan, N. M. (2011). Get the story straight: contextual repetition promotes word learning from storybooks. Front. Psychol. 2:17. doi: $10.3389 /$ fpsyg.2011.00017

Hsiao, Y., and Nation, K. (2018). Semantic diversity, frequency and the development of lexical quality in children's word reading. J. Mem. Lang. 103, 114-126. doi: 10.1016/j.jml.2018.08.005

Huebner, C. E., and Meltzoff, A. N. (2005). Intervention to change parent-child reading style: a comparison of instructional methods. J. Appl. Dev. Psychol. 26, 296-313. doi: 10.1016/j.appdev.2005.02.006

Hume, L. E., Lonigan, C. J., and McQueen, J. D. (2015). Children's literacy interest and its relation to parents' literacy-promoting practices. J. Res. Read. 38, 172-193. doi: 10.1111/j.1467-9817.2012.01548.x

Huttenlocher, J., Vasilyeva, M., Cymerman, E., and Levine, S. (2002). Language input and child syntax. Cogn. Psychol. 45, 337-374. doi: 10.1016/s0010-0285(02)00500-5 
Huttenlocher, J., Waterfall, H., Vasilyeva, M., Vevea, J., and Hedges, L. V. (2010). Sources of variability in children's language growth. Cogn. Psychol. 61, 343-365. doi: 10.1016/j.cogpsych.2010.08.002

Jaeger, E. L. (2016). Negotiating complexity: a bioecological systems perspective on literacy development. Hum. Dev. 59, 163-187. doi: 10.1159/000448743

Kempert, S., Schalk, L., and Saalbach, H. (2019). Sprache als Werkzeug des Lernens: ein Überblick zu den kommunikativen und kognitiven Funktionen der Sprache und deren Bedeutung für den fachlichen Wissenserwerb [language as a tool of learning: an overview of communicative and cognitive functions of language and their role in knowledge acquisition]. Psychol. Erzieh. Unterr. 66, 76-195. doi: 10.2378/peu2018.art19d

Kidd, E., Donnelly, S., and Christiansen, M. H. (2018). Individual differences in language acquisition and processing. Trends Cogn. Sci. 22, 154-169. doi: 10.1016/j.tics.2017.11.006

Kim, Y. -S. (2014). Language and cognitive predictors of text comprehension: evidence from multivariate analysis. Child Dev. 86, 128-144. doi: 10.1111/ cdev. 12293

Kluczniok, K., Lehrl, S., Kuger, S., and Rossbach, H. G. (2013). Quality of the home learning environment during preschool age - domains and contextual conditions. Eur. Early Child. Educ. Res. J. 21, 420-438. doi: 10.1080/1350293X.2013.814356

Kuger, S., Pflieger, K., and Rossbach, H. -G., (2005). Familieneinschätzskala Forschungsversion [Family rating scale. Unpublished research version]. Bavaria, Germany: University of Bamberg.

Language and Reading Research Consortium (2015a). Learning to read: should we keep things simple? Read. Res. Q. 50, 151-169. doi: 10.1002/rrq.99

Language and Reading Research Consortium (2015b). The dimensionality of language ability in young children. Child Dev. 86, 1948-1965. doi: 10.1111/ cdev. 12450

Lee, H., Seong, E., Choi, W., and Lowder, M. W. (2019). Development and assessment of the korean author recognition test. Q. J. Exp. Psychol. 72, 1837-1846. doi: $10.1177 / 1747021818814461$

Lehrl, S. (2018). Qualität häuslicher lernumwelten im Vorschulalter. Eine empirische analyse zu konzept, bedingungen und bedeutung [The quality of preschoolers'home learning environments An empirical analysis]. doctoral dissertation. Wiesbaden (VS) Germany: Springer.

Lehrl, S., Ebert, S., and Rossbach, H. -G. (2013). "Facets of preschoolers' home literacy environments: what contributes to reading literacy in primary school?" in The development of reading literacy from early childhood to adolescence: Empirical findings from the Bamberg BiKS longitudinal studies. eds. M. Pfost, C. Artelt and S. Weinert (Bamberg: University of Bamberg Press), 35-62.

Lehrl, S., Ebert, S., Rossbach, H. -G., and Weinert, S. (2012). Die Bedeutung der familiären Lernumwelt für Vorläufer schriftsprachlicher Kompetenzen im Vorschulalter [the role of the family learning environment for preschoolers' reading precursors]. Z. Fam. Forsch 24, 115-133.

Lenhart, J., Lenhard, W., Vaahtoranta, E., and Suggate, S. (2019). The effects of questions during shared-reading: do demand-level and placement really matter? Early Child. Res. Q. 47, 49-61. doi: 10.1016/j.ecresq.2018.10.006

Lepola, J., Lynch, J., Laakkonen, E., Silvén, M., and Niemi, P. (2012). The role of inference making and other language skills in the development of narrative listening comprehension in 4-6-year-old children. Read. Res. Q. 47, 259-282. doi: $10.1002 /$ rrq.020

Lervåg, A., Hulme, C., and Melby-Lervåg, M. (2018). Unpicking the developmental relationship between oral language skills and reading comprehension: it's simple, but complex. Child Dev. 89, 1821-1838. doi: 10.1111/cdev.12861

Leseman, P. P. M., Scheele, A. F., Mayo, A. Y., and Messer, M. H. (2007). Home literacy as a special language environment to prepare children for school. Z. Erziehwiss. 10, 334-355. doi: 10.1007/s11618-007-0040-9

Lonigan, C. J. (1994). Reading to preschoolers exposed: is the emperor really naked? Dev. Rev. 14, 303-323. doi: 10.1006/drev.1994.1011

Massaro, D. W. (2015). Two different communication genres and implications for vocabulary development and learning to read. J. Lit. Res. 47, 505-527. doi: 10.1177/1086296x15627528

McGillion, M., Pine, J. M., Herbert, J. S., and Matthews, D. (2017). A randomised controlled trial to test the effect of promoting caregiver contingent talk on language development in infants from diverse socioeconomic status backgrounds. J. Child Psychol. Psychiatry 58, 1122-1131. doi: 10.1111/jcpp.12725

McLeod, A. N., and McDade, H. L. (2011). Preschoolers' incidental learning of novel words during storybook reading. Commun. Disord. Q. 32, 256-266. doi: $10.1177 / 1525740109354777$
McNerney, S., Nielsen, D. C., and Clay, P. (2006). Supporting literacy in preschool: using a teacher-observation tool to guide professional development. J. Early. Child Teach. Educ. 27, 19-34. doi: 10.1080/10901020500528838

Mesmer, H. A. E. (2016). Text matters: exploring the lexical reservoirs of books in preschool rooms. Early Child. Res. Q. 34, 67-77. doi: 10.1016/j. ecresq.2015.09.001

Mol, S. E., and Bus, A. G. (2011). To read or not to read: a meta-analysis of print exposure from infancy to early adulthood. Psychol. Bull. 137, 267-296. doi: $10.1037 / \mathrm{a} 0021890$

Mol, S. E., Bus, A. G., and de Jong, M. T. (2009). Interactive book reading in early education: a tool to stimulate print knowledge as well as oral language. Rev. Educ. Res. 79, 979-1007. doi: 10.3102/0034654309332561

Mol, S. E., Bus, A. G., de Jong, M. T., and Smeets, D. J. H. (2008). Added value of dialogic parent-child book readings: a meta-analysis. Early Educ. Dev. 19, 7-26. doi: 10.1080/10409280701838603

Montag, J. L. (2019). Differences in sentence complexity in the text of children's picture books and child-directed speech. First Lang. 39, 527-546. doi: $10.1177 / 0142723719849996$

Montag, J. L., Jones, M. N., and Smith, L. B. (2015). The words children hear: picture books and the statistics for language learning. Psychol. Sci. 26, 1489-1496. doi: 10.1177/0956797615594361

Montag, J. L., and MacDonald, M. C. (2015). Text exposure predicts spoken production of complex sentences in 8- and 12-year-old children and adults. J. Exp. Psychol. Gen. 144, 447-468. doi: 10.1037/xge0000054

Morrow, L. M. (1988). Young children's responses to one-to-one story readings in school settings. Read. Res. Q. 23, 89-107. doi: 10.2307/747906

Muhinyi, A., and Hesketh, A. (2017). Low- and high-text books facilitate the same amount and quality of extratextual talk. First Lang. 37, 410-427. doi: $10.1177 / 0142723717697347$

National Association for the Education of Young Children (2009). Developmentally appropriate practice in early childhood programs serving children from birth through age 8. A position statement of the National Association for the education of young children. Available at: https://www.naeyc.org/sites/ default/files/globally-shared/downloads/PDFs/resources/position-statements/ PSDAP.pdf (Accessed April 24, 2020).

Neuman, S. B., Kaefer, T., and Pinkham, A. M. (2018). A double dose of disadvantage: language experiences for low-income children in home and school. J. Educ. Psychol. 110, 102-118. doi: 10.1037/edu0000201

Niklas, F., and Schneider, W. (2013). Home literacy environment and the beginning of reading and spelling. Contemp. Educ. Psychol. 38, 40-50. doi: 10.1016/j.cedpsych.2012.10.001

Ninio, A. (1983). Joint book reading as a multiple vocabulary acquisition device. Dev. Psychol. 19, 445-451. doi: 10.1037/0012-1649.19.3.445

Ninio, A., and Bruner, J. (1978). The achievement and antecedents of labelling. J. Child Lang. 5, 1-15. doi: 10.1017/s0305000900001896

Noble, C., Sala, G., Peter, M., Lingwood, J., Rowland, C. F., Gobet, F., et al. (2019). The impact of shared book reading on children's language skills: a meta-analysis. Educ. Res. Rev. 28:100290. doi: 10.1016/j.edurev.2019.100290

Nyhout, A., and O'Neill, D. K. (2013). Mothers' complex talk when sharing books with their toddlers: book genre matters. First Lang. 33, 115-131. doi: $10.1177 / 0142723713479438$

Olson, R. K., Keenan, J. M., Byrne, B., Samuelsson, S., Coventry, W. L., Corley, R., et al. (2011). Genetic and environmental influences on vocabulary and reading development. Sci. Stud. Read. 15, 26-46. doi: 10.1080/10888438.2011.536128

Ouellette, G. P. (2006). What's meaning got to do with it: the role of vocabulary in word reading and reading comprehension. J. Educ. Psychol. 98, 554-566. doi: $10.1037 / 0022-0663.98 .3 .554$

Pantaleo, S., and Sipe, L. (2012). Diverse narrative structures in contemporary picturebooks: opportunities for children's meaning-making. Child.'s Lit. 38, 6-15. Available at: http://www.childrensliteratureassembly.org/journal.html (Accessed April 24, 2020).

Perlman, M., Falenchuk, O., Fletcher, B., McMullen, E., Beyene, J., and Shah, P. S. (2016). A systematic review and meta-analysis of a measure of staff/child interaction quality (the classroom assessment scoring system) in early childhood education and care settings and child outcomes. PLoS One 11:e0167660. doi: 10.1371/journal.pone.0167660

Pfost, M., Artelt, C., and Weinert, S. (2013). The development of reading literacy from early childhood to adolescence. Empirical findings from the Bamberg BiKS longitudinal studies. Vol. 14. Bamberg: University of Bamberg Press. 
Pianta, R. C., La Paro, K. M., and Hamre, B. K. (2008). Classroom assessment scoring system (CLASS) manual: K-3. Baltimore, MD: Paul Brookes.

Powell, D. R., Diamond, K. E., Burchinal, M. R., and Koehler, M. J. (2010). Effects of an early literacy professional development intervention on head start teachers and children. J. Educ. Psychol. 102, 299-312. doi: 10.1037/a0017763

Puglisi, M. L., Hulme, C., Hamilton, L. G., and Snowling, M. J. (2017). The home literacy environment is a correlate, but perhaps not a cause, of variations in children's language and literacy development. Sci. Stud. Read. 21, 498-514. doi: 10.1080/10888438.2017.1346660

Reese, E., and Cox, A. (1999). Quality of adult book reading affects children's emergent literacy. Dev. Psychol. 35, 20-28. doi: 10.1037/0012-1649.35.1.20

Rowe, M. L. (2012). A longitudinal investigation of the role of quantity and quality of child-directed speech in vocabulary development. Child Dev. 83, 1762-1774. doi: 10.1111/j.1467-8624.2012.01805.x

Rowe, M. L., and Snow, C. E. (2019). Analyzing input quality along three dimensions: interactive, linguistic, and conceptual. J. Child Lang. 47, 5-21. doi: $10.1017 / \mathrm{s} 0305000919000655$

Ruberg, T., and Rothweiler, M. (2012). Spracherwerb und sprachförderung in der Kita [language development and intervenion in child care]. Stuttgart, Germany: Kohlhammer.

Schmerse, D., Anders, Y., Flöter, M., Wieduwilt, N., Rossbach, H. -G., and Tietze, W. (2018). Differential effects of home and preschool learning environments on early language development. Br. Educ. Res. J. 44, 338-357. doi: 10.1002/berj.3332

Senatsverwaltung für Bildung, Jugend und Wissenschaft (2014). Berliner Bildungsprogramm für Kitas und Kindertagespflege. Available at: https:// www.berlin.de/sen/bildung/schule/bildungswege/fruehkindliche-bildung/ (Accessed April 24, 2020).

Senatsverwaltung für Bildung, Jugend und Wissenschaft (2017). Kindertagesförderungsgesetz. Available at: http://gesetze.berlin.de/jportal/?quell $\mathrm{e}=\mathrm{jlinkandquery}=\mathrm{KitaRefG}+\mathrm{BEandpsml}=$ bsbeprod.psmlandmax $=$ trueandaiz $=$ true (Accessed April 24, 2020).

Sénéchal, M. (1997). The differential effect of storybook reading on preschoolers' acquisition of expressive and receptive vocabulary. J. Child Lang. 24, 123-138. doi: 10.1017/S0305000996003005

Sénéchal, M., and Cornell, E. H. (1993). Vocabulary acquisition through shared reading experiences. Read. Res. Q. 28, 360-374. doi: 10.2307/747933

Sénéchal, M., Cornell, E. H., and Broda, L. S. (1995a). Age-related differences in the organization of parent-infant interactions during picture-book reading. Early Child. Res. Q. 10, 317-337. doi: 10.1016/0885-2006(95)90010-1

Sénéchal, M., and LeFevre, J. (2002). Parental involvement in the development of children's reading skill: a five-year longitudinal study. Child Dev. 73, 445-460. doi: 10.1111/1467-8624.00417

Sénéchal, M., and LeFevre, J. -A. (2014). Continuity and change in the home literacy environment as predictors of growth in vocabulary and reading. Child Dev. 85, 1552-1568. doi: 10.1111/cdev.12222

Sénéchal, M., LeFevre, J. A., Hudson, E., and Lawson, E. P. (1996). Knowledge of storybooks as a predictor of young children's vocabulary. J. Educ. Psychol. 88, 520-536. doi: 10.1037/0022-0663.88.3.520

Sénéchal, M., Pagan, S., Lever, R., and Ouellette, G. P. (2008). Relations among the frequency of shared reading and 4-year-old children's vocabulary, morphological and syntax comprehension, and narrative skills. Early Educ. Dev. 19, 27-44. doi: 10.1080/10409280701838710

Sénéchal, M., Thomas, E. H., and Monker, J. A. (1995b). Individual differences in 4-year-old children's acquisition of vocabulary during storybook reading. J. Educ. Psychol. 87, 218-229. doi: 10.1037/0022-0663.87.2.218

Shneidman, L., Arroyo, M., Levine, S., and Goldin-Meadow, S. (2013). What counts as effective input for word learning? J. Child Lang. 40, 672-686. doi: 10.1017/S0305000912000141

Silva, M., and Cain, K. (2015). The relations between lower and higher level comprehension skills and their role in prediction of early reading comprehension. J. Educ. Psychol. 107, 321-331. doi: 10.1037/a0037769

Silva, M., and Cain, K. (2017). The use of questions to scaffold narrative coherence and cohesion. J. Res. Read. 42, 1-17. doi: 10.1111/1467-9817.12129

Silva, M., Strasser, K., and Cain, K. (2014). Early narrative skills in chilean preschool: questions scaffold the production of coherent narratives. Early Child. Res. Q. 29, 205-213. doi: 10.1016/j.ecresq.2014.02.002

Slot, P. L., Leseman, P. P. M., Verhagen, J., and Mulder, H. (2015). Associations between structural quality aspects and process quality in Dutch early childhood education and care settings. Early Child. Res. Q. 33, 64-76. doi: 10.1016/j. ecresq.2015.06.001

Smith, M. C. (2000). The real-world reading practices of adults. J. Lit. Res. 32, 25-52. doi: 10.1080/10862960009548063

Snow, C. E., and Goldfield, B. A. (1983). Turn the page please: situation-specific language acquisition. J. Child Lang. 10, 551-569. doi: 10.1017/ S0305000900005365

Snow, C. E., and Ninio, A. (1986). "The contracts of literacy: what children learn from learning to read books" in Emergent literacy: Writing and reading. eds. W. H. Teale and E. Sulzby (Norwood, NJ: Ablex), 116-138.

Sonnenschein, S., Baker, L., Serpell, R., Scher, D., Truitt, V. G., and Munsterman, K. (1997). Parental beliefs about ways to help children learn to read: the impact of an entertainment or a skills perspective. Early Child Dev. Care 127, 111-118. doi: 10.1080/0300443971270109

Spinath, F. M., Price, T. S., Dale, P. S., and Plomin, R. (2004). The genetic and environmental origins of language disability and ability. Child Dev. 75, 445-454. doi: 10.1111/j.1467-8624.2004.00685.x

Stanovich, K. E., and West, R. F. (1989). Exposure to print and orthographic processing. Read. Res. Q. 24, 402-433. doi: 10.2307/747605

Stanovich, K. E., West, R. F., and Harrison, M. R. (1995). Knowledge growth and maintenance across the life span: the role of print exposure. Dev. Psychol. 31, 811-826. doi: 10.1037/0012-1649.31.5.811

Stiftung Lesen (2018). Vorlesen: Uneinholbares Startkapital. Vorlesestudie 2018 Bedeutung von Vorlesen und Erzählen für das Lesen [The importance of reading aloud and story-telling for reading development]. Available at: https:// www.stiftunglesen.de/download.php?type=documentpdfandid=2397 (Accessed April 24, 2020).

Storch, S. A., and Whitehurst, G. J. (2002). Oral language and code-related precursors to reading: evidence from a longitudinal structural model. Dev. Psychol. 38, 934-947. doi: 10.1037/0012-1649.38.6.934

Sylva, K., Siraj-Blatchford, I., and Taggart, B. (2003). Assessing quality in the early childhood rating scale extensions (ECERS-E). Stoke On Trent, UK: Trentham Books.

Teale, W. (1986). "Home background and young children's literacy development" in Emergent literacy: Writing and reading. eds. W. Teale and E. Sulzby (Norwood, NJ: Ablex Publishing), 173-206.

Tomasello, M. (2009). "The usage-based theory of language acquisition" in The Cambridge handbook of child language. ed. E. L. Bavin (Cambridge: Cambridge University Press), 69-88.

Torppa, M., Georgiou, G. K., Lerkkanen, M. -K., Niemi, P., Poikkeus, A. -M., and Nurmi, J. -E. (2016). Examining the simple view of reading in a transparent orthography: a longitudinal study from kindergarten to grade 3. Merrill-Palmer Q. 62, 179-206. doi: 10.13110/merrpalmquar1982.62.2.0179

Tosto, M. G., Hayiou-Thomas, M. E., Harlaar, N., Prom-Wormley, E., Dale, P. S., and Plomin, R. (2017). The genetic architecture of oral language, reading fluency, and reading comprehension: a twin study from 7 to 16 years. Dev. Psychol. 53, 1115-1129. doi: 10.1037/dev0000297

Ulferts, H., Wolf, K. M., and Anders, Y. (2019). Impact of process quality in early childhood education and care on academic outcomes: longitudinal meta-analysis. Child Dev. 90, 1474-1489. doi: 10.1111/cdev.13296

van Kleeck, A. (2003). "Research on book sharing: another critical look" in On reading books to children: Parents and teachers. eds. A. van Kleeck, S. Stahl and E. Bauer (Mahwah, NJ: Erlbaum), 271-320.

van Kleeck, A. (2008). Providing preschool foundations for later reading comprehension: the importance of and ideas for targeting inferencing in storybook-sharing interventions. Psychol. Sch. 45, 627-643. doi: 10.1002/pits.20314

van Kleeck, A., and Beckley-McCall, A. (2002). A comparison of mothers' individual and simultaneous book sharing with preschool siblings. Am. J. Speech Lang. Pathol. 11, 175-189. doi: 10.1044/1058-0360(2002/017)

van Kleeck, A., Gillam, R. B., Hamilton, L., and McGrath, C. (1997). The relationship between middle-class parents' book sharing discussion and their preschoolers' abstract language development. J. Speech Lang. Hear. Res. 40, 1261-1271. doi: 10.1044/jslhr.4006.1261

van Kleeck, A., and Schuele, C. M. (2010). Historical perspectives on literacy in early childhood. Am. J. Speech Lang. Pathol. 19, 341-355. doi: 10.1044/ 1058-0360(2010/09-0038)

van Steensel, R. (2006). Relations between socio-cultural factors, the home literacy environment and children's literacy development in the first years of primary education. J. Res. Read. 29, 367-382. doi: 10.1111/ j.1467-9817.2006.00301.x 
von Lehmden, F., Porps, L., and Müller-Brauers, C. (2017). Grammatischer Sprachinput in Kinderliteratur-eine Analyse von Genus-Kasus-Hinweisen in input- und nicht inputoptimierten Bilderbüchern. Forschung Sprache 2, 44-61.

Vasilyeva, M., Huttenlocher, J., and Waterfall, H. (2006). Effects of language intervention on syntactic skill levels in preschoolers. Dev. Psychol. 42, 164-174. doi: 10.1037/0012-1649.42.1.164

Vygotsky, L. S. (1978). Mind in society: The development of higher psychological processes. Cambridge, MA: Harvard University Press.

Wagner, L. (2013). By the numbers: a quantitative content analysis of children's picturebooks. Front. Psychol. 4:850. doi: 10.3389/fpsyg.2013.00850

Wagner, L. (2017). Factors influencing parents' preferences and parents' perceptions of child preferences of picturebooks. Front. Psychol. 8:1448. doi: 10.3389/ fpsyg.2017.01448

Wasik, B. A., Hindman, A. H., and Snell, E. K. (2016). Book reading and vocabulary development: a systematic review. Early Child. Res. Q. 37, 39-57. doi: 10.1016/j.ecresq.2016.04.003

Weigel, D. J., Martin, S. S., and Bennett, K. K. (2005). Ecological influences of the home and the child-care center on preschool-age children's literacy development. Read. Res. Q. 40, 204-233. doi: 10.1598/rrq.40.2.4

Weinert, S., and Ebert, S. (2013). Spracherwerb im vorschulalter. Soziale disparitäten und einflussvariablen auf den grammatikerwerb [language development in pre-school children: social disparities and effects on the acquisition of grammar]. Z. Erziehwiss. 16, 303-332. doi: 10.1007/s11618-013-0354-8

Weisleder, A., and Fernald, A. (2013). Talking to children matters: early language experience strengthens processing and builds vocabulary. Psychol. Sci. 24, 2143-2152. doi: 10.1177/0956797613488145

Weizman, Z. O., and Snow, C. E. (2001). Lexical output as related to children's vocabulary acquisition: effects of sophisticated exposure and support for meaning. Dev. Psychol. 37, 265-279. doi: 10.1037/0012-1649.37.2.265
West, R. F., Stanovich, K. E., and Mitchell, H. R. (1993). Reading in the real world and its correlates. Read. Res. Q. 28, 34-50. doi: 10.2307/747815

Westerveld, M. F., Gillon, G. T., and Moran, C. (2008). A longitudinal investigation of oral narrative skills in children with mixed reading disability. Int. J. Speech Lang. Pathol. 10, 132-145. doi: 10.1080/14417040701422390

Wigfield, A., Gladstone, J., and Turci, L. (2016). Beyond cognition: reading motivation and reading comprehension. Child Dev. Perspect. 10, 190-195. doi: $10.1111 /$ cdep.12184

Zevenbergen, A. A., and Whitehurst, G. J. (2003). "Dialogic reading: a shared picture book intervention for preschoolers" in On reading books to children: Parents and teachers. eds. A. van Kleeck, S. Stahl and E. Bauer (Mahwah, NJ: Erlbaum), 177-200.

Zhang, S. Z., Georgiou, G. K., Xu, J., Liu, J. M., Li, M., and Shu, H. (2018). Different measures of print exposure predict different aspects of vocabulary. Read. Res. Q. 53, 443-454. doi: 10.1002/rrq.205

Zucker, T. A., Justice, L. M., Piasta, S. B., and Kaderavek, J. N. (2010). Preschool teachers' literal and inferential questions and children's responses during whole-class shared reading. Early Child. Res. Q. 25, 65-83. doi: 10.1016/j. ecresq.2009.07.001

Conflict of Interest: The author declares that the research was conducted in the absence of any commercial or financial relationships that could be construed as a potential conflict of interest.

Copyright (C) 2020 Grolig. This is an open-access article distributed under the terms of the Creative Commons Attribution License (CC BY). The use, distribution or reproduction in other forums is permitted, provided the original author(s) and the copyright owner(s) are credited and that the original publication in this journal is cited, in accordance with accepted academic practice. No use, distribution or reproduction is permitted which does not comply with these terms. 


\title{
From Storybooks to Novels: A Retrospective Approach Linking Print Exposure in Childhood to Adolescence
}

\author{
Brittany Tremblay, Monyka L. Rodrigues and Sandra Martin-Chang* \\ Literacy Lab, Concordia University, Department of Education, Montreal, QC, Canada
}

Despite the far-reaching advantages associated with leisure reading, it is an activity that fewer adolescents are choosing to pursue. The present study used a retrospective correlational approach to investigate shared storybook reading in childhood and current print exposure in 45 parent-adolescent dyads. Parents and adolescents completed a Retrospective Title Recognition Test, identifying storybook titles from a backdated list (books published before 2007) containing both real titles and foils. Adolescents also completed Activity Preference and Reading Enjoyment/Frequency questionnaires to assess reading habits as well as an Author Recognition Test to assess current print exposure. In addition, they were asked to name their favorite childhood storybook and favorite current author to investigate whether these two abilities were linked to print exposure. Vocabulary, reading, and spelling skills were also measured. A hierarchical multiple regression demonstrated that adolescents' Retrospective Title Recognition Test scores accounted for unique variance in their Author Recognition Test scores, above and beyond literacy skills. Mediational analyses demonstrated that print exposure contributed to word reading and spelling scores. Our findings highlight the impact of parents' shared storybook reading with children. Here, early reading experiences related to later reading preferences, which in turn, were associated with literacy skills in adolescence.

Keywords: adolescence, print exposure, reading for pleasure, shared storybook reading, spelling, word reading

This article was submitted to

Educational Psychology, a section of the journal

Frontiers in Psychology

Received: 09 June 2020 Accepted: 01 September 2020 Published: 18 September 2020

Citation:

Tremblay B, Rodrigues ML and Martin-Chang S (2020) From

Storybooks to Novels:

A Retrospective Approach Linking

Print Exposure in Childhood

to Adolescence.

Front. Psychol. 11:571033.

doi: 10.3389/fpsyg.2020.571033

The accolades associated with leisure reading are impressive, including gains in spelling, vocabulary, verbal fluency, and cultural knowledge (Cunningham and Stanovich, 2001). Reading fiction specifically, correlates with increases in language skills (Mar and Rain, 2015), empathy (Nomura and Akai, 2012), and interpersonal sensitivity (Fong et al., 2013). Yet sadly, the reading habits of adolescents have been steadily declining (Twenge et al., 2019). Given the evidence supporting a reciprocal relationship between intrinsic motivation and reading volume (Schiefele et al., 2016), we took a retrospective approach to evaluate potential links between shared storybook reading from early childhood and reading habits during adolescence.

Parents have a profound influence on the home literacy environment (Sénéchal and LeFevre, 2014; Grolig et al., 2019). When reading is modeled through informal interactions with preschool children, the focus is on the enjoyable context of the storybook (Arya et al., 2014). In-line with Vygotsky's theory (1978), children's social interactions with knowledgeable adults can shape their later skills and behavior. Viewed from this context, the positive interactions shared during 
storybook reading could contribute to a propensity toward reading in later childhood (Baker et al., 1997). When reading is valued in the home, children's enjoyment might increase, boosting intrinsic reading motivation and ultimately reading proficiency (Schiefele et al., 2012). For example, Weinberger (1996) found that 3-year-olds who could name a favorite book were better readers at age seven. However, more recent links between storybook reading and word reading have been tenuous (see Evans and Shaw, 2008 for review). Furthermore, Weinberger's sample was not followed beyond the elementary grades thus, it remains unknown how long the influence of storybook reading extended.

Baker and colleagues (2001) found that early enjoyable shared storybook reading experiences were closely tied to children's reading activities (as reported by parents) in Grade 3. Similarly, Sénéchal (2006) asked parents about the home literacy environment and found that children who were most exposed to storybooks in kindergarten reported reading for pleasure more often in Grade 4. Finally, as part of a 28-year study, Gottfried et al. (2015) noted that time spent reading to children (estimated by parents before age 5) had a positive direct effect on academic reading motivation and achievement in middle childhood, which in turn predicted the same factors in adolescence and educational attainment in adulthood. The authors concluded that "early reading exposure provides a foundation for subsequent longterm educational success" (p. 31). However, they did not study leisure reading during either childhood or adolescence.

Compared to self-report measures, the Title Recognition Test (TRT) offers a more objective assessment of shared storybook reading taking place in the home (Cunningham and Stanovich, 1990). The TRT was modeled after a measure of print exposure called the Author Recognition Test (ART; Stanovich and West, 1989). The ART is a proxy of reading over the lifetime. Participants are asked to identify the names of popular authors from a list containing foils. Similarly, the TRT relies on signal detection logic but it replaces author names with children's storybook titles. Sénéchal (2000) found that the number of book titles parents recognized was positively associated with the number of characters their children recognized from book illustrations and the number of children's books found in the home. More recently, Grolig et al. (2019) used the TRT with parents and an audiotaped TRT with preschoolers. Once again, parents' knowledge of titles was highly predictive of children's performance on the TRT. Both studies suggest that the TRT taps into children's concurrent storybook reading experiences. However, neither study was designed to examine how early experiences relate to subsequent behaviors.

\section{THE CURRENT STUDY}

Early social interactions may illustrate one possible difference between those who continue to read for pleasure and those who do not. To our knowledge, we are first to examine the association between shared storybook reading and print exposure into adolescence. Leisure reading has been linked to increases in academic reading motivation (Gottfried et al., 2015), reading comprehension (Torppa et al., 2020) and social competence (Kozak and Recchia, 2019), therefore it is critical to understand the factors that could be associated with it as children develop into fully literate adults. Our first aim was to examine whether shared storybook reading was correlated with print exposure in adolescence. Our second aim was to investigate whether having a favorite storybook in childhood and a favorite author in adolescence was linked to current reading habits. Finally, our third aim was to evaluate whether storybook reading, directly or indirectly via print exposure, was related to concurrent vocabulary, word reading, and spelling skills.

\section{METHODS}

\section{Participants}

Forty-five adolescent-parent dyads were recruited via advertisements in an urban community. The parent sample consisted of 36 mothers and 9 fathers $\left(M_{\text {age }}=47.59, S D=4.79\right)$. On average, parents completed 16 years of education $(S D=3.23)$ and reported English as one of their primary languages. The adolescent sample consisted of 27 females and 18 males (for descriptive statistics, see Table 1). Participants ranged from Grades 7-11 (Grade $7 n=13$; Grade $8 n=12$; Grade $9 n=14$; Grade $10 n=1$; Grade $11 n=5$ ).

\section{Materials and Procedure Parent Measures}

Parents reported their birthdate, education, marital status, and language(s). They rated how frequently they read to their children before kindergarten on a 5 -point Likert scale $(0=$ never to 4 = very often). Parents also completed the Retrospective Title Recognition Test (R-TRT) alone, without help from their child.

TABLE 1 | Descriptive statistics for parent and adolescent measures.

\begin{tabular}{|c|c|c|c|}
\hline & $M(S D)$ & Range & Cronbach's \\
\hline \multicolumn{4}{|l|}{ Parent measures } \\
\hline Storybook reading freq. & $3.07(1.01)$ & $0-4$ & - \\
\hline R-TRT & $0.27(0.20)$ & $-0.17-0.72$ & 0.85 \\
\hline \multicolumn{4}{|l|}{ Adolescent measures } \\
\hline Age (years) & $14.49(1.35)$ & $12.25-17.75$ & - \\
\hline Activity preference & $1.02(1.31)$ & $0-4$ & 0.73 \\
\hline Childhood composite & $20.40(11.46)$ & $0-44$ & 0.69 \\
\hline Adolescence composite & $17.61(12.44)$ & $0-48$ & 0.83 \\
\hline R-TRT & $0.18(0.17)$ & $-0.30-0.52$ & 0.82 \\
\hline $\mathrm{ART}$ & $0.07(0.08)$ & $-0.06-0.33$ & 0.87 \\
\hline Vocabulary & $0.22(0.18)$ & $-0.09-0.72$ & 0.83 \\
\hline Word reading ${ }^{a}$ & $105.10(14.85)$ & $75-145$ & - \\
\hline Spelling ${ }^{b}$ & $103.58(16.41)$ & $70-137$ & - \\
\hline
\end{tabular}

R-TRT, Retrospective Title Recognition Test; ART, Author Recognition Test. a Wide Range Achievement Test-Fourth Edition. ${ }^{b}$ Woodcock Johnson-Third Edition Spelling. Three participants were missing data for the word reading task however, excluding these participants from the analyses did not change the pattern of the results. 


\section{Adolescent Measures}

The measures were completed in the order they appear.

\section{Activity Preference Questionnaire}

Participants chose between two leisure activities. Four of the nine questions involved reading (Cunningham and Stanovich, 1997). Participants received one point each time they selected reading (Max score of 4) over other activities, such as spending time on hobbies, watching television, listening to music, or playing sports.

\section{Favorite Storybook/Author}

Participants were asked to name their favorite storybook from childhood and their current favorite author.

\section{Reading Enjoyment and Frequency Questionnaire (REF)}

Adolescents reported how frequently $(0=$ never to $4=$ very often $)$ they engaged in leisure reading during childhood (listening to storybooks, reading chapter books, reading graphic novels) and during adolescence (reading novels, graphic novels, and nonfiction), and how much they enjoyed these activities ( $1=$ disliked a lot to 4 = liked a lot). Childhood and Adolescence REF composites were created by multiplying frequency $\mathrm{x}$ enjoyment, therefore, if the frequency score was 0 for one type of reading (e.g., graphic novels), the total allotted was also 0 for that item. Each questionnaire had a maximum score of 48 .

\section{Retrospective Title Recognition Test (R-TRT)}

Storybook reading was measured by the R-TRT (see Supplementary Appendix A). It was adapted by selecting popular children's titles published before 2007. This ensured that all books were available by the time the youngest adolescents were born and by the time the oldest adolescents were approximately 5 years old. The backdated list was piloted with teachers for our target population. The final list contained 25 real storybook titles and 8 foils. Participants checked off each title they recognized. The proportion of checked foils was subtracted from the proportion of real storybook titles identified: (\# titles correctly identified/25) - (\# of foils checked/8).

\section{Author Recognition Test (ART)}

To assess current print exposure, adolescents completed the ART (see Supplementary Appendix B). The ART-R (Martin-Chang and Gould, 2008) was adapted to include authors of recently published adult, young adult, and children's novels. The ART used here consisted of 110 real authors and 30 foils. Participants were alerted that guessing could be easily detected (\# authors correctly identified/110) - (\# of foils checked/30).

\section{Vocabulary}

Participants recognized words having meaning from foils. The real words with the exception of tulip were found in the SATs. The foils were created by combining free morphemes (e.g. over), bound morphemes (e.g., ful), roots (e.g., rupt), and graphemes (e.g., eigh) to result in non-words (see Supplementary Appendix C). The measure consisted of a list of 25 words and 18 foils. To mirror the other checklists, scores were calculated by subtracting the proportion of checked foils from the proportion of real words identified: (\# words correctly identified/25) - (\# of foils checked/18).

\section{Word Reading}

The word reading subtest of the Wide Range Achievement TestFourth Edition (WRAT-4; Wilkinson and Robertson, 2006) was administered. Fifty-five words were read in isolation. Testing was discontinued after ten consecutive errors. The WRAT-4 has excellent internal consistency ( $\alpha=0.92$; Wilkinson and Robertson, 2006).

\section{Spelling}

The spelling subtest of the Woodcock Johnson Test of Achievement-Third Edition (WJ-III; Woodcock et al., 2001) was administered. Scoring was discontinued after six consecutive errors. The WJ-III has excellent internal consistency $(\alpha=0.90$; Woodcock et al., 2001).

\section{RESULTS}

\section{Preliminary Analyses}

The Cronbach's alpha for the R-TRT (parent and adolescent), ART, and vocabulary test demonstrated great internal consistency (see Table 1; Field, 2013). The Cronbach's alpha for the Activity Preference Questionnaire and the Childhood and Adolescence REF composites were satisfactory.

On average, parents reported remembering reading to their children often (i.e., almost every day; see Table 1). On the R-TRT, parents rarely selected foils $(M=0.13, S D=0.45)$ suggesting that they were not guessing. Their scores were also modest suggesting that they did not consult outside sources. After controlling for parents' education, parental reports about storybook reading were positively correlated with their own R-TRT scores; parents who reported reading more often recognized more storybook titles (see Table 2). Thus, the retrospective parental measures lend support to the titles chosen for the R-TRT. Positive correlations were also noted between parents' and adolescents' R-TRT scores, thus providing further support for the validity of the retrospective aspect of the checklist.

The Childhood and Adolescent REF composites were positively correlated with the Activity Preference Questionnaire and the amount of storybooks they were familiar with (R-TRT). However, only the Adolescent REF composite was correlated with how many authors they recognized over their lifetime (ART). These moderately strong positive correlations extend the literature by demonstrating that those who report reading more and enjoying it more, also recognize more author names.

\section{Linking Storybook Reading to Print Exposure in Adolescence}

Our first aim was to examine whether shared storybook reading during childhood (R-TRT) would be correlated with print exposure in adolescence (ART and Activity Preference Questionnaire). As shown in Table 2, after controlling for parental education, both measures were positively correlated with the R-TRT. Therefore, when adolescents recognized more storybook titles, they were more likely to choose leisure reading over other activities and recognize more authors. 
TABLE 2 | Correlations and partial-correlations between parent and adolescent measures.

\begin{tabular}{|c|c|c|c|c|c|c|c|c|c|c|c|}
\hline & 1 & 2 & 3 & 4 & 5 & 6 & 7 & 8 & 9 & 10 & 11 \\
\hline 1. Storybook reading freq. & - & $0.51^{\star \star \star}$ & $-0.30^{\star}$ & 0.07 & 0.26 & $0.40^{\star \star}$ & 0.23 & 0.11 & 0.21 & 0.13 & 0.07 \\
\hline 2. Parents' R-TRT & $0.44^{\star \star}$ & - & -0.01 & 0.00 & 0.11 & 0.18 & $0.40^{\star \star}$ & $0.36^{\star \star}$ & 0.15 & 0.00 & 0.14 \\
\hline 3. Adolescent's age & $-0.34^{\star}$ & -0.09 & - & 0.03 & 0.02 & -0.19 & 0.00 & $0.32^{\star}$ & 0.04 & -0.04 & 0.11 \\
\hline 4. Activity preference & 0.04 & -0.07 & 0.02 & - & $0.44^{\star \star}$ & $0.52^{\star \star \star}$ & $0.41^{\star *}$ & $0.36^{\star \star}$ & 0.25 & 0.07 & 0.14 \\
\hline 5. REF Childhood & 0.20 & -0.03 & -0.01 & $0.43^{\star \star}$ & - & $0.71^{\star \star \star}$ & $0.45^{\star \star}$ & 0.23 & 0.22 & 0.03 & -0.02 \\
\hline 6. REF adolescence & $0.36^{\star}$ & 0.08 & -0.21 & $0.51^{\star \star \star}$ & $0.70^{\star \star \star}$ & - & $0.40^{\star \star}$ & $0.34^{\star}$ & 0.08 & -0.05 & -0.09 \\
\hline 7. Adolescents' R-TRT & 0.17 & $0.31^{*}$ & -0.03 & $0.40^{\star \star}$ & $0.41^{\star \star}$ & $0.36^{\star}$ & - & $0.48^{\star \star \star}$ & $0.33^{*}$ & 0.16 & $0.30^{*}$ \\
\hline 8. Adolescents' ART & 0.00 & 0.20 & $0.31^{*}$ & $0.35^{\star}$ & 0.17 & $0.30^{*}$ & $0.43^{\star \star}$ & - & $0.44^{\star \star}$ & $0.40^{\star \star}$ & $0.51^{\star \star \star}$ \\
\hline 9. Vocabulary & 0.22 & 0.17 & 0.04 & 0.25 & 0.22 & 0.08 & $0.33^{*}$ & $0.47^{\star \star \star}$ & - & $0.69^{\star \star \star}$ & $0.68^{\star \star \star}$ \\
\hline 10. Word readinga & 0.13 & 0.00 & -0.04 & 0.07 & 0.03 & -0.05 & 0.17 & $0.43^{\star \star}$ & $0.69^{\star \star \star}$ & - & $0.70^{\star * \star}$ \\
\hline 11. Spelling ${ }^{b}$ & 0.07 & 0.19 & 0.11 & 0.14 & -0.01 & -0.09 & $0.31^{*}$ & $0.55^{\star \star \star}$ & $0.68^{\star \star \star}$ & $0.70^{\star \star \star}$ & - \\
\hline
\end{tabular}

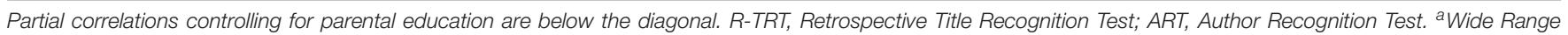
Achievement Test-Fourth Edition. ${ }^{b}$ Woodcock Johnson-Third Edition Spelling. ${ }^{*} p<0.05 .{ }^{* *} p<0.01$. ${ }^{* * *} p<0.001$.

A hierarchical multiple regression was conducted to examine the association between the R-TRT and the ART (see Table 3). To address the multicollinearity between the literacy measures and reduce the number of predictors entered in the regression, we created a composite by averaging the z-scores of the three literacy measures. After parental education, adolescents' age, and literacy skills accounted for $40 \%$ of the variability in adolescents' ART scores, the R-TRT scores still explained $8 \%$ of unique variance, suggesting that shared storybook reading during childhood may play a role in shaping print exposure into adolescence.

\section{Favorite Storybook/Author}

Our second aim was to determine if there were differences in reading habits between those who named a favorite storybook or author and those who did not. Approximately $49 \%$ of adolescents named a favorite storybook title and $40 \%$ named a current favorite author. There was a difference in all means between participants who named a favorite author versus those who did not. Identifying a favorite author was linked to: (1) choosing reading over other activities, $U(43)=140.00, z=-2.58, p=0.01$, $r=-0.38\left(M_{1}=1.61, S D_{1}=1.46 ; M_{2}=0.63, S D_{2}=1.04^{1}\right.$; (2) reporting greater reading enjoyment and frequency during

${ }^{1}$ The data from the Activity Preference Questionnaire were positively skewed, justifying nonparametric tests (Field, 2013).

TABLE 3 | Hierarchical multiple regression analysis estimating associations with the ART.

\begin{tabular}{|c|c|c|c|c|c|c|}
\hline & $R^{2}{ }_{\mathrm{c}}$ & $\boldsymbol{F}$ & B & $S E$ & $\beta$ & $t$ \\
\hline ART & 0.40 & 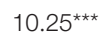 & & & & \\
\hline Parental education & & & 0.01 & 0.01 & 0.32 & $2.67^{\star \star}$ \\
\hline Adolescent's age & & & 0.02 & 0.00 & 0.27 & $2.25^{\star \star}$ \\
\hline \multirow[t]{2}{*}{ Literacy composite $^{a}$} & & & 0.05 & 0.01 & 0.50 & $4.12^{\star \star \star}$ \\
\hline & 0.48 & $6.17^{\star \star}$ & & & & \\
\hline R-TRT & & & 0.14 & 0.06 & 0.31 & $2.48^{\star *}$ \\
\hline
\end{tabular}

R-TRT, Retrospective Title Recognition Test; ART, Author Recognition Test. ${ }^{\text {a The }}$ three literacy measures were z-standardized, summed and divided by three. ${ }^{* *} p<0.01 .{ }^{* * *} p<0.001$. childhood, $t(43)=-3.39, p<0.001, g=1.13\left(M_{1}=26.78\right.$, $\left.S D_{1}=11.35 ; M_{2}=16.15, S D_{2}=9.55\right)$ and adolescence, $t(42)=-3.21, p=0.01, g=0.99\left(M_{1}=24.17, S D_{1}=11.85 ;\right.$ $\left.M_{2}=13.08, S D_{2}=10.80\right),(3)$ recognizing more storybook titles on the R-TRT, $t(43)=-2.82, p=0.01, g=0.88\left(M_{1}=0.26\right.$, $S D_{1}=0.05 ; M_{2}=0.12, S D_{2}=0.17$ ), and (5) recognizing more authors on the ART, $t(43)=-3.62, p<0.001, g=1.15$ $\left(M_{1}=0.12, S D_{1}=0.09 ; M_{2}=0.04, S D_{2}=0.05\right)$. Overall, these findings support the sensitivity of the single-item measure in separating adolescents who read frequently and infrequently. Similar analyses with favorite storybook yielded null results.

\section{Print Exposure and Literacy Skills}

Finally, we investigated whether storybook reading and print exposure were linked to concurrent literacy skills. Adolescents' shared storybook reading (R-TRT) was positively correlated with their spelling and vocabulary, but not with their word reading (see Table 2). Their print exposure (ART) scores were moderately positively correlated with all three literacy measures. Thus, we investigated the associations between the literacy skill outcomes and print exposure scores on the R-TRT and ART in a set of mediational analyses. Of note, each of the literacy skills showed slight multicollinearity with one another (Field, 2013). Thus, the analyses did not control for each literacy skill, permitting a more direct evaluation of the associations.

\section{Mediation Analyses}

To test our hypothesis that early storybook reading (R-TRT) is related to later literacy skills through the support of current print exposure (ART), we submitted the scores for the R-TRT, ART, and the three outcome variables to three separate mediational analyses while also controlling for age (see Figure 1). The analyses were carried out in IBM SPSS Statistics v26 using the PROCESS macro v3.2 (Hayes, 2018). The bootstrap procedure, which is well suited for small-scale studies, computed confidence intervals for mediated effects based on 5,000 resamples (Preacher and Hayes, 2004; Field, 2013).

The indirect association between the R-TRT and vocabulary (through its effect on current print exposure) failed to reach 


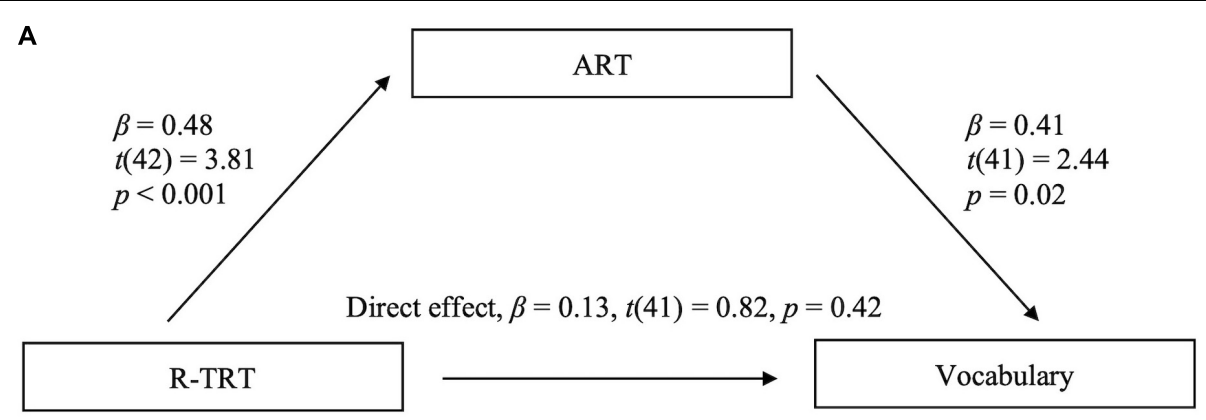

Indirect effect, $\beta=0.20, \mathrm{BCa} \mathrm{CI}[-0.01,0.42]$

B

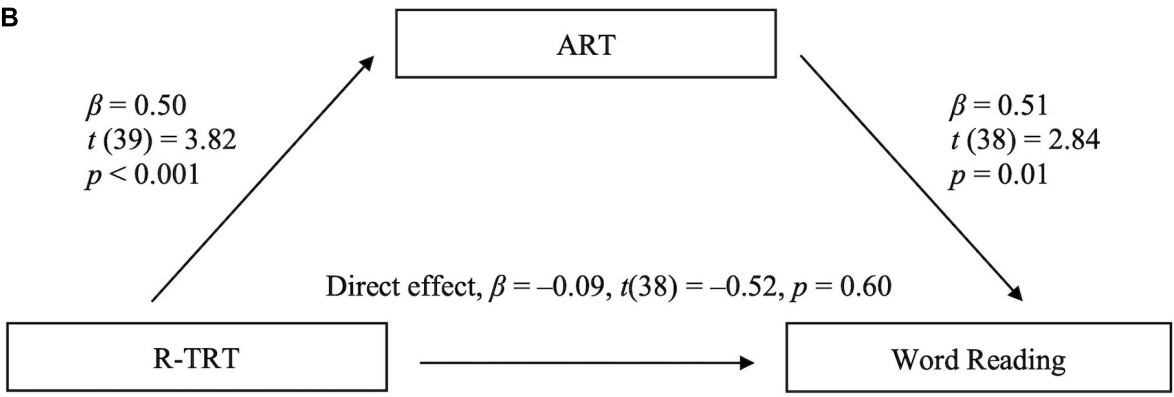

Indirect effect, $\beta=0.25, \mathrm{BCa} \mathrm{CI}[0.03,0.48]$

C

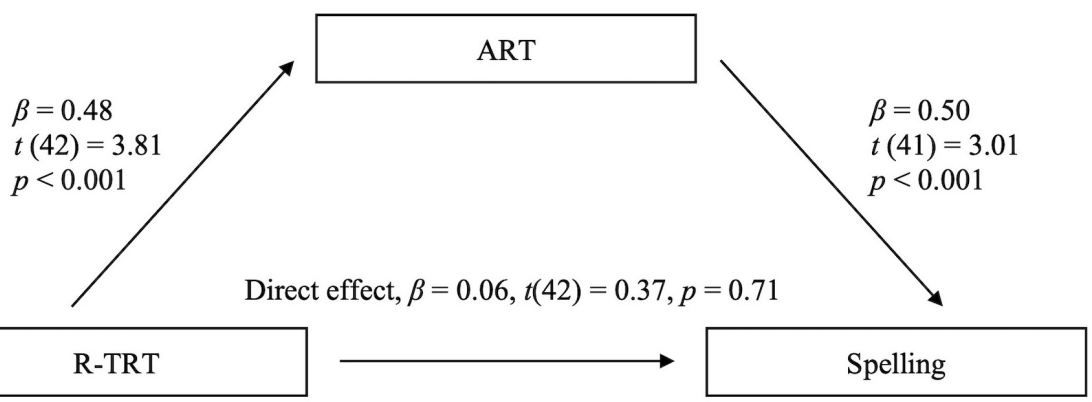

Indirect effect, $\beta=0.24$, CI $[0.03,0.44]$

FIGURE 1 | Mediational model for the association between the R-TRT and literacy skills mediated by the ART (controlling for adolescent's age).

significance. As seen in Panel A, the bootstrapped 95\% biascorrected confidence interval for the completely standardized indirect effect just touched zero. In contrast, as seen in Panels B (word reading) and C (spelling) the R-TRT was indirectly associated with both word reading and spelling through its effect on current print exposure. This indicates that participants who were exposed to more storybooks as children were more likely to read for pleasure as adolescents and in turn, participants who were more likely to read for pleasure were better at word reading and spelling. The bootstrapped $95 \%$ bias-corrected confidence interval for the completely standardized indirect effects were above zero and were supported by small effects of $R^{2}$ med $=0.09$ and $R_{\text {med }}^{2}=0.08$, respectively (Fairchild and McQuillin, 2010; Hayes, 2018). This indicated that storybook reading did not affect word reading or spelling independent of its effect on print exposure.

\section{DISCUSSION}

The overarching goal of our study was to investigate whether shared storybook reading in childhood was associated with print exposure in adolescence. Although researchers often allude to the importance of shared storybook reading on children's emerging language skills and its impact on child enjoyment (e.g., Sénéchal and LeFevre, 2014; Patel et al., 2020), to our knowledge no studies have examined these relationships into adolescence or beyond. We also explored whether remembering a favorite storybook from childhood or having a favorite author as a teenager mirrored 
having a favorite storybook as a child (Weinberger, 1996). Finally, we aimed to replicate the links between print exposure and concurrent literacy skills in a sample of adolescents.

Baker and colleagues (1997) contend that early pleasurable shared storybook experiences are at the root of children's feelings about reading and their eventual desire to read. The present study provides the first empirical evidence that we know of, linking parental reports of storybook reading and adolescents' self-reported reading enjoyment and frequency. Using a more objective measure, we also noted that adolescents who recognized more storybook titles from childhood, were also able to recognize more authors of children's, young adult, and adult novels. Furthermore, Weinberger (1996) first suggested that these early enjoyable experiences contributed to reading ability and to children's involvement with reading for pleasure as they age. In our data, the more storybook titles adolescents recognized from childhood, the more they chose reading over other activities in high school. This pattern extended to current reading habits; adolescents who recognized more authors also reported holding more favorable views toward reading as measured by the Adolescent REF composite.

Electing to read for pleasure is a personal choice that may be related to many factors, however, based on our results, early shared storybook reading could be one of them. Even after employing very stringent controls, shared storybook reading accounted for unique variance in leisure reading. These findings are uniquely compelling because of the retrospective nature of the R-TRT. The fact that identifying titles published 13 years prior (at minimum) was able to predict present day ART scores suggests that storybook reading not only promotes language development in childhood (Nyhout and O'Neill, 2013), but may pave the way to reading for pleasure into adolescence.

Another result to acknowledge stems from adolescents' ability to name their favorite storybook from childhood and their current favorite author. In the present study, recalling a favorite storybook without prompting (as opposed to recognizing titles in the R-TRT) did not differentiate the two sub-samples on any of the variables of interest. This was most likely due to the amount of time that had passed since childhood. Being asked about a participant's current favorite author, however, did broadly separate adolescents who read more from those who read less. Those who named a favorite author chose reading over other activities, reported higher enjoyment and frequency of reading in childhood and adolescence (REF scores), and scored higher on both proxies of print exposure (R-TRT and ART). This places our study among the ranks of others that have noted the efficacy of single items in predicting behavioral outcomes (e.g., Gardner et al., 1998; Hoeppner et al., 2011). Thus, naming a favorite author may be a useful initial assessment for teachers, as this single item was linked to students' prevalent reading habits.

Our findings also align with previous research on the association between shared storybook reading and educational standings (e.g., Gottfried et al., 2015); in our study participants who recognized more storybook titles outperformed their peers on vocabulary and spelling measures. Word reading, on the other hand was not correlated with performance on the R-TRT. This finding was foreshadowed by the literature showing that shared storybook reading is either less positively correlated with emerging reading skills or in some cases negatively correlated with them (e.g., Evans and Shaw, 2008). In contrast, print exposure, which involves individuals actively reading themselves, shows robust associations with reading and spelling skills (Martin-Chang et al., 2020). Therefore, we were not surprised that the R-TRT showed no direct associations to current literacy skills in the mediational models. As expected, the R-TRT was indirectly associated to word reading and spelling through the ART and, although not significant, the same trend was noted for vocabulary. Taken together, a broad pattern emerges where participants who were exposed to more storybooks as children, showed a greater inclination to read for pleasure and in turn, had more advanced literacy skills as adolescents. These effects were modest, explaining between 8 and $9 \%$ of the skills in question, yet we would argue they are nonetheless meaningful. The literacy skills under consideration are complex and have been associated with both genetic predispositions (Friend et al., 2007) and other environmental factors such as quality of schooling (Petrill et al., 2010). Thus, we feel the results discussed here are worth highlighting because increasing storybook reading is easily amenable to change.

Our findings carry two implications. First, they suggest that children who experience reading with a caregiver are more likely to read independently once their reading skills develop. Second, while speculative, it proposes that children who missed the opportunity for shared storybook reading may make up for lost time by choosing to engage in independent reading as they grow. Thus, influential adults (e.g., teachers, extended family, and tutors) should continue to promote reading as an entertaining and worthwhile activity. Likewise, it recommends that parents' jobs as reading partners do not end when their children become too big to sit on their laps. Rather, parents should scaffold reading using storybooks when their children are young and encourage the progression toward reading chapter books and novels independently as their children's skills develop.

The innovative design of our research offers two new contributions to the literature. We demonstrated a relation between shared storybook reading in childhood and an inclination toward reading into adolescence. By extension, it is also the first to compare the relative influence of shared storybook reading versus leisure reading with regards to literacy skills. Further, we created a retrospective measure that avoided many of the complications associated with longitudinal designs, such as the time and cost of tracking participants throughout their lives. The retrospective nature of the task should be interpreted with caution and used alongside corroborating measures. However, because parents R-TRT scores were correlated with their children's (albeit slightly weaker than concurrent TRT scores within parent child dyads; cf. Grolig et al., 2019), it supports the validity of measuring shared storybook reading retrospectively. The R-TRT offers researchers a glimpse into participants' home literacy environments that was previously unavailable.

\section{Limitations}

A potential limitation of this study is the small sample size. Small sample sizes reduce statistical power and make finding 
effects more difficult. Even under the current conditions the analyses yielded reliable results. Nonetheless, due to the risk of Type 1 error, future work should aim to replicate these patterns with larger samples. A second issue is the absence of parents' socioeconomic status (SES). Manolitsis et al. (2013) studied the home literacy environment and found that SES had no effect on formal and informal literacy activities. Similarly, the kinds of literacy activities parents use with their children generalize across SES (Hood et al., 2008). We did, however, include parent's education, which is a reliable predictor of both reading materials found in the home and time spent reading with children (Gottfried et al., 2015). A third limitation is the low recognition rate on the ART. Future studies should consider using the ART-CYA which was created for children and young adults (Martin-Chang et al., 2020).

Another limitation to consider is the correlational nature of the study. Although there was a positive correlation between the number of storybook titles adolescents identified and the number of authors recognized, it could be that the association was mediated by an unmeasured variable. Perhaps adolescents who read to younger children or who place importance on reading, also value their memories of shared storybook reading and therefore are able to identify more storybook titles (e.g., perhaps they still own their storybooks as keepsakes). In addition, it could be that parents who read more storybooks to their children in the early years continued to promote reading as their children grew. Future research should ask adolescents about the role parents, teachers, and peers play in supporting leisure reading, and whether structural support, such as easier access to books via libraries (onsite or online) could promote reading.

\section{Implications}

When parents and children share storybooks, the goal often includes engaging in meaningful experiences (Arya et al., 2014). Vygotsky's Sociocultural Theory (1978) asserts that children develop behaviors and learn social norms through their interactions with more competent individuals. Parents are scaffolding book reading during these social interactions as they model concepts about print (Sénéchal and LeFevre, 2002) as well as higher order thinking through discussion and enjoyment (Patel et al., 2020).

Shared storybook reading is associated with many concurrent benefits, including heightened vocabulary (Flack et al., 2018) and advanced theory of mind (Mar, 2018). Our findings suggest that shared storybook reading may also support children's subsequent print exposure and reading preferences into adolescence.

\section{REFERENCES}

Arya, D. J., McClung, N. A., Maul, A., and Cunningham, A. E. (2014). The effects of early home literacy environments on fourth-grade literacy achievement: an international comparison. Intern. J. Q. Res. Educ. 2, 1-16. doi: 10.1504/ijqre. 2014.060971

Baker, L., Mackler, K., Sonnenschein, S., and Serpell, R. (2001). Parents' interactions with their first-grade children during storybook reading and relations with
Therefore, parents should be encouraged to luxuriate in shared storybook reading as it may very well instill a long-lasting love of reading into adolescence and beyond.

\section{DATA AVAILABILITY STATEMENT}

The raw data supporting the conclusions of this article will be made available by the authors, without undue reservation, to any qualified researcher.

\section{ETHICS STATEMENT}

The studies involving human participants were reviewed and approved by the Office of Research, Concordia University. Written informed consent to participate in this study was provided by the participants' legal guardian/next of kin.

\section{AUTHOR CONTRIBUTIONS}

BT spearheaded this research project, designed the R-TRT, and collected and analyzed the data for her master's thesis, all under the supervision of SM-C. MR collaborated on the data analysis. All authors adapted BT's thesis for this article and approved the final version of the article for publication.

\section{FUNDING}

This research was funded by a fellowship given to BT by the Fonds de recherche du Québec - Société et culture (209529) and a grant to SM-C from the Social Science and Humanities Research Council of Canada (435-2020-1228).

\section{ACKNOWLEDGMENTS}

We thank the adolescents and their parents who participated in the study, as well as Grace Martin-Chang for her assistance in participant recruitment.

\section{SUPPLEMENTARY MATERIAL}

The Supplementary Material for this article can be found online at: https://www.frontiersin.org/articles/10.3389/fpsyg. 2020.571033/full\#supplementary-material

subsequent home reading activity and reading achievement. J. Sch. Psychol. 39, 415-438. doi: 10.1016/S0022-4405(01)00082-6

Baker, L., Scher, D., and Mackler, K. (1997). Home and family influences on motivations for reading. Educ. Psychol. 32, 69-82. doi: 10.1207/s15326985ep3 202_2

Cunningham, A. E., and Stanovich, K. E. (1990). Assessing print exposure and orthographic processing skill in children: a quick measure of reading experience. J. Educ. Psychol. 82, 733-740. doi: 10.1037/0022-0663.82.4.733 
Cunningham, A. E., and Stanovich, K. E. (1997). Early reading acquisition and its relation to reading experience and ability 10 years later. Dev. Psychol. 33, 934-945. doi: 10.1037/0012-1649.33.6.934

Cunningham, A. E., and Stanovich, K. E. (2001). What reading does for the mind. J. Direct Instruct. 1, 137-149.

Evans, M. A., and Shaw, D. (2008). Home grown for reading: parental contributions to young children's emergent literacy and word recognition. Can. Psychol. 49, 89-95. doi: 10.1037/0708-5591.49.2.89

Fairchild, A. J., and McQuillin, S. D. (2010). Evaluating mediation and moderation effects in school psychology: a presentation of methods and review of current practice. J. Sch. Psychol. 48, 53-84. doi: 10.1016/j.jsp.2009.09.001

Field, A. P. (2013). Discovering Statistics Using IBM SPSS Statistics: And Sex and Drugs and Rock ' $n$ ' Roll, 4th Edn, Thousand Oaks, CA: Sage.

Flack, Z. M., Field, A. P., and Horst, J. S. (2018). The effects of shared storybook reading on word learning: a meta-analysis. Dev. Psychol. 54, 1334-1346. doi: 10.1037/dev0000512

Fong, K., Mullin, J. B., and Mar, R. A. (2013). What you read matters: the role of fiction genre in predicting interpersonal sensitivity. Psychol. Aesthet. Creativ. Arts 7, 370-376. doi: 10.1037/a0034084

Friend, A., DeFries, J. C., Wadsworth, S. J., and Olson, R. K. (2007). Genetic and environmental influences on word recognition and spelling deficits as a function of age. Behav. Genet. 37, 477-486. doi: 10.1007/s10519-007-9145-4

Gardner, D. G., Cummings, L. L., Dunham, R. B., and Pierce, J. L. (1998). Singleitem versus multiple-item measurement scales: an empirical comparison. Educ. Psychol. Measur. 58, 898-915. doi: 10.1177/0013164498058006003

Gottfried, A. W., Schlackman, J., Eskeles Gottfried, A., and Boutin-Martinez, A. (2015). Parental provision of early literacy environment as related to reading and educational outcomes across the academic lifespan. Parenting 15, 24-38. doi: 10.1080/15295192.2015.992736

Grolig, L., Cohrdes, C., Tiffin-Richards, S., and Schroeder, S. (2019). Effects of preschoolers' storybook exposure and literacy environments on lower level and higher level language skills. Read. Writ. Interdiscipl. J. 32, 1061-1084. doi: 10.1007/s11145-018-9901-2

Hayes, A. F. (2018). Introduction to Mediation, Moderation, and Conditional Process Analysis: A Regression-Based Approach, 2nd Edn, New York, NY: Guilford Press.

Hoeppner, B. B., Kelly, J. F., Urbanoski, K. A., and Slaymaker, V. (2011). Comparative utility of a single-item vs. multiple-item measure of self-efficacy in predicting relapse among young adults. J. Subst. Abuse Treat. 41, 305-312. doi: 10.1016/j.jsat.2011.04.005

Hood, M., Conlon, E., and Andrews, G. (2008). Preschool home literacy practices and children's literacy development: a longitudinal analysis. J. Educ. Psychol. 100, 252-271. doi: 10.1037/0022-0663.100.2.252

Kozak, S., and Recchia, H. (2019). Reading and the development of social understanding: implications for the literacy classroom. Read. Teach. 72, 569577. doi: 10.1002/trtr.1760

Manolitsis, G., Georgiou, G. K., and Tziraki, N. (2013). Examining the effects of home literacy and numeracy environment on early reading and math acquisition. Early Child. Res. Q. 28, 692-703. doi: 10.1016/j.ecresq.2013.05.004

Mar, R. A. (2018). Stories and the promotion of social cognition. Curr. Direct. Psychol. Sci. 27, 257-262. doi: 10.1177/0963721417749654

Mar, R. A., and Rain, M. (2015). Narrative fiction and expository nonfiction differentially predict verbal ability. Sci. Stud. Read. 19, 419-433. doi: 10.1080/ 10888438.2015.1069296

Martin-Chang, S., Kozak, S., and Rossi, M. (2020). Time to read young adult fiction: print exposure and linguistic correlates in adolescents. Read. Writ. 33, 741-760. doi: 10.1007/s11145-019-09987-y

Martin-Chang, S. L., and Gould, O. N. (2008). Revisiting print exposure: exploring differential links to vocabulary, comprehension and reading rate. J. Res. Read. 31, 273-284. doi: 10.1111/j.1467-9817.2008.00371.x

Nomura, K., and Akai, S. (2012). Empathy with fictional stories: reconsideration of the fantasy scale of the interpersonal reactivity index. Psychol. Rep. 110, 304-314. doi: 10.2466/02.07.09.11.PR0.110.1.304-314

Nyhout, A., and O'Neill, D. K. (2013). Mothers' complex talk when sharing books with toddlers: book genre matters. First Lang. 33, 115-131. doi: 10.1177/ 0142723713479438
Patel, S., Segal, A., and Martin-Chang, S. (2020). "I love this story!" examining parent-child interactions during storybook reading. Early Educ. Dev. doi: 10. 1080/10409289.2020.1755159. [Epub ahead of print].

Petrill, S. A., Hart, S. A., Harlaar, N., Logan, J., Justice, L. M., Schatschneider, C., et al. (2010). Genetic and environmental influences on the growth of early reading skills. J. Child Psychol. Psychiatr. 51, 660-667. doi: 10.1111/j.1469-7610. 2009.02204.x

Preacher, K. J., and Hayes, A. F. (2004). SPSS and SAS procedures for estimating indirect effects in simple mediation models. Behav. Res. Methods Instrum. Comput. 36, 717-731. doi: 10.3758/BF03206553

Schiefele, U., Schaffner, E., Möller, J., Wigfield, A., Nolen, S., and Baker, L. (2012). Dimensions of reading motivation and their relation to reading behavior and competence. Read. Res. Q. 47, 427-463. doi: 10.1002/ RRQ.030

Schiefele, U., Stutz, F., and Schaffner, E. (2016). Longitudinal relations between reading motivation and reading comprehension in the early elementary grades. Learn. Individ. Differ. 51, 49-58. doi: 10.1016/j.lindif.2016.0 8.031

Sénéchal, M. (2000). Examen du lien entre la lecture de livres et le développement du vocabulaire chez l'enfant préscolaire [A naturalistic study of the links between storybook reading and vocabulary development in preschool children]. Enfance 52, 169-186. doi: 10.3406/enfan.2000. 3175

Sénéchal, M. (2006). Testing the home literacy model: parent involvement in kindergarten is differentially related to grade 4 reading comprehension, fluency, spelling, and reading for pleasure. Sci. Stud. Read. 10, 59-87. doi: 10.1207/ s1532799xssr1001_4

Sénéchal, M., and LeFevre, J. (2002). Parental involvement in the development of children's reading skill: A five-year longitudinal study. Child Dev. 73, 445-460. doi: $10.1111 / 1467-8624.00417$

Sénéchal, M., and LeFevre, J. (2014). Continuity and change in the home literacy environment as predictors of growth in vocabulary and reading. Child. Dev. 85, 1552-1568. doi: 10.1111/cdev.12222

Stanovich, K. E., and West, R. F. (1989). Exposure to print and orthographic processing. Read. Res. Q. 24, 402-433. doi: 10.2307/74 7605

Torppa, M., Niemi, P., Vasalampi, K., Lerkkanen, M.-K., Tolvanen, A., and Poikkeus, A.-M. (2020). Leisure reading (but not any kind) and reading comprehension support each other - A longitudinal study across grades 1 and 9. Child. Dev. 91, 876-900. doi: 10.1111/cdev.13241

Twenge, J. M., Martin, G. N., and Spitzberg, B. H. (2019). Trends in U.S. adolescents' media use, 1976-2016: the rise of digital media, the decline of TV and the (near) demise of print. Psychol. Pop. Med. Cult. 8, 329-345. doi: $10.1037 / \mathrm{ppm} 0000203$

Vygotsky, L. S. (1978). "Interaction between learning and development," in Mind and Society: The Development of Higher Psychological Processes, eds M. Cole, V. John Steiner, S. Scribner, and E. Souberman (Cambridge, MA: Harvard University Press), 79-91. doi: 10.2307/j.ctvjf9vz4.11

Weinberger, J. (1996). A longitudinal study of children's early literacy experiences at home and later literacy development at home and school. J. Res. Read. 19, 14-24. doi: 10.1111/j.1467-9817.1996.tb00083.x

Wilkinson, G. S., and Robertson, G. J. (2006). Wide Range Achievement Test, 4th Edn, Lutz, FL: Psychological Assessment Resources.

Woodcock, R. W., McGrew, K. S., and Mather, N. (2001). Woodcock-Johnson III Test. Rolling Meadows, IL: Riverside Publishing.

Conflict of Interest: The authors declare that the research was conducted in the absence of any commercial or financial relationships that could be construed as a potential conflict of interest.

Copyright (c) 2020 Tremblay, Rodrigues and Martin-Chang. This is an open-access article distributed under the terms of the Creative Commons Attribution License (CC BY). The use, distribution or reproduction in other forums is permitted, provided the original author(s) and the copyright owner(s) are credited and that the original publication in this journal is cited, in accordance with accepted academic practice. No use, distribution or reproduction is permitted which does not comply with these terms. 
OPEN ACCESS

Edited by:

Frank Niklas,

Ludwig Maximilian University of

Munich, Germany

Reviewed by:

Judit García-Martín,

University of Salamanca, Spain

Astrid Wirth

Ludwig Maximilian University of

Munich, Germany

*Correspondence:

Eliane Segers

e.segers@pwo.ru.n

Specialty section:

This article was submitted to Educational Psychology, a section of the journal

Frontiers in Psychology

Received: 27 February 2020

Accepted: 28 August 2020

Published: 18 September 2020

Citation:

Segers E and Kleemans T (2020)

The Impact of the Digital Home

Environment on Kindergartners'

Language and Early Literacy.

Front. Psychol. 11:538584.

doi: 10.3389/fpsyg.2020.538584

\section{The Impact of the Digital Home Environment on Kindergartners' Language and Early Literacy}

\author{
Eliane Segers ${ }^{1,2 *}$ and Tijs Kleemans ${ }^{1}$ \\ ${ }^{1}$ Behavioural Science Institute, Radboud University, Nijmegen, Netherlands, '²Department of Instructional Technology, \\ University of Twente, Enschede, Netherlands
}

We examined whether a digital home literacy environment could be distinguished from a (traditional) analog home literacy environment, and whether both were related to kindergartners' language and literacy levels, taking parental expectations into account. Caregivers of 71 kindergarteners filled out a questionnaire on the home environment (expectations, activities, and materials), and the children were assessed on language (vocabulary and grammar) and literacy (begin phoneme awareness, segmentation skill, and grapheme knowledge) skills. Results showed that a digital environment could be distinguished from an analog environment. However, only the analog environment was related to children's language abilities. Parental expectations were related directly to both language and literacy abilities. The fact that there was no relation between the digital home environment and language and literacy outcomes might indicate large variation in the quality of the digital home environment. More attention is needed to this part of daily life when growing up in a digital society.

Keywords: home literacy environment, kindergarten, digital home environment, early literacy, parental expectations

\section{INTRODUCTION}

During their kindergarten years, young children increasingly become aware of language and literacy. They enter kindergarten with heads full of stories that have been told at home and an emergent awareness of the form and function of written language. During their kindergarten years, children have a steep growth in the development of vocabulary (Biemiller, 2006), and also begin to develop phonological awareness and grapheme knowledge (e.g., Verhoeven et al., 2016). The home literacy environment is an important factor in this development, as evidenced by a large body of literature described in meta-analyses by Bus et al. (1995) and more recently by Mol and Bus (2011). The home literacy environment has experienced a sudden shift with the introduction of the tablet computer. Tablet computers entered households in 2010 and, in contrast to the personal computer, became much more a device that young children could easily use and were also allowed to use (Plowman and McPake, 2013). Not only many apps are available for use on tablets, including e-book reading apps, but also apps that focus on early literacy. While there is a large body of research on the additional effects of computer-supported early literacy in kindergarten (see Verhoeven et al., 2020), only very recently has research been published on the use of tablets at home by kindergartners. These studies show positive relations between tablet use at home and early literacy (Neumann, 2016). However, research is lagging behind on the impact of a digital home environment on learning (Radesky et al., 2015). 
In fact, it is unclear to what extent an actual digital home literacy environment (DHLE) can be distinguished from what we will call an analog home environment, and whether such a digital environment further adds to children's language and early literacy.

\section{The Analog Home Literacy Environment}

The (analog) home literacy environment, often described as the shared literacy activities between parents and their children (van Steensel, 2006), accounts for a substantial amount of the variation in the development of language and early literacy (see e.g., Bus et al., 1995; Mol and Bus, 2011). Various facets of the home literacy environment have been studied, such as frequency or amount of parental book reading and shared book reading. Burgess et al. (2002) made clear that the home literacy environment should be studied as a broader concept, for example, by including singing and playing language games or engaging in letter-based activities.

In a landmark study by Sénéchal et al. (1998), it was shown that storybook exposure is mostly related to oral language development (i.e., vocabulary, listening comprehension, and phoneme awareness), while parental teaching predicts written language skills (e.g., knowledge of the alphabet). Burgess et al. (2002) also showed that especially parental activities aimed to engage their child in literacy were predictive of early literacy development.

Following up on these results, Sénéchal and colleagues (e.g., Sénéchal and LeFevre, 2002; Sénéchal, 2006) proposed a Home Literacy Model that distinguishes between informal (e.g., storybook reading) and formal (e.g., parental teaching) literacy activities. Their research again showed that the informal literacy activities in general are predictive of oral language, but not early literacy, while formal literacy activities predict early literacy, but not oral language. These results were recently replicated in a transparent orthography (Finnish), albeit that effects of maternal teaching were smaller (Silinskas et al., 2020).

Along with parent-child literacy activities, the home literacy environment also consists of experiences in which children explore print on their own (see Sénéchal et al., 2017). However, this aspect has often not been taken into consideration in questionnaires, as the focus has mostly been on parent-child interactions.

In addition to activities, parental beliefs and expectations about their children have a major impact on the home literacy environment. Martini and Sénéchal (2012) showed how both beliefs and expectations had a direct and an indirect effect via formal literacy activities on early literacy. In a similar vein, Davis-Kean (2005) showed, in a large longitudinal study, how parental expectations impacted parental (reading) behaviors, which in turn impacted academic achievement in 8-12-year-olds. Again, parental expectations had a strong indirect effect on children's achievement. Also, Silinskas et al. (2020) showed that maternal beliefs and expectations were positively related to formal literacy activities, and not so much to informal literacy activities.

\section{The Digital Home Literacy Environment}

The DHLE can be described as the shared literacy activities between parents and children while using a digital device, and the time children spend playing with such a device on their own. Many Western households nowadays have more than one tablet at home (also including smartphones; MarketingCharts, n.d.), and young children are often allowed to play on them (Plowman and McPake, 2013) or even have one of their own. Holloway et al. (2013) reported that tablet use in young children is growing as well. For example, $50 \%$ of Swedish children aged between 3 and 4 use tablet computers, and these numbers are growing across countries, and they are related to parental use of devices. The development of apps for the tablets is a huge industry, and there are many early literacy tablet-apps available in online stores. In a recent study on media use of young children in Australia, Huber et al. (2018) reported that preschoolers have about $80 \mathrm{~min}$ of screen time per day, which increased to almost $100 \mathrm{~min}$ for school-aged children. Time with a touchscreen seems dominated by watching videos, but also time was spent playing (educational) games. The general role of access to media was studied by Liebeskind et al. (2014). Their results showed little effects of amount of media in the households (e.g., number of computers at home) on language skills of young children (8-36 months). This study did not specifically address tablets or questions about parent-child activities using different media. Parents in the Huber et al. (2018) study reported strong agreement on the potential of technology as a learning tool. Parents tend to have device restrictions to prevent their child to spend too much time with a device, but are also actively involved in their young child's media use (Zaman et al., 2016).

Besides the obvious disadvantages of spending too much time with a tablet, e.g., when using it as a television, and passively watching movies, a world of possibilities has opened regarding home literacy activities. Apps are available that provide digital story books, which have been shown to benefit language development (Ihmeideh, 2014; Takacs et al., 2015). In a similar vein, apps that provide games on phonological awareness of grapheme-phoneme correspondences can boost early literacy (see Verhoeven et al., 2020), and as such may provide an additional effect over and above the traditional/analog home literacy environment (AHLE) specifically regarding early literacy skills. Research has just begun to examine what children can learn from tablet apps. In a pioneering study on this topic, Neumann (2016) showed how home tablet activities of the child correlated with emergent literacy measures in 2-4-year olds. Interestingly, she did not ask about joined parent-child tablet activities. In this study, tablet writing related to print awareness, print knowledge, and sound knowledge, but Neumann did not study whether digital activities predicted emergent literacy over and above non-digital literacy activities, or related the tablet measures to analog (i.e., non-digital) home literacy measures.

Herodotou (2018) is probably the first to have written a review on the effects of tablets on learning and development of young children (2-5-year olds). Herodotou identified five (quasi)-experimental and four descriptive studies on the effects of touch screen tablets on early literacy, but did not include the extensive literature on digital books (Bus et al., 2015). She concluded that effects of tablet use by young children were 
found mostly on vocabulary and print knowledge. Most studies were conducted with parents and children in a joint activity, and not necessarily aiming to compare tablet vs. traditional print, which leaves the question unanswered whether the use of tablets as a digital activity can be distinguished from, and adds to, children's analog home literacy experiences.

Neumann (2018) studied the scaffolding role of the parent in young children's tablet use, but did not relate this to learning outcomes in language and literacy skills. Kim and Anderson (2008), however, showed that mother-child interactions tended to be more complex in electronic context vs. traditional print format. Furthermore, Teepe et al. (2017) showed that technologyenhanced storytelling had a positive effect on children's vocabulary skills in a pretest-posttest control condition. However, it has also been shown that digital storybooks can be distracting. Krcmar and Cingel (2014), for example, compared parent-child book reading on an iPad tablet vs. a traditional book. Children (2-5-year olds) had a better story comprehension in the traditional book condition, probably due to the fact that parents included more distractive talk in the digital condition.

\section{The Present Study}

The home literacy environment is an important influencer of the development of children's language and literacy development. So far, the literature has not made a distinction between a digital vs. an analog home-environment, and also in recent studies regarding the home literacy environment, the digital literacy environment was not included (e.g., Hamilton et al., 2016), while digital technology has invaded the lives of the children. In fact, it remains unclear whether the two can be distinguished empirically, and, if so, whether the DHLE adds to the explanation of language and early literacy in kindergartners. In households with more digital devices, children also use them at a younger age (Holloway et al., 2013). Metaanalyses have shown the possible (additional) benefits of apps focusing on language and literacy (Takacs et al., 2015; Verhoeven et al., 2020). Differences between households with a higher or lower digital literacy environment may thus emerge, and impact language and literacy development.

In the present study, the first research question, therefore, was: can a DHLE be distinguished from an AHLE? We expected to be able to distinguish between an analog and a DHLE.

The second research question was (a) what is the additional value of the digital home literacy environment on language and early literacy over and above parental expectations and the AHLE and (b) do both home environments mediate between parental expectations and children's language and early literacy? We expected effects of the analog home environment to be especially visible regarding language skills, while the digital home environment might have a stronger (and additional) impact on early literacy, as children could be more confronted with exercises in literacy apps. We expected parental expectations to be related to language and early literacy, which would be partly mediated by both the analog and the digital home environment. Since the home literacy environment and children's language and literacy outcomes are associated with intelligence and family's SES (e.g., Pace et al., 2017), we took these into account.

\section{MATERIALS AND METHODS}

\section{Participants}

Three schools with 11 mixed first- and second-year kindergarten classes in the southern part of the Netherlands took part in the study in spring 2017. In the Netherlands, kindergarten is a two-year program, prior to first grade. Teachers pay attention to emergent literacy, and storybook reading is common practice. Letters were sent to the parents of the second-year kindergartners; i.e., the group of children in the year prior to grade 1. Seventy-one parents gave informed consent for their child to participate and filled out the questionnaire. There were no specific exclusion criteria. However, one child was not included in the analysis for having too little knowledge of Dutch to understand the tasks. The average age of the remaining 70 children was 5 ; 11 (i.e. 5 years; 11 months; $S D=4.3$ months). There were 34 boys and 36 girls in the sample.

The main caregiver was asked to fill out the questionnaire; this was done by 57 mothers and 12 fathers, while one parent did not fill in this question. The average age of the main caregiver was 37.65 years $(S D=5.25)$. The educational level was vocational or lower (three only primary education and four only secondary education) for 37 caregivers, the educational level was university of applied sciences or university for the remaining 33 caregivers. This variable was therefore dichotomized $(0=$ lower education level and $1=$ higher educational level $)$ in further analyses. In most households, Dutch was the main language; seven parents indicated that Dutch was hardly ever spoken at home, and one that it was only spoken a few times per week. In $25.7 \%$ of the families, another language was spoken: Chinese $(n=5)$, English $(n=2)$, Turkish $(n=7)$, Moroccan $(n=2)$, Spanish $(n=1)$, and Ghanaian $(n=1)$. This percentage is in line with the percentage of children with a migration background in current Dutch primary education (Central Bureau of Statistics, 2020).

\section{Materials \\ Child Factors}

\section{Non-Verbal Intelligence}

As an indication of non-verbal intelligence, we used the subtest exclusion from the RAKIT-2 (Resing et al., 2012). The subtest consists of 65 items, with increasing difficulty. Each item consisted of four stimuli in which three of them belonged to the same rule(s). Children are asked each time which stimulus did not belong, for example, because of its shape. Testing was stopped after four mistakes in five consecutive items. The score comprised the number of correctly answered items. Reliability is good (Cronbach's alpha $=0.88$; Pieters et al., 2013).

\section{Language and Early Literacy}

Five tasks were administered to assess language and early literacy skills. First, grammatical skills were assessed using the subtasks Sentence Comprehension 1 and 2 from the Taaltoets Alle Kinderen (Language Test for All Children; Verhoeven and Vermeer, 2006). Knowledge of function words and conjunctions are the focus of these tasks. The tests contain 21 items each, preceded by 
two practice items. The child has to choose the correct drawing out of a series of three. An example is "The cat sits on the chair," with pictures showing a cat on a chair, next to a chair, or under a chair. Cronbach's alpha of 0.82 is reported. Furthermore, vocabulary knowledge was measured using the passive vocabulary test from the same Language Test (Verhoeven and Vermeer, 2006). Now, children had to choose the correct picture out of a series of four that matched the word pronounced by the experimenter. The test consists of 96 items, preceded by two practice items. The items increase in difficulty, and assessment is terminated after five consecutive mistakes. Cronbach's alpha of 0.97 is reported. In addition, begin phoneme awareness, segmentation skill, and grapheme knowledge were assessed with tasks developed by Schaars et al. (2017). For begin phoneme awareness, the child is asked to isolate the first phoneme of a one-syllable word pronounced by the experimenter (e.g., say " $/ \mathrm{k} /$ " when the experimenter says "cat"). The task consists of 10 items, preceded by two practice items (Cronbach's alpha $=0.83$; Schaars et al., 2017). For segmentation skills, the child has to pronounce all phonemes of each one-syllable word pronounced by the experimenter (e.g., say "d-o-g" when the experimenter says "dog"). The tasks consist of 10 items, preceded by two practice items. Cronbach's alpha was 0.85 (Schaars et al., 2017), indicating good reliability. And finally, for grapheme knowledge, the child was presented with a card that contained the 34 graphemes that children learn in Dutch Grade 1 (including digraphs, such as "aa"). The child is asked to name the sound of all graphemes it knows. This task had excellent reliability (Cronbach's alpha $=0.93$; Schaars et al., 2017).

A principal component analysis on the five language and literacy measures that were assessed revealed two components, with $80.54 \%$ explained variance (see Table 1). All measures clearly loaded on one dimension, although grammatical skills also loaded $>0.4$ on the second dimension, however, with a clear preference for the first. We transferred the scores on each of the tasks to $\mathrm{z}$-scores and added the two, respectively, three scores to a score for language ability and a score for early literacy.

\section{Home Literacy Environment}

The home literacy environment was measured with a questionnaire based on Segers et al. (2015) that, however, did not take the digital environment into account. The first part contained demographic background questions. Questions were asked who the primary caregiver was and what his/her age was.

TABLE 1 | Structure matrix of the principal component analysis on language and early literacy.

\begin{tabular}{lcc}
\hline Question & \multicolumn{2}{c}{ Component } \\
\cline { 2 - 3 } & Language skills & Early literacy \\
\hline Vocabulary & 0.928 & \\
Grammar & 0.881 & 0.427 \\
Begin phoneme & & 0.896 \\
Segmentation & & 0.884 \\
Grapheme knowledge & & 0.853
\end{tabular}

We also asked how often Dutch was spoken at home [on a 4-point scale, ranging from "(hardly) ever (1)" to "daily (4)"], which language was spoken at home, and what the level of parental education was (as a proxy for socio-economic status).

Regarding the home literacy questions, we made several modifications. First, each question was duplicated, asking whether an activity occurred in an analog manner and, next, whether it occurred digitally. In addition, we also asked about activities that the child did on his/her own, as this may be typical for digital activities. Furthermore, we added questions on the general home environment, regarding number of paper and digital books at home and the number of devices (PCs, tablets, and smartphones) at home. Part 2 asked questions about the availability of materials at home: number of paper and digital books, and number of devices (television, computer/laptop, tablet, smartphone, e-reader, music player, DVD-player, and gaming console). Part 3 asked five questions regarding frequency of both analog and digital parental activities with the child (a total of 10 items): reading to the child; stimulating the child to read; stimulating the child to write; playing language and word games; and singing/reading poems, songs, and rhymes. In a similar vein, four questions were asked about activities the child would conduct on its own both analog and digital formats (i.e., eight items): looking into (picture) books; letter naming; playing language and word games; and listening to poems, songs, and rhymes. The answers could be indicated on a 5-point scale ranging from "hardly ever (1)" to "several times a day (5)." Part 4 focused on math activities, which is not part of the current study. Part 5 asked about parental expectations regarding language, literacy, and numeracy, the latter not being part of the current study. Parental expectations focused on language and early literacy. Parents were asked in six questions to estimate whether, at the end of kindergarten, their child would be able to name all the letters, write his/ her own name, rhyme, segment words, decode cvc-words, and retell a short story using a 4-point Likert scale ranging from "not at all (1)" to "good (4)."

\section{Procedure}

After three schools were found that were willing to participate, all children from those schools who were in the second-year of kindergarten received an envelope from their teacher containing the questionnaire and consent form, following ethical guidelines of our research institute. They were asked to give this envelope to their parent. Filled out questionnaires could be returned to the schools in a sealed envelope and were collected by one of the test assistants. In total, 139 children were given an envelope. The parents of one child reported that they did not want their child to participate, while 67 parents did not respond (also not after receiving an e-mail from the school as a reminder). In total, 71 parents filled out the questionnaire and gave consent for their child to participate. This response rate is quite normal in this type of active consent procedure (Esbensen et al., 1999).

Next, children were tested in three sessions of no longer than $30 \mathrm{~min}$ on language and literacy measures in a quiet room inside the school. Each child had a maximum of two 
test sessions per day, always with at least a lunch break in-between. Early numeracy was also assessed in the first of these sessions, and working memory (being related to early numeracy) in the second, but these were not included in the current paper. In the second session, non-verbal intelligence and early literacy (except grapheme-phoneme knowledge) was assessed and in the final session, grammatical skills, vocabulary, and grapheme-phoneme knowledge were assessed. Sessions two and three were assessed in random order. Test assistants were six undergraduate and graduate students of educational science with experience in testing young children. Before seeing the children, the students received half-day training by the second author (an educational psychologist).

\section{Statistical Approach}

To answer the first research question, we analyzed the data from the parental questionnaires. Questions that did not have a normal division $(-1.5<$ skewness and/or kurtosis > 1.5) were removed. Next, we ran the principal component analysis with direct oblimin rotation and inspected the scree plot as an indication for the number of components. The scores of the questions per component were summed up for the remaining analyses.

To answer the second research question, mediation analyses using the PROCESS add-on in SPSS (Hayes, 2013) were conducted. Parental expectations were the independent variable, digital and analog home environment were the mediators and language ability and early literacy, respectively, were the dependent variables. Boot-strapping was set at 5000 cycles, as recommended by Hayes. The mediation model was set up this way following the theoretical model described in the introduction. The total effect of parental expectations on the outcome measure is broken down into a direct effect and an indirect effect via the mediators.

\section{RESULTS}

\section{Preliminary Considerations}

Within the 70 questionnaires that were returned by the parents, there was a relative high level missing answers in the questions regarding digital activities, even though a computer/tablet was reported to be at home and accessible to the child. The analyses in this Results section, therefore, often reflect the smaller number of respondents who filled out both analog and digital questions. A total of 15 out of the 70 questionnaires that were returned had missing values for the digital, but not the analog questions. Furthermore, two children had a missing score on one of the early literacy skills measures. The group of children of the parents who did not fill in the questions on digital home environment had lower language skills than the other group $[t(68)=-2.18, p=0.03, d=0.62]$, but did not differ in early literacy or non-verbal intelligence (all $p>0.35$ ). Of the 15 , nine parents had a lower education and six parents had a higher educational level. In the remaining group, 28 had a lower education whereas 27 parents had a higher education. Of the six questions on parental expectations, one item was removed because of a high kurtosis (being able to write its own name).
The remaining five items were summed up to reflect "parental expectations." Reliability was good (Cronbach's alpha $=0.846$ ).

\section{Analog vs. Digital Home Literacy Environment}

We first explored the data to find out whether an AHLE could be distinguished from a DHLE (i.e., the first research question). Four questions regarding DHLE did not have a normal division $(-1.5<$ skewness and/or kurtosis > 1.5) and were removed because of this [reading to child, stimulating child to read, stimulating child to write, and looking at (picture) books]. We ran the principal component analysis on the remaining 14 questions of the questionnaire, and inspected of the scree plot showed the point of inflection at three components. We thus reran the analysis forced on two components, which resulted in $62.78 \%$ explained variance. The structure matrix (see Table 2) indicates that a first component can be distinguished as the digital home environment, including five questions with a loading $>0.7$. Reliability was good (Cronbach's alpha $=0.847$ ) The second component that can be distinguished is the analog home environment with four remaining questions with a loading $>0.6$. Reliability was acceptable (Cronbach's alpha $=0.702$ ). Five questions loaded high on both factors and were not included, since they were not distinctive.

\section{The Role of the Digital Home Environment}

The second research question addressed the role of the digital home environment. Table 3 shows means and standard deviations of the variables under study. We checked via independent samples $t$-tests whether the (dichotomized) educational level of the main caregiver made a difference regarding the language ability or the level of early literacy of the child. This was not the case [language ability: $t(68)=-0.63, p=0.53, d=0.15$ and early literacy: $t(66)=-0.93, p=0.36, d=0.22]$, and hence this variable was not taken into account in the remaining analyses, to retain statistical power.

Table 4 depicts the correlations between the different variables. As can be seen, traditional measures such as the number of books at home and the non-verbal intelligence are associated with language ability and early literacy, and so are the parental expectations. The table shows that the (traditional) analog home environment is associated with language ability, but not early literacy nor parental expectations. The digital home environment, however, is only associated with parental expectations. The general digital home environment (digital books at home and the number of devices at home) is only related to the number of (paper) books at home, but not to any of the child factors.

The second research question was asked to examine the role of the digital home environment on both language ability and early literacy. While the correlation table already suggests that no direct effect of the digital home environment on language ability or early literacy will be found (i.e., research question $2 \mathrm{a}$ ), the analyses might reveal a mediating effect (i.e., research question $2 \mathrm{~b}$ ).

Regarding language ability, the $R^{2}$ of the final model of the mediation analysis was $0.21(p=0.01)$, with a sample size of 
TABLE 2 | Structure matrix of the principal component analysis on the home literacy questionnaire.

\begin{tabular}{|c|c|c|}
\hline \multirow[t]{2}{*}{ Question } & \multicolumn{2}{|c|}{ Component } \\
\hline & $\begin{array}{l}\text { Digital home literacy } \\
\text { environment (DHLE) }\end{array}$ & $\begin{array}{c}\text { Analog home literacy } \\
\text { environment (AHLE) }\end{array}$ \\
\hline $\begin{array}{l}\text { Digital together: poems and } \\
\text { songs rhymes }\end{array}$ & 0.885 & \\
\hline $\begin{array}{l}\text { Digital alone: poems and } \\
\text { songs, rhymes }\end{array}$ & 0.882 & \\
\hline $\begin{array}{l}\text { Digital together: language } \\
\text { and word games }\end{array}$ & 0.849 & \\
\hline $\begin{array}{l}\text { Digital alone: language and } \\
\text { word games }\end{array}$ & 0.859 & \\
\hline Digital alone: letter naming & 0.720 & \\
\hline $\begin{array}{l}\text { Analog together: stimulating } \\
\text { child to read }\end{array}$ & & 0.741 \\
\hline $\begin{array}{l}\text { Analog alone: looking into } \\
\text { (picture)books }\end{array}$ & & 0.708 \\
\hline $\begin{array}{l}\text { Analog together: reading to } \\
\text { child }\end{array}$ & & 0.691 \\
\hline $\begin{array}{l}\text { Analog together: stimulating } \\
\text { child to write }\end{array}$ & & 0.644 \\
\hline $\begin{array}{l}\text { Analog together: language } \\
\text { and word games }\end{array}$ & 0.719 & 0.610 \\
\hline $\begin{array}{l}\text { Analog alone: language and } \\
\text { word games }\end{array}$ & 0.610 & 0.500 \\
\hline Analog alone: letter naming & 0.445 & 0.623 \\
\hline $\begin{array}{l}\text { Analog together: poems } \\
\text { and songs rhymes }\end{array}$ & 0.622 & 0.715 \\
\hline $\begin{array}{l}\text { Analog alone: poems and } \\
\text { songs rhymes }\end{array}$ & 0.606 & 0.652 \\
\hline
\end{tabular}

TABLE 3 | Descriptive statistics of home literacy environment (HLE) and child abilities. For language ability and early literacy, the factor scores are provided, as well as the sum scores for each subtest.

\begin{tabular}{|c|c|c|c|c|c|}
\hline Variables & $n$ & $M$ & $S D$ & Min & Max \\
\hline Non-verbal intelligence & 70 & 27.40 & 8.42 & 7 & 46 \\
\hline $\begin{array}{l}\text { Language ability (factor } \\
\text { score) }\end{array}$ & 70 & 0 & 1.81 & -4.31 & 2.86 \\
\hline Grammar & 70 & 34.80 & 4.17 & 23 & 41 \\
\hline Vocabulary & 70 & 64.53 & 13.42 & 33 & 85 \\
\hline $\begin{array}{l}\text { Early literacy (factor } \\
\text { score) }\end{array}$ & 68 & -0.01 & 2.65 & -4.49 & 5.66 \\
\hline Begin phoneme & 70 & 6.34 & 3.12 & 0 & 10 \\
\hline Synthesis & 68 & 2.76 & 2.85 & 0 & 10 \\
\hline Grapheme knowledge & 70 & 13.59 & 8.42 & 1 & 31 \\
\hline $\begin{array}{l}\text { Number of books at } \\
\text { home }\end{array}$ & 69 & 2.94 & 0.95 & 1 & 4 \\
\hline $\begin{array}{l}\text { Number of digital } \\
\text { books at home }\end{array}$ & 54 & 1.87 & 1.23 & 1 & 4 \\
\hline $\begin{array}{l}\text { Number of devices at } \\
\text { home }\end{array}$ & 67 & 8.75 & 1.81 & 4 & 12 \\
\hline Analog HLE & 70 & 12.51 & 3.29 & 5 & 20 \\
\hline Digital HLE & 55 & 10.27 & 4.77 & 5 & 22 \\
\hline $\begin{array}{l}\text { Parental expectations } \\
\text { early literacy }\end{array}$ & 68 & 15.56 & 3.49 & 7 & 20 \\
\hline
\end{tabular}

$n=55$. There was no significant effect from the digital home environment on language ability. Both parental expectations and the analog home environment predicted language ability, but there were no indirect effects [indirect effect via analog home environment 95\% CI $(-0.03-0.07)$ and indirect effect via digital home environment 95\% CI (-0.04-0.09)]. Parental expectations were related to the digital, but not analog environment. When adding non-verbal intelligence as a covariate to the model (on the dependent variable), most of the variance was taken away by this measure. The effects of both the analog home environment and the expectations were no longer significant ( $p=0.09$ and $p=0.06$, respectively), while only the effect of non-verbal intelligence was significant $(B=0.09, p=0.003)$. Adding the number of books at home, instead of non-verbal intelligence led to a still significant model, but with none of the variables having a unique effect.

Regarding early literacy, the $R^{2}$ of the final model of the mediation analysis was $0.42(p<0.01)$, with a sample size of $n=54$. There were no significant direct or indirect effects from the analog or digital home environment on early literacy [indirect effect via analog home environment 95\% CI $(-0.01-$ 0.06 ) and indirect effect via digital home environment $95 \%$ CI (-0.13-0.03)]. Only parental expectations predicted early literacy. Parental expectations were related to the digital, but not analog environment. The total effect of parental expectations on early literacy was 0.54 or 0.50 depending on which home environment was mediator or covariate on the dependent variable in the model. When adding non-verbal intelligence or the number of books at home as a covariate to the model (on the dependent variable), the effects remain similar, and neither non-verbal intelligence nor the number of books was a significant predictor of early literacy.

Figures 1A,B show the results.

\section{DISCUSSION}

The goal of the present study was to find out whether a DHLE could be discriminated from an analog home environment and, if so, whether this would have an additional impact on children's language and early literacy. The results suggest that a DHLE can be seen as separate from an AHLE, but that only the latter is related to language ability. Parental expectations strongly related to both language ability and early literacy, but there was no indirect relation via parental activities.

Our first hypothesis was that we would be able to distinguish between an analog and a digital home environment, and we indeed found evidence for this. We had included questions on whether activities were carried out alone by the child or together with the parent. However, results did not show that the "alone" activities were the ones that were done digitally, and the "together" activities the ones that were done together. This indicates that children do not typically play alone with a digital device, while other language and literacy activities are done with their parents. In other words, digital is not the same as alone for these young children. This is in line with results reported by Huber et al. (2018). An easy way to think about the home environment is that a high-literacy environment is a beneficial environment, regardless. However, the current results suggest that the home environment cannot be seen as 
TABLE 4 | Correlations between child abilities and home environment (Spearman), and home literacy environment (Pearson).

\begin{tabular}{|c|c|c|c|c|c|c|c|c|c|c|}
\hline S. No. & & 1 & 2 & 3 & 4 & 5 & 6 & 7 & 8 & 9 \\
\hline 1 & Non-verbal IQ & - & & & & & & & & \\
\hline 2 & Language ability & $0.30^{*}$ & - & & & & & & & \\
\hline 3 & Early literacy & $0.49^{* *}$ & $0.33^{* *}$ & - & & & & & & \\
\hline 4 & Number of books at home & $0.30^{*}$ & $0.37^{* *}$ & -0.02 & - & & & & & \\
\hline 5 & Number of digital books at home & 0.18 & 0.18 & -0.05 & $0.27^{*}$ & - & & & & \\
\hline 6 & Number of devices at home & 0.14 & 0.08 & 0.09 & 0.17 & 0.20 & - & & & \\
\hline 7 & Analog HLE & $0.27^{*}$ & $0.28^{*}$ & 0.20 & 0.19 & 0.08 & 0.05 & - & & \\
\hline 8 & Digital HLE & 0.04 & 0.22 & 0.18 & -0.05 & 0.11 & 0.13 & 0.05 & - & \\
\hline 9 & Parental expectations & 0.16 & $0.40^{* *}$ & $0.65^{* *}$ & 0.14 & 0.14 & 0.22 & 0.17 & $0.43^{* *}$ & - \\
\hline
\end{tabular}

${ }^{*} p<0.05 ;{ }^{* *} p<0.01$.

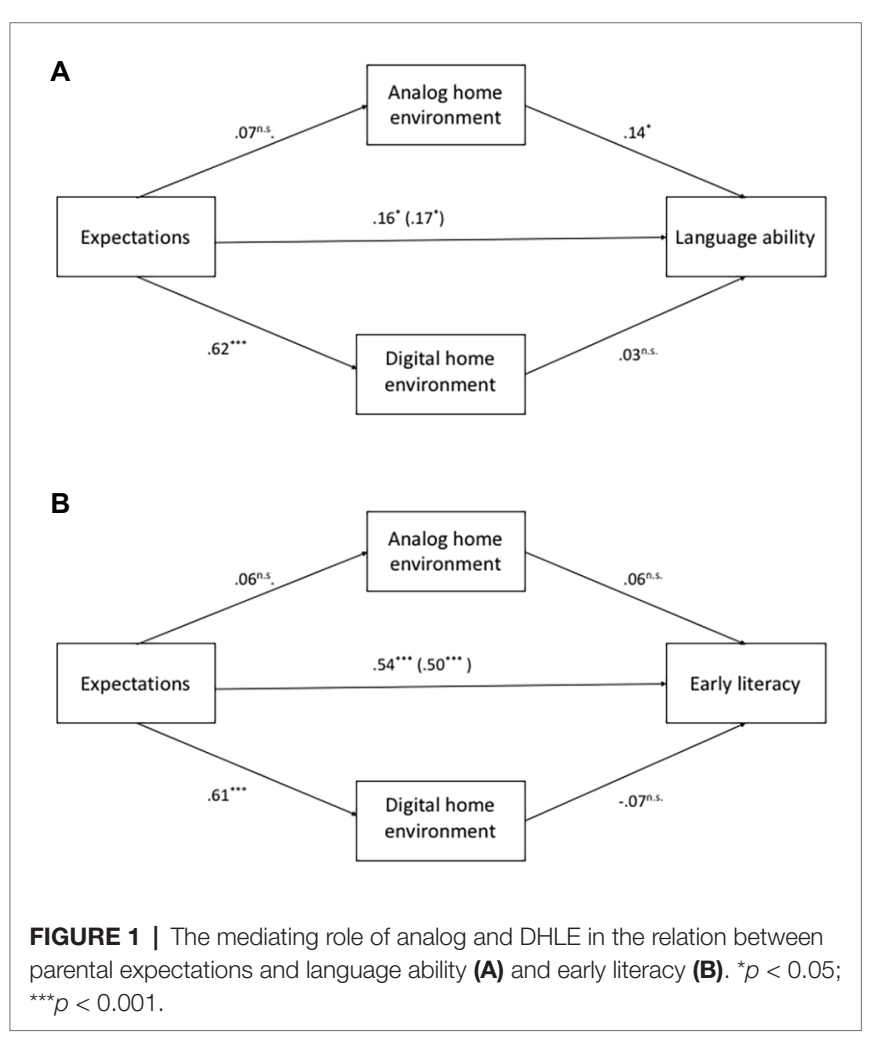

a general factor, and that there is variation in how literacy is addressed at home either analog or digital. The fact that the home environment as such cannot be seen as a general environment is in line with results from Segers et al. (2015) who showed that a literacy environment can be distinguished from a numeracy environment with unique predicting value on literacy and numeracy.

In line with our second hypothesis, we found that the analog home environment was related to language outcomes. We expected effects of the analog home environment to be especially visible regarding language skills. The analog home environment related to language in line with our expectations and previous work (e.g., Sénéchal et al., 1998), but not to literacy. Formal literacy activities have previously been shown to be related to language development (Sénéchal and LeFevre, 2002; Sénéchal, 2006). The questions that remained in the analog home environment factor after we ran the factor analysis, however, did not focus that much on formal literacy activities, as they mostly referred to storybook reading (see Table 2). Those questions that did focus on formal literacy activities had high loadings on both the digital and analog home environment factor and hence excluded from further analyses. More research is clearly needed to further understand this outcome.

In contrast to the second hypothesis, the digital literacy environment as measured in our study was not related to outcome measures regarding language and literacy or to a general measure such as non-verbal intelligence of the child. Similar results were found by Liebeskind et al. (2014) who found little effect of media on language skills of young children. It turns out that the fact that whether children play with language and word games on a computer or do letter naming games is not related to their language and literacy levels. The quality of the apps could very well have played an important role here, and it is a limitation of our study that we did not ask which apps were available at home. In an informal follow-up pilot, we did ask this question to parents of first-graders (Dimmendaal, 2018, unpublished). When asked which language and literacy apps their children played, YouTube was very often mentioned, as well as apps that are low in quality or, for example, use capital letter names instead of lower-case letter sounds. It is interesting to note that parents would mention YouTube as being a language or literacy app (see also Neumann and Herodotou, 2020). Clearly, more research is needed in this area. The results might suggest that the digital environment is rather omnipresent, while the analog home environment is a distinguishable factor in households regarding interest in language and literacy. If, for example, YouTube is used by a young child on a tablet (Neumann and Herodotou, 2020), the contents can have an endless variation in quality. This might suggest that it is not so much the quantity but the quality that matters regarding digital materials (see, e.g., Korat and Shamir, 2012). Also, the quality of the mediating role of the parent (Zaman et al., 2016) will have an impact on the effect of the DHLE. Indeed, we found low, and non-significant, correlations between early literacy skills and tablet use, similar to the results of Neumann (2016). Neumann did show a strong relation between print awareness and number of apps that parents reported and between tablet writing and both print awareness and print knowledge. 
We did not specifically ask about tablet writing or the number of apps on the tablet in our study. However, the number of devices at home or the number of digital books that were reported were not associated with children's language or early literacy either, but only with the number of (paper) books in the home. The availability of materials at home is strongly related to SES and language development (Pace et al., 2017).

Our third hypothesis was that parental expectations would be related to language and early literacy, which would be partly mediated by both the analog and the digital home environment. Indeed, we found parental expectations to be related to both language and literacy, which is in line with results from Martini and Sénéchal (2012), for example. The relation was stronger for literacy, which can be ascribed to the fact that more questions were on literacy expectations than on language expectations. In contrast to previous research, we did not find any indirect effect of parental expectations. This might have a cultural reason, as in the Netherlands, home literacy activities are highly promoted, and parents in general are well aware of the importance of these (see, e.g., McElvany et al., 2012). Whether or not the parent has high expectations of the child would then be less related to how often, for example, the child is being read to at home. It is interesting to note that there was a positive correlation between parental expectations and the digital home environment; parents with higher expectations could be seen as the early adapters who create a more extensive digital literacy environment.

The above discussion already highlighted some limitations of the current study. First, we did not ask about the quality of the apps that were available in the home environment. Second, a substantial part of the sample did not fill out the questions on the digital home environment, and it is not clear why this was the case. In future research, it is recommended to interview the parents to gain more in-depth information about the digital home environment. It should be noted, though, that when we imputed the missing data, the results (both of the factor analyses and of the mediation analyses) remained the same. However, the sample size of the current study is relatively small, and results should therefore be interpreted with caution, also as participants were not the complete population of children in the participating schools, but only those that responded to the invitation. Third, while we asked about the educational level of the parents, research on the effects of the home literacy environment should take genetic factors more into account, by including direct measures of parental reading abilities (see, e.g., Puglisi et al., 2017; van Bergen et al., 2017). This will help to further understand the relation between children's intelligence, parental education, and language and literacy outcomes. Fourth, we used questionnaires

\section{REFERENCES}

Biemiller, A. (2006). "Vocabulary development and instruction: a prerequisite for school learning" in Handbook of early literacy research. Vol. 2. eds. S. Neuman and D. Dickinson (New York: Guilford Press), 41-51.

Burgess, S. R., Hecht, S. A., and Lonigan, C. J. (2002). Relations of the home literacy environment (HLE) to the development of reading-related abilities: to assess the home literacy environment. Observations of the interactions between parents and children will give more insight in the quality of the home literacy environment, while ecological momentary assessments will give insight in real-time day-to-day activities. Finally, we acknowledge that the study had a crosssectional design, so no causal claims can be made. Also, as we used a relatively small convenience sample, generalization of the results should be done with caution. A longitudinal study, in which the impact of both digital and analog home environment on the growth of language and literacy skills can be determined in a broad sample, is needed.

To conclude, we have shown that a DHLE can be distinguished from an analog (more traditional) home environment. The fact that there was no relation between the digital home environment and language and literacy outcomes suggest that there might be large variation in the quality of the digital home environment. More attention is needed to this part of the daily lives of children growing up in a digital society.

\section{DATA AVAILABILITY STATEMENT}

The datasets generated for this study are available on request to the corresponding author.

\section{ETHICS STATEMENT}

Ethical review and approval was not required for the study on human participants in accordance with the local legislation and institutional requirements. Written informed consent to participate in this study was provided by the participants' legal guardian/next of kin.

\section{AUTHOR CONTRIBUTIONS}

ES and TK contributed to conception and design of the study. ES organized the database. ES and TK performed the statistical analysis. ES wrote the first draft of the manuscript. TK wrote sections of the manuscript. Both authors contributed to manuscript revision, read and approved the submitted version.

\section{ACKNOWLEDGMENTS}

We would like to thank Luka Zweekhorst and Maaike van den Oetelaar for their help in designing the questionnaire and collecting data. a one-year longitudinal study. Read. Res. Q. 37, 408-426. doi: 10.1598/ RRQ.37.4.4

Bus, A. G., Takacs, Z. K., and Kegel, C. A. (2015). Affordances and limitations of electronic storybooks for young children's emergent literacy. Dev. Rev. 35, 79-97. doi: 10.1016/j.dr.2014.12.004

Bus, A. G., van IJzendoorn, M. H., and Pellegrini, A. D. (1995). Joint book reading makes for success in learning to read: a meta-analysis on 
intergenerational transmission of literacy. Rev. Educ. Res. 65, 1-21. doi: 10.3102/00346543065001001

Central Bureau of Statistics (2020). Statline. Available at: https://opendata.cbs. $\mathrm{nl} /$ statline/\#/CBS/nl/dataset/83295NED/table?ts=1590160916505 (Accessed May 22, 2020).

Davis-Kean, P. E. (2005). The influence of parent education and family income on child achievement: the indirect role of parental expectations and the home environment. J. Fam. Psychol. 19, 294-304. doi: 10.1037/0893-3200.19.2.294

Esbensen, F. A., Miller, M. H., Taylor, T., He, N., and Freng, A. (1999). Differential attrition rates and active parental consent. Eval. Rev. 23, 316-335. doi: 10.1177/0193841X9902300304

Hamilton, L. G., Hayiou-Thomas, M. E., Hulme, C., and Snowling, M. J. (2016). The home literacy environment as a predictor of the early literacy development of children at family-risk of dyslexia. Sci. Stud. Read. 20, 401-419. doi: 10.1080/10888438.2016.1213266

Hayes, A. F. (2013). Introduction to mediation, moderation, and conditional Process analysis: A regression-based approach. New York, NY: The Guilford Press.

Herodotou, C. (2018). Young children and tablets: a systematic review of effects on learning and development. J. Comput. Assist. Learn. 34, 1-9. doi: 10.1111/ jcal.12220

Holloway, D., Green, L., and Livingstone, S. (2013). Zero to eight. Young children and their internet use. LSE, London: EU Kids Online. Available at: http:// www.eukidsonline.net (Accessed May 22, 2020).

Huber, B., Highfield, K., and Kaufman, J. (2018). Detailing the digital experience: parent reports of children's media use in the home learning environment. Br. J. Educ. Technol. 49, 821-833. doi: 10.1111/bjet.12667

Ihmeideh, F. M. (2014). The effect of electronic books on enhancing emergent literacy skills of pre-school children. Comput. Educ. 79, 40-48. doi: 10.1016/j. compedu.2014.07.008

Kim, J. E., and Anderson, J. (2008). Mother-child shared reading with print and digital texts. J. Early Child. Lit. 8, 213-245. doi: 10.1177/1468798408091855

Korat, O., and Shamir, A. (2012). Direct and indirect teaching: using e-books for supporting vocabulary, word reading, and story comprehension for young children. J. Educ. Comput. Res. 46, 135-152. doi: 10.2190/EC.46.2.b

Krcmar, M., and Cingel, D. P. (2014). Parent-child joint reading in traditional and electronic formats. Media Psychol. 17, 262-281. doi: 10.1080/15213269.2013.840243

Liebeskind, K. G., Piotrowski, J. T., Lapierre, M. A., and Linebarger, D. L. (2014). The home literacy environment: exploring how media and parent-child interactions are associated with children's language production. J. Early Child. Lit. 14, 482-509. doi: 10.1177/1468798413512850

MarketingCharts. (n.d.). "Tablet PC household penetration in the United States from 2012 to 2018" in Statista - The Statistics Portal. Available at: https:// www.statista.com/statistics/736135/tablet-pc-us-household-penetration/ (Accessed: October 16, 2018).

Martini, F., and Sénéchal, M. (2012). Learning literacy skills at home: parent teaching, expectations, and child interest. Can. J. Behav. Sci. 44, 210-221. doi: $10.1037 / \mathrm{a} 0026758$

McElvany, N., van Steensel, R., Guill, K., van Tuijl, C., and Herppich, S. (2012). "Family literacy programs in the Netherlands and in Germany: policies, current programs, and evaluation studies" in Handbook of family literacy. ed. B. H. Wasik (New York: Taylor \& Francis), 339-353.

Mol, S. E., and Bus, A. G. (2011). To read or not to read: a meta-analysis of print exposure from infancy to early adulthood. Psychol. Bull. 137, 267-296. doi: $10.1037 / \mathrm{a} 0021890$

Neumann, M. M. (2016). Young children's use of touch screen tablets for writing and reading at home: relationships with emergent literacy. Comput. Educ. 97, 61-68. doi: 10.1016/j.compedu.2016.02.013

Neumann, M. M. (2018). Maternal scaffolding of preschoolers' writing using tablet and paper-pencil tasks: relations with emergent literacy skills. J. Res. Child. Educ. 32, 67-80. doi: 10.1080/02568543.2017.1386740

Neumann, M. M., and Herodotou, C. (2020). Evaluating YouTube videos for young children. Educ. Inf. Technol. 25, 4459-4475. doi: 10.1007/ s10639-020-10183-7

Pace, A., Luo, R., Hirsh-Pasek, K., and Golinkoff, R. M. (2017). Identifying pathways between socioeconomic status and language development. Annu. Rev. Linguist. 3, 285-308. doi: 10.1146/annurev-linguistics-011516-034226

Pieters, S., Dek, J. E., and Kooij, D. A. P. (2013). RAKIT-2. Psychometrische eigenschappen. [RAKIT-2. Psychometric properties]. Amsterdam: Pearson Assessment and Information BV.
Plowman, L., and McPake, J. (2013). Seven myths about young children and technology. Child. Educ. 89, 27-33. doi: 10.1080/00094056.2013.757490

Puglisi, M. L., Hulme, C., Hamilton, L. G., and Snowling, M. J. (2017). The home literacy environment is a correlate, but perhaps not a cause, of variations in children's language and literacy development. Sci. Stud. Read. 21, 498-514. doi: 10.1080/10888438.2017.1346660

Radesky, J. S., Schumacher, J., and Zuckerman, B. (2015). Mobile and interactive media use by young children: the good, the bad, and the unknown. Pediatrics 135, 1-3. doi: 10.1542/peds.2014-2251

Resing, W. C. M., Bleichrodt, N., Drenth, P. J. D., and Zaal, J. N. (2012). Revisie Amsterdamse kinder intelligentie test 2. Handleiding.[revision Amsterdam child intelligence test 2. Manual]. Amsterdam: Pearson Assessment and Information BV.

Schaars, M. M., Segers, E., and Verhoeven, L. (2017). Word decoding development in incremental phonics instruction in a transparent orthography. Read. Writ. 30, 1529-1550. doi: 10.1007/s11145-017-9735-3

Segers, E., Kleemans, T., and Verhoeven, L. (2015). Role of parent literacy and numeracy expectations and activities in predicting early numeracy skills. Math. Think. Learn. 17, 219-236. doi: 10.1080/10986065.2015.1016819

Sénéchal, M. (2006). Testing the home literacy model: parent involvement in kindergarten is differentially related to grade 4 reading comprehension, fluency, spelling, and reading for pleasure. Sci. Stud. Read. 10, 59-87. doi: 10.1207/s1532799xssr1001_4

Sénéchal, M., and LeFevre, J. A. (2002). Parental involvement in the development of children's reading skill: a five-year longitudinal study. Child Dev. 73, 445-460. doi: 10.1111/1467-8624.00417

Sénéchal, M., Lefevre, J. A., Thomas, E. M., and Daley, K. E. (1998). Differential effects of home literacy experiences on the development of oral and written language. Read. Res. Q. 33, 96-116. doi: 10.1598/RRQ.33.1.5

Sénéchal, M., Whissell, J., and Bildfell, A. (2017). "Starting from home: home literacy practices that make a difference" in Theories of Reading development. eds. K. Cain, D. Compton and R. Parrila (Amsterdam: John Benjamins).

Silinskas, G., Torppa, M., Lerkkanen, M. K., and Nurmi, J. E. (2020). The home literacy model in a highly transparent orthography. Sch. Eff. Sch. Improv. 31, 80-101. doi: 10.1080/09243453.2019.1642213

Takacs, Z. K., Swart, E. K., and Bus, A. G. (2015). Benefits and pitfalls of multimedia and interactive features in technology-enhanced storybooks: a meta-analysis. Rev. Educ. Res. 85, 698-739. doi: 10.3102/0034654314566989

Teepe, R. C., Molenaar, I., and Verhoeven, L. (2017). Technology-enhanced storytelling stimulating parent-child interaction and preschool children's vocabulary knowledge. J. Comput. Assist. Learn. 33, 123-136. doi: 10.1111/jcal.12169

van Bergen, E., van Zuijen, T., Bishop, D., and de Jong, P. F. (2017). Why are home literacy environment and children's reading skills associated? What parental skills reveal. Read. Res. Q. 52, 147-160. doi: 10.1002/rrq.160

van Steensel, R. (2006). Relations between socio-cultural factors, the home literacy environment and children's literacy development in the first years of primary education. J. Res. Read. 29, 367-382. doi: 10.1111/j.1467-9817.2006.00301.x

Verhoeven, L., van Leeuwe, J., Irausquin, R., and Segers, E. (2016). The unique role of lexical accessibility in predicting kindergarten emergent literacy. Read. Writ. 29, 591-608. doi: 10.1007/s11145-015-9614-8

Verhoeven, L., and Vermeer, A. (2006). Taaltoets Alle Kinderen (TAK) [language test all children]. Arnhem: Centraal Instituut voor Toetsontwikkeling.

Verhoeven, L., Voeten, M., van Setten, E., and Segers, E. (2020). Computersupported early literacy intervention effects in preschool and kindergarten: a meta-analysis. Educ. Res. Rev. 30:100325. doi: 10.1016/j.edurev.2020.100325

Zaman, B., Nouwen, M., Vanattenhoven, J., de Ferrerre, E., and van Looy, J. (2016). A qualitative inquiry into the contextualized parental mediation practices of young children's digital media use at home. J. Broadcast. Electron. Media 60, 1-22. doi: 10.1080/08838151.2015.1127240

Conflict of Interest: The authors declare that the research was conducted in the absence of any commercial or financial relationships that could be construed as a potential conflict of interest.

Copyright (c) 2020 Segers and Kleemans. This is an open-access article distributed under the terms of the Creative Commons Attribution License (CC BY). The use, distribution or reproduction in other forums is permitted, provided the original author(s) and the copyright owner(s) are credited and that the original publication in this journal is cited, in accordance with accepted academic practice. No use, distribution or reproduction is permitted which does not comply with these terms. 


\section{OPEN ACCESS}

Edited by:

Frank Niklas,

Ludwig Maximilian University of

Munich, Germany

Reviewed by:

Jo-Anne LeFevre, Carleton University, Canada Maureen Vandermaas-Peeler, Elon University, United States

${ }^{*}$ Correspondence: Belde Mutaf-YIldiz belde.mutaf@gmail.com

Specialty section

This article was submitted to

Educational Psychology, a section of the journal

Frontiers in Psychology

Received: 30 April 2020

Accepted: 27 July 2020

Published: 18 September 2020

Citation:

Mutaf-YIldiz B, Sasanguie $D, D e$ Smedt B and Reynvoet B (2020) Probing the Relationship Between Home Numeracy and Children's Mathematical Skills: A Systematic Review. Front. Psychol. 11:2074. doi: 10.3389/fpsyg.2020.02074

\section{Probing the Relationship Between Home Numeracy and Children's Mathematical Skills: A Systematic Review}

\author{
Belde Mutaf-Yıldız ${ }^{1 *}$, Delphine Sasanguie ${ }^{2}$, Bert De Smedt $^{3}$ and Bert Reynvoet ${ }^{4}$ \\ ${ }^{1}$ Brain and Cognition, Faculty of Psychology and Educational Sciences, KU Leuven, Leuven, Belgium, ${ }^{2}$ Research Centre for \\ Learning in Diversity, HOGENT, Ghent, Belgium, ${ }^{3}$ Parenting and Special Education, Faculty of Psychology and Educational \\ Sciences, KU Leuven, Leuven, Belgium, ${ }^{4}$ Faculty of Psychology and Educational Sciences, KU Leuven Kulak, Kortrijk, \\ Belgium
}

The concept of home numeracy has been defined as parent-child interactions with numerical content. This concept started to receive increasing attention since the last decade. Most of the studies indicated that the more parents and their children engage in numerical experiences, the better children perform in mathematical tasks. However, there are also contrasting results indicating that home numeracy does not play a role or that there is a negative association between the parent-child interactions and children's mathematics performance. To shed light on these discrepancies, a systematic review searching for available articles examining the relationship between home numeracy and mathematical skills was conducted. Thirty-seven articles were retained and a $p$-curve analysis showed a true positive association between home numeracy and children's mathematical skills. A more qualitative investigation of the articles revealed five common findings: (1) Advanced home numeracy interactions but not basic ones are associated with children's mathematical skills. (2) Most participants in the studies were mothers, however, when both parents participated and were compared, only mothers' reports of formal home numeracy activities (i.e., explicit numeracy teaching) were linked to children's mathematical skill. (3) Formal home numeracy activities have been investigated more commonly than informal home numeracy activities (i.e., implicit numeracy teaching). (4) The number of studies that have used questionnaires to assess home numeracy is larger compared with the ones that have used observations. (5) The majority of the studies measured children's mathematical skills with comprehensive tests that index mathematical ability with one composite score rather than with specific numerical tasks. These five common findings might explain the contradictory results regarding the relationship between home numeracy and mathematical skills. Therefore, more research is necessary to draw quantitative conclusions about these five points.

Keywords: home numeracy, mathematical skills, children, systematic review, $p$-curve analysis 


\section{INTRODUCTION}

According to Vygotsky's sociocultural theory (Vygotsky, 1978), culture, community, and social interactions play a fundamental role in children's learning and development. This theoretical framework indicates that people, such as teachers, peers, siblings, and parents, who are present in the environment of children have the power to (educationally) stimulate the children by social interactions, and this process is influenced by environmental factors such as culture and socio-economic status. Especially, the past few years, increasing attention has been paid to understand the learning opportunities brought by parents that affect children's mathematical skills. More specifically, the concept of "home numeracy" has been introduced to describe the various ways in which parents can influence their children's mathematical skills (Blevins-Knabe and Austin, 2016). Most commonly, home numeracy has been operationalized as parent-child interactions related with numerical "activities," such as the frequency of engaging in certain numerical activities or the frequency of using numerical words during certain activities. To a lesser extent, as a part of a home numeracy measure, some researchers also included other indexes, such as parents' academic expectations from their children (e.g., Kleemans et al., 2012) and their own attitudes toward mathematics (e.g., Skwarchuk et al., 2014). However, in this review we use the term "home numeracy" to specifically refer to the parent-child interactions related with numerical "activities" and report findings related to activities only, and not on expectations or attitudes.

Many studies have demonstrated that home numeracy positively correlates with how well-children perform in mathematical tasks (e.g., Blevins-Knabe and Musun-Miller, 1996; LeFevre et al., 2009; Kleemans et al., 2012). On the other hand, some studies reported that home numeracy negatively correlates with children's mathematical abilities (e.g., BlevinsKnabe et al., 2000; Ciping et al., 2015) or has no relation with these at all (e.g., Zhou et al., 2006; Missall et al., 2015). Bearing in mind these contradictory findings, revealing a clear picture of the relationship between home numeracy and mathematical skills is especially important because of the educational impact home numeracy has been suggested to have. First, home numeracy is assumed to explain the variation in kindergartners' early mathematical performance (e.g., LeFevre et al., 2009), which in turn has been shown to affect later mathematical achievement (e.g., Duncan et al., 2007; Gilmore et al., 2010; Sasanguie et al., 2012, 2013). Yet, literature on home numeracy is still in its infancy and lacks a systematic analysis of the available data. Because in the literature there is an abundance of definitions of both home numeracy and mathematical skills, we will first present a clear description of the concepts of home numeracy and mathematical skills.

\section{Home Numeracy}

Different types of home numeracy activities were introduced by LeFevre et al. (2009) based on an analogy with their previous work studying the relation between home literacy activities and children's early literacy skills (e.g., Sénéchal and LeFevre, 2002). LeFevre et al. (2009) developed a comprehensive questionnaire to assess home numeracy via parental self-reports on the frequency of various activities they performed with their child within in a given time frame, e.g., during the last month. Meanwhile, this questionnaire has been used widely. Based on a principal components analysis, the authors suggested that home numeracy activities can be divided into two broad categories, i.e., formal and informal activities. Formal activities are defined as parents' intentional teaching efforts, such as counting objects, practicing simple sums, or reading number story books. Informal activities, on the other hand, consist of parents' unintended teaching that takes place during activities such as playing board or card games, using calendars and reading clocks. LeFevre et al. (2009) reported that both types of activities positively correlate with children's performance in mathematics.

As already mentioned, the origin of the interest in home numeracy goes back to Vygotsky's (1978) sociocultural theory stating that social interactions play a fundamental role in the development of children's cognitive skills. Hereby, Vygotsky emphasized that children's learning is most efficient when knowledgeable others, such as teachers or parents, can identify the level of children's achievement and build their interactions on top of that level, an idea better known as the "Zone of Proximal Development (ZPD)." In accordance with the idea of ZPD, it has been suggested that home numeracy activities can be further divided into two categories based on difficulty level: basic and advanced activities (Skwarchuk, 2009; Skwarchuk et al., 2014). The distinction between basic and advanced activities of course depends on children's age and performance level. For instance, basic activities describe easier number practices, such as counting or recognizing written numbers, whereas advanced activities rather refer to more difficult number practices, such as teaching calculations, for $\sim 5$ year-olds. Therefore, it can be expected that practicing basic activities that children can already do by themselves does not result in improvement; however, practicing advanced activities that are just beyond children's achievement level provides opportunities for improvement.

Another common method to assess home numeracy is through observation (e.g., Levine et al., 2010). Typically, in an observation study, parent-child dyads are observed while they engage in either daily routine activities at home, such as making dinner (i.e., unstructured observations), or during pre-specified activities, such as book reading or playing with Lego blocks, that are preset by researchers at home or in laboratories (i.e., semi-structured observations). In a next step, the recordings are transcribed to reveal the frequency of the numeracy talk. In other words, observation studies do not investigate how often parents and their children engage in numerical activities; instead they focus on how often parents and their children utter numerical words during certain activities. Furthermore, the numeracy talk can be classified based on its content. For instance, Gunderson and Levine (2011) categorized different types of numeracy talk, such as counting objects and naming cardinal values of objects. Classification of numeracy talk also allows for a distinction similar to basic and advanced activities. For instance, basic numeracy talk (e.g., about numbers smaller than 4) and advanced numeracy talk (e.g., about numbers larger than 4) can 
be distinguished relative to children's age (e.g., Gunderson and Levine, 2011).

Although numeracy-related interactions have been proposed as a unique predictor of children's mathematical skills, Anders et al. (2012) observed that not only home numeracy but also home literacy-related interactions were associated with children's mathematical skills. Therefore, some researchers argued that home literacy and numeracy environments are not completely independent from one another, but rather form a more global construct, i.e., the Home Learning Environment (HLE; Melhuish et al., 2008; Dearing et al., 2012; Baker, 2015; Niklas and Schneider, 2017). The HLE is most commonly assessed via questionnaires asking about a wider range of activities, both numerical and non-numerical (e.g., frequency of going to library, painting, drawing, or playing dice games), and family possessions (e.g., number of books or access to educational software at home).

Another factor that affects both parents' engagement in home numeracy activities (e.g., Starkey et al., 1999) and children's mathematical skills (e.g., Siegler and Ramani, 2008) is socio-economic status (SES), mostly operationalized as parents' education level and household income (e.g., Jordan et al., 2006; Dubow et al., 2009). It has been suggested that home numeracy activities are related with SES (Niklas and Schneider, 2017; see for a review, Elliott and Bachman, 2018). A recent meta-analysis has documented that the positive associations of home numeracy activities were larger in high-SES families compared with lowSES families (Dunst et al., 2017). However, the direction of the relation is not very clear, as also negative associations between parents' education level and their engagement in home numeracy activities have been reported (e.g., LeFevre et al., 2010a; Niklas and Schneider, 2014). Therefore, we will include SES as a sample characteristic in this review.

\section{Mathematical Skills}

In the present review, "mathematical skills" refer to a wide range of skills (e.g., non-symbolic and symbolic number discrimination, counting, and arithmetic) that studies have used to correlate with home numeracy. Theoretically, mathematical skills can be divided into two categories; informal and formal (Baroody and Ginsburg, 1990). Informal skills are basic skills that are learned through everyday activities, such as non-symbolic number processing and counting skills (e.g., Purpura et al., 2013). Non-symbolic number processing is suggested to rely on an innate ability to approximately represent, understand and manipulate non-symbolic (e.g., dot arrays) magnitudes (Dehaene, 2001). This representation is typically measured with a non-symbolic comparison task, i.e., a task in which participants have to indicate the larger of two dot arrays (e.g., Piazza et al., 2004) or with a non-symbolic number line estimation task, i.e., a task in which participants have to place a dot array on an empty line going from, e.g., $0-10$ dots (e.g., Sasanguie et al., 2012). Another informal basic skill is counting. It is assumed that verbal rote counting is first practiced as a routine by mimicking others such as parents and teachers, or by singing counting songs (Wynn, 1990) at an age of around 2. However, understanding that each number in the counting list represents one and only one entity in the sequence, i.e., the so-called "oneto-one correspondence," and that the last number in the counting list represents the total number of entities in a set, i.e., the "cardinality principle," are skills that are only acquired from around the age of three and a half (Gelman and Meck, 1983; Wynn, 1990). All these different subskills have been commonly measured with different tasks, such as verbal counting, i.e., counting as high as possible (e.g., Geary et al., 2018) and givea-number tasks, i.e., choosing a given number of entity from a set (Wynn, 1990).

Formal skills are more advanced and require knowledge of symbolic numbers, such as Arabic digits and written number words, which are learned through cultural education and/or direct instructions. Examples of formal skills are for instance symbolic number processing and arithmetic (Baroody and Ginsburg, 1990). Symbolic number processing is the ability to understand and manipulate digits and number words (Dehaene, 2011). Often, this skill is measured with symbolic versions of the comparison task (e.g., Bugden and Ansari, 2011) and number line estimation task (e.g., Siegler and Booth, 2004) that were explained earlier. Another formal, mathematical skill-which is also commonly addressed in home numeracy studies-is arithmetic. Measures of arithmetic skills can tap into accuracy, i.e., solving as many questions correctly, and/or fluency, i.e., solving questions correctly as fast as possible, or making calculations. All these formal and informal skills can be examined with separate specific tasks, but they also can be part of a mathematical test of which performance is then averaged into a composite score. For instance, the Test of Early Mathematics Ability (TEMA, Ginsburg and Baroody, 1990) consists of two subtests: one for formal and one for informal mathematical abilities. The informal subtest measures concepts of relative magnitude and counting skills, whereas the formal subtest measures skills, such as calculation, reading and writing numerals, knowledge of number facts, calculation algorithms, and base 10 concepts. The majority of studies have investigated the role of home numeracy evaluating children's performance based on a composite score of either each subtest separately or both subtests combined.

\section{The Present Study}

Home numeracy on the one hand and mathematical skills on the other hand have been operationalized and measured in various ways in different studies. Therefore, in the current systematic literature review, we aimed to systematically investigate the relationship between home numeracy and children's mathematical skills, by taking the diversities in how both constructs were measured into consideration. Furthermore, to test whether this relationship has a true effect or the findings of the reviewed studies were result of a publication bias, we conducted a p-curve analysis (Simonsohn et al., 2013; Simonsohn et al., 2014).

\section{METHOD}

A systematic review study (Grant and Booth, 2009) was conducted to obtain a comprehensive overview of the studies 


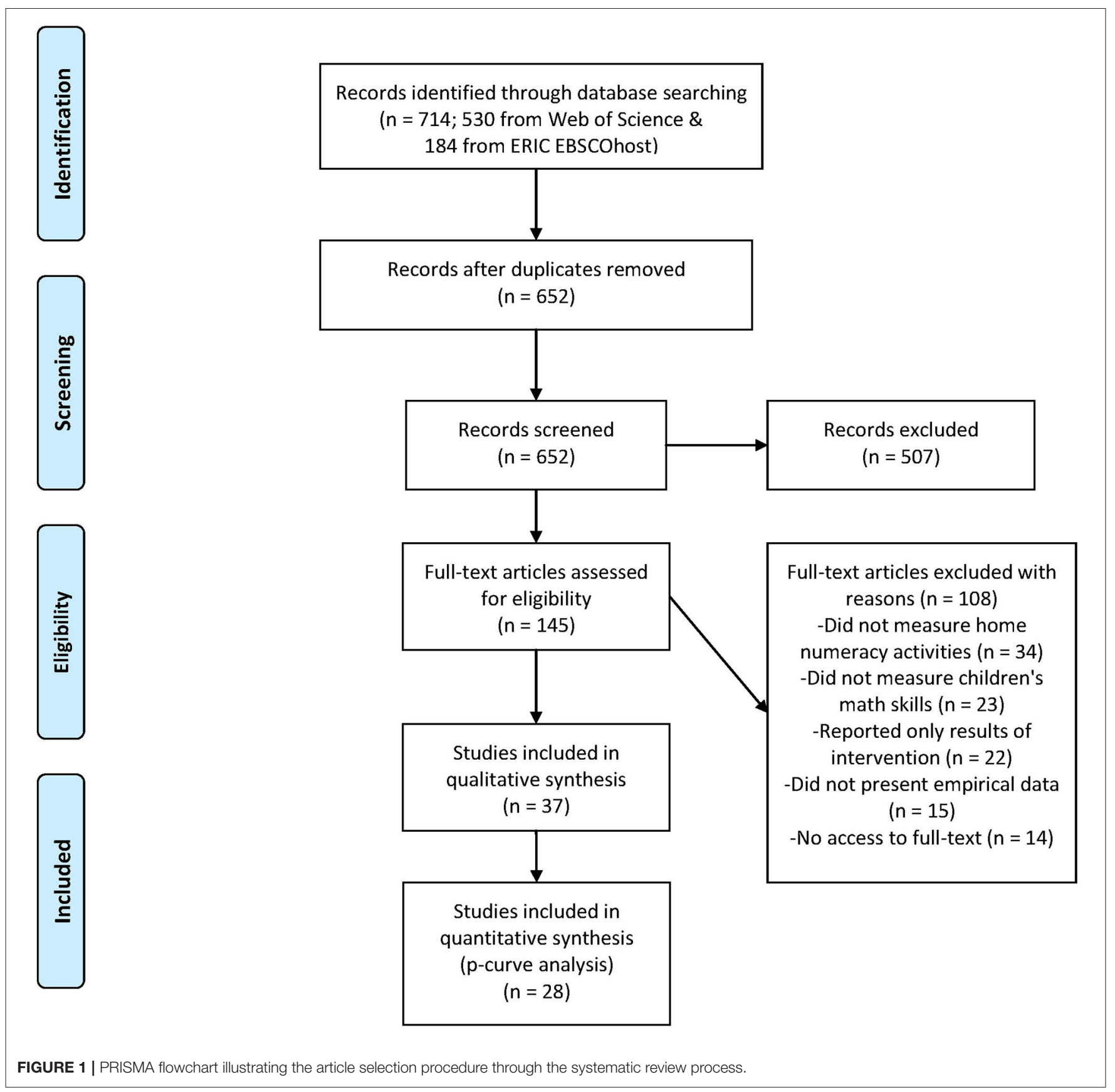

that investigated the relationship between home numeracy and children's mathematical skills. Articles were selected in four steps: First, the two most important databases in the field of psychological and educational research were scanned to reach all relevant articles as possible. Second, the abstracts of the articles were screened by three independent raters (i.e., the first, second and fourth author of this article) taking into account the inclusion and exclusion criteria that are described later. Third, the selected articles were read in full and screened taking into account the additional exclusion criteria described below. Lastly, the final subset of articles was analyzed in detail. An overview of the selection process is presented in Figure 1.

\section{Systematic Search}

The online databases ERIC (EBSCOhost) and Web of Science (SSCI) were scanned to reach potentially relevant articles. Our search strategy was limited to peer-reviewed journal articles written in English. We searched for all articles that were published up to November 2019. The search string was as follows: (child* OR kindergart* OR preschool*) AND (numer* OR "number sense") AND ("home numeracy" OR "home learning" OR "parent talk" OR parent* OR SES* OR socio*) AND (math* OR arithmet* OR calculation OR performance). This yielded 714 hits in total (530 from Web of Science and 184 from ERIC). From these, 62 articles were overlapping and therefore 


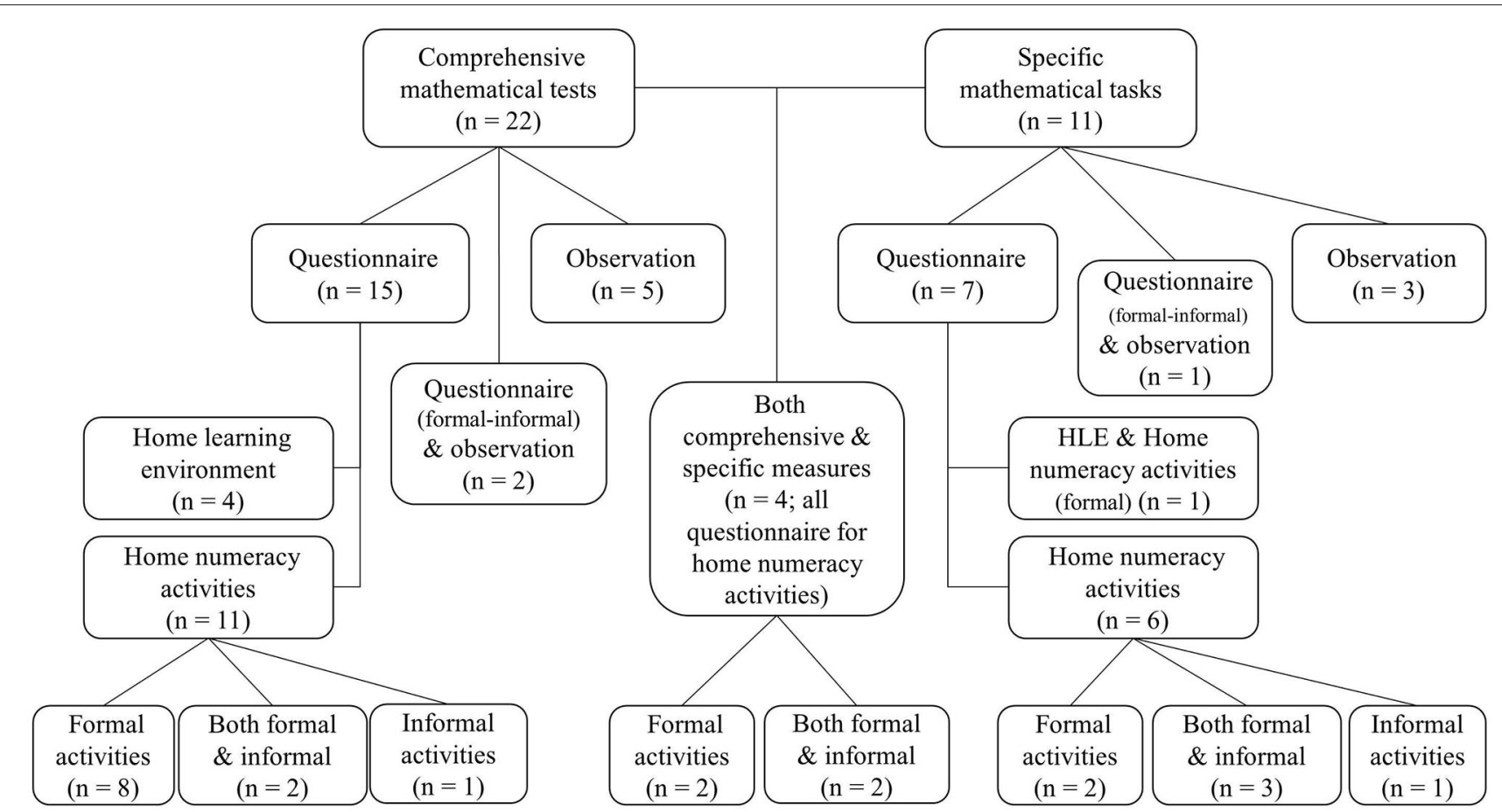

FIGURE 2 | Summary and organizational chart of the reviewed articles.

eliminated. Consequently, we ended up with 652 articles for abstract screening.

\section{Abstract Screening}

The abstracts were read and evaluated by three independent raters: The first author of this study screened all the abstracts, in combination with the second and the fourth authors who shared and screened the abstracts in halves. In other words, every abstract was read by two raters. The raters scored the relevancy for the review on a three-point scale: $1=$ "relevant" if home numeracy (i.e., frequency of activities and talk, but not parents' expectations, attitudes, or SES) was measured as the independent variable and children's mathematical skills were examined as the dependent variable $(n=74) ; 2=$ "maybe relevant" if the assessment of one of the independent or dependent variables was not clearly mentioned in the abstract $(n=71) ; 3=$ "not relevant" if the study was not about home numeracy and mathematical skills at all $(n=507)$. Cohen's Kappa $(\kappa)$ was calculated to determine the level of agreement between the raters (Cohen, 1960). This agreement was substantial, $\kappa=0.736, p<0.001$ (e.g., $\mathrm{McHugh}, 2012)$. The disagreements on the ratings of the articles were overcome via discussions. All papers that were categorized as "related" and "maybe related" $(n=145)$ were entered into the next phase of full-text screening.

\section{Full-Text Screening}

In the full-text screening, all the articles were read in full by the first author and additional inclusion and exclusion criteria were applied: First, in the current study, "home numeracy" was defined as the parent-child interactions that include activities with numerical content. Therefore, the articles that operationalized "home numeracy" in another way (e.g., as parents' attitudes, expectations, perceived parental involvement, or family sociodemographics) were excluded $(n=34)$. Second, articles that did not measure any form of children's mathematical skills but tested for example parents' or teachers math skills were excluded ( $n$ $=23$ ). Third, articles that reported only intervention but not pretest data were excluded $(n=22)$. Fourth, articles that did not present original, empirical data (e.g., reviews, project reports) were excluded $(n=15)$. Fifth, articles of which the full text could not be retrieved online were not included $(n=14)$. Hence, after full-text screening, 108 articles were additionally eliminated. As a result, 37 articles were analyzed in this review.

\section{RESULTS}

Some commonalities were observed regarding the operationalization of both mathematical skills and home numeracy. Therefore, the studies were reviewed in two hierarchical levels (see Figure 2): At the higher level, we distinguished between the ways mathematical skills were operationalized, i.e., (A) comprehensive mathematical tests, which reveal a composite score from more than one task, (B) specific mathematical task(s), which reveal a single score of one task, or (C) both. At the next level, we distinguished between the methods used to evaluate home numeracy, i.e., (1) questionnaire, (2) observation, or (3) both, and elaborated on the assessment details. Finally, all the results were compiled and a $p$-curve 
TABLE 1 | Detailed overview of the reviewed studies.

\begin{tabular}{|c|c|c|c|c|c|c|c|}
\hline References & $\begin{array}{l}\text { Sample size and } \\
\text { children's age in years }\end{array}$ & $\begin{array}{l}\text { Sample location/ethnicity } \\
\text { and SES }\end{array}$ & Home numeracy measure & Comprehensive mathematical tests & $\begin{array}{l}\text { Specific mathematical } \\
\text { tasks }\end{array}$ & Results & $\begin{array}{l}\text { Recomputed } \\
p \text {-values }\end{array}$ \\
\hline \multicolumn{8}{|l|}{ Section A.1 } \\
\hline $\begin{array}{l}\text { Huntsinger et al. } \\
\text { (1997) }\end{array}$ & $\begin{array}{l}N: 120 \\
M_{\text {age }}: 5.6\end{array}$ & $\begin{array}{l}\text { Ethnicity: } \\
\text { Euro-American, } \\
\text { Chinese-American, } \\
\text { Taiwan-Chinese } \\
\text { SES: high }\end{array}$ & $\begin{array}{l}\text { Questionnaire: } \\
\text { Formal activities }\end{array}$ & $\begin{array}{l}\text { Test of Early Mathematics Ability (TEMA-2; } \\
\text { Ginsburg and Baroody, 1990): Informal } \\
\text { (relative magnitude, counting) and Formal } \\
\text { (number facts, calculation, and base-ten } \\
\text { concepts) mathematics subtests }\end{array}$ & - & $\begin{array}{l}\text { Significant paths: } \\
\text { Formal activities } \rightarrow \\
\text { composite math } \\
\left(\beta=0.23^{\star \star}\right)\end{array}$ & Not reported \\
\hline $\begin{array}{l}\text { Kleemans et al. } \\
\text { (2012) }\end{array}$ & $\begin{array}{l}N: 89 \\
M_{\text {age }}: 6.1\end{array}$ & $\begin{array}{l}\text { Location: } \\
\text { The Netherlands } \\
\text { SES: high }\end{array}$ & $\begin{array}{l}\text { Questionnaire; Formal } \\
\text { activities (adapted from } \\
\text { LeFevre et al., 2009) }\end{array}$ & $\begin{array}{l}\text { Utrecht Early Numeracy Test-Revised (Van } \\
\text { Luit and Van de Rijt, 2009); comparison, } \\
\text { linking quantities, correspondence, arranging, } \\
\text { counting, estimation skills, knowledge of } \\
\text { ordinal and cardinal aspects of number } \\
\text { system, and ability to apply knowledge of the } \\
\text { number system }\end{array}$ & - & $\begin{array}{l}\text { Significant regressions: } \\
\text { Formal activities } \rightarrow \\
\text { composite math } \\
\left(\beta=0.33^{\star}\right)\end{array}$ & $\begin{array}{l}t_{(87)}=3.82 \\
p=0.00025\end{array}$ \\
\hline $\begin{array}{l}\text { Segers et al. } \\
\text { (2015) }\end{array}$ & $\begin{array}{l}N: 60 \\
M_{\text {age }}: 5.7\end{array}$ & $\begin{array}{l}\text { Location: } \\
\text { The Netherlands } \\
\text { SES: middle }\end{array}$ & $\begin{array}{l}\text { Questionnaire; } \\
\text { Formal activities (adapted } \\
\text { from Kleemans et al., 2012) }\end{array}$ & Utrecht Early Numeracy Test-Revised & - & $\begin{array}{l}\text { Significant regressions: } \\
\text { Formal activities } \\
\rightarrow \text { composite math } \\
\left(\beta=0.45^{\star \star}\right)\end{array}$ & $\begin{array}{l}t_{(50)}=3.53 \\
p=0.00090\end{array}$ \\
\hline $\begin{array}{l}\text { Cheung et al. } \\
\text { (2018) }\end{array}$ & $\begin{array}{l}N: 673 \\
M_{\text {age }}: 4.3\end{array}$ & $\begin{array}{l}\text { Location: Philippines } \\
\text { SES: Iow to middle }\end{array}$ & $\begin{array}{l}\text { Questionnaire: } \\
\text { Formal activities (adapted } \\
\text { from LeFevre et al., 2009) }\end{array}$ & $\begin{array}{l}\text { Composite math score from six tasks: } \\
\text { numeral identification, object counting, rote } \\
\text { counting, missing number, numerical } \\
\text { magnitude comparison, addition }\end{array}$ & - & $\begin{array}{l}\text { Significant result of } \\
\text { interest: None }\end{array}$ & Not available \\
\hline $\begin{array}{l}\text { Anders et al. } \\
\text { (2012) }\end{array}$ & $\begin{array}{l}\text { N: } 532 \\
M_{\text {age: }}: \text { T1: } 3.7 \\
\text { T2: } 4.7 \\
\text { T3: } 5: 7\end{array}$ & $\begin{array}{l}\text { Location: Germany } \\
\text { SES: diverse }\end{array}$ & $\begin{array}{l}\text { Questionnaire: } \\
\text { Formal activities and } \\
\text { interactions (from the Home } \\
\text { Observation for } \\
\text { Measurement of the } \\
\text { Environment Inventory, } \\
\text { HOME; Caldwell and } \\
\text { Bradley, 1984, and Family } \\
\text { Rating Scale; Kuger et al., } \\
\text { 2005) }\end{array}$ & $\begin{array}{l}\text { The German version of Kaufman Assessment } \\
\text { Battery for Children (KABC; Melchers and } \\
\text { Preuss, 2003): Counting, identifying numbers, } \\
\text { knowledge of shapes, and addition } \\
\text { and subtraction }\end{array}$ & - & $\begin{array}{l}\text { Linear growth: } \\
\text { Formal activities at T1 } \rightarrow \\
\text { composite math at T2 } \\
\text { and T3 } \\
\left(b=0.14^{*}\right)\end{array}$ & $\begin{array}{l}t_{(530)}=2.8 \\
p=0.00530\end{array}$ \\
\hline $\begin{array}{l}\text { Napoli and } \\
\text { Purpura (2018) }\end{array}$ & $\begin{array}{l}\text { N: } 114 \\
M_{\text {age }}: \text { T1: } 4.1 \\
\text { T2: } 4.6\end{array}$ & $\begin{array}{l}\text { Location: USA } \\
\text { SES: middle to high }\end{array}$ & $\begin{array}{l}\text { Questionnaire; } \\
\text { Formal activities (adapted } \\
\text { from LeFevre et al., 2009) } \\
\text { at T1 }\end{array}$ & $\begin{array}{l}\text { Preschool Early Numeracy Skills } \\
\text { Screener-Brief version (PENS-B; Purpura } \\
\text { et al., 2015); Comparison, one-to-one } \\
\text { correspondence, and ordinarily }\end{array}$ & - & $\begin{array}{l}\text { Significant correlations: } \\
\text { Formal activities at T1 } \\
\text { and composite math at } \\
\text { T2 } \\
\left(r=0.40^{\star \star \star}\right)\end{array}$ & $\begin{array}{l}r_{(112)}=0.40 \\
p=0.00001\end{array}$ \\
\hline $\begin{array}{l}\text { Del Rio et al. } \\
\text { (2017) }\end{array}$ & $\begin{array}{l}N: 180 \\
\text { (mothers \& fathers) } \\
M_{\text {age }}: 5.6\end{array}$ & $\begin{array}{l}\text { Location: Chile } \\
\text { SES: Iow and high }\end{array}$ & $\begin{array}{l}\text { Questionnaire; } \\
\text { Advanced formal activities } \\
\text { (adapted from Skwarchuk } \\
\text { et al., 2014) }\end{array}$ & $\begin{array}{l}\text { Applied Problems subset of the } \\
\text { Woodcock-Munoz Bateria III } \\
\text { (Muñoz-Sandoval et al., 2005); Orally and } \\
\text { visually presented numeration and } \\
\text { calculations }\end{array}$ & - & $\begin{array}{l}\text { Significant correlations: } \\
\text { Advanced formal } \\
\text { activities of mothers and } \\
\text { composite math } \\
\left(r=0.21^{\star \star}\right)\end{array}$ & $\begin{array}{l}r_{(178)}=0.21 \\
p=0.00466\end{array}$ \\
\hline $\begin{array}{l}\text { Zippert and } \\
\text { Ramani (2017) }\end{array}$ & $\begin{array}{l}N: 43 \\
M_{\text {age }}: 4.5\end{array}$ & $\begin{array}{l}\text { Location: USA } \\
\text { SES: middle to high }\end{array}$ & $\begin{array}{l}\text { Questionnaire; } \\
\text { Basic and advanced } \\
\text { formal activities }\end{array}$ & $\begin{array}{l}\text { Conventional math; rote counting, counting } \\
\text { principles, numeral identification } \\
\text { Non-symbolic math; non-symbolic magnitude } \\
\text { comparison and addition } \\
\text { Advanced math; symbolic magnitude } \\
\text { comparison and arithmetic }\end{array}$ & - & $\begin{array}{l}\text { Significant correlations: } \\
\text { Advanced formal } \\
\text { activities and composite } \\
\text { advanced math } \\
\left(r=0.41^{\star *}\right)\end{array}$ & $\begin{array}{l}r_{(41)}=0.41 \\
p=0.00632\end{array}$ \\
\hline
\end{tabular}




\begin{tabular}{|c|c|c|c|c|c|c|c|}
\hline References & $\begin{array}{l}\text { Sample size and } \\
\text { children's age in years }\end{array}$ & $\begin{array}{l}\text { Sample location/ethnicity } \\
\text { and SES }\end{array}$ & Home numeracy measure & Comprehensive mathematical tests & $\begin{array}{l}\text { Specific mathematical } \\
\text { tasks }\end{array}$ & Results & $\begin{array}{l}\text { Recomputed } \\
p \text {-values }\end{array}$ \\
\hline $\begin{array}{l}\text { Niklas and } \\
\text { Schneider (2014) }\end{array}$ & $\begin{array}{l}\text { N: } 340 \\
M_{\text {age }}: \text { T1: } 4.8 \\
\text { T2: } 6.1 \\
\text { T3: beginning of grade } 1 \\
\text { T4: end of grade } 1\end{array}$ & $\begin{array}{l}\text { Location: Germany } \\
\text { SES: diverse }\end{array}$ & $\begin{array}{l}\text { Questionnaire: } \\
\text { Informal (game) activities } \\
\text { at T2 }\end{array}$ & $\begin{array}{l}\text { Math battery at T1 and T2 (Krajewski, 2005): } \\
\text { counting, naming numbers, solving simple } \\
\text { calculations, matching, comparing quantities } \\
\text { Performance Indicators in Primary School } \\
\text { (PIPS; Tymms and Albone, 2002): } \\
\text { calculations, naming 2-3-digit numbers, } \\
\text { geometry at T3 } \\
\text { "Deutscher Mathematiktest fur erste Klassen" } \\
\text { (DEMAT 1+; Krajewski et al., 2002) solving } \\
\text { written math problems, linking numbers } \\
\text { to quantities }\end{array}$ & - & $\begin{array}{l}\text { Structural Equation } \\
\text { Modeling: } \\
\text { Informal activities } \rightarrow \\
\text { composite math at } \mathrm{T} 4 \\
\left(\beta=0.18^{\star}\right)\end{array}$ & $\begin{array}{l}r_{(338)}=0.15 \\
p=0.00558\end{array}$ \\
\hline $\begin{array}{l}\text { Ciping et al. } \\
\text { (2015) }\end{array}$ & $\begin{array}{l}\text { N: } 177 \\
\text { Mage: T1: } 6.7 \\
\text { T2: } 7.7\end{array}$ & $\begin{array}{l}\text { Location: China } \\
\text { SES: diverse }\end{array}$ & $\begin{array}{l}\text { Questionnaire; } \\
\text { Formal and informal } \\
\text { activities (adapted from } \\
\text { LeFevre et al., 2009) at T1 } \\
\text { and T2 }\end{array}$ & $\begin{array}{l}\text { Composite score of calculation fluency and } \\
\text { Omitted number task at } \mathrm{T} 1 \text { and } \mathrm{T} 2\end{array}$ & - & $\begin{array}{l}\text { Significant paths: } \\
\text { Composite math at } \mathrm{T} 1 \\
\rightarrow \text { formal activities at T2 } \\
\left(\beta=-0.15^{\star}\right)\end{array}$ & $\begin{array}{l}r_{(175)}=-0.18 \\
p=0.01651\end{array}$ \\
\hline $\begin{array}{l}\text { Huntsinger et al. } \\
\text { (2016) }\end{array}$ & $\begin{array}{l}\text { N: } 97 \\
\text { Mage: T1: } 4.9 \\
\text { T2: } 5.8\end{array}$ & $\begin{array}{l}\text { Location: USA } \\
\text { SES: middle }\end{array}$ & $\begin{array}{l}\text { Questionnaire: } \\
\text { Formal and informal } \\
\text { activities at } \mathrm{T} 1\end{array}$ & TEMA-2: Formal and informal subtests at T2 & - & $\begin{array}{l}\text { Significant regressions: } \\
\text { Formal activities at } \mathrm{T} 1 \\
\rightarrow \text { composite math at } \mathrm{T} 2 \\
\left(\beta=0.13^{\star \star}\right)\end{array}$ & $\begin{array}{l}z=2.43 \\
p=0.01510\end{array}$ \\
\hline Baker (2015) & $\begin{array}{l}\text { N: } 1,202 \\
\text { (boys and mothers) } \\
\text { Mage: } 5.6\end{array}$ & $\begin{array}{l}\text { Ethnicity: } \\
\text { African-American } \\
\text { SES: diverse }\end{array}$ & $\begin{array}{l}\text { Questionnaire: } \\
\text { Home learning environment } \\
\text { (HLE) (adapted from LeFevre } \\
\text { et al., 2009) }\end{array}$ & $\begin{array}{l}\text { Math test battery: } \\
\text { Understanding of numbers, geometry, and } \\
\text { spatial relations }\end{array}$ & - & $\begin{array}{l}\text { Significant regressions: } \\
\text { HLE } \rightarrow \text { composite math } \\
\left(\beta=0.06^{*}\right)\end{array}$ & $\begin{array}{l}r_{(1,200)}=0.08 \\
p=0.00552\end{array}$ \\
\hline $\begin{array}{l}\text { Melhuish et al. } \\
\text { (2008) }\end{array}$ & $\begin{array}{l}\text { N: } 2,354 \\
\text { Mage: T1: } 3 \\
\text { T2: } 5 \\
\text { T3: } 7\end{array}$ & $\begin{array}{l}\text { Location: UK } \\
\text { SES: diverse }\end{array}$ & $\begin{array}{l}\text { Questionnaire: } \\
\text { Home learning environment } \\
\text { (HLE) at T1 }\end{array}$ & $\begin{array}{l}\text { Early Number Concepts subscale of the } \\
\text { British Ability Scales (BAS II; Elliot et al., 1996) } \\
\text { at T2: details not provided } \\
\text { Nationally standardized math achievement } \\
\text { test at T3 }\end{array}$ & - & $\begin{array}{l}\text { Significant regressions: } \\
\text { HLE } \rightarrow \text { composite math } \\
\text { at T2 (effect size }=0.65 \text { ) } \\
\text { and T3 (effect size } \\
=0.50 \text { ) }\end{array}$ & Not reported \\
\hline $\begin{array}{l}\text { Niklas and } \\
\text { Schneider (2017) }\end{array}$ & $\begin{array}{l}N: 434 \\
M_{\text {age }}: \text { T1: } 4.8 \\
\text { T2: end of grade } 1 \\
\text { T3: middle of grade } 4\end{array}$ & $\begin{array}{l}\text { Location: Germany } \\
\text { SES: Iow to medium }\end{array}$ & $\begin{array}{l}\text { Questionnaire: } \\
\text { Home learning environment } \\
\text { (HLE) at T1 }\end{array}$ & $\begin{array}{l}\text { Math battery (Krajewski, 2005) at T1 } \\
\text { DEMAT } 1+\text { at T2 } \\
\text { Standardized and curriculum-based test } \\
\text { KLASSE } 4 \text { (Lenhard et al., 2011): geometrical } \\
\text { and written math problems at T3 }\end{array}$ & - & $\begin{array}{l}\text { Significant regressions: } \\
\text { HLE } \rightarrow \text { composite math } \\
\text { at T3 }\left(\beta=0.72^{\star \star}\right)\end{array}$ & $\begin{array}{l}t_{(432)}=2.98 \\
p=0.00305\end{array}$ \\
\hline Visser et al. (2019) & $\begin{array}{l}\text { N: } 10376 \\
M_{\text {age }}: \text { T1: pre-Grade } 1 \\
\text { T2: Grade } 5\end{array}$ & $\begin{array}{l}\text { Location: South Africa } \\
\text { SES: diverse }\end{array}$ & $\begin{array}{l}\text { Questionnaire: } \\
\text { Home learning environment } \\
\text { (HLE): reading-writing, } \\
\text { playing games, } \\
\text { songs-stories at T1 }\end{array}$ & Math Achievement test at T2 & - & $\begin{array}{l}\text { Significant regressions: } \\
\text { Game-based HLE at T1 } \\
\rightarrow \text { Math skills at T2 }(\beta= \\
\left.0.17^{\star \star \star}\right)\end{array}$ & $\begin{array}{l}r_{(10,374)}=0.19 \\
p \leq 0.00001\end{array}$ \\
\hline \multicolumn{8}{|l|}{ Section A.2 } \\
\hline Elliott et al. (2017) & $\begin{array}{l}N: 54 \\
\text { (mothers) } \\
\text { Mage: } 5.8\end{array}$ & $\begin{array}{l}\text { Location: USA } \\
\text { SES: high }\end{array}$ & $\begin{array}{l}\text { Observation: } \\
\text { Semi-structured play for } \\
10 \text { min with toys, such as } \\
\text { books, kitchen tools, } \\
\text { puppets, cash register }\end{array}$ & $\begin{array}{l}\text { Form A of TEMA-3: } \\
\text { Verbal counting, comparison, numeral literacy, } \\
\text { number facts, calculation, number concepts }\end{array}$ & - & $\begin{array}{l}\text { Significant regressions: } \\
\text { Maternal advanced math } \\
\text { talk } \rightarrow \text { composite math } \\
\left(\beta=0.42^{*}\right)\end{array}$ & $\begin{array}{l}r_{(52)}=0.39 \\
p=0.00355\end{array}$ \\
\hline Leyva (2019) & $\begin{array}{l}N: 210 \\
M_{\text {age }}: \text { T1: beginning of } \\
\text { prekindergarten } \\
\text { T2: end of kindergarten }\end{array}$ & $\begin{array}{l}\text { Location: Chile } \\
\text { SES: low }\end{array}$ & $\begin{array}{l}\text { Observation: } \\
\text { Parent-child interaction } \\
\text { during grocery game play } \\
\text { at T1 }\end{array}$ & $\begin{array}{l}\text { Applied Problems subset of the } \\
\text { Woodcock-Muñoz Bateria III (among other } \\
\text { skills, counting, comparing quantities, adding, } \\
\text { and/or subtracting) at T2 }\end{array}$ & - & $\begin{array}{l}\text { Significant relations: } \\
\text { Math support at } \mathrm{T} 1 \rightarrow \\
\text { Math skills at } \mathrm{T} 2(d \\
=0.13)\end{array}$ & Not reported \\
\hline
\end{tabular}


TABLE 1 | Continued

\begin{tabular}{|c|c|c|c|c|c|c|c|}
\hline References & $\begin{array}{l}\text { Sample size and } \\
\text { children's age in years }\end{array}$ & $\begin{array}{l}\text { Sample location/ethnicity } \\
\text { and SES }\end{array}$ & Home numeracy measure & Comprehensive mathematical tests & $\begin{array}{l}\text { Specific mathematical } \\
\text { tasks }\end{array}$ & Results & $\begin{array}{l}\text { Recomputed } \\
p \text {-values }\end{array}$ \\
\hline $\begin{array}{l}\text { Susperreguy and } \\
\text { Davis-Kean (2016) }\end{array}$ & $\begin{array}{l}N: 40 \\
\text { (mothers) } \\
M_{\text {age: }} \text { T1: } 4.5 \\
\text { T2: } 5.6\end{array}$ & $\begin{array}{l}\text { Location: USA } \\
\text { SES: diverse }\end{array}$ & $\begin{array}{l}\text { Observation: } \\
\text { Unstructured parent-child } \\
\text { interaction during meal } \\
\text { times for } 2 \text { days at } \mathrm{T} 1\end{array}$ & TEMA-3 at T2 & - & $\begin{array}{l}\text { Significant regressions: } \\
\text { Maternal math talk } \rightarrow \\
\text { composite math } \\
\left(\beta=0.31^{\star}\right)\end{array}$ & $\begin{array}{l}t_{(31)}=2.18 \\
p=0.03697\end{array}$ \\
\hline Leyva et al. (2019) & $\begin{array}{l}N: 208 \\
M_{\text {age: }} 6.6 \text { 1st grade }\end{array}$ & $\begin{array}{l}\text { Ethnicity: } \\
\text { Chinese, Mexican } \\
\text { African-American, and } \\
\text { Dominican living in the USA } \\
\text { SES: low }\end{array}$ & $\begin{array}{l}\text { Observation: } \\
\text { Parent-child interaction } \\
\text { during grocery game play }\end{array}$ & $\begin{array}{l}\text { Woodcock-Johnson III Tests of Achievement: } \\
\text { number calculation (counting, adding, } \\
\text { subtracting, and comparing quantities) and } \\
\text { math concepts (understanding whole-number } \\
\text { place value) }\end{array}$ & - & $\begin{array}{l}\text { Significant result of } \\
\text { interest: } \\
\text { None }\end{array}$ & Not available \\
\hline Zhou et al. (2006) & $\begin{array}{l}N: 85 \\
M_{\text {age }}: 4\end{array}$ & $\begin{array}{l}\text { Location: China } \\
\text { SES diverse: }\end{array}$ & $\begin{array}{l}\text { Observation: } \\
\text { Semi-structured activities for } \\
15 \text { min each, book reading, } \\
\text { paper activity, } \\
\text { worksheet, blocks }\end{array}$ & $\begin{array}{l}\text { Composite score of three versions of } \\
\text { give-a-number task }\end{array}$ & - & $\begin{array}{l}\text { Significant result of } \\
\text { interest: } \\
\text { None }\end{array}$ & Not available \\
\hline \multicolumn{8}{|l|}{ Section A.3 } \\
\hline Lehrl et al. (2019) & $\begin{array}{l}N: 229 \\
M_{\text {age }}: \text { T1: } 3 \\
\text { T2: } 4 \\
\text { T3: } 5 \\
\text { T5: } 12\end{array}$ & $\begin{array}{l}\text { Location: Germany } \\
\text { SES: diverse }\end{array}$ & $\begin{array}{l}\text { Questionnaire: } \\
\text { Formal activities } \\
\text { Observation: } \\
\text { Semi-structured book } \\
\text { reading at T1, T2, and T3 }\end{array}$ & $\begin{array}{l}\text { Numerical skills: subscale "arithmetic" of the } \\
\text { German Version of the Kaufman Assessment } \\
\text { Battery for Children (K-ABC) at T3 } \\
\text { Mathematics: content-related subtest } \\
\text { (quantity, space and shape, change and } \\
\text { relationship, data and change) and } \\
\text { Process-related subtest (applying technical } \\
\text { skills, modeling, arguing, communicating, } \\
\text { representing, problem solving) at T5 }\end{array}$ & - & $\begin{array}{l}\text { Significant regressions: } \\
\text { Math talk } \rightarrow \\
\text { mathematics at T5 } \\
\left(\beta=0.13^{*}\right)\end{array}$ & $\begin{array}{l}r_{(227)}=0.20 \\
p=0.00236\end{array}$ \\
\hline $\begin{array}{l}\text { Ramani et al. } \\
\text { (2015) }\end{array}$ & $\begin{array}{l}N: 33 \\
\text { Mage: } 4.3\end{array}$ & $\begin{array}{l}\text { Ethnicity: Caucasian, } \\
\text { African-American, } \\
\text { Hispanic living in the USA } \\
\text { SES: low }\end{array}$ & $\begin{array}{l}\text { Observation: } \\
\text { Semi-structured } \\
\text { parent-child interaction } \\
\text { during book reading, puzzle } \\
\text { making, and board game } \\
\text { playing } \\
\text { Questionnaire: } \\
\text { Formal and informal } \\
\text { activities (adapted from } \\
\text { LeFevre et al., 2009) }\end{array}$ & $\begin{array}{l}\text { Composite score of basic math skills: verbal } \\
\text { counting and number identification } \\
\text { Advanced math skills: counting principles, } \\
\text { enumeration and cardinality, number line } \\
\text { estimation and comparison }\end{array}$ & - & $\begin{array}{l}\text { Significant regressions: } \\
\text { Formal activities } \rightarrow \text { basic } \\
\text { composite math } \\
\left(\beta=0.34^{*}\right) \\
\text { Advanced math talk } \rightarrow \\
\text { advanced composite } \\
\text { math skills } \\
\left(\beta=0.33^{*}\right)\end{array}$ & $\begin{array}{l}r_{(31)}=0.55 \\
p=0.00091\end{array}$ \\
\hline \multicolumn{8}{|l|}{ Section B.1 } \\
\hline $\begin{array}{l}\text { Dearing et al. } \\
\text { (2012) }\end{array}$ & $\begin{array}{l}\text { N: } 127 \\
\text { Mage: } 6.7\end{array}$ & $\begin{array}{l}\text { Ethnicity: Latino, Asian, } \\
\text { African-American and White } \\
\text { living in the USA } \\
\text { SES: diverse }\end{array}$ & $\begin{array}{l}\text { Questionnaire: } \\
\text { Formal activities (adapted } \\
\text { from LeFevre et al., 2009) } \\
\text { and home learning } \\
\text { environment (HLE) }\end{array}$ & - & $\begin{array}{l}\text { Calculations: addition } \\
\text { and subtraction }\end{array}$ & $\begin{array}{l}\text { Structural equation } \\
\text { models: } \\
\text { HLE } \rightarrow \text { calculations } \\
\left(r=0.19^{\star}\right) \\
\text { Formal activities } \rightarrow \\
\text { calculations }\left(r=0.29^{*}\right)\end{array}$ & $\begin{array}{l}r_{(125)}=0.19 \\
p=0.03239\end{array}$ \\
\hline $\begin{array}{l}\text { Kleemans et al. } \\
\text { (2013) }\end{array}$ & $\begin{array}{l}N: 150 \\
M_{\text {age }}: \text { T1: } 6 \text { at } \\
\text { kindergarten } \\
\text { T2: } 7 \text { at } 1 \text { st grade }\end{array}$ & $\begin{array}{l}\text { Location: The Netherlands } \\
\text { SES: middle to high }\end{array}$ & $\begin{array}{l}\text { Questionnaire: } \\
\text { Formal activities } \rightarrow \\
\text { (adapted from LeFevre } \\
\text { et al., 2009) at T1 }\end{array}$ & - & $\begin{array}{l}\text { Calculations: addition } \\
\text { and subtraction at T2 }\end{array}$ & $\begin{array}{l}\text { Significant regressions: } \\
\text { Formal activities } \rightarrow \\
\text { addition }\left(\beta=0.24^{\star \star \star}\right) \\
\text { Formal activities } \rightarrow \\
\text { subtraction } \\
\left(\beta=0.23^{\star \star}\right)\end{array}$ & $\begin{array}{l}r_{(148)}=0.63 \\
p<0.00001\end{array}$ \\
\hline
\end{tabular}




\begin{tabular}{|c|c|c|c|c|c|c|c|}
\hline References & $\begin{array}{l}\text { Sample size and } \\
\text { children's age in years }\end{array}$ & $\begin{array}{l}\text { Sample location/ethnicity } \\
\text { and SES }\end{array}$ & Home numeracy measure & Comprehensive mathematical tests & $\begin{array}{l}\text { Specific mathematical } \\
\text { tasks }\end{array}$ & Results & $\begin{array}{l}\text { Recomputed } \\
p \text {-values }\end{array}$ \\
\hline $\begin{array}{l}\text { Kleemans et al. } \\
\text { (2018) }\end{array}$ & $\begin{array}{l}N: 103 \\
\text { Mage: T1: } 6 \text { at } \\
\text { kindergarten T3: } 8 \text { at } \\
\text { 2nd grade }\end{array}$ & $\begin{array}{l}\text { Location: The Netherlands } \\
\text { SES: middle to high }\end{array}$ & $\begin{array}{l}\text { Questionnaire: Formal } \\
\text { activities (adapted from } \\
\text { LeFevre et al., 2009) at T1 }\end{array}$ & - & $\begin{array}{l}\text { Calculations: addition } \\
\text { and subtraction with } \\
\text { small and large numbers } \\
\text { at T3 }\end{array}$ & $\begin{array}{l}\text { Significant regression: } \\
\text { Formal activities } \rightarrow \text { large } \\
\text { numbers arithmetic } \\
\left(\beta=0.22^{\star \star}\right)\end{array}$ & $\begin{array}{l}r_{(101)}=0.41 \\
p=0.00002\end{array}$ \\
\hline $\begin{array}{l}\text { Huang et al. } \\
\text { (2017) }\end{array}$ & $\begin{array}{l}N: 104 \\
\text { (mothers \& fathers) } \\
M_{\text {age }: ~} 5\end{array}$ & $\begin{array}{l}\text { Location: China } \\
\text { SES: N/A }\end{array}$ & $\begin{array}{l}\text { Questionnaire: } \\
\text { Formal and informal } \\
\text { activities (adapted from } \\
\text { LeFevre et al., 2009) }\end{array}$ & - & $\begin{array}{l}\text { Calculations: } \\
\text { Verbal story problems } \\
\text { and written } \\
\text { arithmetic problems }\end{array}$ & $\begin{array}{l}\text { Significant regressions: } \\
\text { Mothers number } \\
\text { practices }\left(\beta=0.32^{\star}\right) \text { and } \\
\text { number book activities } \\
\left(\beta=-0.31^{\star}\right) \rightarrow \text { story } \\
\text { problems } \\
\text { Mothers' number } \\
\text { practices }\left(\beta=0.35^{\star}\right) \text { and } \\
\text { fathers' games }(\beta= \\
\left.0.29^{*}\right) \text { and applications } \\
\left(\beta=0.30^{\star}\right) \\
\rightarrow \text { written arithmetic }\end{array}$ & $\begin{array}{l}r_{(100)}=0.20 \\
p=0.04386\end{array}$ \\
\hline $\begin{array}{l}\text { Benavides-Varela } \\
\text { et al. (2016) }\end{array}$ & $\begin{array}{l}N: 110 \\
M_{\text {age }}: 5.9\end{array}$ & $\begin{array}{l}\text { Location: Italy } \\
\text { SES: diverse }\end{array}$ & $\begin{array}{l}\text { Questionnaire: } \\
\text { Informal activities (playing } \\
\text { board game) }\end{array}$ & - & $\begin{array}{l}\text { Five tasks: } \\
\text { Counting, one-to-one } \\
\text { correspondence, } \\
\text { magnitude comparison, } \\
\text { number line task, } \\
\text { everyday } \\
\text { numerical problems }\end{array}$ & $\begin{array}{l}\text { Significant correlations: } \\
\text { Informal activities } \rightarrow \\
\text { counting }\left(r=0.31^{\star}\right)\end{array}$ & $\begin{array}{l}r_{(108)}=0.31 \\
p=0.00098\end{array}$ \\
\hline $\begin{array}{l}\text { Mutaf-Yildiz et al. } \\
\text { (2018a) }\end{array}$ & $\begin{array}{l}N: 128 \\
M_{\text {age }}: 5.4\end{array}$ & $\begin{array}{l}\text { Location: Belgium } \\
\text { SES: middle to high }\end{array}$ & $\begin{array}{l}\text { Questionnaire: } \\
\text { Formal and informal } \\
\text { activities (adapted from } \\
\text { LeFevre et al., 2009) }\end{array}$ & - & $\begin{array}{l}\text { Basic number skills: } \\
\text { Non-symbolic and } \\
\text { symbolic comparison } \\
\text { Non-symbolic and } \\
\text { symbolic number line } \\
\text { estimation } \\
\text { Enumeration and } \\
\text { connecting } \\
\text { Pictorial and } \\
\text { symbolic calculations }\end{array}$ & $\begin{array}{l}\text { Significant regressions: } \\
\text { Formal activities } \rightarrow \\
\text { enumeration }\left(\beta=0.21^{\star}\right) \\
\text { Informal activities } \\
\rightarrow \text { symbolic number line } \\
\left(\beta=-0.18^{*}\right) \\
\text { Informal activities } \\
\rightarrow \text { pictorial calculation } \\
\left(\beta=0.17^{*}\right)\end{array}$ & $\begin{array}{l}r_{(126)}=0.21 \\
p=0.01735\end{array}$ \\
\hline $\begin{array}{l}\text { Vasilyeva et al. } \\
\text { (2018) }\end{array}$ & $\begin{array}{l}\text { N: } 98 \\
\text { Mage: T1: } 5.8 \\
\text { T2: } 6.8\end{array}$ & $\begin{array}{l}\text { Location: Russia } \\
\text { SES: N/A }\end{array}$ & $\begin{array}{l}\text { Questionnaire: Formal and } \\
\text { informal activities at } \mathrm{T1}\end{array}$ & - & $\begin{array}{l}4 \text { tasks: Raven's test, } \\
\text { number identification, } \\
\text { numerical magnitude } \\
\text { comparison, arithmetic } \\
\text { at T2 }\end{array}$ & $\begin{array}{l}\text { Significant paths: Formal } \\
\text { activities } \rightarrow \text { number } \\
\text { identification (effect size } \\
=0.42^{\star \star} \text { ) } \\
\text { Informal activities } \rightarrow \\
\text { magnitude comparison } \\
\text { (effect size }=0.37^{\star} \text { ) } \\
\text { Both activities } \rightarrow \\
\text { arithmetic (effect sizes = } \\
0.30^{\star} \text { and. } 39^{\star \star} \text { ) }\end{array}$ & $\begin{array}{l}r_{(96)}=0.41 \\
p=0.00003\end{array}$ \\
\hline \multicolumn{8}{|l|}{ Section B.2 } \\
\hline $\begin{array}{l}\text { Levine et al. } \\
\text { (2010) }\end{array}$ & $\begin{array}{l}\text { N: } 44 \\
\text { Mage: (in months) } \\
\text { T1: } 14 \mathrm{~m} \\
\text { T2: } 18 \mathrm{~m} \\
\text { T3: } 22 \mathrm{~m} \\
\text { T4: } 26 \mathrm{~m} \\
\text { T5: } 30 \mathrm{~m} \\
\text { T6: } 46 \mathrm{~m}\end{array}$ & $\begin{array}{l}\text { Location: USA } \\
\text { SES: diverse }\end{array}$ & $\begin{array}{l}\text { Observation: } \\
\text { Unstructured activity } \\
\text { sessions at } \mathrm{T} 1, \mathrm{~T} 2, \mathrm{~T} 3, \mathrm{~T} 4 \text {, } \\
\text { and } \mathrm{T5}\end{array}$ & - & Point-to-X-task at T6 & $\begin{array}{l}\text { Significant regressions: } \\
\text { Number talk } \rightarrow \\
\text { point-to- } X \\
\left(\beta=0.29^{\star}\right)\end{array}$ & $\begin{array}{l}r_{(42)}=0.47 \\
p=0.00129\end{array}$ \\
\hline
\end{tabular}


TABLE 1 | Continued

\begin{tabular}{|c|c|c|c|c|c|c|c|}
\hline References & $\begin{array}{l}\text { Sample size and } \\
\text { children's age in years }\end{array}$ & $\begin{array}{l}\text { Sample location/ethnicity } \\
\text { and SES }\end{array}$ & Home numeracy measure & Comprehensive mathematical tests & $\begin{array}{l}\text { Specific mathematical } \\
\text { tasks }\end{array}$ & Results & $\begin{array}{l}\text { Recomputed } \\
p \text {-values }\end{array}$ \\
\hline $\begin{array}{l}\text { Gunderson and } \\
\text { Levine (2011) }\end{array}$ & $\begin{array}{l}N: 44 \\
M_{\text {age }} \text { : (in months) } \\
\text { T1: } 14 \mathrm{~m} \\
\text { T2: } 18 \mathrm{~m} \\
\text { T3: } 22 \mathrm{~m} \\
\text { T4: } 26 \mathrm{~m} \\
\text { T5: } 30 \mathrm{~m} \\
\text { T6: } 46 \mathrm{~m}\end{array}$ & $\begin{array}{l}\text { Location: USA } \\
\text { SES: diverse }\end{array}$ & $\begin{array}{l}\text { Observation: } \\
\text { Unstructured activity } \\
\text { sessions at T1, T2, T3, T4, } \\
\text { and T5 }\end{array}$ & - & Point-to-X-task at T6 & $\begin{array}{l}\text { Significant regressions: } \\
\text { Number talk with present } \\
\text { objects in large sets } \\
(4-10) \rightarrow \text { point-to-X } \\
\left(\beta=0.38^{\star}\right)\end{array}$ & Not reported \\
\hline Glenn et al. (2018) & $\begin{array}{l}N: 60 \\
M_{\text {age: }}: \mathrm{T} 1: 2 \\
\text { T2: } 3.5\end{array}$ & $\begin{array}{l}\text { Location: USA } \\
\text { SES: diverse }\end{array}$ & $\begin{array}{l}\text { Observation: } \\
\text { Unstructured activity } \\
\text { sessions at home for } 90 \mathrm{~min} \\
\text { at } \mathrm{T} 1\end{array}$ & - & Point-to-X-task at T2 & $\begin{array}{l}\text { Significant random effect } \\
\text { intercept: } \\
\text { Number talk } \rightarrow \\
\text { point-to-X (random } \\
\text { effects intercept: } 3.95^{\star \star \star} \text { ) }\end{array}$ & Not reported \\
\hline \multicolumn{8}{|l|}{ Section B.3 } \\
\hline $\begin{array}{l}\text { Mutaf-Yildiz et al. } \\
\text { (2018b) }\end{array}$ & $\begin{array}{l}N: 44 \\
M_{\text {age }}: 5.6\end{array}$ & $\begin{array}{l}\text { Location: Belgium } \\
\text { SES: middle to high }\end{array}$ & $\begin{array}{l}\text { Questionnaire: Formal and } \\
\text { informal activities (adapted } \\
\text { from LeFevre et al., 2009) } \\
\text { Observations: } \\
\text { Semi-structured activities for } \\
5 \text { min each, book reading } \\
\text { and Lego building }\end{array}$ & - & $\begin{array}{l}\text { Calculations: } \\
\text { Addition and subtraction }\end{array}$ & $\begin{array}{l}\text { Significant correlations: } \\
\text { Formal activities } \rightarrow \\
\text { calculation }\left(r=0.31^{*}\right) \\
\text { Parent number talk } \rightarrow \\
\text { calculation }\left(r=-0.35^{*}\right)\end{array}$ & $\begin{array}{l}r_{(42)}=0.31 \\
p=0.04057\end{array}$ \\
\hline \multicolumn{8}{|l|}{ Section C } \\
\hline $\begin{array}{l}\text { LeFevre et al. } \\
\text { (2009) }\end{array}$ & $\begin{array}{l}N: 146 \\
M_{\text {age }}: 6.5\end{array}$ & $\begin{array}{l}\text { Location: Canada } \\
\text { SES: diverse }\end{array}$ & $\begin{array}{l}\text { Questionnaire: } \\
\text { Formal and } \\
\text { informal activities }\end{array}$ & $\begin{array}{l}\text { KeyMath Test-Revised Form B (Connolly, } \\
\text { 2000): } \\
\text { The Numeration subtest: "math concepts and } \\
\text { number system knowledge," including } \\
\text { quantity, digit recognition, place value } \\
\text { The addition and subtraction subtests }\end{array}$ & $\begin{array}{l}\text { Calculation fluency } \\
\text { (single-digit addition) }\end{array}$ & $\begin{array}{l}\text { Significant regression: } \\
\text { Game activities } \rightarrow \\
\text { composite math }(\beta= \\
\left.0.18^{*}\right) \\
\text { Number skills }\left(\beta=0.21^{\star}\right) \\
\text { games }\left(\beta=0.21^{\star}\right) \text {, and } \\
\text { application activities }(\beta= \\
\left.0.24^{\star}\right) \rightarrow \text { math fluency }\end{array}$ & $\begin{array}{l}r_{(144)}=0.27 \\
p=0.00098\end{array}$ \\
\hline $\begin{array}{l}\text { Manolitsis et al. } \\
\text { (2013) }\end{array}$ & $\begin{array}{l}N: 82 \\
M \text { age: } 5.4 \\
\text { T1 beginning of } K G \\
\text { T2 end of } K G \\
\text { T3 end of } 1 \text { st grade }\end{array}$ & $\begin{array}{l}\text { Location: Greece } \\
\text { SES: diverse }\end{array}$ & $\begin{array}{l}\text { Questionnaire: } \\
\text { Formal activities (adapted } \\
\text { from LeFevre et al., 2009) }\end{array}$ & $\begin{array}{l}\text { TEMA-3: } \\
\text { Cardinality rule, seriation of numbers, naming } \\
\text { of single-digit numbers, and number } \\
\text { comparison at T1 and T2 }\end{array}$ & $\begin{array}{l}\text { Counting at } \mathrm{T} 1 \text { and } 2 \\
\text { Math fluency at } \mathrm{T3}\end{array}$ & $\begin{array}{l}\text { Significant correlations: } \\
\text { Formal activities and } \\
\text { counting at } \mathrm{T} 1 \\
\left(r=0.28^{*}\right)\end{array}$ & $\begin{array}{l}r_{(80)}=0.28 \\
p=0.01084\end{array}$ \\
\hline $\begin{array}{l}\text { Skwarchuk et al. } \\
\text { (2014) }\end{array}$ & $\begin{array}{l}N: 121 \\
M_{\text {age }}: 5.8\end{array}$ & $\begin{array}{l}\text { Location: Canada } \\
\text { SES: diverse }\end{array}$ & $\begin{array}{l}\text { Questionnaire: } \\
\text { Formal activities and } \\
\text { informal home numeracy } \\
\text { (knowledge of commercially } \\
\text { available number games) }\end{array}$ & The Numeration subtest of Key Math-Revised & Non-symbolic arithmetic & $\begin{array}{l}\text { Significant regressions: } \\
\text { Informal activities } \rightarrow \\
\text { non-symbolic arithmetic } \\
\left(\beta=0.20^{\star}\right) \\
\text { Advanced formal } \\
\text { activities } \rightarrow \text { math } \\
\left(\beta=0.21^{\star}\right)\end{array}$ & $\begin{array}{l}r_{(119)}=0.30 \\
p=0.00083\end{array}$ \\
\hline $\begin{array}{l}\text { Missall et al. } \\
\text { (2015) }\end{array}$ & $\begin{array}{l}N: 72 \\
M_{\text {age }}: 4.4\end{array}$ & $\begin{array}{l}\text { Ethnicity: White, Hispanic, } \\
\text { Asian, multiracial living in the } \\
\text { USA } \\
\text { SES: diverse }\end{array}$ & $\begin{array}{l}\text { Questionnaire: } \\
\text { Numeracy activities }\end{array}$ & $\begin{array}{l}\text { The quantitative subtest and the School } \\
\text { Readiness Composite of Bracken Basic } \\
\text { Concepts Scale-Third edition: Receptive } \\
\text { (BBCS-3:R; Bracken, 2006) }\end{array}$ & $\begin{array}{l}\text { The Individual Growth } \\
\text { and Development } \\
\text { Indicators of Early } \\
\text { Numeracy (IGDIs-EN; } \\
\text { Hojnoski and Floyd, } \\
\text { 2013); } \\
\text { One-to-one } \\
\text { correspondence, verbal } \\
\text { counting, number } \\
\text { naming, and } \\
\text { quantity comparison }\end{array}$ & $\begin{array}{l}\text { Significant correlations: } \\
\text { None } \\
\text { Significant regressions: } \\
\text { None }\end{array}$ & Not available \\
\hline
\end{tabular}


analysis was run. Table 1 presents an overview with all the detailed information of the articles included in the review (e.g., sample characteristics, measures, and results).

\section{A. The Relationship Between Home Numeracy and Children's Performance as Measured by Comprehensive Mathematical Tests}

\section{A.1. Home Numeracy Operationalized With Questionnaires}

In total, 22 studies examined the relationship between home numeracy and comprehensive mathematical tests. Fifteen of these studies used questionnaires to assess home numeracy. Most of these questionnaires were inspired by the work of LeFevre et al. (2009), specifically targeting numeracy activities $(n=11)$. A minority of the studies assessed the broader home learning environment of which home numeracy is a part $(n=4)$.

Of the 11 studies that specifically addressed numeracy activities, 8 investigated the effects of formal home numeracy activities on mathematical skills. Huntsinger et al. (1997) recruited families from different ethnic backgrounds with a high socio-economic status and showed that children $\left(M_{\text {age }}=\right.$ 5.5 years) with a higher composite mathematical score (i.e., TEMA-2) were the ones whose parents spent more time in formal teaching practices, such as helping with mathematics homework, regardless of the ethnicity. They also showed however that Chinese-American and Taiwan-Chinese parents engaged more in formal activities than Euro-American parents and that this higher engagement was associated with higher mathematics scores in Chinese-American and Taiwan-Chinese children. Two studies with participants from middle- to high-SES families showed that formal numeracy activities were positively associated with children's ( $M_{\text {age }}=6$ years $)$ composite mathematical score (i.e., Utrecht Early Numeracy Test-Revised) above and beyond children's cognitive skills, linguistic skills, and their home literacy environment (Kleemans et al., 2012; Segers et al., 2015). However, one study with participants from low- to middle-SES families reported that children's $\left(M_{\text {age }}=4.3\right.$ years $)$ composite mathematical scores were not associated with formal home numeracy activities, but positively related with SES (Cheung et al., 2018). Next to these cross-sectional designs, several studies used a longitudinal approach. Anders et al. (2012) found that both families' SES and formal home numeracy activities were associated with kindergartner's $\left(M_{\text {age }}=3.08\right)$ concurrent mathematical score and also its growth in the following 2 years. Another study showed that in a group of middle- to high-SES participants formal numeracy activities were the most stable (positive) predictors of kindergartners' $\left(M_{\text {age }}=4.09\right.$ years) composite mathematical score one semester later, even after accounting for control variables, such as a child's age, gender, and parental education (Napoli and Purpura, 2018).

Two studies explicitly distinguished between basic and advanced formal numeracy activities (Del Rio et al., 2017; Zippert and Ramani, 2017). In a group of middle- to high-SES American participants advanced formal number activities (e.g., solving simple sums), but not basic ones (e.g., counting), were positively related with children's $\left(M_{\text {age }}=4.5\right.$ years $)$ performance in composite score of advanced (i.e., symbolic comparison and arithmetic) mathematical skills (Zippert and Ramani, 2017). The other study recruited Chilean families from low and high socioeconomic backgrounds and assessed mothers' and fathers' home numeracy separately (Del Rio et al., 2017). These authors found that children's $\left(M_{\text {age }}=5.6\right.$ years $)$ composite mathematical score (i.e., Applied Problems subtest of the Woodcock-Muñoz Batería III) was positively associated with SES and mothers' advanced formal activities at home, but not with the ones of the fathers. However, the relationship between SES and mothers' advanced home numeracy activities was negative.

Niklas and Schneider (2014) recruited participants from diverse socio-economic backgrounds in Germany and assessed only informal activities, the authors reported that the frequency of playing games at the end of kindergarten $\left(M_{\text {age }}=6.4\right.$ years) positively predicted children's mathematical composite score at the end of Grade 1 even after controlling for SES. Furthermore, similar to Del Rio et al. (2017), it was found that SES was negatively related to informal activities whereas it was positively associated with children's mathematical composite score. However, two studies that measured both formal and informal home numeracy activities with a longitudinal approach (Ciping et al., 2015; Huntsinger et al., 2016) reported conflicting results. Huntsinger et al. (2016) showed that in a group of middle- to high-SES American families, formal numeracy activities at the mean age of 4.48 years were the most consistent (positive) predictor of kindergartners' composite mathematical score (TEMA-2) 1 year later $\left(M_{\text {age }}=5.6\right.$ years), but informal activities were not. Ciping et al. (2015) took another approach and investigated the effect of children's mathematical skills on home numeracy in a group of Chinese participants with diverse socio-economic backgrounds. These authors observed that the composite mathematical score of two tasks (i.e., calculation fluency and omitted number) at Grade 1 ( $M_{\text {age }}=6.7$ years $)$ negatively predicted the formal, but not the informal numeracy activities at Grade 2. Furthermore, no moderation effect from SES was found.

In addition to studies that focused on home numeracy activities, four studies investigated the relation between the general home learning environment (HLE) and mathematical skills. Baker (2015) demonstrated in a sample of AfricanAmericans from diverse socio-economic backgrounds that boys' $\left(M_{\text {age }}=5.6\right.$ years $)$ composite mathematical score (i.e., National Assessment of Educational Progress) were positively associated with SES and also with mothers' home learning activities even after controlling for children's age and family demographics (e.g., income, maternal age, and education). Three other studies investigated the longitudinal associations of HLE on mathematics (Melhuish et al., 2008; Niklas and Schneider, 2017; Visser et al., 2019). Home learning environment of participants in the UK from diverse socio-economic backgrounds, assessed at age 3, was the strongest predictor of children's composite mathematical score (i.e., the Early Number Concepts subscale of the British Ability Scale II) both at ages 5 and 7, over and above the effects of maternal education and social class (Melhuish et al., 2008). Niklas and Schneider (2017) recruited families from low- to middle-SES in Germany and found that the composite mathematical scores at the middle of Grade 4 were 
positively predicted by the home learning environment assessed at kindergarten, even when earlier mathematical skills, other child (i.e., age, sex, and intelligence) and family characteristics (i.e., socio-economic status and migration background) were accounted for. Families' SES was not a direct predictor of composite mathematical scores; however, SES was associated with HLE. Similar findings were reported by Visser et al. (2019) in a sample of South African families from diverse socioeconomic backgrounds. Home learning environment measured in kindergarten was positively associated with Grade 5 children's standardized mathematical scores, even after accounting for earlier mathematical skills and SES.

\section{A.2. Home Numeracy Operationalized With Observations}

Five studies used observations to index home numeracy, and two of them focused on mothers only. Elliott et al. (2017) observed that highly educated American mothers' numeracy talk of large numbers $(>10)$ was positively associated with children's $\left(M_{\text {age }}=5.7\right.$ years) composite mathematical score (i.e., TEMA-3), whereas this was not true for talk about small (15) and medium (6-10) numbers, or overall number talk. Two longitudinal studies showed that the frequency of numeracy talk was predictive for children's mathematical skills (Susperreguy and Davis-Kean, 2016; Leyva, 2019). Leyva (2019) showed that low-income Chilean parents' math talk when children were in the beginning of pre-kindergarten $\left(M_{\text {age }}=4.5\right.$ years $)$ was predictive for children's composite mathematical scores (Applied Problems subset of the Woodcock-Munoz Bateria III) at the end of kindergarten, even after controlling for age, earlier mathematical skills, and parents' education. In a sample of children from diverse socio-economic backgrounds, Susperreguy and Davis-Kean (2016) found that American mothers' numeracy talk with their children $\left(M_{\text {age }}=4.5\right.$ years $)$ was predictive for children's composite mathematical scores (TEMA-3) 1 year after the recordings, even after controlling for maternal education and children's self-regulation (i.e., inhibitory control) and working memory. By contrast, two studies reported the absence of a relationship between numeracy talk and mathematical skills (Zhou et al., 2006; Leyva et al., 2019). Leyva et al. showed that the frequency of numeracy talk in low-income families with diverse ethnic backgrounds from the USA did not relate to children's $\left(M_{\text {age }}=6.6\right.$ years) composite math scores (WoodcockJohnson III Tests of Achievement, WJ-III; Woodcock et al., 2001). Ethnicity or mothers' education did not have any effect on children's mathematical skills either. Zhou et al. (2006) found that the frequency of numeracy talk in Chinese families from diverse socio-economic background was equal in "high" and "low" math achievers $\left(M_{\text {age }}=4.1\right.$ years $)$.

\section{A.3. Home Numeracy Operationalized With Both Questionnaires and Observations}

There are two studies that used both a questionnaire and semistructured observations to assess the frequency of numeracy activities and the frequency of numeracy talk, respectively (Ramani et al., 2015; Lehrl et al., 2019). Ramani et al. (2015) recruited children and their parents from Head Start centers (low-SES) in the USA and found that children's $\left(M_{\text {age }}=4.3\right.$ years) composite score of basic mathematical skills (i.e., verbal counting and numeral identification) was positively associated with formal home numeracy activities as indexed by the questionnaire, but not with the observed basic (i.e., counting and identifying numbers) or advanced (i.e., labeling number of elements in a set, ordering numbers, and arithmetic) numeracy talk. By contrast, the composite score of advanced mathematical skills (i.e., counting principles, enumeration and cardinality, number line estimation, and numeral magnitude comparison) was positively related with the observed advanced numeracy talk-but not with basic talk or formal activities. Lehrl et al. (2019) investigated the longitudinal associations between home numeracy and mathematics in participants from Germany from diverse socio-economic backgrounds and showed that numeracy talk, but not home numeracy activities, at ages 3, 4, and 5, positively predicted children's mathematical achievement at age 12 even when SES was controlled for.

\section{B. The Relationship Between Home Numeracy and Children's Performance on Specific Mathematical Tasks B.1. Home Numeracy Operationalized With Questionnaires}

Eleven studies used specific tasks to examine children's mathematical skills. Seven of them made use of questionnaires, of which six specifically focused on home numeracy activities and one on both numeracy activities and the broader concept of home learning environment.

Results from a sample with children from diverse socioeconomic backgrounds living in the USA showed that SES was positively related with the HLE. In turn, both the HLE and formal home numeracy activities were positively associated with girls' $\left(M_{\text {age }}=6.7\right.$ years) addition and subtraction skills (Dearing et al., 2012). Kleemans et al. investigated the long-term effects of formal numeracy activities on children's calculation skills in families from middle- to high-SES living in the Netherlands (Kleemans et al., 2013, 2018). Results showed that formal numeracy activities when children were in kindergarten $\left(M_{\text {age }}=\right.$ 6 years) positively predicted children's addition and subtraction scores 1 year later in first grade, even when cognitive and linguistic child factors were controlled for (Kleemans et al., 2013). Following the same children, Kleemans et al. (2018) found that formal home numeracy activities positively predicted children's arithmetic performance with large but not small problem sizes 2 years later (Kleemans et al., 2018). Huang et al. (2017) assessed mothers and fathers from China separately and found that children's $\left(M_{\text {age }}=5\right.$ years $)$ word problem solving skills (e.g., "Emma has four pens. Her sister gives two more. How many pens does Emma have now?") were positively correlated with mothers' formal number practices and negatively with mothers' number book activities. Symbolic calculation (e.g., $1+3$ ) scores were positively related with mothers' number practices and fathers' informal (games and application) activities. There are three studies that showed that home numeracy is differentially related with specific mathematical tasks (BenavidesVarela et al., 2016; Mutaf-Yildiz et al., 2018a; Vasilyeva et al., 
2018). In a sample of Italian families from diverse socioeconomic backgrounds, Benavides-Varela et al. (2016) found that counting skills in children $\left(M_{\text {age }}=5.9\right.$ years $)$, but not one-to-one correspondence, everyday numerical problems, nonsymbolic magnitude comparison, and number line estimation, were positively correlated with the frequency of playing board games, but not with any other type of home numeracy activities, such as playing videogames or reading book even after controlling for SES. Mutaf-Yildiz et al. (2018a) reported that formal home numeracy activities in Belgian families from middle- to high-SES backgrounds were positively associated with children's $\left(M_{\text {age }}=5.4\right.$ years) enumeration (i.e., sequentially tapping the correct number of dots indicated by a digit), but not with symbolic and non-symbolic comparison or number line estimation tasks, and not with a non-symbolic symbolic connecting task (i.e., choosing a set of dots equivalent to a target digit) or pictorial calculations even after taking SES into account. This study further demonstrated that informal home numeracy was positively associated with pictorial calculations and performance on a symbolic number line estimation task, but not with the other tasks. Finally, in a longitudinal study, Vasilyeva et al. (2018) observed that Russian families' formal home numeracy activities, at age 5.8 on average, positively predicted children's number identification skills and informal activities positively predicted symbolic comparison skills, whereas both types of activities were associated with arithmetic performance 1 year later.

\section{B.2. Home Numeracy Operationalized With Observations}

Three longitudinal studies used observations to index home numeracy and examined its association with specific numerical skills in families from the US with diverse socio-economic backgrounds. Levine et al. (2010) administered the Point-to$\mathrm{X}$ task, i.e., a task in which participants have to indicate which of the two pictures contains a certain number of items (Wynn, 1992) to measure the cardinal-principle knowledge of 3.8-year-old children. Parent-child dyads were observed in an unstructured way during five home visits, each lasting $90 \mathrm{~min}$. Especially parents' number talk positively predicted children's cardinal-principle knowledge, even after controlling for SES (education level of the primary caregiver who interacted with the child during the observations and income) and for parents' total amount of talk (Levine et al., 2010; see also Glenn et al., 2018). A more detailed analysis (Gunderson and Levine, 2011) of the same data revealed that specifically the talk about large sets (4-10) of present objects positively predicted the children's score on a Point-to-X task, even after controlling for SES and other types of parental numeracy and non-numeracy talk. In this sample, SES was positively related with parents' number talk which in turn was positively associated with children's mathematical skills.

\section{B.3. Home Numeracy Operationalized With Both Questionnaires and Observations}

Only one study used both a questionnaire and semi-structured observations to measure home numeracy in Belgian families from middle to high socio-economic backgrounds (MutafYildiz et al., 2018b). Results showed that home numeracy assessed with a questionnaire on the one hand and with observations on the other were not correlated with each other. Moreover, this study showed that children's $\left(M_{\text {age }}=\right.$ 5.6 years) calculation skills positively correlated with the frequency of formal home numeracy activities measured with a questionnaire, whereas these calculation skills negatively correlated with parents' observed numeracy talk (Mutaf-Yildiz et al., 2018b).

\section{The Relation Between Home Numeracy and Children's Performance in Both Comprehensive Mathematical Tests and Specific Mathematical Tasks in One Study}

In four studies, home numeracy was indexed with questionnaires and children's mathematical skills were examined with both a composite score and specific mathematical measures (LeFevre et al., 2009; Manolitsis et al., 2013; Skwarchuk et al., 2014; Missall et al., 2015). These studies revealed conflicting results. In a Canadian sample of children from diverse socio-economic backgrounds, LeFevre et al. (2009) found that a composite mathematical score (i.e., KeyMath-Revised) was positively associated with informal activities (games) over and above the effects of children's $\left(M_{a g e}=6.5\right.$ years $)$ vocabulary, spatial memory span, and SES. On the other hand, in another similar Canadian sample, Skwarchuk et al. (2014) observed that children's $\left(M_{\text {age }}=5.8\right.$ years $)$ composite mathematical score (i.e., KeyMath-Revised) was not associated with informal home numeracy or basic formal activities, but that it was only positively related with advanced formal practices even after accounting for SES. In this study, SES also positively correlated with mathematical skills. Moreover, LeFevre et al. (2009) showed that a specific measure of calculation fluency (solving problems correctly as fast as possible) was positively related to both formal and informal activities, even when SES was accounted for, whereas Manolitsis et al. (2013) reported that formal number activities in Greek families from diverse socio-economic backgrounds were only positively correlated with specific verbal counting skills (counting from 1 to highest number children could) of children $\left(M_{\text {age }}=5.4\right.$ years), but not with math fluency or a composite mathematical score (i.e., TEMA-3). In this study, SES was not related with home numeracy activities or mathematical skills. However, Skwarchuk et al. (2014) reported that a specific measure of non-symbolic calculation was positively associated with informal home numeracy (i.e., parents' number game knowledge) but not with formal activities, even after controlling for family income. By contrast, Missall et al. (2015) recruited families from diverse ethnicities and SES living in the USA and documented that home numeracy-which was calculated as a sum score of both formal and informal activities-did not predict any type of (composite or specific) mathematical skill in children $\left(M_{\text {age }}=4.4\right.$ years $)$. The authors also reported that neither ethnicity nor income were related to home numeracy activities. 


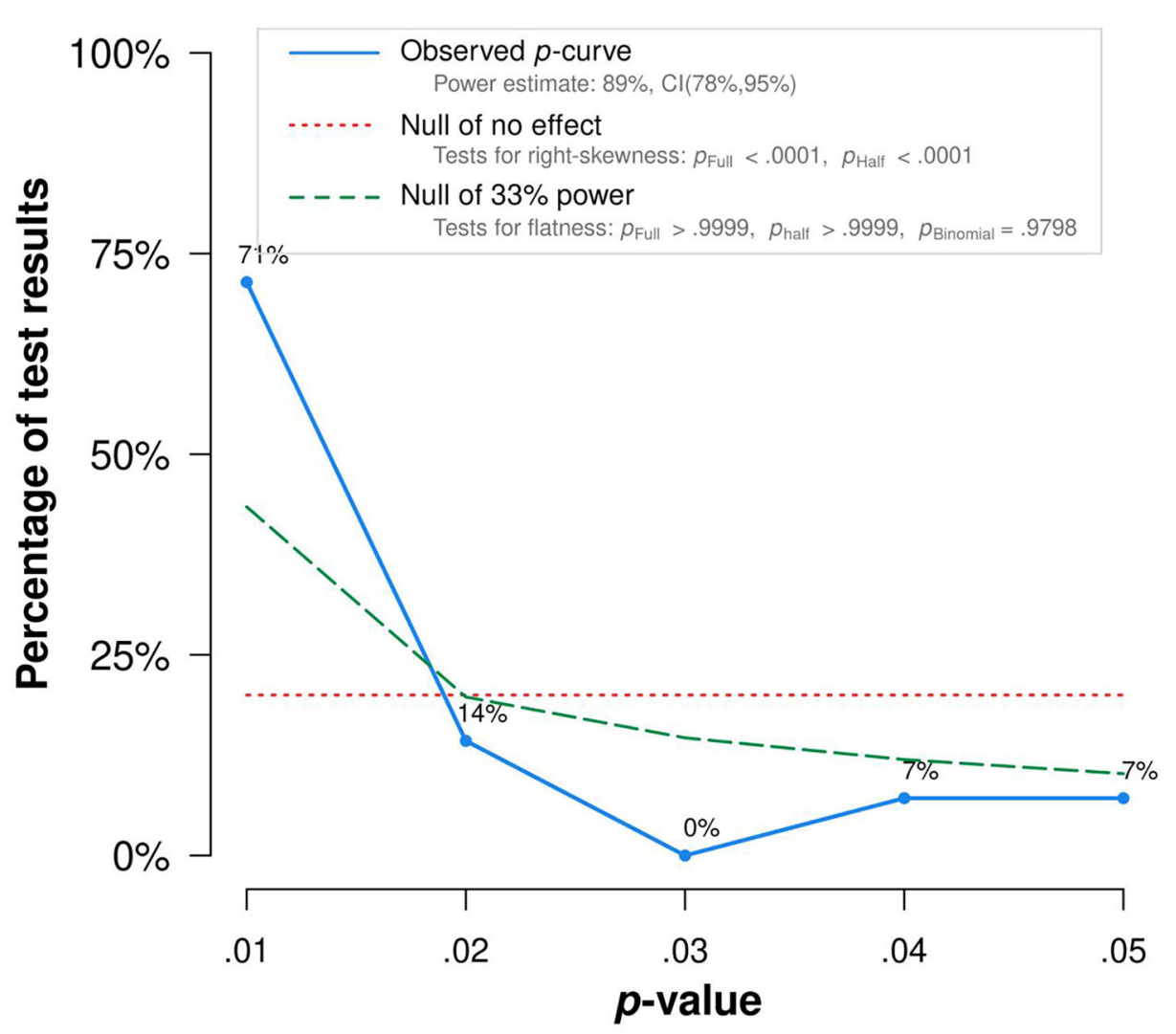

FIGURE 3 | Results of the $p$-curve analysis.

\section{P-Curve Analysis}

It became clear that 33 studies out of 37 observed significant associations between home numeracy and children's mathematical skills. However, one should remember that there is a bias to publish studies with positive findings compared with the ones with negative findings (e.g., Joober et al., 2012). Therefore, we tested whether these significant $(p<0.05)$ relations were the result of a publication bias, or whether they indicate a true effect, by means of a $p$-curve analysis (Simonsohn et al., 2013; Simonsohn et al., 2014). A p-curve analysis answers this possibility of a publication bias by producing a distribution of statistically significant $p$-values for a set of studies. Simonsohn et al. (2014) reasoned that a right-skewed $p$-curve would be generated if there is a true effect because more low (e.g., $p<$ $0.01)$ significant $p$-values are expected than high significant $p$-values (e.g., $p=0.04$ ) in a set of studies. On the contrary, if the significant relations in a set of studies were the result of a publication bias, a left-skewed $p$-curve would be revealed because more high $p$-values (e.g., $p=0.05$ ) and less low $p$-values (e.g., $p<0.01$ ) would be observed in such a set of studies.

Simonsohn et al. (2014) developed an online application " $p$ curve app 4.06" (http://www.p-curve.com/app) to generate a $p$ curve. The app uses available test statistics $\left(r, t, z, f, F\right.$, or $\left.\chi^{2}\right)$ from each study, along with the degrees of freedom, and recalculates the $p$-values (see the last column of Table 1). Because the $p$-curve analysis assumes that all the $p$-values that are to be analyzed are statistically independent from each other, including only one statistical test from each reviewed paper in the analysis is advised. Consequently, in the papers where two or more results were reported, a decision must be made to select only one of them. To keep this choice objective, we followed Simonsohn's (2014) recommendation and chose the result that was reported first in the manuscript to be included in our analysis. The $p$-curve analysis was run on only 28 papers because in four studies no significant relations were observed and in five other studies the required test statistics were not reported. Gunderson and Levine (2011) for instance documented a scatter plot displaying the relationship between home numeracy and mathematical skills, but did not report the actual effect size of the correlation.

Figure 3, revealed by the "p-curve app 4.06," displays the results of the $p$-curve analysis. The two dashed lines are reference lines; the shorter-dashed line represents an expected distribution of $p$-values when there is no true effect and the longer-dashed line represents an expected distribution of $p$-values when there is a true effect. The observed $p$-curve of this set of studies, represented by the straight line, shows that there are more low (e.g.,0.01 s) p-values compared with higher (e.g., $0.04 \mathrm{~s})$ ones, as we would expect when there is a true effect, with a high statistical power (89\%). This result indicates that the positive relation between home numeracy and children's mathematical skills reported in the reviewed studies indeed reflects a true effect and therefore has evidential value. 


\section{DISCUSSION}

The purpose of the current literature review was to provide a synthesized and systematic overview of the studies focusing on the relationship between home numeracy and children's mathematical skills. We observed that both concepts have been operationalized in a variety of ways. However, despite the use of diverse measures for home numeracy and mathematical skills, we found that 32 studies out of 37 revealed a positive association between home numeracy and children's mathematical skills. In addition, a p-curve analysis confirmed that this association reflects a true effect and cannot be explained by a publication bias. The present review holds, however, also some limitations. First, the search for relevant articles was conducted in only two databases, albeit the most important ones in the field of psychological and educational research. Second, owing to the timing of the actual search, only articles published up to November 2019 were analyzed. Third, intervention studies were not included because they felt out of the scope of our research. However, to complete the picture presented, these limitations were defeated by adding relevant papers here the current discussion section that were published recently, not indexed in the databases we scanned, and discussing interventions.

The majority of the studies revealed by our systematic review $(n=22 / 37)$ used comprehensive tests to measure children's mathematical skills, compared with only 11 studies that used specific tasks. Four included both types of mathematical measures. Among the 22 studies that tested children with comprehensive batteries, 15 of them used questionnaires, five used observations, and two included both measures to assess home numeracy. Studies have shown that home learning environment (Melhuish et al., 2008; Niklas and Schneider, 2017; Visser et al., 2019; $n=4$, Baker, 2015), informal ( $n=1$, Niklas and Schneider, 2014), and formal home numeracy (Huntsinger et al., 1997, 2016; Kleemans et al., 2012; Segers et al., 2015; Napoli and Purpura, 2018; $n=6$, Anders et al., 2012) were positively associated with composite mathematical scores. Furthermore, two studies distinguished between basic and advanced formal activities and showed that advanced but not basic activities were related with children's composite mathematical scores (Del Rio et al., 2017; Zippert and Ramani, 2017). In line with the findings from the questionnaires, studies based on observational methods also demonstrated that home numeracy talk ( $n=3$, Susperreguy and Davis-Kean, 2016; Lehrl et al., 2019; Leyva, 2019), especially the advanced talk but not the basic talk ( $n=2$, Ramani et al., 2015; Elliott et al., 2017), was positively associated with children's composite math score.

Out of the 11 studies that tested children with specific mathematical measures, seven used questionnaires, three used observations, and only one used both measures to index home numeracy. The home learning environment $(n=1$, Dearing et al., 2012), informal ( $n=4$, Benavides-Varela et al., 2016; Huang et al., 2017; Mutaf-Yildiz et al., 2018b; Vasilyeva et al., 2018), and formal home numeracy ( $n=5$, Kleemans et al., 2013, 2018; Huang et al., 2017; Mutaf-Yildiz et al., 2018a; Vasilyeva et al., 2018) were positively associated with specific mathematical tasks (i.e., calculations and counting). Moreover, studies using observations showed that home numeracy talk ( $n=2$, Levine et al., 2010; Glenn et al., 2018), especially the advanced talk ( $n$ $=1$, Gunderson and Levine, 2011), was related with the specific mathematical skills, i.e., cardinal-principle knowledge.

All of the four studies that examined children with both comprehensive mathematical tests and specific mathematical tasks used questionnaires to assess home numeracy. Their results showed that informal (LeFevre et al., 2009) and advanced formal activities (Skwarchuk et al., 2014) were associated with composite mathematical scores. Moreover, both formal (LeFevre et al., 2009; Manolitsis et al., 2013) and informal activities (LeFevre et al., 2009; Skwarchuk et al., 2014) were related with some specific mathematical measures (i.e., math fluency, counting, and nonsymbolic calculation).

Overall, only four studies (Zhou et al., 2006; Missall et al., 2015; Cheung et al., 2018; Leyva et al., 2019) did not observe any relationship between home numeracy (both questionnaire and observations) and mathematical skills (both comprehensive and specific mathematical measures). In addition, one study showed that the relationship between formal home numeracy and composite mathematical score was negative (Ciping et al., 2015). Although there are some commonalities, such as age, socioeconomic status, and country in which the study was conducted, among these studies, these factors are probably not conclusive enough to explain the absence and negative direction of the relationship between home numeracy and mathematical skills. With respect to age, at first sight, in the five studies mentioned earlier, children were, on average, either slightly younger or older compared with the children in other studies $(\sim 5.5$ years on average) that did observe a positive relation. In Cheung et al. (2018), Missall et al. (2015), and Zhou et al. (2006), children's mean age was $4.3,4.5$, and 4 years, respectively. The children in Leyva et al. (2019) were 6.6 years on average, which is older than most of the other studies. The age factor applies to the study of Ciping et al. (2015) that found a negative relationship and assessed home numeracy when children were on average 7.7 years old. This is later than all the other studies that collected home numeracy data when children were attending kindergarten. This seems to suggest there is a kind of critical period for home numeracy activities to result in a positive effect. However, this picture is not confirmed by all studies: two other studies (Ramani et al., 2015; Zippert and Ramani, 2017) that examined children's math skills and home numeracy at the age of around 4 and a study by Dearing et al. (2012), examining children's math skills and home numeracy at the age of around 6.7 reported positive associations (see also, Cheung et al., 2020). The number of studies examining relatively younger and older children is too small to establish reliable conclusions about the role of children's age.

Other commonalities between the studies in which a negative or no relation was found between home numeracy and children's mathematical skills are the socio-economic status of the family and the country where the research was conducted. The SES of the samples in those studies was low (Cheung et al., 2018; Leyva et al., 2019) or at least very diverse, with approximately half of the families having a low-SES background (Zhou et al., 2006; Ciping et al., 2015; Missall et al., 2015). Moreover, three (Zhou et al., 2006; Ciping et al., 2015; Cheung et al., 2018) of these five studies 
were conducted in Asian countries, i.e., Philippines and China, and one study included a sample living in the USA and having diverse ethnic backgrounds, $28 \%$ of which were Chinese (Leyva et al., 2019). However, the moderating effect of SES/country on the relation between home numeracy and mathematical skills is, just as age, not consistent. Huang et al. (2017) reported a positive relationship between home numeracy and children's mathematical skills in a Chinese sample [Huang et al., 2017; see also Zhang et al. (2020) for a recent replication]. Moreover, three studies with families from low socio-economic backgrounds (Ramani et al., 2015; Niklas and Schneider, 2017; Leyva, 2019; see also Harris et al., 2014) showed a positive association between home numeracy and children's mathematical skills.

Although the pattern revealed by our systematic review with respect to the moderating effect of SES/country on the relation between home numeracy and mathematical skills is not consistent and needs to be investigated further, it is clear that these factors are related to the frequency of home numeracy activities and children's mathematical skills. The majority of studies found a positive relation between SES and home numeracy activities (except Niklas and Schneider, 2014; Del Rio et al., 2017). In two studies by LeFevre et al. that were not included in our systematic analysis because they were not mentioned in the two databases we examined, it was shown that cultural factors indeed play a role in the relationship between home numeracy and mathematical skills. In one study, LeFevre et al. (2010b) found that Greek parents reported numeracy activities less frequently than Canadian parents, although formal home numeracy activities were associated with children's mathematical skills in both samples. In the other study, LeFevre et al. (2002) showed that French-speaking Canadian parents reported less frequent home numeracy activities than English-speaking Canadians.

In sum, the interactions between age, culture, home numeracy, and mathematical skills is worthy of further investigation, and may help to disentangle the precise moderating effects of age, SES, and culture on the relation between home numeracy and children's mathematical skills.

Beyond the fact that most of the studies have reported a positive relationship between home numeracy and children's mathematical skills, a more qualitative screening revealed five common findings and additional avenues for further research. First, six studies distinguished between basic and advanced home numeracy (either activities or talk) and all these studies have showed that advanced but not basic home numeracy plays an important role in children's mathematical skills (Gunderson and Levine, 2011; Skwarchuk et al., 2014; Ramani et al., 2015; Del Rio et al., 2017; Elliott et al., 2017; Zippert and Ramani, 2017). In these studies, examples of basic home numeracy included counting, reciting numbers, and identifying numerals, especially smaller than four. In combination with the fact that the children's age in these studies ranged from 4 to 6 (see Table 1), it can be assumed that these children already possessed this basic number knowledge. Based on this assumption, our results are in line with Vygotsky's theory of Zone of Proximal Development (ZPD, 1978): Practicing skills that children can already do by themselves does not result in improvement; by contrast, practicing skills that are just above the expertise level of the children provides opportunities for improvement. Following this argument, it can be hypothesized that basic home numeracy activities are more related to mathematical skills than advanced activities in relatively younger samples, whereas the opposite pattern is to be expected in relatively older samples. This needs to be confirmed in future research.

The second common point we observed is that six studies acquired home numeracy data from mothers, whereas only two of them also recruited fathers. The other studies did not explicitly distinguish between mothers and fathers, and gathered data from any parent whoever is the respondent which were mostly mothers. Five studies with mothers found associations between home numeracy and children's mathematical skills (Baker, 2015; Susperreguy and Davis-Kean, 2016; Del Rio et al., 2017; Elliott et al., 2017; Huang et al., 2017), and only one did not observe a relationship (Leyva et al., 2019). However, the two studies (Del Rio et al., 2017; Huang et al., 2017) that compared mothers and fathers showed that only mothers' but not fathers' formal home numeracy activities were linked with the children's mathematical skills. Del Rio et al. (2017) also reported that mothers and fathers did not significantly differ in the frequency of engaging in formal numeracy activities, whereas Huang et al. (2017) observed that mothers' engagement in formal numeracy activities was significantly more frequent than fathers' engagement. Furthermore, Huang et al. (2017) showed that fathers' engagement in informal activities was significantly more frequent than mothers' and that it was related with children's written calculation skills. To date, there are only two studies that compared mothers' and fathers' home numeracy explicitly and more research comparing mothers' and father's home numeracy activities is needed before drawing conclusions. However, it is an interesting topic worthwhile to explore further in future studies.

As the third common finding, we noticed that among the studies that used questionnaires, the number of investigations on informal home numeracy activities $(n=11)$ was smaller compared with investigations on formal home numeracy activities $(n=22)$. Some studies that investigated both formal and informal home numeracy in one sample showed that children's mathematical skills were related with formal home numeracy activities but not with informal ones (LeFevre et al., 2010b; Rosales et al., 2020), whereas others observed the reverse pattern: informal but not formal activities were associated with children's mathematical skills (Zhang et al., 2020). Still other studies reported that formal and informal activities were associated with different mathematical measures (e.g., LeFevre et al., 2009; Skwarchuk et al., 2014; Ciping et al., 2015; Mutaf-Yildiz et al., 2018 b), or that the relation depends on the parent who completed the questionnaire (e.g., Del Rio et al., 2017). Moreover, studies that calculated home numeracy as the sum score of both formal and informal activities (Missall et al., 2015) found no relation between home numeracy and children's mathematical skills (see also Blevins-Knabe and Musun-Miller, 1996). Two studies reported that formal home numeracy activities were related with a wider range of mathematical skills in children compared with informal ones (Ramani et al., 2015; Huntsinger et al., 2016). However, a recent meta-analysis of 11 studies showed 
that informal activities are stronger predictors of mathematical skills compared with formal ones (Dunst et al., 2017). On the other hand, intervention studies (which were not analyzed in the current review) also revealed some conflicting results. Some studies showed playing number games, i.e., informal activities, improved children in mathematical skills (e.g., Ramani and Siegler, 2008; Siegler and Ramani, 2008); whereas others did not observe this effect (Vandermaas-Peeler et al., 2012; Zippert et al., 2019). Overall, both types of home numeracy activities seem to play a role in children's mathematical skills as supported by the recent findings of Susperreguy et al. (2020). Future research is encouraged to include both formal and informal home numeracy activities to better understand the reasons of the differential relations between formal and informal activities and children's mathematical skills.

Fourth, we noticed that observations of parent-child interactions $(n=8)$ were less frequently used to index home numeracy compared with questionnaires $(n=26)$. The more frequent use of questionnaires is understandable. It is less time consuming than observations, thus easily applicable to larger samples. However, responses on questionnaires are retrospective and rely on memory, thus might be influenced by social desirability bias or false memories (e.g., Gravetter and Forzano, 2006). On the other hand, observation studies are less influenced by memory and social desirability bias if a cover story is presented to hide the aim of the study (Harmon-Jones et al., 2007). These technical differences between the two methods call for more research directly comparing them to understand whether they can be used interchangeably or whether they measure different aspects of home numeracy. To date, only four studies used two methods of measuring home numeracy (questionnaire and observations) in one sample. Two of these studies showed that data from a questionnaire on the one hand and from observations on the other were not related (Missall et al., 2017; Mutaf-Yildiz et al., 2018b). In addition, Mutaf-Yildiz et al. (2018b) showed that children's mathematical skills were positively correlated with reported home numeracy activities, whereas it was negatively correlated with observed numeracy talk (see also, Zippert et al., 2019). Also, the other studies observed differences between both methods: Lehrl et al. (2019) found that children's mathematical skills were related with observed numeracy talk but not with formal numeracy activities. Ramani et al. (2015) found that both measures were differentially associated with various mathematical skills: Home numeracy measured with a questionnaire was related with a composite score of basic mathematics, whereas home numeracy measured with observations was related with a composite score of advanced mathematical skills. More research comparing the two methods is required to identify the underlying reasons of their unrelated outcomes and their differential relations to various math measures. It is especially important to reveal what aspects of home numeracy are exactly being measured via the two methods. For instance, it could be tested whether parents who indicate that they play board games with their children frequently on a questionnaire also have frequent number talk observed during a board game session with their children.
Finally, the fifth common finding we noticed is that most of the studies examined children with comprehensive mathematical tests $(n=22)$ compared with specific mathematical tasks ( $n$ $=11$ - -excluding the ones that used both methods $(n=$ 4). However, the use of composite mathematical scores in home numeracy research makes it unclear to observe which specific skills are associated with home numeracy. For instance, Manolitsis et al. (2013) found that formal home numeracy activities were not associated with composite math score (TEMA3 ); however, they were related to counting skills in kindergartners (see also Cheung et al., 2018). Furthermore, recent studies showed that it is important to dissociate between different mathematical skills as they found that formal and informal home numeracy activities were differentially related to specific mathematical tasks (Mutaf-Yildiz et al., 2018a; Vasilyeva et al., 2018).

There are two possible reasons for the differential associations. On the one hand, various numerical skills might rely on (partially) different underlying processes (e.g., Reynvoet and Sasanguie, 2016; Sasanguie et al., 2017). For example, when comparing effect sizes, the relation between mathematics and symbolic number processing is larger and more consistent compared with the effect size of the relation between mathematics and non-symbolic number processing (De Smedt et al., 2013; Schneider et al., 2017). On the other hand, different tasks assumed to measure one concept are not necessarily associated. It has for instance been shown that non-symbolic comparison and number line estimation tasks were not related to each other (Sasanguie and Reynvoet, 2013; Maertens et al., 2016). From these insights, it follows that home numeracy can be correlated with one specific skill but not another. Therefore, future research is needed to clarify which specific type of home numeracy activity is linked with which specific type of mathematical skills, by examining various specific types of mathematical skills.

The present systematic review comes with some limitations due to the decisions made in the search process. First, interest in home numeracy is increasing very fast and new papers are published frequently. The scope of the articles analyzed in this research is limited to the ones published until November 2019. Second, several studies-including some that we were aware ofhave been missed in our search because we screened only two databases and they were not indexed in those databases. To stick to the search strategy, those articles were not included in the analysis. Third, the scope of our research excluded home numeracy intervention studies. In intervention studies, parents are informed about the role they play in the development of their children's mathematical skills and how they can improve their support. Results suggest that home numeracy interventions have a positive effect on mathematical skills (e.g., Starkey and Klein, 2000; Niklas et al., 2016). However, in order to present a complete picture, the discussion was expanded with those recently published, missed, and discussing interventions papers (LeFevre et al., 2002, 2010a,b; Vandermaas-Peeler et al., 2012; Harris et al., 2014; Dunst et al., 2017; Cheung et al., 2020; Susperreguy et al., 2020; Zhang et al., 2020; Zippert 
et al., 2020). Finally, it should be noted that the current results did not inform us about the overall effect size of the relationship between home numeracy and mathematical skills in children.

In conclusion, the current systematic search and review demonstrated that a positively significant link between home numeracy and children's mathematical skills has been observed in the majority of the studies. In addition, a $p$-curve analysis confirmed that this relationship holds a true effect. Moreover, a qualitative inspection of all studies revealed some possible sources for the variance in the relationship between home numeracy and mathematical skills in children across studies. These sources include children's age, family SES, and location of the research, the distinction between basic and advanced activities, differences between mothers and fathers, differences between questionnaires and/or observations, and differences between formal and informal activities. Differences between studies also emerged due to differences in the measurement of mathematical skills, i.e., specific mathematical tasks or comprehensive mathematical tests. These sources all seem to have an impact on observed findings. Therefore, more research is

\section{REFERENCES}

Anders, Y., Rossbach, H.-G., Weinert, S., Ebert, S., Kuger, S., Lehrl, S., et al. (2012). Home and preschool learning environments and their relations to the development of early numeracy skills. Early Child. Res. Q. 27, 231-244. doi: 10.1016/j.ecresq.2011.08.003

Baker, C. E. (2015). Does parent involvement and neighborhood quality matter for African American boys' kindergarten mathematics achievement? Early Educ. Dev. 26, 342-355. doi: 10.1080/10409289.2015.968238

Baroody, A., and Ginsburg, H. (1990). Chapter 4: children's mathematical learning: a cognitive view. J. Res. Math. Educ. Monogr. 4, 51-210. doi: 10.2307/749912

Benavides-Varela, S., Butterworth, B., Burgio, F., Arcara, G., Lucangeli, D., and Semenza, C. (2016). Numerical activities and information learned at home link to exact numeracy skills in 5-6 years-old children. Front. Psychol. 7:94. doi: 10.3389/fpsyg.2016.00094

Blevins-Knabe, B., and Austin, A. B. (2016). Early Childhood Mathematics Skill Development in the Home Environment. Cham: Springer International Publishing. doi: 10.1007/978-3-319-43974-7

Blevins-Knabe, B., Austin, A. B., Musun, L., Eddy, A., and Jones, R. M. (2000). Family home care providers' and parents' beliefs and practices concerning mathematics with young children. Early Child Dev. Care 165, 41-58. doi: 10.1080/0300443001650104

Blevins-Knabe, B., and Musun-Miller, L. (1996). Number use at home by children and their parents and its relationship to early mathematical performance. Early Dev. Paren. 5, 35-45. doi: 10.1002/(SICI)1099-0917(199603)5:1<35::AID-EDP113>3.0.CO;2-0

Bracken, B. A. (2006). Bracken Basic Concepts Scale-Revised. San Antonio, TX: Psychological Corporation. doi: 10.1037/t14979-000

Bugden, S., and Ansari, D. (2011). Individual differences in children's mathematical competence are related to the intentional but not automatic processing of Arabic numerals. Cognition 118, 32-44. doi: 10.1016/j.cognition.2010.09.005

Caldwell, B., and Bradley, R. (1984). Home observation for measurement of the environment (HOME). Little Rock, AR: University of Arkansas at Little Rock.

Cheung, S. K., Dulay, K. M., and McBride, C. (2020). Parents' characteristics, the home environment, and children's numeracy skills: how are they related in low- to middle-income families in the Philippines? J. Exp. Child Psychol. 192. doi: 10.1016/j.jecp.2019.104780

Cheung, S. K., Yang, X., Dulay, K. M., and McBride, C. (2018). Family and individual variables associated with young Filipino children's numeracy necessary to draw quantitative conclusions about these possible sources of variance.

\section{DATA AVAILABILITY STATEMENT}

All datasets presented in this study are included in the article and further inquiries can be directed to the corresponding author.

\section{AUTHOR CONTRIBUTIONS}

BMY, DS, BDS, and BR conceived and designed the study and interpreted the results. BMY organized the data and ran the analyses, wrote the draft of the overall study, and revised the draft carefully. DS, BDS, and BR critically reviewed the draft. All authors contributed to the article and approved the submitted version.

\section{FUNDING}

This research was supported by the Grant DBOF/12/009 'Early mediators of number sense' from the Research Fund KU Leuven. interest and competence. Br. J. Dev. Psychol. 36, 334-353. doi: 10.1111/bjdp. 12222

Ciping, D., Silinskas, G., Wei, W., and Georgiou, G. K. (2015). Cross-lagged relationships between home learning environment and academic achievement in Chinese. Early Child. Res. Q. 33, 12-20. doi: 10.1016/j.ecresq.2015.05.001

Cohen, J. (1960). A coefficient of agreement for nominal scales. Educ. Psychol. Meas. 20, 37-46. doi: 10.1177/001316446002000104

Connolly, A. J. (2000). KeyMath-Revised/Updated Canadian Norms. Richmond Hill, ON: PsyCan.

De Smedt, B., Noël, M.-P., Gilmore, C., and Ansari, D. (2013). The relationship between symbolic and non-symbolic numerical magnitude processing skills and the typical and atypical development of mathematics: a review of evidence from brain and behavior. Trends Neurosc. Educa. 2, 48-55. doi: 10.1016/j.tine.2013.06.001

Dearing, E., Casey, B. M., Ganley, C. M., Tillinger, M., Laski, E., and Montecillo, C. (2012). Young girls' arithemtic and spatial skills: the distal and proximal roles of family socioeconomics and home learning experiences. Early Child. Res. Q. 27, 458-470. doi: 10.1016/j.ecresq.2012.01.002

Dehaene, S. (2001). Precis of the number sense. Mind Lang. 16, 16-36. doi: 10.1111/1468-0017.00154

Dehaene, S. (2011). The Number Sense: How the Mind Creates Mathematics, Revised and Updated Edition. New York, NY: Oxford University Press.

Del Rio, M. F., Susperreguy, M. I., Strasser, K., and Salinas, V. (2017). Distinct influences of mothers and fathers on kindergartners' numeracy performance: the role of math anxiety, home numeracy practices, and numeracy expectations. Early Educ. Dev. 28, 939-955. doi: 10.1080/10409289.2017.1331662

Dubow, E. F., Boxer, P., and Huesmann, L. R. (2009). Long-term effects of parents' education on children's educational and occupational success: mediation by family interactions, child aggression, and teenage aspirations. Merrill Palmer Q. 55, 224-249. doi: 10.1353/mpq.0.0030

Duncan, G. J., Dowsett, C. J., Claessens, A., Magnuson, K., Huston, A. C., Klebanov, P., et al. (2007). School readiness and later achievement. Dev. Psychol. 43, 1428-1446. doi: 10.1037/0012-1649.43.6.1428

Dunst, C. J., Hamby, D. W., Wilkie, H., and Dunst, K. S. (2017). "Metaanalysis of the relationship between home and family experiences and young children's early numeracy learning," in Engaging Families as Children's First Mathematics Educators, eds S. Phillipson, A. Gervasoni, and P. Sullivan (Singapore: Springer), 105-125. doi: 10.1007/978-981-10-2553-2_7

Elliot, C., Smith, P., and McCulloch, K. (1996). British Ability Scales Second Edition (BAS II). Windsor: NFER-Nelson Publishing Company Limited. 
Elliott, L., and Bachman, H. J. (2018). SES disparities in early math abilities: the contributions of parents' math cognitions, practices to support math, and math talk. Dev. Rev. 49, 1-15. doi: 10.1016/j.dr.2018.08.001

Elliott, L., Braham, E. J., and Libertus, M. E. (2017). Understanding sources of individual variability in parents' number talk with young children. J. Exp. Child Psychol. 159, 1-15. doi: 10.1016/j.jecp.2017.01.011

Geary, D. C., vanMarle, K., Chu, F. W., Rouder, J., Hoard, M. K., and Nugent, L. (2018). Early conceptual understanding of cardinality predicts superior school-entry number-system knowledge. Psychol. Sci. 29, 191-205. doi: $10.1177 / 0956797617729817$

Gelman, R., and Meck, E. (1983). Preschoolers' counting: Principles before skills. Cognition 13, 343-359. doi: 10.1016/0010-0277(83)90014-8

Gilmore, C. K., McCarthy, S. E., and Spelke, E. E. (2010). Non-symbolic arithmetic abilities and achievement in the first year of formal schooling in mathematics. Cognition 115, 394-406. doi: 10.1016/j.cognition.2010.02.002

Ginsburg, H., and Baroody, A. J. (1990). TEMA-2: Test of early mathematics ability. Austin, TX: Pro-Ed.

Glenn, D. E., Demir-Lira, Ö. E., Gibson, D. J., Congdon, E. L., and Levine, S. C. (2018). Resilience in mathematics after early brain injury: the roles of parental input and early plasticity. Dev. Cogn. Neurosci 30, 304-313. doi: 10.1016/j.dcn.2017.07.005

Grant, M. J., and Booth, A. (2009). A typology of reviews: an analysis of 14 review types and associated methodologies. Health Info. Libr. J. 26, 91-108. doi: 10.1111/j.1471-1842.2009.00848.x

Gravetter, F. J., and Forzano, L.-A. B. (2006). Research methods for the behavioral sciences. Belmont, CA: Thomson Wadsworth.

Gunderson, E. A., and Levine, S. C. (2011). Some types of parent number talk count more than others: relations between parents' input and children's cardinal-number knowledge. Dev. Sci. 14, 1021-1032. doi: 10.1111/j.1467-7687.2011.01050.x

Harmon-Jones, E., Amodio, D. M., and Zinner, L. R. (2007). Handbook of Emotion Elicitation and Assessment. New York, NY: Oxford University Press, viii, 91-105. 483pp.

Harris, T., Sideris, J., Serpell, Z., Burchinal, M., and Pickett, C. (2014). Domainspecific cognitive stimulation and maternal sensitivity as predictors of early academic outcomes among low-income African American preschoolers. J. Negro Educ. 83, 15-28. doi: 10.7709/jnegroeducation.83.1.0015

Hojnoski, R. L., and Floyd, R. G. (2013). Individual Growth and Development Indicators of Early Numeracy (IGDIs-EN). Retrieved from: http://www.myigdis. com/

Huang, Q., Zhang, X., Liu, Y., Yang, W., and Song, Z. (2017). The contribution of parent-child numeracy activities to young Chinese children's mathematical ability. Br. J. Educ. Psychol. 87, 328-244. doi: 10.1111/bjep.12152

Huntsinger, C. S., Jose, P. E., Liaw, F.-R., and Ching, W.-D. (1997). Cultural differences in early mathematics learning: a comparison of euro-American, Chinese-American, and Taiwan-Chinese families. Int. J. Behav. Dev 21, 371-388. doi: 10.1080/016502597384929

Huntsinger, C. S., Jose, P. E., and Luo, Z. (2016). Parental facilitation of early mathematicas and reading skills and knowledge through encouragement of home-based activities. Early Child. Res. Q. 37, 1-15. doi: 10.1016/j.ecresq.2016.02.005

Joober, R., Schmitz, N., Annable, L., and Boksa, P. (2012). Publication bias: what are the challenges and can they be overcome? J. Psych. Neurosci. 37, 149-152. doi: $10.1503 /$ jpn. 120065

Jordan, N. C., Kaplan, D., Olah, L. N., and Locuniak, M. N. (2006). Number sense growth in kindergarten: a longitudinal investigation of children at risk for mathematics difficulties. Child Dev. 77, 153-175. doi: 10.1111/j.1467-8624.2006.00862.x

Kleemans, T., Peeters, M., Segers, E., and Verhoeven, L. (2012). Child and home predictors of early numeracy skills in kindergarten. Early Child. Res. Q. 27, 471-477. doi: 10.1016/j.ecresq.2011.12.004

Kleemans, T., Segers, E., and Verhoeven, L. (2013). Relations between home numeracy experiences and basic calculation skills of children with and without specific language impairment. Early Child. Res. Q. 28, 415-423. doi: 10.1016/j.ecresq.2012.10.004

Kleemans, T., Segers, E., and Verhoeven, L. (2018). Individual differences in basic arithmetic skills in children with andwithout developmental language disorder: role of home numeracyexperiences. Early Child. Res. Q. 43, 62-72, doi: 10.1016/j.ecresq.2018.01.005

Krajewski, K. (2005). "Vorschulische Mengenbewusstheit von Zahlen und ihre Bedeutung für die Früherkennung von Rechenschwäche [Preschool awareness for quantities of numbers and its importance for the early identification of dyscalculia]," in Diagnostik von Mathematikleistungen, eds M. Hasselhorn, H. Marx, and W. Schneider. (Göttingen: Hogrefe), 49-70.

Krajewski, K., Küspert, P., Schneider, W., and Visé, M. (2002). Deutscher Mathematiktest für erste Klassen (DEMAT 1+) [German mathematical test battery for Grade 1]. Göttingen: Hogrefe.

Kuger, D., Pflieger, K., and Rossbach, H. G. (2005). Familieneinschätzskala Forschungsversion [Family rating scale, research version]. Unpublished instrument, University of Bamberg, Bamberg, Germany.

LeFevre, J. A., Clarke, T., and Stringer, A. P. (2002). Influences of language and parental involvement on the development of counting skills: comparisons of French- and English-speaking Canadian children. Early Child Dev. Care 172, 283-300. doi: 10.1080/03004430212127

LeFevre, J. A., Fast, L., Skwarchuk, S.-L., Smith-Chant, B. L., Bisanz, J., Kamawar, D., et al. (2010a). Pathways to mathematics: longitudinal predictors of performance. Child Dev. 81, 1753-1767. doi: 10.1111/j.1467-8624.2010.01508.x

LeFevre, J. A., Polyzoi, E., Skwarchuk, S., Fast, L., and Sowinski, C. (2010b). Do home numeracy and literacy practices of Greek and Canadian parents predict the numeracy skills of kindergarten children? Int. J. Early Years Educ. 18, 55-70. doi: 10.1080/09669761003693926

LeFevre, J. A., Skwarchuk, S. L., Smith-Chant, B. L., Fast, L., Kamawar, D., and Bisanz, J. (2009). Home numeracy experiences and children's math performance in the early school years. Can. J. Behav. Sci. 41, 55-66. doi: $10.1037 / \mathrm{a} 0014532$

Lehrl, S., Ebert, S., Blaurock, S., Rossbach, H.-G., and Weinert, S. (2019). Longterm and domain-specific relations between the early years home learning environment and students' academic outcomes in secondary school. School Effect. School Improv. 31, 102-124. doi: 10.1080/09243453.2019.1618346

Lenhard, W., Hasselhorn, M., and Schneider, W. (2011). Kombiniertes Leistungsinventar zur allgemeinen Schulleistung und für Schullaufbahnempfehlungen in der vierten Klasse [Combined test for the assessment of general school performance and the recommendation of subsequent school track in Grade 4]. Göttingen: Hogrefe.

Levine, S. C., Suriyakham, L. W., Rowe, M. L., Huttenlocher, J., and Gunderson, E. (2010). What counts in th development of young children's number knowledge? Dev. Psychol. 46, 1309-1319. doi: 10.1037/a0019671

Leyva, D. (2019). How do low-income Chilean parents support their preschoolers' writing and math skills in a grocery game? Early Educ. Dev. 30, 114-130. doi: 10.1080/10409289.2018.1540250

Leyva, D., Tamis-LeMonda, C., and Yoshikawa, H. (2019). What parents bring to the table: Maternal behaviors in a grocery game and first-graders literacy and math skills in a low-income sample. Elem. Sch. J. 119, 629-650. doi: $10.1086 / 703104$

Maertens, B., De Smedt, B., Sasanguie, D., and Reynvoet, B. (2016). Enhancing arithmetic in pre-schoolers with comparison or number line estimation training: does it matter? Learn. Instru. 46, 1-11. doi: 10.1016/j.learninstruc.2016.08.004

Manolitsis, G., Georgiou, G. K., and Tziraki, N. (2013). Examining the effects of home literacy and numeracy environment on early reading and math acquisition. Early Child. Res. Q. 28, 692-703. doi: 10.1016/j.ecresq.2013.05.004

McHugh, M. L. (2012). Interrater reliability: the kappa statistic. Biochem. Med. 22, 276-282. doi: 10.11613/BM.2012.031

Melchers, P., and Preuss, U. (2003). Kaufman Assessment Battery for Children (KABC). German Version (6th ed.). Göttingen: Hogrefe.

Melhuish, E. C., Phan, M. B., Sylva, K., Sammons, P., Siraj-Blatchford, I., and Taggart, B. (2008). Effects of the home learning environemtn and preschool center experience upon literacy and numeracy development in early primary school. J. Soc. 64, 95-114. doi: 10.1111/j.1540-4560.2008.00550.x

Missall, K., Hojnoski, R. L., Caskie, G. I. L., and Repasky, P. (2015). Home numeracy environments of preschoolers: examining relations among mathematical activities, parent mathematical beliefs, and early mathematical skills. Early Educ. Dev. 26, 356-376. doi: 10.1080/10409289.2015. 968243 
Missall, K., Hojnoski, R. L., and Moreano, G. (2017). Parent-child mathematical interactions: examining self-report and direct observation. Early Child Dev. Care 187, 1896-1908. doi: 10.1080/03004430.2016.1193731

Muñoz-Sandoval, A. F., Woodcock, R. W., McGrew, K. S., and Mather, N. (2005). Bateria III Woodcock-Muñoz: Pruebas de Aprovechamiento [Achievement Test]. Itasca, IL: Riverside Publishing.

Mutaf-Yildiz, B., Sasanguie, D., De Smedt, B., and Reynvoet, B. (2018a). Frequency of home numeracy activities is differentially related to basic number processing and calculation skills in kindergartners. Front. Psychol. 9. doi: 10.3389/fpsyg.2018.00340

Mutaf-Yildiz, B., Sasanguie, D., De Smedt, B., and Reynvoet, B. (2018b). Investigating the relationship between two home numeracy measures: a questionnaire and observations during Lego building and book reading. Br. J. Dev. Psychol. 36, 354-370. doi: 10.1111/bjdp.12235

Napoli, A. R., and Purpura, D. J. (2018). The home literacy and numeracy environment in preschool: cross-domain relations of parent-child practices and child outcomes. J. Exp. Child Psychol. 166, 581-603. doi: 10.1016/j.jecp.2017.10.002

Niklas, F., Cohrssen, C., and Tayler, C. (2016). Improving preschoolers' numerical abilities by enhancing the home numeracy environment. Early Educ. Dev. 27, 372-383. doi: 10.1080/10409289.2015.1076676

Niklas, F., and Schneider, W. (2014). Casting the die before the die is cast: the importance of the home numeracy environment for preschool children. Europ. J. Psychol. Educ. 29, 327-345. doi: 10.1007/s10212-013-0201-6

Niklas, F., and Schneider, W. (2017). Home learning environment and development of child competencies form kindergarten until the end of elementary school. Contemp. Educ. Psychol. 49, 263-274. doi: 10.1016/j.cedpsych.2017.03.006

Piazza, M., Izard, V., Pinel, P., Le Bihan, D., and Dehaene, S. (2004). Tuning curves for approximate numerosity in the human intraparietal sulcus. Neuron 44, 547-555. doi: 10.1016/j.neuron.2004.10.014

Purpura, D. J., Baroody, A. J., and Lonigan, C. J. (2013). The transition from informal to formal mathematical knowledge: mediation by numeral knowledge. J. Educ. Psychol. 105, 453-464. doi: 10.1037/a0031753

Purpura, D. J., Reid, E. E., Eiland, M. D., and Baroody, A. J. (2015). Using a brief preschool early numeracy skills screener to identify young children with mathematics difficulties. School Psych. Rev. 44, 41-59. doi: 10.17105/SPR44-1.41-59

Ramani, G. B., Rowe, M. L., Eason, S. H., and Leech, K. A. (2015). Math talk during informal learning activities in Head Start families. Cogn. Dev. 35, 15-33. doi: 10.1016/j.cogdev.2014.11.002

Ramani, G. B., and Siegler, R. S. (2008). Promoting broad and stable improvements in low-income children's numerical knowledge through playing number board games. Child Dev. 79, 375-394. doi: 10.1111/j.1467-8624.2007.01131.x

Reynvoet, B., and Sasanguie, D. (2016). The symbol grounding problem revisited: a thorough evaluation of the ans mapping account and the proposal of an alternative account based on symbol-symbol associations. Front. Psychol. 7:1581. doi: 10.3389/fpsyg.2016.01581

Rosales, J., Ramos, M., Janez, A., and De Sixte, R. (2020). Home numeracy activites in relation to basic number processing in kindergartners. Revista de Educación 389, 45-66. doi: 10.4438/1988-592X-RE-2020-389-454

Sasanguie, D., De Smedt, B., and Reynvoet, B. (2017). Evidence for distinct magnitude systems for symbolic and non-symbolic number. Psychol. Res. 81, 231-242. doi: 10.1007/s00426-015-0734-1

Sasanguie, D., Göbel, S. M., Moll, K., Smets, K., and Reynvoet, B. (2013). Approximate number sense, symbolic number processing, or number-space mappings: what underlies mathematics achievement? J. Exp. Child Psychol. 114, 418-431. doi: 10.1016/j.jecp.2012.10.012

Sasanguie, D., and Reynvoet, B. (2013). Number comparison and number line estimation rely on different mechanisms. Psychol. Belg. 53, 17-35. doi: $10.5334 / \mathrm{pb}-53-4-17$

Sasanguie, D., Van den Bussche, E., and Reynvoet, B. (2012). Predictors for mathematics achievement? Evidence from a longitudinal study. Mind Brain Educ. 6, 119-128. doi: 10.1111/j.1751-228X.2012.01147.x

Schneider, M., Beeres, K., Coban, L., Merz, S., Schmidt, S., Stricker, J., et al. (2017). Associations of non-symbolic and symbolic numerical magnitude processing with mathematical competence: a meta-analysis. Dev. Sci 20. doi: $10.1111 /$ desc. 12372
Segers, E., Kleemans, T., and Verhoeven, L. (2015). Role of parent literacy and numeracy expectations and activities in predicting early numeracy skills. Math Think Learn. 17, 219-236. doi: 10.1080/10986065.2015.1016819

Sénéchal, M., and LeFevre, J. A. (2002). Parental involvement in the development of children's reading skills: a five-year longitudinal study. Child Dev. 73, 445-460. doi: 10.1111/1467-8624.00417

Siegler, R., and Booth, J. (2004). Development of numerical estimation in young children. Child Dev. 75, 428-444. doi: 10.1111/j.1467-8624.2004.00684.x

Siegler, R. S., and Ramani, G. B. (2008). Playing linear numerical board games promotes low-income children's numerical development. Dev. Sci. 11, 655-661. doi: 10.1111/j.1467-7687.2008.00714.x

Simonsohn, U., Nelson, L. D., and Simmons, J. P. (2013, April 24). P-Curve: A Key to the File Drawer. Journal of Experimental Psychology: General, Forthcoming. Available online at: https://ssrn.com/abstract=2256237

Simonsohn, U., Nelson, L. D., and Simmons, J. P. (2014, April 27). P-Curve and Effect Size: Correcting for Publication Bias Using Only Significant Results. doi: $10.2139 /$ ssrn. 2377290

Skwarchuk, S. L. (2009). How do parents support preschoolers' numeracy learning experiences at home? Early Childhood Educ. J. 37, 189-197. doi: 10.1007/s10643-009-0340-1

Skwarchuk, S. L., Sowinski, C., and LeFevre, J. A. (2014). Formal and informal home learning activities in relation to children's early numeracy and literacy skills: the development of a home numeracy model. J. Exp. Child Psychol. 121, 63-84. doi: 10.1016/j.jecp.2013.11.006

Starkey, P., and Klein, A. (2000). Fostering parental support for children's mathematical development: an intervention with head Start families. Early Educ. Dev. 11, 659-680. doi: 10.1207/s15566935eed1105_7

Starkey, P., Klein, A., Chang, I., Dong, Q., Pang, L., and Zhou, Y. (1999). "Environmental supports for young children's mathematical development in Chine and the United States," in Paper Presented at the Meeting of the Society for Research in Child Development (Albuquerque, NM).

Susperreguy, M. I., and Davis-Kean, P. E. (2016). Maternal math talk in the home and math skills in preschool children. Early Educ. Dev. 9289, 1-17. doi: 10.1080/10409289.2016.1148480

Susperreguy, M. I., Douglas, H., Xu, C., Molina-Rojas, N., and LeFevre, J. A. (2020). Expanding the home numeracy model to chilean children: relations among parental expectations, attitudes, activities, and children's mathematical outcomes. Early Child. Res. Q. 50, 16-28. doi: 10.1016/j.ecresq.2018.06.010

Tymms, P., and Albone, S. (2002). "Performance indicators in primary school," in School Improvement Through Performance Feedback, eds A. J. Visscher and R. Coe (Lisse: Routledge; Taylor and Francis Group), 191-218.

Van Luit, J., and Van de Rijt, B. (2009). (Utrecht early numeracy test-revised) Utrechtse Getalbegrip Toets-Revised. Apeldoorn: Graviant.

Vandermaas-Peeler, M., Ferretti, L., and Loving, S. (2012). Playing the ladybug game: parent guidance of young children's numeracy activities. Early Child Dev. Care 182, 1289-1307. doi: 10.1080/03004430.2011.609617

Vasilyeva, M., Laski, E., Veraksa, A., Weber, L., and Bukhalenkova, D. (2018). Distinct pathways from parental beliefs and practices to children's numeric skills. J. Cogn. Dev. 19, 345-366. doi: 10.1080/15248372.2018. 1483371

Visser, M. M., Juan, A. L., and Hannan, S. M. (2019). Early learning experiences, school entry skills and later mathematics achievement in South Africa. South Afr. J. Childhood Educ. 9:a597. doi: 10.4102/sajce.v9i1.597

Vygotsky, L. S. (1978). Mind in Society: The Development of Higher Psychological Processes. Cambridge, MA: Harvard University.

Woodcock, R., McGrew, K., and Mather, N. (2001). Woodcock-Johnson Tests of Achievement. Itasca, IL: Riverside Publishing Company.

Wynn, K. (1990). Children's understanding of counting. Cognition 36, 155-193. doi: 10.1016/0010-0277(90)90003-3

Wynn, K. (1992). Children's acquisition of the number words and the counting system. Cogn. Psychol. 24, 220-251. doi: 10.1016/0010-0285(92)9 0008-P

Zhang, X., Hu, B. Y., Zou, X., and Ren, L. (2020). Parent-child number application activities predict children's math trajectories from preschool to primary school. J. Educ. Psychol. doi: 10.1037/edu0000457. [Epub ahead of print].

Zhou, X., Huang, J., Wang, Z., Wang, B., Zhao, Z., Yang, L., et al. (2006). Parentchild interaction and children's number learning. Early Child Dev. Care 176, 763-775. doi: 10.1080/03004430500232680 
Zippert, E., Daubert, E. N., Scalise, N. R., Noreen, D. D., and Ramani, D. B. (2019). Tap space number three: "promoting math talk during parent-child tablet play." Dev. Psychol. 55, 1605-1614. doi: 10.1037/dev00 00769

Zippert, E., Douglas, A. A., Smith, M. R., and Rittle-Johnson, B. (2020). Preschoolers' broad mathematics experiences with parents during play. J. Exp. Child Psychol. 192. doi: 10.1016/j.jecp.2019. 104757

Zippert, E. L., and Ramani, G. B. (2017). Parents' estimations of preschoolers' number skills relate to at-home number-related activity engagement. Infant Child Dev. 26. doi: 10.1002/icd.1968
Conflict of Interest: The authors declare that the research was conducted in the absence of any commercial or financial relationships that could be construed as a potential conflict of interest.

Copyright (๑) 2020 Mutaf-Ylldiz, Sasanguie, De Smedt and Reynvoet. This is an open-access article distributed under the terms of the Creative Commons Attribution License (CC BY). The use, distribution or reproduction in other forums is permitted, provided the original author(s) and the copyright owner(s) are credited and that the original publication in this journal is cited, in accordance with accepted academic practice. No use, distribution or reproduction is permitted which does not comply with these terms. 


\section{OPEN ACCESS}

Edited by:

Michael S. Dempsey,

Boston University, United States

Reviewed by:

Edward Charles Melhuish, University of Oxford, United Kingdom

Pietro Spataro,

Mercatorum University, Italy

*Correspondence:

Susanne Ebert

susanne.ebert@ntnu.no

Specialty section:

This article was submitted to

Educational Psychology,

a section of the journal

Frontiers in Psychology

Received: 25 April 2020 Accepted: 17 August 2020 Published: 29 October 2020

Citation:

Ebert S, Lehrl S and Weinert S (2020) Differential Effects of the Home Language and Literacy Environment

on Child Language and Theory of Mind and Their Relation

to Socioeconomic Background.

Front. Psychol. 11:555654.

doi: 10.3389/fpsyg.2020.555654

\section{Differential Effects of the Home Language and Literacy Environment on Child Language and Theory of Mind and Their Relation to Socioeconomic Background}

\author{
Susanne Ebert ${ }^{1 *}$, Simone Lehrl ${ }^{2}$ and Sabine Weinert ${ }^{2}$ \\ ${ }^{1}$ Department of Psychology, Norwegian University of Science and Technology, Trondheim, Norway, ${ }^{2}$ Department \\ of Developmental Psychology, University of Bamberg, Bamberg, Germany
}

In this study, we examined differential effects of facets of the home language and literacy environment that are known to be relevant to either language development (i.e., quantity and quality of language and literacy stimulation at home) or theory of mind (ToM) development (i.e., parental mental state language), on both children's language skills and their ToM understanding. Moreover, we investigated whether these relations are particularly relevant for children from homes with low socioeconomic status (SES) and whether they account for SES-related disparities in child language skills and ToM understanding. Using longitudinal data of a sample of 224 monolingual German preschool children (assessment of language skills at age 4;6 and 5;6 and ToM at age $5 ; 6)$, we analyzed the effects of three facets of the home language and literacy environment on later child language and ToM understanding. These facets were book exposure as a measure for quantity of language and literacy stimulation at home, quality of verbal interaction, and parental mental state language assessed between ages 3 and 4. Path analyses showed that book exposure is related to both later ToM understanding and language skills at age 5;6 years; yet, this effect is mediated by earlier language skills at age 4;6 years. Furthermore, book exposure partly mediated the association between SES and language skills and, via earlier language skills at age 4;6, also the relation between SES and ToM. When focusing on children from lower SES families, book exposure and quality of verbal stimulation predicted children's later language skills at age 4;6. Book exposure also predicted change in language skills between age 4;6 and age 5;6. Further, book exposure proved to be significantly associated with children's ToM understanding at age 5;6 via the relation with language skills at 4;6 years. In addition, parental mental state language predicted children's ToM understanding at age 5;6 years. Our findings provide new evidence on how different facets of the home language and literacy environment are related to ToM and language development and their interrelation as well as their SES-related disparities.

Keywords: language, theory of mind, home learning environment, preschool age, socioeconomic status 


\section{INTRODUCTION}

In preschool-age children, language is known as one of the most important predictors of children's developing knowledge and understanding of the mental world, widely defined as theory of mind (ToM) development (Astington and Baird, 2005; Milligan et al., 2007). At the same time, environmental influences and particularly the home language and literacy environment have been shown to play an essential role in the development of both language and ToM (Hoff, 2006; Hughes and Devine, 2017). With the term "home language and literacy environment," we refer to a wide range of facets of the home learning environment that relate to verbal communication, verbal input, and language related material (such as books) including language and literacy stimulating behavior of parents (see for similar definition, for example, Tabors et al., 2001). However, besides the close interrelation between language and ToM during children's development, the question of how the home language and literacy environment impacts developmental progress has mainly been investigated separately for either ToM or language development. Thus, its role in the interrelation between both developmental domains has hardly been addressed. Moreover, the facets of the home language and literacy environment that are investigated in relation to language development differ from those investigated in ToM development. Against this background, the main aim of the present study was to connect these lines of research and to analyze how different facets of the home language and literacy environment that are investigated in relation to either language or ToM development are related to both children's language and ToM as well as their interrelation.

Over and above its functional role in various domains of child development, the home language and literacy environment is also discussed as a potential mediator for differences in developmental progress in children's language skills (e.g., Hoff, 2013) and ToM understanding (e.g., Devine and Hughes, 2016; Ebert et al., 2017) according to the family's socioeconomic status (SES). Again, these SES-related differences in ToM and language development have rarely been connected so far. Thus, in the present study, we also investigate whether and to what extent SES-related differences in ToM and language development are explained by different facets of the home language and literacy environment. Besides, our study explores whether these facets of the home language and literacy environment are particularly relevant for children growing up in low SES families.

\section{Home Language and Literacy Environment and Children's Language Development}

A large body of research suggests that providing children with the experience of a varied and rich language and literacy exposure at home, such as sharing books, involving children in discourse, and using child-directed speech including recasts, extensions, and reformulations of the child's utterances, promotes children's language and literacy development (e.g., Hoff-Ginsberg and
Shatz, 1982; Sénéchal et al., 1998; Burgess et al., 2002; Mol and Neuman, 2014). Thereby, quantitative and qualitative aspects of language and literacy exposure are to be distinguished. The quantity of language and literacy exposure refers, amongst others, to children's more informal experiences with literacy and literacyrelated material (e.g., availability of books at home, frequency of shared book reading) and has been shown to be related to children's language and literacy development (e.g., Sénéchal and LeFevre, 2002; Mol and Bus, 2011; Lehrl et al., 2012). The quality of language exposure during shared book reading is also highly relevant to children's language development; in particular, a varied and complex language input, a high level of decontextualization from the here and now, asking open-ended questions, elaborating on the child's comments, and interacting in a responsive way that adapts to the needs of the child are related to child's language development (e.g., Reese and Cox, 1999; van Kleeck, 2003; Rowe, 2012; Lehrl et al., 2013; Mol and Neuman, 2014). For instance, Lehrl et al. (2012) showed that both book exposure and the quality of parent-child interactions during a shared book reading situation (e.g., asking open-ended questions, using stimulating language) measured when children were 3 years of age explained variance in children's language development during the next year; yet, the correlations between relevant facets of the home language and literacy environment were only low to medium, and differential effects were observed for vocabulary and grammar.

\section{Home Language and Literacy Environment and Children's ToM Development}

As for language development, rich experiences in language input at home are related to children's ToM understanding and development. For instance, studies with deaf children of hearing parents showed that these children are delayed in ToM development; in contrast, deaf children of deaf parents are not (e.g., Peterson and Siegal, 2000). This result is explained by differences in the children's home language and literacy environment: Hearing parents are not proficient in sign language and thus cannot provide a comparatively rich and stimulating home language and literacy environment. Moreover, longitudinal and training studies including typically developing children support the assumption that verbal interaction and language input promote children's ToM development (Ruffman et al., 2002; Lohmann and Tomasello, 2003). In particular, a specific type of verbal interaction, namely mental state language, has been suggested to support children's developing ToM (Ruffman et al., 2002; Gola, 2012; Ebert et al., 2017). Mental state language refers to language that is used to talk about mental states and processes (Bretherton and Beeghly, 1982; Antonietti et al., 2006; Olson et al., 2006). It includes verbal expressions that refer to mental states such as desires, intentions, or knowledge (e.g., "want," "belief," "knowledge," "memory") as well as talk about mental entities in general, even without explicitly naming mental states.

Verbal interactions between parents and their children vary with respect to the frequency and the way in which they 
talk about mental states (e.g., Ruffman et al., 2002; Peterson and Slaughter, 2003). Thus, parents' mental state language can be conceptualized as a specific aspect of the quality of the home language and literacy environment, and differences in this facet have been shown to relate to children's ToM development. For example, Ebert et al. (2017) demonstrated that the children of parents with a higher preference for using mental state language in everyday situations show faster growth in ToM understanding from ages 3 to 5 compared to their peers whose parents preferred mental state language less.

A recent meta-analysis (Tompkins et al., 2018) showed that particularly mental state talk about cognitive mental states as well as mental state talk that explains and elaborates on mental states was most predictive for children's ToM understanding. Moreover, the relations were more pronounced in studies observing mental state talk in a book reading context or when it was self-reported and less when reminiscing or play situations were observed. Further, the correlation between parental mental state talk was higher for children's false-belief understanding than for their emotion understanding. Falsebelief understanding comprises children's understanding that mental states may differ from reality (and thus can be false) but nevertheless motivate peoples' behavior. Typically, such an understanding develops between 3 and 6 years of age. False-belief understanding is widely accepted as one of the most critical steps in children's ToM development (Wellman et al., 2001).

\section{Specific Effects of the Home Language and Literacy Environment?}

In general, parental mental state language shares features with high-quality verbal interactions. For instance, mental state language is usually decontextualized language as mental states are not visible; when talking about what people think or know, this goes beyond the here and now. Moreover, mental state talk is often embedded in complex grammatical sentence structures, known as sentential complements (De Villiers and Pyers, 2002). Furthermore, mental state talk that elaborates and explains mental states comprises features of high-quality verbal interactions as this kind of talk often implies complex grammatical structures and is related to the quantity and quality of language stimulating verbal interactions in general (see also Hoff and Naigles, 2002; Ebert, 2011). Thus, parental mental state language might be conceptualized as high-quality verbal interaction; at the same time, high-quality verbal parent-child interactions may include talking about mental entities. Thus, for example, involving children in discussions about picture books, asking open-ended questions, and using decontextualized talk often means asking children about their own or the story protagonists' mental states. Moreover, the content of stories or books frequently refers to mental states such as the goals, intentions, or feelings of the story characters; thus, providing books and shared picture book reading may also support children's understanding of mental states (Astington and Pelletier, 1996; Dyer et al., 2000; Farkas et al., 2020).
However, until now research has rarely connected the more general facets of home language and literacy environment with the more specific mental aspects of the home language and literacy environment. Moreover, besides the close interrelation between language and ToM in development, there is not much research that investigates the interrelation between these specific facets of the home language and literacy environment and their effects on both ToM and language development.

One of the rare studies that connects the home language and literacy environment with children's ToM and language was conducted by Boerma et al. (2017). This study included children at the age of 9-10 years and showed that a measure of book exposure at home was likewise related to both children's advanced language competencies and their ToM understanding. However, the children were already in primary school, and the relations between measures were only assessed concurrently. Moreover, measures of the ToM-specific home language and literacy environment, i.e., parents' mental state language, were not included in the study.

A study by Adrian et al. (2005) with 4-5-years-old children, in contrary, included parents' mental state language. The authors analyzed how mothers' mental state language during a book reading session and the frequency of book reading were related to children's ToM development. Interestingly no correlations were found between the frequency of joint book reading at home and the number of words or mental state terms (variety and quantity) the mother used during picture book reading. However, both the frequency of joint picture book reading and the usage of mental state terms were related to children's falsebelief understanding, even after controlling for parents' education and age of the children. Mothers' usage of mental state terms during picture book reading even explained additional variance in false-belief understanding after accounting for the frequency of joint picture book reading and the number of other words used during picture book reading. However, although the authors included more general facets of the home language and literacy environment and specific mental facets, they focused only on ToM understanding but not on children's language skills and how these are related to the various facets of the home language and literacy environment. Thus, it remains unclear how the various facets of the home language and literacy environment are related to language in comparison to ToM development and how they might impact the relation between children's language and ToM. Moreover, as their study was cross-sectional, it cannot provide information on how the various facets of the home language and literacy environment affect the relation between language and ToM in development.

Against this background, one aim of the present study was to investigate whether there are specific relations between child language and the quantity as well as quality of language stimulating verbal interactions on the one hand and between ToM and parental mental state talk on the other hand or whether both indicators of the home language and literacy environment are comparably related to both domains of development and may even account for their interrelation. 


\section{Home Language and Literacy Environment as a Mediator and Moderator of SES-Related Disparities in Language and ToM Development}

Children from low SES families, i.e., from families with low income and/or low education, often perform below their peers from higher SES families on cognitive measures and academic achievement (e.g., Bradley and Corwyn, 2002). Accordingly, significant SES-related disparities have been documented for language (see Hoff, 2013) and ToM development (see Devine and Hughes, 2016).

One mechanism or pathway explaining the association between SES and children's language development is via SESrelated differences in language input and the quality of verbal interactions (Huttenlocher et al., 2010; Fernald and Weisleder, 2011; Hoff, 2013; Mol and Neuman, 2014; Pace et al., 2017). Following this assumption, parents with a higher SES provide their children with a comparatively richer home language and literacy environment than parents with a lower SES. They not only offer more books as well as literacy related activities to their children (z.B. Bradley et al., 2001; Fletcher and Reese, 2005; Leseman et al., 2007; Crosnoe et al., 2010), but they also speak more often with their children and use more complex and varied language (Hart and Risley, 1992; Arriaga et al., 1998; Huttenlocher et al., 2002, 2010).

Studies show that differences in the home language and literacy environment can at least partly explain SES-related differences in language skills (Huttenlocher et al., 2002; Hoff, 2003; Huttenlocher et al., 2010; Ebert et al., 2013; Mol and Neuman, 2014). However, the relations between SES, home language and literacy environment, and language development are more complex, and not all studies find this mediating effect. Thus, for example, whereas Huttenlocher et al. (2002) showed that differences in language input including complex grammatical structures accounted for SES-related differences in children's grammar, Weinert and Ebert (2013) did not find a mediating effect of a general indicator of the home language and literacy environment. The partially controversial results suggest that SES-related differences in child language might be differentially related to specific facets of the home language and literacy environment that may account for SES-related differences in child language (for a similar suggestion see also Rowe, 2012).

For ToM development, it is even less clear whether parental (mental state) language accounts for individual differences associated with SES. Only a few studies focused on SES, parental mental state language, and ToM. However, in their meta-analysis, Devine and Hughes (2016) found that the relation between SES and ToM is not completely explained by differences in parental mental state language. Moreover, in a longitudinal study including more than 120 preschoolers, Ebert et al. (2017) did not find differences in parental mental state language according to SES. Thus, parental mental state language did not explain individual differences in the children's ToM development between 3 and 5 years that were associated with SES background. However, the study results showed that, depending on SES, different types of parental mental state language were associated with ToM development: Whereas for children from higher SES backgrounds parents' preference for elaborated mental state language that explains and elaborates on these mental states was associated with children's ToM understanding, for children from lower SES families it was in particular the parents' preference for more basic mental state language, i.e., mental state language without broad elaborations and explanations of the mental states, that promoted children's ToM development. This result suggests that parental (mental state) language may not affect ToM development in the same way for all children.

It is also very likely that the effects of the home language and literacy environment on children's language development are moderated by social background. Thus, correlations between facets of the home language and literacy environment and language development are often documented particularly for low SES samples (e.g., Storch and Whitehurst, 2001; Pan et al., 2005; Mistry et al., 2008; Vernon-Feagans and Bratsch-Hines, 2013; Hirsh-Pasek et al., 2015; Rowe et al., 2017) and seem more pronounced in children from lower SES families (e.g., Bradley et al., 2001; Baydar et al., 2014; Shahaeian et al., 2018). Moreover, a study by Weinert et al. (2012) found differences in the home language and literacy environment to be particularly relevant to vocabulary development in a group of children with less advanced language skills at age 3 as compared to the children with more advanced language skills.

Against this background, another aim of our study was to investigate how different facets of the home language and literacy environment are related to SES and whether they account for differences in language and ToM development that are associated with SES. In addition, we analyze whether the effects of the home language and literacy environment are particularly pronounced in children from lower-SES families.

\section{The Present Study}

Previous studies have shown that various facets of the home language and literacy environment are connected to either language or ToM development. Moreover, ToM understanding and language skills are related in development (e.g., Milligan et al., 2007; Ebert, 2015, 2020). Against this background we investigated the relation of different facets of the home language and literacy environment to both language skills and ToM understanding as well as to their relation in development.

Drawing on longitudinal data, we analyzed how three facets of the home language and literacy environment of 3-4-yearold children are related to their language skills and ToM understanding two years later, i.e., at the age of 5-6 years, and how language skills at age 4-5 years mediate these relations. The three facets of the home language and literacy environment we included in our study are (a) book exposure as a proxy for the quantity of language and literacy stimulation at home, (b) quality of verbal interaction during shared picture book reading as a measure of the quality of verbal stimulation at home, and (c) parental mental state language as a measure of a specific mental facet of the home language and literacy environment that has been shown to be associated with children's ToM development. In particular, we addressed the following research questions: 
1. Is the general quantity and quality of the home language and literacy environment in the development related to language skills and also to ToM understanding?

2. Is parental mental state talk specifically related to ToM understanding even after accounting for more general facets of the home language and literacy environment, or is parental mental state talk a subdimension of overall language stimulation and thus also related to children's language development?

3. Are the various facets of the home language and literacy environment directly related to ToM or only indirectly via children's language development?

Concerning SES, we expected the various facets of the home language and literacy environment to explain SES-related differences in language skills and ToM understanding. Further, we assumed that the effects of the various facets of the home language and literacy environment are particularly significant for children from lower SES families. In particular, we addressed the following research questions:

1. Are the various facets of the home language and literacy environment associated with SES, and do they mediate SES-related disparities in language skills and ToM understanding?

2. Are the effects of the home language and literacy environment particularly pronounced in low-SES families?

\section{MATERIALS AND METHODS}

\section{Sample and Procedure}

The present sample was part of a more comprehensive German longitudinal study on child development and educational processes. The study was funded by the German Research Foundation, and compliance with ethical standards was approved by the review process. Appropriate consent to take part in this study was obtained from parents, and all information provided was voluntary. Data collection started in 2005, including 547 children from 97 preschools in rural and urban areas of Bavaria and Hesse, Germany. All children of one randomly selected group within each preschool who would enter school in 2008 were asked to take part in the study. Thus, at the first measurement point, children were about 3 years old. Various measures of home and preschool environment, as well as of children's development, were collected every half year.

The present study draws on measures collected at assessment waves 1, 2, 3, and 5. At Wave 1, measures of SES and the quantity (book exposure) and quality (quality of verbal interaction) of the home language and literacy environment were assessed. At Wave 2, parents were presented with the instrument for measuring parental mental state language. The outcome measures for child language and ToM were assessed at Wave 5, and we included also child language at Wave 3 as a potential mediator that might explain the relation between home language and literacy environment and ToM development (see Figure 1 for an overview).

\section{Participants}

The present study included the subsample of 267 children, who were - by design - assigned to the subgroup of children who received ToM measures at Wave 5. These children attended preschools in Bavaria. We included only monolingual children (i.e., children whose parents were native German speakers) as we focus on relations including language development and language stimulation. Thus, in total, 224 children (51.3\% boys) took part in the present study. At Wave 1 of the study, these children were, on average, 41.87 months (3;6 years; $S D=3.98$ months) old.

\section{Measures \\ Family Variables}

Families were visited every year at their home and were presented with a computer-assisted personal interview. In this interview, parents were asked for information on various SES indicators such as education and occupation as well as on educational practices and child characteristics. In the middle of the interview, parents were given a picture book and asked to share it with their child. This interaction was observed by a trained interviewer, who rated the quality of verbal interaction (see below). After the parent and child signaled that they had finished the joint picture book reading, the interview was continued. At the end of the visit, parent and child received a small gift.

Parents were also given a questionnaire every half a year asking for further child and family-related variables as well as educational practices, which they should send back by mail.

\section{Socioeconomic status (SES)}

As a general measure for family SES we referred to the International Socio-economic Index of Occupational Status (ISEI; Ganzeboom et al., 1992). The ISEI is based on international data about education, income, and prestige of various occupations. Possible levels range from 16 (e.g., cleaner, unskilled farm worker) to 90 (e.g., judge in a court of law). To avoid underestimating the family's SES, we used the highest ISEI (HISEI) of the parents.

\section{Quantity of language stimulation within the family - book exposure}

To measure the quantity of more informal language and literacyrelated interactions within the family, an index for book exposure was created as a proxy. Therefore, the answers parents gave in the questionnaire at Wave 1 on how frequently they read to their child $(1=$ never to $5=$ daily $)$, on the number of books in the household ( $1=$ up to $30,2=$ up to $100,3=$ up to 200 , and $4=$ more than 200 books), and on the number of children's books in the household ( $1=$ up to $10,2=$ up to $20,3=$ up to 30 , and $4=$ more than 30 books) were used. The items were first standardized to represent a range of $0-1$ and then averaged. Cronbach's alpha was 0.68 .

\section{Quality of verbal parent-child interaction}

To gather information on the quality of verbal parent-child interaction during joint picture book reading the Family Rating Scale (FES; Kuger et al., 2005) was used. Therefore, a semistandardized picture book reading situation between the primary caregiver (96\% mothers) and the child was conducted at the 


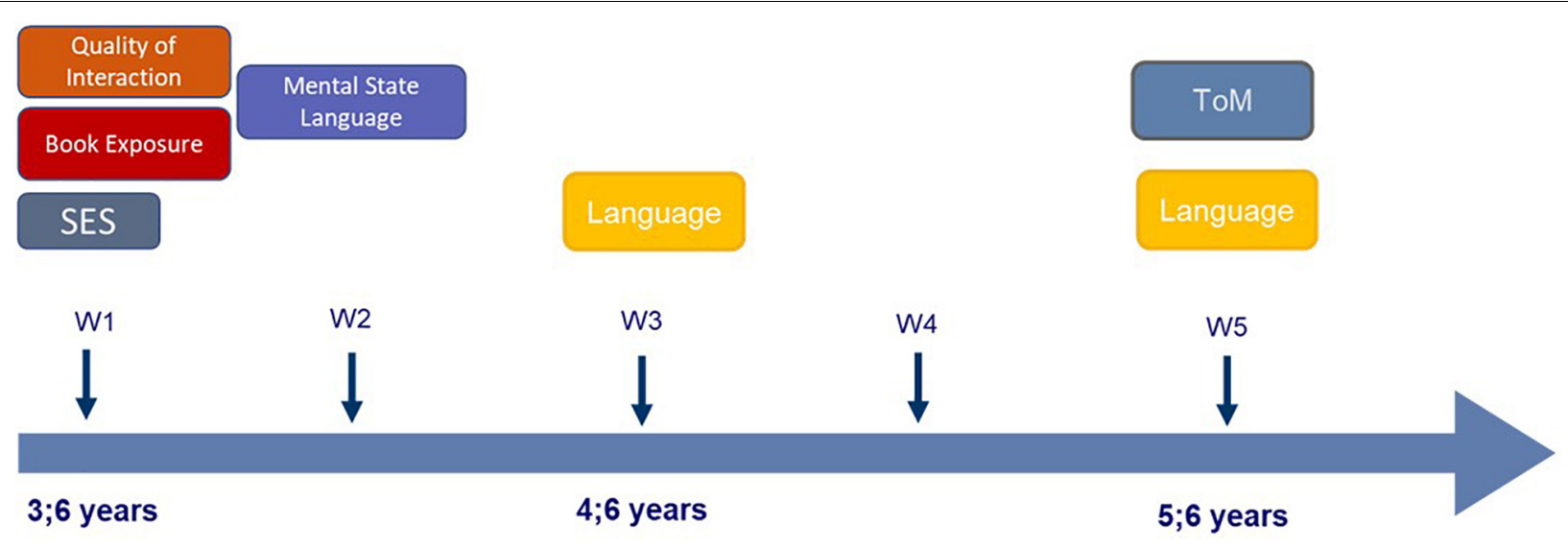

FIGURE 1 | Overview of the included measures at the various waves (W).

family's home (see above). The picture book used at Wave 1 was about a family's visit to a circus and designed within the project. Thus, it was unknown to the parent and the child. The parents were advised to share this book with their child as they usually do in joint picture book situations. The quality of this interaction was rated by a trained observer on 11 subscales. Each subscale includes up to three indicators that are rated on a 7 -point scale $(1=$ low quality to $7=$ high quality). The scalelevels 1 (low quality), 3 (minimal quality), 5 (high quality), and 7 (excellent quality) are qualitatively characterized and described to facilitate and standardize the ratings. A subscale score was calculated as the mean across the indicators. For instance, the subscale "use of questions" comprises three indicators: "questions asked by the parent," "reaction toward the child's questions," "opportunity for dialogues" (see Figure 2 for an example of the qualitative characterizations). For the present study, the mean across those 6 subscales referring to language and literacy was used to represent an indicator for verbal parentchild interaction quality (see Table $\mathbf{1}$ for a brief description). Cronbach's alpha was 0.65 . Beforehand raters had been trained to a criterion of $90 \%$ agreement $( \pm 1)$ to a gold standard of a master rating. Ten percent of observations were double coded by two independent raters; rater agreement was good $(\mathrm{ICC}=0.78)$. The scale was linear transformed to a range of $0-1$.

\section{Parental mental state language}

To assess parents' mental state language, parents filled in a questionnaire that included four vignettes (In the Kitchen, Dad's Birthday, Lost Keys, The Empty Flask) of the Maternal Mental State Input Inventory (MMSII; Peterson and Slaughter, 2003) at Wave 2. These four vignettes were chosen because they had a particularly pronounced cognitive emphasis. Each vignette depicts an episode of everyday interactions (e.g., baking a cake together; searching for lost keys) between a mother and a 4-yearold child and is followed by four possible options what a parent could say in the described situation: Two of these options are mental. One is an Elaborated Mental State (EMS) option, and the other is a Non-Elaborated Mental State (NEMS) option. In the EMS option, the mother explicitly names a mental state (e.g., surprise) and explains or elaborates this mental state while giving further information (e.g., "Dad doesn't know what is inside the box, because he can't see inside the box now that it is all wrapped up. If you tell him, he won't be surprised when he opens it"). In the NEMS option the mother also explicitly mentions the mental state but does not further elaborate on it or explain it (e.g., "John, don't tell Daddy what we've got him. We want him to be surprised on his birthday."). The two other options were mainly included as distractors to enable the respondent to choose between other conversational strategies that were non-mental but comparable in lengths. Thus, one non-mental option was an elaborated one and the other a non-elaborated one (see Peterson and Slaughter, 2003, for more information). For each vignette parents were asked to rank order those four options according to the answer they would themselves most likely give to their child in such a situation (i.e., 1 to their most likely answer, 2 to their second likely answer, and so on). For statistical analyses these hierarchical rankings were converted into preference scores ranging from 4 (highest preference) to 1 (lowest preference) and mean scores for NEMS and EMS options over the four vignettes were calculated. For instance, if parents choose the EMS option in all four vignettes as their first preference and the NEMS option always as second preference, they receive a mean score of 4 for EMS and a mean score of 3 for NEMS. The reliability of the MMSII, even when using only those four vignettes, is moderate (for more information see Ebert et al., 2017).

\section{Child Variables}

Child language and ToM were measured together with other cognitive tests at one of three testing sessions per wave in a separate room of the child's preschool. The individual testing session lasted about 30 minutes and was conducted by a trained research assistant. Parents had provided informed consent beforehand, and the child had the opportunity to withdraw from testing at every time point during testing. After each testing session children received a small gift from the research assistant.

\section{Language skills}

At Wave 3 and Wave 5 children were tested for their receptive vocabulary and grammar. 


\section{Use of questions:}

\begin{tabular}{|c|c|c|c|c|c|c|c|}
\hline & 1 & 2 & 3 & 4 & 5 & 6 & 7 \\
\hline $\begin{array}{l}\text { Questions asked by the } \\
\text { parent }\end{array}$ & Parent asks no question. & & $\begin{array}{l}\text { Parent asks simple, short } \\
\text { questions, that the child } \\
\text { can answer with ,yes" or } \\
\text { "no" }\end{array}$ & & $\begin{array}{l}\text { Parent asks questions that } \\
\text { demand a somewhat more } \\
\text { complex answer (where, } \\
\text { who, what, ...). }\end{array}$ & & $\begin{array}{l}\text { Parent asks questions that } \\
\text { demand a complex } \\
\text { answer, explanation, or } \\
\text { reasoning (why, with } \\
\text { what, wherefore, how } \\
\text { come, ...). }\end{array}$ \\
\hline $\begin{array}{l}\text { Reaction toward the } \\
\text { child's questions }\end{array}$ & $\begin{array}{l}\text { The child's questions } \\
\text { remain unanswered. }\end{array}$ & & $\begin{array}{l}\text { The child's questions are } \\
\text { answered with short } \\
\text { answers (,yes", ,no“, } \\
\text { "there", „this", ...). }\end{array}$ & & $\begin{array}{l}\text { The child's questions are } \\
\text { answered with sometwhat } \\
\text { more complex } \\
\text { explanations that relate to } \\
\text { the book. }\end{array}$ & & $\begin{array}{l}\text { The child's questions are } \\
\text { answered with extensive } \\
\text { explanations/reactions that } \\
\text { also include precise } \\
\text { relations to the child's } \\
\text { everyday experiences/ } \\
\text { activities. }\end{array}$ \\
\hline $\begin{array}{l}\text { Opportunity for } \\
\text { dialogues }\end{array}$ & $\begin{array}{l}\text { There is no opportunity } \\
\text { for a dialogue (no breaks } \\
\text { during reading, no pause, } \\
\text { so the child can express } \\
\text { own thoughts, child's } \\
\text { expressions are internupted } \\
\text { or ignored, ...). }\end{array}$ & & $\begin{array}{l}\text { There are few } \\
\text { opportunities for a } \\
\text { dialogue. }\end{array}$ & & $\begin{array}{l}\text { There are many } \\
\text { opportunities for a } \\
\text { dialogue. }{ }^{*}\end{array}$ & & $\begin{array}{l}\text { The parent's behaviour } \\
\text { very often aims at } \\
\text { provoking the child to join } \\
\text { in a dialogue (asking } \\
\text { questions back, leaving } \\
\text { longer breaks while } \\
\text { reading the text, ...). }\end{array}$ \\
\hline
\end{tabular}

- A dialogue needs at least three verbal statements that relate to the same thought/topic.|

FIGURE 2 | Example of the qualitative characterization of the three indicators ("questions asked by the parent," "reaction toward the child's questions", "opportunity for dialogues") of the subscale "use of questions."

For assessing receptive vocabulary a German research version of the Peabody Picture Vocabulary Test (PPVT; Dunn and Dunn, 1981) was administered. In this test, per item the child has to select the appropriate picture out of four pictures that corresponds to a verbally presented lexical item. Items were presented in order of increasing difficulty and according to the original PPVT procedure, testing was stopped when the child's response to 6 or more items within a set of 12 items (last set 7 items) was incorrect. Each correct response was scored as 1 point (max. 175).

For measuring receptive grammar, a shortened German research version including 48 items of the Test for the Reception of Grammar (TROG, Bishop, 1983/1989; German Version: TROG-D, Fox, 2006) was implemented. In this test children are asked to select (out of 4 choices) the respective picture corresponding to a stimulus sentence with grammatical structures of increasing grammatical complexity. Our version tested for all grammatical structures included in the original test, but with 2 (except for the first three sets) rather than 4 items per structure. Each correct answer scored 1 point, and a maximum of 48 points could be received.

At Wave 3 the correlation between vocabulary and grammar was $r(204)=0.53$ and at Wave 5 it was $r(187)=0.44$. These correlations did not differ significantly between waves. We $\mathrm{z}$-standardized and averaged the scores of vocabulary and grammar at each wave as a general language indicator. The stability of this indicator across waves was numerically higher $(r=0.69)$ than the stability of its components, i.e. of vocabulary $(r=0.56)$ and grammar $(r=0.57)$.

\section{Theory of mind}

At Wave 5 children received one first-order unexpected content false-belief task (based on Perner et al., 1987) and one secondorder false-belief task (Sullivan et al., 1994). Both tasks were presented as narrated stories and were acted out with small figures and props.

For the unexpected content false-belief task the child was shown a familiar, pictorially-labeled container (e.g., an egg box) and was asked what she or he thinks it might hold. Afterwards the child was shown that there was something unexpected (e.g., a toy animal) in the container. Then a naive protagonist $(\mathrm{P})$ was introduced and the false-belief test question was asked: "What does P think is in the box?" A control questions ("Did P look inside the box?") had also to be answered correctly to pass. The child was also given a test question about own belief ("Before you had a look inside the box, what did you think was inside?"). Total first-order false-belief scores range from 0 to $2(M=1.31$, $S D=0.70)$.

In the second-order false-belief task children were told a story about a boy (Peter) who had seen his actual birthday present (a dog) unbeknownst to his mother, who has told him that he will receive a different present (a toy). The mother had a phone call with Peter's grandma talking about Peter's present. While the child listened to the story, she or he is asked two control questions ("What has Mum really got Peter for his birthday?"; "What did Peter's Mum say to him that he got for his birthday?") and three test questions: a knowledge-access first-order question ("Does Mum know that Peter saw the dog?"), a knowledge-access second-order question ("When Grandma rings up and asks if Peter knows what his present is, what will Mum say?"), and a false-belief second-order question ("What present will Peter's 
TABLE 1 | Description of the 6 subscales of the family rating scale referring to language and literacy used as an indicator for verbal parent-child interaction quality.

\begin{tabular}{|c|c|}
\hline Subscale & Description (high quality continuum) \\
\hline Level of distancing & Caregiver initiates dialogue, refers to the pictures in the book and includes distant (not visible) aspects of the situation. \\
\hline Non-verbal behavior & Caregiver shows positive gesture and body language. He or she pays attention and shows interest toward the child's utterances and behavior. \\
\hline Use of questions & Caregiver uses complex questions (e.g., "why?") and responds to child’s questions elaborately. \\
\hline Level of speech & Caregiver uses rare words, provides correct, complex, and appropriate language in terms of vocabulary and syntax to the child. \\
\hline Phonological cues & Caregiver correctly articulates phonemes, emphasizes syllable segmentation, and encourages the child to do rhymes by his/her own. \\
\hline Participation in dialogue & Child gets the opportunity to participate in or even guide the dialogue between caregiver and child. \\
\hline
\end{tabular}

Mum tell Grandma that Peter thinks he is getting?"). For each test question children could earn 1 point, thus in total 3 points for the second order task $(M=1.76, S D=1.10)$. Again, control questions had to be passed along with the test questions or the item was failed.

Scores on the first-order and second-order task were summed to form a comprehensive ToM score $[r(186)=0.34]$. Thus, the total ToM score could range from 0 to 5 points.

\section{Analytic Plan}

In order to address our research questions we ran path analyses using Mplus 7 (Muthén and Muthén, 2012). To explore the relations between the various facets of the home language and literacy environment and children's language skills and ToM understanding, we carried out two path analyses. First, we conducted a path analysis, where we regressed language and ToM at age 5;6 years (Wave 5) on all facets of the home language and literacy environment simultaneously to analyze whether there are specific effects of the different facets. Further, to investigate how the home language and literacy environment affects the relation between language and ToM in development and whether only indirect effects of the various facets of the home language and literacy environment on ToM exist via earlier language skills, we added language at age 3;6 years as a mediator into the analysis.

To explore further whether facets of the home language and literacy environment mediate the relation between SES and the children's language skills and/or their ToM understanding, we conducted a mediational analysis including the family's SES into the model.

Finally, to analyze whether the home language and literacy environment is particularly important for children growing up in families with a lower SES, we ran the path model including all facets of the home language and literacy environment only for children from relatively lower SES families (i.e., those scoring below the median of the HISEI of the whole sample). As our focus is on children from lower SES families, we only report results of this group. However, for integrity the results of a multiple group analysis including also the children from higher SES families can be found in the Supplementary Material (Figure A).

Due to the longitudinal study design, we had dropouts over time as well as missings due to illness or refusal to take part in the study at certain measurement points. However, dropout at Wave 5 was still small, and the children who had no valid score in ToM at Wave 5 did not differ significantly $(p>0.05)$ in any of the variables included in the study from those children with valid data.
Furthermore, not all parents sent back the questionnaire that included the vignettes of the MMSII, and some answers were invalid (e.g., parent gave only one rank) and had to be excluded from the analyses. The children of parents with no valid data on the MMSII differed significantly from the other children in HISEI $[t(119.99)=2.19, p<0.05]$, receptive grammar at age $4 ; 6$ years $[t(79.88)=2.13, p<0.05]$, and marginally significantly in book exposure $[t(39.96)=1.80, p<0.10]$. There were no other significant differences in any of the variables included.

To account for missing data, we used a full information maximum likelihood (FIML) approach, which is recommended especially in case of incomplete outcome variables and results in less biased parameter estimates than other methods (Graham, 2003; Enders, 2013). FIML is superior to listwise deletion, pairwise deletion, and single response imputation, especially in small sample sizes and when missing is at random (Enders and Bandalos, 2001). Due to the small sample size we also calculated bias-corrected bootstrapping confidence intervals for all models. The results of this procedure were very similar to the standard models reported below.

\section{RESULTS}

Table 2 shows descriptive information for all variables included in the study, and Table 3 presents the correlations among our key measures.

First, concerning the intercorrelations between SES and the facets of the home language and literacy environment, Table 3 shows that the HISEI was moderately related to the quantity (book exposure) and quality (verbal interaction during joint book reading) indicators of the home language and literacy environment. In contrast, SES was not related to either of the two indicators of parental mental state language. Moreover, the various facets of the home language and literacy environment were only slightly interrelated. Thus, the correlations between book exposure, quality of verbal interaction, and non-elaborated parental mental state language were all low $(r=0.16-0.21$, $p<0.05)$, and neither book exposure nor quality of verbal interaction was related to elaborated mental state talk. The high negative correlation between NEMS and EMS was due to the fact that parents had to rank order the options; thus, if they choose, for example, NEMS as the first rank, EMS is given a lower number. Therefore, NEMS and EMS are not independent of each other.

Second, Table 3 also shows that, as expected, language skills at Wave 3 and Wave 5 were correlated with ToM understanding, and both language and ToM were related 
TABLE 2 | Descriptives for the key measures of the study.

\begin{tabular}{|c|c|c|c|c|c|}
\hline & $N$ & $M$ & $S D$ & Min & Max \\
\hline \multicolumn{6}{|l|}{ Child variables } \\
\hline Age at Wave 1 (in months) & 216 & 41.87 & 3.98 & 34 & 49 \\
\hline Age at Wave 3 (in months) & 205 & 53.62 & 3.95 & 46 & 61 \\
\hline Age at Wave 5 (in months) & 187 & 65.57 & 3.98 & 58 & 74 \\
\hline PPVT, Wave 3 (age 4;6 years) & 202 & 54.53 & 18.29 & 0 & 109 \\
\hline TROG, Wave 3 (age 4;6 years) & 204 & 30.82 & 6.35 & 10 & 45 \\
\hline PPVT, Wave 5 (age 5;6 years) & 178 & 78.34 & 19.39 & 13 & 139 \\
\hline TROG, Wave 5 (age 5;6 years) & 187 & 36.84 & 4.38 & 23 & 45 \\
\hline ToM, Wave 5 (age 5;6 years) & 186 & 3.07 & 1.49 & 0 & 5 \\
\hline \multicolumn{6}{|l|}{ Family variables } \\
\hline HISEI & 223 & 52.64 & 15.82 & 20 & 88 \\
\hline Book exposure & 186 & 0.74 & 0.21 & 0.11 & 1.00 \\
\hline Quality of verbal interaction & 216 & 0.63 & 0.09 & 0.25 & 0.85 \\
\hline Mental state language (EMS) & 157 & 2.94 & 0.58 & 1.75 & 4.00 \\
\hline Mental state language (NEMS) & 157 & 2.96 & 0.60 & 1.25 & 4.00 \\
\hline
\end{tabular}

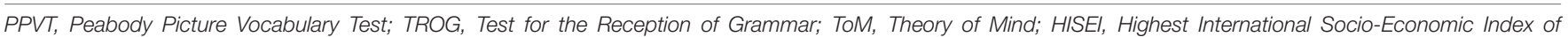
occupational status in the family; EMS, elaborated mental state language; NEMS, non-elaborated mental state language.

TABLE 3 | Correlations between key variables.

\begin{tabular}{|c|c|c|c|c|c|c|c|c|}
\hline & 1. & 2. & 3. & 4. & 5. & 6. & 7. & 8. \\
\hline 1. HISEI & - & $0.39^{\star \star}$ & $0.33^{\star \star}$ & -0.11 & 0.10 & $0.28^{\star \star}$ & $0.35^{\star *}$ & $0.21^{\star *}$ \\
\hline 2. Book exposure & & & $0.21^{\star *}$ & 0.01 & $0.16^{\star}$ & $0.33^{*}$ & $0.32^{\star \star}$ & $0.23^{\star *}$ \\
\hline 3. Quality of interaction & & & & -0.11 & $0.17^{\star}$ & 0.10 & 0.10 & $0.18^{\star}$ \\
\hline 4. Mental language (EMS) & & & & & $-0.47^{\star \star}$ & -0.03 & -0.11 & -0.07 \\
\hline 5. Mental language (NEMS) & & & & & & 0.11 & 0.14 & $0.18^{*}$ \\
\hline 6. Child language (4;6 years) & & & & & & & $0.69^{* *}$ & $0.46^{\star *}$ \\
\hline 7. Child language (5;6 years) & & & & & & & & $0.45^{\star \star}$ \\
\hline 8. ToM (5;6 years) & & & & & & & & \\
\hline
\end{tabular}

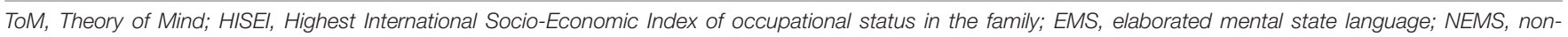
elaborated mental state language. ${ }^{* *} p<0.01,{ }^{*} p<0.05,{ }^{+} p<0.10$.

to SES. However, numerically the correlation between SES and language was higher than the correlation between SES and ToM.

\section{Relation Between the Different Facets of the Home Language and Literacy Environment and Child Variables}

Table 3 shows that the correlations of the various facets of the home language and literacy environment with children's language skills in comparison to their ToM understanding differ in magnitude. Although book exposure was related to language and ToM, ToM was numerically less related to book exposure $(r=0.32$ vs. $r=0.23)$. Concerning the quality of verbal interaction, however, it was ToM understanding that showed a small but significant correlation with the quality of verbal interaction $(r=0.18, p<0.05)$, but not language skills. None of the two measures of parental mental state talk was related to language, but non-elaborated mental state language was associated with ToM understanding to a small but significant degree $(r=0.18, p<0.05)$.
In the first path model, we tested how the different facets of home language and literacy environment are related to later language skills and ToM understanding, when considered simultaneously (see Figure 3). In Model 1a, we included only language and ToM at Wave 5, whereas in Model 1b, we also entered language at Wave 3 to investigate whether early language mediates the relations between home language and literacy environment and ToM.

As Figure 3 shows, when all facets of the home language and literacy environment are considered simultaneously, only book exposure predicted later language skills, whereas book exposure and quality of verbal interaction were related to later ToM understanding. None of the indicators of parental mental state language was correlated with ToM or language when considering the more general indicators of quantity and quality of the home language and literacy environment simultanously (see Model 1a). Model $1 \mathrm{~b}$ demonstrates that the effect of early book exposure on later ToM was completely mediated by early child language and thus had only an indirect effect on ToM $(\beta=0.13, p<0.01)$. In contrast, when considering early child language as a possible mediator, the significant direct effect of the quality of verbal 

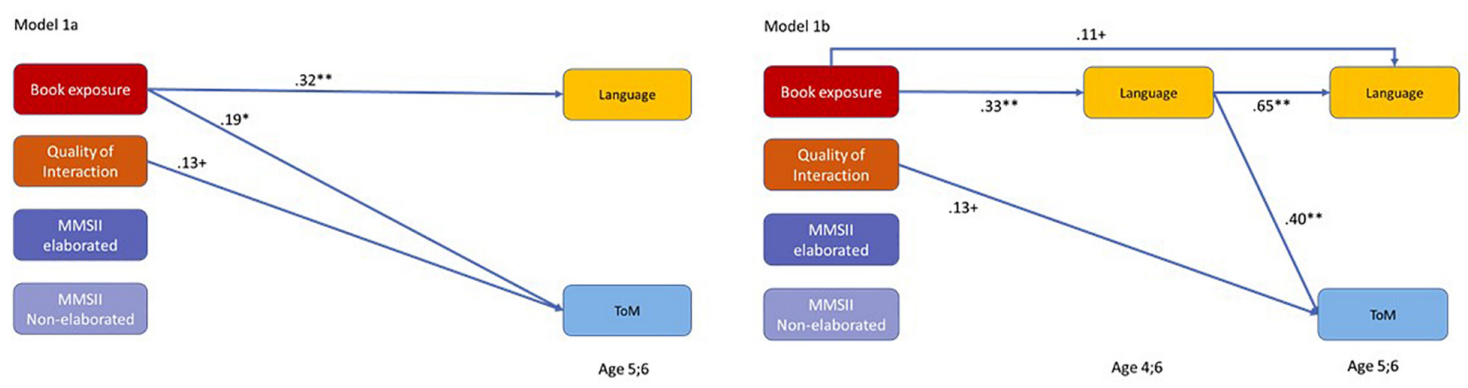

FIGURE 3 | Path models showing the relations between facets of the home language and literacy environment and children's later language as well as theory of mind (ToM). Depicted are only paths that were significant on $p<0.10$. MMSII $=$ Maternal Mental State Input Inventory. ${ }^{* *} p<0.01,{ }^{*} p<0.05,{ }^{+} p<0.10$.

interaction on later ToM as well as the direct effect of book exposure on later language remained. Note that the quality of verbal interaction neither affected language at age 4;6 nor at age $5 ; 6$ directly or indirectly in the model.

\section{Relations Between SES, Child Language, and ToM: Mediating Role of the Home Language and Literacy Environment}

In the next step, we investigated whether facets of the home language and literacy environment can explain the relation between SES and children's later language skills and ToM understanding by including the family's HISEI as an indicator for SES into the model. We specified the direct effects of HISEI on ToM and language measures as well as indirect effects via the various facets of the home language and literacy environment. According to Baron and Kenny (1986), we included only book exposure and quality of interaction in the model as SES was not related to parental mental state language in our study (see Table 3).

Figure 4 shows direct paths of SES on later language, even when considering book exposure and quality of verbal interaction in the model. However, the relation was reduced (compared to the relation shown in Table 3). Moreover, we found an additional indirect effect of SES on language skills at age $4 ; 6$ and $5 ; 6$ via book exposure though not via our measure of the quality of verbal interaction. The indirect effect of SES on language at age $5 ; 6$ via book exposure and language age $4 ; 6$ was $\beta=0.04(p<0.05)$. This result indicates that the relation between SES and language was partly mediated by book exposure.

Figure 4 also shows that, in contrast to child language, SES was not directly related to ToM after considering book exposure, quality of verbal interaction, and child language at age $4 ; 6$. The relation between SES and later ToM $(r=0.21, p<0.01)$ was completely mediated, especially via language skills at age $4 ; 6$ $(\beta=0.07, p<0.05)$ and via book exposure and language skills at age $4 ; 6$ years $(\beta=0.02, p<0.05)$.

\section{Effects of the Home Language and Literacy Environment in Children From Low SES Backgrounds}

To analyze whether the demonstrated relations also hold for the group of children from comparatively lower SES families and may even be particularly pronounced, we ran a model similar to Model 1b (see Figure 3) for children from lower SES families only (see Figure 5).

As Figure 5 shows, there was an overall comparatively high impact of the home language and literacy environment in the lower SES families. We found the quantity and the quality of the home language and literacy environment to be related to the children's later language skills in this group. Also, one specific mental facet of the home language and literacy environment, the non-elaborated parental mental state language, showed a direct path to later ToM, even when the quantity and quality aspects of the home language and literacy environment and earlier language skills were considered simultanously.

Moreover, we found indirect effects of the quality and quantity of the home language and literacy environment on ToM and language skills at age 5;6 via the children's earlier language skills at age 4;6. With regard to ToM understanding at age 5;6 book exposure had an indirect effect of $\beta=0.11(p<0.05)$ and the quality of verbal interaction had an indirect effect of $\beta=0.08$ $(p<0.10)$ via language skills at age $4 ; 6$. With regard to language skills at age $5 ; 6$, book exposure had an indirect effect of $\beta=0.16$ $(p<0.05)$ and the quality of verbal interaction had an indirect effect of $\beta=0.12(p<0.10)$ via language skills at age $4 ; 6$.

The impact of the home language and literacy environment on children's language skills and ToM understanding in the higher SES families was much less pronounced (see Supplementary Figure $\mathbf{A}$ for the results of a multiple-group analysis that differentiates between lower and higher SES families). In the higher SES families only book exposure showed a significant positive effect on language skills at age $4 ; 6$.

\section{DISCUSSION}

In the following, we discuss our results and their implications along with the different research questions of our study. We will mainly focus (a) on the direct and indirect effects of the different facets of the home language and literacy environment on children's language and ToM development, (b) on SES-related differences in language and ToM development and the mediating role of the home language and literacy environment, (c) on the specific pattern of results concerning parental mental state 
Model 2

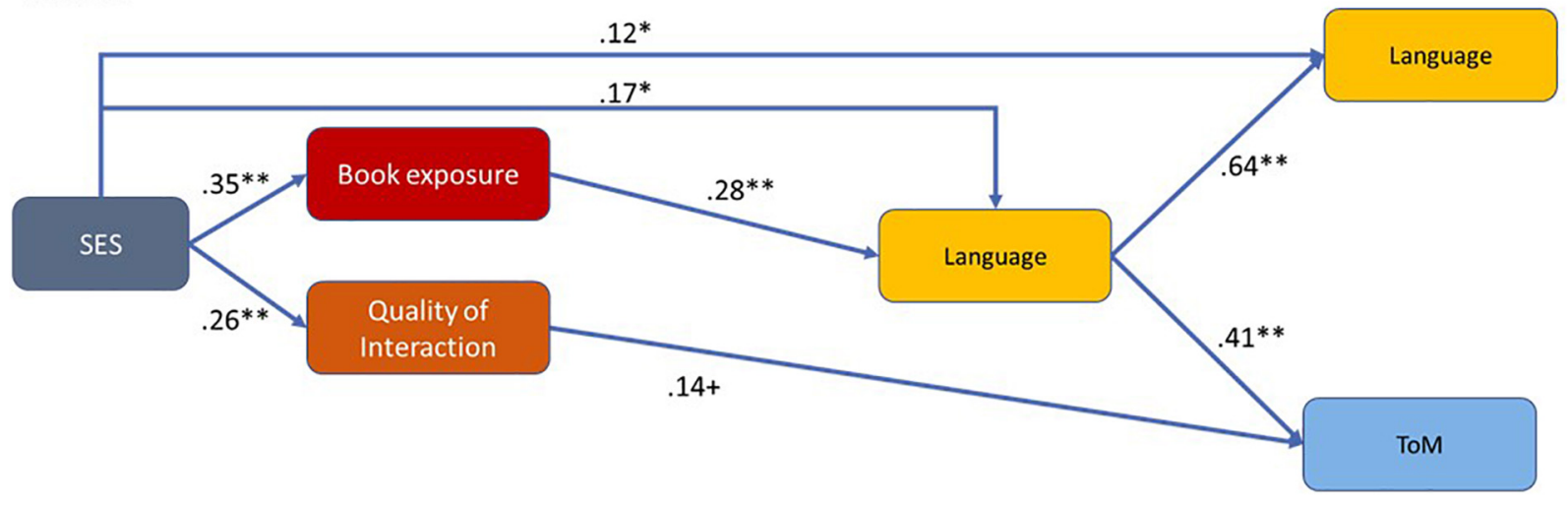

Age $4 ; 6$

Age 5;6

FIGURE 4 | Path model showing the relations between SES, facets of the home language and literacy environment, and children's later language skills and ToM understanding. Depicted are only paths that were significant on $p<0.10 .{ }^{\star \star} p<0.01,{ }^{*} p<0.05,{ }^{+} p<0.10$.

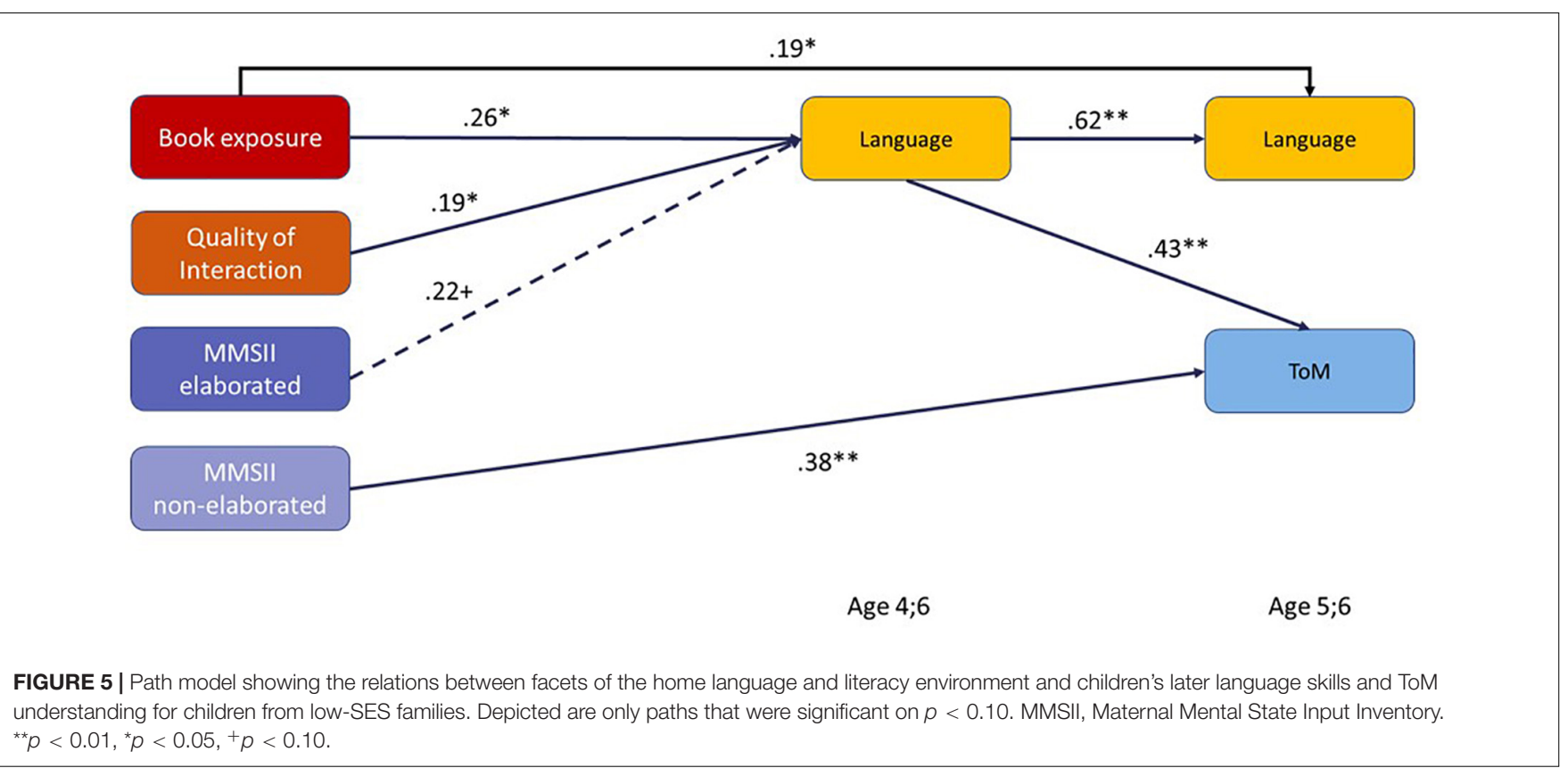

language, and (d) on the effects of the home language and literacy environment of children from less advantaged homes.

\section{Specific Effects of the Various Facets of the Home Language and Literacy Environment on Language and ToM}

A unique aspect of our study was that we connected research on the relation between the home language and literacy environment and children's language development with research on the relation between parental mental state language and ToM. Besides, we considered different specific indicators of the home language and literacy environment as well as children's language and ToM within one longitudinal study. In particular, we analyzed how quantitative and qualitative aspects of language and literacy stimulation at home relate to the children's language development, and also whether and how these effects transfer to a domain that is closely related to language skills in development, namely ToM understanding. As parental mental state language can be conceptualized as a specific facet of the home language and literacy environment, we also analyzed whether and how this specific facet is related to more general facets of the home language and literacy environment and the development of language skills.

In line with numerous other studies, our study supports the assumption that the language and literacy stimulation at home is significantly related to children's language development. Further, our results provide evidence that general aspects of the 
home language and literacy environment are also related to the developing ToM understanding in childhood. Consistent with our results, Boerma et al. (2017) found book exposure at home to be related to both language skills and ToM understanding in children aged 9-10 years. Similarly, Adrian et al. (2005) reported the quantity of joint picture book reading to be related to ToM in preschool children. Our study adds to these results by showing that the effect of book exposure at home unfolds its effects on ToM through children's language development in preschool years.

Contrary to our results concerning book exposure as a measure of the quantity of language and literacy stimulation at home, we did not find a significant effect of the quality of verbal interaction on children's language skills in the whole group but instead found a marginally significant effect on ToM understanding. However, this result does not imply that qualitative aspects of the verbally stimulating home learning environment are irrelevant to language development. Numerous studies, not least intervention studies, convincingly demonstrate that the quality of verbal interaction, e.g., during joint picture book reading, is highly relevant in promoting children's language development (e.g., Whitehurst and Lonigan, 1998; Huttenlocher et al., 2010; Mol and Neuman, 2014).

One explanation why we did not find an effect of the quality of verbal interaction in our study may be that "the quality" of verbal interaction may not exist. Instead, specific aspects have been suggested and empirically demonstrated to promote different language skills or subdomains such as vocabulary, grammar, and early reading. Thus, drawing on data of the same comprehensive study as the present study, Lehrl et al. (2012) showed that the quality of verbal interaction significantly predicted the development of receptive vocabulary between ages 4 and 6, but not the children's acquisition of receptive grammar; yet book exposure was related to changes in receptive grammar. Other studies (e.g., Huttenlocher et al., 2002) add to this by showing that the complexity of language input during mother-child interaction relates to changes in receptive grammar. This supports the assumption that specific aspects of the home language and literacy environment might be particularly relevant to specific subdomains of language development, such as grammar and vocabulary (see for a similar discussion also Ebert et al., 2013; Weinert and Ebert, 2013, 2017). As the various facets of the home language and literacy environment are only low to moderately correlated, averaging across them as well as across language domains may underestimate the specific impact of the quality of the home language and literacy environment. Indeed, when we differentiate between vocabulary and grammar, we find slightly different relations of the home language and literacy environment with the two language components (see Supplementary Figure B). For example, stronger correlations between book exposure and grammar than between book exposure and vocabulary show up. We also find a small effect of the quality of verbal interaction on the change of grammar between ages $4 ; 6$ and $5 ; 6$ but not on vocabulary.

Another explanation why our study did not reveal significant effects of the quality of verbal interaction on children's language might be due to the fact that the quality of interaction was observed and rated within a rather short joint picture book situation. This situation might have been too short to capture the most relevant aspects of language stimulation. However, several studies have demonstrated that such time-economic measures, even some with less observational time $(3 \mathrm{~min})$, lead to valid results (e.g., Hindman et al., 2008; Landry et al., 2012). In addition, the substantial variance in our measure underpins that we were able to capture differences in interaction quality across families. Through implementing a multimethod-design and using observations and questionnaires, we also reduced possible methodological bias. However, as book exposure and mental state language input were measured via parent questionnaire, social desirability cannot be ruled out.

Altogether, our study contributes new evidence to previous studies by showing that the general characteristics of the home language and literacy environment are also relevant to other domains of children's development, such as their ToM understanding. The effects of the home language and literacy environment on ToM thereby seem to unfold via children's language development. Thus, our study adds to others that also show that the effects of the home language and literacy environment generalize to other domains of development via children's language skills. For example, Daneri et al. (2018) documented that differences in the children's vocabulary at 3 years of age mediated the relation between maternal language input and children's executive functions at 4 years of age (with maternal language input being measured by the number of different words and the mean length of utterances during joint picture book reading). Another example is the study by Rose et al. (2017) which demonstrated that language skills partly mediate the relation between aspects of the home language and literacy environment and socioemotional development in children between the ages of 3 and 8 years. Thus, together with these results, our analyses again highlight the importance of the home language and literacy environment for children's language development with far-reaching direct and indirect effects into other domains.

\section{SES and Children's Language and ToM Development: The Mediating Role of the Home Language and Literacy Environment}

In line with previous studies, our results indicate SES-related differences in children's language (see Hoff, 2013) and ToM development (see Devine and Hughes, 2016). As many studies before, we also found that, on average, children from lower SES families lag behind their peers growing up in families with a higher SES in their language and ToM development. One explanation for these SES-related disparities might be confounded differences in the quantity and quality of the home language and literacy environment. In this vein, our findings support previous results in showing that the quantity and quality of language and literacy stimulation at home are related to the families' SES (e.g., Hoff, 2003). Thus, children growing up in higher compared to lower SES families experience a higher quantity of book exposure and a higher quality of 
language stimulation at home. However, parental mental state language as a specific facet of the home language and literacy environment was not related to SES. This evidence points to the relative independence of rather general and more specific facets of the home language and literacy environment. Whether parents provide their children with a rich and varied language environment at home seems to be somewhat independent of whether and how parents speak about the mental world. However, notice that also book exposure as a proxy for the quantity of language and literacy stimulation at home and our measure of the quality of verbal interaction are only slightly related to each other. This result suggests that parents who provide their children with access to literacy and the opportunity to engage with books are not necessarily the same parents who use other language stimulating strategies and activities that are known to promote children's language development. This pattern of a rather low association between facets of parental language stimulation is also found in other studies and for other age groups (e.g., Rodriguez et al., 2009; Lehrl et al., 2012; Attig and Weinert, 2019). However, despite these low associations, the different facets of the more general language environment are all related to SES in the present study as well as in other studies (e.g., Attig and Weinert, 2019; Linberg et al., 2020).

As we used a rather global measure of SES (HISEI), which includes occupation, prestige, income, and education, this might, amongst others, explain why in our study only book exposure mediates - at least partly - the relation between SES and children's language skills as well as ToM understanding. The correlation between the families' HISEI and book exposure might be due to other facets of the SES than the correlation between SES and quality of verbal interaction, and only these facets might be especially crucial for SES-related disparities in language skills. However, the result that book exposure but not the quality of verbal interaction mediated effects of family background on children's language skills was somewhat surprising as other studies found especially the quality of verbal interaction to account for the relation between SES and child development (e.g., Huttenlocher et al., 2002; Hoff, 2003; Mol and Neuman, 2014; Daneri et al., 2018). For instance, Mol and Neuman (2014) showed that particularly parents' contingent responsiveness to their 5-year-old children during a book-sharing task mediated the effects of SES on receptive and productive vocabulary. However, the authors also found book access to account for SES-related differences in productive vocabulary. These results again suggest that for different language components or subdomains, different facets of the home language and literacy environment might be particularly important. Thus, our measure of the quality of verbal interactions as well as our measure of language skills might have been too global to find relations between the assessed and aggregated quality aspects of verbal interactions and the children's language skills (see also section "Specific Effects of the Various Facets of the Home Language and Literacy Environment on Language and ToM"). As already mentioned, other studies (e.g., Huttenlocher et al., 2002; Rowe, 2012; Mol and Neuman, 2014; Hirsh-Pasek et al., 2015) also hint to the assumption that specific facets of parents' language input and language stimulating parenting behavior are related to specific components of language and also account for SES-related disparities in the respective language component or subdomain.

However, we found a significant relation between book exposure as a very global measure of the quantity of language and literacy stimulation at home and children's language skills, which also partly mediated SES-related differences. This, of course, could be due to other variables underlying this relation. Parents who provide their children with many books and who often read together with their children and for their own pleasure might use more complex grammar and a richer and more varied vocabulary. In addition, book exposure might not be just an indicator of the quantity of language and literacy stimulation at home (see Mol and Neuman, 2014) but also a measure of a specific facet of the SES that is related to child development. Thus, book possession in a family might indicate financial resources of the family that are invested in education. And it might be this investment in education that explains why children from higher SES backgrounds show comparatively more advanced language and cognitive skills (see also Conger and Donnellan, 2007). In this vein, Evans et al. (2010) showed that children growing up in families with many books are experiencing, on average, 3 years more of schooling than children from families with less books independent of the family's SES. This suggests that book access might be not just a proxy for how parents promote children's language and literacy, but books at home may also indicate a higher commitment to knowledge acquisition and in scholarly culture (see also Mol and Neuman, 2014).

Concerning children's ToM understanding our results reveal that SES-related differences in ToM are completely mediated by book exposure and the children's early language skills. Other studies found that SES-related differences in ToM are not completely explained by parents' mental state language and children's language skills (Devine and Hughes, 2016; Ebert et al., 2017). Our study complements these findings by showing that the more general language environment and a broader measure of language skills accounted for differences in children's ToM development that are related to SES. This result suggests that SES-related differences in ToM understanding might - to a large degree - be due to differences in children's language skills and their general home language and literacy environment.

In comparison, concerning language skills, the home language and literacy environment did not explain all SES-related differences in language skills. Even if various facets of the home language and literacy environment and earlier language skills are accounted for, relations between SES and child language were still reasonably high and significant. This result suggests that SES affects children's language skills at 4;6 and 5;6 years over and above the variables included in our study and that other variables not measured in the present study additionally account for SES-related differences in children's language skills. As already mentioned, more specific facets of the verbal input may explain SES-related differences in language skills even better. Also other variables that are suggested, e.g., by family stress and family investment models, such as parents' wellbeing, could be associated with both SES and child development and thus play a role in their interrelation (e.g., Conger and Donnellan, 2007; Baydar et al., 2014; Raffington, 2018). 
Overall research results on the effects of SES on children's development indicate that these are multifaceted. The home language and literacy environment is only one factor that explains why children from different SES-backgrounds differ in their language skills. This also implies that the home language and literacy environment might be one starting point for reducing SES-related disparities in language development and thereby, as our study shows, also in other areas of development, such as in children's ToM or social understanding.

\section{Parental Mental State Language and Its Effects on ToM Understanding and Language Skills}

A novel approach of our study, which combined lines of research on ToM and language development, was that we also investigated how a specific facet of the home language and literacy environment, the use of mental state language in everyday conversations, is related not only to ToM but also to language development. We assumed that parents' use of mental state language reflects a specific facet of the home language and literacy environment. Therefore we investigated its impact on children's ToM and language development.

Different from the results of the meta-analyses by Tompkins et al. (2018), we did not find parental elaborated mental state language to be more strongly related to children's ToM than parents' non-elaborated mental state language. We found only parents' non-elaborated mental state language to relate to children's ToM understanding, and only when referring to children from lower SES backgrounds. This result, however, resembles the results of Ebert et al. (2017), who also found that in children from lower SES background, non-elaborated mental state language affects children's ToM development between 3 and 5 years. However, the children who were included in that study were also part of the sample of the present study. Thus, the evidence is not independent. Nevertheless, in extension of Ebert et al. (2017), we showed that this result holds within an extended sample and even when controlling for children's language skills and, more importantly, other facets of the more general home language and literacy environment.

These new results lead to the cautious assumption that specific relations exist between parental mental state language and children's ToM development that go beyond the effects of the general home language and literacy environment parents provide to their children. The results also suggest that whether parents talk about mental states or not is a unique characteristic of parents' verbal interaction with their child. The unique role of parental mental state language also becomes apparent in the low correlations between the quantity and quality of the home language and literacy environment and parents' mental state language. However, this low correlation may also be partly due to methodological reasons and the fact that mental state language was not assessed in an observational situation; instead, parents had to self-evaluate what they might say in fictitious situations described in a questionnaire. This task might have been hard for some parents. However, there is evidence that parents can evaluate the use of their mental state language quite well with the MMSII. Slaughter and Peterson (2012) reported significant correlations between mothers' self-reported elaborated mental state language in the MMSII and their elaborated mental state talk while narrating stories to their children. Additional evidence that parents' mental state talk is a unique characteristic of parents' talk with their children or when narrating stories and that this characteristic affects ToM development over and above more general facets of the home language and literacy environment is provided by Adrian et al. (2005). Different from the present study, the authors used a picture book situation while documenting mother's mental state talk and showed that mother's use of mental state terms explained variance in children's ToM over and above the number of words the mothers used and the frequency of picture book reading at home. In a similar vein Ruffman et al. (2002) showed that mothers' mental state language during a picture book task was correlated with preschoolers' ToM even when other types of mothers' utterances were accounted for.

In fact, a relation between parents' mental state language and ToM may be more easily detected when mental state language is assessed in an interactive context. This assumption is supported by studies investigating children's use of mental state language: Whereas studies that examined the use of mental state language in preschool children in interactive contexts often report a significant relation between ToM skills and the use of mental state language (e.g., Dunn et al., 1991; Hughes and Dunn, 1998), studies testing children in non-interactive tasks often failed to detect a reliable association between children's mental state language and their ToM (e.g., Charman and Shmueli-Goetz, 1998; Longobardi et al., 2016).

Extending earlier studies on the relation between parents' mental state language and ToM, we also considered how parental mental state language is related to their children's language skills. We could not find significant relations within the whole group; however, when focusing on children from comparatively low SES backgrounds, we found that parents' preference to explain and elaborate on mental states was related to children's language skills. This result suggests that a preference for elaborated mental state language might indicate how parents communicate in general, how they explain relations, how talkative they are, and how often they use decontextualized language. These characteristics may dominate elaborated mental state language and thus may also explain the low correlation between non-elaborated parental mental state language and children's language skills.

However, from a methodological point of view a problem of the MMSII is that the preference for elaborated mental state language and non-elaborated mental state language are not independent of each other: If parents choose nonelaborated mental state language as their preference, elaborated mental state language will necessarily get a lower rank. However, analyses where we considered elaborated and nonelaborated mental state language separately did not change our results.

The reason why we, in contrast to others, found nonelaborated mental state talk to be more strongly related 
to ToM compared to elaborated mental state language is still not clear. This result may be due to specific sample characteristics (see also Ebert et al., 2017) or may have cultural reasons. To further explore this issue, more research, including and comparing the MMSII with parents' language use in everyday situations and from different SES backgrounds, is needed.

Most important, however, our study provides evidence that parents' mental state language at home is an important facet of children's home language and literacy environment. Moreover, this facet is specifically related to children's ToM development over and above children's language skills and more general features of the home language and literacy environment, particularly for children from lower SES families. Thus, parents' mental state language is more than just a proxy for the quality of the home language and literacy environment but an additional facet of the home language and literacy environment that is important to children's development over and above other more general facets of the home language and literacy environment.

\section{Relations Between the Home Language and Literacy Environment and Children's Language and ToM Development in Children From Lower SES Homes}

An additional question of our study that is particularly relevant to early intervention was, whether the pattern of relations shown for the whole group of children also holds for children from lower SES homes. Other studies have suggested that the effects of the home language and literacy environment may even be more pronounced in children from more disadvantaged families. Our results are in line with this assumption.

In particular, in the lower SES group, we found effects of all measures of the home language and literacy environment included in our study: Book exposure as a quantitative indicator, quality of verbal interaction, and elaborated parental mental talk were related to child language at age $4 ; 6$, which in turn was highly predictive for the children's language skills one year later. Besides, book exposure had an additional direct effect on later language skills at 5;6 years of age. Furthermore, language skills at 4;6 years were significantly related to children's later ToM understanding, and thus an indirect effect of the home language and literacy environment on later ToM via children's language skills was shown. Not least, non-elaborated parental mental state talk exerted a direct effect on ToM in our model (see also discussion above).

These results show similarities and some differences to the pattern of relations observed in the whole group of children. Thus, the quality of verbal interaction and elaborated parental mental state talk significantly affected early child language, particularly in the low SES group. Concerning ToM, early child language mediated the effects of all the three indicators of the home language and literacy environment that impacted on child language, and non-elaborated mental state language showed an additional direct effect on ToM.
Overall the relational pattern suggests a strong impact of differences in the home language and literacy environment as well as in early child language on children's language and ToM understanding in children from lower SES families. This result is in line with previous studies showing effects of the home language environment particularly in children from low SES families (e.g., Bradley et al., 2001; Shahaeian et al., 2018).

This comparatively strong impact of the home environment within the lower SES group compared to the whole group and the higher SES group may be due to various reasons.

Amongst others, global and more specific language stimulation, as well as qualitative and quantitative aspects of the home language and literacy environment might be particularly crucial for children with less advanced skills (see also Weinert et al., 2012). In fact, it is known that children from lower SES families usually lag behind in their language skills (Hoff, 2013).

Another reason might be that it is especially important what parents with a comparatively low SES do and how they interact with their children to compensate for reduced educational, cultural, financial, or social resources that often go along with low SES. Thus, lower SES families might not have the financial resources, the education, the cultural capital, or might not live in a region where it is easy for children to obtain rich stimulation in the surrounding area (e.g., Conger and Donnellan, 2007). Especially in the countryside, where a considerable part of our sample came from, there may be fewer opportunities to attend cultural activities or to visit a library, a zoo, a museum, or a theater than in a larger town or city. Thus, compared to children growing up in lower SES families, children from higher SES families might have additional resources or a higher availability of sources that might compensate for disadvantages in the home language and literacy environment. Against this background, it might be critical what language and literacy stimulation parents of children from lower SES provide to their children and that they offer them a rich and varied home language and literacy environment no matter what the socioeconomic circumstances are.

From an intervention point of view, it is highly relevant that all aspects of the home language and literacy environment may help to foster child development. In particular, the role of early language is highlighted by the results of our study as it impacts future language development and ToM. As our results suggest, it seems very promising to support the home language and literacy environment as a starting point to reduce SES differences. Our study shows that especially children from lower SES backgrounds can profit from a stimulating home language and literacy environment.

\section{DATA AVAILABILITY STATEMENT}

The raw data supporting the conclusions of this article will be made available by the authors, without undue reservation, to any qualified researcher. 


\section{ETHICS STATEMENT}

The present sample was part of a more comprehensive German longitudinal study on child development and educational processes. The study was funded by the German Research Foundation, and compliance with ethical standards was approved by the review process. Appropriate consent to take part in this study was obtained from parents, and all information provided was voluntary.

\section{AUTHOR CONTRIBUTIONS}

SE developed the research ideas of this manuscript, wrote the first draft of the manuscript and was responsible for the analyses. SL and SW revised drafts of the manuscript, and contributed in discussing analyses. All authors were involved in data collection, development of constructs of the study, contributed to the article and approved the submitted version.

\section{FUNDING}

This study was part of the Research Group "BiKS" ("Bildungsprozesse, Kompetenzentwicklung und Formation

\section{REFERENCES}

Adrian, J. E., Clemente, R. A., Villanueva, L., and Rieffe, C. (2005). Parentchild picture-book reading, mothers' mental state language and children's theory of mind. J. Child Lang. 32, 673-686. doi: 10.1017/s03050009050 06963

Antonietti, A., Liverta-Sempio, O., Marchetti, A., and Astington, J. W. (2006). "Mental language and understanding of epistemic and emotional mental states: contextual aspects," in Theory of Mind and Language in Developmental Contexts, eds A. Antonietti, O. Sempio-Liverta, and A. Marchetti (New York, NY: Springer Science + Business Media), 1-30.

Arriaga, R. I., Fenson, L., Cronan, T., and Pethick, S. J. (1998). Scores on the MacArthur communicative development inventory of children from low- and middle-income families. Appl. Psychol. 19, 209-223. doi: 10.1017/ s0142716400010043

Astington, J. W., and Baird, J. A. (2005). "Introduction: why language matters," in Why Language Matters for Theory of Mind, eds J. W. Astington and J. A. Baird (New York, NY: Oxford University Press), 3-25.

Astington, J. W., and Pelletier, J. (1996). "The language of mind: its role in teaching and learning," in The Handbook of Education and Human Development: New Models of Learning, Teaching and Schooling, eds D. R. Olson and N. Torrance (Malden, MA: Blackwell Publishing), 593-619.

Attig, M., and Weinert, S. (2019). Häusliche Lernumwelt und Spracherwerb in den ersten Lebensjahren [Home learning environment and language acquisition in the first years of life]. Sprache Stimme Gehör 43, 86-92. doi: 10.1055/a-08519049

Baron, R. M., and Kenny, D. A. (1986). The moderator-mediator variable distinction in social psychological research: conceptual, strategic, and statistical considerations. J. Pers. Soc. Psychol. 51, 1173-1182. doi: 10.1037/0022-3514.51. 6.1173

Baydar, N., Küntay, A. C., Yagmurlu, B., Aydemir, N., Cankaya, D., Göksen, F., et al. (2014). "It takes a village" to support the vocabulary development of children with multiple risk factors. Dev. Psychol. 50, 1014-1025. doi: 10.1037/a00 34785

Bishop, D. V. M. (1983/1989). TROG-Test for the Reception of Grammar. Manchester: D. V. M. Bishop, University of Manchester. von Selektionsent scheidungen im Vorschul- und Schulalter; English: "Educational Processes, Competence Development, and Selection Decisions in Preschool and School-age Children") at the University of Bamberg, funded by grants from the German Research Foundation (DFG, FOR 543). The data presented here were for the most part collected in the developmental psychology sub-project (headed by SW) and the early education sub-project (headed by H.G. Roßbach).

\section{ACKNOWLEDGMENTS}

We would like to thank all colleagues involved in data collection for the BiKS study and all participating children, their parents, and their (preschool) teachers, as well as all students engaged in data collection for their most active cooperation.

\section{SUPPLEMENTARY MATERIAL}

The Supplementary Material for this article can be found online at: https://www.frontiersin.org/articles/10.3389/fpsyg. 2020.555654/full\#supplementary-material

Boerma, I. E., Mol, S. E., and Jolles, J. (2017). The role of home literacy environment, mentalizing, expressive verbal ability, and print exposure in third and fourth graders' reading comprehension. Sci. Stud. Reading 21, 179-193. doi: 10.1080/10888438.2016.1277727

Bradley, R. H., and Corwyn, R. F. (2002). Socioeconomic status and child development. Ann. Rev. Psychol. 53, 371-399. doi: 10.1146/annurev.psych.53. 100901.135233

Bradley, R. H., Corwyn, R. F., Pipes, McAdoo, H., and Garcia Coll, C. (2001). The home environments of children in the United States Part I: variations by age, ethnicity, and poverty status. Child Dev. 72, 1844-1867. doi: 10.1111/14678624.t01-1-00382

Bretherton, I., and Beeghly, M. (1982). Talking about internal states: the acquisition of an explicit theory of mind. Dev. Psychol. 18, 906-921. doi: 10.1037/00121649.18.6.906

Burgess, S. R., Hecht, S. A., and Lonigan, C. J. (2002). Relations of the home literacy environment (HLE) to the development of reading-related abilities: a one-year longitudinal study. Reading Res. Q. 37, 408-426. doi: 10.1598/RRQ.37.4.4

Charman, T., and Shmueli-Goetz, Y. (1998). The relationship between theory of mind, language and narrative discourse: an experimental study. Cahiers Psychol. Cogn. Curr. Psychol. Cogn. 17, 245-271.

Conger, R. D., and Donnellan, M. B. (2007). An interactionist perspective on the socioeconomic context of human development. Ann. Rev. Psychol. 58, 175-199. doi: 10.1146/annurev.psych.58.110405.08555116903807

Crosnoe, R., Leventhal, T., Wirth, R. J., Pierce, K. M., and Pianta, R. C. (2010). Family socioeconomic status and consistent environmental stimulation in early childhood. Child Dev. 81, 972-987. doi: 10.1111/j.1467-8624.2010.01446.x

Daneri, M. P., Blair, C., and Kuhn, L. J. (2018). Maternal language and child vocabulary mediate relations between socioeconomic status and executive function during early childhood. Child Dev. 18, 2001-2018. doi: 10.1111/cdev. 13065

De Villiers, J. G., and Pyers, J. E. (2002). Complements to cognition: a longitudinal study of the relationship between complex syntax and false-beliefunderstanding. Cogn. Dev. 17, 1037-1060. doi: 10.1016/s0885-2014(02)000734

Devine, R. T., and Hughes, C. (2016). Family correlates of false belief understanding in early childhood: a meta-analysis. Child Dev. 89, 971-987. doi: 10.1111/cdev. 12682 
Dunn, J., Brown, J., Slomkowski, C., Tesla, C., and Youngblade, L. (1991). Young children's understanding of other people's feelings and beliefs: individual differences and their antecedents. Child Dev. 62, 1352-1366. doi: 10.2307/ 1130811

Dunn, L. M., and Dunn, L. M. (1981). Peabody Picture Vocabulary Test-Revised (PPVT-R). Circle Pines, MN: American Guidance Service.

Dyer, J. R., Shatz, M., and Wellman, H. M. (2000). Young children's storybooks as a source of mental state information. Cogn. Dev. 15, 17-37. doi: 10.1016/S08852014(00)00017-4

Ebert, S. (2011). Was Kinder über die mentale Welt wissen-Die Entwicklung von deklarativem Metagedächtnis aus der Sicht der "Theory of Mind" (Knowledge About the Mental World-The Development of Declarative Metamemory from the View of "Theory of Mind"). Hamburg: Dr. Kovaè.

Ebert, S. (2015). Longitudinal relations between theory of mind and metacognition and the impact of language. J. Cogn. Dev. 16, 559-586. doi: 10.1080/15248372. 2014.926272

Ebert, S. (2020). Theory of mind, language, and reading: developmental relations from early childhood to early adolescence. J. Exp. Child Psychol. 191:104739. doi: 10.1016/j.jecp.2019.104739

Ebert, S., Lockl, K., Weinert, S., Anders, Y., Kluczniok, K., and Roßbach, H.G. (2013). Internal and external influences on vocabulary development in preschool children. Sch. Effect. Sch. Improv. 24, 138-154. doi: 10.1080/09243453. 2012.749791

Ebert, S., Peterson, C., Slaughter, V., and Weinert, S. (2017). Links among parents' mental state language, family socioeconomic status, and preschoolers' theory of mind development. Cogn. Dev. 44, 32-48. doi: 10.1016/j.cogdev.2017.08.005

Enders, C. K. (2013). Dealing with missing data in developmental research. Child Dev. Perspect. 7, 27-31. doi: 10.1111/cdep.12008

Enders, C. K., and Bandalos, D. L. (2001). The relative performance of full information maximum likelihood estimation for missing data in structural equation models. Struct. Equat. Model. 8, 430-457. doi: 10.1207/ S15328007SEM0803_5

Evans, M. D. R., Kelley, J., Sikora, J., and Treiman, D. J. (2010). Family scholarly culture and educational success: Books and schooling in 27 nations. Res. Soc. Stratificat. Mobility 28, 171-197. doi: 10.1016/j.rssm.2010.01.002

Farkas, C., Santelices, M. P., Vallotton, C. D., Brophy-Herb, H. E., Iglesias, M., Sieverson, C., et al. (2020). Children's storybooks as a source of mental state references: comparison between books from Chile, Colombia, Scotland and USA. Cogn. Dev. 53:100845. doi: 10.1016/j.cogdev.2019.100845

Fernald, A., and Weisleder, A. (2011). "Early language experience is vital to developing fluency in understanding," in Handbook of Early Literacy Research, Vol. 3, eds S. B. Neuman and D. K. Dickinson (New York, NY: The Guilford Press), 3-18.

Fletcher, K. L., and Reese, E. (2005). Picture book reading with young children: a conceptual framework. Dev. Rev. 25, 64-103. doi: 10.1016/j.dr.2004.08.009

Fox, A. (2006). TROG-D. Test zur Überprüfung des Grammatikverständnisses [Test for the Reception of Grammar]. Idstein: Schulz-Kirchner.

Ganzeboom, H. B. G., De Graaf, P. M., Treiman, D. J., and De Leeuw, J. (1992). A standard international socio-economic index of occupational status. Soc. Sci. Res. 21, 1-56. doi: 10.1016/0049-089x(92)90017-B

Gola, A. A. H. (2012). Mental verb input for promoting children's theory of mind: a training study. Cogn. Dev. 27, 64-76. doi: 10.1016/j.cogdev.2011. 10.003

Graham, J. W. (2003). Adding missing-data-relevant variables to FIML-based structural equation models. Struct. Equat. Model. 10, 80-100. doi: 10.1207/ s15328007sem1001_4

Hart, B., and Risley, T. R. (1992). American parenting of language-learning children: persisting differences in family-child interactions observed in natural home environments. Dev. Psychol. 28, 1096-1150. doi: 10.1037/0012-1649.28.6. 1096

Hindman, A. H., Connor, C. M., Jewkes, A. M., and Morrison, F. J. (2008). Untangling the effects of shared book reading: multiple factors and their associations with preschool literacy outcomes. Early Childhood Res. Q. 23, 330-350.

Hirsh-Pasek, K., Adamson, L. B., Bakeman, R., Owen, M. T., Golinkoff, R. M., Pace, A., et al. (2015). The contribution of early communication quality to lowincome children's language success. Psychol. Sci. 26, 1071-1083. doi: 10.1177/ 095679761558149326048887
Hoff, E. (2003). The specificity of environmental influence: socioeconomic status affects early vocabulary development via maternal speech. Child Dev. 74, 13681378. doi: 10.1111/1467-8624.00612

Hoff, E. (2006). How social contexts support and shape language development. Dev. Rev. 26, 55-88. doi: 10.1016/j.dr.2005.11.002

Hoff, E. (2013). Interpreting the early language trajectories of children from lowSES and language minority homes: implications for closing achievement gaps. Dev. Psychol. 49, 4-14. doi: 10.1037/a0027238

Hoff, E., and Naigles, L. (2002). How children use input to acquire a lexicon. Child Dev. 73, 418-433. doi: 10.1111/1467-8624.00415

Hoff-Ginsberg, E., and Shatz, M. (1982). Linguistic input and the child's acquisition of language. Psychol. Bullet. 92, 3-26. doi: 10.1037/0033-2909.92.1.371 34327

Hughes, C., and Devine, R. T. (2017). "Family influences on theory of mind: a review," in Theory of Mind Development in Context, eds V. Slaughter and M. de Rosnay (New York, NY: Routledge/Taylor \& Francis Group).

Hughes, C., and Dunn, J. (1998). Understanding mind and emotion: longitudinal associations with mental-state talk between young friends. Dev. Psychol. 34, 1026-1037. doi: 10.1037/0012-1649.34.5.10269779748

Huttenlocher, J., Vasilyeva, M., Cymerman, E., and Levine, S. (2002). Language input and child syntax. Cogn. Psychol. 45, 337-374. doi: 10.1016/s0010-0285(02) 00500-5

Huttenlocher, J., Waterfall, H., Vasilyeva, M., Vevea, J., and Hedges, L. V. (2010). Sources of variability in children's language growth. Cogn. Psychol. 61, 343-365. doi: 10.1016/j.cogpsych.2010.08.002

Kuger, S., Pflieger, K., and Rossbach, H.-G. (2005). Familieneinschaetzskala [Family Rating Scale, Research Version]. Bamberg: BiKS-Research Group University of Bamberg.

Landry, S. H., Smith, K. E., Swank, P. R., Zucker, T., Crawford, A. D., and Solari, E. F. (2012). The effects of a responsive parenting intervention on parent-child interactions during shared book reading. Dev. Psychol. 48:969.

Lehrl, S., Ebert, S., and Rossbach, H.-G. (2013). "Facets of preschoolers' home literacy environments: what contributes to reading literacy in primary school?," in The Development of Reading Literacy from Early Childhood to Adolescence. Empirical Findings from the Bamberg BiKS Longitudinal Studies, eds M. Pfost, C. Artelt, and S. Weinert (Bamberg: University of Bamberg Press), 35-62.

Lehrl, S., Ebert, S., Roßbach, H.-G., and Weinert, S. (2012). Die Bedeutung der familiären Lernumwelt für Vorläufer schriftsprachlicher Kompetenzen im Vorschulalter. Zeitschr. Familienforschung 24, 115-133.

Leseman, P., Scheele, A. F., Mayo, A. Y., and Messer, M. (2007). Home literacy as a special language environment to prepare children for school. Zeitschr. Erziehungswissenschaft 3, 334-355.

Linberg, A., Lehrl, S., and Weinert, S. (2020). The early years home learning environment - associations with parent-child-course attendance and children's vocabulary at age 3. Front. Psychol. 11:1425. doi: 10.3389/fpsyg.2020.01425

Lohmann, H., and Tomasello, M. (2003). The role of language in the development of false belief understanding: a training study. Child Dev. 74, 1130-1144. doi: 10.1111/1467-8624.00597

Longobardi, E., Spataro, P., and Rossi-Arnaud, C. (2016). Relations between theory of mind, mental state language and social adjustment in primary school children. Eur. J. Dev. Psychol. 13, 424-438. doi: 10.1080/17405629.2015.1093930

Milligan, K., Astington, J. W., and Dack, L. A. (2007). Language and theory of mind: meta-analysis of the relation between language ability and false-belief understanding. Child Dev. 78, 622-646. doi: 10.1111/j.1467-8624.2007.01018.x

Mistry, R. S., Biesanz, J. C., Chien, N., Howes, C., and Benner, A. D. (2008). Socioeconomic status, parental investments, and the cognitive and behavioral outcomes of low-income children from immigrant and native households. Early Childhood Res. Q. 23, 193-212. doi: 10.1016/j.ecresq.2008.01.002

Mol, S. E., and Bus, A. G. (2011). To read or not to read: a meta-analysis of print exposure from infancy to early adulthood. Psychol. Bullet. 137, 267-296. doi: 10.1037/a0021890 21219054

Mol, S. E., and Neuman, S. B. (2014). Sharing information books with kindergartners: the role of parents' extra-textual talk and socioeconomic status. Early Childhood Res. Q. 29, 399-410. doi: 10.1016/j.ecresq.2014.04.001

Muthén, L. K., and Muthén, B. (2012). 1998-2012. Mplus User's Guide, Edn 7, Los Angeles, CA: Muthén \& Muthén.

Olson, D. R., Antonietti, A., Liverta-Sempio, O., and Marchetti, A. (2006). “The mental verbs in different conceptual domains and in different cultures," in 
Theory of Mind and Language in Developmental Contexts, eds A. Antonietti, O. Sempio-Liverta, and A. Marchetti (New York, NY: Springer Science + Business Media), 31-64.

Pace, A., Luo, R., Hirsh-Pasek, K., and Golinkoff, R. M. (2017). Identifying pathways between socioeconomic status and language development. Annu. Rev. Linguist. 3, 285-308. doi: 10.1146/annurev-linguistics-011516034226

Pan, B. A., Rowe, M. L., Singer, J. D., and Snow, C. E. (2005). Maternal correlates of growth in toddler vocabulary production in low-income families. Child Dev. 76, 763-782. doi: 10.1111/1467-8624.00498-i1

Perner, J., Leekam, S. R., and Wimmer, H. (1987). Three-year-olds difficulty with false belief: the case for a conceptual deficit. Br. J. Dev. Psychol. 5, 125-137. doi: 10.1111/j.2044-835X.1987.tb01048.x

Peterson, C., and Siegal, M. (2000). Insights into theory of mind from deafness and autism. Mind Lang. 15, 123-145. doi: 10.1111/1468-0017.00126

Peterson, C., and Slaughter, V. (2003). Opening windows into the mind: mothers' preferences for mental state explanations and children's theory of mind. Cogn. Dev. 18, 399-429. doi: 10.1016/s0885-2014(03)00041-8

Raffington, L. (2018). Socioeconomic Disparities in Children's Cognitive Development: Longitudinal Dynamics and Stress Mechanisms. Berlin: Humboldt-Universität zu Berlin.

Reese, E., and Cox, A. (1999). Quality of adult book reading affects children's emergent literacy. Dev. Psychol. 35, 20-28. doi: 10.1037/0012-1649.35.1. 209923461

Rodriguez, E. T., Tamis-LeMonda, C. S., Spellmann, M. E., Pan, B. A., Raikes, H., Lugo-Gil, J., et al. (2009). The formative role of home literacy experiences across the first three years of life in children from low-income families. J. Appl. Dev. Psychol. 30, 677-694. doi: 10.1016/j.appdev.2009.01.003

Rose, E., Lehrl, S., Ebert, S., and Weinert, S. (2017). Long-term relations between children's language, the home literacy environment, and socioemotional development from ages 3 to 8. Early Educ. Dev. 29, 342-356. doi: 10.1080/ 10409289.2017.1409096

Rowe, M. L. (2012). A longitudinal investigation of the role of quantity and quality of child-directed speech in vocabulary development. Child Dev. 83, 1762-1774. doi: 10.1111/j.1467-8624.2012.01805.x

Rowe, M. L., Leech, K. A., and Cabrera, N. (2017). Going beyond input quantity: wh-questions matter for toddlers' language and cognitive development. Cogn. Sci. 41:12349. doi: $10.1111 / \operatorname{cogs} .12349$

Ruffman, T., Slade, L., and Crowe, E. (2002). The relation between children's and mothers' mental state language and theory-of-mind understanding. Child Dev. 73, 734-751. doi: 10.1111/1467-8624.00435

Sénéchal, M., and LeFevre, J.-A. (2002). Parental involvement in the development of children's reading skill: a five-year longitudinal study. Child Dev. 73, 445-460. doi: 10.1111/1467-8624.0041711949902

Sénéchal, M., LeFevre, J.-A., Thomas, E. M., and Daley, K. E. (1998). Differential effects of home literacy experiences on the development of oral and written language. Read. Res. Q. 33, 96-116. doi: 10.1598/RRQ.33.1.5

Shahaeian, A., Wang, C., Tucker-Drob, E., Geiger, V., Bus, A. G., and Harrison, L. J. (2018). Early shared reading, socioeconomic status, and children's cognitive and school competencies: six years of longitudinal evidence. Sci. Stud. Read. 22, 485-502.

Slaughter, V., and Peterson, C. (2012). "How conversational input shapes theory of mind development in infancy and early childhood," in Access to Language and
Cognitive Development, eds M. Siegal and L. Surian (New York, NY: Oxford University Press), 3-22.

Storch, S. A., and Whitehurst, G. J. (2001). "The role of family and home in the literacy development of children from low-income backgrounds," in New Dir Child Adolesc Dev, eds P. R. Britto and J. Brooks-Gunn (San Francisco, CA: Jossey-Bass).

Sullivan, K., Zaitchik, D., and Tager-Flusberg, H. (1994). Preschoolers can attribute second-order beliefs. Dev. Psychol. 30, 395-402. doi: 10.1037/0012-1649.30.3. 395

Tabors, P. O., Roach, K. A., and Snow, C. E. (2001). “Chapter: home language and literacy environment: final results," in Beginning Literacy with Language: Young Children Learning at Home and School, (Baltimore, MD: Paul H Brookes Publishing US), 111-138.

Tompkins, V., Benigno, J. P., Kiger, L. B., Wright, B. M., and Tompkins, V. (2018). The relation between parents' mental state talk and children's social understanding: a meta-analysis. Soc. Dev. 27, 223-243. doi: 10.1111/sode. 12280

van Kleeck, A. (2003). "Research on book sharing: another critical look," in On Reading Books to Children: Parents and Teachers, eds A. van Kleeck, S. A. Stahl, and E. B. Bauer (Mahwah, NJ: Lawrence Erlbaum), 271-320.

Vernon-Feagans, L., and Bratsch-Hines, M. E. (2013). Caregiver-child verbal interactions in child care: a buffer against poor language outcomes when maternal language input is less. Early Childhood Res. Q. 28, 858-873. doi: 10.1016/j.ecresq.2013.08.002

Weinert, S., and Ebert, S. (2013). Spracherwerb im Vorschulalter - soziale Disparitäten und Einflussvariablen auf den Grammatikerwerb. Zeitschr. Erziehungswissens. 16, 303-332. doi: 10.1007/s11618-013-0354-8

Weinert, S., and Ebert, S. (2017). "Verlaufsmerkmale und Wirkfaktoren der frühen kognitiv-sprachlichen Entwicklung - Ergebnisse der BiKS-3-10 Studie," in Entwicklungsstörungen und Chronische Erkrankungen-Diagnose, Behandlungsplanung und Familienbegleitung, eds V. Mall, F. Voigt, and N. H. Jung (Lübeck: Verlag Schmidt-Römhild), 13-33.

Weinert, S., Ebert, S., Lockl, K., and Kuger, S. (2012). Disparitäten im Wortschatzerwerb: Zum Einfluss des Arbeitsgedächtnisses und der Anregungsqualität in Kindergarten und Familie auf den Erwerb lexikalischen Wissens. Unterrichtswissenschaft 40, 4-25.

Wellman, H. M., Cross, D., and Watson, J. (2001). Meta-analysis of theory-ofmind development: the truth about false belief. Child Dev. 72, 655-684. doi: 10.1111/1467-8624.00304

Whitehurst, G. J., and Lonigan, C. J. (1998). Child development and emergent literacy. Child Dev. 69, 848-872. doi: 10.2307/113 2208

Conflict of Interest: The authors declare that the research was conducted in the absence of any commercial or financial relationships that could be construed as a potential conflict of interest.

Copyright (c) 2020 Ebert, Lehrl and Weinert. This is an open-access article distributed under the terms of the Creative Commons Attribution License (CC BY). The use, distribution or reproduction in other forums is permitted, provided the original author(s) and the copyright owner(s) are credited and that the original publication in this journal is cited, in accordance with accepted academic practice. No use, distribution or reproduction is permitted which does not comply with these terms. 


\section{Triangulating Multi-Method Assessments of Parental Support for Early Math Skills}

\author{
Heather J. Bachman ${ }^{1 *}$, Leanne Elliott ${ }^{2}$, Shirley Duong ${ }^{3}$, Laura Betancur ${ }^{3}$, \\ Monica G. Navarro ${ }^{1}$, Elizabeth Votruba-Drzal ${ }^{3}$ and Melissa Libertus ${ }^{3}$
}

${ }^{1}$ Department of Health and Human Development and the Learning Research and Development Center, University of Pittsburgh, Pittsburgh, PA, United States, ${ }^{2}$ Learning Research and Development Center, University of Pittsburgh, Pittsburgh, PA, United States, ${ }^{3}$ Department of Psychology and the Learning Research and Development Center, University of Pittsburgh, Pittsburgh, PA, United States

Past research has examined parental support for math during early childhood using parent-report surveys and observational measures of math talk. However, since most studies only present findings from one of these methods, the construct (parental support for early math) and the method are inextricably linked, and we know little about whether these methods provide similar or unique information about children's exposure to math concepts. This study directly addresses the mono-operation bias operating in past research by collecting and comparing multiple measures of support for number and spatial skills, including math talk during semi-structured observations of parent-child interactions, parent reports on a home math activities questionnaire, and time diaries. Findings from 128 parents of 4-year-old children reveal substantial within-measure variability across all three data sources in the frequency of number and spatial activities and the type and content of parent talk about number and spatial concepts. Convergence in parental math support measures was evident among parent reports from the questionnaire and time diaries, such that scale composites about monthly number activities were related to number activities on the previous work day, and monthly spatial activities were correlated with spatial activities the prior nonwork days. However, few parent report measures from the survey or time diary were significantly correlated with observed quantity or type of math talk in the semi-structured observations. Future research implications of these findings are discussed.

Keywords: math, parenting, structured observation, time diary, home numeracy

\section{INTRODUCTION}

Children's early math learning is gaining widespread interest and investment. Individual differences in children's math skills during early childhood are associated with a wide array of academic, health, and economic characteristics in later adolescence and adulthood. Growth in math skills between preschool and 1st grade predict academic achievement broadly in middle childhood and adolescence (Watts et al., 2016). Moreover, early math skills are related to a range of human capital and labor market outcomes in adulthood, such as educational attainment, earnings, socioeconomic status (SES), and mental and physical health (Murmane et al., 2000; Rose and Betts, 2004; Parsons and Bynner, 2005; Kaufman et al., 2008; Ritchie and Bates, 2013; Weinberger, 2014; Cortes et al., 2015; Hanushek and Woessman, 2015). 
Despite the importance of these early skills for later academic success and adult well-being, growing concerns have been raised about the low quantity and quality of math exposure that most young children experience at home (National Research Council, 2009). However, this concern has been difficult to ascertain from large, longitudinal studies in the United States because parents of preschool-aged children or kindergartners have historically been asked very few questions about their support for early math learning (e.g., Early Childhood Longitudinal Study-Birth cohort; NICHD Study of Early Child Care and Youth Development; ECLS-Kindergarten cohorts). In addition, the few items commonly asked tend to focus on number sense. For example, in the ECLS-K:2011 cohort, parents of kindergarteners were asked how often they practice "reading, writing, or working with numbers" in a week, which combined math and literacy promotion, and only included numeric skills to address math support. However, for young children, emergent math skills include important domains such as geometry, spatial thinking, and measurement, as well as number sense (Klibanoff et al., 2006; Sarama and Clements, 2009), and these early skills promote later math proficiency in procedural and conceptual skills (Ginsburg et al., 2008; National Research Council, 2009). In the present study, we focus on parental support of both number sense and spatial math skills as these are the most widely studied math constructs for young children.

As described in more detail below, the limitations of existing measures of parental support for early math skills as well as the inconsistencies in their interrelations call for a more detailed exploration of various approaches to measure potentially infrequent or episodic math exposure (Cannon and Ginsburg, 2008; Elliott and Bachman, 2018; Elliott et al., 2020). In the present study, we examine an additional methodological approach used across multiple disciplines (economics, sociology, psychology, anthropology) as a tool to capture infrequent math activities during children's daily lives: time diaries. Asking parents to recount their previous day, minute by minute, may unearth brief, episodic math-related activities that could be missed or underestimated in a survey about math activities during the prior week or month, or infrequent interactions that are not captured in short observations of math talk. As mentioned above, a further concern is that the predominant focus on early math support has involved children's developing number sense, with less work focusing on children's developing spatial skills despite their importance for math development.

Thus, the present study addresses two major aims. First, it examines individual differences in parental support for number sense and spatial skills across multi-method assessments, including questionnaires, observed math talk, and time diaries. Second, it identifies areas of triangulation or convergence in the assessment of parental support for number sense and spatial skills across these multi-method data sources. To this end, in the current study we explore the variability in parents' activities and conversations to support early math learning. We also examine the associations among parent questionnaire responses, observed frequencies of math talk, and time diaries to examine the extent to which multiple data sources converge in the assessment of parent support for early math development.

\section{Measurement of Parental Home Math Support Parent Reports in Questionnaires}

Home math activity scales are a commonly used to measure parents' support of young children's math skills (see Elliott and Bachman, 2018 for review). Investigators commonly ask parents about the weekly or monthly frequency of a wide array of activities in the home that may support children's math development, such as counting and sorting objects, playing with number flashcards, or playing card or board games. However, many studies that asked parents about the frequency of a more diverse set of math activities report very low frequencies of math exposure. For example, one study finds that parents of 3- to 5-year-old children in the United States reported engaging their children in math activities such as grouping and ordering objects less than 1-2 times per week, and widely known math activities such as counting occurred only 3-5 times per week on average (Blevins-Knabe and Musun-Miller, 1996). Furthermore, other work finds that more advanced math activities such as comparing numerical magnitudes and arithmetic occur less frequently than counting and grouping (Zippert and Ramani, 2017) and numeracy activities occur more frequently than spatial activities (Zippert and RittleJohnson, 2020; Zippert et al., 2020). This problem is not constrained to the United States: Chilean parents reportedly engage their 4-year-old children in operational activities such as learning simple sums or measuring quantities only weekly on average (Susperreguy et al., 2020). Similar results have been obtained from parents of Greek and Canadian 5-year-olds (LeFevre et al., 2010).

In addition, global composite measures from these inventories of math activities inconsistently predict children's math skills (Kleemans et al., 2012; Missall et al., 2014; Niklas and Schneider, 2014; DeFlorio and Beliakoff, 2015; Hart et al., 2016; Purpura et al., 2020). To address the heterogeneity within these survey items, some researchers have tried to distinguish formal versus informal activities, with explicitly didactic math activities (e.g., number flash cards, writing numerals) compared to more playbased or everyday activities that could provide opportunities to learn math concepts (e.g., board games or cooking) or numeracy and spatial activities. This dichotomy has also produced very mixed findings rather than clarifying key parenting practices that promote early math learning. Some studies report positive associations for formal (LeFevre et al., 2010; Manolitsis et al., 2013; Huntsinger et al., 2016) and informal activities (LeFevre et al., 2009) and math skills. Others report negative associations between informal activities and math skills (Huntsinger et al., 2016), or null associations for formal (Blevins-Knabe and MusunMiller, 1996; LeFevre et al., 2009) and informal activities (LeFevre et al., 2010) and math skills. Furthermore, only numeracy activities seem to be related to both children's numeracy and spatial skills in one study (Purpura et al., 2020), while another study shows that parental report of spatial activities may be 
negatively associated with parent report of children's math skills, albeit a weak association (Hart et al., 2016).

Given the unclear theoretical definitions for formal and informal math activities, the mixed empirical findings regarding their respective relations to children's math skills, and relative dearth of studies on a distinction between numeracy and spatial math activities, the present study explores the latter distinction. Specifically, we examine the consistency with which parents' support of number sense and spatial skills are evident across multiple methods and data sources. In doing so, we aim to address the predominant focus on number sense with a cadre of measurement tools that involve the frequency and duration of spatial activities as well.

\section{Observations of Parental Math Talk}

In an effort to understand whether the low frequency of reported math activities are capturing young children's experiences or may be an artifact of the most widely used tool to measure such exposure - parental questionnaire reports - researchers have explored the frequency of math talk during parent-child observations as an alternate measure of parent support of early math skills. Survey measures of how frequently parents engage in math activities cannot assess whether parents and children are actually discussing math concepts during those interactions, the range of mathematical concepts discussed during these conversations, the qualitative features of the math talk, or math talk that occurs outside of the context of math activities. Rather than focusing on specific activities that are thought to elicit conversation about math, measuring math talk allows researchers to observe math-related interactions that occur during a variety of different activities, regardless of whether they are typically categorized as math-related or not. For example, parents frequently engage in conversations about mathematical concepts during mealtimes even though the activity itself is not be considered math-related (Susperreguy and Davis-Kean, 2016).

The amount and diversity of parents' math talk has repeatedly displayed positive associations with children's math skills (Casey et al., 2018). These relations are most commonly demonstrated with parents' use of number words. For example, parental number talk during naturalistic home observations when children were between 14 and 30 months of age was predictive of children's understanding of cardinality at 46 months after accounting for SES and overall parent talk (Levine et al., 2010). Similarly, studies using structured tasks to elicit math talk in more controlled environments generally find that greater parental number or spatial talk is associated with higher math and spatial skills (Vandermaas-Peeler et al., 2012; Ramani et al., 2015; Elliott et al., 2017; Leyva et al., 2017; but see Zippert et al., 2020, for null results). For example, Vandermaas-Peeler et al. (2012) contrasted the frequency of parental number talk and child responses to parent number talk during dyadic interactions between a numeracy awareness group, in which parents explicitly received suggestions to incorporate numeracy into the activity (e.g., counting and identifying numbers), and a control group. Parents in the numeracy awareness group talked more about number concepts (they incorporated twice as much number talk) compared to controls. Children who were exposed to more questions about number produced more correct responses to parental talk, particularly for more complex math concepts such as arithmetic. Moreover, many of these studies reveal differences in the amount of number talk depending on the nature of the tasks or instructions given to parents (e.g., Vandermaas-Peeler et al., 2012; Ramani et al., 2015; Zippert et al., 2020), suggesting the importance of considering the observational context when measuring math talk. However, parental math talk also seems to occur at very low frequency in young children's everyday lives (Tudge and Doucet, 2004; Gunderson and Levine, 2011). For example, Levine et al. (2010) found that parents of 14- to 30 -month-olds used only an average of 91 number words (e.g., the number words "one" through "ten") over a duration of $7.5 \mathrm{~h}$, ranging from 4 to more than 250 number words.

More recently, several studies have examined parents' use of spatial terms and discussions of spatial content with their young children, either independently or combined with number talk (e.g., Zippert et al., 2019, 2020). Although some studies suggest that children's exposure to spatial talk from their parents is positively associated with children's own spatial language as well as their spatial skills (Pruden et al., 2011; Casasola et al., 2020), others fail to find such a relation (Zippert et al., 2020). In one experimental manipulation, Polinsky et al. (2017) found that providing parents with prompts to discuss spatial content while playing with their children at a museum led to increases in parents' spatial talk as well as children's spatial talk and, in turn, children's performance on a spatial task. Furthermore, much like parental number talk, the frequency of parents' spatial talk varies systematically across different types of activities (Ferrara et al., 2011; Zosh et al., 2015; Ho et al., 2018; Lee et al., 2019; Verdine et al., 2019; Zippert et al., 2020). We extend this further by considering the relations between frequencies of number and spatial talk between parents and children as they engage in different activities.

Despite the consistency in previous results, few studies have explored the qualitative features of parents' math talk. Most studies examine the quantity of number and spatial words, but differential patterns of prediction are increasingly detected across types of math content. For instance, Elliott et al. (2017) found that parents' talk about numbers greater than 10 , not parents' overall number talk, was associated with 5- and 6-year-old children's math skills. Similarly, Casey et al. (2018) found that parental talk about labeling sets of objects with children at age 3 was predictive of children's later math achievement in preschool and first grade after controlling for other forms of numerical support, such as input about identifying numerals and counting. Thus, math talk is not a unitary construct, as parents may emphasize different concepts or children may benefit more from specific forms of number/math talk under varying circumstances (e.g., the nature of the activity, child age, etc.).

In addition to differences in the content being discussed during parent-child interactions, verbal input and scaffolding can occur in the form of questions, directives, or statements (see Mermelshtine, 2017 for a review). Variation in parental language input by utterance format has been explored in the language domain, but evidence is mixed regarding whether questions, statements, or both predict children's language skills 
(Ard and Beverly, 2004; Strouse et al., 2013; Tompkins et al., 2017). On the one hand, through statements, parents can provide rich descriptions or explanations of the events occurring within an activity, expand on their child's utterances, or rephrase their child's speech with more detail or complex vocabulary. On the other hand, questioning can encourage children to verbalize their current knowledge, generate inferences, problem solve, or engage in a higher quantity and diversity of verbal responses (Tompkins et al., 2017).

There is a dearth of studies examining the format through which math talk is conveyed. A numerical statement like, "There are three raccoons and two owls, so there are five animals altogether" focuses a child's attention on numerical information, specifically the link between addends and their sum. For instance, a math question asking, "If each corn is two dollars, how much do I owe you?" requires a child to use higher-order reasoning skills and arithmetic, which likely involves taking multiple steps to respond if multiplication has not yet been learned. In past work, the frequency of parents' questioning during home activities has been associated with children's vocabulary and verbal reasoning (e.g., Rowe et al., 2017) and math skills (Reynolds et al., 2019). However, Casey et al. (2018) categorized parental math input as elicitations (e.g., questions) or statements and reported no differences in how each type of math utterances predicted children's concurrent and later math achievement. Given the varying forms and functions of utterances, we examine whether qualitative aspects of parents' talk about numeric and spatial math content are related to the quantity of their math talk or the frequency of their math activity time at home.

\section{Time Diaries}

Another method of assessing the amount of math exposure that children experience is to collect time diaries, a minute-by-minute report of parent and child activities over the course of $24 \mathrm{~h}$ for parents' work days and non-work days. Time diaries provide a reliable measure of the quantity of academic or educational activities, but studies using this methodology have tended to focus on literacy and reading activities (Juster and Stafford, 1985; Robinson and Godbey, 1999; Phipps and Vernon, 2009). For example, a national longitudinal study from Australia found that the time that children spent in educational activities with parents, which included time reading a story, being talked to, or helping with chores, predicted higher scores in receptive vocabulary and reasoning (Fiorini and Keane, 2014). Similarly, in a study of children under age 13 in the United States, learning activities such as reading for pleasure and structured playing time were associated with higher scores in standardized reading and math tests (Hofferth and Sandberg, 2001). However, previous research has focused on characterizing time spent on broadly defined educational activities or in reading activities (Hofferth and Sandberg, 2001; Price, 2010; Fiorini and Keane, 2014). There is no research to date that has used time diaries to characterize the frequency of math-related activities that occur at home for preschool-aged children. Our collection of time use diaries provides a novel depiction of how and when parents of preschoolers integrate math learning opportunities into their daily schedules.
Time diaries have some advantages when compared with observational and questionnaire methodologies for collecting detailed information about daily routines and activities (Gunthert and Wenze, 2011). Ecological validity is likely stronger in time diaries than structured observations, capturing naturalistic daily family rhythms and activities. In comparison to survey methods, time diaries can minimize recall bias because participants report on a full day of occurrences instead of being prompted to report on one prioritized activity. Also, time diaries are usually collected on the same-day or next-day, and thus participants memory errors decrease in comparison to retrospective surveys that inquire about the time spent in activities over the prior week or month. In addition, time diaries also serve as a bridge between survey and observational methods because of the smaller measurement scale when compared to survey data and the increase in within-subject variability when contrasted with structured observations. In other words, because time diaries are collected multiple times per participant, they provide important information on day-to-day fluctuations in time use. However, like surveys, time diaries indicate the frequency with which activities occur but provide no data on the math content of conversations occurring during those activities.

\section{A Multi-Method Approach to Studying Parental Support of Early Math Skills}

It is unusual for studies to collect and examine multi-method assessments of parental support for math, such as parent reports of home math activities with observed parent math talk. As a consequence, mono-operation bias is prevalent across much of this work, such that the construct under study (i.e., parental support of early math skills) is interwoven with the measurement error in its operationalization (Cook and Campbell, 1979). To date only a handful of studies have combined parent reports of math activities with direct observations of parent math talk. In a sample of low-SES 3- to 5-year-old children and their families, parent reports of math activities but not direct observations of math talk predicted children's foundational number knowledge (e.g., counting), while parents' advanced math talk but not their report of math activities predicted children's advanced number knowledge (e.g., arithmetic) (Ramani et al., 2015). However, Ramani et al. (2015) did not test the association between parent report of math activities and their math talk directly. Missall et al. (2017) observed math-related engagement of parent-child dyads in a semi-structured play session and asked parents to report on the frequency of math activities in the home. They found that these two measures of math input were not correlated. Similarly, Mutaf Yildiz et al. (2018) observed parents' number talk during two structured observations and found that number talk was unrelated to parents' reports of math activities at home. Additionally, survey measures were positively related to children's math performance, whereas parental number talk was negatively associated with math skills. Finally, Thippana et al. (2020) examined number talk during naturalistic free play at home and measured both parental number talk and time spent in math-related activities, finding that both were positively correlated with parental reports of math activities. However, 
number talk at home and parent reports of math activities were both positively associated with children's math skills. Thus, extant work shows inconsistent patterns in the relations between observed parent math input and parental reports warranting further exploration. Importantly, when inconsistencies are found across studies in the predictive validity of any one home learning measure to predict math outcomes, there is little supporting data available to corroborate patterns or provide greater breadth of information about the nature and frequency of parent-child interactions and conversations about math. Furthermore, no work has examined these cross-method associations in parental support of spatial math skills.

One methodological approach to address these measurement limitations is triangulation across methods and data sources (Mathison, 1988; Heath, 2015). To be most effective, the different measures assessing a construct (in this case, parental support of early math) would involve different sources of measurement error, such as differences in methods, response biases, and sources (Heath, 2015). In the present study, triangulation involves collecting in-depth measures of preschoolaged children's math exposure across multiple modalities (i.e., questionnaires, structured observations, and time diary interviews). This approach can provide a richer picture of individual variability in how parents support math than provided by a single measure. In addition, the low frequency of parent-child interactions about math detected in naturalistic assessments (e.g., Tudge and Doucet, 2004) results in a high degree of skewness that makes analyses of the math exposure at home susceptible to floor effects. Combining data across multiple sources could provide more normal distributions of practices and enhance measurement sensitivity. It should be noted that attempts at triangulating multiple assessments of the same construct may not necessarily point to areas of convergence (Mathison, 1988). However, identifying areas of divergence across assessments could also provide valuable breadth of information about math exposure. For example, parents' questionnaire responses provide a global indication of the frequency and type of typical math routines and activities with children. A structured observation facilitates parents and children's shared attention on math games and activities when distractions are minimized and siblings are cared for by research staff. In addition, time diaries capture reports of activities closer to their actual occurrence and can add more detailed information regarding the frequency, duration of and the context in which math activities take place.

The present study draws on multi-method data from multiple sources and modalities to provide an in-depth description of the parental math support for preschool-aged children $(N=128)$ within a socioeconomically diverse sample. First, we will examine within-method variability and interrelations for measures within each data source: parent questionnaires, math talk during semistructured observations, and time diaries. Second, to triangulate across methods and data sources, convergence of methods will be examined with correlations. Since these are novel and exploratory research aims, directional hypotheses are not applicable, although we speculate that shared mono-reporter bias across parent reports (Cook and Campbell, 1979) may result in higher intercorrelations among the parent questionnaires and time diaries than with observed math talk codes.

\section{MATERIALS AND METHODS}

\section{Participants}

This study draws data from the Parents Promoting Early Learning study (PPEL), a community-based longitudinal study of 128 parents of 4-year-old children. Families were recruited from a large, mid-Atlantic metropolitan area through the distribution of fliers in the community and in-person contact between the study team and potential participants at preschools and childcare centers. Data were primarily collected in participants' homes although several families requested to meet in our lab. A socioeconomically diverse sample of families participated: parents reported annual incomes between $\$ 1,000$ and $\$ 425,000$, with a median of $\$ 95,000(\mathrm{SD}=\$ 73,776)$, and the sample included parents who did not finish high school (2\%) parents with a high school diploma only (6\%), parents with an Associate's degree $(6 \%)$, parents who completed vocational or technical training after high school (2\%), parents who completed some college (9\%), parents with a Bachelor's degree (33\%), and parents with or pursuing a graduate degree (43\%). Overall, children were on average 4 years, 4 months old at the first assessment, and $51 \%$ were female. Most participating parents were biological or adoptive mothers (94\%) and were on average 36 years old (range $=24-56$ years). Parents also reported their employment (40\% full-time, 27\% part-time), marital status (73\% married), and race/ethnicity (80\% White, 11\% Black or African American, 9\% Asian, Latino, multiracial, or other).

\section{Measures and Procedures}

Data were collected from parents during home visits, phone calls, and electronic questionnaires. During the first home visit, parent-child interactions with structured tasks were videorecorded. Measures of math talk were drawn from these structured observation tasks. Directly after the first home visit, parents were sent an electronic link via Qualtrics to complete background questionnaires and questions about the frequency of home math activities. Following the first home visit, parents also received two phone calls on separate days to complete the time diaries for the previous days (one work day and one non-work day). Parents and children also completed batteries of cognitive assessments not discussed here. All research activities were approved by the local Institutional Review Board (Protocol PRO19070136), and all parents gave written informed consent to participate in the study prior to completing any research activities.

\section{Measures of Home Math Exposure Parent reports on home math activities}

Parents completed questionnaires designed to assess the frequency of numeracy and spatial activities at home over the last month (LeFevre et al., 2009). Parents were given a list of 40 activities in the home and asked to report how frequently parents and children engaged in each on a scale from 1 ("did 
not occur") to 5 ("almost daily"; LeFevre et al., 2009). Of these items, 22 were identified as math activities based on theory (e.g., "counting objects," "playing board games with die or a spinner," or "playing with puzzles"). Parents' responses on 18 of these items that we categorized as number-related were averaged to form a composite representing numeracy exposure in the home $(\alpha=0.88)$, with higher scores indicating more frequent engagement with number-related learning activities. Similarly, responses on four items categorized as spatial-related were averaged to form a spatial exposure composite $(\alpha=0.68)$. Item-level descriptive statistics are shown in Table $\mathbf{1 .}$

\section{Observations of math talk during semi-structured parent-child interactions}

Parents and children were observed while they engaged in two semi-structured observation tasks designed to elicit number or spatial talk. To measure number talk, researchers provided dyads with developmentally appropriate toys for pretend grocery shopping, including a shopping basket, cash register, pretend money, and a play set of food items. Parents were instructed to play with these toys with their child as they normally would for $8 \mathrm{~min}$. Previous research has shown that a pretend grocery store can elicit high levels of math-related talk (Elliott et al., 2017). To elicit spatial talk, parents and children completed a magnet board puzzle task during which they are given magnets of various colors and shapes and asked to create an animal. "Guided play" tasks like this elicit high frequencies of spatial talk in parents and children (Ferrara et al., 2011). Dyads played for up to $8 \mathrm{~min}$ in the puzzle activity. Each task was videotaped, transcribed verbatim at the utterance-level, and checked by trained research assistants. An utterance was defined as any language input from an individual speaker that is bounded by silence of at least two seconds, a speaker transition, or a grammatical closure, e.g., a terminal punctuation mark such as a period (Pan et al., 2004).

Transcriptions from direct observation tasks were coded for the quantity and diversity of number and spatial talk. Specifically, the total number of numeric utterances during the grocery task was calculated, and then each numeric utterance was coded for the utterance content: identifying number symbols, counting, labeling sets, ordinal relations, patterning, comparing magnitudes, arithmetic, and other abstract number talk (e.g., talk about time, money, ages; see Table 2). The total number of spatial utterances during the magnet board task was also calculated, and each spatial utterance was also coded for the utterance content: shapes, locations, directions and orientations, features and properties, deictics, spatial dimensions, and continuous amount (see Table 2). Additionally, utterance type was coded for each instance of number and spatial talk as either a statement or question (see Table 3). It should be noted that number and spatial talk measures reported below are based on raw frequency counts. Accounting for overall levels of parents' talkativeness by dividing the frequencies of number and spatial talk by the total number of parent utterances respectively yielded the same pattern of results. These additional analyses are available from the authors upon request.

Coders for both number and spatial talk included graduate students, postdoctoral researchers, undergraduate research assistants, and full-time research staff. Following standard practices (Hallgren, 2012; Chorney et al., 2015), inter-rater reliability on the number and spatial codes for each task was assessed for over $20 \%$ of the sample by calculating the kappas for each code between pairs of coders in identifying and categorizing each math utterance. The initial coder's classification was used in the case of disagreements. For number talk, coders examined a total of 2,964 utterances that were flagged as potentially number-related (based on their inclusion of number words or elicitations). Ordinal relations, patterning, and comparing magnitudes occurred infrequently and were not reliably coded, and so these categories were excluded from analyses. Across utterance content codes, kappas ranged from 0.69 (for other) to 0.91 (for counting), reflecting a moderate to strong degree of reliability in labeling utterances across number talk categories (McHugh, 2012). Additionally, kappas were quite high for identifying number statements and questions (both kappas $=0.95)$. For all number talk kappa statistics, reliability was calculated at the utterance level from the full set of utterances. For example, when calculating reliability for utterances involving counting, cases of disagreement could include times where one coder did not identify the utterance as math talk at all and the second coded it as counting as well as times where one coder identified the utterance as a different type of math talk than counting when the second coded it as counting. This method seemed to be the most conservative approach, as coders would have to both correctly identify an utterance as math talk and code it in the correct category of content or utterance type in order to count as agreement.

For spatial talk, coders examined a total of 1,759 utterances. Frequent spatial content codes had almost perfect agreement between coders (e.g., kappas $=0.91$ for both shapes and spatial dimensions) whereas less frequent codes (e.g., spatial features) were coded moderately reliably (kappas $=0.63$ ). Utterance type was also coded reliably for spatial talk, with kappas of 0.91 and 1.00 for identifying questions and statements, respectively. Similar to number talk, agreement was considered as both identifying the utterance as spatial talk and coding the same content or type.

\section{Time diaries}

Parents completed two time diary interviews over the phone, during which they reported all activities carried out by parents and children over a work day and a non-work day. If the parent worked every day or was not employed, the time diaries were completed to reflect activities on a weekday and a weekend day. In total, 108 participants completed time diaries for both a work day and non-work day, and 14 participants only completed one time diary on either a work day or non-work day. The time diary data were collected using a modified format of the American Time Use Survey (U. S. Bureau of Labor Statistics, 2016). The phone interview occurred 1 day after the target day to facilitate accurate recollection of activities. Parents reported all of their activities and their child's activities starting at $4 \mathrm{AM}$ on the target day and ending at 4 AM 1 day later. Parents reported the primary activities, secondary activities (i.e., activities that take place simultaneously), and where and with whom those activities 
TABLE 1 | Item-level descriptive statistics for number and spatial activities at home.

\begin{tabular}{|c|c|c|c|c|}
\hline Number activities & $M$ & $S D$ & Min & Max \\
\hline Using number arithmetic flashcards & 1.55 & 1.11 & 1 & 5 \\
\hline Identifying names of written numbers & 3.47 & 1.38 & 1 & 5 \\
\hline Playing with number fridge magnets & 1.65 & 1.14 & 1 & 5 \\
\hline Counting objects & 4.56 & 0.71 & 2 & 5 \\
\hline Counted down $(10,9,8,7, \ldots)$ & 2.92 & 1.42 & 1 & 5 \\
\hline Learning simple addition (e.g., $2+2=4$ ) & 2.51 & 1.37 & 1 & 5 \\
\hline Printing numbers & 2.49 & 1.38 & 1 & 5 \\
\hline Talking about money when shopping (e.g., "Which costs more?") & 2.33 & 1.28 & 1 & 5 \\
\hline Measuring ingredients when cooking and/or baking & 2.57 & 1.06 & 1 & 5 \\
\hline Being timed & 2.78 & 1.50 & 1 & 5 \\
\hline Playing with calculators & 1.59 & 1.01 & 1 & 5 \\
\hline "Connect-the-dot" activities & 2.14 & 1.09 & 1 & 5 \\
\hline Using calendars and dates & 2.72 & 1.43 & 1 & 5 \\
\hline Having your child wear a watch & 1.53 & 1.10 & 1 & 5 \\
\hline Using number activity books (e.g., "color-by-number") & 2.34 & 1.36 & 1 & 5 \\
\hline Reading number storybooks & 2.76 & 1.26 & 1 & 5 \\
\hline Playing board games with a die or spinner & 2.58 & 1.23 & 1 & 5 \\
\hline Playing card games & 2.28 & 1.18 & 1 & 5 \\
\hline \multicolumn{5}{|l|}{ Spatial activities } \\
\hline Sort things by size, color, or shape & 3.67 & 1.27 & 1 & 5 \\
\hline Making collections & 2.61 & 1.40 & 1 & 5 \\
\hline Putting pegs in a board or shapes into holes, playing with puzzles & 3.03 & 1.24 & 1 & 5 \\
\hline Building Legos or construction set (Duplo, Megablocks, etc.) & 3.73 & 1.15 & 1 & 5 \\
\hline
\end{tabular}

took place. Following Kotila et al. (2013), audio recordings of the parents' primary activity reports were coded into broader categories of math- and non-math related activities by trained research assistants. Importantly, time diary methods have been used widely with families of diverse backgrounds in the American Time Use Survey (Nesteruk and Garrison, 2005; Lee et al., 2016).

Minutes of time use from child time diary (TD) schedule. We modified the American Time Use Survey (ATUS) codes for the present study to better capture the content of preschool-aged children's academic and recreational activities, rather than using a more global ATUS code like "academic time." In addition, we also clustered some of adults' activities in the ATUS (e.g., paying bills, packing bags, etc.) into gross codes (e.g., domestic work). Some additional editing of the time diary interview and codes occurred after piloting the time diary method with 50 families of preschool-aged children. Refer to Table 4 for a list of the final codes used. Overall time reported that the child was engaged in math activities, either as the primary or secondary activity, was summed for both work days and nonwork days. Again, the primary and secondary activities typically occurred simultaneously and "primary" indicates the first activity mentioned by parents, rather than "primary" indicating a predominant focus during those activity minutes.

Time and frequency of academic stimulation activities. In addition, at the end of the time diary interview we asked parents to report whether a list of math and literacy activities had occurred the previous day. The goal of this additional step was to detect any activities that may not have been reported in the daily 24-h report, such as having a conversation about counting while driving to daycare or playing with a puzzle during a lengthy period of play that was characterized by the parent as "general play at home." The list of math activities was identical to the items in the parent report (LeFevre et al., 2009). Due to interviewer error, approximately 14-17 parents were not asked about each item on the list (typically only missing one item or duration), so the amount of missing data is larger for the academic stimulation activities than for the 24$\mathrm{h}$ time diaries. Many parents struggled to estimate the minutes of time that children engaged in math activities, particularly for those activities that occurred naturally throughout the day (e.g., counting), and so minutes in math activities were estimated at the aggregate level (e.g., "How much time was spent in any math games, including puzzles, board games with a card or spinner, or building with Legos or construction sets"). As such, estimates of time in math activities could not be disaggregated into number and spatial activities, although we report them separately for work days and non-work days. From this list of academic stimulation activities, we also counted the number of activities that did or did not occur the previous work day or non-work day. The number of spatial and numeracy activities occurring on each day were summed; these two measures were also summed to calculate an overall math activity composite.

Coding reliability. Time diary coders included graduate students, undergraduate research assistants, and full-time research staff. To ensure inter-coder reliability, $20 \%$ of time diaries were 
TABLE 2 | Number and spatial utterance content codes.

\begin{tabular}{|c|c|c|}
\hline Code & Definition & Examples \\
\hline Identifying number symbols & $\begin{array}{l}\text { Labeling of or identifying an Arabic numeral } \\
\text { Describing how to spell a number word } \\
\text { Providing general commentary about number symbols }\end{array}$ & $\begin{array}{l}\text { "Look at this number, five." } \\
\text { "Can you point to the number two?" } \\
\text { "What numbers are on that cash register?" }\end{array}$ \\
\hline Counting & $\begin{array}{l}\text { Asking the other person to count } \\
\text { Conversations about counting }\end{array}$ & $\begin{array}{l}\text { "There were one, two, three..." } \\
\text { "Let's count." } \\
\text { "What types of things do we count?" }\end{array}$ \\
\hline Labeling the set size & Referring to or labeling the number of elements in a set & $\begin{array}{l}\text { "Let's see how many foxes there are." } \\
\text { "How many coins are there?" } \\
\text { "There are three foxes." }\end{array}$ \\
\hline Ordinal relations & Describing the order of numbers & $\begin{array}{l}\text { "Tell me what comes after the number two." } \\
\text { "What comes before nine?" }\end{array}$ \\
\hline Patterns & $\begin{array}{l}\text { Identifying common repeating elements of objects, people, actions, or } \\
\text { events }\end{array}$ & $\begin{array}{l}\text { "There are two raccoons, three birds, then } \\
\text { four..." }\end{array}$ \\
\hline Comparing magnitudes & $\begin{array}{l}\text { Describing or identifying a numerical match or mismatch between two } \\
\text { or more discrete quantities }\end{array}$ & $\begin{array}{l}\text { "You have four more pizza slices than I do." } \\
\text { "It looks like you have double that amount." }\end{array}$ \\
\hline Arithmetic & $\begin{array}{l}\text { Statements or questions requiring the use of operations, such as } \\
\text { adding or subtracting } \\
\text { Includes using a full or partial equation including the total } \\
\text { Includes specifying the total if there was a calculation previously implied } \\
\text { Providing commentary about calculations }\end{array}$ & $\begin{array}{l}\text { "One plus one is two." } \\
\text { "How much do I owe you if each corn is \$2?" } \\
\text { "We added two numbers together." }\end{array}$ \\
\hline Other abstract math talk & $\begin{array}{l}\text { Requiring the other person to map something numerical to an abstract } \\
\text { idea } \\
\text { Referencing dates or times }\end{array}$ & $\begin{array}{l}\text { "It's five o' clock at the park in this book." } \\
\text { "Can you pass me a ten dollar bill?" }\end{array}$ \\
\hline Spatial dimensions & Describing the size of objects, people, and spaces & $\begin{array}{l}\text { "We don't need the big purple one." } \\
\text { "Can you get the shorter rectangle?" }\end{array}$ \\
\hline Shapes & $\begin{array}{l}\text { Describing the standard or universally recognized form of enclosed 2- } \\
\text { or 3-D objects and spaces }\end{array}$ & $\begin{array}{l}\text { "Now find the green square." } \\
\text { "How many sides does a triangle have?" }\end{array}$ \\
\hline Locations, directions, and orientations & $\begin{array}{l}\text { Describing the relative position, orientation, or transformation of } \\
\text { objects, people, or points in space }\end{array}$ & $\begin{array}{l}\text { "Move toward the bottom." } \\
\text { "That piece should be sideways." }\end{array}$ \\
\hline Continuous amount & $\begin{array}{l}\text { Describing the amount of continuous quantities within the spatial } \\
\text { domain, including the extent of an object, space, or liquid }\end{array}$ & $\begin{array}{l}\text { "That is one half of the giraffe's body." } \\
\text { "That piece is the exact same as that one." }\end{array}$ \\
\hline Deictics & Utterances that rely on place deictics or pro-forms & $\begin{array}{l}\text { "If you move that piece there and this other } \\
\text { piece here, they will be in the correct place." }\end{array}$ \\
\hline Spatial features and properties & $\begin{array}{l}\text { Describing the features and properties of 2- or 3-D objects, spaces, } \\
\text { people, or the properties of their features }\end{array}$ & $\begin{array}{l}\text { "We are looking for the one with a flat side and } \\
\text { a curved edge." }\end{array}$ \\
\hline
\end{tabular}

double coded (Hallgren, 2012; Chorney et al., 2015). Given that the time-diary reports of minutes spent on math activities during the previous day were measured continuously, the interclass correlation (ICC) across coders was calculated to check reliability, which was 0.89 . Few significant inconsistencies were detected in the codes about time spent in math activities. When

TABLE 3 | Math utterance type codes.

\begin{tabular}{lll}
\hline Code & Description & Example \\
\hline Statement & Any utterance made that & "There's two circles." \\
& does not explicitly elicit an & "You just did addition!" \\
& answer from the other & "Let's count these \\
& person; typically declarative & oranges." \\
& Also includes prompts or & "Give me that twenty dollar \\
& imperatives & bill." \\
Question & Any utterance made that & "How many raccoons are \\
& asks a question & there?" \\
& & "How many owls would \\
& there be if two of them
\end{tabular}

inconsistencies among coders occurred, a third expert coder assessed the audio and made a final coding determination.

For the academic stimulation activities measures, ICCs between the coders on each of the assessed numeracy and spatial items were also calculated for both whether an activity occurred as well as the continuous number of minutes in math activities. Specifically, the composite of four spatial activities was highly reliable, with ICCs for whether or not each activity was coded during the day ranging from 0.97 (sorting things) and 1.00 (playing with puzzles and playing with building sets). The numeracy activities composite included 20 items. Several activities were very infrequent, and thus harder to calculate reliability, such as connect the dot activities or wearing a watch. For the remaining 18 items, ICCs were moderate to high, ranging from 0.76 (identifying numbers) to 1.00 (playing with flashcards, playing with fridge magnets, printing numbers, other written number activities, counting, measuring while cooking, using number story books, painting by number, and playing card games). Additionally, reliability for estimates of durations of activities from the academic stimulation measure were high, with ICCs ranging from 0.81 (time in all activities involving math 
TABLE 4 | Time diary items.

\begin{tabular}{|c|c|c|}
\hline \multicolumn{2}{|c|}{ Time use items } & \multirow{2}{*}{$\begin{array}{l}\text { Academic stimulation } \\
\text { Using written numbers }\end{array}$} \\
\hline General activities & Child activities & \\
\hline 1. Sleeping & 27. Preschool & Using number or arithmetic flashcards \\
\hline 2. Grooming/hygiene & 27A. Center & Identifying names of written numbers \\
\hline 2A. Parent & 27B. Home & Playing with number fridge magnets \\
\hline 2B. Child & 27C. Religious & Printing numbers \\
\hline 2C. Give/rec. med/first-aid & 28. Household chores & Playing with calculators \\
\hline 3. Watching TV & 29. Play and recreation at home & Categorizing or counting \\
\hline 3A. Traditional TV & 29A. Arts & Counting objects \\
\hline 3B. Electronic device & 29B. Music & Sorting things by size, color, or shape \\
\hline 4. Eating and drinking & 29C. Blocks/building/puzzles & Making collections \\
\hline 5. Religious activities & 29D. Dramatic & Counting down \\
\hline 6. Errands & 29E. Gross motor & Learning simple sums \\
\hline 7. Interacting family and friends & 29F. Fine motor & Using math while shopping or cooking \\
\hline 7A. From household & 29G. Playing video games & Talking about money when shopping \\
\hline 7B. Not-household & $29 \mathrm{H}$. Electronic media & Measuring ingredients while cooking \\
\hline 7C. Scolding/negative emotion & 29I. Nature/science activities & Talking about dates or times \\
\hline 8. Shopping & 29J. Other & Using calendars and dates \\
\hline 8A. Grocery & 30. Play and recreation out home & Using a watch, clock, or timer \\
\hline 8B. Food/meals & 30A. Arts & Having conversations about time \\
\hline 8C. Other & 30B. Music & Timing child doing something \\
\hline 9. Transportation & 30C. Blocks/building/puzzles & Books or activities that involve math \\
\hline 9A. Car & 30D. Dramatic & Using number activity books \\
\hline 9B. Bus & 30E. Gross motor & Reading number storybooks \\
\hline 9C. Walking & 30F. Fine motor & Paint by number activities \\
\hline 9D. Bike & 30G. Playing video games & Connect the dot activities \\
\hline 10. Resting/leisure & $30 \mathrm{H}$. Electronic media & Playing games that could involve math \\
\hline 11. Child bed time & 30I. Nature/science activities & Board games \\
\hline 12. Other & 30J. Other & Card games \\
\hline Parent activities & 31. Math & Puzzles \\
\hline 13. Working at job & 31A. Hard copy & Legos or construction sets \\
\hline 14. Attend class or studying & 31B. Electronic device & Using video or computer games \\
\hline 15. Preparing meals or snacks & 31C. Talking/interaction & Using educational software \\
\hline 16. Cleaning & 32. Reading & Playing other videogames \\
\hline 17. Laundry & 32A. Hard copy & Reading a book or magazine. \\
\hline 18. Other domestic work & 32B. Electronic device & [If so] While you were reading did you... \\
\hline 19. Reading & 32C. Talking/interaction & Ask questions about what is being read \\
\hline 19A. Electronic device & 33. Other out of home activities & Ask child reading or filling in words \\
\hline 19B. Hard copy & 33A. Museum & Talk about what happened in the story \\
\hline 20. Use phone/electronic media & 33B. Zoo & Point things in pics/ask child to point \\
\hline 21. Exercising & 33C. Library & Child pretend to read \\
\hline 22. Playing with child & 33D. Park & Doing any work with letters or words \\
\hline 23. Academic work with child & 33E. Other & Playing rhyming games \\
\hline 24. Nursing/caring child & 34. Other academic work & Learning the names of the letters \\
\hline 25. Supervising child & 34A. Foreign languages & Playing with alphabet toys at home \\
\hline \multirow[t]{3}{*}{ 26. Interacting with partner } & 34B. Writing & Pointing out letters or words \\
\hline & 34C. Rhyming or word games & Pretending to read independently \\
\hline & 34D. Other & \\
\hline
\end{tabular}

activity or story books) to 1.00 (time discussing time and dates, time spent playing games involving math).

\section{RESULTS}

We first examined individual differences within each data source (i.e., parent questionnaires, math talk, and time diaries) and then examined patterns of correlations across data sources to identify areas of convergence or triangulation.

\section{Parent Reports on Home Math Activities Scale}

Parents' reports of the frequency of math activities at home over the past month are shown in Table 5, including separate 
frequencies for numeracy and spatial activities. In general, these math activities occurred on average between a few times a month (2) and once a week (3). Means were similar but slightly higher for spatial activities than for number activities, but these two survey measures were highly correlated, $r(118)=0.59, p<0.001$.

\section{Observations of Math Talk During Semi-Structured Parent-Child Interactions \\ Number Talk}

During the grocery task, parents used between 7 and 408 utterances $(M=154.82, S D=49.45)$. Of these utterances, approximately $14 \%$ were coded as number-related (see Table 5).
As noted in the methods section, the most frequent math content involved labeling set sizes, counting, and identifying number symbols, with over 14 instances of labeling sets and 2 instances of parents counting and identifying number symbols. As is shown in Table 6, intercorrelations among the utterance content codes were generally positive and significant, with the highest correlations among counting, labeling set sizes, and arithmetic ( $r$ s $=0.33-0.38$ ). However, the frequency of parents' identification of number symbols was unrelated to all number codes aside from the "other abstract number talk" category. The intercorrelation of utterance type number codes was higher than any intercorrelations among the utterance number content codes, such that the frequencies of number statements were correlated 0.53 with the frequency of number questions (see Table 7).

TABLE 5 | Descriptive statistics for parental math support measures.

\begin{tabular}{|c|c|c|c|c|c|}
\hline & $n$ & $M$ & $S D$ & Min & Max \\
\hline Home math activities scale & 120 & 2.63 & 0.61 & 1.36 & 4.32 \\
\hline Numeracy activities & 120 & 2.49 & 0.61 & 1.39 & 4.22 \\
\hline Spatial activities & 120 & 3.25 & 0.87 & 1 & 5 \\
\hline \multicolumn{6}{|l|}{ Number talk } \\
\hline Total number utterances & 119 & 21.05 & 14.18 & 0 & 67 \\
\hline \multicolumn{6}{|l|}{ Utterance content } \\
\hline Identifying number symbols & 119 & 2.38 & 4.58 & 0 & 29 \\
\hline Counting & 119 & 2.15 & 3.35 & 0 & 20 \\
\hline Labeling sets & 119 & 14.55 & 9.74 & 0 & 47 \\
\hline Arithmetic & 119 & 0.80 & 1.90 & 0 & 11 \\
\hline Other abstract math talk & 119 & 1.37 & 2.29 & 0 & 13 \\
\hline \multicolumn{6}{|l|}{ Utterance type } \\
\hline Number statements & 119 & 14.24 & 11.04 & 0 & 46 \\
\hline Number questions & 119 & 8.39 & 6.52 & 0 & 37 \\
\hline \multicolumn{6}{|l|}{ Spatial talk } \\
\hline Total spatial utterances & 119 & 60.42 & 34.26 & 0 & 163 \\
\hline \multicolumn{6}{|l|}{ Utterance content } \\
\hline Shapes & 119 & 11.78 & 9.70 & 0 & 43 \\
\hline Locations, directions and orientations & 119 & 18.51 & 11.44 & 0 & 69 \\
\hline Features and properties & 119 & 1.94 & 3.00 & 0 & 24 \\
\hline Deictics & 119 & 15.44 & 9.52 & 0 & 61 \\
\hline Spatial dimensions & 119 & 4.61 & 4.30 & 0 & 21 \\
\hline Continuous amount & 119 & 11.87 & 7.71 & 0 & 37 \\
\hline \multicolumn{6}{|l|}{ Utterance type } \\
\hline Spatial statements & 119 & 38.71 & 21.96 & 0 & 139 \\
\hline Spatial questions & 119 & 25.47 & 17.74 & 0 & 94 \\
\hline \multicolumn{6}{|l|}{ Time diary (TD) codes } \\
\hline Minutes of math time, work day: Child TD schedule & 114 & 4.42 & 15.51 & 0 & 90 \\
\hline Minutes of math time, non-work day: Child TD schedule & 115 & 8.64 & 31.93 & 0 & 215 \\
\hline Minutes child was awake/not at preschool, work day & 109 & 569.59 & 208.94 & 214 & 960 \\
\hline Minutes child was awake/not at preschool, non-work day & 112 & 736.07 & 111.53 & 205 & 992 \\
\hline Minutes of parent work, work day & 114 & 291.65 & 246.33 & 0 & 847 \\
\hline Minutes of parent work, non-work day & 116 & 21.29 & 65.80 & 0 & 405 \\
\hline Minutes of math time, work day: Acad. stim. activities & 101 & 45.99 & 42.15 & 0 & 212 \\
\hline Minutes of math time, non-work day: Acad. stim. activities & 104 & 71.22 & 68.42 & 0 & 375 \\
\hline Number activities on a work day & 100 & 3.22 & 1.73 & 0 & 8 \\
\hline Number activities on a non-work day & 98 & 3.45 & 2.14 & 0 & 10 \\
\hline Spatial activities on a work day & 111 & 0.60 & 0.85 & 0 & 4 \\
\hline Spatial activities on a non-work day & 109 & 0.93 & 0.87 & 0 & 3 \\
\hline Math activities on a work day & 100 & 3.78 & 2.05 & 0 & 10 \\
\hline Math activities on a non-work day & 98 & 4.37 & 2.60 & 0 & 12 \\
\hline
\end{tabular}




\section{Spatial Talk}

Parents used between 29 and 296 utterances during the magnet board task with their children $(M=140.00, S D=54.14)$. As is shown in Table 3, 43\% of these utterances were coded as containing spatial talk. Locations, directions and orientations talk was most frequent, as parents used these terms in over 18 utterances on average, followed by deictics with an average of 15 utterances. As is shown in Table 6, almost all spatial talk codes were weakly to highly intercorrelated ( $r s=0.23-0.64)$, with the exception of deictics with features and properties and discussion of continuous amount. Spatial utterances were also coded as either statements or questions. As shown in Table 7, these frequencies were also modestly correlated $(r=0.29)$.

\section{Intercorrelations Among Number and Spatial Talk}

In addition to these within-domain associations, we also examined the extent to which parents who used more number talk also used more spatial talk during the observational tasks. Overall counts of number talk and spatial talk were not significantly correlated, $r(112)=0.11, p=0.231$. Similarly, as shown in Table 6, these correlations between number and spatial talk content types were generally non-significant. One exception is that parents with more instances of counting in the grocery task also tended to speak about deictics more frequently in the magnet board task with their children. Marginally significant associations were detected between parents' discussion of number symbols and the frequency of talk about shapes and spatial dimensions, as well as between instances of other abstract number talk and discussions of shapes. Among the utterance type codes (see Table 7), the frequency of statements about number and spatial content were not related as well. However, parents who asked more questions that involved numbers also tended to ask more spatial questions, $r=0.20, p=0.03$.

\section{Parent Time Diary Interviews}

As described in the methods, three measures of math input were provided by the time diaries: time in math activities during the day (i.e., math time from child time diary schedule), estimates of time in math activities aggregated across academic stimulation activities (i.e., total math time estimated), and sums of unique math activities that occurred (i.e., total number of number/spatial activities). During parents' reports of their child's schedule throughout the day in the time diaries, math activities were reported infrequently. Only $11 \%$ of parents reported directly engaging in any math activities on work days, and only $15 \%$ reported engaging in math activities on a non-work day. However, when explicitly asked about whether specific math activities occurred, almost all parents reported that at least one of these activities occurred on a work day and on a nonwork day ( $96 \%$ for both days). Descriptive statistics of time diary variables are shown in Table 5, including estimates of children's available time and parents' time working on each day. On parents' work days, parents worked an average of $5 \mathrm{~h}$ per day $(S D=4 \mathrm{~h})$, and children were awake and not in preschool $9.5 \mathrm{~h}$ a day $(S D=3.5 \mathrm{~h})$. On non-work days, children were awake and not at preschool for approximately $12.25 \mathrm{~h}$ a day $(S D=1.85 \mathrm{~h})$. As described above, reports of math-related time were highly skewed, and math time was considerably longer according to the summed durations of math activities that parents estimated at the end of the interviews compared to children's TD schedules. According to the academic stimulation activities durations, children spent on average 40 to $45 \mathrm{~min}$ in math activities on weekdays and over an hour in math activities on days when their parents were not working. When considering how much time children had available to spend in these activities (i.e., time awake and not in preschool), this corresponded to between $9 \%$ and $10 \%$ of time available during those days, compared to $1 \%$ of children's time available based on children's time diary schedules. Most parents reported about three number activities and one spatial activity on work and nonwork days.

Table 8 shows the intercorrelations of time and frequency variables from the full-time diary interviews across work days and non-work days. First, parents' reports of time in math activities from children's daily schedules were largely unrelated to other time diary measures. One exception to this pattern is that duration of math activities on work days, from the child time diary schedule and the academic stimulation activities, were moderately correlated. Within the academic stimulation

TABLE 6 | Pair-wise correlations among number and spatial utterance content codes.

\begin{tabular}{|c|c|c|c|c|c|c|c|c|c|c|}
\hline Math utterance content & 1 & 2 & 3 & 4 & 5 & 6 & 7 & 8 & 9 & 10 \\
\hline 1. Identifying number symbols & 1.00 & & & & & & & & & \\
\hline 2. Counting & 0.03 & 1.00 & & & & & & & & \\
\hline 3. Labeling set sizes & 0.11 & $0.38^{\star \star \star}$ & 1.00 & & & & & & & \\
\hline 4. Arithmetic & 0.09 & $0.33^{\star \star \star}$ & $0.35^{\star \star \star}$ & 1.00 & & & & & & \\
\hline 5. Other abstract number talk & $0.26^{\star \star}$ & $0.26^{\star \star}$ & 0.08 & 0.13 & 1.00 & & & & & \\
\hline 6. Shapes & $0.17^{\dagger}$ & 0.08 & 0.003 & -0.04 & $0.17^{\dagger}$ & 1.00 & & & & \\
\hline 7. Locations, directions and orientations & 0.12 & 0.05 & -0.01 & -0.04 & 0.09 & $0.39^{\star \star \star}$ & 1.00 & & & \\
\hline 8. Features and properties & 0.09 & -0.05 & 0.04 & -0.09 & -0.02 & $0.23^{\star}$ & $0.64^{\star \star \star}$ & 1.00 & & \\
\hline 9. Deictics & 0.10 & $0.20^{*}$ & 0.10 & 0.02 & 0.12 & $0.40^{\star \star \star}$ & $0.43^{\star \star \star}$ & 0.08 & 1.00 & \\
\hline 10. Spatial dimensions & $0.18^{\dagger}$ & -0.03 & -0.07 & -0.01 & 0.08 & $0.50^{\star \star \star}$ & $0.38^{\star \star \star}$ & $0.23^{*}$ & $0.31^{\star \star \star}$ & 1.00 \\
\hline 11. Continuous amount & 0.09 & -0.08 & 0.02 & -0.06 & 0.09 & $0.23^{\star}$ & $0.58^{\star \star \star}$ & $0.40^{\star \star \star}$ & 0.12 & $0.34^{\star \star \star}$ \\
\hline
\end{tabular}

${ }^{\dagger} p<0.10,{ }^{*} p<0.05,{ }^{* *} p<0.01,{ }^{* * *} p<0.001$. 
TABLE 7 | Pair-wise correlations among math utterance type codes.

\begin{tabular}{llll}
\hline Math utterance type & $\mathbf{1}$ & $\mathbf{2}$ & $\mathbf{3}$ \\
\hline 1. Number statements & 1.00 & & \\
2. Number questions & $0.53^{\star * *}$ & 1.00 & \\
3. Spatial statement & 0.06 & 0.01 & 1.00 \\
4. Spatial questions & 0.07 & $0.20^{*}$ & $0.29^{* *}$ \\
\hline${ }^{*} p<0.05,{ }^{* *} p<0.01,{ }^{* * *} p<0.001$. & &
\end{tabular}

measure, parents' estimates of children's time in math activities (i.e., prompted responses) were highly correlated with frequency counts of number, spatial, and overall math activities on those same days. Additionally, estimated time in math activities were significantly correlated across days, as were counts of number activities and the composite measure of all math activity time. In other words, parents who reported engaging in more number activities or for more math activity time on work days also reported more number activities or more math activity time on non-work days. However, no significant association was evident between the number of spatial activities on work days and non-work days. Overall, parents who reported more number activities also reported significantly more spatial activities, although this association was only marginally significant for work days.

\section{Intercorrelations Across Parental Math Support Assessments}

We then examined the degree to which measures of parental support for early math skills were consistent across modalities (see Table $\mathbf{9}$ for math time, Table $\mathbf{1 0}$ for number support, and Table 11 for spatial support). First, in examining total time in math activities from the child's time diary schedule, few significant correlations were seen between any observed measures of number or spatial talk or the frequency of number or spatial activities from the survey with daily time in math activities (see Table 9). Minutes of math time on non-work days was marginally correlated with number talk about arithmetic, but all other correlations with these other data sources were nonsignificant. In contrast, the time estimates from the academic stimulation activities reports, specifically math activity time on non-work days, were significantly correlated with observed number (identifying number symbol) and spatial (continuous amount) talk, as well as both number and spatial activity composites on the survey. However, estimated time in math activities on a work day was unrelated to observational or survey measures of number or spatial talk.

We then examined interrelations among multiple data sources of parental support for numeracy skills (see Table 10), including observed number talk content and type, the number activities scale, and frequencies of number activities on work and non-work days from the academic stimulation activities interview. The questionnaire measure of home number activities was significantly and positively related with the frequency of arithmetic talk from the semi-structured grocery task. In contrast, the questionnaire measure was unrelated to the remaining number utterances content codes involving number symbols, counting, labeling set sizes, and other abstract number talk. In regard to number talk utterance types, neither number statements nor questions were significantly related to questionnaire responses of number activities at home. The questionnaire measure of home number activities was also positively associated with the count of number activities from the time diary, particularly for work day reports of number activities $(r=0.32)$. Additionally, time diary reports of number activities were marginally associated with several number talk measures, including instances of number activities on non-work days and counting and number statements, whereas number activities on a work day was marginally related to parents' other abstract number talk. Overall, total number utterances were also not associated with the survey measure of number activities, $r(111)=0.14, p=0.140$, parents' reported number activities on a work day, $r(90)=0.16, p=0.121$, or parents' reported number activities on a non-work day, $r(88)=0.18, p=0.086$, although the latter did reach trend-level significance.

Finally, we conducted these analyses with parents' survey reports of spatial activities, spatial talk, and summed spatial activities reported on time diaries (see Table 11). As with number talk, spatial talk observational codes, including spatial content and spatial utterance types, were largely unrelated to the frequency of spatial activities reported on the parent survey. Likewise, total spatial utterances were unrelated to parent reports of spatial activities in the survey, $r(109)=-0.01, p=0.94$. One notable exception to this trend was the frequency of spatial utterances discussing features and properties, which was negatively correlated with the frequency of spatial activities, such that parents who reported more spatial activities actually used these terms less often. Parents' reports of spatial activities on the survey were correlated with time diary reports from nonwork days but not from work days, the opposite pattern of results as observed for number activities. Last, we examined associations between observed spatial talk and time diary reports of spatial activities. The frequency of spatial activities reported on work days was not significantly related to the frequency of any categories of spatial content, or spatial statements or questions, as well as overall spatial talk, $r(101)=0.02, p=0.86$. Spatial activities reported on non-work days were marginally associated with the frequency of utterances discussing continuous amount but were unrelated to all other categories of spatial talk, including overall spatial talk, $r(99)=0.12, p=0.219$.

\section{DISCUSSION}

Within this small but socioeconomically diverse sample, we see both wide individual differences in parental support of early number and spatial skills within each assessment method, as well as promising convergence of parents' support for early math across data sources.

\section{Within-Method Variability Parent Survey Responses}

In these analyses, we attempted to differentiate between number and spatial activities in parent surveys. Parents reported engaging 
TABLE 8 | Pair-wise correlations among reports of time in math activities and counts of numeracy, spatial, and overall math activities from time diary interviews.

\begin{tabular}{|c|c|c|c|c|c|c|c|c|c|}
\hline & 1 & 2 & 3 & 4 & 5 & 6 & 7 & 8 & 9 \\
\hline 1. Minutes of math time, work day: Child TD schedule & 1.00 & & & & & & & & \\
\hline 2. Minutes of math time, non-work day: Child TD schedule & -0.07 & 1.00 & & & & & & & \\
\hline 3. Minutes of math time, work day: Acad. stim. activities & $0.26^{\star \star}$ & 0.16 & 1.00 & & & & & & \\
\hline 4. Minutes of math time, non-work day: Acad. stim. activities & -0.06 & 0.06 & $0.25^{\star}$ & 1.00 & & & & & \\
\hline 5. Work day numeracy activities & 0.13 & -0.04 & $0.49^{\star \star \star}$ & 0.15 & 1.00 & & & & \\
\hline 6. Non-work day numeracy activities & $-0.20^{\dagger}$ & 0.12 & $0.19^{\dagger}$ & $0.42^{\star \star \star}$ & $0.28^{\star \star}$ & 1.00 & & & \\
\hline 7. Work day spatial activities & 0.14 & 0.04 & $0.50^{\star \star \star}$ & 0.14 & $0.18^{\dagger}$ & 0.16 & 1.00 & & \\
\hline 8. Non-work day spatial activities & -0.04 & 0.01 & 0.07 & $0.47^{\star \star \star}$ & 0.01 & $0.37^{\star \star \star}$ & 0.11 & 1.00 & \\
\hline 9. Work day math activities & 0.15 & -0.02 & $0.60^{\star \star \star}$ & 0.18 & $0.92^{\star \star \star}$ & $0.30^{\star \star}$ & $0.56^{\star \star \star}$ & 0.07 & 1.00 \\
\hline 10. Non-work day math activities & $-0.18^{\dagger}$ & 0.11 & 0.18 & $0.51^{\star \star \star}$ & $0.24^{\star}$ & $0.95^{\star \star \star}$ & $0.17^{\dagger}$ & $0.64^{\star \star \star}$ & $0.28^{\star}$ \\
\hline
\end{tabular}

${ }^{\dagger} p<0.10,{ }^{*} p<0.05,{ }^{* *} p<0.01,{ }^{* * *} p<0.001$.

TABLE 9 | Associations among number and spatial talk content from the semi-structured observations, home number and spatial activities scale, and time in math activities reported on work and non-work days from the time diary interview.

\begin{tabular}{|c|c|c|c|c|}
\hline & $\begin{array}{l}\text { Minutes of math } \\
\text { time, work day: Child } \\
\text { TD schedule }\end{array}$ & $\begin{array}{l}\text { Minutes of math } \\
\text { time, non-work day: } \\
\text { Child TD schedule }\end{array}$ & $\begin{array}{l}\text { Minutes of math } \\
\text { time, work day: } \\
\text { Acad. stim. activities }\end{array}$ & $\begin{array}{c}\text { Minutes of math } \\
\text { time, non-work day: } \\
\text { Acad. stim. activities }\end{array}$ \\
\hline Overall number talk & -0.11 & 0.09 & -0.06 & 0.05 \\
\hline \multicolumn{5}{|l|}{ Number talk content } \\
\hline Identifying number symbols & 0.10 & -0.02 & 0.06 & $0.22^{\star}$ \\
\hline Counting & -0.09 & 0.03 & -0.08 & -0.06 \\
\hline Labeling set sizes & -0.15 & 0.07 & -0.09 & -0.03 \\
\hline Arithmetic & -0.03 & $0.19^{\dagger}$ & 0.03 & -0.03 \\
\hline Other abstract math talk & -0.13 & 0.07 & 0.04 & 0.004 \\
\hline \multicolumn{5}{|l|}{ Number talk type } \\
\hline Statements & -0.07 & 0.07 & -0.004 & 0.04 \\
\hline Questions & -0.09 & 0.10 & -0.08 & 0.03 \\
\hline Number activities scale & 0.10 & 0.08 & 0.16 & $0.22^{*}$ \\
\hline Overall spatial talk & -0.001 & -0.03 & 0.02 & 0.11 \\
\hline \multicolumn{5}{|l|}{ Spatial talk content } \\
\hline Shapes & -0.06 & -0.08 & -0.07 & 0.11 \\
\hline Locations, directions and orientations & 0.0004 & -0.04 & -0.01 & 0.06 \\
\hline Features and properties & 0.10 & -0.02 & 0.03 & -0.04 \\
\hline Deictics & -0.05 & -0.11 & -0.12 & -0.08 \\
\hline Spatial dimensions & -0.05 & -0.02 & 0.07 & 0.08 \\
\hline Continuous amount & -0.01 & 0.07 & 0.11 & $0.21^{\star}$ \\
\hline \multicolumn{5}{|l|}{ Spatial talk type } \\
\hline Statements & -0.07 & -0.09 & -0.02 & 0.05 \\
\hline Questions & 0.03 & 0.01 & -0.01 & 0.09 \\
\hline Spatial activities scale & 0.01 & 0.06 & 0.07 & $0.34^{\star \star \star}$ \\
\hline
\end{tabular}

${ }^{*} p<0.05,{ }^{* *} p<0.001$.

in number-related activities several times per month and spatial activities weekly. Past studies have differentiated between parents' numerical and spatial support (Dearing et al., 2012; Hart et al., 2016; Purpura et al., 2020; Zippert and Rittle-Johnson, 2020) but found different relations between them. In some studies, reports of number and spatial activities were positively correlated (Hart et al., 2016; Zippert and Rittle-Johnson, 2020), others found no correlation (Purpura et al., 2020) or did not present this correlation (Dearing et al., 2012). In the present study, these subdimensions of math support were moderately correlated. On the one hand, it is worth noting that the LeFevre et al.
(2009) scale was designed to broadly address possible mathrelated activities and not to assess spatial activities specifically. It is possible that with a more extensive, theoretically driven set of spatial items, spatial and numerical support may emerge as more distinct constructs. Additionally, when recalling activities over the prior month, parents' endorsements of engaging in a wide range of math activities may be susceptible to response biases and these may be shared across number and spatial activities. Parents' reports of the prior day's number and spatial activities differed in frequency and were also much more weakly correlated in the time diary data (see discussion below). Thus, 
TABLE 10 | Associations among number talk content from the semi-structured observations, home number activities scale, and number activities reported on work and non-work days from the time diary interview.

\begin{tabular}{lccc}
\hline & $\begin{array}{c}\text { Number } \\
\text { activities } \\
\text { scale }\end{array}$ & $\begin{array}{c}\text { Work day } \\
\text { number } \\
\text { activities }\end{array}$ & $\begin{array}{c}\text { Non-work day } \\
\text { number } \\
\text { activities }\end{array}$ \\
\hline Overall number talk & 0.14 & 0.16 & $0.18^{\dagger}$ \\
Number talk content & -0.01 & 0.15 & 0.08 \\
Identifying number symbols & 0.08 & -0.05 & $0.20^{\dagger}$ \\
Counting & 0.12 & 0.13 & 0.14 \\
Labeling set sizes & $0.20^{\star}$ & 0.14 & 0.06 \\
Arithmetic & 0.05 & $0.19^{\dagger}$ & 0.10 \\
Other abstract math talk & & & $0.19^{\dagger}$ \\
Number talk type & 0.13 & 0.13 & 0.07 \\
Statements & 0.13 & $0.32^{* *}$ & 0.15 \\
Questions & - & & \\
Number activities scale & & &
\end{tabular}

${ }^{\dagger} p<0.10,{ }^{*} p<0.05,{ }^{* *} p<0.01$.

TABLE 11 | Associations among spatial talk content from the semi-structured observations, home spatial activities scale, and spatial activities reported on work and non-work days from the time diary interview.

\begin{tabular}{lccc}
\hline & $\begin{array}{c}\text { Spatial } \\
\text { activities } \\
\text { scale }\end{array}$ & $\begin{array}{c}\text { Work day } \\
\text { spatial } \\
\text { activities }\end{array}$ & $\begin{array}{c}\text { Non-work day } \\
\text { spatial } \\
\text { activities }\end{array}$ \\
\hline Overall spatial talk & -0.01 & 0.02 & 0.12 \\
Spatial talk content & 0.02 & -0.08 & 0.05 \\
Shapes & -0.10 & 0.02 & 0.16 \\
Locations, directions and orientations & $-0.21^{*}$ & 0.05 & -0.03 \\
Features and properties & 0.11 & -0.02 & -0.04 \\
Deictics & -0.09 & -0.10 & 0.03 \\
Spatial dimensions & -0.03 & 0.04 & $0.20^{\dagger}$ \\
Continuous amount & & -0.05 & 0.01 \\
Spatial talk type & -0.14 & 0.02 & 0.16 \\
Statements & 0.11 & 0.15 & $0.19^{\star}$ \\
Questions & - & & \\
Spatial activities scale & & & \\
\hline
\end{tabular}

${ }^{\dagger} p<0.10,{ }^{*} p<0.05$.

more work developing and validating measures of math support that differentiate spatial- and number-related activities is needed to explore these questions further.

\section{Time Diaries}

During parents' minute-by-minute recounting of activities during the prior day, math-related activities were infrequently reported. Specifically, approximately $1 \%$ of children's available time while not in preschool or sleeping was reported as engaged in a math-related activity by parents completing the time diary interview. However, subsequent probing during the interview about specific math-related activities increased the types and duration of children's exposure to math activities that the time diary interviews did not provide. When asked about daily math activities during the previous day, average sums of number activities were similar across work and non-work days, with a similar pattern reported for spatial activities. However, unlike the survey reports, the time diary reports revealed much less engagement in spatial activities than number activities for both work and non-work days, which is more consistent with previous findings using parent surveys (Zippert and Rittle-Johnson, 2020; Zippert et al., 2020). These differences should be interpreted with caution, however, as parents were asked about fewer spatial activities than number activities, resulting in a lower maximum value (4 spatial activities compared to 21 number activities).

Examination of correlations with each assessment revealed that although engagement in number activities was somewhat consistent across work and non-work days, parent reports of spatial activities was unrelated and thus inconsistent across work and non-work days. One possible explanation is that spatial activities such as puzzles or block play take more time than number activities such as counting or playing with number fridge magnets, and thus, parents are more likely to engage in spatial activities with children on non-work days than work days. It should also be noted that engagement in a variety of mathrelated activities was more likely to occur on non-work days, where the correlation between number and spatial activities was much higher than for work days. Thus, parental employment patterns appear substantively linked to parental support for early math. Notably, the proportion of available time devoted to math activities was comparable across work and non-work days, but families had more opportunities for these activities on non-work days. More research is needed to determine how variation in parents' employment experiences, such as non-standard work hours, changing weekly work schedules, working 6 or 7 days per week, etc., impacts children's exposure to math-related activities at home.

\section{Observations of Parent Math Talk}

The present study also examined parent talk during two semistructured tasks that were designed to elicit number-related talk (grocery task) and spatial talk (magnet board puzzle task). Within each task, parents displayed considerable variability in the frequency and types of math content that they discussed with their child. For example, within an 8-min grocery task, parents provided an average of 14 utterances involving labeling sets with about two instances each of counting and identifying number symbols. Likewise, in the magnet task, parents spoke an average of 11-18 utterances for spatial concepts such as locations, directions and orientations, continuous amount, deictics, and shapes. It is notable that spatial talk occurred much more frequently in the magnet board puzzle task than did number talk in the grocery task. These differences could be due to differences in task design, such that the puzzle task had an end goal that required a solution, whereas the grocery task was much more open-ended. In other words, parents may have used spatial talk more given that they needed to engage with the materials spatially, but in the grocery task parents and children were not necessarily instructed to pretend shop, buy specific quantities of certain items, or discuss and exchange money. Parents' number talk during the grocery task could be lower thus if some parents engaged in other types of interactions around groceries and shopping (see VandermaasPeeler et al., 2009, for an example). 
In addition, within each task, most of the number talk codes and spatial talk codes were intercorrelated, although we did not examine if number or spatial talk codes were correlated across these very different tasks. Among the number talk codes, however, some correlations were low or non-significant, suggesting that number talk may not be a single unitary construct. Instead, future research should aim to capture and differentiate between these distinct types of number talk (e.g., counting compared to identifying numerals). Additionally, few correlations reached statistical significance when examining the math content of parent talk across tasks. In other words, parents who provided high frequencies of number talk did not necessarily provide high levels of spatial talk, and vice versa. Importantly, number talk and spatial talk were measured during separate activities, each designed to elicit a high frequency of the respective type of talk. In contrast, parents' conversational style across the semi-structured observational tasks was modestly consistent, such that number and spatial questions were significantly and positively correlated across tasks. Although statements and questions within each domain of math talk were modestly correlated, one direction for future research is to explore whether these distinct aspects of number and spatial talk differentially relate to children's development in these areas. An additional future research direction is to determine the extent to which these math discussions reflect the parent's appraisal of their child's skills rather than a parent conversational style, such that parents provide more questions if they expect the child can answer them and more statements if they are trying to teach foundational concepts.

\section{Triangulating Across Measures of Parental Support for Early Math Development}

Overall, measures of parental support for early math obtained from parent reports (i.e., surveys and time diaries) demonstrated more convergence than either parent report method with observed math talk codes. This pattern was also consistent across measures of number and spatial activities. When examining the parent report measures, it appears that parents' survey responses about their monthly number-related activities were driven by recollections of activities and interactions during work days. Even though parents varied widely in their hours worked per week, the work day number activities were apparently more salient as they responded to questionnaire items about the activities during the prior month. In contrast, survey reports of monthly spatial activities were somewhat more related to non-work day than work day time diary reports, although the low incidence of spatial activities in the time diary data likely constrained these associations.

Very few significant associations between observed math talk during semi-structured observations and parent reports of math-related activities were detected, and this generally null finding held across number and spatial talk. Instances of discordance across these multi-method assessments may reflect measurement error but also authentic differences in the contexts that each metric assessed (i.e., math talk during semi-structured observations, daily math activities, and monthly engagement in math activities). Parental support of early math skills may be a multidimensional construct, such that each assessment modality is identifying related and distinct features of this construct. For example, math talk may identify best case scenarios for parental math support while parental report may index opportunities for exposure to math content, regardless of the actual occurrence and qualitative features of math support. In addition, math talk likely also reflects a child's interest in the subject matter at the very moment of observation while parental report may signify more sustained, long-term interests in activities. Future research should utilize multivariate approaches such as cluster analyses and mixture modeling to examine the combinations and patterns in ways that parents support their young children's math learning. For example, recent work suggests that although parental number talk is more common during math-related activities, the strength of this association varies, such that some parents are more able to integrate discussion of number concepts into activities that are not related to math than other parents (Thippana et al., 2020). As such, there may be parents who engage in extensive math talk but do not necessarily report a high number of math activities. By simply examining the correlations across measures, we may overlook these theoretically interesting subgroups of parents.

The divergence across methodologies highlighted here also demonstrates the need for intentional selection of measures of math support in future studies. In particular, we suggest that future research includes multiple metrics of math support in order to capture these various dimensions of parents' support of early math skills, including potential interactions between dimensions.

\section{Limitations}

The present study examined rich, in-depth measurement of parental support of early math skills across data sources and methods. This intensive, novel examination offers new insights into how parents are reporting about their math-related home activities. Given the exploratory nature of this investigation, future research is needed to replicate and extend the current findings. In addition, although we heavily focused our summary of results on general patterns of associations, rather than specific intercorrelations, caution is warranted when interpreting the findings given the number of statistical tests performed. Future work should include larger samples and examine the concurrent and predictive validity of these assessments with children's early numeracy and spatial skills. Similarly, more work exploring reliability of these measures, specifically regarding test-retest reliability for observational and time diary measures, would extend these findings. In addition, it should be noted that the majority of participants were recruited from preschool centers, and thus, it is unclear whether parents of 4-yearold's who are not enrolled in early learning programs would display similar frequencies of home math activities or math talk. Furthermore, the cross-sectional, correlational design precludes us from understanding how children's characteristics influence what parents do, why parents differ in what they do, and how daily activities or conversational patterns may change over time as children age and enter formal schooling. 


\section{CONCLUSION}

In conclusion, current evidence of triangulation across multimethod approaches holds great promise for future larger scale studies of early math development. Statistical methods such as latent variable modeling could combine these multiple methods and data sources into a broader, more comprehensive latent construct of home practices to predict children's early math skills. A latent variable approach would address the mono-operation bias occurring in many studies of early math by estimating and partialing out measurement error from the prediction model. Given parents' relatively infrequent efforts to discuss math concepts or engage in math-related activities at home, this multi-method approach holds great promise for furthering our understanding of when and how parents support early math skills with their preschool-aged children.

\section{DATA AVAILABILITY STATEMENT}

Data are drawn from an ongoing longitudinal study, and we have arranged with our funder to release the data at the completion of the study.

\section{ETHICS STATEMENT}

The studies involving human participants were reviewed and approved by University of Pittsburgh Institutional Review Board. Written informed consent to participate in this study was provided by the participants' legal guardian/next of kin.

\section{AUTHOR CONTRIBUTIONS}

$\mathrm{HB}, \mathrm{LE}, \mathrm{MN}, \mathrm{EV}-\mathrm{D}$, and ML contributed to the conception and design of the study. LE and MN organized the database.

\section{REFERENCES}

Ard, L. M., and Beverly, B. L. (2004). Preschool word learning during joint book reading: effect of adult questions and comments. Commun. Disord. Q. 26, 17-28. doi: 10.1177/15257401040260010101

Blevins-Knabe, B., and Musun-Miller, L. (1996). Number use at home by children and their parents and its relationship to early mathematical performance. Early Dev. Parent. 5, 35-45. doi: 10.1002/(sici)1099-0917(199603)5:1<35::aidedp113>3.0.co;2-0

Cannon, J., and Ginsburg, H. P. (2008). “Doing the Math”: maternal beliefs about early mathematics versus language learning. Early Educ. Dev. 19, 238-260. doi: 10.1080/10409280801963913

Casasola, M., Wei, W. S., Suh, D. D., Donskoy, P., and Ransom, A. (2020). Children's exposure to spatial language promotes their spatial thinking. J. Exper. Psychol. Gen. 149, 1116-1136. doi: 10.1037/xge0000699

Casey, B. M., Lombardi, C. M., Thomson, D., Nguyen, H. N., Paz, M., Theriault, C. A., et al. (2018). Maternal support of children's early numerical concept learningpredicts preschool and first-grade math achievement. Child Dev. 89, 156-173. doi: $10.1111 /$ cdev.12676

Chorney, J. M., McMurty, C. M., Chambers, C. T., and Bakeman, R. (2015). Developing and modifying behavioral coding schemes in pediatric psychology: a practical guide. J. Pediatr. Psychol. 40, 154-164. doi: 10.1093/jpepsy/jsu099
LE performed the statistical descriptive analyses. SD and LB conducted reliability analyses for coded data. HB wrote the first draft of the manuscript. LE, SD, LB, and ML wrote sections of the manuscript. All authors contributed to the manuscript revision, read and approved the submitted version.

\section{FUNDING}

Primary funding for this research was provided by the Eunice Kennedy Shriver National Institute of Child Health and Human Development (1 R01 HD093689-01A1) to HB, ML, and EV-D. This project also benefited from intellectual synergies stemming from several related studies funded by the National Science Foundation (Award Number: 1920545), an internal award from the Learning Research and Development Center at the University of Pittsburgh, and a Scholar Award from the James S. McDonnell Foundation to ML.

\section{ACKNOWLEDGMENTS}

We would like to thank the editor and the reviewers for their comments. Any opinions, findings, and conclusions or recommendations expressed in this material are those of the authors and does not necessarily reflect the views of the NICHD, the NSF, the LRDC, the James S. McDonnell Foundation, or the reviewers. We thank our project team for all their assistance with data collection and coding. A special thank you is also extended to the community partners that assisted our recruitment efforts and the children and families who participated in the Parents Promoting Early Learning (PPEL) project. APC charges for this article were fully paid by the University Library System, University of Pittsburgh.

Cook, T. D., and Campbell, D. T. (1979). Quasi-Experimentation: Design and Analysis Issues for Field Settings. Chicago: Rand McNally College Publishing.

Cortes, K. E., Goodman, J. S., and Nomi, T. (2015). Intensive math instruction and educational attainment long-run impacts of double-dose algebra. J. Hum. Resour. 50, 108-158. doi: 10.1353/jhr.2015.0004

Dearing, E., Casey, B. M., Ganley, C. M., Tillinger, M., Laski, E., and Montecillo, C. (2012). Young girls' arithmetic and spatial skills: the distal and proximal roles of family socioeconomics and home learning experiences. Early Childh. Res. Q. 27, 458-470. doi: 10.1016/j.ecresq.2012.01.002

DeFlorio, L., and Beliakoff, A. (2015). Socioeconomic status and preschoolers' mathematical knowledge: the contribution of home activities and parent beliefs. Early Educ. Dev. 26, 319-341. doi: 10.1080/10409289.2015.96 8239

Elliott, L., and Bachman, H. J. (2018). How do parents foster young children's math skills? Child Dev. Perspect. 12, 16-21. doi: 10.1111/cdep.12249

Elliott, L., Bachman, H. J., and Henry, D. (2020). Why and how do parents promote math learning with their young children? Parent. Sci. Pract. 20, 108-140. doi: $10.1080 / 15295192.2019 .1694830$

Elliott, L. E., Braham, E. J., and Libertus, M. E. (2017). Understanding sources of individual variability in parents' number talk with young children. J. Exp. Child Psychol. 159, 1-15. doi: 10.1016/j.jecp.2017.01.011 
Ferrara, K., Hirsh-Pasek, K., Newcombe, N. S., Golinkoff, R. M., and Lam, W. S. (2011). Block talk: spatial language during block play. Mind Brain Educ. 5, 143-151. doi: 10.1111/j.1751-228x.2011.01122.x

Fiorini, M., and Keane, M. P. (2014). How the allocation of children's time affects cognitive and noncognitive development. J. Lab. Econ. 32, 787-836. doi: 10. $1086 / 677232$

Ginsburg, H. P., Lee, J. S., and Boyd, J. S. (2008). Mathematics education for young children: what it is and how to promote it. SRCD Soc. Policy Rep. 22, 1-23. doi: 10.1002/j.2379-3988.2008.tb00054.x

Gunderson, E. A., and Levine, S. C. (2011). Some types of parent number talk count more than others: relations between parents' input and children's cardinalnumber knowledge. Dev. Sci. 14, 1021-1032. doi: 10.1111/j.1467-7687.2011. 01050.x

Gunthert, K., and Wenze, S. (2011). "Time diary methods," in Handbook of Research Methods for Studying Daily Life, eds M. R. Mehl and T. S. Conner (New York, NY: The Guilford Press).

Hallgren, K. A. (2012). Computing inter-rater reliability for observational data: an overview and tutorial. Tutor Q. Methods Psychol. 8, 23-34. doi: 10.20982/tqmp. 08.1.p023

Hanushek, E. A., and Woessman, L. (2015). "Skills, mobility, and growth," in Proceedings of the Ninth Biennial Federal Reserve System Community Development Research Conference, Washington, DC.

Hart, S. A., Ganley, C. M., and Purpura, D. J. (2016). Understanding the home math environment and its role in predicting parent report of children's math skills. PLoS One 11:e0168227. doi: 10.1371/journal.pone.0168227

Heath, L. (2015). "Triangulation," in The International Encyclopedia of Social and Behavioral Sciences, eds N. J. Smelser and P. B. Baltes, 2nd Edn, London: Elsevier Press.

Ho, A., Lee, J., Wood, E., Kassies, S., and Heinbuck, C. (2018). Tap, swipe, and build: parental spatial input during $\mathrm{iPad}^{\circledR}$ and toy play. Infant Child Dev. 27:e2061. doi: 10.1002/icd.2061

Hofferth, S. L., and Sandberg, J. F. (2001). How American children spend their time. J. Marriage Fam. 63, 295-308.

Huntsinger, C. S., Jose, P. E., and Luo, Z. (2016). Parental facilitation of early mathematics and reading skills and knowledge through encouragement of home-based activities. Early Childh. Res. Q. 37, 1-15. doi: 10.1016/j.ecresq.2016. 02.005

Juster, F. T., and Stafford, F. P. (1985). Time, Goods and Well-Being. Ann Arbor, MI: University of Michigan.

Kaufman, A. S., Kaufman, J. C., Liu, X., and Johnson, C. K. (2008). How do educational attainment and gender relate to fluid intelligence, crystalized intelligence, and academic skills at ages 22-90 years? Archiv. Clin. Neuropsychol. 24, 153-163. doi: 10.1093/arclin/acp015

Kleemans, T., Peeters, M., Segers, E., and Verhoeven, L. (2012). Child and home predictors of early numeracy skills in kindergarten. Early Childh. Res. Q. 27, 471-477. doi: 10.1016/j.ecresq.2011.12.004

Klibanoff, R. S., Levine, S. C., Huttenlocher, J., Vasilyeva, M., and Hedges, L. V. (2006). Preschool children's mathematical knowledge: the effect of teacher "math talk. Dev. Psychol. 42, 59-69. doi: 10.1037/0012-1649.42.1.59

Kotila, L. E., Schoppe-Sullivan, S. J., and Kamp Dush, C. M. (2013). Time in parenting activities in dual-earner families at the transition to parenthood. Fam. Relat. 62, 795-807. doi: 10.1111/fare.12037

Lee, J., Hodgins, S., and Wood, E. (2019). "Spatial learning and play with technology: how parental spatial talk differs across contexts," in Mathematical Learning and Cognition in Early Childhood, eds K. Robinson, H. Osana, and D. Kotsopoulos (Cham: Springer), 23-38. doi: 10.1007/978-3-030-12895-1_3

Lee, Y., Hofferth, S. L., Flood, S. M., and Fisher, K. (2016). Reliability, validity, and variability of the subjective well-being questions in the 2010 American Time Use Survey. Soc. Indic. Res. 126, 1355-1373. doi: 10.1007/s11205-0150923-8

LeFevre, J., Polyzoi, E., Skwarchuk, S., Fast, L., and Sowinski, C. (2010). Do home numeracy and literacy practices of Greek and Canadian parents predict the numeracy skills of kindergarten children? Intern. J. Early Years Educ. 18, 55-70. doi: 10.1080/09669761003693926

LeFevre, J., Skwarchuk, S. L., Smith-Chant, B. L., Fast, L., Kamawar, D., and Bisanz, J. (2009). Home numeracy experiences and children's math performance in the early school years. Can. J. Behav. Sci. 41:55. doi: 10.1037/a0014532
Levine, S. C., Suriyakham, L. W., Rowe, M. L., Huttenlocher, J., and Gunderson, E. A. (2010). What counts in the development of young children's number knowledge? Dev. Psychol. 46, 1309-1319. doi: 10.1037/a0019671

Leyva, D., Tamis-LeMonda, C., Yoshikawa, H., Jimenez-Robbins, C., and Malachowski, L. (2017). Grocery games: how ethnically diverse low-income mothers support children's mathematics and literacy. Early Childh. Res. Q. 40, 63-76. doi: 10.1016/j.ecresq.2017.01.001

Manolitsis, G., Georgiou, G. K., and Tziraki, N. (2013). Examining the effects of home literacy and numeracy environment on early reading and math acquisition. Early Childh. Res. Q. 28, 692-703. doi: 10.1016/j.ecresq.2013.05.004

Mathison, S. (1988). Why triangulate? Educ. Res. 17, 13-17. doi: 10.3102/ 0013189x017002013

McHugh, M. L. (2012). Interrater reliability: the kappa statistic. Biochem. Med. Biochem. Med. 22, 276-282. doi: 10.11613/bm.2012.031

Mermelshtine, R. (2017). Parent-child learning interactions: a review of the literature on scaffolding. Br. J. Educ. Psychol. 87, 241-254. doi: 10.1111/bjep. 12147

Missall, K., Hojnoski, R. L., Caskie, G. I. L., and Repasky, P. (2014). Home numeracy environments of preschoolers: examining relations among mathematical activities, parent mathematical beliefs, and early mathematical skills. Early Educ. Dev. 26, 356-376. doi: 10.1080/10409289.2015.968243

Missall, K. N., Hojnoski, R. L., and Moreano, G. (2017). Parent-child mathematical interactions: examining self-report and direct observation. Early Child Dev. Care 187, 1896-1908. doi: 10.1080/03004430.2016.1193731

Murmane, R. J., Willett, J. B., and Duhaldeborde, Y. (2000). How important are the cognitive skills of teenagers in predicting subsequent earnings? J. Policy Analys. Manag. 19, 547-568. doi: 10.1002/1520-6688(200023)19:4<547::aid-pam2>3. $0 . c 0 ; 2-\#$

Mutaf Yıldız, B., Sasanguie, D., De Smedt, B., and Reynvoet, B. (2018). Frequency of home numeracy activities is differentially related to basic number processing and calculation skills in kindergartners. Front. Psychol. 9:340. doi: 10.3389/ fpsyg.2018.00340

National Research Council (2009). "Mathematics learning in early childhood: paths toward excellence and equity. committee on early childhood mathematics," in Center for Education, Division of Behavioral and Social Sciences and Education, eds C. T. Cross, T. A. Woods, and H. Schweingruber (Washington, DC: The National Academies Press).

Nesteruk, O., and Garrison, M. E. B. (2005). An exploratory study of the relationship between family daily hassles and family coping and managing strategies. Fam. Consum. Sci. Res. J. 34, 140-152. doi: 10.1177/ $1077727 \times 05280667$

Niklas, F., and Schneider, W. (2014). Casting the die before the die is cast: the importance of the home numeracy environment for preschool children. Eur. J. Psychol. Educ. 29, 327-345. doi: 10.1007/s10212-013-0201-6

Pan, B. A., Rowe, M. L., Spier, E., and Tamis-LeMonda, C. (2004). Measuring productive vocabulary of toddlers in low-income families: concurrent and predictive validity of three sources of data. J. Child Lang. 31, 587-608. doi: $10.1017 / \mathrm{s} 0305000904006270$

Parsons, S., and Bynner, J. (2005). Does Numeracy Matter More?. London: National Research and Development Centre for Adult Literacy and Numeracy.

Phipps, P. A., and Vernon, M. K. (2009). "Twenty-four hours: an overview of the recall diary method and data quality in the American time use survey," in Calendar and Time Diary: Methods in Life Course Research, eds R. F. Belli, F. P. Stafford and D. F. Alwin (Thousand Oaks, CA: SAGE Publications, Inc).

Polinsky, N., Perez, J., Grehl, M., and McCrink, K. (2017). Encouraging spatial talk: using children's museums to bolster spatial reasoning. Mind Brain Educ. 11, 144-152. doi: $10.1111 / \mathrm{mbe} .12145$

Price, J. (2010). The Effect of Parental Time Investments: Evidence from Natural Within-Family Variation. Provo, UT: Brigham Young University.

Pruden, S. M., Levin, S. C., and Huttenlocher, J. (2011). Children's spatial thinking: does talk about the spatial world matter? Dev. Sci. 14, 1417-1430. doi: 10.1111/ j.1467-7687.2011.01088.x

Purpura, D. J., King, Y. A., Rolan, E., Hornburg, C. B., Schmitt, S. A., Hart, S. A., et al. (2020). Examining the factor structure of the home mathematics environment to delineate its role in predicting preschool numeracy, mathematical language, and spatial skills. Front. Psychol. 11:1925. doi: 10.3389/fpsyg.2020.01925 
Ramani, G. B., Rowe, M. L., Eason, S. H., and Leech, K. A. (2015). Math talk during informal learning activities in head start families. Cogn. Dev. 35, 15-33. doi: 10.1016/j.cogdev.2014.11.002

Reynolds, E., Vernon-Feagans, L., Bratsch-Hines, M., Baker, C. E., and Family Life Project Key Investigators (2019). Mothers' and fathers' language input from 6 to 36 months in rural two-parent-families: relations to children's kindergarten achievement. Early Childh. Res. Q. 47, 385-395. doi: 10.1016/j.ecresq.2018.09.002

Ritchie, S. J., and Bates, T. C. (2013). Enduring links from childhood mathematics and reading achievement to adult socioeconomic status. Psychol. Sci. 24, 13011308. doi: $10.1177 / 0956797612466268$

Robinson, J. P., and Godbey, G. (1999). Time for Life. University Park, PA: Pennsylvania State University Press.

Rose, H., and Betts, J. R. (2004). The effect of high school courses on earnings. Rev. Econ. Statist. 86, 497-513. doi: 10.1162/00346530432303 1076

Rowe, M. L., Leech, K. A., and Cabrera, N. J. (2017). Going beyond input quantity: wh-questions matter for toddlers' language and cognitive development. Cogn. Sci. 41, 162-179. doi: 10.1111/cogs.12349

Sarama, J., and Clements, D. H. (2009). Early Childhood Mathematics Education Research: Learning Trajectories for Young Children. New York, NY: Routledge.

Strouse, G. A., O’Doherty, K., and Troseth, G. L. (2013). Effective coviewing: preschoolers' learning from video after a dialogic questioning intervention. Dev. Psychol. 49, 2368-2382. doi: 10.1037/a0032463

Susperreguy, M. I., Douglas, H., Xu, C., Natalia, M-R., and Lefevre, J. (2020). Expanding the home numeracy model to chilean children: relations among parental expectations, attitudes, activities, and children's mathematical outcomes. Early Child Res. Q. 50, 16-28. doi: 10.1016/j.ecresq.2018. 06.010

Susperreguy, M. I., and Davis-Kean, P. E. (2016). Maternal math talk in the home and math skills in preschool children. Early Educ. Dev. 27, 841-857. doi: 10.1080/10409289.2016.1148480

Thippana, J., Elliott, L., Gehman, S., Libertus, K., and Libertus, M. (2020). Parents' use of number talk with young children: comparing methods, family factors, activity contexts, and relations to math skills. Early Childh. Res. Q. 53, 249-259. doi: 10.1016/j.ecresq.2020.05.002

Tompkins, V., Bengochea, A., Nicol, S., and Justice, L. M. (2017). Maternal inferential input and children's language skills. Read. Res. Q. 52, 397-416. doi: 10.1002/rrq. 176

Tudge, J. R. H., and Doucet, F. (2004). Early mathematical experiences: observing young black and white children's everyday activities. Early Childh. Res. Q. 19, 21-39. doi: 10.1016/j.ecresq.2004.01.007
U. S. Bureau of Labor Statistics (2016). American Time Use Survey User Guide: Understanding ATUS 2003 to 2015. Washington, DC: U. S. Bureau of Labor Statistics.

Vandermaas-Peeler, M., Boomgarden, E., Finn, L., and Pittard, C. (2012). Parental support of numeracy during a cooking activity with four-year-olds. Intern. J. Early Years Educ. 20, 78-93.

Vandermaas-Peeler, M., Nelson, J., Bumpass, C., and Sassine, B. (2009). Numeracyrelated exchanges in joint storybook reading and play. Intern. J. Early Years Educ. 17, 67-84. doi: 10.1080/09669760802699910

Verdine, B. N., Zimmermann, L., Foster, L., Marzouk, M. A., Golinkoff, R. M., Hirsh-Pasek, K., et al. (2019). Effects of geometric toy design on parent-child interactions and spatial language. Early Childh. Res. Q. 46, 126-141.

Watts, T. W., Duncan, G. J., Siegler, R. S., and Davis-Kean, P. E. (2016). What's past is prologue. Educ. Res. 43, 352-360.

Weinberger, C. J. (2014). The increasing complementarity between cognitive and social skills. Rev. Econ. Statist. 96, 849-861.

Zippert, E. L., Daubert, E. N., Scalise, N. R., Noreen, G. D., and Ramani, G. B. (2019). "Tap space number three": promoting math talk during parent-child tablet play. Dev. Psychol. 55, 1605-1614. doi: 10.1037/dev0000769

Zippert, E. L., Douglas, A. A., Smith, M. R., and Rittle-Johnson, B. (2020). Preschoolers' broad mathematics experiences with parents during play. J. Exp. Child Psychol. 192:104757.

Zippert, E. L., and Ramani, G. B. (2017). Parents' estimations of preschoolers' number skills relate to at-home number-related activity engagement. Infant Child Dev. 26:24. doi: 10.1002/icd.1968

Zippert, E. L., and Rittle-Johnson, B. (2020). The home math environment: more than numeracy. Early Childh. Res. Q. 50, 4-15.

Zosh, J. M., Verdine, B. N., Filipowicz, A., Golinkoff, R. M., Hirsh-Pasek, K., and Newcombe, N. S. (2015). Talking shape: parental language with electronic versus traditional shape sorters. Mind Brain Educ. 9, 136-144.

Conflict of Interest: The authors declare that the research was conducted in the absence of any commercial or financial relationships that could be construed as a potential conflict of interest.

Copyright (c) 2020 Bachman, Elliott, Duong, Betancur, Navarro, Votruba-Drzal and Libertus. This is an open-access article distributed under the terms of the Creative Commons Attribution License (CC BY). The use, distribution or reproduction in other forums is permitted, provided the original author(s) and the copyright owner(s) are credited and that the original publication in this journal is cited, in accordance with accepted academic practice. No use, distribution or reproduction is permitted which does not comply with these terms. 
OPEN ACCESS

Edited by:

Amy R. Napoli,

University of Nebraska-Lincoln,

United States

Reviewed by:

Sojung Kim,

West Chester University,

United States

Pamela Sammons,

University of Oxford, United Kingdom

*Correspondence:

Manja Attig

manja.attig@lifbi.de

Specialty section:

This article was submitted to

Educational Psychology,

a section of the journal

Frontiers in Psychology

Received: 30 April 2020 Accepted: 27 October 2020

Published: 08 December 2020

Citation:

Attig $M$ and Weinert S (2020) What Impacts Early Language Skills?

Effects of Social Disparities and Different Process Characteristics of the Home Learning Environment in the First 2 Years.

Front. Psychol. 11:557751. doi: 10.3389/fpsyg.2020.557751

\section{What Impacts Early Language Skills? Effects of Social Disparities and Different Process Characteristics of the Home Learning Environment in the First 2 Years}

\author{
Manja Attig $^{1 *}$ and Sabine Weinert ${ }^{2}$ \\ ${ }^{1}$ Competencies, Personality, Learning Environments, Leibniz Institute for Educational Trajectories, Bamberg, Germany, \\ ${ }^{2}$ Department Psychology I - Developmental Psychology, University of Bamberg, Bamberg, Germany
}

It is well documented that the language skills of preschool children differ substantially and that these differences are highly predictive of their later academic success and achievements. Especially in the early phases of children's lives, the importance of different structural and process characteristics of the home learning environment (HLE) has been emphasized and research results have documented that process characteristics such as the quality of parental interaction behavior and the frequency of joint activities vary according to the socio-economic status (SES) of the family. Further, both structural and process characteristics are associated with children's language development. As most of the studies focus on single indicators or didn't take the dynamics of parenting behavior across age into account, the present paper aims to investigate the associations of different characteristics of the home learning environment as well as their potentially changing impact on the language skills of 2-year-old children. Using data of 2.272 families of the infant cohort study of the German National Educational Panel Study (NEPS), longitudinally assessed process characteristics (sensitivity in the sense of maternal responsivity to the child's behavior and signals in mother-child interaction; maternal stimulation behavior which goes beyond the child's actual level of action and development; frequency of joint picture book reading) and structural characteristics (mother's education, equivalised household income, parental occupational status) were considered. Language skills (vocabulary and grammar) of the children at the age of two were measured by a standardized and validated parent report instrument (child language checklist). Results showed that (1) all three process characteristics of the home learning environment (HLE) are associated with the family's SES; (2) across three assessment waves nearly all process characteristics predicted children's vocabulary and grammar skills with some process-specific changes across waves; (3) despite separate direct effects of nearly all HLE-process characteristics in each wave, the amount of explained variance in a joint 
model including the HLE facets from each wave is hardly higher than in the separate models; and (4) socioeconomic background predicted both language facets of the children in each model even when controlling for the assessed process characteristics of the home learning environment.

Keywords: vocabulary, grammar skills, home learning environment (HLE), social disparities, quality of interaction behavior, picture book reading, first 2 years

\section{INTRODUCTION}

From the very beginning children differ in their individual resources, basic abilities and other characteristics as well as in their developmental progress. Bioecological models of development (e.g., Bronfenbrenner and Morris, 2006) state that from early on - besides individual prerequisites - the learning environments impact the development of children. Accordingly, plethora of research has documented a significant association between different kinds of learning environments and child development (e.g., Hart and Risley, 1995; Nord et al., 2000; Anders et al., 2012; Weinert and Ebert, 2013; Lehrl et al., 2020). Focusing on the first years of life, the family is seen as the most important learning environment (Bornstein, 2002) and parenting behavior has been emphasized as particularly important for the development of children (e.g., NICHD Early Child Care Research Network, 2002a,b). Further, research showed that the early home learning environment also predicts the quality of the later home learning environment (Toth et al., 2020). According to the educational framework of the home learning environment (e.g., Kluczniok et al., 2013), structural characteristics such as parental education, occupation, and household income [as indicators of the socioeconomic status (SES) of the family] affect educational processes (e.g., quality of interaction behavior, joint activities). These educational processes in turn impact child development. In line with these assumptions, research has shown that structural characteristics (SES) as well as process characteristics of the home learning environment (e.g., the above mentioned quality of interaction behavior) are associated with cognitive, socioemotional, and especially language development in childhood (e.g., Hart and Risley, 1995; NICHD Early Child Care Research Network, 1998, 2002a,b; Kluczniok et al., 2013; Weinert and Ebert, 2013; Bradbury et al., 2015; Friedman-Krauss et al., 2016; Hurt and Betancourt, 2016). Overall and in line with the educational model outlined above, research findings suggest that SES-related disparities in language development could be traced back to differences in process characteristics of the home learning environment which are associated with the families' socioeconomic status; however, only few studies address the dynamics of parenting behavior across the first years (LugoGil and Tamis-LeMonda, 2008; Rodriguez and Tamis-LeMonda, 2011; Vallotton et al., 2017). Hence, one aim of the present study is to take a longitudinal perspective by investigating the effect of social background on different characteristics of educational processes, particularly the interaction behavior of the mother (with a focus on maternal sensitivity and stimulation behavior) as well as joint activities across the first 2 years.
Language development is seen as a key factor for later development as well as for school readiness, reading skills, and school success (NICHD Early Child Care Research Network, 2005a; Rowe et al., 2012; Schuth et al., 2017; Weinert and Ebert, 2017; Rose et al., 2018). However, language is not a unitary phenomenon and is comprised of various components or subdomains, including vocabulary and grammar. As these components have been suggested to be differentially related to variations in the early home learning environment (Vasilyeva and Waterfall, 2011) and as language proficiency mutually draws on both components, our study addresses both, early vocabulary and early grammar. In particular, vocabulary is often seen as an indicator of language as well as of more general knowledge acquisition and crystallized intelligence and is thus highly prone to environmental stimulation (e.g., Kail and Pellegrino, 1985; Hart and Risley, 1995; Hoff-Ginsberg, 1998; Weinert et al., 2007; Rowe and Goldin-Meadow, 2009). Early grammar, however, is sometimes conceptualized as a more "inside-out" developmental phenomenon (see e.g., Golinkoff and Hirsh-Pasek, 1990; HirshPasek and Golinkoff, 1996) with environmental input not being the driving force, but instead an enabling force particularly in the early phases of development (Newport et al., 1977; Huttenlocher et al., 2010). Thus, the second aim of our study is to investigate how structural (SES) and the longitudinally assessed process characteristics of the early home learning environment (HLE) predict each language facet at the age of 2 years when the home learning environment plays a major role and whether the association with different environmental processes of the HLE changes over time and varies according to the language component considered.

\section{THEORETICAL AND EMPIRICAL BACKGROUND}

\section{SES-Related Disparities in Process Characteristics of the Home Learning Environment}

As already mentioned, SES-related differences in child development are suggested to be mainly transferred by qualitative and quantitative differences in the home learning environment (e.g., Lugo-Gil and Tamis-LeMonda, 2008). Educational frameworks (e.g., Kluczniok et al., 2013) assume that structural characteristics of the family (SES) affect process characteristics and hence the quality of the home learning environment (e.g., Anders et al., 2012; Lehrl et al., 2012; Weinert et al., 2017). In 
particular, family stress and family investment models (Haveman and Wolfe, 1994; Conger and Donnellan, 2007) presume that higher education, lower economic hardship, and more social resources (e.g., higher occupational status) impact on materials (e.g., books at home), living conditions, and family processes as these parents may, among other factors, gather more information on child development, experience less parental distress, and may thus be more able to provide their children with a high quality home learning environment.

A large number of research findings are in accordance with these assumptions. For example, the overall quality of the home learning environment, as measured by the Home Observation for Measurement of the Environment Inventory (HOME, Caldwell and Bradley, 1984), as well as the quality of parent-child interactions proved to be associated with the education level of parents (Bradley et al., 2001; Lugo-Gil and Tamis-LeMonda, 2008; Rowe, 2008; Magnuson et al., 2009; Neuhauser, 2018). Further, findings also showed that poverty is associated with a decreased quality of interaction behavior and a decreased quantity and quality of language input (Hart and Risley, 1995; Hoff, 2003; NICHD Early Child Care Research Network, 2005b; Rowe, 2008; Gudmundson, 2012).

With respect to SES, various aspects of the quality of interaction behavior have been documented to be associated with social disparities (Bradley et al., 2001; Gudmundson, 2012; Weinert et al., 2017; Attig and Weinert, 2018). Using data of the German National Educational Panel Study (NEPS), Weinert et al. (2017) found that maternal education predicted how sensitive and stimulating the mother interacted with her 7 months old child. This converges with research results demonstrating an association between SES and parent's sensitivity at 12 months of age (Bernier et al., 2010) as well as with findings from the NICHD study (NICHD Early Child Care Research Network, 1999). Thus, mothers with low levels of education and mothers in low income households have been shown to provide their children with a less sensitive and less stimulating home learning environment (Klebanov et al., 1994; Bradley et al., 2001; Dilworth-Bart et al., 2007; Gudmundson, 2012; Neuhauser, 2018). In addition, focusing on language stimulation behavior, findings showed that - for example - mothers with a high socio-economic status talked more to their children compared to lower SES mothers (Hoff et al., 2002). Further, differences according to the family's SES were not only found for spontaneous speech and verbal communication but also with respect to the frequency and quality of joint book reading (Bradley et al., 2001; Niklas and Schneider, 2010; Farrant and Zubrick, 2012; Lehrl et al., 2012; Hayes and Berthelsen, 2020).

To sum up, SES-related differences have been documented for different facets of parenting behavior and the quality of parent-child interaction. As these facets are highly important for the development of children it is assumed that these early differences in parenting behavior in turn affect child development. Restrictions in qualitative and quantitative facets of the home learning environment are seen as a risk factor for child development. Thus, analyzing the impact of social background on facets of parenting behavior longitudinally in the first years of life will help to better understand the specific and potentially changing role of different facets of the home learning environment.

\section{Disparities in Children's Language}

Multiple studies have shown SES-related differences in various areas of child development such as socio-emotional, cognitive, and language development (e.g., Hart and Risley, 1995; NICHD Early Child Care Research Network, 1998; Weinert and Ebert, 2013; Bradbury et al., 2015; Friedman-Krauss et al., 2016; Hurt and Betancourt, 2016). For instance, Hart and Risley (1995) documented that children living in low-income households have smaller vocabularies and more restricted language skills compared to their more advantaged peers. Further, they also showed SES-related differences in the verbal learning environment of the children (the so-called "30 million word gap") which is also shown to be associated with the development of children (Hart and Risley, 1995). In contrast, a recent study by Sperry et al. (2018) showed only weak SES-related disparities in the number of words children heard (see Golinkoff et al., 2019; Sperry et al., 2019 for a critical discussion of the findings). Yet, Nord et al. (2000) had documented that children living in poverty or children with two or more educational risk factors were less likely to recognize the letters of the alphabet, count to 20 and higher, write their names, or read or pretend to read a storybook compared to their more advantaged peers. With respect to different aspects and indicators of language development, findings revealed that children from low-SES homes showed lower levels of oral language skills compared to children from more advantaged backgrounds (Weinert and Ebert, 2013; Linberg and Wenz, 2017; Law et al., 2019). This holds true for language processing skills, language comprehension as well as language production at different ages (Hoff, 2006; Fernald et al., 2013).

These results on the association between economic strains and children's language skills converge with studies focusing on disparities according to maternal education. Thus, maternal education is shown to be associated with receptive and expressive language skills of 4-year-old children (Reilly et al., 2010), the language performance of 5-year-olds, as well as with the longitudinally assessed language performance of 3, 4, and 5 year olds (Weinert and Ebert, 2013).

Further, SES-related disparities in language skills are not only found in preschool or school age children (e.g., Law et al., 2012; Linberg and Wenz, 2017) but are also evident in even younger children below the age of 3 years (Halle et al., 2009; Fernald et al., 2013; Attig and Weinert, 2019; Law et al., 2019). For example, interrelations between parental education as well as occupation with vocabulary were already shown in 18-month-old children (Fernald et al., 2013); and at the age of 24 months, a 6-month gap in language processing skills was evident (Fernald et al., 2013). Looking at 2-year-old children, Law et al. (2019) as well as Attig and Weinert (2019) showed that structural characteristics as well as process characteristics in the second year of life were likely to affect the toddlers' language skills.

A lot of research focuses on vocabulary size and it appears that it is the aspect of language which is most sensitive to vary according to SES (Rescorla, 1989; Hart and Risley, 1995; 
Arriaga et al., 1998; Hoff-Ginsberg, 1998; Dollaghan et al., 1999; Hoff, 2003; Pan et al., 2005; Rowe and Goldin-Meadow, 2009). In contrast, early grammar skills - in accordance with the so-called nativist theories of language acquisition (e.g., Fodor, 1983; Pinker, 1984; Chomsky, 1988; Van der Lely and Pinker, 2014) - were argued to be less influenced by the home learning environment (Vasilyeva and Waterfall, 2011). Although the empirical findings concerning grammar development seem to be somewhat inconsistent and controversial, there is a growing amount of research showing - in accordance with the more social-cognitive theories of language acquisition (Elman et al., 1996; Tomasello, 2003; Karmiloff-Smith, 2015; Weinert and Grimm, 2018) - that not only vocabulary but also child grammar varies according to SES and SES-related differences in the home learning environment (e.g., Vasilyeva et al., 2008; Huttenlocher et al., 2010; Weinert and Ebert, 2013, 2017; Anderka, 2018). For example, Weinert and Ebert (2013) showed SES-related differences in the receptive vocabulary as well as in the receptive grammar of 3-year old children which remained stable across preschool age. This result converges with findings from other studies which also found that children from high SES families outperform lower SES children on language tests including measures of grammatical development (Morisset et al., 1990; Dollaghan et al., 1999) and on various measures of productive and receptive syntax (Huttenlocher et al., 2002). However, it has been presumed that the early stages of grammar acquisition, below age three, may be less prone to environmental variation and more determined by innate factors (Anderka, 2018 for a brief overview; see also the results of Huttenlocher et al., 2010). Thus, from a theoretical as well as from an empirical perspective it seems worthwhile to differentiate both language components and to not only consider vocabulary but also early child grammar when investigating effects of the home learning environment on early child language as SES-related educational processes might affect them differentially.

\section{The Impact of Process Characteristics of the Early Home Learning Environment on Language Skills}

As already mentioned, different facets of the home learning environment are associated with child development (e.g., Melhuish et al., 2001, 2008; Lugo-Gil and Tamis-LeMonda, 2008; Melhuish, 2010). For instance, focusing on language development, the NICHD study revealed a significant relation between maternal sensitivity and child vocabulary at the age of three (NICHD Early Child Care Research Network, 1998). In addition, research results showed maternal sensitivity to be associated with speech comprehension and various milestones of language development (e.g., Ruddy and Bornstein, 1982; TamisLeMonda et al., 2001; Paavola et al., 2005; Nozadi et al., 2013). Thus, for example, the children of more sensitive mothers began to talk earlier and reached the milestone of a 50-word vocabulary at a younger age than children of less responsive mothers (TamisLeMonda et al., 1996; Tamis-LeMonda et al., 1998). In addition, maternal sensitivity at the age of 18 months predicted later language skills (Nozadi et al., 2013).

Most of the above-mentioned studies focused on maternal sensitivity or on a composite score of various facets of parental sensitivity and supportive behavior when investigating the association between interaction quality and language skills of children (e.g., NICHD Early Child Care Research Network, 2002a,b). Drawing on attachment theory (e.g., Ainsworth and Bell, 1970), parental sensitivity or responsivity is defined as a prompt, contingent, and suitable reply to the infant's signals and needs (Ainsworth et al., 1974; Tamis-LeMonda et al., 2014). Such parenting behavior has been suggested to be highly relevant to child development as it allows the child to experience him- or herself as competent and valued and to explore the environment from a secure base (Bowlby, 1988). As a second facet - in accordance with Vygotsky's theory and the concept of the zone of proximal development (Vygotsky, 1978) - parental stimulation of child behavior (also called scaffolding, e.g., Bruner, 1978) has been demonstrated to foster child development; this facet of parenting behavior also includes a sensitive component as the parents have to read the child's signals and to adapt their behavior to the child's needs. Yet, stimulating parenting behavior goes beyond the child's actual level of development or action thereby stimulating developmental progress by supporting the child in exploring the environment, by presenting the child with materials and language that amplifies the actual level of the child's performance and offers new perspectives or exploration opportunities to the child. Recently Linberg (2018) has empirically demonstrated that it is useful to separate these two components even in the very first year of life.

In fact, not only the prompt, contingent, and adequate reaction of the mother to the child's signals has been shown to be associated with language development, but also the described cognitively stimulating behavior that supports the child in exploring the environment and by presenting stimulating materials and toys to foster child development (Olson et al., 1986). For example, research findings showed that besides maternal responsivity at the age of 13 months, maternal verbal stimulation at the age of 24 months was associated with the children's vocabulary progress (Olson et al., 1986). Vallotton et al. (2017) stated that different developmental periods of language development require certain parental behavior (see also Landry et al., 2001). In particular, they showed that maternal sensitivity at the age of 14 months had a stronger effect on vocabulary than cognitive stimulation. At the age of 24 months, both effects were small, but nearly the same size. At the age of 36 months, cognitive stimulation showed a stronger effect on vocabulary than sensitivity (Vallotton et al., 2017). Hence, whereas the effect of sensitivity on the vocabulary development of the children seems to be relatively consistent over the very first years, the effect of stimulation seems to grow throughout toddlerhood. These results fit well with the findings by Farah et al. (2008) who showed that stimulation, but not sensitivity, predicted children's language skills at the age of 4 and 8 years.

However, different facets of mother-child interaction and the home learning environment might be associated with different 
areas of language development. For instance, Lehrl et al. (2012) showed that the quality of parent-child interaction predicted vocabulary but not grammar development, and the amount of experiences with books as well as the amount of complex language input (Anderka, 2018) predicted the development of receptive grammar but not vocabulary. Interestingly, SES-related disparities in vocabulary and grammar were also mediated by the respective factors (Anderka, 2018). Again, such results hint at the necessity to differentiate between language components as well as between different facets of parenting behavior which lead to a high quality of interaction behavior and home learning environment.

Hence, the present study focuses on sensitivity (in the sense of sensitive responsiveness) as well as on stimulation behavior in parent-child interaction as separate dimensions. Although studies such as the NICHD study (NICHD Early Child Care Research Network, 2002b; Belsky et al., 2007) longitudinally assessed the quality of interaction behavior, most analyses included composite scores. As parents adapt their interaction behavior to the behavior and the developmental status of their child (Rodriguez and Tamis-LeMonda, 2011) and because the effectiveness of features of the home learning environment may change over development (Olson et al., 1986; Vallotton et al., 2017; Korucu and Schmitt, 2020), it seems valuable to consider a longitudinal perspective on facets of parenting behavior in mother-child interaction across the first years to investigate possibly changing effects of the different aspects.

Not least and as already mentioned, not only the quality of interaction behavior has been shown to play a role in language development but also joint activities and the home literacy environment (e.g., Bus et al., 1995; Sénéchal and LeFevre, 2002; Farrant and Zubrick, 2012). A positive association with the frequency of joint picture book reading was shown - for example - for the vocabulary of preschoolers (Bus et al., 1995). Adding to this research, joint picture book reading explained variance in children's expressive vocabulary and morphological knowledge in 4-year-old children (Sénéchal et al., 2008). Such results were not only documented for preschool or school-aged children. For example, Bromley (2009) showed that reading to the children at the age of 10 months is associated with their language skills at the age of 34 months (see also Rodriguez et al., 2005; Raikes et al., 2006 for findings in a similar direction).

In summary, different process characteristics of the home learning environment have been shown to predict later child language. Yet, most studies focused on only one or two aspects of the home learning environment. Possible interrelation between the facets of the home learning environment and their consequences for the language development of children were hardly considered (see for an exception Attig and Weinert, 2019; Law et al., 2019). Extending previous work (Attig and Weinert, 2019) which focused on three process characteristics, namely maternal sensitivity (as indicated by responsivity), mother's cognitively stimulating behavior, and the frequency of joint picture book reading, as well as on structural characteristics, the present paper included longitudinal assessments of the process measures of the HLE allowing an investigation of the changes in the associations with SES across 2 years and across child outcomes as well.

\section{PRESENT STUDY}

Research indisputably shows significant associations between SES, parenting behavior, and child language with the home learning environment being a multidimensional construct. The present study considers structural as well as process characteristics of the home learning environment and adds to previous research by taking a longitudinal perspective on process characteristics of the HLE across the first 2 years. Thereby, the present paper extends previous research by Attig and Weinert (2019) which also considered three process characteristics as well as structural characteristics at one measurement point and analyzed their effect on the language skills of 2-years-olds. Attig and Weinert (2019) showed that maternal education as well as maternal sensitivity and stimulation behavior in motherchild interaction and, not least, the frequency of early picture book reading predict children's language skills as indicated by a combined measure of vocabulary and grammar at age two. Using the same dataset [the newborn cohort study of the German National Educational Panel Study (NEPS), Blossfeld et al., 2011; Blossfeld and Roßbach, 2019] ${ }^{1}$, the present paper aims to address the following research issues and questions:

(1) Association of structural (SES) and various process characteristics of the home learning environment across the first 2 years of children's lives.

(a) Extension of findings on SES-related disparities in different process characteristics of the home learning environment across three measurement points;

(b) Investigating the potentially changing associations between SES and various process characteristics of the home learning environment across three measurement points;

(2) Analyzing the predictive effect of structural (SES) and process characteristics on the early vocabulary and grammar outcomes of children at age two; in particular:

(a) To what extent does the SES as well as different process characteristics in the first 2 years predict the vocabulary size of 2-year-old children and does the prediction differ when focusing on different time points in the first years of life?

(b) To what extent does the SES as well as different process characteristics in the first 2 years predict early child grammar at 2 years of age and does the prediction differ across time points in the first years of life?

${ }^{1}$ This paper uses data from the National Educational Panel Study (NEPS): Starting Cohort Newborns, doi: 10.5157/NEPS:SC1:6.0.0. From 2008 to 2013, NEPS data was collected as part of the Framework Program for the Promotion of Empirical Educational Research funded by the German Federal Ministry of Education and Research (BMBF). As of 2014, NEPS is carried out by the Leibniz Institute for Educational Trajectories (LIfBi) at the University of Bamberg in cooperation with a nationwide network. 
When considering SES effects on child development, studies differ according to which structural aspects, such as education, occupation, or income, they take into account. Some studies used single predictors (e.g., Reilly et al., 2007; Law et al., 2012) while others included a combination of different aspects (e.g., Weinert and Ebert, 2013). Overall, across studies the findings substantiate the assumption that - relatively independent of the SES-measure used - the association between SES and early language development seems to be robust (see also Hoff, 2013). In this paper we decided to not only focus on one aspect of the social background but to take the different facets of structural characteristics conjointly into account.

By differentiating the language components we also contribute to the issue of whether early child grammar is less influenced by environmental conditions compared to vocabulary in the early phases of child development as suggested by nativist accounts of language acquisition (e.g., Fodor, 1983; Pinker, 1984; Chomsky, 1988; Van der Lely and Pinker, 2014).

\section{MATERIALS AND METHODS}

\section{Sample}

The present paper used data from the first three waves of the Newborn Cohort Study of the NEPS (Blossfeld and Roßbach, 2019). This cohort study includes a representatively drawn sample of around 3.500 children born between February and June 2012 and their families (Weinert et al., 2016). In each wave, a computer assisted parent interview as well as - amongst others - a parent-child interaction was conducted. In the first wave, the infants were 7 months old; in the second wave they were around 14 months when the parent interview was conducted and 17 months at the assessment of parent-child interaction. By design, only half of the sample (random selection) took part in the parent-child interaction during this wave. In the third wave, the children were 26 months old. For the present paper we included 2.272 families who provided data on the children's language skills in the majority language (German) as an early outcome measure at 26 months of age. All families were excluded who reported only another language than the majority language (German) as interaction language at home. Hence, families with more than one interaction language are part of the analyzed sample as long as one of the interaction languages is German (see Table $\mathbf{1}$ for relevant descriptives on sample characteristics of the families and children included in the present study).

\section{Research Instruments}

\section{Home Learning Environment (HLE) - Process Characteristics}

\section{Parental interaction behavior}

Adapted from the NICHD SECCYD study (NICHD Early Child Care Research Network, 1991), a semi-standardized interaction situation between child and mother ${ }^{2}$ was conducted at the families' home during each of the first three assessment waves

\footnotetext{
${ }^{2}$ In most of the families, the mother was the primary caregiver. Hence, only a few fathers took part in the interviews (wave 1: 22, wave 2: 8 , wave 3: 49). These cases were handled as missing for the parent-child interaction to reduce gender
}

(Linberg A. et al., 2019; full sample in wave 1 and 3; half sample in wave 2). Parents were asked to play as naturally as possible with their child and the standardized toy sets. Interactions were videotaped and lasted $5 \mathrm{~min}$ in the first wave and $10 \mathrm{~min}$ in the second as well as in the third wave. Videos were coded afterward by extensively trained raters using qualitatively defined 5-point Likert scales (rating scales from $1=$ not at all characteristic to 5 = very characteristic; adapted from NICHD Early Child Care Research Network, 1991; see Linberg A. et al., 2019 for a description). In the following analyses, we used the scales sensitivity, which focuses on the prompt and adequate reaction of the mother to the signals of the child, and (global) stimulation, which addresses the mother's stimulating behavior (i.e., stimulation of speech and play). Inter-rater agreement was high (wave 1: $90 \%$ and $94 \%$; wave 2: $92 \%$ and $95 \%$; wave 3: $94 \%$ and 93\%; Linberg A. et al., 2019).

\section{Joint picture book reading}

As another indicator of the home learning environment we considered the frequency of joint picture book reading in each of the three waves. Parents were asked on a 5- (first and second wave: ranging from not at all to several times a day) and 8-point-likert scale (third wave: ranging from never to several times a day) how often they or someone else in their home jointly engage in picture book reading with the child.

\section{Child Language}

To assess the children's language skills at the age of two (wave three), the ELFRA-2 (Grimm and Doil, 2006) was administered. The ELFRA-2 is a standardized parental report measure on child language comparable to the internationally well-known "MacArthur-Bates Communicative Development Inventories (Toddler Form) - CDI" (Fenson et al., 1993). It includes a German vocabulary check-list of 260 words and phrases the child uses actively as well as 26 items on the child's syntax and 11 items on morphological aspects, i.e., on the grammatical structures the child uses. The ELFRA is widely used and validated with scores correlating significantly with language test scores (for the validity of the ELFRA see Sachse et al., 2007). We used the vocabulary scale as well as an indicator of child grammar (mean of the standardized scales on syntax and morphology; inter-correlation $r=0,86)$.

\section{Socio-Economic and Educational Characteristics of the Family}

As structural aspects (SES), the following three variables, all measured in wave 1, were considered: first, the education of the mother based on the CASMIN classification (König et al., 1988) was used. The CASMIN classification was recoded into three categories (see Linberg T. et al., 2019 for a similar procedure):

-1 = Low education (no qualification to intermediate secondary education without vocational qualification).

$-2=$ Medium education (intermediate secondary education and higher education).

- 3 = High education (lower and higher tertiary education).

specific variance (Mills-Koonce et al., 2015; see Linberg A. et al., 2019 for a similar approach). 
TABLE 1 | Descriptives.

\begin{tabular}{|c|c|c|c|c|c|c|c|}
\hline & Mean/\% & Median & Standard deviation & Minimum & Maximum & $N$ & Missing \\
\hline \multicolumn{8}{|c|}{ Maternal interaction behavior (5-point scales) ${ }^{1}$} \\
\hline Sensitivity w1 & 4,15 & 4,00 & 0,74 & 1 & 5 & 1.613 & 659 \\
\hline Sensitivity w2 & 3,44 & 3,00 & 0,71 & 1 & 5 & 926 & $1.346^{\mathrm{a}}$ \\
\hline Sensitivity w3 & 3,73 & 4,00 & 0,79 & 1 & 5 & 1.756 & 516 \\
\hline Stimulation w1 & 2,74 & 3,00 & 0,92 & 1 & 5 & 1.613 & 659 \\
\hline Stimulation w2 & 3,16 & 3,00 & 0,77 & 1 & 5 & 926 & $1.346^{\mathrm{a}}$ \\
\hline Stimulation w3 & 3,23 & 3,00 & 0,78 & 1 & 5 & 1.756 & 516 \\
\hline \multicolumn{8}{|l|}{ Frequency of joint picture book reading } \\
\hline w1 (5-point scale) & 3,05 & 3,00 & 1,46 & 1 & 5 & 2.272 & 0 \\
\hline w2 (5-point scale) & 4,05 & 4,00 & 1,06 & 1 & 5 & 2.112 & 160 \\
\hline w3 (8-point scale) & 7,44 & 8,00 & 0,93 & 1 & 8 & 2.272 & 0 \\
\hline \multicolumn{8}{|l|}{ Child language (ELFRA) } \\
\hline Vocabulary & 142,31 & & 65,17 & 0 & 260 & 2.272 & 0 \\
\hline Grammar (standardized) & 0 & & 0,96 & $-2,25$ & 1,82 & 2.058 & 214 \\
\hline \multicolumn{8}{|l|}{ Socio-economic background } \\
\hline Education (low - high) & & 2,00 & 0,65 & 1 & 3 & 2.270 & 2 \\
\hline Income (Euro) & $1.732,76$ & & 895,24 & 185,76 & $1.4285,71$ & 1.925 & 347 \\
\hline HISEl & 63,78 & & 19,37 & 12,01 & 88,96 & 2.224 & 48 \\
\hline \multicolumn{8}{|l|}{ Controls } \\
\hline Age (w3; in days) & 805,79 & 802,00 & 32,066 & 676 & 977 & 2.271 & 1 \\
\hline Sex: girls & $49 \%$ & & & 0 & 1 & 2.272 & 0 \\
\hline Interaction language: German and other & $22 \%$ & & & 0 & 1 & 2.272 & 0 \\
\hline
\end{tabular}

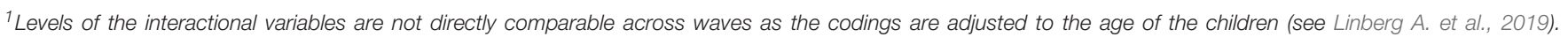

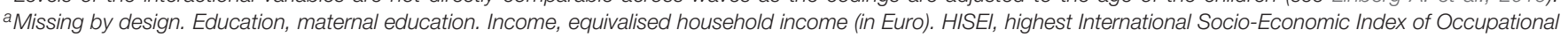
Status. w, wave.

Second, we used the equivalised household income (in Euro) as an SES indicator; hence, the household income was weighted according to the persons living in the household (Organisation for Economic Co-operation and Development [OECD], 2013). In addition, the income was log transformed for structural equation modeling to reduce the skewness of this variable and to reduce a possible bias of increasing income in the high-income groups.

Third, the highest International Socio-Economic Index of Occupational Status (HISEI-08, Ganzeboom et al., 1992) of the family was included. The ISEI codes the prestige of the last occupation of a person. We used the highest ISEI of the parents.

\section{Control Variables}

When analyzing the language skills of the children, we considered the age of the child at wave three as well as the sex of the child as control variables as both are typically associated with early language development. Further, we considered the interaction language in the household (only German vs. children learning another language in addition to German; see also section on "Analytic Strategy" below).

\section{Analytic Strategy}

A two-step approach was used. First, to investigate the effect of the social background variables on HLE process characteristics and, due to missing data, we used mixed-effects linear regression models. The models included social background as a fixed effect as well as a random intercept to account for the correlation between the repeated measures of the process characteristics. The mixed models were conducted in Stata 16. We used multiple imputation by chained equations (MICE) to handle missing values. Note that missing values were partially due to the design with a random selection of half of the sample conducting the interaction situation (see Table $\mathbf{1}$ for the amount of missing data for each variable). The imputation model included all three HLE process characteristics from each wave as well as education, equivalised household income, HISEI, and the different language measures. Further, to improve the imputation model, we added family status, psychological stress, and age of the mother as well as child's negative affectivity to the imputation model. We created $m=50$ imputed data sets using Stata 16. For the mixed models, all three assessments of HLE process characteristics were standardized as well as the three social background variables which were then averaged to create a combined SES measure. Three separate mixed models for each of the three HLE process characteristics were calculated.

In a second step, structural equation modeling (SEM) was applied to investigate the effect of the more distal (SES) measure and the more proximal process characteristics of HLE (maternal interaction behavior, joint book reading) on child vocabulary and child grammar at the age of two in separate models. The socioeconomic status (SES) of the family was modeled as a latent variable (see Weinert and Ebert, 2013 for a similar approach). All other variables were included as manifest variables. SEMs were calculated using Mplus 8.2 (Muthén and Muthén, 2017) and Full Information Maximum Likelihood Estimation (FIML) was used to handle missing data in the predictors. With respect to 
control variables, we considered children's age at wave three, the sex of the child, and the interaction language in the household (as these are typically associated with early language development) and regressed them on child language. The models allowed correlations between the HLE process variables and children's sex and interaction language in the household. We started by analyzing the predictive effects for each wave separately and then combined all waves into one joint model to analyze the stabilities and the separate and joint impact of the predictors on child language across the first 2 years of the children's lives.

\section{RESULTS}

Table 1 shows the descriptive characteristics of the analyzed variables across waves. Further, for all variables the amount of missing values is listed.

Turning to the correlations between the variables of interest, we found only low associations between the measures of maternal sensitivity over the three waves and low to moderate stabilities for mother's stimulating behavior as well as the frequency of joint picture book reading (see Table 2 for all $r$ 's). Correlations between the family's SES and the three HLE process characteristics as well as with the two measures of child language were low but significant. Further, the correlations between the two language measures and the three HLE process characteristics were mostly low (see Table 2).

\section{SES-Related Disparities in HLE Process Measures: Mixed-Effects Regression Models}

Table 3 shows the results of the three separate mixed-effects regression models on SES-related disparities in mother's sensitive interaction behavior, mother's stimulating behavior, and the frequency of joint book reading. Using a combined SES measure of maternal education, HISEI, and household income, SES was significantly related to all three HLE process characteristics; these effects range between 0,12 and 0,25. For maternal sensitivity, the SES effect did not change significantly across waves. Yet, as far as mother's stimulating behavior is concerned, the effect of SES changed across waves. For joint picture book reading, again a changing effect across waves was found, particularly in wave three compared to the first assessment wave.

\section{Predicting Child Language at Age Two: Structural Equation Modeling}

Using structural equation modeling we analyzed the effects of structural (SES) and the more proximal HLE process characteristics of the home learning environment on the children's vocabulary and grammar at age two, first separately for each wave and then conjointly for all three waves.

\section{Disparities in Early Vocabulary: Effects of the Families' SES and HLE Process Characteristics}

All three separate models as well as the integrated model demonstrated sufficient fit to the data (see Figures 1, 2). In all four SEMs, the latent construct SES significantly predicted the vocabulary of the children at age two.

In the separate models, families' SES showed a direct path to all three HLE characteristics. Further, mother's sensitivity and the frequency of joint picture book reading at first, second, and third wave predicted child vocabulary at age two. Hence, children with comparatively more sensitive mothers, and parents who often engaged in joint picture book reading showed a more advanced vocabulary compared to children with less sensitive mothers and parents who reported less joint picture book reading. Further, mother's stimulating behavior in wave 2 and 3 predicted the children's vocabulary at 2 years of age but not in wave 1 when children were 7 months of age. Together, SES and the HLE process characteristics explained about 21\% (wave 1), 23\% (wave 2 ), and $22 \%$ (wave 3 ) of the variance in children's vocabulary.

The integrated model including the HLE process predictors from all three assessment waves substantiates and extends the results of the separate models. First, families' SES proved to be directly associated with mother's sensitivity and stimulation behavior as well as with the frequency of joint picture book reading at each wave, even when considering all waves at the same time. Furthermore, we found a direct effect of SES on children's vocabulary at age two despite considering the three process characteristics across waves in the model. Second, differences in the frequency of joint picture book reading were moderately stable across waves with each wave showing a direct effect on child vocabulary at age two. Third, the sensitivity of the mother (i.e., her prompt and responsive behavior in motherchild interaction) in wave 2 and 3 also predicted child vocabulary positively while maternal sensitivity in the first year of life did not. Stability of maternal sensitivity in mother-child interactions across waves was rather low. Fourth, the stimulation behavior of the mother in the first wave was negatively associated with child vocabulary while it was increasingly positively associated in wave 2 and 3 with a moderate stability across waves.

Overall, SES and all predictors in the full model explained only slightly more variance in children's vocabulary $(25 \%)$ than the separate models.

\section{Disparities in Early Child Grammar: Effects of the Families' SES and HLE Process Characteristics}

Focusing on child grammar, the results were similar to those reported for early vocabulary. All four models showed sufficient fit to the data (see Figures 3, 4). In all four models, the latent SES construct directly predicted child grammar at the age of 2 years in each of the models.

Further, in the three separate models, the latent SES construct also predicted each of the HLE process characteristics and, in each wave, the three process characteristics were positively associated with the grammatical skills of the children with the exception of maternal stimulation behavior in wave 1. SES and the process characteristics explained 17\% (wave 1) and 19\% (wave 2 and 3) of the variance in the grammatical skills of the children.

The integrated model including SES and the HLE process indicators from all three waves as predictors also shows a comparable picture for early child grammar and vocabulary. First, the latent SES construct predicted each of the HLE 
TABLE 2 | Correlations.

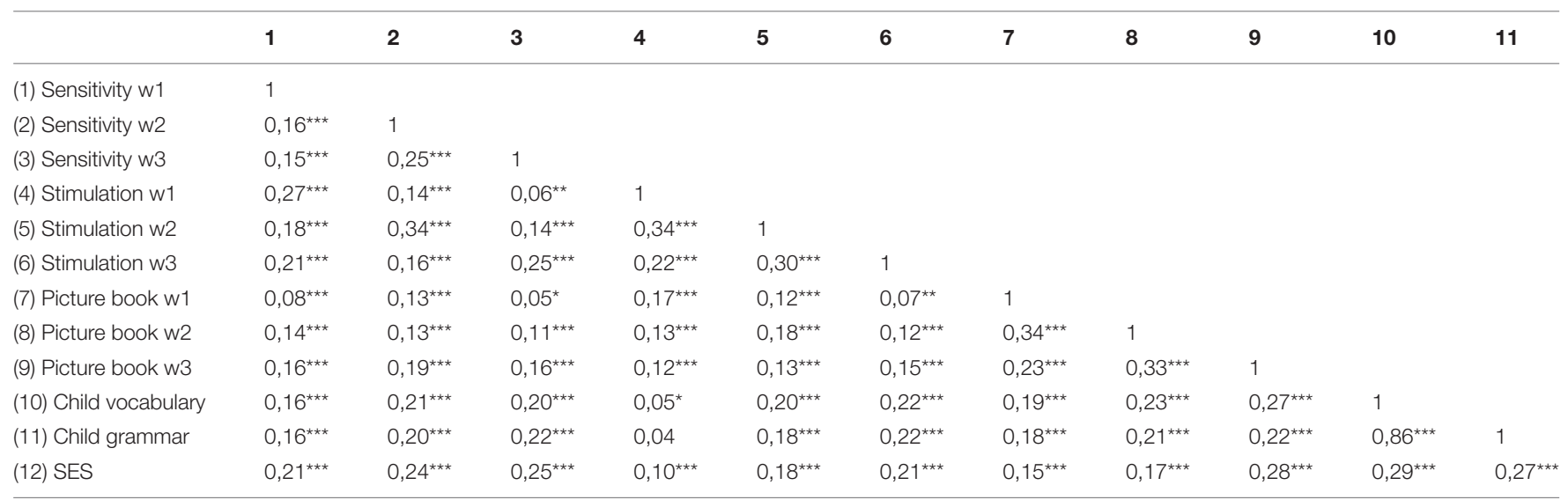

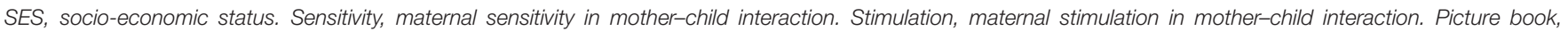
frequency of joint picture book reading. $w$, wave. ${ }^{*} p<0,05$, ${ }^{* *} p<0,01$, ${ }^{* * *} p<0,001$.

TABLE 3 | Coefficients for the three mixed-effects linear regression models.

\begin{tabular}{|c|c|c|c|}
\hline & Sensitivity & Stimulation & Picture book \\
\hline SES & $0,25^{\star \star \star}$ & $0,12^{\star \star \star}$ & $0,18^{\star \star \star}$ \\
\hline \multicolumn{4}{|c|}{ Wave (ref wave1) } \\
\hline Wave 2 & $-0,03$ & $-0,01$ & $-0,01$ \\
\hline Wave 3 & $-0,01$ & $-0,002$ & 0 \\
\hline \multicolumn{4}{|c|}{ SES $\times$ wave (ref wave 1 ) } \\
\hline SES $\times$ wave 2 & 0,05 & $0,11^{*}$ & 0,03 \\
\hline SES $\times$ wave 3 & 0,05 & $0,12^{\star \star}$ & $0,16^{\star \star \star}$ \\
\hline Intercept & $-0,01$ & $-0,01$ & 0 \\
\hline \multicolumn{4}{|c|}{ Random-effects parameters } \\
\hline Sd (intercept) & 0,36 & 0,51 & 0,51 \\
\hline$S d$ (residual) & 0,91 & 0,85 & 0,83 \\
\hline
\end{tabular}

Coefficients presented in SD units. SES, socio-economic status. Sensitivity, maternal sensitivity in mother-child interaction. Stimulation, maternal stimulation in mother-child interaction. Picture book, frequency of joint picture book reading. Ref, reference group. ${ }^{*} p<0,05,{ }^{* *} p<0,01,{ }^{* *} p<0,001$.

process characteristics at each wave even when considering all waves simultaneously as well as the grammar skills of the children at the age of two. Second, for each wave, the model shows a direct effect of the frequency of joint picture book reading on the grammatical skills of the children at age two. Third, the stimulation behavior of the mother in the first wave was negatively associated with early grammar outcomes, while later on (wave 2 and 3), the grammar skills of children were increasingly positively associated with the stimulating behavior of the mothers. Fourth, concerning mother's sensitivity in motherchild interaction, we did not find direct effects of the early waves; there was only a positive effect of the third wave on the children's grammar skills. Overall, SES and HLE process predictors from three waves explained $22 \%$ of the variance of the children's grammar skills at age two.

Table 4 presents an overview of the results concerning early vocabulary and grammar outcomes and the predictive impact of the various predictors across waves highlighting the similarity of the pattern of results for both language components.

\section{DISCUSSION}

In line with theoretical assumptions as outlined in educational frameworks of the home learning environment (e.g., Kluczniok et al., 2013) as well as empirical results, SES-related disparities in language development have been suggested to be mainly transferred by differences in process characteristics of the home learning environment which are themselves influenced by the families' socio-economic status. There is no doubt that the family is the most important learning environment in the first years for most children. Yet so far, only a few studies focused on the dynamics of parenting behavior across the first years (Lugo-Gil and Tamis-LeMonda, 2008; Rodriguez and Tamis-LeMonda, 2011; Vallotton et al., 2017) and their potentially changing effects on the language development of children. Hence, the aim of the present study was to take a longitudinal perspective on three process characteristics of the home learning environment and their association with SES as well as with two aspects of children's language development, namely vocabulary and grammar. These two subdomains of language development have been suggested to be differentially related to differences in the home learning environment (Vasilyeva and Waterfall, 2011).

In particular, the present paper addressed the following main research issues and questions: First, extending the findings on SES-related disparities in the three HLE process characteristics across the first 2 years of children's lives as well as their potentially changing associations across these 2 years. Second, investigating the predictive effects of socio-economic family background and the longitudinally assessed HLE process characteristics on vocabulary size and on early child grammar. These analyses also addressed the question of whether the relation between SES and HLE process characteristics as well as their predictive association with child language differ across assessment waves. Drawing on attachment theory, on Vygotsky's concepts of social learning in the zone of proximal development (Vygotsky, 1978), and on literacy research, we focused on (a) maternal sensitivity (sensitive responsiveness) to child signals, (b) mother's cognitively stimulating behavior, and (c) the frequency of joint 


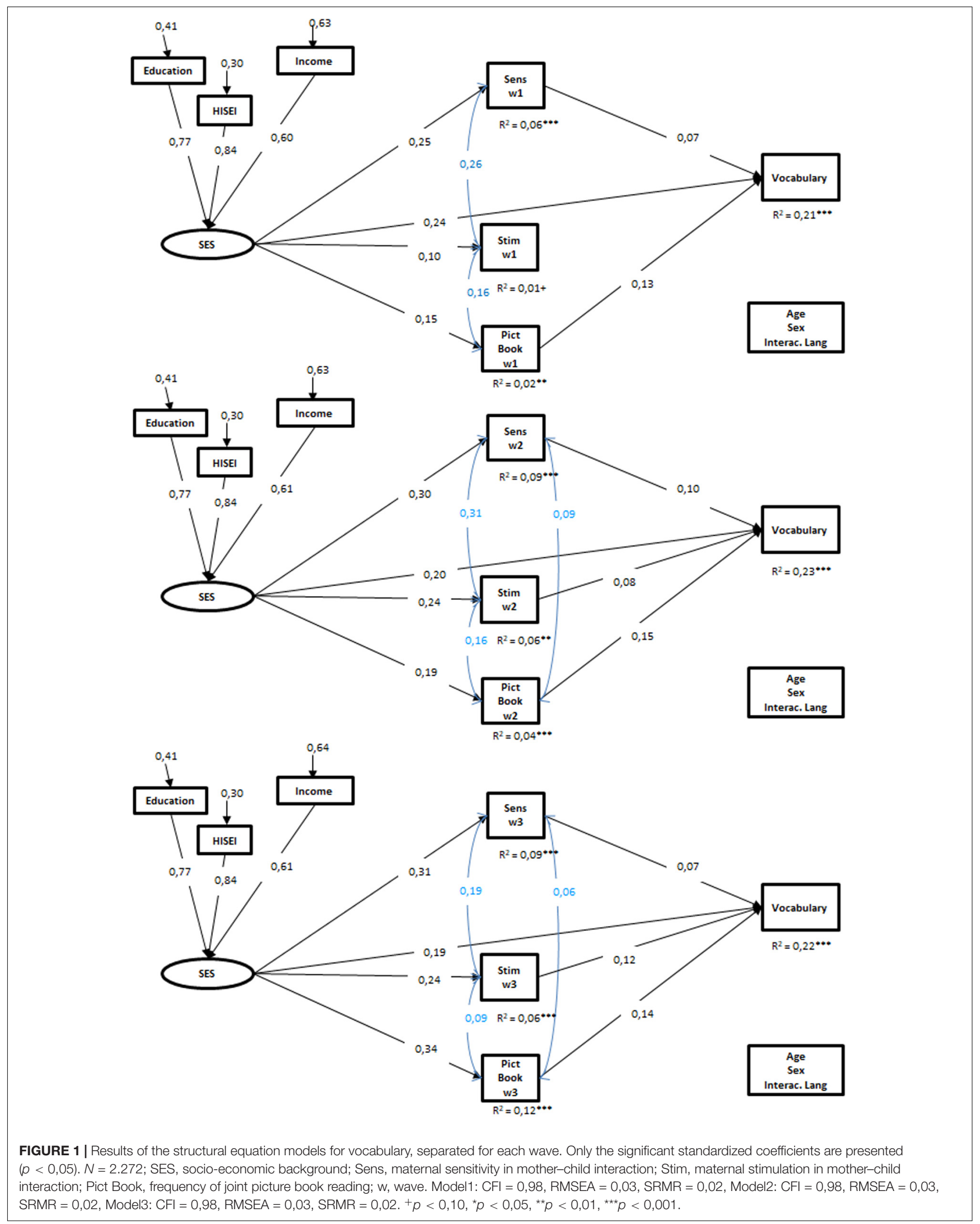




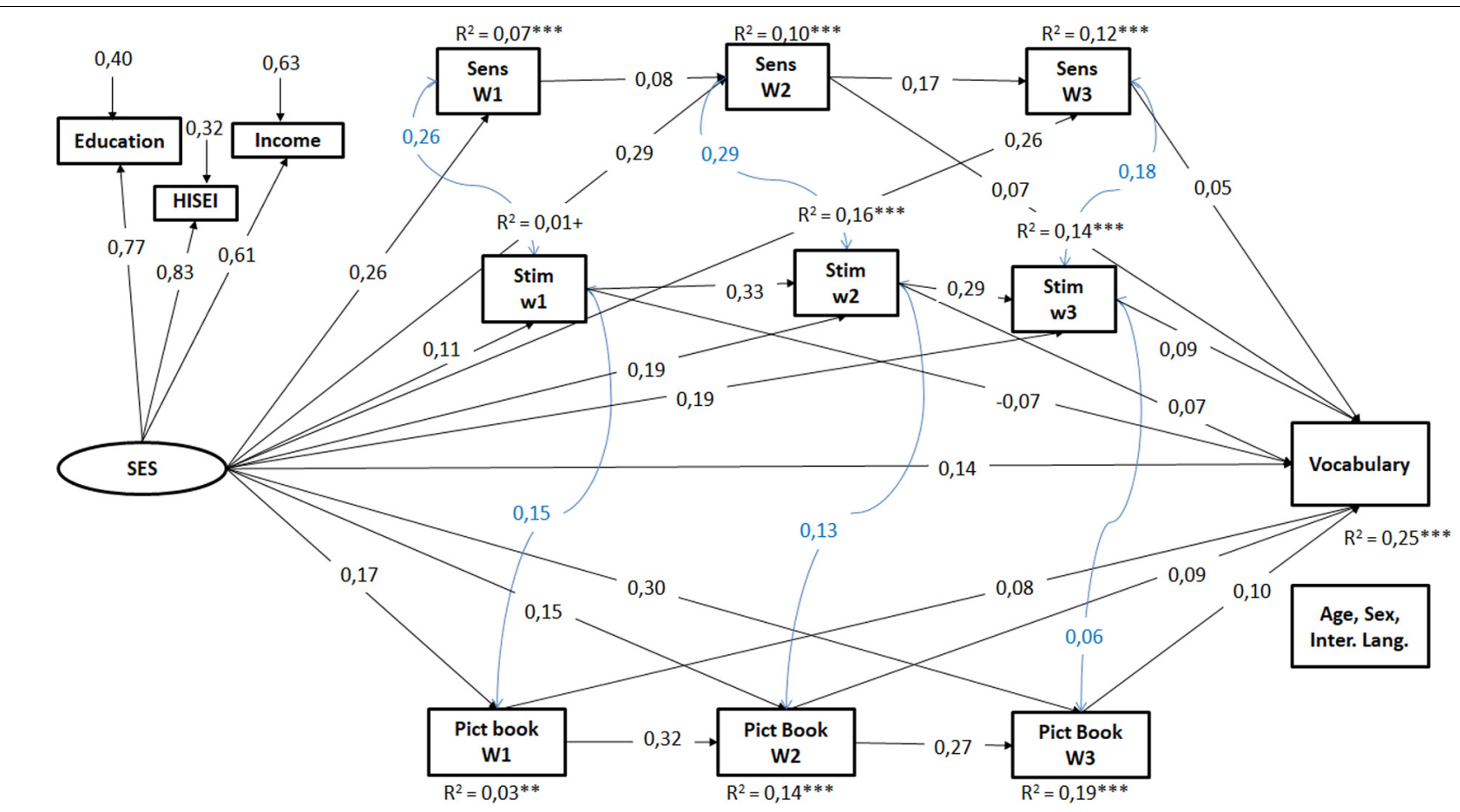

FIGURE 2 | Results of the structural equation model for vocabulary, model above all three waves. Only the significant standardized coefficients are presented $(p<0,05)$. SES, socio-economic background; Sens, maternal sensitivity in mother-child interaction; Stim, maternal stimulation in mother-child interaction; Pict Book, frequency of joint picture book reading; $w$, wave. $N=2.272$; $\mathrm{CFI}=0,96, \operatorname{RMSEA}=0,03, \mathrm{SRMR}=0,04 .{ }^{+} p<0,10,{ }^{*} p<0,05,{ }^{* *} p<0,01,{ }^{* \star *} p<0,001$.

TABLE 4 | Relation of SES, HLE process characteristics, and child language - direct effects within the integrated models including all waves.

\begin{tabular}{|c|c|c|c|c|c|c|c|c|}
\hline & Vocabulary & Vocabulary & Vocabulary & Vocabulary & Grammar & Grammar & Grammar & Grammar \\
\hline Sensitivity w1 & $0,07^{\star \star}$ & & & 0,04 & $0,09^{\star \star}$ & & & $0,05+$ \\
\hline Sensitivity w3 & & & $0,07^{\star \star}$ & $0,05^{\star}$ & & & $0,09^{\star \star \star}$ & $0,08^{\star *}$ \\
\hline Stimulation w1 & $-0,02$ & & & $-0,07^{\star *}$ & $-0,04+$ & & & $-0,10^{\star \star}$ \\
\hline Stimulation w2 & & $0,08^{\star}$ & & $0,07^{\star}$ & & $0,07^{\star}$ & & $0,08^{*}$ \\
\hline Picture book w1 & $0,13^{\star \star \star}$ & & & $0,08^{\star \star \star}$ & $0,12^{\star \star \star}$ & & & $0,08^{\star \star \star}$ \\
\hline Picture book w2 & & $0,15^{\star \star \star}$ & & $0,09^{\star \star \star}$ & & $0,13^{\star \star \star}$ & & $0,08^{* \star *}$ \\
\hline Picture book w3 & & & $0,14^{\star \star *}$ & $0,10^{\star \star \star}$ & & & $0,10^{\star \star *}$ & $0,06^{*}$ \\
\hline Age & $0,18^{\star \star \star}$ & $0,19^{\star \star \star}$ & $0,18^{\star \star \star}$ & $0,19^{\star \star \star}$ & $0,23^{\star \star \star}$ & $0,23^{\star \star \star}$ & $0,23^{\star \star \star}$ & $0,23^{\star \star \star}$ \\
\hline Sex & $0,14^{\star \star \star}$ & $0,13^{\star \star \star}$ & $0,13^{\star \star \star}$ & $0,13^{\star \star \star}$ & $0,14^{\star \star \star}$ & $0,13^{\star \star \star}$ & $0,13^{\star \star \star}$ & $0,13^{\star \star \star}$ \\
\hline Interaction language & $-0,18^{\star \star \star}$ & $-0,17^{\star \star \star}$ & $-0,16^{\star \star \star}$ & $-0,16^{\star \star \star}$ & $-0,12^{\star \star \star}$ & $-0,12^{\star \star \star}$ & $-0,11^{\star \star \star}$ & $-0,11^{\star \star \star}$ \\
\hline
\end{tabular}

Coefficients presented in SD units. SES, socio-economic background; Sensitivity, maternal sensitivity in mother-child interaction. Stimulation, maternal stimulation in mother-child interaction. Picture book, frequency of joint picture book reading. W, wave. Ref, reference group. ${ }^{+} p<0,10,{ }^{*} p<0,05,{ }^{* *} p<0,01,{ }^{* * *} p<0,001$.

picture book reading which all have been suggested to foster child development from early on.

Our results show that the families' socio-economic background is associated with all three HLE process characteristics - maternal responsive sensitivity and stimulating interaction behavior in mother-child interaction as well as the frequency of joint picture book reading - at each of the three assessment waves conducted during the first 2 years of the children's life. Thus, mothers with lower SES interacted with their child less sensitively and in ways that were less stimulating than mothers with a higher SES. And parents with lower SES also engaged less often in joint picture book reading with their child. Hence, we replicated previous research results which also showed an association between the socio-economic status of the family and different HLE process characteristics (e.g., NICHD Early Child Care Research Network, 1999; Bradley et al., 2001; 


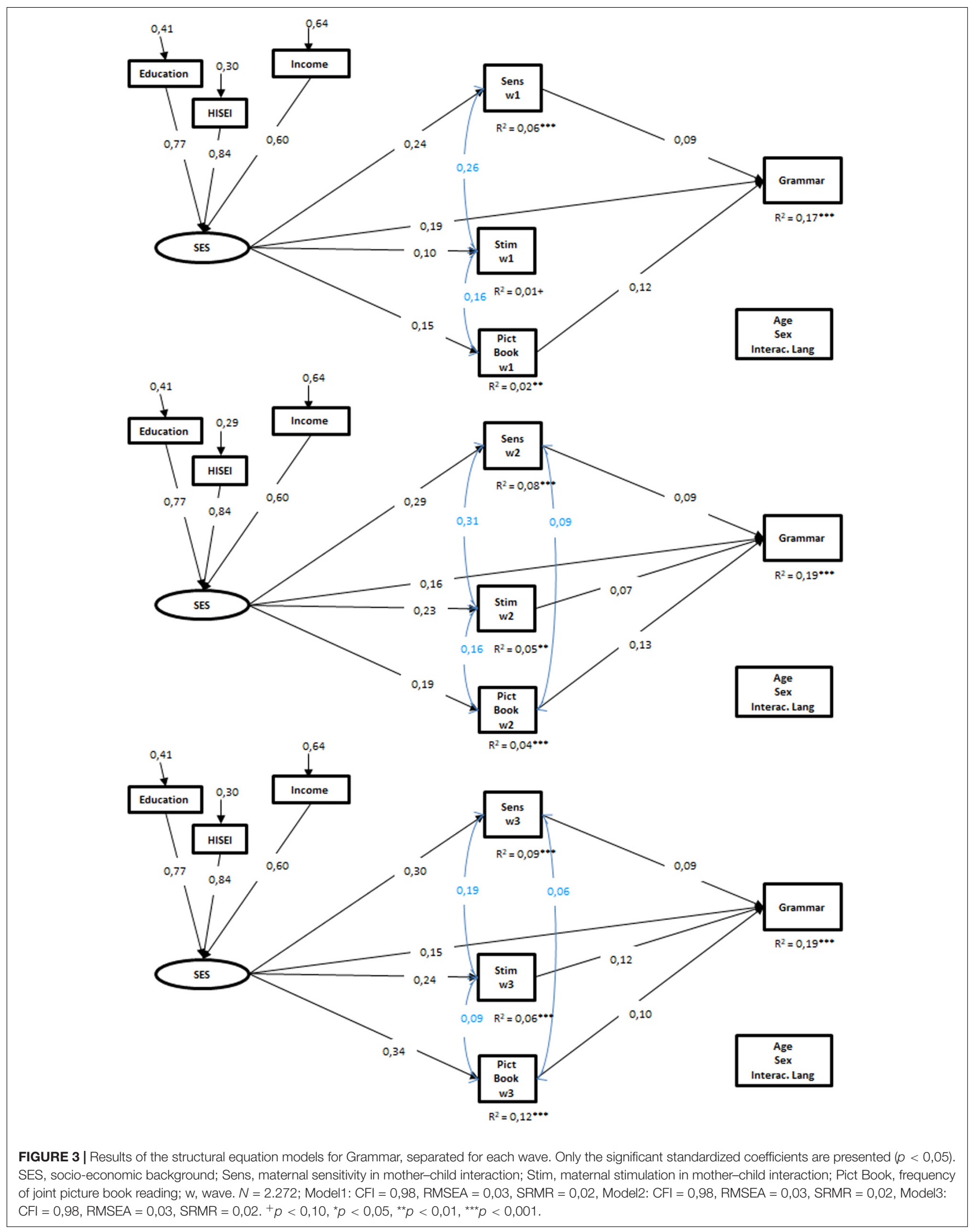




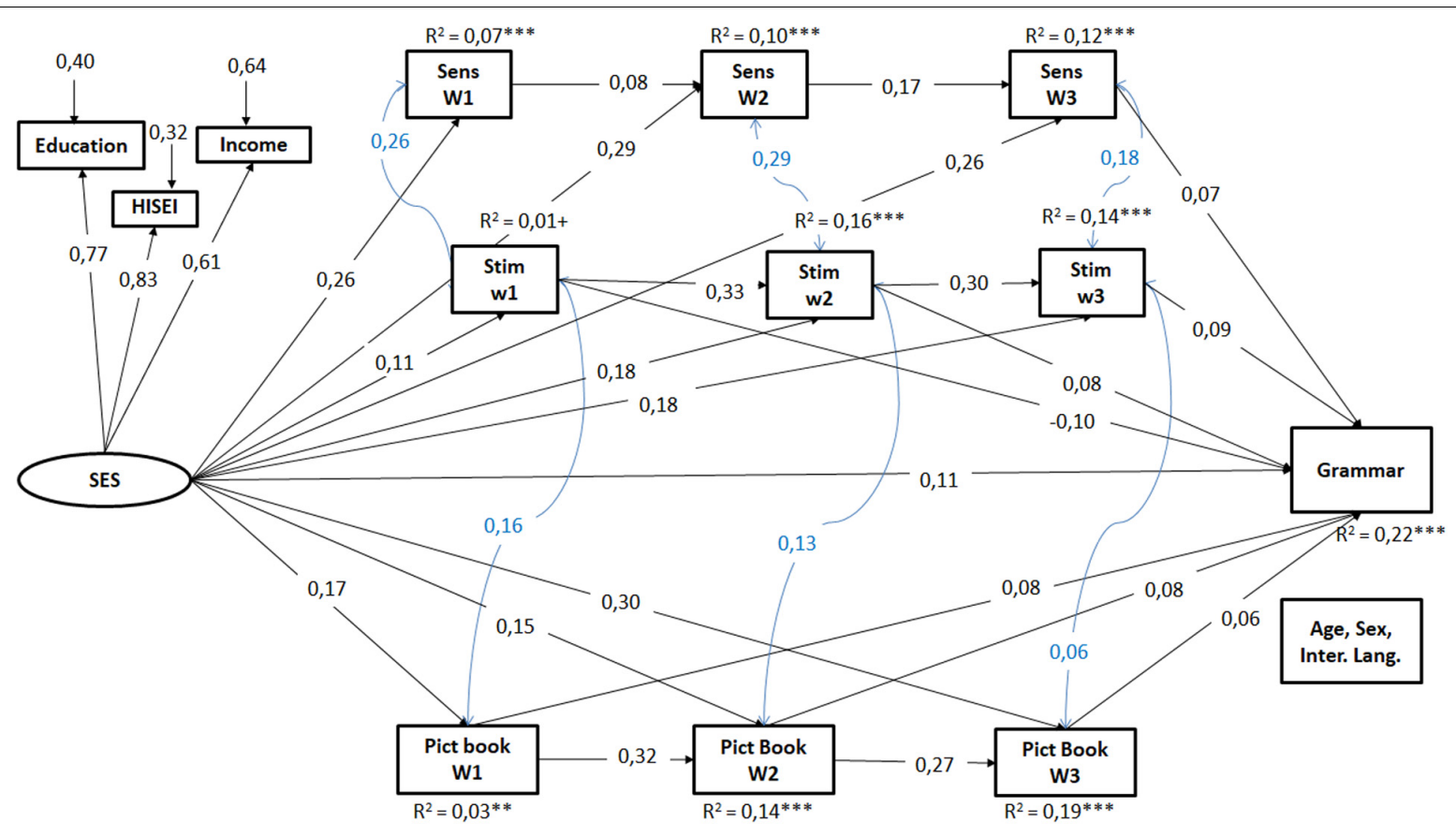

FIGURE 4 | Results of the structural equation model for grammar, model above all three waves. Only the significant standardized coefficients were presented $(p<0,05)$. SES, socio-economic background; Sens, maternal sensitivity in mother-child interaction; Stim, maternal stimulation in mother-child interaction; Pict Book, frequency of joint picture book reading; w, wave. $N=2.272 ; \mathrm{CFI}=0,96, \mathrm{RMSEA}=0,03, \mathrm{SRMR}=0,03 .{ }^{+} p<0,10,{ }^{*} p<0,05,{ }^{* \star} p<0,01,{ }^{* *} p<0,001$.

Farrant and Zubrick, 2012; Lehrl et al., 2012). Using also the Newborn Cohort Study of the NEPS, Attig and Weinert (2018) already documented an association between the quality of maternal interaction behavior in the second year of life and the education level of the mother. Further, not only maternal interaction behavior has been shown to be related to the families' SES but also - for example - joint activities of the parents with their child such as the frequency and quality of joint book reading (Niklas and Schneider, 2010; Farrant and Zubrick, 2012; Lehrl et al., 2012). The present study extends these results and shows their associations across time (by including three measurement points) and indicators, e.g., by using a combined measure of SES and by differentiating between maternal sensitivity and stimulation behavior which are often combined into a global measure of the quality of mother's interaction behavior (e.g., Weinert et al., 2017). Even more importantly, we investigated the effects of the families' SES on the three HLE process measures longitudinally and found that the SES effect on maternal sensitivity stayed stable across the first 2 years, whereas the SES effect on mother's stimulation behavior as well as on the frequency of joint picture book reading changed across the waves. Thus, the associations between SES and the latter two process measures seem to get stronger across the first 2 years of the children's lives hinting to the importance of early intervention.

Turning to the second research question, our results showed that across the three measurement points nearly all process characteristics of the HLE predicted the children's vocabulary and grammar skills at the age of two. Yet, the explained variation in the joined model including all measurement points is not really higher than in the separate models. Again, the results replicate previous research which also showed an association between different process characteristics of the home learning environment and the children's language development (Bus et al., 1995; Tamis-LeMonda et al., 1996, 1998; NICHD Early Child Care Research Network, 1998; Bromley, 2009; Nozadi et al., 2013). For example, Vallotton et al. (2017) found that the importance of early maternal sensitivity and stimulating interaction behavior for later child vocabulary changes across the first 3 years of life. Whereas at the age of 14 months, maternal sensitivity seems to have a greater impact on vocabulary, the effect changed until the age of 36 months with maternal stimulation having a greater effect on vocabulary compared to sensitivity. In the present study, we also see changes across the assessment waves with differences in maternal stimulation behavior at the age of 17 and 26 months predicting the language skills of the children, whereas the effect at the age of 7 months was not significant (in the separate models) or even negative (in the global model). In contrast, maternal sensitivity in mother-child interaction predicted the language skills of the children in the separate models in each wave, while in the global model - considering all waves simultaneously a significant direct effect only appeared for wave 2 and 3 for vocabulary and wave 3 for grammar, but not for the earlier wave(s). Yet, when comparing the effects of maternal sensitivity and stimulating behavior across waves, in line with the results of Vallotton et al. (2017), in the first waves it is particularly maternal sensitivity that seems to foster children's language development while mother's stimulation behavior seems 
to become comparatively and increasingly more important in the later waves.

However, it is important to note that parental sensitivity and stimulation behavior is often defined and coded in different ways and may thus cover partially different concepts across studies. For example, in the present paper we defined maternal sensitivity as a prompt, sensitive, and adequate responsivity to the child's behavior and signals in motherchild interaction and mother's stimulation behavior as going beyond the child's actual level of action and development thus fostering child development by providing the child with new aspects, materials, and suggestions for exploration (see Linberg A. et al., 2019). Other conceptualizations focus on domain-specific maternal parenting behavior, differentiating, for example, socio-emotional supportive parenting behavior (which includes responsivity, sensitivity, and positive regard with a particular focus on socio-emotional signals of the child) and cognitive-verbally stimulating interaction behavior (see Linberg, 2018; Linberg et al., 2020). Further, differentiating sensitive and prompt maternal responsivity from mother's scaffolding and child-adapted stimulating behavior as well as differentiating socio-emotional supportive behavior from cognitive-verbally stimulating behavior may be difficult when using global measures; more detailed coding may help to address these differentiations and their (differential) impact on child behavior and development more in depth (Linberg, 2018). Yet as our measures of maternal sensitivity and stimulating behavior are not highly correlated and as their relative impact seems to change over time, the pattern of results seems to support the assumption that they cover different process characteristics, with sensitivity being particularly relevant in the very early phases of child development and a growing impact of stimulating behavior over time. When interpreting these results, it should also be considered that the sensitivity and the stimulation measure at the age of 26 months and the children's language skills in the present study were measured at the same time point.

Overall, variation in parent behavior (see for example for maternal responsiveness, Bornstein et al., 2008) seems effective as parents adapt their behavior to the developmental status of their child (Rodriguez and Tamis-LeMonda, 2011). As Bowlby (1988) suggested, a prompt, sensitive, and adequate response to the child's signals may help the child to gain a feeling of competence and being valued. Further, this might be particularly relevant in the very early phases of development as the mother focuses on the child's needs, his/her attentional focus and interests, and this may help the child to learn to regulate his/her behavior and to understand the very first words and communicative function of language based on a common ground of the interactional exchange. Later on, adaptive stimulation that goes beyond the child's actual action might become more important as the child starts to follow these hints, offers, and suggestions more actively (Baldwin, 1995).

Not surprisingly, joint picture book reading in each wave predicted the later language skills of the children at the age of 2 years. Thus, our results extend the findings of Bromley
(2009) who showed that picture book reading at the age of 10 months was associated with the language skills of children at the age of 34 months. Our data add to this finding that already at the age of 7 months picture book reading is associated with later language development and that the effect still remains even when considering later joint picture book reading as well as other characteristics of the HLE within the same model. The results are in line with research showing a relation of joint reading with language development not only at this young age (e.g., Bromley, 2009) but also for preschoolers (Bus et al., 1995; Sénéchal et al., 2008). This latter research also highlights the importance of the quality of joint picture book reading as well as specific differential associations with different language measures such as vocabulary, grammar, or early literacy (Lehrl et al., 2012; Anderka, 2018). Unfortunately, the NEPS data does not include measures of the quality of joint picture book reading and related questions should be investigated in further studies for even younger children as the specific impact of interactional characteristics during joint picture book reading, i.e., which characteristics are particularly important in promoting language development, seem to change with development.

Besides the HLE process characteristics, the families' socioeconomic status also proved to be related to child vocabulary and grammar skills at age two. This converges with previous findings from the Newborn Cohort Study of the NEPS which showed an effect of education on the vocabulary (Linberg et al., 2020) and on a language measure which takes vocabulary and grammar into account (Attig and Weinert, 2019). Further, the results are in line with other studies which also showed an association between language and the families' socio-economic background at the age of 2 years (Fernald et al., 2013; Law et al., 2019). Weinert and Ebert (2013) found that the social background measured with a combined SES construct accounted for $15,6 \%$ of the differences in the language skills of 4-year-old children. An increase of SES-related disparities over time was shown in studies focusing on even older children (Linberg and Wenz, 2017; Volodina et al., 2020). A mediation of the SES effect on child language through the process characteristics was not directly investigated in the present paper. Yet, although the structural equation models considered all process characteristics and, in the joint models all process characteristics across the three waves, together with the effects of SES on the process measures, there was still a direct effect from the SES to both measures of child language. This result hints to the assumption that the parenting behavior considered did not (fully) mediate and thus cannot (fully) explain the SES effect on the children's language skills. Linberg et al. (2020) showed with the same data set from the NEPS that early language-stimulating interaction behavior only mediated $9 \%$ of the effect of maternal education on vocabulary development in the second year of life. It is up to future research to investigate which (other) mechanisms could explain the effect of SES on early child language. Further, even in the two global models that included HLE characteristics of three measurement points as well as family SES and some control variables, the models only explained $25 \%$ and $22 \%$ of 
the variation of the children's language skills. Hence, other child characteristics as well as facets of the home learning environment, for example more domain-specific aspects such as maternal guiding language (Shruti et al., 2018), may also influence language development.

Adding to previous research, the present study focused not only on one aspect of language development but took vocabulary size as well as grammar skills of the children into account. It has been assumed that in the early stages grammar is less influenced by the learning environments compared to vocabulary (Anderka, 2018 for a brief overview; see also the results of Huttenlocher et al., 2010). In line with social-cognitive theories of language acquisition (Tomasello, 2003; Weinert and Grimm, 2018) and extending the results of Weinert and Ebert (2013) to even younger children, the present results showed that nearly all process characteristics as well as the families' socio-economic background predicted vocabulary size and grammar skills at the age of two to about the same extent. Hence, both aspects of language development are influenced by the home learning environment in the first years of life. Note, however, that our grammar indicator was rather superficial as it drew on a parent report measure (see e.g., Newport et al., 1977 for more sophisticated measures). Further, we used rather unspecific characteristics of the home learning environment. In fact, drawing on other studies, we suspect different facets of the home learning environment to affect vocabulary and grammar development differently at least beyond age three, as it has been shown that these subdomains of language development are differentially related to different process characteristics of the home learning environment (Lehrl et al., 2012; Anderka, 2018) which also explain their relation to families' SES (Anderka, 2018).

\section{Strength and Limitations}

First of all, using data from a large longitudinal cohort study is one of the strengths of the current study. Second, different process characteristics including observational measures as well as a comprehensive indicator of the families' socio-economic background were considered in joint models. Third, two subdomains of language development, namely vocabulary and grammar, were analyzed allowing to differentiate the effects for these two aspects of language development.

Besides several strengths of the study, the study also has important limitations. First, as a language measure we used a standardized parental report measure (ELFRA; Grimm and Doil, 2006). Of course, a potential bias, related to the social status of the parents, in answering the questionnaire can't be ruled out, and hence a misjudgment of the results should be considered. However, the ELFRA is a well-established instrument which has been shown to significantly correlate with language test scores (Sachse et al., 2007). Further, it is not unusual to work with such checklists (see for example Nozadi et al., 2013; Morgan et al., 2015; Law et al., 2019) especially in large panel studies because testing children at the age of two by standardized tests appears to be difficult in largescale assessments (Weinert et al., 2016). Further, our results concerning the association between SES and early language skills are in line with previous research (e.g., Fernald et al., 2013; Law et al., 2019) supporting their validity. Fortunately, at a later age, the NEPS applied a standardized language test (Peabody Picture Vocabulary test, Dunn and Dunn, 2007; Lenhard et al., 2015) so that for older children a potential bias can be excluded. Second, due to the split design in the second wave which randomly assigned only half of the sample to take part in the observational assessments, the study had to handle a high amount of missing data. Although the dropouts mainly resulted from the split design, this should be considered when interpreting the results. Further research should underpin the current results to make the interpretation and conclusions stronger. As a third limitation, the measurement of the three HLE process characteristics should be mentioned. Thus, the interactional measures were derived from a 5 (wave 1 ) or $10 \mathrm{~min}$ (wave 2 and 3 ) interaction situation with standardized material. Although control studies showed some stability of maternal interaction behavior, this situation is rather short and thus may underestimate differences between mothers' behavior. In addition, the measures of all three HLE process characteristics considered are based on a single rating scale each. In fact, when aggregating across scales, the stabilities of the quality of maternal interaction behavior is much higher (see e.g., Freund et al., 2019). Without doubt, to use more scales or more differentiated codings would be desirable to make the constructs and also the results more robust. Further, although the paper addresses three different process characteristics of the home learning environment, only positive parenting and interaction behavior that was not domain-specific has been considered. Further research may not only differentiate between sensitivity and stimulation behavior but may also include, for example, domain-specific language stimulation behavior (see Linberg et al., 2020 for an example).

\section{CONCLUSION}

Taking the families' socio-economic status as well as various process characteristics of the home learning environment, such as different characteristics of maternal interaction behavior and the frequency of joint picture book reading across the first 2 years into account, will help to better understand what happens in families in the first 2 years and what precisely impacts the language development of children. First, as assumed, significant associations were found between the socio-economic family background and all three HLE process characteristics, with two of them showing a change in their association across the waves. Second, our results clearly show that not just one aspect of parent behavior is associated with the children's language development, but all three aspects are related to child language with at least partially changing effects across early child development. Further, the direct effect of the socioeconomic background remained even after including the HLE process characteristics from all three measurement points. In addition, across waves the various aspects did not just 
exert influence via the same measure at a later time-point but most measures also asserted a direct effect from earlier waves. Interestingly, the present results showed that in the first 2 years, and with respect to the rather domain-general aspects of the HLE characteristics considered, a comparable effect on vocabulary and grammar was demonstrated. This is in contrast to research with older children that showed different facets of the home learning environment to be differentially related to vocabulary and grammar acquisition (Lehrl et al., 2012; Anderka, 2018).

\section{DATA AVAILABILITY STATEMENT}

The present article analyzed data of the National Educational Panel Study in Germany. The anonymized data is available for the scientific community at http://www.neps-data.de.

\section{ETHICS STATEMENT}

The NEPS study is conducted under the supervision of the German Federal Commissioner for Data Protection and Freedom of Information (BfDI) and in coordination with the German Standing Conference of the Ministers of Education and Cultural Affairs (KMK) and - in the case of surveys at schools the Educational Ministries of the respective Federal States. All data collection procedures, instruments and documents were checked by the data protection unit of the Leibniz Institute for Educational Trajectories (LIfBi). The necessary steps are taken to protect participants' confidentiality according to national and international regulations of data security. Participation in the NEPS study is voluntary and based on the informed consent of participants. This consent to participate in the NEPS study can be revoked at any time. All parent of the Newborn Cohort of the NEPS give their agreement for participation and answering

\section{REFERENCES}

Ainsworth, M., Bell, S., and Stayton, D. (1974). "Infant-mother attachment and social development: socialization as a product of reciprocal responsiveness to signals," in The Integration of a Child Into a Social World, ed. M. Richards (Cambridge: Cambridge University Press), 99-135.

Ainsworth, M. D. S., and Bell, S. M. (1970). Attachment, exploration, and separation: illustrated by the behavior of one-year-olds in a strange situation. Child. Dev. 41, 49-67. doi: 10.2307/112 7388

Anderka, A. (2018). Elterliches Sprachangebot und vorschulischer Spracherwerb. Eine empirische Analyse zu Zusammenhängen und sozialen Disparitäten. Münster: Waxmann.

Anders, Y., Roßbach, H.-G., Weinert, S., Ebert, S., Kuger, S., Lehrl, S., et al. (2012). Home and preschool learning environments and their relations to the development of early numeracy skills. Early Child Res. Q. 27, 231-244. doi: 10.1016/j.ecresq.2011.08.003

Arriaga, R. I., Fenson, L., Cronan, T., and Pethick, S. J. (1998). Scores on the MacArthur Communicative Development Inventory of children from lowand middle-income families. Appl. Psycholinguist. 19, 209-223. doi: 10.1017/ S0142716400010043

Attig, M., and Weinert, S. (2018). Soziale Disparitäten im Kontext von MutterKind-Interaktionen und frühen Entwicklungsmaßen von Kindern. Frühe Bildung. 7, 22-31. doi: 10.1026/2191-9186/a000356 questions during the assessments as well as a written consent for participating in the video-taped measures to each measurement point.

\section{AUTHOR CONTRIBUTIONS}

MA and SW contributed to the conception and the design of the manuscript. MA performed the statistical analysis and wrote the first draft of the manuscript. SW revised the manuscript critically to improve the draft and contributed to the Theoretical Background and Discussion sections. Both authors contribute to manuscript revision, read and approved the submitted version.

\section{FUNDING}

The publication of this article was funded by the Open Access Fund of the Leibniz Association.

\section{ACKNOWLEDGMENTS}

This manuscript uses data from the National Educational Panel Study (NEPS): Starting Cohort Newborns, doi: 10.5157/NEPS:SC1:6.0.0. From 2008 to 2013, NEPS data was collected as part of the Framework Program for the Promotion of Empirical Educational Research funded by the German Federal Ministry of Education and Research (BMBF). As of 2014, NEPS is carried out by the Leibniz Institute for Educational Trajectories (LIfBi) at the University of Bamberg in cooperation with a nationwide network. We would like to thank all families who participated in the NEPS.

Attig, M., and Weinert, S. (2019). Häusliche Lernumwelt und Spracherwerb in den ersten Lebensjahren. Sprache ${ }^{\circ}$ Stimme $^{\circ}$ Gehör. 43, 86-92. doi: 10.1055/a-08519049

Baldwin, D. A. (1995). "Understanding the link between joint attention and language," in Joint Attention: Its Origins and Role in Development, eds C. Moore and P. J. Dunham (Hove: Psychology Press), 131-158.

Belsky, J., Vandell, D. L., Burchinal, M., Clarke-Stewart, K. A., McCartney, K., Owen, M. T., et al. (2007). Are there long-term effects of early child care? Child Dev. 78, 681-701. doi: 10.1111/j.1467-8624.2007.01021.x

Bernier, A., Jarry-Boileau, V., Tarabulsy, G. M., and Milijkovitsch, R. (2010). Initiating a caregiving relationship: pregnancy and childbirth factors as predictors of maternal sensitivity. Infancy 15, 197-208. doi: 10.1111/j.15327078.2009.00006.x

Blossfeld, H.-P., and Roßbach, H.-G. (2019). Education as a Lifelong Process. The German National Educational Panel Study (NEPS), 2nd Edn. Wiesbaden: VS Verlag für Sozialwissenschaften. doi: 10.1007/978-3-658-23 162-0

Blossfeld, H.-P., Roßbach, H.-G., and von Maurice, J. (2011). Education as a lifelong process: The German National Educational Panel Study (NEPS). Z. Erziehwiss. 14, 19-34. doi: 10.1007/s11618-011-0179-2

Bornstein, M. H. (2002). "Parenting infants," in Handbook of Parenting. Children and parenting, Vol. 1, ed. M. H. Bornstein (Mahwah, NJ: Lawrence Erlbaum Associates), 3-43. doi: 10.4324/9780429440847-1

Bornstein, M. H., Tamis-LeMonda, C. S., Hahn, C.-S., and Haynes, M. (2008). Maternal responsiveness to young children at three ages: longitudinal analysis 
of a multidimensional, modular, and specific parenting construct. Dev. Psychol. 44, 867-874. doi: 10.1037/0012-1649.44.3.867

Bowlby, J. (1988). A Secure Base. Parent-Child Attachment and Healthy Human Development. New York, NY: Basic Books.

Bradbury, B., Corak, M., Waldfogel, J., and Washbrook, E. (2015). Too Many Children Left Behind: The US Achievement Gap in Comparative Perspective. New York, NY: Russell Sage Foundation.

Bradley, R. H., Corwyn, R., McAdoo, H., and Coll, C. G. (2001). The home environments of children in the United States. Part I: variations by age, ethnicity, and poverty status. Child Dev. 72, 1844-1867. doi: 10.1111/14678624.t01-1-00382

Bromley, C. (2009). Growing Up In Scotland: The Impact of Children's Early Activities on Cognitive Development. Edinburgh: Scottish Government.

Bronfenbrenner, U., and Morris, P. A. (2006). "The bioecological model of human development," in Handbook of Child Psychology. Theoretical Models of Human Development, Vol. 1, ed. R. M. Lerner (Hoboken, NJ: John Wiley \& Sons), 793-828. doi: 10.1002/9780470147658.chpsy0114

Bruner, J. (1978). "The role of dialogue in language acquisition," in The Child's Conception to Language, eds A. Sinclair, R. J. Jarvelle, and W. J. Levelt (New York, NY: Springer-Verlag), 241-256.

Bus, A. G., Van Ijzendoorn, M. H., and Pellegrini, A. D. (1995). Joint book reading makes for success in learning to read: a meta-analysis on intergenerational transmission of literacy. Rev. Educ. Res. 65, 1-21. doi: 10.3102/ 00346543065001001

Caldwell, B. M., and Bradley, R. H. (1984). Home Inventory for Measurement of the Environment. Arkansas: Little RockRock.

Chomsky, N. (1988). Language and Problems of Knowledge: The Managua Lectures. Cambridge, MA: MIT Press.

Conger, R. D., and Donnellan, M. B. (2007). An interactionist perspective on the socio-economic context of human development. Annu. Rev. Psychol. 58, 175-199. doi: 10.1146/annurev.psych.58.110405.08 5551

Dilworth-Bart, J., Khurshid, A., and Vandell, D. L. (2007). Do maternal stress and home environment mediate the relation between early income-to-need and 54months attentional abilities? Infant Child Dev. 16, 525-552. doi: 10.1002/icd. 528

Dollaghan, C. A., Campbell, T. F., Paradise, J. L., Feldman, H. M., Janosky, J. E., Pitcairn, D. N., et al. (1999). Maternal education and measures of early speech and language. J. Speech Lang. Hear. Res. 42, 1432-1443. doi: 10.1044/jslhr.4206. 1432

Dunn, L. M., and Dunn, D. M. (2007). PPVT-4: Peabody Picture Vocabulary Test. Minneapolis, MN: Pearson Assessments, doi: 10.1037/t15144-000

Elman, J. L., Bates, E., Johnson, M. H., Karmiloff-Smith, A., Parisi, D., and Plunkett, K. (1996). Rethinking Innateness: Connectionism in a Developmental Framework. Cambridge, MA: MIT Press.

Farah, M. J., Betancourt, L., Shera, D. M., Savage, J. H., Giannetta, J. M., Brodsky, N. L., et al. (2008). Environmental stimulation, parental nurturance and cognitive development. Hum. Dev. Sci. 11, 793-801. doi: 10.1111/j.1467-7687. 2008.00688.x

Farrant, B. M., and Zubrick, S. R. (2012). Early vocabulary development: the importance of joint attention and parent-child book reading. First Lang. 32, 343-364. doi: 10.1177/0142723711422626

Fenson, L., Dale, P. S., Reznick, J. S., Thal, D., Bates, E., Hartung, J. P., et al. (1993). Technical Manual for the MacArthur Communicative Development Inventories. San Diego, CA: Singular Publishing Group.

Fernald, A., Marchman, V. A., and Weisleder, A. (2013). SES differences in language processing skill and vocabulary are evident at 18 months. Dev. Sci. 16, 234-248. doi: 10.1111/desc. 12019

Fodor, J. A. (1983). Modularity of Mind: An Essay on Faculty Psychology. Cambridge, MA: MIT Press, doi: 10.7551/mitpress/4737.001. 0001

Freund, J.-D., Linberg, A., and Weinert, S. (2019). Longitudinal interplay of young children's negative affectivity and maternal interaction quality in the context of unequal psychosocial resources. Infant Behav. Dev. 55, 123-132. doi: 10.1016/j. infbeh.2019.01.003

Friedman-Krauss, A., Barnett, W. S., and Nores, M. (2016). How Much can HighQuality Universal Pre-K Reduce Achievement Gaps?. Washington, DC: Center for American Progress.
Ganzeboom, H. B. G., de Graaf, P. M., and Treiman, D. J. (1992). A standard international socio-economic index of occupational status. Soc. Sci. Res. 21, 1-56. doi: 10.1016/0049-089X(92)90017-B

Golinkoff, R. M., and Hirsh-Pasek, K. (1990). Let the mute speak: what infants can tell us about language acquisition. Merrill Palmer Q. 36, 67-91.

Golinkoff, R. M., Hoff, E., Rowe, M. L., Tamis-LeMonda, C. S., and Hirsh-Pasek, K. (2019). Language matters: denying the existence of the 30-million-word gap has serious consequences. Child Dev. 90, 985-992. doi: 10.1111/cdev.13128

Grimm, H., and Doil, H. (2006). ELFRA-Elternfragebögen für die Früherkennung von Risikokindern, 2nd Edn. Göttingen: Hogrefe.

Gudmundson, J. A. (2012). Links Between Maternal Education and Parenting Quality During Children's First Three Years: The Moderating Role of Income and Partner Status. Dissertation, University of North Carolina, Chapel Hill, NC.

Halle, T., Forry, N., Hair, E., Perper, K., Wandner, L., Wessel, J., et al. (2009). Disparities in Early Learning and Development: Lessons From the Early Childhood Longitudinal Study-Birth Cohort (ECLS-B). Washington, DC: Child Trends.

Hart, B., and Risley, T. R. (1995). Meaningful Differences in the Everyday Experience of Young American Children. Baltimore, MD: Paul H. Brookes Publishing.

Haveman, R., and Wolfe, B. (1994). Succeeding Generations: On the Effects of Investments in Children. New York, NY: Russell Sage Foundation.

Hayes, N., and Berthelsen, D. C. (2020). Longitudinal profiles of shared book reading in early childhood and children's academic achievement in Year 3 of school. Sch. Eff. Sch. Improv. 31, 31-49. doi: 10.1080/09243453.2019.161 8347

Hirsh-Pasek, K., and Golinkoff, R. M. (1996). The Origins of Grammar: Evidence From Early Language Comprehension. Cambridge: MIT Press.

Hoff, E. (2003). The specificity of environmental influence: socioeconomic status affects early vocabulary development via maternal speech. Child Dev. 74, 13681378. doi: $10.1111 / 1467-8624.00612$

Hoff, E. (2006). How social contexts support and shape language development. Dev. Rev. 26, 55-88. doi: 10.1016/j.dr.2005.11.002

Hoff, E. (2013). Interpreting the early language trajectories of children from lowSES and language minority homes: implications for closing achievement gaps. Dev. Psychol. 49, 4-14. doi: 10.1037/a0027238

Hoff, E., Laursen, B., and Tardif, T. (2002). "Socioeconomic status and parenting," in Handbook of Parenting. Biology and Ecology of Parenting, Vol. 2, ed. M. Bornstein (Mahwah, NJ: Lawrence Erlbaum Associates), 231-252.

Hoff-Ginsberg, E. (1998). The relation of birth order and socioeconomic status to children's language experience and language development. Appl. Psycholinguist. 19, 603-629. doi: 10.1017/S0142716400010389

Hurt, H., and Betancourt, L. M. (2016). Effect of socioeconomic status disparity on child language and neural outcome: how early is early? Pediatr. Res. 79, 148-158. doi: 10.1038/pr.2015.202

Huttenlocher, J., Vasilyeva, M., Cymerman, E., and Levine, S. (2002). Language input and child syntax. Cogn. Psychol. 45, 337-374. doi: 10.1016/S00100285(02)00500-5

Huttenlocher, J., Waterfall, H., Vasilyeva, M., Vevea, J., and Hedges, L. V. (2010). Sources of variability in children's language growth. Cogn. Psychol. 61, 343-365. doi: 10.1016/j.cogpsych.2010.08.002

Kail, R., and Pellegrino, J. W. (1985). Human Intelligence: Perspectives and Prospects. New York, NY: Freeman.

Karmiloff-Smith, A. (2015). An alternative to domain-general or domainspecific frameworks for theorizing about human evolution and ontogenesis. Neuroscience 2, 91-104. doi: 10.3934/Neuroscience.2015.2.91

Klebanov, P. K., Brooks-Gunn, J., and Duncan, G. J. (1994). Does neighborhood and family poverty affect mothers' parenting, mental health, and social support? J. Marriage Fam. 56, 441. doi: 10.2307/353111

Kluczniok, K., Lehrl, S., Kuger, S., and Roßbach, H.-G. (2013). Quality of the home learning environment during preschool age - Domains and contextual conditions. Eur. Early Child. Educ. Res. J. 21, 420-438. doi: 10.1080/1350293X. 2013.814356

König, W., Lüttinger, P., and Müller, W. (1988). A Comparative Analysis of the Development and Structure of Educational Systems. Methodological Foundations and the Construction of a Comparative Educational Scale. Mannheim: Institut für Sozialwissenschaften. 
Korucu, I., and Schmitt, S. A. (2020). Continuity and change in the home environment: associations with school readiness. Early Child. Res. Q. 53, 97107. doi: 10.1016/j.ecresq.2020.03.002

Landry, S. H., Smith, K. E., Swank, P. R., Assel, M. A., and Vellet, S. (2001). Does early responsive parenting have a special importance for children's development or is consistency across early childhood necessary? Dev. Psychol. 37, 387-403. doi: 10.1037/0012-1649.37.3.387

Law, J., Clegg, J., Rush, R., Roulstone, S., and Peters, T. J. (2019). Association of proximal elements of social disadvantage with children's language development at 2 years: an analysis of data from the Children in Focus (CiF) sample from the ALSPAC birth cohort. Int. J. Lang. Commun. Disord. 54, 362-376. doi: 10.1111/1460-6984.12442

Law, J., Rush, R., Anandan, C., Cox, M., and Wood, R. (2012). Predicting language change between 3 and 5 years and its implications for early identification. Pediatrics 130, e132-e137. doi: 10.1542/peds.2011-1673

Lehrl, S., Ebert, S., Roßbach, H.-G., and Weinert, S. (2012). Die Bedeutung der familiären Lernumwelt für Vorläufer schriftsprachlicher Kompetenzen im Vorschulalter. J. Fam. Res. 24, 115-133.

Lehrl, S., Evangelou, M., and Sammons, P. (2020). The home learning environment and its role in shaping children's educational development. Sch. Eff. Sch. Improv. 31, 1-6. doi: 10.1080/09243453.2020.1693487

Lenhard, A., Lenhard, W., Segerer, R., and Suggate, S. P. (2015). Peabody Picture Vocabulary Test (PPVT-4). German Edition. London: Pearson.

Linberg, A. (2018). Interaktion zwischen Mutter und Kind: Dimensionen, Bedingungen und Effekte. Münster: Waxmann Verlag.

Linberg, A., Attig, M., and Weinert, S. (2020). Social disparities in the vocabulary of 2-year-old children and the mediating effect of language-stimulating interaction behavior. J. Educ. Res. Online.12, 12-35.

Linberg, A., Mann, D., Attig, M., Vogel, F., Weinert, S., and Roßbach, H.-G. (2019). Assessment of Interactions With the Macro-Analytic Rating System of ParentChild-Interactions in the NEPS at the Child's Age of 7, 17, and 26 Months. Bamberg: Leibniz Institute for Educational Trajectories.

Linberg, T., Schneider, T., Waldfogel, J., and Wang, Y. (2019). Socioeconomic status gaps in child cognitive development in Germany and the United States. Soc. Sci. Res. 79, 1-31. doi: 10.1016/j.ssresearch.2018.11.002

Linberg, T., and Wenz, S. E. (2017). Ausmaß und Verteilung sozioökonomischer und migrationsspezifischer Ungleichheit im Sprachstand fünfjähriger Kindergartenkinder. J. Educ. Res. Online 9, 77-98.

Lugo-Gil, J., and Tamis-LeMonda, C. S. (2008). Family resources and parenting quality: links to children's cognitive development across the first 3 years. Child Dev. 79, 1065-1085. doi: 10.1111/j.1467-8624.2008.01176.x

Magnuson, K. A., Sexton, H. R., Davis-Kean, P. E., and Huston, A. C. (2009). Increases in maternal education and young children's language skills. Merrill Palmer Q. 55, 319-350. doi: 10.1353/mpq.0.0024

Melhuish, E. C. (2010). Impact of the Home Learning Environment on Child Cognitive Development: Secondary Analysis of Data From "Growing Up in Scotland”. Edinburgh: Scottish Government Social Research.

Melhuish, E. C., Phan, M. B., Sylva, K., Siraj-Blachford, I., and Taggart, B. (2008). Effects of the home learning environment and preschool center experience upon literacy and numeracy development in early primary school. J. Soc. Issues 64, 95-114. doi: 10.1111/j.1540-4560.2008.00550.x

Melhuish, E. C., Sylva, K., Sammons, P., Siraj-Blatchford, I., and Taggart, B. (2001). ). The Effective Provision of Pre-school Education Project, Technical Paper 7: Social/behavioural and Cognitive Development at 3-4 Years in Relation to Family Background. London: Institute of Education/DfES.

Mills-Koonce, W. R., Willoughby, M. T., Zvara, B., Barnett, M., Gustafsson, H., Cox, M. J., et al. (2015). Mothers' and fathers' sensitivity and children's cognitive development in low-income, rural families. J. Appl.Dev. Psychol. 38, 1-10. doi: 10.1016/j.appdev.2015.01.001

Morgan, P. L., Farkas, G., Hillemeier, M. M., Hammer, C. S., and Maczuga, S. (2015). 24-month-old children with larger oral vocabularies display greater academic and behavioral functioning at kindergarten entry. Child Dev. 86, 1351-1370. doi: 10.1111/cdev.12398

Morisset, C. E., Barnard, K. E., Greenberg, M. T., Booth, C. L., and Spieker, S. J. (1990). Environmental influences on early language development: the context of social risk. Dev. Psychopathol. 2, 127-149. doi: 10.1017/S0954579400000663

Muthén, L. K., and Muthén, B. O. (2017). 1998-2017. Mplus User's Guide. Los Angeles, CA: Muthén \& Muthén.
Neuhauser, A. (2018). Predictors of maternal sensitivity in at-risk families. Early Child Dev. Care 188, 126-142. doi: 10.1080/03004430.2016.1207065

Newport, E. L., Gleitman, H., and Gleitman, L. (1977). "Mother, I'd rather do it myself: some effects and non-effects of maternal speech style," in Talking to Children: Language Input and Acquisition: Papers From a Conference Sponsored by the Committee on Sociolinguistics of the Social Science Research Council (USA), eds C. E. Snow, C. A. Ferguson, Social Science Research Council (U.S.), and Committee on Sociolinguistics (Cambridge, NY: Cambridge University Press), 109-150.

NICHD Early Child Care Research Network (1991). NICHD Study of Early Child Care: Volume II: 5 Month Manual, 6 Month Manuals, Time Use Manuals. Bethesda: National Institute of Child Health and Human Development.

NICHD Early Child Care Research Network (1998). Relations between family predictors and child outcomes: are they weaker for children in child care? Dev. Psychol. 34, 1119-1128. doi: 10.1037/0012-1649.34.5.1119

NICHD Early Child Care Research Network (1999). Child care and mother-child interaction in the first 3 years of life. Dev. Psychol. 35, 1399-1413.

NICHD Early Child Care Research Network (2002a). Child-care structure $\rightarrow$ process $\rightarrow$ outcome: direct and indirect effects of child-care quality on young children's development. Psychol. Sci. 13, 199-206. doi: 10.1111/1467-9280. 00438

NICHD Early Child Care Research Network (2002b). Early child care and children's development prior to school entry: results from the NICHD study of early child care. Am. Educ. Res. J. 39, 133-164. doi: 10.3102/ 00028312039001133

NICHD Early Child Care Research Network (2005a). Early child care and children's development in the primary grades. Follow-up results from the NICHD Study of Early Child Care. Am. Educ. Res. J. 42, 537-570. doi: 10.3102/ 00028312042003537

NICHD Early Child Care Research Network (2005b). Duration and developmental timing of poverty and children's cognitive and social development from birth through third grade. Child Dev. 76, 795-810. doi: 10.1111/j.1467-8624.2005. 00878.x

Niklas, F., and Schneider, W. (2010). Der Zusammenhang von familiärer Lernumwelt mit schulrelevanten Kompetenzen im Vorschulalter. Zeitschrift für Soziologie der Erziehung und Sozialisation 30, 149-165.

Nord, C. W., Lennon, J., Liu, B., and Chandler, K. (2000). Home literacy activities and signs of children's emerging literacy: 1993 and 1999. Edu. Stat. Q. 2, 19-27.

Nozadi, S. S., Spinrad, T. L., Eisenberg, N., Bolnick, R., Eggum-Wilkens, N. D., Smith, C. L., et al. (2013). Prediction of toddlers' expressive language from maternal sensitivity and toddlers' anger expressions: a developmental perspective. Infant Behav. Dev. 36, 650-661. doi: 10.1016/j.infbeh.2013.06.002

Olson, S. L., Bayles, K., and Bates, J. E. (1986). Mother-child interaction and children's speech progress: a longitudinal study of the first two years. Merrill Palmer Q. 32, 1-20.

Organisation for Economic Co-operation and Development [OECD] (2013). Framework of Statistics on the Distribution of Household Income, Consumption and Wealth. Paris: OECD Publishing.

Paavola, L., Kunnari, S., and Moilanen, I. (2005). Maternal responsiveness and infant intentional communication: implications for the early communicative and linguistic development. Child Care Health Dev. 31, 727-735. doi: 10.1111/j. 1365-2214.2005.00566.x

Pan, B. A., Rowe, M. L., Singer, J. D., and Snow, C. E. (2005). Maternal correlates of growth in toddler vocabulary production in low-income families. Child Dev. 76, 763-782. doi: 10.1111/j.1467-8624.2005.00876.x

Pinker, S. (1984). Visual cognition: an introduction. Cognition 18, 1-63. doi: 10. 1016/0010-0277(84)90021-0

Raikes, H., Luze, G., Brooks-Gunn, J., Raikes, H. A., Pan, B. A., Tamis-LeMonda, C. S., et al. (2006). Mother - child book reading in low-income families: correlates and outcomes during the first three years of life. Child Dev. 77, 924-953. doi: 10.1111/j.1467-8624.2006.00911.x

Reilly, S., Wake, M., Bavin, E. L., Prior, M., Williams, J., Bretherton, L., et al. (2007). Predicting language at 2 years of age: a prospective community study. Pediatrics 120, e1441-e1449. doi: 10.1542/peds.2007-0045

Reilly, S., Wake, M., Ukoumunne, O. C., Bavin, E., Prior, M., Cini, E., et al. (2010). Predicting language outcomes at 4 years of age: findings from early language in victoria study. Pediatrics 126, e1530-e1537. doi: 10.1542/peds.2010-0254 
Rescorla, L. (1989). The language-development survey: A Screening tool for delayed language in toddlers. J. Speech Lang. Hear. Disord. 54, 587-599. doi: 10.1044/jshd.5404.587

Rodriguez, E. T., and Tamis-LeMonda, C. S. (2011). Trajectories of the home learning environment across the first 5 years: associations with children's vocabulary and literacy skills at prekindergarten. Child Dev. 82, 1058-1075. doi: 10.1111/j.1467-8624.2011.01614.x

Rodriguez, E. T., Tamis-LeMonda, C. S., and Spellmann, M. (2005). “Children's early literacy environment: Promoting language and cognitive development over the first four years of life," in Paper Presented at the Society for Research in Child Development Biennial Meeting, Atlanta, GA.

Rose, E., Lehrl, S., Ebert, S., and Weinert, S. (2018). Long-term relations between children's language, the home literacy environment, and socioemotional development from ages 3 to 8. Early Educ. Dev. 29, 342-356. doi: 10.1080/ 10409289.2017.1409096

Rowe, M. (2008). Child-directed speech: relation to socioeconomic status, knowledge of child development and child vocabulary skill. J. Child Lang. 35, 185-205. doi: 10.1017/S0305000907008343

Rowe, M. L., and Goldin-Meadow, S. (2009). Differences in early gesture explain SES disparities in child vocabulary size at school entry. Science 323, 951-953. doi: $10.1126 /$ science. 1167025

Rowe, M. L., Raudenbush, S. W., and Goldin-Meadow, S. (2012). The pace of vocabulary growth helps predict later vocabulary skill. Child Dev. 83, 508-525. doi: 10.1111/j.1467-8624.2011.01710.x

Ruddy, M. G., and Bornstein, M. H. (1982). Cognitive correlates of infant attention and maternal stimulation over the first year of life. Child Dev. 53, 183-188. doi: $10.2307 / 1129651$

Sachse, S., Anke, B., and von Suchodoletz, W. (2007). Früherkennung von Sprachentwicklungsstörungen - ein Methodenvergleich. Z. Kinder Jugendpsychiatr. Psychother. 35, 323-331. doi: 10.1024/1422-4917.35.5.323

Schuth, E., Köhne, J., and Weinert, S. (2017). The influence of academic vocabulary knowledge on school performance. Learn. Instr. 49, 157-165. doi: 10.1016/j. learninstruc.2017.01.005

Sénéchal, M., and LeFevre, J. A. (2002). Parental involvement in the development of children's reading skill: a five-year longitudinal study. Child Dev. 73, 445-460. doi: 10.1111/1467-8624.00417

Sénéchal, M., Pagan, S., Lever, R., and Ouellette, G. P. (2008). Relations among the frequency of shared reading and 4-year-old children's vocabulary, morphological and syntax comprehension, and narrative skills. Early Educ. Dev. 19, 27-44. doi: 10.1080/10409280701838710

Shruti, D. A. V. E., Mastergeorge, A. M., and Olswang, L. B. (2018). Motherese, affect, and vocabulary development: dyadic communicative interactions in infants and toddlers. J. Child Lang. 45, 917-938. doi: 10.1017/ S0305000917000551

Sperry, D. E., Sperry, L. L., and Miller, P. J. (2018). Reexamining the verbal environments of children from different socioeconomic backgrounds. Child Dev. 90, 1303-1318. doi: 10.1111/cdev.13072

Sperry, D. E., Sperry, L. L., and Miller, P. J. (2019). Language does matter: But there is more to language than vocabulary and directed speech. Child Dev. 90, 993-997. doi: 10.1111/cdev.13125

Tamis-LeMonda, C. S., Bornstein, M. H., and Baumwell, L. (2001). Maternal responsiveness and children's achievement of language milestones. Child Dev. 72, 748-767. doi: 10.1111/1467-8624.00313

Tamis-LeMonda, C. S., Bornstein, M. H., Baumwell, L., and Damast, A. M. (1996). Responsive parenting in the second year: specific influences on children's language and play. Early Dev. Parent. 5, 173-183. doi: 10.1002/(SICI)10990917(199612)5:4<173::AID-EDP131<3.0.CO;2-V

Tamis-LeMonda, C. S., Bornstein, M. H., Kahana-Kalman, R., Baumwell, L., and Cyphers, L. (1998). Predicting variation in the timing of language milestones in the second year: AN events history approach. J. Child Lang. 25, 675-700. doi: $10.1017 /$ S0305000998003572

Tamis-LeMonda, C. S., Kuchirko, Y., and Song, L. (2014). Why is infant language learning facilitated by parental responsiveness? Current Directions in Psychol. Sci. 23, 121-126. doi: 10.1177/0963721414522813
Tomasello, M. (2003). Constructing a Language: A Usage-Based Theory of Language Acquisition. Cambridge, MA: Harvard University Press.

Toth, K., Sammons, P., Sylva, K., Melhuish, E., Siraj, I., and Taggart, B. (2020). Home learning environment across time: the role of early years HLE and background in predicting HLE at later ages. Sch. Eff. Sch. Improv. 31, 7-30. doi: 10.1080/09243453.2019.1618348

Vallotton, C. D., Mastergeorge, A., Foster, T., Decker, K. B., and Ayoub, C. (2017). Parenting supports for early vocabulary development: specific effects of sensitivity and stimulation through infancy. Infancy 22, 78-107. doi: 10.1111/ infa. 12147

Van der Lely, J. K. J., and Pinker, S. (2014). The biological basis of language: insights from developmental grammatical impairments. Trends Cogn. Sci. 18, 586-595. doi: 10.1016/j.tics.2014.07.001

Vasilyeva, M., and Waterfall, H. (2011). "Variability in language development: relation to socioeconomic status and environmental input," in Handbook of Early Literacy Research, Vol. 3, eds S. B. Neumann and D. K. Dickinson (New York, NY: Guilford press), 36-48.

Vasilyeva, M., Waterfall, H., and Huttenlocher, J. (2008). Emergence of syntax: commonalities and differences across children. Dev. Sci. 11, 84-97. doi: 10.1111/ j.1467-7687.2007.00656.x

Volodina, A., Weinert, S., and Mursin, K. (2020). Development of academic vocabulary across primary school age: differential growth and influential factors for German monolinguals and language minority learners. Dev. Psychol. 56, 922-936. doi: $10.1037 /$ dev0000910

Vygotsky, L. S. (1978). Mind in Society: The Development of Higher Psychological Processes. Cambridge: MA: Harvard University Press.

Weinert, S., Attig, M., and Roßbach, H.-G. (2017). "The emergence of social disparities: evidence on early mother-child interaction and infant development from the German National Educational Panel Study (NEPS)," in Childcare, Early Education, and Social Inequality. An International Perspective, eds H.-P. Blossfeld, N. Kulic, J. Skopek, and M. Triventi (Cheltenham: Edward Elgar Publishing), 89-108. doi: 10.4337/9781786432094. 00014

Weinert, S., Doil, H., and Frevert, S. (2007). "Kognitiv-sprachliche Kompetenzen," in Expertise zur Erfassung von psychologischen Personmerkmalen bei Kindern im Alter von fünf Jahren im Rahmen des SOEP (DIW: Data Documentation 20), eds S. Weinert, J. B. Asendorf, A. Beelmann, H. Doil, S. Frevert, and A. Lohhaus (Berlin: Deutsches Institut für Wirtschaftsforschung), 9-29.

Weinert, S., and Ebert, S. (2013). Spracherwerb im Vorschulalter: Soziale Disparitäten und Einflussvariablen auf den Grammatikerwerb. Z. Erziehwiss. 16, 303-332. doi: 10.1007/s11618-013-0354-8

Weinert, S., and Ebert, S. (2017). "Verlaufsmerkmale und Wirkfaktoren der frühen kognitiv-sprachlichen Entwicklung - Ergebnisse aus der BiKS-3- 10 Studie," in Entwicklungsstörungen und Chronische Erkrankungen: Diagnose, Behandlungsplanung und Familienbegleitung, eds V. Mall, F. Voigt, and N. H. Jung (Lübeck: Schmid-Römhild Verlag), 13-33.

Weinert, S., and Grimm, H. (2018). "Sprachentwicklung," in Entwicklungspsychologie, 8th Edn, eds W. Schneider and U. Lindenberger (Weinheim: Beltz), 445-470.

Weinert, S., Linberg, A., Attig, M., Freund, J.-D., and Linberg, T. (2016). Analyzing early child development, influential conditions, and future impacts: prospects of a German newborn cohort study. Int. J. Child Care Educ. Policy 10, 1-20. doi: 10.1186/s40723-016-0022-6

Conflict of Interest: The authors declare that the research was conducted in the absence of any commercial or financial relationships that could be construed as a potential conflict of interest.

Copyright (c) 2020 Attig and Weinert. This is an open-access article distributed under the terms of the Creative Commons Attribution License (CC BY). The use, distribution or reproduction in other forums is permitted, provided the original author(s) and the copyright owner(s) are credited and that the original publication in this journal is cited, in accordance with accepted academic practice. No use, distribution or reproduction is permitted which does not comply with these terms. 


\title{
No Association Between the Home Math Environment and Numerical and Patterning Skills in a Large and Diverse Sample of 5- to 6-year-olds
}

\author{
Laure De Keyser, Merel Bakker, Sanne Rathé, Nore Wijns, Joke Torbeyns, \\ Lieven Verschaffel and Bert De Smedt*
}

Faculty of Psychology and Educational Sciences, KU Leuven, Leuven, Belgium

\section{OPEN ACCESS}

Edited by:

Caroline Cohrssen,

The University of Hong Kong,

Hong Kong

Reviewed by:

Manja Attig,

Leibniz Institute for Educational

Trajectories (LG), Germany

Naomi Hackworth,

Parenting Research Centre, Australia

${ }^{*}$ Correspondence: Bert De Smedt

Bert.DeSmedt@ppw.kuleuven.be

Specialty section:

This article was submitted to Educational Psychology,

a section of the journal

Frontiers in Psychology

Received: 31 March 2020 Accepted: 28 October 2020 Published: 10 December 2020

Citation:

De Keyser L, Bakker M, Rathé S, Wijns N, Torbeyns J, Verschaffel $L$ and De Smedt B (2020) No Association Between the Home Math Environment and Numerical and Patterning Skills in a Large and Diverse Sample of

5- to 6-year-olds.

Front. Psychol. 11:547626. doi: 10.3389/fpsyg.2020.547626
Selecting a large and diverse sample of 5-6-year-old preschool children (179 boys and 174 girls; $M_{\text {age }}=70.03$ months, $S D_{\text {age }}=3.43$ ), we aimed to extend previous findings on variability in children's home math environment (i.e., home math activities, parental expectations, and attitudes) and its association with children's mathematical skills. We operationalized mathematics in a broader way than in previous studies, by considering not only children's numerical skills but also their patterning skills as integral components of early mathematical development. We investigated the effects of children's gender and socioeconomic status (SES) on their home math environment, examined the associations between children's home math environment and their mathematical skills, and verified whether these associations were moderated by children's gender and/or SES. Parents of 353 children completed a home math environment questionnaire and all children completed measures of their numerical (e.g., object counting) and patterning skills (e.g., extending repeating patterns). Results indicated no effect of children's gender on their home math environment. There was no effect of SES on the performed home math activities, but small SES differences existed in parents' math-related expectations and their attitudes. We found no evidence for associations between children's home math environment and their mathematical skills. Furthermore, there were no moderating effects of gender or SES on these associations. One explanation for these findings might relate to the characteristics of the general preschool system in the country of the present study (Belgium). Future studies should consider the effect of the preschool learning environment because it might explain differences between studies and countries with regard to the home math environment and its association with mathematical skills.

Keywords: home math environment, preschool, mathematics, numeracy, patterning, moderators, gender, SES

\section{INTRODUCTION}

Children's early mathematical skills at the age of 5 are strong and stable predictors of their later mathematics achievement (e.g., Duncan et al., 2007). Researchers have become increasingly interested in the role of children's home environment in the development of these early mathematical skills (e.g., LeFevre et al., 2009; Kleemans et al., 2012; Skwarchuk et al., 2014; Blevins-Knabe and Berghout Austin(eds), 2016; Susperreguy et al., 2020b). This is not surprising, given that, for example, Vygotsky (1978) 
stated in his social development theory that more knowledgeable others can influence and stimulate children's cognitive skills by means of social interactions, which proceed the process of developmental change. Parents are important agents in young children's social environments and can therefore create learning opportunities from an early age onwards. In addition, not only parents' behavior, but also their expectations, beliefs, attitudes, and demographic characteristics (see Eccles, 1993) might impact early child development and achievement (Huntsinger et al., 2000; Blevins-Knabe and Berghout Austin(eds), 2016). Against this background, children's home math environment as provided by their parents must be considered as a broad construct, including parental activities, expectations, and attitudes. Previous research has revealed large variability in the characteristics of children's home math environment. These studies have additionally shown that the home environment is positively associated with children's mathematical skills, even before they start formal schooling in first grade (e.g., Anders et al., 2012; Kleemans et al., 2012; Skwarchuk et al., 2014; Segers et al., 2015; Mutaf-Yildiz et al., 2018a; Napoli and Purpura, 2018; Susperreguy et al., 2020a). However, some studies observed no associations between children's home math environment and their mathematical skills (Missall et al., 2015) and some studies even reported negative associations (Blevins-Knabe and MusunMiller, 1996). These observations make the existing body of research less conclusive.

Selecting a large and diverse sample of children, the current study aimed to extend previous findings on the variability in children's home math environment and on its association with children's mathematical skills. We operationalized mathematics in a broader way than in most previous studies. We did so by considering not only children's numerical skills but also their patterning skills as integral components of early mathematical development (e.g., Zippert and Rittle-Johnson, 2020, for a similar discussion). To unravel potential explanations for the observed variability in children's home math environment, we investigated the effects of children's gender and socioeconomic status (SES) on their home math environment. We further examined the associations between children's home math environment and their numerical and patterning skills and investigated whether these associations were moderated by children's gender and/or SES.

\section{Variability in Children's Home Math Environment}

Children's home math environment has been defined as a wideranged, multi-componential construct, consisting of various components in children's home environment that are thought to be beneficial or predictive for children's mathematical skills (e.g., Niklas and Schneider, 2014; Hart et al., 2016; Napoli and Purpura, 2018). These components include, for example, the math-related activities parents do with their child (e.g., counting, cooking, playing with blocks, creating patterns, and playing games that involve adding or subtracting), as well as parents' math-related expectations for their children (e.g., mastering mathematical skills such as counting to 100 , solving simple additions, reading printed numbers, and multiplying) and their personal attitudes toward mathematics (e.g., considering mathematics as important, enjoying mathematical activities, and considering themselves as good at mathematics) (LeFevre et al., 2010; Missall et al., 2015; Susperreguy et al., 2020b; Zippert and Rittle-Johnson, 2020). Many studies have examined the math-related activities that parents do with their preschoolers, showing large individual differences in the nature and frequency of these activities at this age (e.g., Blevins-Knabe and Musun-Miller, 1996; LeFevre et al., 2009; Missall et al., 2017; Zippert and Rittle-Johnson, 2020). Because socioemotional or affective aspects of the home math environment, such as parental expectations or attitudes, can affect children's motivation or belief systems toward mathematics, as well as their performance (e.g., Segers et al., 2015; BlevinsKnabe, 2016; see also Eccles, 1993), these affective aspects have also been included in assessments of children's home math environment. Several studies have shown that these affective variables were positively correlated with the frequency of parentchild math-related activities at home. Thus, parents reporting higher academic expectations for their children or having more positive personal attitudes toward mathematics engage in more math-related activities with their children than parents with lower expectations or less positive attitudes (e.g., LeFevre et al., 2010; Missall et al., 2015; Susperreguy et al., 2020b). However, not all studies have found such associations (Kleemans et al., 2012).

It is important to note that most studies exclusively focused on home math activities and expectations related to early numeracy, and on their relationship with children's basic numerical skills. Criticizing this limited view on children's mathematical development, Rittle-Johnson et al. (2015) as well as Zippert and Rittle-Johnson (2020) also considered more complex mathematical skills in their assessment of the home math environment. Specifically, they included items about activities and expectations related to early patterning in their questionnaires. These studies revealed substantial individual differences in the extent to which parents engaged in these patterning activities with their children.

The observed variability in the nature and frequency of various home math environment components raises questions about the factors that might explain this variability. One such factor might be children's gender. Although gender differences have been the focus of many studies on children's mathematical development (e.g., Jordan et al., 2006; Stoet and Geary, 2013; Kersey et al., 2018; Bakker et al., 2019; see also Hyde et al., 1990; Lindberg et al., 2010 for meta-analyses), only a limited number of studies has addressed gender differences in children's home math environment. This body of research has revealed equivocal results. On the one hand, Chang et al. (2011) found that North-American mothers used significantly more overall number-related speech as well as cardinal number speech with boys than with girls. Similarly, Hart et al. (2016) showed that parents of boys reported more home math activities than parents of girls. On the other hand, del Río et al. (2017) found that mothers of Chilean children reported to involve girls significantly more in advanced formal numeracy practices, compared to boys. Similarly, Blevins-Knabe and Musun-Miller (1996) demonstrated that Euro-American mothers reported to significantly engage 
more in number-related activities, such as counting and singing number songs, with girls than boys. Other studies, however, did not observe gender differences in children's home math environment (e.g., Jordan et al., 2006; Zippert and Rittle-Johnson, 2020).

A second factor that might explain variability in children's home math environment is their SES, which refers to "the individual's or a family's ranking on a hierarchy according to access to or control over some combination of valued commodities such as wealth, power, and social status" (Sirin, 2005 , p. 418). In general, parental education, parental income, and parental occupation are considered as the main indicators of SES (e.g., Sirin, 2005). Parental education has been identified as the most commonly used proxy for SES (Calvo and Bialystok, 2014), and has been used as such in many studies on children's home math environment. It can be considered as a very stable indicator that is also strongly correlated with other important SES indicators (Sirin, 2005), and it has been identified as the indicator of SES with the strongest associations with children's educational outcomes (Davis-Kean, 2005; Calvo and Bialystok, 2014).

The studies that investigated the association between children's SES and their home math environment have yielded, again, inconsistent results, reporting positive, negative, and null relationships. Jordan et al. (2006), for example, observed an association between SES (income) and the frequency of several home math activities, such as talking about numbers and counting objects, and found that middle-income families provided their children with more math-related activities at home, in comparison to low-income households (see also Starkey et al., 1999, as cited in Starkey et al., 2004; Anders et al., 2012; Dearing et al., 2012, for similar results). Likewise, Susperreguy et al. (2020b) reported significantly more shared number-game play as well as counting and arithmetic activities in high SES (parent education) families. Similarly, LeFevre et al. (2010) found positive correlations between SES (parent education) and parental attitudes toward mathematics. Other studies, however, did not find an association between children's SES (income) and their home math environment (Missall et al., 2015; Hart et al., 2016). Some studies even reported a negative association between SES and math-related activities at home (LeFevre et al., 2010; Niklas and Schneider, 2014). Unfortunately, many studies on children's home math environment were done in small samples and in samples that were homogeneous in terms of children's SES (for exceptions see Anders et al., 2012; Niklas and Schneider, 2014; Susperreguy et al., 2020a). To more thoroughly examine the effects of children's SES on their home math environment, it is critical that samples are sufficiently large and diverse in terms of SES. This is also essential to further understand the association between children's home math environment and their mathematical skills, as we will document below.

\section{Associations Between Children's Home Math Environment and Their Mathematical Skills}

The literature on the association between children's home math environment and their mathematical skills is, again, equivocal.
Various studies provide support for positive associations between the frequency of home math-related activities and children's numerical skills (e.g., Kleemans et al., 2012; Skwarchuk et al., 2014; Segers et al., 2015; Mutaf-Yildiz et al., 2018a; Napoli and Purpura, 2018; Susperreguy et al., 2020a; Zippert and RittleJohnson, 2020). Similar positive associations have been observed between parents' math-related expectations and attitudes, and children's numerical skills. Segers et al. (2015), for example, found that parents' numeracy expectations for their children were positively associated with children's early numerical skills. In addition, LeFevre et al. (2010) found that parental mathrelated attitudes (e.g., I enjoy mathematics) predicted children's early numeracy outcomes. Other studies, however, reported negative associations. For example, Skwarchuk (2009) observed that parents' engagement in basic numerical activities (e.g., counting objects and reciting numerals) was negatively related to 3- to 5-year-olds' mathematical ability (see also Blevins-Knabe and Musun-Miller, 1996). Some studies, however, reported no association between children's home math environment and their numerical (Blevins-Knabe et al., 2000; Missall et al., 2015) or patterning skills (Zippert and Rittle-Johnson, 2020).

These varying results between studies on the association between children's home math environment and their mathematical skills might be explained by moderating variables. Against the background of the above-reviewed studies on the variability in children's home math environment, gender and SES might be such moderating variables. We therefore examined the moderating effects of gender and SES on the association between children's home math environment and their mathematical skills. The examination of these moderating effects requires a large and diverse sample, for which reason we selected a large number of children who came from a diversity of SES backgrounds.

\section{The Current Study}

We investigated children's home math environment and its association with children's mathematical skills in the specific educational context of Flanders (Belgium). In the Flemish educational system, nearly all children (98\%) attend fully government subsidized preschool (age 2.5-6 years), which includes a playful non-formal introduction in various mathematical domains. We extended the existing literature through a more thorough assessment of children's math-related home experiences and early mathematical skills by focusing not only on early numeracy but also on patterning, which can also be considered as a critical aspect of preschool children's mathematical development (e.g., Klein and Starkey, 2004; Clements and Sarama, 2014; Rittle-Johnson et al., 2015; Wijns et al., 2019b; Zippert and Rittle-Johnson, 2020). We also extended the previous literature on the role of SES and gender in children's home math environment by examining this in a diverse and large sample. Moreover, in most home math environment studies only frequentist analytical approaches have been used. We extended the existing literature by additionally using Bayesian analyses.

Specifically, we investigated the home math environment in children who were enrolled in the third year of preschool (5- to 6-year-olds). Via a parent questionnaire, which was similar to the one applied in previous studies (e.g., LeFevre et al., 2009; 
Kleemans et al., 2012; Mutaf-Yildiz et al., 2018b; Rathé et al., 2020), we assessed parents' home math activities as well as their expectations and attitudes toward mathematics, and included questions on both number and patterning. Children's SES was determined by the mother's educational level, as parental educational level has been shown to be a critical predictor of children's achievement (e.g., Davis-Kean, 2005). Previous research has documented high correlations between the educational levels of mothers and fathers (Eika et al., 2019) and has shown that the effects of mothers' and fathers' education appear to be comparable (Marks et al., 2000). Due to the specific role mothers often occupy in children's life (Marks et al., 2000), we primarily focused on the educational level of the mother. All children completed two measures that were designed to assess their mathematical skills. The first measure focused on children's numerical skills and consisted of a set of tasks (e.g., counting, number comparison, number identification, and arithmetic) that have been frequently used to investigate children's early numerical skills (e.g., Jordan et al., 2006; Purpura and Lonigan, 2013) and that overlap with conventional standardized tests, such as TEMA. Similar measures have often been used in research on children's home math environment at this age (e.g., LeFevre et al., 2009; Kleemans et al., 2012; Susperreguy et al., 2020b). The second measure assessed children's repeating patterning skills, and this measure was highly similar to the measures that have been used in previous research on preschoolers' patterning skills (e.g., Rittle-Johnson et al., 2015; Zippert and Rittle-Johnson, 2020).

We posited three research questions: (1) Are there effects of children's gender and/or SES on the home math environment? (2) Is there evidence for an association between children's home math environment and their mathematical skills, i.e., numerical and patterning skills? (3) Is the association between children's home math environment and their mathematical skills moderated by their gender and/or SES? In view of the abovementioned conflicting findings reported in the literature, no directional hypotheses were put forward.

\section{MATERIALS AND METHODS}

\section{Participants}

The current study reports on data that have been collected in a large-scale longitudinal research project on young children's core mathematical competencies ${ }^{1}$. The study was approved by the Social and Societal Ethics Committee of KU Leuven (G-2016 07 591). This ongoing research project follows a cohort of 410 children from their second year of preschool, when they were 4-5 years old (2017), until the third year of elementary school (2021). Data of the first year of this longitudinal study have already been published (Bakker et al., 2019; Wijns et al., 2019a,b). The current study reports on data that were collected in the second year of the research project, during which children were in their third and final preschool year. In that year, data on children's home math

${ }^{1}$ https://ppw.kuleuven.be/o_en_o/CIPenT/wis-co-start environment as well as on their numerical and patterning skills were collected.

The original sample was selected by means of a stratified cluster strategy to obtain a sample with an SES distribution that is representative for the Flemish context. Stratification was based on the so-called school-level SES, which is determined by the relative number of children receiving a study allowance and the relative number of children whose mother did not obtain a secondary school certificate. Schools were classified into quartiles that range from having children with predominantly low (Q1) to high (Q4) SES. We recruited 17 schools, which were equally distributed across the four SES quartiles. All children attending the second year of preschool in these schools $(N=517)$ were eligible to participate. Parents of 410/517 children $(Q 1=112$, $Q 2=103, Q 3=94, Q 4=101$ ) gave written informed consent for participation in the research project (Response rate $=79 \%$ ).

The current sample, i.e., participants in the second year of our longitudinal study, consisted of 389 children. Parents of the participating children were asked to complete the parent questionnaire, when their children were enrolled in the first semester (fall 2017) of their third year of preschool. We received 363/389 questionnaires (Response rate $=93 \%$ ). Children's numerical and patterning skills were measured later in the school year (spring 2018). At this point, data of 10 children were missing due to changing schools or technical problems during data collection, and the data of these 10 children were further discarded. The final sample consisted of 353 children, including 179 boys $\left(M_{\text {age }}=70.03\right.$ months, $\left.S D_{\text {age }}=3.36\right)$ and 174 girls $\left(M_{\text {age }}=70.01\right.$ months, $\left.S D_{\text {age }}=3.51\right)$. Most of these children were Belgian (92\%) and had Dutch as their mother tongue (82\%). All participating children were sufficiently proficient in Dutch to understand and complete the tasks they were asked to perform.

Most respondents to the parent questionnaire were mothers $(269 / 353$ or $76 \%)$. The respondents in the remaining cases were fathers $(75 / 353$ or $21 \%)$, grandparents $(2 / 353$ or $0.6 \%)$ or unknown $(7 / 353$ or $2 \%)$. Of the 353 respondents, $51 \%$ was in the 35-40 age group. Information on the educational level of 348/353 mothers (99\%) and 322/335 fathers (96\%) was available. These data showed that the participating children came from a diverse range of socioeconomic backgrounds. The educational level of 41 (12\%), 95 (27\%), 79 (23\%), and 133 (38\%) mothers was distributed across the low (= no education, primary education or lower secondary level education), belowaverage (= upper secondary level education), above-average (= professional bachelor degree) and high (= academic bachelor's degree, master's degree or doctoral degree) SES categories, respectively. In addition, the educational level of 51 (16\%), $97(30 \%), 58(18 \%)$, and $116(36 \%)$ fathers was distributed across the low (= no education, primary education or lower secondary level education), below-average (= upper secondary level education), above-average (= professional bachelor degree) and high (= academic bachelor's degree, master's degree or doctoral degree) SES categories, respectively. Most parents were Belgian (85\%) and had Dutch as their mother tongue (75\%).

As stated above, the educational context in which the current data were collected is characterized by a 3-year non-compulsory 
fully government subsidized preschool system, which starts at the age of 2.5 years and guarantees freedom of school choice. As documented by the Economist Intelligence Unit (2012), Belgium scores very high on several indicators of the Starting Well Index: quality (e.g., teacher quality and training, setting out curriculum guidelines and standards, ensuring parental engagement; 5 th place of 45 countries), availability (preschool enrolment ratio and legal right to preschool education, 1st place of 45 countries) and affordability of the provided preschool program (e.g., government pre-primary education spending and subsidies for underprivileged families, 5 th place of 45 countries). Moreover, preschool quality is homogeneous in Belgium. This is a result of, for example, the regulations regarding educational standards, which are designed and supervised by the federal government. Because nearly all children (98\%) attend preschool, almost all children receive a specific, high-quality, albeit nonformal, introduction to several mathematical domains (e.g., counting, measuring, and patterning) from an early age at school. Schools are free to develop their own curricula - including their math-related activities - but they have to aim for specific core learning goals that are specified by the government (Agentschap voor Hoger Onderwijs, Volwassenenonderwijs, Kwalificaties en Studietoelagen, n.d.). The section on math-related preschool learning focuses on various mathematical domains and consists of core learning goals, such as counting up to five objects, comparing quantities, and extending patterns.

\section{Measures \\ Home Math Environment}

The home math environment was measured via a paperand-pencil questionnaire that included questions pertaining to the frequency of parent-child mathematical home activities (7 items), parents' expectations regarding their child's mathematical skills (10 items), as well as their attitudes toward mathematics (3 items). This questionnaire was based on Dutch adaptations of the original questionnaire of LeFevre et al. (2009) by Kleemans et al. (2012) and Rathé et al. (2020). An overview of the items in this questionnaire is included in Supplementary Appendix A. The frequency of home math activities had to be indicated on a 5-point Likert scale ranging from never (0) to every day (4). Parents were asked how often they engaged with their child in several math-related activities, such as counting or elementary calculations during daily activities and creating patterns with concrete materials. Parental expectations were measured on a 4point Likert scale, ranging from not at all important (0) to very important (3), in which they had to indicate how important it was for them that their child masters certain competencies at the start of first grade (e.g., reciting the number sequence up to 10 and extending a pattern). For the last section, parents had to indicate their personal attitudes toward mathematics (e.g., mathematics is important) on a 5-point Likert scale, ranging from completely disagree (0) to completely agree (4). For every participant, an average score was calculated for the three subscales separately. The questionnaire had sufficient reliability with Cronbach's alpha of $0.79,0.89$, and 0.74 for the activities, expectations, and attitudes items, respectively.

\section{Socioeconomic Status (SES)}

Children's SES was also investigated via the parent questionnaire. Respondents had to indicate the highest educational level of both mother and father. These responses were then categorized into four SES categories: low = no education, primary education or lower secondary level education; below-average = upper secondary level education; above-average = professional bachelor degree; high = academic bachelor's degree, master's degree or doctoral degree. Analyses were based on the SES category of the mother. When data on mother's SES category were missing, we checked whether we could use the category of the father. However, for all participants, when data on the educational level of the mother were missing, information on the educational level of the father was also not available.

\section{Numerical Skills}

This measure was highly similar to the materials used in Bakker et al. (2019) and Wijns et al. (2019a,b), which reported on the first year of our longitudinal research project, when children were in their second preschool year (age 4-5). The measure comprised the following tasks: verbal counting (i.e., "Count as high as you can"; 1 item), verbal arithmetic (i.e., "I put N stones in a box, $\mathrm{I}$ add/subtract $\mathrm{M}$ stones, how many stones are in my box now?"; 8 items), object counting (i.e., "Put $\mathrm{N}$ stones on the table."; 8 items), Arabic numeral recognition (i.e., "Which number is this?"; 30 items), number order (i.e., "Which number comes before and after N?"; 8 items), symbolic calculation (i.e., "Look at the card, how much do you get when you add/subtract $\mathrm{N}$ and M?"; 8 items), symbolic number comparison (i.e., "Which of the two numbers is the largest?"; 12 items), non-symbolic number comparison (i.e., "Which dot array has more dots?"; 12 items), and dot enumeration (i.e., "How many dots do you see?"; 18 items). Data were standardized per task, and the average of these standardized scores was used as dependent variable in our analyses. The reliability of this score was high $(\alpha=0.94)$.

\section{Patterning Skills}

Children's repeating patterning skills were assessed by means of the same materials as used by Wijns et al. (2019a). The measure consisted of 18 items that focused on three repeating patterning activities, namely extending (i.e., "Which figure has to be placed in the empty spot at the end of the row?"; 6 items), translating (i.e., "Make the same pattern as above with these figures."; 6 items), and identifying (i.e., "Look at this row, remember the pattern, and reconstruct it."; 6 items) a pattern. All patterns were spatial to minimize the impact of verbal abilities. For each task, data were standardized and the average of the standardized scores was used as dependent variable in our analyses. The reliability of this measure was good $(\alpha=0.80)$.

\section{Procedure}

Parents completed the home math environment questionnaire in the fall of 2017, when children were enrolled in their first semester of the third year of preschool. The questionnaire was available in multiple languages (i.e., Dutch, French, and English) and was distributed via the schools of the children. Data on children's numerical and patterning skills were collected 6 months later, 
in the spring of 2018. Children were tested in two individual sessions of approximately $30 \mathrm{~min}$, which took place in a quiet room at the children's school. Patterning skills were measured in the first session and numerical skills were measured in the second session. The test sessions took place on two different days and all tasks were administered in the same order to each child. The child assessments were conducted by the Ph.D. students working on the longitudinal research project and by several research assistants. All experimenters followed extensive training sessions to get familiar with the tasks and to ensure data quality by minimizing tester effects.

\section{Analytic Approach}

We employed both frequentist and Bayesian statistics to analyze our data with the IBM SPSS Statistics 25 (IBM Corp., 2017), IBM SPSS Statistics 26 (IBM Corp., 2019), PROCESS Macro for SPSS 3.5 (Hayes, 2020), and JASP 0.11.1 software (JASP Team, 2019). Against the background of conflicting evidence on the association between the home math environment and mathematical skills, Bayesian analyses were added because they allowed us to quantify the evidence in support of the alternative hypothesis $\left(\mathrm{H}_{1}\right)$ compared to the null hypothesis $\left(\mathrm{H}_{0}\right)$. This is expressed in the Bayes Factor $\left(\mathrm{BF}_{10}\right)$, which indicates the ratio of the evidence in support of $\mathrm{H}_{1}$ over $\mathrm{H}_{0}$. For example, $\mathrm{BF}_{10}=15$ indicates that the data are 15 times more likely under the alternative hypothesis than under the null hypothesis. These Bayes Factors are a continuous index of support for one or another hypothesis, although there are some conventions for interpreting the size of these factors (Andraszewicz et al., 2015). Specifically, $\mathrm{BF}_{10}=1$ provides no evidence either way, whereas $\mathrm{BF}_{10}>1$ provides anecdotal evidence, $\mathrm{BF}_{10}>3$ provides moderate evidence, $\mathrm{BF}_{10}>10$ provides strong evidence, $\mathrm{BF}_{10}>30$ provides very strong evidence, and $\mathrm{BF}_{10}>100$ provides decisive evidence for the alternative hypothesis. On the other hand, $\mathrm{BF}_{10}<1$ provides anecdotal evidence, $\mathrm{BF}_{10}<1 / 3$ provides moderate evidence, $\mathrm{BF}_{10}<1 / 10$ provides strong evidence, $\mathrm{BF}_{10}<1 / 30$ provides very strong evidence, and $\mathrm{BF}_{10}<1 / 100$ provides decisive evidence for the null hypothesis.

Pearson correlations were calculated to examine the associations between the different variables under study. The Bayesian analyses used the default prior (stretched beta with prior of 1). Effects of child gender and SES on children's home math environment were investigated via $t$-tests and ANOVAs, respectively, the latter of which were corrected for multiple comparisons via Bonferroni post hoc tests. The Bayesian $t$-tests used the default Cauchy distribution centered around 0 with a width of 0.707 and the Bayesian ANOVAs used the default prior of $r$ scale $=0.5$.

We examined the moderating effects of child gender and SES on the relationship between children's home math environment and their numerical and patterning skills by calculating regression models using the PROCESS Macro for SPSS 3.5 (Hayes, 2020). In these models, numerical and patterning skills were predicted by home math environment variables, child gender or SES, and, critically, by the interaction between a particular home math environment variable (activities/expectations/attitudes) and child gender or SES. This interaction indicates whether moderation occurred or not.

All home math environment factors were centered before they were included in the models. We used Helmert coding when including the multicategorical SES factor in our regression models, because of the ordinal dimension of this variable (Hayes, 2017). Using this coding system, the mean of each level of the SES variable, starting from the lowest SES category, is compared with the mean of all the subsequent SES levels (low versus below-average, above-average, and high SES; below-average versus above-average and high SES; above-average versus high SES) (UCLA Statistical Consulting Group, 2020). Lastly, if the interaction of a home math environment variable and gender or SES was significant, we further examined the association between numerical or patterning skills and home math factors for each level of the moderator.

All abovementioned analyses were repeated controlling for children's age. This did not change any of our findings.

\section{RESULTS}

Descriptive statistics of all administered measures are presented in Table 1. A detailed description per item of the home math measure is included in Supplementary Appendix B. There were some missing data on the home environment questionnaire, due to parents skipping one or multiple items. Pairwise deletion was used when substantial information (i.e., non-response on more than half of the items of a subscale) was missing on the activities, expectations, and attitudes scales, for which reason the sample size varied across subscales. The rate of missing data was less than $5 \%$ for all items and data were missing completely at random [Little's MCAR test $\chi^{2}(471)=466.52, p=0.550$ ].

There was considerable variability across the different activities, expectations, and attitudes reported by the parents and for most of the items the full range of response options was used. The home math activities that occurred most frequently (Supplementary Appendix B) were "counting or elementary calculations during daily activities (e.g., counting the number of apples during cooking)" ( $M=2.57)$ and "attending to written numerals during daily activities (e.g., cooking)" $(M=2.13)$. The two patterning-related activities were performed the least frequently $(M=1.17$ and 1.36). Parents reported to have the highest expectations for their children on "reciting the number sequence up to 10 (e.g., $1,2,3,4, \ldots)$ " $(M=2.68)$ and "counting up to 10 objects (e.g., counting 3 candies)" $(M=2.57)$, and the lowest expectations on "solving sums up to 10 (e.g., $5+4)$ " $(M=1.23)$. Frequentist correlation analyses showed significant correlations between all three home

TABLE 1 | Descriptive statistics of the administered home math environment and outcome measures.

Informant $n \quad M \quad$ Min Max $S D$

Home math environment

Activities (0-4 scale)

Expectations (0-3 scale)

Attitudes (0-4 scale)

Numerical skills (standardized composite)

Patterning skills (standardized composite)
Parent $\begin{array}{lllll}351 & 1.81 & 0.00 & 3.71 & 0.69\end{array}$

Parent $\begin{array}{llllll}347 & 2.03 & 0.20 & 3.00 & 0.54\end{array}$

Parent $3482.92 \quad 0.00 \quad 4.00 \quad 0.77$

Child $3530.04-1.91 \quad 1.370 .68$

Child $3530.05-2.091 .120 .73$ 
math environment components. Parents who engaged in more math-related activities had higher math-related expectations for their children, and the Bayesian evidence for this association was decisive $\left[r(345)=0.39, p<0.001, \mathrm{BF}_{10}>100\right]$. There were small positive associations between parents' attitudes and their activities $\left[r(346)=0.12, p=0.024, \mathrm{BF}_{10}=0.86\right]$ and expectations $\left[r(342)=0.12, p=0.023, \mathrm{BF}_{10}=0.90\right]$, but the Bayes factors were close to 1 suggesting neither evidence in favor nor against an association.

\section{Effects of Gender}

As indicated in Table 2, there were no gender differences in any of the home math-related variables. The Bayesian analyses provided substantial evidence in favor of the null hypothesis of gender equality in children's home math experiences $\left(\mathrm{BF}_{10}<1 / 3\right)$.

Although not the primary focus of this study, we additionally explored gender differences in children's numerical and patterning skills. There were no gender differences in numerical skills, yet a small difference favoring girls was observed for children's patterning skills, but the evidence was only anecdotal $\left(\mathrm{BF}_{10}=1.73\right)$.

\section{Effects of SES}

There were no differences in the frequency of parent-child home math activities between the SES groups (Table 3). The Bayes Factors indicated strong evidence in favor of this null hypothesis $\left(\mathrm{BF}_{10}<1 / 3\right)$. The SES groups differed significantly in terms of parental math-related child expectations: parents with low SES had significantly higher expectations than those with aboveaverage ( $p=0.008 ; d=0.67)$ and high SES $(p=0.005 ; d=0.57)$. The evidence for SES differences in parental expectations was moderate $\left(\mathrm{BF}_{10}=9.64\right)$. Parents of children from the SES groups also differed significantly in their math attitudes and the evidence for this hypothesis was strong $\left(\mathrm{BF}_{10}=18.57\right)$.

TABLE 2 | Gender differences in the home math environment and children's numerical and patterning skills.

\begin{tabular}{|c|c|c|c|c|c|c|c|}
\hline \multirow[t]{2}{*}{ Variable } & \multirow{2}{*}{$\frac{\text { Girls }}{M(S D)}$} & \multirow{2}{*}{$\frac{\text { Boys }}{M(S D)}$} & \multirow[b]{2}{*}{$d f$} & \multirow[b]{2}{*}{$t$} & \multirow[b]{2}{*}{$p$} & \multirow[b]{2}{*}{ Cohen's $d$} & \multirow[b]{2}{*}{$\mathrm{BF}_{10}$} \\
\hline & & & & & & & \\
\hline \multicolumn{8}{|l|}{ Home math } \\
\hline \multirow[t]{2}{*}{ Activities } & 1.76 & 1.85 & 349 & 1.22 & 0.225 & 0.13 & 0.24 \\
\hline & $(0.66)$ & $(0.72)$ & & & & & \\
\hline$n$ & 173 & 178 & & & & & \\
\hline \multirow[t]{2}{*}{ Expectations } & 2.00 & 2.06 & 345 & 0.93 & 0.351 & 0.10 & 0.18 \\
\hline & $(0.54)$ & $(0.54)$ & & & & & \\
\hline$n$ & 172 & 175 & & & & & \\
\hline \multirow[t]{2}{*}{ Attitudes } & 2.89 & 2.95 & 346 & 0.66 & 0.507 & 0.07 & 0.15 \\
\hline & $(0.79)$ & $(0.74)$ & & & & & \\
\hline$n$ & 172 & 176 & & & & & \\
\hline \multirow[t]{2}{*}{ Numerical skills } & -0.02 & 0.09 & 351 & 1.61 & 0.107 & 0.17 & 0.41 \\
\hline & $(0.65)$ & $(0.70)$ & & & & & \\
\hline$n$ & 174 & 179 & & & & & \\
\hline \multirow[t]{2}{*}{ Patterning skills } & 0.14 & -0.04 & 351 & -2.37 & 0.018 & -0.25 & 1.73 \\
\hline & $(0.72)$ & $(0.74)$ & & & & & \\
\hline$n$ & 174 & 179 & & & & & \\
\hline
\end{tabular}

TABLE 3 | SES differences in the home math environment and children's numerical and patterning skills.

\begin{tabular}{|c|c|c|c|c|c|c|c|c|c|}
\hline \multirow[b]{2}{*}{ Variable } & \multirow{2}{*}{$\frac{\text { Low }}{}$} & \multirow{2}{*}{$\begin{array}{c}\begin{array}{c}\text { Below- } \\
\text { average }\end{array} \\
M(S D)\end{array}$} & \multirow{2}{*}{$\begin{array}{c}\begin{array}{c}\text { Above- } \\
\text { average }\end{array} \\
M(S D)\end{array}$} & \multirow{2}{*}{$\begin{array}{c}\text { High } \\
M(S D)\end{array}$} & \multirow[b]{2}{*}{$d f$} & \multirow[b]{2}{*}{$F$} & \multirow[b]{2}{*}{$p$} & \multirow[b]{2}{*}{$\eta^{2}$} & \multirow[b]{2}{*}{$\mathrm{BF}_{10}$} \\
\hline & & & & & & & & & \\
\hline Home math & 1.65 & 1.90 & 1.75 & 1.82 & & & & & \\
\hline activities & $(0.88)$ & $(0.66)$ & $(0.69)$ & $(0.65)$ & 3,342 & 1.51 & 0.212 & 0.01 & 0.10 \\
\hline \multirow[t]{2}{*}{$n$} & 39 & 95 & 79 & 133 & & & & & \\
\hline & 2.28 & 2.11 & 1.94 & 1.95 & & & & & \\
\hline Expectations & $(0.50)$ & $(0.48)$ & $(0.50)$ & $(0.59)$ & 3,338 & 5.16 & 0.002 & 0.04 & 9.64 \\
\hline$n$ & 40 & 93 & 78 & 131 & & & & & \\
\hline Attitudes & $\begin{array}{c}2.94 \\
(0.62)\end{array}$ & $\begin{array}{c}2.74 \\
(0.76)\end{array}$ & $\begin{array}{c}2.80 \\
(0.85)\end{array}$ & $\begin{array}{c}3.11 \\
(0.72)\end{array}$ & 3,339 & 5.33 & 0.001 & 0.05 & 18.57 \\
\hline$n$ & 38 & 93 & 79 & 133 & & & & & \\
\hline Numerical skills & $\begin{array}{l}-0.24 \\
(0.70)\end{array}$ & $\begin{array}{c}-0.15 \\
(0.70)\end{array}$ & $\begin{array}{c}0.11 \\
(0.62)\end{array}$ & $\begin{array}{c}0.22 \\
(0.63)\end{array}$ & 3,344 & 8.90 & $<0.001$ & 0.07 & 1503.58 \\
\hline$n$ & 41 & 95 & 79 & 133 & & & & & \\
\hline Patterning skills & $\begin{array}{c}-0.21 \\
(0.76)\end{array}$ & $\begin{array}{c}-0.14 \\
(0.80)\end{array}$ & $\begin{array}{c}0.17 \\
(0.61)\end{array}$ & $\begin{array}{c}0.22 \\
(0.70)\end{array}$ & 3,344 & 7.14 & $<0.001$ & 0.06 & 152.63 \\
\hline$n$ & 41 & 95 & 79 & 133 & & & & & \\
\hline
\end{tabular}

Mothers' educational level was used as a proxy of children's SES.

Follow-up comparisons revealed significant differences between the attitudes from parents of the high SES group and both the above-average $(p=0.027 ; d=-0.40)$ and below-average SES group ( $p=0.002 ; d=-0.51$ ), with the former having more positive attitudes than the latter ones.

Although it was not the primary focus of this study, we additionally explored SES differences in children's numerical and patterning abilities. Significant differences between the SES groups were observed for both numerical and patterning abilities, and these differences were decisive $\left(\mathrm{BF}_{10}>100\right)$. Follow-up comparisons revealed that children from the low SES group performed significantly more poorly on both numerical and patterning tasks than children from the aboveaverage or high SES group $(p<0.05)$. Children with below-average SES showed poorer numerical abilities than children of the high SES group and poorer patterning abilities than children of both the above-average and high SES group $(p<0.05)$.

\section{Associations Between the Home Math Environment and Children's Mathematical Skills}

We subsequently analyzed the associations between children's home math environment and their numerical and patterning skills (Table 4). Parent-child math activities and parental expectations were not correlated with children's numerical skills. The Bayesian approach even indicated strong evidence for the absence of these correlations. A small positive correlation between parents' math attitudes and children's numerical skills was observed, yet the evidence for this association was anecdotal. No associations were observed between the three components of children's home math environment and their patterning skills, and the evidence for an absence of these associations was moderate to strong. Children's numerical and patterning skills were highly correlated $\left[r(352)=0.59, p<0.001, \mathrm{BF}_{10}>100\right]$ and this remained when children's age was additionally controlled for. 
TABLE 4 | Correlations between children's home math environment, numerical skills, and patterning skills.

\begin{tabular}{|c|c|c|c|c|c|c|c|c|}
\hline \multirow[t]{2}{*}{ Home math environment } & \multicolumn{4}{|c|}{ Numerical skills } & \multicolumn{4}{|c|}{ Patterning skills } \\
\hline & $d f$ & $r$ & $p$ & $\mathbf{B F}_{10}$ & $d f$ & $r$ & $p$ & $\mathrm{BF}_{10}$ \\
\hline Activities & 349 & 0.02 & 0.751 & 0.07 & 349 & -0.09 & 0.109 & 0.24 \\
\hline Expectations & 345 & 0.04 & 0.449 & 0.09 & 345 & -0.04 & 0.469 & 0.09 \\
\hline Attitudes & 346 & 0.14 & 0.011 & 1.70 & 346 & 0.01 & 0.894 & 0.07 \\
\hline
\end{tabular}

TABLE 5 | Moderation analyses of the association between children's home math environment and their numerical skills.

\begin{tabular}{|c|c|c|c|c|}
\hline & $B$ & SE & $t$ & $p$ \\
\hline \multicolumn{5}{|l|}{ Gender } \\
\hline Activities*Gender & -0.06 & 0.11 & -0.61 & 0.545 \\
\hline Expectations ${ }^{\star}$ Gender & -0.25 & 0.14 & -1.84 & 0.067 \\
\hline Attitudes*Gender & 0.00 & 0.09 & -0.01 & 0.990 \\
\hline \multicolumn{5}{|l|}{ SES } \\
\hline Activities*SES-1 (1 vs. 2, 3, 4) & 0.11 & 0.13 & 0.85 & 0.398 \\
\hline Activities*SES-2 (2 vs. 3, 4) & -0.09 & 0.12 & -0.75 & 0.454 \\
\hline ActivitiesSES-3 (3 vs. 4) & -0.05 & 0.14 & -0.33 & 0.744 \\
\hline Expectations ${ }^{\star}$ SES-1 (1 vs. $\left.2,3,4\right)$ & 0.03 & 0.22 & 0.12 & 0.904 \\
\hline Expectations ${ }^{\star}$ SES-2 $(2$ vs. 3,4$)$ & -0.28 & 0.17 & -1.67 & 0.095 \\
\hline Expectations*SES-3 (3 vs. 4) & 0.10 & 0.18 & 0.58 & 0.564 \\
\hline Attitudes*SES-1 (1 vs. 2, 3, 4) & -0.14 & 0.18 & -0.80 & 0.424 \\
\hline Attitudes*SES-2 (2 vs. 3, 4) & -0.07 & 0.11 & -0.63 & 0.527 \\
\hline Attitudes*SES-3 (3 vs. 4) & -0.15 & 0.12 & -1.31 & 0.192 \\
\hline
\end{tabular}

Coefficients correspond to the interaction term between the moderator (gender or SES) and components of the home math environment. Analyses including SES as a predictor were performed using Helmert coding (1 = low SES; 2 = below-average SES; 3 = above-average SES; 4 = high SES).

\section{Moderating Effects of Gender and SES}

Additionally, we verified whether the associations between children's home math environment and their numerical as well as patterning skills were moderated by their gender or SES. This was done via regression models in which numerical and patterning skills were predicted by home math environment components, gender or SES, and, critically, by the interaction between a particular home math environment component (activities, expectations, or attitudes) and gender or SES. These interactions are reported in Tables 5, 6 and indicate whether moderation occurred or not (see Supplementary Appendix C for full details of the regression analyses). The analyses revealed that neither gender nor SES moderated the associations between children's home math environment and their numerical (Table 5) and patterning (Table 6) skills, given that all interaction effects were non-significant.

\section{DISCUSSION}

Social interactions with more knowledgeable others can stimulate children's early cognitive development (Vygotsky, 1978). This suggests that parents might be able to create important learning opportunities for their children even before the start of formal schooling and confirms the importance of children's home environment. Not only the activities parents engage in with their children, but also their expectations, beliefs, and attitudes
TABLE 6 | Moderation analyses of the association between children's home math environment and their patterning skills.

\begin{tabular}{|c|c|c|c|c|}
\hline & $B$ & $S E$ & $t$ & $p$ \\
\hline \multicolumn{5}{|l|}{ Gender } \\
\hline Activities ${ }^{\star}$ Gender & -0.01 & 0.11 & -0.05 & 0.963 \\
\hline Expectations ${ }^{\star}$ Gender & -0.11 & 0.15 & -0.72 & 0.474 \\
\hline Attitudes ${ }^{\star}$ Gender & 0.14 & 0.10 & 1.33 & 0.184 \\
\hline \multicolumn{5}{|l|}{ SES } \\
\hline Activities*SES-1 (1 vs. $2,3,4)$ & 0.16 & 0.15 & 1.12 & 0.264 \\
\hline Activities*SES-2 (2 vs. 3, 4) & 0.19 & 0.13 & 1.40 & 0.162 \\
\hline Activities*SES-3 (3 vs. 4) & -0.08 & 0.15 & -0.55 & 0.585 \\
\hline Expectations*SES-1 (1 vs. 2, 3, 4) & -0.10 & 0.24 & -0.40 & 0.694 \\
\hline ExpectationsSES-2 (2 vs. 3, 4) & -0.01 & 0.19 & -0.06 & 0.955 \\
\hline Expectations*SES-3 (3 vs. 4) & 0.04 & 0.20 & 0.22 & 0.824 \\
\hline Attitudes*SES-1 (1 vs. 2, 3, 4) & -0.12 & 0.20 & -0.62 & 0.538 \\
\hline Attitudes*SES-2 (2 vs. 3, 4) & 0.13 & 0.12 & 1.08 & 0.282 \\
\hline Attitudes*SES-3 (3 vs. 4) & -0.13 & 0.13 & -1.03 & 0.302 \\
\hline
\end{tabular}

Coefficients correspond to the interaction term between the moderator (gender or SES) and components of the home math environment. Analyses including SES as a predictor were performed using Helmert coding (1 = low SES; 2 = below-average SES; 3 = above-average SES; 4 = high SES).

can influence children's early cognitive outcomes (e.g., Eccles, 1993; Huntsinger et al., 2000). Against this background, children's home math environment as provided by their parents has been considered as a broad construct, including parental activities, expectations, and attitudes. We extended the existing body of literature on children's home math environment and its association with their mathematical performance by operationalizing mathematics in a more comprehensive way than previous work, considering not only number but also patterning as critical domains of children's home math environment and of their early mathematical development. In order to more carefully investigate the broad spectrum of individual differences, we specifically recruited a large, representative, and diverse sample of children. This allowed us to analyze the effects of children's gender and SES on the variability in children's home math environment, and even more critically, whether these variables moderated the associations between children's home math environment and their mathematical skills. Understanding such moderating effects might explain why previous studies have reported conflicting findings on these associations.

Our data revealed that, despite substantial variability in the home math environment of Flemish children aged 5-6 years old, no gender differences in children's home math environment were observed. There were also no differences between the SES groups in performed home math activities, but small differences existed in parents' math-related expectations and attitudes. We found no evidence for associations between children's home math environment and their numerical and patterning skills. Neither gender nor SES moderated the home math environment mathematical skills associations.

\section{Children's Home Math Environment: Activities, Expectations and Attitudes}

The current study revealed substantial variability in children's home math environment. In line with previous studies (LeFevre et al., 2010; Susperreguy et al., 2020b), parents' math-related 
expectations correlated with the frequency of math-related activities such that parents with higher expectations performed more math-related activities at home, and the evidence for this association was decisive. We also observed, similar to BlevinsKnabe et al. (2000), Missall et al. (2015), and Susperreguy et al. (2020b), an association between parents' attitudes toward mathematics and the math-related activities they performed at home. This association was significant but small (see also Susperreguy et al., 2020a) and the Bayesian analyses indicated that there was neither evidence in favor nor against such an association. The same pattern of findings was observed for the association between parents' attitudes toward mathematics and their math-related expectations for their children.

\section{Variability in Children's Home Math Environment: Effects of Gender and SES}

We did not find any evidence for gender differences in children's home math environment, which is different from what has been observed in Blevins-Knabe and Musun-Miller (1996), Chang et al. (2011), Hart et al. (2016), and del Río et al. (2017). On the other hand, our data are in line with Jordan et al. (2006) and Zippert and Rittle-Johnson (2020), who did not find any gender differences in young children's home math environment. The Bayesian analyses extend these earlier findings by clearly showing moderate evidence for the null hypothesis of no gender differences. Research of Stoet and Geary (2013) has shown variability in the existence of gender differences in 15-year-olds' mathematical performances between (mostly high-achieving) countries. Gender differences in mathematics performances, which vary between countries, might be related to differences in young boys' and girls' home math environment (see Chang et al., 2011), which may also vary across countries, a possibility that requires further investigation.

Although not the specific focus of the current study, our data further replicate earlier reports of no gender differences in children's numerical skills at this young age (Kersey et al., 2018; Bakker et al., 2019; Hutchison et al., 2019). The current sample was the same as in Bakker et al. (2019), yet the present study extends their findings by showing that the earlier reported evidence for gender equality in numerical abilities at the age of 4-5 years continues to exist 1 year later at the age of 5-6 years. We further observed a small gender difference favoring girls in patterning ability, although the evidence for this finding was only anecdotal. Similar findings were recently observed by Lüken and Sauzet (2020). These authors suggested that gender differences in children's early patterning ability might be due to girls engaging more in patterning activities during free play at this age, leading girls to have more experience with these activities. This is a possibility that needs further investigation.

We did not find an effect of children's SES on the reported math-related activities in their home environment. This is similar to Missall et al. (2015) and Hart et al. (2016). Other researchers have, however, reported positive associations between SES and parent-child math-related activities (Starkey et al., 1999, as cited in Starkey et al., 2004; Jordan et al., 2006; Dearing et al., 2012). One explanation for these conflicting findings might be that such positive associations are only observed for certain types of activities. For example, Susperreguy et al. (2020a) recently found that children's SES was positively correlated with some math-related activities (i.e., operational activities and shared number-game play) but not with others (i.e., mapping activities). Future studies should investigate differences in the type and frequency of math-related activities that are provided for children stemming from different SES backgrounds.

In line with Susperreguy et al. (2020b), we found that parents from low SES backgrounds had higher math-related expectations for their children than parents from above-average and high SES backgrounds, and that parents from high SES backgrounds had more positive attitudes toward mathematics than parents from above-average or below-average backgrounds. One explanation for the first finding could be that parents of low SES children find it important for their children to master several mathematical skills from an early age onwards, while parents of children with high socioeconomic background believe that these skills will develop automatically in their children when they grow older and, for example, receive more schooling. The more positive attitudes (e.g., I like mathematics) from high SES parents might stem from their own prior experiences with mathematics, as high SES parents may be more likely to have higher mathematical skills, leading to more positive experiences with mathematics. Future research is necessary to provide further insight into these matters, as the present study cannot confirm these hypotheses.

Not unexpectedly, our data revealed strong associations between SES and children's numerical and patterning skills, with children from higher SES backgrounds showing better performance. This aligns with earlier data on the association between SES and children's early mathematical competencies (e.g., Jordan and Levine, 2009).

Importantly, it needs to be acknowledged that we operationalized SES only via the educational level of the mother. This was motivated by the fact that parental educational level has been identified as the strongest SES predictor of children's educational success (Davis-Kean, 2005). The educational level of the mothers in this study was strongly correlated with that of the fathers $(r=0.67)$, a phenomenon known as educational assortative mating (Eika et al., 2019). A post hoc analysis of the data moreover indicated that the findings were generally the same when the educational level of the father was used instead of that of the mother.

We would like to emphasize that, despite our deliberate sampling procedure to include diverse SES backgrounds, the number of children in the low SES group was small. Moreover, the educational level of the parents of the children in this group was much more heterogeneous than in the other SES groups: the low SES group comprised parents with widely varying profiles, ranging from no education to lower secondary education degree. We also speculate that the parents who consented to participate in this study, but who did not complete the home math questionnaire (26/379 or 7\%), came from lower SES backgrounds, given that children of parents who did return the questionnaire showed significantly better numerical $[t(378)=-3.42, p=0.001]$ and patterning abilities $[t(26.73)=-3.21, p=0.003]$ (see also Sirin, 2005). This possibility is, however, hard to verify, given that for these parents no information about their educational level 
was available. This should be kept in mind when considering the generalizability of our findings.

\section{Associations Between Children's Home Math Environment and Their Mathematical Skills}

We observed little to no associations between children's home math environment and their numerical and patterning skills. The Bayesian analyses even indicated that there was moderate to strong evidence for the null hypothesis of no association for most of the home math components. These observations align with earlier studies focusing on children's early mathematical skills (e.g., Blevins-Knabe et al., 2000; Missall et al., 2015; Zippert and Rittle-Johnson, 2020) and children's spontaneous number focusing tendencies (e.g., Batchelor, 2014; Rathé et al., 2020). They, however, contrast with findings from other studies (e.g., LeFevre et al., 2009; Anders et al., 2012; Dearing et al., 2012; Kleemans et al., 2012; Niklas and Schneider, 2014; Hart et al., 2016; Mutaf-Yildiz et al., 2018a; Susperreguy et al., 2020a) in the same age group that used similar questionnaires to assess the home math environment.

The absence of an association between children's home math environment and their mathematical ability may be due to the presence of moderating variables, such as gender or SES. We tested this by examining the moderating impact of the latter two variables. These analyses revealed that neither gender nor SES moderated the association between children's home math environment and their mathematical skills. This lack of moderating effects of gender and SES on the relationship between the home environment and children's academic achievement aligns with what has been observed in older primary school children (Ciping et al., 2015).

How might the absence of an association between children's home math environment and their mathematical skills in our study be explained? One explanation relates to the characteristics of the preschool learning environment of the children in the current study. This is a factor that has been relatively ignored in research on the home math environment, despite the evidence showing that the quality of children's preschool is associated with their early mathematical development (e.g., Anders et al., 2012). Unfortunately, it was not possible to measure and analyze the quality of the preschools in our study, which should be considered as an important limitation. However, we contend that the general context in which the data were collected might explain our results. More specifically, the present study was executed in Flanders (Belgium) were nearly all children (98\%) of a particular birth cohort participate in a high-quality preschool system, which is fully subsidized by the government and where parents can freely choose the preschool of their choice (Bos et al., 2016). Preschool education is delivered by trained preschool teachers, who aim for specific learning goals with their children before they transition to the first grade of primary school in the year they turn 6 years. An important part of these learning objectives is focused on children's mathematical development (e.g., goals related to counting, number, measurement, and patterning). As a result, the current data were collected in a relatively homogeneous preschool education context, where nearly all children are introduced to various mathematical activities from an early age, and several of these activities were included in the administered home math questionnaire. The systematic attention to mathematical activities in this rather homogeneous and open preschool context with a high participation rate might have an impact on the home math environment parents provide. This context might weaken the association between children's home environment and their early mathematical skills. Such an explanation remains, however, speculative in the absence of cross-cultural studies or studies that are able to compare different preschool systems. Future studies are therefore needed to compare the association between children's home math environment and their mathematical skills in countries that vary widely in their preschool system and participation rate. Against the background of the current data, we predict that the association between children's home math environment and their mathematical skills will be weaker in countries with open preschool education systems and high participation rates. In any case, it is critical for future studies on children's home math environment to also provide explicit information on the preschool system in which children are enrolled. This undoubtedly impacts the home math environment, and consequently its association with children's mathematical skills, and might explain differences between different studies and countries. Taking into account Vygotsky's social development theory (1978), and in line with the assumption of the potential impact of children's preschool on children's development and outcomes (e.g., Sammons et al., 2008; Anders et al., 2012), it might be possible that young children's teachers are (the most) important knowledgeable others when it comes to the development of early mathematical skills. This would suggest that it might be critical to aim for high participation rates in preschool from an early age onwards as well as to invest in high-quality preschool systems for all children. It seems therefore important to further investigate the role of children's preschool and its quality in the development of early mathematical skills, as the present study cannot confirm this hypothesis.

A second reason for the absence of an association between children's home math environment and their mathematical skills might lie in the use of questionnaire data to investigate children's home environment. Our measure had good reliability and was highly similar to questionnaires that have been used in previous research that observed associations between children's home math environment and their mathematical skills (e.g., LeFevre et al., 2009; Kleemans et al., 2012). There are nevertheless several issues that challenge the validity of such questionnaire data. One problem is that parents have to retrospectively report on their activities and that they might not always precisely remember the frequency of these activities. Second, their responses might also be biased due to personal beliefs about their parental role or their intentions, such as spending more time with the child (Green et al., 2007). Third, Likert scales are not always unequivocal to interpret for respondents, and can therefore lead to different interpretations of the provided answer options (Schwarz and Oyserman, 2001). A fourth issue is that the activities that are being questioned are all considered on the same scale of frequency, whereas, in fact, they might vary considerably in their duration and therefore 
result in different relationships with children's mathematical skills. For example, playing math-related games or reading picture books are activities that are much more time-consuming than counting the apples during cooking, and are therefore not fully comparable. This requires a fine-grained psychometric item analysis of the different items that are used in home math questionnaires, to determine a score that optimally reflects such differences in the duration of activities (see Purpura et al., 2019). A final, yet related, problem is that information obtained through questionnaires might not capture information about the quality of parent-child interactions. For example, this quality might be determined by the mathematical language parents use when they engage in math-related activities (e.g., Gunderson and Levine, 2011; Ramani et al., 2015; Susperreguy and Davis-Kean, 2016; Elliott et al., 2017). Moreover, according to Vygotsky (1978) it is important to stimulate children's development by providing activities and practicing skills that are between the child's own achievement level (problems that can be solved independently) and the level of potential development (problems that can be solved under guidance or in collaboration with more knowledgeable others). Additional support might be necessary for parents to provide high-quality home math activities that are appropriate and meaningful for their children, and that are, as claimed by Vygotsky, within their children's zone of proximal development (1978). The quality of home math activities is, however, hard to investigate through questionnaires and requires the use of observational methods, which was, unfortunately, not possible in the present study. The association between such observational measures of parent-child math-related interactions and home math questionnaires has been investigated, yet this research revealed that observational data and questionnaire data were not related to each other (Missall et al., 2017; Mutaf-Yildiz et al., 2018b). Observational data on parent-child math-related interactions when collected in an ecologically valid environment - might provide a more accurate measure of the quality of mathrelated parent-child activities and interactions. Therefore, these data may provide more fine-grained information on how the home environment impacts on children's mathematical ability, as compared to research done exclusively by collecting home environment data through questionnaires. From an educational point of view, such research might also suggest which types of interactions are more effective for parents in stimulating their child's mathematical development. For example, Walsh et al. (2016) showed that asking specific types of questions (i.e., high demanding questions) during shared storybook reading led to improvements in children's vocabulary, whereas others (i.e., interrupting questions) did not. These findings might also be applicable to the enhancement of children's mathematical development and this should be investigated in future studies.

\section{CONCLUSION}

The present study revealed that variability in the parent-child home math activities was not dependent on children's gender nor SES. Variability in parental math-related expectations and attitudes, however, was related to children's SES. We found no evidence for associations between 5- to 6-yearold children's home math environment and their early numerical and patterning skills, and children's gender or SES did not moderate these relationships. We contend that the educational context in which our investigation was executed might explain these findings. We therefore suggest that future studies should investigate the effects of different educational contexts between as well as within countries to verify the extent to which such differences explain the discrepant findings in the current literature on the relationship between children's home math environment and their early mathematical skills.

\section{DATA AVAILABILITY STATEMENT}

The raw data supporting the conclusions of this article will be made available by the authors, without undue reservation.

\section{ETHICS STATEMENT}

The studies involving human participants were reviewed and approved by the Social and Societal Ethics Committee (SMEC) of KU Leuven. Written informed consent to participate in this study was provided by the participants' legal guardian/next of kin.

\section{AUTHOR CONTRIBUTIONS}

LDK: conceptualization, methodology, formal analysis, writing original draft, and project administration. MB: conceptualization, methodology, formal analysis, and writing - original draft. SR and NW: methodology and writing - review and editing. JT: conceptualization, methodology, writing - review and editing, and project administration. LV: conceptualization, methodology, writing - review and editing, and funding acquisition. BDS: conceptualization, methodology, formal analysis, writing original draft, and funding acquisition. All authors contributed to the article and aoved the submitted version.

\section{FUNDING}

This research was supported by Grant KU Leuven project C16/16/001 'Development and stimulation of core mathematical competencies.' MB and SR are both Ph.D. Fellow of the Research Foundation-Flanders (FWO).

\section{SUPPLEMENTARY MATERIAL}

The Supplementary Material for this article can be found online at: https://www.frontiersin.org/articles/10.3389/fpsyg.2020. 547626/full\#supplementary-material 


\section{REFERENCES}

Agentschap voor Hoger Onderwijs, Volwassenenonderwijs, Kwalificaties en Studietoelagen (n.d.). Basisonderwijs. Available online at: https://onderwijsdoelen.be/resultaten?intro=basisonderwijserfilters=onderwijsniveau\%255B0\%255D\%255Bid\%255D\%3Df7dcdedc9e9c97a653c7dba05896ef57a333480b\%26onderwijsniveau\%255B0\%255D\%255Btitel\%255D\%3DBasisonderwijs\%26onderwijsniveau\%255B0\%255D\%255Bwaarde\%255D\%3DBasisonderwijs\%26bo_onderwijs_subniveau\%255B0\%255D\%255Bid\%255D\%3D34a77761b6bb8b9e691aec7c5ff36410d430cc6e\%26bo_onderwijs_subniveau\%255B0\%255D\%255Btitel\%255D\%3DBasisonderwijs\%2520\%253E\%2520Kleuteronderwijs\%26bo_onderwijs_subniveau\%255B0$\% 255 D \% 255$ Bwaarde\%255D\%3DKleuteronderwijs (accessed on 14 January 2020).

Anders, Y., Rossbach, H.-G., Weinert, S., Ebert, S., Kuger, S., Lehrl, S., et al. (2012). Home and preschool learning environments and their relations to the development of early numeracy skills. Early Child. Res. Q. 27, 231-244. doi: 10.1016/j.ecresq.2011.08.003

Andraszewicz, S., Scheibehenne, B., Rieskamp, J., Grasman, R., Verhagen, J., and Wagenmakers, E.-J. (2015). An introduction to Bayesian hypothesis testing for management research. J. Manag. 41, 521-543. doi: 10.1177/0149206314560412

Bakker, M., Torbeyns, J., Wijns, N., Verschaffel, L., and De Smedt, B. (2019). Gender equality in 4- to 5-year-old preschoolers' early numerical competencies. Dev. Sci. 22:e12718. doi: 10.1111/desc. 12718

Batchelor, S. (2014). Dispositional Factors Affecting Children's Early Numerical Development. $\mathrm{PhD}$ dissertation. Loughborough: Loughborough University.

Blevins-Knabe, B. (2016). "Early mathematical development: how the home environment matters," in Early Childhood Mathematics Skill Development in the Home Environment, eds B. Blevins-Knabe and A. Berghout Austin (Cham: Springer International Publishing), 7-28. doi: 10.1007/978-3-319-43974-7_2

Blevins-Knabe, B., and Berghout Austin, A. (eds) (2016). Early Childhood Mathematics Skill Development in the Home Environment. Cham: Springer International Publishing.

Blevins-Knabe, B., Berghout Austin, A., Musun, L., Eddy, A., and Jones, R. M. (2000). Family home care providers' and parents' beliefs and practices concerning mathematics with young children. Early Child. Dev. Care 165, 41-58. doi: 10.1080/0300443001650104

Blevins-Knabe, B., and Musun-Miller, L. (1996). Number use at home by children and their parents and its relationship to early mathematical performance. Early Dev. Parent. 5, 35-45. doi: 10.1002/(sici)1099-0917(199603)5:1<35::aidedp113<3.0.co;2-0

Bos, J. M., Phillips-Fain, G., Rein, E., Weinberg, E., and Chavez, S. (2016). Connecting all Children to High-Quality Early Care and Education: Promising Strategies From the International Community. Washington, DC: American Institutes of Research.

Calvo, A., and Bialystok, E. (2014). Independent effects of bilingualism and socioeconomic status on language ability and executive functioning. Cognition 130, 278-288. doi: 10.1016/j.cognition.2013.11.015

Chang, A., Sandhofer, C. M., and Brown, C. S. (2011). Gender biases in early number exposure to preschool-aged children. J. Lang. Soc. Psychol. 30, 440-450. doi: 10.1177/0261927X11416207

Ciping, D., Silinskas, G., Wei, W., and Georgiou, G. K. (2015). Cross-lagged relationships between home learning environment and academic achievement in Chinese. Early Child. Res. Q. 33, 12-20. doi: 10.1016/j.ecresq.2015.05.001

Clements, D. H., and Sarama, J. (2014). "Other content domains," in Learning and Teaching Early Math: The Learning Trajectories Approach, eds D. H. Clements and J. Sarama (New York, NY: Routledge), 214-229.

Davis-Kean, P. E. (2005). The influence of parent education and family income on child achievement: the indirect role of parental expectations and the home environment. J. Fam. Psychol. 19, 294-304. doi: 10.1037/0893-3200.19.2.294

Dearing, E., Casey, B. M., Ganley, C. M., Tillinger, M., Laski, E., and Montecillo, C. (2012). Young girls' arithmetic and spatial skills: the distal and proximal roles of family socioeconomics and home learning experiences. Early Child. Res. Q. 27, 458-470. doi: 10.1016/j.ecresq.2012.01.002

del Río, M. F., Susperreguy, M. I., Strasser, K., and Salinas, V. (2017). Distinct influences of mothers and fathers on kindergartners' numeracy performance: the role of math anxiety, home numeracy practices, and numeracy expectations. Early Educ. Dev. 28, 939-955. doi: 10.1080/10409289.2017.1331662
Duncan, G. J., Dowsett, C. J., Claessens, A., Magnuson, K., Huston, A. C., Klebanov, P., et al. (2007). School readiness and later achievement. Dev. Psychol. 43, 1428-1446. doi: 10.1037/0012-1649.43.6.1428

Eccles, J. S. (1993). "School and family effects on the ontogeny of children's interests, self-perceptions, and activity choices," in Nebraska Symposium on Motivation, 1992: Developmental Perspectives on Motivation, ed. J. E. Jacobs (Lincoln, NE: University of Nebraska Press), 145-208.

Economist Intelligence Unit (2012). Starting Well: Benchmarking Early Education Across the World. London: The Economist Intelligence Unit.

Eika, L., Mogstad, M., and Zafar, B. (2019). Educational assortative mating and household income inequality. J. Polit. Econ. 127, 2795-2835. doi: 10.1086/ 702018

Elliott, L., Braham, E. J., and Libertus, M. E. (2017). Understanding sources of individual variability in parents' number talk with young children. J. Exp. Child Psychol. 159, 1-15. doi: 10.1016/j.jecp.2017.01.011

Green, C. L., Walker, J. M. T., Hoover-Dempsey, K. V., and Sandler, H. M. (2007). Parents' motivations for involvement in children's education: an empirical test of a theoretical model of parental involvement. J. Educ. Psychol. 99, 532-544. doi: 10.1037/0022-0663.99.3.532

Gunderson, E. A., and Levine, S. C. (2011). Some types of parent number talk count more than others: relations between parents' input and children's cardinalnumber knowledge. Dev. Sci. 14, 1021-1032. doi: 10.1111/j.1467-7687.2011. 01050.x

Hart, S. A., Ganley, C. M., and Purpura, D. J. (2016). Understanding the home math environment and its role in predicting parent report of children's math skills. PLoS One 11:e0168227. doi: 10.1371/journal.pone.0168227

Hayes, A. F. (2017). Introduction to Mediation, Moderation, and Conditional Process Analysis: A Regression-Based Approach, 2nd Edn. New York, NY: The Guilford Press.

Hayes, A. F. (2020). PROCESS Macro (Version 3.5). Computer software.

Huntsinger, C. S., Jose, P. E., Larson, S. L., Balsink Krieg, D., and Shaligram, C. (2000). Mathematics, vocabulary, and reading development in Chinese American and European American children over the primary school years. J. Educ. Psychol. 92, 745-760. doi: 10.1037//0022-0663.92.4.745

Hutchison, J. E., Lyons, I. M., and Ansari, D. (2019). More similar than different: gender differences in children's basic numerical skills are the exception not the rule. Child Dev. 90, e66-e79. doi: 10.1111/cdev.13044

Hyde, J. S., Fennema, E., and Lamon, S. J. (1990). Gender differences in mathematics performance: a meta-analysis. Psychol. Bull. 107, 139-155. doi: 10.1037//0033-2909.107.2.139

IBM Corp. (2017). SPSS statistics (Version 25). Computer software. Armonk, NY: IBM Corp.

IBM Corp. (2019). SPSS statistics (Version 26). Computer software. Armonk, NY: IBM Corp.

JASP Team (2019). JASP (Version 0.11.1). Computer software.

Jordan, N. C., Kaplan, D., Nabors Oláh, L., and Locuniak, M. N. (2006). Number sense growth in kindergarten: a longitudinal investigation of children at risk for mathematics difficulties. Child Dev. 77, 153-175. doi: 10.1111/j.1467-8624. 2006.00862.x

Jordan, N. C., and Levine, S. C. (2009). Socioeconomic variation, number competence, and mathematics learning difficulties in young children. Dev. Disabil. Res. Rev. 15, 60-68. doi: 10.1002/ddrr.46

Kersey, A. J., Braham, E. J., Csumitta, K. D., Libertus, M. E., and Cantlon, J. F. (2018). No intrinsic gender differences in children's earliest numerical abilities. NPJ Sci. Learn. 3, 1-10. doi: 10.1038/s41539-018-0028-7

Kleemans, T., Peeters, M., Segers, E., and Verhoeven, L. (2012). Child and home predictors of early numeracy skills in kindergarten. Early Child. Res. Q. 27, 471-477. doi: 10.1016/j.ecresq.2011.12.004

Klein, A., and Starkey, P. (2004). "Fostering preschool children's mathematical knowledge: findings from the Berkeley math readiness project," in Engaging Young Children in Mathematics: Standards for Early Childhood Mathematics in Education, eds D. H. Clements, J. Sarama, and A.-M. DiBiase (Mahwah, NJ: Lawrence Erlbaum Associates), 343-360.

LeFevre, J.-A., Polyzoi, E., Skwarchuk, S.-L., Fast, L., and Sowinski, C. (2010). Do home numeracy and literacy practices of Greek and Canadian parents predict the numeracy skills of kindergarten children? Int. J. Early Years Educ. 18, 55-70. doi: 10.1080/09669761003693926 
LeFevre, J.-A., Skwarchuk, S.-L., Smith-Chant, B. L., Fast, L., Kamawar, D., and Bisanz, J. (2009). Home numeracy experiences and children's math performance in the early school years. Can. J. Behav. Sci. 41, 55-66. doi: 10. $1037 / \mathrm{a} 0014532$

Lindberg, S. M., Hyde, J. S., Petersen, J. L., and Linn, M. C. (2010). New trends in gender and mathematics performance: a meta-analysis. Psychol. Bull. 136, 1123-1135. doi: 10.1037/a0021276

Lüken, M. M., and Sauzet, O. (2020). Patterning strategies in early childhood: a mixed methods study examining 3- to 5-year-old children's patterning competencies. Math. Think. Learn. doi: 10.1080/10986065.2020.1719452 [Epub ahead of print].

Marks, G. N., McMillan, J., Jones, F. L., and Ainley, J. (2000). The Measurement of Socioeconomic Status for the Reporting of Nationally Comparable Outcomes of Schooling. Camberwell, VI: Australian Council for Educational Research.

Missall, K., Hojnoski, R. L., Caskie, G. I. L., and Repasky, P. (2015). Home numeracy environments of preschoolers: examining relations among mathematical activities, parent mathematical beliefs, and early mathematical skills. Early Educ. Dev. 26, 356-376. doi: 10.1080/10409289.2015.968243

Missall, K. N., Hojnoski, R. L., and Moreano, G. (2017). Parent-child mathematical interactions: examining self-report and direct observation. Early Child Dev. Care 187, 1896-1908. doi: 10.1080/03004430.2016.1193731

Mutaf-Yildiz, B., Sasanguie, D., De Smedt, B., and Reynvoet, B. (2018a). Frequency of home numeracy activities is differentially related to basic number processing and calculation skills in kindergartners. Front. Psychol. 9:340. doi: 10.3389/ fpsyg.2018.00340

Mutaf-Yildiz, B., Sasanguie, D., De Smedt, B., and Reynvoet, B. (2018b). Investigating the relationship between two home numeracy measures: a questionnaire and observations during lego building and book reading. $\mathrm{Br}$. J. Dev. Psychol. 36, 354-370. doi: 10.1111/bjdp.12235

Napoli, A. R., and Purpura, D. J. (2018). The home literacy and numeracy environment in preschool: cross-domain relations of parent-child practices and child outcomes. J. Exp. Child Psychol. 166, 581-603. doi: 10.1016/j.jecp.2017.10. 002

Niklas, F., and Schneider, W. (2014). Casting the die before the die is cast: the importance of the home numeracy environment for preschool children. Eur. J. Psychol. Educ. 29, 327-345. doi: 10.1007/s10212-013-0201-6

Purpura, D. J., Borriello, G., and Schmitt, S. A. (2019). "Item-level variability in the assessment of the home numeracy environment: a graded response model analysis," in Proceedings of the Symposium Conducted at the Annual Meeting of the Mathematical Learning and Cognition Society on V. Simms (chair) A Tricky Mathematical Problem: Developing Rigorous and Valid Measurements of the Preschool Home Numeracy Environment, Ottawa, ON.

Purpura, D. J., and Lonigan, C. J. (2013). Informal numeracy skills: the structure and relations among numbering, relations, and arithmetic operations in preschool. Am. Educ. Res. J. 50, 178-209. doi: 10.3102/0002831212465332

Ramani, G. B., Rowe, M. L., Eason, S. H., and Leech, K. A. (2015). Math talk during informal learning activities in head start families. Cogn. Dev. 35, 15-33. doi: 10.1016/j.cogdev.2014.11.002

Rathé, S., Torbeyns, J., De Smedt, B., and Verschaffel, L. (2020). Are children's spontaneous number focusing tendencies related to their home numeracy environment? ZDM 52, 729-742. doi: 10.1007/s11858-020-01127-z

Rittle-Johnson, B., Fyfe, E. R., Loehr, A. M., and Miller, M. R. (2015). Beyond numeracy in preschool: adding patterns to the equation. Early Child. Res. Q. 31, 101-112. doi: 10.1016/j.ecresq.2015.01.005

Sammons, P., Anders, Y., Sylva, K., Melhuish, E., Siraj-Blatchford, I., Taggart, B., et al. (2008). Children's cognitive attainment and progress in English primary schools during key stage 2: investigating the potential continuing influences of pre-school education. ZfE 10, 179-198. doi: 10.1007/978-3-531-91452-7

Schwarz, N., and Oyserman, D. (2001). Asking questions about behavior: cognition, communication, and questionnaire construction. AJE 22, 127-160. doi: 10.1016/S1098-2140(01)00133-3
Segers, E., Kleemans, T., and Verhoeven, L. (2015). Role of parent literacy and numeracy expectations and activities in predicting early numeracy skills. Math. Think. Learn. 17, 219-236. doi: 10.1080/10986065.2015.1016819

Sirin, S. R. (2005). Socioeconomic status and academic achievement: a metaanalytic review of research. Rev. Educ. Res. 75, 417-453. doi: 10.3102/ 00346543075003417

Skwarchuk, S.-L. (2009). How do parents support preschoolers' numeracy learning experiences at home? Early Child Educ. J. 37, 189-197. doi: 10.1007/s10643009-0340-1

Skwarchuk, S.-L., Sowinski, C., and LeFevre, J.-A. (2014). Formal and informal home learning activities in relation to children's early numeracy and literacy skills: the development of a home numeracy model. J. Exp. Child Psychol. 121, 63-84. doi: 10.1016/j.jecp.2013.11.006

Starkey, P., Klein, A., and Wakeley, A. (2004). Enhancing young children's mathematical knowledge through a pre-kindergarten mathematics intervention. Early Child. Res. Q. 19, 99-120. doi: 10.1016/j.ecresq.2004.01.002

Stoet, G., and Geary, D. C. (2013). Sex differences in mathematics and reading achievement are inversely related: within- and across-nation assessment of 10 Years of PISA data. PLoS One 8:e57988. doi: 10.1371/journal.pone.0057988

Susperreguy, M. I., and Davis-Kean, P. E. (2016). Maternal math talk in the home and math skills in preschool children. Early Educ. Dev. 27, 841-857. doi: 10.1080/10409289.2016.1148480

Susperreguy, M. I., Di Lonardo, Burr, S., Xu, C., Douglas, H., and LeFevre, J.-A. (2020a). Children's home numeracy environment predicts growth of their early mathematical skills in kindergarten. Child Dev. 91, 1663-1680. doi: 10.1111/ cdev.13353

Susperreguy, M. I., Douglas, H., Xu, C., Molina-Rojas, N., and LeFevre, J.-A. (2020b). Expanding the home numeracy model to Chilean children: relations among parental expectations, attitudes, activities, and children's mathematical outcomes. Early Child. Res. Q. 50, 16-28. doi: 10.1016/j.ecresq.2018.06.010

UCLA Statistical Consulting Group (2020). Coding Systems for Categorical Variables in Regression Analysis. Available online at: https://stats.idre.ucla. edu/spss/faq/coding-systems-for-categorical-variables-in-regression-analysis- $2 /$ (accessed on September 15, 2020).

Vygotsky, L. S. (1978). Mind in Society: The Development of Higher Psychological Processes. Cambridge: Harvard University Press.

Walsh, B. A., Sanchez, C., and Burnham, M. M. (2016). Shared storybook reading in head start: impact of questioning styles on the vocabulary of Hispanic dual language learners. Early Child. Educ. J. 44, 263-273. doi: 10.1007/s10643-0150708-3

Wijns, N., De Smedt, B., Verschaffel, L., and Torbeyns, J. (2019a). Are preschoolers who spontaneously create patterns better in mathematics? Br. J. Educ. Psychol. 90, 753-769. doi: 10.1111/bjep.12329

Wijns, N., Torbeyns, J., Bakker, M., De Smedt, B., and Verschaffel, L. (2019b). Fouryear olds' understanding of repeating and growing patterns and its association with early numerical ability. Early Child. Res. Q. 49, 152-163. doi: 10.1016/j. ecresq.2019.06.004

Zippert, E. L., and Rittle-Johnson, B. (2020). The home math environment: more than numeracy. Early Child. Res. Q. 50, 4-15. doi: 10.1016/j.ecresq.2018.07.009

Conflict of Interest: The authors declare that the research was conducted in the absence of any commercial or financial relationships that could be construed as a potential conflict of interest.

Copyright (C) 2020 De Keyser, Bakker, Rathé, Wijns, Torbeyns, Verschaffel and De Smedt. This is an open-access article distributed under the terms of the Creative Commons Attribution License (CC BY). The use, distribution or reproduction in other forums is permitted, provided the original author(s) and the copyright owner(s) are credited and that the original publication in this journal is cited, in accordance with accepted academic practice. No use, distribution or reproduction is permitted which does not comply with these terms. 


\title{
Home Literacy Environment and Children's English Language and Literacy Skills in Hong Kong
}

\author{
Carrie Lau* and Ben Richards \\ Faculty of Education, The University of Hong Kong, Pokfulam, Hong Kong
}

Emerging evidence has shown a positive association between the home literacy environment (HLE) and monolingual children's language and literacy development. Yet, far fewer studies have examined the impact of the HLE on second language development. This study examined relations between the HLE and children's development of English as a second language in Hong Kong. Participants were 149 ethnic Chinese children (80 girls; $M_{\text {age }}=59$ months, $S D_{\text {age }}=10$ months) and one of their caregivers. Caregivers completed questionnaires about their family backgrounds and HLE and children were assessed on their English language and literacy skills. Findings revealed considerable variability in the types of literacy activities that caregivers were

OPEN ACCESS

Edited by: Amy R. Napoli, University of Nebraska-Lincoln, United States

Reviewed by:

Heikki Juhani Lyytinen, University of Jyväskylä, Finland Jinger Pan,

The Education University of Hong Kong, Hong Kong

*Correspondence:

Carrie Lau carrieg/@hku.hk

Specialty section: This article was submitted to Educational Psychology, a section of the journal

Frontiers in Psychology

Received: 04 June 2020 Accepted: 30 December 2020 Published: 29 January 2021

Citation:

Lau C and Richards B (2021) Home Literacy Environment and Children's English Language and Literacy Skills in Hong Kong.

Front. Psychol. 11:569581. doi: 10.3389/fpsyg.2020.569581 engaged in at home with their children. A series of multilevel regressions demonstrated that the HLE was differentially associated with English vocabulary, letter knowledge, phonological awareness, and word reading skills after controlling for child and family characteristics. Results highlight the importance of a literacy-rich home environment for children's development of English as a second language and the need to support caregivers in providing a range of home literacy activities to facilitate different language and literacy skills.

Keywords: home literacy environment, English as a second language, language and literacy, early years, parent-child engagement

\section{INTRODUCTION}

It has been well documented that differences in language and literacy skills emerge early in life (Hart and Risley, 1995; Fernald et al., 2013). Extant research has explored individual and environmental factors that underlie variability in language growth and development (Dickinson and Tabors, 2001). Mounting evidence suggests that the home literacy environment (HLE) is one of the most significant predictors of early language and literacy development (Frijters et al., 2000; Niklas et al., 2015). As gaps in language, literacy and achievement persist over time and can have long-lasting impact on children (Stanovich, 1986), it is critical to understand the characteristics and role of the HLE starting from the early years in order to disentangle the factors and processes associated with language and literacy outcomes and to identify the kinds of support needed for children and families.

With the rise of English as a global language (Crystal, 2012), a growing number of studies has investigated the association between the HLE and children's development of English as a second language. However, to date, most studies that examined the influence of the HLE on children's proficiency in English as a second language have primarily been conducted in predominantly 
English-speaking contexts (e.g., Duursma et al., 2007; Farver et al., 2013). Far less research has focused on HLE and second language learners of English in multilingual contexts (e.g., Kalia and Reese, 2009; Dixon, 2011). Against this background, the present study examined whether and how HLE is associated with the development of English as a second language in a sample of ethnic Chinese children from Hong Kong.

\section{CONCEPTUALIZING THE HOME LITERACY ENVIRONMENT}

Much of the early research on the HLE primarily focused on differences in HLE by family socioeconomic background (e.g., income and parental education) or on a single literacy activity, most notably parent-child reading as a defining feature of the HLE (Payne et al., 1994; Scarborough and Dobrich, 1994). Later work conceptualized the HLE as a multidimensional construct that encompassed a variety of literacy-related interactions, resources and attitudes, consisting of parent-child joint activities, such as shared reading, parental teaching of print-related skills, singing songs and rhymes, storytelling and watching educational television programs (Frijters et al., 2000; Wood, 2002); availability of learning materials, such as the number of books at home (Sénéchal et al., 1998); and parental beliefs and attitudes toward literacy (Debaryshe, 1995; Weigel et al., 2006). Based on the Home Literacy Model (Sénéchal and LeFevre, 2002; Sénéchal, 2006), home literacy experiences can be categorized into formal and informal interactions. Formal literacy interactions refer to activities in which the focus is on the features of print (e.g., adults directly teaching children printrelated skills, such as letter names and sounds; adults pointing to letters in the text), whereas informal literacy interactions refer to opportunities that are centered on the meaning attached to print (e.g., often manifested by shared reading; adults focusing on meaning carried by the text during shared reading). The HLE can be further differentiated into active components, which emphasize parent-child engagement in literacy activities and passive components, which refer to children's observations of parents modeling literacy behaviors (e.g., parents' engagement in reading) (Burgess et al., 2002).

\section{HOME LITERACY ENVIRONMENT AND CHILDREN'S LANGUAGE AND LITERACY OUTCOMES}

An extensive body of research has shown concurrent and longitudinal links between the HLE and children's early language and literacy development (Burgess et al., 2002; Manolitsis et al., 2011; Rodriguez and Tamis-Lemonda, 2011; Sénéchal and LeFevre, 2014; Tamis-Lemonda et al., 2019). Shared reading -the most studied aspect of the HLE-has been found to contribute significantly to the development of receptive and expressive vocabulary (Sénéchal et al., 1998; Evans and Shaw, 2008; Farrant and Zubrick, 2012), letter name and letter sound knowledge (Frijters et al., 2000), and as well as listening comprehension
(Sénéchal and LeFevre, 2002). In several meta-analytic reviews (e.g., Scarborough and Dobrich, 1994; Bus et al., 1995; Mol et al., 2008, 2009), the frequency of exposure to parent-child reading accounted for unique variance in children's language and literacy skills, and later reading achievement. Other indices of shared reading, such as the number of books in the home, visits to the library, children's requests to be read to and the age at which children were first read to by their parents contributed substantial variance to language growth (Debaryshe, 1993; Payne et al., 1994; Raikes et al., 2006). The quality of book reading, including the reading behaviors of parents and interactions during shared reading was also found to be significant correlates of children's language and literacy outcomes (van Kleeck et al., 1997; Deckner et al., 2006). Correlational (e.g., Haden et al., 1996) and intervention studies (e.g., Whitehurst et al., 1988; Reese and Cox, 1999; Justice and Ezell, 2000) revealed that reading behaviors, such as asking questions, labeling and describing objects, and providing feedback and focusing on print yielded significant positive effects on vocabulary and print knowledge.

Another aspect of the HLE, direct teaching of print-related skills (e.g., letter recognition and letter sounds) has been found to predict children's alphabet knowledge (Evans et al., 2000; Hood et al., 2008; Hindman and Morrison, 2012; Martini and Sénéchal, 2012), phonological awareness (Foy and Mann, 2003; Johnson et al., 2008; Niklas and Schneider, 2013), word reading (Puglisi et al., 2017), and writing (Puranik et al., 2018). Existing studies have combined a range of parent-child joint activities as a measure of the HLE in predicting early language and literacy outcomes (e.g., Griffin and Morrison, 1997; Leseman and de Jong, 1998; Wood, 2002; Van Steensel, 2006). For instance, Van Steensel (2006) found that children who participated in a variety of joint literacy activities, such as shared reading, library visits and singing nursery songs, as well as observed parents and/or siblings engaging in literacy activities themselves exhibited gains in vocabulary and general reading comprehension. Wood (2002)'s study demonstrated that children who were exposed to four types of parent-child literacy activities (i.e., storybook reading, letter-based activities, singing, and playing language games) had significantly higher vocabulary and reading ability scores as compared to their counterparts who were engaged in singing only or to those that did not participate in almost any of the literacy activities. Weigel et al. (2006)'s findings revealed that children's engagement in a variety of parent-child joint activities, such as shared reading, storytelling, singing rhymes, drawing pictures, playing games and television viewing was associated with enhanced print knowledge. Indeed, several large-scale longitudinal studies have adopted a multidimensional approach in examining the HLE that captures variations in the type of literacy activities that children are exposed to at home. For instance, the Index of Early Home Literacy Activities of the Progress in International Reading Literacy Study (Mullis et al., 2007) examines early literacy experiences through six activities, namely reading books, telling stories, singing songs, playing with alphabet toys, playing word games and reading aloud signs and labels.

Cumulative research has demonstrated the associations between aspects of the HLE and children's early language and 
literacy skills in their native language (Sénéchal et al., 1998; Hindman and Morrison, 2012). Studies with children from different ethnic backgrounds and/or contexts who are learning English as a second or foreign language have found similar results (e.g., Hammer et al., 2003; Duursma et al., 2007; Kalia and Reese, 2009). Farver et al. (2013)'s study with Latino immigrant children in the United States found that parents' engagement in activities was positively associated with children's oral language skills in both English and Spanish. Further, home literacy resources in English and parents' literacy behaviors in Spanish were associated with children's print knowledge in both English and Spanish. In another study with Indian children learning English, it was found that book reading practices and parental teaching predicted children's print skills in English and that book reading practices moderated the relationship between the degree of English spoken at home and children's English receptive vocabulary skills (Kalia and Reese, 2009). Indeed, as there is greater complexity in the HLE of children and families that navigate multiple languages in their homes and community contexts, it is worthwhile to identify specific pathways through which the HLE may impact children's language and literacy development. Oral language and early literacy skills are interrelated components that provide a crucial basis for children's academic success and subsequent educational attainment in school. In the development of English, vocabulary, phonological awareness, and letter knowledge have been found to predict word reading abilities among first and second language learners (Whitehurst and Lonigan, 1998; Muter et al., 2004). This study therefore, explores the relationship between a combination of home literacy activities and the development of English as a second language among ethnic Chinese children in Hong Kong and focuses specifically on English vocabulary, phonological awareness, letter knowledge, and word reading skills.

\section{THE HONG KONG CONTEXT}

Hong Kong was a British colony from 1841 to 1997. During most of the colonial period, English was the sole official language. In 1974, Chinese became a co-official language alongside with English. Since 1997, the Hong Kong government has adopted the "biliterate and trilingual" language policy to enable its citizens to become proficient in written English and Chinese and in spoken English, Cantonese, and Putonghua. Cantonese is the mother tongue of the majority of the local population and is used most often in workplace and non-workplace settings, such as in the communication with spouses, children, parents, friends, colleagues, and clients (Bacon-Shone et al., 2015; Census and Statistics Department HKSAR, 2019). Over time, the proportion of the population using English as the usual language (i.e., in daily communication) increased from $2.2 \%$ in 2001 to $4.3 \%$ in 2016 (Census and Statistics Department HKSAR, 2017). Among individuals with children aged six and below and whose mother tongue is not English, around 13.7\% must or often use English to communicate with their children. The most cited reasons for parents to use English were to offer children the opportunities to be exposed to English and the belief that it is better for their children to learn English earlier (Census and Statistics Department HKSAR, 2019).

Despite the predominant use of Cantonese among the general population in Hong Kong, proficiency in English is highly prized and is viewed as a vehicle for upward social mobility (Evans, 2000). English is one of the languages used in the Government and in legal, professional and business sectors. In education, English is the medium of instruction in private universities and in six out of eight government-funded universities (Kirkpatrick and Liddicoat, 2017). The outpouring of criticism of the compulsory Chinese medium instruction policy for secondary schools in 1998 eventually led to the fine-tuning of the medium of instruction policy in 2010 (Tollefson and Tsui, 2018), reflecting the priorities placed on English language education by stakeholders such as parents and the business community. Owing to the marketdriven nature of the kindergarten sector in Hong Kong, parental preference for English further contributed to the push toward the early provision of English language teaching in schools amidst the implementation of the 'biliterate and trilingual' language policy (Leung et al., 2013).

English is promoted as a second language in the local school curriculum starting from the early years. As recommended in government curriculum and policy documents, English is introduced in kindergartens on condition that teachers possess appropriate levels of language proficiency and adopt an informal teaching approach, such as through the use of songs, storytelling, and language activities (Education Department, 1994, 1999; SCOLAR, 2003). The objectives of English language teaching in the early years are to nurture children's interest, attitude and confidence toward English and to develop basic skills, such as understanding simple conversations and words (Curriculum Development Council, 2006, 2017). The frequency and structure of English language teaching, however, vary considerably across kindergartens such that English is: (i) taught as a subject by local and/or native English-speaking language teachers (i.e., children are exposed to the language for only a certain amount of time per week); (ii) introduced within a bilingual/trilingual program (i.e., children are simultaneously exposed to multiple languages during the school period and an English class teacher may be present alongside a Cantonese and/or Putonghua class teacher in the classroom); or (iii) used as the main medium of instruction (Lau and Rao, 2013; $\mathrm{Ng}$ and Rao, 2013). In Hong Kong, kindergartens are categorized as either privateindependent or non-profit making. The latter makes up 80\% of all kindergartens in Hong Kong (Education Bureau, 2019) and are eligible to apply for the Kindergarten Education Scheme (in which kindergartens are funded by the government to provide free half-day services for children) (Education Bureau, 2016). In most non-profit making kindergartens, Chinese (Cantonese) is the medium of instruction and English is taught as a subject (Lau, 2020). The variation in exposure to English, coupled with differences between the first and second language (Chinese as a morphosyllabic language versus English orthography), poses some unique challenges for children in learning English in Hong Kong.

To date, only limited empirical studies have examined factors and contexts that underlie English language development among 
young children in Hong Kong. A small number of studies have specifically explored the HLE and children's English language and literacy development (e.g., Yeung and King, 2016; Tse et al., 2017). In Yeung and King's (2016)'s study of the HLE among children learning English as a second language, it was found that there were variations in home support and parents were engaged in home teaching (e.g., homework instruction) more frequently than in shared reading and in the provision of literacy materials. Findings revealed differential impacts of the HLE on children's English language and literacy outcomes. Shared reading predicted children's receptive and expressive vocabulary, syllable awareness and word reading skills while home teaching predicted letter knowledge and the provision of literacy materials predicted expressive vocabulary only. Tse et al. (2017) further demonstrated the long-term impact of early home reading activities (i.e., prior to entry into primary school) on the Chinese and English reading attainment of 1376 Grade 4 students. Specifically, a combination of activities including storybook reading, storytelling, singing songs, playing word games, writing letters and reading aloud signs contributed to children's reading performance in English. However, it was noted that a sizeable number of parents never or almost never engaged in home reading activities in English prior to or during their children's primary schooling. Related studies point to the role of family processes in children's school readiness in Hong Kong. Lau et al. (2011) found that parents were engaged more in home-based involvement than in school-based involvement. Home-based involvement, including the provision of language and cognitive activities had the strongest predictive relationship to children's school readiness. In another study, Ip et al. (2016) demonstrated that reading (e.g., storybook reading and storytelling) and recreational activities (e.g., listening to music and playing together) in the home learning environment significantly mediated socioeconomic gradients in children's school readiness. Intervention studies on parent-child reading also revealed positive effects on children's language and literacy development. Chow et al. (2010)'s study demonstrated the effectiveness of a 12-week parent-child reading intervention (dialogic reading vs. typical reading vs. control) on children's development of English as a second language. More specifically, both typical reading and dialogic reading yielded significant intra-group gains in word reading skills. Further, children in the dialogic reading condition had gains in phonological awareness. Together, these studies suggest the importance of parental engagement at home and the provision of a literacy-rich environment to support children's development.

However, much remains unknown about the types of home literacy activities that caregivers are engaged in to support children's English language learning, as well as the potential role of related factors in children's development of English as a second language in Hong Kong. The current study extends previous research by examining the HLE more extensively (e.g., including reading behaviors and media-based activities) in relation to a range of early English language and literacy skills. Further, this study considers a host of factors that underlie children's exposure to English (e.g., enrolment in extracurricular English lessons, amount of English exposure at school) in the analysis of the predictive role of the HLE on early English language and literacy outcomes. The present work is situated within theoretical frameworks that highlight the interactions and interrelationships among individual and environmental factors and is underpinned by: (i) the bioecological theory that views home experiences as proximal processes that serve as primary engines in predicting child development (Bronfenbrenner and Morris, 2006); (ii) the social learning theory, which stresses the role of interactions with more experienced others, such as parents in optimizing development and learning (Vygotsky, 1978); and (iii) the attachment theory, which highlights the significance of responsive, stimulating and supportive caregiving in child development (Bretherton, 1985). Arising from the aforementioned theories is also the notion that culture plays an integral part of proximal processes that shape children's development, including language and thought. Hong Kong is uniquely positioned for the study of the HLE amidst culturally specific parenting values and practices among Chinese parents (e.g., priorities on academic preparedness) (Luo et al., 2013), the implementation of the "biliterate and trilingual" language education policy (Wang and Kirkpatrick, 2019) and the status of English in a post-colonial society (Bolton, 2012). Findings from this study will provide important insights into the nuances and complexities of the contextual support for English language learning in a multilingual context and enable the identification of specific dimensions of the HLE that effectively facilitate the development of English as a second language among young learners. The research questions for this study were as follows: (a) What kinds of home literacy practices are caregivers engaged in to support children's English language and literacy development?; (b) What is the relationship between the HLE and children's English language and literacy skills?; (c) To what extent does the HLE predict children's English language and literacy skills? Based on the review of learning-related practices of Chinese parents in Chinese contexts (Ng and Wei, 2020), it is hypothesized that caregivers will engage more in direct teaching of print-related skills than in other home literacy activities, such as shared reading. The HLE, as measured by caregivers' reports of their engagement in literacy activities with children, will be positively associated with early English language and literacy outcomes even when controlling for child and family characteristics. It is expected that different aspects of the HLE will be differentially related to children's English language and literacy skills. Specifically, based on Chow et al.'s (2010) findings, it is expected that shared reading will be associated with a range of English language and literacy skills.

\section{MATERIALS AND METHODS}

\section{Participants}

A total of 149 children ( 69 boys and 80 girls) between the ages of 39 and 81 months ( $M_{\text {age }}=59$ months, $S D_{\text {age }}=10$ months $)$ and one of their caregivers were recruited from one K1 (for 3- to 4-year olds), K2 (for 4- to 5- year olds) or K3 (for 5- to 6- year olds) class from 10 non-profit making kindergartens in Hong Kong. The number of children recruited from each kindergarten ranged from 8 to 26. Information on 
the frequency and content of English language teaching was collected through an interview with the English teacher in the participating kindergartens. English language teaching ranged from 20 to 40 min per session and from 1 to 5 days per week. The curricula and teaching contents in English language teaching were comparable across kindergartens and emphases were placed on the development of letter knowledge and sounds, vocabulary and sentence structures through a variety of activities, such as storybook reading, singing songs, playing word games, and prereading and pre-writing opportunities.

Table 1 shows descriptive statistics of children and their families. Participating caregivers were mostly the child's mother $(81 \%)$ or father $(17 \%)$, whilst $2 \%$ were other caregivers. Caregivers provided demographic and socioeconomic information about both parents using a questionnaire. All children in the sample were exposed to English lessons at school, ranging from $0.7 \mathrm{~h}$ per week to $2 \mathrm{~h}$ per week. Parents' highest educational qualification was measured over 7 levels from primary education to doctoral degree. The mean highest qualification for both mothers and fathers was close to level 3 (upper secondary), with a mean of 3.1 for mothers and 3.2 for fathers. Household income was measured across 10 bands, from less than $\$ 4,000 \mathrm{HKD}$ per month to greater than or equal to $\$ 100,000 \mathrm{HKD}$ per month. The mean (4.8) was close to band 5 ( $\$ 30,000$ to $\$ 39,999 \mathrm{HKD}$ per month). Respondents reported

TABLE 1 | Descriptive statistics of key variables for children in the sample.

\begin{tabular}{|c|c|c|c|c|c|}
\hline & $n$ & Mean (\%) & SD & Minimum & Maximun \\
\hline \multicolumn{6}{|l|}{ Background variables } \\
\hline Age (months) & 149 & 59.29 & 9.69 & 39.80 & 80.63 \\
\hline Non-verbal IQ & 149 & 6.89 & 2.03 & 2.00 & 11.00 \\
\hline Gender (\% girls) & 149 & 54 & & & \\
\hline $\begin{array}{l}\text { English primary language at } \\
\text { home (\%) }\end{array}$ & 148 & 15 & & & \\
\hline $\begin{array}{l}\text { Extracurricular English } \\
\text { lessons (\%) }\end{array}$ & 149 & 23 & & & \\
\hline $\begin{array}{l}\text { Hours of English at school } \\
\text { per week }\end{array}$ & 149 & 1.13 & 0.45 & 0.67 & 2.00 \\
\hline $\begin{array}{l}\text { Mother's highest } \\
\text { qualification (7 levels) }\end{array}$ & 148 & 3.15 & 1.21 & 1.00 & 6.00 \\
\hline $\begin{array}{l}\text { Father's highest } \\
\text { qualification ( } 7 \text { levels) }\end{array}$ & 146 & 3.23 & 1.30 & 1.00 & 6.00 \\
\hline $\begin{array}{l}\text { Household income (10 } \\
\text { income bands) }\end{array}$ & 148 & 4.81 & 1.98 & 2.00 & 10.00 \\
\hline \multicolumn{6}{|c|}{ Language and literacy measures } \\
\hline Phonological awareness & 149 & 1.63 & 2.22 & 0.00 & 10.00 \\
\hline Receptive vocabulary & 149 & 16.97 & 4.61 & 7.00 & 24.00 \\
\hline Letter knowledge & 149 & 18.06 & 7.60 & 1.00 & 26.00 \\
\hline Word reading & 149 & 4.25 & 8.03 & 0.00 & 30.00 \\
\hline
\end{tabular}

Descriptive statistics are shown before imputation of missing values and before variable standardization. There were 7 levels of qualifications: Primary; Lower Secondary (Grade 7-9); Upper Secondary (Grade 10-12); Higher Certificate, Diploma, or Associate Degree; Bachelor's degree; Master's degree; and Doctoral Degree. Income was measured as household monthly income in HKD, across 10 bands: under \$4,000; \$4,000-\$9,999; \$10,000 - \$19,999; \$20,000 - \$29,999; $\$ 30,000-\$ 39,999 ; \$ 40,000-\$ 49,999 ; \$ 50,000-\$ 59,999 ; \$ 60,000-\$ 79,999$; $\$ 80,000-\$ 99,999 ;$ and $\geq \$ 100,000$. the primary language(s) used at home, with 95\% of respondents using Cantonese, 20\% using Mandarin, 15\% using English, and $2 \%$ using another language (respondents could select all options that applied). Twenty-three percent of children had extracurricular English lessons.

\section{Measures}

Children were directly assessed using one measure of non-verbal intelligence, and four measures of English language and literacy: receptive vocabulary, phonological awareness, letter knowledge, and word reading. The HLE was measured based on responses to the caregiver questionnaire. Socio-demographic variables were also created based on responses to the caregiver questionnaire. School information on English language teaching was obtained through the teacher interview.

\section{Non-verbal Intelligence}

Sets A and B (24 items) of the Raven's Colored Progressive Matrices (Raven et al., 1995) were administered to assess children's non-verbal intelligence. Children were asked to select one missing piece from six available options to complete a matrixlike pattern with a missing section. One point was awarded for every correct answer. Cronbach's alpha was 0.58 .

\section{Receptive Vocabulary}

Two item sets (24 items) of the Peabody Picture Vocabulary Test- IV (PPVT-4; Dunn and Dunn, 2007) were used to measure children's receptive vocabulary. Children were presented with four pictures and asked to point to the illustration that corresponded to the word that was orally presented by the assessor. One point was awarded for every correct answer. As the PPVT-4 was not normed within the local Hong Kong population, raw scores were used in the analysis. Cronbach's alpha was 0.84 .

\section{Phonological Awareness}

The elision sub-test (20 items) of the Comprehensive Test of Phonological Processing - Second Edition (CTOPP-2) (Wagner et al., 2013) was used to measure children's phonological awareness. The assessor read aloud a two-syllable word and children were asked to delete a target syllable (e.g., say airplane without saying plane) or to delete phonemes from each word that was presented orally by the assessor (e.g., say cup without saying/k/). One point was awarded for every correct answer. As the CTOPP-2 was not normed within the local Hong Kong population, raw scores were used in the analysis. Cronbach's alpha was 0.76 .

\section{Letter Knowledge}

Children were asked to name the lowercase letters of all 26 letters of the alphabet that were presented in random order. One point was awarded for every correct answer. Cronbach's alpha was 0.95.

\section{Word Reading}

Children's word reading skills were assessed using a locally developed test by McBride-Chang and Kail (2002). This test consisted of 30 English words that were constructed from textbooks used in kindergartens in Hong Kong. Children were presented with the English words and asked to read each 
word aloud. One point was awarded for every correct answer. Cronbach's alpha was 0.98 .

\section{Home Literacy Environment}

The caregiver questionnaire consisted of items that tapped into the frequency of caregivers' engagement in English literacy activities with children, such as shared reading (e.g., number of children's books, age at which the child was first read to, frequency of shared reading and parents' reading behavior during shared reading), storytelling, direct teaching of print-related skills (e.g., letter sounds and alphabets), visiting the library, singing rhymes/songs, using apps or digital media, watching television programs and helping with schoolwork. The frequency of engagement was assessed on a 7-point likert scale ranging from 0 (never) to 7 (daily). Caregivers were also asked to indicate the extent to which they agreed with statements about their behaviors if and when they read to children (e.g., I emphasize printed words while reading) on a continuum from strongly disagree to strongly agree. Response choices for the number of children's books in English were coded on a 7-point scale ranging from 0 (none) to 7 (more than 100). An overall composite variable representing the HLE was created by standardizing each item, taking the mean of all items, and standardizing the composite HLE variable.

\section{Socio-Demographic Variables}

The caregiver questionnaire also included items on child characteristics, as well as family demographic and socioeconomic information, such as household monthly income (10 levels), mother's and father's education level (highest educational qualification over 7 levels), the primary language(s) spoken at home, and whether or not children participated in extracurricular English lessons (see Table 1).

\section{School-Level Data on English Language Teaching}

Information about the structure and arrangement of English language teaching in each of the participating kindergartens was obtained through an interview with the English teacher in the participating child's class. The interviewed teacher was asked about the duration and frequency of English language teaching per week, as well as the teaching content of the English curriculum at the school.

\section{Procedure}

Written informed consent was obtained from kindergarten principals, teachers and parents. Caregivers completed a questionnaire to provide socio-demographic information about children and both parents. The questionnaires were distributed to caregivers and returned in sealed envelopes via children's class teachers at the school. Children were individually assessed on their non-verbal intelligence and English language and literacy skills by trained assessors, who were undergraduates and graduates majoring in early childhood education. The assessments took place in a quiet area at the school and lasted around 20 to $30 \mathrm{~min}$ for each child. The English teacher in each of the participating class was interviewed about the structure and arrangement of English language teaching in the school. The interview lasted for about $5 \mathrm{~min}$.

\section{Analytic Plan}

All analyses were conducted using Stata 15.1. Descriptive statistics were calculated for the raw scores of each of the key variables. Composite variables representing receptive vocabulary, phonological awareness, letter knowledge, and word reading were calculated by summing the relevant items and standardizing the total.

Exploratory factor analysis (principal component factors) was conducted on all HLE items to explore the factor structure of the HLE measure. Loadings for each item were examined after orthogonal varimax rotation with the objective of attaining an optimal simple structure (Yong and Pearce, 2013). Variables were excluded if they had a high proportion of uniqueness or did not load onto a common factor, and the factor analysis was repeated. The result was the exclusion of three variables, and a final 3 factor solution explaining $75 \%$ of variance with 3 factors having eigenvalues greater than 1 (Table 2). A composite variable was created to represent each factor, based on the items that had high loadings ( 0.6 or above) on that factor. Each composite factor variable was calculated using the standardized mean of the items with high loadings and was then also standardized.

A variable representing composite parental socioeconomic status (SES) was created using a latent factor measurement model using maximum likelihood estimation and allowing

TABLE 2 | Rotated 3 factor solution of Home Literacy Environment variables.

\begin{tabular}{|c|c|c|c|c|}
\hline Variable & $\begin{array}{l}\text { Factor 1: } \\
\text { Shared } \\
\text { reading and } \\
\text { storytelling }\end{array}$ & $\begin{array}{l}\text { Factor 2: } \\
\text { Teaching } \\
\text { of print- } \\
\text { related } \\
\text { skills }\end{array}$ & $\begin{array}{c}\text { Factor 3: } \\
\text { Play and } \\
\text { media- } \\
\text { based } \\
\text { activities }\end{array}$ & Uniqueness \\
\hline $\begin{array}{l}\text { Age of child when first } \\
\text { read to }\end{array}$ & 0.86 & 0.11 & 0.19 & 0.22 \\
\hline Ask questions & 0.92 & 0.12 & 0.15 & 0.12 \\
\hline $\begin{array}{l}\text { Highlight or explain } \\
\text { vocabularies }\end{array}$ & 0.93 & 0.13 & 0.14 & 0.10 \\
\hline Emphasize printed words & 0.91 & 0.09 & 0.09 & 0.15 \\
\hline Discuss sounds of words & 0.93 & 0.17 & 0.10 & 0.09 \\
\hline Read English books & 0.81 & 0.18 & 0.26 & 0.24 \\
\hline Tell stories in English & 0.70 & 0.06 & 0.31 & 0.41 \\
\hline $\begin{array}{l}\text { Sing English nursery } \\
\text { rhymes/songs }\end{array}$ & 0.29 & 0.16 & 0.66 & 0.46 \\
\hline $\begin{array}{l}\text { Play with English digital } \\
\text { media }\end{array}$ & 0.27 & 0.14 & 0.82 & 0.24 \\
\hline $\begin{array}{l}\text { Watch English TV } \\
\text { programmes }\end{array}$ & 0.20 & 0.21 & 0.72 & 0.40 \\
\hline $\begin{array}{l}\text { Teach child English } \\
\text { alphabet letters }\end{array}$ & 0.19 & 0.71 & 0.46 & 0.25 \\
\hline Teach child letters sounds & 0.18 & 0.78 & 0.22 & 0.32 \\
\hline $\begin{array}{l}\text { Teach child to read } \\
\text { English words }\end{array}$ & 0.10 & 0.83 & 0.23 & 0.25 \\
\hline $\begin{array}{l}\text { Teach child to write } \\
\text { English words }\end{array}$ & 0.19 & 0.79 & -0.19 & 0.30 \\
\hline
\end{tabular}

The table shows the 3-factor solution (principal component factors) after orthogonal varimax rotation, explaining $75 \%$ of variance. Three factors had eigenvalues of greater than 1. Loadings of greater than 0.6 are in bold for ease of interpretation. 
for missing values, based on the mother's highest level of education, father's highest level of education, and monthly household income. Correlations between all key variables were calculated (Table 3). Four OLS regressions were run, with each of receptive vocabulary, phonological awareness, letter knowledge, and word reading being the dependent variable in one of the four models, and age, non-verbal IQ, gender, whether English was the primary language at home, whether the child had experienced extracurricular English lessons, the composite SES variable, and the amount of English exposure at school included as control variables. Models were run twice, first without including the mean overall HLE independent variable, and then again whilst including the HLE independent variable. $R^{2}$ values were noted in each case to examine model fit with and without the inclusion of the independent variable.

Next, four separate random slope multilevel regressions were run, with each of receptive vocabulary, phonological awareness, letter knowledge, and word reading being the dependent variable in one of the four models, and the mean overall HLE variable being the independent variable in all four models. This procedure was then repeated three times, by replacing the overall HLE variable with the HLE variable representing factor 1 , then factor 2 , and then factor 3 . The procedure was repeated once more, but this time with all three HLE factor variables included at the same time in each of the regression models. This process resulted in a total of 20 multilevel regressions. All models controlled for age, nonverbal IQ, gender, whether English was the primary language at home, whether the child had experienced extracurricular English lessons, the composite SES variable, and the amount of English exposure at school, and used kindergarten as the level 2 variable. Independent and dependent variables were standardized in all models. Non-verbal IQ, composite SES, and English exposure at school were also standardized, and age was recentered at its grand mean.

To check for the possibility that floor or ceiling effects might be biasing the results, sensitivity analysis was conducted using a Tobit regression model, which is capable of correct inference in cases where there are floor or ceiling effects (McBee, 2010). All regressions were run once more, this time using a mixed-effects Tobit model. Coefficient magnitudes between models were not directly comparable because it was necessary to use raw rather than standardized versions of each dependent variable. However, this procedure made it possible to check whether the direction (positive or negative) of any association, and the presence or absence of statistical significance, were consistent between the random slope multilevel regressions and the regressions using the Tobit model.

Missing values were found for maternal education $(n=1)$, paternal education $(n=3)$, and household income $(n=1)$, which were estimated as part of the calculation of the composite SES variable as described above. Missing values were also found for English as a primary language at home $(n=1)$, and this was imputed using multiple imputation. The mixed-effects Tobit regression function in Stata 15.1 does not support multiple imputation so this one case was dropped listwise for the Tobit models only. No other values were missing.

\section{RESULTS}

Descriptive statistics for the measures of children's nonverbal intelligence and language and literacy skills (before standardization) are presented in Table 1. The HLE was measured based on questions from the caregiver questionnaire.

TABLE 3 | Correlations between key variables.

\begin{tabular}{|c|c|c|c|c|c|c|c|c|c|c|c|c|c|c|c|}
\hline & PA & RV & LK & WR & Age & IQ & Gender & $\begin{array}{l}\text { Eng. } \\
\text { home }\end{array}$ & $\begin{array}{c}\text { Extracur } \\
\text { Eng. }\end{array}$ & $\begin{array}{l}\text { Eng. } \\
\text { school }\end{array}$ & SES & $\begin{array}{l}\text { Overall } \\
\text { HLE }\end{array}$ & $\begin{array}{l}\text { HLE } \\
\text { fac1 }\end{array}$ & $\begin{array}{l}\text { HLE } \\
\text { fac2 }\end{array}$ & $\begin{array}{l}\text { HLE } \\
\text { fac3 }\end{array}$ \\
\hline Phonological awareness & 1.00 & & & & & & & & & & & & & & \\
\hline Receptive vocabulary & 0.40 & 1.00 & & & & & & & & & & & & & \\
\hline Letter knowledge & 0.41 & 0.32 & 1.00 & & & & & & & & & & & & \\
\hline Word reading & 0.42 & 0.42 & 0.46 & 1.00 & & & & & & & & & & & \\
\hline Age (months) & 0.41 & 0.21 & 0.39 & 0.36 & 1.00 & & & & & & & & & & \\
\hline Non-verbal IQ & 0.29 & 0.17 & 0.36 & 0.22 & 0.50 & 1.00 & & & & & & & & & \\
\hline Gender (girl) & -0.06 & 0.09 & -0.05 & -0.09 & 0.03 & -0.01 & 1.00 & & & & & & & & \\
\hline English primary language at home & 0.19 & 0.34 & 0.08 & 0.18 & 0.14 & 0.01 & 0.01 & 1.00 & & & & & & & \\
\hline Extracurricular English & 0.13 & 0.16 & 0.15 & 0.09 & 0.19 & 0.17 & -0.10 & 0.00 & 1.00 & & & & & & \\
\hline Hours of English at school & 0.06 & 0.31 & 0.06 & 0.34 & 0.22 & 0.05 & 0.08 & 0.27 & 0.07 & 1.00 & & & & & \\
\hline SES composite score & 0.16 & 0.26 & 0.01 & 0.14 & -0.04 & -0.11 & 0.00 & 0.09 & 0.12 & 0.13 & 1.00 & & & & \\
\hline Mean overall HLE & 0.10 & 0.40 & 0.19 & 0.21 & -0.07 & -0.03 & 0.04 & 0.26 & 0.05 & 0.12 & 0.19 & 1.00 & & & \\
\hline $\begin{array}{l}\text { Factor 1: Shared reading and } \\
\text { storytelling }\end{array}$ & 0.05 & 0.35 & 0.13 & 0.20 & -0.10 & 0.00 & 0.08 & 0.23 & 0.03 & 0.11 & 0.24 & 0.90 & 1.00 & & \\
\hline $\begin{array}{l}\text { Factor 2: Teaching of print-related } \\
\text { skills }\end{array}$ & 0.09 & 0.18 & 0.26 & 0.11 & 0.11 & 0.00 & 0.10 & 0.14 & 0.06 & 0.06 & -0.06 & 0.63 & 0.29 & 1.00 & \\
\hline $\begin{array}{l}\text { Factor 3: Play and media-based } \\
\text { activities }\end{array}$ & 0.05 & 0.31 & 0.03 & 0.10 & -0.22 & -0.17 & -0.09 & 0.15 & 0.01 & -0.01 & 0.14 & 0.70 & 0.46 & 0.46 & 1.00 \\
\hline
\end{tabular}

Significant correlations (ps <0.05) are shown in bold. Full variable names are shown in the left-hand row, and abbreviations of variable names are shown in the top column. 
Caregivers reported the number of English children's books in the household. Six percent of caregivers reported having no books, $67 \%$ reported having between 1 and 20 books, and 27\% reported having more than 20 books. Caregivers also reported the age at which their child was when they first started to have English read to them. Forty-one percent of caregivers stated that they did not read English to their child, 15\% reported reading within the first 12 months, $15 \%$ reported reading within 13 and 23 months, and $29 \%$ reported starting reading English when their child was more than 2 years old. Of those that reported reading English to their child ( $n=88)$, a majority of parents agreed that they asked questions (69\%), highlighted or explained key vocabularies from the text $(68 \%)$, emphasized printed words $(68 \%)$, and discussed sounds of the words $(66 \%)$ while reading.

Figure 1 shows caregiver responses to a question about the frequency of engaging in English activities with their child. More than $40 \%$ of parents reported never reading English books, telling stories, visiting the library, or using English apps or digital media. Around $21 \%$ of caregivers read books and $15 \%$ told stories at least once a week as compared to $76 \%$ of caregivers helping their child with English schoolwork at the same frequency. Figure 2 shows responses to a question asking about how often caregivers teach their child print-related skills. The most common daily practice reported by caregivers was teaching English alphabet letters, with $24 \%$ of respondents reporting teaching alphabet letters daily, and $53 \%$ of respondents reporting teaching alphabet letters at least 2 to 3 times a week. By contrast, $40 \%$ of caregivers said they had never taught letter sounds.

Table 2 shows the final rotated 3 factor solution from an exploratory factor analysis (principal component factors) of caregiver responses to questions on the HLE, with loadings above 0.6 shown in bold. Factor 1 had high loadings on questions related to reading with children, including the age of the child when reading in English first commenced, highlighting and explaining vocabularies whilst reading, and telling stories in English. Factor 2 had high loadings on questions related to teaching children English letters and words. Factor 3 had high loadings on questions related to activities conducted with children, including singing songs, playing with apps, and watching TV programs. Factor 1 was therefore named "Shared reading and storytelling",

\section{0}

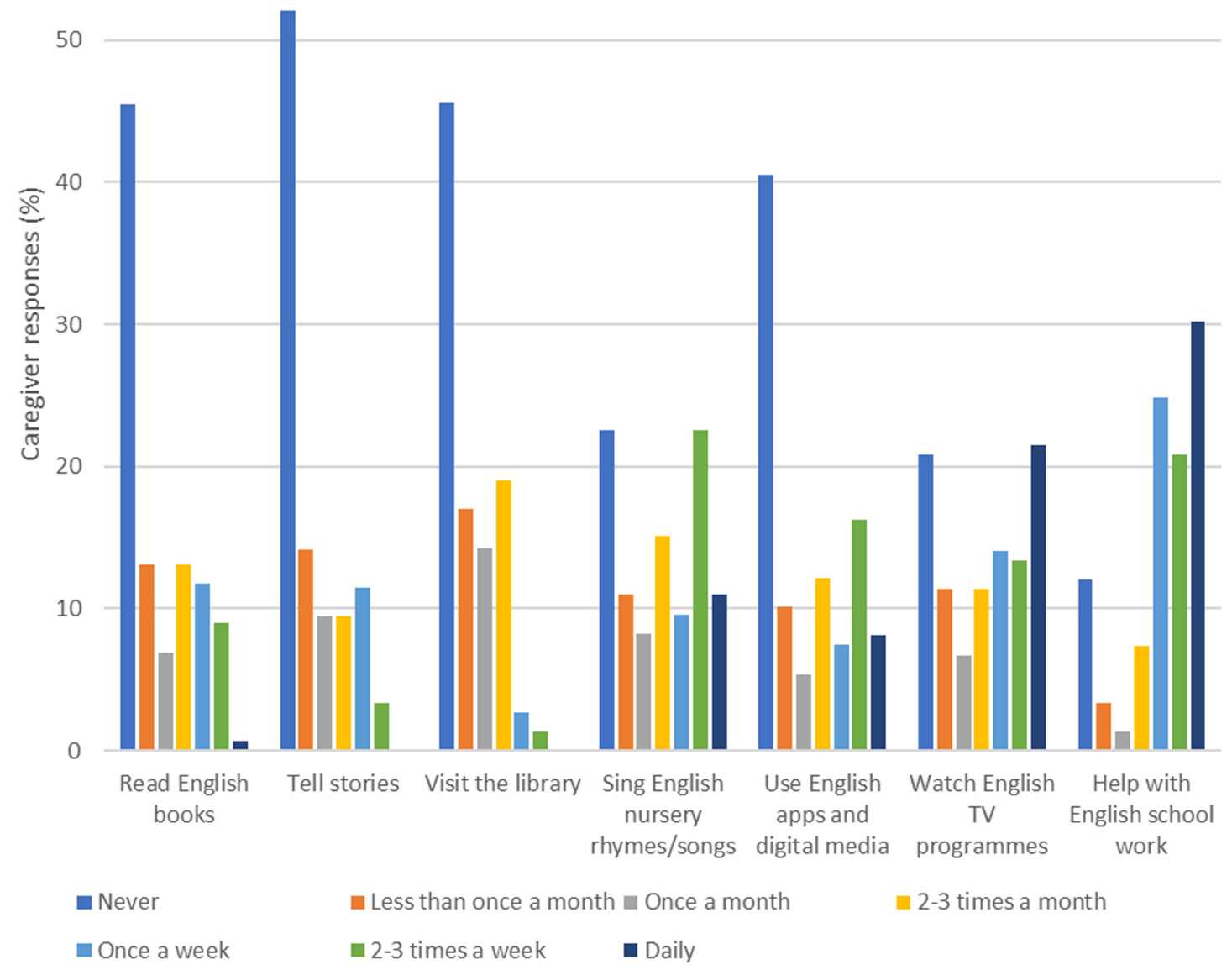

FIGURE 1 | Proportion of caregivers reporting engaging in English activities with their child, by frequency of engagement $(n=149)$. 


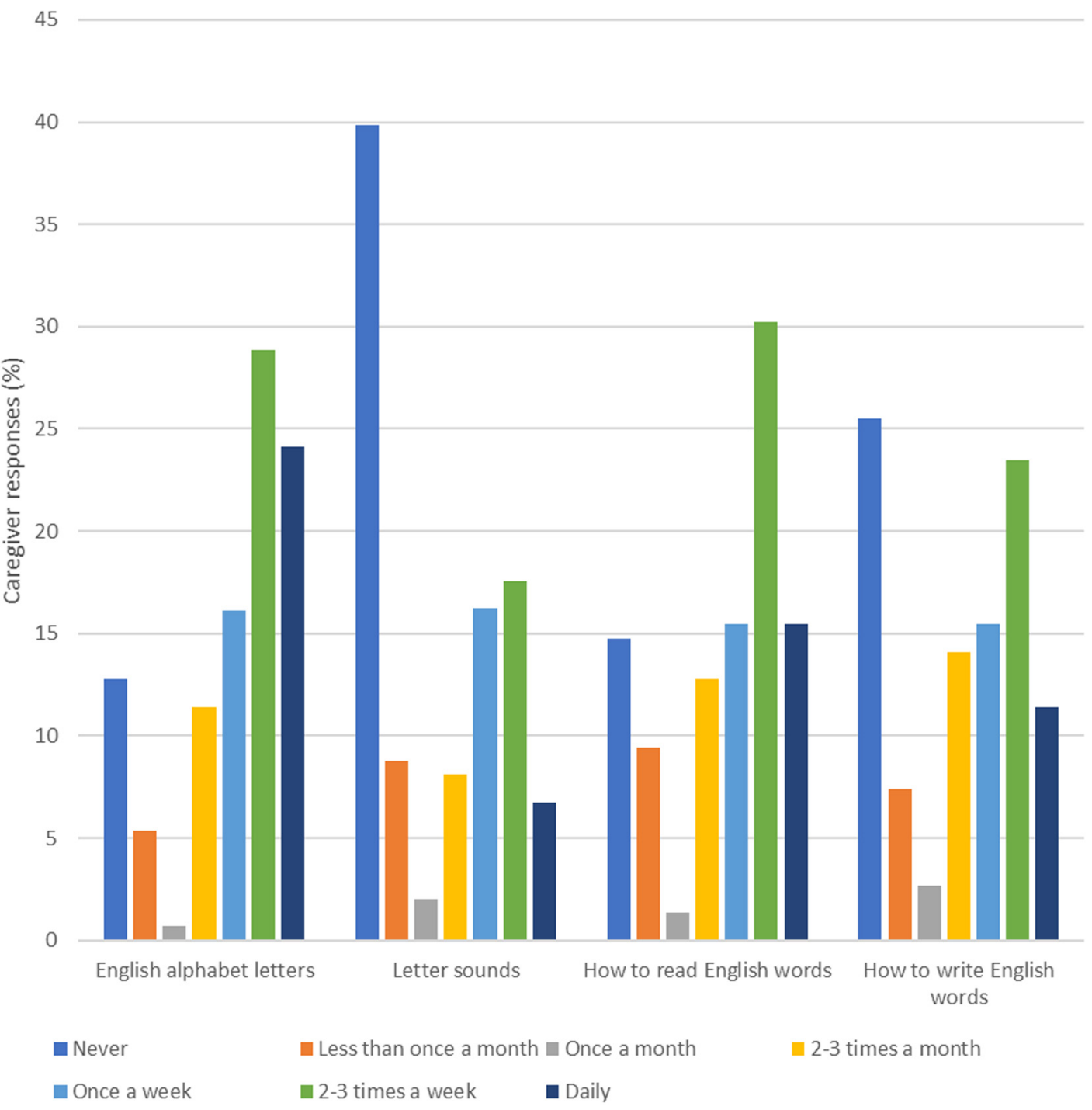

FIGURE 2 | Proportion of caregivers reporting teaching printed-related skills in English to their child, by frequency of teaching $(n=149)$.

Factor 2 was named "Teaching of print-related skills", and Factor 3 was named "Play and media-based activities".

Correlations between key variables are shown in Table 3. The four measures of language and literacy were all positively correlated with each other $(r=0.32$ to $0.46, p s<0.05)$. Child age was positively correlated with all four measures of language and literacy, and with the measure of non-verbal intelligence $(p s<0.05)$. Gender was not significantly correlated with any of the variables $(p s>0.05)$. The measure of receptive vocabulary was positively correlated with the overall HLE variable and all 3 individual HLE factor variables ( $p s<0.05)$, whilst the measure of phonological awareness was not significantly correlated with any of the HLE variables ( $p$ s $>0.05$ ). All HLE variables were positively correlated with each other $(r=0.29$ to $0.90, p s<0.05$ ), with the largest correlation between the overall HLE variable and the variable for factor 1 (shared reading and storytelling $)(r=0.90)$. OLS regressions demonstrated the proportion of variance in each of the four measures of language and literacy explained by (i) all control variables only (receptive vocabulary $R^{2}=0.24$; phonological awareness $R^{2}=0.26$; letter knowledge $R^{2}=0.19$; word reading $R^{2}=0.24$ ), and (ii) all control variables and the overall mean HLE variable combined (receptive vocabulary $R^{2}=0.24$; phonological awareness $R^{2}=0.34$; letter knowledge $R^{2}=0.24$; word reading $\left.R^{2}=0.27\right)$.

The results of four separate multilevel regressions are shown in Table 4, with each of receptive vocabulary, phonological awareness, letter knowledge, and word reading being the dependent variable in one of the four models, and the mean overall HLE variable being the independent variable in all four models. Mean overall HLE was positively associated with receptive vocabulary $(\beta=0.28, p<0.001)$, letter knowledge $(\beta=0.22, p<0.01)$, and word reading $(\beta=0.18, p<0.05)$. Table 5 shows the results of the same set of four multilevel 
TABLE 4 | Associations between mean overall HLE scores and 4 different measures of language and literacy.

\begin{tabular}{|c|c|c|c|c|c|c|c|c|c|c|c|c|}
\hline & \multicolumn{3}{|c|}{ Phonological awareness } & \multicolumn{3}{|c|}{ Receptive vocabulary } & \multicolumn{3}{|c|}{ Letter knowledge } & \multicolumn{3}{|c|}{ Word reading } \\
\hline & $b$ & SE & $p$ & $b$ & SE & $p$ & $b$ & SE & $p$ & $b$ & SE & $p$ \\
\hline \multicolumn{13}{|l|}{ Fixed part } \\
\hline Age (months) & 0.04 & 0.01 & $<0.001$ & 0.00 & 0.01 & 0.692 & 0.03 & 0.01 & $<0.001$ & 0.03 & 0.01 & 0.006 \\
\hline Non-verbal IQ (SD) & 0.13 & 0.10 & 0.174 & 0.15 & 0.10 & 0.156 & 0.20 & 0.05 & $<0.001$ & 0.08 & 0.13 & 0.548 \\
\hline Gender (girl) & -0.13 & 0.18 & 0.482 & 0.15 & 0.09 & 0.082 & -0.12 & 0.12 & 0.289 & -0.30 & 0.12 & 0.017 \\
\hline English at home (binary) & 0.35 & 0.15 & 0.022 & 0.52 & 0.26 & 0.043 & -0.04 & 0.23 & 0.860 & -0.04 & 0.24 & 0.883 \\
\hline English extracurricular (binary) & 0.03 & 0.26 & 0.893 & 0.24 & 0.15 & 0.108 & 0.11 & 0.12 & 0.319 & -0.14 & 0.11 & 0.183 \\
\hline SES composite (SD) & 0.17 & 0.07 & 0.012 & 0.14 & 0.07 & 0.046 & 0.00 & 0.13 & 0.996 & 0.05 & 0.10 & 0.576 \\
\hline English time at school (SD) & -0.09 & 0.08 & 0.251 & 0.20 & 0.12 & 0.112 & -0.04 & 0.08 & 0.636 & 0.36 & 0.11 & 0.001 \\
\hline Mean overall HLE & 0.07 & 0.10 & 0.459 & 0.28 & 0.07 & $<0.001$ & 0.22 & 0.07 & 0.003 & 0.18 & 0.08 & 0.025 \\
\hline Constant & 0.01 & 0.15 & 0.959 & -0.15 & 0.16 & 0.341 & 0.05 & 0.11 & 0.681 & 0.21 & 0.08 & 0.010 \\
\hline \multicolumn{13}{|l|}{ Random part } \\
\hline English time at school (SD) & 0.00 & - & & 0.00 & 0.05 & & 0.00 & - & & 0.22 & 0.07 & \\
\hline Kindergarten (SD) & 0.00 & - & & 0.27 & 0.09 & & 0.00 & - & & 0.00 & & \\
\hline Residual (SD) & 0.87 & - & & 0.77 & 0.06 & & 0.87 & - & & 0.82 & 0.14 & \\
\hline
\end{tabular}

Results are from 4 different multilevel regressions, with each of 4 different standardized measures of language and literacy as the dependent variable in each model.

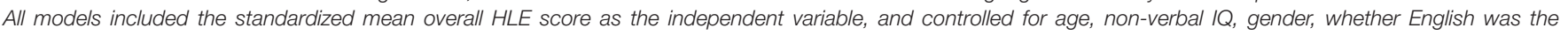
primary language at home, whether the child had extracurricular English lessons, SES, and amount of English exposure at school. Kindergarten was the level 2 variable. "-" indicates that it was not possible to calculate SES due to random estimates being very close to 0.

TABLE 5 | Associations between mean HLE factor 1 scores (Shared reading and storytelling) and 4 different measures of language and literacy.

\begin{tabular}{|c|c|c|c|c|c|c|c|c|c|c|c|c|}
\hline & \multicolumn{3}{|c|}{ Phonological awareness } & \multicolumn{3}{|c|}{ Receptive vocabulary } & \multicolumn{3}{|c|}{ Letter knowledge } & \multicolumn{3}{|c|}{ Word reading } \\
\hline & $b$ & SE & $p$ & $b$ & SE & $p$ & $b$ & SE & $p$ & $b$ & SE & $p$ \\
\hline \multicolumn{13}{|l|}{ Fixed part } \\
\hline Age (months) & 0.04 & 0.01 & $<0.001$ & 0.00 & 0.01 & 0.752 & 0.03 & 0.00 & $<0.001$ & 0.03 & 0.01 & 0.006 \\
\hline Non-verbal IQ (SD) & 0.13 & 0.09 & 0.154 & 0.13 & 0.10 & 0.189 & 0.19 & 0.06 & $<0.001$ & 0.07 & 0.12 & 0.598 \\
\hline Gender (girl) & -0.12 & 0.17 & 0.481 & 0.14 & 0.09 & 0.098 & -0.13 & 0.11 & 0.258 & -0.31 & 0.13 & 0.017 \\
\hline English at home (binary) & 0.39 & 0.15 & 0.010 & 0.59 & 0.24 & 0.012 & 0.01 & 0.23 & 0.966 & -0.01 & 0.24 & 0.977 \\
\hline English extracurricular (binary) & 0.04 & 0.25 & 0.869 & 0.26 & 0.14 & 0.068 & 0.13 & 0.12 & 0.278 & -0.13 & 0.11 & 0.234 \\
\hline SES composite (SD) & 0.18 & 0.07 & 0.008 & 0.14 & 0.07 & 0.054 & 0.00 & 0.13 & 0.981 & 0.05 & 0.09 & 0.614 \\
\hline English time at school (SD) & -0.08 & 0.08 & 0.266 & 0.19 & 0.12 & 0.103 & -0.04 & 0.08 & 0.629 & 0.35 & 0.11 & 0.001 \\
\hline HLE 1: Storytelling and story reading & 0.02 & 0.09 & 0.837 & 0.23 & 0.06 & $<0.001$ & 0.17 & 0.09 & 0.058 & 0.17 & 0.08 & 0.031 \\
\hline Constant & 0.00 & 0.14 & 0.989 & -0.16 & 0.15 & 0.287 & 0.04 & 0.11 & 0.731 & 0.21 & 0.08 & 0.008 \\
\hline \multicolumn{13}{|l|}{ Random part } \\
\hline English time at school (SD) & 0.00 & - & & 0.00 & 0.00 & & 0.00 & - & & 0.22 & 0.07 & \\
\hline Kindergarten (SD) & 0.00 & - & & 0.26 & 0.10 & & 0.00 & - & & 0.00 & & \\
\hline Residual (SD) & 0.87 & - & & 0.79 & 0.05 & & 0.88 & - & & 0.82 & 0.14 & \\
\hline
\end{tabular}

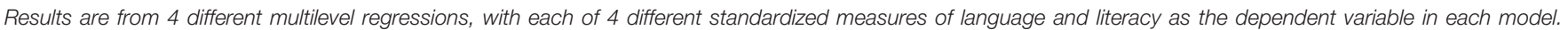

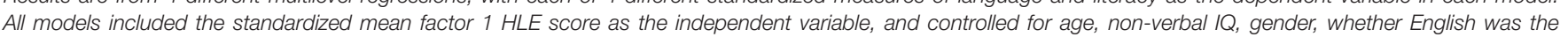

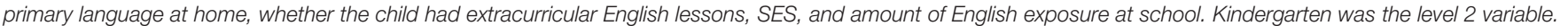
"-" indicates that it was not possible to calculate SEs due to random estimates being very close to 0.

regressions as before, but this time using HLE factor 1 (Shared reading and storytelling) as the independent variable. All control variables and the level 2 variable were the same as before. Factor 1 (Shared reading and storytelling) was positively associated with receptive vocabulary $(\beta=0.23, p<0.001)$, and word reading $(\beta=0.17, p<0.05)$. Table 6 shows the results of the same set of four multilevel regressions as before, but this time using HLE factor 2 (Teaching of printrelated skills) as the independent variable. Factor 2 (Teaching of print-related skills) was positively associated with receptive vocabulary $(\beta=0.15, p<0.05)$, and letter knowledge $(\beta=0.24$, $p<0.001)$. Similarly, Table 7 shows the results of four multilevel regressions using HLE factor 3 (Play and media-based activities) as the independent variable. Factor 3 (Play and mediabased activities) was also positively associated with receptive vocabulary $(\beta=0.32, p<0.001)$, and letter knowledge $(\beta=0.12$, $p<0.01)$.

Table 8 shows the results of four multilevel regressions, but this time including all three HLE factors as independent variables at the same time. After adjusting for the other two HLE factors: 
TABLE 6 | Associations between mean HLE factor 2 scores (Teaching of print-related skills) and 4 different measures of language and literacy.

\begin{tabular}{|c|c|c|c|c|c|c|c|c|c|c|c|c|}
\hline & \multicolumn{3}{|c|}{ Phonological awareness } & \multicolumn{3}{|c|}{ Receptive vocabulary } & \multicolumn{3}{|c|}{ Letter knowledge } & \multicolumn{3}{|c|}{ Word reading } \\
\hline & $b$ & SE & $p$ & $b$ & SE & $p$ & $b$ & SE & $p$ & $b$ & SE & $p$ \\
\hline \multicolumn{13}{|l|}{ Fixed part } \\
\hline Age (months) & 0.03 & 0.01 & $<0.001$ & -0.01 & 0.01 & 0.174 & 0.03 & 0.01 & $<0.001$ & 0.03 & 0.01 & 0.021 \\
\hline Non-verbal IQ (SD) & 0.14 & 0.09 & 0.149 & 0.17 & 0.11 & 0.112 & 0.23 & 0.06 & $<0.001$ & 0.09 & 0.13 & 0.473 \\
\hline Gender (girl) & -0.13 & 0.18 & 0.470 & 0.14 & 0.08 & 0.065 & -0.15 & 0.11 & 0.182 & -0.30 & 0.12 & 0.013 \\
\hline English at home (binary) & 0.38 & 0.15 & 0.011 & 0.66 & 0.27 & 0.014 & 0.03 & 0.22 & 0.878 & 0.05 & 0.27 & 0.844 \\
\hline English extracurricular (binary) & 0.03 & 0.26 & 0.895 & 0.24 & 0.18 & 0.177 & 0.10 & 0.12 & 0.415 & -0.14 & 0.11 & 0.203 \\
\hline SES composite (SD) & 0.19 & 0.07 & 0.010 & 0.18 & 0.06 & 0.005 & 0.05 & 0.13 & 0.675 & 0.08 & 0.09 & 0.340 \\
\hline English time at school (SD) & -0.08 & 0.08 & 0.290 & 0.24 & 0.15 & 0.126 & -0.03 & 0.09 & 0.746 & 0.37 & 0.11 & 0.001 \\
\hline HLE 2: Teaching of print-related skills & 0.05 & 0.06 & 0.397 & 0.15 & 0.06 & 0.015 & 0.24 & 0.04 & $<0.001$ & 0.09 & 0.06 & 0.142 \\
\hline Constant & 0.00 & 0.16 & 0.975 & -0.16 & 0.17 & 0.355 & 0.05 & 0.11 & 0.616 & 0.20 & 0.09 & 0.017 \\
\hline \multicolumn{13}{|l|}{ Random part } \\
\hline English time at school (SD) & 0.00 & - & & 0.24 & 0.27 & & 0.00 & - & & 0.24 & 0.13 & \\
\hline Kindergarten (SD) & 0.00 & - & & 0.22 & 0.29 & & 0.00 & - & & 0.00 & & \\
\hline Residual (SD) & 0.87 & - & & 0.80 & 0.06 & & 0.86 & - & & 0.83 & 0.35 & \\
\hline
\end{tabular}

Results are from 4 different multilevel regressions, with each of 4 different standardized measures of language and literacy as the dependent variable in each model. All models included the standardized mean factor 2 HLE score as the independent variable, and controlled for age, non-verbal IQ, gender, whether English was the primary language at home, whether the child had extracurricular English lessons, SES, and amount of English exposure at school. Kindergarten was the level 2 variable. "-" indicates that it was not possible to calculate SES due to random estimates being very close to 0.

TABLE 7 | Associations between mean HLE factor 3 scores (Play and media-based activities) and 4 different measures of language and literacy.

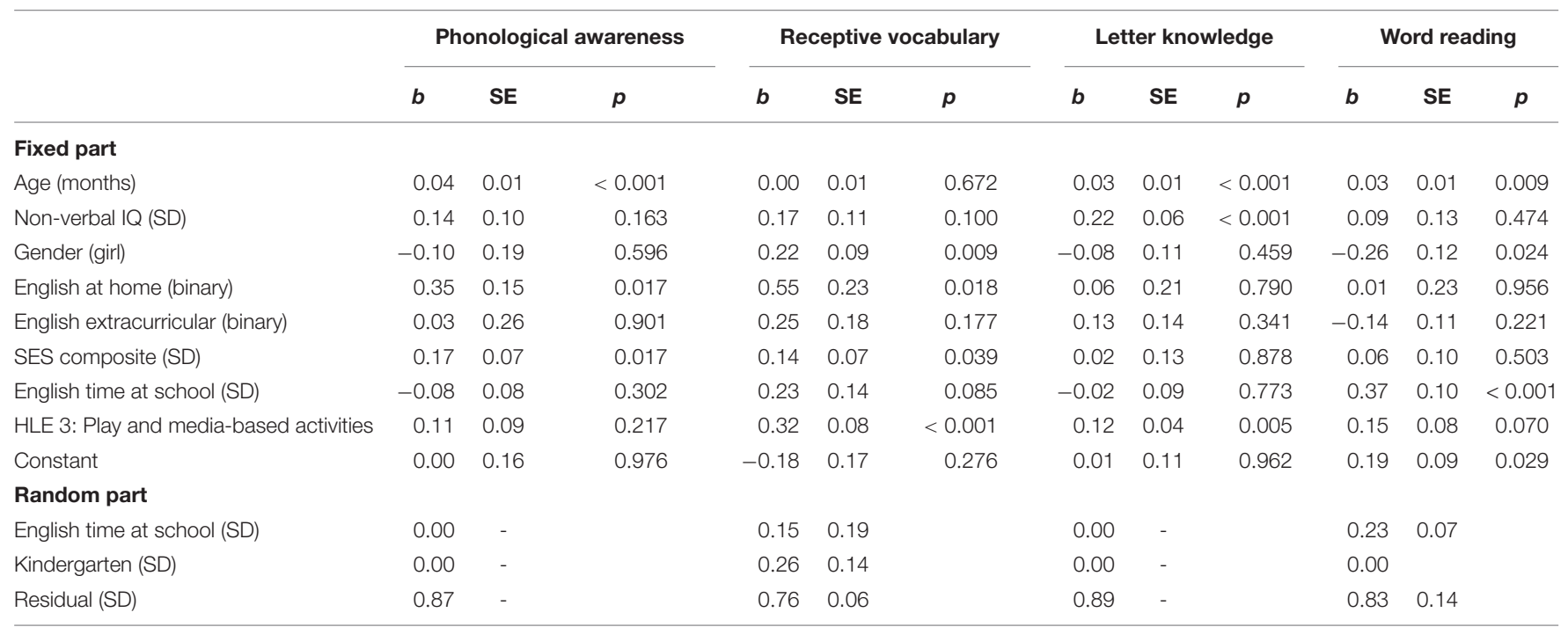

Results are from 4 different multilevel regressions, with each of 4 different standardized measures of language and literacy as the dependent variable in each model.

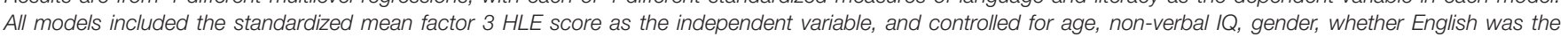

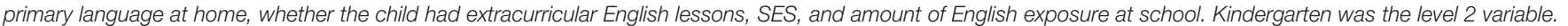

"-" indicates that it was not possible to calculate SES due to random estimates being very close to 0.

HLE factor 1 (Shared reading and storytelling) was positively associated with word reading $(\beta=0.13, p<0.05)$; HLE factor 2 (Teaching of print-related skills) was positively associated with letter knowledge $(\beta=0.23, p<0.001)$; and HLE factor 3 (Play and media-based activities) was positively associated with receptive vocabulary $(\beta=0.29, p<0.001)$.

Sensitivity analysis was conducted by running all regressions once more but using mixed-effects Tobit models. The directionality of any significant association (positive or negative) between independent and dependent variables was consistent between all random slope multilevel regressions and all corresponding Tobit regressions. The presence or absence of statistical significance at the 5\% level was also consistent, with the following exceptions. When using a Tobit model, HLE factor 1 (Shared reading and storytelling) was positively and significantly associated with letter knowledge $(b=1.51, p=0.028$ ); and HLE factor 3 (Play and media-based activities) was positively and significantly associated with phonological awareness $(b=0.67, p=0.044)$, and with word reading $(b=2.70, p=0.038)$, but not with letter knowledge 
TABLE 8 | Associations between mean HLE factor scores (all 3 factors included) and 4 different measures of language and literacy.

\begin{tabular}{|c|c|c|c|c|c|c|c|c|c|c|c|c|}
\hline & \multicolumn{3}{|c|}{ Phonological awareness } & \multicolumn{3}{|c|}{ Receptive vocabulary } & \multicolumn{3}{|c|}{ Letter knowledge } & \multicolumn{3}{|c|}{ Word reading } \\
\hline & $b$ & SE & $p$ & $b$ & SE & $p$ & $b$ & SE & $p$ & $b$ & SE & $p$ \\
\hline \multicolumn{13}{|l|}{ Fixed part } \\
\hline Age (months) & 0.04 & 0.01 & $<0.001$ & 0.00 & 0.01 & 0.993 & 0.03 & 0.01 & $<0.001$ & 0.03 & 0.01 & 0.008 \\
\hline Non-verbal IQ (SD) & 0.15 & 0.10 & 0.133 & 0.16 & 0.10 & 0.118 & 0.21 & 0.06 & $<0.001$ & 0.08 & 0.13 & 0.546 \\
\hline Gender (girl) & -0.09 & 0.18 & 0.612 & 0.21 & 0.09 & 0.018 & -0.18 & 0.12 & 0.136 & -0.29 & 0.13 & 0.026 \\
\hline English at home (binary) & 0.36 & 0.15 & 0.013 & 0.52 & 0.23 & 0.022 & -0.01 & 0.22 & 0.950 & -0.03 & 0.24 & 0.886 \\
\hline English extracurricular (binary) & 0.03 & 0.26 & 0.897 & 0.25 & 0.17 & 0.142 & 0.10 & 0.11 & 0.374 & -0.14 & 0.11 & 0.217 \\
\hline SES composite (SD) & 0.18 & 0.07 & 0.009 & 0.12 & 0.08 & 0.099 & 0.03 & 0.12 & 0.796 & 0.05 & 0.09 & 0.603 \\
\hline English time at school (SD) & -0.08 & 0.08 & 0.319 & 0.21 & 0.12 & 0.085 & -0.04 & 0.09 & 0.670 & 0.36 & 0.10 & 0.001 \\
\hline HLE 1: Storytelling and story reading & -0.04 & 0.08 & 0.663 & 0.11 & 0.06 & 0.061 & 0.12 & 0.12 & 0.332 & 0.13 & 0.06 & 0.041 \\
\hline HLE 2: Teaching of print-related skills & 0.00 & 0.04 & 0.985 & -0.04 & 0.06 & 0.533 & 0.23 & 0.04 & $<0.001$ & 0.01 & 0.10 & 0.957 \\
\hline HLE 3: Play and media-based activities & 0.13 & 0.07 & 0.090 & 0.29 & 0.08 & $<0.001$ & -0.05 & 0.08 & 0.556 & 0.09 & 0.08 & 0.257 \\
\hline Constant & -0.01 & 0.15 & 0.936 & -0.18 & 0.17 & 0.280 & 0.07 & 0.11 & 0.517 & 0.21 & 0.09 & 0.015 \\
\hline \multicolumn{13}{|l|}{ Random part } \\
\hline English time at school (SD) & 0.00 & - & & 0.03 & 1.11 & & 0.00 & - & & 0.22 & 0.65 & \\
\hline Kindergarten (SD) & 0.00 & - & & 0.27 & 0.26 & & 0.00 & - & & 0.00 & & \\
\hline Residual (SD) & 0.86 & - & & 0.75 & 0.06 & & 0.86 & - & & 0.82 & 0.39 & \\
\hline
\end{tabular}

Results are from 4 different multilevel regressions, with each of 4 different standardized measures of language and literacy as the dependent variable in each model.

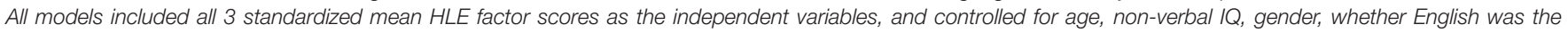

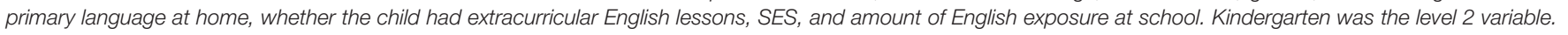
"-" indicates that it was not possible to calculate SEs due to random estimates being very close to 0.

$(p>0.05)$. When all three HLE factor variables were included as independent variables at the same time, results were consistent, with the exception that HLE factor 1 (Shared reading and storytelling) was not significantly associated with word reading $(p>0.05)$.

\section{DISCUSSION}

This study examined relations between multiple aspects of the HLE and the development of English as a second language among ethnic Chinese children in Hong Kong. It addressed three questions: (a) What kinds of home literacy practices are caregivers engaged in to support children's English language and literacy development?; (b) What is the relationship between the HLE and children's English language and literacy skills?; and (c) To what extent does the HLE predict children's English language and literacy development? Our work captured the multifaceted nature of the HLE and examined a range of literacy activities and behaviors in predicting variability in early English language and literacy skills. The findings from this study extended current knowledge by providing new evidence on the HLE of children from different linguistic and cultural backgrounds and contributed to further understanding of the processes that support second language development across different contexts in the early years.

The present work revealed considerable variability in the types of literacy activities that caregivers were engaged in at home with their children. Two notable findings emerged: (1) a sizable portion of caregivers never read books, told stories, visited the library or used digital media to support children's English language learning; and (2) the tendency for caregivers to teach children print-related skills and help with English schoolwork on a more frequent basis (i.e., at least once a week) was relatively higher than that of reading English books and telling stories with their children. These results suggest that in the context of Hong Kong, caregivers tend to prioritize formal literacy activities that are deemed related to school progress and achievement. Consistent with previous work that indicates Hong Kong parents' demands for a rigorous academic curriculum to support children's entry to primary school (e.g., Leung et al., 2013), the emphasis on printrelated activities and schoolwork in the HLE reflect caregivers' priorities in preparing children to meet academic requirements and excel in school. In turn, caregivers may not be as active in activities beyond schoolwork, such as telling stories or reading for pleasure with their children. The extent to which caregivers are involved in literacy activities in a second language, however, may be largely linked to their language proficiency levels (Dixon and Wu, 2014). For instance, as more complex language and vocabulary are found in children's books than in adult conversations (Hayes and Ahrens, 1988), shared reading may require caregivers to possess a certain level of language proficiency in order to read the text and to engage in verbal exchanges with their children. Thus, the quantity and quality of shared reading may potentially be undermined by caregivers' proficiency and confidence in English. Furthermore, while activity-based approaches have increasingly been implemented in English language teaching in kindergarten classrooms in Hong Kong, studies have also documented the use of traditional paper and pencil exercises and the emphasis on recognition of letters, sounds and words in the teaching and learning process 
(Lau and Rao, 2013; Ng and Rao, 2013). The value attached to formal approaches in language teaching in schools may potentially influence caregivers' tendency to use more didactic approaches when exposing children to English at home and to target print-related skills rather than oral language skills in their interactions with children.

The results of this study indicated that the HLE was differentially related to children's English language and literacy development. The overall HLE was positively correlated with receptive vocabulary, letter knowledge, and word reading. Specifically, shared reading and storytelling, as a factor, was correlated with receptive vocabulary and word reading; direct teaching of print-related skills (e.g., letter names and sounds) was correlated with receptive vocabulary and letter knowledge; and play and media-based activities (e.g., singing rhymes/songs, watching television programs) were correlated with receptive vocabulary. There were no significant correlations between any aspects of the HLE and phonological awareness. Multilevel regression analyses further confirmed the unique contribution of the HLE to children's development of English as a second language regardless of children's age, non-verbal IQ, gender, whether English was the primary language at home, whether there were extracurricular English lessons, SES backgrounds, and the amount of English exposure at school. Shared reading and storytelling contributed significantly to receptive vocabulary and word reading, and results were robust to sensitivity analysis. After the inclusion of all three factors in the same model simultaneously, shared reading and storytelling also significantly contributed to word reading. The findings are consistent with research evidence on the benefits of shared reading and storytelling on early language and literacy skills (Wood, 2002; Curenton et al., 2008; Evans and Shaw, 2008). Explicit teaching and coaching by adults (e.g., introducing and explaining vocabulary, helping children decode words, drawing attention to letter names and sounds), as well as provision of opportunities for children's active participation during the reading process (e.g., adults prompting children to talk about the book) enable children to be exposed to varied vocabulary and elaborate forms of language (Whitehurst et al., 1988; Justice et al., 2005). In this study, a composite measure of shared reading and storytelling was used which included the frequency of shared reading, age of onset of reading, number of books at home, and reading behavior (i.e., verbal interactions during reading) and storytelling. It was, therefore, unclear whether the positive relation to receptive vocabulary and word reading was primarily due to aspects of shared reading or storytelling, or both. Further research will be needed to delineate the specific impacts of shared reading and storytelling on children's language and literacy development. Nonetheless, the current study provides preliminary evidence suggesting that both the quantity and quality of shared reading, as well as storytelling play important roles in fostering children's vocabulary and word reading skills in a second language.

Direct teaching of print-related skills predicted children's receptive vocabulary and letter knowledge, and results were robust to sensitivity analysis. While past research found that the primary impact of parental teaching of print-related skills is on code-based skills, such as letter knowledge and phonological awareness (e.g., Evans et al., 2000; Sénéchal and LeFevre, 2002), the findings in this study supported the relations with receptive vocabulary skills as well. One plausible explanation for this association is the caregivers' interaction style during printfocused activities. It is possible that caregivers may introduce new words while discussing about letter sounds or talk with children about words when teaching reading and writing, which may facilitate children's oral language development. However, when all three factors were included in the same model simultaneously, teaching of print-related skills predicted letter knowledge only, suggesting that after controlling for letter knowledge, associations between teaching of print-related skills and receptive vocabulary were no longer significant. Another explanation may therefore be that receptive vocabulary and letter knowledge skills are related but teaching of print-related skills is more directly relevant for letter knowledge than receptive vocabulary. Further research is warranted into the mechanisms through which caregivers teach print-related skills and the verbal interactions that occur during print-focused activities. Further, our study did not find significant associations between any aspects of the HLE and phonological awareness skills. While there may be other mechanisms underlying the lack of association between HLE and phonological awareness (Sénéchal, 2006; Sénéchal and LeFevre, 2014), it may be the case that the HLE alone may not be sufficient in facilitating change in children's development of phonological skills. Given the differences in the phonological features and orthographies between children's L1 (Chinese) and L2 (English), children may specifically require explicit instruction both at home and at school, and frequent and varied exposure in different contexts to develop phonological skills in a second language.

Play and media-based activities contributed significantly to receptive vocabulary and letter knowledge, although only the contribution to receptive vocabulary was robust to sensitivity analysis. Specifically, play and media-based activities was a stronger predictor of children's receptive vocabulary skills than either of the other HLE factors, and also compared to the overall HLE. When all three factors were included in the model simultaneously, play and media-based activities predicted receptive vocabulary only. These findings support previous research which documented positive links between individual or composite measures of activities other than shared reading and parental teaching of print-related skills and children's oral language and/or code-related skills (Passenger et al., 2000; Levy et al., 2006; Uchikoshi, 2006). This study points to the importance of adopting a broad conceptualization of the HLE to facilitate a more comprehensive understanding of the range of home literacy experiences that may contribute to early language and literacy development. The inclusion of an array of literacy-related activities in the measure of the HLE may be particularly important in second language and/or multilingual contexts. There is a likelihood that caregivers who are not fully fluent in the second language may utilize audio-visual materials as additional sources of language exposure to children. Indeed, in our study, the tendency for caregivers to sing English nursery rhymes/songs, use English digital media and 
watch English television programs with children on a more frequent basis (i.e., at least once a week) was relatively higher than that of shared reading and storytelling. It is possible that caregivers rely on readily available audio-visual materials to serve as language models for children's second language development. It is, however, unknown whether and to what extent caregivers are involved with their children during singing, television viewing and the use of digital media. As current research evidence suggests, children learn languages better from live social interactions than from screens alone (e.g., Roseberry et al., 2009). Future studies can consider examining the interactions between caregivers and children when activities, such as television viewing and use of digital media, are included as measures of the HLE.

Taken together, this study corroborates previous findings concerning the importance of active home literacy activities (i.e., caregivers' efforts to directly engage children in literacy activities) (Burgess et al., 2002). As Sylva et al. (2004) concluded, the quality of interaction between caregivers and children is a more significant predictor of children's outcomes than family background characteristics, such as income and education. There is thus, a need to enhance caregivers' knowledge, skills and attitude in enriching the HLE and to mobilize resources to support caregivers in facilitating children's language and literacy development. Prior studies have demonstrated the effectiveness of family literacy interventions that are aimed at developing parents' capacity to engage children in literacy activities (Zevenbergen and Whitehurst, 2003; Sénéchal and Young, 2008; Manz et al., 2010; van Steensel et al., 2011). Practitioners, policymakers and researchers can capitalize on the potential of family literacy programs to address compelling issues surrounding children's development of English as a second language. In a 12-week intervention program on parent-child reading in English in Hong Kong, children in the intervention group made gains in both English word reading and phonological awareness skills, suggesting the effectiveness of dialogic reading on second language development among ethnic Chinese children (Chow et al., 2010). Early childhood education programs that encourage school-based and home-based family engagement practices and have family engagement as a core component of their policies can further support children's language and literacy development (Goodall and Vorhaus, 2011). For instance, schools that provide workshops on specific strategies for literacy improvement (e.g., reading strategies) or design curricula that connect home and school practices (e.g., extended learning activities at home) may promote involvement in children's education and enable caregivers to develop the competencies to support their children. Indeed, caregivers are more likely to be involved in schools and at home when they recognize the importance of their roles in children's learning, feel capable of assisting their children and feel invited by the school and their children (Hoover-Dempsey and Sandler, 1997). Further, public campaigns or community events that strengthen family and public participation in literacy activities may help support the development of children's language and literacy skills. Particularly, community efforts to provide books, as well as support on home literacy activities for families from disadvantaged backgrounds can increase parent-child engagement at home (Odom et al., 2012).

It should be noted that there are several limitations to this study. First, caregivers' self-reports of their engagement in home literacy practices may be subject to social desirability bias. Future studies can consider supplementing survey data with direct observations of literacy interactions or interviews with caregivers. Respondents to the caregiver survey were also not always the child's primary caregiver, so interviewing primary caregivers or using direct observations could be helpful to triangulate across several data sources. Second, this study mainly examined the frequency of caregivers' engagement in literacy activities as a measure of the HLE in predicting early language and literacy outcomes. It would be valuable to examine additional aspects of the HLE that have been found to explain variability in language and literacy development, such as parental beliefs and attitudes about literacy (Debaryshe, 1995; Weigel et al., 2006), parent-child interactions, such as maternal responsiveness and sensitivity (de Jong and Leseman, 2001; Tamis-Lemonda et al., 2001), parental modeling of reading behavior (Burgess et al., 2002), child literacy interest (Baroody and Diamond, 2012; Carroll et al., 2019), and parents' and children's foreign language reading anxiety (Chow et al., 2017). Third, this study did not consider the home literacy practices and development of children in the first language. Such data may contribute to more refined understanding of the HLE across languages and may yield important findings on the impact of the HLE on first and second language development. Fourth, while this study considered children's exposure to English at home (whether English was the primary language), we did not have in-depth information about the circumstances under which English is spoken. More detailed information about the extent of children's exposure to English, including language use of the child and each family member in the household may enable a more comprehensive understanding of the home language environment. Finally, this study only accounted for amount of exposure to English lessons in schools when analyzing the prediction of the HLE on children's English language and literacy outcome. Future research can examine the quality of English language teaching in schools to further disentangle the processes that explain the effects of the HLE on children's development of English as a second language.

\section{CONCLUSION}

This study highlights variability in the home literacy practices of ethnic Chinese families in Hong Kong and demonstrates that aspects of the HLE are differentially related to children's English vocabulary, phonological awareness, letter knowledge, and word reading skills. The present work provides a more nuanced understanding of the characteristics and influences of the HLE in the development of English as a second language in a multilingual context. It adds to a growing body of knowledge that points to the significant role of the HLE in children's language and literacy skills and has the potential to inform policies and 
programs that promote family literacy practices. The findings from this study can serve as a basis for future cross-cultural comparisons of the HLE and the development of English as a second language among young children.

\section{DATA AVAILABILITY STATEMENT}

The raw data supporting the conclusions of this article will be made available by the authors, without undue reservation.

\section{ETHICS STATEMENT}

The studies involving human participants were reviewed and approved by Human Research Ethics Committee, The University

\section{REFERENCES}

Bacon-Shone, J., Bolton, K. R., and Luke, K. K. (2015). Language Use, Proficiency and Attitudes in Hong Kong. Hong Kong: Social Sciences Research Centre, the University of Hong Kong.

Baroody, A. E., and Diamond, K. E. (2012). Links among home literacy environment, literacy interest, and emergent literacy skills in preschoolers at risk for reading difficulties. Top. Early Childhood Special Educ. 32, 78-87. doi: $10.1177 / 0271121410392803$

Bolton, K. (2012). "Language policy and planning in Hong Kong: the historical context and current realities," in English in Southeast Asia: Features, Policy and Language in Use, eds E. Low and A. Hashim (Amsterdam: John Benjamins), 221-240.

Bretherton, I. (1985). Attachment Theory: Retrospect and Prospect. Monographs of the Society for Research in Child Development, 50:3. doi: 10.2307/3333824

Bronfenbrenner, U., and Morris, P. A. (2006). "The bioecological model of human development," in Handbook of Child Psychology: Theoretical Models of Human Development, eds R. M. Lerner and W. Damon (Hoboken, NJ: John Wiley \& Sons Inc), 793-828.

Burgess, S. R., Hecht, S. A., and Lonigan, C. J. (2002). Relations of home literacy environment to the development of reading-related abilities: a one-year longitudinal study. Reading Res. Q. 37, 408-426. doi: 10.1598/RRQ.37.4.4

Bus, A., Van Ijzendoorn, M., and Pellegrini, A. (1995). Joint book reading makes for success in learning to read: a meta-analysis on intergenerational transmission of literacy. Rev. Educ. Res. 65, 1-21.

Carroll, J. M., Holliman, A. J., Weir, F., and Baroody, A. E. (2019). Literacy interest, home literacy environment and emergent literacy skills in preschoolers. J. Res. Reading 42, 150-161. doi: 10.1111/1467-9817.12255

Census and Statistics Department HKSAR (2017). 2016 Population By-Census Main Results. Hong Kong: Census and Statistics Department, HKSAR.

Census and Statistics Department HKSAR (2019). Thematic Household Survey Report No. 66. Hong Kong: Census and Statistics Department, HKSAR.

Chow, B., Chui, B., Lai, M., and Kwok, S. (2017). Differential influences of parental home literacy practices and anxiety in English as a foreign language on Chinese children's English development. Int. J. Bilingual Educ. Bilingualism 20, 625-637. doi: 10.1080/13670050.2015.1062468

Chow, B., McBride-Chang, C., and Cheung, H. (2010). Parent-child reading in English as a second language: effects on language and literacy development of Chinese kindergarteners. J. Res. Reading 33, 284-301.

Crystal, D. (2012). English as a Global Language. Cambridge: Cambridge University Press.

Curenton, S. M., Craig, M. J., and Flanigan, N. (2008). Use of decontextualized talk across story contexts: how oral storytelling and emergent reading can scaffold children's development. Early Educ. Dev. 19, 161-187. doi: 10.1080/ 10409280701839296

Curriculum Development Council (2017). Kindergarten Education Curriculum Guide. Hong Kong: Government Printer. of Hong Kong. Written informed consent to participate in this study was provided by school principals, teachers and the participants' legal guardian/next of kin.

\section{AUTHOR CONTRIBUTIONS}

CL conceptualized and implemented the study. BR conducted the statistical analysis. Both authors contributed to the article and approved the submitted version.

\section{FUNDING}

This research was supported by an internal grant from the Faculty of Education, The University of Hong Kong.

Curriculum Development Council. (2006). Guide to the pre-primary curriculum. Government Printer.

de Jong, P., and Leseman, P. (2001). Lasting effects on home literacy on reading achievement in school. J. School Psychol. 39, 389-414. doi: 10.1016/S00224405(01)00080-2

Debaryshe, B. (1993). Joint picture-book reading correlates of early oral language skill. J. Child Lang. 20, 455-461. doi: 10.1017/S030500090000 8370

Debaryshe, B. (1995). Maternal belief systems: linchpin in the home reading process. J. Appl. Dev. Psychol. 16, 1-20. doi: 10.1016/0193-3973(95)90013-6

Deckner, D. F., Adamson, L. B., and Bakeman, R. (2006). Child and maternal contributions to shared reading: effects on language and literacy development. J. Appl. Dev. Psychol. 27, 31-41. doi: 10.1016/j.appdev.2005.12.001

Dickinson, D. K., and Tabors, P. O. (2001). Beginning Literacy with Language: Young Children Learning at Home and School. Baltimore, MD: Paul H Brookes Publishing.

Dixon, L. Q. (2011). The role of home and school factors in predicting English vocabulary among bilingual kindergarten children in Singapore. Appl. Psycholinguistics 32, 141-168. doi: 10.1017/S0142716410000329

Dixon, L. Q., and Wu, S. (2014). Home language and literacy practices among immigrant second-language learners. Lang. Teaching 47, 414-449. doi: 10.1017/ S0261444814000160

Dunn, D. M., and Dunn, L. M. (2007). Peabody Picture Vocabulary Test: Fourth Edition (PPVT $\left.{ }^{\mathrm{TM}} 4\right)$. San Antonio, TX: Pearson.

Duursma, E., Romero-Contreras, S., Szuber, A., Proctor, P., Snow, C., August, D., et al. (2007). The role of home literacy and language environment on bilinguals' English and Spanish vocabulary development. Appl. Psycholinguistics 28, 171-190.

Education Bureau (2016). Education Bureau Circular no. 7/2016: Free Quality Kindergarten Education. Hong Kong: Education Bureau.

Education Bureau (2019). Student Enrolment Statistics, 2018/19 (Kindergarten, Primary and Secondary Levels). Hong Kong: Education Bureau.

Education Department (1994). Manual of Kindergarten Practice. Hong Kong: Education Department.

Education Department (1999). List of Do's and Don'ts for Kindergartens. Hong Kong: Education Department.

Evans, M. A., and Shaw, D. (2008). Home grown for reading: parental contributions to young children's emergent literacy and word recognition. Can. Psychol. 49, 89-95. doi: 10.1037/0708-5591.49.2.89

Evans, M. A., Shaw, D., and Bell, M. (2000). Home literacy activities and their influence on early literacy skills. Can. J. Exp. Psychol. 54:65. doi: 10.1037/ h0087330

Evans, S. (2000). Hong Kong's new English language policy in education. World Englishes 19, 185-204. doi: 10.1111/1467-971X.00168

Farrant, B. M., and Zubrick, S. R. (2012). Early vocabulary development: the importance of joint attention and parent-child book reading. First Language 32, 343-364. doi: 10.1177/0142723711422626 
Farver, J. A. M., Xu, Y., Lonigan, C. J., and Eppe, S. (2013). The home literacy environment and Latino head start children's emergent literacy skills. Dev. Psychol. 49, 775-791. doi: 10.1037/a0028766

Fernald, A., Marchman, V. A., and Weisleder, A. (2013). SES differences in language processing skill and vocabulary are evident at 18 months. Dev. Sci. 16, 234-248. doi: 10.1111/desc.12019

Foy, J., and Mann, V. (2003). Home literacy environment and phonological awareness in preschool children: Differential effects for rhyme and phoneme awareness. Appl. Psycholinguistics 24, 59-88. doi: 10.1017/S01427164030000 43

Frijters, J. C., Barron, R. W., and Brunello, M. (2000). Direct and mediated influences of home literacy and literacy interest on pre-readers' oral vocabulary and early written language skills. J. Educ. Psychol. 92, 466-477.

Goodall, J., and Vorhaus, J. (2011). Review of Best Practice in Parental Engagement. London: Department of Education.

Griffin, E., and Morrison, F. (1997). The unique contribution of home literacy environment to differences in early literacy skills. Early Child Dev. Care 127, 233-243. doi: 10.1080/0300443971270119

Haden, C. A., Reese, E., and Fivush, R. (1996). Mothers' extratextual comments during storybook reading: stylistic differences over time and across texts. Discourse Processes 21, 135-169.

Hammer, C. S., Miccio, A. W., and Wagstaff, D. A. (2003). Home literacy experiences and their relationship to bilingual preschoolers' developing English literacy abilities: an initial investigation. Language Speech Hearing Serv. Schools 14, 20-30. doi: 10.1044/0161-1461(2003/003)

Hart, B., and Risley, T. R. (1995). Meaningful Differences in the Everyday Experience of Young American Children. Baltimore, MD: Paul H Brookes Publishing.

Hayes, D. P., and Ahrens, M. G. (1988). Vocabulary simplification for children: a special case of "motherese?". J. Child Language 15, 395-410. doi: 10.1017/ S0305000900012411

Hindman, A. H., and Morrison, F. J. (2012). Differential contributions of three parenting dimensions to preschool literacy and social skills in a middle-income sample. Merrill-Palmer Q. 58, 191-223.

Hood, M., Conlon, E., and Andrews, G. (2008). Preschool home literacy practices and children's literacy development: a longitudinal analysis. J. Educ. Psychol. 100, 252-271. doi: 10.1037/0022-0663.100.2.252

Hoover-Dempsey, K. V., and Sandler, H. M. (1997). Why do parents become involved in their children's education? Rev. Educ. Res. 67, 3-42.

Ip, P., Rao, N., Bacon-Shone, J., Li, S. L., Ho, F. K. W., Chow, C. B., et al. (2016). Socioeconomic gradients in school readiness of Chinese preschool children: the mediating role of family processes and kindergarten quality. Early Childhood Res. Q. 35, 111-123. doi: 10.1016/j.ecresq.2015.10.005

Johnson, A. D., Martin, A., Brooks-Gunn, J., and Petrill, S. A. (2008). Order in the house!Associations among household chaos, the home literacy environment, maternal reading ability, and children's early reading. Merrill-Palmer Q. 54, 445-472. doi: 10.1353/mpq.0.0009

Justice, L. M., and Ezell, H. K. (2000). Enhancing children's print and word awareness through home-based parent intervention. Am. J. Speech-Language Pathol. 9, 257-269. doi: 10.1044/1058-0360.0903.257

Justice, L. M., Kaderavek, J., Bowles, R., and Grimm, K. (2005). Language impairment, parent-child shared reading, and phonological awareness. Top. Early Childhood Special Educ. 25, 143-156. doi: 10.1177/02711214050250030201

Kalia, V., and Reese, E. (2009). Relations between Indian children's home literacy environment and their English oral language and literacy skills. Sci. Stud. Reading 13, 122-145. doi: 10.1080/10888430902769517

Kirkpatrick, A., and Liddicoat, A. J. (2017). Language education policy and practice in East and Southeast Asia. Language Teaching 50, 155-188. doi: 10.1017/ S0261444817000027

Lau, C. (2020). English language education in Hong Kong: a review of policy and practice. Curr. Issues Language Planning 21, 1-18. doi: 10.1080/14664208.2020. 1741239

Lau, C., and Rao, N. (2013). English vocabulary instruction in six early childhood classrooms in Hong Kong. Early Child Dev. Care 183, 1363-1380. doi: 10.1080/ 03004430.2013 .788815

Lau, E. Y. H., Li, H., and Rao, N. (2011). Parental involvement and children's readiness for school in China. Educ. Res. 53, 95-113. doi: 10.1080/00131881. 2011.552243
Leseman, P. P. M., and de Jong, P. F. (1998). Home literacy: opportunity, instruction, cooperation and social-emotional quality predicting early reading achievement. Reading Res. Q. 33, 294-318. doi: 10.1598/RRQ.33.3.3

Leung, C. S. S., Lim, S. E. A., and Li, Y. L. (2013). Implementation of the Hong Kong language policy in pre-school settings. Early Child Dev. Care 183, 1381-1396. doi: 10.1080/03004430.2013.788816

Levy, B. A., Gong, Z., Hessels, S., Evans, M., and Jared, D. (2006). Understanding print: early reading development and the contributions of home literacy experiences. J. Exp. Child Psychol. 95:78. doi: 10.1016/j.jecp.2006. 06.003

Luo, R., Tamis-LeMonda, C. S., and Song, L. (2013). Chinese parents' goals andpractices in early childhood. Early Childhood Res. Q. 28, 843-857. doi: 10.1016/j.ecresq.2013.08.001

Manolitsis, G., Georgiou, G. K., and Parrila, R. (2011). Revisiting the home literacy model of reading development in an orthographically consistent language. Learn. Instruction 21, 496-505. doi: 10.1016/j.learninstruc.2010.06.005

Manz, P. H., Hughes, C., Barnabas, E., Bracaliello, C., and Ginsburg-Block, M. (2010). A descriptive review and meta-analysis of family-based emergent literacy interventions: To what extent is the research applicable to low-income, ethnic-minority or linguistically-diverse young children? Early Childhood Res. Q. 25, 409-431. doi: 10.1016/j.ecresq.2010.03.002

Martini, F., and Sénéchal, M. (2012). Learning literacy skills at home: parent teaching, expectations, and child interest. Can. J. Behav. Sci. 44, 210-221. doi: $10.1037 / \mathrm{a} 0026758$

McBee, M. (2010). Modeling outcomes with floor or ceiling effects: an introduction to the Tobit Model. Gifted Child Q. 54, 314-320. doi: 10.1177/ 0016986210379095

McBride-Chang, C., and Kail, R. V. (2002). Cross-cultural similarities in the predictors of reading acquisition. Child Dev. 73, 1392-1407. doi: 10.1111/14678624.00479

Mol, S. E., Bus, A. G., and de Jong, M. T. (2009). Interactive book reading in early education: a tool to stimulate print knowledge as well as oral language. Rev. Educ. Res. 79, 979-1007. doi: 10.3102/0034654309332561

Mol, S. E., Bus, A. G., de Jong, M. T., and Smeets, D. J. H. (2008). Added value of dialogic parent-child book readings: a meta-analysis. Early Educ. Dev. 19, 7-26. doi: 10.1080/10409280701838603

Mullis, I. V. S., Martin, M. O., Kennedy, A. M., and Foy, P. (2007). IEA's Progress in International Reading Literacy Study in Primary School in 40 Countries. Chestnut Hill, MA: TIMSS \& PIRLS International Study Center, Boston College.

Muter, V., Hulme, C., Snowling, M. J., and Stevenson, J. (2004). Phonemes, rimes, vocabulary, and grammatical skills as foundations of early reading development: evidence from a longitudinal study. Dev. Psychol. 40:665.

Ng, F. F. Y., and Wei, J. (2020). Delving into the minds of Chinese parents: what beliefs motivate their learning-related practices? Child Dev. Perspect. 14, 61-67. doi: $10.1111 /$ cdep. 12358

Ng, M. L., and Rao, N. (2013). Teaching English in Hong Kong kindergartens: a survey of practices. Int. J. Literacies 19, 25-47.

Niklas, F., and Schneider, W. (2013). Home literacy environment and the beginning of reading and spelling. Contemp. Educ. Psychol. 38, 40-50. doi: 10.1016/j. cedpsych.2012.10.001

Niklas, F., Tayler, C., and Schneider, W. (2015). Home-based literacy activities and children's cognitive outcomes: a comparison between Australia and Germany. Int. J. Educ. Res. 71, 75-85. doi: 10.1016/j.ijer.2015.04.001

Odom, S. L., Pungello, E. P., and Gardner-Neblett, N. (eds). (2012). Infants, Toddlers, and Families in Poverty: Research Implications for Early Child Care. New York, NY: Guilford Press.

Passenger, T., Stuart, M., and Terrell, C. (2000). Phonological processing and early literacy. J. Res. Reading 23, 55-66. doi: 10.1111/1467-9817.00102

Payne, A. C., Whitehurst, G. J., and Angell, A. L. (1994). The role of home literacy environment in the development of language ability in preschool children from low-income families. Early Childhood Res. Q. 9, 427-440. doi: 10.1016/08852006(94)90018-3

Puglisi, M., Hulme, C., Hamilton, L., and Snowling, M. (2017). The home literacy environment is a correlate, but perhaps not a cause, of variations in children's language and literacy development. Sci. Stud. Reading 21, 498-514. doi: 10. 1080/10888438.2017.1346660

Puranik, C. S., Phillips, B. M., Lonigan, C. J., and Gibson, E. (2018). Home literacy practices and preschool children's emergent writing skills: an initial 
investigation. Early Childhood Res. Q. 42, 228-238. doi: 10.1016/j.ecresq.2017. 10.004

Raikes, H., Pan, A. B., Luze, G., Tamis-Lemonda, C. S., Brooks-Gunn, J., Constantine, J., et al. (2006). Mother-child book reading in low-income families: correlates and outcomes during the first three years of life. Child Dev. 77, 924-953. doi: 10.1111/j.1467-8624.2006.00911.x

Raven, J. C., Court, J. H., and Raven, J. (1995). Raven's Coloured Progressive Matrices. Oxford: Oxford Psychologists Press.

Reese, E., and Cox, A. (1999). Quality of adult book reading affects children's emergent literacy. Dev. Psychol. 35, 20-28.

Rodriguez, E. T., and Tamis-Lemonda, C. S. (2011). Trajectories of the home learning environment across the first 5 years: associations with children's vocabulary and literacy skills at prekindergarten. Child Dev. 82, 1058-1075. doi: 10.1111/j.1467-8624.2011.01614.x

Roseberry, S., Hirsh-Pasek, K., Parish-Morris, J., and Golinkoff, R. M. (2009). Live action: Can young children learn verbs from video? Child Dev. 80, 1360-1375. doi: 10.1111/j.1467-8624.2009.01338.x

Scarborough, H. S., and Dobrich, W. (1994). On the efficacy of reading to preschoolers. Dev. Rev. 14, 245-302. doi: 10.1006/drev.1994.1010

SCOLAR (2003). Action Plan to Raise Language Standards in Hong Kong - Final Report of Language Education Review. Hong Kong: Standing Committee on Language Education and Research.

Sénéchal, M. (2006). Testing the home literacy model: Parent involvement in kindergarten is differentially related to Grade 4 reading comprehension fluency, spelling and reading for pleasure. Sci. Stud. Reading 10, 59-87. doi: 10.1207/ s1532799xssr1001_4

Sénéchal, M., and LeFevre, J. (2002). Parental involvement in the development of children's reading skill: a five-year longitudinal study. Child Dev. 73, 445-460. doi: 10.1111/1467-8624.00417

Sénéchal, M., and LeFevre, J. A. (2014). Continuity and change in the home literacy environment as predictors of growth in vocabulary and reading. Child Dev. 85, 1552-1568. doi: 10.1111/cdev.12222

Sénéchal, M., LeFevre, J. A., Thomas, E. M., and Daley, K. E. (1998). Differential effects of home literacy experiences on the development of oral and written language. Reading Res. Q. 33, 96-116. doi: 10.1598/RRQ.33.1.5

Sénéchal, M., and Young, L. (2008). The effect of family literacy interventions on children's acquisition of reading from kindergarten to Grade 3: a metaanalytic review. Rev. Educ. Res. 78, 880-907. doi: 10.3102/00346543083203 19

Stanovich, K. E. (1986). "Cognitive processes and the reading problems of learning disabled children: Evaluating the assumption of specificity," in Psychological and Educational Perspectives on Learning Disabilities, eds J. Torgesen and B. Wong (New York, NY: Academic Press), 87-131.

Sylva, K., Melhuish, E., Sammons, P., Siraj-Blatchford, I., and Taggart, B. (2004). The Effective Provision of Pre-School Education (EPPE) Project: Final Report. London: University of London.

Tamis-Lemonda, C., Luo, R., Mcfadden, K., Bandel, E., and Vallotton, C. (2019). Early home learning environment predicts children's 5 th grade academic skills. Appl. Dev. Sci. 23, 153-169. doi: 10.1080/10888691.2017.1345634

Tamis-Lemonda, C. S., Bornstein, M. H., and Baumwell, L. (2001). Maternal responsiveness and children's achievement of language milestones. Child Dev. 72, 748-767. doi: 10.1111/1467-8624.00313

Tollefson, J. W., and Tsui, A. B. M. (2018). "Medium of instruction policy," in The Oxford Handbook of Language Policy and Planning, eds J. W. Tollefson and M. Pérez-Milans (Oxford: Oxford University Press), 257-275.

Tse, S. K., Zhu, Y., Hui, Y. S., and Ng, H. W. (2017). The effects of home reading activities during preschool and Grade 4 on children's reading performance in
Chinese and English in Hong Kong. Aust. J. Educ. 61, 5-23. doi: 10.1177/ 0004944116689093

Uchikoshi, Y. (2006). Early reading in bilingual kindergartners: can educational television help? Sci. Stud. Reading 10, 89-120. doi: 10.1207/s1532799xssr 1001_5

van Kleeck, A., Gillam, R. B., Hamilton, L., and McGrath, C. (1997). The relationship between middle-class parents' book-sharing discussion and their preschoolers' abstract language development. J. Speech Hearing Res. 40, 12611271. doi: 10.1044/jslhr.4006.1261

Van Steensel, R. (2006). Relations between socio-cultural factors, the home literacy environment and children's literacy development in the first years of primary education. J. Res. Reading 29, 367-382. doi: 10.1111/j.1467-9817.2006.00301.x

van Steensel, R., McElvany, N., Kurvers, J., and Herppich, S. (2011). How effective are family literacy programs? Results of a meta-analysis. Rev. Educ. Res. 81, 69-96. doi: 10.3102/0034654310388819

Vygotsky, L. S. (1978). Mind in Society: The Development of Higher Psychological Processes. Cambridge, MA: Harvard University Press.

Wagner, R. K., Torgesen, J. K., Rashotte, C. A., and Pearson, N. A. (2013). Comprehensive Test of Phonological Processing $-2^{\text {nd }} e d$. (CTOPP-2. Austin, TX: Pro-Ed.

Wang, L., and Kirkpatrick, A. (2019). Trilingual education in Hong Kong primary schools. Springer Nature Switzerland.

Weigel, D. J., Martin, S. S., and Bennett, K. K. (2006). Contributions of the home literacy environment to preschool-aged children's emerging literacy and language skills. Early Child Dev. Care 176, 357-378. doi: 10.1080/ 03004430500063747

Whitehurst, G. J., Falco, F. L., Lonigan, C. J., Fischel, J. E., DeBaryshe, B. D., ValdezMenchaca, M. C., et al. (1988). Accelerating language development through picture book reading. Dev. Psychol. 24, 552-559. doi: 10.1037/0012-1649.24. 4.552

Whitehurst, G. J., and Lonigan, C. J. (1998). Child development and emergent literacy. Child Dev. 69, 848-872.

Wood, C. (2002). Parent-child pre-school activities can affect the development of literacy skills. J. Res. Reading 25, 241-258. doi: 10.1111/1467-9817.00173

Yeung, S. S., and King, R. B. (2016). Home literacy environment and English language and literacy skills among Chinese young children who learn English as a second language. Reading Psychol. 37, 92-120. doi: 10.1080/02702711.2015. 1009591

Yong, A. G., and Pearce, S. (2013). A beginner's guide to factor analysis: focusing on exploratory factor analysis. Tutorials Quantitative Methods Psychol. 9, 79-94. doi: 10.20982/tqmp.09.2.p079

Zevenbergen, A. A., and Whitehurst, G. J. (2003). "Dialogic reading: a shared picture book reading intervention for preschoolers," in On Reading Books to Children: Parents and Teachers, eds A. Van Kleeck, S. A. Stahl, and E. B. Bauer (New Jersey: Lawrence Erlbaum Associates), 170-192. doi: 10.4324/ 9781410607355

Conflict of Interest: The authors declare that the research was conducted in the absence of any commercial or financial relationships that could be construed as a potential conflict of interest.

Copyright (c) 2021 Lau and Richards. This is an open-access article distributed under the terms of the Creative Commons Attribution License (CC BY). The use, distribution or reproduction in other forums is permitted, provided the original author(s) and the copyright owner(s) are credited and that the original publication in this journal is cited, in accordance with accepted academic practice. No use, distribution or reproduction is permitted which does not comply with these terms. 


\title{
Home Numeracy and Preschool Children's Mathematical Development: Expanding Home Numeracy Models to Include Parental Attitudes and Emotions
}

\author{
Ann Dowker* \\ Department of Experimental Psychology, University of Oxford, Oxford, United Kingdom
}

Most studies suggest that home numeracy is correlated with preschool children's current mathematical performance, and also predicts their mathematical performance longitudinally. However, this finding is not universal, and some studies do not suggest

OPEN ACCESS

Edited by: Amy R Napoli,

University of Nebraska-Lincoln,

United States

Reviewed by:

Monika Szczygiet,

Pedagogical University of Kraków,

Poland

Sarah Eason,

Purdue University, United States Lydia DeFlorio,

University of Nevada, Reno, United States

*Correspondence: Ann Dowker

ann.dowker@psy.ox.ac.uk

Specialty section:

This article was submitted to Educational Psychology, a section of the journal

Frontiers in Education

Received: 24 June 2020 Accepted: 04 January 2021 Published: 18 February 2021

Citation:

Dowker A (2021) Home Numeracy and

Preschool Children's Mathematical

Development: Expanding Home Numeracy Models to Include Parental

Attitudes and Emotions.

Front. Educ. 6:575664.

doi: 10.3389/feduc.2021.575664 a close relationship between home numeracy and preschoolers' mathematical development. There are several possible reasons for the discrepant findings, including the exact nature of numeracy activities provided, and possible unreliability of parental reports of home numeracy. However, parental attitudes might also lead to differing results: because attitudes might influence actual home numeracy provision or the ways in which it is reported; because parental attitudes and beliefs might be transmitted intergenerationally; and because parental mathematics anxiety may interact with home numeracy activities to create early negative emotional associations about mathematics, as some research suggests to be the case with regard to school-age children. There has been a significant amount of research in the first two of these areas, but very little in the third area with regard to preschoolers. It should be seen as an important area for further research.

Keywords: home numeracy, preschoolers, parental attitudes, parental beliefs, gender stereotypes, mathematics anxiety

\section{INTRODUCTION}

The aim of this article is to point out the importance of incorporating into definitions and models of the early home numeracy environment, not only home provision of numeracy activities for preschool children, but also parental attitudes to mathematics (LeFevre et al., 2009; Skwarchuk et al., 2014) and, in particular, parental emotional reactions to mathematics, in particular mathematics anxiety. The article will start by discussing definitional issues with regard to both 'home numeracy environment' and 'attitudes to mathematics'. In both cases, I will argue in favor of a broadly inclusive definition, whereby home numeracy environment includes not only activities but attitudes, and attitudes include not only cognitive evaluations but emotions. I will proceed to describe Skwarchuk et al.s home numeracy model; and then to review some evidence as to the predictive role of home numeracy environment on children's mathematical development; and to discuss reasons why this evidence does not lead to absolutely consistent conclusions on this issue. I will then discuss the possible differential role of different types of mathematical activities in predicting different aspects of 
mathematical development. I will then argue that it is insufficient to view home numeracy environment solely in terms of provision of mathematical activities, and that parental attitudes to mathematics are also important.

I will give some evidence from studies so far about how parental attitudes may affect children's mathematical development, both because of effects of parental attitudes on the quantity and quality of their provision of the mathematical activities, and because of intergenerational transmission of attitudes. I will point out that there has been relatively little research on the effects of parental emotions about mathematics such as mathematics anxiety on preschool children's mathematical development. A few studies of school-age children suggest that this may have a crucial impact. I will conclude by emphasizing the need for further study of this highly important topic.

Most studies suggest that numeracy-related activities at home have at least some influence on preschool children's numeracy development (LeFevre et al., 2002; Gunderson and Levine, 2011; Skwarchuk et al., 2014). This is often portrayed in terms of 'home numeracy environment', though it is not always clear how broadly this phrase should be interpreted, and whether it refers just to the activities provided for children, or also to the parents' own engagement in mathematical activities, their attitudes toward numeracy in general, and/or their expectations regarding their children's current and future numeracy performance. I would argue that the home numeracy environment needs to be seen as including not only the mathematical activities directly available to children, but all the characteristics of the home environment that involve mathematics, including parents' own mathematical activities and their attitudes and emotions regarding mathematics.

If we are to include parental attitudes and emotions toward mathematics in our definition of 'home numeracy environment', we need to define 'attitudes' in this context and specify what they do and do not include. It would generally be agreed that attitudes to mathematics include enjoyment of mathematics, self-rating of one's own mathematical ability, and expectations regarding one's ability to learn and improve mathematics skills in the future. In the context of home numeracy environment, attitudes should also be seen as including evaluations of one's children's mathematical ability and expectations of their future mathematical learning. Attitudes to mathematics are often defined and studied more broadly. For example, Fennema and Sherman (1976) include among their attitude measures not only confidence in one's mathematical ability, but also perceived usefulness of mathematics; perception of the support received from teachers; and gender stereotypes with regard to perceiving mathematics as a male domain. As discussed below, gender stereotypes are one of the topics that has received most study regarding how parental attitudes may influence children's mathematical performance.

A more potentially controversial issue is whether emotional reactions such as mathematics anxiety should be classed as attitudes. However, many theories of attitudes, such as Breckler's ABC model (Breckler, 1984), do include affective components, and I will here follow researchers such as $\mathrm{Ma}$ and Kishor (1997) in treating mathematics anxiety as an attitude. (This topic is discussed in more detail by Dowker et al. (2016)). It will be argued here that, while there is a general need for greater consideration of parental attitudes to mathematics as part of the home numeracy environment, there is a particular need for greater consideration of parental emotional reactions to mathematics, especially mathematics anxiety.

\section{HOME NUMERACY MODEL}

As a means of clarifying how specific aspects of home numeracy may predict specific aspects of children's mathematical development, Skwarchuk et al. (2014) proposed a Home Numeracy Model, based on a survey of parents of almost 200 children beginning kindergarten (median age 58 months). The parents were asked about their own attitudes toward numeracy (e.g., whether they enjoyed doing sums), their academic expectations for their children, and reports of formal and informal numeracy activities at home. The children were given numeracy tests a year later, involving both symbolic and nonsymbolic arithmetic. Hierarchical regression analyses were used to investigate what were predictors of numeracy test scores. Parents' reports of formal home numeracy practices (for example, practicing simple sums) predicted children's symbolic arithmetic, while their reports of children's exposure to games with numerical content predicted children's non-symbolic arithmetic. Parental attitudes toward arithmetic predicted mainly the children's non-symbolic arithmetic. Their model proposed that parental academic expectations for their children predict formal numeracy activities in the home, which in turn predict the children's formal (mainly symbolic) numeracy, while their own attitudes toward numeracy and the children's exposure to informal activities are predictors of the children's informal (mostly nonsymbolic) numeracy.

As discussed in the next section, many studies have indeed suggested that numeracy-related activities in the home do predict young children's mathematical performance. However, some studies have failed to support this hypothesis, and not all studies that do support it have shown the sharp distinction between informal and formal home numeracy practices that the model proposes.

\section{HOME NUMERACY ACTIVITIES: EVIDENCE FOR THEIR PREDICTIVE ROLE}

Most studies suggest that the extent of parental provision of home numeracy activities is correlated with children's current numeracy performance (Blevins-Knabe and Musun-Miller, 1996; Skwarchuk, 2009; De Florio and Beliakoff, 2015; Zippert and Ramani, 2017). This does not necessarily indicate that the home numeracy activities are causing the children's better numeracy performance. It could either reflect parental response to their children's interest and ability in numeracy, or parental influence on their children's numeracy ability: it is not possible to draw strong conclusions from a study of correlations at a single time-point.

Longitudinal studies do, however, give some support to the hypothesis that home numeracy environment influences 
children's future numeracy development (e.g., LeFevre et al., 2002; Gunderson and Levine, 2011; Skwarchuk et al., 2014). For example, Niklas and Schneider (2012, 2014) studied the home numeracy environment of about 600 German children starting kindergarten and followed them up longitudinally to the end of Grade 1. Family mathematical activities, such as playing dice or number games, predicted children's mathematical abilities, not only concurrently but longitudinally, even after controlling for IQ.

Dunst et al. (2017) carried out a meta-analysis of studies of relationships between early home numeracy activities and preschool children's mathematics performance. The metaanalysis included 13 studies of children between 36 and 84 months: a total of over 5,000 children in all. Results indicated that home numeracy experiences were associated with children's mathematical performance.

Most of the relevant studies have been carried out in Europe or North America; but some studies outside of these areas have given similar results. For example, Cheung et al. (2020) studied 290 preschool children living in low to middle income communities in the Philippines, and found that home numeracy resources and activities directly predicted children's numeracy skills, as did the parents' education, calculation fluency and own mathematical activities.

However, not all studies do show a strong relationship between home numeracy environment and young children's numeracy (Blevins-Knabe et al., 2000). Zippert et al. (2020) found a very limited level of association, but much less than in some of the other studies. They observed 45 parent-preschooler dyads engaging in three play activities: playing cards, building blocks, and stringing beads, all with activity suggestions from the researchers. The children underwent a mathematics and numeracy test (the Research-Based Early Mathematics Short Form), and additional tests of spatial skills and patterning, concurrently and 7 months later. Children's exploration of space and patterns correlated with their concurrent spatial and pattern skills, and parental support in numeracy correlated with children's concurrent numeracy abilities, but not with their growth in numeracy. Otherwise, parental mathematics support was not related to their children's concurrent or subsequent mathematical abilities. Missall et al. (2015) also found no statistically significant relationship between home numeracy activities and children's mathematical performance.

Wolf and McCoy (2019) in a study of 2,137 Ghanaian preschool children (mean age 5.2 years) found that, after taking SES into account, parental reports of cognitive stimulation at home (including, but not restricted, to numerical activities) was actually negatively related to children's motor, literacy and numeracy skills. This is most likely to be because parents were more likely to provide home stimulation to children who were showing signs of difficulties, rather than due to any actual negative effect of stimulation.

There are several possible reasons for the somewhat conflicting results. One of them is that the assessment of the level of home numeracy may not be totally reliable. One problem with the methodology of most studies of home numeracy is that they involve the parents answering questions or filling in questionnaires about their provision of home numeracy. Thus, the parental reports may be affected both by what the parents regard as socially desirable and by what they regard as mathematics. They may over-report provision of numeracy activities because they view provision of such activities as socially desirable, or may under-report them because they may only regard a limited range of activities as mathematical: the latter would seem most likely to include formal counting-type activities. Researchers can reduce the risk of such under-reporting by asking parents about specific activities, but this then carries the risk that the results will be influenced by the researchers' assumptions about what mathematical activities are likely to be provided.

A minority of studies involve researchers' observations of parental provision of numeracy activities, instead of, or in addition to, parental reports (Gunderson and Levine, 2011; Zippert et al., 2020). These observational studies avoid some of the problems of parental report studies, but have some problems of their own: if the researchers are non-directive, they may be relying a limited sample of observations, and if they are directive, they may influence the parents' practices in a way that does not reflect real life. Zippert et al. (2020) asked parents to engage in three types of activities with their children: card games, building with Lego Duplo blocks, and stringing beads. The researchers coded the frequency of various types of mathematical content within these activities (e.g., magnitude comparison, counting objects, numeral identification, mention of shapes, mention of spatial locations, verbal identification of patterns, nonverbal gesturing toward patterns). These activities were chosen to elicit mathematically related speech and behaviors by parents and children, but may not have resembled the parents' typical practices. Moreover, the constraints resulting from the researchers requesting specific types of activities may have to some degree reduced variability in the parents' behavior and this may have contributed to a reduction in the level of associations that were found. Even in observational studies where the researchers are not directive, the parents may behave uncharacteristically in response to being observed. It is noteworthy that some studies which included both parental reports and observational measures found little or no correlation between the two (Missall et al., 2015; Mutaf Yilsiz et al., 2018). It is important that studies in the future include both observational and parental report measures, and examine systematically which are better predictors of children's mathematical development.

\section{WHAT TYPES OF MATHEMATICAL ACTIVITIES PREDICT WHICH ASPECTS OF YOUNG CHILDREN'S MATHEMATICS?}

One factor that may influence findings about the importance of home numeracy is the particular aspects of mathematics that are studied. The very term 'home numeracy' seems to imply a focus on numbers and counting. Where home mathematics activities have been investigated from the point of view of comparing the extent of activities involving number skills and those involving other mathematical domains such as shape, space and pattern, it has generally been found that parents engage in a variety of mathematical activities, but emphasize number skills more than 
others (Zippert and Rittle-Johnson, 2020; Zippert et al., 2020). This is in fact not specific to the home. Similar results have been found for preschool teachers (Von Spreckelsen et al., 2019).

Several studies have examined the distinction made in the Home Numeracy Model (Skwarchuk et al., 2014) between formal and informal activities. Formal activities are typically defined as those that emphasize quasi-educational activities such as counting and numeral recognition, while informal activities include number games and numerical activities embedded in everyday tasks such as preparing meals. On the whole, studies support the Home Numeracy Model's hypothesis that more formal activities mainly predict symbolic skills, while more informal activities tend to predict non-symbolic skills (LeFevre et al., 2010; Ramani et al., 2015; Hart et al., 2016).

For example, Susperreguy et al. (2018) asked the parents of 390 Chilean preschoolers (mean age at start of study 4 years 7 months) about the home numeracy activities that they engaged in with their children, and about their attitudes toward numeracy and their early academic expectations for their children. They were also asked about home literacy activities. Parents with more positive attitudes toward numeracy and higher academic expectations for their children reported more formal numeracy activities (mapping and operational activities). Formal numeracy activities predicted children's number line estimation. Informal activities, such as parents' knowledge of number games, predicted non-symbolic arithmetic and non-symbolic number comparison tasks. Both types of activities predicted children's applied problem-solving skills. Home literacy activities were not related to children's early numeracy skills.

There have sometimes been variations in the findings of what is most predicted by different types of activity. (Mutaf Yildiz et al., 2018) found that formal home numeracy activities were associated with children's counting abilities, while informal home numeracy activities were associated with calculation and symbolic number line estimation. Benavides-Varela et al. (2016) studied 110 children (mean age 5 years 11 months) and found that their knowledge of number information learned at home, and their parents' reports of home numeracy activities predicted their exact but not their approximate number skills.

One type of informal home mathematical activity seems to be a particularly strong predictor of children's numeracy: playing numerical board games (Benavides-Varela et al., 2016; Ramani and Siegler, 2008; Ramani and Siegler, 2011). There is evidence that in this case, the board games play a causal role, as playing such games with children who have not played them at home seems to result in significant improvements in early numeracy knowledge (Ramani and Siegler, 2008; Ramani and Siegler, 2011).

Another aspect of home numeracy activities that may be influential is the complexity of the activities provided. (Thompson et al., 2017) studied 184 preschool children (71 three-year-olds and 113 four-year-olds and investigated their parents' reports of home numeracy activities and the children's numeracy skills. After controlling for parental educational level, the level of provision of home numeracy activities predicted the numeracy skills of the four-year-olds but not the three-year-olds. In the case of the four-year-olds, complex but not basic home numeracy activities predicted children's numeracy skills. Since complex activities were commoner for the older children, this might explain why home numeracy environment only predicted the numeracy skills of the older children. It is not clear whether the more complex home numeracy activities lead to better mathematical development, or whether parents are more likely to engage in complex numeracy activities with more mathematically advanced children.

It should be noted that parental reports of home numeracy activities do not usually give much indication of the quality of the parent-child interactions during these activities, and in particular of the quantity and quality of the mathematical language that the children hear during these activities. Knowledge of mathematical language has been shown to be an important aspect of mathematical development (e.g., Gunderson and Levine, 2011; Ramani et al., 2015; Thompson et al., 2017; Casey et al., 2018). The role of exposure to mathematical language in home numeracy activities warrants further study.

However important the types of activities provided are to children's mathematical development, they are unlikely to be the whole story. Parental attitudes toward mathematics are also likely to be important, as referenced in the Home Numeracy Model (Skwarchuk et al., 2014), and it is very important to study these.

\section{POSSIBLE EFFECTS OF PARENTAL ATTITUDES TOWARD MATHEMATICS ON CHILDREN'S MATHEMATICAL DEVELOPMENT}

It is well known that there is wide variation in attitudes toward mathematics, and that many people have extremely negative attitudes toward mathematics, often involving strong emotions of fear and anxiety (Hembree, 1990; Ashcraft, 2002; Carey et al., 2016; Dowker et al., 2016). Therefore, it must be assumed that the parents in studies of home numeracy will vary considerably in their attitudes toward mathematics, and it is likely that these variations in attitudes will affect children's experience of home numeracy, and the children's own attitudes and emotions toward mathematics.

Mathematics anxiety as such is not the main topic of this paper, which focusses specifically on its possible impact on the home numeracy environment of very young children. However, it is important to note that mathematics anxiety is common, though estimates of its exact frequency vary quite widely depending on the criteria used (Carey et al., 2016; Dowker et al., 2016); that it tends to increase with age during the school years (Gierl and Bisanz, 1995; Gottfried et al., 2007; Krinzinger et al., 2009; Ma and Kishor, 1997; Wigfield and Meece, 1988; but see; Sorvo et al., 2017); and that it is usually higher in females than males (Hembree, 1990; Else-Quest et al., 2010; Devine et al., 2012). It is negatively related to mathematics achievement and to pursuit of mathematical activities: for example, it is negatively associated with performance on secondary school and college mathematics examinations, and with choice to take advanced mathematics 
courses (Hembree, 1990; Ma and Kishor, 1997). The negative relationship between mathematics anxiety and mathematics performance is bidirectional ( $\mathrm{Ma}$ and $\mathrm{Xu}, 2004$; Carey et al., 2016; Ganley and Lubienski, 2016). Longitudinal studies show that attainment in mathematics negatively predicts mathematics anxiety (Maloney and Beilock, 2012; Jansen et al., 2013), presumably because experiences of failure are aversive and experiences of success are rewarding; but mathematics anxiety also predicts reduced attainment (Cargnelutti et al., 2017).

There are several ways, discussed in the following sections, in which negative parental attitudes toward mathematics, and in particular mathematics anxiety may affect their children's home numeracy experience. The first, perhaps most obvious way is that if parents have negative attitudes toward mathematics, they may be less likely to engage in mathematics-related activities at home at all, thus reducing their children's home numeracy exposure (Zippert et al., 2020). The second is that parents may pass their own negative attitudes on to their children (Szczygiel, 2020a; Szczygiel, 2020b). The third is that if parents have high levels of mathematics anxiety, their interactions with their children, when attempting to teach them aspects of mathematics or engage them in numeracy -related activities may be fraught and stressful (DiStefano et al., 2020). For example, parents may threaten their children with failure due to their own fear of failure, or be gloomy or bad-tempered with them because any mathematical activity causes them to be in a bad mood. This may lead to the children developing negative associations with mathematics.

\section{PARENTAL ATTITUDES AND PROVISION OF HOME NUMERACY ACTIVITIES}

Aspects of parental attitudes toward mathematics that have been studied in connection with links to home numeracy and to children's performance in mathematics are quite diverse and have included their beliefs about their own and their children's ability in mathematics (Blevins-Knabe et al., 2000; Hart et al., 2016; Zippert et al., 2020) their beliefs about the importance of mathematics to themselves and their children (Skwarchuk et al., 2014); their gender stereotypes about mathematics (Bleeker and Jacobs, 2004; Tomasetto et al., 2015; Del Rio et al., 2019); and -so far, almost exclusively with regard to school-age children - their level of anxiety about mathematics (Maloney et al., 2015; DiStefano et al., 2020; Vanbinst et al., 2020). As discussed below, gender stereotypes and parents' beliefs about their own and their children's numerical abilities seem to be the attitudes that have received the largest amount of study in this connection.

There is some evidence that parental beliefs about their children's and their own ability in mathematics may influence their provision of home mathematics activity, supporting the Home Numeracy Model's prediction that parental academic expectations for their children would influence their provision of formal numeracy activities in particular. For example, (Zippert et al., 2020), who examined a wider variety of home mathematical activities than typical, found that parents' beliefs about their children's abilities were positively related to their support for numeracy, pattern, and mathematics as a whole, while their beliefs about their own abilities were positively related to their support for spatial activities. With regard to their beliefs about their children's abilities, it is difficult to say whether their children's interest in mathematics is driving both the parents' beliefs and their numeracy provision, or whether a more general belief in children's mathematical capacity is leading to greater numeracy provision, or even whether their numeracy provision leads to greater interest and better performance on the part of their children, which in turn influences the parents' child-specific beliefs. With regard to the parents' beliefs about their own abilities, it is difficult to say whether their beliefs are directly affecting their mathematical provision for their children, or whether their actual ability in mathematics is influencing both their beliefs and their provision.

DeFlorio and Beliakoff (2015) studied 90 children in their first year of preschool and 88 in their prekindergarten year, and compared those from middle and lower SES backgrounds. There was relatively little difference in the extent of home mathematical activities that they received, but significant differences in parental beliefs about early mathematical development. Middle SES parents had higher expectations, and also a more accurate understanding of what skills can be expected from children by the age of 5 . The parents'beliefs were associated with their children's mathematical performance. Once again, it is hard to disentangle the effects of parental beliefs on their children's mathematical performance from the effects of children's performance on their parents' beliefs.

A number of studies indicate that parents' beliefs about their own interest and ability in mathematics are associated with their provision of home numeracy activities (BlevinsKnabe et al., 2000; Skwarchuk, 2009); but there are some that do not (Skwarchuk et al., 2014; Hart et al., 2016). Parents' beliefs about their children's abilities have been more consistently been found to be associated with home numeracy provision (Hart et al., 2016; Huntsinger et al., 2016). Parents who believed their children had high ability in numeracy tasks engaged in frequent home numeracy support. Parents' beliefs that attainment of early numeracy skills is important for their children have also been found to be associated with the home numeracy environment in some studies (Skwarchuk et al., 2014) but not in others (LeFevre et al., 2010).

It must be remembered that parental attitudes may influence not only actual provision of home numeracy, but parental reports of it, thus possibly biasing the results of surveys. As indicated above, parents' beliefs about what is mathematical may influence their reporting. For parents who are highly anxious about mathematics, certain activities may become particularly salient and more likely to be reported than others. One possible hypothesis is that such parents may place a particularly high emphasis on formal activities, because they are likely to associate such activities with the content of school instruction and in particular with school tests and examinations. This possibility must be considered when interpreting the results of studies of relationships between parental attitudes and home numeracy provision. 


\section{INTERGENERATIONAL TRANSMISSION OF NEGATIVE ATTITUDES: THE CASE OF GENDER STEREOTYPES}

Intergenerational transmission of negative attitudes toward mathematics also appears to occur. This has perhaps received more attention with regard to transmission of gender stereotypes about mathematics than other aspects of attitudes toward mathematics. As mentioned above, it is known that females tend to report more anxiety about mathematics than males, though nowadays males and females usually perform similarly in mathematics (Devine et al., 2012; Dowker et al., 2016). Among very young children, gender differences in mathematics anxiety are not so consistently found. Szczygiel (2020a) found that girls in early elementary grades showed greater mathematics test anxiety, but not greater anxiety about other aspects of mathematics, than boys. Evidence for transmission of mathematics anxiety by women to girls comes from studies of teachers as well as parents. Beilock et al. (2010) reported that mathematics anxiety in female elementary school teachers longitudinally predicted mathematics anxiety and reduced mathematical attainment in their female but not male pupils.

Some studies suggest intergenerational transmission of parental gender stereotypes even at a very young age, when children have had little or no school experience. Del Rio et al. (2019) studied a sample of Chilean five-year-olds and their parents. Both fathers and mothers showed gender stereotypes regarding mathematics ('mathematics is for boys') and fathers associated themselves with mathematics more than mothers did. These stereotypes seemed to have already been communicated to their children. Five-year-old boys already showed the stereotype, in implicit measures, that mathematics is for boys, though girls did not. Girls' mathematics self-concepts were positively related to their mothers' mathematics self-concepts, but negatively to their fathers' mathematical self-concepts. While it is possible that both parents and children were independently influenced by gender stereotypes about mathematics in the wider culture, it seems more likely, especially in view of the children's young age, that the parents' attitudes were being transmitted to their children.

Jacobs and colleagues (Jacobs, 1991; Bleeker and Jacobs, 2004) found that boys at all ages, tended to rate themselves higher in mathematics and to actually perform better if their fathers had strong gender stereotypes about mathematics, but such paternal stereotypes were associated with lower self-rating and lower actual performance by girls. If mothers had strong gender stereotypes about mathematics, both their sons and daughters tended to rate themselves lower and actually to perform worse in mathematics. The authors suggested, on the basis of path analyses that the parents' gender stereotypes influenced their perceptions of their children's abilities, which in turn influenced the children's own beliefs about their abilities and their actual performance. It cannot, however, be ruled out that the parents may have been aware of their children's level of mathematical performance, and that fathers, in particular, might have used gender stereotypes to explain these. The reason why mothers' gender stereotypes were associated with worse self-rating and performance by both sons and daughters may be that gender stereotyping by mothers was associated with a negative personal attitude to mathematics, which may have been transmitted to children of both genders and/or reduced their provision of home numeracy activities.

Tomasetto et al. (2015) studied a group of Italian 6-year-olds and their parents and also found associations between parents' gender stereotyping and children's self-rating, but it was not as consistent as in the previously mentioned studies. Girls' selfrating of their own mathematical performance was associated with their mothers', but not their fathers', gender stereotyping with regard to boys being better at mathematics. Boys' self-rating was not associated with gender stereotyping by either mother or father.

All the studies mentioned above lacked measures of parental mathematical performance, parental mathematics anxiety, or provision of home numeracy activities, which means that some of the interpretations must be speculative.

\section{POSSIBLE EFFECTS OF PARENTAL MATHEMATICS ANXIETY ON CHILDREN'S ANXIETY AND PERFORMANCE}

There is evidence that parental mathematics anxiety predicts mathematics anxiety and lower mathematical performance in their children, even when parental educational level is taken into account. For example, Vanbinst et al. (2020) found that sixth-grade children's mathematics anxiety was significantly associated with their mothers' mathematics anxiety and both their mothers' and fathers' educational level. Most relevant to the present review, parental mathematics anxiety appears to be negative predictor of young, though already school-age, children's performance in mathematics. Maloney et al. (2015) found that parental anxiety about mathematics is negatively correlated with their children's level of progress in mathematics in first and second grade. However, this is only the case if parents with high levels of mathematics anxiety also report providing frequent help with mathematics homework. In the case of parents, who did not often help with homework, there was no such relationship between parental mathematics anxiety and children's performance. Moreover, parental mathematics anxiety seemed to be specifically associated with children's performance in mathematics and was not related to their performance with regard to reading.

Szczygiel (2020b) found some associations between parental mathematics anxiety and young schoolchildren's mathematics anxiety and performance, but also found that these associations were highly dependent on the gender of the child, the gender of the parent, and the child's school grade. She found that mathematics anxiety in fathers was associated with mathematics anxiety in firstgrade children of both genders and in third grade girls, but not significantly with their children's mathematical achievement. Mathematics anxiety in mothers (and teachers) was associated with third grade children's mathematics anxiety, but not significantly with their achievement.

Since the parents' mathematical performance in these studies was not directly tested, it is not possible to rule out the possibility that the parents' mathematics anxiety was associated with their 
own limited understanding of mathematics, reducing their effectiveness in helping their children with mathematics. At first sight, it might appear unlikely that many parents would have difficulty with early primary school mathematics, but some studies suggest that severe numeracy difficulties in adults are surprisingly common (Parsons and Bynner, 2005). However, a more likely explanation is that if the parents are highly anxious about mathematics, they may transmit their anxiety to their children while assisting them with mathematics, or may react to their children's mistakes and failures with frustration or even with scolding or punishment.

Evidence for this proposed explanation comes from a study by (DiStefano et al., 2020), who found that level of mathematics anxiety in parents was associated with their reported level of conflict, stress, frustration, and emotionality when helping children with their mathematics homework. It is at least possible that these experiences of conflict and parents' expression of negative emotions build up negative associations with mathematics in children.

The above studies deal with children, who are already attending primary school, and receiving formal homework assignments. Could similar factors also affect preschool children's attitudes and performance in numeracy? This is something that still needs to be studied; but it is certainly not impossible. Parents, especially those who themselves have negative attitudes toward mathematics, may be more likely to express impatience or frustration with children who are demonstrating difficulties with counting or are slow at working out how to play a mathematics-related game. They may also demonstrate discomfort with mathematical activities and show more negative moods when carrying out such activities than at other times. This could at least in theory result in the children developing negative associations with mathematics from a very early age. It is important to investigate whether this is indeed the case, and, if so, whether it applies more to formal or informal numerical activities. The Home Numeracy Model might suggest that informal numerical activities might be more affected, as it indicates that parental attitudes toward numeracy mainly predict provision of informal activities. However, it must be remembered that 1) the Home Numeracy Model deals with the extent and type of provision of such activities, not with the emotions associated with them; and 2) the research on which the model was based (Skwarchuk et al., 2014) included relatively few parents with extremely negative attitudes toward mathematics. It is quite possible that parental negative emotions toward mathematics would be stronger and more likely to be transmitted to children in the case of formal home numeracy activities than that of informal home numeracy activities, as parents may be more likely to associate the former with their negative experiences and anxieties relating to school mathematics.

\section{AREAS FOR FUTURE RESEARCH}

The focus of studies of home numeracy and its effects on very young children has usually not focused strongly on parental attitudes to mathematics, and, in particular, has not generally emphasized parental emotional reactions to mathematics. Where attitudes have been studied, this has usually involved the more cognitive aspects of attitudes such as beliefs and stereotypes, rather than emotions such as anxiety. Yet there is much evidence both that adult emotional reactions to mathematics are highly variable and often negative (Hembree, 1990; Ashcraft, 2002; Maloney and Beilock, 2012; Dowker et al., 2016), and that these emotions may influence both the provision of mathematical activities for their school-age children, and the ways in which school-age children respond to these activities (Maloney et al., 2015; DiStefano et al., 2020).

Although the Home Numeracy Model (Skwarchuk et al., 2014) incorporates parental attitudes toward mathematics, and although the attitude measures that it references include questions about anxiety, the effects of parental mathematics anxiety on preschoolers have so far received remarkably little study. If we are to gain a fuller understanding both of the role of early home numeracy activities, and of the origins of mathematics anxiety in children, it is vital to carry out more studies of the effects on preschoolers of such parental emotions. The factors need to be studied both with regard to their influences on the provision of home numeracy activities, and with regard to children's responses to home numeracy, including the possible intergenerational transmission of mathematics anxiety.

It is also important to go beyond numeracy in the narrower sense and carry out more studies of the influences of parental attitudes and emotions on the provision and effects of other aspects of mathematics, such as shape, space, measurement, and pattern. These aspects of mathematics are important in children's mathematical development, and are known to feature in home numeracy activities (Zippert et al., 2020); but even less is known about the possible influence of parental attitudes and emotions on these than on numeracy in the narrower sense. It is important to expand our knowledge in this area.

It is also important to investigate systematically whether different aspects of parental mathematics anxiety may have different effects on home numeracy provision, and on its possible predictive role in children's mathematical performance. For example, some studies (Wigfield and Meece, 1988; Sorvo et al., 2017) indicate separate components of mathematics anxiety: cognitive (performance anxiety) and affective (negative emotional reactions to numerical stimuli). It is at least possible that the cognitive component might result in more pressure for success and negative reactions to failure in association with home numeracy activities, while the affective component might be more likely to result in avoidance of provision of home numeracy activities.

Finally, if we are to understand the interactions between the effects of home numeracy environment and parental mathematics anxiety, an important issue is the question of how early children can develop mathematics anxiety and other negative attitudes toward mathematics. In general, younger children tend to show more positive attitudes and less anxiety than older children (e.g., Ma and Kishor, 1997; Krinzinger et al., 2009). However, several studies indicate that even school beginners can demonstrate mathematics anxiety (Ramirez 
et al., 2013; Vukovic et al., 2013; Jameson, 2014; Petronzi, 2016). It has not been established whether preschoolers can show the beginnings of anxiety or other negative reactions to numbers and counting, and whether parents' negative attitudes toward mathematics can influence preschool children's reactions; and this is an important topic for future study. Studying mathematics anxiety and attitudes in preschoolers may be more difficult than studying the same things in older, more articulate children. However, methods have already been devised for assessing mathematics anxiety in children as young as four in the United Kingdom, where formal schooling typically begins at around this age (Petronzi, 2016; Petronzi et al., 2017; Petronzi et al., 2019). By extending these methods to children in countries where formal schooling begins at a later age, it may be possible to investigate whether mathematics anxiety may sometimes have roots in experiences even before schooling begins.

Learning more about the possible role of parental mathematics anxiety in children's mathematical development may have important practical and educational implications. If parental

\section{REFERENCES}

Ashcraft, M. H. (2002). Math anxiety: personal, educational, and cognitive consequences. Curr. Dir. Psychol. Sci. 11, 181-185. doi:10.1111/1467-8721.00196

Beilock, S. L., Gunderson, E. A., Ramirez, G., and Levine, S. C. (2010). Female teachers' math anxiety affects girls' math achievement. Proc. Natl. Acad. Sci. Unit. States Am. 107, 1860-1863. doi:10.1073/pnas.0910967107

Benavides-Varela, S., Butterworth, B., Burgio, F., Arcara, G., Lucangeli, D., and Semenza, C. (2016). Numerical activities and information learned at home link to exact numeracy skills in 5-6 years-old children. Front. Psychol. 7, 94. doi:10. 3389/fpsyg.2016.00094

Bleeker, M. M., and Jacobs, J. E. (2004). Achievement in math and science: do mothers' beliefs matter 12 years later? J. Educ. Psychol. 96 (1), 97-109. doi:10. 1037/0022-0663.96.1.97

Blevins-Knabe, B., Austin, A. B., Musun, L., Eddy, A., and Jones, R. M. (2000). Family home care providers' and parents' beliefs and practices concerning mathematics with young children. Early Child. Dev. Care. 165, 41-58. doi:10. 1080/0300443001650104

Blevins-Knabe, B., and Musun-Miller, L. (1996). Number use at home by children and their parents and its relationship to early mathematical performance. Early Dev. Parent. 5 (1), 35-45. doi:10.1002/(SICI)1099-0917(199603)5:1<35::AIDEDP113>3.0.CO;2-0

Breckler, S. J. (1984). Empirical validation of affect, behavior, and cognition as distinct components of attitude. J. Pers. Soc. Psychol. 47 (6), 1191-1205. doi:10. 1037/0022-3514.47.6.1191

Carey, E., Hill, F., Devine, A., and Szücs, D. (2016). The chicken or the egg? The direction of the relationship between mathematics anxiety and mathematics performance. Front. Psychol. 6, 1987. doi:10.3389/fpsyg.2015.01987

Cargnelutti, E., Tomasetto, C., and Passolunghi, M. C. (2017). The interplay between affective and cognitive factors in shaping early proficiency in mathematics. Trends Neurosci. Educ. 8-9, 28-36. doi:10.1016/j.tine.2017.10.002

Casey, B., Lombardi, C. M., Thomson, D., Nguyen, H. N., Paz, M., Theriault, C., et al. (2018). Maternal support of early numerical concept learning predicts preschool and first grade math achievement. Child Dev. 89 (1), 156-173. doi:10. 1016/j.ecresq.2017.07.004

Cheung, S. K., Dulay, K. M., and McBride, C. (2020). Parents' characteristics, home environment, and children's numeracy skills: how are they related in low- to middle-income families in the Philippines? J. Exp. Child Psychol. 192, 104780. doi:10.1016/j.jecp.2019.104780

DeFlorio, L., and Beliakoff, A. (2015). Numeracy activities and parent beliefs. Early Educ. Dev. 26, 319-341. doi:10.1080/10409289.2015.968239 anxiety has a highly negative effect on children's attitudes and/ or performance, then it would be desirable to find ways of treating and reducing parents' anxiety, for their children's sake as well as their own. If it is important only if the parents engage in a lot of home numeracy activities with their children, then perhaps home numeracy activities should not be encouraged if the parents are highly anxious, and perhaps might be replaced by preschool numeracy programmes. If, on the other hand, parental mathematics anxiety seems not to affect children directly, but reduces provision of home numeracy activities, perhaps parents with high mathematics anxiety should be actively encouraged to provide such activities. Much more research is needed in order to guide such decision-making.

\section{AUTHOR CONTRIBUTIONS}

The author confirms being the sole contributor of this work and has approved it for publication.

Del Rio, M. F., Strasser, K., Cvencek, D., Susperreguy, M. I., and Meltzoff, A. N. (2019). Chilean kindergarten children's beliefs about mathematics: family matters. Develop. Psychol. 55, 687-702. doi:10.1037/dev0000658

Devine, A., Fawcett, K., Szucs, D., and Dowker, A. (2012). Gender differences in mathematics anxiety and the relation to mathematics performance while controlling for test anxiety. Behav. Brain Funct. 8, 33. doi:10.1186/1744-9081-8-33

DiStefano, M., O’Brien, B., Storozuk, A., Ramirez, G., and Maloney, E. (2020). Exploring math anxious parents' emotional experience surrounding math homework-help. Int. J. Educ. Res. 99, 101526. doi:10.1016/j.ijer.2019.101526

Dowker, A., Sarkar, A., and Looi, C. Y. (2016). Mathematics anxiety: what have we learned in 60 years? Front. Psychol. 7, 508. doi:10.3389/fpsyg.2016.00508

Dunst, C. J., Hamby, D. W., Wilkie, H., and Dunst, K. S. (2017). "Meta-analysis of the relationship between home and family experiences and young children's early numeracy learning," in Engaging families as children's first mathematics educators: international perspectives. 2nd Edn, Editors S. Phillipson, A. Gervasoni, and P. Sullivan (Heidelberg, Germany: Springer), 105-125. doi:10.1007/978-981-10-2553-2_7

Else-Quest, N., Hyde, J. S., and Linn, M. (2010). Cross-national patterns of gender differences in mathematics: a meta-analysis. Psychol. Bull. 136, 103-127. doi:10. 1037/a0018053

Fennema, E., and Sherman, J. A. (1976). Fennema-Sherman mathematics attitudes scales: instruments designed to measure attitudes toward the learning of mathematics by females and males. J. Res. Math. Educ. 7, 324-326. doi:10. $2307 / 748467$

Ganley, C. M., and Lubienski, S. T. (2016). Mathematics confidence, interest, and performance: examining gender patterns and reciprocal relations. Learn. Indiv Differ. 47, 182-193. doi:10.1016/j.lindif.2016.01.002

Gierl, M. J., and Bisanz, J. (1995). Anxieties and attitudes related to mathematics in grades 3 and 6. J. Exp. Educ. 63, 139-158. doi:10.1080/00220973.1995.9943818

Gottfried, A. E., Marcoulides, G. A., Gottfried, A. W., Oliver, P. H., and Guerin, G. W. (2007). Multivariate latent change modelling of developmental decline in academic intrinsic math motivation and achievement: childhood through adolescence. Int. J. Behav. Dev. 31, 317-327. doi:10.1177/0165025407077752

Gunderson, E. A., and Levine, S. C. (2011). Some types of parent number talk count more than others: relations between parents' input and children's cardinal number knowledge. Dev. Sci. 14, 1021-1032. doi:10.1111/j.1467-7687.2011. 01050.x

Hart, S. A., Ganley, C. M., and Purpura, D. J. (2016). Understanding the home math environment and its role in predicting parent report of children's math skills. PloS One. 11, e0168227. doi:10.1371/journal.pone.016822

Hembree, R. (1990). The nature, effects, and relief of mathematics anxiety. J. Res. Math. Educ. 21, 33-46. doi:10.2307/749455 
Huntsinger, C., Jose, P., and Luo, Z. (2016). Parental facilitation of early mathematics and reading skills and knowledge through encouragement of home-based activities. Early Child. Res. Q. 37, 1-15. doi:10.1016/j.ecresq.2016.02.005

Jacobs, J. E. (1991). Influences of gender stereotypes on parent and child mathematics attitudes. J. Educ. Psychol. 83, 518-527. doi:10.1037/0022-0663.83.4.518

Jameson, M. M. (2014). Contextual factors related to math anxiety in second-grade children. J. Exp. Educ. 82, 518-536. doi:10.1080/00220973.2013.813367

Jansen, B. R. J., Louwerse, J., Straatemeier, M., Van der Ven, S. H. G., Klinkenberg, S., and Van der Maas, H. L. J. (2013). The influence of experiencing success in math on math anxiety, perceived math competence, and math performance. Learn. Indiv. Differ. 24, 190-197. doi:10.1016/j.lindif.2012.12.014

Krinzinger, H., Kaufmann, L., and Willmes, L. (2009). Math anxiety and math ability in early primary school years. J. Psychoeduc. Assess. 27, 206-225. doi:10. 1177/0734282908330583

LeFevre, J.-A., Polyzoi, E., Skwarchuk, S. L., Fast, L., and Sowinski, C. (2010). Do home numeracy and literacy practices of Greek and Canadian parents predict the numeracy skills of kindergarten children? Int. J. Early Years Educ. 18, 55-70. doi:10.1080/09669761003693926

LeFevre, J. A., Clarke, T., and Stringer, A. P. (2002). Influences of language and parental involvement on the development of counting skills: comparisons of French- and English-speaking Canadian children. Early Child. Dev. Care. 172, 283-300. doi:10.1080/03004430212127

LeFevre, J. A., Skwarchuk, S. L., Smith-Chant, B. L., Fast, L., Kamawar, D., and Bisanz, J. (2009). Home numeracy experiences and children's math performance in the early school years. Can. J. Behav. Sci. 41, 55-66. doi:10.1037/a0014532

Ma, X., and Kishor, N. (1997). Assessing the relationship between attitude toward mathematics and achievement in mathematics: a meta-analysis. J. Res. Math. Educ. 28, 26-47. doi:10.2307/749662

$\mathrm{Ma}, \mathrm{X}$., and Xu, J. (2004). Determining the causal order between attitude toward mathematics and achievement in mathematics. Am. J. Educ. 100, 256-281. doi:10.1086/383074

Maloney, E. A., and Beilock, S. (2012). Math anxiety: who has it, why it develops, and how to guard against it. Trends Cognit. Sci. 16, 404-406. doi:10.1016/j.tics. 2012.06.008

Maloney, E. A., Ramirez, G., Gunderson, E. A., Levine, S. C., and Beilock, S. L. (2015). Intergenerational effects of parents' math anxiety on children's math achievement and anxiety. Psychol. Sci. 26, 1480-1488. doi:10.1177/0956797615592630

Missall, K., Hoinoski, R., Caskie, G., and Repasky, P. (2015). Home numeracy environments of preschoolers: examining relations among mathematical activities, parent mathematical beliefs and early mathematical skills. Early Educ. Dev. 26, 356-376. doi:10.1080/10409289.2015.968243

Mutaf Yilsiz, B., Sasanguie, D., DeSmedt, B., and Reynvoet, B. (2018). Frequency of home numeracy activities is differentially related to basic number processing and calculation skills in kindergartners. Front. Psychol. 9, 340. doi:10.3389/ fpsyg.2018.00340

Niklas, F., and Schneider, W. (2014). Casting the die before the die is cast: the importance of the home numeracy environment for preschool children. Eur. J. Psychol. Educ. 29, 327-345. doi:10.1007/s10212-013-0201-6

Niklas, F., and Schneider, W. (2012). The impact of Home Numeracy Environment on the development of mathematical competencies from pre-school until the end of Grade 1. J. Family Res. 24, 134-147.

Parsons, S., and Bynner, J. (2005). Does numeracy matter more? London, United Kingdom: NRDC.

Petronzi, D., Staples, P., Sheffield, D., Hunt, T., and Fitton-Wilde, S. (2019). Further development of the children's mathematics anxiety scale UK (CMAS-UK) for ages 4-7 years. Educ. Stud. Math. 100, 231-249. doi:10.1007/s10649-018-9860-1

Petronzi, D., Staples, P., Sheffield, D., Hunt, T., and Fitton-Wilde, S. (2017). Numeracy apprehension in young children: insights from children aged 47 years and primary care providers. Psychol. Educ. 54, 1-33.

Petronzi, D. (2016). The development of the numeracy apprehension scale for children aged 4-7 years: qualitative exploration of associated factors and quantitative testing. Ph.D. Thesis. University of Derby.

Ramani, G. B., Rowe, M. L., Eason, S. H., and Leech, K. A. (2015). Math talk during informal learning activities in Head Start families. Cognit. Dev. 35, 15-33. doi:10.1016/j.cogdev.2014.11.002

Ramani, G. B., and Siegler, R. S. (2008). Promoting broad and stable improvements in low-income children's numerical knowledge through playing number board games. Child Dev. 79, 375-394. doi:10.1111/j.1467-8624.2007.01131.x
Ramani, G. B., and Siegler, R. S. (2011). Reducing the gap in numerical knowledge between low- and middle-income pre-schoolers. J. Appl. Dev. Psychol. 32, 146-169. doi:10.1016/j.appdev.2011.02.005

Ramirez, G., Gunderson, E. A., Levine, S. C., and Beilock, S. L. (2013). Math anxiety, working memory and math achievement in early elementary school. J. Cognit. Dev. 14, 187-202. doi:10.1080/15248372.2012.664593

Skwarchuk, S. L. (2009). How do parents support preschoolers' numeracy learning experiences at home?. Early Child. Educ. J. 37, 189-197. doi:10.1007/s10643009-0340-1

Skwarchuk, S. L., Sowinski, C., and LeFevre, J. A. (2014). Formal and informal home learning activities in relation to children's early numeracy and literacy skills: the development of a home numeracy model. J. Exp. Child Psychol. 121, 63-84. doi:10.1016/j.jecp.2013.11.006

Sorvo, R., Koponen, T., Viholainen, H., Aro, T., Raikkönen, E., Peura, P., et al. (2017). Math anxiety and its relationship with basic arithmetic skills among primary school children. Br. J. Educ. Psychol. 87, 309-327. doi:10.1111/bjep.12151

Susperreguy, M. I., Douglas, H., Xu, C., Molina-Rojas, N., and LeFevre, J.-A. (2018). Expanding the home numeracy model to Chilean children: relations among parental expectations, attitudes, activities, and children's mathematical outcomes. Early Child. Res. Q. 50, 16-28. doi:10.1016/j.ecresq.2018.06.010

Szczygiel, M. (2020a). Gender, general anxiety, math anxiety and math achievement in early school-age children. Issues Educ. Res. 30, 1126-1142.

Szczygiel, M. (2020b). When does math anxiety in parents and teachers predict math anxiety and math achievement in elementary school children? The role of gender and grade year. Soc. Psychol. Educ. 23, 1023-1054. doi:10.1007/s11218-020-09570-2

Thompson, R. J., Napoli, A. R., and Purpura, D. J. (2017). Age-related differences in the relation between the home numeracy environment and numeracy skills. Infant Child Dev. 26, e2019. doi:10.1002/icd.2019

Tomasetto, C., Mirisola, A., Galdi, S., and Cadinu, M. (2015). Parents' math-gender stereotypes, children's self-perception of ability, and children's appraisal of parents' evaluations in 6-year-olds. Contemp. Educ. Psychol. 42, 186-198. doi:10.1016/j.cedpsych.2015.06.007

Vanbinst, K., Bellon, E., and Dowker, A. (2020). Mathematics anxiety: an intergenerational approach. Front. Psychol. 11, 1648. doi:10.3389/fpsyg.2020. 01648

Von Spreckelsen, M., Dove, E., Coolen, I., Mills, A., Dowker, A., Sylva, K., et al. (2019). Let's talk about maths: the role of observed "maths-talk" and maths provisions in preschoolers' numeracy. Mind Brain Educ. 13, 326-340. doi:10. $1111 /$ mbe. 12221

Vukovic, R. K., Kieffer, M. J., Bailey, S. P., and Harari, R. R. (2013). Mathematics anxiety in young children: concurrent and longitudinal associations with mathematical performance. Contemp. Educ. Psychol. 38, 1-10. doi:10.1016/j. cedpsych.2012.09.001

Wigfield, A., and Meece, J. L. (1988). Math anxiety in elementary and secondary school students. J. Educ. Psychol. 80, 210-216. doi:10.1037/0022-0663.80.2.210

Wolf, S., and McCoy, D. C. (2019). Household socioeconomic status and parental investments: direct and indirect relations with school readiness in Ghana. Child Dev. 90, 260-278. doi:10.1111/cdev.12899

Zippert, E. L., Douglas, A. A., Smith, M. R., and Rittle-Johnson, B. (2020). Preschoolers' broad mathematics experiences with parents during play. J. Exp. Child Psychol. 192, e104757. doi:10.1016/j.jecp.2019.10475

Zippert, E. L., and Ramani, G. B. (2017). Parents' estimations of preschoolers' number skills relate to at-home number-related activity engagement. Infant Child Dev. 26 (2), 24. doi:10.1002/icd.1968

Zippert, E. L., and Rittle-Johnson, B. (2020). The home math environment: more than numeracy. Early Childhood Res. Quart. 50, 4-15. doi:10.1016/j.ecresq. 2018.07.009

Conflict of Interest: The author declares that the research was conducted in the absence of any commercial or financial relationships that could be construed as a potential conflict of interest.

Copyright $\odot 2021$ Dowker. This is an open-access article distributed under the terms of the Creative Commons Attribution License (CC BY). The use, distribution or reproduction in other forums is permitted, provided the original author(s) and the copyright owner(s) are credited and that the original publication in this journal is cited, in accordance with accepted academic practice. No use, distribution or reproduction is permitted which does not comply with these terms. 


\section{OPEN ACCESS}

Edited by:

Simone Lehrl,

University of Bamberg, Germany

Reviewed by:

Rocío Lavigne Cerván,

University of Malaga, Spain

Robert Nicholas Serpell,

University of Zambia, Zambia

${ }^{*}$ Correspondence:

Catherine McBride

cmcbride@psy.cuhk.edu.hk

Specialty section:

This article was submitted to Educational Psychology, a section of the journal

Frontiers in Psychology

Received: 01 July 2020 Accepted: 15 February 2021

Published: 11 March 2021

Citation:

Cheung SK, Dulay KM, Yang $X$, Mohseni F and McBride C (2021)

Home Literacy and Numeracy

Environments in Asia.

Front. Psychol. 12:578764.

doi: 10.3389/fpsyg.2021.578764

\section{Home Literacy and Numeracy Environments in Asia}

\author{
Sum Kwing Cheung ${ }^{1}$, Katrina May Dulay ${ }^{2}$, Xiujie Yang ${ }^{3}$, Fateme Mohseni ${ }^{4}$ and \\ Catherine McBride ${ }^{4 *}$
}

${ }^{1}$ Department of Early Childhood Education, The Education University of Hong Kong, Hong Kong, China, ${ }^{2}$ Department of Education, University of Oxford, Oxford, United Kingdom, ${ }^{3}$ Faculty of Psychology, Beijing Normal University, Beijing, China, ${ }^{4}$ Department of Psychology, The Chinese University of Hong Kong, Hong Kong, China

The home learning environment includes what parents do to stimulate children's literacy and numeracy skills at home and their overall beliefs and attitudes about children's learning. The home literacy and numeracy environments are two of the most widely discussed aspects of the home learning environment, and past studies have identified how socioeconomic status and parents' own abilities and interest in these domains also play a part in shaping children's learning experiences. However, these studies are mostly from the West, and there has been little focus on the situation of homes in Asia, which captures a large geographical area and a wide diversity of social, ethnic, and linguistic groups. Therefore, this paper aims to review extant studies on the home literacy and numeracy environments that have been conducted in different parts of Asia, such as China, the Philippines, India, Iran, Turkey, and the United Arab Emirates. Specifically, we explore how parents in these places perceive their roles in children's early literacy and numeracy development, the methods they regard as effective for promoting young children's literacy and numeracy learning, and the frequency with which they engage their young children in different types of home literacy and numeracy activities. We also examine studies on the relationship of the home literacy and numeracy environment with young children's developmental outcomes, and the effectiveness of parent training programs to improve the home literacy and numeracy environments in these contexts. By examining potential trends in findings obtained in different geographical areas, we can initially determine whether there are characteristics that are potentially unique to contexts in Asia. We propose future research directions that acknowledge the role of cultural values and social factors in shaping the home learning environment, and, by extension, in facilitating children's early literacy and numeracy development.

Keywords: home literacy environment, home numeracy environment, parents, young children, Asia

\section{INTRODUCTION}

The home learning environment encompasses the beliefs and attitudes that parents hold about children's learning, as well as their practices for helping children to learn at home (Dearing and Tang, 2009). Over the past several decades, considerable attention has been given to the learning environments that support children's reading and mathematics skills - also known 
as the home literacy environment and the home numeracy environment, respectively (e.g., Manolitsis et al., 2013; Niklas and Schneider, 2013, 2014; Skwarchuk et al., 2014; Napoli and Purpura, 2018). There is wide support for the idea that they play an imperative role in early literacy and numeracy development, which, in turn, can influence academic attainment in subsequent school years (Melhuish et al., 2008; Manolitsis et al., 2013; Bywater et al., 2015; Niklas and Schneider, 2017).

To date, the majority of studies and frameworks that inform our understanding of home literacy and numeracy environments have been conducted in Western societies; relatively little attention has been given to the situation in Asia. This matters because from theoretical perspectives, culture plays a critical role in the home environments and child development. According to social constructivism theory, knowledge is situated in specific sociocultural contexts, and children construct knowledge through communications and interactions with more experienced members of the society (Vygotsky, 1978; Simina, 2013). Moreover, the ecological systems theory posits that larger social contexts (e.g., communities and education policies) and cultural values can affect children by shaping their immediate environments, such as the ways their parents interact with them and the physical environment that their parents provide to them (Bronfenbrenner, 1979). The cultural practices approach to development further suggests that people and contexts co-create each other (Miller and Goodnow, 1995). Whereas the cultural practices of a specific place shape its citizens, cultural practices may be reproduced or transformed upon agreement within a particular group, and this mechanism can operate at societal, community, and family levels (Miller and Goodnow, 1995). Literacy (which can broadly include reading, mathematical, as well as scientific literacies) is one kind of cultural practices, and it can be conceptualized as the skills necessary for a specific place at a particular time point to meet certain purposes (Street, 1993; Kell and Kell, 2014). In any place, (a) certain kind(s) of literacy (e.g., a specific language) may be more privileged over others, and it can maintain its dominant position through the government policies, school curricula, and/or pedagogies advocated (Kell and Kell, 2014). In light of the above, joint parent-child literacy and numeracy activities have the potential to contribute to children's acquisition of literacy and numeracy skills; however, the content of the activities and the knowledge derived from the activities may vary across families, communities, and the wider sociocultural contexts.

Asia is the largest continent by geographical area and by population on Earth (United Nations, 2019). According to the United Nations geoscheme, it can be divided into five sub-regions, namely Eastern Asia (e.g., China, Japan, and Korea), Southeastern Asia (e.g., Philippines, Thailand, and Vietnam), Southern Asia (e.g., Bangladesh, India, and Nepal), Central Asia (e.g., Kazakhstan, Kyrgyzstan, and Tajikistan), and Western Asia (e.g., Israel, Turkey, and United Arab Emirates; United Nations, 2020). Whereas a number of economies, particularly clustered within Eastern and Western Asia, are classified as high-income economies, a larger number of economies in Asia are within the low- and middle-income classification (World Bank, 2019). Such variations in income levels should be taken into account when understanding the home learning environments in Asia, because the economic strength of a place can have implications for the educational policies and child-bearing practices there. At the macro level, compared to low- and middle-income economies, high-income economies may place a greater demand on educational attainment on its workforce and are able to invest more resources in education (Cheng, 2001). At the micro level, children in lowand middle-income economies are more prone to school dropout than their peers in high-income economies, because their families may not be able to afford the costs for schooling, and teens may be engaged in income-earning activities instead (Cheng, 2001; Joshi, 2015). On the linguistic landscape, there are great variations in the languages spoken and scripts used across Asia (Adamson, 2018). In numerous places, children are supported in learning two or more languages from the early grades (Joshi, 2015; Adamson, 2018; Wang, 2018). For example, in Singapore, English has been adopted as the major language of instruction in schools, so as to prevent the dominant ethnic Chinese there from being privileged and ensure opportunities (including educational and social ones) for all children; and each child is taught their mother tongue as a second language (Kell and Kell, 2014). Broadly speaking, most Asian societies are collectivistic in nature: Support among extended family members is common, and members within the society feel some responsibility for one another (Hofstede, 2001; Hofstede et al., 2010). Specifically, in Eastern Asia, as well as Vietnam and Singapore in Southeastern Asia, under the influence of Confucianism, formal education and success in examinations are typically regarded as the major ways to move up the social ladder and are, thus, heavily emphasized (Cheng, 2001). There is keen academic competition, and parents are generally very willing to invest in children's education, including shadow education (i.e., extracurricular classes for improving children's academic performance; Yamamoto and Brinton, 2010; Byun et al., 2012; Bray, 2013). In line with these observations, children in some of these places (e.g., Hong Kong, Macao, Korea, Japan, and Singapore) tend to excel in international assessment studies such as the Programme for International Student Assessment (PISA), Progress in International Reading Literacy Study (PIRLS), and Trends in International Mathematics and Science Study (TIMSS; Mullis et al., 2016, 2017; Organisation for Economic Co-operation and Development, 2020). These assessment results, however, have to be interpreted with caution, because the "local" language used for test administration is determined by the gatekeepers, and such "privileged" language may not be the first language of all children living in a place (Kell and Kell, 2014). Despite the above, cultural diversities can exist across and within territories in each sub-region (Miller and Goodnow, 1995). In view of the complex sociocultural contexts of Asia, it is worthwhile to look more closely into the home learning environments there.

What are the characteristics of home literacy and numeracy environments in Asia? How are children's literacy and numeracy skills supported in different places there? With these questions 
in mind, this review paper has four major goals: (1) to uncover the learning-related beliefs and attitudes held by parents in Asia; (2) to present a portrait of the home literacy and numeracy practices in Asia; (3) to examine relations between home literacy and numeracy environments and children's learning in Asia; and (4) to explore the effectiveness of family-based interventions to improve home literacy and numeracy environments in Asia. Here, it should be noted that our primary goal is not to highlight and explain how the home literacy and numeracy environments in Asia are distinct from those in the West, because there have only been minimal studies making direct in-depth comparisons between the home learning experiences of children with comparable demographic backgrounds in Asia and the West, making it insufficient to draw conclusions regarding the exact East-West differences, if any, and the underlying cultural mechanisms. Instead, by addressing the above four issues, we seek to further our understanding and appreciation for the wide diversity in the ways in which homes facilitate children's literacy and numeracy learning across sociocultural contexts in Asia.

To achieve our research goals, in the following, we review studies published in English that examine the home literacy and numeracy environments experienced by children aged eight or below in Asia (as defined by the United Nations geoscheme). However, results of large-scale international datasets of older children may be reported to provide additional context for cross-context comparisons. Studies that were conducted with Asian parents and children living in places other than Asia (e.g., migrant families in Western societies) were beyond the scope of this article and, thus, are not discussed here. To obtain a picture of the more recent situation in Asia, only studies published in 2001 and thereafter (i.e., the most recent two decades) were included in this review. Where possible, we cite studies that involve children living in different sub-regions of Asia. Study searches were conducted using APA PsycINFO, ERIC, PubMed, and Google Scholar. Examples of keywords used for our search include home learning/educational environment, home language/literacy environment, home math/ numeracy environment, home learning/educational activities, home language/literacy activities, home numeracy/math activities, home learning/educational practices, home learning/educational resources, home language/literacy resources, home numeracy/ math resources, educational toys, parental learning beliefs/ attitudes, parent-child (joint) activities/play, parent-child interactions, math talk, parental/family involvement, parent training/coaching, and parent intervention. This procedure yielded the majority of studies included in this review. Given that there is a lack of studies for certain places (especially those in Southern, Southeastern, Central, and Western Asia) based on the search strategy stated above, we also considered gray literature (e.g., student dissertations, reports by non-governmental organizations such as Save the Children, UNICEF, and RTI International) about those places in our review; these reports were found either using Google with the same set of search keywords or through hand searches of the websites of the aforementioned organizations. The following sections are organized around our four research goals.

\section{WHAT LEARNING-RELATED BELIEFS AND ATTITUDES DO PARENTS IN ASIA HOLD?}

In this section, we explore various learning-related beliefs and attitudes held by parents in Asia. These include parents' perceptions of the nature and importance of academic achievement, their perceptions of the importance of parental involvement in children's learning, their expectations of children's academic abilities, and their beliefs about effective methods for teaching and learning.

\section{How Important Is Academic Achievement for Parents in Asia?}

Consistent with Confucian values, Chinese parents have traditionally considered it important for children to excel in their studies (Luo et al., 2013). Parents place a high value on diligence, academic training, concentration, and persistence in the learning process, as these attributes are perceived as keys for academic success $(\mathrm{Li}, 2012)$. Consistent with these values, cross-cultural studies have demonstrated that parents in Taiwan and Hong Kong put greater emphasis on young children's academic attainment than do parents in the United States and United Kingdom (Pearson and Rao, 2003; Wang and TamisLemonda, 2003). Similarly, in one study, parents in Mainland China expressed high aspirations for their children's academic achievement, with about $76.38 \%$ of parents of 3-6-year-old children in rural areas and about $86.05 \%$ of those in urban areas expecting their children to get a bachelor's degree ( $\mathrm{Su}$ et al., 2020). In another study in Japan, all of the mothers interviewed hoped that their preschool children would like going to school, have high motivation to study, and excel in academic performance (Yamamoto, 2015).

In the case of Mainland China, parents' emphasis on children's academic success can also be attributed to broad societal factors; these include the one-child policy and keen competition following the transition from a planned to a free market economy (Luo et al., 2013). Similarly, socioeconomic motivations have been observed in samples from South and Southeastern Asia. Among low-income families in India, Vietnam, and the Philippines, parents aspire for children to finish school to escape poverty (Boyden, 2013) or to provide educational opportunities that were not available to the parents' or grandparents' generations (Tatel-Suatengco and Florida, 2018). However, inequalities related to gender in India and minority ethnic status in Vietnam are examples of additional hurdles for children to access educational opportunities in these contexts (Boyden, 2013; Rao et al., 2013). Parents also make schooling decisions against a backdrop of sociopolitical tension within their respective society. For example, in Western Asia, a sample of upper-middle class Palestinian parents in Israel expressed aspirations for better educational opportunities and multicultural education for their children, thus informing their decision to enroll their children in a PalestinianJewish bilingual primary school (Bekerman and Tatar, 2009).

Though our selection of studies highlighted here is rather limited, collectively, they suggest that parents generally strongly 
desire for their children to obtain a good education. However, cultural values, socioeconomic motivations, and sociopolitical factors can create a wide variety of situations among families in Asia that influence the educational decisions they make for their children.

\section{Should Parents Be Involved in Children's Learning?}

While Asian parents generally have high aspirations for their children's academic achievement, to what extent do they believe that they play a direct role in their children's learning? In Korea, parents generally subscribe to the belief that helping their children to learn is one of their major responsibilities (Lee, 2002; Park and Kwon, 2009). Parents in Hong Kong and Mainland China tend to endorse the idea that parents should engage their preschool children in learning activities (such as language and cognitive activities) at home, so as to enrich their knowledge base and promote their all-round development (Lau et al., 2012). In Iraq, one study showed that most parents of 4-7-year-old children strongly agreed that it was essential to teach literacy skills to their children at home (Okello and Mahammed, 2019). Parents in Oman were also conscious that children's educational problems could be solved gradually over time through the cooperation among children, families, and schools (Tekin, 2015).

However, parents in some studies appear to view their responsibilities as relatively small in their children's early formal learning. For example, in a study involving six parents in the United Arab Emirates, the parents showed little awareness of the importance of parent-child interactions and stimulating early home environments to support their children's emergent writing skills (Tibi et al., 2013). The Kazakhstani mother in a case study by Amantay (2017) also expressed the idea that literacy was "something special" (p. 31) and believed that parents had little to do at home to promote children's literacy development. In focus group discussions, parents in Laos expressed a belief that pre-primary teachers, not families, are responsible for fostering children's basic literacy and numeracy skills before they enter primary school (Vongxaiya, 2019).

It is not clear whether or not the diverging beliefs reported in these samples reflect broadly-held views within their respective societies. It is also unclear what factors shape these beliefs. Nonetheless, it is important to explore in more depth how parents' perceptions of their role in their children's learning are related to the home literacy and numeracy environment they create and to children's developmental outcomes more generally across countries and territories.

\section{What Should Children Know Before Entering Formal Education?}

Generally speaking, Asian parents place great importance on preparing their children to enter formal education. For example, in Korea, reading and writing are typically regarded by parents as important skills that should be developed even before entering primary school (Lee, 2002). In Hong Kong, "high interest in reading" and "basic writing skills" were rated as the two most important qualities required for a smooth transition from kindergarten to primary school in one study (Chan, 2012). Parents in Laos also view literacy and numeracy competencies as essential components of school readiness (Vongxaiya, 2019). In Mainland China, parents generally acknowledge the importance of learning about "numeracy and quantity" (e.g., counting one to nine objects and telling the amount) and "geometry and space" (e.g., the main characteristics of geometric shapes) before entering school, though skills related to "numeracy and quantity" are expected to be mastered slightly earlier than are skills related to "geometry and space" (Pan et al., 2018).

Beliefs about early childhood education are, of course, influenced strongly by the ideas and policies of one's government. For example, although parents in a study in Turkey were familiar with the importance of providing developmentally appropriate practices to their preschool children, they gave the lowest rating to children's emergent literacy development as compared to other items on the scale (Demircan and Tantekin-Erden, 2015). This relatively low rating was attributed to early childhood education guidelines released by the education ministry, which did not identify emergent literacy as a major goal in preschool. Similarly, in a large-scale study in Nepal, mothers generally believed that they should start reading to children at 1-3 years old, which was older than the recommended milestone of 4-6 months in the United States (Shrestha et al., 2017). The overall results of the study were interpreted to reflect a relatively low level of knowledge about child development among Nepalese mothers and were identified as an area for intervention. In Cambodia, most parents believed that preparing children for school involved buying bags and stationery; in contrast, very few mentioned preparing children by building their basic literacy and numeracy skills in one study (Howell et al., 2016). The authors highlighted the need to address this knowledge gap through parent education programs. Thus, parents' beliefs about what constitutes "school readiness" likely reflects a confluence of cultural values, socioeconomic opportunities, and sociopolitical factors.

\section{What Methods of Learning Are Considered Effective?}

In East Asia, evidence suggests a tension between "traditional methods" and "Western ideas" around child-centered learning and a focus on non-academic domains of child development. In Chinese societies, rote memorization and drill-and-practice are traditionally relied upon for literacy and numeracy learning (Rao et al., 2010; Lam and McBride-Chang, 2013). In a study conducted in Hong Kong, Chan (2016) revealed that some parents still preferred the use of traditional drill-and-practice approach to help kindergarteners learn, despite the active promotion of constructivist learning methods in the city over the past decade. In contrast, parents in Mainland China have demonstrated an increased awareness of the importance of play during early childhood years (Rao and Li, 2009; Lin and Yawkey, 2013). Lin and Li (2019) examined the extent to which mothers of Mainland Chinese children value pre-academic activities and free play, and their results aligned with the idea that parents in Mainland China have diverse views on what should be emphasized in children's development. In their study, about $44 \%$ of the samples was classified as eclectic mothers, 
who place high value on both pre-academic activities and free play (Lin and Li, 2019). Of the remaining sample, half were classified as traditional mothers (i.e., valuing pre-academic activities highly but free play at a lower level), and half of them were classified as contemporary mothers (i.e., valuing free play highly but pre-academic activities at a lower level).

In traditional Chinese culture, play is not favored, as it is regarded as distracting children from pre-academic learning (Leung, 2011; Luo et al., 2013). With the promotion of the idea of "learning through play" in recent years, parents in Mainland China, Hong Kong, and Taiwan nowadays are more aware of the role of play in children's learning (Rao and Li, 2009; Fung and Cheng, 2012; Lin, 2013; Lin and Yawkey, 2013). Nonetheless, the study of Fung and Cheng (2012) showed that some Hong Kong parents still have some concerns about the extent to which play-based learning can build school readiness skills among children.

Similarly, Lee and Kim (2016) found that mothers in Korea gave a slightly higher endorsement of the behaviorist approach than the constructivist approach to mathematics learning; this is inconsistent with the child-centered educational practices recently advocated there. Though "raising a child with good socio-emotional competence" was considered by upper-middleclass mothers as one of the most important parenting goals, parents reportedly spend most of the time with their preschool children on teaching them academic skills (Park and Kwon, 2009, p. 58). This discrepancy between parenting beliefs and behaviors, to a certain extent, reflects the fact that, though Korean mothers recognize the importance of children's socioemotional development, considerable attention is still paid to children's academic achievement.

There are fewer studies pertaining to these topics outside of East Asia. However, mothers in Bangladesh (Mehnaz, 2013) and parents in the Philippines (Leer and Teodosio, 2016) appear to agree that play stimulates children's literacy development. In addition, while most families in India appear to believe that children can learn skills through play (Bora et al., 2018), there was less consensus with this idea as compared to other attitudes measured. Furthermore, Cypriot parents demonstrate inconsistent attitudes toward play and learning. They value play more than academic training; however, the type of play they organize for their children tends to be more academically oriented, rather than play-oriented (Shiakou and Belsky, 2013). Broadly speaking, studies suggest that play-based learning and constructivist approaches as a route for early literacy and numeracy learning are being actively promoted in Asia, whether through initiatives backed by the education system or international non-government organizations; however, its uptake among parents varies considerably across contexts.

\section{WHAT ARE THE HOME LITERACY AND NUMERACY PRACTICES OF PARENTS IN ASIA?}

In the following section, we begin by looking into various aspects of home literacy and numeracy practices of parents in Asia, including the number and types of learning resources they provide for children at home, the frequency with which they engage children in different types of learning activities, the content and style of parent-child interactions during home learning activities, and the family members involved in home learning activities. Following this, we identify factors that influence parents' home literacy and numeracy practices.

\section{What Kinds of Literacy and Numeracy Resources Are Available and How Many?}

At home, there are a variety of educational resources that parents can provide for children to promote their literacy development (e.g., storybooks, letter flash cards, literacy workbooks, board games, card games, and computer games) and numeracy development (e.g., number charts, counting picture books, number workbooks, and games; e.g., Cheung et al., 2018; Dulay et al., 2018). It is natural to expect that children in high- and upper-middle-income economies tend to have a greater number of home learning resources than those in low- and lowermiddle-income economies. For instance, in a study conducted in Korea, households of 4-5-year-old children, on average, reportedly contained, on average, 60-100 children's books (Kim, 2009). In Hong Kong, all kindergarten children in the study of Chow et al. (2010) had at least 10 Chinese storybooks at home, with 30-49 storybooks available on average. In contrast, in the Philippines, a study showed that children in low- and middle-income families only had 1-9 storybooks on average (Dulay et al., 2019). Although the samples in the aforementioned studies are not directly comparable due to differences in study aims and recruitment methods, these findings are generally consistent with an analysis of the Progress in International Reading Literacy Study 2001 which reported a higher national average of the number of books at home (among fourth graders) in high-income economies (e.g., Singapore) compared to lowand middle-income economies (e.g., Iran; Park, 2008).

A similar trend can be observed within the spectrum of low- and middle-income economies. Studies from economies in the upper middle-income category generally report high rates of the availability of learning resources at home. In a sample in Sri Lanka, for example, more than $90 \%$ of third graders reported having storybooks and newspapers at home (Wickramasekara et al., 2014). As demonstrated in two studies, nearly all children in Jordan and $78 \%$ of children in Lebanon were even found to own four or more types of reading materials and toys (Queen Rania Foundation, 2017; Save the Children, 2017). In contrast, in low- to lower middle-income economies, such as India, Nepal, and Indonesia, there is evidence that fewer than half of families own print materials, storybooks, and number toys (Bhattacharjea et al., 2011; Research Inputs and Development Action, 2016a,b; Mayasya, 2017; Bora et al., 2018).

The above observations are also consistent with an analysis by the Multiple Indicator Cluster Survey Round 3 (MICS3), which compared the availability of formal learning resources (e.g., children's books and store-bought toys) in households with children aged 5 or below in 28 developing countries (Bradley and Putnick, 2012). Of the nine Asian countries investigated, Kazakhstan, Uzbekistan, Kyrgyzstan, and Thailand (from highest to lowest scoring) were above the grand mean, 
whereas Mongolia, Syria, Vietnam, Tajikistan, and Yemen (from highest to lowest scoring) were below the grand mean.

Though it is easy to assume that the home learning environments in low- and lower-middle-income economies are impoverished and devoid of materials for cognitive enrichment, whereas homes in high-income economies are always wellresourced, empirical studies suggest a wider variety of trends across families within a sample, as well as across samples within a country. For example, in a case study involving six mothers of 4-year-olds in the United Arab Emirates, three of the participating mothers often provided children with literacy materials, two of them only sometimes did so, and one of them never did so (Tibi et al., 2013). Samples in Singapore also varied in the reported availability of books, with fewer than 10 children's books in a sample of mixed ethnicities (Mascarenhas et al., 2017), an average of 10-29 Chinese language books among Singaporean Chinese families ( $\mathrm{Li}$ et al., 2016), and an average of 10-30 Mandarin books and 30-60 English books among Chinese-English bilinguals (Sun, 2019).

In a qualitative study with five middle-class and uppermiddle class mothers of children aged 3-4.5 in Bangladesh, all of them reported having counting, rhyming, and letter books but not illustrated storybooks (Mehnaz, 2013). In contrast, as shown in a survey with 1,856 families with 4-year-old children in Bangladesh, only about $47 \%$ had storybooks, $39 \%$ had drawing/writing materials, and $23 \%$ had number number/ counting toys or games (Spier et al., 2018). Among families with low education levels in Iraq, 52\% reported having four or more types of toys, as opposed to only $13 \%$ for types of reading materials (Okello and Mahammed, 2019). In a lowand middle-income sample from the Philippines, whereas about $20 \%$ of families indicated that they have no numeracy-related educational games at home, about $15 \%$ of families reported having 10 sets or above of such games (Cheung et al., 2020).

Taken together, the cited studies suggest substantial variation between and within contexts in the number of home learning resources available to children. Furthermore, there appear to be variations in the specific types of literacy or numeracy materials that families own, perhaps in part reflecting what families consider essential to their children's learning.

\section{What Literacy and Numeracy Activities Are Carried Out at Home and How Often?}

At home, parents can involve children in various learning activities. Some of them involve direct and intentional teaching of literacy and numeracy skills and can be termed as formal (or direct) learning activities (Skwarchuk et al., 2014). Examples include helping children to read words, introducing new words and their definitions, writing numbers, and practicing simple sums (Skwarchuk et al., 2014). Some others are called informal (or indirect) learning activities, because teaching literacy and numeracy skills is not the major goal of such shared activities but may emerge incidentally (Skwarchuk et al., 2014). Examples include reading books, telling stories, and playing number board and card games (Mullis et al., 2016).

In contrast to the trends observed in the number of home resources available, large-scale surveys have revealed that parents of high- and upper-middle-income economies do not necessarily engage children in early literacy and numeracy activities more frequently than those in low- and lower-middle-income economies. In the TIMSS 2015 (Mullis et al., 2016), parents of fourth graders were asked to report their frequency of engaging children in 16 formal and informal learning activities (e.g., reading aloud signs and labels, playing word games, and playing with number toys) at home before their children entered primary school. Results showed that parents in Kazakhstan and Korea often did so, whereas parents in Bahrain, United Arab Emirates, Qatar, Singapore, Jordan, Saudi Arabia, Kuwait, Indonesia, Iran, Turkey, Oman, Chinese Taipei, Japan, and Hong Kong only sometimes did so (Mullis et al., 2016). Using MICS3 data, Zainiddinov and Habibov (2019) compared mothers' average interaction time with their children under 5 years old (e.g., time spent on reading books, telling stories, and practicing naming and counting) in various countries in Central Asia. The greatest amount of mother-child interaction time was found in Turkmenistan and Uzbekistan, followed by Tajikistan, Kazakhstan, and Kyrgyzstan (Zainiddinov and Habibov, 2019).

Among the various home literacy activities, some seem to be more popular than others. In a cross-cultural comparison between home environments in Iran and Germany, Iranian children were found to engage more frequently in learning poems, rhymes, and songs, but less frequently in book reading, than did German children (Aminipour et al., 2018). In a lowand middle-income sample in Korea, parents, on average, helped children with homework about three to four times a week, taught children Korean alphabet letters/symbols (Hangul) and literacy and read books with children about once a week, but brought children to the library or bookstore only about once a month (Kim, 2009). In Japan, a study showed that parents taught first graders character/kanji names, word reading and character writing a few times a month, and read to children about 5-30 min per day on average (Inoue et al., 2018). In some places, families tend to prioritize the direct instruction of literacy skills over storybook reading and storytelling, as is the case in samples from Cambodia (Howell et al., 2016) and Indonesia (Mayasya, 2017). In contrast, trends have varied across samples in Nepal, with one study reporting more letter teaching than storybook reading (LeVine et al., 2012), a second study reporting that a majority of parents engage in storytelling, book reading, and teaching letters (Research Inputs and Development Action, 2016a), and a third study reporting higher rates of reading and storytelling over the teaching of letters (Research Inputs and Development Action, 2016b). In Bangladesh, two studies have shown that a majority of parents provide direct teaching of letters at home (Pisani et al., 2017b; Spier et al., 2018). However, reports of oral storytelling and book reading slightly diverged in the two studies: $41-55 \%$ of mothers in the study by Pisani et al. (2017b) reported engaging in these activities; $68-69 \%$ of parents reported doing so in the study by Spier et al. (2018).

Furthermore, parents may rely more on formal than informal activities to facilitate children's second language acquisition at home, at least in Hong Kong. In a study conducted with 
Hong Kong kindergarteners and their parents, instructing children to do English homework was the activity that most frequently occurred, followed by teaching the recognition and writing of English words, watching English educational CD-ROMs, and shared reading (Yeung and King, 2016). Likewise, in another study conducted with Hong Kong parents of 5-8-yearold children, about $72 \%$ of them reported engaging in some English learning practices with children at home (Forey et al., 2015). Among the six activities under investigation, teaching English word reading was more prevalent than watching English programs, reading English stories, conversing in English, singing English songs, or playing English games (from highest to lowest frequency; Forey et al., 2015).

What types of home numeracy activities are children more likely to participate in? Few studies have focused on this topic in samples from Asia; however, there may be variations in the formal and informal numeracy activities practiced in different places. In Hong Kong, number skills activities (e.g., printing numbers, counting objects, and learning simple sums) tend to occur more frequently than number book activities, mathematical games (e.g., playing board games with dice or spinner), and application activities (e.g., using calendars and dates; e.g., Huang et al., 2017). In contrast, Cheung et al. (2020) found that in the Philippines, the three most common home numeracy activities mentioned by parents were talking about money and the prices of goods, teaching how to do math in one's head, and talking about counting and practicing counting skills during everyday activities, whereas the three least common home numeracy activities were playing number card games, board games, and/or computer games, completing exercise books related to numbers, and talking about the meaning of numbers during everyday activities.

Finally, are parents more likely to engage children in literacy or numeracy activities at home? Numeracy learning may be especially important for Indian families, with $98 \%$ of caregivers reporting that they have taught their children numbers, in contrast to $45-61 \%$ for teaching letters (Bora et al., 2018). The reverse pattern, however, was observed in the Philippines when we compared the findings obtained from the studies of Cheung et al. (2020) and Dulay et al. (2019): Home literacy activities, on average, were reported to occur more frequently than home numeracy activities among Filipino families. The overall picture that emerges is of considerable heterogeneity in the frequency and variety of home literacy and numeracy practices in Asia, with no clear trends across and within contexts.

\section{How Do Parents and Children Interact During Literacy and Numeracy Activities?}

Comparatively, studies that focus on the content and style of parent-child interactions during home learning activities are scarce and scattered. In Israel, Korat et al. (2012) found that when Arabic-speaking mothers engaged kindergarten children in book reading at home, "paraphrasing the text" and "discussing the story" were the two most common maternal mediation behaviors, whereas "talking about illustrations," "telling the story in spoken language," and "discussing about the written system" rarely occurred. This probably happens at least in part because of the diglossic nature of Arabic. Arabic-speaking children usually do not understand much about the formal written language when they are young; thus, mothers are inclined to spend much time on helping children to understand the meaning of the story, leaving little room for in-depth discussions on things beyond the text (Korat et al., 2012). On the topic of children's early writing, the strategies that parents employ to help their children to write partly depend on their writing system. Observations of parent-child dyads in Israel have revealed that mothers utilize different strategies to help their child to write in Hebrew, ranging from writing the word for the child to helping the child to break down the component sounds of words and connect each with the appropriate letter (Aram and Levin, 2001). In another study, asking children to write letters was found to be the most frequently used strategy by Israeli mothers when teaching children to write in Arabic; these mothers seldom guided their children to make connections between sounds and letters (Korat et al., 2014). In contrast, a study that focused on Hong Kong mothers identified a different set of scaffolding strategies, given that Chinese characters have a different level of visual complexity and can contain cues to both pronunciation and meaning (Lin et al., 2011). This study demonstrated that stroke-focused strategies (e.g., telling children where a line should go) and component segmentation strategies (e.g., telling children what components a Chinese character is made up of) were the most frequently used strategies (Lin et al., 2011). On the other hand, visualization strategies and strategies that focused on shared phonetic components were the least frequently used (Lin et al., 2011). One potential reason for these finding is that the drill-and-practice method is traditionally adopted to teach children how to write in Chinese societies (Wu et al., 1999). Despite the fact that the scripts involved in the above studies are different, the findings seem to provide converging evidence that during joint writing, not all parents carry out higher levels of mediation that helps children to understand the writing system (i.e., guiding children through the graphophonemic encoding process for an alphabetic writing system, drawing children's attention to the morphological information conveyed by a character for a logographic writing system; Aram and Levin, 2001; Lin et al., 2011; Korat et al., 2014).

On the topic of early numeracy, Cheung and McBride (2017) observed how parents in Hong Kong interacted with their kindergarteners when playing a number board game: Parents varied greatly in their sensitivity to incorporating developmentally and educationally appropriate numeracy elements in their discourse with children (Cheung and McBride, 2017). Specifically, many parents focused on asking children to count aloud the number of moves (which ranged from one to six only), but overlooked the possibility that they could ask children to announce the numbers shown on the board or the numerical distance from one place to another on the board (Cheung and McBride, 2017). In Israel, Tzuriel and Mandel (2020) examined the mathematical discourse between parents and children during joint tasks related to mathematics. Their results showed that "using mathematical language" was the most 
prevalent, followed by "extending learning with varied mathematical information" and "illustrating the problem and/ or solution with visualization strategies." Detailed observations of such parent-child interactions can provide a valuable window for strategies that parents in Asia may adopt while conducting literacy and numeracy activities with their children and remains an open area for investigation.

\section{Which Family Members Are Involved in Home Literacy and Numeracy Activities?}

Unsurprisingly, mothers in Asia tend to be more likely than fathers to report being involved with their children in home learning activities. For example, in Cambodia, Mongolia, and Timor-Leste, mothers were more likely to report engaging in learning activities at home (including literacy, numeracy, and socioemotional activities) than fathers were (Sun et al., 2018a). In Turkey, Şad and Gürbüztürk (2013) also found that mothers reported providing more support to children for their homework than fathers did. In Hong Kong, mothers report a higher frequency of engaging 5-year-olds in literacy and numeracy activities than fathers did at home (Huang et al., 2017; Xiao et al., 2020).

However, the differences between maternal and paternal engagement might be less clear for home numeracy activities in Hong Kong. In one of the aforementioned studies on 5-yearolds, for example, no significant differences were found between mothers and fathers in their frequency of engaging in number game activities (Huang et al., 2017). In a sample with young children (approximately 3-year-olds), mothers and fathers also reported a similar frequency of engaging children in number skill activities, number book activities, and application activities and fathers reported a higher level of engagement in number game activities (Liu et al., 2019).

Interestingly, numerous studies in Asia have highlighted the role of non-parental family members in promoting home learning activities; namely, siblings and grandparents. In Myanmar, non-parental family members were the most likely to read books or play with the child in one study, for example (Rao et al., 2017). In Mainland China, grandparents' involvement in the daily care of young children is a tradition, and a recent study showed that between 30 and $40 \%$ of 3-6-year-old children in rural and urban areas were taken care by their grandparents in the daytime ( $\mathrm{Su}$ et al., 2020). Grandparents in Korea read books with young children (Chung and Koo, 2001), whereas grandparents in the Philippines provide children with exposure to the mother tongues (Tatel-Suatengco and Florida, 2018). Siblings have been reported to help with homework in Laos (Vongxaiya, 2019) or to provide help with reading at home in Korea (Chung and Koo, 2001) and in the Philippines (Education Development Center, Inc., 2015). The intergenerational nature of the home literacy environment has also been emphasized in Singapore (Ren and Hu, 2013a,b). These studies demonstrate that the responsibility of creating a home learning environment for children tends to be distributed across different household members in Asia. In some places, such as in Hong Kong, Singapore, and the Arabian Peninsula, foreign domestic workers might even be expected to participate in this role, particularly vis-à-vis English language learning (e.g., Dulay et al., 2017).

\section{What Drives Parents to Engage in Home Literacy and Numeracy Practices?}

Parents can either encourage or hinder children in learning via home learning practices. For example, parents' perceptions of the self and aspirations for their children can play a role in the home environment that they foster. For instance, in Japan, mothers who regarded themselves as bearing responsibility for children's learning were more likely to engage children in home cognitive and intellectual activities in two studies (Yamamoto, 2016; Yamamoto et al., 2016). Mothers' occupational aspirations for children have been found to be positively correlated with the amount of cognitive stimulation they give children at home (e.g., reading and playing card and board games with them) in Japan (Holloway et al., 2008), and the frequency with which they check and monitor children's homework (e.g., spelling, writing, and mathematics practice) in Korea (Kim et al., 2011). Qualitative studies in South and Southeastern Asia have also identified pragmatic and strategic reasons for teaching their children literacy and numeracy skills at home. In Bangladesh, middle and upper-class mothers who were interviewed tend to view the perceived toughness of school admissions processes as a factor that determines how much children should be taught about basic literacy and numeracy skills at home (Mehnaz, 2013). Similarly, the fear of losing in a competitive society is thought to motivate some Chinese families in Singapore to provide a strong learning environment for their children (Ren and $\mathrm{Hu}, 2013 \mathrm{a}$ ). In Indonesia, some parents consider English language learning as a key for their children to eventually study overseas (Dharmaputra, 2019). In Singapore, a small sample of Chinese families have shared that they value their cultural identity and language and seek to preserve it at home; nevertheless, most parents additionally value English-language opportunities given the educational system in Singapore (Ren and Hu, 2013a,b).

Parents' home literacy and numeracy practices are also related to their access to tangible and non-tangible resources. In one study from Mainland China, the higher the family's socioeconomic status, the greater the number of home literacy resources owned by kindergarteners (Liu et al., 2018). Similarly, parents' education and occupational status have been linked to preschool children's readiness through the frequency of parents' engagement in home learning activities, as well as children's participation in extracurricular activities; similarly, parents' income has been linked with preschool children's school readiness via children's participation in extracurricular activities (Liu et al., 2020; Ren et al., 2020). In Japan, mothers from higher socioeconomic backgrounds have reported a higher frequency of reading to preschool children at home (Yamamoto et al., 2006). In one study from Turkey, parents' education level and the household income tend to be positively associated with the number of home literacy experiences they provide to their preschool children (Altun, 2019). Consistent with this, another study has found that mothers with higher levels of education are more likely to teach their 3-7-year-old children 
reading at home than mothers with lower levels of education (Iflazoglu Sabah et al., 2018). In Kazakhstan, Kyrgyzstan, Tajikistan, and Uzbekistan, a large-scale dataset has revealed that the wealthier the families, the greater the number of mother-child interactions (Zainiddinov and Habibov, 2019). In studies from Israel, 5-6-year-olds from low socioeconomic families are found to have fewer educational games related to reading and arithmetic at home than their peers from higher socioeconomic families (Korat et al., 2007). Moreover, mothers from higher socioeconomic backgrounds are also found to discuss more with children about the written system during joint book reading (Korat et al., 2012), and intrude less frequently into the children's space during joint writing (Aram et al., 2013b).

Finally, parents' own ability and interest in literacy and numeracy may drive variations in the home environments they provide. In two studies from the Philippines, parents' own reading and calculation skills, as well as their own interest in literacy and numeracy activities, were each positively correlated with home resources and activities related to the two domains (Dulay et al., 2019; Cheung et al., 2020). On the other hand, when Hong Kong parents were asked about the reasons for not supporting children's English learning at home, "lack of time" was the most commonly cited, followed by "lack of English teaching skills" and "not knowing English" in one study (Forey et al., 2015).

Overall, studies suggest that parents in Asia engage in home learning practices to cope with the expectations and demands of the societies they live in, and that this can be made easier if they possess adequate economic and social capital as well as skills and interest in the two learning domains.

\section{ARE THE HOME LITERACY AND NUMERACY ENVIRONMENTS IN ASIA CONDUCIVE TO YOUNG CHILDREN'S LEARNING?}

Presumably, the home learning environment plays a vital role in children's early literacy and numeracy development. The real-life situation, however, is much more complicated than assumed. In the following, we first examine the extent to which various aspects of the home learning environment in Asia (including the quantity and quality of home literacy and numeracy practices, as well as parents' beliefs, attitudes, own academic abilities, and interest) are predictive of young children's learning. Next, we discuss what factors may affect the relation between the home learning environment and children's development.

\section{Do Home Literacy and Numeracy Resources and Activities Matter?}

\section{Home Literacy and Numeracy Resources}

Across different places in Asia, there have been studies demonstrating positive correlations between the number of home educational resources available and children's literacy and numeracy outcomes. Such a pattern of results is evident among studies conducted with children of different ages.
Among preschool children, the number of books and reading materials at home has a significant relationship with children's literacy skills in Japan (Hamano and Uchida, 2012) and early literacy and numeracy scores among preschool children in Thailand (Morales et al., 2016). More broadly, owning other types of literacy materials or child-friendly materials was positively correlated with children's early literacy and numeracy scores in Vietnam in one study (Pava, 2016) and with children's vocabulary scores in the Philippines in another (Dulay et al., 2018). Among primary school-aged children, having books at home was related to higher levels of letter knowledge in Bangladesh (Dowd et al., 2017), word reading in Hong Kong (Lau and McBride-Chang, 2005), reading fluency and comprehension in the Philippines (Education Development Center, Inc., 2015), reading fluency in Indonesia (Brown, 2013), and reading fluency in the West Bank and Gaza (Weatherholt et al., 2018) across different studies. Conversely, in Iraq, having fewer toys and learning materials at home was negatively associated with 4-7-year-old children's performance in literacy and numeracy skills (Okello and Mahammed, 2019). The presence of relevant learning resources also appears to be beneficial for second language acquisition. Exposure to English materials has been found to be a significant correlate of English vocabulary skills among kindergarteners in Hong Kong (Yeung and King, 2016) and Singapore (Sun et al., 2018b). Few studies have analyzed numeracy-related materials as a distinct type of home learning resource, as opposed to grouping them together with literacy materials and toys. However, a similar trend could be expected; for example, the number of numeracy resources available at home had a positive link with 5-8-year-old children's numeracy competence in the Philippines in one study (Cheung et al., 2020).

\section{Home Literacy and Numeracy Activities}

Among the different home learning environment variables, the relationship between the provision of home learning activities and children's learning has received the greatest amount of attention among researchers in Asia. While many studies have found positive relationships between the two, there have also been studies that have demonstrated mixed trends across skill domains.

In general, children's engagement in book reading at home tends to be positively related to their language and literacy outcomes among kindergarten and early primary grade children; specifically for emergent and conventional literacy skills in Korea (Kim, 2009), early literacy scores in Thailand (Yampratoom et al., 2017), reading skills in Iraq (Brombacher et al., 2012), verbal abilities (including vocabulary, syntax, and conversation) in Israel (Aram and Levin, 2002), and reading fluency in the West Bank and Gaza (Weatherholt et al., 2018). In relation to second language acquisition, English book reading has been positively associated with English language and literacy skills in Hong Kong (Yeung and King, 2016) and in India (Kalia, 2007). Another study in India found that kindergarten children who practiced writing at home had higher year-end English reading achievement scores (Sen and Blatchford, 2001). However, in one example of a non-significant relationship between book 
reading and children's literacy, the frequency of book reading was not a significant correlate of first graders' reading and writing skills in Israel (Aram et al., 2013a).

Studies that have included literacy activities other than book reading likewise have shown that they had positive impacts on various literacy outcomes. Home teaching of English at home was a significant correlate of kindergarteners' letter knowledge in Hong Kong in one study (Yeung and King, 2016), for example. The provision of various literacy activities (e.g., writing) have also been associated with young children's reading competence and interest in Singapore (Yeo et al., 2014) and narrative skills in Turkey (Işıtan et al., 2018). In Mainland China, early scaffolding of pinyin knowledge has been associated with subsequent literacy skills (McBride-Chang et al., 2012), and joint parent-child literacy activities in general contributed directly to first graders' reading performance (Shu et al., 2002).

Home numeracy activities, or home learning activities in general, also have positive associations with children's numeracy outcomes. In the Philippines, the frequency of home numeracy activities was found to be a positive correlate of 5-8-year-old children's numeracy skills (Cheung et al., 2020). In Bhutan, the number of home learning activities was also positively related to children's literacy and numeracy scores, regardless of whether they received early childhood care and development services (Pisani et al., 2017a). In Jordan, conducting more learning activities at home was associated with 3-6-year-old children's emergent literacy and numeracy skills (Queen Rania Foundation, 2017). However, in one study conducted in Mainland China, neither formal nor informal home numeracy environment dimensions were significant correlates of children's later mathematical performance (Deng et al., 2015). To account for this, the authors speculated that the home learning environment questionnaire had only captured parental teaching and no other aspects of parent-child interactions (Morrison, 2009).

Some researchers have found differential patterns of relations between home learning activities and different aspects of literacy and numeracy development. For example, a cross-national study involving second to third graders revealed that family members' engagement in reading activities at home was positively related to children's letter knowledge, fluency, and comprehension in Indonesia and in the Philippines (Dowd et al., 2017). In Bangladesh, reading engagement was only related to letter knowledge and not the other skills.

In the same way, different types of home learning activities could be more beneficial for some skills than in others. In Mainland China, Chen et al. (2010) found that the amount of formal home literacy experiences (e.g., teaching Chinese characters) was positively correlated with first graders' reading skills, whereas the amount of informal home literacy experiences (e.g., shared book reading) was positively correlated with first graders' vocabulary knowledge. In Japan, only parent teaching, but not shared reading, was associated with 5-6-year-old children's early Hiragana (i.e., Japanese syllabary) spelling acquisition (Inomata et al., 2016). Similar findings have been observed in Western societies, wherein formal and informal activities had differential relations with literacy subdomains (Sénéchal et al., 1998; Frijters et al., 2000). A similar trend has been observed in the numeracy domain. In Mainland China, Zhang et al. (2020) found that preschoolers' frequency of engagement in informal home numeracy activities (including number game and application activities) predicted their formal mathematical skills and their growth, whereas the frequency of engagement in formal home numeracy activities (including number skill and book activities) was not a significant correlate of formal or informal mathematical skills. Consistent with the overall trend in this review, there are many more studies that have focused on the literacy domain as compared to the numeracy domain. For this reason, we are unable to provide much detail across Asian contexts.

Differential relations have additionally been observed according to the family member who engaged in home learning practices, at least in Hong Kong. In a sample of 5-year-old children, fathers' frequency of literacy teaching activities, but not mother's frequency, was a significant correlate of children's word reading skills (Xiao et al., 2020). In contrast, mothers' involvement in number skill activities was a positive correlate of children's abilities to solve written arithmetic problems and mathematical story problems, whereas father-child game activities and application activities were predictive of children's abilities in solving written arithmetic problems (Huang et al., 2017). Using a younger sample of 3-year-old children, Liu et al. (2019), however, found that only fathers' involvement in number game activities, but not mothers' involvement in the four types of numeracy activities or fathers' involvement in the other three types of numeracy activities, made a unique contribution to children's number skills. It is currently difficult to explain why such results have emerged; however, it is interesting to consider the roles that different family members play in providing cognitive stimulation to children at home, and what characteristics might make them effective teachers in the home learning context.

In a few cases, the frequency of home learning activities and children's literacy and numeracy outcomes were observed to be negatively correlated. In Hong Kong, although the frequency of home literacy activities was a significant correlate of second graders' reading comprehension, parents' involvement in children's homework (e.g., dictation, reading, and writing tasks) was shown to be negatively correlated (Law, 2008). In the study by Deng et al. (2015) conducted in Mainland China, it was revealed that parents tended to engage more frequently in shared book reading with first graders and second graders who were reported to have poorer reading skills. In Korea, Kim (2009) also found that after taking frequency of reading into consideration, frequent teaching was negatively associated with preschool children's scores on measures of phonological awareness, vocabulary, word reading, and pseudoword reading. One potential explanation for these results is that parents were responsive to their children's learning needs; as such, they provided more support when they discovered that their children were weak in certain skill areas (Kim, 2009).

In the study by Cheung et al. (2020), both home numeracy resources and activities were significant correlates of 5-8-yearold children's numeracy competence. However, home learning resources and activities did not always have an equally positive association with children's outcomes. For instance, in the study 
by Dowd et al. (2017), both reading materials and activities were positively related to children's letter knowledge in Bangladesh; in contrast, only reading activities were related to the same skill among children in Indonesia and the Philippines. In Mainland China, the number of formal literacy activities was a significant predictor of kindergarten children's phonological awareness, whereas the number of home literacy resources was a significant predictor of their vocabulary knowledge (Liu et al., 2018). Another study demonstrated not only differential patterns of relations for literacy resources vs. activities, but also between types of home literacy activities. Zhang et al. (2019) found that among 3rd-year kindergarteners in Mainland China, formal literacy experiences were positively linked with reading comprehension via pinyin knowledge, but informal literacy experiences were not a significant correlate of emergent literacy skills and reading outcomes. In contrast, exposure to literacy resources was positively linked to reading comprehension through rapid naming, phonological awareness, and vocabulary (Zhang et al., 2019).

\section{So Do Home Resources and Activities Matter?}

In general, it is reasonable to conclude that both home resources and activities matter for children's literacy and numeracy development in Asia. It is important for families to own materials that can be used to support children's learning. As far as home learning practices are concerned, their effectiveness could in part be determined by the appropriateness of the activity to the skill domain that is being targeted, the skill of the family member who is conducting the activities, and family members' sensitivity to the child's learning needs.

\section{Does the Quality of Parent-Child Interactions Matter?}

Relatively few studies have examined how the process characteristics of home learning activities are related to young children's learning outcomes. Findings of the existing studies, however, show that the content and style of parent-child interaction play a critical role in children's learning outcomes. In a study on shared reading activities in Hong Kong, Lau and McBride-Chang (2005) found that asking questions related to the content of the story during parent-child reading was a significant predictor of second graders' Chinese character recognition skills. A study in Israel found that after controlling for family socioeconomic status and home literacy environment, mothers' intrusion into children's space during joint writing was negatively correlated with children's alphabetic knowledge, concepts about print, phonological awareness, and vocabulary knowledge (Aram et al., 2013a). In another study, the higher the quality of Israeli mothers' writing mediation, the better first graders' early reading and writing skills (Aram et al., 2013a). Similarly, in Hong Kong, mothers' use of higher-level writing mediation strategies was associated with children's stronger reading and writing skills (Lin et al., 2011). Supportive parent-child interactions during numeracy activities have also been found to benefit children's learning behaviors. In Mainland China, Huang et al. (2020) found that mothers' emotional support was positively correlated with preschoolers' initiative-taking behaviors (e.g., finding solutions independently and showing persistence when difficulties arise) during mathrelated application activities. In contrast, father's cognitive and autonomy support were generally related to children's initiativetaking behaviors across different types of math-related learning activities (e.g., worksheets, games, and application; Huang et al., 2020). Identifying strategies that are best suited to children across different contexts in Asia, and strategies that parents can confidently and effectively utilize in the home context, will, no doubt, be interesting to researchers, practitioners, and organizations involved in developing intervention programs for and in Asia.

\section{Do Parents' Beliefs and Attitudes About Learning Matter?}

Several studies have shown that parents' beliefs and attitudes toward learning can have direct as well as indirect influences on children's literacy and numeracy outcomes. For example, a study in Mainland China demonstrated that parents' expectations had indirect positive links with kindergarten children's word reading skills via the amount of formal literacy experiences they provided to children and the number of literacy resources available at home (Liu et al., 2018). Both direct and indirect relationships were evident in studies focusing on the numeracy domain. In Korea, mothers' attitudes toward math (including enjoyment, anxiety, and self-concept) had indirect links with 4-6-year-old children's abilities and attitudes through their perceptions of children as active math learners (Lee and Kim, 2016). In contrast, mothers' constructivist views about mathematical learning were positively correlated with 4-6-yearold children's abilities and attitudes (Lee and Kim, 2016). In the Philippines, parents' attitudes toward numeracy, including their beliefs about their teaching abilities and the role of parents and play in children's learning, were positively associated with children's interest in numeracy activities (Cheung et al., 2018).

However, one study in Singapore demonstrated a mix of positive and negative relations with children's reading outcomes. In a study by Yeo et al. (2014), parents' perceptions of their role in preparing children for formal schooling were associated with kindergarten children's reading competence and parents' positive affect shown while parent-child reading was found to be associated with children's reading interest (Yeo et al., 2014). In contrast, parents' beliefs about children's verbal participation during reading were negatively related to these children's reading competence (Yeo et al., 2014). From the few studies available, parents' attitudes and beliefs toward literacy, numeracy, and child development are likely to influence the way they behave in terms of fostering their children's skills at home. Understanding these underlying attitudes and beliefs might help explain the wide heterogeneity of trends observed across and within contexts and might be an interesting avenue for future research.

\section{Do Parents' Own Literacy and Numeracy Abilities, Interest, and Practices Matter?}

Family members can serve as positive role models for literacy and numeracy behaviors that children could emulate. In Thailand, 
having a father who could read was associated with better numeracy scores than those whose fathers could not in one study (Morales et al., 2016). In India, adult literacy practices were related to children's vocabulary scores at the end of the year (Vagh, 2009). In Bangladesh, children who reported seeing more than three family members reading at home were more likely to perform better on reading tasks (Islam et al., 2018). In Hong Kong, having an English-speaking foreign domestic helpers benefited 5-year-olds' English vocabulary performance (Dulay et al., 2017). However, family members could serve as negative role models in some instances. For example, mothers' foreign language reading anxiety was positively associated with first graders' foreign language reading anxiety in Hong Kong in one study (Chow et al., 2017).

Children's and parents' literacy and numeracy skills have also been found to be related. In Nepal and the Philippines, parents' own literacy skills were significantly related to their children's literacy (LeVine et al., 2012; Education Development Center, Inc., 2015; Dulay et al., 2019). Similarly, in the Philippines, parents' own computation skills and engagement in mathematical activities had direct links with children's numeracy skills, as well as indirect links via the number of home numeracy resources and the frequency of home numeracy activities (Cheung et al., 2020). Overall, these studies have highlighted the intergenerational nature of literacy and numeracy transmission within families and further emphasize the importance of studying what happens within homes in Asia.

\section{What Factors Affect the Relation Between the Home Learning Environment and Children's Development?}

Why does the home learning environment sometimes fail to predict young children's learning outcomes in studies from Asia? One possible reason is that the relation between the home learning environment and young children's learning outcomes is subject to third variables. For example, there is some evidence that home learning environments might function differently between age groups and over time. In a sample of 3-, 4-, and 5-year-olds in the Philippines, no relationships between home literacy environment factors and children's literacy and numeracy were found, except for home literacy resources and children's vocabulary in the 5-year-old group (Cheung et al., 2018; Dulay et al., 2018). When the same cohort was between 5 and 8 years old, there were significant relationships between home literacy activities and children's oral and print skills (Dulay et al., 2019), and both home numeracy activities and resources were significantly related to children's numeracy performance at the same time point (Cheung et al., 2020).

Speaking the school language at home has also been highlighted as an important facet of academic achievement. A mismatch between the home language and the school language was associated with worse reading and math outcomes in India in one study (Bhattacharjea et al., 2011), whereas speaking Nepali at home was associated with higher overall scores in a child development assessment in Nepal (Research Inputs and Development Action, 2016a). However, the same research group did not find this same home language advantage in a different location in Nepal (Research Inputs and Development Action, 2016b). This is consistent with a recent systematic review that examined the effects of home language-school language among low-to-middle-income countries around the world, noting heterogeneity in the evidence for a "home language advantage" (Nag et al., 2019, p. 91). The broader challenge of multilingualism and becoming proficient in more than one language has also been a topic of concern for some studies in South and Southeastern Asia. Unsurprisingly, studies in Singapore have demonstrated that greater input in the mother tongue (Li et al., 2016; Li and Tan, 2016; Sun, 2019) and English (Sun et al., 2018b) were both related to higher literacy scores in these respective languages. However, another study in Singapore demonstrated that children could achieve a high degree of proficiency in both languages regardless of the degree of relative home language exposure in the mother tongue and in English (Dixon et al., 2012). There might be compensatory mechanisms that make up for the lack of home language exposure in a particular language. For example, a study in India revealed that reading at home mitigated the impact of low English language exposure on children's English oral and print skills (Kalia and Reese, 2009).

In a more general sense, it might be possible to identify aspects of home environments in Asia that are especially lacking or challenging in certain places. In the same way, there could be compensatory mechanisms within homes and communities that have not yet been identified and accounted for in the research literature. Nevertheless, researchers and organizations have sought to implement interventions to address perceived gaps in the home learning environment of families living in Asia. These initiatives are discussed in the next section.

\section{CAN FAMILY-BASED INTERVENTIONS IMPROVE HOME ENVIRONMENTS AND CHILDREN'S SKILLS IN ASIA?}

What kinds of home literacy and numeracy interventions have been implemented in Asia and are they effective? Based on the studies considered for this review, we identified two types of intervention programs that aimed to improve children's literacy and numeracy skills. The first type comprises broad parent education programs. Typically, these cover multiple domains of child development such as nutrition, behavior, discipline, and learning in the cognitive, language, and numeracy domains. The second type is characterized by programs that focus more specifically on children's literacy and/or numeracy skills. The effectiveness of these two types of intervention programs will be evaluated separately, in the sections that follow.

\section{How Effective Are Broad Parent Education Programs?}

Broad education programs can potentially influence both parents' behaviors and children's skills; however, results vary across and within samples. In Bhutan, a broad parent education program 
resulted in positive gains on learning materials, learning activities, and children's literacy and numeracy skills (Department of Public Health and Save the Children, 2017). However, the variability in program effects was best exemplified by various programs implemented in Bangladesh. In two studies, mothers that received parent education sessions demonstrated better knowledge about child development and were observed to provide more stimulating talk and activities with their children; thus, they demonstrated a positive change in the home learning environment (Aboud, 2007; Aboud et al., 2013). Interestingly, the earlier program only increased boys', but not girls', vocabulary scores (Aboud, 2007), but the latter program resulted in significantly higher cognitive and language scores among all children in the intervention group compared to the control group (Aboud et al., 2013). In another case, changes were observed in some aspects of the home environment, but not others. A preschool program that included a parent education and parent-child reading component resulted in an increased percentage of households with learning materials and stronger attitudes about talking to children; however, the frequency of conducting home learning activities did not increase (Guajardo and Nath, 2016). In the least successful program in this set of studies, parent education sessions and messages for mothers and fathers did not result in increased indices of home activities, home resources, or children's literacy and numeracy skills (Pisani et al., 2017b).

In contrast, promising short-term and long-term effects were reported in interventions conducted in Western Asia. After joining an early childhood care and development and child protection-focused intervention program in Iraq, participating boys and girls in conflict-affected areas generally outperformed the control group in most developmental domains, and their parents likewise demonstrated better literacy skills than parents in the control group (Hamakareem and Okello, 2019). Parents who participated in the program were also observed to provide more reading and play materials to support children's literacy and motor development than parents in the control group (Hamakareem and Okello, 2019). Furthermore, one program in Turkey demonstrated how a 2 -year mother training program for promoting children's early literacy, early numeracy, and socioemotional skills, as well as mothers' own empowerment, could result in long-lasting benefits to children's academic and behavioral outcomes. In the 7-year follow-up of the Turkish Early Enrichment Program (TEEP), Kagitcibasi et al. (2001) revealed that mother training resulted in higher levels of school attainment, vocabulary scores, parental educational expectations, and better behavioral outcomes for the children (Kagitcibasi et al., 2001). While most of the benefits of mother training in particular had largely disappeared in the 19-year follow-up, the children who received some form of early enrichment demonstrated evidence of positive educational, occupational, and social outcomes later in life (Kagitcibasi et al., 2009).

\section{How Effective Are Domain-Specific Parent Education Programs?}

The second program type appeared to more reliably benefit children's literacy and numeracy skills due to its narrower focus. Though there is less emphasis on outcomes on parents' attitudes, practices, and skills as well as other domains of children's development, studies have sometimes reported potential effects of intervention on these aspects as well. For example, researcher-designed interventions in East Asia have generally reported positive results. In Hong Kong, Chow et al. (2008) tested the effectiveness of a 12 -week dialogic reading intervention. Results showed that the program could promote kindergarteners' improvement in Chinese vocabulary and reading interest, and children whose parents received explicit metalinguistic training also demonstrated improvements in character recognition and morphological awareness (Chow et al., 2008). Cheung and McBride (2017), on the other hand, conducted a 4-week intervention program for kindergarten children who were relatively unskilled in the numeracy domain. Children who completed mathematics workbooks with their parents improved on their addition skills, whereas children who played number board games with their parents demonstrated increased scores in measures of rote counting, numeral identification, and mathematics interest. In a third group wherein parents received additional training on how to play number board games more effectively, the children demonstrated improvements in rote counting, numeral identification, addition, and mathematics interest from pre- to post-test (Cheung and McBride, 2017). Meanwhile, in a case study conducted in Japan, a young girl demonstrated certain improvements in mathematics after being given a simple mathematics quiz game to play at home over a 3-year period (Watanabe, 2019). Although these studies normally focused on children's cognitive outcomes, researchers have sometimes examined the positive impacts of intervention on parental attitudes and parent-child relationships. In a study involving a 7-week paired reading program for preschoolers and their parents in Hong Kong, the program was observed to not only benefit the preschoolers but also their parents (Lam et al., 2013). Preschoolers demonstrated better word recognition skills, reading fluency, and motivation in reading, whereas parents increased in their self-efficacy in helping children to read after joining the program. Parents also reported an improved relationship with their children.

In South and Southeastern Asia, programs implemented by researchers and non-government organizations were generally found to have positive results, and effects on parents were sometimes reported as well. In India, two types of home reading programs that involved either child-facilitated reading or parentchild reading were both effective in improving children's English reading skills relative to a control group (Shah-Wundenberg et al., 2013). In another study, the combined effect of an intervention that targeted maternal literacy and encouraged mother-child activities improved literacy and numeracy skills among mothers and children (Banerji et al., 2017). The two programs administered individually were similarly effective for children's numeracy and mothers' literacy and numeracy scores, but not for children's literacy scores. Mothers who participated in the programs also demonstrated stronger beliefs about their responsibility over their children's education and were more likely to be involved in their children's homework. In the Philippines, a parent education program with a significant reading and storytelling component (First Read) was found to increase 
home reading behavior and children's language and emergent literacy skills (Leer and Teodosio, 2016). In another study, a parent coaching program that focused on dialogic reading, early literacy activities, or early numeracy games resulted in improved children's skills in the specific domain targeted (Dulay et al., 2019). Finally, a combined family math program in Singapore, which involved both parent workshops and a parent newsletter, resulted in the greatest gains in math scores compared to a workshop-only, newsletter-only, or control condition (Ho, 2007). However, no treatment effects were observed on parental involvement, encouragement, and confidence outcomes.

A positive trend of results for the home learning environment was also found for interventions implemented in Central and Western Asia. In Whitsel and Lapham's (2014) study, referred to as a parent empowering program, in Tajikistan, parents re-learned mathematics and reading to support children's learning at school. Results showed that parents, especially young mothers, demonstrated more confidence, self-esteem, and control toward their children's literacy as a result. Also, all family members were encouraged to get involved in learning activities with children, including counting, painting, singing, and poetry. In the beginning of the program, most of the Tajikistani parents held the opinion that they should not begin any pre-literacy or pre-numeracy skills before school. After participating in the program, parents expressed the belief that early learning is useful for children's future performance, and that they should focus on their children's early literacy and numeracy (Whitsel and Lapham, 2014). Unfortunately, no direct evaluation of intervention effects on children's outcomes was conducted following this program. Meanwhile, in a study by Aram and Levin (2014) with low socioeconomic status families in Israel, children showed significant improvement in linguistic competencies after joining a mediated reading program with their parents. Children's alphabetic skills improved the most after joining a mediated writing program with their parents, though the mediated reading program was also found to bring positive impacts on children's alphabetic skills.

In general, broad parent education programs and focused literacy or numeracy interventions both have the potential to positively impact the home learning environment, and ultimately, children's literacy and numeracy development. Both types of programs are valuable for different reasons. Broad parent education programs acknowledge the multiple overlapping concerns that could keep parents from fostering their children's literacy and numeracy development, whereas focused programs can provide parents with techniques that work very well on a particular area of concern for children's learning. In general, more detailed process documentation and more investigations of long-term intervention effects are needed to understand how such programs can be more effective at improving home learning environments and children's outcomes in Asia.

\section{DISCUSSION}

This review paper has aimed to examine the learning-related beliefs and attitudes of parents in Asia, their home literacy and numeracy practices, the role of the home literacy and numeracy environments in the literacy and numeracy development of young children in Asia, and the effectiveness of programs that aim to improve the home literacy and numeracy environments in Asia. Generally speaking, our review shows that the home learning environments created by parents in Asia are generally consistent with their educational goals and aspirations for their children and are conducive to children's early literacy and numeracy development. While broad parent education programs have positively benefited children's outcomes in several instances, focused interventions are more consistent at producing direct (but potentially short-term) impacts on children's literacy and numeracy skills.

To what extent are the home literacy and numeracy environments in Asia similar or different from those in the West? As mentioned at the beginning of this paper, we cannot give a solid answer to the question given the limited number of relevant cross-cultural studies in the literature. However, the above review does provide some initial insights into the home literacy and numeracy environments in Asia in relation to those in Western societies. Consistent with the situations observed in the West, the home learning environments tend to play a critical role in children's early development. Generally, the greater the number of home resources available at home and the higher the frequency of home learning activities, the better children's literacy and numeracy competence and interest. Moreover, parents can often be coached to provide more stimulating home literacy and numeracy environments, which in turn benefits children's development. Meanwhile, there are at least three issues about the home literacy and numeracy environments in Asia that are not commonly observed or discussed in Western contexts. First, some parents in Asia, especially those in East Asia, tend to place great emphasis on academic achievement and their own responsibility to help children learn at home (Yamamoto and Brinton, 2010; Byun et al., 2012; Bray, 2013). Play is not always favored as it is associated with laziness (Leung, 2011; Luo et al., 2013). Under the influence of the Western idea of child-centeredness, parents' beliefs appear to be changing, however (Rao and Li, 2009; Fung and Cheng, 2012; Lin and Yawkey, 2013). Second, several studies appear to acknowledge the role of non-parental household members in fostering children's development in Asian homes, which sometimes span three generations and might even involve non-family members such as domestic helpers (Chung and Koo, 2001; Dulay et al., 2017; Rao et al., 2017; Su et al., 2020). Third, there is a great demand to learn multiple languages in these contexts, as often the children are growing up in multilingual environments (Joshi, 2015; Adamson, 2018; Wang, 2018). In many contexts, children have to be proficient in languages they do not necessarily speak at home in order to attain educational success.

Looking more closely, it should be noted that home environments across different contexts in Asia comprise a certain degree of heterogeneity in parental beliefs, home practices, associations between the home learning environment and child outcomes, and effectiveness of parent training programs. For instance, parents in some places seem to vary in their perceived 
importance of developing children's reading and writing competencies prior to formal school entry, as well as the roles of homes and play in children's learning (Lee, 2002; Howell et al., 2016; Chan, 2012). They also reported different frequencies in various formal and informal home learning activities with children (Kim, 2009; Howell et al., 2016; Huang et al., 2017; Inoue et al., 2018; Cheung et al., 2020). Though these differing parental beliefs and home practices may be attributed to inexplicable variance, individual differences between participants, and different research methodologies adopted across studies, they may also emerge from variations in cultural values and social situations of different places within the vast region of Asia. Specifically, as influenced by Confucianism and the competitive social environment, parents in certain places such as Mainland China, Hong Kong, Japan, Korea, and Singapore, tend to hold higher academic expectations for children and thus invest more in fostering children's literacy and numeracy skills in the early years (Yamamoto and Brinton, 2010; Byun et al., 2012; Bray, 2013; Luo et al., 2013). On the other hand, Israel is a developed, industrialized country with individualistic values as the dominant culture, though it is also a highly familial society with strong emphasis on communal values (Scharf, 2014). It is thus not surprising that showing warmth toward children, supporting children's autonomy support and setting expectations for children's appropriate behaviors are valued more by Israeli parents than providing children with academic-related materials and activities at home (Aram et al., 2020).

Furthermore, our review shows that home learning resources and activities were not uniformly impoverished among the low- and middle-income economies in a given region; in fact, there is considerable variability in home resources and practices even within high-income economies such as Singapore. Home learning resources and activities also demonstrate non-uniform relationships with children's skills across home learning variables, literacy and numeracy sub-domains, family members, and sample characteristics. One possible source of such disparities is that parents' education and income levels, as well as other demographic variables (e.g., family size) and personal variables (e.g., personal abilities, feelings, and experiences with literacy and numeracy), may affect their parental beliefs about early literacy and numeracy learning, the extent to which they can enact such beliefs, and the effectiveness of their home practices in promoting various aspects of child development (Wolff and Breit, 2012; Chow et al., 2017; Dulay et al., 2019; Cheung et al., 2020). Further examination is thus warranted to enhance our understanding of how various personal, socioeconomic, and cultural factors interact with each other to contribute to the diverse home learning environments within and across regions in Asia.

\section{Limitations}

There are several limitations to note in this review. First, though we endeavored to include studies from all possible territories in Asia, we did not find studies from many important and representative locations, including Afghanistan, Azerbaijan, Armenia, Brunei Darussalam, Kuwait, Malaysia, and the Maldives, as well as many others that fit the scope of the review.
One possible reason for this omission is that the studies conducted in these places, if any, are not written in English or are not easily accessible on the internet. Second, for some locations (especially those in Southern, Southeastern, Central, and Western Asia), the best-known studies have been funded through initiatives by governmental (e.g., USAID) or non-government organizations (e.g., Save the Children and UNICEF) and are reported in the gray literature. In contrast, many studies from East Asia are peer-reviewed articles and have been funded largely by academic grants. Hence, the research frameworks used, nature of sample recruitment, and degree of detail in reporting tended to vary across sources. Third, the samples in many of these studies are not representative of the whole population. Therefore, it is not advisable to use the results of a single study to make sweeping generalizations about the situation of a particular country or territory; comparison of the situation across contexts should be done with great caution. Meanwhile, it is not surprising to see that there are significant variations across contexts in Asia, as well as across samples within a context. Indeed, apart from the large list of countries and territories covered, the generalizability of any single study is limited by the diversity of socioeconomic and linguistic profiles among people living in these regions. Fourth, there are relatively fewer studies on the home numeracy environment than on the home literacy environment. Studies on the quality of the home learning environment, such as the content and style of parent-child interactions during home learning activities, are also limited. Last but not least, there is a great variety of terms used in the literature to describe the home learning environment. This lack of standardization in the terminology used as well as the assessment frameworks made the search for relevant articles and drawing comparisons across studies more difficult.

\section{Future Directions}

As shown above, there are several topics regarding the home literacy and numeracy environments in Asia that are still under-explored and require further investigation. Indeed, there is a great need for more research on this diverse and huge population of those from Asia, given that children's immediate learning environments (including the home learning environments) are affected by the larger sociocultural contexts in which they live (Bronfenbrenner, 1979); at the same time, children and families play an active role in sustaining or changing the cultural practices within the group (Miller and Goodnow, 1995). We briefly highlight just four suggested research directions here. First, more cross-cultural studies with comparable samples can be conducted. For example, we may wish to explore relatively wealthier and poorer citizens across countries in order to understand the interplay of culture and relative income level for educational attainment. Second, more longitudinal studies should be carried out to investigate the direct and indirect effects of the home learning environments on children's literacy and numeracy development. We may also compare the relative role of the home and school experience over time. Third, the mechanisms underlying the interactions between parental beliefs and attitudes, parental practices, and children's outcomes can be explored further. Specifically, we may 
evaluate whether there are any gaps between parents' beliefs and practices and identify which types of parents are more likely to have such a gap. Finally, more work needs to be done in order to identify underlying sources of variability in the home learning environments across countries and to find the best routes by which to empower homes that fit various Asian contexts. In particular, the optimal content, form and intensity of programs for parents in different sociocultural settings can be examined.

\section{Conclusion}

This review paper is one of only a few, if any, to examine the home literacy and numeracy environments across different regions in Asia. On the one hand, we have discussed how the home learning environments in Asia are shaped by some sociocultural variables. On the other hand, by appreciating the sheer diversity in home learning environments and children's experiences in the contexts that we have covered, we have been able to identify some features of the home environment that warrant further exploration, such as the underlying role of cultural values and social situations in determining how parents provide educational experiences to their children at home, the relatively underexplored role of non-parental caregivers in shaping the home environment, the need to identify contextrelevant mediators and moderators that underlie the relationship between the home learning environment and children's outcomes,

\section{REFERENCES}

Aboud, F. E. (2007). Evaluation of an early childhood parenting programme in rural Bangladesh. J. Health Popul. Nutr. 25, 3-13.

Aboud, F. E., Singla, D. R., Nahil, M. I., and Borisova, I. (2013). Effectiveness of a parenting program in Bangladesh to address early childhood health, growth and development. Soc. Sci. Med. 97, 250-258. doi: 10.1016/j.socscimed.2013.06.020

Adamson, B. (2018). "Tensions of language education in Asia" in Routledge international handbook of schools and schooling in Asia. eds. K. J. Kennedy and J. C. K. Lee (Georgetown: Routledge), 489-491.

Altun, D. (2019). Young children's theory of mind: home literacy environment, technology usage, and preschool education. J. Educ. Train. Stud. 7, 86-98. doi: $10.11114 /$ jets.v7i3.4057

Amantay, A. (2017). Kazakh family engagement in early language and literacy learning: a case study in urban Kazakhstan. unpublished doctoral dissertation. Nazarbayev University.

Aminipour, S., Asgari, A., Hejazi, E., and Roßbach, H. G. (2018). Home learning environments: a cross-cultural study between Germany and Iran. J. Psychoeduc. Assess. 38:0734282918778465. doi: 10.1177/0734282918778465

Aram, D., Korat, O., and Hassunah-Arafat, S. (2013a). The contribution of early home literacy activities to first grade reading and writing achievements in Arabic. Read. Writ. 26, 1517-1536. doi: 10.1007/s11145-013-9430-y

Aram, D., Korat, O., Saiegh-Haddad, E., Hassunha Arafat, S., Khoury, R., and Elhija, J. A. (2013b). Early literacy among Arabic-speaking kindergartners: the role of socioeconomic status, home literacy environment and maternal mediation of writing. Cogn. Dev. 28, 193-208. doi: 10.1016/j.cogdev.2012.10.003

Aram, D., and Levin, I. (2001). Mother-child joint writing in low SES: sociocultural factors, maternal mediation, and emergent literacy. Cogn. Dev. 16, 831-852. doi: $10.1016 /$ S0885-2014(01)00067-3

Aram, D., and Levin, I. (2002). Mother-child joint writing and storybook reading: relations with literacy among low SES kindergartners. Merrill-Palmer Q. 48, 202-224. doi: 10.1353/mpq.2002.0005

Aram, D., and Levin, I. (2014). "Promoting early literacy: the differential effects of parent-child joint writing and joint storybook reading interventions" in and the need to identify the most effective means for delivering intervention in these skill domains. Overall, this review paper enhances our understanding of the role of sociocultural factors in shaping home environments, and thus children's early development, in Asia. Beyond that, we have identified potential avenues where we can deepen our understanding of how homes can support children's literacy and numeracy around the world.

\section{AUTHOR CONTRIBUTIONS}

SC, KD, and CM developed the research idea. SC, KD, XY, FM, and CM wrote and reviewed the manuscript. All authors contributed to the article and approved the submitted version.

\section{FUNDING}

This study was supported by the General Research Fund of the Research Grants Council of Hong Kong (18611219).

\section{ACKNOWLEDGMENTS}

We would like to thank Faustine Beloso for her efforts in aiding this research.

Cognitive development: Theories, stages \& processes and challenges. ed. R. Chen (NY: Nova Science Publishers), 189-212.

Aram, D., Skibbe, L., Hindman, A., Bindman, S., Atlas, Y. H., and Morrison, F. (2020). Parents' early writing support and its associations with parenting practices in the United States and Israel. Merrill-Palmer Q. 66, 392-420. doi: 10.13110/merrpalmquar1982.66.4.0392

Banerji, R., Berry, J., and Shotland, M. (2017). The impact of maternal literacy and participation programs: evidence from a randomized evaluation in India. Am. Econ. J. Appl. Econ. 9, 303-337. doi: 10.1257/app.20150390

Bekerman, Z., and Tatar, M. (2009). Parental choice of schools and parents' perceptions of multicultural and co-existence education: the case of the Israeli Palestinian-Jewish bilingual primary schools. Eur. Early Child. Educ. Res. J. 17, 171-185. doi: 10.1080/13502930902951304

Bhattacharjea, S., Wadhwa, W., and Banerji, R. (2011). Inside primary schools: A study of teaching and learning in rural India. Mumbai, Maharashtra: Pratham Mumbai Education Initiative.

Bora, P., Bajantri, H., Raj, A., Roy, P., and Seiden, J. (2018). Partnering for early childhood education in India: Impact evaluation endline report. Save the Children. Available at: https://resourcecentre.savethechildren.net/library/ partnering-early-childhood-education-india-impact-evaluation-endline-report (Accessed May 1, 2020).

Boyden, J. (2013). 'We're not going to suffer like this in the mud': educational aspirations, social mobility and independent child migration among populations living in poverty. Comp. J. Comp. Int. Educ. 43, 580-600. doi: 10.1080/ 03057925.2013.821317

Bradley, R. H., and Putnick, D. L. (2012). Housing quality and access to material and learning resources within the home environment in developing countries. Child Dev. 83, 76-91. doi: 10.1111/j.1467-8624.2011.01674.x

Bray, M. (2013). Benefits and tensions of shadow education: comparative perspectives on the roles and impact of private supplementary tutoring in the lives of Hong Kong students. J. Int. Comp. Educ. 2, 18-30. doi: $10.14425 / 00.45 .72$

Brombacher, A., Collins, P., Cummiskey, C., Galbert, P. D., Kochetkova, E., and Mulcahy-Dunn, A. (2012). Education data for decision making (EdData II): Iraq 
education surveys- MAHARAT. Available at: https://www.globalreadingnetwork. net/eddata/iraq-education-surveys $\% \mathrm{E} 2 \% 80 \% 93$ maharat-task-1-analysis-studentperformance-reading-and-mathematics (Accessed April 18, 2020).

Bronfenbrenner, U. (1979). The ecology of human development: Experiments by nature and design. Cambridge, MA: Harvard University Press (Republished in 2006).

Brown, C. (2013). Literacy Boost Indonesia: Endline report. Save the Children. Available at: https://resourcecentre.savethechildren.net/library/literacy-boostindonesia-endline-report-2013 (Accessed May 1, 2020).

Byun, S. Y., Schofer, E., and Kim, K. K. (2012). Revisiting the role of cultural capital in East Asian educational systems: the case of South Korea. Sociol. Educ. 85, 219-239. doi: 10.1177/0038040712447180

Bywater, T., Sammons, P., Toth, K., Sylva, K., Melhuish, E., Siraj, I., et al. (2015). The long-term role of the home learning environment in shaping students' academic attainment in secondary school. J. Child. Serv. 10, 189-201. doi: 10.1108/JCS-02-2015-0007

Chan, W. L. (2012). Expectations for the transition from kindergarten to primary school amongst teachers, parents and children. Early Child Dev. Care 182, 639-664. doi: 10.1080/03004430.2011.569543

Chan, W. L. (2016). The discrepancy between teachers' beliefs and practices: a study of kindergarten teachers in Hong Kong. Teach. Dev. 20, 417-433. doi: $10.1080 / 13664530.2016 .1161658$

Chen, X., Zhou, H., Zhao, J., and Davey, G. (2010). Home literacy experiences and literacy acquisition among children in Guangzhou, South China. Psychol. Rep. 107, 354-366. doi: 10.2466/04.11.17.21.28.PR0.107.5.354-366

Cheng, K. M. (2001). "Educational systems: Asia" in International encyclopedia of the social \& behavioral sciences. eds. N. J. Smelser and P. B. Baltes (Amsterdam, New York: Elsevier), 4333-4338.

Cheung, S. K., Dulay, K. M., and McBride, C. (2020). Parents' characteristics, the home environment, and children's numeracy skills: how are they related in low- to middle-income families in the Philippines? J. Exp. Child Psychol. 192, 1-19. doi: 10.1016/j.jecp.2019.104780

Cheung, S. K., and McBride, C. (2017). Effectiveness of parent-child number board game playing in promoting Chinese kindergarteners' numeracy skills and mathematics interest. Early Educ. Dev. 28, 572-589. doi: 10.1080/10409289.2016.1258932

Cheung, S. K., Yang, X., Dulay, K. M., and McBride, C. (2018). Family and individual variables associated with young Filipino children's numeracy interest and competence. Br. J. Dev. Psychol. 36, 334-353. doi: 10.1111/bjdp.12222

Chow, B. W. Y., Chui, B. H. T., Lai, M. W. C., and Kwok, S. Y. (2017). Differential influences of parental home literacy practices and anxiety in English as a foreign language on Chinese children's English development. Int. J. Biling. Educ. Biling. 20, 625-637. doi: 10.1080/13670050.2015.1062468

Chow, B. W. Y., McBride-Chang, C., and Cheung, H. (2010). Parent-child reading in English as a second language: effects on language and literacy development of Chinese kindergarteners. J. Res. Read. 33, 284-301. doi: 10.1111/j.1467-9817.2009.01414.x

Chow, B. W. Y., McBride-Chang, C., Cheung, H., and Chow, C. S. L. (2008). Dialogic reading and morphology training in Chinese children: effects on language and literacy. Dev. Psychol. 44:233. doi: 10.1037/0012-1649.44.1.233

Chung, D., and Koo, H. (2001). A study on young children's reading activity at home. Life Sci. Res. 6, 175-188.

Dearing, E., and Tang, S. (2009). “The home learning environment and achievement during childhood" in Handbook of school-family partnerships. eds. S. L. Christenson and A. L. Reschly (New York: Routledge), 131-157.

Demircan, O., and Tantekin-Erden, F. (2015). Parental involvement and developmentally appropriate practices: a comparison of parent and teacher beliefs. Early Child Dev. Care 185, 209-225. doi: 10.1080/03004430.2014.919493

Deng, C., Silinskas, G., Wei, W., and Georgiou, G. K. (2015). Cross-lagged relationships between home learning environment and academic achievement in Chinese. Early Child Res. Q. 33, 12-20. doi: 10.1016/j.ecresq.2015.05.001

Department of Public Health and Save the Children (2017). Care for Child Development (C4CD) Plus impact evaluation. Available at: https://idela-network. org/resource/care-for-child-development-c4cd-plus-impact-evaluation/ (Accessed May 1, 2020).

Dharmaputra, G. A. (2019). Language policy, ideology and language attitudes: a study of Indonesian parents and their choice of language in the home. unpublished doctoral dissertation. University of Sydney.

Dixon, L. Q., Wu, S., and Daraghmeh, A. (2012). Profiles in bilingualism: factors influencing kindergartners' language proficiency. Early Childhood Educ. J. 40, 25-34. doi: 10.1007/s10643-011-0491-8
Dowd, A. J., Friedlander, E., Jonason, C., Leer, J., Sorensen, L. Z., Guajardo, J., et al. (2017). Lifewide learning for early reading development. New Dir. Child Adolesc. Dev. 2017, 31-49. doi: 10.1002/cad.20193

Dulay, K. M., Cheung, S. K., and McBride, C. (2018). Environmental correlates of early language and literacy in low- to middle-income Filipino families. Contemp. Educ. Psychol. 53, 45-56. doi: 10.1016/j.cedpsych.2018.02.002

Dulay, K. M., Cheung, S. K., and McBride, C. (2019). Intergenerational transmission of literacy skills among Filipino families. Dev. Sci. 22, 1-14. doi: 10.1111/ desc. 12859

Dulay, K. M., Cheung, S. K., Reyes, P., and McBride, C. (2019). Effects of parent coaching on Filipino children's numeracy, language, and literacy skills. J. Educ. Psychol. 111, 641-662. doi: 10.1037/edu0000315

Dulay, K. M., Tong, X., and McBride, C. (2017). The role of foreign domestic helpers in Hong Kong Chinese children's English and Chinese skills: a longitudinal study. Lang. Learn. 67, 321-347. doi: 10.1111/lang.12222

Education Development Center, Inc (2015). USAID/Philippines Basa Pilipinas Program: Evaluation Report for School Years 2013/14 and 2014/15.

Forey, G., Besser, S., and Sampson, N. (2015). Parental involvement in foreign language learning: the case of Hong Kong. J. Early Child. Lit. 16, 383-413. doi: $10.1177 / 1468798415597469$

Frijters, J. C., Barron, R. W., and Brunello, M. (2000). Direct and mediated influences of home literacy and literacy interest on prereaders' oral vocabulary and early written language skill. J. Educ. Psychol. 92:466. doi: 10.1037/ 0022-0663.92.3.466

Fung, C. K. H., and Cheng, D. P. W. (2012). Consensus or dissensus? Stakeholders' views on the role of play in learning. Early Years 32, 17-33. doi: $10.1080 / 09575146.2011 .599794$

Guajardo, J., and Nath, B. K. D. (2016). Bangladesh Shishuder Jonno, two-year preeschool program IDELA endline report. Save the Children. Available at: https://resourcecentre.savethechildren.net/library/bangladesh-shishuder-jonnotwo-year-preeschool-program-idela-endline-report (Accessed May 1, 2020).

Hamakareem, D., and Okello, L. (2019). IDELA end line evaluation report. Save the children. Available at: https://idela-network.org/resource/endlinelearning-parents-and-children-iraq/ (Accessed April 18, 2020).

Hamano, T., and Uchida, N. (2012). Cross-cultural study on the process of literacy acquisition and its relationship with environmental factors. Annual Report of Ochanomizu University Research Center for Human Development and Education. 4, 13-26. Available at: http://hdl.handle.net/10083/51285 (Accessed May 12, 2020).

Ho, C. L. (2007). Fostering parental involvement in children's mathematics homework in Singapore pre-primary education: an intervention using parental education and school-home communication. unpublished doctoral dissertation. Durham University.

Hofstede, G. (2001). Culture's consequences: Comparing values, behaviors, institutions, and organizations across nations. Thousand Oaks, CA: Sage Publications.

Hofstede, G., Hofstede, G. J., and Minkov, M. (2010). Cultures and organizations: Software of the mind. Revised and expanded. 3rd Edn. New York: McGraw-Hill.

Holloway, S. D., Yamamoto, Y., Suzuki, S., and Mindnich, J. D. (2008). Determinants of parental involvement in early schooling: evidence from Japan. Early Child. Res. Pract. 10:n1.

Howell, H., Pisani, L., Kou, B., and Hok, P. (2016). Cambodia First Read baseline report. Save the Children Available at: https://resourcecentre. savethechildren.net/library/cambodia-first-read-baseline-report (Accessed May 1, 2020).

Huang, Q., Sun, J., and Tang, Y. X. (2020). Chinese parents' scaffolding and children's initiative in mother-child and father-child interactions across different types of problem-solving activities. Early Educ. Dev. 32, 249-271. doi: $10.1080 / 10409289.2020 .1752591$

Huang, Q., Zhang, X., Liu, Y. Y., Yang, W., and Song, Z. M. (2017). The contribution of parent-child numeracy activities to young Chinese children's mathematical ability. Br. J. Educ. Psychol. 87, 328-344. doi: 10.1111/bjep.12152

Iflazoglu Sabah, A., Altinkamis, F., and Deretarla Gul, E. (2018). Investigation of parents' early literacy beliefs in the context of Turkey through the parent Reading belief inventory (PRBI). Euro. J. Educ. Res. 7, 985-997. doi: 10.12973/ eu-jer.7.4.985

Inomata, T., Uno, A., Sakai, A., and Haruhara, N. (2016). Contribution of cognitive abilities and home literacy activities to Hiragana reading and spelling skills in kindergarten children. Japan J. Logopedics Phoniatrics 57, 208-216. doi: 10.5112/jjlp.57.208 
Inoue, T., Georgiou, G. K., Muroya, N., Maekawa, H., and Parrila, R. (2018). Can earlier literacy skills have a negative impact on future home literacy activities? Evidence from Japanese. J. Res. Read. 41, 159-175. doi: 10.1111/ 1467-9817.12109

Işıtan, S., Saçkes, M., Justice, L. M., and Logan, J. A. R. (2018). Do early learning and literacy support at home predict preschoolers' narrative skills? Educ. Sci. Theory Pract. 18, 661-671. doi: 10.12738/estp.2018.3.0012

Islam, S., Mohanta, R. C., Gayen, P., Lata, S. P., Richardson, E., Islam, A., et al. (2018). Early grade reading skills: Endline assessment of read interventions in Khagrachari, Chittgong Hill tracts. Bangladesh Educ. J. 17, 9-36.

Joshi, R. M. (2015). "Education in South Asia" in International encyclopedia of the social and behavioral sciences. 2nd Edn. Vol. 7. ed. J. D. Wright (London: Elsevier), 194-197.

Kagitcibasi, C., Sunar, D., and Bekman, S. (2001). Long-term effects of early intervention: Turkish low-income mothers and children. J. Appl. Dev. Psychol. 22, 333-361. doi: 10.1016/S0193-3973(01)00071-5

Kagitcibasi, C., Sunar, D., Bekman, S., Baydar, N., and Cemalcilar, Z. (2009). Continuing effects of early enrichment in adult life: the Turkish early enrichment project 22 years later. J. Appl. Dev. Psychol. 30, 764-779. doi: 10.1016/j.appdev.2009.05.003

Kalia, V. (2007). Assessing the role of book reading practices in Indian bilingual children's English language and literacy development. Early Childhood Educ. J. 35, 149-153. doi: 10.1007/s10643-007-0179-2

Kalia, V., and Reese, E. (2009). Relations between Indian children's home literacy environment and their English oral language and literacy skills. Sci. Stud. Read. 13, 122-145. doi: 10.1080/10888430902769517

Kell, M., and Kell, P. (2014). Literacy and language in East Asia: Shifting meanings, values and approaches. Singapore: Springer Singapore.

Kim, Y. S. (2009). The relationship between home literacy practices and developmental trajectories of emergent literacy and conventional literacy skills for Korean children. Read. Writ. 22, 57-84. doi: 10.1007/s11145-007-9103-9

Kim, J. W., Jung, A. W., and Kim, Y. J. (2011). The effects of contextual variables and parental cognition on maternal involvement in Korean children's early education. Int. J. Hum. Ecol. 12, 1-14. doi: 10.6115/ljhe.2011.12.1.1

Korat, O., Arafat, S. H., Aram, D., and Klein, P. (2012). Book reading mediation, SES, home literacy environment, and children's literacy: evidence from Arabicspeaking families. First Lang. 33, 132-154. doi: 10.1177/0142723712455283

Korat, O., Aram, D., and Hassunha-Arafat, S. (2014). "Mother-child literacy activities and early literacy in the Israeli Arab family" in Handbook of Arabic literacy. eds. E. Saiegh-Haddad and M. Joshi (New York: Springer), 323-350.

Korat, O., Klein, P., and Segal-Drori, O. (2007). Maternal mediation in book reading, home literacy environment, and children's emergent literacy: a comparison between two social groups. Read. Writ. 20, 361-398. doi: 10.1007/ s11145-006-9034-x

Lam, S. F., Chow-Yeung, K., Wong, B. P., Lau, K. K., and Tse, S. I. (2013). Involving parents in paired reading with preschoolers: results from a randomized controlled trial. Contemp. Educ. Psychol. 38, 126-135. doi: 10.1016/j.cedpsych.2012.12.003

Lam, S. S. Y., and McBride-Chang, C. (2013). Parent-child joint writing in Chinese kindergartens: explicit instruction in radical knowledge and stroke writing skills. Writ. Syst. Res. 5, 88-109. doi: 10.1080/17586801.2013.812532

Lau, E. Y. H., Li, H., and Rao, N. (2012). Exploring parental involvement in early years education in China: development and validation of the Chinese early parental involvement scale (CEPIS). Int. J. Early Years Educ. 20, 405-421. doi: 10.1080/09669760.2012.743099

Lau, J. Y. -H., and McBride-Chang, C. (2005). Home literacy and Chinese reading in Hong Kong children. Early Educ. Dev. 16, 5-22. doi: 10.1207/ s15566935eed1601_1

Law, Y. K. (2008). The relationship between extrinsic motivation, home literacy, classroom instructional practices, and reading proficiency in second-grade Chinese children. Res. Educ. 80, 37-51. doi: 10.7227/RIE.80.4

Lee, G. L. (2002). The role of Korean parents in the literacy development of their children. Int. J. Early Childhood 34, 1-8. doi: 10.1007/BF03177318

Lee, H. J., and Kim, J. (2016). A structural analysis on Korean young children's mathematical ability and its related children's and mothers' variables. Early Child Dev. Care 186, 1675-1692. doi: 10.1080/03004430.2015.1122597

Leer, J., and Teodosio, M. (2016). Philippines First Read: Endline evaluation. Save the Children. Available at: https://resourcecentre.savethechildren.net/ library/philippines-first-read-endline-evaluatioin (Accessed May 1, 2020).
Leung, C. H. (2011). An experimental study of eduplay and social competence among preschool students in Hong Kong. Early Child Dev. Care 181, 535-548. doi: 10.1080/03004431003611487

LeVine, R. A., LeVine, S., Schnell-Anzola, B., Rowe, M. L., and Dexter, E. (2012). Literacy and mothering: How women's schooling changes the lives of the world's children. Oxford: Oxford University Press.

Li, J. (2012). Cultural foundations of learning: East and west. New York, NY: Cambridge University Press.

Li, L., and Tan, C. L. (2016). Home literacy environment and its influence on Singaporean children's Chinese oral and written language abilities. Early Childhood Educ. J. 44, 381-387. doi: 10.1007/s10643-015-0723-4

Li, L., Tan, C. L., and Goh, H. H. (2016). Home language shift and its implications for Chinese language teaching in Singapore. Cogent Educ. 3:1161958. doi: 10.1080/2331186X.2016.1161958

Lin, X. Y. (2013). An interview study of Chinese parents' beliefs about play and learning in younger children. Hong Kong J. Early Childhood 12, 35-43.

Lin, X., and Li, H. (2019). Chinese mothers' profile which values both play and academics predicts better developmental outcome in young children. Int. J. Behav. Dev. 43, 61-66. doi: 10.1177/0165025418767062

Lin, D., McBride-Chang, C., Aram, D., and Levin, I. (2011). Mother-child joint writing in Chinese kindergarteners: metalinguistic awareness, maternal mediation and literacy acquisition. J. Res. Read. 34, 426-442. doi: 10.1111/j. 1467-9817.2010.01446.x

Lin, Y. C., and Yawkey, T. (2013). Does play matter to parents? Taiwanese parents' perceptions of child's play. Education 134, 244-254.

Liu, C., Georgiou, G. K., and Manolitsis, G. (2018). Modeling the relationships of parents' expectations, family's SES, and home literacy environment with emergent literacy skills and word reading in Chinese. Early Child Res. Q. 43, 1-10. doi: 10.1016/j.ecresq.2017.11.001

Liu, T., Zhang, X., and Jiang, Y. (2020). Family socioeconomic status and the cognitive competence of very young children from migrant and non-migrant Chinese families: the mediating role of parenting self-efficacy and parental involvement. Early Child Res. Q. 51, 229-241. doi: 10.1016/j.ecresq.2019.12.004

Liu, Y., Zhang, X., Song, Z., and Yang, W. (2019). The unique role of fatherchild numeracy activities in number competence of very young Chinese children. Infant Child Dev. 28:e2135. doi: 10.1002/icd.2135

Luo, R., Tamis-LeMonda, C. S., and Song, L. (2013). Chinese parents' goals and practices in early childhood. Early Child Res. Q. 28, 843-857. doi: 10.1016/j.ecresq.2013.08.001

Manolitsis, G., Georgiou, G. K., and Tziraki, N. (2013). Examining the effects of home literacy and numeracy environment on early reading and math acquisition. Early Child Res. Q. 28, 692-703. doi: 10.1016/j.ecresq.2013.05.004

Mascarenhas, S. S., Moorakonda, R., Agarwal, P., Lim, S. B., Sensaki, S., Chong, Y. S., et al. (2017). Characteristics and influence of home literacy environment in early childhood-centered literacy orientation. Proc. Singapore Healthcare 26, 81-97. doi: 10.1177/2010105816674738

Mayasya, Y. (2017). International Development and Early Learning Assessment: Qualcomm project. Save the Children. Available at: https://resourcecentre savethechildren.net/library/international-development-and-early-learningassessment-qualcomm-project (Accessed May 1, 2020).

McBride-Chang, C., Lin, D., Liu, P. D., Aram, D., Cho, J.-R., Shu, H., et al. (2012). The ABC's of Chinese: maternal mediation of pinyin for Chinese children's early literacy skills. Read. Writ. 25, 283-300. doi: 10.1007/s11145-010-9270-y

Mehnaz, A. (2013). Early literacy development and school readiness: perceptions and practices of parents having 3-5 years old children in Dhaka city. unpublished master's thesis. BRAC University.

Melhuish, E. C., Phan, M. B., Sylva, K., Sammons, P., Siraj-Blatchford, I., and Taggart, B. (2008). Effects of the home learning environment and preschool center experience upon literacy and numeracy development in early primary school. J. Soc. Issues 64, 95-114. doi: 10.1111/j.1540-4560.2008.00550.x

Miller, P., and Goodnow, J. J. (1995). Cultural practices: toward an integration of culture and development. New Dir. Child Adolesc. Dev. 67, 5-16. doi: $10.1002 / \mathrm{cd} .23219956703$

Morales, I. R., Pisani, L., Sornsomrit, K., Ladlia, K., and McDermott, K. (2016). First Read Thailand baseline report. Save the Children. Available at: https:// resourcecentre.savethechildren.net/library/first-read-thailand-baseline-report (Accessed May 1, 2020).

Morrison, F. J. (2009). Parenting and academic development. Merill-Palmer Q. $55,361-372$. 
Mullis, I. V. S., Martin, M. O., Foy, P., and Hooper, M. (2016). TIMSS 2015 International Results in Mathematics. Available at: http://timssandpirls.bc. edu/timss2015/international-results/ (Accessed June 12, 2020).

Mullis, I. V. S., Martin, M. O., Foy, P., and Hooper, M. (2017). PIRLS 2016 International Results in Reading. Available at: http://timssandpirls.bc.edu/ pirls2016/international-results/ (Accessed June 12, 2020).

Nag, S., Vagh, S. B., Dulay, K. M., and Snowling, M. J. (2019). Home language, school language and children's literacy attainments: a systematic review of evidence from low-and middle-income countries. Rev. Educ. 7, 91-150. doi: 10.1002/rev3.3130

Napoli, A. R., and Purpura, D. J. (2018). The home literacy and numeracy environment in preschool: cross-domain relations of parent-child practices and child outcomes. J. Exp. Child Psychol. 166, 581-603. doi: 10.1016/j. jecp.2017.10.002

Niklas, F., and Schneider, W. (2013). Home literacy environment and the beginning of reading and spelling. Contemp. Educ. Psychol. 38, 40-50. doi: 10.1016/j.cedpsych.2012.10.001

Niklas, F., and Schneider, W. (2014). Casting the die before the die is cast: the importance of the home numeracy environment for preschool children. Eur. J. Psychol. Educ. 29, 327-345. doi: 10.1007/s10212-013-0201-6

Niklas, F., and Schneider, W. (2017). Home learning environment and development of child competencies from kindergarten until the end of elementary school. Contemp. Educ. Psychol. 49, 263-274. doi: 10.1016/j.cedpsych.2017.03.006

Okello, L., and Mahammed, D. (2019). Baseline assessment in Iraq. Save the children. Available at: https://idela-network.org/wp-content/uploads/2019/12/ Save-the-Children-Iraq_BPRM_-Baseline-Presentation.pdf (Accessed April 18, 2020).

Organisation for Economic Co-operation and Development (2020). "PISA 2018 results" in What students know and can do. Vol. 1. Paris: OECD.

Pan, Y., Yang, Q., Li, Y., Liu, L., and Liu, S. (2018). Effects of family socioeconomic status on home math activities in urban China: the role of parental beliefs. Child Youth Serv. Rev. 93, 60-68. doi: 10.1016/j.childyouth.2018.07.006

Park, H. (2008). Home literacy environments and children's reading performance: a comparative study of 25 countries. Educ. Res. Eval. 14, 489-505. doi: $10.1080 / 13803610802576734$

Park, J. H., and Kwon, Y. I. (2009). Parental goals and parenting practices of upper-middle-class Korean mothers with preschool children. J. Early Child. Res. 7, 58-75. doi: 10.1177/1476718X08098354

Pava, C. (2016). Vietnam SCHK baseline. Save the Children. Available at: https:// idela-network.org/resource/vietnam-shck-baseline/ (Accessed May 1, 2020).

Pearson, E., and Rao, N. (2003). Socialization goals, parenting practices, and peer competence in Chinese and English preschoolers. Early Child Dev. Care 173, 131-146. doi: 10.1080/0300443022000022486

Pisani, L., Dyenka, K., Sharma, P., Chhetri, N., Dang, S., Gayleg, K., et al. (2017a). Bhutan's national ECCD impact evaluation: local, national, and global perspectives. Early Child Dev. Care 187, 1511-1527. doi: 10.1080/ 03004430.2017.1302944

Pisani, L., Nath, B. K. D., and Khanom, R. (2017b). 0-3 parenting program innovations in Bangladesh: Follow up study 2015-2016. Save the Children. Available at: https://resourcecentre.savethechildren.net/library/0-3-parentingprogram-innovations-bangladesh-follow-study-2015-2016 (Accessed May 1, 2020).

Queen Rania Foundation (2017). ECD baseline evaluation from a mobile application learning program. Available at: https://idela-network.org/data_set/east-amman/ (Accessed April 18, 2020).

Rao, N., and Li, H. (2009). Quality matters: early childhood education policy in Hong Kong. Early Child Dev. Care 179, 233-245. doi: 10.1080/ 03004430601078644

Rao, N., Ng, S. S., and Pearson, E. (2010). "Preschool pedagogy: a fusion of traditional Chinese beliefs and contemporary notions of appropriate practice" in Revisiting the Chinese learner. eds. C. Chan and N. Rao (Dordrecht: Springer), 255-279.

Rao, N., Pearson, E., Cheng, K. M., and Taplin, M. (2013). Teaching in primary schools in China and India: Contexts of learning. Abingdon, UK: Routledge.

Rao, N., Richards, B., Umayahara, M., Sun, J., Bacon-Shone, J., Ip, P., et al. (2017). Myanmar East Asia-Pacific Early Child Development Scales (EAPECDS). UNICEF. Available at: https://www.unicef.org/myanmar/reports/ myanmar-east-asia-pacific-early-child-development-scales-report-eap-ecds (Accessed May 1, 2020).
Ren, L., and Hu, G. (2013a). Prolepsis, syncretism, and synergy in early language and literacy practices: a case study of family language policy in Singapore. Lang. Policy 12, 63-82. doi: 10.1007/s10993-012-9260-9

Ren, L., and Hu, G. (2013b). A comparative study of family social capital and literacy practices in Singapore. J. Early Child. Lit. 13, 98-130. doi: 10.1177/ 1468798411429934

Ren, L., Hu, B. Y., and Zhang, X. (2020). Disentangling the relations between different components of family socioeconomic status and Chinese preschoolers' school readiness. Fam. Process. doi: 10.1111/famp.12534 [Epub ahead of print]

Research Inputs and Development Action (2016a). Baseline study on International Development of Early Learning Assessment (IDELA): Kavre. Available at https://resourcecentre.savethechildren.net/library/baseline-study-internationaldevelopment-and-early-learning-assessment-idela-kavre (Accessed May 1, 2020).

Research Inputs and Development Action (2016b). Baseline study on International Development of Early Learning Assessment (IDELA): Saptari. Available at https://resourcecentre.savethechildren.net/library/baseline-study-internationaldevelopment-early-learning-assessment-idela-saptari (Accessed May 1, 2020).

Şad, S. N., and Gürbüztürk, O. (2013). Primary school Students' Parents' level of involvement into their Children's education. Educ. Sci. Theory and Practice 13, 1006-1011.

Save the Children (2017). Child development through ELM preschool programming in Lebanon. Available at: https://idela-network.org/data-set/child-developmentthrough-elm-preschool-programming-lebanon/ (Accessed April 18, 2020).

Scharf, M. (2014). "Parenting in Israel: together hand in hand, you are mine and I am yours" in Parenting across cultures: Childrearing, motherhood and fatherhood in non-Western cultures. ed. H. Selin (Dordrecht: Springer), 193-206.

Sen, R., and Blatchford, P. (2001). Reading in a second language: factors associated with progress in young children. Educ. Psychol. 21, 189-202. doi: 10.1080/01443410020043887

Sénéchal, M., Lefevre, J. A., Thomas, E. M., and Daley, K. E. (1998). Differential effects of home literacy experiences on the development of oral and written language. Read. Res. Q. 33, 96-116. doi: 10.1598/RRQ.33.1.5

Shah-Wundenberg, M., Wyse, D., and Chaplain, R. (2013). Parents helping their children learn to read: the effectiveness of paired reading and hearing reading in a developing country context. J. Early Child. Lit. 13, 471-500. doi: $10.1177 / 1468798412438067$

Shiakou, M., and Belsky, J. (2013). Exploring parent attitudes toward children's play and learning in Cyprus. J. Res. Child. Educ. 27, 17-30. doi: 10.1080/02568543.2012.739592

Shrestha, M., Ulak, M., Strand, T. A., Kvestad, I., and Hysing, M. (2017). How much do Nepalese mothers know about child development? Early Child Dev. Care 189, 135-142. doi: 10.1080/03004430.2017.1304391

Shu, H., Li, W., Anderson, R., Ku, Y. -M., and Yue, X. (2002). "The role of home-literacy environment in learning to read Chinese" in Chinese children's reading acquisition: Theoretical and pedagogicalissues. eds. W. Li, J. S. Gaffney, and J. L. Packard (London: Kluwer Academic Publishers), 207-224.

Simina, V. K. (2013). "Socio-constructivist models of learning, in encyclopedia of the sciences of learning" in Encyclopedia of the sciences of learning. ed. N. M. Seel (US, Boston, MA: Springer), 3128-3131.

Skwarchuk, S. L., Sowinski, C., and LeFevre, J. A. (2014). Formal and informal home learning activities in relation to children's early numeracy and literacy skills: the development of a home numeracy model. J. Exp. Child Psychol. 121, 63-84. doi: 10.1016/j.jecp.2013.11.006

Spier, E., Srinivasan, V., Kamto, K., Rahman, A., Hossain, N., Nahar, Z., et al. (2018). Bangladesh Early Years Preschool Program impact evaluation: Baseline report for the World Bank Strategic Impact Evaluation Fund. American Institutes for Research. Available at: http://pubdocs.worldbank.org/en/311791528140704115/ Bangladesh-ECD-baseline.pdf (Accessed May 1, 2020).

Street, B. (1993). "Introduction: the new literacy studies" in Cross-cultural approaches to literacy. ed. B. Street (New York: Cambridge University Press), $1-22$.

Su, Y., Lau, C., and Rao, N. (2020). Early educational policy and preschool attendance in China: findings from the China family panel studies. Early Child Res. Q. 53, 11-22. doi: 10.1016/j.ecresq.2020.02.001

Sun, H. (2019). Home environment, bilingual preschooler's receptive mother tongue language outcomes, and social-emotional and behavioral skills: one stone for two birds? Front. Psychol. 10:1640. doi: 10.3389/fpsyg.2019.01640 
Sun, J., Lau, C., Sincovich, A., and Rao, N. (2018a). Socioceconomic status and early childhood development in East Asia and the Pacific: the protective role of parental engagement in learning activities. Child Youth Serv. Rev. 93, 321-330. doi: 10.1016/j.childyouth.2018.08.010

Sun, H., Yin, B., Amsah, N. F. B. B., and O’Brien, B. A. (2018b). Differential effects of internal and external factors in early bilingual vocabulary learning: the case of Singapore. Appl. Psycholinguist. 39, 383-411. doi: 10.1017/ S014271641700039X

Tatel-Suatengco, R., and Florida, J. S. (2018). Family literacy in a low-income urban community in the Philippines. J. Early Child. Lit. 20, 327-355. doi: $10.1177 / 1468798418766604$

Tekin, A. K. (2015). Early EFL education is on the rise in Oman: a qualitative inquiry of parental beliefs about early EFL learning. Engl. Lang. Teach. 8, 35-43. doi: 10.5539/elt.v8n2p35

Tibi, S., Joshi, R. M., and McLeod, L. (2013). Emergent writing of young children in the United Arab Emirates. Writ. Lang. Literacy 16, 77-105. doi: 10.1075/wll.16.1.04tib

Tzuriel, D., and Mandel, R. (2020). Parent-child math discourse and children's math thinking in early childhood. J. Cogn. Educ. Psychol. 19, 3-19. doi: 10.1891/JCEP-D-18-00015

United Nations (2019). World Statistics Pocketbook 2019 edition. Available at: https://unstats.un.org/unsd/publications/pocketbook/files/world-statspocketbook-2019.pdf (Accessed June 30, 2020).

United Nations (2020). Standard country or area codes for statistical use. Available at: https://unstats.un.org/unsd/methodology/m49/ (Accessed June 30, 2020).

Vagh, S. B. (2009). Learning at home and at school: a longitudinal study of Hindi language and emergent literacy skills of young children from lowincome families in India. unpublished doctoral dissertation. Harvard University.

Vongxaiya, S. (2019). Families' perceptions and involvement in school readiness in Lao PDR. unpublished master's thesis. Seoul National University.

Vygotsky, L. S. (1978). Mind in society: The development of higher psychological processes. Cambridge, MA: Harvard University Press.

Wang, D. (2018). "Chinese as a second language education in Asian schools" in Routledge international handbook of schools and schooling in Asia. eds. K. J. Kennedy and J. C. K. Lee (Georgetown: Routledge), 502-509.

Wang, S., and Tamis-Lemonda, C. S. (2003). Do child-rearing values in Taiwan and the United States reflect cultural values of collectivism and individualism? J. Cross-Cult. Psychol. 34, 629-642. doi: 10.1177/0022022103255498

Watanabe, N. (2019). Effective simple mathematics play at home in early childhood: promoting both non-cognitive and cognitive skills in early childhood. Int. Elect. J. Math. Educ. 14, 401-417. doi: 10.29333/iejme/5739

Weatherholt, T., Cummiskey, C., Husary, D., and DeStefano, J. (2018). Baseline report on USAID West Bank early grade reading baseline report. Available at: https://ierc-publicfiles.s3.amazonaws.com/public/resources/USAID\%20West $\% 20$ Bank\%20Early\%20Grade\%20Reading\%20Baseline\%20report\%20FINAL\%20 from\%20DEC\%202018.pdf (Accessed April 18, 2020).

Whitsel, C. M., and Lapham, K. (2014). Increasing program effectiveness through parent empowerment: the getting ready for school project in Tajikistan. Int. J. Early Years Educ. 22, 105-116. doi: 10.1080/09669760.2013.809658

Wickramasekara, P., Navaratnam, S., and Guajardo, J. (2014). Literacy Boost: Gampaha District Sri Lanka Country Office endline report - December 2014. Save the Children. Available at: https://resourcecentre.savethechildren.net/ library/literacy-boost-gampaha-district-sri-lanka-country-office-endline-reportdecember-2014 (Accessed May 1, 2020).
Wolff, L., and Breit, E. (2012). Education in Israel: The challenges ahead. Research Paper 8. The Gildenhorn Institute for Israel Studies (GIIS); University of Maryland.

World Bank (2019). World Bank Open Data. The World Bank. Available at: https://data.worldbank.org/ (Accessed June 12, 2020).

Wu, X., Li, W., and Anderson, R. C. (1999). Reading instruction in China. J. Curric. Stud. 31, 571-586. doi: 10.1080/002202799183016

Xiao, N., Che, Y., Zhang, X., Song, Z., Zhang, Y., and Yin, S. (2020). Fatherchild literacy teaching activities as a unique predictor of Chinese preschool children's word reading skills. Infant Child Dev. 29:e2183. doi: 10.1002/icd.2183

Yamamoto, Y. (2015). Social class and Japanese mothers' support of young children's education: a qualitative study. J. Early Child. Res. 13, 165-180. doi: $10.1177 / 1476718 X 13482303$

Yamamoto, Y. (2016). Gender and social class differences in Japanese mothers' beliefs about children's education and socialisation. Gend. Educ. 28, 72-88.

Yamamoto, Y., and Brinton, M. C. (2010). Cultural capital in east Asian educational systems: the case of Japan. Sociol. Educ. 83, 67-83.

Yamamoto, Y., Holloway, S. D., and Suzuki, S. (2006). Maternal involvement in preschool children's education in Japan: relation to parenting beliefs and socioeconomic status. Early Child Res. Q. 21, 332-346. doi: 10.1016/j. ecresq.2006.07.008

Yamamoto, Y., Holloway, S. D., and Suzuki, S. (2016). Parental engagement in children's education: motivating factors in Japan and the US. Sch. Community J. 26, 45-66.

Yampratoom, R., Aroonyadech, N., Ruangdaraganon, N., Roongpraiwan, R., and Kositprapa, J. (2017). Emergent literacy in thai preschoolers: a preliminary study. Behav. Pediatr. 38, 395-400. doi: 10.1097/DBP.0000000000000457

Yeo, L. S., Ong, W. W., and Ng, C. M. (2014). The home literacy environment and preschool children's reading skills and interest. Early Educ. Dev. 25, 791-814. doi: 10.1080/10409289.2014.862147

Yeung, S. S., and King, R. B. (2016). Home literacy environment and English language and literacy skills among Chinese young children who learn English as a second language. Read. Psychol. 37, 92-120. doi: 10.1080/ 02702711.2015.1009591

Zainiddinov, H., and Habibov, N. (2019). Factors shaping mother-child interaction in post-soviet countries of Eastern Europe and Central Asia. Early Child Dev. Care 190, 1-12. doi: 10.1080/03004430.2019.1572133

Zhang, X., Hu, B. Y., Zou, X., and Ren, L. (2020). Parent-child number application activities predict children's math trajectories from preschool to primary school. J. Educ. Psychol. 112, 1521-1531. doi: 10.1037/edu0000457

Zhang, S. Z., Inoue, T., Shu, H., and Georgiou, G. K. (2019). How does home literacy environment influence reading comprehension in Chinese? Evidence from a 3-year longitudinal study. Read. Writ. 33, 1745-1767. doi: 10.1007/ s11145-019-09991-2

Conflict of Interest: The authors declare that the research was conducted in the absence of any commercial or financial relationships that could be construed as a potential conflict of interest.

Copyright (C) 2021 Cheung, Dulay, Yang, Mohseni and McBride. This is an open-access article distributed under the terms of the Creative Commons Attribution License (CC BY). The use, distribution or reproduction in other forums is permitted, provided the original author(s) and the copyright owner(s) are credited and that the original publication in this journal is cited, in accordance with accepted academic practice. No use, distribution or reproduction is permitted which does not comply with these terms. 


\title{
Home Learning Environments of Children in Mexico in Relation to Socioeconomic Status
}

\author{
María Inés Susperreguy ${ }^{1}$, Carolina Jiménez Lira ${ }^{2 *}$, Chang $X u^{3}$, Jo-Anne LeFevre ${ }^{3,4}$, \\ Humberto Blanco Vega ${ }^{2}$, Elia Verónica Benavides Pando ${ }^{2}$ and \\ Martha Ornelas Contreras ${ }^{2}$
}

${ }^{1}$ Faculty of Education, Pontificia Universidad Católica de Chile, Santiago, Chile, ${ }^{2}$ Faculty of Physical Culture Sciences, Universidad Autónoma de Chihuahua, Chihuahua, Mexico, ${ }^{3}$ Department of Psychology, Carleton University, Ottawa, ON, Canada, ${ }^{4}$ Department of Cognitive Science, Carleton University, Ottawa, ON, Canada

We explored the home learning environments of 173 Mexican preschool children (aged 3-6 years) in relation to their numeracy performance. Parents indicated the frequency of their formal home numeracy and literacy activities, and their academic expectations for children's numeracy and literacy performance. Children completed measures of early

OPEN ACCESS

Edited by:

Frank Niklas,

Ludwig Maximilian University of Munich, Germany

Reviewed by: Simone Lehrl, University of Bamberg, Germany Boris Mayer,

University of Bern, Switzerland

${ }^{*}$ Correspondence:

Carolina Jiménez Lira cajimenez@uach.mx

Specialty section:

This article was submitted to Educational Psychology, a section of the journal Frontiers in Psychology

Received: 05 November 2020 Accepted: 22 February 2021 Published: 19 March 2021

Citation:

Susperreguy MI, Jiménez Lira $C$, Xu C, LeFevre J-A, Blanco Vega $\mathrm{H}$, Benavides Pando EV and Ornelas Contreras M (2021) Home Learning Environments of Children in Mexico in Relation

to Socioeconomic Status.

Front. Psychol. 12:626159. doi: 10.3389/fpsyg.2021.626159 numeracy skills. Mexican parent-child dyads from families with either high- or lowsocioeconomic status (SES) participated. Low-SES parents $(n=99)$ reported higher numeracy expectations than high-SES parents $(n=74)$, but similar frequency of home numeracy activities. In contrast, high-SES parents reported higher frequency of literacy activities. Path analyses showed that operational (i.e., advanced) numeracy activities were positively related to children's numeracy skills in the high- but not in the low-SES group. These findings improve the understanding of the role of the home environment in different contexts and provide some insights into the sources of the variable patterns of relations between home learning activities and children's numeracy outcomes. They also suggest that SES is a critical factor to consider in research on children's home numeracy experiences.

\footnotetext{
Keywords: early numeracy, home learning, home numeracy, children, numeracy activities, literacy activities, Mexico, socioeconomic status
}

\section{INTRODUCTION}

Children's early numeracy skills are strongly related to the development of their mathematical knowledge in the first few years of schooling (e.g., Jordan et al., 2009; Aunio and Niemivirta, 2010; LeFevre et al., 2010a; Martin et al., 2014). Because these individual differences in early numeracy knowledge precede children's school entry (Duncan et al., 2007), researchers have identified the home learning environment as a potential source of some of this variability (Blevins-Knabe and Musun-Miller, 1996; LeFevre et al., 2009; Skwarchuk et al., 2014; Soto-Calvo et al., 2020a,b). Consistent with the view that home numeracy experiences are related to children's numeracy preparation, parents' reports of home numeracy activities are correlated with children's early numeracy performance in many countries, including Canada (LeFevre et al., 2009; Skwarchuk et al., 2014), the United States (Blevins-Knabe and Musun-Miller, 1996; Huntsinger et al., 2016), Netherlands (Kleemans et al., 2012, 2013; Segers et al., 2015), Germany (Anders et al., 2012; 
Niklas and Schneider, 2014), Greece (LeFevre et al., 2010b; Manolitsis et al., 2013), and China (Pan et al., 2006; Huang et al., 2017). Early numeracy skills have also been found to be related to parental reports of literacy activities in the United Kingdom (Soto-Calvo et al., 2020a,b), the United States (Napoli and Purpura, 2018), and Germany (Anders et al., 2012). Thus, research suggests that the home numeracy and literacy experiences of children in North American, European, and Asian nations are related to the development of their early numeracy skills.

In Latin America, researchers have also identified the home numeracy environment as a correlate of children's early numeracy skills (Becerra Orellana, 2016; del Río et al., 2017; de León et al., 2020; Susperreguy et al., 2020a,b). However, although they show that the parental reports of home numeracy activities predict children's numeracy outcomes, the connections are weaker (Susperreguy et al., 2020b) than those reported in prior research (Skwarchuk et al., 2014). A model of home learning environment simultaneously including both literacy and numeracy to predict children's numeracy outcomes has not been tested in Latin American countries.

The present research examines these relations in Mexico. The Mexican economy is one of the most inequitable among Latin American countries (Reyes et al., 2017), with $44 \%$ of the population living in poverty (Varela Llamas and Ocegueda Hernández, 2020). Mexico is ranked as number 74 in the Human Development Index (HDI) ranking, which is a measure of the development of a country that considers three dimensions life expectancy, education (i.e., expected years of schooling and mean years of schooling), and gross national income per capita (United Nations Development Programme, 2020). With regards to education, Mexicans attain a mean of 8.8 years of schooling, which corresponds to some secondary education. These socioeconomic status (SES) inequalities may be linked to differences in children's home learning environments, for example, parental educational backgrounds and access to educational resources, which might affect parental academic expectations and home activities (Davis-Kean et al., 2020). Thus, SES may be an important factor in the home learning experiences of Mexican children.

The goals of the present research are (a) to examine the home learning environment of children in Mexico, a Latin American country that has received little attention in this literature, and (b) to explore whether there are differences between low- and highSES Mexican samples in the relations between the home learning environments and children's numeracy outcomes.

\section{Contextual Factors in Early Numeracy Skills}

According to the socio-cultural theory, children develop skills from their social and cultural contexts (Vygotsky, 1978; Rogoff, 2003). These contexts involve not only broader social institutions, such as schools, but also the formal and informal practices carried out by the primary caregivers in their day-to-day interactions with their children (Rogoff, 1990). For example, with respect to children's learning, some research indicates that Latino parents engage in relatively few academic activities with their children given that they tend to rely on the school system to teach their preschool children the relevant academic concepts and skills (Goldenberg, 2001). Furthermore, when Latino parents do engage their children in academic activities, these are consistent or complementary with the teacher's recommendations and assigned homework (Gonzalez et al., 2019; Sonnenschein and Dowling, 2019). In addition, Latin American families show some differences regarding access to resources, home learning experiences, and academic expectations, compared to parents from other countries (Strasser et al., 2016). Thus, early numeracy skills develop from an early age within the home learning environment, where parents provide a wide range of opportunities depending on their cultural context.

\section{The Home Numeracy Model}

The influence of the learning environment on early numeracy skills has been explained by the Home Numeracy Model proposed by Skwarchuk et al. (2014). This model shows that parental academic expectations are linked to the frequency of engaging in home learning activities, which in turn predict children's numeracy skills. Thus, parents who report higher expectations about their children's achievement of academic benchmarks also engage in home learning activities with their children more frequently (Kleemans et al., 2012; Segers et al., 2015).

In addition to parental academic expectations, the home learning environment includes literacy and numeracy activities (i.e., home learning activities). These typically have been assessed with parental reports of how frequently they engage with their children in distinct types of activities that promote learning (e.g., Skwarchuk et al., 2014; Mutaf-Yıldız et al., 2018; Susperreguy et al., 2020b). These activities have been classified according to the nature and focus of the interactions. For literacy, activities that involve attention to print are referred to as code-based activities, whereas those in which the focus is on the meaning of the print are referred to as meaningrelated activities (Sénéchal et al., 2017). For numeracy, activities have been classified as either mapping activities (i.e., basic numerical activities that link different number representations, such as naming or writing numbers), or operational activities (i.e., more complex number activities that involve manipulation of symbolic quantities; Susperreguy et al., 2020b). Of these learning activities, operational numeracy activities are related to children's mathematics performance, as found by several studies (Mutaf-Yildiz et al., 2020).

Home numeracy and literacy activities are differentially related to children's mathematics performance (Skwarchuk et al., 2014; Soto-Calvo et al., 2020a,b). For example, in a sample of families from the United Kingdom, Soto-Calvo et al. (2020a) found that parents' reports of the frequency of mapping numeracy activities and code-based literacy activities were correlated with preschool children's symbolic numeracy skills (i.e., counting, number transcoding, and calculation). However, only code-based literacy activities (not meaningrelated activities) predicted unique variance in children's 
symbolic numeracy skills. Soto-Calvo et al. (2020a) did not ask parents about more advanced numeracy activities (i.e., operational activities such as practicing calculations). In most other research on home numeracy activities, only operational activities (i.e., more advanced), were related to numeracy performance (Skwarchuk et al., 2014; del Río et al., 2017; Susperreguy et al., 2020a). For Chilean children (Susperreguy et al., 2020a), only operational activities predicted mathematical performance. Code-based activities did not predict unique variance in children's numeracy outcomes. Thus, although both numeracy and code-based literacy activities may be correlated with children's mathematical skills, the pattern of unique variance may depend on whether parents' reports are collected about advanced early numeracy activities.

The Home Numeracy Model has been tested with some Latin American parents. Researchers have found that this model extends to Chilean children (Susperreguy et al., 2020b). However, to our knowledge this model has not been tested in Mexico. In addition, although Susperreguy et al. (2020b) controlled for SES in their Chilean sample, they did not directly assess whether there were any differential relations between home learning environments and children's numeracy skills by SES. It is important to examine these relations in different SES groups given the large social disparities that exist in Mexico. These disparities may translate into different access to resources, distinct degrees of cognitive stimulation in children's learning environments, and unequal provision of opportunities for children's numeracy learning (Davis-Kean et al., 2020). Consequently, academic expectations and home learning activities may vary by SES, and thus the relation of home learning activities to children's numeracy outcomes may also differ.

\section{Home Learning Environments of Latino Families}

\section{Academic Expectations and Home Activities}

Parental academic expectations have been studied with Mexican immigrant families to the United States. Some studies showed that parents whose children had not started formal schooling did not expect them to understand early literacy concepts, and thus home activities (e.g., teaching letter or words) were not considered useful (Reese and Gallimore, 2000). In more recent studies including Mexican immigrants, parents saw themselves as having an important role in their children's math learning and reported that they engaged in home numeracy activities (Sonnenschein et al., 2016; Galindo et al., 2019). These findings are consistent with a study conducted by Gonzalez et al. (2019) with native Mexican parents. Gonzalez et al. (2019) found that parents viewed themselves as contributors to their children's early literacy skills. Thus, the evidence regarding Latino parents' views of the role of home versus school experiences is mixed (Goldenberg et al., 2001; Gonzalez et al., 2019). Adding to the differential findings, in these studies expectations have been assessed in terms of educational aspirations and other beliefs that parents have in terms of child development and home learning, and not about specific benchmarks to be achieved during elementary school (c.f., Susperreguy et al., 2020b). The Home Numeracy Model includes particular numeracy and literacy milestones as its measure of academic expectations. Thus, it is important to explore academic expectations in parents from Mexico to better understand those home learning environments.

As predicted by the Home Numeracy Model, research has found that parental academic expectations are related to home learning activities (Skwarchuk et al., 2014; Segers et al., 2015; Kleemans et al., 2018; Susperreguy et al., 2020b). In two Chilean studies in which parents reported on the importance of numeracy benchmarks and frequency of home numeracy activities (del Río et al., 2017; Susperreguy et al., 2020b), parents' numeracy expectations were related to their reported home numeracy activities, consistent with prior research (Skwarchuk et al., 2014).

Research with Latino immigrant parents in North America (Jung et al., 2012) and Latino parents living in Latin America (Susperreguy et al., 2007; Strasser and Lissi, 2009) showed that these parents engaged in fewer literacy activities than non-Latino North American parents. For example, half of the parents of Chilean kindergarten children did not read children's books to them (Susperreguy et al., 2007). Access to books, educational resources, and materials is limited because of the high cost of books and the lack of public libraries, factors that may influence home literacy experiences for Latin American children (Strasser et al., 2017). Additionally, although immigrant Latina mothers living in the United States stressed the importance of math, they did not have a systematic plan of action for promoting their children's skills (i.e., did not provide relevant home experiences), compared to Chinese immigrant mothers (Sonnenschein et al., 2018). Similarly, immigrant mothers from Mexico predominantly taught math concepts at a basic level whereas Chinese mothers were more likely to teach these concepts at an advanced level (Tamis-LeMonda et al., 2013). In sum, the home environments provided by Latino parents may be different than those provided by other parents in North American contexts.

\section{Home Learning Activities and Children's Numeracy Outcomes in Latin America}

Researchers studying children's home experiences in Latin America have focused on the relations between numeracy outcomes and numeracy experiences rather than on the relations between numeracy outcomes and literacy activities, as in SotoCalvo et al. (2020a). In terms of home numeracy environments, del Río et al. (2017) compared reports of home numeracy activities of fathers and mothers, and correlations of those reports with the problem-solving skills of 180 Chilean kindergarteners. They found that the frequency of the numeracy activities reported by mothers was related to their children's performance on a numeracy test. Similar links between numeracy activities and children's numeracy outcomes were reported by Becerra Orellana (2016) for Ecuadorian children, by de León et al. (2020) for Uruguayan children, and by Susperreguy et al. (2020b) for a different sample of Chilean children. Moreover, Leyva (2019) found that Chilean parents provided moderate levels of math support to their Chilean children in a grocery game and that the degree of support predicted children's gains in a problem-solving task. These studies suggest that similar relations exist between parents' reports of home numeracy activities and their children's performance as in North American and European studies. 
Although most of the studies in Latin America have focused on the relations, within a single domain (i.e., literacy or numeracy), between home activities and children's outcomes, few studies have assessed cross-domain relations between numeracy and literacy activities and children's numeracy outcomes (e.g., Susperreguy et al., 2020b). Contrary to the results for children in the United Kingdom reported by Soto-Calvo et al. (2020a,b), Susperreguy et al. (2020b) found that only numeracy, not literacy, activities predicted Chilean children's numeracy outcomes. Notably, Susperreguy et al. (2020b) assessed complex home numeracy activities (i.e., operational activities), whereas SotoCalvo et al. (2020a,b) only assessed basic numeracy activities. In Susperreguy et al. (2020b), only operational activities predicted children's skills (see also Skwarchuk et al., 2014). Thus, we did not expect to find cross-domain relations between literacy activities and children's numeracy in Latin American contexts.

\section{Home Learning Activities and Numeracy Outcomes of Latino Children in the United States}

Research conducted with Latino families living abroad (mainly in the United States) suggests more variable relations between parents' reports of home activities and children's early skills for Latino families. Although Sonnenschein et al. (2016) found a significant relation between math activities and performance in a sample comprising low-income Latino-American immigrant and African-American families, in other studies that included Hispanic families, parents' reports of math activities were not related to their children's early numeracy skills (DeFlorio and Beliakoff, 2015; Missall et al., 2015; Leyva et al., 2017). Notably, those three studies assessed home numeracy experiences using different measures than the studies that have found positive links. Thus, the differential findings may not be related to the inclusion of Hispanic families in these studies but to the ways in which home numeracy experiences were assessed. In summary, there is a need for better understanding of the links between children's home experiences and their early numeracy performance in families with roots in Latin American countries.

\section{Socioeconomic Status and Home Learning Environment}

Socioeconomic status is related to many aspects of children's academic and social development (Elliott and Bachman, 2018; Davis-Kean et al., 2020). SES is usually operationalized as parents' educational attainment or as family income (DavisKean et al., 2020). Researchers interested in the home math environment have most often controlled statistically for SES (Hart et al., 2016; Mutaf-Yildiz et al., 2020). Other researchers have explored the home mathematics environment for low-SES families more directly (Jordan and Levine, 2009; Ramani et al., 2015). Results of these studies suggested that low-SES parents in the United States provided fewer opportunities for children to engage in complex math-related activities than high-SES parents, had fewer resources such as books or games (Starkey and Klein, 2008), and engaged in less math-related talk (Ramani et al., 2015). These studies support the view that SES is an important variable to consider in research on the home mathematics environment.
In Latin American countries, access to educational resources is unequal and parents are less likely to engage in activities that are common in other countries with access to more resources, such as shared book reading (see Strasser et al., 2016, for a review). Such factors may contribute to different patterns of parental activities in Latin American countries. In Mexico, given the vast inequities in SES, it is important to examine whether the patterns of relations between the home learning activities and children's numeracy outcomes vary by SES. Thus, simply controlling for SES may not be sufficient for understanding the variability of home environments in Mexican families.

Findings with respect to parental academic expectations and SES are mixed. For example, DeFlorio and Beliakoff (2015) concluded that low-SES American parents have a less accurate understanding of the development of early academic capabilities in relation to their 3- and 4-year-old children's skills than do parents from middle-SES backgrounds. In particular, lowSES parents underestimated the importance of mathematical benchmarks that were within children's expected abilities according to their developmental stage and overestimated the importance of solving arithmetic problems which were beyond what would be expected. However, low-SES parents of 5- and 6-year-old children in Belgium reported significantly higher academic expectations than did high-SES parents (De Keyser et al., 2020). Similarly, for Chilean 4-year-old children, less-educated parents had higher academic expectations for their children than more-educated parents (Susperreguy et al., 2020b). However, Susperreguy et al. (2020b) did not compare parental academic expectations in different SES groups. The inconclusive findings on the relation between parental academic expectations and SES highlight the need to further explore academic expectations in other contexts with large SES disparities and compare the home learning environments in different SES groups.

\section{Current Study}

Accordingly, the current study extends research on home learning environments and numeracy outcomes to Mexican families. We used a Home Learning Environment survey tested on Chilean families (Susperreguy et al., 2020b) to explore the home environments of children from low- versus high-SES communities in Mexico. We then assessed whether the patterns of relations between parents' reports of learning activities at home and children's numeracy performance varied by SES.

For our first hypothesis, we expected that low-SES parents would report higher academic expectations than high-SES parents (Hypothesis 1). This was based on the findings that lowSES parents have less accurate expectations for their children (DeFlorio and Beliakoff, 2015), and the negative association between SES and expectations in a Latin American study (Susperreguy et al., 2020b) using the same questionnaire as in the present study. Second, we expected that low-SES parents would report fewer activities (Starkey and Klein, 2008) than highSES parents (Hypothesis 2). Third, we hypothesized that parents' academic expectations would be associated with the frequency of engaging in home learning activities (Skwarchuk et al., 2014) in both SES groups (Hypothesis 3). Fourth, based on prior 
research (Skwarchuk et al., 2014; Susperreguy et al., 2020b) we hypothesized that parent's reports of operational, but not mapping, home numeracy activities would be linked to children's numeracy performance in both SES groups (Hypothesis 4). Fifth, we hypothesized that when numeracy activities were included in the model, neither code-based nor meaning-related (Susperreguy et al., 2020b) literacy activities would predict children's numeracy outcomes in either SES groups (Hypothesis 5). Finally, given the expected SES differences in parental reports of home activities and academic expectations, we hypothesized that the strength of the associations between home learning activities and children's numeracy outcomes would be stronger for the high-SES group than for the low-SES group (Hypothesis 6).

\section{MATERIALS AND METHODS}

\section{Participants}

One hundred and seventy-three children and one of their parents participated in the study. Ninety-nine children (43 girls) were recruited from two public schools in very low-SES neighborhoods in a southern community of the State of Chihuahua (see Table 1 for descriptive information), whereas 74 children (34 girls) were recruited from four private schools in the city of Chihuahua. Mean age for high-SES children was 4 years and 8 months ( $S D=11.06$ months; range $=35-76$ months), and mean age for low-SES children was 4 years and 9 months $(S D=9.52$ months; range $=36-72$ months). All children were monolingual Spanish speakers. Mothers' education differed by SES. Eighteen mothers in the high-SES group, and four in the low-SES group did not respond to this question; however, the other 56 high-SES mothers were significantly more highly educated than their low-SES counterparts. The educational attainment of mothers from highSES backgrounds ranged from "graduated from technical/applied college" to "have a postgraduate degree," with a median of "graduated from university." Low-SES mothers' educational levels ranged from "less than high school" to "graduation from university," with a median of "less than high school." Mother's education was higher for the high-SES group than for the low-SES group, $\chi^{2}(4, N=151)=110.06, p<0.001$.

\section{Materials}

\section{Parent Questionnaire}

We used the same items as Skwarchuk et al. (2014) to assess parents' academic expectations for children entering Grade 1 (see Supplementary Table A1 in Appendix A) and the frequency with which they engaged their children in home numeracy and literacy activities (see Supplementary Table A2 in Appendix A). The Spanish version of this questionnaire has been used and tested in other Latin American samples (see Jiménez Lira, 2016; Susperreguy et al., 2020b). Similar questions have been employed with parents in a range of countries, including the United States (Zippert and Ramani, 2017), Canada (LeFevre et al., 2009), Greece (LeFevre et al., 2010b), Germany (Anders et al., 2012), and China (Huang et al., 2017), supporting the use of these questions in a range of countries.

For numeracy, the questionnaire asked about mapping activities and operational activities. Mapping activities included five items describing activities in which children were encouraged to learn or practice number symbols (verbal or visual; Susperreguy et al., 2020b): singing number songs, recognizing digits, asking about quantities, reciting numbers, and indicating quantities with fingers. Operational activities included five items describing more complex tasks that involve manipulating numbers and/or quantities (Susperreguy et al., 2020b): doing mental math; weighing, measuring, or comparing quantities; learning simple sums; playing games involving counting, adding, or subtracting; and talking about time with clocks and calendars. For literacy, six items were code-based activities (i.e., activities that involve attention to print) and five were meaning-related items (i.e., the meaning of the print is the focus of the interaction) (Sénéchal et al., 2017). However, one of the meaning-related items (i.e., visiting the library for children's books) showed a very low frequency (see Supplementary Table A2 in Appendix A) and thus only the other four items were considered in further analyses.

TABLE 1 | Descriptive statistics for low-SES and high-SES groups.

\begin{tabular}{|c|c|c|c|c|c|c|c|c|c|c|}
\hline & \multicolumn{3}{|c|}{ Low-SES } & \multicolumn{3}{|c|}{ High-SES } & \multicolumn{4}{|c|}{ Independent $t$-test } \\
\hline & $M$ & $S D$ & $N$ & $M(S D)$ & $S D$ & $N$ & $t$ & $d f$ & $\mathrm{Cls}$ & Cohen's $d$ \\
\hline Age (in months) & 56.75 & 9.52 & 99 & 55.56 & 11.06 & 73 & 0.75 & 170 & {$[-1.92,4.29]$} & 0.12 \\
\hline Numeracy expectations & 0.27 & 0.91 & 87 & -0.33 & 0.92 & 70 & $4.11^{\star \star \star}$ & 155 & {$[0.31,0.89]$} & 0.66 \\
\hline Literacy expectations & -0.03 & 0.88 & 87 & 0.03 & 1.08 & 70 & -0.37 & 155 & {$[-0.37,0.25]$} & 0.07 \\
\hline Mapping activities ${ }^{a}$ & -0.07 & 1.00 & 92 & 0.08 & 0.84 & 71 & -1.02 & 159.83 & {$[-0.44,0.14]$} & 0.16 \\
\hline Operational activities & 0.00 & 0.95 & 92 & 0.00 & 0.90 & 71 & -0.06 & 161 & {$[-0.30,0.28]$} & 0.00 \\
\hline Code-based activities & -0.15 & 0.98 & 91 & 0.19 & 0.90 & 71 & $-2.31^{\star}$ & 160 & {$[-0.64,-0.05]$} & 0.36 \\
\hline Meaning-related activities & -0.22 & 0.95 & 91 & 0.29 & 0.82 & 71 & $-3.61^{\star \star \star}$ & 160 & {$[-0.79,-0.23]$} & 0.57 \\
\hline Number comparison & 13.69 & 5.08 & 87 & 14.41 & 4.92 & 70 & -0.90 & 155 & {$[-2.31,0.86]$} & 0.14 \\
\hline Cardinality & 3.99 & 2.23 & 96 & 4.65 & 2.10 & 72 & -1.96 & 166 & {$[-1.33,0.01]$} & 0.30 \\
\hline Verbal counting ${ }^{a}$ & 15.84 & 11.66 & 96 & 20.76 & 18.21 & 72 & $-2.01^{\star}$ & 113.36 & {$[-9.78,-0.06]$} & 0.32 \\
\hline
\end{tabular}

adjusted df was used to correct for unequal variance.

Descriptive statistics for academic expectations and home learning activities are factor scores.

${ }^{*} p<0.05$ and ${ }^{* * *} p<0.001$. 


\section{Numeracy Measures}

The data for this study are part of a larger ongoing research project in which children complete motor skill assessments, literacy, and numeracy measures. We assessed numeracy skills by using three tasks that capture different aspects of early number knowledge: verbal counting, cardinality, and verbal number comparison.

\section{Verbal counting}

Children were asked to count as high as possible. Their highest verbal count without any errors was used as the measure of performance. The reported test-retest reliability for this measure with 3- and 4-year-old Canadian children in prior research was $r=0.580$ (Dunbar et al., 2017).

\section{Cardinality}

Children completed a Give- $\mathrm{N}$ task, where they were asked to give a puppet a set of 1 to 6 foam cubes. First, the child was asked to provide 1 cube. If the child succeeded, he or she was asked for 2; if the child failed to correctly provide 2 cubes, the experimenter again asked for 1; if the child was successful, the experimenter asked for 2 cubes again; and if the child succeeded, the experimenter would ask for the next number (i.e., 3). The task continued until the child had at least two successes at a given number or the child reached the highest number assessed (i.e., 6) (Sarnecka and Carey, 2008). The score was the highest set size with two correct trials. Cronbach's $\alpha$ for the pass/fail score of each number 1-6 for low- and high-SES were 0.911 and 0.932 , respectively.

\section{Verbal number comparison}

The purpose of this task was to assess children's ability to mentally compare two number words and determine which represented the greater quantity. Children completed a total of 20 trials in which they were told that the puppets Dolly the sheep and Belle the cow had gone shopping for fruits and vegetables. Children were told the amount of food each one had bought (e.g., "Dolly bought five apples and Belle bought eight apples"), without showing any visual stimuli, and the experimenter would then ask the child to point to the puppet that had bought more fruit (e.g., "Who bought more apples?"). All the numbers from 1 to 9 were assessed. No feedback was provided as to the correctness of the answer, but children were verbally encouraged at all times. The score on this task was the total number of correct responses. Cronbach's $\alpha$ for the twenty items for the low- and high-SES were 0.925 and 0.890 , respectively.

\section{Procedure}

Parents were recruited from schools, serving either low-SES (public) or high-SES (private) communities. The public schools were classified as low-SES according to the information obtained from the Educational Services of the State of Chihuahua, who provided a list of schools from which participants were selected. To obtain permission to test children in the public schools, letters were sent to the director of the Chihuahua Board of Preschool Education, to the supervisor of the school district, and to the school principal explaining the nature of the study. For the private schools, a letter explaining the nature of the study was provided to the school principal of several institutions (by convenience). Once authorization was granted, we sent the informed consent form and the parent questionnaires home to the parents by asking each of the teachers to hand them out. Parents were asked to return the questionnaires in a sealed envelope (which was included) in order to ensure confidentiality. Children whose parents provided informed consent were asked whether they wished to participate. Prior to testing, children gave verbal assent. After completing the tasks children were thanked for their participation and awarded a sticker.

Testing took place in a quiet area of the school. A trained experimenter visited the children twice within one week to complete the measures. The tasks were presented to the children in one of five fixed orders, which was done to avoid task order effects. Testing of all children took four months.

\section{Analytical Strategy}

First, we used Principal Axis Factoring analyses (PAFs) to explore the structure of the components of the questionnaire (i.e., expectations, numeracy activities, and literacy activities). Second, we compared the low- and high-SES groups on parental expectations (Hypothesis 1) and reported home activities (Hypothesis 2), using independent $t$-tests. For these analyses, we used SPSS (version 25). Third, we used multi-group path analyses to assess the associations among parental expectations and home learning activities by SES (Hypothesis 3), and to test the relations among children's numeracy performance and parents' reports of their home activities in the two SES groups. Thus, we tested whether home learning activities predicted numeracy performance in both SES groups (Hypotheses 4 and 5 ); and we examined whether the strength of the associations differed by the SES of the families (Hypothesis 6). For the multi-group analyses, Mplus 8 (version 1.6) was used (Muthén and Muthén, 1998-2012). Data were missing for some children on the six home numeracy factors (ranging from 5.8 to 9.2\% across children) and on the numeracy outcome (9.2\%). Little's test for missingness showed that data were missing completely at random, $\chi^{2}(25)=35.23, p=0.084$. Thus, the models were estimated by a full information maximum likelihood method, which uses all available information to estimate the model. Furthermore, children's age was included as a control variable; however, no differences by gender were found for parental numeracy and literacy expectations, or for home learning activities (i.e., operational, mapping, codebased and meaning-related activities) nor for the numeracy outcome, all $p s>0.05$, thus, gender was not included in further analyses.

\section{RESULTS}

\section{Factor Analyses of the Parent Questionnaire}

Given that the low- and high-SES groups differ substantially on most of the item scores (see Supplementary Tables A1, A2 in Appendix A), we standardized the item scores within each 
group to reduce the possibility that correlations would be inflated due to scaling differences. Principal Axis Factoring analyses with oblique rotation using the Promax procedure with Kaizer Normalization were then conducted for each of the three scales of the home questionnaire (i.e., parental academic expectations, numeracy activities, and literacy activities). Note that in many previous studies, orthogonal rotation was chosen to create uncorrelated factors. In contrast, oblique rotation was used in the current study because preliminary analyses indicated that factors were correlated above 0.30 (Field, 2013). The general patterns of correlations across items were similar between the low- and high-SES parents, thus we proceeded with a single factor analysis based on the data for all participants for each of the questionnaire scales. For parental expectations, the factor analyses resulted in two components (numeracy and literacy expectations) that accounted for $57.8 \%$ of the variance (see Supplementary Table B1 in Appendix B). The factor analyses for the numeracy activities resulted in two components (mapping and operational activities) that accounted for $44.0 \%$ of the variance (see Supplementary Table B2 in Appendix B). For literacy activities, as shown in Supplementary Table B3 (Appendix B), factor analyses resulted in two components (codebased and meaning-related activities) that accounted for $52.7 \%$ of the variance. The factor scores from each analysis were saved and used in the subsequent analyses. The reliability for the numeracy and literacy expectations were Cronbach's $\alpha=0.886$ (0.879), 0.908 (0.943), respectively for the low-SES (high-SES) group. For the home learning activities, Cronbach's $\alpha$ for mapping activities, operational activities, code-based activities, and meaning-related activities were 0.830 (0.859), 0.814 (0.821), 0.908 (0.885), and 0.775 (0.834), respectively for the low-SES (high-SES) group.

\section{Similarities and Differences of Parental Expectations and Activities by SES}

Descriptive statistics and group comparisons (high- vs lowSES) for the variables can be found in Table 1. For parental academic expectations and home learning activities, factor scores are shown. Detailed item-level information about parent's reports of academic expectations and home learning activities by SES is available in Supplementary Tables A1 and A2 in Appendix A. Correlations among the variables are found in Table 2 .

\section{Parents' Numeracy and Literacy Expectations}

We hypothesized that low-SES parents would report higher academic expectations than high-SES parents (Hypothesis 1). As shown in Table 1, low-SES parents reported higher numeracy expectations than high-SES parents, $t(155)=4.11, p<0.001$, $d=0.66$. Specifically, the low-SES parents rated all but the know simple sums item as more important than did the high-SES parents (see Supplementary Table A1 in Appendix A), even though several of these are unrealistic benchmarks for most children to achieve before Grade 1. However, there were no differences in their literacy expectations factor, $t(155)=-0.37$, $p>0.05, d=0.07$. These results provide partial evidence in favor of our hypothesis: Low-SES parents reported higher numeracy, but not literacy, expectations than high-SES parents.

\section{Parents' Reports of Numeracy and Literacy Activities} We expected that low-SES parents would report engaging in activities less frequently than high-SES parents (Hypothesis 2). Our findings support the hypothesis for the literacy activities, but not for numeracy (see Table 1 and Supplementary Table A2 in the Appendix A). High-SES parents reported higher frequency of both code-based, $t(160)=-2.31, p<0.05, d=0.36$, and meaningrelated activities, $t(160)=-3.61, p<0.001, d=0.57$, compared to low-SES parents. In contrast, no differences between high- and low-SES parents were found in reported frequencies of mapping and operational activities.

\section{Multi-Group Path Analyses}

Multi-group path analyses were conducted to assess the links between parental academic expectations and home learning activities (Hypothesis 3), and between parental reports of numeracy (Hypothesis 4) and literacy (Hypothesis 5) activities and children's numeracy performance, and whether the strength of these relations would vary by SES (Hypothesis 6).

For data reduction, a principal component analysis (PCA) was used to create a numeracy factor using the three measures: number comparison, cardinality, and counting (factor loadings of $0.89,0.84$, and 0.83 , respectively). The factor accounted for $72.9 \%$ of the variance in these measures. This factor score was saved and used in the subsequent analyses.

Prior to the modeling, given the high correlations between the numeracy and literacy expectations, and among the four

TABLE 2 | Correlations of factor scores for expectations and home numeracy and literacy activities and child outcomes.

\begin{tabular}{|c|c|c|c|c|c|c|c|c|}
\hline & 1 & 2 & 3 & 4 & 5 & 6 & 7 & 8 \\
\hline 1. Age & - & -0.152 & -0.058 & -0.090 & 0.066 & $0.424^{\star \star \star}$ & 0.241 & $0.769^{\star \star \star}$ \\
\hline 2. Numeracy exp. & -0.063 & - & $0.693^{\star \star \star}$ & $0.288^{\star}$ & $0.323^{\star \star}$ & $0.325^{\star \star}$ & $0.264^{\star}$ & 0.047 \\
\hline 3. Literacy exp. & -0.082 & $0.746^{\star \star \star}$ & - & $0.329^{\star \star}$ & $0.298^{\star}$ & $0.412^{\star \star \star}$ & $0.239^{\star}$ & 0.151 \\
\hline 4. Mapping & 0.167 & 0.039 & $0.292^{\star \star}$ & - & $0.748^{\star \star \star}$ & $0.574^{\star \star \star}$ & $0.666^{\star \star \star}$ & 0.010 \\
\hline 5. Operational & $0.330^{\star \star}$ & 0.139 & $0.309^{\star \star}$ & $0.757^{\star \star \star}$ & - & $0.575^{\star \star \star}$ & $0.605^{\star \star \star}$ & $0.294^{\star}$ \\
\hline 6. Code & $0.292^{\star \star}$ & 0.068 & $0.248^{*}$ & $0.754^{\star \star \star}$ & $0.718^{\star \star \star}$ & - & $0.757^{\star \star \star}$ & $0.486^{\star \star \star}$ \\
\hline 7. Meaning & 0.200 & 0.096 & $0.261^{\star}$ & $0.722^{\star \star \star}$ & $0.803^{\star \star \star}$ & $0.843^{\star \star \star}$ & - & $0.292^{\star}$ \\
\hline 8. Numeracy factor & $0.637^{\star \star \star}$ & 0.019 & 0.034 & 0.114 & 0.173 & 0.192 & 0.114 & - \\
\hline
\end{tabular}

Low-SES group below the diagonal, high-SES group above the diagonal.

${ }^{*} p<0.05,{ }^{* *} p<0.01$, and ${ }^{* * *} p<0.001$. 
types of home activities (i.e., mapping, operational, coded-based, and meaning-related, see Table 2), we examined multicollinearity among these variables. A variance inflation factor (VIF) of 5 or more, and/or a tolerance of 0.2 or less, indicates that there is multicollinearity among the variables (Belsley, 1991; Field, 2013). In the present study, in initial analyses, multicollinearity was detected for the meaning-related activities for the low-SES group $(\mathrm{VIF}=6.67$; tolerance $=0.150)$, suggesting that meaningrelated activities were not distinguishable from the other home learning activities for this group of parents. Moreover, there were no significant correlations between meaning-related activities and numeracy skills for either low- or high-SES groups (see Table 2). Because relations between meaning-related activities and children's numeracy have not been reported in previous research, we did not hypothesize that meaning-related activities would be linked to children's numeracy performance. Thus, we removed meaning-related activities from the model.

Although multicollinearity was not detected for mapping activities, the bivariate correlation between mapping and operational activities was over 0.70 for both SES groups, which might affect the stability of the findings. Because mapping activities was also uncorrelated with the numeracy factor, and we did not hypothesize a link, we also excluded mapping activities from the model.

The initial analyses in which both numeracy and literacy expectations were included in the same model showed that there was a strong suppressor relation among expectations and activities, which distorted the interpretation of the pattern of results (Ludlow and Klein, 2014). These patterns were probably a function of the high correlations among these variables, especially for the expectations. Thus, in the following analyses, we tested two separate models: one involving numeracy expectations and one involving literacy expectations.

The multi-group path analysis involves testing the cross-group invariance, that is, the assumption that the structural parameters are statistically different between the two groups. In particular, we compared nested models: 1) an unconstrained model in which the coefficients for each of the paths were estimated freely for each group, and 2) a constrained model in which the coefficients were set to be equal across groups. Note that the models for the full sample without the grouping variable are shown in Appendix C (Supplementary Figure C1).

For the model that included numeracy expectations, the unconstrained model had an excellent fit to the data, $\chi^{2}(2)=1.15$, $p=0.564, \mathrm{SRMR}=0.01, \mathrm{CFI}=1, \mathrm{RMSEA}=0(90 \% \mathrm{CI}=[0$, $0.18]$ ) whereas the fully constrained model had a poor fit to the data, $\chi^{2}(10)=22.36, p=0.013, \mathrm{SRMR}=0.07$, CFI $=0.95$, RMSEA $=0.12(90 \% \mathrm{CI}=[0.05,0.19])$. Accordingly, the constrained model had a statistically poorer fit to the data than the unconstrained model, $\Delta \chi^{2}(8)=21.21, p=0.007$, suggesting that the path coefficients were different for the low-versus highSES children. These models are shown in Figure 1.

Similarly, for the model that included literacy expectations, the unconstrained model had an excellent fit to the data, $\chi^{2}(2)=2.94$, $p=0.230, \mathrm{SRMR}=0.02, \mathrm{CFI}=1, \mathrm{RMSEA}=0.07(90 \% \mathrm{CI}=[0$, $0.24]$ ) whereas the fully constrained model had a poor fit to the data, $\chi^{2}(10)=21.30, p=0.019, \mathrm{SRMR}=0.06, \mathrm{CFI}=0.96$,
RMSEA $=0.11(90 \%$ CI $=[0.04,0.18])$. Accordingly, the constrained model had a statistically poorer fit to the data than the unconstrained model, $\Delta \chi^{2}(8)=18.36, p=0.019$, suggesting that the path coefficients were different for the low-versus highSES children. These models are shown in Figure 2.

In all of the models, we controlled for child's age (not shown in figures for readability). In terms of the associations of the control variable with the home learning activities, for the lowSES group, age was a significant predictor of operational activities ( $\beta=0.34, p<0.001 ; \beta=0.36, p<0.001$, for the numeracy and literacy expectation models respectively) and code-based activities $(\beta=0.29, p<0.01 ; \beta=0.30, p<0.01$, for the numeracy and literacy expectation models, respectively). For the high-SES group, age was only related to code-based activities $(\beta=0.49$, $p<0.001 ; \beta=0.46, p<0.001$, for the numeracy and literacy expectation models respectively), but not to operational activities ( $\beta=0.12, p>0.05 ; \beta=0.09, p>0.05$, for the numeracy and literacy expectation models, respectively). Age was a significant predictor of numeracy skills for both low- $(\beta=0.68, p<0.001)$ and high- $(\beta=0.73, p<0.001)$ SES groups in both models.

In summary, low-SES parents reported more home numeracy and code-based home literacy activities for older than for younger children. High-SES parents reported more code-based activities for older than for younger children.

\section{Relations Between Academic Expectations and Home Learning Activities}

The paths from parental academic expectations to home activities differed across groups for the model that included numeracy expectations (see Figure 1). We hypothesized that parents' academic expectations for children's performance would be related to their reports of home learning activities in both SES groups (Hypothesis 3). However, for the low-SES group, we found that numeracy expectations were unrelated to either operational or code-based activities whereas literacy expectations were positively related to both operational and code-based activities (see Figure 2). For the high-SES group, both numeracy and literacy expectations were significantly related to both operational and code-based activities. In summary, although there were some differences in the patterns of relations by SES, Hypothesis 3 was partially supported in the low-SES group, whereas full support was provided for the high-SES group.

\section{Relations Between Learning Activities and Children's Numeracy Performance}

We hypothesized that parents' reports of operational numeracy (Hypothesis 4) but not code-based literacy or meaning-related literacy (Hypothesis 5) activities would be correlated with children's numeracy performance in both SES groups. As shown in Figure 1 and consistent with our hypothesis, for the high-SES group, operational activities were positively related to numeracy skills $(\beta=0.21, p<0.05)$. For the low-SES group, however, none of the home learning activities were related to numeracy skills. As expected, code-based activities were not related to numeracy skills in either group.

With regards to Hypothesis 6, the unconstrained models described above showed significantly better fit than the 


\section{A}

\section{Low-SES}

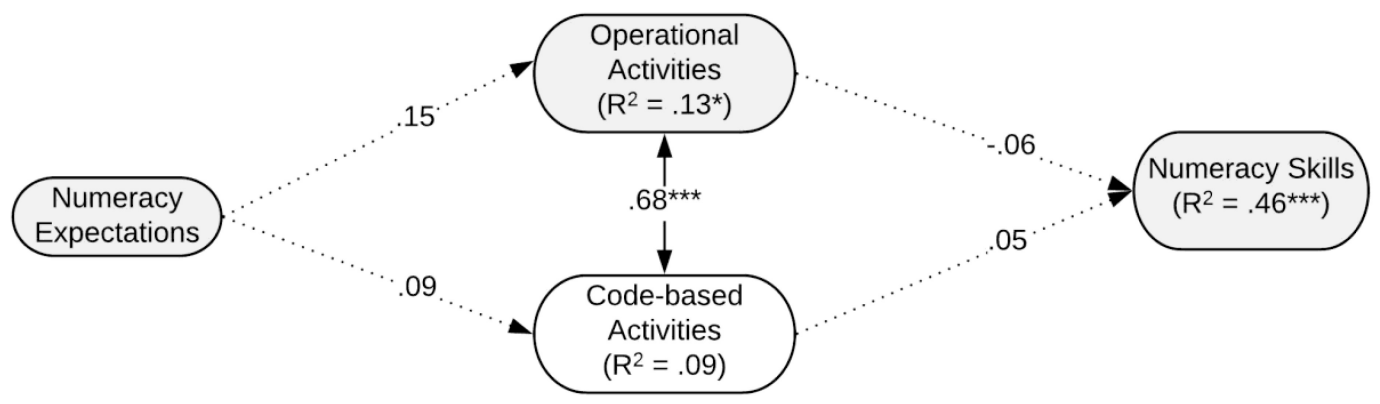

B

\section{High-SES}

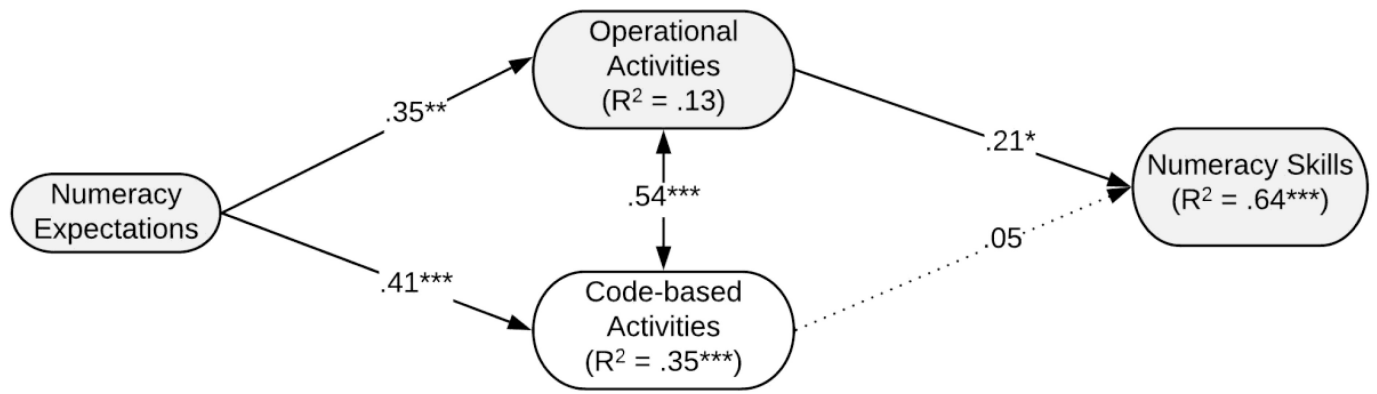

FIGURE 1 | Final path model shows relations among numeracy expectations, home learning activities, and children's outcome for low SES group (A: $n=99$ ) and high SES group (B: $n=74$ ) controlling for child's age. The $R^{2}$ values shown include variance predicted by the control measure. The numbers on the arrows are the standardized coefficients. Dashed lines present no significant paths. ${ }^{*} p<0.05,{ }^{* *} p<0.01$, and ${ }^{* * *} p<0.001$.

constrained models, indicating that the path coefficients differed between low- and high-SES groups.

In summary, these findings provide support for Hypothesis 4 (i.e., operational activities were positively related to children's numeracy) and for Hypothesis 5 (i.e., code-based activities were not related to the outcome) for the high-SES group. For the low-SES group, there were no significant relations between parents' reports of home activities and numeracy outcomes. Overall, in support of Hypothesis 6, the relations among the variables (expectations, activities, and the numeracy outcome) were different for the SES groups.

\section{DISCUSSION}

We explored parents' academic expectations, parents' reported home learning activities, and their links with early numeracy scores of low- and high-SES Mexican children. Our findings were generally consistent with prior research, showing different patterns of results for low- and high-SES parents in terms of their numeracy expectations (De Keyser et al., 2020) and literacy activities (Neumann, 2016; Ergül et al., 2017). Moreover, parents' reports of the frequency of engaging in numeracy activities were related to children's numeracy performance, but only in the high-SES group. These results add to the emerging literature on home learning environments in Latin America (Susperreguy et al., 2020a), and expand our understanding of the relations among SES, home numeracy activities, and children's numeracy performance to Mexican families (Mutaf-Yıldız et al., 2020).

\section{Expectations for Numeracy and Literacy Achievement}

Low-SES parents rated numeracy expectations as more important than did the high-SES parents. Overall, high-SES parents' ratings of the importance of the numeracy benchmarks appear to be more closely calibrated to children's skills (see Supplementary Table A1; DeFlorio and Beliakoff, 2015; Susperreguy et al., 2020b). For example, low-SES parents rated being able to "read printed numbers to 100," "count to 1,000," and "know multiplication" higher than high-SES parents. These skills are unlikely to be achieved by most children before starting Grade 1. The relatively high numeracy expectations of low-SES Mexican parents might indicate that their expectations are not informed by knowledge of children's skills and their development (DeFlorio and Beliakoff, 2015) nor by their beliefs about the role of home experiences in children's education (Reese et al., 1995; Goldenberg, 2001). Alternatively, the higher expectations of low-SES parents might reflect their high aspirations for their children. Research which explores the interpretations 


\section{A}

\section{Low-SES}

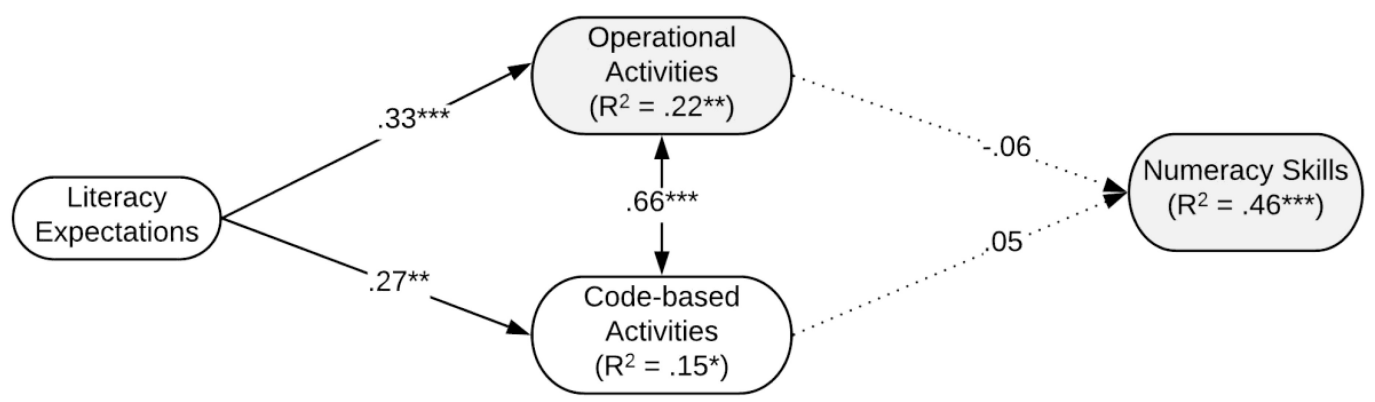

B

High-SES

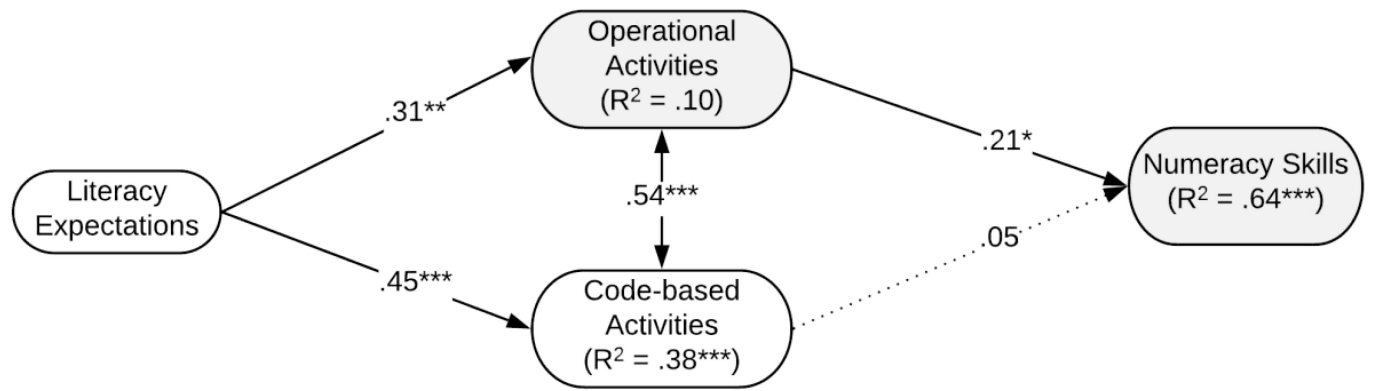

FIGURE 2 | Final path model shows relations among literacy expectations, home learning activities, and children's outcome for low SES group (A: $n=99)$ and high SES group (B: $n=74)$ controlling for child's age. The $R^{2}$ values shown include variance predicted by the control measure. The numbers on the arrows are the standardized coefficients. Dashed lines present no significant paths. ${ }^{*} p<0.05,{ }^{* *} p<0.01$, and ${ }^{* \star *} p<0.001$.

of these items by low-SES parents would help to illuminate these differences.

\section{Home Numeracy and Literacy Activities}

We hypothesized that low-SES parents would report less frequent engagement in numeracy and literacy activities compared to high-SES parents. However, there were no SES differences in parents' reported frequency of engaging in numeracy activities. This finding might indicate that both groups of parents are influenced by schooling and specifically, by the activities that teachers suggest or prescribe (Perry et al., 2008). Ongoing research including interviews with Mexican parents support this interpretation: the majority of the participating parents reported that they obtained most of the information on numeracy activities from their children's teacher (Authors, manuscript in preparation), rather than from other sources.

In contrast, for literacy, high-SES parents reported a higher frequency of engaging in code-based and meaning-related activities than low-SES parents. These differences across SES groups in literacy activities might reflect different levels of knowledge and/or parents' differential access to appropriate resources. High-SES families have more educational materials at home (Davis-Kean et al., 2020), a pattern that has also been reported in research with Latin American families
(Strasser et al., 2017) and they may use these resources to facilitate home literacy activities. For example, high-SES parents may use children's books to engage children, asking them to define words or point to letters or words as the parent reads. Low-SES parents, in contrast, may have only adult-level reading materials available, or possibly none other than what children need for school. Frequency of shared activities, on this view, may depend both on the resources that parents have available, as well as on their knowledge or beliefs about what types of activities are important for early learning.

\section{Academic Expectations and Home Learning Activities}

Prior work shows that parents' academic expectations are related to the reported frequency of engaging in home activities with their children (LeFevre et al., 2002; Martini and Sénéchal, 2012; Susperreguy et al., 2020b). In the present research, we found that for low-SES parents, literacy, but not numeracy, expectations were related to their reports of the frequency of home learning activities. In contrast, for high-SES parents both types of academic expectations were related to home learning activities.

An association between parents' numeracy expectations and their numeracy activities has been found in previous work from various countries (LeFevre et al., 2002; Skwarchuk et al., 2014; 
del Río et al., 2017; Susperreguy et al., 2020b). In the present research, we found that parents' numeracy expectations were unrelated to home learning activities for the low-SES group and that their expectations were generally higher than those of highSES parents. However, these high expectations of the low-SES parents did not translate into a higher frequency of engaging in numeracy activities. This pattern suggests that, for the lowSES parents, reporting high expectations could reflect a social desirability bias. Alternatively, these parents may have a narrow understanding of early numeracy benchmarks needed to succeed in Grade 1. Galindo et al. (2019) found that Latina immigrant mothers to the United States, mostly from El Salvador, viewed mathematics as involving mainly arithmetic. They did not have a broad understanding of other aspects of mathematics that children learn in school. In the present study, the low-SES parents might not have an extensive knowledge of early numeracy and thus they rated all benchmarks as relatively important.

In contrast, for the high-SES group, numeracy and literacy expectations were positively related to both operational and codebased activities, as found in prior research (Skwarchuk et al., 2014). Thus, parents who had a more accurate understanding of the numeracy and literacy skills needed for school reported engaging in more frequent home activities that promote learning.

The differential findings between SES groups in the relations among numeracy and literacy expectations and home learning activities need to be further studied in Mexican and Latin American families in order to better understand the relations between SES and home learning experiences of children and their parents.

\section{Home Learning Activities and their Relation to Early Numeracy Skills}

We hypothesized that parents' reports of the frequency of home numeracy activities would be related to children's numeracy performance in both SES groups, although we expected to find differences in the strength of the associations. This relation has been found in many, but not all, published studies (see Elliott and Bachman, 2017; Mutaf-Yild1z et al., 2020, for reviews). In the present study, there were no significant associations between the frequency of home numeracy activities and the numeracy performance of the low-SES children. In contrast, numeracy activities were related to the numeracy skills of high-SES children, as was found in prior research with Chilean children (del Río et al., 2017; Susperreguy et al., 2020b). del Río et al. (2017) included families from low- and high-SES backgrounds but they did not assess the differences in the relations between mother's reported activities and children's performance by SES. Moreover, most children in Susperreguy et al. (2020a) were from middle- to high-SES families. Thus, more systematic evaluation of the relations among children's home numeracy environments, numeracy skills, and SES is clearly needed.

The lack of significant relations between the home activities and numeracy outcomes for the low-SES group in the current research suggests that the socioeconomic background of families is a key factor in understanding the links between home activities and children's outcomes in Mexico. Studies with low-SES groups did not find correlations between parents' reports of home numeracy activities and their children's skills (e.g., DeFlorio and Beliakoff, 2015; Leyva et al., 2017). Various factors may lead to differential results for low-SES groups. First, differences in economic and educational conditions might influence the type of educational materials and learning opportunities provided by parents from different SES milieu (Starkey and Klein, 2008; Davis-Kean et al., 2020). These diverse conditions might translate to differential patterns of performance in low- and highSES children. Second, the results could be related to parental knowledge of children's skills and how to foster them (Zippert and Ramani, 2017). For example, low-SES parents may not have an understanding of children's developmental stages (DeFlorio and Beliakoff, 2015), resulting in a lack of differentiation of home learning activities as a function of children's age or accomplishments. Third, low-SES parents might engage in other activities not captured by the current assessment that was focused on formal activities. Low-SES parents could involve their children in activities linked to their everyday experiences, which they might not conceptualize as math (Civil et al., 2020). These activities may be more directly related to children's numerical knowledge than the activities proposed in the questionnaire used in this study, which were all formal activities where parents had the intention to teach children about numbers.

In the present research we hypothesized that code-based activities would not be linked to children's numeracy skills. In accord with this hypothesis but contrary to the findings by SotoCalvo et al. (2020a,b), we did not find a link between code-based activities and children's performance. Importantly, Soto-Calvo et al. (2020a,b) focused on basic numeracy activities and did not include operational activities in their model. Our results clearly show that only operational activities (i.e., relatively more complex) are related to children's numeracy performance (see also Skwarchuk et al., 2014; Susperreguy et al., 2020a,b). Thus, when code-based literacy and operational numeracy activities are considered together, only operational activities were significantly related to children's numeracy performance. We expect that code-based activities would be related to children's early literacy performance (Sénéchal and LeFevre, 2014; Sénéchal et al., 2017). Thus, the present results are consistent with the view that the frequencies of home activities reported by parents are most closely linked to within-domain skills (Skwarchuk et al., 2014; Susperreguy et al., 2020b).

\section{Limitations and Future Directions}

The current research has some limitations that should be considered in interpreting the findings. First, future studies should include alternative methods of data collection, such as interviews (Cahoon et al., 2017; Galindo et al., 2019), to understand differences in the experiences of children in lowversus high-SES families. These studies would help delineate the nature of parents' academic expectations, identify variation in the quality of the activities, and therefore increase our understanding of the ways in which parents' home activities are linked to children's early mathematical skills in diverse SES groups (Ginsburg et al., 2012). Second, the study was not longitudinal and thus does not allow us to test the direction of the associations between home learning environments and children's outcomes. 
Longitudinal studies that include assessments of the home learning environments and children's numeracy performance at various time points are necessary to provide a clearer picture of the directionality of the links (Silinskas et al., 2020). Third, the current study used PCA and multi-group path analyses separately. Future studies with larger samples could test a multigroup SEM model, thereby testing the measurement invariance assumption of the latent home numeracy constructs between low- and high-SES groups. Fourth, we did not control for other cognitive skills that are relevant for children's numeracy performance, such as executive functions (Blair and Razza, 2007) or children's intelligence (Niklas and Schneider, 2014). Skwarchuk et al. (2014) controlled for spatial working memory in their work, whereas Kleemans et al. (2012) included a measure of working memory to account for child and family factors when predicting early numeracy skills. Beyond simply accounting for variability, home activities might also influence children's cognitive skills and thus confound the role of domain-general and domain-specific influences on children's academic skills.

Despite the limitations, our results are important for several reasons. This is the first study exploring the home learning environments and numeracy outcomes for Mexican children. We provide descriptive information on the similarities and differences in parents' academic expectations and home activities in Mexican families by SES. Moreover, SES emerged as a critical moderating variable, suggesting that it should be closely examined in future work on the home numeracy environment.

\section{CONCLUSION}

In conclusion, numeracy expectations were differentially associated with the frequency of home learning activities between the low- and high-SES groups. Significant associations were found between home numeracy activities and numeracy skills for Mexican children in high- but not low-SES families. Thus, high-SES families showed similar patterns of relations between parents' reported numeracy activities and children's numeracy performance as were found in other studies, whereas low-SES families did not. Most other research was done either with samples of predominately middle-class families (e.g., Skwarchuk et al., 2014; Susperreguy et al., 2020b) or with samples of low-SES families (Leyva, 2019). The present research highlights the need to consider the role of socioeconomic status as a moderator of the relations between home numeracy environment and children's developing skills.

\section{DATA AVAILABILITY STATEMENT}

The raw data supporting the conclusions of this article will be made available by the authors, without undue reservation.

\section{REFERENCES}

Anders, Y., Rossbach, H.-G., Weinert, S., Ebert, S., Kuger, S., Lehrl, S., et al. (2012). Home and preschool learning environments and their relations to the development of early numeracy skills. Early Child. Res. Q. 27, 231-244.

\section{ETHICS STATEMENT}

The present study was reviewed and approved by Comité de Ética en Investigación de la Facultad de Medicina y Ciencias Biomédicas de la Universidad Autónoma de Chihuahua. Written informed consent to participate in this study was provided by the participants' legal guardian/next of kin.

\section{AUTHOR CONTRIBUTIONS}

MS wrote the manuscript and developed the theoretical framework for the study. CJ designed and implementation of the study, supervised the data collection and analyses, interpretation of the results, and contributed to the manuscript writing. CX contributed to the data analyses, interpretation of the results, manuscript writing, and design of the figures. J-AL contributed to data analyses, interpretation of the results, manuscript writing, and to the theoretical framework for the study. HB contributed in design, implementation, and supervision of data collection, and contribution to the data analyses for the study. EB and MO contributed in design, implementation, and supervision of data collection for the study. All authors contributed to the article and approved the submitted version.

\section{FUNDING}

This work was supported by the Vicerrectoría de Investigación of the Pontificia Universidad Católica de Chile through the 2019 Research Internship and Short Stay Grant to MIS; by Consejo Nacional de Ciencia y Tecnología (CONACyT) to CJ; and by the Social Sciences and Humanities Research Council of Canada through an Insight Grant (PI: J-AL).

\section{ACKNOWLEDGMENTS}

We are grateful to the schools, daycares, teachers, children, and parents who participated in the study, as well as to the research assistants who contributed to data collection: Azaneth Laguna Celia, Rossy Esmeralda Bolívar Jurado, Rogelio Eduardo Solis Grado, Carlos Alberto Sias Rivera, Rocio Guadalupe González Aragón, and Jonathan Almanza Montes.

\section{SUPPLEMENTARY MATERIAL}

The Supplementary Material for this article can be found online at: https://www.frontiersin.org/articles/10.3389/fpsyg. 2021.626159/full\#supplementary-material

Aunio, P., and Niemivirta, M. (2010). Predicting children's mathematical performance in grade one by early numeracy. Learn. Individ. Differ. 20, 427435. doi: 10.1016/j.lindif.2010.06.003

Becerra Orellana, L. E. (2016). Relación Entre las Experiencias Numéricas en el Hogar y el Desempeño Numérico de los Niños de Primer Año de 
Básica de la ciudad de Cuenca. Master's thesis, Universidad de Cuenca, Cuenca.

Belsley, D. A. (1991). Conditioning Diagnostics: Collinearity and Weak Data in Regression. New York, NY: John Wiley \& Sons, Inc.

Blair, C., and Razza, R. P. (2007). Relating effortful control, executive function, and false belief understanding to emerging math and literacy ability in kindergarten. Child Dev. 78, 647-663. doi: 10.1111/j.1467-8624.2007.01019.x

Blevins-Knabe, B., and Musun-Miller, L. (1996). Number use at home by children and their parents and its relationship to early mathematical performance. Early Dev. Parent. 5, 35-45.

Cahoon, A., Cassidy, T., and Simms, V. (2017). Parents' views and experiences of the informal and formal home numeracy environment. Learn. Cult. Soc. Interact. 15, 69-79. doi: 10.1016/j.lcsi.2017.08.002

Civil, M., Stoehr, K. J., and Salazar, F. (2020). Learning with and from immigrant mothers: implications for adult numeracy. ZDM 52, 489-500. doi: 10.1007/ s11858-019-01076-2

Davis-Kean, P., Tighe, L. A., and Waters, N. E. (2020). The role of parent educational attainment on parenting and the developing child (Accepted manuscript). PsyArXiv [Preprint]. doi: 10.31234/osf.io/ndmxb

De Keyser, L., Bakker, M., Rathé, S., Wijns, N., Torbeyns, J., Verschaffel, L., et al. (2020). No association between the home math environment and numerical and patterning skills in a large and diverse sample of 5- to 6-year-olds. Front. Psychol. 11:547626. doi: 10.3389/fpsyg.2020.547626

de León, D., Sánchez, I., Koleszar, V., Cervieri, I., and Maiche, A. (2020). Actividades numéricas en el hogar y desempeño matemático en niños preescolares (Accepted manuscript). Revista Argentina de Ciencias del Comportamiento.

DeFlorio, L., and Beliakoff, A. (2015). Socioeconomic status and preschoolers' mathematical knowledge: the contribution of home activities and parent beliefs. Early Educ. Dev. 26, 319-341. doi: 10.1080/10409289.2015.968239

del Río, M. F., Susperreguy, M. I., Strasser, K., and Salinas, V. (2017). Distinct influences of mothers and fathers on kindergartners' numeracy performance: the role of math anxiety, home numeracy practices, and numeracy expectations. Early Educ. Dev. 28, 939-955. doi: 10.1080/10409289.2017.1331662

Dunbar, K., Ridha, A., Cankaya, O., Jiménez Lira, C., and LeFevre, J.-A. (2017). Learning to count: structured practice with spatial cues supports the development of counting sequence knowledge in 3-year-old English-speaking children. Early Educ. Dev. 28, 308-322. doi: 10.1080/10409289.2016.121 0458

Duncan, G. J., Dowsett, C. J., Claessens, A., Magnuson, K., Huston, A. C., Klebanov, P., et al. (2007). School readiness and later achievement. Dev. Psychol. 43, 1428-1446. doi: 10.1037/0012-1649.43.6.1428

Elliott, L., and Bachman, H. J. (2017). How do parents foster young children's math skills? Child Dev. Perspect. 12, 16-21. doi: 10.1111/cdep.12249

Elliott, L., and Bachman, H. J. (2018). SES disparities in early math abilities: the contributions of parents' math cognitions, practices to support math, and math talk. Dev. Rev. 49, 1-15. doi: 10.1016/j.dr.2018.08.001

Ergül, C., Sarica, A. D., Akoglu, G., and Karaman, G. (2017). The home literacy environments of Turkish kindergarteners: Does SES make a difference? Int. J. Instr. 10, 187-202.

Field, A. (2013). Discovering Statistics using IBM SPSS Statistics, 4 Edn. London: Sage.

Galindo, C., Sonnenschein, S., and Montoya-Ávila, A. (2019). Latina mothers' engagement in children's math learning in the early school years: conceptions of math and socialization practices. Early Child. Res. Q. 47, 271-283. doi: 10.1016/ j.ecresq.2018.11.007

Ginsburg, H. P., Duch, H., Ertle, B., and Noble, K. G. (2012). "How can parents help their children learn math?" in Handbook of Family Literacy, eds B. H. Wasik and B. V. Horn (New York, NY: Routledge Press), 51-65.

Goldenberg, C. (2001). "Home and communities," in Handbook of Literacy Research, eds S. Neuman and D. K. Dickinson (New York, NY: Guilford), 211-231.

Goldenberg, C., Gallimore, R., Reese, L., and Garnier, H. (2001). Cause or effect? A longitudinal study of immigrant Latino parents' aspirations and expectations, and their children's school performance. Am. Educ. Res. J. 38, 547-582. doi: 10.3102/00028312038003547

Gonzalez, J. E., Bengochea, A., Justice, L., Yeomans-Maldonado, G., and McCormick, A. (2019). Native Mexican parents' beliefs about children's literacy and language development: a mixed-methods study. Early Educ. Dev. 30, 259-279. doi: 10.1080/10409289.2018.1542889

Hart, S. A., Ganley, C. M., and Purpura, D. J. (2016). Understanding the home math environment and its role in predicting parent report of children's math skills. PLoS One 11:e0168227. doi: 10.1371/journal.pone.0168227

Huang, Q., Zhang, X., Liu, Y., Yang, W., and Song, Z. (2017). The contribution of parent-child numeracy activities to young Chinese children's mathematical ability. Br. J. Educ. Psychol. 87, 328-344. doi: 10.1111/bjep.12152

Huntsinger, C. S., Jose, P. E., and Luo, Z. (2016). Parental facilitation of early mathematics and reading skills and knowledge through encouragement of home-based activities. Early Child. Res. Q. 37, 1-15. doi: 10.1016/j.ecresq.2016. 02.005

Jiménez Lira, C. (2016). Children's Acquisition of the Mappings Among the Number Representations. Ph.D. thesis, Carleton University, Ottawa, ON.

Jordan, N. C., Kaplan, D., Ramineni, C., and Locuniak, M. N. (2009). Early math matters: kindergarten number competence and later mathematics outcomes. Dev. Psychol. 45, 850-867. doi: 10.1037/a0014939

Jordan, N. C., and Levine, S. C. (2009). Socioeconomic variation, number competence, and mathematics learning difficulties in young children. Dev. Disabil. Res. Rev. 15, 60-68. doi: 10.1002/ddrr.46

Jung, S., Fuller, B., and Galindo, C. (2012). Family functioning and early learning practices in immigrant homes. Child Dev. 83, 1510-1526. doi: 10.1111/j.14678624.2012.01788.x

Kleemans, T., Peeters, M., Segers, E., and Verhoeven, L. (2012). Child and home predictors of early numeracy skills in kindergarten. Early Child. Res. Q. 27, 471-477. doi: 10.1016/j.ecresq.2011.12.004

Kleemans, T., Segers, E., and Verhoeven, L. (2013). Relations between home numeracy experiences and basic calculation skills of children with and without specific language impairment. Early Child. Res. Q. 28, 415-423. doi: 10.1016/j. ecresq.2012.10.004

Kleemans, T., Segers, E., and Verhoeven, L. (2018). Individual differences in basic arithmetic skills in children with and without developmental language disorder: role of home numeracy experiences. Early Child. Res. Q. 43, 62-72. doi: 10.1016/j.ecresq.2018.01.005

LeFevre, J.-A., Clarke, T., and Stringer, A. P. (2002). Influences of language and parental involvement on the development of counting skills: comparisons of French-and English-speaking Canadian children. Early Child Dev. Care 172, 283-300. doi: 10.1080/03004430212127

LeFevre, J.-A., Fast, L., Skwarchuk, S. L., Smith-Chant, B. L., Bisanz, J., Kamawar, D., et al. (2010a). Pathways to mathematics: longitudinal predictors of performance. Child Dev. 81, 1753-1767. doi: 10.1111/j.1467-8624.2010.01508.x

LeFevre, J.-A., Polyzoi, E., Skwarchuk, S. L., Fast, L., and Sowinski, C. (2010b). Do home numeracy and literacy practices of Greek and Canadian parents predict the numeracy skills of kindergarten children? Int. J. Early Years Educ. 18, 55-70. doi: 10.1080/09669761003693926

LeFevre, J.-A., Skwarchuk, S. L., Smith-Chant, B. L., Fast, L., Kamawar, D., and Bisanz, J. (2009). Home numeracy experiences and children's math performance in the early school years. Can. J. Behav. Sci. 41, 55-66. doi: 10. $1037 / \mathrm{a} 0014532$

Leyva, D. (2019). How do low-income Chilean parents support their preschoolers' writing and math skills in a grocery game? Early Educ. Dev. 30, 114-130. doi: 10.1080/10409289.2018.1540250

Leyva, D., Tamis-LeMonda, C. S., Yoshikawa, H., Jimenez-Robbins, C., and Malachowski, L. (2017). Grocery games: how ethnically diverse low-income mothers support children's reading and mathematics. Early Child. Res. Q. 40, 63-76. doi: 10.1016/j.ecresq.2017.01.001

Ludlow, L., and Klein, K. (2014). Suppressor variables: the difference between 'is' versus 'acting as'. J. Stat. Educ. 22, 1-28. doi: 10.1080/10691898.2014.1188 9703

Manolitsis, G., Georgiou, G. K., and Tziraki, N. (2013). Examining the effects of home literacy and numeracy environment on early reading and math acquisition. Early Child. Res. Q. 28, 692-703. doi: 10.1016/j.ecresq.2013.05.004

Martin, R. B., Cirino, P. T., Sharp, C., and Barnes, M. (2014). Number and counting skills in kindergarten as predictors of grade 1 mathematical skills. Learn. Individ. Differ. 34, 12-23. doi: 10.1016/j.lindif.2014.05.006

Martini, F., and Sénéchal, M. (2012). Learning literacy skills at home: parent teaching, expectations, and child interest. Can. J. Behav. Sci. 44, 210-221. doi: $10.1037 / \mathrm{a} 0026758$ 
Missall, K., Hojnoski, R. L., Caskie, G. I. L., and Repasky, P. (2015). Home numeracy environments of preschoolers: examining relations among mathematical activities, parent mathematical beliefs, and early mathematical skills. Early Educ. Dev. 26, 356-376. doi: 10.1080/10409289.2015.968243

Mutaf-Yıldız, B., Sasanguie, D., De Smedt, B., and Reynvoet, B. (2018). Frequency of home numeracy activities is differentially related to basic number processing and calculation skills in kindergartners. Front. Psychol. 9:340. doi: 10.3389/ fpsyg.2018.00340

Mutaf-Yıldız, B., Sasanguie, D., De Smedt, B., and Reynvoet, B. (2020). Probing the relationship between home numeracy and children's mathematical skills: a systematic review. Front. Psychol. 11:2074. doi: 10.3389/fpsyg.2020.02074

Muthén, L. K., and Muthén, B. O. (1998-2012). Mplus User's Guide, 7th Edn. Los Angeles, CA: Muthén \& Muthén.

Napoli, A. R., and Purpura, D. J. (2018). The home literacy and numeracy environment in preschool: cross-domain relations of parent-child practices and child outcomes. J. Exp. Child Psychol. 166, 581-603. doi: 10.1016/j.jecp.2017. 10.002

Neumann, M. M. (2016). A socioeconomic comparison of emergent literacy and home literacy in Australian preschoolers. Eur. Early Child. Educ. Res. J. 24, 555-566. doi: 10.1080/1350293X.2016.1189722

Niklas, F., and Schneider, W. (2014). Casting the die before the die is cast: the importance of the home numeracy environment for preschool children. Eur. J. Psychol. Educ. 29, 327-345. doi: 10.1007/s10212-013-0201-6

Pan, Y., Gauvain, M., Liu, Z., and Cheng, L. (2006). American and Chinese parental involvement in young children's mathematics learning. Cogn. Dev. 21, 17-35. doi: 10.1016/j.cogdev.2005.08.001

Perry, N. J., Kay, S. M., and Brown, A. (2008). Continuity and change in home literacy practices of Hispanic families with preschool children. Early Child Dev. Care 178, 99-113. doi: 10.1080/03004430701482191

Ramani, G. B., Rowe, M. L., Eason, S. H., and Leech, K. A. (2015). Math talk during informal learning activities in Head Start families. Cogn. Dev. 35, 15-33. doi: 10.1016/j.cogdev.2014.11.002

Reese, L., Balzano, S., Gallimore, R., and Goldenberg, C. (1995). The concept of educación: latino family values and American schooling. Int. J. Educ. Res. 23, 57-81. doi: 10.1016/0883-0355(95)93535-4

Reese, L., and Gallimore, R. (2000). Immigrant Latinos' cultural model of literacy development: an evolving perspective on home-school discontinuities. Am. J. Educ. 108, 103-134. doi: 10.1086/444236

Reyes, M., Teruel, G., and López, M. (2017). Measuring true income inequality in Mexico. Lat. Am. Policy 8, 127-148. doi: 10.1111/lamp.12111

Rogoff, B. (1990). Apprenticeship in Thinking: Cognitive Development in Social Context. Oxford: Oxford University Press.

Rogoff, B. (2003). The Cultural Nature of Human Development. Oxford: Oxford University Press.

Sarnecka, B. W., and Carey, S. (2008). How counting represents number: what children must learn and when they learn it. Cognition 108, 662-674. doi: 10. 1016/j.cognition.2008.05.007

Segers, E., Kleemans, T., and Verhoeven, L. (2015). Role of parent literacy and numeracy expectations and activities in predicting early numeracy skills. Math. Think. Learn. 17, 219-236. doi: 10.1080/10986065.2015.1016819

Sénéchal, M., and LeFevre, J.-A. (2014). Continuity and change in the home literacy environment as predictors of growth in vocabulary and reading. Child Dev. 85, 1552-1568. doi: 10.1111/cdev.12222

Sénéchal, M., Whissell, J., and Bidfell, A. (2017). "Starting from home: home literacy practices that make a difference," in Theories of Reading Development, eds K. Cain, D. Compton, and R. Parrila (Amsterdam: John Benjamins), 383-408.

Silinskas, G., Di Lonardo, S., Douglas, H., Xu, C., LeFevre, J.-A., Garckija, R., et al (2020). Responsive home numeracy as children progress from kindergarten through Grade 1. Early Child. Res. Q. 53, 484-495. doi: 10.1016/j.ecresq.2020. 06.003

Skwarchuk, S. L., Sowinski, C., and LeFevre, J.-A. (2014). Formal and informal home learning activities in relation to children's early numeracy and literacy skills: the development of a home numeracy model. J. Exp. Child Psychol. 121, 63-84. doi: 10.1016/j.jecp.2013.11.006

Sonnenschein, S., and Dowling, R. (2019). "Parents' socialization of their young children's interest in math," in Contemporary Perspectives on Research on Motivation in Early Childhood Education, ed. O. Saracho (Charlotte, NC: Information Age Publishing), 75-100.
Sonnenschein, S., Galindo, C., Simons, C. L., Metzger, S. R., Thompson, J. A., and Chung, M. F. (2018). "How do children learn mathematics? Chinese and Latina immigrant perspectives," in Parental Roles and Relationships in Immigrant Families: An International Approach, eds S. S. Chuang and C. L. Costigan (Cham: Springer International Publishing), 111-128.

Sonnenschein, S., Metzger, S. R., and Thompson, J. A. (2016). Low-income parents' socialization of their preschoolers' early reading and math skills. Res. Hum. Dev. 13, 207-224. doi: 10.1080/15427609.2016.1194707

Soto-Calvo, E., Simmons, F. R., Adams, A.-M., Francis, H. N., and Giofre, D. (2020a). Pre-schoolers' home numeracy and home literacy experiences and their relationships with early number skills: evidence from a UK study. Early Educ. Dev. 31, 113-136. doi: 10.1080/10409289.2019.1617012

Soto-Calvo, E., Simmons, F. R., Adams, A.-M., Francis, H. N., Patel, H., and Giofrè, D. (2020b). Identifying the preschool home learning experiences that predict early number skills: evidence from a longitudinal study. Early Child. Res. Q. 53, 314-328. doi: 10.1016/j.ecresq.2020.04.004

Starkey, P., and Klein, A. (2008). "Sociocultural influences on young children's mathematical knowledge," in Contemporary Perspectives on Mathematics in Early Childhood Education, eds O. N. Saracho and B. Spodek (Charlotte, NC: Information Age Publishing Inc), 253-276.

Strasser, K., and Lissi, M. R. (2009). Home and instruction effects on emergent literacy in a sample of Chilean kindergarten children. Sci. Stud. Read. 13, 175-204. doi: 10.1080/10888430902769525

Strasser, K., Rolla, A., and Romero-Contreras, S. (2016). School readiness research in Latin America: findings and challenges. New Dir. Child Adolesc. Dev. 2016, 31-44. doi: 10.1002/cad.20160

Strasser, K., Vergara, D., and del Río, M. F. (2017). Contributions of print exposure to first and second grade oral language and reading in Chile. J. Res. Read. 40, S87-S106. doi: 10.1111/1467-9817.12086

Susperreguy, M. I., Di Lonardo, Burr, S., Xu, C., Douglas, H., and LeFevre, J.-A. (2020a). Children's home numeracy environment predicts growth of their early mathematical skills in kindergarten. Child Dev. 91, 1663-1680. doi: 10.1111/ cdev.13353

Susperreguy, M. I., Douglas, H., Xu, C., Molina-Rojas, N., and LeFevre, J.-A. (2020b). Expanding the Home Numeracy Model to Chilean children: relations among parental expectations, attitudes, activities, and children's mathematical outcomes. Early Child. Res. Q. 50, 16-28. doi: 10.1016/j.ecresq.2018. 06.010

Susperreguy, M. I., Strasser, K., Lissi, M. R., and Mendive, S. (2007). Creencias y prácticas de literacidad en familias chilenas con distintos niveles educativos [Literacy beliefs and practices in Chilean families with different educational backgrounds]. Rev. Latinoam. Psicol. 39, 239-251.

Tamis-LeMonda, C. S., Sze, I. N. L., Ng, F. F. Y., Kahana-Kalman, R., and Yoshikawa, H. (2013). Maternal teaching during play with four-yearolds: variation by ethnicity and family resources. Merrill Palmer Q. 59, 361-398.

United Nations Development Programme (2020). Human Development Report. New York, NY: United Nations Development Programme.

Varela Llamas, R., and Ocegueda Hernández, J. M. (2020). La Pobreza en México y su Interrelación con el Mercado Laboral. Cuadernos de Economía (Santafé de Bogotá), 39, 139-165.

Vygotsky, L. S. (1978). Mind and Society: The Development of Higher Psychological Processes. Cambridge, MA: Harvard University.

Zippert, E. L., and Ramani, G. B. (2017). Parents' estimations of preschoolers' number skills relate to at-home number-related activity engagement. Infant Child Dev. 26:e1968. doi: 10.1002/icd.1968

Conflict of Interest: The authors declare that the research was conducted in the absence of any commercial or financial relationships that could be construed as a potential conflict of interest.

Copyright (c) 2021 Susperreguy, Jiménez Lira, Xu, LeFevre, Blanco Vega, Benavides Pando and Ornelas Contreras. This is an open-access article distributed under the terms of the Creative Commons Attribution License (CC BY). The use, distribution or reproduction in other forums is permitted, provided the original author(s) and the copyright owner(s) are credited and that the original publication in this journal is cited, in accordance with accepted academic practice. No use, distribution or reproduction is permitted which does not comply with these terms. 


\section{OPEN ACCESS}

Edited by:

Melissa Libertus,

University of Pittsburgh, United States

Reviewed by:

Eric Dearing,

Boston College, United States Susan Sonnenschein,

University of Maryland, Baltimore

County, United States

*Correspondence:

Amy R. Napoli

amynapoli@unl.edu

Specialty section:

This article was submitted to Educational Psychology,

a section of the journal

Frontiers in Education

Received: 17 February 2020 Accepted: 09 February 2021

Published: 22 March 2021

Citation:

Napoli AR, Korucu I, Lin J, Schmitt SA and Purpura DJ (2021) Characteristics

Related to Parent-Child Literacy and

Numeracy Practices in Preschool.

Front. Educ. 6:535832.

doi: 10.3389/feduc.2021.535832

\section{Characteristics Related to Parent-Child Literacy and Numeracy Practices in Preschool}

\author{
Amy R. Napoli ${ }^{1 *}$, Irem Korucu ${ }^{2}$, Joyce Lin ${ }^{3}$, Sara A. Schmitt ${ }^{4}$ and David J. Purpura ${ }^{4}$ \\ ${ }^{1}$ Department of Child, Youth, and Family Studies, University of Nebraska-Lincoln, Lincoln, NE, United States, ${ }^{2}$ Yale Center for \\ Emotional Intelligence, Child Study Center, Yale University, New Haven, CT, United States, ${ }^{3}$ Department of Child and Adolescent \\ Studies, California State University, Fullerton, Fullerton, CA, United States, ${ }^{4}$ Department of Human Development and Family \\ Studies, Purdue University, West Lafayette, IN, United States
}

Despite evidence suggesting that home literacy and numeracy environments are related to children's school readiness skills, little research has examined the child and family characteristics that relate to the home literacy and numeracy environments within the same sample. These factors are important to investigate in order to determine what may foster or prevent parent-child engagement. The primary purpose of this study was to examine the shared and unique parent-reported child and parent variables that are related to the frequency of parent-child literacy and numeracy practices. The 199 preschoolers included in the study ranged in age from 3.00 to $5.17^{\circ}$ years $(M=4.16, S D=0.57)$. Parents reported on child and family characteristics. Two multiple regression analyses were conducted (one each for home literacy and numeracy environments). Results indicated that parent education and children's age were positively related to the frequency of both literacy and numeracy practices. However, parents' beliefs of the importance of numeracy were positively associated with the frequency of parent-reported numeracy practices, whereas beliefs of the importance of literacy were not related to the frequency of literacy practices. In line with other research, parents reported finding literacy development to be more important than numeracy development and engaging in parent-child literacy practices more frequently than numeracy practices. Understanding factors that are related to the home literacy and numeracy environments may be an important step in identifying how to best encourage parents to engage their children in these practices at home.

Keywords: parents, mathematics, literacy, preschool, home learning environment, home numeracy environment, home literacy environment

\section{INTRODUCTION}

Early academic skills-literacy and numeracy skills in particular-are important for the development of later skills and are predictive of long-term academic achievement (Pagani et al., 2010; Nguyen et al., 2016). Despite the importance of these early skills, children enter the school setting with varying literacy and numeracy abilities (Starkey et al., 2004; Klibanoff et al., 2006). Children who enter school with less-developed numeracy and literacy skills often experience difficulties in later reading and mathematics (Claessens et al., 2009). Parents' support of preschool children's learning is related to a number of school readiness skills (Parker et al., 1999); specifically, parent-child literacy 
and numeracy practices are related to the development of children's literacy and numeracy skills (Kleemans et al., 2012; Baker, 2014). However, there are significant differences in the home learning environments that parents provide for their children (Young-Loveridge, 1989) and there are likely various parent and child factors that are related to these differences. Unfortunately, it is unclear which factors are related to the frequency of parent-child practices. Though researchers have some understanding of factors that are related to the home literacy and numeracy environments (e.g., socioeconomic status; Hoff et al., 2002), there is little research examining all of these factors within the same sample. Additionally, researchers often focus on either the home literacy or home numeracy environment, or a broader construct of the general home learning environment (cf. Sonnenschein et al., 2016). Thus, additional research that examines factors related to literacy and numeracy practices within the same sample is critical to researchers' and practitioners' understanding of how to best aid parents in providing a supportive home literacy environment (HLE) and home numeracy environment (HNE) for preschool children.

The aim of the current study is to determine the shared and unique parent and child characteristics that relate to the frequency of parent-child literacy and numeracy practices. Specifically, we explored whether parental educational attainment, child's sex and age, the number of children living in the home, and parents' beliefs of the importance of literacy and numeracy development are related to parent-reported HLE and HNE. An additional aim was to compare the frequency of parentchild literacy and numeracy practices, as well as parents' beliefs of the importance of literacy and numeracy.

\section{BACKGROUND}

\section{The Home Learning Environment}

The home learning environment is comprised of factors in the home, such as activities and access to learning materials, that contribute to children's learning and development of academic skills. Literacy and numeracy are two specific domains among many that comprise the home learning environment. Parentchild literacy practices, such as joint reading (Wood, 2002), and numeracy practices, such as teaching the counting sequence and the names of numerals (Anders et al., 2012), are important for children's developing academic skills (Melhuish et al., 2008). Similar to the extant literature emphasizing the role of the HLE in children's literacy development, emerging evidence emphasizes a strong relation between the HNE and children's numeracy development (Hart et al., 2016; Napoli and Purpura, 2018).

\section{Home Literacy Environment}

The HLE is comprised of characteristics of the home environment that contribute to the development of children's emergent literacy skills (Foster et al., 2005). The HLE is categorized into two types of parent-child practices: coderelated interactions (e.g., pointing out alphabet letters and sounds) which are related to children's print-based skills, and meaning-related interactions (e.g., shared reading) which are related to children's language and vocabulary skills (Sénéchal and LeFevre, 2002; Sénéchal, 2015). Unsupportive early HLEs are related to difficulties in developing reading skills, and these difficulties persist years later (Sonnenschein et al., 2010; Schmitt et al., 2011).

\section{Home Numeracy Environment}

In the past decade, researchers have shown an increased interest in the HNE. The HNE has been found to predict children's numeracy abilities in preschool (Anders et al., 2012) and kindergarten (Kleemans et al., 2012). The HNE is comprised of direct (e.g., teaching numeral names, counting objects, learning simple sums) and indirect (e.g., playing store, playing board games that involve counting) parent-child practices that are thought to contribute to the development of children's early mathematics skills (Niklas and Schneider, 2013; Skwarchuk et al., 2014). Positive relations between direct practices and child outcomes have been more consistently found (LeFevre et al., 2010). Thus, the present study includes only direct practices.

\section{Factors Related to the Home Learning Environment}

It is important to understand which factors predict parent-child literacy and numeracy practices, especially given the relations between these practices and the development of children's early academic skills. Notably, certain characteristics of children, such as birth order, are related to the HLE (Raikes et al., 2006). Despite emerging evidence on the importance of the HNE, there are marked differences in parents' reports of their literacy and numeracy practices with their children. Parents report valuing literacy over numeracy and engaging their children in literacy practices more frequently than numeracy practices (BlevinsKnabe et al., 2000; Cannon and Ginsburg, 2008). Given that the HLE and HNE have been shown to be distinct domains of the overall home learning environment, and that parents often place greater emphasis on literacy practices than numeracy practices, different parent and child characteristics may predict practices in each domain. Understanding the relations between child and parent characteristics and the HLE and HNE may inform subsequent targeting of interventions. Several key child and parent variables have been linked to the frequency of HLE and HNE activities. However, these variables are often studied separately, and have typically been examined in the context of either the HLE or HNE or the general home learning environment, but not both the HLE and HNE in the same sample. These variables include: child's age and sex, parent education, the number of children living in the home, and parental beliefs about the importance of attaining early academic milestones.

\section{Child's Age}

The relation between children's age and the home learning environment is important to understand given persistent 
evidence from longitudinal studies showing that the effects of the home learning environment may be strongest during the preschool years (Bradley et al., 2001). Children's age is related to the quality of stimulation in the home learning environment (Bradley et al., 2001) in that parents often improve the quality of both the HNE and HLE as children get older and approach school entry (Son and Morrison, 2010). However, there is considerable variation in the HLE that parents provide as children approach school entry (Rodriguez and Tamis-LeMonda, 2011). Findings on the HNE trajectory are more consistent. Parent reports indicate that the HNE differs for children of different ages, often indicating that older children are engaged in more advanced activities and younger children are engaged in more basic activities (LeFevre et al., 2002; Sonnenschein et al., 2012). Importantly, this is true for children even within the same age group (i.e., preschool-aged children). For example, Thompson et al. (2016) found that parents engage older preschool children (i.e., 4year-olds) in more frequent HNE activities than younger preschool children (i.e., 3year-olds).

\section{Child's Sex}

In addition to children's age, children's sex is another factor that may be related to differences in the HLE and HNE. Some research indicates that there are sex-based differences in parents' reports of children's interest in literacy favoring girls (Baroody and Diamond, 2013), but these sex-based differences are not always seen in the HLE (Sénéchal and LeFevre, 2014). There is also evidence that parents have sex-based biases toward their children's mathematics abilities. Compared to parents of girls, parents of boys typically report having higher expectations for their sons' mathematics achievement and believe they will be more successful in mathematics-related careers (Gunderson et al., 2012). Additionally, there is evidence that parents include mathematics-related language in interactions with boys more frequently than in interactions with girls (Chang et al., 2011).

\section{Parent Education}

Variability in children's early cognitive outcomes are related to differences in socioeconomic status (SES), and these SES-based differences can be seen in children as young as $18^{\circ}$ months (Fernald et al., 2013; Larson et al., 2015). One reason for SESbased differences may be the home learning environment. Parents with lower levels of education tend to provide less complex academic experiences at home (Saxe et al., 1987; Hoff et al., 2002) and a lower quality home learning environment overall (e.g., the frequency of reading, teaching numbers and letters, and parent-child play; Davis-Kean, 2005; Hoff et al., 2002). There is also evidence that children's numeracy skills are related to parent education (Anders et al., 2012), and one factor that may explain this relation is the HNE.

\section{Children in the Home}

Evidence suggests that the number of children living in the home is negatively related to the quality of the broad home learning environment (Baharudin and Luster, 1998). Downey (1995) found evidence that the more children there are living in the home, the more divided resources are (e.g., time and money).
Another explanation is that parents are less likely to use activities (e.g., playing board games) as learning opportunities when more than one child is involved (Benigno and Ellis, 2004). Although there are relations between the quality of the home environment and the number of children living in the home, it is unclear whether the number of children living in the home is related to the frequency of parent-child literacy and numeracy practices.

\section{Parents' Beliefs}

Parents' decisions to involve themselves in educational practices with their children at home is informed by their beliefs about child development, what they should be doing to raise their children, and how they can help their children succeed academically (Hoover-Dempsey et al., 2005). Researchers have examined the importance of parents' beliefs about a range of topics related to literacy, such as best practices for teaching children in the home (DeBaryshe, 1995) and how children develop skills (Bingham, 2007). Additionally, research demonstrates that parents' beliefs regarding the importance of academic development is related to the HLE (Sénéchal and LeFevre, 2002; Martini and Sénéchal, 2012). In the domain of numeracy, this research has focused on parents' opinions about numeracy (Blevins-Knabe et al., 2000; Missall et al., 2015), including the importance of reaching specific academic milestones in early elementary school (LeFevre et al., 2009; Skwarchuk et al., 2014). Less research has focused on the importance of numeracy as a predictor for parents of preschoolers. This relation is important to understand because children are more likely to be exposed to numeracy practices at home when their parents believe that home numeracy practices are important (Sonnenschein et al., 2012). These findings indicate that parents' beliefs may be related to their practices and are an important step in determining the importance of beliefs for practices. However, the sample examined by Sonnenschein and colleagues included children ranging from preschool to fourth grade. It is critical to determine if these relations are consistent specifically for preschool-aged children.

\section{Parents' Beliefs of the Importance of Literacy and Numeracy} In addition to understanding how parents' beliefs of the importance of literacy and numeracy development relate to the HLE and HNE, it is important to understand how these beliefs relate to each other. Parents often report believing that literacy development is more important than numeracy development (Blevins-Knabe et al., 2000; Cannon and Ginsburg, 2008). Additionally, parents report feeling less comfortable with numeracy than with literacy (Warren and Young, 2002), and often are unaware of numeracy practices beyond counting (Coates and Thompson, 1999), which may contribute to their beliefs that these skills are not as important as literacy skills. Parents' beliefs of the importance of skills is related to the frequency of their practices of those skills (LeFevre et al., 2002). As such, considering whether parents' beliefs in the importance of literacy and numeracy development differ, and the frequency of literacy and numeracy practices, may help researchers to understand whether promoting the importance of specific activities may also promote the frequency of those activities. 


\section{Present Study}

The primary purpose of the present study was to identify parentreported parent and child characteristics that are related to the HLE and HNE in a sample of preschool children. Specifically, we hypothesized that parent education and children's age would positively relate to the HLE and HNE, and the number of children in the home would negatively relate to the HLE and HNE. Additionally, we hypothesized that parents' beliefs of the importance of literacy would be positively related to the HLE and importance of numeracy would be positively related to the HNE. Due to evidence that parents have sex-based biases towards children's numeracy development, we hypothesized that parents would report more frequent HNE activities with boys than girls, but that sex-based differences would not be observed for the HLE. An additional goal was to examine differences in parents' views of literacy and numeracy. Specifically, we expected that parents would report believing literacy development to be more important than numeracy development and report more frequent literacy than numeracy practices.

\section{METHOD}

\section{Participants}

Participants were recruited from 16 preschools as a part of two larger studies examining the development of school readiness skills in preschoolers in the Midwestern United States. All parents of 3 to $5^{\circ}$ year-old children attending these schools were invited to participate in the studies given that they were comfortable enough with English to complete the questionnaire. Parents of 210 students completed both the background questionnaire and permission forms. Of those children, 11 were excluded from analyses because the child was in kindergarten (some preschools were located within elementary schools). The 199 preschoolers included in the analyses are 52\% female, 56\% white, $11 \%$ Latino, $7 \%$ Asian, $7 \%$ Black, and 19\% other or multiracial. Children ranged in age from 3.00 to $5.17^{\circ}$ years $(M=4.16, S D=0.57)$ at the time of parental consent. Parents' highest education ranged from eighth grade or less to obtainment of a graduate degree: $32 \%$ had a graduate degree, $25 \%$ had an Associate's or Bachelor's degree, and $43 \%$ had less than a college degree.

\section{Measures}

Participating parents completed a researcher-created background questionnaire modified from previous research (LeFevre et al., 2009). They provided information regarding their educational attainment, and characteristics of the family and home environment.

\section{Parent Education}

SES has been measured in a variety of ways, and parental educational attainment is considered a central component of SES (National Center for Educational Statistics, 2012; National Forum on Education Statistics, 2015). As such, parent education is used as a proxy for SES in this study. Parental education was categorized as follows: eighth grade education or less (1), some high school (2), GED (3), high school diploma (4), some college
(5), Associate's degree (6), Bachelor's degree (7), Master's degree (8), and $\mathrm{PhD}$ or postgraduate degree (9). If education was reported for two parents in the household, the highest level of education was included in models.

\section{Home Literacy and Numeracy Practices}

Parents also reported the frequency of practicing specific literacy and numeracy activities in the home with their children, on a sixpoint scale ranging from never (0) to multiple times a day (5). Four questions regarding the frequency of parents' practices were used to create a composite variable of the HLE $(\alpha=0.73)$ : reading storybooks, printing letters, identifying letters, and identifying letter sounds. Eight questions regarding the frequency of parents' numeracy practices were used to create a composite variable of the HNE $(\alpha=0.79)$ : counting objects, printing numbers, reading number storybooks, using number activity books, using the terms more than and less than, counting down, learning simple sums, and identifying written numbers.

\section{Parents' Beliefs of the Importance of Literacy and Numeracy}

In addition to home practices, parents rated how important they believed it was for their children to meet specific literacy and numeracy milestones by kindergarten entry, on a scale from not important (0) to very important (4). Five questions regarding parents' views of the importance of their children reaching specific literacy milestones by kindergarten entry were used to create a composite variable of parents' views of the importance of literacy $(\alpha=0.77)$ : identifying/recognizing alphabet letters, printing name, rehearsing the alphabet, sounding out three letter words, and printing alphabet letters. Seven questions regarding parents' views of the importance of their children reaching specific numeracy milestones by kindergarten entry were used to create a composite variable of parents' views of the importance of numeracy $(\alpha=0.86)$ : calculating simple sums, using the terms more than and less than, solving basic word problems, verbally counting to 40 , accurately counting 1 to 15 objects, reading numerals 1 to 10 , and counting out 1 to 5 objects from a larger group.

\section{Analytic Strategy}

Two multiple regression analyses were conducted to determine the predictors of parents' literacy and numeracy practices. We controlled for race/ethnicity in regression analyses by entering dummy coded variables for Black, Asian, Latino, and multiracial, using white as the reference group. Dependent variables included HLE and HNE composites and independent variables included child's age and sex, number of children in the home, parent education, and parents' beliefs of the importance of the domain (i.e., literacy or numeracy). Of parents who completed the background questionnaire, 4 (2\%) were missing all of the HLE and HNE items and 13 (6.5\%) were missing between one and three of the HLE or HNE items. Results from Little's missing completely at random (MCAR) test indicate that data were missing at random for both the $\operatorname{HLE}\left(\chi^{2}=3.47, \mathrm{df}=6, p=\right.$ $0.748)$ and $\operatorname{HNE}(\chi 2=71.60, \mathrm{df}=68, p=0.359)$ variables. Missing values function in SPSS was used to impute missing items using linear interpolation. 
TABLE 1 | Descriptive statistics of covariates, child outcomes, and home environment.

\begin{tabular}{|c|c|c|c|c|c|c|c|}
\hline Variable & $M$ & $S D$ & Range & Min & Max & Skew & Kurtosis \\
\hline Child age & 4.16 & 0.57 & 2.17 & 3.00 & 5.17 & -0.21 & -0.79 \\
\hline Children in the home & 2.01 & 0.95 & 5.00 & 1.00 & 6.00 & 1.06 & 1.59 \\
\hline $\begin{array}{l}\text { Importance of } \\
\text { literacy }\end{array}$ & 3.52 & 0.60 & 3.00 & 1.00 & 4.00 & -1.65 & 3.16 \\
\hline $\begin{array}{l}\text { Importance of } \\
\text { numeracy }\end{array}$ & 3.22 & 0.76 & 3.86 & 0.14 & 4.00 & -1.11 & 1.13 \\
\hline $\begin{array}{l}\text { Home literacy } \\
\text { environment }\end{array}$ & 3.00 & 1.00 & 4.50 & 0.50 & 5.00 & -0.27 & -0.54 \\
\hline $\begin{array}{l}\text { Home numeracy } \\
\text { environment }\end{array}$ & 2.20 & 0.87 & 4.75 & 0.13 & 4.88 & 0.25 & 0.03 \\
\hline
\end{tabular}

$\mathrm{N}=199$.

TABLE 2 | Correlations between parent and child characteristics and the home literacy and numeracy environments.

\begin{tabular}{llllllllll}
\hline 1 & 2 & 3 & 4 & 5 & 6 & 7 & 8 \\
\hline
\end{tabular}

1. Child age

2. Child sex

3. Parent

education

4. Children in $0.22^{\star \star} \quad 0.10-0.16^{\star}$

the home

5. Importance $\quad 0.20^{\star \star} \quad-0.03 \quad-0.06 \quad 0.00 \quad-$

of literacy

6. Importance $\quad 0.17^{\star \star} \quad-0.02 \quad 0.00 \quad 0.08 \quad 0.77^{\star \star} \quad-$

of numeracy

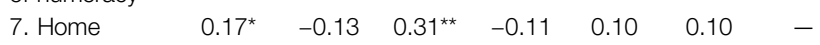

literacy

environment

8. Home

numeracy

environment

${ }^{*} \mathrm{p}<0.05 ;{ }^{* *} \mathrm{p}<0.01$

$\mathrm{N}=199$.

\section{RESULTS}

\section{Descriptive Statistics}

Means, standard deviations, skew, and kurtosis are presented in Table 1. Parents reported reading storybooks with their children almost daily $(M=3.76, S D=1.10)$ and reading number storybooks with their children about once per week $(M=2.47$, $S D=1.27)$. Parents reported printing letters $(M=2.48, S D=1.43)$ and numbers $(M=1.91, S D=1.38)$ less frequently. Of the numeracy practices, parents reported practicing simple sums with their children least; on average, parents practiced simple sums with their children only one to three times per month $(M=$ $1.43, S D=1.32$ ). The most common numeracy practice was counting objects, which parents reported doing with their children almost daily $(M=3.50, S D=0.95)$. Correlations are presented in Table 2 .
TABLE 3 | Multiple regression analysis predicting home literacy environment controlling for race/ethnicity.

\begin{tabular}{lrrll}
\hline Variable & $\boldsymbol{B}$ & SE & B & $\boldsymbol{R}^{\mathbf{2}}$ \\
& & & & 0.20 \\
Child age & 0.45 & 0.12 & $0.26^{\star \star \star}$ & \\
Child sex & -0.33 & 0.13 & $-0.17^{\star}$ & \\
Parent education & 0.15 & 0.04 & $0.31^{\star \star \star}$ & \\
Children in home & -0.14 & 0.07 & -0.13 & \\
Importance of literacy & 0.08 & 0.12 & 0.05 &
\end{tabular}

${ }^{*} p \leq 0.05 ;{ }^{* *} p \leq 0.01 ;{ }^{* *} p \leq 0.001$.

TABLE 4 | Multiple regression analysis predicting home numeracy environment controlling for race/ethnicity.

\begin{tabular}{lrrrr}
\hline Variable & $\boldsymbol{B}$ & SE & B & $\boldsymbol{R}^{\mathbf{2}}$ \\
& & & & 0.15 \\
Child age & 0.37 & 0.11 & $0.24^{\star * \star}$ & \\
Child sex & -0.07 & 0.12 & -0.04 & \\
Parent education & 0.09 & 0.04 & $0.21^{*}$ & \\
Children in the home & -0.06 & 0.07 & -0.07 & \\
Importance of math & 0.24 & 0.08 & $0.21^{\star *}$ & \\
\end{tabular}

${ }^{*} p \leq 0.05,{ }^{* *} p \leq 0.01 ;{ }^{* * *} p \leq 0.001$

\section{Predicting the Home Learning Environment Home Literacy Environment}

A multiple regression analysis was conducted to determine which factors predicted home literacy practices (see Table 3). As expected, parents of older children $(\beta=0.26, S E=0.12, p<$ $0.001)$ and parents with greater education attainment $(\beta=0.31$, $S E=0.04, p<0.001)$ engaged children in literacy practices more frequently than parents of younger children and those with lower educational attainment, respectively. Contrary to our hypothesis, the HLE score was also greater for female children $(\beta=-0.17, S E$ $=0.13, p=0.012)$. The number of children in the home and parents' beliefs of the importance of literacy were not significantly related to the HLE.

\section{Home Numeracy Environment}

A separate multiple regression analysis was conducted to determine which factors predict home numeracy practices (see Table 4). As expected, parents engaged older children in numeracy practices more frequently than younger children $(\beta=0.24, S E=0.11, p=0.001)$. Additionally, as hypothesized, parents with greater educational attainment reported more frequent numeracy practices than those with lower educational attainment $(\beta=0.21, S E=0.04, p=0.013)$. Finally, as expected, parents who reported believing mathematics skills to be more important reported more frequent parent-child numeracy practices $(\beta=0.21, S E=$ $0.08, p=0.004)$. Contrary to expectations, children's sex and the number of children in the home were not related to the frequency of HNE practices. 


\section{Differences Between Literacy and Numeracy}

Paired samples t-tests were conducted to analyze differences between parents' beliefs of the importance of literacy and numeracy, as well as the HLE and HNE. There was a significant difference between parents' beliefs of the importance of literacy $(M=3.52, S D=0.60)$ and the importance of numeracy $(M=3.22, S D=0.76), t(198)=$ 8.74, $p<0.001$, Cohen's $d=0.62$, indicating that parents believed literacy to be more important than numeracy. There was also a significant difference between the HLE $(M=3.00, S D=$ $1.00)$ and the HNE $(M=2.20, S D=0.87), t(198)=-15.58, p<$ 0.001 , Cohen's $d=1.11$, indicating that parents reported practicing literacy activities with their children more frequently than numeracy practices. Parents reported engaging in literacy practices two to five times per week and engaging in numeracy practices about once per week.

\section{DISCUSSION}

The results of this study suggest that there are key child and parent characteristics that are related to the frequency of parentchild literacy and numeracy practices in the home environment. However, these characteristics may not always be the same across academic domains. Understanding predictors of parent-child literacy and numeracy practices, particularly within the same sample of parents and children, is important for researchers' understanding of how to assist parents in providing an adequate HLE and HNE for their children.

\section{Factors Related to the Home Literacy and Numeracy Environments Children's Age}

As hypothesized, children's age was related to both the HLE and the HNE. On average, compared to younger children, parents reported engaging older children in more frequent literacy and numeracy activities. Research has found that parents adjust home literacy practices as elementary-aged children develop more advanced skills (Sénéchal and LeFevre, 2014), and one way this may be reflected is in more frequent literacy practices. This has also been found for numeracy practices with preschool-aged children; parents tend to engage older preschool children with more complex numeracy activities than younger preschool children (Thompson et al., 2016). A potential explanation for this is that parents do not believe that younger children are developmentally ready to engage in some of the specific practices that were reported (e.g., writing letters or numerals). Further, parents' awareness of the importance of these practices may increase as children grow closer to kindergarten entry.

\section{Children's Sex}

In contrast to our hypotheses, children's sex was related to the HLE, but not the HNE. However, it is important to note that sex was not significantly correlated with either the HLE or HNE (see Table 2). There may not have been a difference for the HNE because parents reported infrequent engagement in numeracy practices overall, resulting in limited variability in the $\mathrm{HNE}$ variable. Although there is evidence that sex biases for mathematics are present as early as preschool (Gunderson et al., 2012), the current sample may not have been practicing numeracy activities enough for such differences to be apparent. Given that the bivariate correlation was not significant, it is possible that the relation between sex and the HLE was a spurious finding.

\section{Parent Education}

As hypothesized, parent education was positively related to both the HLE and the HNE. These findings are in line with previous research that has found that parents with higher educational attainment engage their children in more complex academic activities compared to parents with lower educational attainment (Hoff et al., 2002). Parents with lower educational attainment may be working multiple jobs or have atypical work hours, which may limit their ability to engage their children in academic activities. Additionally, parents with lower educational attainment may undervalue the role they play in helping their children develop early academic skills, or feel that teachers are better suited to teach their children, or may not have the resources to do so (Jones and Prinz, 2005). It is important to identify the barriers that parents face in order to support them in providing a quality HLE and HNE.

\section{Children in the Home}

Contrary to expectations, the number of children living in the home was not related to the frequency of HLE or HNE practices. This finding is inconsistent with previous research that has found that the number of children in the home is negatively related to the home learning environment (Baharudin and Luster, 1998). However, previous research showing this relation often measured the general home environment and did not assess specific aspects (e.g., HLE and HNE). There are a few possible explanations for the lack of relation between the number of children in the home and the HLE and HNE. Some practices, such as reading, may be easily done with more than one child. Additionally, if children had older, school-aged siblings, parents may include younger children in academic activities while assisting older children with homework. Future research on the home learning environment should consider the role of siblings in more detail by collecting information on ages of the children (rather than only the number of children) and more specific contexts in which practices are conducted.

\section{Parents' Beliefs}

Our hypotheses regarding parents' beliefs were partially supported. Parents' beliefs in the importance of numeracy was significantly related to the HNE, but parents' beliefs in the important of literacy was not significantly related to the HLE. The findings regarding the HLE are in contrast to other findings that parents' beliefs of the importance of literacy are related to the HLE (Silinskas et al., 2020). The relation between parents' beliefs 
and the HNE is aligned with and contributes to previous findings that children are more likely to be exposed to numeracy practices when their parents report believing numeracy development is important (Sonnenschein et al., 2012). The finding that parents' beliefs are related to the HNE but not the HLE may be because parents report differential levels of importance for literacy and numeracy. Whereas literacy exposure is widely recognized as being an important part of development, the importance of exposure to numeracy activities early on is not as widely recognized in the United States (Mazzocco, 2016). As such, parents who hold stronger beliefs regarding numeracy development are more likely to engage their children in numeracy-related activities.

In line with previous research findings and our hypothesis, parents reported believing that literacy development is more important than numeracy development (Blevins-Knabe et al., 2000; Cannon and Ginsburg, 2008). Further, parents reported engaging their children in literacy practices more frequently than numeracy practices. Differences between parents' literacy and numeracy beliefs and practices are likely a result of the widespread public emphasis that is placed on literacy development. In contrast, parents of preschool-aged children rarely receive information on the importance of numeracy development, despite the fact that this development is longitudinally related to children's achievement (Nguyen et al., 2016).

\section{Limitations and Future Directions}

A few limitations of this study should be noted. First, there are likely several additional factors that are related to the HLE and HNE that were not measured in this study. Given that the included variables explained only $19 \%$ and $12 \%$ of the HLE and HNE, respectively, future studies should include additional factors, such as social risk (Foster et al., 2005), to determine their relation to the HLE and HNE and to potentially explain additional variance. Additionally, we only had information on how many children were living in the home and not birth order. Future studies should consider collecting this information as birth order may be related to the home learning environment (Bradley and Caldwell, 1984). Second, the indicators of the HLE and HNE relied on parent report. Although the infrequency of numeracy practices indicates that parents may not have overestimated the frequency of practices, self-report always includes a potential for reporter bias and issues related to social desirability. It is also important to note that our findings may be affected by shared method variance. Researchers may consider the use of daily diary methods, direct observation, or video recording parent-child interactions in future studies. Observations and recordings would also allow researchers to consider the quality of the interactions, rather than being limited to quantity. Third, the measures of the HLE and HNE were not exhaustive, particularly for the HLE measure. Future research should include additional activities that parents may engage in with their children. Fourth, this study was concurrent in nature. Future research should consider assessing how parent and child characteristics are related to the HLE and HNE longitudinally. Finally, children's outcomes were not included in this study. Future research should address the relations between parent and child characteristics related to the HLE and HNE, measures of the HLE and HNE, and children's literacy and numeracy skills.

\section{Implications}

Awareness of the characteristics that are related to the HLE and HNE may allow researchers and practitioners to identify characteristics of parents and children who may benefit from additional support in building a higher quality HLE and HNE. Additionally, the findings indicate particular factors that interventions may need to address in order to effectively implement change, such as emphasizing the importance of early numeracy development in order to affect change in the HNE. Additionally, there is a need to support parents in their involvement in HNE activities, such as providing them with suggestions for activities and strategies for incorporating numeracy at home.

The findings may also help researchers better understand the mechanisms underlying parents' choices to engage with their children in various learning activities. Given that HLE and HNE practices have implications for children's outcomes, it may not be that there is a direct relation between child or family factors (e.g., parental education) and children's outcomes, but rather that the HLE and HNE may mediate the relations. Future studies should address whether the HLE and HNE mediate the relation between family factors and preschool children's outcomes, and particularly look at this potential mediation within the same sample of children. Identifying the shared and unique characteristics related to learning experiences in the home, particularly numeracy experiences, may help researchers understand the complex relations between the HLE, HNE, and children's literacy and numeracy skills. Further, the findings that some family and child characteristics predict the HLE or HNE, but not both, support previous research indicating that the HLE and HNE are related but distinct factors of the home environment (Napoli and Purpura, 2018). These differences may indicate that rather than examining the home learning environment as a broad construct, researchers should consider domain-specific aspects of the home environment.

Findings that parents value literacy development over numeracy development may also indicate the need for public dissemination of information regarding the importance of early numeracy development, such as strategies used to circulate information on literacy (Mazzocco, 2016). Educators and practitioners who work with young children and their parents may be helpful resources for distributing this information. If parents continue to receive information regarding the importance of only early literacy skills, and do not receive the same messages about numeracy skills, they will likely continue to prioritize parent-child literacy practices over numeracy practices.

\section{DATA AVAILABILITY STATEMENT}

The datasets generated for this study are available on request to the corresponding author.

\section{ETHICS STATEMENT}

The studies involving human participants were reviewed and approved by the Institutional Review Board, Purdue University. The patients/participants provided their written informed consent to participate in this study. 


\section{AUTHOR CONTRIBUTIONS}

AN made substantial contributions to the conception and drafting of the manuscript. IK made substantial contributions

\section{REFERENCES}

Anders, Y., Rossbach, H.-G., Weinert, S., Ebert, S., Kuger, S., Lehrl, S., et al. (2012). Home and preschool learning environments and their relations to the development of early numeracy skills. Early Child. Res. Q. 27, 231-244. doi:10.1016/j.ecresq.2011.08.003

Baharudin, R., and Luster, T. (1998). Factors related to the quality of the home environment and children's achievement. J. Fam. Issues 19, 375-403. doi:10. $1177 / 019251398019004002$

Baker, C. E. (2014). African American fathers' contributions to children's early academic achievement: evidence from two-parent families from the early childhood longitudinal study-birth Cohort. Early Educ. Dev. 25, 19-35. doi:10.1080/10409289.2013.764225

Baroody, A. E., and Diamond, K. E. (2013). Measures of preschool children's interest and engagement in literacy activities: examining gender differences and construct dimensions. Early Child. Res. Q. 28, 291-301. doi:10.1016/j.ecresq. 2012.07.002

Benigno, J. P., and Ellis, S. (2004). Two is greater than three: effects of older siblings on parental support of preschoolers' counting in middle-income families. Early Child. Res. Q. 19, 4-20. doi:10.1016/j.ecresq.2004.01.006

Bingham, G. E. (2007). Maternal literacy beliefs and the quality of mother-child book-reading interactions: associations with children's early literacy development. Early Educ. Dev. 18, 23-49. doi:10.1080/10409280701274428

Blevins-Knabe, B., Austin, A. B., Musun, L., Eddy, A., and Jones, R. M. (2000). Family home care providers' and parents' beliefs and practices concerning mathematics with young children. Early Child. Dev. Care 165, 41-58. doi:10. 1080/0300443001650104

Bradley, R. H., and Caldwell, B. M. (1984). The HOME Inventory and family demographics. Dev. Psychol. 20 (2), 315-320. doi:10.1037/0012-1649.20.2.315

Bradley, R. H., Corwyn, R. F., McAdoo, H. P., and Coll, C. G. (2001). The home environments of children in the United States part I: variations by age, ethnicity, and poverty status. Child. Dev. 72, 1844-1867. doi:10.1111/1467-8624.t01-100382

Cannon, J., and Ginsburg, H. P. (2008). "Doing the math": maternal beliefs about early mathematics versus language learning. Early Educ. Dev. 19, 238-260. doi:10.1080/10409280801963913

Chang, A., Sandhofer, C. M., and Brown, C. S. (2011). Gender biases in early number exposure to preschool-aged children. J. Lang. Soc. Psychol. 30, 440-450. doi:10.1177/0261927X11416207

Claessens, A., Duncan, G., and Engel, M. (2009). Kindergarten skills and fifth-grade achievement: evidence from the ECLS-K. Econ. Educ. Rev. 28, 415-427. doi:10. 1016/j.econedurev.2008.09.003

Coates, G. D., and Thompson, V. (1999). "Involving parents of four- and five-yearolds in their children's mathematics education: the FAMILY MATH experience," in Mathematics in the early years. Editor J. V. Copley (Reston, United States: National Council of Teachers of Mathematics), 205-214.

Davis-Kean, P. E. (2005). The influence of parent education and family income on child achievement: the indirect role of parental expectations and the home environment. J. Fam. Psychol. 19, 294-304. doi:10.1037/0893-3200.19. 2.294

DeBaryshe, B. D. (1995). Maternal belief systems: linchpin in the home reading process. J. Appl. Dev. Psychol. 16, 1-20. doi:10.1016/0193-3973(95)90013-6

Downey, D. B. (1995). When bigger is not better: family size, parental resources, and children's educational performance. Am. Sociol. Rev. 60, 746-761. doi:10. 2307/2096320

Fernald, A., Marchman, V. A., and Weisleder, A. (2013). SES differences in language processing skill and vocabulary are evident at 18 months. Dev. Sci. 16, 234-248. doi:10.1111/desc.12019

Foster, M. A., Lambert, R., Abbott-Shim, M., McCarty, F., and Franze, S. (2005). A model of home learning environment and social risk factors in relation to to the conception and drafting of the manuscript. JL made substantial contributions to analyses and revisions. SS made substantial contributions to the conception and revisions. DP made substantial contributions to the conception and revisions.

children's emergent literacy and social outcomes. Early Child. Res. Q. 20, 13-36. doi:10.1016/j.ecresq.2005.01.006

Gunderson, E. A., Ramirez, G., Levine, S. C., and Beilock, S. L. (2012). The role of parents and teachers in the development of gender-related math attitudes. Sex Roles 66 (12), 153-166. doi:10.1007/s11199-011-9996-2

Hart, S. A., Ganley, C. M., and Purpura, D. J. (2016). Understanding the home math environment and its role in predicting parent report of children's math skills. PLoS One 11 (12), e0168227. doi:10.1371/journal.pone.0168227

Hoff, E., Laursen, B., and Tardif, T. (2002). "Socioeconomic status and parenting," in Handbook of parenting. Biology and ecology of parenting. Editor M. Bornstein (Mahwah, NJ: Lawrence Erlbaum Associates), Vol. 2, 231-252.

Hoover-Dempsey, K. V., Walker, J. M. T., Sandler, H. M., Whetsel, D., Green, C. L. Wilkins, A. S., et al. (2005). Why do parents become involved? research findings and implications. Elem. Sch. J. 106 (2), 105-130. doi:10.1086/499194

Jones, T. L., and Prinz, R. J. (2005). Potential roles of parental self-efficacy in parent and child adjustment: a review. Clin. Psychol. Rev. 25, 341-363. doi:10.1016/j. cpr.2004.12.004

Kleemans, T., Peeters, M., Segers, E., and Verhoeven, L. (2012). Child and home predictors of early numeracy skills in kindergarten. Early Child. Res. Q. 27, 471-477. doi:10.1016/j.ecresq.2011.12.004

Klibanoff, R. S., Levine, S. C., Huttenlocher, J., Vasilyeva, M., and Hedges, L. V. (2006). Preschool children's mathematical knowledge: the effect of teacher "math talk". Dev. Psychol. 42, 59-69. doi:10.1037/0012-1649.42.1.59

Larson, K., Russ, S. A., Nelson, B. B., Olson, L. M., and Halfon, N. (2015). Cognitive ability at kindergarten entry and socioeconomic status. Pediatrics 135, e440-e448. doi:10.1542/peds.2014-0434

LeFevre, J.-A., Clarke, T., and Stringer, A. P. (2002). Influences of language and parental involvement on the development of counting skills: comparisons of French- and English-speaking Canadian children. Early Child. Dev. Care 172, 283-300. doi:10.1080/03004430212127

LeFevre, J.-A., Polyzoi, E., Skwarchuk, S. L., Fast, L., and Sowinski, C. (2010). Do home numeracy and literacy practices of Greek and Canadian parents predict the numeracy skills of kindergarten children?. Int. J. Early Years Educ. 18, 55-70. doi:10.1080/09669761003693926

LeFevre, J.-A., Skwarchuk, S.-L., Smith-Chant, B. L., Fast, L., Kamawar, D., and Bisanz, J. (2009). Home numeracy experiences and children's math performance in the early school years. Can. J. Behav. Sci. 41, 55-66. doi:10. 1037/a0014532

Martini, F., and Sénéchal, M. (2012). Learning literacy skills at home: parent teaching, expectations, and child interest. Can. J. Behav. Sci. 44, 210-221. doi: $10.1037 / \mathrm{a} 0026758$

Mazzocco, M. (2016). Mathematics awareness Month: why should pediatricians be aware of mathematics and numeracy?. J. Dev. Behav. Pediatr. 37, 251-253. doi:10.1097/DBP.0000000000000294

Melhuish, E. C., Phan, M. B., Sylva, K., Sammons, P., Siraj-Blatchford, I., and Taggart, B. (2008). Effects of the home learning environment and preschool center experience upon literacy and numeracy development in early primary school. J. Soc. Issues 64, 95-114. doi:10.1111/j.1540-4560. 2008.00550.x

Missall, K., Hojnoski, R. L., Caskie, G. I. L., and Repasky, P. (2015). Home numeracy environments of preschoolers: examining relations among mathematical activities, parent mathematical beliefs, and early mathematical skills. Early Educ. Dev. 26, 356-376. doi:10.1080/10409289.2015.968243

Napoli, A. R., and Purpura, D. J. (2018). The home literacy and numeracy environment in preschool: cross-domain relations of parent-child practices and child outcomes. J. Exp. Child Psychol. 166, 581-603. doi:10.1016/j.jecp. 2017.10.002

National Center for Educational Statistics (2012). Improving the measurement of socioeconomic status for the National Assessment of Educational Progress: a theoretical foundation. Available at: https://nces.ed.gov/nationsreportcard/pdf/ researchcenter/Socioeconomic_Factors.pdf (Accessed April 2, 2018). 
National Forum on Education Statistics (2015). Forum guide to alternative measures of socioeconomic status in education data systems. Available at: https://nces.ed.gov/pubs2015/2015158.pdf (Accessed April 2, 2018).

Nguyen, T., Watts, T. W., Duncan, G. J., Clements, D. H., Sarama, J. S., Wolfe, C., et al. (2016). Which preschool mathematics competencies are most predictive of fifth grade achievement?. Early Child Res. Q. 36, 550-560. doi:10.1016/j.ecresq.2016.02.003

Niklas, F., and Schneider, W. (2013). Casting the die before the die is cast: the importance of the home numeracy environment for preschool children. Eur. J. Psychol. Educ., 29, 327-345. doi:10.1007/s10212-013-0201-6

Pagani, L. S., Fitzpatrick, C., Archambault, I., and Janosz, M. (2010). School readiness and later achievement: a French Canadian replication and extension. Dev. Psychol. 46, 984-994. doi:10.1037/a0018881

Parker, F. L., Boak, A. Y., Griffin, K. W., Ripple, C., and Peay, L. (1999). Parentchild relationship, home learning environment, and school readiness. Sch. Psychol. Rev. 28, 413-425. doi:10.1080/02796015.1999.12085974

Raikes, H., Pan, B. A., Luze, G., Tamis-LeMonda, C. S., Brooks-Gunn, J., Constantine, J., et al. (2006). Mother-child bookreading in low-income families: correlates and outcomes during the first three years of life. Child Dev. 77, 924-953. doi:10.1111/j.1467-8624.2006.00911.x

Rodriguez, E. T., and Tamis-LeMonda, C. S. (2011). Trajectories of the home learning environment across the first 5 years: associations with children's vocabulary and literacy skills in prekindergarten. Child Dev. 82, 1058-1075. doi:10.1111/j.1467-8624.2011.01614.x

Saxe, G. B., Guberman, S. R., Gearhart, M., Gelman, R., Massey, C. M., and Rogoff, B. (1987). Social processes in early number development. Monogr. Soc. Res. Child Dev. 52, i. doi:10.2307/1166071

Schmitt, S. A., Simpson, A. M., and Friend, M. (2011). A longitudinal assessment of the home literacy environment and early language. Infant Child Dev. 20, 409-431. doi:10.1002/icd.733

Sénéchal, M., and LeFevre, J.-A. (2014). Continuity and change in the home literacy environment as predictors of growth in vocabulary and reading. Child Dev. 85, 1552-1568. doi:10.1111/cdev.12222

Sénéchal, M., and LeFevre, J.-A. (2002). Parental involvement in the development of children's reading skills: a five-year longitudinal study. Child Dev. 73, 445-460. doi:10.1111/1467-8624.00417

Sénéchal, M. (2015). "Young children's home literacy experiences," in The Oxford handbook of reading. Editors A. Pollatsek and R. Treiman (Oxford, United Kingdom: Oxford University Press), 397-414.

Silinskas, G., Torppa, M., Lerkkanen, M.-K., and Nurmi, J.-E. (2020). The home literacy model in a highly transparent orthography. Sch. Eff. Sch. Improv. 31 (1), 80-101. doi:10.1080/09243453.2019.1642213

Skwarchuk, S.-L., Sowinski, C., and LeFevre, J.-A. (2014). Formal and informal home learning activities in relation to children's early numeracy and literacy skills: the development of a home numeracy model. J. Exp. Child Psychol. 121, 63-84. doi:10.1016/j.jecp.2013.11.006

Son, S.-H., and Morrison, F. J. (2010). The nature and impact of changes in home learning environment on development of language and academic skills in preschool children. Dev. Psychol. 46, 1103-1118. doi:10.1037/ a0020065

Sonnenschein, S., Baker, L., and Serpell, R. (2010). “The early childhood project: a 5 -year longitudinal investigation of children's literacy development in sociocultural context," in Literacy development and enhancement across orthographies and cultures. Editors D. Aram and O. Lorat (Berlin, Germany: Springer), 85-96. doi:10.1007/978-1-4419-0834-6

Sonnenschein, S., Galindo, C., Metzger, S. R., Thompson, J. A., Huang, H. C., and Lewis, H. (2012). Parents' beliefs about children's math development and children's participation in math activities. Child Dev. Res. 2012, 1-13. doi: $10.1155 / 2012 / 851657$

Sonnenschein, S., Metzger, S. R., and Thompson, J. A. (2016). Low-income parents' socialization of their preschoolers' early reading and math skills. Res. Hum. Dev. 13 (3), 207-224. doi:10.1080/15427609.2016.1194707

Starkey, P., Klein, A., and Wakeley, A. (2004). Enhancing young children's mathematical knowledge through a pre-kindergarten mathematics intervention. Early Child. Res. Q. 19, 99-120. doi:10.1016/j.ecresq.2004.01.002

Thompson, R. J., Napoli, A. R., and Purpura, D. J. (2017). Age-related differences in the relation between the home numeracy environment and numeracy skills. Inf. Child. Dev. 26 (5), e2019. doi:10.1002/icd.2019

Warren, E., and Young, J. (2002). Parent and school partnerships in supporting literacy and numeracy. Asia-Pac. J. Teach. Educ. 30, 217-228. doi:10.1080/ 1359866022000048385

Wood, C. (2002). Parent-child pre-school activities can affect the development of literacy skills. J. Res. Read. 25, 241-258. doi:10.1111/1467-9817.00173

Young-Loveridge, J. M. (1989). The relationship between children's home experiences and their mathematical skills on entry to school. Early Child. Dev. Care 43, 43-59. doi:10.1080/030044389043010

Conflict of Interest: The authors declare that the research was conducted in the absence of any commercial or financial relationships that could be construed as a potential conflict of interest.

Copyright (C) 2021 Napoli, Korucu, Lin, Schmitt and Purpura. This is an open-access article distributed under the terms of the Creative Commons Attribution License (CC BY). The use, distribution or reproduction in other forums is permitted, provided the original author(s) and the copyright owner(s) are credited and that the original publication in this journal is cited, in accordance with accepted academic practice. No use, distribution or reproduction is permitted which does not comply with these terms. 


\section{OPEN ACCESS}

Edited by:

Sergio Tobon,

University Center CIFE, Mexico

Reviewed by:

Rabiu Muazu Musa

University Malaysia Terengganu,

Malaysia

Christian Tarchi,

University of Florence, Italy Jason Small,

Oregon Research Institute,

United States

*Correspondence:

Simone Lehrl

simone.lehrl@uni-bamberg.de

Specialty section: This article was submitted to Educational Psychology, a section of the journal

Frontiers in Psychology

Received: 07 August 2020 Accepted: 26 January 2021

Published: 25 March 2021

Citation:

Lehrl S, Linberg A, Niklas F and Kuger S (2021) The Home Learning

Environment in the Digital

Age-Associations Between

Self-Reported "Analog" and "Digital"

Home Learning Environment and Children's Socio-Emotional

and Academic Outcomes.

Front. Psychol. 12:592513. doi: 10.3389/fpsyg.2021.592513
The Home Learning Environment in the Digital Age-Associations Between Self-Reported "Analog" and "Digital" Home Learning Environment and Children's Socio-Emotional and Academic Outcomes

\author{
Simone Lehrl'*, Anja Linberg ${ }^{2}$, Frank Niklas ${ }^{3}$ and Susanne Kuger ${ }^{2}$ \\ ${ }^{1}$ Department of Psychology, University of Bamberg, Bamberg, Germany, ${ }^{2}$ Department of Social Monitoring \\ and Methodology, German Youth Institute, Munich, Germany, ${ }^{3}$ Department of Psychology, LMU Munich, Munich, Germany
}

We analyzed the association between the analog and the digital home learning environment (HLE) in toddlers' and preschoolers' homes, and whether both aspects are associated with children's social and academic competencies. Here, we used data of the national representative sample of Growing up in Germany II, which includes 4,914 children aged 0-5 years. The HLE was assessed via parental survey that included items on the analog HLE (e.g., playing word games, reading, and counting) and items on the digital HLE (e.g., using apps or playing with apps). Children's socio-emotional, practical life skills, and academic competencies were assessed via standardized parental ratings. Our results indicate that there are two dimensions of the HLE, an analog and a digital, that are slightly positively associated, especially in the toddler age group. For toddlers, only analog HLE activities were associated with better socio-emotional outcomes and practical life skills. However, interaction effects indicate that toddlers with less frequent analog HLE activities showed better socio-emotional skills in households with more frequent digital activities. For preschoolers, digital HLE activities were associated with weaker socio-emotional skills but higher academic skills, although the analog HLE shows higher effect sizes for the academic outcomes. Our study points out that analog and digital HLE activities seem to be partly associated, but not interchangeable. Further, they seem to be important variables that can explain individual differences in young children's socio-emotional, practical life, and academic competencies. However, digital media usage at home may also have negative effects on children's social-emotional competencies. This association needs to be investigated further.

Keywords: preschoolers, toddlers, home learning environment (HLE), digital media and learning, socio-emotional competencies, academic competencies 


\section{INTRODUCTION}

It is becoming increasingly evident that the nature of activities in the home learning environment (HLE) in the digital age of the 21st century is rapidly changing in terms of the resources available and the ways in which these resources are used in different contexts (Marsh et al., 2005). Digital media are commonplace nowadays in families, and European children grow up in media-rich homes (Chaudron et al., 2015). As children's immediate caregivers usually interact with digital media daily, children consider digital devices as very important (Wirth et al., 2020b). Toddlers and preschoolers learn by observing their parents and by interacting with older siblings, and from an early age onward, they are in contact with a wide range of digital tools daily and imitate older family members' usage (Wong, 2015).

On average, many 3- to 5-year-olds use digital technologies more than 30 min on weekdays and even longer during weekends and thus use computer-based and internet-based digital technologies at home on a regular basis (Palaiologou, 2016). Further, about a third of the children aged 0-3 years already participate in computer- and internet-based activities at home, regularly (Palaiologou, 2016). Given that children use digital media from an early age onwards, these tools can be utilized to support children's competencies development.

The social context is crucial for learning, and this also applies to interactions with digital media (Buckingham, 2007). Given the changes that have taken place in our digital environment, concepts that have been developed to describe the early years HLE may need reconsideration. In this paper, we therefore investigate the association between the analog and the digital HLE and its associations with children's social and academic outcomes from the first year of life onwards.

\section{The Concept of the "Analog" HLE and Its Effects on Child Outcomes}

Children's HLEs are typically described by the access to books, the frequency of reading to the children, and the availability of learning-oriented materials and toys. Further, parent-child interactions during a variety of learning opportunities within and out of the home, such as singing songs to the child, rhyming, and visiting cultural places (e.g., Bradley and Caldwell, 1984; Melhuish et al., 2008), and the quality of interactions during play or shared reading are considered important aspects of the HLE (e.g., Son and Morrison, 2010; Linberg, 2018; Tamis-LeMonda et al., 2019; Lehrl et al., 2020a). Although many research studies currently conceptualize the HLE domain-specifically according to the home literacy and/or numeracy model into aspects that capture formal and informal stimulation of language, literacy, and mathematics (e.g., Sénéchal and LeFevre, 2002; Manolitsis et al., 2013; Skwarchuk et al., 2014; Niklas et al., 2016; Lehrl et al., 2020a), there are also numerous studies that combine the different facets of the HLE into one indicator to capture the overall stimulation of the HLE (e.g., Melhuish et al., 2008; Son and Morrison, 2010; Niklas and Schneider, 2017; Kuger et al., 2019).
For instance, within the Effective Preschool, Primary and Secondary Education Project (EPPSE 3-16), an indicator of the early years HLE was developed that combined the frequency of seven educational activities, such as the frequency of shared book reading, visits to the library, playing games with numbers, teaching the child the alphabet, playing with letters, and teaching the child songs or nursery rhymes (Melhuish et al., 2008). This measure predicted preschooler's literacy and numeracy outcomes, reading, and mathematics 2 years later (Melhuish et al., 2008), as well as second grader's school grades (Bywater et al., 2015). Similarly, Son and Morrison (2010) found positive associations between the quality of the home environment as measured by a global indicator of the Home Observation for Measurement of the Environment Inventory (HOME, Bradley and Caldwell, 1984) and child outcomes including general cognitive ability and language. Furthermore, Niklas and Schneider (2017) found positive links between a kindergarten HLE-Measure comprising similar activities as in the EPPSE-HLE Index (Melhuish et al., 2008) and children's literacy and math concurrent and grade 4 outcomes in a German sample. Consequently, when predicting various child outcomes, a broad HLE-Measure might serve as an economic, readily assessable alternative. This assumption is supported by findings of absent domain-specific effects of specific HLE measures on specific developmental domains when contrasted to each other (for an overview see, e.g., Lehrl et al., 2020a).

In addition to the well-documented positive effects of the HLE on language and academic outcomes, there is also evidence that HLE effects are not limited to these domains but are also important for children's socio-emotional and self-regulation skills (Huntsinger et al., 2016; Rose et al., 2018; Wirth et al., 2019). In a longitudinal study, Rose et al. (2018) investigated the predictive role of the early HLE on children's cooperative behavior, physical aggression, and emotional self-regulation at age 8 , mainly mediated through early language competencies (see Wirth et al., 2019 for similar results). Further, intervention studies showed that enhancing the quality of the HLE also impacts on very young (i.e., 12 months old; O'Farrelly et al., 2018) and older (i.e., 4 years old; Bierman et al., 2015) children's socioemotional competencies.

To sum up, an extensive body of research has shown that the HLE is positively associated with children's language, literacy, math, and socio-emotional skills development in early childhood (Anders et al., 2012; Niklas et al., 2018; Rose et al., 2018; TamisLeMonda et al., 2019; Lehrl et al., 2020b) and beyond (e.g., Niklas and Schneider, 2017; Rose et al., 2018; Lehrl et al., 2020a). However, against the background of the increasing use of digital media within the home, we are in need of research investigating how such "analog" HLEs are associated with "digital" HLEs and how both concepts relate to child outcomes in different age groups and to various developmental domains.

\section{The Concept of "Digital" HLE and Its Effects on Child Outcomes}

Similar to the "analog" HLE, children's "digital" HLEs may be described by the access and the frequency of usage as well as the 
quality of assistance/support while interacting with digital tools in the family context. This includes the access to and frequency of using, for instance, electronic toys and touchscreen devices and the parental stimulation within such contexts. In addition to e-books, digital game-based learning, which uses the entertaining power of digital games, serves an educational purpose, such as teaching math or language (All et al., 2016). An explosion in available e-books and apps has been noted over the last couple of years, especially for young children, and the majority of top-selling paid apps in 2011 were targeted for young children (Judge et al., 2015).

Although there is widespread concern that time spent with screen media replaces more traditional forms of learning (e.g., Cristia and Seidl, 2015), other researchers point out that digital technologies should be viewed as being complimentary to other resources, rather than alternatives or in competition with traditional modalities (Yelland, 2018). Through employing animated images and sound effects, digital technologies provide new and interesting experiences to the child that might motivate children more than analog tools to participate in learning opportunities (Hirsh-Pasek et al., 2015). Clearly, the HLE is an important space where digital literacy can be both employed and cultivated, and thus children's learning and development can be supported (Meyers et al., 2013).

Actually, young children's usage of touchscreen tablets is positively associated with emergent literacy, print awareness, print knowledge, and sound knowledge (Neumann, 2016). Further, digital media can be adapted more easily to match children's needs and interests concerning content selection and text layout (Biancarosa and Griffiths, 2012). Consequently, in many countries, a higher number of digital devices in households coincide with better reading skills in children (Mullis and Martin, 2017). According to these findings, a digital HLE offers new possibilities to support children's literacy development and reflects the current convergence of literacy and multimedia skills (Wirth et al., 2020a). In addition, Korat and Shneor (2019) showed that joint mother-child e-book reading compared with independent e-book reading is more effective for children's receptive and expressive word learning. Consequently, it is preferable for young children not to use digital media alone or only passively as digital media cannot act as a substitute for human interaction (see also Hirsh-Pasek et al., 2015). However, in Germany, where this study was conducted, parents in only every second household supervise their (preschool-aged) children's use of digital media (Marci-Boehncke et al., 2012).

Similarly, research has shown that digital learning tools can support the development of children's numeracy competencies when used together with parents. For instance, Berkowitz et al. (2015) used an iPad app to deliver short numerical story problems to first graders and their parents. Compared with a reading control group, children's mathematical achievement increased significantly.

As the quality of the analog HLE is associated with children's socio-emotional competencies (e.g., O'Farrelly et al., 2018; Wirth et al., 2019), it is to be expected that the digital learning environment in families should also influence these competencies. However, research evidence regarding this point is mixed, and thus further studies and analyses are needed. In general, reviews suggest that screen time (TV, computer use, and video game) is not or negatively associated with children's social skills. For instance, Ogelman et al. (2016) analyzed the association between 162 5- and 6-year-old children's screen time and their social skills, which were rated by teachers. Their results revealed that children's digital media usage duration had no effect on social skills.

Gómez et al. (2013) investigated the effect of collaborative learning on a single display computer on the social skills of 2685 and 6-year-old children in 10 classrooms in a quasi-experimental design. The control group followed the collaborative planned activities based on the national kindergarten curriculum in an analog way. In the experimental group, children engaged in collaborative activities in a computer classroom twice each week for a period of 4 months. The activities included exchange, sort, and roleplay applications. The control and experimental groups did not differ concerning the content of activities. The experimental group showed significantly greater scores on social skills than the control group $(d=0.51)$. Some further conclusions can be drawn from Radesky et al. (2016) who examined how parents use digital media to calm difficult infants/toddlers. Toddlers rated as having social-emotional difficulties were more likely to be exposed to digital media to calm down when upset than their peers without social-emotional difficulties.

To sum up, there is some evidence that digitally supported learning with very specific high-quality digital media can support children's learning and development (e.g., Gómez et al., 2013; Berkowitz et al., 2015; Neumann, 2016). However, there is a lack of research evidence concerning the importance of the broader defined digital HLE, i.e., access and frequency of usage of digital media, for various child outcomes, and its conjunction with the analog HLE in this context.

\section{THE PRESENT STUDY}

With the widespread use of tablets and smartphones, children have increasing opportunities for interacting and learning via electronic devices. Unfortunately, research has not kept up with the speed of the spread of digital media-based interactions during childhood. Although research on preschool-aged children's digital media use is increasing to some extent, studies of infant and toddlers' digital media use are still rare (Chaudron et al., 2015). Consequently, research is needed to find out whether early shared use of digital media might harm or foster children's development across various domains and whether digital media interactions replace traditional interactions between parents and children that have been effective in supporting children's learning in the past century.

The present study investigates the following:

(1) The frequency of shared digital media activities, also referred to as digital HLE, in the home from an early age on, to discover the prevalence of shared digital media use in the home, 
(2) How these aspects of digital HLE are associated with the analog HLE, to investigate a possible shift from analog to digital home learning environmental activities,

(3) How digital HLE and analog HLE are associated with concurrent child academic and socio-emotional outcomes, and

(4) Whether possible beneficial or harmful effects of early digital HLE are moderated by analog HLE or children's language/practical life skills.

We assume that the analog and the digital HLE can be differentiated in two independent facets that are only slightly correlated and thus represent two distinct facets of the HLE. We furthermore assume that the frequency of digital HLE increases with age. We expect the effects of the analog and digital HLEs to be more pronounced regarding academic skills, whereas the digital HLE might have a stronger impact on socio-emotional skills, as children could be more confronted with exercises, e.g., in literacy apps.

\section{MATERIALS AND METHODS}

\section{Sample}

We use data of the national representative sample of Growing up in Germany (AID:A II; Bien et al., 2015). The AID:A II study was carried out between 2013 and 2015 and assessed information on over 20.000 persons up to the age of 32 years $(N=22.424)$. The sample includes persons who had already taken part in the AID:A I study, a representative register-based survey, which was conducted in 2009, and a register-based refreshment sample (response rate: $34.2 \%$ ). For our analyses, we used data of children aged 0 to 5 years (before school enrollment) and split them into two age-dependent samples, as we were a) interested in the differences between the very early (toddler) and the later HLE (preschool) of young children, and as b) children's competencies and skills were assessed age-specifically. Sample 1, the "toddler sample," includes all children at the age of 11-46 months $(n=2,637)$, and sample 2, the "preschool sample", includes all children at the age from 47 to 71 months $(n=1,399)$.

\section{Measures}

\section{Indicators of the HLE: Analog and Digital Activities}

Information on analog as well as digital media activities in the HLE was derived from an interview in which parents indicated the frequency of joint activities of the child and the parent or other persons in the household on a six-point scale, ranging from (1) never to (6) daily. The "analog HLE activities" indicator includes the mean of 11 items (e.g., reading to the child, counting, playing with alphabet toys, attending cultural activities, singing; $\left.\alpha_{\text {toddler }}=0.70, \alpha_{\text {preschool }}=0.67\right)$. "Digital HLE activities" indicator was assessed with three items by asking the parents about the frequency of joint digital media-related activities (i.e., looking at/playing with apps, going online, doing something with the computer; $\alpha_{\text {toddler }}=0.67, \alpha_{\text {preschool }}=0.71$ ). These three items capture a very general assessment of the shared use of digital media in the home environment.

\section{Child Functioning}

Children's competencies and skills were assessed age-specifically for the toddler and preschool age groups.

In the toddler age group, socio-emotional as well as life skills were assessed using a selection of age-specific items derived from the monitoring of child development within the health screening of pediatricians (Petermann and Macha, 2003). Here, parents were asked to report whether the described behavior is true for the child $(0=$ no, $1=$ yes). These values were classified into categories, which were generated age-specifically within a 2-month interval: (2) maximum to smaller than one standard deviation from the mean, (1) one to under two standard deviation from the mean, and (0) two or more standard deviations from the mean. An index of practical life skills was summed up across eight items, and another set of eight items make up an index for socioemotional development. Practical life skills for children at the age of 10 months included items such as pointing to an object in order to get the parent's attention or removing barriers in order to reach an object or speaking double-sounds (such as baba, dada). Socioemotional development at the age of 24 months included aspects such as displaying signs of joy when another child appears, if the child responds to a calmly spoken "no," and if the child can be quickly calmed in everyday irritations.

In the group of preschool children, socio-emotional as well as domain-specific skills were also assessed via parent report. Socioemotional skills were captured using the Strength and Difficulties Questionnaire (SDQ; Klasen et al., 2003).

Parents reported on five items about the children's prosocial behavior, e.g., if the child is considerate of other people's feelings or shares readily with other children (treats, toys, pencils, etc.), ranging from ( 0 ) not true to (2) certainly true. All five items were summed up $\left(\alpha_{\text {preschool }}=0.62\right)$. Additionally, the four subscales on total difficulties, including 20 items $^{1}$ covering emotional problems, conduct problems, hyperactivity/inattention, and peer problems, were summed up to build another index. Items referred to whether the child often seems to be worried; often has tantrums or hot tempers; is restless, overactive, and fidgety; is rather solitary; or tends to play alone were captured with the same procedure $\left(\alpha_{\text {preschool }}=0.74\right)$.

Domain-specific skills in the age group of the 3-5-yearolds were assessed using items of the TIMMS/IGLU 2011 study (Wendt et al., 2016), which capture language as well as math skills. Parents were asked to indicate their child's level of ability on a four-point scale, ranging from (1) not at all to (4) very good. Language skills comprise six items, such as recognizing letters, reading some words, reading sentences, writing letters, and writing some words $\left(\alpha_{\text {preschool }}=0.78\right)$, whereas math skills capture abilities, such as counting, recognizing numbers from 0 to 10 , simple summation, and simple subtraction within five items $\left(\alpha_{\text {preschool }}=0.80\right)$.

${ }^{1}$ Please note that as the SDQ version for children from the age of 4-17 years was used, two items ("lies" and "steals") were only answered if children were 48 months or older. 


\section{Indicators of Child and Family Background}

As indicators for socio-economic background of the family, we included the number of siblings living in the household, the weighted household income (OECD, 2013), the highest socioeconomic status, measured via the International Socio-Economic Index of Occupational Status (HISEI; Ganzeboom et al., 1992), as well as the highest educational level in the household. Here, we used the CASMIN-classification (Comparative Analysis of Social Mobility in Industrial Nations; Müller et al., 1989), which contains information on school and vocational training certificates, ranging from 1 to 8 with (1) indicating general elementary education, (4) secondary school leaving certificate with vocational training, and (8) higher tertiary education (university degree). As child background information, children's age (in months) and their gender ( $0=$ girl, $1=$ boy) were considered. Additionally, we controlled for "positive parenting" as an omnibus indicator for the socio-emotional support within the family. Parents answered four questions, such as if they praise their child or comfort their child if he/she is sad. For parents of children aged 24 months, two additional items were presented, such as "I talk to my child about what he/she has experienced" ( $\alpha=0.58)$.

\section{Tendency of Agreement}

Acquiescence has long been known to influence survey data. A particular thread to the data's validity is differential effects depending on the respondent's education, age, or gender (O'Muircheartaigh et al., 1999). All data used for this study were collected in a phone-based survey (CATI) with parents. In order to prevent our analyses to be corroborated by such a response bias, all multivariate analyses include a correction factor "tendency to agree." For this, we built a ratio "tendency to agree" by dividing the number of agreeing responses across all six-point rating scales throughout the full questionnaire by the number of all valid responses. Descriptive statistics for all variables included are provided in Tables 1, 2.

\section{Analytic Strategy}

First, to examine whether the analog and the digital HLE can be differentiated into two separate facets of the HLE, we conducted confirmatory factor analyses and used chi-square difference

TABLE 1 | Descriptive statistics for the toddler age group.

\begin{tabular}{lcccc}
\hline & Mean & SD & Min & Max \\
\hline Analog HLE & 3.82 & 0.78 & 1 & 5.82 \\
Digital HLE & 1.67 & 0.96 & 1 & 6 \\
Practical life skills & 5.69 & 1.64 & 0 & 8 \\
Socio-emotional development & 6.64 & 1.14 & 1 & 8 \\
Positive parenting & 3.72 & 0.30 & 1.50 & 4 \\
Income & $1,875.6$ & $1,675.3$ & 3.33 & $47,617.1$ \\
HISEl & 63.8 & 18.6 & 14.2 & 89.0 \\
Education (CASMIN) & 6.47 & 1.82 & 0 & 8 \\
Siblings & 1.93 & 0.90 & 1 & 13 \\
Age in months & 27.4 & 10.6 & 11 & 46 \\
Gender (0 = girl, 1 = boy) & 0.52 & 0.50 & 0 & 1 \\
Tendency of agreement & 0.51 & 0.075 & 0.28 & 0.96
\end{tabular}

TABLE 2 | Descriptive statistics for the preschool age group.

\begin{tabular}{lcccc}
\hline & Mean & SD & Min & Max \\
\hline Analog HLE & 4.20 & 0.60 & 2.18 & 5.73 \\
Digital HLE & 2.16 & 1.07 & 1 & 6 \\
SDQ: prosocial behavior & 8.18 & 1.61 & 1 & 10 \\
SDQ: total difficulties & 7.27 & 4.40 & 0 & 26 \\
Language skills & 2.93 & 0.64 & 1 & 4 \\
Math skills & 2.08 & 0.68 & 1 & 4 \\
Positive parenting & 3.64 & 0.31 & 2 & 4 \\
Income & $1,968.5$ & $1,683.6$ & 115.4 & $33,333.3$ \\
HISEl & 63.0 & 18.7 & 14.2 & 89.0 \\
Education (CASMIN) & 6.44 & 1.77 & 0 & 8 \\
Siblings & 2.16 & 0.91 & 0 & 12 \\
Age in months & 58.3 & 6.15 & 48 & 71 \\
Gender (0 = girl, 1 = boy) & 0.52 & 0.50 & 0 & 1 \\
Tendency of agreement & 0.50 & 0.08 & 0.21 & 0.79 \\
\hline
\end{tabular}

testing to decide on model selection. Second, we explored (a) the frequency of shared digital media use by investigating the proportion of families sharing digital media at least seldom with their child, as an indicator of having overall shared contact with digital devices at several ages (the age groups were split to get a better impression of the increase across ages within the toddler and preschool age groups) and (b) the relation between analog and digital HLEs using bivariate correlations. Third, the associations between digital and analog HLEs with child outcomes were analyzed using multiple regression models for both age groups. Here, we included the tendency of agreement to capture the variance between HLE and child outcomes that can be attributed to a general tendency of agreement to different items. Note that we did not control for child age in the toddler age group years as the used instrument (Petermann and Macha, 2003) comprises age-specific items and thus age-specific practical life skills as well as socio-emotional development (2-month intervals) were used in the analyses.

Fourth, to analyze whether the analog HLE moderates the effects of the digital HLE, we included interaction terms for all regression models. Furthermore, for the models with the socioemotional skills as outcomes, we analyzed whether practical life skills (toddlers) or language skills (preschoolers) moderate the effects of the digital HLE by including interaction terms into the regression models. To visualize the interaction effects, we plotted predictive margins in which we only visualized results for low (mean $-1 \mathrm{SD}$ ), medium (mean), and high (mean +1 $\mathrm{SD})$ value of the respective scale, for visual clarity. Interaction effects were plotted when $p$ was smaller than 0.10. All models were run using Stata 15.

\section{RESULTS}

\section{Digital and Analog HLE: Frequencies and Internal Associations}

We first explored whether digital and analog HLEs can be differentiated into two separate dimensions. We ran confirmatory factor analyses to decide whether a one-factor solution or 
the proposed two factor solution would fit the data better. Results of $\mathrm{chi}^{2}$ difference testing were in favor of the two-factor model $\left(\Delta \chi^{2}=2,380.734, d f=1, p<0.001\right)$. In addition, the correlational analyses (Tables 3,4$)$ showed only small correlations between the two dimensions.

As depicted in Table 5, shared digital media activities increased across age, in particular concerning the shared use of a computer. However, about $15 \%$ of children in the sample had experiences with sharing digital media already in their toddler years.

\section{Relations Between HLE and Child Outcomes and Potential Moderators}

As can be seen in Table 6, toddler's socio-emotional skills were associated with analog $\operatorname{HLE}(\beta=0.23, p<0.001)$, but not with digital HLE ( $\beta=-0.03$, ns) (Model 1). A similar pattern is visible for the association of practical life skills (Model 4, analog HLE: $\beta=0.24, p<0.001$; digital HLE: $\beta=0.03, p<0.10)$. In addition, the interaction between digital and analog HLEs was significant for socio-emotional skills (Model 2, $\beta=-0.34, p<0.01$ ). As depicted in Figure 1, digital HLE moderates the effect of analog
TABLE 5 | Proportion of shared digital media activities in the home (at least seldom).

\begin{tabular}{lccccccc}
\hline & \multicolumn{7}{c}{ Age of child in years } \\
\cline { 2 - 8 } & \multicolumn{1}{c}{} & $\mathbf{1}$ & $\mathbf{2}$ & $\mathbf{3}$ & $\mathbf{4}$ & $\mathbf{5}$ & $\mathbf{6}$ \\
\hline Overall digital HLE & 14.7 & 30.3 & 57.4 & 67.8 & 72.6 & 83.0 & 85.2 \\
Sharing apps & 5.4 & 18.1 & 34.3 & 39.5 & 45.9 & 49.5 & 45.0 \\
Using the internet & 5.4 & 10.1 & 25.8 & 39.4 & 48.3 & 56.4 & 64.9 \\
Doing something & 9.0 & 20.0 & 40.7 & 49.5 & 58.4 & 69.4 & 75.1 \\
with the computer & & & & & & &
\end{tabular}

Digital HLE, percentage of children who are at least seldom involved in either sharing apps, using the internet, or doing something with the computer.

HLE in that way, that socio-emotional skills increase for children with low analog HLE when being involved in more digital HLE. No other interaction terms were significant (Models 3 and 5).

Table 7 shows the results for the preschoolers, that differ slightly: While the analog HLE is positively associated with prosocial behavior (Model $6, \beta=0.06, p<0.05$ ) but not with total difficulties (Model 9, $\beta=-0.02$, ns), a greater experience of

TABLE 3 | Bivariate correlations of the study variables in the toddler age group.

\begin{tabular}{|c|c|c|c|c|c|c|c|c|c|c|}
\hline & 1 & 2 & 3 & 4 & 5 & 6 & 7 & 8 & 9 & 10 \\
\hline Analog HLE & 1.00 & & & & & & & & & \\
\hline Digital HLE & $0.19^{\star \star \star}$ & 1.00 & & & & & & & & \\
\hline Practical life skills & $0.21^{\star \star \star}$ & $0.07^{\star \star \star}$ & 1.00 & & & & & & & \\
\hline Socio-emotional development & $0.19^{\star \star \star}$ & 0.01 & $0.42^{\star \star \star}$ & 1.00 & & & & & & \\
\hline Positive parenting & $0.03^{+}$ & $-0.09^{\star \star \star}$ & $0.10^{\star \star \star}$ & $0.07^{\star \star \star}$ & 1.00 & & & & & \\
\hline Income & $-0.03^{+}$ & 0.01 & 0.03 & $0.06^{\star \star}$ & $0.04^{\star}$ & 1.00 & & & & \\
\hline HISEI & 0.02 & 0.02 & $0.04^{*}$ & $0.05^{\star *}$ & 0.01 & $0.26^{\star \star \star}$ & 1.00 & & & \\
\hline Education (CASMIN) & 0.03 & $0.07^{\star \star}$ & 0.03 & $0.07^{\star \star \star}$ & 0.01 & $0.24^{\star \star \star}$ & $0.74^{\star \star \star}$ & 1.00 & & \\
\hline Siblings & -0.01 & $-0.09^{\star \star \star}$ & 0.01 & $0.03^{+}$ & $-0.13^{\star \star \star}$ & $-0.06^{\star \star}$ & -0.02 & $-0.04^{*}$ & 1.00 & \\
\hline Age in months & $0.35^{\star \star \star}$ & $0.28^{\star \star \star}$ & $0.18^{\star \star \star}$ & $0.16^{\star \star \star}$ & $-0.25^{\star \star \star}$ & 0.00 & $0.05^{\star *}$ & $0.05^{\star}$ & $0.13^{\star \star \star}$ & 1.00 \\
\hline Gender ( $0=$ girl, $1=$ boy $)$ & $-0.06^{\star \star}$ & -0.01 & $-0.07^{\star \star \star}$ & $-0.10^{\star \star \star}$ & -0.01 & 0.01 & 0.02 & 0.01 & -0.01 & -0.01 \\
\hline
\end{tabular}

$n=2,637 ;{ }^{+} p<0.10,{ }^{*} p<0.05,{ }^{* *} p<0.01,{ }^{* * *} p<0.001$; controlled for tendency of agreement.

TABLE 4 | Bivariate correlations of the study variables in the preschooler age group.

\begin{tabular}{|c|c|c|c|c|c|c|c|c|c|c|c|c|}
\hline & 1 & 2 & 3 & 4 & 5 & 6 & 7 & 8 & 9 & 10 & 11 & 12 \\
\hline Analog HLE & 1.00 & & & & & & & & & & & \\
\hline Digital HLE & $0.05^{+}$ & 1.00 & & & & & & & & & & \\
\hline SDQ: prosocial behavior & $0.08^{\star \star}$ & $-0.07^{\star \star}$ & 1.00 & & & & & & & & & \\
\hline SDQ: total difficulties & $-0.07^{\star \star}$ & $0.08^{\star \star}$ & $-0.31^{\star \star \star}$ & 1.00 & & & & & & & & \\
\hline Language skills & $0.19^{\star \star \star}$ & $0.16^{\star \star \star}$ & $0.12^{\star \star \star}$ & $-0.16^{\star \star \star}$ & 1.00 & & & & & & & \\
\hline Math skills & $0.20^{\star \star \star}$ & $0.14^{\star \star \star}$ & $0.16^{\star \star \star}$ & $-0.15^{\star \star \star}$ & $0.65^{\star \star \star}$ & 1.00 & & & & & & \\
\hline Positive parenting & $0.18^{\star \star \star}$ & -0.03 & $0.16^{\star \star \star}$ & $-0.18^{\star \star \star}$ & $0.06^{\star}$ & 0.01 & 1.00 & & & & & \\
\hline Income & $0.04^{+}$ & 0.04 & $-0.05^{\star}$ & $-0.09^{\star \star}$ & $0.10^{\star \star \star}$ & $0.09^{\star \star}$ & 0.04 & 1.00 & & & & \\
\hline HISEI & $0.09^{\star \star \star}$ & 0.02 & -0.02 & $-0.19^{\star \star \star}$ & $0.17^{\star \star \star}$ & $0.11^{\star \star \star}$ & 0.01 & $0.28^{\star \star \star}$ & 1.00 & & & \\
\hline Education (CASMIN) & $0.11^{\star \star \star}$ & $0.05^{+}$ & -0.01 & $-0.20^{\star \star \star}$ & $0.17^{\star \star \star}$ & $0.12^{\star \star \star}$ & 0.01 & $0.22^{\star \star \star}$ & $0.68^{\star \star \star}$ & 1.00 & & \\
\hline Siblings & $-0.09^{\star \star \star}$ & $-0.10^{\star \star \star}$ & 0.00 & $-0.05^{+}$ & $-0.07^{\star \star}$ & $-0.05^{\star}$ & $-0.11^{\star \star \star}$ & $-0.06^{\star}$ & $0.06^{\star}$ & 0.02 & 1.00 & \\
\hline Age in months & -0.02 & 0.04 & $0.08^{\star \star}$ & $-0.08^{\star \star}$ & $0.50^{\star \star \star}$ & $0.39^{\star \star \star}$ & -0.02 & 0.03 & $0.11^{\star \star \star}$ & $0.06^{\star \star}$ & 0.01 & 1.00 \\
\hline Gender ( $0=$ girl, $1=$ boy $)$ & $-0.07^{\star \star}$ & 0.03 & $-0.15^{\star \star \star}$ & $0.14^{\star \star \star}$ & -0.03 & $-0.23^{\star \star \star}$ & -0.01 & 0.00 & 0.01 & 0.01 & -0.00 & -0.00 \\
\hline
\end{tabular}

$n=1,399 ;{ }^{+} p<0.10,{ }^{*} p<0.05,{ }^{* *} p<0.01,{ }^{* *} p<0.001$; controlled for tendency of agreement. 
TABLE 6 | Multivariate regressions: associations between toddler's socio-emotional outcomes, practical life skills, and digital and analog HLEs.

\begin{tabular}{|c|c|c|c|c|c|}
\hline & Model 1 & Model 2 & Model 3 & Model 4 & Model 5 \\
\hline & $\begin{array}{c}\text { Socio-emotional } \\
\text { development }\end{array}$ & $\begin{array}{c}\text { Socio-emotional } \\
\text { development }\end{array}$ & $\begin{array}{c}\text { Socio-emotional } \\
\text { development }\end{array}$ & $\begin{array}{l}\text { Practical life } \\
\text { skills }\end{array}$ & $\begin{array}{c}\text { Practical life } \\
\text { skills }\end{array}$ \\
\hline Analog HLE & $0.23^{\star \star \star}$ & $0.33^{\star \star \star}$ & $0.14^{\star \star \star}$ & $0.24^{\star \star \star}$ & $0.28^{\star \star \star}$ \\
\hline Digital HLE & -0.03 & $0.27^{\star \star}$ & $-0.14^{*}$ & $0.03^{+}$ & $0.18^{+}$ \\
\hline Positive parenting & $0.07^{\star \star \star}$ & $0.07^{\star \star \star}$ & 0.03 & $0.10^{\star \star \star}$ & $0.10^{\star \star \star}$ \\
\hline Income & $0.05^{\star \star}$ & $0.05^{\star \star}$ & $0.04^{\star}$ & 0.03 & 0.03 \\
\hline HISEI & -0.02 & -0.02 & $-0.04^{+}$ & 0.05 & 0.05 \\
\hline Education (CASMIN) & $0.08^{\star \star}$ & $0.08^{\star \star}$ & $0.09^{\star \star \star}$ & -0.02 & -0.02 \\
\hline Siblings & $0.04^{*}$ & $0.04^{*}$ & $0.03^{+}$ & 0.03 & 0.03 \\
\hline Gender $(0=$ girl, $1=$ boy $)$ & $-0.09^{\star \star \star}$ & $-0.09^{\star \star \star}$ & $-0.07^{\star \star \star}$ & $-0.06^{\star \star}$ & $-0.06^{\star \star}$ \\
\hline Tendency of agreement & 0.03 & 0.03 & 0.02 & 0.02 & 0.02 \\
\hline $\begin{array}{l}\text { HLE media activities } \times \text { HLE } \\
\text { educational activities }\end{array}$ & & $-0.34^{\star \star}$ & & & -0.17 \\
\hline Practical life skills & & & $0.34^{\star \star \star}$ & & \\
\hline $\begin{array}{l}\text { HLE media activities } \times \text { practical } \\
\text { life skills }\end{array}$ & & & 0.11 & & \\
\hline Observations & 2,637 & 2,637 & 2,637 & 2,637 & 2,637 \\
\hline$R^{2}$ & 0.08 & 0.08 & 0.22 & 0.08 & 0.08 \\
\hline Adjusted $R^{2}$ & 0.08 & 0.08 & 0.21 & 0.08 & 0.08 \\
\hline
\end{tabular}

Standardized beta coefficients, ${ }^{+} p<0.10,{ }^{*} p<0.05,{ }^{* *} p<0.01,{ }^{* * *} p<0.001$.

digital HLE goes along with less socio-emotional skills (Models 6 and 9, prosocial behavior: $\beta=-0.06, p<0.001$; total difficulties: $\beta=0.07, p<0.01)$. No significant interaction terms were found (Models 7, 8, 10, and 11). For parent-rated academic skills (see Table 8), we found positive associations of both, the analog and the digital HLE with language (Model 12) and math skills (Model 14). Here, the effects were more pronounced for the analog HLE. For language skills, we found a small moderator effect (Model 13). For children with high analog HLEs, the digital HLE makes no difference for their language skills. However, children with low analog HLE showed greater language skills when experiencing a higher level of digital HLE (Figure 2). No significant interaction terms were found for math skills (Model 14).

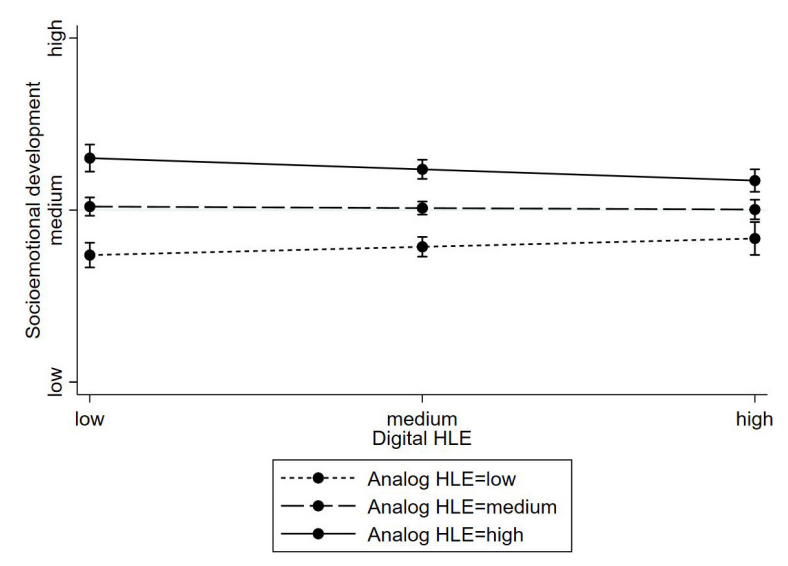

FIGURE 1 | Moderating effects of analog HLE on the association between digital HLE and socioemotional development (toddler age group).

\section{DISCUSSION}

The aim of the present study was to investigate a potentially new dimension of the HLE, i.e., a digital HLE, that includes the frequency of shared digital media activities from an early age on, its association with analog HLE, and how these two dimensions of the HLE are related to children's socio-emotional, practical life, and academic outcomes at toddler and preschool age. Furthermore, we explored whether potentially beneficial or harmful effects of digital HLE are enhanced or compensated by an analog HLE or by children's language/practical life skills. Our results indicate that digital and analog HLEs can be seen as separate dimensions that are only marginally related to each other and differentially related to children's outcomes.

The positive correlations between digital and analog HLEs in the toddler age group show that parents who actively involve their children in educational "analog" activities in this early phase of development do so with digital media, too. This finding aligns with previous research that showed that parents of children below the age of 3 years who read more often to their children also tended to show a greater frequency in various other activities, such as singing, playing with dolls, and doing crafts (Wirth et al., 2020b). We found that children's digital HLE activities rapidly increase with age. However, in the older age group, digital and analog HLEs were no longer associated. Consequently, there seems to be neither a shift from an analog to a digital HLE, which would have been indicated by a negative correlation, nor a hint to a general indicator of the HLE comprising analog and digital aspects, which would have been indicated by a high, positive correlation. Rather, families' HLE seems to follow differential developmental 
TABLE 7 | Multivariate regressions: associations between preschooler's socio-emotional outcomes and digital and analog HLEs.

\begin{tabular}{|c|c|c|c|c|c|c|}
\hline & Model 6 & Model 7 & Model 8 & Model 9 & Model 10 & Model 11 \\
\hline & $\begin{array}{c}\text { SDQ: prosocial } \\
\text { behavior }\end{array}$ & $\begin{array}{c}\text { SDQ: prosocial } \\
\text { behavior }\end{array}$ & $\begin{array}{c}\text { SDQ: prosocial } \\
\text { behavior }\end{array}$ & $\begin{array}{l}\text { SDQ: total } \\
\text { difficulties }\end{array}$ & $\begin{array}{l}\text { SDQ: total } \\
\text { difficulties }\end{array}$ & $\begin{array}{l}\text { SDQ: total } \\
\text { difficulties }\end{array}$ \\
\hline Analog HLE & $0.06^{*}$ & 0.03 & 0.04 & -0.02 & -0.02 & 0.01 \\
\hline Digital HLE & $-0.06^{\star}$ & -0.17 & $-0.20^{+}$ & $0.07^{* \star}$ & 0.08 & $0.26^{\star}$ \\
\hline Positive parenting & $0.15^{\star \star \star}$ & $0.15^{\star \star \star}$ & $0.14^{\star \star \star}$ & $-0.18^{\star \star \star}$ & $-0.18^{\star \star \star}$ & $-0.17^{\star \star \star}$ \\
\hline Income & $-0.06^{*}$ & $-0.06^{*}$ & $-0.06^{\star}$ & -0.03 & -0.03 & -0.03 \\
\hline HISEI & -0.03 & -0.03 & -0.04 & $-0.08^{*}$ & $-0.08^{*}$ & $-0.08^{*}$ \\
\hline Education (CASMIN) & 0.02 & 0.02 & 0.01 & $-0.13^{\star \star \star}$ & $-0.13^{\star \star \star}$ & $-0.12^{\star \star \star}$ \\
\hline Siblings & 0.01 & 0.01 & 0.02 & $-0.06^{*}$ & $-0.06^{\star}$ & $-0.06^{\star}$ \\
\hline Age in months & $0.10^{\star \star \star}$ & $0.10^{\star \star \star}$ & 0.05 & $-0.06^{\star}$ & $-0.06^{\star}$ & 0.00 \\
\hline Gender ( $0=$ girl, $1=$ boy) & $-0.14^{\star \star \star}$ & $-0.14^{\star \star \star}$ & $-0.14^{\star \star \star}$ & $0.14^{\star \star \star}$ & $0.14^{\star \star \star}$ & $0.13^{\star \star \star}$ \\
\hline Tendency of agreement & $0.19^{\star \star \star}$ & $0.19^{\star \star \star}$ & $0.19^{\star \star \star}$ & $-0.08^{\star \star}$ & $-0.08^{\star \star}$ & $-0.08^{\star \star}$ \\
\hline Analog HLE $\times$ digital HLE & & 0.12 & & & -0.01 & \\
\hline Language skills & & & 0.04 & & & -0.06 \\
\hline Digital HLE $\times$ language skills & & & 0.15 & & & -0.20 \\
\hline Observations & 1,399 & 1,399 & 1,399 & 1,399 & 1,399 & 1,399 \\
\hline$R^{2}$ & 0.13 & 0.13 & 0.13 & 0.11 & 0.11 & 0.13 \\
\hline Adjusted $R^{2}$ & 0.12 & 0.12 & 0.13 & 0.11 & 0.11 & 0.12 \\
\hline
\end{tabular}

Standardized beta coefficients, ${ }^{+} p<0.10,{ }^{*} p<0.05,{ }^{* *} p<0.01,{ }^{* *} p<0.001$.

patterns, as their children grow older. Therefore, as shown in many studies before, the HLE is no unitary construct and needs to be differentiated (e.g., Skwarchuk et al., 2014; Wirth et al., 2019; Lehrl et al., 2020a). The present study gives further evidence that the medium through which stimulation in the home takes place is another variable that distinguishes dimensions of the HLE.

This differentiation gains further importance when inspecting the differential association between the digital and analog HLEs

TABLE 8 | Multivariate regressions: associations between preschooler's academic outcomes and digital and analog HLEs.

\begin{tabular}{|c|c|c|c|c|}
\hline & Model 12 & Model 13 & Model 14 & Model 15 \\
\hline & $\begin{array}{c}\text { Language } \\
\text { skills }\end{array}$ & $\begin{array}{c}\text { Language } \\
\text { skills }\end{array}$ & $\begin{array}{l}\text { Math } \\
\text { skills }\end{array}$ & $\begin{array}{l}\text { Math } \\
\text { skills }\end{array}$ \\
\hline Analog HLE & $0.20^{\star \star \star}$ & $0.28^{\star \star \star}$ & $0.21^{\star \star \star}$ & $0.26^{\star \star \star}$ \\
\hline Digital HLE & $0.12^{\star \star \star}$ & $0.40^{\star \star}$ & $0.11^{\star \star \star}$ & $0.27^{+}$ \\
\hline Positive parenting & 0.03 & 0.03 & -0.02 & -0.02 \\
\hline Income & $0.04^{+}$ & $0.04^{+}$ & $0.05^{\star}$ & $0.05^{\star}$ \\
\hline HISEI & 0.02 & 0.02 & -0.01 & -0.01 \\
\hline Education (CASMIN) & $0.09^{\star \star}$ & $0.09^{\star \star}$ & $0.07^{\star}$ & $0.07^{\star}$ \\
\hline Siblings & $-0.04^{+}$ & $-0.04^{+}$ & -0.03 & -0.03 \\
\hline Age in months & $0.49^{\star \star \star}$ & $0.49^{\star \star \star}$ & $0.39^{\star \star \star}$ & $0.39^{\star \star \star}$ \\
\hline Gender $(0=$ girl, $1=$ boy $)$ & -0.02 & -0.03 & $-0.22^{\star \star \star}$ & $-0.22^{\star \star \star}$ \\
\hline Tendency of agreement & -0.03 & -0.03 & 0.02 & 0.01 \\
\hline Analog HLE $\times$ digital HLE & & $-0.30^{+}$ & & -0.17 \\
\hline Observations & 1,399 & 1,399 & 1,399 & 1,399 \\
\hline$R^{2}$ & 0.33 & 0.33 & 0.28 & 0.28 \\
\hline Adjusted $R^{2}$ & 0.32 & 0.33 & 0.27 & 0.27 \\
\hline
\end{tabular}

Standardized beta coefficients, ${ }^{+} p<0.10,{ }^{*} p<0.05,{ }^{* *} p<0.01,{ }^{* * *} p<0.001$.

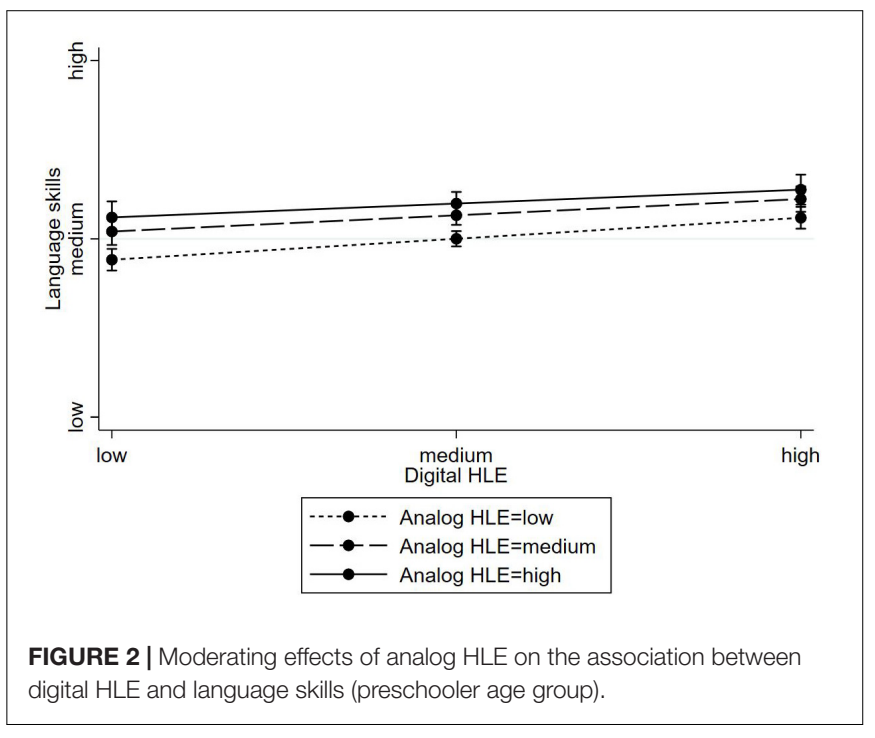

and child outcomes in the two age groups. In the younger age group, analog HLE activities were important for explaining variance in self-reported socio-emotional and practical life skills, whereas digital HLE activities were not. However, moderation analyses revealed that children with less frequent analog HLE activities showed greater socio-emotional skills when experiencing more frequent digital activities. Research has shown that low stimulating (analog) HLEs might be a risk factor for children's developing academic and social skills (e.g., Mistry et al., 2008, 2010). Consequently, for children being at risk in terms of their low stimulating analog HLEs, sharing digital media may bring parents and children together in meaningful interactions that in turn may protect children 
from unfavorable developmental trajectories. There are hints that low socioeconomic status (SES) families are more involved in the education of their children when using digital tools, such as electronic books or apps (e.g., Erdogan et al., 2019; Wirth et al., 2020a). However, one has to bear in mind that we measured the digital HLE as the frequency of parent-child interaction when sharing digital devices, and not, for instance, as the frequency of the child passively watching TV alone.

In the preschooler's age group, however, digital HLE activities were associated with weaker self-reported socio-emotional skills. Although the effect sizes are small, these results are alarming, especially when considering the non-significant moderator effects, which indicate that the negative digital HLE effect cannot be compensated by a high-quality analog HLE. As children grow older, interactions with digital media might be less communicative or guided by parents than the same interactions conducted with toddlers. For instance, a Korean study with 5-year-old children showed that an earlier onset of computer usage was associated with longer computer usage later. In addition, children with an early onset were more likely to play computer games and were less likely to be supervised while using the computer, which, in turn, was associated with higher scores on internet addiction and lower scores in socio-emotional competencies (Seo et al., 2011). Contrary to these findings, Gómez et al. (2013) reported positive effects of collaborative activities around computers on children's social development skills. Obviously, the social and emotional effects of shared or non-shared digital media use on young children are underexplored, and more research is needed, especially in light of the often-proclaimed negative effects (e.g., Cordes and Miller, 2000; Sigman, 2012; Fröhlich-Gildhoff and Fröhlich-Gildhoff, 2017) and the resulting possible lost resources that may instead foster academic skills (Plowman and McPake, 2013).

Although only used as a control variable, our analyses show that the effects of overall warm and responsive interactions as indicated through the variable "positive parenting" compared with the digital HLE were twice as large (Tables 6, 7) and seemed to be more meaningful in the development of socioemotional skills of children (see also Thomas and ZimmerGembeck, 2007 for an overview on the effects of positiveparenting interventions). The digital HLE was significantly associated with academic skills, although the analog HLE showed higher effect sizes. Concerning vocabulary acquisition, some studies also reported positive effects of digital media use, yet the greatest effects were observed when such use was guided by adults (Teepe et al., 2016; Walter-Laager et al., 2016). In addition, a meta-analysis showed that animated pictures as additions to stories can boost vocabulary development when they are congruent to the story (Takacs et al., 2015). Similar improvements have been shown in early number skills after interacting with math apps (Mattoon et al., 2015; Schacter and Jo, 2016; Watts et al., 2016). Consequently, our research is in line with the huge body of results that emphasizes the role of the analog HLE in shaping children's language and mathematical skills (e.g., Hindman and Morrison, 2012; Niklas and Schneider, 2017; Tamis-LeMonda et al., 2019; Lehrl et al., 2020a,b). In addition, the present study adds to our knowledge by showing that the digital HLE adds to the effects of analog HLE activities.

However, the following limitations mark this study: HLE activities as well as child's competencies were reported by parents, and although they are based on established measures often used in other studies (such as the SDQ), they might be biased. Although we tried to diminish this effect by controlling for the general tendency of agreement, we cannot completely rule this possibility out.

Furthermore, our analyses are only cross-sectional; thus, we do not know the direction of effects and no causal claims can be made. Potentially, child's competence level may influence the frequency of digital HLE activities and not the other way around (Hygen et al., 2019). Indications of such associations are mainly found in the area of socio-emotional competences. For example, parents might react to social-emotional difficulties by trying to calm difficult infants/toddlers with digital media activities (Radesky et al., 2016). To disentangle such complex interrelations and the impact of both digital and analog HLEs on the development of socio-emotional and academic skills is certainly an avenue for future research. Furthermore, the data of our study are representative for families in 2013. The rapid growth in the digital sector in the last years underlines the need for further research in this area to investigate possible drifts and changes regarding the analog and digital HLEs.

Additionally, it must be considered that our digital HLE measure was a very general assessment of the shared use of digital media in the home environment that consists of only three items, and that we have no information on the content of the digital media activities and the quality of the interaction between parent and child during shared digital media use. Some study results point out that parent-child interaction and parents' talk may be impoverished when they use digitally enhanced books (Zosh et al., 2015). However, as already mentioned, digital media might also foster children's learning (e.g., Takacs et al., 2015), but only if it is designed appropriately (Hirsh-Pasek et al., 2015). For example, Parish-Morris et al. (2013) examined and compared interactions of parents with their 3-year-old children with digital books, containing different enhanced features (e.g., pre-recorded sounds), and found more enhanced features to be less beneficial for the parent's use of high-quality language (dialogic reading strategies) and the child's learning (story comprehension). This finding might even be true for younger children. Sosa (2016) demonstrated in a controlled experiment that in the condition with electronic toys, both adults and children produced fewer words, and conversation turns occurred less often than parentchild play with traditional toys and books.

Therefore, more research is needed to understand under which circumstances digital devices and apps may benefit children's development. Here, policy for children's media as well as research should also move away from focus on "screen time" and provide parents with specific guidelines to select quality content to optimize media experiences for young children (Huber et al., 2018). Detailing children's screen media experience in a digital HLE will provide a better understanding of whether digital media can be used to promote learning in young children. 


\section{CONCLUSION}

Children's experiences with technology and interactive digital media are increasingly a part of their daily lives. With the present study, we have shown that sharing digital media at home may be seen as the digital facet of the HLE, which can be differentiated from the analog HLE. Our findings show once more the important role of the analog HLE for children's competencies, but extend research by showing that the digital HLE also affects aspects of children's development. Digital HLE means that children and parents share digital devices, and that parents are actively involved. Thus, here, parents are clearly the most important partners for young children's interaction with digital technologies, and it is to be expected that the effect of digital media will depend on parents' choice of suitable media and the support of their children. Useful support for parents in deciding how children can best benefit from digital technologies might be needed.

\section{DATA AVAILABILITY STATEMENT}

Publicly available datasets were analyzed in this study. Data can be retrieved under this URL: https://surveys.dji.de.

\section{REFERENCES}

All, A., Nunez Castellar, E. P., and van Looy, J. (2016). Assessing the effectiveness of digital game-based learning: best practices. Comput. Educ. 9, 90-103. doi: 10.1016/j.compedu.2015.10.007

Anders, Y., Rossbach, H. G., Weinert, S., Ebert, S., Kuger, S., Lehrl, S., et al. (2012). Home and preschool learning environments and their relations to the development of early numeracy skills. Early Child. Res. Q. 27, 231-244. doi: 10.1016/j.ecresq.2011.08.003

Berkowitz, T., Schaeffer, M. W., Maloney, E. A., Peterson, L., Gregor, C., Levine, S. C., et al. (2015). Math at home adds up to achievement in school. Science 350, 196-198. doi: 10.1126/science.aac7427

Biancarosa, G., and Griffiths, G. G. (2012). Technology tools to support reading in the digital age. Future Child 22, 139-160. doi: 10.1353/foc.2012.0014

Bien, W., Pötter, U., and Quellenberg, H. (2015). "Methodische grundlagen von AID:A II. Stichprobe und Fallzahlen. Stichprobe und Fallzahlen," in Aufwachsen in Deutschland heute. Erste Befunde aus dem DJI-Survey AID:A 2015, eds S. Walper, W. Bien, and T. Rauschenbach (München: Verlag Deutsches Jugendinstitut), 63-68.

Bierman, K. L., Welsh, J. A., Heinrichs, B. S., Nix, R. L., and Mathis, E. T. (2015). Helping head start parents promote their children's kindergarten adjustment: the research-based developmentally informed parent program. Child Dev. 86, 1877-1891. doi: 10.1111/cdev.12448

Bradley, R. H., and Caldwell, B. M. (1984). The HOME Inventory and family demographics. Dev. Psychol. 20, 315. doi: 10.1037/0012-1649.20.2.315

Buckingham, D. (2007). Youth, Identity, and Digital Media. Cambridge, MA: The MIT Press, 216.

Bywater, T., Sammons, P., Toth, K., Sylva, K., Melhuish, E., Siraj, I., et al. (2015). The long-term role of the home learning environment in shaping students' academic attainment in secondary school. J. Childrens Serv. 10, 189-201. doi: 10.1108/jcs-02-2015-0007

Chaudron, S., Beutel, M., Cernikova, M., Navarette, V. D., Dreier, M., FletcherWatson, B., et al. (2015). Young Children (0-8) and Digital Technology. A Qualitative Exploratory Study Across Seven Countries. Ispra: Joint Research Centre European Commission.

Cordes, C., and Miller, E. (2000). Fool's Gold: A Critical Look at Computers in Childhood. Alliance for Childhood. Available online at: https://eric.ed.gov/?id= ED445803 (accessed April, 2020).

\section{ETHICS STATEMENT}

Ethical review and approval was not required for the study on human participants in accordance with the local legislation and institutional requirements. Written informed consent to participate in this study was provided by the participants' legal guardian/next of kin.

\section{AUTHOR CONTRIBUTIONS}

SL and AL developed the research ideas, the constructs, and were responsible for the analyses. SL wrote the first draft of the manuscript. FN and SK contributed to the theoretical and discussion section and revised the manuscript. All authors contributed to the article and approved the submitted version.

\section{FUNDING}

Data collection has been supported by funding of the German Federal Ministry for Family Affairs, Senior Citizens, Women, and Youth.

Cristia, A., and Seidl, A. (2015). Parental reports on touch screen use in early childhood. PLoS One 10:e0128338. doi: 10.1371/journal.pone.0128338

Erdogan, N. I., Johnson, J. E., Dong, P. I., and Qiu, Z. (2019). Do parents prefer digital play? Examination of parental preferences and beliefs in four nations. Early Childhood Educ. J. 47, 131-142. doi: 10.1007/s10643-018-0901-2

Fröhlich-Gildhoff, K., and Fröhlich-Gildhoff, M. (2017). Digitale medien in der Kita-die Risiken werden unterschätzt! Frühe Bildung 6, 225-228. doi: 10.1026/ 2191-9186/a000332

Ganzeboom, H. B., De Graaf, P. M., and Treiman, D. J. (1992). A standard international socio-economic index of occupational status. Soc. Sci. Res. 21, 1-56. doi: 10.1016/0049-089x(92)90017-b

Gómez, F., Nussbaum, M., Weitz, J. F., Lopez, X., Mena, J., and Torres, A. (2013). Co-located single display collaborative learning for early childhood education. Int. J. Comput. Supp. Collab. Learn. 8, 225-244. doi: 10.1007/s11412-0139168-1

Hindman, A. H., and Morrison, F. J. (2012). Differential contributions of three parenting dimensions to preschool literacy and social skills in a middle-income sample. Merrill Palmer Q. 58, 191-223. doi: 10.1353/mpq.2012.0012

Hirsh-Pasek, K., Zosh, J. M., Golinkoff, R. M., Gray, J. H., Robb, M. B., and Kaufman, J. (2015). Putting education in "educational" apps: Lessons from the science of learning. Psychol. Sci. Public Interest 16, 3-34. doi: 10.1177/ 1529100615569721

Huber, B., Highfield, K., and Kaufman, J. (2018). Detailing the digital experience: parent reports of children's media use in the home learning environment. Br. J. Educ. Technol. 49, 821-833. doi: 10.1111/bjet.12667

Huntsinger, C. S., Jose, P. E., and Luo, Z. (2016). Parental facilitation of early mathematics and reading skills and knowledge through encouragement of home-based activities. Early Childhood Res. Q. 37, 1-15. doi: 10.1016/j.ecresq. 2016.02.005

Hygen, B. W., Belsky, J., Stenseng, F., Skalicka, V., Kvande, M. N., Zahl-Thanem, T., et al. (2019). Time spent gaming and social competence in children: reciprocal effects across childhood. Child Dev. 91, 861-875. doi: 10.1111/cdev. 13243

Judge, S., Floyd, K., and Jeffs, T. (2015). "Using mobile media devices and apps to promote young children's learning," in Young Children and Families in the Information Age: Applications of Technology in Early Childhood, eds K. L. Heider and M. Renck Jalongo (Dordrecht: Springer), 117-131. doi: 10.1007/978-94017-9184-7_7 
Klasen, H., Woerner, W., Rothenberger, A., and Goodman, R. (2003). German version of the strength and difficulties questionnaire (SDQ-German)-overview and evaluation of initial validation and normative results. Prax. Kinderpsychol. Kinderpsychiatr 52, 491.

Korat, O., and Shneor, D. (2019). Can e-books support low SES parental mediation to enrich children's vocabulary? First Lang. 39, 344-364. doi: 10.1177/ 0142723718822443

Kuger, S., Marcus, J., and Spieß, C. K. (2019). Day care quality and changes in the home learning environment of children. Educ. Econ. 27, 265-286. doi: 10.1080/09645292.2019.1565401

Lehrl, S., Ebert, S., Blaurock, S., Rossbach, H. G., and Weinert, S. (2020a). Longterm and domain-specific relations between the early years home learning environment and students' academic outcomes in secondary school. Sch. Effect. Sch. Improv. 31, 102-124. doi: 10.1080/09243453.2019.1618346

Lehrl, S., Evangelou, M., and Sammons, P. (2020b). The home learning environment and its role in shaping children's educational development. Sch. Effect. Sch. Improv. 31, 1-6. doi: 10.1080/09243453.2020.1693487

Linberg, A. (2018). Interaktion zwischen Mutter und Kind. Dimensionen, Bedingungen und Effekte. Empirische Erziehungswissenschaft. Münster: Waxmann.

Manolitsis, G., Georgiou, G. K., and Tziraki, N. (2013). Examining the effects of home literacy and numeracy environment on early reading and math acquisition. Early Childhood Res. Q. 28, 692-703. doi: 10.1016/j.ecresq.2013. 05.004

Marci-Boehncke, G., Müller, A., and Rath, M. (2012). Medienkompetent zum Schulübergang, Erste Ergebnisse einer Forschungs- und Interventionsstudie zum Medienumgang in der frühen Bildung [Being media-literate for school transition: first results of a research and intervention study on media usage in early education]. Medienpädagogik. Zeitschrift Theorie Praxis Medienbildung 22, 1-22. doi: 10.21240/mpaed/22/2012.12.27.x

Marsh, J., Brooks, G., Hughes, J., Ritchie, L., Roberts, S., and Wright, K. (2005). Digital Beginnings: Young Children's Use of Popular Culture, Media and New Technologies. Sheffield: University of Sheffield.

Mattoon, C., Bates, A., Shifflet, R., Latham, N., and Ennis, S. (2015). Examining computational skills in prekindergartners: the effects of traditional and digital manipulatives in a prekindergarten classroom. Early Childhood Res. Pract. $17,1-9$.

Melhuish, E. C., Phan, M. B., Sylva, K., Sammons, P., Siraj-Blatchford, I., and Taggart, B. (2008). Effects of the home learning environment and preschool center experience upon literacy and numeracy development in early primary school. J. Soc. Issues 64, 95-114. doi: 10.1111/j.1540-4560.2008.00550.x

Meyers, E. M., Erickson, I., and Small, R. V. (2013). Digital literacy and informal learning environments: an introduction. Learn. Media Technol. 38, 355-367. doi: 10.1080/17439884.2013.783597

Mistry, R. S., Benner, A. D., Biesanz, J. C., and Clark, S. L. (2010). Family and social risk, and parental investments during the early childhood years as predictors of low-income children's school readiness outcomes. Early Childhood Res. Q. 25, 432-449. doi: 10.1016/j.ecresq.2010.01.002

Mistry, R. S., Biesanz, J. C., Chien, N., Howes, C., and Benner, A. D. (2008). Socioeconomic status, parental investments, and the cognitive and behavioral outcomes of low-income children from immigrant and native households. Early Childhood Res. Q. 23, 193-212. doi: 10.1016/j.ecresq.2008.01.002

Müller, W., Lüttinger, P., König, W., and Karle, W. (1989). Class and education in industrial nations. Int. J. Sociol. 19, 3-39. doi: 10.1080/15579336.1989.11769981

Mullis, I. V., and Martin, M. O. (2017). TIMSS 2019 Assessment Frameworks. Amsterdam: International Association for the Evaluation of Educational Achievement.

Neumann, M. M. (2016). Young children's use of touch screen tablets for writing and reading at home: relationships with emergent literacy. Comput. Educ. 97, 61-68. doi: 10.1016/j.compedu.2016.02.013

Niklas, F., Cohrssen, C., and Tayler, C. (2018). Making a difference to children's reasoning skills before school-entry: the contribution of the home learning environment. Contemp. Educ. Psychol. 54, 79-88. doi: 10.1016/j.cedpsych.2018. 06.001

Niklas, F., Nguyen, C., Cloney, D. S., Tayler, C., and Adams, R. (2016). Selfreport measures of the home learning environment in large scale research: measurement properties and associations with key developmental outcomes. Learn. Environ. Res. 19, 181-202. doi: 10.1007/s10984-016-9206-9
Niklas, F., and Schneider, W. (2017). Home learning environment and development of child competencies from kindergarten until the end of elementary school. Contemp. Educ. Psychol. 49, 263-274. doi: 10.1016/j. cedpsych.2017.03.006

OECD (2013). "Framework for integrated analysis," in OECD Framework for Statistics on the Distribution of Household Income, Consumption and Wealth (OECD Publishing). doi: 10.1787/9789264194830-11-en

O’Farrelly, C., Doyle, O., Victory, G., and Palamaro-Munsell, E. (2018). Shared reading in infancy and later development: evidence from an early intervention. J. Appl. Dev. Psychol. 54, 69-83. doi: 10.1016/j.appdev.2017.12.001

Ogelman, H. G., Gungor, H., Korukcu, O., and Sarkaya, H. E. (2016). The examination of the relationship between technology use of 5-6-year-old children and their social skills and social status. Early Childhood Dev. Care 188, 168-182. doi: 10.1080/03004430.2016.1208190

O’Muircheartaigh, C., Krosnick, J. A., and Helic, A. (1999). "Middle alternatives, acquiescence, and thequality of questionnaire data," in Paper Presented at the Annual Meeting of the American Association for Public Opinion Research, (St. Petersburg, FL: AAPOR).

Palaiologou, I. (2016). Children under five and digital technologies: implications for early years pedagogy. Eur. Early Childhood Educ. Res. J. 24, 5-24. doi: 10.1080/1350293x.2014.929876

Parish-Morris, J., Mahajan, N., Hirsh-Pasek, K., Golinkoff, R. M., and Collins, M. F. (2013). Once upon a time: parent-child dialogue and storybook reading in the electronic era. Mind Brain Educ. 7, 200-211. doi: 10.1111/mbe.12028

Petermann, F., and Macha, T. (2003). Elternfragebögen zur ergänzenden Entwicklungsbeurteilung bei den kinderärztlichen Vorsorgeuntersuchungen U6 bis U9 (EEE U6-U9). Frankfurt: Swets Test Services.

Plowman, L., and McPake, J. (2013). Seven myths about young children and technology. Childhood Educ. 89, 27-33. doi: 10.1080/00094056.2013.757490

Radesky, J. S., Peacock-Chambers, E., Zuckerman, B., and Silverstein, M. (2016). Use of mobile technology to calm upset children: associations with social-emotional development. JAMA Pediatr. 170, 397-399. doi: 10.1001/ jamapediatrics.2015.4260

Rose, E., Lehrl, S., Ebert, S., and Weinert, S. (2018). Long-term relations between children's language, the home literacy environment, and socioemotional development from ages 3 to 8. Early Educ. Dev. 29, 342-356. doi: 10.1080/ 10409289.2017.1409096

Schacter, J., and Jo, B. (2016). Improving low-income preschoolers mathe-matics achievement with Math Shelf, a preschool tablet computercurriculum. Comput. Hum. Behav. 55, 223-229. doi: 10.1016/j.chb.2015.09.013

Sénéchal, M., and LeFevre, J. A. (2002). Parental involvement in the development of children's reading skill: a five-year longitudinal study. Child Dev. 73, 445-460. doi: 10.1111/1467-8624.00417

Seo, H. A., Chun, H. Y., Jwa, S. H., and Choi, M. H. (2011). Relationship between young children's habitual computer use and influencing variables on socioemotional development. Child Dev. Care 181, 245-265. doi: 10.1080/03004430. 2011.536644

Sigman, A. (2012). Time for a view on screen time. Arch. Dis. Child. 97, 935. doi: 10.1136/archdischild-2012-302196

Skwarchuk, S. L., Sowinski, C., and LeFevre, J. A. (2014). Formal and informal home learning activities in relation to children's early numeracy and literacy skills: the development of a home numeracy model. J. Exp. Child Psychol. 121, 63-84. doi: 10.1016/j.jecp.2013.11.006

Son, S. H., and Morrison, F. J. (2010). The nature and impact of changes in home learning environment on development of language and academic skills in preschool children. Dev. Psychol. 46, 1103-1118. doi: 10.1037/a0020065

Sosa, A. V. (2016). Association of the type of toy used during play with the quantity and quality of parent-infant communication. JAMA Pediatr. 170, 132-137. doi: 10.1001/jamapediatrics.2015.3753

Takacs, Z. K., Swart, E. K., and Bus, A. G. (2015). Benefits and pitfalls of multimedia and interactive features in technology-enhanced storybooks: a meta-analysis. Rev. Educ. Res 85, 698-739. doi: 10.3102/0034654314566989

Tamis-LeMonda, C. S., Luo, R., McFadden, K. E., Bandel, E. T., and Vallotton, C. (2019). Early home learning environment predicts children's 5th grade academic skills. Appl. Dev. Sci. 23, 153-169. doi: 10.1080/10888691.2017. 1345634

Teepe, R. C., Molenaar, I., and Verhoeven, L. (2016). Technology-enhanced storytelling stimulating parent-Child interaction and preschool children's 
vocabulary knowledge. J. Comput. Assist. Learn. 33, 123-136. doi: 10.1111/jcal. 12169

Thomas, R., and Zimmer-Gembeck, M. J. (2007). Behavioral outcomes of parentchild interaction therapy and triple P-positive parenting program: a review and meta-analysis. J. Abnorm. Child Psychol. 35, 475-495. doi: 10.1007/s10802-0079104-9

Walter-Laager, C., Brandenberg, K., Tinguely, L., Pfiffner, M. R., and Moschner, B. (2016). Media-assisted language learning for young children: effects of a word-learning app on the vocabulary acquisition of two-year-olds. Br. J. Educ. Technol. 48, 1062-1072. doi: 10.1111/bjet.12472

Watts, C. M., Moyer-packenham, P. S., Tucker, S. I., Bullock, E. P., Shumway, J. F., Westenskow, A., et al. (2016). An examination of children's learning progression shifts while using touch screen virtual manipulative mathematics apps. Comput. Hum. Behav. 64, 814-828. doi: 10.1016/j.chb.2016.07.029

Wendt, H., Bos, W., Tarelli, I., Vaskova, A., and Hussmann, A. (2016). IGLU and TIMSS 2011. Skalenhandbuch zur Dokumentation der Erhebungsinstrumente und Arbeit mit den Datensätzen. Münster: Waxmann.

Wirth, A., Ehmig, S. C., Drescher, N., Guffler, S., and Niklas, F. (2019). Facets of the early home literacy environment and children's linguistic and socioemotional competencies. Early Educ. Dev. doi: 10.1080/10409289.2019.1706826 [Epub ahead of print].

Wirth, A., Ehmig, S. C., Heymann, L., and Niklas, F. (2020a). "Promising interactive functions in digital storybooks for young children," in International Perspectives on Digital Media and Early Literacy (pp.), eds K. J. Rohlfing and C. Müller-Brauers (Milton Park: Routledge).
Wirth, A., Ehmig, S. C., Heymann, L., and Niklas, F. (2020b). Das Vorleseverhalten von Eltern mit Kindern in den ersten drei Lebensjahren in Zusammenhang mit familiärer Lernumwelt und Sprachentwicklung [Reading to Children Aged 0 3 years and the association with home literacy environment and early langugage development]. Frühe Bildung 9, 26-32. doi: 10.1026/2191-9186/a000464

Wong, S. S. H. (2015). Mobile digital devices and preschoolers' home multiliteracy practices. Lang. Literacy 17, 75-90. doi: 10.20360/g2cp49

Yelland, N. J. (2018). A pedagogy of multiliteracies: young children and multimodal learning with tablets. Br. J. Educ. Technol. 49, 847-858. doi: 10.1111/bjet. 12635

Zosh, J. M., Verdine, B. N., Filipowicz, A., Golinkoff, R. M., Hirsh-Pasek, K., and Newcombe, N. S. (2015). Talking shape: parental language with electronic versus traditional shape sorters. Mind Brain Educ. 9, 136-144. doi: 10.1111/ mbe. 12082

Conflict of Interest: The authors declare that the research was conducted in the absence of any commercial or financial relationships that could be construed as a potential conflict of interest.

Copyright (C) 2021 Lehrl, Linberg, Niklas and Kuger. This is an open-access article distributed under the terms of the Creative Commons Attribution License (CC BY). The use, distribution or reproduction in other forums is permitted, provided the original author(s) and the copyright owner(s) are credited and that the original publication in this journal is cited, in accordance with accepted academic practice. No use, distribution or reproduction is permitted which does not comply with these terms. 


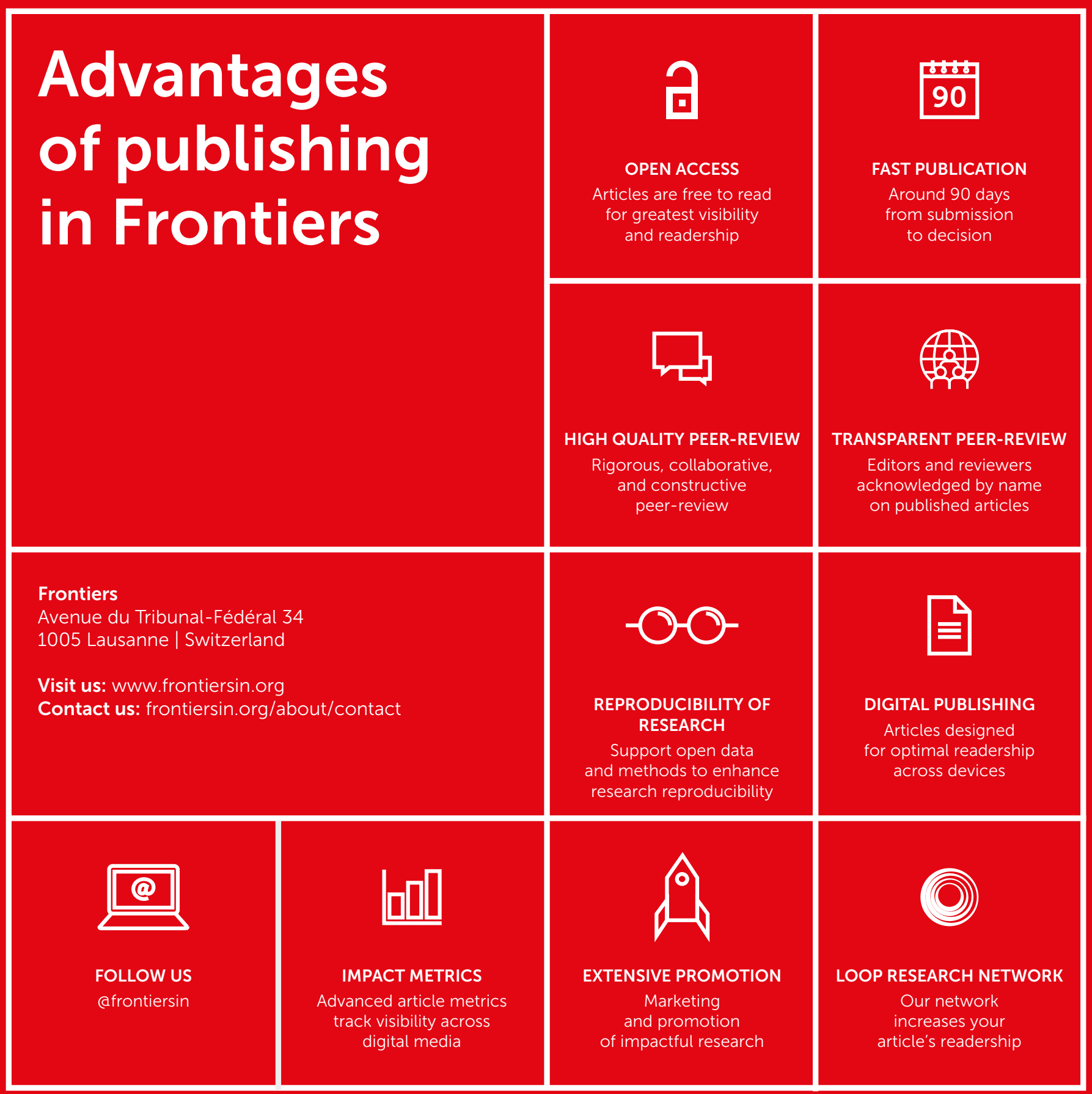

